\title{
Distribution of Recent Benthic Foraminifera in the Gulf of Mexico
}

Volume I

\section{7 \\ STEPHEN J: CULVER \\ and \\ MARTIN A. BUZAS}

SMITHSONIAN CONTRIBUTIONS TO THE MARINE SCIENCES • - NUMBER 8 - 


\title{
SERIES PUBLICATIONS OF THE SMITHSONIAN INSTITUTION
}

Emphasis upon publication as a means of "diffusing knowledge" was expressed by the first Secretary of the Smithsonian. In his formal plan for the Institution, Joseph Henry outlined a program that included the following statement: "It is proposed to publish a series of reports, giving an account of the new discoveries in science, and of the changes made from year to year in all branches of knowledge." This theme of basic research has been adhered to through the years by thousands of titles issued in series publications under the Smithsonian imprint, commencing with Smithsonian Contributions to Knowledge in 1848 and continuing with the following active series:

\author{
Smithsonian Contributions to Anthropology \\ Smithsonian Contributions to Astrophysics \\ Smithsonian Contributions to Botany \\ Smithsonian Contributions to the Earth Sciences \\ Smithsonian Contributions to the Marine Sciences \\ Smithsonian Contributions to Paleobiology \\ Smithsonian Contributions to Zoology \\ Smithsonian Studies in Air and Space \\ Smithsonian Studies in History and Technology
}

In these series, the Institution publishes small papers and full-scale monographs that report the research and collections of its various museums and bureaux or of professional colleagues in the world of science and scholarship. The publications are distributed by mailing lists to libraries, universities, and similar institutions throughout the world.

Papers or monographs submitted for series publication are received by the Smithsonian Institution Press, subject to its own review for format and style, only through departments of the various Smithsonian museums or bureaux, where the manuscripts are given substantive review. Press requirements for manuscript and art preparation are outlined on the inside back cover.

\author{
S. Dillon Ripley \\ Secretary \\ Smithsonian Institution
}




\title{
Distribution of Recent Benthic Foraminifera in the Gulf of Mexico
}

\author{
VOLUME I
}

Stephen J. Culver

and Martin A. Buzas

\section{ISSUED}

DEC 317981

SMITHSONIAN PUBLICATIONS

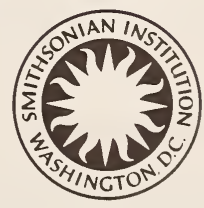

SMITHSONIAN INSTITUTION PRESS

City of Washington 


\section{A B S T R A C T}

Culver, Stephen J., and Martin A. Buzas. Distribution of Recent Benthic Foraminifera in the Gulf of Mexico. Smithsonian Contributions to the Marine Sciences, number 8, 2 volumes, 898 pages, 296 figures, 3 tables, 1981.-A computer file of all published (presence or absence) distributional data on the living and dead recent benthic foraminifera in the Gulf of Mexico was constructed from 77 papers published since 1918. Manipulation of this file produced 5 catalogs and 296 maps.

Catalog 1 lists alphabetically species names with publication and locality information as recorded in the literature (i.e., unsynonymized). Catalog 2 lists synonymized species names (in the same numerical line order as Catalog 1) with publication and locality information. Catalogs 3 and 4 list alphabetically all unsynonymized and synonymized species names, respectively. Catalog 5 lists synonymized names by increasing latitude and longitude.

During the past 60 years, 1219 names have been used to record benthic foraminifera in the Gulf of Mexico. Through synonymization, these were reduced to 848 species, of which 295 occur at 16 or more of the 426 sample localities. Computer-generated maps were drawn for these 295 most commonly recorded species.

Species were grouped by depth and geographic distribution through visual examination of the maps. Twenty overlapping categories describe the depth distribution of the commonly recorded species. The depth distribution of 15 species varies considerably around the Gulf.

Geographically the 295 most commonly recorded species may be grouped into 11 categories. Forty-eight percent of the species are ubiquitous around the Gulf. Circum-Gulf of Mexico provincial boundaries cannot be recognized but preliminary analysis distinguishes concentric benthic foraminiferal provinces whose margins can be related to particular depths and physiographic regions.

Official publication date is handstamped in a limited number of initial copies and is recorded in the Institution's annual report, Smithsonian Year. Series cover design: Seascape along the Atlantic coast of eastern North America.

Library of Congress Cataloging in Publication Data

Culver, Stephen J

Distribution of Recent Benthic Foraminifera in the Gulf of Mexicc

(Smithsonian contributions to the marine sciences ; no. 8)

Bibliography: p.

1. Foraminifera-Mexico, Gulf of. 2. Foraminifera-Mexico, Gulf of-Geographical distribution. 3. Protozoa-Mexico, Gulf of. 4. Protozoa-Mexico, Gulf of-Geographical distribution. I. Buzas, Martin A., joint author. II. Title. III. Series: Smithsonian Institution. Smithsonian contributions to the marine sciences; no. 8

QL368.F6C618 593.1'20916364 80-28882 


\section{Contents}

\section{Volume I}

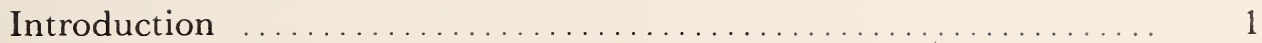

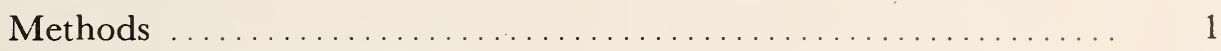

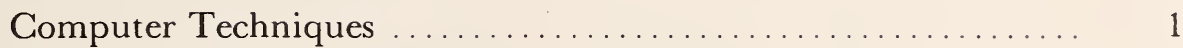

Data Compilation ................................. 1

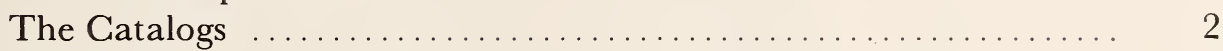

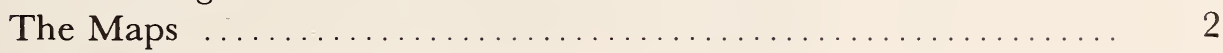

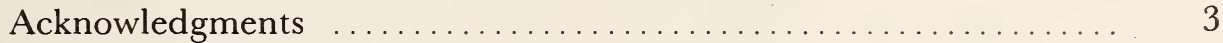

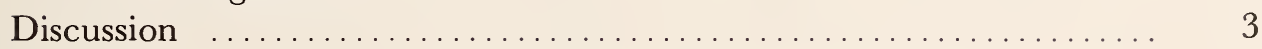

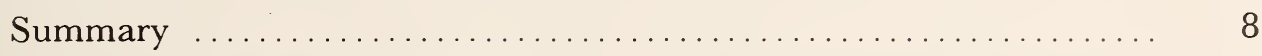

Key to the Species on the Maps $\ldots \ldots \ldots \ldots \ldots \ldots \ldots \ldots \ldots \ldots \ldots$

Index to Publications That Illustrate Our Concept of the 295 Most

Commonly Recorded Species .......................... 9

References ............................................. 15

Catalog 1: Unsynonymized Species with Publication and Location .. 20

Catalog 2: Synonymized Species with Publication and Location .... 210

Catalog 3: Unsynonymized Species ....................... 400

Catalog 4: Synonymized Species ...................... 407

\section{Volume II}

Catalog 5: Latitude and Longitude of Synonymized Species . . . . . . 413

Maps: Figures 1-296 ................................. 603 



\title{
Distribution of Recent Benthic Foraminifera in the Gulf of Mexico
}

\author{
Stephen J. Culver \\ and Martin A. Buzas
}

\section{Introduction}

Study of the recent benthic foraminifera in the Gulf of Mexico began in earnest in the early 1900s when Cushman published the first of several monographs on the foraminifera of the Atlantic Ocean. Since then, many other workers have contributed papers on the taxonomy, distribution, and ecology of Gulf of Mexico benthic foraminifera. Poag (1975) presented an abstract summarizing Circum-Gulf of Mexico distributions but a more detailed account was not published at the time of the writing of this paper. Between 1918 and 1978, 103 papers concerning Gulf of Mexico foraminifera were published. This paper represents the first attempt to synthesize these data and is the second of a series including and summarizing all published data on the distribution of recent benthic foraminifera around North America. All published distributional data for the east coast is presented in Culver and Buzas (1980) and the results of subsequent analysis are given in Buzas and Culver (1980), Culver and Buzas (in press, a; in press, b).

The work presented here can be divided into three main parts. First, there is a references sec-

Stephen J. Culver and Martin A. Buzas, Department of Paleobiology, National Museum of Natural History, Smithsonian Institution, Washington, D.C. 20560. tion consisting of (1) the 77 papers used in compiling the presence-absence data utilized by this study and (2) additional references that are cited in this paper. Second, there are five computergenerated catalogs listing every species ever recorded in publications on the Gulf of Mexico. Third, there are computer-generated maps of the 295 most commonly recorded species together with a map showing all sample localities in the Gulf. Explanatory notes for the catalogs and maps can be found later in this introduction. The discussion section contains tabulated summaries and treats various aspects of the distribution of individual species and groups of species.

Following the format of our study of the benthic foraminifera off the east coast of North America (Culver and Buzas, 1980), we have included a key to our concept of each of the 295 most commonly recorded species of the Gulf of Mexico.

\section{Methods}

Computer Techniques.-The computerization methods utilized in this work were the same as those described in detail in Culver and Buzas (1980).

Data Compilation.-Of the 103 papers published on the benthic foraminifera of the Gulf of 
Mexico, 77 contained data in a form enabling their incorporation in this study. The name of one or more species (living or dead) and the locality where they were found was all that was required. The information entered in the basic compilation file consisted of (1) author of publication, (2) date of publication, (3) generic name used in publication, (4) specific name used in publication, (5) locality, (6) latitude and longitude (see "Catalog 1").

When numerous sample sites of a particular study were in very close proximity they were summarized by one or several representative localities. Thus, all species recorded in the sampled area were considered to have been found at the representative points. Modification and sorting of this basic data file resulted in the production of five catalogs that are described below. The 296 maps in this publication are also computer-generated and were drawn on a Calcomp Plotter.

\section{The Catalogs}

Five catalogs are included in this section and are designed to enable the reader to have rapid access to all published distributional data on recent benthic foraminifera in the Gulf of Mexico. Catalog 1 lists (alphabetically by binomen) all the records of every species ever recorded in the Gulf and includes publication and locality information. This catalog contains over 18,000 entries and over 90,000 pieces of information. Catalog 2 is the synonymized version of Catalog 1 . This list is identical to Catalog 1 except that generic and specific names have been changed where necessary. To aid referral between Catalogs 1 and 2, line numbers starting at 10001 are included at the lefthand margin of the files. Thus, for example, it can be seen that Borelis pulchra from the Tortugas (Catalog 2, line 10118) was originally recorded (Cushman, 1922a) as Alveolina pulchra (Catalog 1, line 10118).

Catalogs 3 and 4 aid rapid use of the first two catalogs. Catalog 3 is an alphabetized list of the 1219 taxa that have been recorded in the Gulf of Mexico. Catalog 4 lists alphabetically the 848 species recorded in this area after synonymization achieved by reference to published illustrations and to specimens lodged in the USNM collections (National Museum of Natural History, Smithsonian Institution) and the British Museum (Natural History) collections. Catalogs 3 and 4, therefore, are derived directly from Catalogs 1 and 2 respectively.

Catalog 5 is intended for the researcher interested in specific areas. This catalog contains alphabetized lists of synonymized species for each locality (localities are listed by increasing latitude and longitude). If, in the case of a synonymized species, the investigator questions the generic or specific name used, he can refer to Catalogs 1 and 2 to find the original name used by the author of the publication in which that species was recorded.

A compilation of this magnitude inevitably contains some errors. At this time we are aware of three that were discovered too late to correct. The records of Plectina apicularis in Catalog 1 should have been referred to Karreriella apicularis in Catalogs 2, 4, and 5. These records, therefore, should be referred by the reader to the latter name in the synonymized catalogs. Similarly, the records of Siphotrochammina squamata in Catalog 1 should have been referred to Trochammina squamata in Catalog 2, 4, and 5. The maps drawn for the distribution of Karreriella apicularis and Trochammina squamata are complete and correct. Both Amphicoryna sublineata and Nodosaria sublineata appear in Catalogs 2, 4, and 5, and a map has been included for each of them; however, reference to the key of commonly recorded species indicates that they are conspecific. Hence, the records shown on the two maps should be combined. Tables 1 and 3 refer to this species as Nodosaria sublineata.

\section{The Maps}

Two hundred and ninety-six computer-generated maps are included in this section and, like the catalogs, are provided as a reference tool for use in distributional studies of recent benthic foraminifera. Figure 1 illustrates the distribution of all the 426 sample localities included in this 
study. The $183 \mathrm{~m}$ and $1830 \mathrm{~m}$ submarine contours roughly approximate the edge of the continental shelf and the bottom of the continental slope, respectively. The distribution of the sample localities must be taken into account when examining the maps illustrating the distributions of species.

Figures 2-296 are computer-generated maps for the 295 most commonly recorded species. These are species that have been recorded 16 times or more, or at approximately $4 \%$ or more of the 426 localities: the figure $4 \%$ was chosen to achieve conformity with the study of the Atlantic continental margin of North American (Culver and Buzas, 1980) where maps were drawn for those species that have been recorded 20 times or more, again approximately $4 \%$ or more of the 542 localities in question. The maps are arranged alphabetically by genera and by species within each genus. A brief discussion and tabulated summary of the distribution of each of the illustrated species follows.

\section{AcKnowledgments}

We thank Dante Piacesi and Ken McCormick for their considerable efforts in the computer production of this work. Angela Lanham and Laurel Smith contributed invaluable library research and secretarial services. James Ingle supplied the type specimens of several species for our examination and C. G. Adams allowed access to British Museum (Natural History) collections.

\section{Discussion}

The main purpose of this publication is to present all the published distributional data of the recent benthic foraminifera of the Gulf of Mexico. The discussion of these data, therefore, will be brief and of a summary nature as more detailed discussion will be the subject of subsequent publications.

A total of 1219 taxa have been recorded in the Gulf of Mexico from 426 localities. Synonymization has reduced this number to 848 . Of these 848 species, 295 occurred at 16 or more of the 426 localities; that is, $35 \%$ of the species occur at $4 \%$ or more of the sample localities.

Distributional data of the 295 most commonly recorded species have been summarized by tabulation. Tables 1 and 2 present depth distribution and Table 3 is a synopsis of geographic distribution. Original analysis of depth distribution involved placing the species in three categories, coastal, less than $200 \mathrm{~m}$, and more than $200 \mathrm{~m}$. This clearly indicated species diversity increasing continuously offshore; however, much detailed information was lost in using only these three categories. Thus, the overlapping distribution categories in Table 1 more accurately convey depth distribution information for the 295 most commonly recorded species. Twenty-three species occur at depths of less than $50 \mathrm{~m}, 13$ at less than $100 \mathrm{~m}$, eight at less than $200 \mathrm{~m}$, one between 50 and $200 \mathrm{~m}, 23$ at less than $500 \mathrm{~m}$, two between 50 and $500 \mathrm{~m}, 28$ less than $1000 \mathrm{~m}, 13$ between 50 and $1000 \mathrm{~m}$, five between 100 and $1000 \mathrm{~m}$, one between 200 and $1000 \mathrm{~m}, 11$ at less than 2000 $\mathrm{m}$, six between 50 and $2000 \mathrm{~m}, 16$ between 200 and $2000 \mathrm{~m}, 16$ between 500 and $2000 \mathrm{~m}, 31$ at depths of more than $50 \mathrm{~m}, 13$ deeper than $100 \mathrm{~m}$, 37 deeper than $200 \mathrm{~m}, 18$ deeper than $500 \mathrm{~m}$, and 11 deeper than $1000 \mathrm{~m}$. Eighteen species are ubiquitous.

No species are confined to depths of more than $2000 \mathrm{~m}$. All species that occur deeper than 2000 $\mathrm{m}$-those in the more than $50 \mathrm{~m}, 100 \mathrm{~m}, 200 \mathrm{~m}$, $500 \mathrm{~m}, 1000 \mathrm{~m}$, and ubiquitous categories in Table 1-range, therefore, from abyssal depths up onto the slope or shelf. Thus, a deep water association composed of solely abyssal species does not occur.

The depth range of species is very variable. Marginulina planata (Figure 160) has a very narrow range of 50 to $200 \mathrm{~m}$, as do the 23 species listed in the less than $50 \mathrm{~m}$ category. By contrast, 18 species are ubiquitous from inner shelf to abyssal depths and a further 31 species are almost as eurybathyal, occurring at depths of more than $50 \mathrm{~m}$.

Depth distributions of various organisms have been noted as changing with latitude (e.g., Hazel, 1970). Several species exhibit some changing of 
TABLE 1.-Depth Distribution

$$
<50 \mathrm{~m}
$$

Ammoastuta inepta

Ammobaculites exiguus

Ammotium salsum

Arenoparrella mexicana

Bolivina striatula

Elphidium delicatulum

Elphidium excavatum

Elphidium koeboeense

Gaudryina exilis

Massilina peruviana

Miliammina fusca

Miliolinella obliquinoda

Palmerinella palmerae

Quinqueloculina cultrata

Quinqueloculina funafutiensis

Quinqueloculina poeyana

Quinqueloculina rhodiensis

Quinqueloculina seminula

Reophax nana

Tiphotrocha comprimata

Triloculina sidebottomi

Trochammina inflata

Trochammina macrescens

$$
<100 \mathrm{~m}
$$

Ammonia pauciloculata

Ammonia rolshauseni

Elphidium fimbriatulum

Elphidium galvestonense

Elphidium mexicanum

Haynesina germanica

Nodobaculariella atlantica

Nouria polymorphinoides

Peneroplis proteus

Quinqueloculina agglutinans

Quinqueloculina bosciana

Quinqueloculina subpoeyana

Sorites orbitolitoides

$$
<200 \mathrm{~m}
$$

Amphistegina gibbosa

Archaias angulatus

Asterigerina carinata

Buliminella elegantissima

Cancris sagra

Elphidium poeyanum

Planulina ornata

Quinqueloculina compta

50-200 m

Marginulina planata
$<500$ m

Ammoscalaria pseudospiralis

Bigenerina irregularis

Bigenerina textularioidea

Elphidium advenum

Elphidium gunteri

Eponides repandus

Fursenkoina spinicostata

Guttulina australis

Gypsina vesicularis

Hanzawaia strattoni

Neoconorbina terquemi

Nodobaculariella cassis

Planorbulina mediterranensis

Quinqueloculina bicostata

Quinqueloculina polygona

Rosalina bulbosa

Rosalina floridana

Rosalina floridensis

Spiroplectammina floridana

Textularia candeiana

Textularia conica

Textularia mayori

Wiesnerella auriculata

$$
\text { 50-500 m }
$$

Gaudryina aequa

Textulariella barrettii

$$
<1000 \mathrm{~m}
$$

Ammonia beccarii

Bolivina fragilis

Bolivina striatula spinata

Bulimina marginata

Bulimina tenuis

Buliminella bassendorfensis

Cancris oblonga

Cibicides deprimus

Cibicides protuberans

Discorbinella bertheloti

Elphidium discoidale

Eponides antillarum

Fursenkoina pontoni

Fursenkoina punctata

Fursenkoina schreibersiana

Hanzawaia concentrica

Planulina exorna

Pyrgo nasuta

Quinqueloculina lamarckiana

Rectobolivina advena

Reussella atlantica

Rosalina concinna
Rosalina suezensis

Siphonaperta horrida

Siphonina pulchra

Textularia earlandi

Trifarina bella

Triloculina brevidentata

$$
\text { 50-1000 m }
$$

Bolivina goesii

Bolivina minima

Cibicides io

Cibicides mollis

Cibicides umbonatus

Clavulina mexicana

Marginulinopsis marginulinoides

Nodosaria sublineata

Planulina foveolata

Siphonina bradyana

Spirillina vivipara

Textularia foliacea occidentalis Uvigerina flintii

\section{$100-1000 \mathrm{~m}$}

Gaudryina atlantica

Marginulinopsis subaculeata glabrata

Nodosaria comatula

Oridorsalis tener stellatus

Textularia mexicana

$$
\text { 200-1000 m }
$$

Uvigerina peregrina mediterranea

$$
<2000 \text { m }
$$

Ammomarginulina foliacea

Buccella hannai

Gaudryina minuta

Lenticulina calcar

Nonionella atlantica

Nonionella grateloupi

Trifarina bradyi

Trifarina jamaicensis

Trochammina advena

Trochammina squamata

Uvigerina parvula

$$
\text { 50-2000 m }
$$

Bolivina barbata

Cassidulina laevigata

Cibicides pseudoungerianus

Nonion formosum

Planulina ariminensis
Uvigerina hispidocostata

$$
200 \text { m-2000 m }
$$

Ammobaculites agglutinans

Anomalinoides mexicana

Astrononion tumidum

Cassidulinoides mexicanus

Cibicides bantamensis

Cibicides corpulentus

Eggerella propinqua

Fursenkoina tessellata

Globobulimina ovula

Gyroidina altiformis cushmani

Haplophragmoides scitulum

Hyperammina laevigata

Pyrgo depressa

Rectobolivina dimorpha

Reticulophragmium venezuelanum

Tosaia weaveri

500-2000 m

Ammodiscus planorbis

Ammodiscus tenuis

Bathysiphon filiformis

Coryphostoma spinescens

Cribrostomoides lobatus

Cyclammina cancellata

Cystammina pauciloculata

Ehrenbergina pupa

Fissurina formosa

Fursenkoina seminuda

Globocassidulina murrhyna

Haplophragmoides ringens

Lituotuba lituiformis

Reophax pilulifer

Uvigerina spinicostata

Valvulineria opima

$$
>50 \mathrm{~m}
$$

Ammonia translucens

Bolivina daggarius

Bolivina ordinaria

Bolivina subaenariensis mexicana

Bolivina translucens

Bulimina inflata mexicana

Bulimina spicata

Cassidulina carinata

Cassidulina crassa

Cassidulina curvata

Cassidulina neocarinata

Cibicides robertsonianus

Eponides regularis 
TABLE 1.-Continued

Eponides tumidulus

Eponides turgidus

Eponides umbonatus

Glomospira charoides

Hoeglundina elegans

Lenticulina peregrina

Melonis pompilioides (see p. 5)

Nodosaria pyrula

Pullenia bulloides

Pullenia quinqueloba

Pyrgo murrhina

Reophax dentaliniformis

Reophax scorpiurus

Sphaeroidina bulloides

Triloculina tricarinata

Uvigerina peregrina

Valvulineria mexicana

Valvulineria minuta

$$
>100 \mathrm{~m}
$$

Bulimina aculeata

Cibicides kullenbergi

Cribrostomoides subglobosum

Dentalina communis

Fursenkoina mexicana

Karreriella bradyi

Nodellum membranaceum

Reophax hispidulus

Robertinoides bradyi

Sigmoilina tenuis

Trochammina tasmanica

Uvigerina auberiana
Valvulineria laevigata

$$
>200 \mathrm{~m}
$$

Adercotryma glomerata

Alabamina decorata

Ammodiscoides turbinatus

Bulimina affinis

Bulimina alazanensis

Cassidulinoides tenuis

Chilostomella oolina

Cibicides bradyi

Cibicides rugosus

Cribrostomoides nitidum

Dentalina cuvieri

Dentalina intorta

Eggerella bradyi

Eponides polius

Gaudryina flintii

Globocassidulina pacifica

Glomospira gordialis

Gyroidina altiformis

Gyroidina orbicularis

Gyroidina umbonata

Haplophragmoides sphaeriloculus

Karreriella apicularis

Laticarinina pauperata

Lenticulina gibba

Martinottiella occidentalis

Oridorsalis tener tener

Osangularia cultur

Osangularia rugosa

Pullenia osloensis
Rectobolivina abrupta

Reophax distans delicatulus

Saccorhiza ramosa

Sigmoilopsis schlumbergeri

Tolypammina schaudinni

Trochammina japonica

Uvigerina peregrina dirupta

Valvulineria complanata

$$
>500 \mathrm{~m}
$$

Ammoglobigerinoides dehiscens

Ammolagena clavata

Bolivina alata

Cribrostomoides wiesneri

Hormosina carpenteri

Hormosina globulifera

Hormosina ovicula

Hyperammina friabilis

Planulina wuellerstorfi

Pleurostomella bolivinoides

Pullenia trinitatensis

Quinqueloculina vulgaris

Recurvoides contortus $f$. subglobosus

Rhabdammina abyssorum

Rhabdammina linearis

Rhizammina algaeformis

Thurammina papillata

Trochammina globulosa

$$
>1000 \mathrm{~m}
$$

Bolivina pusilla
Florilus clavatus

Francesita advena

Gyroidina altiformis acuta

Pseudotrochammina triloba

Pullenia subsphaerica

Pyrgo lucernula

Quinqueloculina venusta

Recurvoides contortus $f$. scitulus

Siphotextularia rolshauseni

Uvigerina hispida

Ubiquitous

Bolivina albatrossi

Bolivina lowmani

Bolivina subspinescens

Cassidulina subglobosa

Cibicides floridanus

Epistominella exigua

Epistominella vitrea

Fursenkoina loeblichi

Lagena laevis

Nonionella opima

Rosalina williamsoni

Saccammina atlantica

Sagrina pulchella

Seabrookia earlandi

Spirosigmoilina distorta

Stetsonia minuta

Triloculina trigonula

Uvigerina bellula depth distributions around the Gulf. The most distinct examples of these distributions are summarized in Table 2. The depth distribution noted for Melonis pompilioides (Figure 165) in this table and in Table 1 may be somewhat misleading. The shelf occurrences were recorded by Phleger (1951). In the associated taxonomic paper (Phleger and Parker, 1951) it was noted that shallower records were probably referable to Nonion barleeanum (= Melonis barleeanus) (Phleger and Parker, 1951:11). These authors, however, did not expressly state at what depth the compressed form, $M$. barleeanus, was replaced by the more inflated M. pompilioides. Thus, to preclude subjectivity in synonymization of species records at particular localities, all records of Melonis pompilioides in
TABLE 2.-Examples of changing depth distribution

\begin{tabular}{ll}
\hline Buliminella elegantissima & Textularia candeiana \\
Epistominella exigua & Textularia conica \\
Epistominella vitrea & Textularia earlandi \\
Eponides turgidus & Textularia foliacea occidentalis \\
Eponides umbonatus & Textularia mayori \\
Fursenkoina loeblichi & Trochammina squamata \\
Melonis pompilioides (see p. 5) & Uvigerina peregrina \\
Stetsonia minuta &
\end{tabular}

Phleger (1951) were retained as such. This species, however, as generally believed, is probably restricted to bathyal and abyssal depths.

The genus Textularia is of particular interest as all of its species incorporated in Table 1 are 
TABLE 3.-Geographic distribution

Northeast
Bigenerina textularioidea
Cassidulina carinata
Cibicides protuberans
Gypsina vesicularis
Sigmoilina tenuis

Northeast-Northcentral

Bolivina daggarius

Bolivina goësii

Bolivina pusilla

Cassidulinoides tenuis

Francesita advena

Pyrgo lucernula

Quinqueloculina venusta

Rectobolivina abrupta

Reophax distans delicatulus

Reophax hispidulus

Robertinoides bradyi

Trochammina japonica

Valvulineria mexicana

Northcentral

Ammobaculites agglutinans

Bolivina alata

Dentalina intorta

Globobulimina ovula

Hyperammina friabilis

Hyperammina laevigata

Lenticulina gibba

Lituotuba lituiformis

Pleurostomella bolivinoides

Pseudotrochammina triloba

Recurvoides contortus f. scitulus

Recurvoides contortus f. subglobosus

Reophax pilulifer

Rhabdammina abyssorum

Northeast-NorthcentralNorthwest

Adercotryma glomerata

Ammobaculites exiguus

Ammoscalaria pseudospiralis

Anomalinoides mexicana

Astrononion tumidum

Bolivina minima

Bolivina ordinaria

Chilostomella oolina

Cibicides io

Cribrostomoides wiesneri

Dentalina communis

\section{Discorbinella bertheloti}

Elphidium excavatum

Epistominella vitrea

Eponides tumidulus

Fissurina formosa

Fursenkoina mexicana

Fursenkoina schreibersiana

Fursenkoina tessellata

Gaudryina exilis

Gaudryina minuta

Glomospira charoides

Glomospira gordialis

Gyroidina orbicularis

Haplophragmoides ringens

Haplophragmoides scitulum

Lenticulina calcar

Lenticulina peregrina

Nodosaria pyrula

Nouria polymorphinoides

Osangularia rugosa

Planorbulina mediterranensis

Quinqueloculina cultrata

Quinqueloculina vulgaris

Rectobolivina dimorpha

Reophax scorpiurus

Saccammina atlantica

Seabrookia earlandi

Sigmoilopsis schlumbergeri

Sorites orbitolitoides

Spirosigmoilina distorta

Stetsonia minuta

Textularia earlandi

Tolypammina schaudinni

Trifarina bradyi

Triloculina brevidentata

Triloculina sidebottomi

Triloculina tricarinata

Trochammina globulosa

Trochammina squamata

Trochammina tasmanica

Uvigerina auberiana

Valvulineria laevigata

Wiesnerella auriculata

Northcentral-Northwest

Ammodiscoides turbinatus

Ammodiscus planorbis

Ammodiscus tenuis

Ammoglobigerinoides dehiscens

Ammolagena clavata

Ammomarginulina foliacea

Ammonia rolshauseni
Bathysiphon filiformis

Cassidulinoides mexicanus

Cibicides bantamensis

Cibicides bradyi

Coryphostoma spinescens

Cribrostomoides lobatus

Cystammina pauciloculata

Dentalina cuvieri

Florilus clavatus

Fursenkoina seminuda

Globocassidulina murrhyna

Gyroidina altiformis acuta

Gyroidina altiformis cushmani

Gyroidina umbonata

Haplophragmoides sphaeriloculus

Hormosina globulifera

Hormosina ovicula

Nodellum membranaceum

Nodosaria sublineata

Oridorsalis tener stellatus

Oridorsalis tener tener

Pullenia subsphaerica

Pullenia trinitatensis

Reophax dentaliniformis

Reticulophragmium venezuelanum

Rhabdammina linearis

Saccorhiza ramosa

Thurammina papillata

Tiphotrocha comprimata

Tosaia weaveri

Trochammina macrescens

Uvigerina hispida

Uvigerina peregrina dirupta

Uvigerina peregrina mediterranea

Uvigerina spinicostata

Valvulineria complanata

Valvulineria opima

\section{Northwest}

Ammonia pauciloculata

Bulimina tenuis

Ehrenbergina pupa

Globocassidulina pacifica

Hormosina carpenteri

Massilina peruviana

Pullenia osloensis

Northeast-NorthcentralSouth

Cassidulina laevigata

Cribrostomoides nitidum
Peneroplis proteus

Trifarina jamaicensis

Northeast-South

Archaias angulatus

Quinqueloculina agglutinans

Northcentral-NorthwestSouth

Ammoastuta inepta

Cyclammina cancellata

Eggerella propinqua

Elphidium koeboeense

Martinottiella occidentalis

Palmerinella palmerae

Northeast-Northwest

Miliolinella obliquinoda

Nonion formosum

Quinqueloculina bosciana

Rhizammina algaeformis

Ubiquitous

Alabamina decorata

Ammonia beccarii

Ammonia translucens

Ammotium salsum

Amphistegina gibbosa

Arenoparrella mexicana

Asterigerina carinata

Bigenerina irregularis

Bolivina albatrossi

Bolivina barbata

Bolivina fragilis

Bolivina lowmani

Bolivina striatula

Bolivina striatula spinata

Bolivina subaenariensis mexicana

Bolivina subspinescens

Bolivina translucens

Buccella hannai

Bulimina aculeata

Bulimina affinis

Bulimina alazanensis

Bulimina inflata mexicana

Bulimina marginata

Bulimina spicata

Buliminella bassendorfensis

Buliminella elegantissima

Cancris oblonga

Cancris sagra 
Table 3.- Continued

Cassidulina crassa

Cassidulina curvata

Cassidulina neocarinata

Cassidulina subglobosa

Cibicides corpulentus

Cibicides deprimus

Cibicides floridanus

Cibicides kullenbergi

Cibicides mollis

Cibicides pseudoungerianus

Cibicides robertsonianus

Cibicides rugosus

Cibicides umbonatus

Clavulina mexicana

Cribrostomoides subglobosum

Eggerella bradyi

Elphidium advenum

Elphidium delicatulum

Elphidium discoidale

Elphidium fimbriatulum

Elphidium galvestonense

Elphidium gunteri

Elphidium mexicanum

Elphidium poeyanum

Epistominella exigua

Eponides antillarum

Eponides polius

Eponides regularis

Eponides repandus
Eponides turgidus

Eponides umbonatus

Fursenkoina loeblichi

Fursenkoina pontoni

Fursenkoina punctata

Fursenkoina spinicostata

Gaudryina aequa

Gaudryina atlantica

Gaudryina flintii

Guttulina australis

Gyroidina altiformis

Hanzawaia concentrica

Hanzawaia strattoni

Haynesina germanica

Hoeglundina elegans

Karreriella apicularis

Karreriella bradyi

Lagena laevis

Laticarinina pauperata

Marginulina planata

Marginulinopsis marginulinoides

Marginulinopsis subaculeata glabrata

Melonis pompilioides

Miliammina fusca

Neoconorbina terquemi

Nodobaculariella atlantica

Nodobaculariella cassis

Nodosaria comatula
Nonionella atlantica

Nonionella grateloupi

Nonionella opima

Osangularia cultur

Planulina ariminensis

Planulina exorna

Planulina foveolata

Planulina ornata

Planulina wuellerstorfi

Pullenia bulloides

Pullenia quinqueloba

Pyrgo depressa

Pyrgo murrhina

Pyrgo nasuta

Quinqueloculina bicostata

Quinqueloculina compta

Quinqueloculina funafutiensis

Quinqueloculina lamarckiana

Quinqueloculina poeyana

Quinqueloculina polygona

Quinqueloculina rhodiensis

Quinqueloculina seminula

Quinqueloculina subpoeyana

Rectobolivina advena

Reophax nana

Reussella atlantica

Rosalina bulbosa

Rosalina concinna

Rosalina floridana
Rosalina floridensis

Rosalina suezensis

Rosalina williamsoni

Sagrina pulchella

Siphonaperta horrida

Siphonina bradyana

Siphonina pulchra

Siphotextularia rolshausen

Sphaeroidina bulloides

Spirillina vivipara

Spiroplectammina floridana

Textularia candeiana

Textularia conica

Textularia foliacea occidentalis

Textularia mayori

Textularia mexicana

Textulariella barrettii

Trifarina bella

Triloculina trigonula

Trochammina advena

Trochammina inflata

Uvigerina bellula

Uvigerina flintii

Uvigerina hispidocostata

Uvigerina parvula

Uvigerina peregrina

Valvulineria minuta shown in Table 2 to exhibit changing distributions around the Gulf of Mexico. Three species move into deeper water eastwards across the Gulf and one species occupies deeper habitats to both the south and east. Textularia earlandi, generally a coastal form both on the east cost of North America and in the Gulf of Mexico, clearly moves into deeper water off the Mississippi delta (Figure 258).

Comparisons of depth distributions for species occurring off more than one coast of North America will be the subject of a future publication. For the present, the reader is referred to the maps in this publication and in Culver and Buzas (1980) for comparison purposes.

Generic distributions may also provide useful depth information. For example, in the Gulf of Mexico, most species of the genus Elphidium occur shallower than $500 \mathrm{~m}$. The genus Bigenerina is also restricted to depths of less than $500 \mathrm{~m}$ and Buliminella species occur shallower than $1000 \mathrm{~m}$. The genus Francesita (represented by one species) is indicative of deep water, occurring at more than $1000 \mathrm{~m}$ depth. In contrast, species of the genus Quinqueloculina are not so restricted: of a total of 14 species, 8 occur at depths of less than $100 \mathrm{~m}$, 12 shallower than $1000 \mathrm{~m}$, while another species (Q. vulgaris, Figure 216) is only found deeper than $500 \mathrm{~m}$ and $Q$. venusta (Figure 215) is restricted to depths of greater than $1000 \mathrm{~m}$. Thus, as expected, generic distributions are of some use as depth indicators but are not so applicable as individual species distributions.

Consideration of the depth distribution of benthic foraminifera as described here must take into account the limitations of the sample frame- 
work as defined in Figure 1. Data are lacking for the deepest part of the Gulf and for the Campeche Shelf. So much information is available, however, for the northern half of the Gulf of Mexico that the species depth distributions given herein are almost certainly representative of the Gulf as a whole.

Geographic distribution of recent benthic foraminifera is the subject of Table 3. Visual examination of Figures 2-296 suggests 11 categories of distribution. Five species are restricted to the northeastern part of the Gulf, 13 species occur in the northeastern to northcentral area, 14 species are restricted to the northcentral segment, 54 species occur across the Gulf in northeast, northcentral, and northwest segments, 44 species occur in the northcentral to northwest area, seven species are restricted to the northwestern part of the Gulf, four species occur in northeast, northcentral, and southern areas, two species occur in northeastern and southern areas, and six species occur in northcentral, northwest, and southern segments of the Gulf. Four species exhibit a disjunct distribution occurring in the northeast and northwest parts of the Gulf but not in the northcentral area, and 141 species have a ubiquitous, around-the-Gulf, geographic distribution.

The species comprising each category in Table 3 are generally restricted to the geographic area under which they are listed. Thus, a list of all the species that have been recorded in the northwest part of the Gulf of Mexico would include those listed under that particular category ("Northwest") plus those listed under the headings "Northeast-Northcentral-Northwest," "Northcentral-Northwest," "Northcentral-NorthwestSouth," "Northeast-Northwest," and "Ubiquitous." To save lengthy and repetitive description, the reader is referred to the relevant maps that illustrate these areas.

Zoogeography of the Gulf of Mexico has been the subject of several papers (e.g., Dall, 1889; Hedgpeth, 1953; Pulley, 1953). These papers are based on marine macrofaunal distributions and, as far as the authors know, benthic foraminiferal provinces in the Gulf of Mexico have not been discussed in print. The results of the present study, summarized in Tables 1-3, and prelimi- nary cluster analysis suggest that provincial boundaries in the Gulf of Mexico can be distinguished only at particular depths or at physiographic boundaries. The large number of geographically ubiquitous species (Table 3 ) in shelf and slope areas suggests that any chemical and physical environmental changes laterally around the Gulf or at the Mississippi delta are not large enough to promote provincialism. The most recognizable lateral geographic restriction of species that can be related to provincialism is the occurrence of the larger miliolids Archaias angulatus (Figure 22), Sorites orbitolitoides (Figure 250) and Peneropolis proteus (Figure 185), and Gypsina vesicularis (Figure 134) generally in the eastern part of the Gulf of Mexico. These records probably represent westward migration (now or in the recent past) from highly carbonate Caribbean environments where they abound.

Benthic foraminiferal provinces in the Gulf of Mexico are being investigated using the same techniques as were used for the eastern continental margin off North America (Buzas and Culver, 1980; Culver and Buzas, in press, a).

\section{Summary}

1. All published data on the distribution of recent benthic foraminifera in the Gulf of Mexico are presented in the form of 5 catalogs and 296 maps.

2. 1219 taxa have been recorded in the area of study.

3. The taxa have been reduced to 848 by synonymization.

4. Of the 848 synonymized species, 295 occurred at 16 or more of the sample locations; that is, $35 \%$ of the species occur at $4 \%$ or more of the 426 sample localities.

5. Nineteen groups of commonly recorded species characterize overlapping depth zones.

6. Another group of species is ubiquitous to all depths.

7. Commonly recorded genera and species vary in their usefulness for delimiting depth zones.

8. The depth distribution of 14 commonly recorded species changes considerably around the 
Gulf of Mexico and one species moves into deeper environments off the Mississippi delta.

9. Ten groups of commonly recorded species characterize overlapping zoogeographic categories.

10. Another group, represented by 141 of the 295 commonly recorded species, is ubiquitous in its geographic distribution in the area of study.

11. Foraminiferal provincial boundaries cannot be distinguished laterally around the Gulf, as circum-Gulf of Mexico physical and chemical environmental changes at any given depth are probably not large enough to promote provincialism.

\section{Key to the Species on the Maps}

Following Culver and Buzas (1980) we list below a key to our concept of the 295 most commonly recorded species in the Gulf of Mexico. Genera are listed alphabetically as are the species within each genus. Under each species, the reference or references are given where the reader can find published illustrations that adequately convey our concept of each of the commonly recorded species in this study. Many of the 295 species were also included in the key to commonly recorded species for the east coast of North America (Culver and Buzas, 1980); the references given here for these species are generally the same.

\section{Index to Publications That Illustrate Our Concept of the 295 Most Commonly RECORdEd SPECIES}

Adercotryma glomerata (Brady): Parker, 1954:486, pl. 1: fig. 18 [as Adercotryma glomeratum].

Alabamina decorata (Phleger and Parker): Phleger and Parker, 1951:28, pl. 15: figs. 4a,b, 5a,b [as Pseudoparella (?) decorata]. Pflum and Frerichs, 1976:107, pl. 6: figs. 8, 9, pl. 7: fig. 1.

Ammoastuta inepta (Cushman and McCulloch): Parker, Phelger, and Peirson, 1953:4, pl. 1: fig. 12.

Ammobaculites agglutinans (d'Orbigny): Cushman, 1920:60, pl. 12: fig. 3.

Ammobaculites exiguus Cushman and Bronnimann: Ellison and Nichols, 1970:15, pl. 2: fig. 6 [as Ammobaculites cf. A. exiguus].

Ammodiscoides turbinatus Cushman: Cushman, 1918:98, pl. 36: figs. 3-6, pl. 37: figs. 1-6.
Ammodiscus planorbis Höglund: Höglund, 1947:125, pl. 8: figs. 4, 9, pl. 28: figs. 13, 14, text figs. 91, 105, 109.

Ammodiscus tenuis Brady: Brady, 1884:332, pl. 38: figs. 5, 6 .

Ammoglobigerinoides dehiscens Frerichs: Frerichs, 1969:1, pl. 1: fig. 1, pl. 2: fig. 1.

Ammolagena clavata (Parker and Jones): Cushman, 1918:89, pl. 34: figs. 2-5, pl. 35: figs. 1-3.

Ammomarginulina foliacea (Brady): Brady, 1884:304, pl. 33: figs. 20-25 [as Haplophragmium foliaceum].

Ammonia beccarii (Linné): Schnitker, 1974:217-223, pl. 1.

Ammonia pauciloculata (Phleger and Parker): Phleger and Parker, 1951:23, pl. 12: figs. 8a,b, 9a,b [as "Rotalia" pauciloculata].

Ammonia rolshauseni (Cushman and Bermudez): Cushman and Bermudez, 1946:119, pl. 19: figs. 11-13 [as Rotalia rolshauseni].

Ammonia translucens (Phleger and Parker): Phleger and Parker, 1951:24, pl. 12: figs. 11a,b, 12a,b [as "Rotalia" translucens].

Ammoscalaria pseudospiralis (Williamson): Brady, 1884:302, pl. 33: figs. 1-4 [as Haplophragmium pseudospirale].

Ammotium salsum (Cushman and Bronnimann): Scott, Medioli, and Schafer, 1977:1578, pl. 2: figs. 4, 5.

Amphicoryna sublineata (Brady): Brady, 1884:508, pl. 63: figs. 19-22 [as Nodosaria hispida var. sublineata]. LeRoy and Levinson, 1974:7, pl. 3: fig. 9.

Amphistegina gibbosa d'Orbigny: d'Orbigny, 1839a:120, pl. 8: figs. 1-3. Crouch and Poag, 1979:91-92, pls. 1-4.

Anomalinoides mexicana Parker: Parker, 1954:539, pl. 11: figs. 21-23.

Archaias angulatus (Fichtel and Moll): Cushman, 1930:46, pl. 16: figs. 1-3, pl. 17: figs. 3-5.

Arenoparrella mexicana (Kornfeld): Kornfeld, 1931:86, pl. 13: figs. 5a-c [as Trochammina inflata var. mexicana]. Andersen, 1951a:31, figs. 1a-c. Andersen, 1951b:96.

Asterigerina carinata d'Orbigny: Cushman, 1931:77, pl. 15: figs. 4,5 .

Astrononion tumidum Cushman and Edwards: Brady, 1884: 728, pl. 109: fig. 5 [as Nonionina stelligera]. Parker, 1954 507, pl. 6: fig. 5.

Bathysiphon filiformis Sars: Cushman, 1918:27, pl. 11: figs. 4, 5.

Bigenerina irregularis Phleger and Parker: Phleger and Parker, 1951:4, pl. 1: figs. 16-21.

Bigenerina textularioidea (Goës): Goës, 1894:41, pl. 8: figs. 387 399 [as Clavulina textularioidea]. Parker, 1954:492, pl. 3: figs. 4,5 .

Bolivina alata (Seguenza): Brady, 1884:422, pl. 53: figs. 2-4 [as Bolivina beyrichi var. alata].

Bolivina albatrossi Cushman: Cushman, 1922b:31, pl. 6: fig 4.

Bolivina barbata Phleger and Parker: Phleger and Parker, 1951:13, pl. 6: figs. 12a,b. 13.

Bolivina daggarius Parker: Parker, 1954:514, pl. 7: figs. 17-20 [as Bolivina lanceolata].

Bolivina fragilis Phleger and Parker: Phleger and Parker, 
1951:13, pl. 6: figs. 14, 23, 24a,b.

Bolivina goësii Cushman: Cushman, 1922b:34, pl. 6: fig. 5.

Bolivina lowmani Phleger and Parker: Phleger and Parker, 1951:13, pl. 6: figs. 20a,b, 21.

Bolivina minima Phleger and Parker: Phleger and Parker, 1951:14, pl. 6: figs. 22a,b, 25, pl. 7: figs. 1, 2.

Bolivina ordinaria Phleger and Parker: Phleger and Parker, 1951:14, pl. 7: figs. 4-6 [as Bolivina simplex.].

Bolivina pusilla Schwager: Parker, 1954:516, pl. 7: fig. 31.

Bolivina striatula Cushman: Cushman, 1944:29, pl. 4: figs. 4, 5.

Bolivina striatula Cushman spinata Cushman: Cushman, 1936: 59, pl. 8: figs. 9a,b.

Bolivina subaenariensis Cushman mexicana Cushman: Cushman, 1922b:47, pl. 8: fig. 1.

Bolivina subspinescens Cushman: Cushman, 1922b:48, pl. 7: fig. 5.

Bolivina translucens Phleger and Parker: Phleger and Parker, 1951:15,. pl. 7: figs. 13, 14a,b.

Buccella hannai Phleger and Parker: Phleger and Parker, 1951:21, pl. 10: figs. 11-14.

Bulimina aculeata d'Orbigny: Cushman, 1922b:96, pl. 22: figs. $1,2$.

Bulimina affinis d'Orbigny: Cushman, 1922b:103, pl. 20: fig. 6.

Bulimina alazanensis Cushman: Parker, 1954:510, pl. 6: fig. 21.

Bulimina inflata Seguenza mexicana Cushman: Cushman, 1922b:95, pl. 21: fig. 2.

Bulimina marginata d'Orbigny: Schnitker, 1971:194, pl. 5: fig. 5.

Bulimina spicata Phleger and Parker: Phleger and Parker, 1951:16, pl. 7: figs. 25a-c, 30, 31.

Bulimina tenuis Phleger and Parker: Phleger and Parker, 1951: 16, pl. 7: figs. 33a,b, 34a,b.

Buliminella bassendorfensis Cushman and Parker: Cushman and Parker, 1947:66, pl. 17: fig. 6.

Buliminella elegantissima (d'Orbigny): Schnitker, 1971:194, pl. 4: fig. 17.

Cancris oblonga (Williamson): Williamson, 1858:51, pl. 4: figs. 98-100 [as Rotalina oblonga]. Parker, 1954:532, pl. 10: figs. $13,14$.

Cancris sagra (d'Orbigny): Schnitker, 1971:194, pl. 6: fig. 5.

Cassidulina carinata Silvestri: Silvestri, 1896:104, pl. 2: fig. 10 [as Cassidulina laevigata var. carinata]. Parker, 1954:535, pl. 10: fig. 30.

Cassidulina crassa d'Orbigny: d'Orbigny, 1839b:56, pl. 7: figs. 18-20. More than one species may be represented by $C$. crassa of various authors included in this study.

Cassidulina curvata Phleger and Parker: Phleger and Parker, 1951:26, pl. 14: figs. 5a,b.

Cassidulina laevigata d'Orbigny: Schnitker, 1971:196, pl. 10: fig. 5.

Cassidulina neocarinata Thalmann: Cushman, 1922b:124, pl. 25: figs. 6, 7 [as Cassidulina laevigata var. carinata].
Cassidulina subglobosa Brady: Parker, 1948:237, pl. 6: figs. 3a,b.

Cassidulinoides mexicanus (Cushman): Cushman, 1922b:131, pl. 24: fig. 5 [as Cassidulina mexicana].

Cassidulinoides tenuis Phleger and Parker: Phleger and Parker, 1951:27, pl. 14: figs. 14-17.

Chilostomella oolina Schwager: Parker, 1954:537, pl. 11: fig. 15.

Cibicides bantamensis LeRoy: LeRoy, 1941:119, pl. 2: figs. 10$12,16-18$

Cibicides bradyi (Trauth): Pflum and Frerichs, 1976:107, pl. 3: figs. $6,7$.

Cibicides corpulentus Phleger and Parker: Phleger and Parker, 1951:31, pl. 17: figs. 1-4 [as Cibicides robustus].

Cibicides deprimus Phleger and Parker: Phleger and Parker, 1951:29, pl. 15: figs. 15-17.

Cibicides floridanus (Cushman): Phleger and Parker, 1951:30, pl. 16: figs. 1-4 [as Cibicides aff. floridanus].

Cibicides io Cushman: Cushman, 1931:125, pl. 23: figs. 1, 2 [as Cibicides pseudoungeriana var. io].

Cibicides kullenbergi Parker: Parker, 1954:542, pl. 12: figs. 10, 11.

Cibicides mollis Phleger and Parker: Phleger and Parker, 1951 30, pl. 16: figs. 7-9.

Cibicides protuberans Parker: Parker, 1954:542, pl. 12: figs. 13, $14,16$.

Cibicides pseudoungerianus (Cushman): Cushman, 1931:123, pl. 22: figs. 3-7 [as Cibicides pseudoungeriana].

Cibicides robertsonianus (Brady): Brady, 1884:664, pl. 95: figs. $4 \mathrm{a}-\mathrm{c}$ [as Truncatulina robertsonianus].

Cibicides rugosus Phleger and Parker: Phleger and Parker, 1951: 31, pl. 17: figs. 5, 6 [as Cibicides rugosa].

Cibicides umbonatus Phleger and Parker: Phleger and Parker, 1951:31, pl. 17: figs. 7-9.

Clavulina mexicana (Cushman): Cushman, 1922b:83, pl. 16: figs. 1-3 [as Clavulina humilis var. mexicana].

Coryphostoma spinescens (Cushman): Cushman, 1911:46, text figs. 76a,b [as Bolivina spinescens].

Cribrostomoides lobatus Saidova: Saidova, 1961:32, pl. 9: fig. 49.

Cribrostomoides nitidum (Goës): Parker, 1954:486, pl. 1: fig. 17 [as Alveolophragmium nitidum].

Cribrostomoides subglobosum (Sars): Loeblich and Tappan, 1964:C225, fig. 136(1,2).

Cribrostomoides wiesneri (Parr): Parker, 1954:488, pl. 1: fig. 23 [as Alveolophragmium wiesneri].

Cyclammina cancellata Brady: Cushman, 1920:53, pl. 10: figs. 4,5 .

Cystammina pauciloculata (Brady): Loeblich and Tappan, 1964:C263, fig. 177(1).

Dentalina communis (d'Orbigny): Cushman, 1920:75, pl. 12: figs. 3, 4, 15-17 [as Nodosaria communis].

Dentalina cuvieri (d'Orbigny): Loeblich and Tappan, 1964: C516, figs. 403(2,3).

Dentalina intorta (Dervieux): Andersen, 1961:66, pl. 17: fig. 5. 
Discorbinella bertheloti (d'Orbigny): Parker, 1954:523, pl. 8: figs. 22, 23 [as Rosalina bertheloti].

Eggerella bradyi Cushman: Cushman, 1922b:59, pl. 11: fig. 1 [as Verneuilina bradyi].

Eggerella propinqua (Brady): Brady, 1884:387, pl. 47: figs. 812 [as Verneuilina propinqua]. Cushman, 1922b:56, pl. 9: figs. 10, 11 [as Verneuilina propinqua].

Ehrenbergina pupa (d'Orbigny): Brady, 1884:433, pl. 111: figs. $10 \mathrm{a}-\mathrm{c}$.

Elphidium advenum (Cushman): Schnitker, 1971:198, pl. 7: fig. 2.

Elphidium delicatulum Bermudez: Bermudez, 1949:168, pl. 11: figs. 22, 23.

Elphidium discoidale (d'Orbigny): Schnitker, 1971:198, pl. 7: fig. 6 [as Elphidiella sp., cf. E. mexicana].

Elphidium excavatum (Terquem): Cushman, 1930:20, pl. 7: figs. 10a, b [as Elphidium incertum var. clavatum]. Schnitker, 1971:198, pl. 7: fig. 4 [as Elphidium incertum].

Elphidium fimbriatulum (Cushman): Phleger and Parker, 1951: 10, pl. 5: fig. 12 [as Elphidium cf. fimbriatulum].

Elphidium galvestonense Kornfeld: Kornfeld, 1931:87, pl. 15: figs. 1a,b [not figs. 2, 3] [as Elphidium gunteri var. galvestonense].

Elphidium gunteri Cole: Grossman, 1967:59, pl. 8: figs. 1-4.

Elphidium koeboeense LeRoy: Ayala-Castanares, 1963:95, pl. 8: figs. 8a, b [as Elphidium cf. E. koeboeense].

Elphidium mexicanum (Kornfeld): Todd and Low, 1961:20, pl. 2: fig. 7 [as Elphidium poeyanum].

Elphidium poeyanum (d'Orbigny): Loeblich and Tappan, 1964: C635, fig. 508(3, 4) [as Cribroelphidium poeyanum].

Espistominella exigua (Brady): Phleger and Parker, 1951:28, pl. 15: figs. 6, 7 [as Pseudoparrella exigua].

Epistominella vitrea Parker: Parker, Phleger, and Peirson, 1953:9, pl. 4: figs. 34-36, 40, 41.

Eponides antillarum (d'Orbigny): Cushman, 1931:42, pl. 9: figs. $2 \mathrm{a}$, c.

Eponides polius Phleger and Parker: Phleger and Parker, 1951: 21, pl. 11: figs. 1, 2.

Eponides regularis Phleger and Parker: Phleger and Parker, 1951:21, pl. 11: figs. 3, 4 .

Eponides repandus (Fichtel and Moll): Phleger and Parker, 1951: 21, pl. 11: figs. 5, 6 .

Eponides tumidulus (Brady): Brady, 1884:666, pl. 95: figs. 8a$\mathrm{d}$ [as Truncatulina tumidula].

Eponides turgidus Phleger and Parker: Phleger and Parker, 1951:22, pl. 11: figs. 9a, b.

Eponides umbonatus (Reuss): Cushman, 1931:52, pl. 11: figs. 1-3 [as Eponides umbonata].

Fissurina formosa (Schwager): Cushman, Todd, and Post, 1954:351, pl. 87: fig. 31.

Florilus clavatus (Cushman): Cushman, 1931:30, pl. 4: figs. 9a-c [as Nonionella clavata].

Francesita advena (Cushman): Cushman, 1922b:120, pl. 25: figs. 1-3 [as Virgulina (?) advena]. Parker, 1954:512, pl. 7: fig. 5 [as Virgulina advena].
Fursenkoina loeblichi '(Feyling-Hanssen): Phleger and Parker, 1951:18, pl. 9: figs. 1-3 [as Virgulina complanata].

Fursenkoina mexicana (Cushman): Phleger and Parker, 1951: 19, pl. 9: figs. 6-8 [as Virgulina mexicana].

Fursenkoina pontoni (Cushman): Phleger and Parker, 1951:19, pl. 9: figs. 9, 10 [as Virgulina pontoni].

Fursenkoina punctata (d'Orbigny): Parker, 1954:513, pl. 7: fig. 11 [as Virgulina punctata].

Fursenkoina schreibersiana (Czjek): Cushman, 1922b:117, pl. 26: fig. 6 [as Virgulina schreibersiana].

Fursenkoina seminuda (Natland): Natland, 1938:145, pl. 5: fig. 12 [as Virgulina seminuda].

Fursenkoina spinicostata (Phleger and Parker): Phleger and Parker, 1951:19, pl. 9: figs. 11-14 [as Virgulina spinicostata].

Fursenkoina tessellata (Phleger and Parker): Phleger and Parker, 1951: 19, pl. 9: figs. 15, 16 [as Virgulina tessellata].

Gaudryina aequa Cushman: Phleger and Parker, 1951:6, pl. 2: figs. 11, 12 [as Gaudryina cf. aequa].

Gaudryina atlantica (Bailey): Cushman, 1922b:70, pl. 13: figs. $1-3$.

Gaudryina exilis Cushman and Bronnimann: Parker, Phleger, and Peirson, 1953:9, pl. 1: figs. 37, 38.

Gaudryina flintii Cushman: Parker, 1954:493, pl. 3: fig. 6.

Gaudryina minuta Earland: Parker, 1954:493, pl. 3: figs. 15, 16.

Globobulimina ovula (d'Orbigny): Cushman and Parker, 1947: 122, pl. 28: figs. 20-22 [as Bulimina ovula].

Globocassidulina murrhyna (Schwager): Belford, 1966:152, pl. 26: figs. 10-13.

Globocassidulina pacifica (Cushman): Brady, 1884:431, pl. 113: figs. 8a-c [as Cassidulina calabra].

Glomospira charoides (Jones and Parker): Parker, 1954:485, pl. 1: fig. 14.

Glomospira gordialis (Jones and Parker): Cushman, 1918:99, pl. 36: figs. 7-9.

Guttulina australis (d'Orbigny): Bandy, 1954:136, pl. 29: fig. 7 [as Guttulina regina].

Gypsina vesicularis (Parker and Jones): Brady, 1884:718, pl. 101: figs. 9-12.

Gyroidina altiformis R. E. and K. C. Stewart: Phleger and Parker, 1951:22, pl. 11: figs. 15, 16 [as Groidina soldanii altiformis]. More than one subspecies may be represented by $G$. altiformis of various authors included in this study.

Gyroidina altiformis R. E. and K. C. Stewart acuta Boomgaart: Boomgaart, 1949:125, pl. 14: figs. 1a-c [as Gyroidina neosoldanii var. acuta].

Gyroidina altiformis R. E. and K. C. Stewart cushmani Boomgaart: Boomgaart, 1949:124, pl. 9: figs. 9a-c [as G)roidina cushmani].

Gyroidina orbicularis d'Orbigny: Phleger and Parker, 1951:22, pl. 11: figs. 11, 12.

Gyroidina umbonata (Silvestri): Silvestri, 1898:329, pl. 6: figs. $14 \mathrm{a}-\mathrm{c}$ [as Rotalia soldanii var. umbonata].

Hanzawaia concentrica (Cushman): 1931:120, pl. 21: figs. 4. 5 . 
pl. 22: figs. 1, 2 [as Cibicides concentrica].

Hanzawaia strattoni (Applin): Bandy, 1954:136, pl. 31: fig. 4. Haplophragmoides ringens (Brady): Cushman, 1920:49, pl. 9: fig. 2.

Haplophragmoides scitulum (Brady): Parker, 1954:487, pl. 1: figs. 20, 21 [as Alveolophragmium scitulum].

Haplophragmoides sphaeriloculus Cushman: Cushman, 1920:44, pl. 8: fig. 3 [as Haplophragmoides sphaeriloculum].

Haynesina germanica (Ehrenberg): Butcher, 1948:22, figs. 1-3 [as Nonion tisburyensis]. Scott, Medioli, and Schafer, 1977: 1579, pl. 5: fig. 6 [as Protelphidium orbiculare].

Hoeglundina elegans (d'Orbigny): Schnitker, 1971:204, pl. 10: fig. 15.

Hormosina carpenteri Brady: Brady, 1884:327, pl. 39: figs. 1418.

Hormosina globulifera Brady: Cushman, 1920:26, pl. 6: fig. 1. Hormosina ovicula Brady: Brady, 1884:327, pl. 39: figs. 7-9.

Hyperammina friabilis Brady: Brady, 1884:258, pl. 23: figs. 1$3,5,6$.

Hyperammina laevigata Wright: Cushman, 1918:77, pl. 29: figs. $5,6$.

Karreriella apicularis (Cushman): Brady, 1884:382, pl. 46: figs. 17-19 [as Gaudryina siphonella].

Karreriella bradyi (Cushman): Cushman, 1922b:74, pl. 12: fig. 8 [as Gaudryina bradyi].

Lagena laevis (Montagu): Schafer and Cole, 1978:28, pl. 6: fig. 10 .

Laticarinina pauperata (Parker and Jones): Phleger and Parker, 1951:32, pl. 18: fig. 3 .

Lenticulina calcar (Linné): Bandy, 1956:197, pl. 30: fig. 11 [as Robulus calcar].

Lenticulina gibba (d'Orbigny): Cushman, 1923:105, pl. 25: fig. 4 [as Cristellaria gibba].

Lenticulina peregrina (Schwager): Brady, 1884:541, pl. 68: figs. 11-16 [as Cristellaria variabilis].

Lituotuba lituiformis (Brady): Cushman, 1920:59, pl. 12: figs. $1,2$.

Marginulina planata Phleger and Parker: Phleger and Parker, 1951:9, pl. 4: figs. 21, 22, pl. 5: figs. 1-3.

Marginulinopsis marginulinoides (Goës): Phleger and Parker, 1951:9, pl. 4: figs. 17, 18.

Marginulinopsis subaculeata (Cushman) glabrata (Cushman): Cushman, 1923:124, pl. 32: fig. 4, pl. 33: fig. 3, pl. 34: figs. 2, 3 [as Cristellaria subaculeata glabrata].

Martinottiella occidentalis (Cushman): Cushman, 1922b:87, pl. 17: figs. 1, 2 [as Clavulina occidentalis].

Massilina peruviana (d'Orbigny): Kornfeld, 1931:85, pl. 14: fig. 1 .

Melonis pompilioides (Fichtel and Moll): Pflum and Frerichs, 1976:108, pl. 7: figs. 7, 8.

Miliammina fusca (Brady): Parker, 1952:452, pl. 2: figs. 6a,b. Miliolinella obliquinoda (Riccio): Parker, Phleger, and Peirson, 1953:14, pl. 2: figs. 30-32 [as Triloculinella obliquinoda].

Neoconorbina terquemi (Rzehak): Schnitker, 1971:206, pl. 5: fig. 16.

Nodellum membranaceum (Brady): Brady, 1884:297, pl. 32: figs.
1-4 [as Reophax membranaceum].

Nodobaculariella atlantica Cushman and Hanzawa: Bandy, 1954: 137, pl. 29: fig. 4.

Nodobaculariella cassis (d'Orbigny): d'Orbigny, 1839a:51, pl.

7: figs. 14, 15 [as Vertebralina cassis]. Parker, 1954:501, pl.

5: fig. 8.

Nodosaria comatula Cushman: Cushman, 1923:83, pl. 14: fig. 5.

Nodosaria pyrula d'Orbigny: Cushman, 1923:69, pl. 16: figs. 1-4.

Nodosaria sublineata Brady: Brady, 1884:508, pl. 63: figs. 1922 [as Nodosaria hispida var. sublineala].

Nonion formosum (Seguenza): Seguenza, 1880:63, pl. 7: fig. 6 [as Nonionina formosa].

Nonionella atlantica Cushman: Cushman, 1947:90, pl. 30: figs $4,5$.

Nonionella grateloupi (d'Orbigny): Schnitker, 1971:206, pl. 10: fig. 6 [as Nonion grateloupi].

Nonionella opima Cushman: Parker, 1954:507, pl. 6: figs. 1012.

Nouria polymorphinoides Heron-Allen and Earland: Parker, Phleger, and Peirson, 1953:11, pl. 3: figs. 1, 2.

Oridorsalis tener stellatus (Silvestri): Pflum and Frerichs, 1976: 108, pl. 5: figs. 8, 9, pl. 6: fig. 1.

Oridorsalis tener tener (Brady): Pflum and Frerichs, 1976:108, pl. 6: figs. 2-4.

Osangularia cultur (Parker and Jones): Phleger and Parker, 1951:23, pl. 12: figs. 3a,b [as Parrella cultur].

Osangularia rugosa (Phleger and Parker): Parker, 1954:533, pl. 10: figs. 24, 25 [as Epistominella rugosa].

Palmerinella palmerae Bermudez: Poag, 1978:404, pl. 4: figs. 10-14, 17, 22, 23 [as Palmerinella palmerae forma typica].

Peneroplis proteus d'Orbigny: Cushman, 1930:37, pl. 13: figs. 1-7.

Planorbulina mediterranensis d'Orbigny: Schnitker, 1971:206, pl. 9: fig. 11.

Planulina ariminensis d'Orbigny: Parker, 1954:540, pl. 11: figs. 27, 30 .

Planulina exorna Phleger and Parker: Schnitker, 1971:206, pl. 9: fig. 6.

Planulina foveolata (Brady): Parker, 1954:540, p1. 11: figs. 25, 26.

Planulina ornata (d'Orbigny): Bandy, 1954:137, pl. 31: fig. 2. Planulina wuellerstorfi (Schwager): Phleger and Parker, 1951: 33, pl. 18: figs. $11 \mathrm{a}, \mathrm{b}$, pl. 19: figs. 1-3.

Pleurostomella bolivinoides Schubert: Cushman, Todd, and Post, 1954:356, pl. 88: fig. 29.

Pseudotrochammina triloba Frerichs: Frerichs, 1969:2, pl. 1: fig. 3, pl. 2: fig. 3.

Pullenia bulloides (d'Orbigny): Phleger and Parker, 1951:29, pl. 15: fig. 11.

Pullenia osloensis Feyling-Hanssen: Feyling-Hanssen, 1954: 133, pl. 2: figs. 3a,b [as Pullenia quinqueloba minuta].

Pullenia quinqueloba (Reuss): Schnitker, 1971:206, pl. 10: fig. 11.

Pullenia subsphaerica Parr: LeRoy and Hodgkinson, 1975:436, 
pl. 9: figs. 9, 10.

Pullenia trinitatensis Cushman and Stainforth: Cushman and Stainforth, 1945:66, pl. 12: fig. 11.

Pyrgo depressa (d'Orbigny): Cushman, 1929:71, pl. 19: figs. 4, 5.

Pyrgo lucernula (Schwager): LeRoy and Hodgkinson, 1975: 436, pl. 7: figs. 13, 14.

Pyrgo murrhina (Schwager): Cushman, 1929:71, pl. 19: figs. 6, 7.

Pyrgo nasuta Cushman: Phleger and Parker, 1951:7, pl. 3: figs. 12-14 [as Pyrgo cf. nasutus].

Quinqueloculina agglutinans d'Orbigny: d'Orbigny, 1839a:195, pl. 12: figs. 11-13.

Quinqueloculina bicostata d'Orbigny: Phleger and Parker, 1951: 7, pl. 3: figs. 15a,b.

Quinqueloculina bosciana d'Orbigny: Schnitker, 1971:208, pl. 2: fig. 13.

Quinqueloculina compta Cushman: Schnitker, 1971:208, pl. 2: fig. 14.

Quinqueloculina cultrata (Brady): Parker, Phleger, and Peirson, 1953:12, pl. 2: figs. 7, 8.

Quinqueloculina funatutiensis (Chapman): Cushman, 1922a:67, pl. 13: fig. 3.

Quinqueloculina lamarckiana d'Orbigny: Schnitker, 1971:208, pl. 3: fig. 16.

Quinqueloculina poeyana d'Orbigny: Schnitker, 1971:208, pl. 2, fig. 17.

Quinqueloculina polygona d'Orbigny: Parker, 1954:497, pl. 4: figs. 7, 8.

Quinqueloculina rhodiensis Parker: Bandy, 1956:196, pl. 29: fig. 10.

Quinqueloculina seminula (Linné): Sen Gupta, 1971:85, pl. 1: figs. 25-27.

Quinqueloculina subpoeyana Cushman: Bermudez and Seiglie, 1963:141, pl. 9: fig. 6.

Quinqueloculina venusta Karrer: Parker, 1954:498, pl. 4: figs. $13,14$.

Quinqueloculina vulgaris d'Orbigny: Phleger and Parker, 1951: 8, pl. 4: figs. 2a,b [as Quinqueloculina cf. vulgaris].

Rectobolivina abrupta (Phleger and Parker): Phleger and Parker, 1951:17, pl. 7: figs. 15-19 [as Loxostomum truncatum].

Rectobolivina advena (Cushman): Schnitker, 1971:208, pl. 4: fig. 26.

Rectobolivina dimorpha (Parker and Jones): Parker, 1954:519, pl. 7: fig. 37.

Recurvoides contortus Earland forma scitulus (Brady): Pflum and Frerichs, 1976:78. This form was not figured by Pflum and Frerichs who also recorded Cribrostomoides scitulus (Brady). The reader is referred to Loeblich and Tappan, 1964:C226, fig. 136(9a-c) for illustrations of $R$. contortus Earland.

Recurvoides contortus Earland forma subglobosus (Sars): Pflum and Frerichs, 1976:58 [as Recurvoides contortus forma subglobosa]. This form was not figured by Pflum and Frerichs who also recorded Cribrostomoides subglobosus (Sars). The reader is referred to Loeblich and Tappan, 1964:C226, fig. 136(9a-c) for illustrations of $R$. contortus Earland.

Reophax dentaliniformis Brady: Cushman, 1920:18, pl. 5: figs. $4,5$.

Reophax distans Brady delicatulus Cushman: Parker, 1954:482, pl. 1: fig. 4.

Reophax hispidulus Cushman: Parker, 1954:483, pl. 1: figs. 6, 7.

Reophax nana Rhumbler: Parker, Phleger, and Peirson, 1953: 13, pl. 1: fig. 11.

Reophax pilulifer Brady: Brady, 1884:292, pl. 30: fig. 18-20.

Reophax scorpiurus Montfort: Cushman, 1920:6, pl. 1: figs. 57.

Reticulophragmium venezuelanum (Maync): Loeblich and Tappan, 1964:C233, fig. 142(5a,b).

Reussella atlantica (Cushman): Schnitker, 1971:210, pl. 5: fig. 8.

Rhabdammina abyssorum Carpenter: Cushman, 1918:15, pl. 6: fig. 1, pl. 7: fig. 1.

Rhabdammina linearis Brady: Cushman, 1918:19, pl. 7: figs. 2-5.

Rhizammina algaeformis Brady: Brady, 1884:274, pl. 28: figs. 1-11. Cushman, 1918:31, pl. 11: figs. 2, 3.

Robertinoides bradyi (Cushman and Parker): Parker, 1954:510, pl. 6: fig. 18 [as Robertina bradyl].

Rosalina bulbosa (Parker): Parker, 1954:523, pl. 8: figs. 10-12 [as "Discorbis" bulbosa].

Rosalina concinna (Brady): Bandy, 1956:193, pl. 31: fig. 4 [as Discorbis concinnus].

Rosalina floridana (Cushman): Schnitker, 1971:210, pl. 5: fig. 19.

Rosalina floridensis (Cushman): Parker, 1954:525, pl. 8: figs. 28, 29.

Rosalina suezensis (Said): Parker, 1954:525, pl. 8: figs. 21, 26 , 27.

Rosalina williamsoni (Parr): Parker, 1954:525, pl. 8: figs. 24, 25 [as Rosalina parkerae].

Saccammina atlantica (Cushman): Sen Gupta, 1971:83, pl. 1: fig. 1.

Saccorhiza ramosa (Brady): Cushman, 1918:81, pl. 30: figs. 3, 4.

Sagrina pulchella d'Orbigny: Buzas, Smith, and Beem, 1977: 81, pl. 3: figs. 3-6.

Seabrookia earlandi Wright: Parker, 1954:538, pl. 11: fig. 13.

Sigmoilina tenuis (Czjzek): Phleger and Parker, 1951:8, pl. 4: fig. 7.

Sigmoilopsis schlumbergeri (Silvestri): Phleger and Parker, 1951 8, pl. 4: fig. 6 [as Sigmoilina schlumbergeri].

Siphonaperta horrida (Cushman): Parker, 1954:497, pl. 4: figs. 3, 4 [as Quinqueloculina horrida].

Siphonina bradyana Cushman: Phleger and Parker, 1951:24. pl. 12: figs. 13, 14.

Siphonina pulchra Cushman: Phleger and Parker, 1951:24, pl 12: figs. 15a,b.

Siphotextularia rolshauseni Phleger and Parker: Phleger and Parker, 1951:4, pl. 1: figs. 23, 24.

Sorites orbitolitoides (Hofker): Bandy, 1954:137, pl. 29: fig. 5 
[as Praesorites orbitolitoides].

Sphaeroidina bulloides d'Orbigny: Parker, 1954:539, pl. 11: fig. 18.

Spirillina vivipara Ehrenberg: Cushman, 1931:3, pl. 1: figs. 14.

Spiroplectammina floridana (Cushman): Phleger and Parker, 1951:4, pl. 1: figs. 25, 26.

Spirosigmoilina distorta (Phleger and Parker): Phleger and Parker, 1951:8, pl. 4: figs. 3-5 [as Sigmoilina distorta].

Stetsonia minuta Parker: Parker, 1954:534, pl. 10: figs. 27-29.

Textularia candeiana d'Orbigny: Schnitker, 1971:212, pl. 1: fig. 10.

Textularia conica d'Orbigny: Schnitker, 1971:212, pl. 1: fig. 11.

Textularia earlandi Phleger: Schafer and Cole, 1978:29, pl. 3: fig. 4.

Textularia foliacea Heron-Allen and Earland occidentalis Cushman: Phleger and Parker, 1951:5, pl. 1: figs. 28, 29.

Textularia mayori Cushman: Cushman, 1922a:23, pl. 2: fig. 3. Textularia mexicana Cushman: Cushman, 1922b:17, pl. 2: fig. 9.

Textulariella barrettii (Jones and Parker): Cushman, 1922b:20, pl. 3: figs. 3-6 [as Textularia barrettii]. Parker, 1954:491, pl. 2: fig. 11 .

Thurammina papillata Brady: Brady, 1884:321, pl. 36: figs. 718.

Tiphotrocha comprimata (Cushman and Bronnimann): Saunders, 1957:11, pl. 4: figs. 1-4.

Tolypammina schaudinni Rhumbler: Parker, 1954:485, pl. 1: fig. 15.

Tosaia weaveri Seiglie and Bermudez: Seiglie and Bermudez, 1966:66, pl. 1: figs. 4-7.

Trifarina bella (Phleger and Parker): Phleger and Parker, 1951:12, pl. 6: figs. 7, 8 [as Angulogerina bella].

Trifarina bradyi Cushman: Phleger and Parker, 1951:18, pl. 8: figs. 10-11.

Trifarina jamaicensis (Cushman and Todd): Parker, 1954:521, pl. 8: fig. 8 [as Angulogerina jamaicensis].

Triloculina brevidentata Cushman: Parker, 1954:500, pl. 5: figs. $2,3$.

Triloculina sidebottomi (Martinotti): Parker, Phleger, and Peirson, 1953:14, pl. 2: figs. 25-28.

Triloculina tricarinata d'Orbigny: Parker, 1954:500, pl. 4: fig. 22.

Triloculina trigonula (Lamarck): Schnitker, 1971:212, pl. 3: fig. 11.
Trochammina advena Cushman: Cushman, 1922a:20, pl. 1: figs. $2-4$.

Trochammina globulosa Cushman: Cushman, 1920:77, pl. 16: figs. $3,4$.

Trochammina inflata (Montagu): Parker, 1952:459, pl. 3: figs. la,b.

Trochammina japonica Ishiwada: Parker, 1954:502, pl. 5: figs. 9, 10 [as Trochammina cf. japonica].

Trochammina macrescens Brady: Scott, Medioli, and Schafer, 1977:1579, pl. 4: figs. 6, 7 [as Trochammina inflata macrescens].

Trochammina squamata Jones and Parker: Schafer and Cole, 1978:29, pl. 5: fig. 1.

Trochammina tasmanica Parr: Parker, 1954:503, pl. 5: figs. 16, 17 [as Trochammina cf. tasmanica].

Uvigerina auberiana d'Orbigny: Parker, 1954:519, pl. 7: fig. 38, pl. 8: fig. 1.

Uvigerina bellula Bandy: Bandy, 1956:199, pl. 31: fig. 13.

Uvigerina flintii Cushman: Cushman, 1923:165, pl. 42: fig. 13. Pflum and Frerichs, 1976:108, pl. 7: fig. 9.

Uvigerina hispida Schwager: LeRoy and Hodgkinson, 1975: 438, pl. 9: fig. 5. Pflum and Frerichs, 1976:108, pl. 8: figs. $8,9,10$.

Uvigerina hispidocostata Cushman and Todd: Cushman and Todd, 1945:51, pl. 7: figs. 27, 31.

Uvigerina parvula Cushman: Phleger and Parker, 1951:18, pl. 8: figs. 27-30 [as Uvigerina peregrina var. parvula].

Uvigerina peregrina Cushman: Cushman, 1923:166, pl. 42: figs. 7-10. Pflum and Frerichs, 1976:108, pl. 8: figs. 2, 3 [as Uvigerina peregrina peregrina].

Uvigerina peregrina Cushman dirupta Todd: Pflum and Frerichs, 1976:108, pl. 8: figs. 4, 5 .

Uvigerina peregrina Cushman mediterranea Hofker: Pflum and Frerichs, 1976:108, pl. 8: fig. 1.

Uvigerina spinicostata Cushman and Jarvis: Pflum and Frerichs, 1976:108, pl. 8: figs. 6, 7.

Valvulineria complanata (d'Orbigny): Parker, 1958:268, pl. 3: figs. 42-44.

Valvulineria laevigata Phleger and Parker: Phleger and Parker, 1951:25, pl. 13: figs. 11, 12.

Valvulineria mexicana Parker: Parker, 1954:526, pl. 9: figs. 13.

Valvulineria minuta Parker: Parker, 1954:527, pl. 9: figs. 4-6.

Valvulineria opima (Cushman): Cushman, 1933:88, pl. 9: figs. 3a-c [as Discorbis opima].

Wiesnerella auriculata (Egger): Parker, 1954:501, pl. 5: fig. 13. 


\section{References}

(An asterisk marks each of the 77 publications from which distribution data were drawn for construction of the catalogs)

Akers, W. H.

*1952. General Ecology of the Foraminiferal Genus Eponidella with Description of a Recent Species. Journal of Paleontology, 26(4):645-649.

Andersen, $\mathrm{H}$. V.

*1951a. Two New Genera of Foraminifera from Recent Deposits in Louisiana. Journal of Paleontology, 25(1): 31-34.

*1951b. An Addenda to Arenoparrella and Arenoparrella mexicana Kornfeld. Contributions from the Cushman Foundation for Foraminiferal Research, 2(3):96-97.

*1952. Two New Species of Haplophragmoides from the Louisiana Coast. Contributions from the Cushman Foundation for Foraminiferal Research, 4(2):21-22.

*1961. Genesis and Paleontology of the Mississippi River Mudlumps, Part II: Foraminifera of the Mudlumps, Lower Mississippi River Delta. Louisiana Department of Conservation, Geological Bulletin, 35:1208.

Anderson, J. B.

*1968. Ecology of Foraminifera from Mississippi Sound and Surrounding Waters. Journal of the Alabama Academy of Science, 39:261-269.

Arnal, R. E.

* 1955. Some Occurrences of Abnormal Foraminifera. The Compass, 32:185-194.

Arnold, Z. M.

*1953. An Introduction to the Study of Movement and Dispersal in Allogromia laticollaris Arnold. Contributions from the Cushman Foundation for Foraminiferal Research, 4(1):15-21.

Ayala-Castanares, A.

*1963. Sistemática y distribución de los foraminíferos recientes de la Laguna de Terminos, Campeche, México. Universidad Nacional Autónoma de México, Instituto de Geologia, Boletín, 67(3):1-133.

Ayala-Castanares, A., and L. R. Segura

*1968. Ecologia y distribución de los foraminíferos recientes de la Laguna Madre, Tamaulipas, México. Universidad Nacional Autónoma de México, Instituto de Geologia, Boletín, 87:1-89.

Bandy, O. L.

*1954. Distribution of Some Shallow-Water Foraminifera in the Gulf of Mexico. United States Geological Survey Professional Paper, 254-F:123-141.
*1956. Ecology of Foraminifera in Northeastern Gulf of Mexico. United States Geological Survey Professional Paper, 274-G: 179-204.

Belford, D. J.

1966. Miocene and Pliocene Smaller Foraminifera from Papua and New Guinea. Commonwealth of Australia, Department of National Development, Bureau of Mineral Resources, Geology and Geophysics, Bulletin, 79:1-306.

Benda, W. R., and H. S. Puri

*1962. The Distribution of Foraminifera and Ostracoda off the Gulf Coast of the Cape Romano Area, Florida. Transactions, Gulf Coast Association of Geological Societies, 12:303-341.

Bermudez, P. J.

1949. Tertiary Smaller Foraminifera of the Dominican Republic. Cushman Laboratory for Foraminiferal Research, Special Publication, 25:1-322.

Bermudez, P. J., and G. A. Seiglie

1963. Estudio sistemático de los foraminíferos del Golfo de Cariaco. Boletín del Instituto Oceanográfico de la Universidad de Oriente, 2(2):1-267.

Bock, W. D.

*1976. Distribution and Significance of Foraminifera in the MAFLA Area. In C. T. Schafer and B. R. Pelletier, editors, First International Symposium on Benthonic Foraminifera of Continental Margins, Part A: Ecology and Biology. Maritime Sediments, Special Publication, 1:221-237.

Bock, W. D., and D. R. Moore

*1968. A Commensal Relationship between a Foraminifer and a Bivalve Mollusk. Gulf Research Reports, 2(3):273-279.

Boomgaart, L.

1949. Smaller Foraminifera from Bodjonegoro (Java). 175 pages. Sappemeer: Smit and Dontje.

Bradshaw, J. S.

*1957. Laboratory Studies on the Rate of Growth of the Foraminifer Streblus beccarii (Linné) var. tepida (Cushman). Journal of Paleontology, 31(6):11381147.

Brady, H. B.

1884. Report on the Foraminifera Collected by H. M. S. Challenger during the Years 1873-76. In Report Challenger, Zoology, 9(22):xxi +814 pages. 115 plates. London. 
Butcher, W. S.

1948. A New Species of Nonion (Foraminifera) from the Woods Hole Region. Contributions from the Cushman Laboratory for Foraminiferal Research, 24(1):21-23.

Buzas, M. A., and S. J. Culver

1980. Foraminifera: Distribution of Provinces in the Western North Atlantic. Science, 209:687-689.

Buzas, M. A., R. K. Smith, and K. A. Beem

1977. Ecology and Systematics of Foraminifera in Two Thalassia Habitats, Jamaica, West Indies. Smithsonian Contributions to Paleobiology, 31:1-139

Creager, J. S.

*1958. Bathymetry and Sediments of the Bay of Campeche. 188 pages. College Station: Department of Oceanography and Meteorology, Texas A and M University.

Crouch, R. W., and C. W. Poag

1979. Amphistegina gibbosa d'Orbigny from the California Borderlands: The Caribbean Connection. Journal of Foraminiferal Research, 9(2):85-105.

Culver, S. J., and M. A. Buzas

1980. Distribution of Recent Benthic Foraminifera off the Northern American Atlantic Coast. Smithsonian Contributions to the Marine Sciences, 6:1-512.

In press, a. Recent Benthic Foraminiferal Provinces of the Atlantic Continental Margin of North America. Journal of Foraminiferal Research, 11.

In press, b. Distribution of Selected Recent Benthic Foraminiferal Genera in the Western North Atlantic. In J. W. Neale and M. D. Brasier, editors, Microfossils from Recent and Fossil Shelf Seas. Chichester, England: Ellis Horwood.

Cushman, J. A.

1911. A Monograph of the Foraminifera of the North Pacific Ocean, Part II: Texulariidae. Bulletin of the United States National Museum, 71:1-108.

*1918. The Foraminifera of the Atlantic Ocean, Part 1: Astrorhizidae. Bulletin of the United States National Museum, 104:1-111.

*1920. The Foraminifera of the Atlantic Ocean, Part 2: Lituolidae. Bulletin of the United States National Museum, 104:1-111.

*1922a. Shallow Water Foraminifera of the Tortugas Region. Carnegie Institute of Washington, 17(311):3-85.

*1922b. The Foraminifera of the Atlantic Ocean, Part 3: Texulariidae. Bulletin of the United States National Museum, 104:1-149.

*1923. The Foraminifera of the Atlantic Ocean, Part 4: Lagenidae. Bulletin of the United States National Museum, 104:1-228.

*1924. The Foraminifera of the Atlantic Ocean, Part 5: Chilostomellidae and Globigerinidae. Bulletin of the United States National Museum, 104:1-55.

*1929. The Foraminifera of the Atlantic Ocean, Part 6: Miliolidae. Bulletin of the United States National Museum, 104:1-129.
*1930. The Foraminifera of the Atlantic Ocean, Part 7 : Nonionidae, Camerinidae, Peneroplidae and Alveolinellidae. Bulletin of the United States National Museum, 104:1-79.

*1931. The Foraminifera of the Atlantic Ocean, Part 8: Rotaliidae, Amphisteginidae, Calcarinidae, Cymbaloporettidae, Globorotaliidae, Anomalinidae, Planorbulinidae, Ruptertiidae and Homotremidae. Bulletin of the United States National Museum, 104:1-179.

1933. Some New Recent Foraminifera from the Tropical Pacific. Contributions from the Cushman Laboratory for Foraminiferal Research, 9(4):77-95.

1936. New Genera and Species of the Families Verneuilinidae and Valvulinidae and of the Subfamily Virgulininae. Cushman Laboratory for Foraminiferal Research, Special Publication, 6:1-71.

1944. Foraminifera from the Shallow-Water of the New England Coast. Cushman Laboratory for Foraminiferal Research, Special Publication, 12:1-37.

1947. New Species and Varieties of Foraminifera from off the Southeastern Coast of the United States. Contributions from the Cushman Laboratory for Foraminiferal Research, 23(4):86-92.

Cushman, J. A., and P. J. Bermudez

1946. A New Genus Cribropyrgo and a New Species of Rotalia. Contributions from the Cushman Laboratory for Foraminiferal Research, 22(4):119-120.

Cushman, J. A., and F. L. Parker

1947. Bulimina and Related Foraminiferal Genera. United States Geological Survey Professional Paper, 210-D:55176.

Cushman, J. A., and R. M. Stainforth

1945. The Foraminifera of the Cipero Marl Formation of Trinidad, British West Indies. Cushman Laboratory for Foraminiferal Research, Special Publication, 14: $1-91$.

Cushman, J. A., and R. Todd

1945. Miocene Foraminifera from Buff Bay, Jamaica. Cushman Laboratory for Foraminiferal Research, Special Publication, 15:1-85.

Cushman, J. A., R. Todd, and R. J. Post

1954. Recent Foraminifera of the Marshall Islands, Bikini and Nearby Atolls, Part 2: Oceanography (Biologic). United States Geological Survey Professional Paper, 260-H:319-384.

Dall, W. H.

1889. A Preliminary Catalogue of the Shell-bearing Marine Mollusks and Brachiopods of the Southeastern Coast of the United States, with Illustrations of Many of the Species. Bulletin of the United States National Museum, 37:1-202.

Davis, R. A.

*1964. Foraminiferal Assemblages of Alacran Reef, Campeche Bank, Mexico. Journal of Paleontology, 38(2): 417-421. 
d'Orbigny. See Orbigny, A., d'

Ellison, R. L., and M. M. Nichols

1970. Estuarine Foraminifera from the Rappahannock River, Virginia. Contributions from the Cushman Foundation for Foraminiferal Research, 21(1):1-17.

Feyling-Hanssen, R. W.

1954. Late-Pleistocene Foraminifera from the Oslofjord Area, Southeast Norway. Norsk Geologisk Tidsskrift, 33(1-2):109-152.

Frerichs, W. E.

*1969. Recent Arenaceous Foraminifera from the Gulf of Mexico. University of Kansas Paleontological Contributions, 46:1-2.

Goës, A.

1894. A Synopsis of the Arctic and Scandinavian Recent Marine Foraminifera Hitherto Discovered. Kongl. Svenska Vetenskaps-Akademiens Handlingar, 25(9):1127.

Grossman, S.

1967. Living and Subfossil Rhizopod and Ostracode Populations. In S. Grossman, and R. H. Benson, Ecology of Rhizopodea and Ostracoda of Southern Pamlico Sound Region, North Carolina. Kansas University, Paleontology Contributions, 44:1-82.

Hazel, J. E.

1970. Atlantic Continental Shelf and Slope of the United States: Ostracod Zoogeography in the Southern Nova Scotian and Northern Virginia Faunal Provinces. United States Geological Survey Professional Paper, 529-E:E1-E21.

Hedgpeth, J. W.

1953. An Introduction to the Zoogeography of the Northwestern Gulf of Mexico with Reference to the Invertebrate Fauna. Institute of Marine Science, The University of Texas, 3(1):111-224.

Höglund, $\mathrm{H}$.

1947. Foraminifera in the Gullmar Fjord and the Skagerak. Zoologiska Bidrag Fran Uppsala, 26:1-328.

Kane, H. E.

*1962. The Distribution of the Foraminifera of Sabine Lake and Sabine Pass, Texas and Louisiana, and the Near-Shore Area of the Gulf of Mexico. Journal of Paleontology, 36(4):834-836.

*1967. Recent Microfaunal Biofacies in Sabine Lake and Environs, Texas and Louisiana. Journal of Paleontology, 41(4):947-964.

Kellough, G. R.

* 1956. Distribution of Foraminifera around a Submerged Hill in the Gulf of Mexico. Transactions, Gulf Coast Association of Geological Societies, 6:205-216.

Kornfeld, M. M.

*1931. Recent Littoral Foraminifera from Texas and Louisiana. Contributions from the Department of Geology, Stanford University, 1(3):77-107.

Lamb, G. M

*1972. Distribution of Holocene Foraminiferida in Mo- bile Bay and the Effect of Salinity Changes. Geological Survey of Alabama, 82:1-12.

Lankford, R. R.

*1959. Distribution and Ecology of Foraminifera from East Mississippi Delta Margin. American Association of Petroleum Geologists, Bulletin, 43(9):2068-2099.

Lehmann, E. P.

*1957. Statistical Study of Texas Gulf Coast Recent Foraminiferal Facies. Micropaleontology, 3(4):325-356.

LeRoy, D. O., and K. A. Hodgkinson

*1975. Benthonic Foraminifera and Some Pteropoda from a Deep-Water Dredge Sample, Northern Gulf of Mexico. Micropaleontology, 21(4):420-447.

LeRoy, D. O., and S. A. Levinson

1974. A Deep-Water Pleistocene Microfossil Assemblage from a Well in the Northern Gulf of Mexico. Micropaleontology, 20(1):1-37.

LeRoy, L. W.

1941. Small Foraminifera from the Late Tertiary of the Nederlands East Indies, Part 3: Some Small Foraminifera from the Type Locality of the Bantamien Substage, Bodjong Beds, Bantam Residency, West Java, Nederlands East Indies. Colorado School of Mines, Quarterly, 36(1):1-132.

Lidz, L., and B. Lidz

*1966. Foraminiferal Biofacies of Veracruz Reefs. American Association of Petroleum Geologists, Bulletin, 50(7): 1514-1517.

Loeblich, A. L., Jr., and H. Tappan

1964. Treatise on Invertebrate Paleontology, Part C (Protista 2): Sarcodina Chiefly "Thecamoebans" and Foraminiferida. Volumes 1-2, 900 pages. Lawrence: University of Kansas Press for Geological Society of America.

Loep, K. J.

*1965. A Study of the Ecology and Distribution of Recent Foraminifera in the North-West Gulf of Mexico. Transactions, Gulf Coast Association of Geological Societies, 15:167-177.

Lowman, S. W.

*1949. Sedimentary Facies in Gulf Coast. American Association of Petroleum Geologists, Bulletin, 33(12):19391997.

Ludwick, J. C., and W. R. Walton

*1957. Shelf-Edge Calcareous Prominences in Northeastern Gulf of Mexico. American Association of Petroleum Geologists, Bulletin, 41(9):205ł-2101.

Lynts, G. W., and R. M. Pfister

*1967. Surface Ultrastructure of Some Tests of Recent Foraminifera from the Dry Tortugas. Florida. Journal of Protozoology, 14(3):387-399.

Natland, M. L.

1938. New Species of Foraminifera from off the West Coast of North America and from the Later Tertiary of the Los Angeles Basin. Bulletin of the Scripps Institution of Oceanography, Technical Series. 4(5):137 164. 
Norton, R.

*1930. Ecologic Relations of Some Foraminifera. Bulletin of the Scripps Institute of Oceanography, Technical Series, 2(9):331-388.

Orbigny, A., d'

1839a. Foraminifêres. In de la Sagra, Histoire physique, politique et naturelle de l'Ile de Cuba: Natural History, 2:1-224 [plates published separately]. Paris: Bertrand.

1839b. Foraminiferes. In Voyage dans l'Amérique Meridionale, 5(5):1-86. Strasbourg: P. Bertrand.

Otvos, E. G

* 1978. Calcareous Benthic Foraminiferal Fauna in a Very Low Salinity Setting, Lake Pontchartrain, Louisiana. Journal of Foraminiferal Research, 8(3):262-269.

Parker, F. L.

1948. Foraminifera of the Continental Shelf from the Gulf of Maine to Maryland. Bulletin of the Museum of Comparative Zoology, 100(2):213-241.

1952. Foraminiferal Distribution in the Long Island Sound-Buzzards Bay Area. Bulletin of the Museum of Comparative Zoology, 106(10):425-473.

* 1954. Distribution of the Foraminifera in the Northeastern Gulf of Mexico. Bulletin of the Museum of Comparative Zoology, 111(10):451-588.

1958. Eastern Mediterranean Foraminifera. Reports of the Swedish Deep-Sea Expedition, 8(4):219-285.

Parker, F. L., F. B Phleger, and J. F. Peirson

*1953. Ecology of Foraminifera from San Antonio Bay and Environs, Southwest Texas. Cushman Foundation for Foraminiferal Research, Special Publication, 2: $1-75$.

Pflum, C. E., and W. E. Frerichs

*1976. Gulf of Mexico Deep-Water Foraminifers. Cushman Foundation for Foraminiferal Research, Special Publication, 14:1-125.

Phleger, F. B

*1951a. Ecology of Foraminifera, Northwest Gulf of Mexico, Part 1: Foraminifera Distribution. Geological Society of America, Memoir, 46:1-88.

*1951b. Displaced Foraminifera Faunas. Society of Economic Paleontologists and Mineralogists, Special Publication, 2: 66-75.

* 1954. Ecology of Foraminifera and Associated Microorganisms from Mississippi Sound and Environs. American Association of Petroleum Geologists, Bulletin, 38(4):584-687.

*1955a. Foraminiferal Faunas in Cores Offshore from the Mississippi Delta. In Deep-Sea Research. Papers in Marine Biology and Oceanography Dedicated to Henry Bryant Bigelow, 3(supplement):45-57.

* 1955b. Ecology of Foraminifera in South-Eastern Mississippi Delta Area. American Association of Petroleum Geologists, Bulletin, 39(5):712-752.

*1956. Significance of Living Foraminiferal Populations along the Central Texas Coast. Contributions from the Cushman Foundation for Foraminiferal Research, 7(4):106-151.

*1960. Foraminiferal Populations in Laguna Madre, Texas. Science Reports of the Tohoku University, series 2, 4:83-91.

*1965a. Patterns of Living Marsh Foraminifera in South Texas Coastal Lagoons. Boletín Sociedad Geológica Mexicana, 28(1):1-44.

*1965b. Living Foraminifera from Coastal Marsh Southwestern Florida. Boletín Sociedad Geológica Mexicana, 28(1):45-59.

*1965c. Patterns of Marsh Foraminifera, Galveston Bay, Texas. Limnology and Oceanography, 10 (supplement, Nov 1965):R169-R184.

Phleger, F. B, and R. R. Lankford

*1957. Seasonal Occurrences of Living Benthonic Foraminifera in Some Texas Bays. Contributions from the Cushman Foundation for Foraminiferal Research, 8(3): 93-105.

*1978. Foraminifera and Ecological Processes in the Alvarado Lagoon Area, Mexico. Journal of Foraminiferal Research, 8(2):127-131.

Phleger, F. B, and F. L. Parker

*1951. Ecology of Foraminifera, Northwest Gulf of Mexico, Part 2: Foraminifera Species. Geological Society of America, Memoir, 46:1-64.

*1952. New Names for Northwestern Gulf of Mexico Foraminifera. Contributions from the Cushman Foundation for Foraminiferal Research, 3(1):14.

*1954. Gulf of Mexico Foraminifera. Fishery Bulletin, Fish and Wildlife Service, 55:235-241.

Poag, C. W.

*1972. Shelf-Edge Submarine Banks in the Gulf of Mexico: Paleoecology and Biostratigraphy. Transactions, Gulf Coast Association of Geological Societies, 22: 267-287.

1975. A Synthesis of Benthic Foraminiferal Distributions: Circum-Gulf of Mexico [abstract]. In $A b$ stracts, Benthonics '75, page 35. Halifax, Nova Scotia: Dalhousie University.

*1976. The Foraminiferal Community of San Antonio Bay. In A. H. Bouma, editor, Shell Dredging and Its Influence on Gulf Coast Environments, pages 304-336. Houston: Gulf Publishing Company.

* 1978. Paired Foraminiferal Ecophenotypes in Gulf Coast Estuaries: Ecological and Paleoecological Implications. Transactions, Gulf Coast Association of Geological Societies, 28:395-421.

Poag, C. W., and W. E. Sweet

*1972. Claypile Bank, Texas Continental Shelf. In R. Rezak and V. J. Henry, Contribution on the Geological and Geophysical Oceanography of the Gulf of Mexico. Texas $A$ and $M$ University, Oceanography Studies, 3:223-261. 
Post, R. J.

*1951. Foraminifera of the South Texas Coast. Publications of the Institute of Marine Science, Texas University, 2(1): 165-176.

Pulley, T. E.

1953. Distribution of Mollusks in the Gulf of Mexico [abstract]. Annual Report, American Malacological Union, 1952:2-3.

Saidova, H. M.

1961. Ekologija Foraminifer $i$ Paleogeografija Dal'nevostochnykh Morej SSSR i Severo-Zapadnoj Chasti Tikhogo Okeana. 232 pages. Akademiia Nauk SSSR, Institut Okeanologi.

Saunders, J. B.

1957. Trochamminidae and Certain Lituolidae (Foraminifera) from the Recent Brackish-Water Sediments of Trinidad, British West Indies. Smithsonian Miscellaneous Collections, 134(5):1-16.

Schafer, C. T., and F. E. Cole

1978. Distribution of Foraminifera in Chaleur Bay, Gulf of St. Lawrence. Geological Survey of Canada, 77-30: $1-55$.

Schnitker, D.

1971. Distribution of Foraminifera on the North Carolina Continental Shelf. Tulane Studies in Geology and Paleontology, 8(4): 169-215.

1974. Ecotypic Variation in Ammonia beccarii (Linné). Journal of Foraminiferal Research, 4(4):216-223.

Scott, D. B., F. S. Medioli, and C. T. Schafer

1977. Temporal Changes in Foraminiferal Distribution in Mirimichi River Estuary, New Brunswick. Canadian Journal of Earth Science, 14(7):1566-1587.

Seguenza, C.

1880. Le Formazioni Terziarie nella Provincia di Reggio (Calabria). Reale Accademia dei Lincei, 6:1-446.

Segura, L. R.

*1963. Sistemático y distribución de los foraminíferos littorales de la "Playa Washington" al sureste de Matamoros, Tamaulipas, México. Universidad $\mathrm{Na}$ cional Autónoma de México, Instituto de Geologia, Boletín, 68: 1-92.

Seiglie, G. A., and P. J. Bermudez

1966. Notes on Genus Tosaia Takayanagi in America and Description of a New Species. Caribbean Journal of Science, 6(1-2):65-69.

Sen Gupta, B. K.

1971. The Benthonic Foraminifera of the Tail of the Grand Banks. Micropaleontology, 17(1):69-98.

Shenton, E. H.

*1957. A Study of the Foraminifera and Sediments of Matagorda Bay, Texas. Transactions, Gulf Coast Association of Geological Societies, 7:135-150.

Shepard, F. P., and D. G. Moore

*1955. Central Texas Coast Sedimentation: Characteris- tics of Sedimentary Environment, Recent History and Diagenesis. American Association of Petroleum Geologists, Bulletin, 39(8):1463-1593.

Shifflett, E.

*1961. Living, Dead, and Total Foraminiferal Faunas, Heald Bank, Gulf of Mexico. Micropaleontology, $7(1): 45-54$.

Silvestri, A.

1896. Foraminiferi pliocenici della Provincia di Sienna, Parte 1. Memorie della Pontificia Accademia dei Nuovi Lincei, 12:1-204.

1898. Foraminiferi pliocenici della Provincia di Sienna, Parte 2. Memorie della Pontificia Accademia dei Nuovi Lincei, 15:155-381.

Todd, R., and D. Low

1961. Near-Shore Foraminifera of Martha's Vineyard Island, Massachusetts. Contributions from the Cushman Foundation for Foraminiferal Research, 12(1):5-21.

Vaughan, T. W.

*1918. Some Shoal-Water Bottom Samples from Murray Island, Australia, and Comparisons of Them with Samples from Florida and the Bahamas. Carnegie Institute of Washington, 213:235-288.

Waldron, R. P.

*1963. A Seasonal Ecological Study of Foraminifera from Timbalier Bay, Louisiana. Gulf Research Reports, 1(4):132-188

Walton, W. R.

*1960. Diagnostic Faunal Characteristics on and near a Barrier Island, Horn Island, Mississippi. Transactions, Gulf Coast Assocation of Geological Societies, 10: 7-24.

*1964. Ecology of Benthic Foraminifera in the TampaSarasota Bay Area, Florida. In R. L. Miller, editor, Papers in Marine Geology, Shepard Commemorative Volume, pages 429-454. New York: Macmillan Company.

Wantland, K. F.

*1969. Distribution of Modern Brackish-Water Foraminifera in Trinity Bay. In R. R. Lankford and J. J. W. Rogers, editors, Holocene Geology of the Galveston Bay Area, pages 93-117. Houston: Houston Geological Society.

Warren, A. D.

*1956. Ecology of Foraminifera of the Buras-Scofield Bayou Region, Southeast Louisiana. Transactions, Gulf Coast Association of Geological Societies, 6:131152.

* 1957. Foraminifera of the Buras-Scofield Bayou Region, Southeast Louisiana. Contributions from the Cushman Foundation for Foraminiferal Research, 8(1):29-40.

Williamson, W. C.

1858. On the Recent Foraminifera of Great Britain. 107 pages. London: Ray Society. 


\section{Catalog 1}

\section{Unsynonymized Species with Publication and Location}

\section{Publication}

10001 PFLUM FRERICHS 1976 10002 PFLUM FRERICHS 1976 10003 PFLUM FRERICHS 1976 10004 PFLUM FRERICHS 1976 10005 PFLUM FRERICHS 1976 10006 PFLUM FRERICHS 1976 10007 PFLUM FRERICHS 1976 10008 PFLUM FRERICHS 1976 10009 PFLUM FRERICHS 1976 10010 PFLUM FRERICHS 1976 10011 PFLUM FRERICHS 1976 10012 PFLUM FRERICHS 1976 10013 PFLUM FRERICHS 1976 10014 PFLUM FRERICHS 1976 10015 PFLUM FRERICHS 1976 10016 PFLUM FRERICHS 1976 10017 PFLUM FRERICHS 1976 10018 PFLUM FRERICHS 1976 10019 PFLUM FRERICHS 1976 10020 PFLUM FRERICHS 1976 10021 PFLUM FRERICHS 1976 10022 PFLUM FRERICHS 1976 10023 PFLUM FRERICHS 1976 10024 PFLUM FRERICHS 1976 10025 PFLUM FRERICHS 1976 10026 PFLUM FRERICHS 1976 10027 PARKER 1954

10028 PARKER 1954

10029 PFLUM FRERICHS 1976 10030 PFLUM FRERICHS 1976

10031 PARKER 1954

10032 PARKER 1954

10033 PARKER 1954

10034 PARKER 1954

PARKER 1954

10036 PARKER 1954

10037
10038 PARKER 1954
10039 PARER 1954

10039 PFLUM FRERICHS 1976 10040 PFLUM FRERICHS 1976 10041 PFLUM FRERICHS 1976 10042 PFLUM FRERICHS 1976 10043 PFLUM FRERICHS 1976 10044 PFLUM FRERICHS 1976 10045 PFLUM FRERICHS 1976 10046 PFLUM FRERICHS 1976 10047 PFLUM FRERICHS 1976 10048 PFLUM FRERICHS 1976 10049 PFLUM FRERICHS 1976 10050 PFLUM FRERICHS 1976 10051 PFLUM FRERICHS 1976 10052 PFLUM FRERICHS 1976 10053 PFLUM FRERICHS 1976 10054 PFLUM FRERICHS 1976 10055 PFLUM FRERICHS 1976 10056 PFLUM FRERICHS 1976 10057 PFLUM FRERICHS 1976 10058 PFLUM FRERICHS 1976 10059 PFLUM FRERICHS 1976 10060 PFLUM FRERICHS 1976 10061 PFLUM FRERICHS 1976 10062 PFLUM FRERICHS 1976 10063 PFLUM FRERICHS 1976 10064 PFLUM FRERICHS 1976 10065 PFLUM FRERICHS 1976 10066 PFLUM FRERICHS 1976 10067 PFLUM FRERICHS 1976 10068 PFLUM FRERICHS 1976 10069 PARKER 1954

10070 PARKER 1954

10071 PARKER 1954

10072 PARKER 1954

10073 PARKER 1954

10074 PARKER 1954

10075 PARKER 1954

10076 PARKER 1954

10078 PARKER 1954

10079 PFLUM FRERICHS 1976 10080 PFLUM FRERICHS 1976 10081 PFLUM FRERICHS 1976 10082 PFLUM FRERICHS 1976 10083 PFLUM FRERICHS 1976 10084 PFLUM FRERICHS 1976 10085 PFLUM FRERICHS 1976

\section{Generic Name}

A DERCOTRYMA

ADERCOTRYMA

ADERCOTRYMA

ADERCOTRYMA

A DERCOTRYMA

ADERCOTRYMA

A DERCOTRYMA

ADERCOTRYMA

ADERCOTR YMA

ADERC OTRYMA

ADERCOTRYMA

ADERCOTRYMA

ADERCOTRYMA

ADERCOTRYMA

ADERCOTRYMA

ADERCOTRYMA

ADERCOTRYMA

ADERCOTRYMA

A DERC OTRYMA

ADERC OTRYMA

ADERCOTR YMA

ADERCOTRYMA

ADERCOTRYMA

ADER COTRYMA

ADERCOTRYMA

ADERC OTRYMA

ADERCOTRYMA

ADERCOTRYMA

ADERCOTRYMA

ADERCOTRYMA

ADERCOTRYMA

A DERCOTR YMA

A DERCOTRYMA

ADERCOTRYMA

ADERCOTRYMA

ADER C OTRYMA

ADERCOTRYMA

A DERCOTRYMA

ADERCOTRYMA

ADERCOTRYMA

ADERCOTRYMA

ADERCOTRYMA

ADERCOTRYMA

ADERCOTRYMA

A DERCOTRYMA

ADERCOTRYMA

ADERCOTRYMA

ADERCOTRYMA

ADERCOTRYMA

ADER COTR YMA

ADERCOTRYMA

ADERCOTRYMA

ADERCOTRYMA

A DERCOTRYMA

ADERCOTRYMA

ADER COTRYMA

ADERCOTRYMA

ADERCOTRYMA

ADERCOTRYMA

ADERCOTRYMA

ADERC OTRYMA

ADERCOTRYMA

ADERCOIRYMA

A DERCOTRYMA

ADERCOTRYMA

ADERCOTRYMA

ADERCOTRYMA

ADERC OTRYMA

ADER COTRYMA

ADERCOTRYMA

ADER COTRYMA

A DERCOTRYMA

ADERCOTRYMA

ADERCOTR YMA

ADERCOTRYMA

ADERCOTRYMA

ALABAMINA

ALABAMINA

AL AB AMINA

AL ABAMINA

AL ABAMINA

AL ABAMINA

AL ABAMINA
Specific Name

GL OMERATA

GL OMERATA

GL OMERATA

GLOMERATA

GL OMERATA

GLOMERATA

GL OMERATA

GL OMERATA

GLOMERATA

GL OMERATA

GL OMERATA

GLOMERATA

GLOMERATA

GL OMERATA

GL OMERATA

GLOMERATA

GL OMERATA

GLOMERATA

GLOMERATA

GLOMERATA

GLOMERATA

GL OMERATA

GLOMERATA

GL OMERATA

GL OMERATA

GLOMERATUM

GLOMERA TUM

GL CMERATUM

GL OMERA TUM

GLOMERATUM

GL OMERATUM

GLOMERATUM

GLOMERATUM

GLOMERATUM

GL OMERATUM

GLOMERATUM

GLOMERATUM

GLOMERA TUM

GL OMERATUM

GLOMERATUM

GLOMERATUM

GL OMERATUM

GLOMERATUM

GLOMERATUM

GLOMERA TUM

GL OMERATUM

GLOMERATUM

GLOMERATUM

GL OMERATUM

GLOMERATUM

GL OMERATUM

GL OMERA TUM

GLOMERATUM

GLOMERATUM

GLOMERATUM

GLOMERATU M

GLOMERATUM

GLOMERATUM

GLOMERATUM

GLOMERATUM

GLOMERATUM

GL OMERATUM

GL OMERATJM

GLOMERATUM

GLOMERATJM

GL OMERATUM

GLOMERA TUM

GLOMERATUM

GL OMERA TUM

GLOMERATUM

GL OMERATUM

GLOMERATUM

GL OMERATUM

GLOMERA TUM

GL OMERATUM

GLOMERATUM

GLOMERAT."

DE CORATA

DE CORATA

DE CORATA

DE CORATA

DE CORATA

DE CORATA

DE CORATA

\section{Locality}

CENTRAL GULF OF MEXICO CENTRAL GULF OF MEXICO CENTRAL GULF OF MEXICO CENTRAL GULF OF MEXICO CENTRAL GULF OF MEXICO CENTRAL GULF OF MEXICO CENTRAL GULF OF MEXICO CENTRAL GULF OF MEXICO CENTRAL GULF OF MEXICO CENTRAL GULF OF MEXICO CENTRAL GULF OF MEXICO CENTRAL GULF OF MEXICO CENTRAL GULF OF MEXICO CENTRAL GULF OF MEXICO CENTRAL GULF OF MEXICO CENTRAL GULF OF MEXICO CENTRAL GULF OF MEXICO CENTRAL GULF OF MEXICO CENTRAL GULF OF MEXICO CENTRAL GULF OF MEXICO CENTRAL GULF OF MEXICO CENTRAL GULF OF MEXICO CENTRAL GULF OF MEXICO CENTRAL GULF OF MEXICO CENTRAL GULF OF MEXICO CENTRAL GULF OF MEXICO NE GULF OF MEXICO NE GULF OF MEXICO

NH GULF OF MEXICO NH GULF OF MEXICO NE GULF OF MEXICO 


\section{Publication}

10086 PFLUM FRERICHS 1976 10087 PFLUM FRERICHS 1976 10088 PFLUM FRERICHS 1976 10089 PFLUM FRERICHS 1976 10090 PFLUM FRERICHS 1976 10091 PFLUM FRERICHS 1976 10092 PFLUM FRERICHS 1976 10093 PFLUM FRERICHS 1976 10094 PFLUM FRERICHS 1976 10095 PFLUM FRERICHS 1976 10096 PFLUM FRERICHS 1976 10097 PFLUM FRERICHS 9976 10098 PFLUM FRERICHS 1976 10099 PFLUM FRERICHS 1976 10100 PFLUM FRERICHS 1976 10101 PFLUM FRERICHS 1976 10102 PFLUM FRERICHS 1976 10103 PFLUM FRERICHS 1976 10104 PFLUM FRERICHS 1976 10105 PFLUM FRERICHS 1976 10106 PFLUM FRERICHS 1976 10107 PFLUM FRERICHS 1976 10108 PFLUM FRERICHS 1976 10109 PFLUM FRERICHS 1976 10110 PFLUM FRERICHS 1976 10111 PFLUM FRERICHS 1976 10112 PFLUM FRERICHS 1976 10113 PFLUM FRERICHS 1976 10114 PFLUM FRERICHS 1976 10115 ANDERSEN 1961

10116 ARNOLD 1953

10117 PFLUM FRERICHS 1976

10118 CUSHMAN 1922A

10119 PARKER 195

10120 PARKER 1954

10121 CREAGER 1958

10122 PARKER 1954

10123 PARKER 1954

10124 PARKER 1954

10125 PARKER 1954

10126 PARKER 1954

10127 PARKER 1954

10128 PARKER 1954

10129 PARKER 1954

10130 PARKER 1954

10131 CREAGER 1958

10132 CREAGER 1958

10134 PARKER 1954

10134 PARKER 1954
10135 PARKER 1954

10136 PARKER 1954

10137 PARKER 1954

10138 PARKER 1954

10139 PARKER 1954

10140 PARKER 1954

10141 PARKER 1954

10142 PARKER 1954

10143 PARKER 1954

10144 PARKER 1954

10146 PARKER 1954

10147 PARKER 1954

10148 PARKER 1954

10149 PARKER 1954

10150 PARKER 1954

10151 PARKER 1954

10153 PARKER 1954

10154 PARKER 1954

10155 PARKER 1954

10156 PARKER 1954

10157 PARKER 1954

10158 PARKER 1954

10159 PARKER 195

10160 PARKER 1954

10161 PARKER 1954

10162 PARKER 1954

10163 PARKER 1954

10164 PARKER 1954

10166 CREAGER 1958

10167 CREAGER 1958

10168 PARKER 1954

10169 PARKER 1954

10170 PARKER 1954

10171 PARKER 1954

10172 PARKER 1954

10173 PARKER 1954

10174 PARKER 1954

10175 LUDWICK WALTON 1957

10176 PARKER 1954

10177 PARKER 1954

10178 PARKER 1954

10180 PARKER 1954
Generic Name

\begin{tabular}{|c|}
\hline ALABAMINA \\
\hline $\begin{array}{l}A L A B A M I N A \\
A L A B A M I N A\end{array}$ \\
\hline $\begin{array}{l}A L A B A M I N A \\
A L A B A M I N A\end{array}$ \\
\hline $\begin{array}{l}\text { ALABAMINA } \\
\text { AL ABAMINA }\end{array}$ \\
\hline ALABAMINA \\
\hline AL ABAM I NA \\
\hline$A L A B A M I N A$ \\
\hline AL ABAM I NA \\
\hline AL ABAMINA \\
\hline AL AB A M I NA \\
\hline AL ABAM I NA \\
\hline ALABAMINA \\
\hline$A L A B A M I N A$ \\
\hline AL ABAMINA \\
\hline AL ABAM I NA \\
\hline ALABAMINA \\
\hline AL ABAMINA \\
\hline AL ABAM INA \\
\hline ALABA MI NA \\
\hline AL ABAMINA \\
\hline ALABAMINA \\
\hline$A L A B A M I N A$ \\
\hline AL ABAMINA \\
\hline ALABA M I N A \\
\hline$A L A B A M I N A$ \\
\hline AL ABAMINA \\
\hline AL AB A M I NA \\
\hline ALABAMINA \\
\hline
\end{tabular}

ALFREDOSILVESTRIS

ALLOGROMIA

ALLOMORPHINA

ALVE OL INA

ALVEOLOPHRAGMIUM

ALVE OLOPHR A GM IUM

AL VE OLOPHRAGMIUM

AL VE OLOPHRAGMIUM

AL VE OL OPHRAGM IUM

AL VE OL OP HR A GN IUM

ALVE OLOPHR A GM IUM

AL VE OLOP HR A GMIUM

AL VEOLOPHRAGMIUM

AL VE OL OPHRAGMIUM

ALVE OL OPHRAGM IUM

ALVE OLOPHRAGMIUM

AL VE OL OP HR A GM IUM

ALVE OL OPHRAGMIUM

ALVE OLOPHR AGMIUM

AL VE OL OP HR A GM IUM

AL VE OLOPHR AGMIUM

AL VEOLOPHRAGMIUM

AL VE OLOPHRA GMIUM

AL VEOLOPHRAGM IUM

AL VE OL OPHR A GMIUM

AL VE OL OPHRAGMIUM

AL VEOL OPHRA GMIUM

AL VE OLOPHRAGMIUM

ALVE OLOPHRA GM IUM

ALVEOLOPHRAGMIUM

AL VE OL OPHRAGM IUM

ALVEOLOPHR AGMIUM

AL VE OLOPHR AGMIUM

AL VE OLOP HR A GM IUM

AL VE OLOPHRA GM IUM

ALVEOLOP HR A GM IUM

AL VE OLOPHRAGMIUM

AL VEOLOPHRAGMIUM

AL VEOLOPHRAGM IUM

AL VEOL OPHRAGMIUM

AL VE OLOPHR AGM IUM

AL VE OL OPHR A GMIUM

AL VE OLOPHRAGMIUM

ALVEOLOP HRAGMIUM

ALVE OL OP HR A GMIUM

AL VEOLOPHRA GMIUM

AL VE OL OP HR A GM IUM

AL VE OLOPHRAGMIUM

ALVE OLOPHRAGM IUM

AL VE OLOPHRAGMIUM

AL VE OL OPHRAGMIUM

AL VEOL OPHRAGMIUM

AL VE OL OP HR A GM IUM

AL VEOLOPHR A GMIUM

AL VE OL OPHR AGMIUY

ALVEOLOPHR AGMIUM

AL VE OL OPHR A GM IUM

AL VE OL OPHRAGMIUM

AL VEOL OPHRAGM IUM

ALVEOLOPHRAGMIUM

AL VEOL OPHRAGMIUM

ALVEOLOPHRAGMIUM

AL VE OL OPHR AGM IUM

AL VEOLOPHRAGMIUM

AL VE OL OPHRAGM IUM

AL VE OL OPHR A GM IUM
Specific Name

Locality

DE CORATA

DE CORATA

DE CORATA

DE CORATA

DE CORATA

DE CORATA

DE CORATA

DE CORATA

DE CORAT A

DE CORATA

DE CORATA

DE CORATA

DE CORATA

DE CORATA

DE CORATA

DECORATA

DE CORATA

DE CORATA

DE CORATA

DE CORATA

DE CORATA

DE CORATA

DE CORATA

DE CORATA

DE CORATA

DE CORATA

DE CORATA

DE CORATA

LEVINSONI

LA TICOLLARIS

TR IGONA

PULCHRA

NI TIDUM

NI TIDUM

NITIDUM

NI TI DUM

NI TI DUM

NI TIDUM

NI TIDUM

NI TI DUM

NITIDUM

NI TIDUM

NI TI DUM

NI TIDUM

NI TIDUM

NI TIDUM

NI TIDUM

NI TIDUM

NITI DUM

NI TI DUM

NI TI DUM

NI TIDUM

N I TI DUM

NITIDUM

NI T I DUM

R I NGENS

RI NGENS

RI NGENS

RI AGENS

RI NGENS

RI NGENS

SCITULUM

SC I TULUM

SC ITULUM

SC ITULUM

SCITULUM

SC I TULUM

SC ITULUM

SCITULUM

SCITULUM

SC ITULUM

SCITULUM

SU BGLOBOS UM

SU GGL OB OS UM

SU BGL OB OS UM

SUBGL OB OS UM

SU EGL OBOS UM

SUEGL OB OS UM

SU BGL OB OS UM

SUBGLOBOS UM

SU

SUBGLOBOS UM

SU EGLOBOS UM

SUEGLOBOS UM

SU BGL OB OS UM

SUEGLOBOS UM

SUBGLOBOS UM

SUEGL OB OS UM

WI ESNER I

WIESNERI

WIESNER I

WIESNER I

WIESNER I

WIESNER I

TORTUGAS

NW GULF OF MEXICO

NW GULF OF MEXICO

NW GULF OF MEXICO

NW GULF OF MEXICO

NW GULF OF MEXICO

$N W$ GULF OF MEXICO

NW GULF OF MEXICO

NW GULF OF MEXICO

NW GULF OF MEXICO

$N W$ GULF OF MEXICO

NW GULF OF MEXICO

CENTRAL GULF OF MEXICO

CENTRAL GULF OF MEXICO

CENTRAL GULF OF MEXICO

CENTRAL GULF OF MEXICO

CENTRAL GULF OF MEXICO

CENTRAL GULF OF MEXICO

CENTRAL GULF OF MEXICO

CENTRAL GULF OF MEXICO

CENTRAL GULF OF MEXICO

CENTRAL GULF OF MEXICO

CENTRAL GULF OF MEXICO

CENTRAL GULF OF MEXICO

CENTRAL GULF OF MEXICO

CENTRAL GULF OF MEXICO

CENTRAL GULF OF MEXICO

CENTRAL GULF OF MEXICO

CENTRAL GULF OF MEXICO

CENTRAL GULF OF MEXICO

MISSISSIPPI DELTA

PANAMA CITY, FLA.

NW GULF OF MEXICO

NE GULF OF MEXICO 


\section{Publication}

10181 PARKER 1954 10182 PARKER 1954 10183 PARKER 1954 10184 PARKER 1954 10185 PARKER 1954 10186 PARKER 1954 10187 PFLUM FRERICHS 1976 10188 PFLUM FRERICHS 1976 10189 PFLUM FRERICHS 1976 10190 PHLEGER 1965 A 10191 WANTLAND 1969 10192 PHLEGER 1965A 10193 PHLEGER 1954 10194 PHLEGER LANKFORD 1978 10195 OTVOS 1978 10196 WALTON 1960 10197 PHLEGER 19558 10198 POAG 1976 10199 KANE 1967 10200 KANE 1962 10201 LEHMANN 1957 10202 SHEPARD MOORE 1955 10203 PARKER PHLEGER PEIRSON 1953 10204 PARKER PHLEGER PEIRSON 1953 10205 PARKER PHLEGER PEIRSON 1953 10206 LANKFORD 1959 10207 PHLEGER $1965 \mathrm{C}$ 10208 PHLEGER 1954 10209 PHLEGER 1954 10210 KANE 1967

10211 WARREN 1957

10212 WARREN 1956

10213 WALDRON 1963

10214 PFLUM FRERICHS 1976 10215 PFLUM FRERICHS 1976 10216 PFLUM FRERICHS 1976 10217 PFLUM FRERICHS 1976 10218 PFLUM FRERICHS 1976 10219 PFLUM FRERICHS 1976 10220 PFLUM FRERICHS 1976 10221 PFLUM FRERICHS 1976 10222 PFLUM FRERICHS 1976 10223 PFLUM FRERICHS 1976 10224 PFLUM FRERICHS 1976 10225 PFLUM FRERICHS 1976 10226 PFLUM FRERICHS 1976 10227 PFLUM FRERICHS 1976 10228 CUSHMAN 1920 10229 CUSHMAN 1920 10230 CUSHMAN 1920 10231 PFLUM FRERICHS 1976 10232 PFLUM FRERICHS 1976 10233 PFLUM FRERICHS 1976 10234 PFLUM FRERICHS 1976 10235 PFLUM FRERICHS 1976 10236 PFLUM FRERICHS 1976 10237 PFLUM FRERICHS 1976 10238 PFLUM FRERICHS 1976 10239 PFLUM FRERICHS 1976 10240 PFLUM FRERICHS 1976 10241 PFLUM FRERICHS 1976 10242 PFLUM FRERICHS 1976 10243 PFLUM FRERICHS 1976 10244 PFLUM FRERICHS 1976 10245 PFLUM FRERICHS 1976 10246 PFLUM FRERICHS 1976 10247 PFLUM FRERICHS 1976 10248 PFLUM FRERICHS 1976 10249 PFLUM FRERICHS 1976 10250 PFLUM FRERICHS 1976 10251 PFLUM FRERICHS 1976 10252 PFLUM FRERICHS 1976 10253 PFLUM FRERICHS 1976 10254 LEHMANN 1957 10255 WARREN 1957 10256 WANTLAND 1969 10257 WALDRON 1963 10258 PFLUM FRERICHS 1976 10259 WALTON 1964 10260 WALTON 1960 10261 PHLEGER LANKFORD 1957 10262 PHLEGER $1965 \mathrm{C}$

10263 WARREN 1956

10264 AYALA-CASTANARES SEGURA 1968 10265 PARKER PHLEGER PEIRSON 1953 10266 PARKER PHLEGER PEIRSON 1953 10267 PHLEGER 1954

10268 LEHMANN 1957

10269 PHLEGER 19558

10270 POST 1951

10271 PARKER PHLEGER PEIRSON 1953 10272 POST 1951

10273 PARKER PHLEGER PEIRSON 1953 10274
10275
$10 A R K E R$

\section{Generic Name}

AL VE OLOPHRAGMIUM

AL VE OLOPHRAGMIUM ALVEOLOPHRAGMIUM AL VE OLOPHR AGM IUM ALVE OLOPHRAGMIUM ALVE OLOPHRAGMIUM AL VEOVALVULINELL A AL VEOVALVULINELLA ALVEOVALVUL INELLA AMMOASTUTA AMMOASTUTA

AMMOASTUTA

AMMOASTUTA

AMMOASTUTA

AMMOASTUTA

AMMOASTUTA

AMMOASTUTA

AMMOASTUTA

AMMOASTUTA

AMMOASTUTA

AMMOASTUTA

AMMOASTUTA

AMMOASTUTA

AMMOASTUTA

AMMOASTUTA

AMMOASTUTA

AMMOASTUTA

AMMOASTUTA

AMMOASTUTA

AMMOASTUTA

AMMOASTUTA

AMMOASTUTA

AMMOBACULITES

AMMOBACULITES

AMMOBACULITES

AMMOBACULITES

AMMOBACULITES

AMMOBACULITES

AMMOBACULITES

AMMOBACULITES

AMMOBACULITES

AMMOBACULITES

AMMOBACULITES

AMMOBACULITES

AMMOBACULITES

AMMOBACULITES

AMMOBACULITES

AMMOBACULITES

AMMOBACULITES

AMMOBACULITES

AMMOBACULITES

AMMOBACULITES

AMMOBACULITES

AMMOBACULITES

AMMOBACULITES

AMMOBACULITES

AMMOBACULITES

AMMOBACULITES

AMMOBACULITES

AMMOBACULITES

AMMOBACULITES

AMMOBACULITES

AMMOBACULITES

AMMOBACULITES

AMMOBACULITES

AMMOBACULITES

AMMOBACULITES

AMMOB ACULITES

AMMOBACULITES

AMMOBACULITES

AMMOBACULITES

AMMOBACULITES

AMMOBACULITES

AMMOBACULITES

AMMOBACULITES

AMMOBACULITES

AMMOBACULITES

A MMOBACULITES

AMMOBACULITES

AMMOBACULITES

AMMOBACULITES

AMMOBACULITES

AMMOBACULITES

AMMOBACULITES

AMMOBACULITES

AMMOBACULITES

AMMOBACULITES

AMMOBACULITES

AMMOBACULITES

AMMOBACULITES

AMMOBACULITES

AMMOBACULITES

AMMOBACULITES

AMMOBACULITES
Specific Name

WIESNER I

W IESNER I

WIESNER I

WIESNERI

WIESNERI

POZONENSIS

POZONENSIS

POZONENSIS

INEPT A

INEPTA

INEPTA

INEPTA

IN EPTA

INEPTA

INEPTA

INEPTA

INEPTA

INEPTA

INEPTA

IN EPTA

IN EPTA

INEPTA

INEPTA

INEPTA

INEPTA

INEPTA

INEPTA

INEPTA

SALSA

SALSA

SALSA

SALSA

AGGLUTINANS

AGGLUTINANS

AGGLUTINANS

AGGLUTI NANS

AGGLUTINANS

AG GLUTINANS

AGGLUTINANS

AGGLUTINANS

A GGLUTINANS

A G GLUTINANS

AGGLUTINANS

AGGLUTINANS

AG GLUTINANS

AGGLUTINANS

AG GLUTI NANS

AG GLUTINANS

AGGLUTINANS

AG GLUTI NANS

AG GLUTINANS

A GGLUTI NANS

AG GLUTINANS

AGGLUTINANS

AGGLUTI NANS

A G GLUTI INANS

A G GLUTINANS

A G GLUTINANS

AMERI CANUS

AMERICANUS

AMERICANJS

AMERI CANUS

AMERI CANUS

AMERI CANUS

AMERI CANUS

AMERI CANUS

AMERICANUS

AMERICANUS

AMERI CANUS

AMER I CANUS

AMERICANUS

ARENARIUS

CRASSUS

CRASSUS

CRASSUS

CYLINDROIDES

DILATATUS

DILATATUS

DILATATUS

DI LATATUS

Dilatatus

Dilatatus

Dilatatus

Dilatatus

DI LATATUS

DI LATATUS

DI LATATUS

DI LATATUS

DilataTus

DilataTUS

DILATATUS

DILATATUS

Dilatatus

\section{Locality}

NE GULF OF MEXICO

NE GULF OF MEXICO 
Publication

10276 PARKER PHLEGER PEIRSON 1953 10277 PARKER PHLEGER PEIRSON 1953 10278 PHLEGER 1956

10279 PHLEGER 1956

10280 PHLEGER 1956

10281 PHLEGER 1956

10282 WARREN 1957

10283 PHLEGER 1954

10285 PHLEGER 195

10286 PHLEGER 1954

10287 HALTON 1960

10288 PHLEGER 1954

10289 PHLEGER 1954
10290 PHLEGER 1954

10291 HALTON 1960

10292 OTVOS 1978

10293 WALTON 1964

10294 BEN DA PURI 1962

10295 PHLEGER 1965 A
10296 PHLEGER 1965 B

10297 PHLEGER $1965 \mathrm{~B}$

10298 BEN DA PURI 1962

10299 BANDY 1956

10300 BANDY 1956

10301 BANDY 1956

10302 BANDY 1956

10303 BANDY 1956

10304 BANDY 1956

10306 PHLE GER 1956

10307 PHLEGER 1956

10308 PHLEGER 1956

10309 PHLEGER 1956

10310 PHLEGER 1956

0311 PARKER PHLEGER PEIRSON 1953

PARKER PHLEGER PEIRSON 1953

10314 BOCK 1976

10315 SEGURA 1963

10316 PHLEGER 19558

10317 LANKFORD 195

10318 PHLEGER 1954

10319 PHLEGER $1965 \mathrm{C}$

10320 PHLEGER 1954

10321 PHLEGER 1954

10322 PHLEGER 195

10323 OTVOS 1978

10324 WALTON 1960

10326 PHLEGER 1954

10327 PHLEGER 1954

10328 WANTLAND 1969

10329 BANDY 1956

10330 PFLUM FRERICHS 1976

10331 PFLUM FRERICHS 1976

10332 PFLUM FRERICHS 1976

10333 PFLUM FRERICHS 1976

10334 PFLUM FRERICHS 1976

10335 PFLUM FRERICHS 1976

10336 KORNFELD 1931

10337 KORNFELD 1931

10338 KORNFELD 1931

10339 KORNFELD 1931

10340 KORNFELD 1931

10341 KORNFELD 1931

10342 PHLEGER 1951A

10343 CUSHMAN 1920

10344 PHLEGER 1951A

10345 PHLEGER 1951A

10346 PHLEGER 1951A

10347 PHLEGER 1951A

10348 PHLEGER 1951 A

10349 PHLEGER 1951A

10350 PHLEGER 1951 A

10351 PHLEGER 1951 A

10352 PHLEGER 1951 A

10353 PHLEGER $1951 \mathrm{~A}$

10354 PHLEGER 1951A

10355 PHLEGER 1951 A

10356 PHLEGER 1951A

10357 PHLEGER 1951A

10358 PHLEGER 1951A

10359 PHLEGER 1951A

10360 PHLEGER 1951A

10361 PHLEGER 1951A

10362 PHLEGER 1951A

10363 PHLEGER 1951A

10364 PHLEGER 1951A

10365 PHLEGER 1951A

10366 NORTON 1930

10367 CUSHMAN $1922 \mathrm{~A}$

10368 ANDERSON 1968

10369 BANDY 1956

10370 BANDY 1956
Generic Name

AMMOBACULITES AMMOBACULITES AMMOBACULITES AMMOBACULITES A MMOBACUL ITES AMMOBACULITES AMMOBACULITES AMMOBACULITES AMMOBACULITES AMMOBACULITES AMMOBACULITES AMMOBACULITES AMMOBACULITES AMMOBACULITES AMMOBACULITES AMMOBACULITES AMMOBACULITES AMMOBACUL ITES AMMOBACULITES AMMOBACULITES AMMOBACULITES AMMOBACULITES AMMOBACULITES AMMOBACULITES AMMOBACULITES AMMOBACULITES AMMOBACULITES AMMOBACULI TES AMMOBACULITES AMMOBACULITES AMMOBACUL ITES AMMOBACULITES AMMOBACULITES AMMOBACULITES

AMMOBACULITES

AMMOBACULITES

AMMOBACULITES

AM MOBACUL ITES

AMMOBACULITES

AMMOBACULITES

AMMOBACULITES

AMMOBACULITES

AMMOBACULITES

AMMOBACULITES

AMMOBACULITES

AMMOBACULITES

AMMOBACULITES

AMMOBACULITES

AMMOBACULITES

AMMOBACULITES

AMMOBACULITES

AMMOBACULITES

AMMOBACULITES

AMMOBACUL I TES

AMMOBACULITES

AMMOBACULITES

AMMOBACULITES

AMMOBACULITES

AMMOBACULITES

AMMOBACULITES

AMMOBACULITES

AMMOBACULITES

AMMOBACUL ITES

AMMOBACULITES

AMMOBAC ULITES

AMMOBACULITES

AMMOBAC UL I TES

AMMOB ACULITES

AMMOBACUL I TES

AMMOBACULITES

AMMOBACUL ITES

AMMOBACULITES

AMMOBACULITES

AMMOB ACUL ITES

AMMOBACULITES

AMMOBACULITES

AMMOBACUL ITES

AMMOBACULITES

AMMOBACULITES

AMMOBACULITES

AMMOBACULITES

AMMOBACULITES

AMMOBACU

AMMOBACULITES

AMMOBACULITES

AMMOBACULITES

AMMOB ACUL I TES

AMMOBACULITES

AMMOBACULITES

AMMOBACULITES

AMMOBACULITES

AMMOBACULITES
Specific Name

D ILATATUS

DILATATUS

D I LATATUS

D Latatus

DILATATUS

D I LATATUS

D I LATATUS

D ILATATUS

D I LATATUS

DI LATATUS

DIVERSUS

EXIGUUS

EXIGUUS

EXIGUUS

EXIGUUS

EXIGUUS

EXIGUUS

EXIGUUS

EXIGUUS

EXIGUUS

EXIGUUS

EXIGUUS

EXIGUUS

EXIGUUS

EXIGUUS

EXIGUUS

EXIGUUS

EXIGUUS

EXIGUUS

EXIGUUS

EXIGUUS

EXIGUUS

EXIGUUS

EXIGUUS

EXIGUUS

EXIGUUS

EXIGUUS

EXIGUUS

EXIGUUS

EXIGUUS

EXIGUUS

EXIGUUS

EXILIS

EXILIS

EXILIS

EXILIS

EXILIS

EXILIS

$x$ ILIS

EXILIS

FILIFORMIS

FILIFORMIS

FILIFORMIS

FI LIFORMIS

F ILIFORMIS

F I L I F ORMI S

FOLI ACEUM

FOLIACEUM

FOL I A CEUM

FOLI A CE UM

FOLI ACE UM

FOLI ACE UM

FOLIACEUS

FOLIACEUS

OLIACEUS

FOLIACEUS

FOLI A CEUS

FOLIACEUS

FOLIACEUS

FOLIACEUS

FOLIACEUS

FOLIACEUS

FOLIACEUS

FOLIACEUS

FOLIACEUS

FOLI A CEUS

FOLIACEUS

OLIACEUS

FOLIACEUS

FOLIACEUS

FOLIACE US

FOLIACEUS

FOLIACEUS

FOLIACE US

FOLIACEUS

FOLIACEUS

RE OPHAC IF ORMIS

RE OPHAC IF ORMIS

SALSUS

SALSUS

SALSUS

Locality

TEXAS GULF COAST

TEXAS GULF COAST

NH GULF OF MEXICO

NW GULF OF MEXICO

NW GULF OF MEXICO

CENTRAL TEXAS BAYS

SE LOUIS IANA

PASCAGOULA R.. MISS.

MISSISSIPPI SOUND

GRAVELINE B., MISS. 


\section{Publication}

10371 PHLEGER LANKFORD 1957 10372 PHLEGER 19558

10373 HALTON 1960

10374 BANDY 1956

10375 BANDY 1956

10376 BANDY 1956

10377 PHLEGER 19658

10378 PHLEGER 19658

10379 WALTON 1964

10380 LAMB 1972

10381 PHLEGER 1956

10382 PARKER PHLEGER PEIRSON 1953

10383 PARKER PHLEGER PEIRSON 1953

10384 PARKER PHLEGER PEIRSON 1953

10385 PARKER PHLEGER PEIRSON 1953

10386 PARKER PHLEGER PEIRSON 1953

10387 PARKER PHLEGER PEIRSON 1953

10388 PARKER PHLEGER PEIRSON 1953

10389 PARKER PHLEGER PEIRSON 1953

10390 PARKER PHLEGER PEIRSON 1953

10391 LEHMANN 1957

10392 SHEPARD MOORE 1955

10393 PHLEGER 1954

10394 PHLEGER 1954

10395 PHLEGER 1954

10396 PHLEGER 1954

10397 PHLEGER 1954

10398 PHLEGER 1954

10399 POST 1951

10400 HALDRON 1963

10401 WARREN 1957

10402 CUSHMAN 1920

10403 PFLUM FRERICHS 1976

10404 LEROY HODGKINSON 1975

10405 PFLUM FRERICHS 1976

10406 PFLUM FRERICHS 1976

10407 PFLUM FRERICHS 1976

10408 PFLUM FRERICHS 1976

10409 PFLUM FRERICHS 1976

10410 PFLUM FRERICHS 1976

10411 PFLUM FRERICHS 1976

10412 PFLUM FRERICHS 1976

10413 PFLUM FRERICHS 1976

10414 PFLUM FRERICHS 1976

10415 PFLUM FRERICHS 1976

10416 PFLUM FRERICHS 1976

10417 CUSHMAN 1918

10418 CUSHMAN 1918

10419 PFLUM FRERICHS 1976

10420 PFLUM FRERICHS 1976

10421 PFLUM FRERICHS 1976

10422 PFLUM FRERICHS 1976

10423 PFLUM FRERICHS 1976

10424 PFLUM FRERICHS 1976

10425 PFLUM FRERICHS 1976

10426 PFLUM FRERICHS 1976

10427 PFLUM FRERICHS 1976

10428 PFLUM FRERICHS 1976

10429 PFLUM FRERICHS 1976

10430 PFLUM FRERICHS 1976

10431 PFLUM FRERICHS 1976

10432 PFLUM FRERICHS 1976

10433 PFLUM FRERICHS 1976

10434 PFLUM FRERICHS 1976

10435 PFLUM FRERICHS 1976

10436 CUSHMAN 1918

10437 CUSHMAN 1918

10438 CUSHMAN 1918

10439 CUSHMAN 1918

10440 CUSHMAN 1918

10441 PFLUM FRERICHS 1976

10442 BOCK 1976

10443 CUSHMAN 1918

10444 CUSHMAN 1918

10445 PFLUM FRERICHS 1976

10446 PFLUM FRERICHS 1976

10447 PFLUM FRERICHS 1976

10448 PFLUM FRERICHS 1976

10449 PFLUM FRERICHS 1976

10450 PFLUM FRERICHS 1976

10451 PFLUM FRERICHS 1976

10452 PFLUM FRERICHS 1976

10453 PFLUM FRERICHS 1976

10454 PFLUM FRERICHS 1976

10455 PFLUM FRERICHS 1976

10456 PFLUM FRERICHS 1976

10457 PFLUM FRERICHS 1976

10458 PFLUM FRERICHS 1976

10459 PFLUM FRERICHS 1976

10460 PFLUM FRERICHS 1976

10461 PFLUM FRERICHS 1976

10462 PFLUM FRERICHS 1976

10463 PFLUM FRERICHS 1976

10464 PFLUM FRERICHS 1976

10465 PFLUM FRERICHS 1976
Generic Name

AMMOBACULITES

AMMOBACULITES

AMMOBACULITE

AMMOBACULITES

AMMOBACULITES

AMMOBACULITES

AMMOB'ACULITES

AMMOBAC ULITES

AMMOBACULITE

AMMOBACULITES

AMMOBACULITES

AMMOBACULITES

AMMOBACULITES

AMMOBACULITES

AMMOBACULITES

AMMOBACULITES

AMMOBACULITES

AMMOBACULITES

AMMOBACULITES

AMMOBACULITES

AMMOBACULITES

AMMOBA CULITES

AMMOBACULITES

AMMOBACULITES

AMMOBACULITES

AMMOBACUL ITES

AMMOBACULITES

AMMOBACULITES

AMMOBACULI TES

AMMOBACULITES

AMMOBACULITES

AMMOBACULITES

AMMODISCOIDES

AMMODISCOIDES

AMMODISCOIDE

AMMODISCOIDES

AMMODISCOIDES

AMMODISCOIDES

AMMODISCOIDES

AMMODISCOIDES

AMMODI SCOIDES

AMMODISCOIDES

AMMOD I SC OIDES

AMMODISCOIDES

AMMODISCOIDES

AMMODISCOIDES

AMMODISCOIDES

AMMODISCOIDE

AMMODISC OI DES

AMMODISCOIDES

AMMODISCOIDES

AMMODI SCOIDES

AMMODISCOIDES

AMMODI SCOIDES

AMMODISCOIDES

AMMODISCOIDES

AMMODISCOIDES

AMMODISCOIDES

AMMOD ISCOIDES

AMMODI SCOI DES

AMMODI SC OIDES

AMMODISCOIDES

AMMODISCOIDES

AMMODISCOIDES

AMMODISCOIDES

AMMODIS COIDES

AMMODISCOIDES

AMMODISCOIDES

AMMODISCOIDES

AMMODISCOIDES

AMMODISCOIDES

AMMODISCUS

AMMODIS CUS

AMMODISCUS

AMMODISCUS

AMMODISCUS

AMMODISCUS

AMMODISC US

AMMOD I SCUS

AMMODISCUS

AMMODIS CUS

AMMODISCUS

AMMODI SCUS

AMMODISCUS

AMMODIS CUS

AMMODISCUS

AMMODISCUS

AMMODISCUS

AMMODIS CUS

AMMODISCUS

AMMODISCUS

AMMODISCUS

AMMODISCUS

AMMODISCUS

AMMODISCUS
Specific Name

SALSUS

SALSUS

SALSUS

SALSUS

SALSUS

SALSUS

SALSUS

SALSUS

SALSUS

SALSUS

SALSUS

SALSUS

SALSUS

SALSUS

SALSUS

SALSUS

SALSUS

SALSUS

SALSUS

SALSUS

SALSUS

SALSUS

SALSUS

SALSUS

SALSUS

SALSUS DISTINCTUS

SUBCATE NULATUS

SUBC ATE NULATUS

TENUIMARG $O$

TURBINATUS

TURBINATUS

TURBINATUS

TURB INA TUS

TURBINATUS

TURBINATUS

TURBINATUS

TURBINATUS

TURBINATUS

TURBINATUS

TURBI NA TUS

TURBINATUS

TURBINATUS

TURBINATUS

TURBINATUS

TURBINATUS

TURBINATUS

TURBINATUS

TURBINATUS

TURBINATUS

TURBINATUS

TURBINATUS

TURBINATUS

TURBINATUS

TURBINATUS

TURBINATUS

TURBINATUS

TURBINATUS

TURBINATUS

TURBINATUS

TURBINA TUS

TURBINATUS

TURB INATUS

TURBINATUS

TURBI NATUS

TURBINATUS

TURBINATUS

TURB INATUS

TURBINATUS

TURBINATUS

IN CERTUS

IN CERTUS

PLANORB IS

PLANORB IS

PLANORB IS

PLANORB IS

PL ANORB IS

PL ANORBIS

PLANORB IS

PLANORBIS

PLANORB IS

PLANORBIS

PLANORBIS

PLANORBIS

PLANORBIS

PLANORBIS

PLANORBIS

PL ANORBIS

PL AN ORBIS

PLANORBIS

PLANORBIS

PLANORBIS

PL ANORB IS

\section{Locality}

TEXAS GULF COAST

MISSISSIPPI DELTA 


\section{Publication}

10466 PFLUM FRERICHS 1976 10467 PFLUM FRERICHS 1976 10468 PFLUM FRERICHS 1976 10469 PFLUM FRERICHS 1976 10470 PFLUM FRERICHS 1976 10471 PFLUM FRERICHS 1976 10472 PFLUM FRERICHS 1976 10473 PFLUM FRERICHS 1976 10474 PFLUM FRERICHS 1976 10475 PFLUM FRERICHS 1976 10476 PFLUM FRERICHS 1976 10477 PFLUM FRERICHS 1976 10478 PFLUM FRERICHS 1976 10479 PFLUM FRERICHS 1976 10480 PFLUM FRERICHS 1976 10481 PFLUM FRERICHS 1976 10482 PFLUM FRERICHS 1976 10483 PFLUM FRERICHS 1976 10486 PFLUM FRERICHS 1976
10485 LEROY HODGINSON 1975 10485 LEROY HODGKINSON 19
10486 PFLUM FRERICHS 1976 10487 PFLUM FRERICHS 1976 10488 PFLUM FRERICHS 1976 10489 PFLUM FRERICHS 1976 10490 PFLUM FRERICHS 1976 10491 PFLUM FRERICHS 1976 10492 PFLUM FRERICHS 1976 10493 PFLUM FRERICHS 1976 10494 PFLUM FRERICHS 1976 10495 PFLUM FRERICHS 1976 10496 PFLUM FRERICHS 1976 10497 PFLUM FRERICHS 1976 10498 LERCY HODGKINSON 1975 10499 PFLUM FRERICHS 1976 10500 PFLUM FRERICHS 1976 10501 PFLUM FRERICHS 1976 10502 PFLUM FRERICHS 1976 10503 PFLUM FRERICHS 1976 10504 PFLUM FRERICHS 1976 10505 PFLUM FRERICHS 1976 10506 FRERICHS 1969 10507 PFLUM FRERICHS 1976 10508 PFLUM FRERICHS 1976 10509 PFLUM FRERICHS 1976 10510 PFLUM FRERICHS 1976 10511 PFLUM FRERICHS 1976 10512 PFLUM FRERICHS 1976 10513 PFLUM FRERICHS 1976 10514 PFLUM FRERICHS 1976 10515 PFLUM FRERICHS 1976 10516 PFLUM FRERICHS 1976 10517 PFLUM FRERICHS 1976 10518 PFLUM FRERICHS 1976 10519 PFLUM FRERICHS 1976 10520 PFLUM FRERICHS 1976 10521 PFLUM FRERICHS 1976 10522 PFLUM FRERICHS 1976 10523 PFLUM FRERICHS 1976 10526 PFLUM FRERICHS 1976 10525 PFLUM FRERICHS 1976 10526 CUSHMAN 1918

10527 CUSHMAN 1918

10528 PFLUM FRERICHS 1976 10529 PFLUM FRERICHS 1976 10530 PFLUM FRERICHS 1976 10531 PFLUM FRERICHS 1976 10532 PFLUM FRERICHS 1976 10533 PFLUM FRERICHS 1976 10534 PFLUM FRERICHS 1976 10535 PFLUM FRERICHS 1976 10536 PFLUM FRERICHS 1976 10537 PFLUM FRERICHS 1976 10538 LEROY HODGKINSON 1975 10539 PFLUM FRERICHS 1976 10540 PFLUM FRERICHS 1976 10541 PFLUM FRERICHS 1976 10542 PFLUM FRERICHS 1976 10543 PFLUM FRERICHS 1976 10544 PFLUM FRERICHS 1976 10545 PFLUM FRERICHS 1976 10546 PFLUH FRERICHS 1976 10547 PFLUM FRERICHS 1976 10548 PFLUM FRERICHS 1976 10549 PFLUM FRERICHS 1976 10550 PFLUM FRERICHS 1976 10551 CUSHMAN 1918

\section{CUSHMAN 1918}

10553 PFLUM FRERICHS 1976 10554 PFLUM FRERICHS 1976 10555 PFLUM FRERICHS 1976 10556 PFLUM FRERICHS 1976 10557 PFLUM FRERICHS 1976 10558 PFLUM FRERICHS 1976 10559 PFLUM FRERICHS 1976 10560 PFLUM FRERICHS 1976

\section{Generic Name}

Specific Name

AMMODISCUS

AMMODISCUS

AMMODISCUS

AMMODISCUS

AMMODISCUS

AMMODISCUS

AMMODISCUS

AMMODISCUS

AMMODISCUS

AMMODISCUS

AMMODISCUS

AMMODISCUS

AMMODIS CUS

AMMODISCUS

AMMODISCUS

AMMODISCUS

AMMODISCUS

AMMODISCUS

AMMODISCUS

AMMODISCUS

AMMODISCUS

AMMODISCUS

AMMODISCUS

AMMODISCUS

AMMODISCUS

AMMODISCUS

AMMODISCUS

AMMODISCUS

AMMODISCUS

TRIHEDRA

AMMOGLOBIGERINOI DES DEHISCENS

AMMOGLOBIGERINOIDES DEHISCENS

AMMOGLOBIGERINOI DES DEHISCENS

AMMOGLOBIGERINOI DES DEHISCENS

AMMOGLOBIGER INOI DES DEHISCENS

AMMOGLOBIGERINOI DES DEHISCENS

AMMOGLOBIGERINOI DES DEHISCENS

AMMOGLOBIGERINOIDES DEHISCENS

AMMOGLOBIGERINOI DES DEHISCENS

AMMOGLOBIGERINOIDES DEHISCENS

AMMOGLOBIGERINOIDES DEHISCENS

AMMOGLOBIGERINOIDES DEHISCENS

AMMOGLOBIGERINOIDES DEHISCENS

AMMOGLOBIGERINOI DES DEHISCENS

AMMOGLOBIGERINOI DES DEHISCENS

AMMOGLOBIGERINOI DES DEHISCENS

AMMOGLOBIGERINOI DES DEHISCENS

AMMOGLOBIGERINOI DES DEHISCENS

AMMOGLOBIGERINOI DES DEHISCENS

AMMOGLOBIGERINOI DES DEHISCENS

AMMOGLOBIGERINOI DES DEHISCENS

AMMOGLOBIGERINOI DES DEHISCENS

AMMOGLOBIGERINOI DES DEHISCENS

AMMOLAGENA

AMMOLAGENA

AMMOLAGENA

AMMOL AGENA

AMMOLAGENA

AMMOLAGENA

AMMOLAGENA

AMMOLAGENA

AMMOLAGENA

AMMOLAGENA

A MMOLAGENA

AMMOL A GENA

AMMOLAGENA

AMMOLAGENA

AMMOL AGENA

AMMOL AGENA

AMMOLAGENA

AMMOLAGENA

AMMOL AGENA

AMMOLAGENA

AMMOLAGENA

AMMOLAGENA

AMMOLAGENA

AMMOLAGENA

AMMOLAGENA

AMMOL A GENA

AMMOLAGENA

AMMOLAGENA

AMMOLAGENA

AMMOL AGENA

AMMOLAGENA

AMMOLAGENA

AMMOLAGENA

AMMOLAGENA

AMMOL A GENA

AMMOL AGENA

AMMOL AGENA
CLAVATA

CLAVATA

CLAVATA

CLAVATA

CLAVATA

CLAVATA

CLAVATA

CLAVATA

CLAVATA

CLAVATA

CLAVATA

CLAVATA

CLAVATA

CLAVATA

CL AVATA

CLAVATA

CLAVATA

CLAVATA

CLAVATA

CLAVATA

CLAVATA

CLAVATA

CLAVATA

CL AVATA

CLAVATA

CLAVATA

CLAVATA

CLAVATA

CLAVATA

CLAVATA

CLAVATA

Locality

NW GULF OF MEXICO

NW GULF OF MEXICO

NW GULF OF MEXICO

NW GULF OF MEXICO

NW GULF OF MEXICO

NW GULF OF MEXICO

NW GULF OF MEXICO

NW GULF OF MEXICO

NW GULF OF MEXICO

NW GULF OF MEXICO

CENTRAL GULF OF MEXICO

CENTRAL GULF OF MEXICO

$N W$ GULF OF MEXICO

NW GULF OF MEXICO

NW GULF OF MEXICO

CENTRAL GULF OF MEXICO

CENTRAL GULF OF MEXICO

CENTRAL GULF OF MEXICO

CENTRAL GULF OF MEXICO

$N$ GULF OF MEXICO

NW GULF OF MEXICO

$N W$ GULF OF MEXICO

NW GULF OF MEXICO

CENTRAL GULF OF MEXICO

CENTRAL GULF OF MEXICO

CENTRAL GULF OF MEXICO

CENTRAL GULF OF MEXICO

CENTRAL GULF OF MEXICO

CENTRAL GULF OF MEXICO

CENTRAL GULF OF MEXICO

CENTRAL GULF OF MEXICO

CENTRAL GULF OF MEXICO

$N$ GULF OF MEXICO

NW GULF OF MEXICO

NW GULF OF MEXICO

CENTRAL GULF OF MEXICO

CENTRAL GULF OF MEXICO

CENTRAL GULF OF MEX

CENTRAL GULF OF MEXICO

CENTRAL G. OF MEXICO

CENTRAL GULF OF MEXICO

NW GULF OF MEXICO

$N W$ GULF OF MEXICO

NW GULF OF MEXICO

NW GULF OF MEXICO

NW GULF OF MEXICO

$N W$ GULF OF MEXICO

NW GULF OF MEXICO

NW GULF OF MEXICO

NW GULF OF MEXICO

$N W$ GULF OF MEXICO

NH GULF OF MEXICO

NW GULF OF MEXICO

NW GULF OF MEXICO

CENTRAL GULF OF MEXICO

CENTRAL GULF OF MEXICO

CENTRAL GULF OF MEXICO

CENTRAL GULF OF MEXICO

CENTRAL GULF OF MEXICO

NE GULF OF MEXICO

NE GULF OF MEXICO

CENTRAL GULF OF MEXICO

NW GULF OF MEXICO

NH GULF OF MEXICO 


\section{Publication}

10561 PFLUM FRERICHS 1976 10562 PFLUM FRERICHS 1976 10563 PFLUM FRERICHS 1976 10564 PFLUM FRERICHS 1976 10565 PFLUM FRERICHS 1976 10566 PFLUM FRERICHS 1976 10567 PFLUM FRERICHS 1976 10568 PFLUM FRERICHS 1976 10569 PFLUM FRERICHS 1976 10570 PFLUM FRERICHS 1976 10571 PFLUM FRERICHS 1976 10572 PFLUM FRERICHS 1976 10573 PFLUM FRERICHS 1976 10574 PHLEGER 19658 10575 ANDERSON 1968 10576 PHLEGER 1965 A 10577 PHLEGER $1965 \mathrm{C}$ 10578 PHLEGER 1965A 10579 PHLEGER 1965 A

10580 PFLUM FRERICHS 1976

10581 PFLUM FRERICHS 1976

10582 AYALA-CASTANARES 1963

10583 LAMB 1972

10584 AYALA-CASTANARES SEGURA 1968 10585 PHLEGER 1965A

10586 PHLEGER 1965 A

10587 PHLEGER 1965 A

10588 PHLEGER 19658

10589 PHLEGER 1965 A

10590 PHLEGER 1965 A

10591 PHLEGER 1965A

10592 PHLEGER 1965A

10594 PHLEGER LANKFORD 1978

10595 WANTLAND 1969

10596 SEGURA 1963

10597 LOEP 1965

10598 BOCK 1976

1059980 CK 1976

10600 POAG 1976

10601 OTVOS 1978

10602 LOEP 1965

10603 OTVOS 1978

10604 OTVOS 1978

10605 LOEP 1965

10606 PFLUM FRERICHS 1976

10607 PFLUM FRERICHS 1976

10608 LOEP 1965

10609 BOCK 1976

10610 BOCK 1976

10611 POAG 1978

10612 POAG 1978

10613 AYALA-CASTANARES SEGURA 1968

10614 BOCK 1976

10615 PHLEGER 1954

10616 PHLEGER 1954

10617 PHLEGER 1954

10618 PHLEGER 1954

10619 PHLEGER 1955A
10620 LANKFORD 1959

10621 BENDA PURI 1962

10622 BENDA PURI 1962

10623 OTVOS 1978

10624 PHLEGER 1955 A

10625 PARKER 1954

10626 PARKER 1954

10627 PARKER 1954

10628 PARKER 1954

10629 PARKER 1954

10630 PARKER 1954

10631 SHIFFLETT 1961

10632 PARKER PHLEGER PEIRSON 1953

10633 PARKER PHLEGER PEIRSON 1953

10634 BENDA PURI 1962

10635 PHLEGER 1956

10636 PARKER 1954

10637 PARKER PHLEGER PEIRSON 1953 10638 PARKER PHLEGER PEIRSON 1953 10639 PARKER PHLEGER PEIRSON 1953

10640 PARKER PHLEGER PEIRSON 1953

10640 PARKER PHLEGER PEIRSON 1953
10641 PARKER PHLEGER PEIRSON 1953

10642 PHLEGER 1956

10643 PHLEGER 1956

10644 PARKER 1954

10645 PARKER 1954

10646 PARKER 1954

10647 PARKER 1954

10648 PHLEGER LANKFORD 1957

10649 PARKER 1954

10650 PHLEGER 19558

10651 PHLEGER 1956

10652 PHLEGER 1956

10653 PARKER 1954

10654 PARKER 1954

10655 PARKER 1954
Generic Name

AM MOL AGENA

AMMOLAGENA

AMMOL AGENA

A MMOL A GENA

AMMOL AGENA

AMMOL AGENA

AMMOL AGENA

AMMOMARG INUL INA

AMMOMAR GINUL I NA

AMMOMAR G INUL INA

AMMOMARGINUL INA

AMMOMAR G INUL I NA

AMMOMAR GINUL INA

AMMONI A

AMMONIA

AMMONIA

AMMONIA

AMMON I A

AMMON I A

AMMON I A

AMMON I A

AM MON I A

AMMON I A

AMMONIA

AM MON I A

AMMON I A

AMMONIA

AMMONIA

AMMONIA

AMMONIA

AMMONIA

AMMONIA

AMMONIA

AMMONIA

AMMONIA

AMMON I A

AMMON I A

AMMONIA

AMMON I A

AM MONI A

AMMONIA

AMMONIA

AMMONIA

AMMON I A

AMMONIA

AMMONIA

AMMONIA

AMMON I A

AMMON I A

AMMON I A

AMMONIA

AMMOSCALAR I A

AMMOS CALARIA

AMMOSCAL AR IA

AMMOS CALAR I A

AMMOS CAL AR IA

AMMOS CALARI A

AMMOS CALARI A

AMMOSC ALAR I A

AMMOSCALAR IA

AMMOS CALAR I A

AMMOSCAL AR I A

AMMOS CAL AR I A

AMMOSCALAR IA

AMMOS CAL AR I A

AMMOS CAL AR I A

AMMOSCALARIA

AMMOS CAL AR I A

AMMOSCALAR IA

AMMOSCAL AR IA

AMMOSCALARIA

AMMOS CALARIA

AMMOS C ALAR I

AMMOSCALAR IA

AMMOSCAL AR IA

AMMOSCALARIA

AMMOS C ALAR IA

AMMOSCALARI A

AMMOS CAL AR I A

AMMOSCALAR IA

AMMOS CALAR IA

AMMOSCALAR IA

AMMOS CALARIA

AMMOS CALARIA

AMMOS CALAR I A

AMMOS CAL AR I A

AMMOS CAL AR I

AMMOS CALAR IA

AMMOS CALAR IA

AMMOSCALARIA

AMMOS CALAR I A

AMMOSCAL AR I A
Specific Name

CLAVATA

CL AVATA

CL AVATA

CL AVATA

CL AVATA

CL AVATA

FOLIACEA

FOLIACEA

FOLIACEA

OLIACEA

FOLIACEA

BE CCARII

BE CCAR I I

BECCARI

BECCARI

BE CCARI I

BE CCARII

BE CCARII

BECCARII

BE CCARI

BE CCARII

BE CCARII

BECCARII

BE CCARI I

BE CCARI I

BE CCARII

BE CCARI

BECCARI

BE CCARI I

BE CCARII

BECCARII

BECCARII

BECCARII

BECCARI I PARKINSONIANA

BECCARI I PARKINSONIANA

BECCARII PARKINSONIANA

BECCARI I PARKINSONIANA

BECCARII PARKINSONIANA

BE CCARII PARKINSONIANA

BECCARII SOBRINA

BECCARII TEPIDA

BECCARII TEPIDA

BECCARI I TEPIDA

BECCARII TEPIDA

BECCARII TEPIDA

BECCARII TEPIDA

BECCARII TEPIDA

PARKINS OYIANA TEPIDA

PARKINSONIANA TYPICA

ROLSHAUSENI

TRANSLU CENS

FLUVIAL IS

FLUVIAL IS

FLUVIAL IS

FLUVIAL IS

PSEUDOSPIRALIS

PSEUDOSPI RALIS

PSEUDOSPIRALIS

PSEUDOSPIRALIS

PS EUDOSPIRALIS

PSEUDOSPIRALIS

PSEUDOSPI RALIS

PSEUDOSPIRALIS

PSEUDOSPI RALIS

PSEUDOSPI RALIS

PSEUDOSPIRALIS

PSEUDOSPI RALIS

PSEUDOSPIRALIS

PSEUDOSPIRALIS

PSEUDOSPIRALIS

PSEUDOSPIRALIS

PSEUDOSPIRALIS

PSEUDOSPIRALIS

PS EUDOSPI RALIS

PSEUDOSPIRALIS

PSEUDOSPI RALIS

PSEUDOSPIRALIS

PSEUDOSPIRALIS

PSEUDOSPIRALIS

PSEUDOSPIRALIS

PS EUDOSPIRALIS

PSEUDOSPIRALIS

PSEUDOSPI RALIS

PSEUDOSPI RALIS

PSEUDOSPIRALIS

PSEUDOSPIRALIS

PSEUDOSPIRALIS

PSEUDOSPI RALIS

PSEUDOSPI RALIS

TENU I MA RG $O$

TE NU IMARG 0

TENUIMARGO

Locality

NW GULF OF MEXICO

NW GULF OF MEXICO

$N W$ GULF OF MEXICO

NW GULF OF MEXICO

NW GULF OF MEXICO

NW GULF OF MEXICO

NH GUL 


\section{Publication}

10656 PARKER 1954 10657 PARKER 1954

10658 PARKER 1954

10659 PARKER 1954

10660 PARKER 195

10661 PARKER 1954

10662 PARKER 1954

10663 PARKER 1954

10665 PFLUM FRERICHS 1976

10666 PHLEGER 1965 A

10667 PHLEGER $1965 \mathrm{~A}$

10668 PHLEGER 1965

10669 PHLEGER 1965A

10670 PHLEGER 1965 A

10671 PHLEGER 1965A

10672 WALDRON 1963

10673 PHLEGER $1965 \mathrm{~A}$
10674 WARREN 1957

10674 WARREN 1957
10675 WALDRON 1963

10675 WALDRON 1957

10677 WARREN 1957

10678 WARREN 1957

10679 WARREN 1956

10680 AYALA-CASTANARES 1963

10681 PHLEGER 1965

10682 WARREN 1956

10683 PHLEGER 1965

10684 WARREN 1957

10685 LANKFORD 1959

10686 PHLEGER 1960

10687 WALDRON 1963

10688 AYALA-CASTANARES SEGURA 1968

10689 BENDA PURI 1962

10690 PHLEGER 1965 A

10691 BOCK 1976

10692 PHLEGER 1965 A

10693 PHLEGER $1965 \mathrm{~A}$

10694 PHLEGER 1965 A

10695 PHLEGER 1965

10696 WANTLAND 1969

10697 BENDA PURI 1962

10698 PHLEGER 1965 A

10699 PHLEGER LANKFORD 1978

10700 OTVOS 1978

10701 BENDA PURI 1962

10702 PHLEGER 1965 A

10703 PHLEGER 1965 A

10704 PHLEGER 1965 A

10705 POAG 1976

10706 POAG 1978

10707 POAG 1976

10708 POAG 1978

10709 WARREN 1957

10710 ANDERSEN 1961

10711 PFLUM FRERICHS 1976

10712 PFLUM FRERICHS 1976

10713 PFLUM FRERICHS 1976

10714 PFLUM FRERICHS 1976

10715 PFLUM FRERICHS 1976

10716 PFLUM FRERICHS 1976

10717 PFLUM FRERICHS 1976

10718 PFLUM FRERICHS 1976

10719 PFLUM FRERICHS 1976

10720 PFLUM FRERICHS 1976

10721 PFLUM FRERICHS 1976

10722 PFLUM FRERICHS 1976

10723 PFLUM FRERICHS 1976

10724 ANDERSEN 1961

10725 BOCK 1976

10726 BOCK 1976

10727 PFLUM FRERICHS 1976

10728 PFLUM FRERICHS 1976

10729 PFLUM FRERICHS 1976

10730 PFLUM FRERICHS 1976

10731 PFLUM FRERICHS 1976

10732 PFLUM FRERICHS 1976

10733 PFLUM FRERICHS 197

10734 PFLUM FRERICHS 1976

10735 PFLUM FRERICHS 1976

10736 PFLUM FRERICHS 1976

10737 PFLUM FRERICHS 1976

10738 PFLUM FRERICHS 1976

10739 PFLUM FRERICHS 1976

10740 PFLUM FRERICHS 1976

10741 PFLUM FRERICHS 197

10742 PFLUM FRERICHS 1976

10743 PFLUM FRERICHS 1976

10744 NORTON 1930

10745 CUSHMAN 1930

10746 CUSHMAN 1930

10747 POAG SWEET 1972

10748 POAG 1972

10749 POAG 1972

10750 BOCK 1976
Generic Name

AMMOSCALAR IA

AMMOSCAL AR I A

AMMOS CALAR I A

AMMOSCALAR IA

AMMOS CALAR I A

AMMOS CALAR IA

AMMOSCAL AR I A

AMMO SPHAER O I D INA

AMMOSPHAER OIDINA

AMMO TIUM

AMMOTIUM

AMMOT I UM

AMMOTIUM

AMMOTIUM

AMMOTIUM

AMMOT IUM

AMMOT I UM

AMMOTIUM

AMMOTIUM

AMMOTIUM

AMMO TIUM

AMMOT IUM

A MMOTIUM

AMMOT I UM

AMMOT IUM

AMMOTIUM

AMMOTIUM

AMMO TI UM

AMMOTIUM

AMMOTIUM

AMMOTIUM

AMMOTIUM

AMMO TI UM

AMMO TIUM

AMMOT IUM

AMMOT I UM

AMMOTIUM

AMMOTIUM

AM YO TIUM

AMMOTIUM

AMMOT IUM

AMMOT IUM

AMMOTIUM

AMMOTIUM

AMMOT IUM

AMMOT I UM

AMMOT IUM

AMMOTIUM

AMMOTIUM

AMPHICORYNA

AMPHICORYNA

AMPHICORYNA

AMPH I CORYNA

AMPHICORYNA

AMPH ICORYNA

AMPHICORYNA

AMPH I CORYNA

AMPH I COR YNA

AMPHICORYNA

AMPHICORYNA

AMPH I CORYNA

AMPHICORYNA

AMPHICORYNA

AMPH I CORYNA

AMPHICORYNA

AMPHICORYNA

AMPHICORYNA

AMPHICORYNA

AMPH I CORYNA

AMPH ICORYNA

AMPH ICORYNA

AMPHICORYNA

AMPH I CORYNA

AMPHICORYNA

AMPHICORYNA

AMPHICORYNA

AMPHI CORYNA

AMPHICORYNA

AMPHICORYNA

AMPHICORYNA

AMPH I CORYNA

AMPHICORYNA

AMPHISORUS

AMPHISORUS

AMPHISORUS

AMPH ISTEGINA

AMPH ISTEG INA

AMPHISTEGINA

AMPHISTEGINA
Specific Name

TENLIMARGO

TENUIMARG O

TE NU I MARG 0

TE NUIMARS O

TENUIMARG O

TE NU I MARGO

TE NU I MARG O

TE NUIMARG $O$

SP HAERO I) IN IF ORMIS

SP HAERO I ) IN I F ORMIS

DILATATUM

DI LATATUM

DI LATATUV

DI LATATUM

DILATATUM

DILATATUM

DILATATUM

DI LATATUM

FRAGILE

FRAGILE

MULTILOCJLATUM

PALUSTRE

PSEUDOCASSIS

PSEUDOCAS SIS

SALSUM

SALSUM

SALSUM

SALSUM

SALSUM

SALSUM

SALSUM

SALSUM

SALSUM

SALSUM

SALSUM

SALSUM

SALSUM

SALSUM

SALSUM

SALSUM

SALSUM

SALSUM

SALSUM

SALSUM

SALSUM

SALSUM

SALSUM

SALSUM

SALSUM EYACIATUM

SALSUM EXILE

SALSUM TUMIDUM

SUEDIRECT UM

CAMACHOI

HI SPIDA

H I SP I DA

HI SPIDA

HISPIDA

HI SPIDA

HI SP IDA

H I SPIDA

HI SPIDA

HI SPIDA

HI SPIDA

HI SPIDA

$H$ I SP IDA

$H$ I SPIDA

ROEDERERI

SCALARIS

SEPARANS

SU BL INEAT A

SUEL INEAT A

SUBLINEAT A

SUBLINEAT A

SUBLINEAT A

SUBL INEAT A

SUBLINEAT A

SUEL INEATA

SUBL INEAT A

SUBL INE AT A

SU OL INEAT A

SUBL INEAT A

SUBL INEAT A

SUBL INEAT A

SUBL INEAT A

SUBL INE AT A

SU BL INE AT A

DUPLEX

HEMPR I CHI

HE MPR ICHI I

GI BBOSA

GIEBOSA

GIEBOSA

GI BBOSA

Locality

NE GULF OF MEXICO

NE GULF OF MEXICO

NE GULF OF MEXICO

NE GULF OF MEXICO

NE GULF OF MEXICO

NE GULF OF MEXICO

NE GULF OF MEXICO

NE GULF OF MEXICO

NE GULF OF MEXICO 


\section{Publication}

10751 BOCK 1976

10752 BOCK 1976

10753 BOCK 1976

10754 ANDERSEN 1961

10755 POAG 1972

10756 BANDY 1956

10757 VAUGHAN 1918

O750 LUDUICK HALTON 1957

10760 DAVIS 1964

10761 CUSH MAN 1922 A

10762 VAUGHAN 1918

10763 NORTON 1930

10764 CUSHMAN 1931

10765 CUSHMAN 1931

10766 CUSHMAN 1931

10767 LOEP 1965

10768 BANDY 1956

10769 KELLOUGH 1956

10770 KELLOUGH 1956

10771 BANDY 1956

10772 BANDY 1956

10773 BANDY 1956

10774 BANDY 1956

10775 LYNTS PFISTER 1967

10776 BANDY 1956

10777 BANDY 1956

10778 BANDY 1956

10779 BANDY 1956

10780 BANDY 1956

10781 ANDERSEN 1961

10782 ANDERSEN 1961

10783 PFLUM FRERICHS 1976

10784 PFLUM FRERICHS 1976

10785 PFLUM FRERICHS 1976

10786 PFLUM FRERICHS 1976

10787 WALTON 1964

10788 PFLUM FRERICHS 1976 10789 PFLUM FRERICHS 1976 10790 PFLUM FRERICHS 1976 10791 PFLUM FRERICHS 1976 10792 PFLUM FRERICHS 1976

10793 BANDY 1956

10794 AYALA-CASTANARES 1963 10795 BANDY 1956

10796 LOEP 1965

10797 BANDY 1956

10798 BANDY 1956

10799 KELLOUGH 1956

10800 KELLOUGH 1956

10801 KELLOUGH 1956

10802 KELLOUGH 1956

10803 KELLOUGH 1956

10804 PFLUM FRERICHS 1976

10805 PARKER 9954

10806 PARKER 1954

10807 PHLEGER 1956

10808 PARKER 1954

10809 PHLEGER 1956

10810 PARKER 1954

10811 PHLEGER 1951A

10812 PHLEGER 1951A

10813 PHLEGER 1951A

10814 PHLEGER 1951A

10815 BANDY 1956

10816 BANDY 1956

10817 BANDY 1956

10818 BANDY 1956

10819 BANDY 1956

10820 BANDY 1956

10821 ANDERSEN 1961

10822 WALTON 1960

10823 CREAGER 1958

10824 BANDY 1956

10825 KELLOUGH 1956

10826 BANDY 1956

10827 PHLEGER 1951A

10828 PHLEGER $1951 \mathrm{~A}$

10829 PHLEGER $1951 \mathrm{~A}$

10830 PHLEGER 1951A

10831 PHLEGER 1951A

10832 PFLUM FRERICHS 1976

10833 PFLUM FRERICHS 1976

10834 PHLEGER 1951A

10835 PARKER 1954

10836 PARKER 1954

10837 PARKER 1954

10838 PARKER 195

10839 PFLUM FRERICHS 1976

10840 PFLUM FRERICHS 1976

10841 PFLUM FRERICHS 1976

10842 LANKFORD 1959

10843 PHLEGER 1951 A

10844 PHLEGER 1951 A

10845 PHLEGER 1951 A
Generic Name

AMPH ISTEGINA

AMPHI STEGINA

AMPHISTEGINA

AMPHISTEGINA

AMPH ISTEGINA

AMPHISTEGINA

AMPHISTEGINA

AMPHISTEGINA

AMPHISTEGINA

AMPHISTEGINA

AMPHISTE GINA

AMPHISTEGINA

AMPHISTEGINA

AMPHISTEGINA

AMPHISTEGINA

AMPHISTEGINA

AMPHISTEGINA

AMPHISTEGINA

AMPHISTE GINA

AMPHISTEGINA

AMPHISTEGINA

AMPHISTEGINA

AMPH ISTEGINA

AMPHISTEGINA

AMPHISTEGINA

AMPHISTEGINA

AMPHISTEGINA

AMPHISTEGINA

AMPHISTEGINA

AMPHORINA

AMPHORINA

AN GULOGERINA

AN GULOGERINA

ANGULOGERINA

ANGULOGERINA

AN GULOGERINA

AN GULOGERINA

AN GULOGERINA

ANGULOGERINA

ANGULOGERINA

ANGULOGER INA

ANGULOGERINA

AN GULOGERINA

AN GULOGERINA

AN GULOGERINA

ANGULOGER INA

ANGULOGERINA

AN GULOGER INA

AN GULOGERINA

ANGULOGERINA

ANGULOGERINA

ANGULOGERINA

AN GULOGERINA

ANGULOGERINA

AN GULOGERINA

AN GULOGER INA

ANGULOGERINA

AN GULOGERINA

AN GULOGERINA

ANGULOGERINA

ANGULOGER INA

ANGULOGER INA

ANGULOGERINA

AN GULOGERINA

ANGULOGERINA

AN GULOGER INA

ANGULOGERINA

ANGULOGERINA

AN GULOGERINA

N GULOGERINA

ANGULOGERINA

ANGULOGERINA

ANGULOGERINA

ANGULOGERINA

DERINA

ANGULOGERINA

ANGULOGERINA

ANGULOGERINA

AN GULOGER INA

ANGULOGERINA

ANGUL OGERINA

ANGULOGERINA

ANGULOGERINA

AN GUL OGERINA

AN GULOGERINA

A N GUL OGERINA

ANGUL OGERINA

ANGULOGERINA

ANGULOGER INA

ANGUL OGERINA

ANGULOGERINA

ANGULOGERINA

AN GULOGERINA
Specific Name

GI BBOSA

GI BSOSA

GI BBOSA

GI BBOSA

GI EBOSA

LESSONI I

LESSONII

LESSONII

LESSONII

LESSONII

LESSONII

LESSONII

LE SSONII

LESSONII

LESSONII

LESSONII

LESSONII

LESSONII

LESSONII

LESSONII

LESSONII

LESSONII

LESSONI I

LESSONII

LE SSONII

LESSONII

LE SSONII

LE SSONII

MOLLIS

PURII

AN GULOSA

ANGUL OSA

AN GULOSA

AN GULOSA

AN GULOSA

AN GULOSA

AN GULOSA

AN GULOSA

AN GULOSA

ANGULOS

BELLA

BELLA

BELLA

BELLA

BELLA

BE LLA

BELLA

BE LLA

BELLA

BE LLA

BELLA

BELLA

BELLA

BELLA

BELLA

BELLA

BELLA

BELLA

BELLA

BELLA

BE LLA

BELLA

BELLA

BELLA

BELLA

BELLA

BELLA

BELLA

BELLA

BE LLA

BELLA

BELLA

BELLA

BELLA

BELLA

BELLA

BE LLA

Bella

BELLA

BELLA

BELLA

BELLA

BE LLA

BELLA

BELLA

BELLA

BELLA

BE LLA

BELLA

BELLA

Locality

Lat. Long.

NE GULF OF MEXICO NE GULF OF MEXICO 


\section{Publication}

10846 PHLEGER 1951A 10847 PHLEGER 1951A 10848 PHLEGER 1951A 10849 PHLEGER 1951A 10850 PHLEGER 1951A 10851 PHLEGER 1951A 10852 PHLEGER $1951 \mathrm{~A}$ 10853 PHLEGER 1951A 10854 PHLEGER 1951A 10855 PARKER 1954 10856 PARKER 1954 10857 PARKER 1954 10858 PARKER 1954 10859 PARKER 1954 10860 PARKER 1954 10861 PARKER 1954 10862 PARKER 1954 10863 PARKER 1954 10864 PARKER 1954 10865 PARKER 195 10866 PARKER 1954 10867 PARKER 1954 10869 PARKER 1954 10870 PARKER 1954 10871 LUDWICK WALTON 1957 10872 PARKER 1954 10873 PARKER 1954 10874 PARKER 1954 10875 PARKER 1954 10876 PARKER 1754 10877 CREAGER 1958 10878 CREAGER 1958 10879 CREAGER 1958 10880 ANDERSEN 1961 10881 CUSHMAN 1922A 10882 NORTON 1930

10883 NORTON 1930

10884 PFLUM FRERICHS 1976 10885 PFLUM FRERICHS 1976 10886 PFLUM FRERICHS 1976 10887 PFLUM FRERICHS 1976 10888 PFLUM FRERICHS 1976 10889 PFLUM FRERICHS 1976 10890 PFLUM FRERICHS 1976 10891 PFLUM FRERICHS 1976 10892 PFLUM FRERICHS 1976 10893 PFLUM FRERICHS 1976 10894 PFLUM FRERICHS 1976 10895 PFLUM FRERICHS 1976 10896 PFLUM FRERICHS 1976 10897 PFLUM FRERICHS 1976 10898 PFLUM FRERICHS 1976 10899 PFLUM FRERICHS 1976 10900 PFLUM FRERICHS 1976 10901 PFLUM FRERICHS 1976 10902 PFLUM FRERICHS 1976 10903 PFLUM FRERICHS 1976 10904 PFLUM FRERICHS 1976 10905 PFLUM FRERICHS 1976 10906 PFLUM FRERICHS 1976 10906 PFLUM FRER ICHS 1976 10908 PFLUM FRERICHS 1976 10909 PFLUM FRERICHS 1976 10910 PFLUM FRERICHS 1976 10911 PFLUM FRERICHS 1976 10912 PFLUM FRERICHS 1976 10913 PFLUM FRERICHS 1976 10914 PFLUM FRERICHS 1976 10915 PFLUM FRERICHS 1976 10916 PFLUM FRERICHS 1976 10917 PFLUM FRERICHS 1976 10918 PFLUM FRERICHS 1976 10919 PFLUM FRERICHS 1976 10920 PFLUM FRERICHS 1976 10921 PFLUM FRERICHS 1976 10922 PFLUM FRERICHS 1976 10923 PFLUM FRERICHS 1976 10924 PFLUM FRERICHS 1976 10925 PFLUM FRERICHS 1976 10926 PFLUM FRERICHS 1976 10927 PFLUM FRERICHS 1976 10928 PFLUM FRERICHS 1976 10929 PFLUM FRERICHS 1976 10930 PFLUM FRERICHS 1976 10931 PFLUM FRERICHS 1976 10932 CUSHMAN 1931

10933 CUSHMAN 1922A

10934 NORTON 1930

10935 NORTON 1930

10936 PFLUM FRERICHS 1976 10937 PFLUM FRERICHS 1976 10938 PFLUM FRERICHS 1976 10939 PFLUM FRERICHS 1976 10940 NORTON 1930
Generic Name

Specific Name

AN GUL OGERINA AN GUL OGERINA AN GUL OGER INA ANGUL OGERINA ANGULOGERINA AN GUL OGERINA

AN GUL OGER INA

ANGULOGERINA ANGULOGERINA ANGULOGERINA ANGULOGERINA AN GULOGERINA AN GUL OGER INA ANGULOGERINA ANGULOGERINA ANGULOGERINA ANGULOGERINA ANGULOGERINA ANGULOGERINA ANGULOGERINA ANGULOGERINA ANGUL OGERINA ANGUL OGERINA ANGULOGERINA ANGUL OGERINA AN GULOGERINA ANGUL OGERINA ANGULOGERINA ANGULOGERINA ANGULOGERINA ANGULOGERINA ANGUL OGERINA ANGULOGERINA ANGULOGERINA ANGUL OGERINA ANOMAL INA AN OMALI INA ANOMAL INA ANOMALINA

ANOMALINA

AN OMAL INA

AN OMALINA

ANOMA LINA

ANOMALINA

ANOMAL INA

ANOMAL INA

ANOMALINA

ANOMAL INA

ANOMALI INA

AN OMAL INA

AN OMAL INA

ANOMALI INA

AN OMAL INA

AN OMA L I NA

AN OMALINA

ANOMALINA

ANOMA LINA

AN OMAL INA

ANOMALINA

A NOMAL INA

ANOMAL INA

ANOMAL INA

ANOMAL INA

ANOMAL INA

ANOMAL INA

ANOMALINA

ANOMALINA

AN OMAL I NA

ANOMAL INA

AN OMAL INA

ANOMAL INA

ANOMAL INA

ANOMAL INA

ANOMALINA

A NOMAL INA

AN OMALINA

ANOMAL INA

AN OMAL INA

A N OMAL INA

ANOMALINA

ANOMAL INA

ANOMAL INA

ANOMALINA

AN OMAL INA

ANOMAL INA

ANOMALINA

AN OMAL INA

ANOMAL INA

AN OMAL INA

ANOMALINA

AN OMAL INA

ANOMALINA

AN OMALINA

AN OMAL INA

ANOMAL INA
BELLA

BELLA

BELLA

BELLA

BELLA

BELLA

BELLA

BELLA

BELLA

BELLA

BELLA

JA MAI I E NS IS

JAMAICENS IS

JAMAICENS IS

JA MAICENS IS

JAMAI CENS IS

JANAICENS IS

JAMAICENS IS

JAMAICENS IS

JANAI CENS IS
JAMAI CENS IS

JANAICENS IS

JAMAICENS IS

J AMA I CENS IS

JAMAICENS IS

JANAICENS IS

JAMAICENS IS

JAMAICENS IS

JAMAICENS IS

J AMA I CENS IS

JAMAICENS IS

JAMA I CENS IS

OCCIDENTALIS

AMNONOIDES

CORONATA

CORPULENT A

CORPULENTA

CORPULENTA

CORPULENT

CORPULENTA

CORPULENTA

CORPULENTA

CORPULENTA

CORPULENTA

CORPULENTA

CORPULENT A

CORPULENTA

CORPULENTA

CORPULENTA

CORPULENTA

CORPULENTA

CORPULENTA

CORPULENT A

CORPULENTA

CORPULENTA

CORPULENTA

CORPULENTA
CORPULENT A

CORPULENTA

CORPULENTA

CORPULENTA

CORPULENTA

CORPULENTA

CORPULENTA

CORPULENTA

CORPULENTA

CORPULENTA

CORPULENTA

CORPULENTA

CORPULENTA

CORPULENTA

CORPULENTA

CORPULENTA

CORPULENTA

CORPULENTA

CORPULENTA

CORPULENTA

CORPULENT A

CORPULENTA

CORPULENTA

CORPULENTA

EDWARDSIANA

EDWARDSIANA

FOVEOLATA

GL OBULOSA

GL OBUL OSA

GL OBULOSA

GL CBULOSA

GR OSSERUG OSA

Locality

Lat. Long.

NW GULF OF MEXICO

NW GULF OF MEXICO

NW GULF OF MEXICO

NW GULF OF MEXICO

NW GULF OF MEXICO

NW GULF OF MEXICO 


\section{Publication}

10941 BANDY 1956 10942 BANDY 1956 10943 BANDY 1956 10944 BANDY 1956 10945 BANDY 1956 10946 ANDERSEN 1961 10947 BANDY 1956 10948 BANDY 1956

10949 PFLUM FRERICHS 1976 10950 PFLUM FRERICHS 1976 10951 PFLUM FRERICHS 1976 10952 PFLUM FRERICHS 1976 10953 PFLUM FRERICHS 1976 10954 PFLUM FRERICHS 1976 10955 PFLUM FRERICHS 1976 10956 PFLUM FRERICHS 1976 10957 PFLUM FRERICHS 1976 10958 PFLUM FRERICHS 1976 10959 PFLUM FRERICHS 1976 10960 PFLUM FRERICHS 1976 10961 PFLUM FRERICHS 1976 10962 PFLUM FRERICHS 1976 10963 PFLUM FRERICHS 1976 10964 PFLUM FRERICHS 1976 10965 PFLUM FRERICHS 1976 10966 PFLUM FRERICHS 1976 10967 PFLUM FRERICHS 1976 10968 PFLUM FRERICHS 1976 10969 PFLUM FRERICHS 1976 10970 PFLUM FRERICHS 1976 10971 PFLUM FRERICHS 1976 10972 PFLUM FRERICHS 1976 10973 PFLUM FRERICHS 1976 10974 PFLUM FRERICHS 1976 10975 LEROY HODGKINSON 1975 10976 PHLEGER 1955A

10977 PARKER 1954

10978 PARKER 1954

10979 PARKER 1954

10980 PARKER 1954

10981 PARKER 1954

10982 PARKER 1954

10983 PARKER 1954

10984 PARKER 1954

10985 PARKER 1954

10986 PARKER 1954

10987 PARKER 1954

10988 PARKER 1954

10989 PARKER 1954

10990 PARKER 1954

10991 PFLUM FRERICHS 1976

10992 PFLUM FRERICHS 1976

10993 PFLUM FRERICHS 1976

10994 PFLUM FRERICHS 1976

10995 PFLUM FRERICHS 1976

10996 PFLUM FRERICHS 1976

10997 PFLUM FRERICHS 1976

10998 PFLUM FRERICHS 1976

10999 PFLUM FRERICHS 1976 11000 PFLUM FRERICHS 1976 11001 PFLUM FRERICHS 1976 11002 PFLUM FRERICHS 1976 11003 PFLUM FRERICHS 1976 11004 PFLUM FRERICHS 1976 11005 PFLUM FRERICHS 1976 11006 PFLUM FRERICHS 1976 11007 PFLUM FRERICHS 1976 11008 PFLUM FRERICHS 1976 11009 PFLUM FRERICHS 1976 11010 PFLUM FRERICHS 1976 11011 PFLUM FRERICHS 1976 11012 PFLUM FRERICHS 1976 11013 NORTON 1930

11014 CUSHMAN 1930

11015 BANDY 1956

11016 CUSHMAN 1930

11017 BANDY 1956

11018 BENDA PURI 1962

11019 BANDY 1956

11020 BANDY 1956

11021 DAVIS 1964

11022 BANDY 1956

11023 BANDY 1956

11024 BANDY 1956

11025 BANDY 1956

11026 BANDY 1956

11027 BANDY 1956

11028 BANDY 1956

11029 LYNTS PFISTER 1967

11030 BOCK 1976

11031 NORTON 1930

11032 BENDA PURI 1962

11033 PHLEGER $1951 \mathrm{~A}$

11034 CUSHMAN 1930

11035 CREAGER 1958
Generic Name

Specific Name

AN OMALINA

A NOMAL INA

A NOMAL I NA

ANOMALINA

AN OMALINA

A NOMAL INA

ANOMALINA

ANOMALINA

ANOMALINA

ANOMALINA

A NOMALINA

ANOMALINA

ANOMALINA

ANOMALINA

AN OMALINA

ANOMAL INA

ANOMAL INA

ANOMALINA

ANOMALINA

ANOMALINA

ANOMALINA

ANOMALINA

ANOMALINA

ANOMAL INA

ANOMALINA

ANOMAL INA

ANOMALINA

AN OMALINA

ANOMALINA

ANOMALINA

ANOMALINOIDES

ANOMAL INOIDES

ANOMAL INOI DES

ANOMALINOIDES

ANOMAL INOIDES

ANOMALINOIDES

AN OMALI NOI DES

A NOMAL INOIDES

ANOMALINOIDES

ANOMAL INOI DES

ANOMALINOIDES

ANOMAL INOIDES

ANOMALINOIDES

ANOMALINOIDE

ANOMAL INOIDES

ANOMALINOIDES

AP IOPTER INA

AP IOP TER INA

AP IOPTER INA

APIOPTER INA

APIOPTERINA

APIOPTER INA

AP. IOP TER INA

APIOPTER INA

APIOPTER INA

APIOPTER INA

APIOPTER INA

APIOPTERINA

A P IOPTER INA

APIOPTER INA

APIOPTER INA

APIOPTER INA

APIOPTERINA

APIOPTER INA

APIOPTER INA

APIOPTER INA

APIOPTER INA

APIOPTER INA

ARCHAIAS

ARCHAIAS

ARCHAIAS

ARCHAIAS

ARCHAIAS

ARCHAIAS

ARCHAIAS

ARCHAIAS

ARCHAIAS

ARCHAIAS

AR CHAIAS

ARCHAIAS

ARCHAIAS

AR CHAIAS

ARCHAIAS

ARCHAIAS

ARCHAIAS

ARCHAIAS

ARCHAIAS

ARCHAIAS

ARCHAIAS

ARCHAIAS

ARCHAIAS
10
10

10

10

10

10
10

I 0

MEXI CANA

MEXICANA

MEXICANA

MEXICANA

MEXICANA

MEXICANA

MEXICANA

MEXICANA

MEXICANA

MEXI CANA

MEXICANA

MEXICANA

MEXI CANA

MEXICANA

MEXICAN

MEXI CANA

MEXICANA

MEXICANA

MEXI CANA

MEXICANA

ME XI CANA

MEXICANA

MEXICANA

MEXICANA

CORPULENTUS

MEXICANA

MEXICANA

ME XICANA

MEXI CANA

MEXI CANA

MEXICANA

ME XICANA

MEXICANA

MEXICANA

MEXICANA

MEXICANA

ME XI CANA

MEXICANA

MEXICANA

ANGUSTA

AN GUSTA

AN GUSTA

AN GUSTA

AN GUSTA

ANGUSTA

ANGUSTA

EXTENSA

EXTENSA

EXTENSA

EXTENSA

EXTENSA

EXTENSA

EXTENSA

EXTENSA

EXTENSA

EXTENSA

EXTENSA

EXTENSA

EXTENSA

EXTENSA

ADUNCA

AN GULATUS

AN GULATUS

AN GULATUS

ANGULATUS

ANGULATUS

ANGULATUS

AN GULATUS

AN GULATUS

ANGULATUS

ANGULATUS

AN GULATUS

ANGULATUS

AN GULATUS

AN GULATUS

AN GULATUS

ANGULATUS

ANGULATUS

CONPRESSUS

COMPRESSUS

COMPRESSUS

COMPRESSUS

Locality

NE GULF OF MEXICO

NE GULF OF MEXICO

NE GULF OF MEXICO

NE GULF OF MEXICO

NE GULF OF MEXICO

MISSISSIPPI DELTA

NE GULF OF MEXICO

NE GULF OF MEXICO

NW GULF OF MEXICO

$\mathrm{NW}$ GUI.F OF MEXICO

NW GULF OF MEXICO 
Publication

11036 LOEP 1965

11037 PHLEGER 19558

11038 ANDERSEN 1951A

11039 ANDERSEN 19518

11040 ANDERSEN 1951A

11041 PHLEGER 1965 A

11042 ANDERSEN 195

11043 WARREN 1956
11044 AYALA-CASTANARES 1963

11045 PHLEGER 1954

11046 PHLEGER 1965 A

11047 PHLEGER 1965A

11048 PHLEGER 1965 A

11049 BENDA PURI 1962

11050 PHLEGER 1965 A

11051 PHLEGER 1965A

11052 PHLEGER 1965 A

11053 PHLEGER 1965A

11054 OTVOS 1978

11055 PHLEGER LANKFORD 1978

11056 WALTON 1960
11057 WANTLAND 1969

11058 PARKER PHLEGER PEIRSON 1953

11059 PARKER PHLEGER PEIRSON 1953

11060 PARKER PHLEGER PEIRSON 1953

11061 WARREN 1957

11062 KANE 1962

11063 PHLEGER 1954

11064 PHLEGER $1965 \mathrm{C}$

11065 PHLEGER 1954

11066 LANKFORD 1959

11067 PHLEGER 1954 1955

11068 SHEPARD MOORE
11069 WALDRON 1963

11070 LEHMANN 1957

11071 KANE 1967

11072 CUSHMAN $1922 \mathrm{~A}$

11073 NORTON 1930

11074 CUSHMAN 1922A

11075 BOCK 1976

11076 ANDERSEN 1961

11077 CUSHMAN $1922 \mathrm{~A}$

11078 DAVIS 1964

11079 NORTON 1930

11080 NORTON 1930

11081 KELLOUGH 1956

11082 CUSHMAN 1922 A

11083 BOCK 1976

11084 BENDA PURI 1962

11085 BOCK 1976

11086 BOCK 1976

11087 CUSHMAN 1922A

11088 VAUGHAN 1918

11089 NORTON 1930

11090 BOCK 1976

11091 NORTON 1930

11092 PFLUM FRERICHS 1976

11093 PFLUM FRERICHS 1976

11094 PFLUM FRERICHS 1976

11095 PFLUM FRERICHS 1976

11096 BOCK 1976

11097 BANDY 1956

11098 BANDY 1956

11099 BANDY 1956

11100 BANDY 1956

11101 BANDY 1956

11102 PHLEGER 1951A

11103 BOCK 1976

11104
11105 PARKER
1954
11106

11106 PARKER 1954

11107 SHIFFLETT 1961

11108 CUSHMAN 1922A

11109 PHLEGER 1951A

11110 PHLEGER 1951A

11111 PARKER 195

11112 PARKER 1954

11113 PARKER 1954

11115 CREAGER 1958

11116 CREAGER 1958

11117 PHLEGER 1954

11117 PHLEGER 1954

11119 LUDWICK WALTON 1957

11120 DAVIS 1964

11121 PARKER 1954

11122 PARKER 1954

11123 PARKER 1954

11124 PARKER 1954

11125 BOCK 1976

11126 LYNTS PFISTER 1967

11127 PARKER 1954

11128 BOCK 1976

11129 BANDY 1956

11130 BANDY 1956
Generic Name

ARCHAIAS

ARENOPARRELLA

ARENOPARRELLA

ARENOPARRELLA

ARENOPARRELLA

ARENOPARRELLA

AREN OPAR RELLA

ARENOPARRELLA

ARENOPARRELLA

ARENOPARRELLA

ARENOPARRELLA

ARENOPARRELLA

ARENOPARRELLA

ARENOPARRELLA

ARENOPARRELLA

ARENOPARRELLA

ARENOPARRELLA

ARENOPARRELLA

ARENOPARRELLA

ARENOPARRELLA

ARENOPARRELLA

ARENOPARRELLA

ARENOPARRELLA

ARENOPARRELLA

ARENOPARRELLA

ARENOPARRELLA

ARENOPARRELLA

AREN OPARRELLA

ARENOPARRELLA

AR ENOPAR RELLA

ARENOPARRELLA

ARENOPAR RELLA

ARENOPARRELLA

ARENOPARRELLA

ARENOPARRELLA

AR TI CUL INA

ARTICULINA

ARTICULINA

ARTI CUL I NA

ARTI I UL I NA

AR T I CUL I NA

AR TI CUL INA

ARTI CULINA

ARTI CULINA

ART I CUL I NA

ARTI CUL I NA

ARTI CULINA

ARTI CULINA

ARTI CUL INA

AR TI CUL INA

ARTICULINA

ARTI CULINA

AR T I CUL I NA

AR TI CUL INA

ARTICULINA

ASCHEMONELLA

AS CHE MONELLA

ASCHEMONELLA

ASTACOLUS

ASTACOLUS

ASTACOLUS

ASTACOLUS

ASTER IGERINA

A STERIGERINA

AS TER I GERINA

A TERIGERINA

A STER IGERINA

A STERIGERINA

A STER I GERINA

ASTER IGERINA

ASTERIGERINA

A STER I GERINA

ASTERIGERINA

ASTERIGERINA

A STERIGERINA

AS TER I GER IN

ASTERIGERINA

A STER I GER INA

AS TER I GERINA

A STER IGERINA

ASTERIGERINA

ASTERIGERINA

A STERIGERINA

A STER I GER IN A

AS TERIGERINA

A STERIGERINA

ASTERIGERINA

ASTER I GERINA

A STER I GERINA

A STERIGERINA

ASTERIGERINA

AS TER I GERIN A
Specific Name

COMPRESSUS

MEXICANA

MEXICANA

MEXICANA

MEXICANA

MEXICANA

MEXICANA

MEXICANA

MEXICANA

MEXICANA

MEXICANA

MEXICANA

MEXICANA

MEXICANA

MEXICANA

MEXICANA

ME XICANA

MEXICANA

ME XICANA

MEXICANA

MEXICANA

MEXICANA

MEXI CANA

MEXICANA

MEXI CANA

MEXICANA

MEXICANA

MEXI CANA

MEXICANA

MEXICANA

MEXICANA

MEXICANA

ANTILLLARJM

CONICO-ARTICULATA

LINEATA

LINEATA

MAYORI

MAYORI

MA YORI

MAYORI

MEXICANA

MEXICANA

MEXICANA

MEXICANA

MUCRONATA

MUCRONATA

PACIFIC

SAGRA

SAGRA

SAGRA

SAGRA

SULCATA

RA MULI IF ORMIS

RAMUL IF ORMIS

RAMULIFORMIS

SCABRA

CREPIDULUS

OVATUS

OVATUS

CARINATA

CARINATA

CARINATA

CARINATA

CARINATA

CARINATA

CARINATA

CARINATA

CARINATA

CARINATA

CARINATA

CARINATA

CARINATA

CARINATA

CARINATA

CARINATA

CARINATA

CARINATA

CARINATA

CARINATA

CARINATA

CARINATA

CARINATA

CARINATA

CARINATA

CARINATA

CARINATA

CARINATA

CARINATA

CARINATA

CARINATA

Locality

NH GULF OF MEXICO

MISSISSIPPI DELTA

MISSISSIPPI DELTA

MISSISSIPPI DELTA

MISSISSIPPI DELTA

MUSTANG LAKE, TEXAS

MISSISSIPPI DELTA

BURAS SE LOUISIANA

L. DE TERMINOS. CAMPECHE

GRAVELINE B., MISS

AVACA BAY, TEXAS

GOOSE IS.. TEXAS 


\section{Publication}

11131 BANDY 1954 11132 BANDY 1956 11133 BANDY 1956 11134 BANDY 1956 11135 BANDY 195 11136 BANDY 1954 11137 KELLOUGH 1956 11138 BANDY 1956 11139 CUSHMAN 193 11140 HALTON 1960 11141 CUSHMAN 1931 11142 CUSHMAN 193 11143 NORTON 1730 11144 CREAGER 1958 11145 BANDY 1956 11146 BANDY 1956 11147 BANDY 1956 11148 BANDY 1956 11149 BANDY 1956 11150 BANDY 1956 11151 BANDY 1956 11152 BANDY 1954 11153 BANDY 1956 11154 BANDY 1250 11155 BANDY 1956 11156 BANDY 1956 11157 BANDY 1956 11158 PARKER 1954 11160 PARKER 1954 11161 PARKER 1054 11162 PARKER 1954 11163 PFLUM FRERICHS 1976 11164 PFLUM FRERICHS 1976 11165 PFLUM FPERICHS 1976 11166 PFLUM FRERICHS 1976 11167 PFLUM FRERICHS 1976 11168 PFLUM FRERICHS 1976 11169 PFLUM FRERICHS 1976 11170 PFLUM FRERICHS 1976 11171 PFLUM FRERICHS 1976 11172 PFLUM FRERICHS 1976 11173 PFLUM FRERICHS 1976 11174 PFLUM FRERICHS 1976 11175 PARKER 1954

11176 PARKER 1754

11177 PFLUM FRERICHS 1976 11178 PFLUM FRERICHS 1976 11179 PARKER 1954

11180 CUSHMAN 1918

11181 CUSHMAN 1918

11182 PFLUM FRERICHS 1976 11183 PFLUM FRERICHS 1976 11184 PFLUM FRERICHS 1976 11185 PFLUM FRERICHS 1976 11186 PFLUM FRERICHS 1976 11187 PFLUM FRERICHS 1976 11188 PFLUM FRERICHS 1976 11189 PFLUM FRERICHS 1976 11190 PFLUM FRERICHS 1976 11191 PFLUM FRERICHS 1976 11192 PFLUM FRERICHS 1976 11193 PFLUM FRERICHS 1976 11194 PFLUM FRERICHS 1976 11195 PFLUM FRERICHS 1976 11196 PFLUM FRERICHS 1976 11197 PFLUM FRERICHS 1976 11198 PFLUM FRERICHS 1976 11199 PFLUM FRERICHS 1976 11200 PFLUM FRERICHS 1976 11201 PFLUM FRERICHS 1976 11202 LEROY HODGKINSON 1975 11203 CUSHMAN 1918 11204 CREAGER 1958 11205 KELLOUGH 1956 11206 KELLOUGH 1956 11207 KELLOUGH 1956 11208 KELLOUGH 1956 11209 PHLEGER $1951 \mathrm{~A}$ 11210 PHLEGER $1951 \mathrm{~A}$ 11211 PHLEGER $1951 \mathrm{~A}$ 11212 PHLEGER 1951 A 11214 PHLEGER 1951 A 11215 PHLEGER 1951 A 11216 PHLEGER $1951 \mathrm{~A}$ 11217 PHLEGER $1951 \mathrm{~A}$ 11218 PHLEGER 1951A 11219 PHLEGER 1951A 11220 PHLEGER 1951A 11221 KELLOUGH 1956 11222 KELLOUSH 1956 11223 PHLEGER $1951 \mathrm{~A}$
11224 PHLEGER $1951 \mathrm{~A}$ 11225 KELLOUGH 1956
Generic Name

ASTERI GERINA

ASTERIGERINA

ASTERIGERINA

ASTERIGERINA

ASTERIGERINA

ASTERIGERINA

A STERIGER INA

ASTER I GERINA

ASTERIGERINA

A STERIGERINA

ASTER IGERINA

A STERIGERINA

ASTERIGERINA

ASTERIGERINA

ASTERIGERINA

ASTERIGERINA

ASTERI GERINA

ASTERIGERINA

AS TERIGERINA

ASTERIGERINA

ASTER IGERINA

A STER I GERINA

AS TERIGERINA

ASTER IGERINA

A STER I GER I N A

ASTRONONION

ASTRONONION

ASTRONONION

ASTRONONION

ASTRONONION

ASTRONONION

A STRONONION

ASTRONONION

ASTRONONION

ASTRONONION

ASTRONONION

ASTRONONION

A STRONONION

ASTRONONION

ASTRONONION

ASTRONONION

ASTRONONION

ASTRONONION

ASTRONONION

AS TRONONION

ASTRONONION

ASTRONONION

ASTRORHIZA

ASTRORHIZA

BATHYSIPHON

BATHYSIPHON

BATHYSIPHON

BATHYSIPHON

BATHYSIPHON

BATHYSIPHON

BATHYSIPHON

BATHYSIPHON

BATHYSIPHON

BATHYSI PHON

BATHYSIPHON

BATHYSIPHON

BATHYSIPHON

BATHYSIPHON

BATHYSI PHON

BATHYSIPHON

BATHYSIPHON

BATHYSIPHON

BATHYSIPHON

BATHYSIPHON

BATHYSIPHON

BATHYSIPHON

BI FARINA

BI FARINA

BI FARINA

BI FAR INA

BIFARINA

BIFARINA

BI FARINA

B I FAR INA

BIFARINA

BI FAR INA

BI FAR INA

B I FAR INA

BIFARINA

BIFAR INA

B I FAR INA

BIFARINA

BI FAR INA

BIFAR INA

BIFARINA

BIFARINA

BI FAR INA

BIFAR INA
Specific Name

CARINATA

CARINATA

CARINATA

CARINATA

CARINATA

CARINATA

CARINATA

CARINATA

CARINATA

CARINATA

CARINATA

CARINATA

CARINATA

CARINATA

CARINATA

CARINATA

CARINATA

CARINATA

CARINATA

CARINATA

CARINATA

CARINATA

CARINATA

CARINATA

TUNIDUM

TUNIDUM

TUNIDUM

TUNIDUM

TUNIDUM

TUMI DUM

TUMIDUM

TUNIDUM

TUNI DUM

TUNIDUM

TUMIDUM

TUMIDUM

TUMI DUM

TUMIDUM

TUNIDUM

TUNIDUM

TUNIDUM

TUNI DUM

TUNIDUM

TUMIDUM

VERMIFORM IS

VERMI FORM IS

FILIFORMIS

F I LIFORMIS

F I LI F ORMI S

FILIFORMIS

F I LIF ORMI S

FILIFORMIS

FILIFORMIS

FILIFORMIS

FI LIFORMI S

FILIFORMIS

FILIFORMIS

F I LIFORMI S

FI LI FORMI S

FI LIFORMI S

FI LIFORMIS

FILIFORMIS

FILIFORMIS

F I LI FORMI S

FILIFORMI

FILIFORMI S

RUFUS

RUFUS

DE CORATA

DE CORATA

DE CORATA

DE CORATA

DE CORATA

DE CORATA

DE CORATA

DE CORATA

DE CORATA

DE CORATA

DE CORATA

DE CORATA

DE CORAT A

DE CORATA

DE COR AT A

DE CORATA

DE CORATA

DE CORATA

DE CORATA

DE CORATA

Locality

NW GULF OF MEXICO

NE GULF OF MEXICO

NE GULF OF MEXICO

NE GULF OF MEXICO

NW GULF OF MEXICO

NW GULF OF MEXICO

NW GULF OF MEXICO

NE GULF OF MEXICO

TORTUGAS, FLA

MISSISSIPPI SOUND

NE GULF OF MEXICO 


\section{Publication}

11226 PHLEGER 1951A 11227 PHLEGER 1951A 11228 PHLEGER 1951A 11229 PHLEGER 1951A 11230 PHLEGER 1951A 11231 PHLEGER 1951A 11232 PHLEGER 1951A 11233 PHLEGER 1951A 11234 PHLEGER 1951A 11235 PHLEGER 1951A 11236 PHLEGER 1951A 11237 PHLEGER 1951A 11238 DAVIS 1964

11239 PHLEGER 1955B

11240 PHLEGER 1954

11241 PHLEGER 1951A

11242 PHLEGER 1951A

11243 PHLEGER $1951 \mathrm{~A}$

11244 PHLEGER 1951A

11245 PHLEGER 1951A

11246 PHLEGER 1951A

11247 PHLEGER 1951 A

11248 LUDWICK WALTON 1957

11249 PHLEGER 1951A

11250 PHLEGER 1951A

11251 PHLEGER 1951A

11252 PHLEGER 1951A

11253 PHLEGER 1951A

11254 PHLEGER $1951 \mathrm{~A}$
11255 PARKER 1954

11256 PARKER 1954

11257 PARKER 1954

11258 PARKER 1954

11259 PARKER 1954

11260 PARKER 1954

11261 PARKER 1954

11262 PARKER 1954

11263 PARKER PHLEGER PEIRSON 1953

11264 PARKER PHLEGER PEIRSON 1953

11265 BANDY 1954

11266 BANDY 1956

11267 BANDY 1954

11268 BANDY 1956

11269 BANDY 1956

11271 SHEPARD MOORE 1955

11272 SHIFFLETT 1961

11273 KELLOUGH 1956

11274 PHLEGER 1954

11275 AYALA-CASTANARES 1963

11276 LOEP 1965

11277 LANKFORD 1959

11278 WARREN 1957

11279 PHLEGER 1951A

11280 PHLEGER 1951A

11281 KELLOUGH 1956

11282 KELLOUGH 1956

11283 KELLOUGH 1956

11284 KELLOUGH 1956

11285 KELLOUGH 1956

11286 LOEP 1965

11287 WARREN 1956

11288 LOEP 1965

11289 BANDY 1954

11290 BANDY 1954

11291 BENDA PURI 1962

11292 BANDY 1954

11293 BANDY 1956

11294 BANDY 1956

11295 PARKER 1954

11296 PARKER 1954

11297 PARKER 1954

11299 PHLEGER 1956

11300 PHLEGER 1956

11301 PHLEGER 1956

11302 BANDY 1956

11303 BANDY 1956

11304 BANDY 1956

11305 ANDERSEN 1961

11306 CREAGER 1958

11307 CREAGER 1958

11308 WALTON 1960

11309 PHLEGER 1956

11310 PARKER 1954

11311 BOCK 1976

11312 BOCK 1976

11313 BOCK 1976

11314 BOCK 1976

11315 CREAGER 1958

11316 PARKER PHLEGER PEIRSON 1953

11317 PARKER PHLEGER PEIRSON 1953

11318 BANDY 1956

11319 PARKER PHLEGER PEIRSON 1953

11320 PARKER PHLEGER PEIRSON 1953
Generic Name

BIFARINA

BI FAR INA

BIFARINA

BIFARINA

BIFARINA

BIFARINA

BIFARINA

BI GENERINA

B I GENER INA

BI GENERINA

BI GENERINA

BI GENER INA

B I GENER INA

BI GENER INA

B I GENER INA

BI GENER INA

B I GENERINA

BI GENERINA

B I GENER INA

I GENER I NA

B I GENER I NA

BI GENER INA

B I GENER INA

B I GENER INA

B I GENER I NA

B IGENERINA

B IGENER INA

BI GENER INA

B IGENER INA

B I GENER INA

B I GENER I NA

BI GENERINA

B I GENER INA

B I GENER INA

B I GENERINA

B I GENER INA

B I GENERI NA

B I GENER INA

BI GENER INA

B I GENERINA

BI GENERINA

B I GENER INA

B I GENER I NA

B I GENER INA

B I GENERINA

B I GENER INA

B GENERINA

BI GENERINA

BI GENERINA

B I GENERINA

BI GENER INA

B I GENER INA

BI GENER I NA

B I GENER I NA

I GENER I NA

I GENER I NA

B I GENER I NA

B IGENER INA

B I GENER I NA

B I GENER I NA

BI GENER INA

B I GENER INA

BI GENERINA

B I GENER INA

BI GENER INA

BI GENER INA

BI GENERINA

B I GENER INA

B I GENER INA

BI GENER I NA

B I GENER INA

B I GENER I NA

B I GENER INA

B I GENERINA

BI GENER INA

BI GENERINA

BI GENER INA

B I GENER I NA

BI GENER I NA

B I GENERINA

B I GENERINA

B I GENERINA

BI GENERINA

BI GENER I NA

B I GENER INA

B I GENER INA

B I GENER INA

B I GENER INA

B I GENER I NA

B GENERINA

B I GENER INA

B I GENER INA

I GENER INA
Specific Name

DE CORAT A

DE CORATA

DE CORATA

DE CORATA

DE CORATA

DE CORATA

DE CORATA

IR REGULAR IS

IRREGUL AR IS

IRREGUL AR IS

IRREGULAR IS

IRREGULAR IS

IRREGULAR IS

IRREGULAR IS

IRRE GULAR IS

I R RE GULAR IS

IRRE GUL AR IS

IRREGULAR IS

IR REGULAR IS

IRREGUL AR IS

IRRE GULAR IS

I RREGULAR IS

I RRE GUL AR IS

IRRE GUL AP IS

IRREGULAR IS

IRREGUL AR IS

IRREGULAR IS

IRREGULAR IS

I RREGULAR IS

IR RE GUL AR IS

IRREGULAR IS

IRREGULAR IS

IRREGUL AR IS

IRRE GUL AR IS

I RREGULAR IS

I R REGUL AP IS

I R REGUL AR IS

IRREGULAR IS

IRREGULAR

IRREGULAR IS

IRREGULAR IS

IRREGULAR IS

IRREGULAR IS

IRREGULAR IS

IR REGUL AR IS

IRREGULAR IS

IRREGULAR IS

I RRE GUL AR IS

I RRE GULAR IS

IRREGULAR IS

IRREGULAR IS

I RREGUL AR IS

I RREGULAR IS

I RREGUL AR IS

I RRE GULAR IS

I RRE GULAR IS

IR REGULAR IS

IRREGULAR IS

I RREGULAR IS

IRREGULAR IS

IRREGULAR IS

I RRE GULAR IS

IRREGUL AR IS

IRRE GULAR IS

IRREGULAR IS

IR REGULAR IS

IRREGULAR IS

IRREGULAR IS

IRRE GULAR IS

I RRE GULAR IS

IRREGULAR IS

IRREGULAR IS

IRREGUL AR IS

IRREGULAR IS

IRREGULAR IS

IRREGULAR IS

IRREGULAR IS

IRREGULAR IS

IRREGUL AP IS

I RREGULAR IS

IRREGULAR IS

IRREGULAR IS

IRRE GULAR IS

IRREGULAR IS

IRRE GULAP IS

IR RE GUL AR IS

IRRE GUL AR IS

IRREGULAR IS

IRREGULAR IS

IRREGULAR IS

IRREGULAR IS

IRREGULAR IS

I RREGULAR IS

IRREGUL AR IS

Locality

NW GULF OF MEXICO

NW GULF OF MEXICO

$N W$ GULF OF MEXICO

NW GULF OF MEXICO

NW GULF OF MEXICO

NW GULF OF MEXICO 


\section{Publication}

11321 PARKER PHLEGER PEIRSON 1953 11322 BANDY 1956

11323 BANDY 1956

11324 BANDY 1956

11325 BANDY 1956

11326 BANDY 1956

11327 BANDY 1956

11328 BANDY 1956

11329 BANDY 1956

11330 BANDY 1956

11331 BANDY 1956

11332 BANDY 1956

11333 BANDY 1956

11334 BANDY 1956

11335 SEGURA 1963

11337 NORTON 1930

11338 CUSHMAN 1922 A

11339 VAUGHAN 1918

11340 VAUGHAN 1918
11341 BENDA PURI 196

11341 BENDA PURI 1962
11342 CUSHMAN 19228

11343 NORTON 1930

11344 CUSHMAN 19228

11345 CUSHMAN 19228

11346 CUSHMAN 19228

11347 NORTON 1930

11348 PARKER
1954
11349 PARKER 1954

11350 PARKER 1954

11351 PARKER 1954

11352 PARKER 1954

11353 PARKER 1954

11354 PARKER 1954

11355 PARKER 1954
11356 PARKER 1954

11357 LUDWICK WALTON 1957

11358 LANKFORD 1959

11359 PARKER 1954

11360 PARKER 1954

11361 CUSHMAN 1922A

11362 CUSHMAN 1922 A

11363 CUSHMAN $1922 \mathrm{~A}$

11364 ANDERSEN 1961

11365 ANDERSEN 1961

11366 ANDERSEN 1951A

11367 ANDERSEN $1951 \mathrm{~A}$

11368 WARREN 1957

11369 ANDERSEN 1951 A

11370 WARREN 1956

11371 PHLEGER 1955A

11372 PFLUM FRERICHS 1976

11373 PFLUM FRERICHS 1976

11374 PFLUM FRERICHS 1976

11375 PFLUM FRERICHS 1976

11376 PHLEGER 1955A

11378 PFLUM FRERICHS 1976

11379 PFLUM FRERICHS 1976

11380 ANDERSEN 1961

11381 PFLUM FRERICHS 1976 11382 PFLUM FRERICHS 1976 11383 PFLUM FRERICHS 1976 11384 PFLUM FRERICHS 1976 11385 PFLUM FRERICHS 1976 11386 PFLUM FRERICHS 1976 11387 PFLUM FRERICHS 1976 11388 PFLUM FRERICHS 1976 11389 PFLUM FRERICHS 1976 11390 PFLUM FRERICHS 1976 11391 PFLUM FRERICHS 1976 11392 PFLUM FRERICHS 1976 11393 PFLUM FRERICHS 1976 11394 PFLUM FRERICHS 1976 11395 PFLUM FRERICHS 1976 11396 PFLUM FRERICHS 1976 11397 PFLUM FRERICHS 1976 11398 PFLUM FRERICHS 1976 11399 PFLUM FRERICHS 1976 11400 PFLUM FRERICHS 1776 11401 PARKER 1954 11402 PARKER 1954 11403 PARKER 1954 11404 PARKER 1954 11405 PARKER 1954 11407 PARKER 1954 11408 PARKER 1954

11409 PFLUM FRERICHS 1976 11410 PFLUM FRERICHS 1976 11411 PFLUM FRERICHS 1976 11412 PFLUM FRERICHS 1976 11413 PFLUM FRERICHS 1976 11414 PFLUM FRERICHS 1976 11415 PFLUM FRERICHS 1976
Generic Name

BI GENERINA BI GENER I NA

BIGENERINA

BI GENER I NA

BI GENER INA

BI GENER I NA

BI GENER I NA

B I GENER INA

B I GENER INA

B I GENER I NA

B I GENER I NA

B I GENER I NA

B I GENER INA

B I GENERINA

BI GENER I NA

B I GENER I NA

BI GENERINA

B I GENERINA

BI GENER INA

BI GENERINA

B I GENER I NA

B I GENER I NA

B I GENER I NA

B I GENER I NA

B I GENER INA

BI GENERINA

B I GENER I NA

B I GENER I NA

BI GENERINA

B I GENER INA

BI GENER INA

BI GENER INA

B I GENER INA

B I GENERINA

B I GENERINA

BI GENER INA

B I GENER INA

B I GENERINA

BI GENER I NA

B I LOCULINA

B I LOCULINA

B I LOCUL INA

B I LOCUL I NE LLA

B I LOCUL INELLA

BISACCIUM

BISACCIUM

BISACCIUM

BISACCIUM

B I SACCI UM

BOLIVINA

BOLIVINA

BOLIVINA

BOLIVINA

BOLIVINA

BOLIVINA

BOLIVINA

BOLIVINA

BOLIVINA

BOLIVINA

BOLIVINA

BOLIVINA

BOLIVINA

BOLIVINA

BOLIVINA

BOLIVINA

BOLIVINA

BOLIVINA

BOLIVINA

BOLIVINA

BOLIVINA

BOLIVINA

BOLIVINA

BOLIVINA

BOLIVINA

BOLIVINA

BOLIVINA

B OLIVINA

BOLIVINA

BOLIVINA

BOLIVINA

BOLIVINA

BOLIVINA

BOLIVINA

BOLIVINA

BOLIVINA

BOLIVINA

BOLIVINA

BOLIVINA

BOLIVINA

BOLIVINA

BOLIVINA

BOLIVINA

BOL IVINA
Specific Name

I RREGULAR IS

I RREGULAR IS

I RREGULAR IS

I RRE GULAR IS

I RRE GULAR IS

I RRE GULAR IS

IRREGULAR IS

IRREGULAR IS

I RREGULAR IS

I RREG UL AR IS

I RREGUL AR IS

I RRE GUL AR IS

IRREGUL AR IS

IRREGULAR IS

IRREGULA? IS

IRREGULAR IS

NODOSARIA

NO DOS AR IA

NODOSAR IA

NODOSAR IA

NO DOSARIA

NODOSARIA TEXTULARIOIDEA

NODOSARIA TEXTULARIOIDEA

NODOSAR IA TEXTULARIOIDEA

NODOSARIA TEXTULARIOIDEA

PENNA TULA

ROEUSTA

TE XTULARI OIDEA

TEXTULARI OIDEA

TE XTULARI OIDEA

TE XTULARIOIDEA

TE XTULARI OI DEA

TE XTULARI OIDEA

TEXTULARI OIDEA

TE XTULARI OIDEA

TE XTULARI OIDEA

TE XTULARI OIDEA

TE XTULARI OIDEA

TEXTULARI OIDEA

DENTICULATA STRIOLATA

MILLETTII

SUESPHAER ICA

LABIATA

LABIATA

I MBR I CA TUM

IMERI CA TUM

IMERI CA TUM

IM BR I CA TUM

IMER I CA TUM

AL ATA

ALATA

AL ATA

AL ATA

AL ATA

AL ATA

AL AT A

ALATA

AL AT A

AL ATA

AL ATA

AL ATA

AL ATA

AL AT A

ALBATROSSI

ALEATROSS I

ALBATROSS I

AL BATROSS I

AL BATROSS I

AL BATROSS I

ALBATROSS I

AL BATROSS I

AL BATROSS I

ALBATROSS I

ALBATROSS I

AL EATROSS I

ALBATROSS I

ALBATROSS I

AL BATROSS I

AL BATROSS I

AL BATROSS I

ALBATROSS I

ALBATROSS I

ALBATROSS I

ALBATROSS I

AL BATROSS I

ALEATROSS I

ALEATROSS I

AL BATROSS I

AL BATROSS I

ALEATROSS I

AL BATROSS I

ALBATROSS I

\section{Locality}

TEXAS GULF COAST

NE GULF OF MEXICO

NE GULF OF MEXICO

NE GULF OF MEXICO

NE GULF OF MEXICO

NE GULF OF MEXICO

NE GULF OF MEXICO

NE GULF OF MEXICO 
Publication

11416 PFLUM FRERICHS 1976 11417 PFLUM FRERICHS 1976 11418 ANDERSEN 1961

11419 LOEP 1965

11420 LOEP 1965

11421 PARKER 1954

11422 PARKER 1954

11423 PARKER 1954

11424 PARKER 1954

11426 CUSHMAN $1922 \mathrm{~B}$

11426 CUSHMAN 1922

11428 CREAGER 1958

11429 CREAGER 1958

11430 CREAGER 1958

11431 CREAGER 1958

11432 CREAGER 1958

11433 DARKER 1954

11434 PHLEGER 1951A

11436 PFLUM FRERICHS 1976 11437 PFLUM FRERICHS 1976 11438 PFLUM FRERICHS 1976 11439 PHLEGER 1951A

11440 PFLUM FRERICHS 1976 11441 PFLUM FRERICHS 1976 11442 PFLUM FRERICHS 1976 11443 PFLUM FRERICHS 1976 11444 PFLUM FRERICHS 1976 11445 PFLUM FRERICHS 1976 11446 PFLUM FRERICHS 1976 11447 PFLUM FRERICHS 1976 11448 PFLUM FRERICHS 1976 11449 PFLUM FRERICHS 1976 11450 PFLUM FRERICHS 1976 11451 PFLUM FRERICHS 1976 11452 PFLUM FRERICHS 1976 11453 PFLUM FRERICHS 1976 11454 PFLUM FRERICHS 1976 11455 PFLUM FRERICHS 1976 11456 PFLUM FRERICHS 1976 11457 PFLUM FRERICHS 1976 11458 PFLUM FRERICHS 1976 11459 PFLUM FRERICHS 1976 11460 PFLUM FRERICHS 1976 11461 PFLUM FRERICHS 1976 11462 PFLUM FRERICHS 1976 11463 PFLUM FRERICHS 1976 11464 PFLUM FRERICHS 1976 11465 PFLUM FRERICHS 1976 11466 PARKER 1954

11467 PARKER 1954

11468 LEROY HODGKINSON 1975 11469 PFLUM FRERICHS 1976 11470 PFLUM FRERICHS 1976

11471 PFLUM FRERICHS 1976

11472 PFLUM FRERICHS 1976

11473 PARKER 1954

11474 PFLUM FRERICHS 1976

11475 PFLUM FRERICHS 1976

11476 PFLUM FRERICHS 1976

11477 PFLUM FRERICHS 1976

11478 PFLUM FRERICHS 1976

11479 PFLUM FRERICHS 1976

11480 PFLUM FRERICHS 1976

11481 PFLUM FRERICHS 1976

11482 PFLUM FRERICHS 1976

11483 PFLUM FRERICHS 1976

11484 PFLUM FRERICHS 1976

11485 PFLUM FRERICHS 1976

11486 PFLUM FRERICHS 1976

11487 PHLEGER 1955A

11488 PHLEGER 1955A

11489 PHLEGER 1955A

11490 PHLEGER 1955A

11491 PHLEGER 1955 A

11492 PHLEGER 1955 A

11493 PHLEGER $1955 \mathrm{~A}$

11494 PHLEGER 1955A

11495 LUDWICK WALTON

11496 PARKER 1954
11497 PHLEGER $1951 \mathrm{~A}$

11497 PHLEGER 1951A

11498 PHLEGER $1951 \mathrm{~A}$
11490 PHLEGER $1951 \mathrm{~A}$

11500 PHLEGER 1951A

11501 PHLEGER 1951A

11502 PHLEGER 1951A

11503 PHLEGER $1951 \mathrm{~A}$

11504 PHLEGER 1951A

11505 PHLEGER $1951 \mathrm{~A}$

11506 PHLEGER 1951A

11507 PHLEGER 1951A

11508 PHLEGER 1951A

11509 PHLEGER 1951A

11510 PHLEGER 1951A
Generic Name

BOLIVINA

BOLIVINA

BOLIVINA

BOLIVINA

BOLIVINA

BOLIVINA

BOLIVINA

BOLIVINA

BOLIVINA

BOLIVINA

BOLIVINA

BOLIVINA

BOLIVINA

BOLIVINA

BOLIVINA

BOLIVINA

BOLIVINA

BOLIVINA

BOLIVINA

BOLIVINA

BOLIVINA

BOLIVINA

BOLIVINA

BOLIVINA

BOLIVINA

BOLIVINA

BOLIVINA

BOLIVINA

BOLIVINA

BOLIVINA

BOLIVINA

BOLIVINA

BOLIVINA

BOLIVINA

BOLIVINA

BOLIVINA

BOLIVINA

BOLIVINA

BOLIVINA

BOLIVINA

BOLIVINA

BOLIVINA

BOLIVINA

BOLIVINA

BOLIVINA

BOLIVINA

BOLIVINA

BOLIVINA

BOLIVINA

BOLIVINA

BOLIVINA

BOLIVINA

BOLIVINA

BOLIVINA

BOLIVINA

BOLIVINA

BOLIVINA

BOLIVINA

BOLIVINA

BOLIVINA

BOLIVINA

BOLIVINA

BOLIVINA

BOLIVINA

BOLIVINA

BOLIVINA

BOLIVINA

BOLIVINA

BOLIVINA

BOLIVINA

BOLIVINA

BOLIVINA

BOLIVINA

BOLIVINA

BOLIVINA

BOLIVINA

BOLIVINA

BOLIVINA

BOLIVINA

BOLIVINA

BOLIVINA

BOLIVINA

BOLIVINA

BOLIVINA

BOLIVINA

BOLIVINA

BOLIVINA

BOLIVINA

BOLIVINA

BOLIVINA

BOLIVINA

BOLIVINA

BOLIVINA
Specific Name

Locality

Lat. Long.

ALBATROSS I

ALBATROSS I

ALBATROSSI

ALBATROSS I

ALEATROSS I

ALBATROSS I

ALBATROSS I

ALBATROSS I

ALBATROSS I

AL BATROSS I

ALEATROSS I

ALBATROSS I

ALBATROSS I

AL BATROSS I

AL BATROSS I

ALBATROSS I

ALBATROSS I

AL BATROSS I

ALEATROSS I

AL BATROSS I

ALBATROSS

AL BATROSS I

ALBATROSS I

AL BATROSS I

ALBATROSS I

ALBATROSS I

ALEATROSS I

AL BATROSS I

ALBATROSS I

ALBATROSS I

ALBATROSS I

ALBATROSS I

ALBATROSS I

AL BATROSS I

A BATROSSI

ALBATROSS I

ALEATROSS I

AL BATROSS I

AL BATROSS I

AL BATROSS I

AL BATROSS I

ALBATROSS I

ALEATROSS I

AL BATROSS I

AL BATROSS I

ALEATROSS I

ALBATROSSI

AL BATROSS I

ALBATROSS I

ALBATROSS I

ALEATROSS I

AL BATROSS I

AL BATROSS I

AL BATROSS I

AL BATROSS I

AL BATROSS I

ALEATROSS I

ALBATROSS I

ALBATROSS I

ALBATROSS I

ALBATROSS I

AL BATROSS I

AL BATROSS I

AL BATROSS I

ALBATROSS I

ALBATROSS I

AL BATROSS I

AL BATROSS I

ALEATROSS I

AL BATROSS I

ALBATROSS I

AL BATROSS I

ALBATROSS I

AL BATROSS I

AL BATROSS I

AL BATROSS I

ALBATROSS I

ALBATROSS I

AL BATROSSI

ALBATROSSI

AL BA TROSS I

ALBATROSS I

ALBATROSS I

ALBATROSS I

AL BATROSS I

ALBATROSSI

AL BATROSS I

CENTRAL GULF OF MEXICO CENTRAL GULF OF MEXICO MISSISSIPPI DELTA

NW GULF OF MEXICO

NW GULF OF MEXICO

NE GULF OF MEXICO

NE GULF OF MEXICO

NE GULF OF MEXICO

NE GULF OF MEXICO

NW GULF OF MEXICO

NE GULF OF MEXICO 


\section{Publication}

19519 PHLEGER 1951

11512 PHLEGER $1951 \mathrm{~A}$

11513 PHLEGER $1951 \mathrm{~A}$

11516 PHLEGER 1951A

11515 PHLEGER $1951 \mathrm{~A}$

11517 PHLEGER 1951A

11518 PHLEGER 1951A

11519 PHLEGER 1951A

19520 PHLEGER $1951 \mathrm{~A}$

11522 PARKER 1054

19523 PARKER 1954

11524 PARKER 1954

11525 PARKER 1954
11526 PHLEGER 1951 A

11527 PHLEGER 1951A

11528 PHLEGER $1951 \mathrm{~A}$

11529 PHLEGER $1951 \mathrm{~A}$

11530 PHLEGER $1951 \mathrm{~A}$

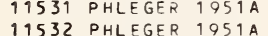

11533 PHLEGER $1951 \mathrm{~A}$

11534 PHLEGER $1951 \mathrm{~A}$

11535 PHLEGER $1951 \mathrm{~A}$

11536
11537 PHLEGER
$19519 \mathrm{~A}$
11538

11538 PHLEGER $1951 \mathrm{~A}$

11539 PHLEGER 1951 A

11540 PARKER 1954

11549 PHLEGER 1951A

11542 PHLEGER $1951 \mathrm{~A}$

11543 PHLEGER $1951 \mathrm{~A}$

11544 PARKER 1954
11545 PFLUM FRERICHS 1976

11546 PARKER 1954

11547 PFLUM FRERICHS 1976

11548 PHLEGER 1951 A

11540 PFLUM FRERICHS 1976

11550 PFLUM FRERICHS 1976

11551 PFLUM FRFRICHS 1976

11552 PARKER 1954

11553
11554
115

11555 PHLEGER 1951A

11556 PHLEGER 1951A

11557 PARKER 1954

19558 PARKER 1954

11559 PARKER 1954

19560 PARKER 1954

11561 PHLEGER 1951A

11562 PHLEGER $1951 \mathrm{~A}$

11563 PHLEGER $1955 \mathrm{~A}$

11565 LUDWICK WALTON 1957

11566 PFLUM FRERICHS 1976

11567 LANKFORD 1959

11568 PHLEGER $1951 \mathrm{~A}$

11569 PFLUM FRERICHS 1976

11570 PFLUM FRERICHS 1976

11571 PFLUM FRERICHS 1976

11572 CREAGER 1958

11573 PFLUM FRERICHS 1976

11574 PFLIJM FPERICHS 1976

11575 ANDERSEN 1961

11576 PFLUM FRERICHS 1976

11577 ANDERSEN 1961

11578 PFLUM FRERICHS 1776

11579 PFLUM FRERICHS 1976

11580 PFLUM FRFRICHS 1976

11581 PFLUM FRERICHS 1976

11582 PFLUM FRFRICHS 1976

11583 CUSHMAN $1922 \mathrm{~B}$

11584 CUSHMAN 1922

11586 BANDY 1956

11587 BANDY 1056

11588 BANDY 1956

11589 BANDY 1056

11590 BANOY 1056

11591 PHLEGER 1956

11593 PHLEGER 1958

11594 BANDY 1956

11595 PARKER 1254

11596 PARKER 1954

11597 PARKER 1954

11598 PARKER 1054

11599 ANDERSEN 1761

11600 CREAGER 1959

11601 CREAGER 1958

11602 PARKER 1954

11603 PFLUM FRERICHS 1976

11604 LUDWICK WALTON 1957

91905 PARKER 1954
Generic Name

Specific Name

BOLIVINA

BOLIVINA

BOLIVINA

BOLIVINA

BOLIVINA

BOLIVINA

BOLIVINA

BOLIVINA

BOLIVINA

BOLIVINA

BOLIVINA

BOLIVINA

BOLIVINA

BOLIVINA

BOLIVINA

BOLIVINA

BOLIVINA

BOLIVINA

BOLIVINA

BOLIVINA

BOLIVINA

BOLIVINA

BOLIVINA

BOLIVINA

BOLIVINA

BOLIVINA

BOLIVINA

BOLIVINA

BOLIVINA

BOLIVINA

BOLIVINA

BOLIVINA

BOLIVINA

BOLIVINA

BOLIVINA

BOLIVINA

BOLIVINA

BOLIVINA

BOLIVINA

BOLIVINA

BOLIVINA

BOLIVINA

BOLIVINA

BOLIVINA

BOLIVINA

BOLIVINA

BOLIVINA

BOLIVINA

BOLIVINA

BOLIVINA

BOLIVINA

BOLIVINA

BOLIVINA

BOLIVINA

BOLIVINA

BOLIVINA

BOLIVINA

BOLIVINA

BOLIVINA

BOLIVINA

BOLIVINA

BOLIVINA

BOLIVINA

BOLIVINA

BOLIVINA

BOLIVINA

BOLIVINA

BOLIVINA

BOLIVINA

BOLIVINA

BOLIVINA

BOLIVINA

BOLIVINA

BOLIVINA

BOLIVINA

BOLIVINA

BOLIVINA

BOLIVINA

BOLIVINA

BOLIVINA

BOLIVINA

BOLIVINA

BOLIVINA

BOLIVINA

BOLIVINA

BOLIVINA

BOLIVINA

BOLIVINA

BOLIVINA

BOLIVINA

BOLIVINA

BOLIVINA

BOLIVINA

BOLIVINA
ALEATROSS I

ALBATROSS I

ALBATROSS I

AL BATROSS I

ALEATROSS I

AL BATROSS I

AL EATROSS I

AL BATROSS I

AL BATROSS I

ALBATROSS

ALBATROSS I

ALEATROSS I

ALBATROSS I

ALBATROSS I

ALBATROSS

ALEATROSS I

AL BATROSS

AL BATROSS I

BARBATA

BARBATA

BARBATA

BARBATA

BARBATA

BARBATA

BARBATA

BARBATA

BARBATA

BAFBATA

BARBATA

BARBATA

BARBATA

BARBATA

BARBATA

BARBATA

BARBATA

BARBATA

BARBATA

BARBATA

BA RBATA

BA RBATA

BARBATA

BARBATA

BARBATA

BARBATA

BARBATA

BARBATA

BARBATA

BARBATA

BARBATA

BARBATA

BARBATA

BARBATA

BARBATA

BARBATA

BA KBATA

BARBATA

BARBATA

BARBATA

BARBATA

BARBATA

BARBATA

BARBATA

BARBATA

BARBATA

BARBATA

BARBATA

BARBATA

BARBATA

BARBATA

BARBATA

BARBATA

BEYRICHI ALATA

CONPACTA

DAGGARI US

DAGGARIUS

ARI US

DAGGARIUS

DAGGARI US

DAGGARI US

DAGGARI US

FRAGILIS

FRAGILIS

FRAGILIS

FRAGILIS

FRAGILIS

FRAGILIS

FRAGILIS

FRAGILIS

FRAGILIS

FRAGILIS

FRAGILIS

FRAGILIS

FRAGILIS

FRAGILIS
ALBATROSS I

Locality

NW GULF OF MEXICO

NW GULF OF MEXICO

NW GULF OF MEXICO

NW GULF OF MEXIC

NW GULF OF MEXICO

$N W$ GULF OF MEXICO

NW GULF OF MEXICO

NW GULF OF MEXICO

NW GULF OF MEXICO

$N W$ GULF OF MEXICO 
Publication

11606 PARKER 1954 11607 PARKER 1954 11608 PARKER 1954 11609 PARKER 1954 11610 PARKER 1954 11611 PHLEGER 1951A 11612 PHLEGER 1951A 11613 PHLEGER 1951A 11614 BANDY 1956 11615 LOEP 1965
11616 LOEP 1965 11616 LOEP 1965 11617 KELLOUGH 1956 11619 PHLEGER 1951A 11620 PHLEGER 1951A 11621 PHLEGER 1951A 11622 PHLEGER 1951A 11623 PHLEGER 1951A 11624 PHLEGER 1951A 11625 PHLEGER 1951A 11626 PHLEGER 1951A 11627 PHLEGER 1951A 11628 PHLEGER $1951 \mathrm{~A}$ 11629 PHLEGER 1951A 11630 PHLEGER 1951A 11631 PHLEGER 1951A

11633 PFLUM FRERICHS 1976

11633 PFLUM FRERICHS 1976

11635 PHLEGER 1951A

11636 PHLEGER 1951 A

11637 PHLEGER 1951A

11638 PHLEGER $1951 \mathrm{~A}$

11639 PHLEGER 1951 A

11640 PHLEGER 1951A

11641 PHLEGER 1951A

11642 PHLEGER $1951 \mathrm{~A}$

11643 PHLEGER $1951 \mathrm{~A}$

11644 PARKER 1954

11645 PHLEGER 1951A

11646 LUDWICK WALTON 1957

11647 PHLEGER 1951A

11648 PHLEGER $1951 \mathrm{~A}$

11649 PARKER 1954

11650 PFLUM FRERICHS 1976

11651 PFLUM FRERICHS 1976

11652 PFLUM FRERICHS 1976

11653 PARKER 1954

11654 PARKER 1954

11655 PARKER 1954

11656 PARKER 1954
11657 PARKER 1954

11658 BANDY 1956

11659 BANDY 1956

11660 BANDY 1956

11661 BANDY 1956

11662 PFLUM FRERICHS 1976

11663 PHLEGER $1951 \mathrm{~A}$

11664 BENDA PURI 1962

11665 PHLEGER 1951 A

11666 PHLEGER 1951 A

11667 PHLEGER 1951 A

11668 PHLEGER 1951A

11669 PHLEGER $1951 \mathrm{~A}$

11670 PHLEGER 1951A

11671 PHLEGER 1951A

11672 PHLEGER 1951A

11673 BENDA PURI 1962

11674 PFLUM FRERICHS 1976

11675 PFLUM FRERICHS 1976

11676 PFLUM FRERICHS 1976

11677 PFLUM FRERICHS 1976

11678 PFLUM FRERICHS 1976

11679 PFLUM FRERICHS 1976

11680 PFLUM FRERICHS 1976

11681 PARKER 1954

11682 PARKER 1954

11683 PFLUM FRERICHS 1976
11684 PFLUM FRERICHS 1976

11684 PFLUM FRERICHS 1976
11685 PFLUM FRERICHS 1976

11686 PARKER 1954

11687 PARKER 1954

11688 PARKER 1954

11689 PARKER 1954

11690 PARKER 1954

11691 LUDWICK WALTON 1957

11692 PARKER 1954

11693 PARKER 1954

11694 PARKER 1954

11695 PARKER 1954

11696 PARKER 1954

11697 PARKER 1954

11698 PARKER 1954

11699 SHIFFLETT 1961

11700 NORTON 1930

\section{Generic Name}

BOLIVINA

BOLIVINA

BOLIVINA

BOLIVINA

BOLIVINA

BOLIVINA

BOLIVINA

BOLIVINA

BOLIVINA

BOLIVINA

BOLIVINA

BOLIVINA

BOLIVINA

BOLIVINA

BOLIVINA

BOLIVINA

BOLIVINA

BOLIVINA

BOLIVINA

BOLIVINA

BOLIVINA

BOLIVINA

BOLIVINA

BOLIVINA

BOLIVINA

BOLIVINA

BOLIVINA

BOLIVINA

BOLIVINA

BOLIVINA

BOLIVINA

BOLIVINA

BOLIVINA

BOLIVINA

BOLIVINA

BOLIVINA

BOLIVINA

BOLIVINA

BOLIVINA

BOLIVINA

BO LIVINA

BOLIVINA

BOLIVINA

BOLIVINA

BOLIVINA

BOLIVINA

BOLIVINA

BOLIVINA

BOLIVINA

BOLIVINA

BOLIVINA

BOLIVINA

BOLIVIN

BOLIVINA

BOLIVINA

BOLIVINA

BOLIVINA

BOLIVINA

BOLIVINA

BOLIVINA

BOLIVINA

BOLIVINA

BOLIVINA

BOLIVINA

BOLIVINA

BO LIVINA

BOLIVINA

BOLIVINA

BOLIVINA

BOLIVINA

BOLIVINA

BOLIVINA

BOLIVINA

BOLIVINA

BOLIVINA

BOLIVINA

BOLIVINA

BOLIVINA

BOLIVINA

BOLIVINA

BOLIVINA

BOLIVINA

BOLIVINA

BOLIVINA

BOLIVINA

BOLIVINA

BOLIVINA

BOLIVINA

BOLIVINA

BOLIVINA
Specific Name

FRAGILIS

FRAGILIS

FRAG I LIS

FRAGILIS

FRAGILIS

RAGILIS

FRAGILIS

FRAGILIS

FRAGILIS

R AG ILIS

FRAGILIS

FRAGILIS

FRAGILIS

FRAGIIIS

FRAGILIS

FRAGILIS

FRAGILIS

FRAGILIS

FRAGILIS

FRAG ILIS

FRAGILIS

FRAGILIS

FRAGILIS

FRAGILIS

FRAGILIS

FRAGILIS

FRAGILIS

FRAGILIS

FRAGILIS

FRAGILIS

FRAGILIS

FRAGILIS

FRAGILIS

FRAGILIS

FRAGILIS

FRAGILIS

FRAG ILIS

GOES I I

GOESI I

GOESII

GOES I I

GOES I I

GOES I I

GOES I I

GOESII

GOES I I

GOESI I

GOESI I

GOES I I

GOESII

GOESI I

GOESI I

GOESII

GOESII

GOESII

GOESII

HASTATA

HA STATA

HASTATA

A STATA

HASTATA

HASTATA

HASTATA

HASTATA

HASTATA

HASTATA

LANCEOLATA

LAACEOLATA

LANCEOLATA

ANCEOLATA

LANCEOLAT A

LANCEOLATA

LANCEOLATA

LANCEOLAT A

LANCEOLATA

LANCEOLATA

ANCEOLATA

ANCEOLATA

LANCEOLAT A

LANCEOLATA

LANCEOLAT A

LANCEOLATA

LANCEOLATA

LANCEOLATA

ANCEOLATA

LANCEOLAT A

LANCEOLAT A

LANCEOLAT A

LANCEOLATA

LANCEOLATA

LANCEOLAT A

LI MBA TA

LIMBATA COSTULATA

\section{Locality}

Lat. Long.

NE GULF OF MEXICO

NE GULF OF MEXICO

NE GULF OF MEXICO

NE GULF OF MEXICO

NE GULF OF MEXICO

NW GULF OF MEXICO

NW GULF OF MEXICO

NW GULF OF MEXICO

NE GULF OF MEXICO 


\section{Publication}

11701 CUSHMAN $1922 \mathrm{~A}$ 11702 PHLEGER 1951 A 11703 PHLEGER 1951 A 11704
11705 PHLEGER 1951 PHEGER 1951 A 11706 PHLEGER 1951A 11707 PHLEGER 1951A 19708 PHLEGER $1951 \mathrm{~A}$ 11709 PHLEGER 1951A 11710 PHLEGER 1951A 11711 PHLEGER 1951A 11712 PHLEGER 1951A 11713 PHLEGER 1951A 11714 PHLEGER 1951A 11715 PHLEGER 1951A 11716 PHLEGER 1951A 11717 PHLEGER 1951A 11718 PHLEGER $1951 \mathrm{~A}$
11719 PHLEGER $1951 \mathrm{~A}$ 11720 PHLEGER 1951A 11721 PHLEGER 1951A 11722 PHLEGER 1951A 11723 PHLEGER 1951A 11724 PHLEGER 1951A 11725 PHLEGER 1951A 11726 PHLEGER 1951A 11727 PHLEGER 1951A 11728 PHLEGER 1951A 11729 PHLEGER 1951A 11730 PHLEGER 1951A 11731 PHLEGER 1951A 11732 PHLEGER 1951A 11733 PHLEGER 1951A 11734 PHLEGER 1951A 11735 PHLEGER 1951A 11736 PHLEGER 1951A 11737 PHLEGER 1951A 11738 PHLEGER 1951A 11739 PHLEGER 1951A 11740 PHLEGER 1951A 11741 PHLEGER 1951A 11742 PARKER 1954 11743 PARKER 1954 11744 PHLEGER $1951 \mathrm{~A}$ 11745 PHLEGER 1951A 11746 PARKER 1954
11747 PARKER 1954 11748 PARKER 1954 11749 PARKER 1954 11750 PARKER 1954 11751 PARKER 1954 11752 PARKER 1954

11753 PARKER PHLEGER PEIRSON 1953 11754 PARKER PHLEGER PEIRSON 1953 11755 PARKER PHLEGER PEIRSON 1953 11756 PHLEGER 1951A 11757 PHLEGER 1951A 11758 PARKER 1954 11759 PARKER 1954 11760 PARKER 1954 11761 PARKER 1954 11762 PHLEGER 1956 11763 PARKER 1954 11764 PARKER 1954

11765 LUDWICK WALTON 1957 11766 PHLEGER 1954 11767 WARREN 1957

11768 LANKFORD 1959

11769 PHLEGER 1954

11770 PHLEGER 1955 A

11771 PHLEGER $1955 \mathrm{~B}$

11772 PHLEGER LANKFORD 1957

11773 PHLEGER 1955 A

11774 PHLEGER 1955A

11775 PHLEGER 1955 A

11776 PHLEGER 1955 A

11777 PHLEGER 1955 A

11778 PHLEGER 1955A

11779 PARKER 1954

11780 PARKER 1954

11781 PARKER 1954

11782 PARKER 1954

11783 PARKER 1954

11784 PARKER 1954

11785 PHLEGER 1956
11786 PARKER 1954

11787 PHLEGER 1956

11788 PARKER 1954

11789 PARKER 1954

11790 PARKER 1954

11791 PARKER 1954

11792 PARKER 1954

11794 PHLEGER 1956

11795 PHLEGER 1956
Generic Name

BOLIVINA

BOLIVINA

BOLIVINA

BOLIVINA

BOLIVINA

BOLIVINA

BOLIVINA

BOLIVINA

BOLIVINA

BOLIVINA

BOLIVINA

BOLIVINA

BOLIVINA

BOLIVINA

BOLIVINA

BOLIVINA

BOLIVINA

BOLIVINA

BOLIVINA

BOLIVINA

BOLIVINA

BOLIVINA

BOLIVINA

BOLIVINA

BOLIVINA

BOLIVINA

BOLIVINA

BOLIVINA

BOLIVINA

BOLIVINA

BOLIVINA

BOLIVINA

BOLIVINA

BOLIVINA

BOLIVINA

BOLIVINA

BOLIVINA

BOLIVINA

BOLIVINA

BOLIVINA

BOLIVINA

BOLIVINA

OOLIVINA

BOLIVINA

BOLIVINA

BOLIVINA

BOLIVINA

BOLIVINA

BOLIVINA

BOLIVINA

BOLIVINA

BOLIVINA

BOLIVINA

BOLIVINA

BOLIVINA

BOLIVINA

BOLIVINA

BOLIVINA

BOLIVINA

BOLIVINA

BOLIVINA

BOLIVINA

BOLIVINA

BOLIVINA

BOLIVINA

BOLIVINA

BOLIVINA

BOLIVINA

BOLIVINA

BOLIVINA

BOLIVINA

BOLIVINA

BOLIVINA

BOLIVINA

BOLIVINA

BOLIVINA

BOLIVINA

BOLIVINA

BOLIVINA

BOLIVINA

OLIVINA

BOLIVINA

BOLIVINA

BOLIVINA

BOLIVINA

BOLIVINA
Specific Name

LIMBATA COSTULATA TORTUGAS

LOWMANI NW GULF OF MEXICO

LOWMANI

LOWMANI

LOWMANI

LOWMANI

LOWMANI

LOWMANI

LOWMANI

LOWMANI

LOWMANI

LOWMAN I

LOWMANI

OWMAN I

LOWMANI

LOWMANI

LOWMAN I

LOWMAN I

LOWMANI

DWMANI

LOGMANI

LOWMANI

LOWMAN I

LOWMANI

LOWMANI

LCWMAN I

LOWMAN I

LOWMAN I

LOWMANI

LOWMAN I

LOWMANI

LOWMANI

LOWMAN I

LOWMAN I

LOWMAN I

LOWMAN I

LOWMANI

LOWMANI

LOWMAN I

OWMAN I

I. OWMAN I

LOWMAN I

LOWMAN I

LOWMANI

LOWMANI

LOWMAN I

LOWMANI

LOWMAN I

LOWMANI

OWMANI

LOWMANI

LOWMAN I

LOWMAN I

LOWMAN I

OWMAN I

LOWMANI

LOWMANI

LOWMAN I

LOWMANI

LOWMAN I

LOWMANI

LOWMAN I

LOWMAN I

LOWMANI

LOWMAN I

LOWMAN I

LOWMANI

LOWMANI

OWMANI

LOWMANI

LOWMANI

LOWMANI

LOWMAN I

LOWMAN I

LOWMANI

LOWMANI

LOUMANI

LOWMANI

LOWMANI

LOWMANI

LOWMANI

LOWMAN I

LOWMAN I

LOWMAN I

LOWMAN I

LOWMANI

Locality

NW GULF OF MEXICO

$N W$ GULF OF MEXICO

$N W$ GULF OF MEXICO

NW GULF OF MEXICO

$N W$ GULF OF MEXICO

NW GULF OF MEXICO

NW GULF OF MEXICO

NW GULF OF MEXICO

$N$ GULF OF MEXICO

$N$ GULF OF MEXICO

$N W$ GULF OF MEXICO

NW GULF OF MEXICO

NW GULF OF MEXICO

NH GULF OF MEXICO

$N W$ GULF OF MEXICO

$N W$ GULF OF MEXICO

NW GULF OF MEXICO

NW GULF OF MEXICO

$N W$ GULF OF MEXICO

NW GULF OF MEXICO 


\section{Publication}

11796 PHLEGER 1955A 11797 PARKER 1954 11798 PHLEGER $1951 \mathrm{~A}$ 11799 PHLEGER $1951 \mathrm{~A}$ 11800 SEGURA 1963

11801 PARKER 1754

11802 PARKER 1954

1803 PARKER 1954

11804 KANE 1962

11806 PHLEGER 1965A

11807 PHLEGER 1965A

11808 WALTON 1964

11809 WARREN 1956

11810 AYALA-CASTANARES SEGURA 1968

11811 AYALA-CASTANARES 1963

11812 PHLEGER $1951 \mathrm{~A}$

11813 PHLEGER 1

11815 WALTON 1960

11816 ANDERSEN 1961

11817 ANDERSEN 1961

11818 ANDERSEN 1961

11819 ANDERSEN 1961

11820 CUSHMAN 1922 A

11821 ANDERSEN 1961

$\begin{array}{lll}11822 & \text { PFLUM FRERICHS } & 1976 \\ 11823 & \text { PFLUM FRERICHS } & 1976\end{array}$

11824 PARKER 1954

11825 PARKER 1954

11826 PARKER 1954

11827 PARKER 1954

11828 PARKER 1954

$\begin{array}{lll}11829 & \text { PFLUM FRERICHS } & 1976 \\ 11830 & \text { PFLUM FRERICHS } & 1976\end{array}$

11830 PFLUM FRERICHS 1976
11831 PFLUM FRERICHS 1976

11832 PFLUM FRERICHS 1976

11833 PFLUM FRERICHS 1976

11834 PFLUM FRERICHS 1976

11835 PARKER 1954

11836 PARKER 1954

11837 PFLUM FRERICHS 1976

11838 PFLUM FRERICHS 1976

11839 PHLEGER 1951 A

11840 PARKER 1954

11841 PARKER 1954

11842 PARKER 1954

11843 PARKER 1954

11844 PARKER 1954
11845 PARKER 1954

11845 PARKER 1954
11846 PHLEGER 1951 A

11847 PHLEGER 1951A

11848 PFLUM FRERICHS 1976

11849 PFLUM FRERICHS 1976

11850 PFLUM FRERICHS 1976

11851 LUDWICK WALTON 1957

11852 PHLEGER $1951 \mathrm{~A}$

11853 PHLEGER 1951A

11854 PARKER 1954

11855 PHLEGER $1951 \mathrm{~A}$

11856 PHLEGER $1951 \mathrm{~A}$

11857 PHLEGER 1951A

11858 PHLEGER 1951A

11859 PHLEGER 1951A

11860 PHLEGER 1951A

11861 PHLEGER 1951A

11862 PHLEGER 1951A

11863 PHLEGER 1951A

11864 PHLEGER 1951A

11865 PARKER 1954

11866 PARKER 1954

11867 PARKER 1954

11868 PARKER 1954

11869 PARKER 1954

11870 PFLUM FRERICHS 1976

11871 PFLUM FRERICHS 1976

11872 PARKER 1954

1873 PARKER 1954

11874 PARKER 195

11875 PARKER 1954

11876 PARKER 1954

11877 PARKER 1954

11878 PARKER 1954

11879 PARKER 1954

11879 PARKER 1954

11881 PARKER 1954

11882 PFLUM FRERICHS 1976

11883 PFLUM FRERICHS 1976

11884 PFLUM FRERICHS 1976

11885 PFLUM FRERICHS 1976

11886 PFLUM FRERICHS 1976

11887 PFLUM FRERICHS 1976

11888 PFLUM FRERICHS 1976

11889 PFLUM FRERICHS 1976

11890 PFLUM FRERICHS 1976
Generic Name Specific Name

LOWMANI

LOWMANI

LO WMANI

LOWMANI

LOWMANI

LOWMANI

LOWMANI

LOWMANI

LO WMAN I

LOWMANI

LOWMAN I

LOWMANI

LOWMANI

LOWMANI

LOWMANI

LOWMANI

LOWMANI

LOWMAN I

LOWMANI

LO WMANI

LOWMANI

LOWMANI

LO WMAN

MEXICANA

MI IIMA

MINIMA

MI I MA

MI I MA

MI I MA

$M I \cap I M A$

MINIMA

MINIMA

MI I MA

MI I MA

MI I MA

MINIMA

MI I MA

MINIMA

MINIMA

MI I MA

MI I MA

MINIMA

MINIMA

MINIMA

MINIMA

MINIMA

MINIMA

MINIMA

MINIMA

MINIMA

MINIMA

MINIMA

MINIMA

MI IIMA

MINIMA

MINIMA

MINIMA

MINIMA

MI IIMA

MI IIMA

MINIMA

MINIMA

M I N I MA

MINIMA

MINIMA

OR DINAR IA

OR DINARIA

ORDINARIA

ORDINARIA

OR CINARIA

OR DINARIA

ORDINARIA

OR DINARIA

OR DINAR IA

OR DINAR IA

ORDINARIA

OR DINARIA

ORDINAR IA

OR DINARIA

OR DINARIA

ORDINAR IA

OR DINAR IA

ORDINAR IA

OR DINARIA

OR DINARIA

OR DINARIA

OR OINARIA

OR DINAR IA

OR DINARIA

OR DINAR IA

OR DINAR IA
Locality

Lat. Long.

N GULF OF MEXICO

NE GULF OF MEXICO

NW GULF OF MEXICO

NW GULF OF MEXICO

MAT AMOROS, MEXICO

NE GULF OF MEXICO

NE GULF OF MEXICO

NE GULF OF MEXICO

SABINE LAKE, TEXAS

NE GULF OF MEXICO

PASS CAVALLO, TEXAS

COLORADO R. DELTA. TEXAS

TAMPA-SARASOTA BAY, FLA.

BURAS SE LOUISIANA

LAGUNA MADRE, NE TEXAS

L. DE TERMINOS, CAMPECHE

$N W$ GULF OF MAEXICO

NW GULF OF MEXICO

SABINE LAKE, TEXAS

MISSISSIPPI SOUND

MISSISSIPPI DELTA

MISSISSIPPI DELTA

MISSISSIPPI DELTA

MISSISSIPPI DELTA

TORTUGAS

MISSISSIPPI DELTA

CENTRAL GULF OF MEXICO

CENTRAL GULF OF MEXICO

NE GULF OF MEXICO

NE GULF OF MEXICO

NE GULF OF MEXICO

NE GULF OF MEXICO

NE GULF OF MEXICO

NW GULF OF MEXICO

NW GULF OF MEXICO

NW GULF OF MEXICO

NW GULF OF MEXICO

$N W$ GULF OF MEXICO

NW GULF OF MEXICO

NE GULF OF MEXICO

NE GULF OF MEXICO

NW GULF OF MEXICO

NW GULF OF MEXICO

NW GULF OF MEXICO

$N E$ GULF OF MEXICO

NE GULF OF MEXICO

NE GULF OF MEXICO

NE GULF OF MEXICO

NE GULF OF MEXICO

NE GULF OF MEXICO

NW GULF OF MEXICO

NW GULF OF MEXICO

NW GULF OF MEXICO

NW GULF OF MEXICO

NW GULF OF MEXICO

NE GULF OF MEXICO

NW GULF OF MEXICO

NW GULF OF MEXICO

NE GULF OF MEXICO

NW GULF OF MEXICO

NW GULF OF MEXICO

WULF OF MEXICO

NW GULF OF MEXICO

NW GULF OF MEXICO

NW GULF OF MEXICO

NW GULF OF MEXICO

NW GULF OF MEXICO

NW GULF OF MEXICO

NW GULF OF MEXICO

NE GULF OF MEXICO

NE GULF OF MEXICO

NE GULF OF MEXICO

NE GULF OF MEXICO

NE GULF OF MEXICO

NW GULF OF MEXIC

NW GULF OF MEXICO

NE GULF OF MEXICO

NE GULF OF MEXICO

NE GULF OF MEXICO

NE GULF OF MEXICO

NE GULF OF MEXICO

NE GULF OF MEXICO

NE GULF OF MEXICO

NE GULF OF MEXICO

NE GULF OF MEXICO

NE GULF OF MEXICO

CENTRAL GULF OF MEXIC

CENTRAL GULF OF MEXICO

CENTRAL GULF OF MEXICO

CENTRAL GULF OF MEXICO

NW GULF OF MEXICO

NW GULF OF MEXICO

WULF OF MEXICO

W GULF OF MEXICO

NW GULF OF MEXICO

$2802 \mathrm{~N} 08919 \mathrm{~W}$

$2857 \mathrm{~N} 085 \quad 54 \mathrm{~W}$

$2622 \mathrm{~N} 09640 \mathrm{~W}$

$2500 \mathrm{~N} 09455 \mathrm{~W}$

$2550 \mathrm{~N} 09638 \mathrm{~W}$

$2 t 43 \mathrm{~N} 08508 \mathrm{~W}$

$2530 \mathrm{~N} 08459 \mathrm{~W}$

$2546 \mathrm{~N} 084 \quad 12 \mathrm{~W}$

$2950 N 09347 \mathrm{~W}$ 


\section{Publication}

11891 PFLUM FRERICHS 1970 11892 PFLUM FRERICHS 1976 11893 PFLUM FRERICHS 1976 11894 PFLUM FRERICHS 1976 11895 PFLUM FRERICHS 1976 11896 PFLUM FRERICHS 1976 11897 PFLIJM FRERICHS 1976 11898 PFLUM FRERICHS 1976 11899 PFLUM FRERICHS 1976 11900 PFLUM FRERICHS 1976 11901 PFLUM FRERICHS 1976 11902 PFLUM FRERICHS 1976 11903 PFLUM FRERICHS 1976 11904 PFLUM FRERICHS 1976 11905 PFLUM FRERICHS 1976 11906 PFLUM FRERICHS 1976 11907 PARKER 1954

11908 PARKER 1954

11010 PARKER 1954

11911 PHLEGER 1955A

11912 PARKER 1954

11913 PHLEGER 1955A

11914 PHLEGER 1955 A

11915 PFLUM FRERICHS 1976

11916 PARKER 1954

11917 PARKER 1054

11918 PARKER 1954

11919 PARKER 1754

11920 PARKER 1954

11921 PARKER 1954

11922 PARKER 1254

11923 PHLEGER 1955 A

11924 PHLEGER 1955

11925 PARKER 1954

11926 PARKFR 1754

11927 PARKER 1054

11928 PARKER 1954

11929 PARKER 1954

11931 PHLEGER 19658

11932 PHLEGER 19658

11933 PFLUM FRERICHS 1976

11934 PFLUM FRERICHS 1976

11935 AYALA-CASTANARES 1963

11936 WALTON 1960

11937 NORTOV 1730

11938 CUSHMAN $1922 \mathrm{~A}$

11939 SEGURA 1963

11940 PARKER 1954

11941 PHLEGER $1951 \mathrm{~A}$

11943 PHLEGER $1951 \mathrm{~A}$

11944 PARKER 1954

11945 PARKER 1754

11946 PARKER 1954

11947 PARKER 1954

11948 LUDWICK WALTON 1957

11949 PHLEGER 1954

11950 PARKER 1054

11951 PARKER 1954

11952 PARKER 1954

11953 PARKER 1954

11954 PARKER 1954

11955 PHLEGER $1951 \mathrm{~A}$

11956 PHLEGER 1955A

11957 PHLEGER 1955 A

11958 PHLEGER 1954

11959 LANKFORD 1959

11960 PHLEGER $1955 \mathrm{~A}$

11961 PHLEGER $1951 \mathrm{~A}$

11962 PARKER 1954

11963 PARKER 1954

11964 PHLEGFR 1956

11965 PHLEGER 1956

11966 PARKER 1754

11967 PARKER 1954

11968 BENDA PURI 1962

11969 KELLOUGH 1956

11970 BANDY 1956

11971 BANDY 1956

11972 PHLEGER 1951 A

11973 PHLEGER $1951 \mathrm{~A}$

11974 PHLEGER 1951 A

11975 PHLEGER $1951 \mathrm{~A}$

11976 PHLEGER $1951 \mathrm{~A}$

11977 PHLEGER $1951 \mathrm{~A}$

11978 PHLEGER 1951 A

11979 AYALA-CASTANARES 1963

11980 PARKER PHLEGER PEIRSON 1953

11981 PHLEGER $1951 \mathrm{~A}$

11982 PHLEGER 1951 A

11983 PHLEGER 1951 A

11984 PHLEGER 1951 A

11985 PHLEGER 1951A

\section{Generic Name}

BOLIVINA

BOLIVINA

BOLIVINA

BOLIVINA

BOLIVINA

BOLIVINA

BOLIVINA

BOLIVINA

BOLIVINA

BOLIVINA

BOLIVINA

BOLIVINA

BOLIVINA

BOLIVINA

BOLIVINA

BOLIVINA

BOLIVINA

BOLIVINA

BOLIVINA

BOLIVINA

BOLIVINA

BOLIVINA

BOLIVINA

BOLIVINA

BOLIVINA

BOLIVINA

BOLIVINA

BOLIVINA

BOLIVINA

BOLIVINA

BOLIVINA

BOLIVINA

BOLIVINA

BOLIVINA

BOLIVINA

BOLIVINA

BOLIVINA

BOLIVINA

BOLIVINA

BOLIVINA

BOLIVINA

BOLIVINA

BOLIVINA

BOLIVINA

BOLIVINA

BOLIVINA

BOLIVINA

BOLIVINA

BOLIVINA

BOLIVINA

BOLIVINA

BOLIVINA

BOLIVINA

BOLIVINA

BOLIVINA

BOLIVINA

BOLIVINA

BOLIVINA

BOLIVINA

BOLIVINA

BOLIVINA

BOLIVINA

BOLIVINA

BOLIVINA

BOLIVINA

BOLIVINA

BOLIVINA

BOLIVINA

BOLIVINA

BOLIVINA

BOLIVINA

BOLIVINA

BOLIVINA

BOLIVINA

BOLIVINA

BOLIVINA

BOLIVINA

BOLIVINA

BO LIVINA

BOLIVINA

BOLIVINA

BOLIVINA

BOLIVINA

BOLIVINA

BOLIVINA

BOLIVINA

BOLIVINA

BOLIVINA

BOLIVINA

BOLIVINA

BOLIVINA

BOLIVINA

BOLIVINA

BOLIVINA

BOLIVINA
Specific Name

OR DINAR IA

OR DINAR IA

OR DINAR I A

OR D INAR IA

OR DINARIA

OR DINAR IA

OR DINAR IA

OR DINARIA

OR DINAR IA

OR DINAR IA

OR DINARIA

OR DINAR I A

OR DINAR IA

OR DINAR IA

OR DINARIA

OR DINAR IA

OR DINAR IA

OR DINAR IA

ORDINARIA

OR DINAR IA

OR DINAR IA

OR DINAR IA

OR DINAR IA

OR DINAR I

OR DINAR IA

OR DINARIA

PAULA

PAULA

PAULA

PAULA

PALLA

PALLA

PAULA

PAULA

PAULA

PAULA

PAULA

PAULA

PSEUDOPLI CATA

PSEUDOPLI CATA

PSEUDOPLI CATA

PSEUDOPLI CATA

PSEUDOPLI CATA

PSEUDOPLI CATA

PULCHELLA

PULCHELLA

PULCHELLA

PULCHELLA PRIMITIVA PULCHELLA PRIMITIVA PULCHELLA PRIMITIVA PULCHELLA PRIMITIVA PULCHELLA PRIMITIVA PULCHELLA PRIMITIVA PULCHELLA PRIMITIVA PULCHELLA PRIMITIVA PULCHELLA PRIMITIVA PULCHELLA PRIMITIVA PULCHELLA PRIMITIVA PULCHELLA PRIMITIVA PULCHELLA PRIMITIVA PULCHELLA PRIMITIVA PULCHELLA PRIMITIVA PULCHELLA PRIMITIVA PULCHELLA PRIMITIVA PULCHELLA PRIMITIVA PULCHELLA PRIMITIVA PULCHELLA PRIMITIVA PULCHELLA PRIMITIVA PULCHELLA PRIMITIVA PULCHELLA PRIMITIVA PULCHELLA PRIMITIVA PULCHELLA PRIMITIVA PULCHELLA PRIMITIVA PULCHELLA PRIMITIVA PULCHELLA PRIMITIVA PULCHELLA PRIMITIVA PULCHELLA PRIMITIVA PULCHELLA PRIMITIVA PULCHELLA PRIMITIVA PULCHELLA PRIMITIVA PULCHELLA PRIMITIVA PULCHELLA PRIMITIVA PULCHELLA PRIMITIVA PULCHELLA PRIMITIVA PULCHELLA PRIMITIVA PULCHELLA PRIMITIVA PULCHELLA PRIMITIVA PULCHELLA PRIMITIVA PULCHELLA PRIMITIVA PULCHELLA PRIMITIVA PULCHELLA PRIMITIVA PULCHELLA PRIMITIVA PULCHELLA PRIMITIVA PULCHELLA PRIMITIVA

\section{Locality}

NW GULF OF MEXICO

NW GULF OF MEXICO 


\section{Publication}

11986. PHLEGER 1951 A 11987 PHLEGER 1951A 11988 PHLEGER 1951A 11989 PHLEGER $1951 \mathrm{~A}$ 11990 PHLEGER 1956 11991 PHLEGER 1956

11992 PARKER 1954

11993 PARKER 1956

11994 PARKER 1954

11995 PARKER 1954

11996 PARKER 1954

11997 PARKER 1954

11998 CUSHMAN 19228

11999 DAVIS 1964

12000 PARKER 1954

12001 PARKER 1954

12002 PFLUM FRERICHS 1976

12003 PFLUM FRERICHS 1976

12004 PFLUM FRERICHS 1976

12005 PARKER 1954

12006 PFLUM FRERICHS 1976

12007 PFLUM FRERICHS 1976

12008 PFLUM FRERICHS 1976

12009 PARKER 1954

12010 PARKER 1954

12011 PARKER 1954

12012 PFLUM FRERICHS 1976

12013 PFLUM FRERICHS 1976

12014 PFLUM FRERICHS 1976

12015 PFLUM FRERICHS 1976

12016 PFLUM FRERICHS 1976

12017 PFLUM FRERICHS 1976

12018 PFLUM FRERICHS 1976

12019 PFLUM FRERICHS 1976

12020 PFLUM FRERICHS 1976

12021 PFLUM FRERICHS 1976

12022 PFLUM FRERICHS 1976

12023 PARKER 1954

12024 PARKER 1954

12025 PARKER 1954

12026 PARKER 1954

12027 PARKER 1954

12028 PARKER 1954

12029 PARKER 1954

12030 PFLUM FRERICHS 1976

12031 PFLUM FRERICHS 1976

12032 PFLUM FRERICHS 1976

12033 PFLUM FRERICHS 1976

12034 PFLUM FRERICHS 1976

12035 PFLUM FRERICHS 1976

12036 PFLUM FRERICHS 1976

12037 PFLUM FRERICHS 1976

12038 PFLUM FRERICHS 1976

12039 PFLUM FRERICHS 1976

12040 PFLUM FRERICHS 1976

12041 PFLUM FRERICHS 1976

12042 PFLUM FRERICHS 1976

12043 PFLUM FRERICHS 1976

12044 PFLUM FRERICHS 1976

12045 PFLUM FRERICHS 1976

12046 PFLUM FRERICHS 1976

12047 PFLUM FRERICHS 1976

12048 PFLUM FRERICHS 1976

12049 CUSHMAN $1922 A$

12050 PFLUM FRERICHS 1976

12051 PFLUM FRERICHS 1976

12052 PHLEGER $1951 \mathrm{~A}$

12053 PHLEGER $1951 \mathrm{~A}$

12054 PHLEGER 1951A

12055. PHLEGER 1951 A

12056 PHLEGER 1951A

12057 PHLEGER 1951A

12058 PHLEGER $1951 \mathrm{~A}$

12059 PHLEGER $1951 \mathrm{~A}$

12060 PHLEGER $1951 \mathrm{~A}$

12061 PHLEGER 1951A

12062 PHLEGER 1951A

12063 PHLEGER 1951A

12064 PHLEGER 1951A

12065 PHLEGER 1951A

12066 PHLEGER $1951 \mathrm{~A}$

12067 PHLEGER 1951A

12068 PHLEGER 1951A

12069 PHLEGER 1951 A

12070 PHLEGER 1951A

12071 PHLEGER 1951A

12072 PHLEGER 1951A

12073 PHLEGER 1951A

12074 PHLEGER 1951A

12075 PHLEGER 1951A

12076 PHLEGER 1951A

12077 PHLEGER 1951 A

12078 PHLEGER 1951A

12079 BENDA PURI 1962

12080 CREAGER 1958
Generic Name

BOLIVINA

BOLIVINA

BOLIVINA

BOLIVINA

BOLIVINA

BOLIVINA

BOLIVINA

BOLIVINA

BOLIVINA

BOLIVINA

BOLIVINA

BOLIVINA

BOLIVINA

BOLIVINA

BOLIVINA

BOLIVINA

BOLIVINA

BOLIVINA

BOLIVINA

BOLIVINA

BOLIVINA

BOLIVINA

BOLIVINA

BOLIVINA

BOLIVINA

BOLIVINA

BOLIVINA

BOLIVINA

BOLIVINA

BOLIVINA

BOLIVINA

BOLIVINA

BOLIVINA

BOLIVINA

BOLIVINA

BOLIVINA

BOLIVINA

BOLIVINA

BOLIVINA

BOLIVINA

BOLIVINA

BOLIVINA

BOLIVINA

BOLIVINA

BOLIVINA

BOLIVINA

BOLIVINA

BOLIVINA

BOLIVINA

BOLIVINA

BOLIVINA

BOLIVINA

BOLIVINA

BOLIVINA

BOLIVINA

BOLIVINA

BOLIVINA

BOLIVINA

BOLIVINA

BOLIVINA

BOLIVINA

BOLIVINA

BOLIVINA

BOLIVINA

BOLIVINA

BOLIVINA

BOLIVINA

BOLIVINA

BOLIVINA

BOLIVINA

BOLIVINA

BOLIVINA

BOLIVINA

BOLIVINA

BOLIVINA

BOLIVINA

BOLIVINA

BOLIVINA

BOLIVINA

BOLIVINA

BOLIVINA

BOLIVINA

BOLIVINA

BOLIVINA

BOLIVINA

BOLIVINA
BOLIVINA

BOLIVINA

BOLIVINA

BOLIVINA

BOLIVINA

BOLIVINA

BOLIVINA

BOLIVINA
Specific Name

PULCHELLA PRIMITIVA

PULCHELLA PRIMITIVA

PULCHELLA PRIMITIVA

PULCHELLA PRIMITIVA

PULCHELLA PRIMITIVA

PULCHELLA PRIMITIVA

PULCHELLA PRIMITIVA

PULCHELLA PRIMITIVA

PULCHELLA PRIMITIVA

PULCHELLA PRIMITIVA

PULCHELLA PRIMITIVA

PULCHELLA PRIMITIVA

PUNCTATA

PUNCTATA

PUSILLA

PUSILLA

PUSILLA

PUSILLA

PUSILLA

PUSILLA

PUSILLA

PUSILLA

PUSILLA

PUSILLA

PUSILLA

PUSILLA

PUSILLA

PUSILLA

PUSILLA

PUSILLA

PUSILLA

PUSILLA

PUSILLA

PUSILLA

PUSILLA

PUSILLA

PUSILLA

PUSILLA

PUSILLA

PUSILLA

PUSILLA

PUSILLA

PUSILLA

PUSILLA

PUSILLA

PUSILLA

PUSILLA

PUSILLA

PUSILLA

QUADRATA

QUADRATA

QUADRATA

QUADRATA

QUADRATA

QU ADRAT A

QUADRATA

QU ADRATA

QUADRATA

QUADRAT A

QUADRATA

QUADRATA

QUADRATA

QUADRAT A

RHCMBOI DALIS

SENINUDA

SENINUDA

SI NPLEX

SINPLEX

SINPLEX

SI NPLEX

SINPLEX

SINPLEX

SI NPLEX

SI NPLEX

SI NPLEX

SI MPLEX

SI MPLEX

SINPLEX

SINPLEX

SI MPLEX

SI NPLEX

SIMPLEX

SI MPLEX

SINPLEX

SI NPLEX

SI MPLEX

SINPLEX

SIMPLEX

SI NPLEX

SI NPLEX

SI MPLEX

SINPLEX

SINPLEX

SINPLEX

SPATHULAT A

SPICATA 


\section{Publication}

12081 CREAGER 1958

12082 CREAGER 1958

12083 ANDERSEN 1961

12084 ANDERSEN 1961

12085 CREAGER 1958

12086 CREAGER 1958

12087 CREAGER 1958

12088 CREAGER 1958

12089 CREAGER 1958

12090 HALTON 1960

12091 AYALA-CASTANARES SEGURA 1968

12092 AYALA-CASTANARES 1963

12093 WALTON 1964

12094 NORTON 1930

12095 POST 1951

12096 PARKER PHLEGER PEIRSON 1953

12097 PARKER PHLEGER PEIRSON 1953

12098 WARREN 1957

12099 LANKFORD 1959

12100 PHLEGER 1955B

12101 PHLEGER LANKFORD 1957

12102 WARREN 1956

12103 PHLEGER 1956

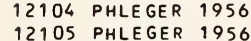

12106 PHLEGER 1956

12107 PARKER PHLEGER PEIRSON 1953

12108 PARKER PHLEGER PEIRSON 1953

12109 PARKER PHLEGER PEIRSON 1953

12110 PARKER PHLEGER PEIRSON 1953

12111 PARKER PHLEGER PEIRSON 1953

12112 BANDY 1954

12113 BANDY 1954

12114 BANDY 1954

12116 BANDY 1954

12117 PARKER PHLEGER PEIRSON 1953

12118 POST 1951

12119 PHLEGER 1956

12120 CUSHMAN 1922A

12121 PHLEGER 1965 A

12122 BENDA PURI 1962

12123 PHLEGER 1965A

12124 BANDY 1956

12125 LEHMANN 1957

12126 HALDRON 1963

12127 PHLEGER 1960

12128 KANE 1962

12129 KANE 1967

12130 SEGURA 1963

12131 PHLEGER $1965 \mathrm{~B}$

12132 PHLEGER 1965B

12133 PHLEGER 1951 A

12134 LANKFORD 1959

12135 PHLEGER 1951A

12136 PHLEGER 1951A

12137 PFLUM FRERICHS 1976

12138 PFLUM FRERICHS 1976

12139 PARKER 1954

12140 PARKER 1954

12141 PHLEGER 1954

12142 LUDWICK WALTON 1957

12143 PARKER 1954

12144 PARKER 1954

12145 PARKER 1954

12146 PHLEGER 1951A

12147 WARREN 1957

12148 PARKER 1954

12149 PARKER 1954

12150 CREAGER 1958

12151 CREAGER 1958

12152 PHLEGER 1951A

12153 PHLEGER 1951A

12154 PHLEGER 1951A

12155 PHLEGER 1951A

12156 PHLEGER 1951A

12157 PHLEGER 1951A

12158 PHLEGER 1951A

12159 PHLEGER 1951A

12160 PARKER 1954

12161 PHLEGER 1951A

12162 PHLEGER $1951 \mathrm{~A}$

12163 PHLEGER 1951A

12164 PARKER 1954

12165 PHLEGER 1951A

12166 CREAGER 1958

12167 WARREN 1956

12168 KELLOUGH 1956

12169 LOEP 1965

12170 PHLEGER 1956

12171 PHLEGER 1956

12172 PARKER 1254

12173 KELLOUGH 1956

12174 PHLEGER 1951A

12175 PHLEGER $1951 \mathrm{~A}$
Generic Name

BOLIVINA

BOLIVINA

BOLIVINA

BOLIVINA

BOLIVINA

BOLIVINA

BOLIVINA

BOLIVINA

BOLIVINA

BOLIVINA

BOLIVINA

BOLIVINA

BOLIVINA

BOLIVINA

BOLIVINA

BOLIVINA

BOLIVINA

BOLIVINA

BOLIVINA

BOLIVINA

BOLIVINA

BOLIVINA

BOLIVINA

OLIVINA

BOLIVINA

BOLIVINA

BOLIVINA

BOLIVINA

BOLIVINA

BOLIVINA

BOL IVINA

BOLIVINA

BOLIVINA

BOLIVINA

BOLIVINA

BOLIVINA

BOLIVINA

BOLIVINA

BOLIVINA

BOLIVINA

BOLIVINA

BOLIVINA

BOLIVINA

BOLIVINA

BOLIVINA

BOLIVINA

BOLIVINA

BOLIVINA

BOLIVINA

BOLIVINA

BOLIVINA

BOLIVINA

BOLIVINA

BOLIVINA

BOLIVINA

BOLIVINA

BOLIVINA

BOLIVINA

BOLIVINA

BOLIVINA

BOLIVINA

BOLIVINA

BOLIVINA

BOLIVINA

BOLIVINA

BOLIVINA

BOLIVINA

BOLIVINA

BOLIVINA

BOLIVINA

BOLIVINA

BOLIVINA

BOLIVINA

BOLIVINA

BOLIVINA

BOLIVINA

BOLIVINA

BOLIVINA

BOLIVINA

BOLIVINA

BOLIVINA

BOL IVINA

BOLIVINA

BOLIVINA

BOLIVINA

BOLIVINA

BOLIVINA

BCLIVINA

BOLIVINA
Specific Name

SPICATA

SP ICATA

SP INATA

STRIATA MEXICANA

STRIATA MEXICANA

STRIATA MEXICANA

STRIATA MEXICANA

STRIATA MEXICANA

STRIATULA

STRIATULA

ST RI ATULA

STRIA TULA

STRIATULA

STRIATULA

STRIATULA

STRIATULA

STRIATULA

STRIATULA

STRIATULA

STRI ATULA

STRIATULA

STRIATULA

STRIATULA

STRIATULA

STRIATULA

STRIATULA

STRIATULA

STRIATULA

STRIATULA

STRIATULA

STRIATULA

STRIATULA

STRIATULA

STRIATULA

STRIATULA

STRIATULA

STRIA TULA

STRIATULA

STRIATULA

STRIATULA

STRIATULA

STRIATULA

STRIATULA

STRIA TULA

STRIATULA

STRIATULA

STRIA TULA

STRIA TULA

STRIATULA

STRIATULA SPINATA

STRIATULA SPINATA

STRIATULA SPINATA

STRIATULA SPINATA

STRIATULA SPINATA

STRIATULA SPINATA

STRIATULA SPINATA

STRIATULA SPINATA

STRIATULA SPINATA

STRIATULA SPINATA

STRIATULA SPINATA

STRIATULA SPINATA

STRIATULA SPINATA

STRIATULA SPINATA

STRIATULA SPINATA

STRIATULA SPINATA

STRIATULA SPINATA

STRIATULA SPINATA

STRIATULA SPINATA

STRIATULA SPINATA

STRIATULA SPINATA

STRIATULA SPINATA

STRIATULA SPINATA

STRIATULA SPINATA

STRIATULA SPINATA

STRIATULA SPINATA

STRIATULA SPINATA

STRIATULA SPINATA

STRIATULA SPINATA

STRIATULA SPINATA

STRIATULA SPINATA

STRIATULA SPINATA

STRIATULA SPINATA

STRIATULA SPINATA

STRIATULA SPINATA

STRIATULA SPINATA

STRIATULA SPINATA

STRIATULA SPINATA

STRIATULA SPINATA

STRIATULA SPINATA

STRIATULA SPINATA

STRIATULA SPINATA

STRIATULA SPINATA

Locality

BAY OF CAMPECHE

BAY OF CAMPECHE

MISSISSIPPI DELTA

MISSISSIPPI DELTA

BAY OF CAMPECHE

BAY OF CAMPECHE

BAY OF CAMPECHE

BAY OF CAMPECHE

BAY OF CAMPECHE

MISSISSIPPI SOUND 


\section{Publication}

12176 PHLEGER $1951 \mathrm{~A}$ 12177 PHLEGER $1951 \mathrm{~A}$ 12178 PHLEGER $1951 \mathrm{~A}$ 12179 PHLEGER $1951 \mathrm{~A}$ 12180 PHLEGER 1956 12181 PHLEGER 1956
12182 PHLEGER $1951 \mathrm{~A}$ 12183 PHLEGER $1951 \mathrm{~A}$ 12184 PHLEGER 1951A 12185 PHLEGER $1951 \mathrm{~A}$ 12186 PHLEGER 1951A 12187 PHLEGER $1951 \mathrm{~A}$

12188 PARKER 1954

12189 PHLEGER 1951A

12190 PHLEGER 1951 A
12191 PFLUM FRERICHS 1976

12192 PARKER 1954

12193 PARKER 1954

12194 PARKER 1954

12195 PARKER 1954

12196 PARKER 1954

12197 PFLUM FRERICHS 1976

12198 PFLUM FRERICHS 1976

12199 PARKER 1954

12200 PARKER 1954

12201 PFLUM FRERICHS 1976

12202 PFLUM FRERICHS 1976
12203 PFLUM FRERICHS 1976

12203 PFLUM FRERICHS 1976
12204 PFLUM FRERICHS 1976

12205 PFLUM FRERICHS 1976

12206 PFLUM FRERICHS 1976

12207 PFLUM FRERICHS 1976

12208 PFLUM FRERICHS 1976

12209 PARKER 1954

12210 PARKER 1954

12211 PARKER 1954

12212 PARKER 1954

12213 PFLUM FRERICHS 1976

12214 PFLUM FRERICHS 1976

12215 PFLUM FRERICHS 1976

12216 PFLUM FRERICHS 1976

12217 PFLUM FRERICHS 1976

12218 PFLUM FRERICHS 1976

12219 PFLUM FRERICHS 1976

12220 PFLUM FRERICHS 1976

12221 PFLUM FRERICHS 1976

12222 PFLUM FRERICHS 1976

12223 PFLUM FRERICHS 1976

12224 PFLUM FRERICHS 1976

12225 PARKER 1954

12226 PARKER 1954

12227 PARKER 1954

12228 PARKER 1954

12229 PHLEGER $1951 \mathrm{~A}$

12231 PFLUM FRERICHS 1976

12232 PFLUM FRERICHS 1976

12233 PFLUM FRERICHS 1976

12234 PFLUM FRERICHS 1976

12235 PFLUM FRERICHS 1976

12236 PHLEGER 1951 A

12237 PFLUM FRERICHS 1976

12238 PFLUM FRERICHS 1976

12239 PFLUM FRERICHS 1976

12240 PFLUM FRERICHS 1976

12241 PARKER 1954

12242 PHLEGER $1955 \mathrm{~A}$

12243 PARKER 1954

12244 PHLEGER 1951A

12245 PHLEGER 1951A

12246 PHLEGER 1951 A

12247 LUDWICK WALTON 1957

12248 PHLEGER $1951 \mathrm{~A}$

12249 PHLEGER 1951A

12250 PHLEGER 1951A

12251 PHLEGER 1955A

12252 PHLEGER 1951 A

12253 PHLEGER 1955 A
12254 PHLEGER 1951 A

12255 PHLEGER $1951 \mathrm{~A}$

12256 CUSHMAN 19228

12257 CUSHMAN 19228

12258 CUSHMAN 19228

12259 CUSHMAN 19228

12260 LOEP 1965

12261 LOEP 1965

12262 BANDY 1956
12263 KELLOUGH 1956

12264 BANDY 1956

12265 PFLUM FRERICHS 1976

12266 PHLEGER $1951 \mathrm{~A}$

12267 PHLEGER $1951 \mathrm{~A}$

12268 PHLEGER 1951 A

12269 PHLEGER 1951A
12270 PHLEGER $1951 \mathrm{~A}$
Generic Name

Specific Name

BOLIVINA

BOLIVINA

BOLIVINA

BOLIVINA

BOLIVINA

BOLIVINA

BOLIVINA

BOLIVINA

BOLIVINA

BOLIVINA

BOLIVINA

BOLIVINA

BOLIVINA

BOLIVINA

BOLIVINA

BOLIVINA

BOLIVINA

BOLIVINA

BOLIVINA

BOLIVINA

BOLIVINA

B.OLIVINA

BOL IVINA

BOLIVINA

BOLIVINA

BOLIVINA

BOLIVINA

BOLIVINA

BOLIVINA

BOLIVINA

BOLIVINA

BOLIVINA

BOLIVINA

BOLIVINA

BOLIVINA

BOLIVINA

BOLIVINA

BOLIVINA

BOLIVINA

BOLIVINA

BOLIVINA

BOLIVINA

BOLIVINA

BOLIVINA

BOLIVINA

BOLIVINA

BOLIVINA

BOLIVINA

BOLIVINA

BOLIVINA

BOLIVINA

BOLIVINA

BOLIVINA

BOLIVINA

BOLIVINA

BOLIVINA

BOLIVINA

BOLIVINA

BOLIVINA

BOLIVINA

BOLIVINA

BOLIVINA

BOLIVINA

BOLIVINA

BOLIVINA

BOLIVINA

BOLIVINA

BOLIVINA

BOLIVINA

BOLIVINA

BOLIVINA

BOLIVINA

BOLIVINA

BOLIVINA

BOLIVINA

BOLIVINA

BOLIVINA

BOLIVINA

BOLIVINA

BOLIVINA

BOLIVINA

BOLIVINA

BOLIVINA

BOLIVINA

BOLIVINA

BOLIVINA

BOLIVINA

BOLIVINA

BOLIVINA

BOLIVINA

BOLIVINA

BOLIVINA

SUBAENARI ENSIS
STRIATULA SPINATA

STRIATULA SPINATA

STRIATULA SPINATA

STRIATULA SPINATA

STRIATULA SPINATA

STRIATULA SPINATA

STRIATULA SPINATA

STRIATULA SPINATA

STRIATULA SPINATA

STRIATULA SPINATA

STRIATULA SPINATA

SUEAENARI ENSIS

SUEAENARI ENSIS

SUEAENARI ENSIS

SUEAENARI ENSIS MEXICANA

SUEAENARIENSIS MEXI CANA

SUEAENARI ENSIS MEXICANA

SUEAENARIENSIS MEXICANA

SUEAENARIENSIS MEXI CANA

SUBAENARI ENSIS MEXI CANA

SUBAENARIENSIS MEXICANA

SUBAENARIENSIS MEXICANA

SUEAENARIENSIS MEXI CANA

SUEAENARIENSIS MEXICANA

SUEAENARI ENSIS MEXI CANA

SUBAENARIENSIS MEXICANA

SUBAENARIENSIS MEXICANA

SUEAENARIENSIS MEXICANA

SUEAENARIENSIS MEXI CANA

SUEAENARIENSIS MEXICANA

SUBAENARI ENSIS MEXI CANA

SUEAENARIENSIS MEXI CANA

SUBAENARIENSIS MEXICANA

SUEAENARIENSIS MEXICANA

SUEAENARIENSIS MEXICANA

SUEAENARIENSIS MEXI CANA

SUEAENARIENSIS MEXI CANA

SUEAENARIENSIS MEXICANA

SUEAENARIENSIS MEXICANA

SUEAENARIENSIS MEXI CANA

SUEAENARIENSIS MEXICANA

SUBAENARIENSIS MEXI CANA

SUEAENARIENSIS MEXI CANA

SUEAENARIENSIS MEXI CANA

SUEAENARIENSIS MEXI CANA

SUEAENARIENSIS MEXI CANA

SUBAENARIENSIS MEXICANA

SUEAENARIENSIS MEXI CANA

SUEAENARIENSIS MEXI CANA

SUEAENARIENSIS MEXICANA

SUEAENARIENSIS MEXICANA

SUEAENARI ENSIS MEXI CANA

SUBAENARIENSIS MEXICANA

SUBAENARI ENSIS MEXI CANA

SUEAENARIENSIS MEXI CANA

SUEAENARIENSIS MEXICANA

SUEAENARI ENSIS MEXI CANA

SUEAENARIENSIS MEXICANA

SUEAENARIENSIS MEXICANA

SUEAENARIENSIS MEXICANA

SUEAENARIENSIS MEXICANA

SUEAENARIENSIS MEXICANA

SUEAENARIENSIS MEXICANA

SUBAENARIENSIS MEXI CANA

SUEAENARI ENSIS MEXI CANA

SUEAENARIENSIS MEXI CANA

SUBAENARIENSIS MEXI CANA

SUEAENARIENSIS MEXICANA

SUEAENARIENSIS MEXICANA

SUEAENARIENSIS MEXICANA

SUEAENARIENSIS MEXICANA

SUEAENARI ENSIS MEXI CANA

SUEAENARIENSIS MEXICANA

SUEAENARIENSIS MEXICANA

SUPAENARIENSIS MEXICANA

SUEAENARIENSIS MEXICANA

SUEAENARIENSIS MEXICANA

SUBAENARIENSIS MEXICANA

SUEAENARIENSIS MEXI CANA

SUBAENARIENSIS MEXICANA

SUBAENARIENSIS MEXICANA

SUPAENARIENSIS MEXICANA

SU BAENARIENSIS MEXICANA

SURAENARIENSIS MEXI CANA

SUEAENARIENSIS MEXI CANA

SUBAENARIENSIS MEXI CANA

SUEAENARIENSIS MEXICANA

SUEAENARI ENSIS MEXICANA

SUPAENARIENSIS MEXICANA

SUPAENARIENSIS MEXICANA

SUBAENARIENSIS MEXICANA

SUEAENARIENSIS MEXICANA

SUEAENARI ENSIS MEXI CANA

SUEAENARIENSIS MEXICANA

Locality

Lat. Long.

NW GULF OF MEXICO

NW GULF OF MEXICO

NW GULF OF MEXICO

NW GULF OF MEXICO

NW GULF OF MEXICO

NW GULF OF MEXICO

NW GULF OF MEXICO

NW GULF OF MEXICO

NW GULF OF MEXICO 


\section{Publication}

12271 PHLEGER 1951 A

12272 CREAGER 1958

12273 CREAGER 1958

12274 CREAGER 1958

12275 CREAGER 1958

12276 CREAGER 1958

12277 CREAGER 1958

12278 BENDA PURI 1962

12279 PARKER 1954

12280 LOEP 1965

12281 PHLEGER $1951 \mathrm{~A}$

12282 PARKER 1954

12283 PARKER 1954

12284 PARKER 1954

12285 PHLEGER 1956
12286 PARKER 1954

12286 PARKER 1954
12287 PARKER 1954

12288 PARKER 1954

12289 PARKER 1954

12290 PARKER 1954

12292 PHLEGER 1955 A

12293 PHLEGER 1951 A

12294 PHLEGER 1951 A

12295 PHLEGER 1951 A

12296 PHLEGER 1951A

12297 PHLEGER 1951A

12298 PHLEGER 1951 A

12299 PHLEGER $1955 \mathrm{~A}$

12300 PHLEGER $1955 \mathrm{~A}$

12301 PHLEGER $1955 \mathrm{~A}$

12302 PHLEGER 1951A

12303 PHLEGER 1951A

12304 PHLEGER $1951 \mathrm{~A}$

12305 PHLEGER 1951 A

12306 PHLEGER 1951A

12307 PHLEGER 1951A

12308 PHLEGER $1951 \mathrm{~A}$

12309 PHLEGER 1951A

12310 PHLEGER 1951A

12311 PHLEGER $1951 \mathrm{~A}$

12313 PHLEGER 1951A

12314 PHLEGER 1951A

12315 PHLEGER 1951A

12316 PHLEGER 1951A

12317 PHLEGER 1951A

12318 PHLEGER 1951A

12319 PHLEGER 1951A

12320 PHLEGER 1951A

12321 PHLEGER 1951A

12322 PHLEGER 1951A

12323 PARKER 1954

12324 PARKER 1954

12325 PHLEGER 1951A

12326
12327
1

12328 PHLEGER 1951A

12329 PARKER 1954

12330 PARKER 1954

12331 KELLOUGH 1956

12332 KELLOUGH 1956

12333 KELLOUGH 1956

12334 KELLOUGH 1956

12335 CREAGER 1958

12336 CUSHMAN 19228

12337 CREAGER 1958

12338 LUDWICK WALTON 1957

12339 PHLEGER 1955 A

12340 PHLEGER 1955 A

12341 PARKER 1954

12342 PARKER 1954

12343 PARKER 1954

12344 PARKER 1954

12345 PARKER 1954

12346 PARKER 1954

12347 PARKER 1954

12348 PARKER 1954

12349 PARKER 1954

12350 PARKER 1954

12351 PARKER 1954

12352 PHLEGER 1956

12354 PHLEGER 1951 A

12355 PHLEGER 1951 A

12356 PARKER 1954

12357 PARKER 1954

12358 PARKER 1954

12359 PARKER 1954

12360 PHLEGER 1951A

12361 PHLEGER 1951A

12362 PHLEGER $1951 \mathrm{~A}$

12363 PHLEGER 1951A

12364 PHLEGER $1951 \mathrm{~A}$

12365 PHLEGER 1951A
Generic Name

BOLIVINA

BOLIVINA

BOLIVINA

BOLIVINA

BOLIVINA

BOLIVINA

BOLIVINA

BOLIVINA

BOLIVINA

BOLIVINA

BOLIVINA

BOLIVINA

BOLIVINA

BOLIVINA

BOLIVINA

BOLIVINA

BOLIVINA

BOLIVINA

BOLIVINA

BOLIVINA

BOLIVINA

BOLIVINA

BOLIVINA

BOLIVINA

BOLIVINA

BOLIVINA

BOLIVINA

BOLIVINA

BOLIVINA

BOLIVINA

BOLIVINA

BOLIVINA

BOLIVINA

BOLIVINA

BOLIVINA

BOLIVINA

BOLIVINA

BOLIVINA

BOLIVINA

BOLIVINA

BOLIVINA

BOLIVINA

BOLIVINA

BOLIVINA

BOLIVINA

BOLIVINA

BOLIVINA

BOLIVINA

BOLIVINA

BOLIVINA

BOLIVINA

BOLIVINA

BOLIVINA

BOLIVINA

BOLIVINA

BOLIVINA

BOLIVINA

BOLIVINA

BOLIVINA

BOLIVINA

BOLIVINA

BOLIVINA

BOLIVINA

BOLIVINA

BOLIVINA

BOLIVINA

BOLIVINA

BOLIVINA

BOLIVINA

BOLIVINA

BOLIVINA

BOLIVINA

BOLIVINA

BOLIVINA

BOLIVINA

BOLIVINA

BOLIVINA

BOLIVINA

BOLIVINA

BOLIVINA

BOLIVINA

BOLIVINA

BOLIVINA

BOLIVINA

BOLIVINA

BOLIVINA

BOLIVINA

BOLIVINA

BOLIVINA

BOLIVINA

BOLIVINA
Specific Name

SUBAENARIENSIS MEXICANA

SUEAENARI ENSIS MEXI CANA

SUBAENARIENSIS MEXICANA

SUBAENARIENSIS MEXI CANA

SUBAENARIENSIS MEXI CANA

SUBAENARIENSIS MEXI CANA

SUEAENARIENSIS MEXICANA

SUEEX CAVATA

SUBSPINES CENS

SUBSPINES CENS

SUBSPINES CENS

SUBSPINES CENS

SUESPINES CENS

SUESPINES CENS

SUBSPINES CENS

SUBSPINES CENS

SUBSPINES CENS

SUESPINES CENS

SURSPINES CENS

SUBSPINES CENS

SUBSPINES CENS

SUBSPINES CENS

SUBSPINES CENS

SUESPINES CENS

SUESPINES CENS

SUBSPINES CENS

SUBSPINES CENS

SUBSPINES CENS

SUBSPINES CENS

SUESPINES CENS

SUESPINES CENS

SUBSPINES CENS

SUBSPINES CENS

SUBSPINES CENS

SUBSPINES CENS

SUESPINES CENS

SUBSPINES CENS

SUBSPINES CENS

SUBSPINES CENS

SUBSPINES CENS

SUBSPINES CENS

SUBSPINES CENS

SU BSPINES CENS

SUBSPINES CENS

SUBSP INES CENS

SUESPINES CENS

SUBSPINES CENS

SUBSPINES CENS

SUBSPINES CENS

SUBSP INES CENS

SUESPINES CENS

SUBSPINES CENS

SU BSPINES CENS

SUESPINES CENS

SUBSP INES CENS

SU BSPINES CENS

SUESPINES CENS

SUBSPINES CENS

SUBSPINES CENS

SUBSPINES CENS

SUBSP INES CENS

SUESPINES CENS

SUESPINES CENS

SUBSPINES CENS

SUBSPINES CENS

SUESPINES CENS

SUBSPINES CENS

SUBSPINES CENS

SUBSPINES CENS

SUBSPINES CENS

SUBSPINES CENS

SUBSP INES CENS

SUBSPINES CENS

SUBSP INES CENS

SUBSPINES CENS

SUBSP INES CENS

SUBSPINES CENS

SUESPINES CENS

SUBSPINES CENS

SUBSPINES CENS

SU BSP INES CENS

SU BSPINES CENS

SUESPINES CENS

SUBSPINES CENS

SUBSPINES CENS

SUBSP INES CENS

SUBSPINES CENS

SUBSPINES CENS

SUESPINES CENS

TRANSLUCENS

TRANSLU CENS

TRANSLU CENS

TR ANSLUCE NS

TRANSLUCENS

TRANSLUCENS

Locality

Lat. Long.

NH GULF OF MEXICO

BAY OF CAMPECHE

BAY OF CAMPECHE

BAY OF CAMPECHE

BAY OF CAMPECHE

BAY OF CAMPECHE

BAY OF CAMPECHE 


\section{Publication}

12366 PHLEGER $1951 \mathrm{~A}$

12367 PHLEGER $1951 \mathrm{~A}$

12369 PFLUM FRERICHS 1976

12369 PFLUM FRERICHS 1976

2371 PFLUM FRERICHS 1976

12372 PFLUM FRERICHS 1976

12373 PARKER 1954

12374 PARKER 1954

12375 PARKER 1954

12376 PARKER 1954

12377 PARKER 1954

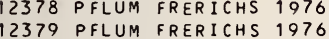

12379 PFLUM FRERICHS 1976
12380 PFLUM FRERICHS 1976

2381 PFLUM FRERICHS 1976

12382 PFLUM FRERICHS 1976

12383 PFLUM FRERICHS 1976

12384 PFLUM FRERICHS 1976

12385 PFLUM FRERICHS 1976

12386 PFLUM FRERICHS 1976

12387 PFLUM FRERICHS 1976

12388 PFLUM FRERICHS 1976

12389 PFLUM FRERICHS 1976

12390 PFLUM FRERICHS 1976

12391 PFLUM FRERICHS 1976

12392 PARKER 1954

12393 PARKER 1954

12394 PFLUM FRERICHS 1976

12395 PFLUM FRERICHS 1976

12396 PHLEGER 1951 A

12397 PHLEGER 1951A

12398 PHLEGER $1951 \mathrm{~A}$

12399 PFLUM FRERICHS 1976

12400 PARKER 1954

12401 PARKER 1954

12402 LUDWICK WALTON 1957

12403 PARKER 1954

12404 PARKER 1954

12405 CREAGER 1958

12406 PFLUM FRERICHS 1976

12407 PFLUM FRERICHS 1976

12408 PFLUM FRERICHS 1976

12409 PFLUM FRERICHS 1976

12410 PFLUM FRERICHS 1976

12411 PFLUM FRERICHS 1976

12412 PHLEGER 1951A

12413 PFLUM FRERICHS 1976

12414 PFLUM FRERICHS 1976

12415 PHLEGER 1951A

12416 PARKER 1954

12417 PHLEGER 1951A

12418 PHLEGER 1951A

12419 PARKER 1954

12420 PARKER 1954

12421 PHLEGER 19658

12422 PHLEGER 19658

12423 PFLUM FRERICHS 1976

12424 BOCK 1976

12425 CUSHMAN 1930

12426 DAVIS 1964

12427 NORTON 1930

12428 BOCK 1976

12429 BOCK 1976

12430 BOCK 1976

12431 BOCK 1976

12432 BOCK 1976

12433 POAG 1976

12434 BOCK 1976

12435 BOCK 1976

12436 BOCK 1976

12437 BOCK 1976

12438 BOCK 1976

12439 POAG 1976

12440 POAG 1972

12441 POAG 1976

12442 BOCK 1976

12443 BOCK 1976

12445 PHLEGER 1956

12446 PARKER 1954

12447 WALTON 1960

12448 ANDERSEN 1961

12449 PHLEGER 1965 A

12450 BANDY 1956

12451 BANDY 1956

12452 BANDY 1956

12453 WARREN 1956

12454 PHLEGER 1956

12455 PHLEGER 1956

12456 PHLEGER 1956

12457 PARKER 1954

12458 LUDWICK WALTON 1957

12459 LANKFORD 1959

12460 PHLEGER $1955 \mathrm{~B}$

\section{Generic Name \\ Specific Name}

BOLIVINA

BOLIVINA

BOLIVINA

BOLIVINA

BOLIVINA

BOLIVINA

BOLIVINA

BOLIVINA

BOLIVINA

BOLIVINA

BOLIVINA

BOLIVINA

BOLIVINA

BOLIVINA

BOLIVINA

BOLIVINA

BOLIVINA

BOLIVINA

BOLIVINA

BOLIVINA

BOLIVINA

BOLIVINA

BOLIVINA

BOLIVINA

BOLIVINA

BOLIVINA

BOLIVINA

BOLIVINA

BOLIVINA

BOLIVINA

BOLIVINA

BOLIVINA

BOLIVINA

BOLIVINA

BOLIVINA

BOLIVINA

BOLIVINA

BOLIVINA

BOLIVINA

BOLIVINA

BOLIVINA

BOLIVINA

BOLIVINA

BOLIVINA

BOLIVINA

BOLIVINA

BOLIVINA

BOLIVINA

BOLIVINA

BOLIVINA

BOLIVINA

BOLIVINA

BOLIVINA

BOLIVINA

BOLIVINA

BOLIVINITA

BOLIVINITA

BORELIS

BORELIS

BORELIS

BR I Z ALINA

BR I Z AL INA

BR IZAL INA

BRIZAL INA

BR I Z ALINA

BR I Z AL INA

BR I Z ALINA

BR I ZAL INA

BR IZAL INA

BR IZAL INA

BR I ZAL INA

BR I Z AL INA

BRIZALINA

BR I Z AL IN

BRIZAL INA

BR IZAL INA

BUCCELLA

BUCCELLA

BUCCELLA

BUCCELLA

BUCCELLA

BUCCELLA

BUCCELLA

BUCCELLA

BUCCELLA

BUCCELLA

BUCCELLA

BUCCELLA

BUCCELLA

BUCCELLA

BUCCELLA

BUCCELLA

BUCCELLA
TRANSLUCENS

TR ANSLUCENS

TRANSLUCENS

TRANSLUCENS

TRANSLUCENS

TRANSLUCENS

TRANSLUCENS

TRANSLUCENS

TRANSLUCENS

TRANSLUCENS

TR ANSLUCENS

TRANSLUCENS

TRANSLUCENS

TRANSLUCENS

TRANSLUCENS

TRANSLUCENS

TRANSLUCENS

TRANSLUCENS

TRANSLUCENS

TRANSLUCENS

TRANSLUCENS

TRANSLUCENS

TRANSLUCENS

TRANSLUCENS

TRANSLUCENS

TRANSLUCENS

TRANSLUCENS

TRANSLUCENS

TRANSLUCENS

TRANSLUCENS

TRANSLUCENS

TRANSLUCENS

TRANSLUCENS

TRANSLUCENS

TRANSLU CENS

TR ANSLUCENS

TRANSLUCENS

TRANSLUCENS

TRANSLUCENS

TRANSLUCENS

TRANSLUCENS

TR ANSLUCENS

TR ANSLU CENS

TR AN SLUCENS

TR ANSLUCENS

TRANSLUCENS

TRANSLUCENS

TRANSLUCENS

TR ANSLUCE NS

TR ANSLUCENS

TRANSLUCENS

TRANSLUCENS

TRANSLUCENS

TRANSLUCENS

TRANSLUCENS

VARIABILIS

VARIABILIS

QUADRILATERATA

RHCMBOIDALIS

PULCHRA

PULCHRA

PULCHRA

BARBATA

FRAGILIS

GOESII

HASTATA

LANCEOLATA

LOWMAN I

LOWMAN I

LOWMANI

LOWMAN I

MINIMA

PAULA

PULCHELLA PRIMITIVA

SP INATA

STRIATULA

STRIATULA

SUBSPINES CENS

HANNAI

HANNAI

HANNAI

HANNAI

HANNAI

HANNAI

HANNAI

HANNAI

HANNAI

HANNAI

HANNAI

HANNAI

HANNAI

HANNAI

HANNAI

HANNAI

Locality

Lat. Long.

NW GULF OF MEXICO

$\mathrm{NW}$ GULF OF MEXICO

NW GULF OF MEXICO

NW GULF OF MEXICO 


\section{Publication}

12461 PARKER 1954

12462 PARKER 1954

12463 PARKER 1954

12464 PARKER 1954

12465 PARKER 1954

12466 PARKER 1954

12467 PARKER 1954

12468 PARKER 1954

12469 BANDY 1956

12470 BANDY 1956

12471 BANDY 1956

12472 BANDY 1956

12473 BANDY 1956
12474 WARREN 1957

12475 BANDY 1956

12476 SEGURA 1963

12477 BANDY 1956

12478 BANDY 1956

12479 BANDY 1956

12480 KANE 1967

12481 KANE 1962
12482 PARKER 1954

12483 PFLUM FRERICHS 197

12484 PFLUM FRERICHS 1976

12485 PFLUM FRERICHS 1976

12486 PFLUM FREPICHS 1976

12487 PHLEGER 1951A

12488 PFLUM FRERICHS 1976

12489 LEROY HODGKINSON 1975

12491 PHLEGER 1951 A

12492 PFLUM FRERICHS 1976

12493 PFLUM FRERICHS 1976

12494 PFLIJM FRERICHS 1976

12495 PFLUM FRERICHS 1976

12496 PARKER 1954

12497 PARKER 1954

12498 PARKER 1954

12499 PARKER 1954

12500 PFLUM FRERICHS 1976

12501 PARKER 1954

12502 PARKER 1954

12503 PFLUM FRERICHS 1976

12504 PFLUM FRERICHS 1976

12505 PFLIJM FRERICHS 1976

12506 PFLUM FRERICHS 1976

12507 PFLUM FRERICHS 1976

12508 PARKER 1954

12509 PARKER 1954

12510 PARKER 1754

12511 PARKER 1354

12512 PARKER 1954

12513 PARKER 1954

12514 PARKER 1354

12515 PFLUM FRERICHS 1976

12516 PFLUM FRERICHS 1976

12517 PFLUM FRERICHS 1976

12518 PFLUM FRERICHS 1976

12519 PFLUM FRERICHS 1976

12520 PFLUP FRFRICHS 1976

12521 PFLUM FRFRICHS 1976

12522 PFLUM FRERICHS 1976

12523 PFLUM FRERICHS 1976

12524 PFLUM FRERICHS 1976

12525 PFLUM FRERICHS 1976

12526 PFLUM FRERICHS 1976

12527 PFLUM FRERICHS 1976

12528 PFLUM FRERICHS 1976

12529 PFLUM FRERICHS 1976

12530 PFLUM FRERICHS 1976

12531 PFLUM FREKICHS 1976

12532 PFLUM FRERICHS 1976

12533 PFLUM FRERICHS 1976

12534 PFLUM FRERICHS 1976

12535 PFLUM FRERICHS 1976

12536 PFLUM FRERICHS 1976

12537 PFLUM FRERICHS 1976

12538 PFLUM FRERICHS 1976

12539 PFLUM FRERICHS 1976

12540 PARKER 1954

12541 PHLEGER 1955 A

12542 PARKER 1954

12543 PHLEGER 1955 A

12544 PARKER 1054

12545 PHLEGER 1955 A

12546 PHLEGER 1955 A

12547 PHLEGER 1955A

12548 PHLEGER $1951 \mathrm{~A}$

12549 PHLEGER $1951 \mathrm{~A}$

12550 LUDWICK WALTON 1957

12551 PHLEGER $1951 \mathrm{~A}$

12552 PHLEGER 1951A

12553 PHLEGER 1951A

12554 PHLEGER 1951 A

12555 PFLUM FRERICHS 1976

\section{Generic Name}

BUCCELLA

BUCCELLA

BUCCELLA

BUCCELLA

BUCCELLA

$B U C C E L L A$

BUCCELLA

BUCCELLA

BUCCELLA

BUCCELLA

BUCCELLA

BUCCELLA

BUCCELLA

BUCCELLA

BUCCELLA

BUCCELLA

BUCCELLA

BUCCELLA

BUCCELLA

BULIMINA

BULIMINA

BULIMINA

BULIMINA

BULIMINA

BULIMINA

BULIMINA

BUL IMINA

BULIMINA

BULIMINA

BULIMINA

BULIMINA

BULIMINA

BULIMINA

BULIMINA

BULIMINA

BULIMINA

BULIMINA

BULIMINA

BULIMINA

BULIMINA

BULIMINA

BULIMINA

BULIMINA

BULIMINA

BULIMINA

BULIMINA

BULIMINA

BULIMINA

BULIMINA

BULIMINA

BULIMINA

BULIMINA

BULIMINA

BULIMINA

BULIMINA

BULIMINA

BULIMINA

BULIMINA

BULIMINA

BULIMINA

BULIMINA

BULIMINA

BULIMINA

BULIMINA

BULIMINA

BULIMINA

BULIMINA

BULIMINA

BULIMINA

BULIMINA

BULIMINA

BULIMINA

BULIMINA

BULIMINA

BULIMINA

BULIMINA

BULIMINA

BULIMINA

BULIMINA

BULIMINA

BULIMINA

BULIMINA

BULIMINA

BULIMINA

BULIMINA
Specific Name

Locality

Lat. Long.

HANNAI

HANNAI

HANNAI

HANNAI

HANNAI

HANNAI

HANNAI

HANNAI

HANNAI

HANNAI

HANNAI

HANNAI

HANNAI

HANNAI

HANNAI

HANNAI

HANNAI

HANNAI

HANNAI

AC ULEATA

AC ULEATA

AC ULEATA

AC ULEATA

AC LLEATA

ACLLEATA

AC LLEATA

AC ULEATA

AC ULEATA

AC ULEATA

AC ULEATA

ACLLEATA

ACLLEATA

AC ULEATA

AC ULEATA

ACLLEATA

ACLLEATA

AC LLEATA

AC ULEATA

AC ULEATA

ACLLEATA

ACLLEATA

AC ULEATA

AC ULEATA

AC ULEATA

AC ULEATA

ACLLEATA

ACLLEATA

AC ULEATA

ACLLEATA

ACLLEATA

ACLLEATA

ACLLEATA
AC ULEATA

ACLLEATA

AC ULEATA

AC LLEATA

ACLLEATA

AC ULEATA

AC LLEATA

AC LLEATA

AC ULEATA

ACLLEATA

ACLLEATA

A C LLEATA

AC ULEATA

AC ULEATA

A C LLEATA

ACLLEATA

AC ULEATA

ACLLEATA

AC LLEATA

AC LLEATA

ACLLEATA

ACULEATA

ACLLEATA

AC ULEATA

AC ULEATA

AC ULEATA

ACLLEATA

AC ULEATA
AC ULEATA

AC ULEATA

AC ULEATA

AC LLEATA

ACLLEATA

ACLLEATA

AC LLEATA

ACULEATA

AC ULEATA

NE GULF OF MEXICO

NE GULF OF MEXICO

NE GULF OF MEXICO

NE GULF OF MEXICO

NE GULF OF MEXICO

NE GULF OF MEXICO

NE GULF OF MEXICO

NE GULF OF MEXICO

NE GULF OF MEXICO

NE GULF OF MEXICO

NE GULF OF MEXICO

NE GULF OF MEXICO

NE GULF OF MEXICO

SE LOU IS IANA

NE GULF OF MEXICO

MATAMOROS, MEXICO

NE GULF OF MEXICO

NE GULF OF MEXICO

NE GULF OF MEXICO 


\section{Publication}

12556 PFLUM FRERICHS 1976 12557 PFLUM FRERICHS 1976 12558 PFLUM FRERICHS 1976 12559 PFLUM FRERICHS 1976 12560 PHLEGEP 1951A 12561 PHLEGER 1951A 12562 PHLEGER 1951 A 12563 PHLEGER 1951A 12564 PHLEGER $1951 \mathrm{~A}$

12565 PARKER 1954

12566 PARKER 1954

12567 PARKER 1954

12568 PHLEGER 1955 A

12569 PHLEGER 1955 A
12570 PHLEGER 1951 A

12571 CREAGER 1958

12572 PARKER 1954

12573 PHLEGER 1951A

12574 PHLEGER 1951 A

12575 PHLEGER 1951 A

12576 PHLEGER $1951 \mathrm{~A}$

12577 PHLEGER 1951A

12579 PARKER 1954

12580 PHLEGER 1951 A

12581 CREAGER 1958

$\begin{array}{lll}12582 & \text { CREAGER } & 1958 \\ 12583 & \text { CREAGER } & 1958\end{array}$

12584 CREAGER 1958

12585 CREAGER 1958

12586 CREAGER 1958

12587 CREAGER 1958

12588 PARKER 1954

12589
12590 PHLEGER 1951 A
1259 PHER $1951 \mathrm{~A}$

12591 PHLEGER 1951A

12592 PHLEGER $1951 \mathrm{~A}$

12593 PHLEGER $1951 \mathrm{~A}$

12594 LOEP 1965

12595 LOEP 1965

12596 LOEP 1965

12597 PFLUM FRERICHS 1976

12598 PFLUM FRERICHS 1976

12599 PFLUM FRERICHS 1976

12600 PFLUM FRERICHS 1976

12601 PFLUM FRERICHS 1976

12602 PFLUM FRERICHS 1976
12603 PFLUM FRERICHS 1976

12603 PFLUM FRERICHS 1976
12604 PFLUM FRERICHS 1976

12605 PFLUM FRERICHS 1976

12606 PFLUM FRERICHS 1976

12607 PFLUM FRERICHS 1976

12608 PFLUM FRERICHS 1976

12609 PFLUM FRERICHS 1976

12610 PFLUM FRERICHS 1976

12611 PFLUM FRERICHS 1976

12612 PFLUM FRERICHS 1976

12613 PFLUM FRERICHS 1976

12614 PFLUM FRERICHS 1976

12615 PFLUM FRERICHS 1976

12616 PFLUM FRERICHS 1976

12617 PFLUM FRERICHS 1976

12618 CUSHMAN 19228

12619 CUSHMAN 19228

12620 CUSHMAN 19228

12621 CUSHMAN 19228

12622 CUSHMAN 19228

12623 CUSHMAN 19228

12624 CUSHMAN 19228

12625 CUSHMAN 19228

12626 CUSHMAN 19228

12627 CUSHMAN 19228

12628 CREAGER 1958

12629 CREAGER 1958

12630 CREAGER 1958

12631 CUSHMAN 19228

12632 CUSHMAN 19228

12633 CUSHMAN 19228

12634 ANDERSEN 1961

12635 LOEP 1965

12636 LOEP 1965

12637 CUSHMAN 19228

12638 CREAGER 1958

12639 LOEP 1965

12640 LOEP 1965

12641 PARKER 1954

12643 PHLEGER $1951 \mathrm{~A}$

12644 PHLEGER 1955A

12645 PARKER 1954

12646 PARKER 1954

12647 PARKER 1954

12648 PARKER 1954

12649 PARKER 1954

12650 PARKER 1954
Generic Name

BU LIMINA

BULIMINA

BULIMINA

BULIMINA

BULIMINA

BULIMINA

BULIMINA

BULIMINA

BULIMINA

BULIMINA

BULIMINA

BULIMINA

BULIMINA

BULIMINA

BULIMINA

BULIMINA

BULIMINA

BULIMINA

BULIMINA

BULIMINA

BU LIMINA

BULIMINA

BULIMINA

BULIMINA

BULIMINA

BULIMINA

BULIMINA

BULIMINA

BULIMINA

BULIMINA

BULIMINA

BULIMINA

BULIMINA

BULIMINA

BULIMINA

BULIMINA

BUL IMINA

BULIMINA

BULIMINA

BULIMINA

BULIMINA

BULIMINA

BULIMINA

BULIMINA

BULIMINA

BULIMINA

BULIMINA

BULIMINA

BULIMINA

BULIMINA

BULIMINA

BULIMINA

BULIMINA

BULIMINA

BULIMINA

BULIMINA

BULIMINA

BULIMINA

BULIMINA

BULIMINA

BULIMINA

BULIMINA

BULIMINA

BULIMINA

BULIMINA

BULIMINA

BULIMINA

BULIMINA

BULIMINA

BULIMINA

BULIMINA

BULIMINA

BULIMINA

BULIMINA

BULIMINA

BULIMINA

BULIMINA

BULIMINA

BULIMINA

BULIMINA

BU LIMINA

BULIMINA

BULIMINA

BULIMINA

BULIMINA

BULIMINA

BULIMINA

BULIMINA

BULIMINA

BULIMINA

BULIMINA

BULIMINA

BULIMINA

BULIMINA

BULIMINA
Specific Name

Locality

Lat. Long.

ACLLFATA

ACULEATA

AC ULEATA

AC LLEATA

AC ULEATA

AC ULEATA

ACLLEATA

AC ULEATA

ACLLEATA

ACULEATA

ACULEATA

AC ULEATA

AC ULEATA

ACLLEATA

ACULEATA

AC ULEATA

AC LLEATA
AC ULEATA

ACLLEATA

AC ULEATA

ACLLEATA

ACULEATA

ACLLEATA

ACLLEATA

AC ULEATA

AC ULEATA

ACLLEATA

AC ULEATA

AC LLEATA

AC ULEATA

AC ULEATA

ACLLEATA

ACULEATA

ACLLEATA

AC LLEATA

AC ULEATA

AC LLEATA

ACULEATA

AC ULEATA

AC ULEATA

ACULEATA

AC ULEATA

ACLLEATA

ACLLEATA

AC ULEATA

AC LLEATA

AC LLEATA

AC ULEATA

ACLLEATA
ACLLEATA

AC ULEATA

AC ULEATA

AC ULEATA

AC ULEATA

ACLLEATA

AC ULEATA

A CLLEATA

ACLLEATA

AC LLEATA

ACLLEATA

AC LLEATA

A CLLEATA

AC LLEATA

AC LLEATA

ACLLEATA

AC LLEATA

AC LLEATA

AC ULEATA

ACLLEATA

AFFINIS

AFFINIS

AFFINIS

AFFINIS

AFFINIS

AF FINIS

AFFINIS

AL AZANENS IS

ALAZANE NS IS

AL AZANENS IS

ALAZANENS IS

AL AZANENS IS

AL AZANENS IS

AL AZANENS IS

AL AZANENS IS

AL AZANENS IS

AL AZ ANENS IS

AL AZANENS IS

ALAZANENS IS

ALAZANENS IS

CENTRAL GULF OF MEXICO

CENTRAL GULF OF MEXICO

CENTRAL GULF OF MEXICO

CEITTAL GULF OF MEXICO

NW GULF OF MEXICO

NW GULF OF MEXICO

NW GULF OF MEXICO

NW GULF OF MEXICO

NW GULF OF MEXICO

NE GULF OF MEXICO

NE GULF OF MEXICO

NE GULF OF MEXICO

$N$ GULF OF MEXICO 


\section{Publication}

12651 PARKER 1954

12652 CREAGER 1958 12653 CREAGER 1958

12654 CREAGER 1958

12655 CREAGER 1958

12656 PHLEGER 1955 A

12657 PARKER 1954
12658 PHLEGER 1955 A

12659 PARKER 1954

12660 PHLEGER $1951 \mathrm{~A}$

12661 PHLEGER 1951A

12662 PHLEGER 1951

12663 PARKER 1954

12665 PARKER 1954

12666 PARKER 1954

12667 PARKER 1954

12668 PARKER 1954

12669 PARKER 1954

12670 PARKER 1954

12671 PARKER 1954

12672 CREAGER 1958

12673 CREAGER 1958

12674 CREAGER 1958

12675 CREAGER 1958

12676 PHLEGER 1951A

12677 PHLEGER 1951A

12678 CREAGER 1958

12679 PHLEGER 1951A

12680 PHLEGER 1951A

12681 PHLEGER 1951A

12682 PHLEGER 1951A

12683 PHLEGER 1951 A

12684 PHLEGER 1951A

12685 PHLEGER 1951A

12686 PHLEGER $1951 \mathrm{~A}$

12687 PHLEGER 1951A

12688 PHLEGER 1951A

12689 PHLEGER 1951A

12690 PHLEGER 1951 A

12691 PHLEGER 1951A

12692 PHLEGER $1951 \mathrm{~A}$

12693 PHLEGER $1951 \mathrm{~A}$
12694 PHLEGER $1951 \mathrm{~A}$

12695 LEROY HODGKINSON 1975

12696 PHLEGER 1951A

12697 PHLEGER 1951A

12698 PFLUM FRERICHS 1976

12699 PFLUM FRERICHS 1976

12700 PHLEGER 1951 A

12701 CUSHMAN $1922 \mathrm{~B}$

12702 CUSHMAN $1922 \mathrm{~B}$

12703 CUSHMAN 19228

12704 CUSHMAN $1922 \mathrm{~B}$

12705 CUSHMAN $1922 \mathrm{~B}$

12706 CUSHMAN $1922 \mathrm{~B}$

12707 CUSHMAN $1922 \mathrm{~B}$

12708 CUSHMAN $1922 \mathrm{~B}$

12709 CREAGER 1958

12710 PHLEGER $1951 \mathrm{~A}$

12711 PHLEGER 1951A

12712 BOCK 1976

12713 PHLEGER 1951A

12714 PHLEGER 1956

12715 PFLUM FRERICHS 1976

12716 PFLUM FRERICHS 1976

12717 PFLUM FRERICHS 1976

12718 PFLUM FRERICHS 1976

12719 LOEP 1965

12720 AYALA-CASTANARES 1963

12721 WARREN 1956

12722 PHLEGER 1965 B

12723 BENDA PURI 1962

12724 PHLEGER 1965 B

12725 KELLOUGH 1956

12726 KELLOUGH 1956

12727 BANDY 1956

12728 PHLEGER 1956

12729 PHLEGER 1956

12730 PHLEGER 1956

12731 CREAGER 1958

12732 CREAGER 1958

12733 PFLUM FRERICHS 1976

12734 PFLUM FRERICHS 1976

12735 PFLUM FRERICHS 1976

12736 ANDERSEN 1961

12737 PFLUM FRERICHS 1976

12738 PFLUM FRERICHS 1976

12739 CUSHYAN $1922 \mathrm{~B}$

12740 CUSHMAN 19228

12741 VAUGHAN 1918

12742 PHLEGER 1951A

12743 PHLEGER 1951A

12744 PHLEGER 1951A

12745 PHLEGER 1951 A
Generic Name

Specific Name

BUL IMINA

BULIMINA

BULIMINA

BULIMINA

BULIMINA

BULIMINA

BULIMINA

BULIMINA

BULIMINA

BULIMINA

BULIMINA

BULIMINA

BULIMINA

BULIMINA

BULIMINA

BULIMINA

BULIMINA

BULIMINA

BULIMINA

BUL IMINA

BULIMINA

BULIMINA

BULIMINA

BULIMINA

BULIMINA

BULIMINA

BULIMINA

BULIMINA

BULIMINA

BULIMINA

BULIMINA

BULIMINA

BULIMINA

BULIMINA

BULIMINA

BULIMINA

BULIMINA

BULIMINA

BULIMINA

BULIMINA

BULIMINA

BULIMINA

BULIMINA

BULIMINA

BULIMINA

BULIMINA

BULIMINA

BULIMINA

BULIMINA

BULIMINA

BULIMINA

BULIMINA

BULIMINA

BULIMINA

BULIMINA

BULIMINA

BULIMINA

BULIMINA

BULIMINA

BULIMINA

BULIMINA

BULIMINA

BULIMINA

BULIMINA

BULIMINA

BULIMINA

BU LIMINA

BULIMINA

BULIMINA

BULIMINA

BU LIMINA

BULIMINA

BULIMINA

BULIMINA

BULIMINA

BULIMINA

BULIMINA

BULIMINA

BULIMINA

BULIMINA

BULIMINA

BULIMINA

BULIMINA

BULIMINA

BULIMINA

BULIMINA

BULIMINA

BULIMINA

BULIMINA

BULIMINA

BULIMINA

BUL IMINA

BU LIMINA
AL AZ ANENS IS

AL AZANE NS IS

ALAZANENS IS

AL AZANENS IS

AL AZANENS IS

AL AZ ANENS IS

AL AZANENS IS

AL AZ ANENS IS

ALAZANENS IS

AL AZ ANENS IS

AL AZANENS IS

AL AZANENS IS

AL AZANENS IS

AL AZANENS IS

AL AZANENS IS

ALAZANE NS IS

AL AZANENS IS

AL AZ ANE NS IS

AL AZANENS IS

ALAZANE NS IS

AL AZANE NS IS

AL AZ ANENS IS

AL AZANENS IS

AL AZANENS IS

AL AZ ANENS IS

AL AZANENS IS

AL AZANENSIS

AL AZANENS IS

AL AZANENS IS

AL AZANENS IS

AL AZANENS IS

ALAZANENS IS

AL AZ ANENS IS

AL AZANENS IS

AL AZANENS IS

AL AZANENS IS

AL AZANENS IS

AL AZANENS IS

AL AZANENS IS

AL AZANENS IS

AL AZANENS IS

AL AZANENS IS

ALAZANENS IS

AL AZANENS IS

AL AZANENS IS

BARBATA

BARBATA

BASSENDOR FENS IS

BU CHIANA

BUCHIANA

INFLATA MEXICANA

INFLATA MEXICANA

INFLATA MEXICANA

INFLATA MEXICANA

INFLATA MEXICANA

INFLATA MEXICANA

MARGINATA

MARGINATA

MARGINATA

MARG INATA

MARG INATA

MARGINATA

MARGINATA

MARGINATA

MARGINATA

MARG INATA

MA RG INATA

MARG INATA

MARGINATA

MARGINATA

MARGINATA

MARGINATA

MARGINATA

MARGINATA

MARGINATA

MARGINATA

MARG INATA

MARGINATA

MARG INATA

MARGINATA

MARGINATA

MARGINATA

MARGINATA

MARGINATA

MARGINATA

MARGINATA

MARG INATA

MARGINATA

MARGINATA

MARGINATA

Locality

Lat. Long.

NE GULF OF MEXICO

BAY OF CAMPECHE

BAY OF CAMPECHE

BAY OF CAMPECHE

BAY OF CAMPECHE

$N$ GULF OF MEXICO

NE GULF OF MEXICO

$N$ GULF OF MEXICO 


\section{Publication}

12746 PHLEGER 1951A

12747 PHLEGER 1951A

12748 PHLEGER $1951 \mathrm{~A}$

12749 PHLEGER $1951 \mathrm{~A}$

12750 PHLEGER 1951A

12751 PHLEGER 1951A

12752 PHLEGER 1951A

12753 PHLEGER 1951 A

12754 PHLEGER $1951 \mathrm{~A}$

12755 PHLEGER 1951A

12756 PHLEGER 1951A

12757 PFLUM FRERICHS 1976

12758 PFLUM FRERICHS 1976

12759 PFLUM FRERICHS 1976

12760 PFLUM FRERICHS 1976

12761 PFLUM FRERICHS 1976

12762 PFLUM FRERICHS 1976

12763 PFLUM FRERICHS 1976

12764 PFLUM FRERICHS 1976

12765 PFLUM FRERICHS 1976

12766 PFLUM FRERICHS 1976

12767 PFLUM FRERICHS 1976

12768 PHLEGER 1951A

12769 PHLEGER 1951A

12770 PHLEGER 1951A

12771 PHLEGER 1951A

12772 SEGURA 1963

12773 LANKFORD 1959

12774 PHLEGER 1951

12775 PARKER 1954

12776 PARKER 1954

12777 PARKER 1954

12778 PARKER 1954

12779 PARKER 1954

12780 PARKER 1954

12782 PARKER 1954

12783 PARKER 1954

12784 PARKER 195

12785 PARKER 1954

12786 PARKER 1954

12788 PHLEGER 1955A

12789 WARREN 1957

12790 LUDWICK WALTON 1957

12791 PHLEGER 1951A

12792 PHLEGER 1951A

12793 CUSHMAN 1922B

12794 CUSHMAN $1922 \mathrm{~B}$

12795 CUSHMAN $1922 \mathrm{~B}$

12796 CUSHMAN 19228

12797 CUSHMAN 19228

12798 CUSHMAN 19228

12799 CUSHMAN 19228

12800 CUSHMAN 19228

12801 CUSHMAN 19228

12802 CUSHMAN $1922 \mathrm{~B}$

12803 CUSHMAN 1922B

12804 PFLUM FRERICHS 1976

12805 PFLUM FRERICHS 1976

12806 PFLUM FRERICHS 1976

12807 PFLUM FRERICHS 1976

12808 PFLUM FRERICHS 1976

12809 PFLUM FRERICHS 1976

12810 PFLUM FRERICHS 1976

12811 PFLUM FRERICHS 1976

12812 PFLUM FRERICHS 1976

12813 PFLUM FRERICHS 1976

12814 PFLUM FRERICHS 1976

12815 PFLUM FRERICHS 1976

12816 PFLUM FRERICHS 1976

12817 PFLUM FRERICHS 1976

12818 PFLUM FRERICHS 1976

12819 PFLUM FRERICHS 1976

12820 PFLUM FRERICHS 1976

12821 PFLUM FRERICHS 1976

12822 PFLUM FRERICHS 1976

12823 PFLUM FRERICHS 1976

12824 PFLUM FRERICHS 1976

12825 PFLUM FRERICHS 1976

12826 PFLUM FRERICHS 1976

12827 PFLUM FRERICHS 1976

12828 PFLUM FRERICHS 1976

12829 PFLUM FRERICHS 1976

12830 PFLUM FRERICHS 1976

12831 PFLUM FRERICHS 1976

12832 PFLUM FRERICHS 1976

12833 PFLUM FRERICHS 1976

12834 PFLUM FRERICHS 1976

12835 PFLUM FRERICHS 1976

12836 PFLUM FRERICHS 1976

12837 PFLUM FRERICHS 1976

12838 PFLUM FRERICHS 1976

12839 PFLUM FRERICHS 1976

12840 PFLUM FRERICHS 1976
Generic Name

Specific Name

Locality

Lat. Long.

BULIMINA

BULIMINA

BULIMINA

BULIMINA

BULIMINA

BULIMINA

BULIMINA

BULIMINA

BULIMINA

BULIMINA

BULIMINA

BULIMINA

BULIMINA

BULIMINA

BULIMINA

BULIMINA

BUL. IMINA

BUL IMINA

BULIMINA

BULIMINA

BULIMINA

BULIMINA

BULIMINA

BULIMINA

BULIMINA

BULIMINA

BULIMINA

BULIMINA

BULIMINA

BULIMINA

BULIMINA

BULIMINA

BULIMINA

BULIMINA

BULIMINA

BULIMINA

BULIMINA

BUL IMINA

BULIMINA

BULIMINA

BULIMINA

BULIMINA

BULIMINA

BULIMINA

BULIMINA

BULIMINA

BULIMINA

BULIMINA

BULIMINA

BULIMINA

BULIMINA

BULIMINA

BULIMINA

BULIMINA

BULIMINA

BULIMINA

BULIMINA

BULIMINA

BULIMINA

BULIMINA

BULIMINA

BULIMINA

BULIMINA

BULIMINA

BULIMINA

BULIMINA

BULIMINA

BULIMINA

BULIMINA

BULIMIN A

BULIMINA

BULIMINA

BULIMINA

BULIMINA

BULIMINA

BULIMINA

BULIMINA

BULIMINA

BULIMINA

BULIMINA

BULIMINA

BULIMINA

BULIMINA

BULIMINA

BULIMINA

BULIMINA

BULIMINA

BULIMINA

BULIMINA

BULIMINA
MARGINATA

MARGINATA

MARGINATA

MARG INA TA

MARGINATA

MARGINATA

MARGINATA

MARGINATA

MA FGINATA

MARG INATA

MARG INATA

MARGINATA

MARG INATA

MARGINATA

MARGINATA

MARG INATA

MARGINATA

MA RG INATA

MARG INATA

MARGINATA

MARGINATA

MARGINATA

MARG INATA

MARG INATA

MA RG INATA

MARG I NATA

MARG INATA

MARGINATA

MARG INATA

MARGINATA

MARG INATA

MARG INATA

MARG INATA

MARGINATA

MARGINATA

MARGINATA

MARGINATA

MARG INATA

MARGINATA

MARGINATA

MARGINATA

MARGINATA

OVATA

OVATA

OVATA

OVATA

OVATA

OVATA

OVATA

OVATA

PUPOIDES

PYRULA SOINESCENS

PYRULA SPINESCENS

ROSTRATA ALAZANENSIS

ROSTRATA ALAZANENSIS

RO STRATA AL AZANENSIS

ROSTRATA ALAZANENSIS

ROSTRATA ALAZANENSIS

ROSTRATA ALAZANENSIS

ROSTRATA ALAZANENSIS

ROSTRATA ALAZANENSIS

ROSTRATA ALAZANENSIS

ROSTRATA ALAZANENSIS

ROSTRATA ALAZANENSIS

ROSTRATA ALAZANENSIS

ROSTRATA ALAZANENSIS

ROSTRATA ALAZANENSIS

ROSTRATA ALAZANENSIS

ROSTRATA ALAZANENSIS

ROSTRATA ALAZ ANENSIS

ROSTRATA ALAZANENSIS

ROSTRATA ALAZ ANENSIS

ROSTRATA ALAZ ANENSIS

RO STRATA ALAZANENSI

ROSTRATA ALAZANENSIS

ROSTRATA ALAZANENSIS

ROSTRATA ALAZANENSIS

RO STRATA ALAZANENSIS

ROSTRATA ALAZANENSIS

ROSIRATA ALAZANENSIS

ROSTRATA ALAZANENSI

ROSTRATA ALAZ ANENSIS

ROSTRATA ALAZANENSIS

ROSTRATA ALAZANENSIS

ROSTRATA ALAZANENSIS

ROSTRATA ALAZANENSIS

ROSTRATA ALAZANENSIS

ROSTRATA ALAZ ANENSIS

ROSIRATA ALAZANENSIS

ROSTRATA ALAZANENSIS
NW GULF OF MEXICO

NW GULF OF MEXICO

NW GULF OF MEXICO

NW GULF OF MEXICO

NW GULF OF MEXICO

NW GULF OF MEXICO

NW GULF OF MEXICO

NW GULF OF MEXICO 


\section{Publication}

12841 PFLUM FRERICHS 1976 12842 PFLUM FRERICHS 1976 12843 PFLUM FRERICHS 1976 12844 PFLUM FRERICHS 1976 12845 PFLUM FRERICHS 1976 12846 PFLUM FRERICHS 1976 12847 PFLUM FRERICHS 1976 12848 PFLUM FRERICHS 1976 12849 PFLUM FRERICHS 1976 12850 PFLUM FRERICHS 1976 12851 PFLUM FRERICHS 1976 12852 PFLUM FRERICHS 1976 12853 PFLUM FRERICHS 1976 12854 PFLUM FRERICHS 1976 12855 PFLUM FRERICHS 1976 12856 PFLUM FRERICHS 1976 12857 PFLIIM FRERICHS 1976 12858 PFLUM FRERICHS 1976 12859 PFLUM FRERICHS 1976 12860 PFLUM FRERICHS 1976 12861 PFLUM FRERICHS 1976 12862 PFLUM FRERICHS 1976 12863 PFLUM FRERICHS 1976 12864 PFLUM FRERICHS 1976 12865 PFLUM FRERICHS 1976 12866 PFLUM FRERICHS 1976 12867 PFLUM FRERICHS 1976 12868 PFLUM FRERICHS 1976 12869 PFLUM FRERICHS 1976 12870 PARKER 1954

12871 PARKER 1954

12872 PFLUM FRERICHS 1976 12873 PFLUM FRERICHS 1976 12874 PFLUM FRERICHS 1976 12875 PFLUM FRERICHS 1976 12876 PFLUM FRERICHS 1976 12877 PFLUM FRERICHS 1976 12878 PHLEGER $1951 \mathrm{~A}$

12879 PHLEGER 1951A 12881 PFLUM FRERICHS 1976

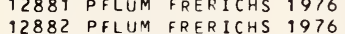
12883 PFLUM FRERICHS 1976 12884 PARKER 1954

12885 PARKER 1954

12886 PARKER 1954

12887 PARKER 1954

12888 PARKER 1954

12889 PARKFR 1954

12890 PARKER 1954

12891 PARKER 1954

12892 PFLUM FRERICHS 1976

12893 PFLIJM FRERICHS 1976

12894 PFLUM FRERICHS 1976 12895 PFLUM FRERICHS 1976 12896 PFLUM FRERICHS 1976 12897 PFLUM FRERICHS 1976 12898 PFLUM FRERICHS 1976 12899 PFLUM FRERICHS 1976 12900 PFLUM FRERICHS 1976 12901 PFLUM FRERICHS 1976 12902 PARKER 1954

12903 PFLUM FRERICHS 1976 12904 PFLUM FRERICHS 1976 12905 PFLUM FRERICHS 1976 12906 PFLUM FRERICHS 1976 12907 PFLUM FRERICHS 1976 12908 PFLUM FRERICHS 1976 12908 PFLUM FRERICHS 1976
12909 PFLUM FRERICHS 1976 12910 PARKER 1254

12911 PFLUM FRERICHS 1976 12912 PFLUM FRERICHS 1976 12913 PFLUM FRERICHS 1976 12914 PFLUM FRERICHS 1976 12915 PFLUM FRERICHS 1976 12916 PFLUM FRERICHS 1976 12917 PFLUM FRERICHS 1976 12918 PFLUM FRERICHS 1976 12919 PARKER 1954

12920 PHLEGER $1951 \mathrm{~A}$ 12921 PHLEGER 1951A 12922 PHLEGER 1951 A 12923 PHLEGER $1951 \mathrm{~A}$ 12924 PHLEGER 1959 A 12925 PHLEGER $1951 \mathrm{~A}$ 12926 PHLEGER 1951A 12927 PHLEGER $1951 \mathrm{~A}$ 12928 PHLEGER 1951 A 12930 PHLEGER 1951A 12931 PHLESER 1951A 12932 PHLEGER 1951 A 12933 PHLEGER 1951 A 12934 PHLEGER $1951 \mathrm{~A}$ 12935 PHLEGER 1051A
Generic Name

Specific Name

ROSTRATA ALAZANENSIS ROSIRATA ALAZANENSIS ROSTRATA ALAZANENSIS ROSTRATA ALAZANENSIS ROSTRATA AL AZANENSIS ROSTRATA ALAZANENSIS ROSTRATA ALAZANENSIS ROSTRATA ALAZANENSIS ROSTRATA ALAZANENSIS ROSTRATA ALAZANENSIS ROSTRATA ALAZANENSIS ROSTRATA ALAZANENSIS ROSTRATA ALAZANENSIS ROSTRATA ALAZANENSIS ROSTRATA ALAZANENSIS ROSTRATA ALAZANENSIS ROSTRATA ALAZANENSIS ROSTRATA ALAZANENSIS ROSTRATA ALAZANENSIS ROSTRATA ALAZANENSIS ROSTRATA ALAZANENSIS ROSTRATA ALAZANENSIS ROSTRATA ALAZANENSIS ROSTRATA ALAZANENSIS ROSTRATA ALAZANENSIS ROSTRATA ALAZANENSIS ROSTRATA ALAZANENSIS SPICATA

SPICATA

SP ICATA

SP ICATA

SP I CA TA

SPICATA

SPICATA

SPICATA

SP ICATA

SPICATA

SP ICATA

SPICATA

SPICATA

SP ICATA

SPICATA

SPICATA

SPICATA

SPICATA

SP ICATA

SPICATA

SPICATA

SP ICATA

SPICATA

SPICATA

SPICATA

SPICATA

SP ICATA

SP ICATA

SPICATA

SP ICATA

SPICATA

SP ICATA

SPICATA

SP ICATA

SPICATA

SP ICATA

SPICATA

SPICATA

SPICATA

SPICATA

SPICATA

SP ICATA

SPICATA

SPICATA

SPICATA

SP ICATA

SPICATA

SPICATA

SPICATA

SPICATA

SPICATA

SPICATA

SPICATA

SPICATA

SPICATA

SPICATA

SPICATA

SP ICATA

SPICATA

SPICATA

SP ICATA
Locality

Lat. Long.

NW GULF OF MEXICO NH GULF OF MEXICO NW GULF OF MEXICO NW GULF OF MEXICO NW GULF OF MEXICO NW GULF OF MEXICO NW GULF OF MEXICO NW GULF OF MEXICO NW GULF OF MEXICO NW GULF OF MEXICO $N W$ GULF OF MEXICO CENTRAL GULF OF MEXICO $N W$ GULF OF MEXICO NW GULF OF MEXICO NW GULF OF MEXICO NW GULF OF MEXICO NW GULF OF MEXICO NW GULF OF MEXICO $N W$ GULF OF MEXICO NW GULF OF MEXICO NW GULF OF MEXICO NW GULF OF MEXICO NW GULF OF MEXICO NW GULF OF MEXICO NW GULF OF MEXICO NW GULF OF MEXICO NW GULF OF MEXICO NW GULF OF MEXICO $N W$ GULF OF MEXICO NE GULF OF MEXICO NE GULF OF MEXICO NW GULF OF MEXICO $N W$ GULF OF MEXICO NW GULF OF MEXICO NW GULF OF MEXICO NW GULF OF MEXICO NW GULF OF MEXICO NW GULF OF MEXICO NW GULF OF MEXICO CENTRAL GULF OF MEXICO CENTRAL GULF OF MEXICO CENTRAL GULF OF MEXICO CENTRAL GULF OF MEXICO NE GULF OF MEXICO NE GULF OF MEXICO NE GULF OF MEXICO NE GULF OF MEXICO NE GULF OF MEXICO NE GULF OF MEXICO NE GULF OF MEXICO NE GULF OF MEXICO NW GULF OF MEXICO NW GULF OF MEXICO NW GULF OF MEXICO NW GULF OF MEXICO NW GULF OF MEXICO NW GULF OF MEXICO NW GULF OF MEXICO NW GULF OF MEXICO NW GULF OF MEXICO NW GULF OF MEXICO NE GULF OF MEXICO $N W$ GULF OF MEXICO $N W$ GULF OF MEXICO $N W$ GULF OF MEXICO NW GULF OF MEXICO NW GULF OF MEXICO NW GULF OF MEXICO NH GULF OF MEXICO NE GULF OF MEXICO $N W$ GULF OF MEXICO NW GULF OF MEXICO NW GULF OF MEXICO NW GULF OF MEXICO $N W$ GULF OF MEXICO NW GULF OF MEXICO $N W$ GULF OF MEXICO NW GULF OF MEXICO NE GULF OF MEXICO NW GULF OF MEXICO NW GULF OF MEXICO NW GULF OF MEXICO $N H$ GULF OF MEXICO NW GULF OF MEXICO NW GULF OF MEXICO $N W$ GULF OF MEXICO NW GULF OF MEXICO NW GULF OF MEXICO NW GULF OF MEXICO NW GULF OF MEXICO NW GULF OF MEXICO NW GULF OF MEXICO NW GULF OF MEXICO NW GULF OF MEXICO

$2749 \mathrm{~N} 09292 \mathrm{~W}$ $2730 \mathrm{~N} 09540 \mathrm{~W}$ $2725 \mathrm{~N} 09536 \mathrm{~W}$ $2717 N 09531 \mathrm{~N}$ $2721 \mathrm{~N} 09534 \mathrm{~W}$ $2728 \mathrm{~N} 09293 \mathrm{~W}$ $2719 \mathrm{~N} 09227 \mathrm{~W}$ $2734 \mathrm{~N} 092 \quad 14 \mathrm{~W}$ $2719 \mathrm{~N} 09227 \mathrm{~W}$ 


\section{Publication}

12936 PHLEGER 1951 A 12937 PHLEGER $1951 \mathrm{~A}$ 12938 PHLEGER $1951 \mathrm{~A}$ 12939 PHLEGER 1951A 12940 PHLEGER $1951 \mathrm{~A}$ 12941 PHLEGER $1951 \mathrm{~A}$ 12942 PHLEGER $1951 \mathrm{~A}$ 12943 PHLEGER 1951A 12944 LEROY HODGKINSON 1975 12945 PHLEGER 1951

12946 PFLUM FRERICHS 1976 12947 PFLUM FRERICHS 1976 12948 PFLUM FRERICHS 1976 12949 PFLUM FRERICHS 1976 12950 PFLUM FRERICHS 1976 12951 PFLUM FRERICHS 1976 12952 PFLUM FRERICHS 1976 12953 PFLUM FRERICHS 1976 12954 PFLUM FRERICHS 1976 12955 PARKER 1954

12956 PARKER 1954

12957 PARKER 1954

12958 PARKER 1954

12959 PFLUM FRERICHS 1976

12960 PFLUM FRERICHS 1976

12961 PFLUM FRERICHS 1976

12962 LUDWICK WALTON 1957

12963 PHLEGER 1955 A

12964 PHLEGER 1955A

12965 PHLEGER 1955

12966 PHLEGER 1955A

12967 PHLEGER 1955A

12968 PHLEGER $1955 \mathrm{~A}$

12969 PHLEGER 1955A

12970 PARKER 1954

12971 PARKER 1954
12972 PARKER 1954

12972 PARKER 1954

12973 PARKER 1954

12975 PHLEGER $1951 \mathrm{~A}$

12976 PHLEGER 1951 A

12977 CREAGER 1958

12978 CREAGER 1958

12979 CREAGER 1958

12980 CREAGER 1958

12981 CREAGER 1958

12982 BOCK 1976

12983 PHLEGER 1956

12984 PFLUM FRERICHS 1976

12985 PFLUM FRERICHS 1976

12986 PFLUM FRERICHS 1976

12987 PFLUM FRERICHS 1976

12988 PFLUM FRERICHS 1976

12989 PFLUM FRERICHS 1976

12990 PFLUM FRERICHS 1976

12991 PFLUM FRERICHS 1976

12992 PFLUM FRERICHS 1976

12993 PFLUM FRERICHS 1976

12994 PFLUM FRERICHS 1976

12995 PFLUM FRERICHS 1976

12996 PFLUM FRERICHS 1976

12997 LOEP 1965

12998 LOEP 1965

12999 CREAGER 1958

13000 CREAGER 1958

13001 CREAGER 1958

13002 PFLUM FRERICHS 1976

13003 PFLUM FRERICHS 1976

13004 PFLUM FRERICHS 1976

13005 PFLUM FRERICHS 1976

13006 PFLUM FRERICHS 1976

13007 PFLUM FRERICHS 1976

13008 PFLUM FRERICHS 1976

13009 PFLUM FRERICHS 1976

13010 PFLUM FRERICHS 1976

13011 PFLUM FRERICHS 1976

13012 PFLUM FRERICHS 1976

13013 PFLUM FRERICHS 1976

13014 PFLUM FRERICHS 1976

13015 PFLUM FRERICHS 1976

13016 PFLUM FRERICHS 1976

13017 PFLUM FRERICHS 1976

13018 PFLUM FRERICHS 1976

13019 PARKER 1954

13020 LOEP 1965

13021 PFLUM FRERICHS 1976

13022 PFLUM FRERICHS 1976

13023 PFLUM FRERICHS 1976

13024 PFLUM FRERICHS 1976

13025 PFLUM FRERICHS 1976

13026 PFLUM FRERICHS 1976

13027 PFLUM FRERICHS 1970

13028 PFLIJM FRERICHS 1976

13029 PFLUM FRERICHS 1976

13030 PFLUM FRERICHS 1976

\section{Generic Name}

BULIMINA

BULIMINA

BULIMINA

BULIMINA

BULIMINA

BULIMINA

BULIMINA

BULIMINA

BULIMINA

BULIMINA

BULIMINA

BULIMINA

BULIMINA

BULIMINA

BULIMINA

BULIMINA

BULIMINA

BULIMINA

BULIMINA

BULIMINA

BULIMINA

BULIMINA

BULIMINA

BULIMINA

BULIMINA

BULIMINA

BULIMINA

BULIMINA

BULIMINA

BULIMINA

BULIMINA

BULIMINA

BULIMINA

BULIMINA

BULIMINA

BULIMINA

BULIMINA

BULIMINA

BULIMINA

BULIMINA

BULIMINA

BULIMINA

BUL IMINA

BULIMINA

BULIMINA

BULIMINA

BULIMINA

BULIMINA

BULIMINA

BULIMINA

BULIMINA

BULIMINA

BULIMINA

BULIMINA

BULIMINA

BULIMINA

BULIMINA

BULIMINA

BULIMINA

BULIMINA

BUL I MINA

BULIMINA

BULIMINA

BULIMINA

BULIMINA

BULIMINA

BULIMINA

BULIMINA

BULIMINA

BULIMINA

BULIMINA

BULIMINA

BULIMINA

BULIMINA

BULIMINA

BULIMINA

BULIMINA

BULIMINA

BULIMINA

BULIMINA

BULIMINA

BULIMINA

BULIMINA

BULIMINA

BULIMINA

BULIMINA

BULIMINA

BULIMINA
BULIMINA

BULIMINA

BULIMINA

BULIMINA

BULIMINA
Specific Name

Locality

SPICATA

SPICATA

SPICATA

SPICATA

SPICATA

SPICATA

SPICATA

SPICATA

SPICATA

SPICATA

SPICATA

SPICATA

SPICATA

SPICATA

SPICATA

SPICATA

SPICATA

SPICATA

SPICATA

SPICATA

SPICATA

SPICATA

SP ICATA

SPICATA

SPICATA

SPICATA

SP ICATA

SPICATA

SPICATA

SPICATA

SPICATA

SPICATA

SPICATA

SPICATA

SPICATA

SPICATA

SPICATA

SPICATA

SPICATA

SPICATA

SPICATA

SPICATA

SPICATA

SPICATA

SPICATA

SPICATA

SPICATA

SPICATA

SPICATA

SPICATA

SPICATA

SPICATA

SPICATA

SPICATA

SPICATA

SPICATA

SPICATA

SPICATA

SPICATA

SPICATA

SPICATA

SPICATA

STRIATA MEXICANA

STRIATA MEXICANA

STRIATA MEXICANA

STRIATA YEXICANA

STRIATA MEXICANA

STRIATA YEXICANA

STRIATA YEX ICANA

STRIATA $Y E X I C A N A$

STRIATA YEXICANA

STRIATA MEXICANA

STRIATA MEXICANA

STRIATA MEXICANA

STRIATA YEXICANA

STRIATA MEXICANA

ST RIATA MEXICANA

STRIATA MEXICANA

STRIATA MEXICANA

STRIATA MEXICANA

STRIATA MEXICANA

STRIATA MEXICANA

STRIATA YEXICANA

STRIATA MEXICANA

STRIATA MEXICANA

STRIATA YEXICANA

STRIATA MEXICANA

STRIATA MEXICANA

STRIATA MEXICANA

STRIATA MEXICANA

NW GULF OF MEXICO

NW GULF OF MEXICO

NW GULF OF MEXICO

NW GULF OF MEXICO

NW GULF OF MEXICO

$N W$ GULF OF MEXICO

NW GULF OF MEXICO 


\section{Publication}

13031 PFLUM FRERICHS 1976 13032 PFLUM FRERICHS 1976 13033 PFLUM FRERICHS 1976 13034 PFLUM FRERICHS 1976 13035 PARKER 1954

13036 PARKER 1954

13037 PARKER 1954

13038 PARKER 1954
13039 PARKER 1954

13040 PARKER 1954

13041 PFLUM FRERICHS 1976

13042 LOEP 1965

13043 LOEP 1965

13044 CREAGER 1958

13045 CREAGER 1958
13046 CREAGER 1958

13047 CREAGEP 1958

13048 CREAGER 1958

13049 PHLEGER $1951 \mathrm{~A}$

13050 PHLEGER $1951 \mathrm{~A}$

13052 PHLEGER 1951A

13053 PHLEGER 1951A

13054 PHLEGER $1951 \mathrm{~A}$

13055 PHLEGER $1951 \mathrm{~A}$

13056 PHLEGER $1951 \mathrm{~A}$

13057 PHLEGER $1951 \mathrm{~A}$

13058 PHLEGER 1951A

13059 PHLEGER 1951A
13060 PHLEGER 1951A

13061 PHLEGER 1951A

13062 PHLEGER 1951A

13063 PHLEGER 1951A

13064 PHLEGER 1951A

13065 PHLEGER 1951A

13066 PHLEGER 1951A

13067 PHLEGER 1951A

13068 PHLEGER 1951A

13069 PHLEGER 1951 A

13070 PHLEGER $1951 \mathrm{~A}$

13071 PHLEGER 1951A

13072 PHLEGER 1951A

13073 PFLUM FRERICHS 1976

13074 PHLEGER 1951A

13075 PHLEGER $1951 \mathrm{~A}$

13076 PHLEGER 1951A
13077 PFLUM FRERICHS 1976

13078 PFLUM FRERICHS 1976

13079 PHLEGER 1951A

13080 PHLEGER 1951 A

13081 PARKER 1954

13082 PARKER 1954

13083 PARKER 1954

13084 PARKER 1954

13085 PARKER 1954

13086 PARKER 1954

13087 PARKER 1954

13088 PARKER 1954

13089 PARKER 1954

13090 PARKER 1954

13091 PARKER 1954

13092 CREAGER 1958

13093 PARKER 1954

13094 PARKER 1954
13095 PHLEGER 1955 A

13095 PHLEGER $1955 \mathrm{~A}$

13097 PHLEGER 1955 A

13098 PHLEGER 1955 A

13099 PHLEGER 1955A

13100 PHLEGER 1955 A

13101 PHLEGER 1955 A

13102 PHLEGER 1955A

13103 PHLEGER 1955A

13104 LUDWICK WALTON 1957

13105 PFLUM FRERICHS 1976

13106 PFLUM FRERICHS 1976

13107 PFLUM FRERICHS 1976

13108 PFLUM FRERICHS 1976

13109 PFLUM FRERICHS 1976

13110 PFLUM FRERICHS 1976

13111 PFLUM FRERICHS 1976

13112 PFLUM FRERICHS 1976

13113 PFLUM FRERICHS 1976

13114 PFLUM FRERICHS 1976

13115 PFLUM FRERICHS 1976

13116 PFLUM FRERICHS 1976

13117 PFLUM FRERICHS 1976

13118 PFLUM FRERICHS 1976

13119 PFLUM FRERICHS 1976

13120 PFLUM FRERICHS 1976

13121 PFLUM FRERICHS 1976

13122 PFLUM FRERICHS 1976

13123 PFLUM FRERICHS 1976

13124 PFLUM FRERICHS 1976

\begin{tabular}{l}
13125 PFLUM FRERICHS 1976 \\
\hline
\end{tabular}
Generic Name

Specific Name

STRIATA MEXICANA

STRIATA MEXICANA

STRIATA YEXICANA

STRIATA YEXICANA

STRIATA MEXICANA

STRIATA MEXICANA

STRIATA MEXICANA

SIRIATA MEXICANA

STRIATA MEXICANA

STRIATA MEXICANA

STRIATA YEXICANA

STRIATA MEXICANA

STRIATA MEXICANA

STRIATA YEXICANA

STRIATA MEXICANA

STRIATA YEXICANA

STRIATA YEXICANA

STRIATA MEXICANA

STRIATA MEXICANA

STRIATA YEXICANA

STRIATA MEXICANA

STRIATA MEXICANA

STRIATA MEXICANA

STRIATA YEXICANA

STRIATA MEXICANA

STRIATA MEXICANA

STRIATA YEXICANA

STRIATA YEXICANA

STRIATA MEXICANA

STRIATA MEXICANA

STRIATA YEXICANA

STRIATA MEXICANA

STRIATA MEXICANA

ST RIATA YEXICANA

STRIATA MEXICANA

STRIATA MEXICANA

STRIATA YEXICANA

STRIATA MEXICANA

STRIATA MEXICANA

STRIATA MEXICANA

STRIATA YEXICANA

STRIATA MEXICANA

STRIATA MEXICANA

STRIATA MEXICANA

STRIATA MEXICANA

STRIATA MEXICANA

STRIATA MEXICANA

STRIATA MEXICANA

STRIATA MEXICANA

STRIATA MEXICANA

STRIATA MEXICANA

STRIATA MEXICANA

STRIATA MEXICANA

STRIATA MEXICANA

STRIATA MEXICANA

STRIATA MEXICANA

STRIATA YEXICANA

STRIATA MEXICANA

STRIATA MEXICANA

STRIATA MEXICANA

STRIATA MEXICANA

STRIATA MEXICANA

STRIATA MEXICANA

STRIATA MEXICANA

STRIATA MEXICANA

STRIATA MEXICANA

STRIATA MEXICANA

STRIATA MEXICANA

STRIATA MEXICANA

STRIATA YEXICANA

STRIATA MEXICANA

STRIATA MEXICANA

STRIATA MEXICANA

STRIATA YEXICANA

STRIATA MEXICANA

STRIATA MEXICANA

STRIATA MEXICANA

STRIATA MEXICANA

STRIATA MEXICANA

STRIATA MEXICANA

STRIATA MEXICANA

STRIATA MEXICANA

STRIATA MEXICANA

STRIATA MEXICANA

STRIATA MEXICANA

STRIATA YEXICANA

STRIATA MEXICANA

STRIATA MEXICANA

STRIATA YEXICANA

STRIATA YEXICANA

STRIATA MEXICANA

STRIATA MEXICANA

STRIATA MEXICANA
Locality

Lat. Long.

NW GULF OF MEXICO

NW GULF OF MEXICO

NW GULF OF MEXICO

NW GULF OF MEXICO

NE GULF OF MEXICO

NE GULF OF MEXICO

NE GULF OF MEXICO

NE GULF OF MEXICO

NE GULF OF MEXICO

NE GULF OF MEXICO

CENTRAL GULF OF MEXICO

NW GULF OF MEXICO

NW GULF OF MEXICO

BAY OF CAMPECHE

BAY OF CAMPECHE

BAY OF CAMPECHE

BAY OF CAMPECHE

BAY OF CAMPECHE

NW GULF OF MEXICO

$N W$ GULF OF MEXICO

NW GULF OF MEXICO

NW GULF OF MEXICO

NW GULF OF MEXICO

NW GULF OF MEXICO

NW GULF OF MEXICO

NW GULF OF MEXICO

NW GULF OF MEXICO

NW GULF OF MEXICO

NW GULF OF MEXICO

NW GULF OF MEXICO

NW GULF OF MEXICO

NW GULF OF MEXICO

NW GULF OF MEXICO

NW GULF OF MEXICO

NW GULF OF MEXICO

NW GULF OF MEXICO

NW GULF OF MEXICO

NW GULF OF MEXICO

NW GULF OF MEXICO

NW GULF OF MEXICO

NH GULF OF MEXICO

NW GULF OF MEXICO

NW GULF OF MEXICO

NW GULF OF MEXICO

NW GULF OF MEXICO

NW GULF OF MEXICO

NW GULF OF MEXICO

$N W$ GULF OF MEXICO

NW GULF OF MEXICO

NW GULF OF MEXICO

NE GULF OF MEXICO

NE GULF OF MEXICO

NE GULF OF MEXICO

NE GULF OF MEXICO

NE GULF OF MEXICO

NE GULF OF MEXICO

NE GULF OF MEXICO

NE GULF OF MEXICO

NE GULF OF MEXICO

NE GULF OF MEXICO

NE GULF OF MEXICO

BAY OF CAMPECHE

NE GULF OF MEXICO

NE GULF OF MEXICO

$N$ GULF OF MEXICO

N GULF OF MEXICO

$N$ GULF OF MEXICO

$N$ GULF OF MEXICO

$N$ GULF OF MEXICO

$N$ GULF OF MEXICO

$N$ GULF OF MEXICO

$N$ GULF OF MEXICO

$N$ GULF OF MEXICO

NE GULF OF MEXICO

CENTRAL GULF OF MEXICO

CENTRAL GULF OF MEXICO

CENTRAL GULF OF MEXICO

CENTRAL GULF OF MEXICO

CENTRAL GULF OF MEXICO

CENTRAL GULF OF MEXICO

CENTRAL GULF OF MEXICO

CENTRAL GULF OF MEXICO

CENTRAL GULF OF MEXICO

CENTRAL GULF OF MEXICO

CENTRAL GULF OF MEXICO

CENTRAL GULF OF MEXICO

CENTRAL GULF OF MEXICO

CENTRAL GULF OF MEXICO

CENTRAL GULF OF MEXICO

CENTRAL GULF OF MEXICO

NW GULF OF MEXICO

NW GULF OF MEXICO

NW GULF OF MEXICO

NW GULF OF MEXICO

NW GULF OF MEXICO

$2747 \mathrm{~N} 09215 \mathrm{~W}$ $2737 \mathrm{~N} 09213$. $2719 \mathrm{~N} 092 \quad 27 \mathrm{~W}$ $2734 \mathrm{~N} 09213 \mathrm{~W}$ 2द $58 \mathrm{~N} 086 \quad 22$. $\begin{array}{llll}28 & 02 N & 085 & 20 W \\ 27 & 40 N & 085 & 43 W\end{array}$ 


\section{Publication}

13126 PFLUM FRERICHS 1976 13127 PFLUM FRERICHS 1976 13128 PFLUM FRERICHS 1976 13129 PFLUM FRERICHS 1976 13130 PFLUM FRERICHS 1976 13131 PFLUM FRERICHS 1976 13132 PFLUM FRERICHS 1976 13133 PFLUM FRERICHS 1976 13134 PFLUM FRERICHS 1976 13135 PFLUM FRERICHS 1976 13136 PFLUM FRERICHS 1976 13137 PFLUM FRERICHS 1976 13138 PFLUM FRERICHS 1976 13139 PFLUM FRERICHS 1976 13140 PFLUM FRERICHS 1976 13141 PFLUM FRERICHS 1976 13142 PFLUM FRERICHS 1976 13143 PFLUM FRERICHS 1976 13144 PHLEGER 1956

13145 PHLEGER 1951A

13146 PHLEGER 1951A 13147 PHLEGER 1951A 13148 PHLEGER 1951A 13149 PHLEGER $1951 \mathrm{~A}$ 13150 PHLEGER 1951A 13151 PHLEGER $1951 \mathrm{~A}$ 13152 PHLEGEP 1951A
13153 KELLOUGH 1956 13153 KELLOUGH 1956
13154 KELLOUGH 1956 13155 KELLOUSH 1956 13156 ANDERSEN 1961 13157 PHLEGER 1951 A 13158 PHLEGER 1951A 13159 PHLEGER 1951A 13160 PHLEGEP 1951A 13161 PHLEGER 1951A 13162 PHLEGER 1951A 13163 PHLEGER 1951A 13164 PHLEGER 1951A 13165 PHLEGER 1951A 13166 PHLEGER 1951A 13167 PHLEGER 1951A 13168 PHLEGER 1951A 13169 PHLEGER 1956

13170 KELLOUGH 1956 13171 PFLUM FRERICHS 1976 13172 WALTON 1960

13173 PHLEGER 1965 A

13174 AYALA-CASTANARES 1963

13175 WARREN 1956

13177 PARKER PHLEGER PEIRSON 1953

13178 PHLEGER 1951A

13179 PHLEGER $1951 \mathrm{~A}$

13180 PHLEGER $1951 \mathrm{~A}$

13181 PHLEGER 1951A

13183 PHLEGER $1951 \mathrm{~A}$

13184 PHLEGER $1951 \mathrm{~A}$

13185 PHLEGER 1951A

13186 PHLEGER $1951 \mathrm{~A}$

13187 PHLEGER $1951 \mathrm{~A}$

13188 PARKER PHLEGER PEIRSON 1953 13189 PHLEGEP 1956

13190 PHLEGER 1956

13191 PHLEGER 1956

13192 PHLEGER 1956

13193 PHLEGER 1956

13194 BOCK. 1976

13195 PHLEGER 19558

13196 P.HLEGER $1951 \mathrm{~A}$

13197 PHLEGER 1951A

13198 PHLEGER 1951A

13199 PHLEGER 1951A

13200 PHLEGER 1951A
13201 LANKFORD 1959

13201 LANKFORD 1959
13202 PHLEGER 1954

13203 PHLEGER 1954

13204 PARKER 1954

13205 WARREN 1957

13206 PHLEGER 1955A

13207 PARKER 1954

$\begin{array}{lll}13208 & \text { PARKER } & 1954 \\ 13209 & \text { PARKER } & 1954\end{array}$

13210 PARKER 1954

13211 PARKER 1954

13212 PARKER 1954

13213 PARKER 1954

13214 PARKER 1954

13215 PARKER 1954

13216 PARKER 1954

13217 PARKER 1954

13218 SEGURA 1963

13219 PHLEGER $1951 \mathrm{~A}$

13220 PHLEGER 1951A

\section{Generic Name}

BULIMINA

BULIMINA

BULIMINA

BULIMINA

BULIMINA

BULIMINA

BULIMINA

BULIMINA

BULIMINA

BULIMINA

BULIMINA

BULIMINA

BULIMINA

BULIMINA

BULIMINA

BULIMINA

BULIMINA

BULIMINA

BULIMINA

BULIMINA

BULIMINA

BULIMINA

BULIMINA

BULIMINA

BULIMINA

BULIMINA

BULIMINA

BULIMINA

BULIMINA

BULIMINA

BULIMINA

BULIMINA

BULIMINA

BULIMINA

BULIMINA

BULIMINA

BULIMINA

BULIMINA

BULIMINA

BULIMINA

BULIMINA

BULIMINELLA

BULIMINELLA

BULIMINELLA

BULIMINELLA

BULIMINELLA

BULIMINELLA

BULIMINELLA

BULIMINELLA

BULIMINELLA

BULIMINELLA

BULIMINELLA

BULIMINELLA

BULIMINELLA

BULIMINELLA

BULIMINELLA

BULIMINELLA

BULIMINELLA

BULIMINELLA

BULIMINELLA

BULIMINELLA

BULIMINELLA

BULIMINELLA

BULIMINELLA

BULIMINELLA

BULIMINELLA

BULIMINELLA

BULIMINELLA

BULIMINELLA

BULIMINELLA

QULIMINELLA

BULIMINELLA

BULIMINELLA

BULIMINELLA

BULIMINELLA

BULIMINELLA

BULIMINELLA

BULIMINELLA

BUL IMINELLA

BULIMINELLA

BULIMINELLA

BULIMINELLA

BULIMINELLA

BULIMINELLA

BULIMINELLA

BULIMINELLA

BULIMINELLA

BULIMINELLA

BULIMINELLA

BULIMINELLA
Specific Name

STRIATA MEXICANA

STRIATA MEXICANA

STRIATA MEXICANA

STRIATA MEXICANA

STRIATA MEXICANA

STRIATA YEXICANA

STRIATA MEXICANA

STRIATA MEXICANA

STRIATA YEXICANA

STRIATA YEXICANA

STRIATA MEXICANA

STRIATA YEXICANA

STRIATA YEXICANA

STRIATA MEXICANA

STRIATA MEXICANA

STRIATA MEXICANA

STRIATA YEXICANA

STRIATA YEXICANA

TENUIS

TENUIS

TENUIS

TENUIS

TENUIS

TENUIS

TENUIS

TENUIS

TENUIS

TENUIS

TENUIS

TENUIS

TENUIS

TENUIS

TENUIS

TENUIS

TENUIS

TENUIS

TENUIS

TEAUIS

TENUIS

TENUIS

TENUIS

TENUIS

TENUIS

TENUIS

BASSENDOR FENSIS

BASSENDOR FENSIS

BASSENDORFENSIS

BASSEND OR FENSIS

BASSENDOR FENSIS

BASSENDOR FENSIS

BASSENDOR FENSIS

BA SSENDORFENSIS

BASSENDORFENSIS

BA SSENDOR FENSIS

BA SSENDOR FENSIS

BA SSENDOR FENSIS

BASSENDOR FENSIS

BASSENDOR FENSIS

BASSENDORFENSIS

BASSENDOR FENSIS

BASSENDOR FEN IIS

BASSENDOR FENS IS

BASSENDOR FENSIS

BA SSENDOR FENSIS

BASSENDOR FENSIS

BASSENDOR FENSIS

BASSENDOR FENSIS

BASSENDOR FENS IS

BASSENDOR FENSIS

BASSENDOR FENSI S

BA SSENDOR FENSIS

BASSENDOR FENSIS

BASSENDORFENSIS

BASSENDOR FENS IS

BASSENDOR FENSIS

BASSENDOR FENSIS

BA SSENDOR FENSIS

BA SSENDOR FENS IS

BASSENDOR FENS IS

BASSENDOR FENSIS

BASSENDORFENSIS

BASSENDOR FENSIS

BASSENDOR FENSIS

BA SSENDOR FENSIS

BASSENDOR FENSIS

BASSENDOR FENSIS

BASSENDOR FENSIS

BASSENDOR FENSIS

BASSENDOR FENSIS

BASSENDOZ FENSIS

BASSENDOR FENS IS

BASSENDOR FENSIS

BASSENDOR FENSIS

BA SSENDOR FENS IS

\section{Locality}

Lat. Long.

NW GULF OF MEXICO

CENTRAL GULF OF MEXICO

CENTRAL GULF OF MEXICO

NW GULF OF MEXICO

NW GULF OF MEXICO

$N W$ GULF OF MEXICO

CENTRAL GULF OF MEXICO 


\section{Publication}

13221 PHLEGER 1951A 13222 PHLEGER 1951A 13223 PHLEGER 1951 A 13224 KANE 1962 13225 KANE 1967

13226 PHLEGER 1951A 13227 PHLEGER 1951A 13228 PHLEGER 1951A 13229 PHLEGER 1951 A 13230 KANE 1962

13231 SEGURA 1963

13232 KANE 1967

13233 PHLEGER 1960

13234 BENDA PURI 1962

13235 BENDA PURI 1962

13236 PHLEGER 1951

13238 LANKFORD 1959

13239 PHLEGER 1951 A

13240 PHLEGER 1951A

13241 PHLEGER LANKFORD 1957

13242 PHLEGER 1954

13243 PHLEGER 1965 A

13244 BANDY 1956
13245 PHLEGER 195

13246 PHLEGER 1951A

13247 PHLEGER 1951A

13248 PHLEGER 1955B

13249 PHLEGER 1951A

13250 PHLEGER 1951A

13251 PHLEGER 1965A

13252 PHLEGER 1965A

13253 PHLEGER 19658

13254 WALTON 1964

13255 AYALA-CASTANARES SEGURA 1968 13256 AYALA-CASTANARES 1963

13257 PHLEGER 19658

13258 PHLEGER 1956

13259 PHLEGER 1956

13260 PHLEGER 1956

13261 PHLEGER 1956

13262 PARKER PHLEGER PEIRSON 1953

13263 WALTON 1960

13264 OTVOS 1978
13265 ANDERSEN 1961

13266 BANDY 1956

13267 PHLEGER $1951 \mathrm{~A}$

13268 PHLEGER $1951 \mathrm{~A}$

13270 PHLEGER 1951A

13270 PHLEGER 1951A

13272 PHLEGER 1951A

13273 PHLEGER 1951A

13274 PHLEGER $1951 \mathrm{~A}$

13275 PARKER PHLEGER PEIRSON 1953

13276 POST 1951

13277 PARKER PHLEGER PEIRSON 1953

13278 PARKER PHLEGER PEIRSON 1953 13279 POST 1951

13280 PARKER PHLEGER PEIRSON 1953 13281 BOCK 1976

13282 BANDY 1956

13283 BANDY 1956

13284 BANDY 1956

13285 PFLUM FRERICHS 1976

13286 PFLUM FRERICHS 1976

13287 ANDERSEN 1961

13288 ANDERSEN 1969

13289 ANDERSEN 1961

13290 ANDERSEN 1961

13291 ANDERSEN 1961

13292 ANDERSEN 1961

13293 ANDERSEN 1961

13294 ANDERSEN 1961

13295 CUSH MAN 19228

13296 NORTON 1930

13297 CUSHMAN 1922A

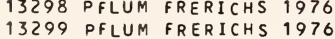

$\begin{array}{ll}13299 & \text { PFLUM FRERICHS } 1976 \\ 13300 & \text { PFLUM FRERICHS } 1976\end{array}$

13301 PFLUM FRERICHS 1976

13302 PFLUM FRERICHS 1976

13303 PFLUM FRERICHS 1976

13304 PHLEGER 1951 A

13305 PHLEGER 1951A

13306 PHLEGER 1951A

13307 PHLEGER 1951A

13308 PHLEGER 1951A

13309 PHLEGER 1951A

13310 PHLEGER 1951 A

13312 PARKER 1954

13312 PARKER 1954
13313 PARKER 1954

13314 PARKER 1954

13315 KELLOUGH 1956
Generic Name

BULIMINELLA

BULIMINELLA

BULIMINELLA

BUL IMINELL A

BULIMINELLA

BULIMINELLA

BULIMINELLA

BULIMIN ELL A

BULIMINELLA

BUL IM INELL A

BULIMINELLA

BULIMINELLA

BULIMINELL A

BULIMINELL A

BULIM INELLA

BUL IMINELLA

BULIMINELLA

BULIMINELLA

BULIMINELL A

BULIMINELLA

BULIMINELLA

BULIMINELLA

BULIMINELL A

BULIMINELLA

BULIMINELLA

BULIMINELLA

BULIMINELLA

BULIMINELL A

BULIMINELLA

BULIMINELLA

BULIMINELLA

BULIMINELLA

BULIMINELLA

BULIMINELL A

BULIMINELL A

BULIMINELL A

BULIMINELLA

BULIMINELLA

BULIMINELLA

BULIMINELLA

BULIMINELLA

BULIMINELLA

BULIMINELLA

BUL IM I NELL A

BULIMINELLA

BULI MINELLA

BULIMINELLA

BULIMINELLA

BULIMINELL A

BULIMINELLA

BULIMINELLA

BULIMINELLA

BULIMINELLA

BULIMINELLA

BULIMINELLA

BULIMINELLA

BULIMI NELL A

BULIMINELLA

BULIMINELLA

BULIMINELLA

BULIMINELLA

BULIMINELLA

BULIMINELLA

BULIMINELLA

BULIMINELL A

BULIMINELLA

BULIMINELLA

BULIMINELLA

BULIMINELLA

BULIMINELLA

BULIMINELL A

BULIMINOIDES

CANCRIS

CANCRIS

CANCRIS

CANCRIS

CANCRIS

CANCRIS

CANCRIS

CANCRIS

CANCRIS

CANCRIS

CANCRIS

CANCRIS

CANCRIS

CANCRIS

CANCRIS

CANCRIS

CANCRIS

CANCRIS
Specific Name

BASSENDOR FENSIS BASSENDOR FENSIS BASSENDOR FENSIS BASSENDOR FENSIS BASSENDOR FENSIS BASSENDOR FENSIS BASSENDOR FENSIS BASSENDOR FENSIS BASSENDOR FENSIS

EL EGANTIS S IMA

EL EGANTIS SIMA

ELEGANT IS SI MA

ELEGANT IS SIMA

ELEGANTIS SIMA

EL EGANT IS SIMA

ELEGANT IS SIMA

ELEGANT IS SIMA

ELEGANT IS SI MA

ELEGANTIS I IMA

ELEGANT IS SI MA

EL EGANT IS SIMA

EL EGANT IS SIMA

ELEGANT IS SIMA

ELEGANT IS SIMA

EL EGANTIS SIMA

ELEGANTIS SIMA

ELEGANTIS SIMA

EL EGANT IS SIMA

ELEGANT IS SIMA

ELEGANTIS SI MA

ELEGANT IS SIMA

EL EGANTIS SIMA

ELEGANT IS SIMA

ELEGANT IS SIMA

ELEGANT IS SIMA

ELEGANTIS SIMA

EL EGANT IS SIMA

EL EGANT IS SIMA

ELEGANTIS SIMA

ELEGANTIS SIMA

ELEGANT IS SIMA

ELEGANTIS SIMA

EL EGANT IS SIMA

ELEGANTIS SIMA

ELEGANT IS SIMA

ELEGANT IS S I MA

EL EGANT IS SIMA

ELEGANT IS S IMA

ELEGANT IS SIMA

EL EGANT IS SIMA

ELEGANT IS SIMA

EL EGANT IS SIMA

ELEGANT IS SI MA

EL EGANTIS SIMA

EL EGANT IS SIMA

ELEGANT IS SIMA

ELEGANTIS SIMA

EL EGANTIS SIMA

ELEGANT IS SI MA

ELEGANTISSIMA

EL EGANT IS S IMA

ELEGANTIS SIMA

EL EGANT IS SIMA

EXILIS

EXILIS

MORG AN I

MORGANI

MORGANI

MORGANI

MORGANI

MORGANI

MORGANI

MORGANI

SUBTERES

SUBTERES

WI LLI AMSONI ANA

AURI CULA

AURI CULA

AURI CULA

AURICULA

AURICULA

AURI CULA

OB LONGA

OBLONGA

OBLONGA

OB LONGA

OBLONGA

OBLONGA

OBLONGA

OBLONGA

$O B$ LONGA

OB LONGA

OBLONGA

OBLONGA

Locality

NW GULF OF MEXICO

NW GULF OF MEXICO

$N W$ GULF OF MEXICO

SABINE LAKE, TEXAS

SABINE LAKE, TEXAS

$N W$ GULF OF MEXICO

$N W$ GULF OF MEXICO

NW GULF OF MEXICO

NW GULF OF MEXICO

SABINE LAKE, TEXAS

MATAMOROS, MEXICO 
Publication

13316 KELLOUGH 1956

13317 KELLOUGH 1956

13318 PARKER 1954

13319 PARKER 1954
13320 LANKFORD 1959

13321 LUOWICK HALTON 1957

13322 PARKER 1954

13323 PARKER 1954

13324 PARKER 1954

13325 PARKER 1954

13326 PARKER 1954

13327 PHLEGER 1951A

13328 PHLEGER $1951 \mathrm{~A}$

13329 PHLEGER 1951A

13330 PHLEGER 1951A

13331 PHLEGER $1951 \mathrm{~A}$

13332 PHLEGER 1951A

13333 PHLEGER 1951A

13334 PHLEGER 1951A

13335 PHLEGER. 1951A

13336 PHLEGER 1951A

13337 PHLEGER 1951A

13338 PHLEGER 1951A

13339 PHLEGER 1951A

13340 PHLEGER 1951A

13341 PHLEGER 1951A

13342 PHLEGER $1951 \mathrm{~A}$

13344 PHLEGER 1951 A

13345 PHLEGER 1951 A

13346 PARKER 1954

13347 PARKER 1954

13348 PARKER 1954

13349 CREAGER 1958

13350 CREAGER 1958

13351 PHLEGER 1956

13352 PHLEGER 1956

13353 PHLEGER 1956

13354 PARKER 1954

13355 PARKER 1954

13356 PARKER 1954

13357 PARKER 19

13358 BOCK 1976

13360 KELLOUGH 1956

13361 KELLOUGH 1956

13362 KELLOUGH 1956

13363 CREAGER 1958

13364 BOCK 1976

13365 WARREN 1956

13366 BANDY 1954

13367 BANDY 1956

13368 BANDY 1954

13369 POAG 1972

13370 POAG SWEET 1972

13371 CUSHMAN 1931

13372 KELLOUGH 1956

13373 BANDY 1954

13374 BANDY 1954

13375 BANDY 1956

13376 BANDY 1956

13377 BANDY 1956

13378 BANOY 1956

13379 BANDY 1956

13380 BANDY 1954

13381 BANDY 1956

13382 BANDY 1956

13383 BANDY 1956

13384 BANDY 1956

13385 ANDERSEN 1961

13386 DAVIS 1964

13387 WARREN 1957

13388 BANDY 1956

13389 BANDY 1954

13390 BANDY 1956

13391 BOCK 1976

13392 CUSHMAN $1922 \mathrm{~A}$

13393 PARKER 1954

13394 PARKER 1954

13395 PARKER 1954

13396 PARKER 1954

13397 PARKER 1954

13398 PARKER 1954

13399 PARKER 1954

13400 PARKER 1954

13401 PARKER 1954

13402 PARKER 1954

13403 PARKER 195

13404 PARKER 195

13405 PARKER 195

13406 PARKER 1954

13407 PARKER 1954

13408 PARKER 1954

13409 PARKER 1954

13410 PARKER 1954

Generic Name Specific Name

Locality

Lat. Long.

CANCRIS

CANCRIS

CANCRIS

CANCRIS

CANCRIS

CANCRIS

CANCRIS

CANCRIS

CANCRIS

CANCRIS

CANCRIS

CANCRIS

CANCRIS

CANCRIS

CANCRIS

CANCRIS

CANCRIS

CANCRIS

CANCRIS

CANCRIS

CANCRIS

CANCRIS

CANCRIS

CANCRIS

CANCRIS

CANCRIS

CANCRIS

CANCRIS

CANCRIS

CANCRIS

CANCRIS

CANCRIS

CANCRIS

CANCRIS

CANCRIS

CANCRIS

CANCRIS

CANCRIS

CANCRIS

CANCRIS

CANCRIS

CANCRIS

CANCRIS

CANCRIS

CANCRIS

CANCRIS

CANCRIS

CANCRIS

CANCRIS

CANCRIS

CANCRIS

CANCRIS

CANCRIS

CANCRIS

CANCRIS

CANCRIS

CANCR IS

CANCRIS

CANCRIS

CANCRIS

CANCRIS

CANCRIS

CANCRIS

CANCRIS

CANCRIS

CANCRIS

CANCRIS

CANCRIS

CANCRIS

CANCRIS

CANCRIS

CANCRIS

CANCRIS

CANCRIS

CANCRIS

CARTERINA

CARTERINA

CASSI DULINA

CASSIDULINA

CASSIDULINA

CASSI DULINA

CASSI DULINA

CASSIDULINA

CASS IDULINA

CASSI DUL INA

CASSIDULINA

CASSI DULINA

CASSI DULINA

CASSIDULINA

CASSIDULINA

CASSIDULINA

CASSIDULINA

CASSIOULINA

CASSI DULINA

CASSI DULINA
OB LONGA

OBLONGA

OBLONGA

OB LONGA

OBLONGA

OBLONGA

OB LONGA

OBLONGA

OBLONGA

OBLONGA

OBLONGA

OBLONGA

OB LONGA

OBLONGA

OBLONGA

OBLONGA

OB LONGA

OBLONGA

OBLONGA

OBLONGA

OBLONGA

OBLONGA

OBLONGA

OBLONGA

OBLONGA

OBLONGA

OB LONGA

OBLONGA

OB LONGA

OBLONGA

OBLONGA

OB LONGA

OBLONGA

OBLONGA

OB LONGA

OB LONGA

OBLONGA

OBLONGA

OB LONGA

OB LONGA

OBLONGA

OBLONGA

OBLONGA

OB LONGA

OBLONGA

OB LONGA

OB LONGA

SAGRA

SA GRA

SAGRA

SAGRA

SAGRA

SAGRA

SAGRA

SA GRA

SAGRA

SAGRA

SAGRA

SAGRA

SAGRA

SAGRA

SAGRA

SAGRA

SA GRA

SAGRA

SAGRA

SAGRA

SAGRA

SAGRA

SAGRA

SA GRA

SAGRA

SP I CULOTE STA

SP I CULOTE STA

CARINATA

CARINATA

CARINATA

CARINATA

CARINATA

CARINATA

CARINAIA

CARINATA

CARINATA

CARINATA

CARINATA

CARINATA

CARINATA

CARINATA

CARINATA

CARINATA

CARINATA

CARINATA

NW GULF OF MEXICO NW GULF OF MEXICO NE GULF OF MEXICO 


\section{Publication}

13411 PARKER 1954

13412 PARKER 1954

13414 PHLEGER 1951 A

13415 PHLEGER 1951 A

13416 PARKER 1954

13417 PARKER 1954

13418 PARKER 1954

13419 PARKER
1954
13420 PARKER 1954

13420 PARKER 1954
13421 PARKER 1954

13422 PHLEGER 1951A

13423 PHLEGER 1951A

13424 PHLEGER 1951A

13425 PHLEGER 1951

13426 PARKER 1954

13427
13428 PARKER 1954
PARKER 1954

13429 LUDWICK WALTON 1957

13430 PHLEGER 1951 A

13431 PHLEGER 1951 A

13432 PHLEGER 1951 A

13433 PHLEGER $1951 \mathrm{~A}$

13434 PHLEGER 1951A

13435 PHLEGER 1951 A

13436 PHLEGER 1951 A

13437 PHLEGER $1951 \mathrm{~A}$

13438 PHLEGER $1951 \mathrm{~A}$

13439 PHLEGER $1951 \mathrm{~A}$

13440 PARKER 1954

13441 PHLEGER 1951A

13442 PHLEGER $1951 \mathrm{~A}$

13443 PHLEGER $1951 \mathrm{~A}$

13444 PHLEGER 1951A

13445 LOEP 1965

13446 LOEP 1965

13447 CUSHMAN 19228

13448 CREAGER 1958

13449 CREAGER 1958

13450 CREAGER 1958

13451 PHLEGER 1951 A

13453 AYALA-CASTANARES 1963

13454 PARKER 1954

13455 SOCK 1976

13456 PARKER 1954

13457 PARKER 1954

13458 PARKER 1954

13459 PARKER 1954

13460 PARKER 1954

13461 CREAGER 1958

13462 PFLUM FRERICHS 1976

13463 CREAGER 1958

13464 BANDY 1956

13465 PFLUM FRERICHS 1976

13466 PFLUM FRERICHS 1976

13467 PFLUM FRERICHS 1976

13468 PARKER 1954

13469 PARKER 1954

13470 PARKER 1954

13471 PARKER 1954

13472 PARKER 1954

13473 CREAGER 1958

13474 CREAGER 1958

13475 CREAGER 1958

13476 CREAGER 1958

13477 BANDY 1956

13478 BANDY 1956

13479 BANDY 1956

13480 BANDY 1956

13481 BANDY 1956

13482 BANDY 1956

13483 BANDY 1956

13484 PFLUM FRERICHS 1976

13485 ANDERSEN 1961

13486 BOCK 1976

13487 BOCK 1976

13488 BOCK 1976

13489 CREAGER 1958

13490 PARKER 1954

13491 PARKER 1954

13492 PARKER 1954

13493 PARKER 1954

13494 PARKER 1954

13495 PARKER 1954

13496 PARKER 1954

13497 PHLEGER 1956

13498 PARKER 1954

13499 PHLEGER 1951A

13500 PHLEGER 1951A

13501 PFLUM FRERICHS 1976

13502 PFLUM FRERICHS 1976

13503 PFLUM FRERICHS 1976

13504 PFLUM FRERICHS 1976

13505 PFLUM FRERICHS 1976
Generic Name

CASSI DUL INA

CASSIDULINA

CASSIDULINA

CASSIDULINA

CASSIDULINA

CASSIDULINA

CASSI DUL INA

CA SSIDULINA

CASSIDULINA

CASSIDULINA

CASSIDULINA

CASSIDULINA

CASSIDUL INA

CASSIDULINA

CASSIDULINA

CASSIDULINA

CASSIDULINA

CASSIDULINA

CASSIDULINA

CASSI DUL INA

CASSI DUL INA

CASSIDUL INA

CASSIDULINA

CASSIDULINA

CASSIDULINA

CASSIDULINA

CASSIDULINA

CASSIDULINA

CASSIDUL INA

CASSIDULINA

CASSIDULINA

CASSIDULINA

CASSIDULINA

CASSIDULINA

CASSIDULINA

CASSIDULINA

CASSIDULINA

CASSIDULINA

CASSIDULINA

CASSIDULINA

CASSIDULINA

CASSIDULINA

CASSIDULINA

CASSIDULINA

CASSIDULINA

CASSIDULINA

CASSIDULINA

CASSIDULINA

CASSIDULINA

CASSIDULINA

CASSIDULINA

CASSIDULINA

CASSIDULINA

CASSIDULINA

CASSIDULINA

CASSIDULINA

CASS I DULINA

CASSIDULINA

CASSIDULINA

CASSIDULINA

CASSIDULINA

CASSIDULINA

CASSIDULINA

CASSIDULINA

CASSIDULINA

CASSIDULINA

CASSIDULINA

CASSIDULINA

CASSIDULINA

CASSIDULINA

CASS IDULINA

CASSIDUL INA

CASSIDULINA

CASS I DUL INA

CASSIDULINA

CASSIDULINA

CASSIDULINA

CASSIDULINA

CASSIDULINA

CA SSIDULINA

CA SSIDULINA

CASSI DULINA

CASSIDULINA

CASSIDULINA

CASSI DULINA

CASSIDUL INA

CASSIDULINA

CASSIDULINA

CASSIDULINA

CASSI DULINA

CASSIDULINA
Specific Name

CARINATA

CARINATA

CRASSA

CRASSA

CRASSA

CRASSA

CRASSA

CRASSA

CRASSA

CRASSA

CRASSA

CRASSA

CRASSA

CR ASSA

CRASSA

CRASSA

CRASSA

CRASSA

CRASSA

CRASSA

CRASSA

CRASSA

CRASSA

CRASSA

CRASSA

CRASSA

CRASSA

CRASSA

CRASSA

CRASSA

CRASSA

CR ASSA

CR ASSA

CRASSA

CRASSA

CRASSA

CR ASSA

CRASSA

CR ASSA

CRASSA

CR ASSA

CRASSA

CRASSA

CR ASSA

CRASSA

CRASSA

CR ASSA

CURVATA

CURVATA

CURVATA

CURVATA

CURVATA

CURVATA

CURVATA

CURVATA

CURVATA

CURVATA

CURVATA

CURVATA

CURVATA

CURVATA

CURVATA

CURVATA

CURVATA

CURVATA

CURVATA

CURVATA

CURVATA

CURVATA

CURVATA

CURVATA

CURVATA

CURVATA

CURVATA

CURVATA

CURVATA

CURVATA

CURVATA

CURVATA

CURVATA

CURVATA

CURVATA

CURVATA

CURVATA

CURVATA

CURVATA

CURVATA

CURVATA

CURVATA

CURVATA

CURVATA

Locality

Lat. Long.

NE GULF OF MEXICO

NE GULF OF MEXICO

NE GULF OF MEXICO

NW GULF OF MEXICO

NW GULF OF MEXICO

NE GULF OF MEXICO

NE GULF OF MEXICO

NE GULF OF MEXICO

NE GULF OF MEXICO 


\section{Publication}

13506 PFLUM FRERICHS 1976 13507 PFLUM FRERICHS 1976 13508 PFLUM FRERICHS 1976 13509 PFLUM FRERICHS 1976

13510 PFLUM FRERICHS 1976 13511 PFLUM FRERICHS 1976 13512 PFLU:A FRERICHS 1976 13513 PFLUM FRERICHS 1976 13514 PFLUM FRERICHS 1976 13515 PFLUM FRERICHS 1976 13516 PFLUM FRERICHS 1976

13517 PFLUM FRERICHS 1976

13518 PFLUM FRERICHS 1976

13519 PFLUM FRERICHS 1976

13520 PHLFGER 1951A

13521 PHLEGER $1951 \mathrm{~A}$

13522 PHLEGEP 1951A

13523 PHLFGE2.1951A

13524 PHLEGER 1951 A

13525 PHLEGER 1951A

13526 PHLEGER $1951 \mathrm{~A}$

13527 PHLEGER 1951A

13528 PHLEGER 1951A

13529 PHLEGER 1951 A

13530 PHLEGER 1951A

13531 PHLEGER $1951 \mathrm{~A}$

13532 PHLEGER $1951 \mathrm{~A}$

13534 PHLEGER 1951A

13535 PHLEGER 1951A

13536 PHLEGER 1951A

13537 PHLEGER 1951A

13538 PHLEGER $1951 \mathrm{~A}$

13539 PHLEGER $1951 \mathrm{~A}$

13540 LUDWICK WALTON 1957

13541 PHLEGER 1955A

13542 PHLES,ER 1955A

13543 PARKER 1954

13544 PARKER 1954

13545 PARKER 1954

13546 PARKER 1954

13547 PARKER 1954

13548 PARKER 1954

13549 PARKER 1954

13550 PARKER 1754

13551 PARKER 1954

13552 PARKER 195

13553 LUDWICK WALTON 1957

13554 PHLEGER 1951A

13555 PARKER 1054

13556 PARKER 1954

13557 PARKER 1954

13558 PARKER 1954

13559 CREAGER 1958

13560 PARKER 1954

13561 PARKER 1954

13562 PARKER 1954
13563 BANDY 1956

13564 BANDY 1956

13565 BANDY 1956

13566 BANDY 1956

13567 BANDY 1956

13568 CREAGER 1958

13569 SANDY 1956

13570 SANDY 1956

13571 BANDY 1956

13572 CREAGER 1958

13573 CREAGER 1958

13574 CREAGER 1958

13575 CREAGER 1958

13576 CREAGER 1958

13577 CREAGER 1958

13578 CREAGER 1958

13579 CREAGER 1958

13580 CREAGER 1958

13581 PHLEGER 1951A

13582 CREAGER 1958

13583 PHLEGER 1951 A

13584 PHLEGER 1951A

13585 PHLEGER 1951A

13586 PHLEGER 1951A

13587 PHLEGER 1951A

13588 CUSHMAN 19228

13589 PHLEGER 1951 A

13590 PHLEGER 1951 A

13591 KELLOUGH 1956

13592 CUSHMAN 19228

13593 PHLEGER 1951A

13594 PHLEGER 1951A

13595 PHLEGER 1951A

13596 PHLEGER 1951A

13597 PHLEGER 1951 A

13598 PHLEGER 1951A

13599 PHLEGER 1951A

13600 PHLEGER $1951 \mathrm{~A}$
Generic Name Specific Name

Locality

Lat. Long.

CASSIDULINA

CASSIDULINA

CASSIDULINA

CASSIDULINA

CASSIDULINA

CASSI DUL INA

CASSIDULINA

CASSIDULINA

CASS IDUL INA

CASSIDULINA

CASSIDUL INA

CASSIDUL INA

CASSI DUL INA

CASSIDULINA

CASSI DUL INA

CASS IDUL INA

CASSIDUL INA

CASSI DUL INA

CASSIDUL INA

CASSI DULINA

CASSIDULINA

CASSI DULINA

CASSIDULINA

CASSI DUL INA

CASSIDUL INA

CASSIDULINA

CASSIDUL INA

CASSIDULINA

CASSI DUL INA

CASSIDULINA

CASSIDULINA

CASSIDULINA

CASS I DUL INA

CASSIDULINA

CASSIDULINA

CASSI DULINA

CASSIDUL INA

CASSI DUL INA

CASSI DUL INA

CASS I DUL INA

CASSI DUL INA

CASSIDUL INA

CASS I DULINA

CASSIDULINA

CASS I DUL INA

CASSIDULINA

CASSIDULINA

CASSIDULINA

CASSI DUL INA

CASSI DUL INA

CASSI DULINA

CASSIDULINA

CASSIDULINA

CASSI DULINA

CASSIDULINA

CASSIDUL INA

CASSI DULINA

CASS IDULINA

CASSIDUL INA

CASSIDUL INA

CASSI DUL INA

CASSIDULINA

CASSI DUL INA

CASSI DULINA

CASSI DULINA

CASS IDULINA

CASSI DULINA

CASSIDULINA

CASSI DULINA

CASSIDULINA

CASSIDULINA

CASSIDULINA

CASSIDULINA

CASSI DULINA

CASSIDULINA

CASSIDULINA

CASSIDUL INA

CASSI DUL INA

CASSIDULINA

CASSIDULINA

CASSI DULINA

CASSIDULINA

CASSIDULINA

CASS I DULINA

CASSIDULINA

CASSIDULINA

CASSI DULINA

CASSIDULINA

CASSIDULINA

CASSI DULINA

CASSIDULINA

CASSIDULINA

CASSIDULINA

CASSIDULINA

CASSIDUL INA
CURVATA

CURVATA

CURVATA

CURVATA

CURVATA

CURVATA

CURVATA

CURVATA

CURVATA

CURVATA

CURVATA

CURVATA

CURVATA

CURVATA

CURVATA

CURVATA

CURVATA

CURVATA

CURVATA

CURVATA

CURVATA

CURVATA

CURVATA

CURVATA

CURVATA

CURVATA

CURVATA

CURVATA

CURVATA

CURVATA

CURVATA

CURVATA

CURVATA

CURVATA

CURVATA

CURVATA

CURVATA

CURVATA

CURVATA

CURVATA

LAEVIGATA

LAEVIGATA

LAEVIGATA

LAEVIGATA

LAEVIGATA

LAEVIGATA

LAEVIGATA

LAEVIGATA

LAEVIGATA

LAEVIGATA

LAEVIGATA

LAEVIGATA

LAEVIGATA

LAEVIGATA

LAEVIGATA

LAEVIGATA

LAEVIGATA

LAEVIGATA

LAEVIGATA

LAEVIGATA

LAEVIGATA

LAEVIGATA

LAEVIGATA CARINATA

LAEVIGATA CARINATA

LAEVIGATA CARINATA

LAEVIGATA CARINATA

LAEVIGATA CARINATA

LAEVIGATA CARINATA

LAEVIGATA CARINATA

LAEVIGATA CARINATA

LAEVIGATA CARINATA

LEVIGATA CARINATA

LAEVIGATA CARINATA

LAEVIGATA CARINATA

LAEVIGATA CARINATA

LAEVIGATA CARINATA

LAEVIGATA CARINATA

LAEVIGATA CARINATA

LAEVIGATA CARINATA

LEVIGATA CARINATA

LAEVIGATA CARINATA

LAEVIGATA CARINATA

LAEVIGATA CARINATA

LAEVIGATA CARINATA

LAEVIGATA CARINATA

LAEVIGATA CARINATA

LAEVIGATA CARINATA

LAEVIGATA CARINATA

LAEVIGATA CARINATA
NW GULF OF MEXICO

NW GULF OF MEXICO

$N W$ GULF OF MEXICO

$N W$ GULF OF MEXICO

$N W$ GULF OF MEXICO

NW GULF OF MEXICO

NW GULF OF MEXICO 


\section{Publication}

13601 PHLEGER $1951 \mathrm{~A}$ 13602 PHLEGER 1951 A 13603 PHLEGER 1951A 13604 PHLEGER 1951A 13605 PHLFGER 1951 A 13606 PHLEGER 1951 A 13607 PHLEGER 1951 A 13608 PHLEGER $1951 \mathrm{~A}$ 13609 PHLEGER 1951A

13610 PFLUM FRERICHS 1976 13611 PFLUM FRERICHS 1976 13692 PFLUM FRERICHS 1976 13613 PFLUM FRERICHS 1976 13614 PFLUM FRERICHS 1976 13615 PFLUM FRERICHS 1976 13616 PFLUM FRERICHS 1976 13617 PFLUM FRERICHS 1976 13618 PFLUM FRERICHS 1976 13619 PFLUM FRERICHS 1976 13620 PFLUM FRERICHS 1976 13621 PFLUM FRERICHS 1976 13622 PFLUM FRERICHS 1976 13623 PFLUM FRERICHS 1976 13624 PARKER 1754

13625 PARKER 1954

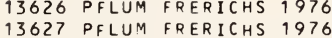
13628 PFLUM FRERICHS 1976 13629 PFLUY FRERICHS 1976 13630 PFLUM FRERICHS 1976 13631 PFLUM FRERICHS 1976 13632 PFLUM FRERICHS 1976 13633 PFLUM FRERICHS 1976 13634 PARKER 1954

13635 PFLUM FRERICHS 1976 13636 PARKER 1954

13637 PFLUM FRERICHS 1976 13638 PFLUM FRERICHS 1976 13639 PFLUM FRERICHS 1976 13640 PFLUM FRERICHS 1976 13641 PARKER 1954

13642 PARKER 1954

13643 PHLEGER $1955 \mathrm{~A}$

13644 PHLEGER $1955 \mathrm{~A}$

13645 PHLEGER 1955

13646 PARKER 1954

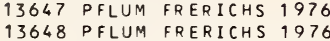

13649 PFLUM FRERICHS 1976

13650 PARKER 1354

13651 PARKER 1954

13652 PARKER 1954

13653 PFLUM FRERICHS 1976

13654 LUDWICK WALTON 1957

13655 PFLUM FRERICHS 1976

13656 PFLUM FRERICHS 1976

13657 PFLUM FRERICHS 1976

13658 PFLU'A FRERICHS 1976

13659 PFLUM FRERICHS 1976

13660 PFLUM FRERICHS 1976

13661 PFLUM FRERICHS 1976

13662 PARKER 1954

13663 PARKER 1954

13664 PARKER 1954

13665 PFLUM FRERICHS 1976

13666 PFLUM FRERICHS 1976

13667 PFLUM FRERICHS 1976

13668 PFLUM FRERICHS 1976

13669 PFLUM FRERICHS 1976

13670 PARKER 1954

13671 PARKER 1954

1367 ? PARKER 1954

13673 PFLUM FRERICHS 1976

13674 ANDERSEN 1961

13675 PFLUM FRERICHS 1976

13676 PFLUM FRERICHS 1976

13677 PFLUM FRERICHS 1976

13678 PARKER 1954

13679 PARKER 1954

13680 PARKER 1954

13681
13682

13683 PHLEGER 1951 A

13684 PHLEGER 1951 A

13685 PHLEGER $1951 \mathrm{~A}$

13686 PHLEGEP $1951 \mathrm{~A}$

13687 PHLEGER $1951 \mathrm{~A}$

13688 PHLEGER $1951 \mathrm{~A}$

13689 PHLEGER $1951 \mathrm{~A}$

13690 PHLEGER 1951 A

13691 PHLEGER 1951 A

13692 PHLEGER $1951 \mathrm{~A}$

13693 PHLEGER $1951 \mathrm{~A}$

13695 PHLEGER 1951A

\section{Generic Name}

CASSIDULINA

CASSIDULINA

CASSIDULINA

CASSIDUL INA

CASSIDULINA

CASSIDULINA

CASSIDUL INA

CASSIDULINA

CASSI DUL INA

CASSIDULINA

CASSIDUL INA

CASSIDULINA

CASSIDULINA

CASSIDUL INA

CASSIDUL INA

CASSIDUL INA

CASSIDULINA

CASSIDULINA

CASSIDUL INA

CASSIDULINA

CASSIDULINA

CASSIDULINA

CASSIDULINA

CASSIDULINA

CASSI DUL INA

CASSIDULINA

CASSIDULINA

CASSIDULINA

CASSIDULINA

CASSIDULINA

CASSIDULINA

CASSIDULINA

CASSIDULINA

CASSI DUL INA

CASSIDUL INA

CASSIDUL INA

CASSIDULINA

CASSIDULINA

CASSIDULINA

CASSIDULINA

CASSIDULINA

CASSIDULINA

CASSIDULINA

CASSIDULINA

CASSIDULINA

CASSIDUL INA

CASSIDULINA

CASSIDULINA

CASSIDULINA

CASSIDULINA

CASSIDULINA

CASSIDULINA

CASSIDULINA

CASSIDUL INA

CASSIDULINA

CASSIDULINA

CASSIDULINA

CASSIDULINA

CASSIDULINA

CASSIDULINA

CASSIDULINA

CASSIDUL INA

CASSIDULINA

CASSIDULINA

CASSIDULINA

CASSIDULINA

CASSIDULINA

CASSIDULINA

CASSIDULINA

CASSIDUL INA

CASSIDULINA

CASSIDULINA

CASSIDULINA

CASSIDULINA

CASSIDULINA

CASSIDULINA

CASSIDULINA

CASSI DUL INA

CASSIDULINA

CASSIDULINA

CASSIDULINA

CASSIDULINA

CASSIDULINA

CASSIDULINA

CASSIDULINA

CASSI DULINA

CASSIDULINA

CASSI DULINA

CASSIDULINA

CASSIDULINA

CASSIDULINA

CASSIDULINA

CASSIDULINA

CASSIDULINA

\section{Specific Name}

LAEVIGATA CARINATA

LAEVIGATA CARINATA

LAEVIGATA CARINATA

LAEVIGATA CARINATA

LAEVIGATA CARINATA

LAEVIGATA CARINATA

LAEVIGATA CARINATA

LAEVIGATA CARINATA

NE CCARINATA

NE OCAR I NA TA

NECCARINATA

NE OCARINATA

NE CCARINATA

NECCARINATA

NE CCARINA TA

NE CCARINATA

NEOCARINATA

NECCARINATA

NECCAR INA TA

NEOCARINA TA

NEOCAR INA TA

NE CCARINATA

NECCARINATA

NE OCARINATA

NE OCAR I NA TA

NE OCARINATA

NE OCARINATA

NE CCARINATA

NECCARINATA

NE CCARINA TA

NE OCAR I NA TA

NE CCAR I NA TA

NEOCARINA TA

NE CCARINATA

NECCARINA TA

NE CCARINATA

NECCARINATA

NEOCAR INATA

NECCARINATA

NEOCAR INA TA

NECCARINA TA

NE CCARINATA

NEOCARINA TA

NEOCAR INA TA

NE OCAR I NA TA

NECCARI NA TA

NE CCAR INA TA

NE OCAR INA TA

NECCARINATA

NE CCARINATA

NE CCAR INA TA

NE CCARI NA TA

NE CCARINATA

NEOCARINA TA

NE CCAR INA TA

NE CCARINATA

NEOCARINATA

NECCARINATA

NECCARINATA

NE OCARINATA

NE CCARI

NE CCARINA TA

NE CCARINATA

NE CCARINATA

NE OCAR I NA TA

NE CCAR INATA

NE OCAR INA TA

NE C CAR I NA TA

NEOCARINATA

NEOCARINATA

NE OCAR I NATA

NE OCAR I NA TA

NE CCAR I NA TA

NECCARI NA TA

NE OCAR I NA TA

NORCROSSI AUSTRALIS

NORCROSSI AUSTRALIS NORCROSSI AUSTRALIS NORCROSSI AUSTRALIS NORCROSSI AUSTRALIS NORCROSSI AUSTRALIS NORCROSSI AUSTRALIS NORCROSSI AUSTRAL NORCROSSI AUSTRALIS NORCROSSI AUSTRALIS NORCROSSI AUSTRALIS NORCROSSI AUSTRALIS NORCROSSI AUSTRALIS SUEGLOBOSA SUBGL OBOSA

SUBGL OBOSA

\section{Locality}

Lat. Long.

NW GULF OF MEXICO

NW GULF OF MEXICO 


\section{Publication}

13696 PHLEGER 1951A 13697 PHLEGER $1951 \mathrm{~A}$ 13698 PHLEGER $1951 \mathrm{~A}$ 13700 PHLEGER 1951A 13700 PHLEGER 1951A 13701 PHLEGER 1951 A
13702 PARKER 1954 13703 PHLEGER 1951A 13704 PHLEGER 1951A 13705 PHLEGER 1951A 13706 PHLEGER 1951A 13707 PHLEGER 1955A 13708 PHLEGER 1951A 13709 PHLEGER 1951A 13710 PHLEGER 1951A 13711 PHLEGER 1951A 13712 PHLEGER $1951 \mathrm{~A}$ 13713 PHLEGER 1951A 13714 PHLEGER 1951A 13715 PHLEGER 1951 A 13716 PHLEGER 1951A 13717 PHLEGER 1951A 13718 PHLEGER 1955A 13719 PARKER 1954 13720 PARKER 1954 13721 PARKER 1954 13722 PHLEGER 1951A 13723 PHLEGER 1951A 13724 PHLEGER 1951A 13725 PHLEGER 1951A 13726 PHLEGER 1951A 13727 PHLEGER 1951A 13728 PHLEGER 1951A 13729 PHLEGER 1951A 13730 PHLEGER 1951A 13731 PHLEGER 1951A 13732 PHLEGER 1951A 13733 PHLEGER 1951A 13734 PHLEGER 1951A 13735 PHLEGER 1951A 13736 PHLEGER 1951A 13737 PHLEGER 1951A 13738 PARKER 1954 13739 PARKER 1954 13740 PARKER 1954 13741 PARKER 1954 13742 PARKER 1954 3743 PARKER 1954 13744 PARKER 1954 13745 PARKER 1954 13746 PARKER 1954 13747 PARKER 1954 13748 PARKER 1954 13749 PARKER 1954 13750 PHLEGER 1955A 13751 WALTON 1964 13752 CUSHMAN 19228 13753 CREAGER 1958 13754 PARKER 1954 13755 PARKER 1954 13756 PARKER 1954 13757 PHLEGER 1955A 13758 PHLEGER 1955A 13759 LANKFORD 1959 13760 LUDWICK WALTON 195? 13761 PHLEGER 1955A 13762 PHLEGER 1955 A 13763 PARKER 1954 13764 PARKER 1954 13765 PARKER 1954 13766 PARKER 1954 13767 PARKER 1954 13768 PHLEGER 1955A 13769 PARKER 1954 13770 PHLEGER 1955A 13771 PHLEGER 1951A 13771 PHLEGER 1951 A 13772 PARKER 1954
13773 PARKER 1954 13773 PARKER 1954 13774 PARKER 1954 13775 PARKER 1956 13776 PARKER 1954 13777 PARKER 1954 13778 PARKER 1954 $\begin{array}{ll}13779 & \text { PHLEGER } \\ 137956 & \text { PHLEGER } 1951 \text { A }\end{array}$ 13781 PHLEGER 1951A 13782 PHLEGER 1951A 13783 KELLOUGH 1956 13784 KELLOUGH 1956 13785 CREAGER 1958 13786 CREAGER 1958 13787 CREAGER 1958 13788 CREAGER 1958 13789 CREAGER 1958 13790 PHLEGER 1956

\section{Generic Name}

CASSIDULINA CASSIDULINA CASSIDULINA CASSIDULINA CASSIDULINA CASSIDULINA CASSIDULINA CASSIDULINA CASSIDULINA CASSIDULINA CASS IDUI INA CASSIDULINA CASSIDULINA CASSIDULINA CASSIDULINA CASSIDULINA CASSIDULINA CASSIDULINA CASSIDUL INA CASSIDULINA CASSI DUL INA CASSIDULINA CASSIDULINA CASSIDUL INA CASSIDULINA CASSIDULINA CASSIDULINA CASSIDULINA CASS IDULINA CASSIDULINA CASSIDULINA CASSIDULINA CASSIDULINA CASSIDULINA CASSIDUL INA CASSIDUL INA CASSIDUL INA CASSI DULINA CASS IDULINA CASSIDULINA CASSI DULINA CASS IDULINA CASSIDUL INA CASSIDULINA CASSIDULINA CASS IDULINA CASSI DUL INA CA SSIDULINA CA SSIDULINA CASSIDUL INA CASSIDULINA CASSIDULINA CASSIDULINA CASSIDULINA CASSI DUL INA CASSI DUL INA CASSIDULINA CASSI DULINA CASSIDUL INA CASSIDULINA CASSIDULINA CASS IDULINA CASSIDULINA CASSIDULINA CASSI DUL INA CASS I DUL INA CASSIDULINA CASSIDULINA CASSI DUL INA CASS IDULINA CASSIDUL INA CASSIDULINA CASSIDULINA CASSIDULINA CASSIDULINA CASSIDULINA CASSIDULINA CASSIDULINA CASSIDULINA CASSIOULINA CASSIDULINA CASSIDULINA CASSI DULINA CASSIDULINA CA SSIDULINA CASSIDULINA CASSIDULINA CASSIDULINA CASSI DULINA CASSIDULINA CASSIDULINA CASSIDULINA CASSIDULINA CASSIDULINA
Specific Name

Locality

Lat.

Long.

SU BGL OBOSA

SU BGL OBOSA

SUEGL OBOSA

SUBGLOBOSA

SURGLOBOS

SUEGL OBOSA

SU BGL OB OS A

SUEGL OBOSA

SUEGL OBOSA

SUEGLOBOSA

SUEGLOBOSA

SUBGL OBOSA

SURGLOBOSA

SUEGLOBOSA

SUBGL OBOSA

SLIBGLOBOS A

SUBGLOBOSA

SUEGLOBOSA

SUEGL OBOSA

SUBGL OBOSA

SUEGLOBOSA

SUEGLOBOSA

SU BGL OB OS A

SUEGL OBOSA

SUEGL OB OS A

SUEGLOBOSA

SUBGL OBOSA

SU EGL OBOSA

SUBGLOBOSA

SUEGLOBOSA

SUEGL OBOSA

SUBGLOBOSA

SUBGLOBOSA

SU BGL OB OSA

SU BGL OB OS A

SUEGLOBOSA

SU BGL OB OSA

SUEGL OBOS A

SU BGL OBOSA

SUBGL OBOS

SUEGL OBOSA

SUEGLOBOSA

SU EGLOBOSA

SU BGLOBOSA

SUEGL OBOSA

SU EGLOBOSA

SUEGL OB OSA

SUEGLOBOSA

SUBGL OBOS

SUEGLOBOSA

SUBGLOBOSA

SU BGL OBOSA

SUEGL OBOS

SUEGL OBOS A

SUEGL OBOSA

SU BGL OBOSA

SU BGL OBOSA

SU BGL OBOSA

SUEGLOBOS $A$

SU BGLOBOSA

SU BGL OBOSA

SUEGL OBOSA

SU EGL OBOSA

SUEGL OBOSA

SUEGLOBOSA

SU BGL OBOSA

SUEGLOBOSA

SUBGLOBOSA

SUEGLOBOSA

SUEGLOBOS

SUBGL OBOSA

SU BGL OBOSA

SU EGL OBOS

SUBGL OBOS A

SUEGLOBOSA

SUBGL OBOSA

SUBGLOBOSA

SU BGL OBOS

SUEGLOBOSA

SUEGLOBOSA

SUEGLOBOSA

SUEGLOBOSA

SUBGL OBOSA

SUEGL OBOSA

SU BGLOBOSA

SUEGLOBOS

SUEGLOBOSA

SU BGL OBOSA

SU RGL OBOS

SUBGLOBOSA

SUEGL OBOSA

SUEGL OBOS A

SUEGLOBOS A

SU BGLOBOSA

SUEGL OB OS A 


\section{Publication}

13791 PHLEGER 1956 13792 PHLEGER 1956 13793 CREAGER 1958 13794 BOCK 1976

13795 BOCK.1976 13796 CREAGER 1958 13797 BOCK 1976

13798 BOCK 1976

13799 ANDERSEN 1961

13800 PFLUM FRERICHS 1976

13801 CREAGER 1958

13802 CREAGER 1958

13803 CREAGER 1958

13804 CREAGER 1958

13805 CREAGER 1958

13806 CREAGER 1958

13807 CREAGER 1958

13808 CREAGER 1958

13809 CREAGER 1958

13810 CREAGER 1958

13811 CREAGER 1958

13812 CREAGER 1958

13813 CREAGER 1958

13814 CREAGER 1958

13815 PFLUM FRERICHS 1976

13816 PFLUM FRERICHS 1976

13817 PFLUM FRERICHS 1976

13818 PFLUM FRERICHS 1976

13819 PFLUM FRERICHS 1976

13820 PFLUM FRERICHS 1976

13821 PFLUM FRERICHS 1976

13822 ANDERSEN 1961

13823 PFLUM FRERICHS 1976

13824 PFLUM FRERICHS 1976

13825 PFLUM FRERICHS 1976

13826 PFLUM FRERICHS 1976

13827 PFLUM FRERICHS 1976

13828 PFLUM FRERICHS 1976

13829. PFLUM FRERICHS 1976

13830 PFLUM FRERICHS 1976

13831 PFLUM FRERICHS 1976

13832 PFLUM FRERICHS 1976

13833 PFLUM FRERICHS 1976

13834 PFLUM FRERICHS 1976

13835 PFLUM FRERICHS 1976

13836 PFLUM FRERICHS 1976

13837 PFLUM FRERICHS 1976

13838 PFLUM FRERICHS 1976

13839 PFLUM FRERICHS 1976

13840 PFLUM FRERICHS 1976

13841 PFLUM FRERICHS 1976

13842 PFLUM FRERICHS 1976

13843 PFLUM FRERICHS 1976

13844 PFLUM FRERICHS 1976

13845 PFLUM FRERICHS 1976

13846 PFLUM FRERICHS 1976

13847 PFLUM FRERICHS 1976

13848 PFLUM FRERICHS 1976

13849 PFLUM FRERICHS 1976

13850 PFLUM FRERICHS 1976

13851 PFLUM FRERICHS 1976

13852 PFLUM FRERICHS 1976

13853 PFLUM FRERICHS 1976

13854 PFLUM FRERICHS 1976

13855 PFLUM FRERICHS 1976

13856 PFLUM FRERICHS 1976

13857 PFLUM FRERICHS 1976

13858 PFLUM FRERICHS 1976

13859 PFLUM FRERICHS 1976

13860 PFLUM FRERICHS 1976

13861 PFLUM FRERICHS 1976

13862 PFLUM FRERICHS 1976

13863 PFLUM FRERICHS 1976

13864 PFLUM FRERICHS 1976

13865 PFLUM FRERICHS 1976

13866 PFLUM FRERICHS 1976

13867 PFLUM FRERICHS 1976

13868 PFLUM FRERICHS 1976

13869 PFLUM FRERICHS 1976

13870 PARKER 1954

13871 PFLUM FRERICHS 1976

13872 PARKER 1954

13873 PARKER 1954

13874 PARKER 1954

13876 PHLEGER 1955 A

13876 PHLEGER 1955

13878 PARKER 1954

13879 PARKER 1954

13880 PARKER 1954

13881 PFLUM FRERICHS 1976

13882 PFLUM FRERICHS 1976

13883 PFLUM FRERICHS 1976

13884 PFLUM FRERICHS 1976

13885 PFLUM FRERICHS 1976
Generic Name

CASSIDUL INA

CASSIDUL INA

CASSIDULINA

CASSIDULINA

CASSIDULINA

CASSIDULINA

CASSIDULINA

CASSI DULINA

CASSI DULINA

CASSIDULINA

CASS IDULINA

CASSIDULINA

CASSIDULINA

CASSIDULINA

CASSIDULINA

CASSIDULINA

CASSIDULINA

CASSIDULINA

CASS I DUL INA

CASSIDULINA

CASSIDULINA

CASSIDULINA

CASSIDULINOIDES

CASSIDULINOIDES

CASSIDULINOIDES

CASSI DUL INOIDES

CASSIDULINOIDES

CASSIDULINOIDES

CASSIDULINOIDES

CASSIDULINOIDES

CASSI DULINOIDES

CASSI DULINOIDES

CASSIDULINOIDES

CASSIDULINOIDES

CASSIDULINOIDES

CASSIDUL INOIDES

CASSIDULINOIDES

CASSIDULINOIDES

CASSIDULINOIDES

CASSI DULINOIDES

CASSIDULINOIDES

CASSIDULINOIDES

CASSIDULINOIDES

CASSIDULINOIDES

CASSIDULINOIDES

CA SSIDULINOIDES

CASSIDULINOIDES

CASSIDUL INOIDES

CASSIDULINOIDES

CASSIDULINOIDES

CASSIDULINOIDES

CASSIDULINOIDES

CASSIDULINOIDES

CASSIDULINOIDES

CASSIDULINOIDES

CASSIDULINOIDES

CASSIDULINOIDES

CASSIDULINOIDES

CASSIDULINOIDES

CASSIDULINOIDES

CASSI DULINOIDES

CASSIDUL INOI DES

CASSIDULINOIDES

CASSI DUL INOIDES

CASSI DULINOIDES

CASSIDULINOIDES

CASS I DUL INO IDES

CASSI DULINOIDES

CASSIDUL INOIDES

CASS I DULINOIDES

CASSI DUL INOIDES

CASSI DULINOIDES

CASSIDULINOIDES

CASSI DULINOIDES

CASSIDULINOIDES

CASSIDULINOIDES

CASSIDULINOIDES

CASSI DULINOIDES

CASSIDULINOIDES

CASSIDUL INOIDES

CASSI DULINOIDES

CASSI DUL INOIDES

CASSIDULINOIDES

CASSIDULINOIDES

CASSI DUL INOIDES

CASSIDULINOIDES

CASSIDULINOIDES

CASSIDUL INOIDES

CASS IDULINOIDES

CASSIDULINOIDES

CASSIDULINOIDES

CASSIDULINOIDES

CASSIDULINOIDES
Specific Name

SUBGLOBOSA

UBGL OBOS A

SUBGL OB OSA

SUEGL OBOS A

SUBGL OBOS A

SUBGL OBOSA

SU BGL OBOSA

SUEGLOBOSA

SUBGLOBOSA

SUEGL OBOSA

SUBGL OBOSA

SUEGL OBOS A

SUBGLOBOSA

SUEGL OB OS A

SUBGL OB OS A

SU BGL OBOSA

SUBGL OBOSA

SUBGL OBOSA

SUBGL OBOSA

SUBGL OB OSA

SU BGL OBOSA

SUBGL OBOSA

SUBGL OBOS A

BRADYI

BRADYI

BRADYI

BRADYI

BRADYI

ME XICANA

ME XI CANUS

MEXI CANUS

MEXICANUS

MEXICANUS

MEXI CANUS

MEXICANUS

MEXICANUS

ME XI CANUS

ME XI CANUS

MEXICANUS

MEXI CANUS

MEXICANUS

MEXI CANUS

ME XI C ANUS

MEXICANUS

MEXICANUS

ME XICANUS

ME XI CANUS

MEXI CANUS

ME XI CANUS

MEXICANUS

MEXICANUS

ME XI CANUS

MEXICANUS

MEXI CANUS

ME XICANUS

ME XI CANUS

MEXICANUS

MEXICANUS

MEXICANUS

MEXICANUS

ME XICANUS

EXICANUS

ME XICANUS

MEXICANUS

PARKERI AN US

PARKERIANUS

PARKERI AN US

PARKERI AN US

PARKERI AN US

PA RKERI AN US

TENUIS

TENUIS

TENUIS

TENUIS

TENUIS

TE NUIS

TENUIS

TENUIS

TENUIS

TENUIS

TENUIS

TENUIS

TENUIS

TENUIS

TENUIS

Locality

Lat. Long.

NW GULF OF MEXICO NW GULF OF MEXICO

BAY OF CAMPECHE

NE GULF OF MEXICO

NE GULF OF MEXICO

BAY OF CAMPECHE

NE GULF OF MEXICO

NE GULF OF MEXICO 


\section{Publication}

13886 PFLUM FRERICHS 1976 13887 PFLUM FRERICHS 1976 13888 PFLUM FRERICHS 1976 13889 PFLUM FRERICHS 1976 13890 PFLUM FRERICHS 1976 13891 PFLUM FRERICHS 1976 13892 PARKER 1954

13893 PHLEGER 1955 A

13894 PARKER 1954

13895 PFLUM FRERICHS 1976

13896 PFLUM FRERICHS 1976

13897 LANKFORD 1959

13898 LUDWICK WALTON 1957

13899 PHLEGER 1951A

13900 PHLEGER 1951A

13901 PHLEGER 1951A

13902 PHLEGER $1951 \mathrm{~A}$

13903 PHLEGER 1951 A

13904 PFLUM FRERICHS 1976

13905 PFLUM FRERICHS 1976

13906 PFLUM FRERICHS 1976

13907 PFLIJM FRERICHS 1976

13908 PFLUM FRERICHS 1976

13909 PHLEGER 1951A

13910 PHLEGER 1951A

13911 PHLEGER 1951A

13912 PHLEGER 1951A

13913 PHLEGER 1951A

13914 PHLEGER 1951A

13915 PHLEGER 1951A

13916 PHLEGER 1951A

13917 PHLEGER 1951A

13918 PHLEGER $1951 \mathrm{~A}$

13919 PHLEGER $1951 \mathrm{~A}$

13920 PFLUM FRERICHS 1976

13921 PFLUM FRERICHS 1976

13922 PFLUM FRERICHS 1976

13923 PFLUM FRERICHS 1976

13924 PFLUM FRERICHS 1976

13925 PFLUM FRERICHS 1976

13926 PFLUM FRERICHS 1976

13927 PFLUM FRERICHS 1976

13928 PHLEGER 1951A

13929 PARKER 1954

13930 PARKER 1954

13931 PARKER 1954

13932 PARKER 1954

13933 PARKER 1954

13934 PARKER 1954

13935 PARKER 1754

13936 PARKER 1954

13937 PARKER 1954

13938 PARKER 1954

13939 PARKER 1954

13940 PARKER 1954

13941 PARKER 1954

13942 PHLEGER 1955 A

13943 LUDWICK WALTON 1957

13944 PFLUM FRERICHS 1976

13945 PFLUM FRERICHS 1976

13946 PFLUM FRERICHS 1976

13947 PFLUM FRERICHS 1976

13948 PFLUM FRERICHS 1976

13949 PFLUM FRERICHS 1976

13950 PFLUM FRERICHS 1976

13951 PFLUM FRERICHS 1976

13952 PFLUM FRERICHS 1976

13953 PFLUM FRERICHS 1976

13954 ANDERSEN 1961

13955 PFLUM FRERICHS 1976

13956 PFLUM FRERICHS 1976

13957. PFLUM FRERICHS 1976

13958 PFLUM FRERICHS 1976

13959 PFLUM FRERICHS 1976

13960 PFLUM FRERICHS 1976

13961 PFLUM FRERICHS 1976

13962 PFLUM FRERICHS 1976

13963 PFLUM FRERICHS 1976

13964 PFLUM FRERICHS 1976

13965 PFLUM FRERICHS 1976

13966 PFLUM FRERICHS 1976

13967 PFLUM FRERICHS 1976

13968 PFLUM FRERICHS 1976

13969 PFLUM FRERICHS 1976

13970 PFLUM FRERICHS 1976

13971 PFLUM FRERICHS 1976

13972 PHLEGER 1951A

13973 PHLEGER 1951A

13974 PARKER 1954

13975 PARKER 1954

13976 PARKER 1954

13977 PFLUM FRERICHS 1976

13978 PFLUM FRERICHS 1976

13979 PFLUM FRERICHS 1976

13980 PFLUM FRERICHS 1976
Generic Name

Specific Name

Locality

CASSIDULINOIDES

CASSIDULINOIDES

CASSI DULINOIDES

CASSI DULINOIDES

CASSI DUL INOIDES

CASSI DUL INOIDES

CASSIDULINOIDES

CASSIDULINOIDES

CASSIDULINOIDES

CASSIDULINOIDES

CASSI DULINOIDES

CASSIDULINOIDES

CASSI DUL INOIDES

CHILOSTOMELLA

CHILOSTOMELLA

CHILOSTOMELLA

CHILOSTOMELLA

CH ILOSTOMELLA

CHILOSTOMELLA

CHILOSTOMELLA

CHILOSTOMELLA

CHILOSTOMELLA

CHILOSTOMELLA

CHILOSTOMELLA

CHILOSTOMELLA

CHILOSTOMELLA

CHILOSTOMELLA

CHILOSTOMELLA

CHILOSTOMELLA

CHILOSTOMELLA

CHILOSTOMELLA

CHILOST OME LLA

CHILOSTOMELLA

CHILOSTOMELLA

CHILOSTOMELLA

CHILOSTOMELLA

CHILOSTOMELLA

CHILOSTOMELLA

CHILOSTOMELLA

CHILOSTOMELLA

CHILOSTOMELLA

CH I LOSTOMELLA

CHILOSTOMELLA

CHILOSTOMELLA

CHILOSTOMELLA

CHILOSTOMELLA

CHILOSTOMELLA

CHILOSTOMELLA

CHILOSTOMELLA

CHILOSTOMELLA

CHILOSTOMELLA

CHILOSTOMELLA

CHILOSTOMELLA

CHILOSTOMELLA

CHILOSTOMELLA

CH ILOSTOMELLA

CH ILOSTOMELLA

CHILOSTOMELLA

CHILOSTOMELLA

CHILOSTOMELLA

CH ILOSTOMELLA

CH ILOSTOMELLA

CHILOSTOMELLA

CHILOSTOMELLA

CHILOSTOMELLA

CHILOSTOMELLA

CHILOSTOMELLA

CHILOSTOMELLA

CHILOSTOMELLA

CHILOSTOMELLA

CHILOSTOMELLA

CHILOST OME LLA

CHILOSTOMELLA

CHILOSTOMELLA

CHILOSTOMELLA

CHILOSTOMELLA

CHILOSTOMELLA

CHILOSTOMELLA

CHILOSTOMELLA

CHILOSTOMELLA

CHILOSTOMELLA

CHILOSTOMELLA

CHILOSTOMELLA

CHILOSTOMELLA

CHILOSTOME LLA

CHILOSTOMELLA

CH ILOSTOME LLA

CHILOSTOMELLA

CHILOSTOMELLA

CHILOSTOMELA

CHILOSTOMELLA

CHILOSTOMELLA

CHILOSTOMELLA

CHILOSTOMELLA

CHILOSTOMELLA
TENUIS

TENUIS

TENUIS

TE NUIS

TENUIS

TENUIS

TENUIS

TENUIS

TENUIS

TENUIS

TENUIS

TENUIS

TENUIS

OOLINA

OOLINA

OOLINA

OOLINA

OOLINA

OOLINA

OOLINA

O OLINA

OLINA

OOLINA

OOLINA

OOLINA

DOLINA

OOLINA

OOLINA

OOLINA

OOLINA

OOLINA

OOLINA

OOLINA

DOLINA

OOLINA

OLIN

OOLINA

OOLINA

O LINA

OOLINA

OOLINA

OOLINA

OOLINA

OOLINA

OOLINA

OOLINA

OOLINA

OOLINA

OOLINA

OOLINA

OOLINA

OOLINA

OOLINA

OOLINA

OOLINA

OOLINA

OOLINA

OOLINA

OOLINA

OOLINA

OOLINA

OOLINA

OOLINA

OOLINA

OOLINA

OOLINA

DOLINA

OOLINA

OOLINA

OOLINA

OOLINA

OOLINA

OOLINA

OOLINA

OOLINA

OOLINA

OOLINA

OOLINA

OOLINA

OOLINA

OOLINA

OOLINA

OOLINA

OOLINA

OOLINA

OOLINA

DOL INA

DOLA

OOLINA

OOLINA

OOLINA

OOLINA

CENTRAL GULF OF MEXICO 


\section{Publication}

13981 PFLUM FRERICHS 1976 13982 PFLUM FRERICHS 1976 13983 PFLUM FRERICHS 1976 13984 PFLUM FRERICHS 1976 13985 PFLUM FRERICHS 1976 13986 PFLUM FRERICHS 1976 13987 PFLUM FRERICHS 1976 13988 PFLUM FRERICHS 1976 13989 PFLUM FRERICHS 1976 13990 CUSHMAN 1924

13991 BOCK 1976

13992 ANDERSEN 1961

13993 NORTON 1930

13994 KORNFELD 193

13995 KORNFELD 1931

13996 KORNFELD 1931

13997 KORNFELD 1931

13998 KORNFELD 1931

13999 NORTON 1930

14000 PFLUM FRERICHS 1976 14001 PFLUM FRERICHS 1976 14002 PFLUM FRERICHS 1976 14003 PFLUM FRERICHS 1976 14004 PFLUM FRERICHS 1976 14005 PFLUM FRERICHS 1976 14006 PFLUM FRERICHS 1976 14007 PFLUM FRERICHS 1976 14008 PFLUM FRERICHS 1976 14009 PFLUM FRERICHS 1976 14010 PFLUM FRERICHS 1976 14011 PFLUM FRERICHS 1976 14012 PFLUM FRERICHS 1976 14013 PFLUM FRERICHS 1976 14014 PFLUM FRERICHS 1976 14015 PFLUM FRERICHS 1976 14016 PFLUM FRERICHS 1976 14017 PFLUM FRERICHS 1976 14018 PFLUM FRERICHS 1976 14019 PFLUM FRERICHS 1976 14020 PFLUM FRERICHS 1976 14021 PFLUM FRERICHS 1976 14022 PFLUM FRERICHS 1976 14023 PFLUM FRERICHS 1976 14024 PFLUM FRERICHS 1976 14025 PFLUM FRERICHS 1976 14026 PFLUM FRERICHS 1976 14027 PFLUM FRERICHS 1976 14028 PFLUM FRERICHS 1976 14029 PFLUM FRERICHS 1976 14030 PFLUM FRERICHS 1976 14031 PFLUM FRERICHS 1976 14032 PFLUM FRERICHS 1976 14033 PFLUM FRERICHS 1976 14034 PFLUM FRERICHS 1976 14035 PFLUM FRERICHS 1976 14036 PFLUM FRERICHS 1976 14037 PFLUM FRERICHS 1976 14038 PFLUM FRERICHS 1976 14039 PFLUM FRERICHS 1976 14040 PFLUM FRERICHS 1976 14041 PFLUM FRERICHS 1976 14042 PFLUM FRERICHS 1976 14043 PFLUM FRERICHS 1976 14044 PFLUM FRERICHS 1976 14045 PFLUM FRERICHS 1976 14046 PFLUM FRERICHS 1976 14047 PFLUM FRERICHS 1976 14048 PFLUM FRERICHS 1976 14049 PFLUM FRERICHS 1976 14050 PFLUM FRERICHS 1976 14051 PFLUM FRERICHS 1976 14052 PFLUM FRERICHS 1976 14053 PFLUM FRERICHS 1976 14054 PFLUM FRERICHS 1976 14055 PFLUM FRERICHS 1976 14056 PFLUM FRERICHS 1976 14057 PFLUM FRERICHS 1976 14058 PFLUM FRERICHS 1976 14059 PFLUM FRERICHS 1976 14060 PFLUM FRERICHS 1976 14061 PFLUM FRERICHS 1976 14062 PFLUM FRERICHS 1976 14063 PFLUM FRERICHS 1976 14064 PFLUM FRERICHS 1976 14065 PFLUM FRERICHS 1976 14066 PFLUM FRERICHS 1976 14067 PFLUM FRERICHS 1976 14068 PFLUM FRERICHS 1976 14069 PFLUM FRERICHS 1976 14070 PFLUM FRERICHS 1976 14071 PFLUM FRERICHS 1976 14072 PFLUM FRERICHS 1976 14073 PFLUM FRERICHS 1976 14074 PFLUM FRERICHS 1976 14075 PFLUH FRERICHS 1976
Generic Name

Specific Name

Locality

CHILOSTOMELLA

CHILOSTOMELLA

CHILOSTOMELLA

CHILOSTOMELLA

CHILOSTOMELLA

CHILOSTOMELLA

CH I LOSTOMELLA

CH ILOST OMELLA

CHILOSTOMELLA

CHRYSAL IDINELLA

CHRYSAL I DINELLA

CIBICIDES

CIBICIDES

CIBICIDES

CIBICIDES

CIBICIDES

CIBICIDES

CIBICIDES

CIBICIDES

CIBICIDES

CIBICIDES

CIBICIDES

CIBICIDES

CIBICIDES

CIBICIDES

CIBICIDES

CIBICIDES

CIBICIDES

CIBICIDES

CIBICIDES

CIBICIDES

CIBICIDES

CIBICIDES

CI BICIDES

CIBICIDES

CIBICIDES

CIBICIDES

CIBICIDES

CIBICIDES

CIBICIDES

CIBICIDES

CIBICIDES

CIBICIDES

CIBICIDES

CIBICIDES

CIBICIDES

CIBICIDES

CIBICIDES

CIBICIDES

CIBICIDES

CIBICIDES

CIBICIDES

CIBICIDES

CIBICIDES

CIBICIDES

CIBICIDES

CIBICIDES

CIBICIDES

CIBICIDES

CIBICIDES

CIBICIDES

CIBICIDES

CIBICIDES

CIBICIDES

CIBICIDES

CIBICIDES

CIBICIDES

CI BICIDES

CIBICIDES

CIBICIDES

CIBICIDES

CIBICIDES

CIBICIDES

CIBICIDES

CIBICIDES

CIBICIDES

CIBICIDES

CIBICIDES

CIBICIDES

CIBICIDES

CIBICIDES

CIBICIDES

CIBICIDES

CIBICIDES

CIBICIDES

CIBICIDES

CIBICIDES

CIBICIDES

CIBICIDES

CIBICIDES

CIBICIDES

CIBICIDES

CIBICIDES
OOLINA

OOLINA

OOLINA

OOLINA

OOLINA

OOLINA

OOLINA

OVIINA

DI MORPHA

POPEI

ADVENA

AMERICANA STRATTONI

AMERI CANA STRATTON

AMERICANA STRATTONI

AMERICANA STRATTONI

AMERICANA STRATTONI

ANTILLARJM

BANTAMENS IS

BANTAMENS IS

BA ATAMENS IS

BANTAMENS IS

BANTAMENS IS

BANTAMENS IS

BANTAMENS IS

BANTAMENS IS

BANT AMENS IS

BAATAMENS IS

BANTAMENS IS

BANTAMENS IS

BANTAMENS IS

BANTAMENS IS

BANTAMENS IS

BANTAMENS IS

BAATAMENS IS

BANTAMENS IS

BANTAMENS IS

BANTAMENS IS

BR ADY I

BRADYI

BRADY I

BRADYI

BRADYI

BRADYI

BRADYI

BRADYI

BR ADY

BRADY

BRADY I

BRADYI

BRADYI

BRADY I

BRADYI

BRADYI

BRADY

BRADY

BRADYI

BRADYI

BR ADY I

BRADYI

BRADY

BRADYI

BRADYI

BRADYI

BRADYI

BRADYI

BR ADYI

BRADY

BRADY I

BRADYI

BRADY I

BRADYI

BRADYI

BRADY I

BRADY

BRADYI

BRADYI

BRADYI

BRADYI

BRADYI

BRADY I

BRADYI

BRADYI

BRADYI

BRADYI

BRADYI

BR ADY I

BR ADY

$B R A D Y I$

BRADY

BR ADY I

BRADYI

NW GULF OF MEXICO

NW GULF OF MEXICO

NW GULF OF MEXICO

NW GULF OF MEXICO

CENTRAL GULF OF MEXICO 


\section{Publication}

14076 PFLUM FRERICHS 1976 14077 PFLUM FRERICHS 1976 14078 PFLUM FRERICHS 1976 14079 PFLUM FRERICHS 1976 14080 PFLUM FRERICHS 1976 14081 PFLUM FRERICHS 1976 14082 PFLUM FRERICHS 1976 14083 PFLUM FRERICHS 1976 14084 CUSHMAN 1931

14085 CUSHMAN 1931

14086 PHLEGER 1951A

14087 CREAGER 1958

14088 CREAGER 1958

14089 CREAGER 1958

14090 PHLEGER 1951A

14091 PHLEGER 1951A

14092 PHLEGER $1951 \mathrm{~A}$

14093 PHLEGER 1951A

14094 PHLEGER $1951 \mathrm{~A}$

14095 PHLEGER $1951 \mathrm{~A}$

14096 PHLEGER 1951A

14097 PHLEGER $1951 \mathrm{~A}$

14098 PHLEGER $1951 \mathrm{~A}$

14099 PHLEGER 1951A

14100 PHLEGER 1951A

14101 PHLEGER 1951A

14102 PHLEGER 1951A

14103 PHLEGER 1951A

14104 PHLEGER $1951 \mathrm{~A}$

14105 PHLEGER 1951A

14106 PHLEGER $1951 \mathrm{~A}$

14107 PHLEGER 1951A

14108 PHLEGER 1951 A

14110 PHLEGER 1951A

14111 PHLEGER 1951A

14112 POST 1951

14113 PHLEGER 1951A

14114 PHLEGER $1951 \mathrm{~A}$

14116 PHLEGER 1951A

14117 PHLEGER $1951 \mathrm{~A}$

14119 CREAGER 1958

14119 CREAGER 1958

14120 CREAGER 1958

14121 POST 1951

14122 NORTON 1730

14123 PARKER 1954

14124 PARKER 1954

14125 ANDERSEN 196

14126 PARKER 1954

14127 PARKER 1954

14128 PARKER 1954

14129 PARKER 1954

14130 PARKER 1054

14131 PARKER 1954

14132 PARKER 1954

14133 PARKER 1954
14134 PARKER 1954

14134 PARKER 1954

14135 PARKER 1354

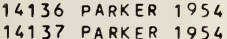

14137 PARKER 1954
14138 PARKER 1954

14139 DARKER 1754

14140 LUDWICK NALTON 1957

14141 PARKER 1954

14142 PARKER 1054

14143 DAVIS 1964

14144 PARKER 1954

14145 PARKER 1954

14146 PARKER 1954

14147 PHLEGER 1951A

14148 PARKER 1954

14950 PARKER 1054

14150 PARKER 1954

14151 PARKER 1954
14152 PARKER 1954

14153 PARKER 1954

14154 LUDWICK NALTON 1957

14155 PHLEGER 1951A

14156 AYALA-CASTANARES 1963

14157 BANDY 1956

14158 BANDY 1956

14159 BANDY 1956

14160 CREAGER 1958

14161 CREAGER 1958

14162 PHLEGER 1956

14163 CREAGER 1958

14164 CREAGER 1958

14165 PFLUY FRERICHS 1976

14166 PFLUM FRERICHS 1976

14167 PARKER 1054

14168 PARKER 1954

14169 PARKER 1954
14170 PARKER 1954

\section{Generic Name}

CIBICIDES

CIBICIDES

CIBICIDES

CIBICIDES

CIBICIDES

CIBICIDES

CIBICIDES

CIBICIDES

CIBICIDES

CIBICIDES

CIBICIDES

CIBICIDES

CIBICIDES

CIBICIDES

CIBICIDES

CIBICIDES

CIBICIDES

CIBICIDES

CIBICIDES

CIBICIDES

CIBICIDES

CIBICIDES

CIBICIDES

CIBICIDES

CIBICIDES

CI BICIDES

CIBICIDES

CIBICIDES

CIBICIDES

CIBICIDES

CIBICIDES

CI BICIDES

CIBICIDES

CIBICIDES

CIBICIDES

CIBICIDES

CIBICIDES

CIBICIDES

CIBICIDES

CIBICIDES

CIBICIDES

CIBICIDES

CIBICIDES

CIBICIDES

CIBICIDES

CIBICIDES

CIBICIDES

CIBICIDES

CI BICIDES

CIBICIDES

CI BICIDES

CIBICIDES

CI BICIDES

CIBICIDES

CI BICIDES

CI BICIDES

CIBICIDES

CIBICIDES

CIBICIDES

CIBICIDES

CIBICIDES

CIBICIDES

CIBICIDES

CIBICIDES

CIBICIDES

CIBICIDES

CIBICIDES

CIBICIDES

CIBICIDES

CIBICIDES

CIBICIDES

CIBICIDES

CIBICIDES

CIBICIDES

CIBICIDES

CIBICIDES

CIBICIDES

CI BICIDES

CIBICIDES

CIBICIDES

CIBICIDES

CIBICIDES

CIBICIDES

CIBICIDES

CI HICIDES

CIBICIDES

CIBICIDES

CIBICIDES

CISICIDES

CIBICIDES

CIBICIDES

CIBICIDES

CIBICIDES
Specific Name

BRADYI

BR ADYI

BRADY

BRADYI

BRADYI

BRADYI

BRADYI

CONCENTRI CA

CONCENTRI CA

CONCENTRI CUS

CONCENTRI CUS

CONCENTRI CUS

CONCENTRI CUS

CONCENTRI CUS

CONCENTRI CUS

CONCENTRI CUS

CONCENTRI CUS

CONCENTRI CUS

CONCENTRI CUS

CONCENTRI CUS

CONCENTRI CUS

CONCENTRI CUS

CONCENTRI CUS

CONCENTRI CUS

CONCENTRI CUS

CONCENTRI CUS

CONCENTRI CUS

CONCENTRI CUS

CONCENTRI CUS

CONCENTRI CUS

CONCENTRI CUS

CONCENTRI CUS

CONCENTRI CUS

CONCENTRI CUS

CONCENTRI CUS

CONCENTRI CUS

CONCENTRI CUS

CONCENTRI CUS

CONCENTRI CUS

CONCENTRI CUS

CONCENTRI CUS

CONCENTRI CUS

CONCENTRI CUS

CONCENTRI CUS

CONCENTRI CUS

CORA

CORPULENTUS

CORPULENT US

CORPULENT US

CORPULENT US

CORPULENT US

CORPULENT US

CORPULENT US

CORPULENT US

CORPULENT US

CORPULENT US

CORPULENTUS

CORPULENT US

CORPULENTUS

CORPULENT US

CORPULENT US

CORPULENT US

CORPULENT US

CORPULENT US

DEPRIMUS

DEPRIMUS

DEPRIMUS

DEPRIMUS

DEPRIMUS

DEPRIMUS

DEPRIMUS

DEPRIMUS

DEPRIMUS

DEPRIMUS

DEPRIMUS

DEPRIMUS

DEPRIMUS

DEPRIMUS

DEPRIMUS

DEPRIMUS

DE PRIMUS

DEPRIMUS

DEPRIMUS

DEPRIMUS

DEPRIMUS

DEPRIMUS

DEPRIMUS

DEPRIMUS

DEPRIMUS

DE FRIMUS

DEFRIMUS

DE PR I MUS

DEPRIMUS

DEPRIMUS

\section{Locality}

CENTRAL GULF OF MEXICO

NW GULF OF MEXICO

NW GULF OF MEXICO

$N W$ GULF OF MEXICO

NW GULF OF MEXICO 


\section{Publication}

14171 PARKER 1954

14172 PARKER 1954

14173 PARKER 1954

14174 PARKER 1954

14175 PHLEGER 1951A

14176 PHLEGER 1951A

14177 PFLUM FRERICHS 1976

14178 PFLUM FRERICHS 1976

14179 PFLUM FRERICHS 1976

14180 PFLUM FRERICHS 1976

14181 PFLUM FRERICHS 1976

14182 PFLUM FRERICHS 1976

14183 PHLEGER $1951 \mathrm{~A}$

14184 PHLEGER 1951A

14185 PHLEGER 1951A

14186 PHLEGER 1951 A

14188 PHLEGER 1951A

14189 PHLEGER $1951 \mathrm{~A}$

14190 PHLEGER 1951A

14191 PHLEGER $1951 \mathrm{~A}$

14192 PHLEGER $1951 \mathrm{~A}$

14193 PHLEGER 1951A

14194 PHLEGER $1951 \mathrm{~A}$

14195 PHLEGER $1951 \mathrm{~A}$

14196 PHLEGER 1951A

14197 PHLEGER 1951 A

14199 PHLEGER 1951A

14200 PHLEGER 1951A

14201 PHLEGER 1951A

14202 PHLEGER $1951 \mathrm{~A}$

14203 PARKER 1954

14204 PARKER 1954

14205 PARKER 1954

14206 PARKER 1954

14207 PARKER 1954

14208 PARKER 1954

14209 PHLEGER 1951A

14210 PHLEGER 1951A

14211 PARKER 1954

14212 PARKER 1954

14213 PARKER 1954

14214 PARKER 1954

14215 PARKER 1954

14216 PARKER 1954

14217 PARKER 1954

14218 PHLEGER 1951 A
14219 PARKER 1954

14219 PARKER 1954
14220 PARKER 1954

14221 PHLEGER $1951 \mathrm{~A}$

14222 PHLEGER 1951A

14223 PHLEGER 1951A

14224 PHLEGER 1951A

14225 PHLEGER 1951A

14226 LANKFORD 1959

14227 LUDHICK WALTON 1957

14228 PHLEGER 1955A

14229 PHLEGER 1955A

14230 PHLEGER 1955A

14231 PHLEGER 1955A

14232 PHLEGER $1951 \mathrm{~B}$

14233 PHLEGER 1955 A

14234 PHLEGER 1955A

14235 CREAGER 1958

14236 CREAGER 1958

14237 BOCK 1976

14238 BOCK 1976

14239 BOCK 1976

14240 BOCK 1976

14242 CREAGER 1958

14243 BOCK 1976

14244 PHLEGER 1956

14245 PARKER 1954
14246 PARKER 1954

14246 PARKER 1954
14247 PARKER 1954

14248 PARKER 1954

14249 PARKER 1954

14250 CREAGER 1958

14251 CREAGER 1958

14252 CREAGER 1958

14253 PHLEGER 1951A

14254 PHLEGER $1951 \mathrm{~A}$

14255 PHLEGER $1951 \mathrm{~A}$

14256 PHLEGER 1951 A

14258 PHLEGER 1951 A

14259 PHLEGER 1951A

14260 CREAGER 1958

14261 KELLOUGH 1956

14262 KELLOUGH 1956

14263 KELLOUGH 1956

14264 PFLUM FRERICHS 1976

14265 CREAGER 1958
Generic Name

CIBICIDES

CIBICIDES

CIBICIDES

CIBICIDES

CI BICIDES

CI BICIDES

CIBICIDES

CI BICIDES

CIBICIDES

CIBICIDES

CIBICIDES

CIBICIDES

CI BICIDES

CIBICIDES

CIBICIDES

CI BICIDES

CI BICIDES

CIBICIDES

CI BICIDES

CIBICIDES

CIBICIDES

CIBICIDES

CI BICIDES

CIBICIDES

CIBICIDES

CIBICIDES

CIBICIDES

CIBICIDES

CIBICIDES

CIBICIDES

CIBICIDES

CIBICIDES

CIBICIDES

CIBICIDES

CI BICIDES

CIBICIDES

CIBICIDES

CIBICIDES

CI BICIDES

C I BICIDES

CI BICIDES

CIBICIDES

CIBICIDES

CIBICIDES

CIBICIDES

CIBICIDES

CIBICIDES

CIBICIDES

CIBICIDES

CI BICIDES

CIBICIDES

CIBICIDES

CIBICIDES

CIBICIDES

CIBICIDES

CIBICIDES

CIBICIDES

CIBICIDES

CIBICIDES

CIBICIDES

CIBICIDES

CIBICIDES

CI BICIDES

CIBICIDES

CI BICIDES

CI BICIDES

CIBICIDES

CI BI CIDES

CIBICIDES

CIBICIDES

CI BI CIDES

CIBICIDES

CIBICIDES

CI BICIDES

CI BICIDES

CIBICIDES

CI BICIDES

CI BICIDES

CIBICIDES

CIBICIDES

CIBICIDES

CIBICIDES

CIBICIDES

CIBICIDES

CIBICIDES

CIBICIDES

CIBICIDES

CI BICIDES

CI BICIDES

CIBICIDES

CIBICIDES

CIBICIDES

CIBICIDES

CI BICIDES
Specific Name

DEPRIMUS

DEPRIMUS

DEPRIMUS

DEPRIMU

DEPRIMUS

DEPRIMUS

DEPRIMUS

DEPRIMUS

DEPRIMUS

EPRIMU

DEPRIMUS

DEPRIMUS

DE PRI MUS

DE PRIMUS

FL ORI DANA

FL OR I DANUS

FL ORI DANUS

FL ORIDANUS

FLORIDANUS

FL ORI DANUS

FLORI DANUS

FLORIDANJS

FL ORI DANUS

FL OR I DANUS

FL ORI DANUS

FL ORI DANUS

FL ORI DANUS

FLORI DANUS

FL ORI DANUS

FL ORIDANUS

FL ORI DANU S

FL ORI DANUS

FL ORIDANJS

FLORIDANUS

FLORIDANUS

FL OR I DANUS

FL ORIDANUS

FLORI DANUS

FL ORIDANUS

FL ORI DANUS

FL ORI DANUS

FL ORIDANUS

FL ORIDANUS

FL ORIDANUS

FL ORI DANUS

FLORIDANUS

FL ORIDANUS

FLORIDANU S

FLORIDANUS

FL OR I DANUS

FL ORI DANUS

FL ORIDANUS

FLORIDANUS

FL CRI DANUS

FL ORIDANUS

FL OR I DANUS

FL ORID

FL ORI DANUS

FL OR IDANUS

FL ORI DANUS

FL ORI DANUS

FL ORIDANUS

FL ORI DANUS

FLORIDANUS

FL ORI DANUS

FL OR I DANU S

FL ORI DANUS

FL OR IDANUS

FL ORI DANUS

FL ORIDANUS

FL OR IDANUS

FL ORI DANUS

FL OR I DANUS

FLCRIDANUS

FLCRIDANUS

FL ORIDANUS

FL ORI DANUS

FL ORI DANUS

FL ORI DANUS

FL OR I DANUS

FL ORI DANUS

FL ORI DANUS

FL ORIDANUS

FL ORIDANUS

FL CRIDANUS

FL ORI DANUS

FLORIDANUS

FL ORI DANUS

FLORI DANUS

FL ORIDANUS

FLORIDANUS

FLORIDANUS

Locality

NE GULF OF MEXICO

NE GULF OF MEXICO

NE GULF OF MEXICO

NE GULF OF MEXICO

NW GULF OF MEXICO

NW GULF OF MEXICO

NW GULF OF MEXICO

NW GULF OF MEXICO 


\section{Publication}

14266 CREAGER 1958

14267 CREAGER 1958

14268 ANDERSEN 1961

14269 PHLEGER 1951A

14 ? 70 PHLEGER 1951A

14271 PHLEGER 1951A

14272 PHLEGER 1951A

14273 PHLEGER $1951 \mathrm{~A}$

14274 PHLEGER 1951 A

14275 PHLEGER $1951 \mathrm{~A}$

14276 PHLEGER 1951A

14277 PHLEGER $1951 \mathrm{~A}$

14278 PARKER 1954

14279 PFLUM FRERICHS 1976

14280 PFLUM FRERICHS 1976

14281 PHLEGER 1951A

14282 PARKER 1954

14283 CREAGER 1958

14284 CREAGER 1958

14285 CREAGER 1958

14286 CREAGER 1958

14287 CREAGER 1958

14288 CREAGER 1958

14289 CREAGER 1958

14290 CREAGER 1958

14291 LOEP 1965

14292 KELLOUGH 1956

14293 KELLOUGH 1956

14294 KELLOUGH 1956

14295 PHLEGER 1954

14296 PARKER 1954

14298 PHLEGER 1951A

14299 PHLEGER 1951A

14300 PHLEGER $1951 \mathrm{~A}$

14301 PARKER 1954

14302 LUDWICK WALTON 1957

14303 PHLEGER 1951 A

14304 PHLEGER 1951A

14305 PHLEGER $1951 \mathrm{~A}$

14306 PHLEGER $1951 \mathrm{~A}$

14307 PHLEGER 1951A

14308 PHLEGER 1951A

14309 PHLEGER 1951A

14310 PHLEGER 1951A

14311 PHLEGER 1951A

14312 PHLEGER 1951A

14313 PHLEGER $1951 \mathrm{~A}$

14314 PARKER 1954

14315 PARKER 1954

14316 BOCK 1976

14317 PHLEGER 1951A

14318 PARKER 1954

14319 PARKER 1954

14320 PARKER 1954

14321 PARKER 1954

14322 PARKER 1954

14323 PARKER 1954

14324 PARKER 1954

14325 CREAGER 1958

14326 CREAGER 1958

14327 PARKER 1954

14328 PARKER 1954

14330 PFLUM FRERICHS 1976

14331 PFLUM FRERICHS 1976

14331 PFLUM FRERICHS 1976
14332 PFLUM FRERICHS 1976

14333 PFLUM FRERICHS 1976

14334 CREAGER 1958

14335 CREAGER 1958

14336 CREAGER 1958

14337 CREAGER 1958

14338 PFLUM FRERICHS 1976

14339 PFLUM FRERICHS 1976

14340 PFLUM FRERICHS 1976

14341 PFLUM FRERICHS 1976

14342 PFLUM FRERICHS 1976

14343 PFLUM FRERICHS 1976

14344 PFLUM FRERICHS 1976

14345 PFLUM FRERICHS 1976

14346 PFLUM FRERICHS 1976

14347 PFLUM FRERICHS 1976

14348 PFLUM FRERICHS 1976

14349 PARKER 1954

14350 PARKER 1954

14351 PARKER 1954

14352 PFLUM FRERICHS 1976

14353 PARKER 1954

14354 PARKER 1954

14355 PFLUM FRERICHS 1976

14356 PFLUM FRERICHS 1976

14357 PFLUM FRERICHS 1976

14358 PFLUM FRERICHS 1976

14359 PFLUM FRERICHS 1976

14360 PFLUM FRERICHS 1976
Generic Name

Specific Name

Locality

Lat. Long.

CIBICIDES

CIBICIDES

CIBICIDES

CIBICIDES

CIBICIOES

CIBICIDES

CIBICIDES

CI BICIDES

CIBICIDES

CIBICIDES

CIBICIDES

CIBICIDES

CIBICIDES

CIBICIDES

CIBICIDES

C IBICIDES

CIBICIDES

CIBICIDES

CIBICIDES

CIBICIDES

CIBICIDES

CIBICIDES

CIBICIDES

CIBICIDES

CIBICIDES

CIBICIDES

CIBICIDES

CIBICIDES

CIBICIDES

CIBICIDES

CIBICIDES

CIBICIDES

CIBICIDES

CIBICIDES

CIBICIDES

CIBICIDES

CIBICIDES

CIBICIDES

CIBICIDES

CIBICIDES

CI BICIDES

CIBICIDES

CIBICIDES

CIBICIDES

CIBICIDES

CIBICIDES

CIBICIDES

CI BICIDES

CIBICIDES

CIBICIDES

CIBICIDES

CIBICIDES

CIBICIDES

CIBICIDES

CIBICIDES

CIBICIDES

CIBICIDES

CIBICIDES

CIBICIDES

CIBICIDES

CIBICIDES

CI BICIDES

CIBICIDES

CIBICIDES

CIBICIDES

CIBICIDES

CIBICIDES

CIBICIDES

CIBICIDES

CIBICIDES

CIBICIDES

CIBICIDES

CIBICIDES

CI BICIDES

CIBICIDES

CIBICIDES

CIBICIDES

CIBICIDES

CIBICIDES

CIBICIDES

CIBICIDES

CIBICIDES

CIBICIDES

CIBICIOES

CIBICIDES

CIBICIDES

CIBICIDES

CIBICIDES

CIBICIDES

CIBICIDES

CIBICIDES

CIBICIDES

CI IICIDES

CIBICIDES
FLORIDANUS

FLORI DANUS

FL OR I DANUS

FL ORI DANUS

FLORI DANUS

FLORI DANU S

FLORIDANUS

FLCRIDANUS

FLORIDANUS

FL OR IDANUS

FLORI DANUS

FLORIDANJS

FLCRIDANUS

FLORI DANUS

FLCRIDANUS

FL ORIDANUS

FL ORI DANUS

FLORI DANUS

FL ORIDANUS

FLORIDANUS

FLORIDANUS

FL ORIDANJ S

FLORI DANUS

FLORIDANUS

FL ORI DANUS

FL ORIDANUS

FLORI DANUS

FL ORI DANUS

I 0

IO

I 0

I 0

10

I 0

10

I 0

10
10

I0

I 0

I 0

10

I 0

I0

I 0

I 0

I 0

I 0

I 0

I 0

KULLENBER GI

KULLENBERGI

KULLENBER GI

KULLENBER GI

KULLENBER GI

KULLENBER GI

KULLENBER GI

KULLENBER GI

KULLENBER GI

KULLENBER GI

KULLENBER GI

KULLENBER GI

KULLENBERGI

KULLENBER GI

KULLENBEP GI

KULLENBER I

KULLENBER GI

KULLENBER GI

KULLENBERGI

KULLENBER G I

KULLENBER GI

KULLENBER GI

KULLENBER G I

KULLEN

KULLENBER G I

KULLENBER G I

KULLE NBER GI

KULLENBER GI

KULLENBER GI

KULLENBER I

KULL

KULLENBERGI

KULLENBER GI

KULLENBER GI

KULLENBER GI

KULLLENBER G I

KULLENBER G I

KULLENBER I
KULLENBER GI
BAY OF CAMPECHE

BAY OF CAMPECHE

MISSISSIPPI DELTA

NW GULF OF MEXICO

NW GULF OF MEXICO

NW GULF OF MEXICO

NW GULF OF MEXICO

$N W$ GULF OF MEXICO

$N W$ GULF OF MEXICO 


\section{Publication}

14361 CREAGER 1958

14362 PFLUM FRERICHS 1976

14363 CREAGER 1958

14364 CREAGER 1958

14365 CREAGER 1958

14366 CREAGER 1958

14367 CREAGER 1958

14368 PFLUM FRERICHS 1976

14369 PFLUM FRERICHS 1976

14370 PFLUM FRERICHS 1976

14371 PFLUM FRERICHS 1976

14372 PFLUM FRERICHS 1976

14373 PFLUM FRERICHS 1976

14374 CREAGER 1958

14375 CREAGER 1958

14376 CREAGER 1958

14377 CREAGER 1958

14378 PFLUM FRERICHS 1976

14379 PFLUM FRERICHS 1976

14380 PHLEGER 1955A

14381 PFLUM FRERICHS 1976

14382 PFLUM FRERICHS 1976

14383 PFLUM FRERICHS 1976

14384 PFLUM FRERICHS 1976

14385 PARKER 1954

14386 PARKER 1954

14387 PARKER 1954

14388 PARKER 1954

14389 PFLUM FRERICHS 1976

14390 PFLUM FRERICHS 1976

14391 PFLUM FRERICHS 1976

14392 PFLUM FRERICHS 1976

14393 PFLUM FRERICHS 1976

14394 NORTON 1930

14395 CREAGER 1958

14396 CREAGER 1958

14397 BENDA PURI 1962

14398 CREAGER 1958

14399 PFLUM FRERICHS 1976

14400 PFLUM FRERICHS 1976

14401 PARKER 1954

14402 PARKER 1954

14403 PARKER 1954

14404 PARKER 1954

14405 PHLEGER 1951A

14406 PHLEGER 1951A

14407 PHLEGER 1951A

14408 PHLEGER $1951 \mathrm{~A}$

14409 PHLEGER $1951 \mathrm{~A}$

14410 PHLEGER 1951A

14411 PHLEGER 1951A

14412 PHLEGER 1951A

14414 PHLEGER $1951 \mathrm{~A}$

14415 PHLEGER 1951A

14416 PHLEGER 1951A

14417 PFLUM FRERICHS 1976

14418 PHLEGER $1951 \mathrm{~A}$

14419 PHLEGER 1951 A

14420 PARKER 1954
14421 LUDWICK WALTON 1957

14422 LANKFORD 1959

14423 PHLEGER 1951 A

14424 PHLEGER 1951A

14425 BOCK 1976

14426 PARKER 1954

14427 PHLEGER 1956

14428 PARKER 1954

14429 PARKER 1954

14430 PFLUM FRERICHS 1976

14431 CREAGER 1958

14432 CREAGER 1958

14433 CREAGER 1958

14434 PHLEGER 1951A

14435 PHLEGER 1951A

14436 PHLEGER 1951A

14437 PHLEGER $1951 \mathrm{~A}$

14438 PHLEGER 1951A

14439 PARKER 1954

14440 PARKER 1954

14441 PARKER 1954

14442 PARKER 1954

14443 PARKER 1954

14444 PARKER 1954

14445 PARKER 1954

14446 PARKER 1954

14447 PARKER 1954

14448 PARKER 1954

14449 PARKER 1954

14450 PARKER 1954

14451 PARKER 1954

14452 PARKER 1954

14453 PARKER 1954

14454 PARKER 1954

14455 PARKER 1954
Generic Name

CI BICIDES

CIBICIDES

CIBICIDES

CIBICIDES

CIBICIDES

CI BICIDES

CIBICIDES

CIBICIDES

CIBICIDES

CI BICIDES

CIBICIDES

CIBICIDES

CIBICIDES

CIBICIDES

CIBICIDES

CIBICIDES

CIBICIDES

CIBICIDES

CIBICIDES

CIBICIDES

CIBICIDES

CIBICIDES

CIBICIDES

CIBICIDES

CI BICIDES

CIBICIDES

CIBICIDES

CIBICIDES

CIBICIDES

CI BICIDES

CIBICIDES

CIBICIDES

CI BICIDES

CIBICIDES

CIBICIDES

CIBICIDES

CIBICIDES

CIBICIDES

CIBICIDES

CIBICIDES

CIBICIDES

CIBICIDES

CI BICIDES

CIBICIDES

CIBICIDES

CIBICIDES

CI BICIDES

CIBICIDES

CIBICIDES

CIBICIDES

CI BICIDES

CIBICIDES

CIBICIDES

CIBICIDES

CI BICIDES

CI BICIDES

CIBICIDES

CIBICIDES

CIBICIDES

CIBICIDES

CIBICIDES

CIBICIOES

C I BI CIDES

CIBICIDES

CIBICIDES

CIBICIDES

CIBICIDES

CIBICIDES

CI BICIDES

CIBICIDES

CIBICIDES

CIBICIDES

CIBICIDES

C I BICIDES

CIBICIDES

CIBICIDES

CI BICIDES

CI BICIDES

CIBICIDES

CI BICIDES

CIBICIDES

CIBICIDES

CI BI CIDES

CIBICIDES

CIBICIDES

CI BICIDES

CIBICIDES

CIBICIDES

CIBICIDE

CIBICIDES

CIBICIDES

CIBICIDES

CIOICIDES

CIBICIDES
Specific Name

KULLENBER GI

KULLENB ER GI

KULLENBER G

KULLENBER G

KULLENBER GI

KULLENBER G

KU LLENB ER GI

KULLENB

KULLENBER GI

KULLENBER GI

KULLENB ER G

KULLENBER G

KULLENB ER GI

KULLENBER GI

KULLENBER GI

KULLENBER GI

KULLENBER G

KULLENBER G

KULLENBER G

KULLENBER GI

KULLENBER G I

KULLENBER GI

KULLENBER G

KULLENBER G

KULLENBER G

KULLENBER G

KULLENBER GI

KULLENB ER

LOEATULA

LOBATULUS

LOBATUL US

LOBATUL US

LOBATULUS

LOBATUL US

LOBATULUS

MOLLIS

MOLLIS

MOLLIS

MOLLIS

MOLLIS

MOLLIS

MOLLIS

MOLLIS

MOLLIS

MOLLIS

MOLLIS

MOLLIS

MOLLIS

MOLLIS

MOLLIS

MOLLIS

MOLLIS

MOLLIS

MOLLIS

MOLLIS

MOLLIS

MOLLIS

MOLLIS

MOLLIS

MOLLIS

MOLLIS

MOLLIS

MOLLIS

MOLLIS

MOLLIS

MOLLIS

MOLLIS

MOLLIS

MOLLIS

MOLLIS

MOLLIS

MOLLIS

MOLLIS

MOLLIS

MOLLIS

PROTUBERANS

PROTUBERANS

PROTUBERANS

PR CTUBERANS

PR OTUBERANS

PROTUBE RANS

PROTUBERANS

PR OTUBERANS

PROTUBERANS

PR OTUBERANS

PR OTUBERANS

PROTUBERANS

PR OTUBERANS

P OTUBERA NS

PROTUBERANS

Locality

Lat. Long.

BAY OF CAMPECHE

NW GULF OF MEXICO

BAY OF CAMPECHE

BAY OF CAMPECHE

BAY OF CAMPECHE 
Publication

14456 PARKER 1954

14458 LUDWICK WALTON 1957

14459 CUSHMAN 1931

14460 CREAGER 1958

14461 CREAGER 1958

14462 CREAGER 1958

14463 CREAGER 1958

14464 CREAGER 1958

14465 CREAGER 1958

14466 CREAGER 1958

14467 CREAGER 1958

14468 CUSHMAN 1931

14469 CUSHMAN 1931

14470 CUSHMAN 1931

14471 CUSHMAN 193

14472 CUSHMAN

14473 CUSHMAN 1931

14474 CUSHMAN 1931
14475 CUSHMAN 1931

14476 CUSHMAN 1931

14477 CUSHMAN 1931

14478 PFLUM FRERICHS 1976

14479 PFLUM FRERICHS 1976

14480 PFLUM FRERICHS 1976

14481 PFLUM FRERICHS 1976

14482 PFLUM FRERICHS 1976

14483 PFLUM FRERICHS 1976

14484 PFLUM FRERICHS 1976

14485 PFLUM FRERICHS 1976

14486 PFLUM FRERICHS 1976

14487 PFLUM FRERICHS 1976

14488 PFLUM FRERICHS 1976

14489 PFLUM FRERICHS 1976

14490 PFLUM FRERICHS 1976

14491 PFLUM FRERICHS 1976

14492 PFLUM FRERICHS 1976

14493 PFLUM FRERICHS 1976

14494 PFLUM FRERICHS 1976

14495 PFLUM FRERICHS 1976

14496 PFLUM FRERICHS 1976

14497 PFLUM FRERICHS 1976

14498 PFLUM FRERICHS 1976

14499 PFLUM FRERICHS 1976

14500 PFLUM FRERICHS 1976

14501 PFLUM FRFRICHS 1976

14502 PFLUM FRERICHS 1976

14503 PFLUM FRERICHS 1976

14504 BANDY 1956

14505 PFLUM FRERICHS 1976

14506 PFLUM FRERICHS 1976

14507 PFLUM FRERICHS 1976

14508 PFLUM FRERICHS 1976

14509 PFLUM FRERICHS 1976

14510 PFLUM FRERICHS 1976

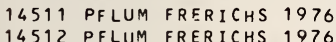

14513 AYALA-CASTANARES 1963

14514 BANDY 1956

14515 BANDY 1956

14516 BANDY 1956

14517 PFLUM FRERICHS 1976

14518 PFLUM FRERICHS 1976

14519 BANDY 1956

14520 BANDY 1956

14521 BANDY 1956

14522 BANDY 1956

14523 BANDY 1956

14524 BANDY 1956

14525 BANDY 1956

14527 PFLUM FRERICHS 1976

14528 PFLUM FRERICHS 1976

14528 PFLUM FRERICHS 1976

14530 PFLUM FRERICHS 1976

14531 PFLUM FRERICHS 1976

14532 PFLUM FRERICHS 1976

14533 PFLUM FRERICHS 1976

14534 PFLUM FRERICHS 1976

14535 PFLUM FRERICHS 1976

14536 PFLUM FRERICHS 1976

14537 PFLUM FRERICHS 1976

14538 PFLUM FRERICHS 1976

14539 PFLUM FRERICHS 1976

14540 PFLUM FRERICHS 1976

14541 PFLUM FRERICHS 1976

14542 PFLUM FRERICHS 1976

14543 PFLUM FRERICHS 1976

14544 PFLUM FRERICHS 1976

14545 PFLUM FRERICHS 1976

14546 PFLUM FRERICHS 1976

14547 PFLUM FRERICHS 1976

14548 PFLUM FRERICHS 1976

14549 CREAGER 1958

14550 PFLUM FRERICHS 1976
Generic Name

CIBICIDES

CIBICIDES

CIBICIDES

CISICIDES

CIBICIDES

CIBICIDES

CIBICIDES

CIBICIDES

CIBICIDES

CIBICIDES

CIBICIDES

CIBICIDES

CI BICIDES

CIBICIDES

CI BICIDES

CIBICIOES

CIBICIDES

CIBICIDES

CIBICIDES

CIBICIDES

CIBICIDES

CIBICIDES

CIBICIDES

CIBICIDES

CIBICIDES

CIBICIDES

CIBICIDES

CIBICIDES

CIBICIDES

CIBICIDES

CIBICIDES

CIBICIDES

CIBICIDES

CIBICIDES

CIBICIDES

CIBICIDES

CIBICIDES

CIBICIOES

CI BICIDES

CIBICIDES

CIBICIDES

CIBICIDES

CIBICIDES

CIBICIDES

CIBICIDES

CIBICIDES

CIBICIDES

CIBICIDES

CIBICIDES

CIBICIDES

CIBICIDES

CIBICIDES

CIBICIDES

CI BICIDES

CIBICIDES

CIBICIDES

CIBICIDES

CIBICIDES

CIBICIDES

CIBICIDES

CIBICIDES

CIBICIDES

CIBICIDES

CI IICIDES

CIBICIDES

CIBICIDES

CIBICIDES

CIBICIDES

CIBICIDES

CIBICIDES

CIBICIDES

CIBICIDES

CI BICIDES

CI RICIDES

CI BICIDES

CI BICIDES

CIBICIDES

CIBICIDES

CIBICIDES

CIBICIDES

CIBICIDES

CIBICIDES

CIBICIDES

CIBICIDES

CIBICIDES

CIBICIDES

CIBICIDES

CIBICIDES

CIBICIDES

CIBICIDES

CIBICIDES

CIBICIDES

CIBICIDES

CIBICIDES
Specific Name

PROTUBERANS

PROTUBERANS

PSEUDOUNGERIANA

PSEUDOUNG ER I ANA

PSEUDOUNGERIANA

PSEUDOUNGERIANA

PSEUDOUNGERIANA

PSEUDOUNGER IANA

PSEUDOUNG ER IANA

PSEUDOUNGER I ANA

PSEUDOUNGER I ANA

PS EUDOUNGER IANA IO

PSEUDOUNGERIANA IO

PSEUDOUNGER IANA IO

PSEUDOUNGER IANA IO

PSEUDOUNGERIANA IO

PSEUDOUNGERIANA IO

PSEUDOUNGERIANA IO

PSEUDOUNGERIANA IO

PSEUDOUNGERIANA IO

PSEUDOUNJERIANUS

PSEUDOUNGERIANUS

PS EUDOUNG ERIANUS

PSEUDOUNGER I ANUS

PSEUDOUNGERI ANUS

PS EUDOUNGER I ANUS

PSEUDOUNGERIANUS

PS EUDOUNG ER I ANUS

PSEUDOUNG ER I ANUS

PSEUDOUNGERI ANUS

PSEUDOUNGER IANUS

PSEUDOUNGERIANUS

PSEUDOUNGERI ANUS

PSEUDOUNOERIANUS

PS EUDOUNGERIANUS

PSEUDOUNOERIANUS

PSEUDOUNGERIANUS

PSEUDOUNOERI I ANUS

PSEUDOUNGER IANUS

PSEUDOUNGER IANUS

PS EUDOUNGERIANUS

PSEUDOUNGERIANUS

PS EUDOUNG ER IANUS

PSEUDOUNG ERIANUS

PS EUDOUNJ ER I ANUS

PSEUDOUNG ERI ANUS

PS EUDOUNG ER I ANUS

PSEUDOUNG ER I ANUS

PSEUDOUNGERIANUS

PS EUDOUNGERI ANUS

PSEUDOUNGER I ANUS

PSEUDOUNG ER I ANUS

PS EUDOUNOER I ANUS

PSEUDOUNGERIANUS

PSEUDOUNSERIANUS

PSEUDOUNSERIANUS

PSEUDOUNG ER IANUS

PS EUDOUNGERIANUS

PSEUDOUNG ERIANUS

PSEUDOUNG ER I ANUS

PSEUDOUNOERIANUS

PS EUDOUNGERIANUS

PS EUDOUNG ERIANUS

PSEUDOUNG ERIANUS

PS EUDOUNG ER IANUS

PSEUDOUNGERIANUS

PSEUDOUNG ER I ANUS

PSEUDOUNGER I ANUS

PS EUDOUNG ER I ANUS

PSEUDOUNG ER IANUS

PSEUDOUNGER IANUS

PSEUDOUNGER IANUS

PSEUDOUNG ERI ANUS

PSEUDOUNG ER I ANUS

PSEUDOUNG ER IANUS

PS EUDOUNG ER I ANUS

PSEUDOUNGER IANUS

PSEUDOUNOERIANUS

PSEUDOUNG ER I ANUS

PS EUDOUNG ER IANUS

PSEUDOUNG ER I ANUS

PSEUDOUNSER IANUS

PSEUDOUNOERIANUS

PS EUDOUNG ER I ANUS

PSEUDOUNGER IANUS

PSEUDOUNG ER IANUS

PSEUDOUNGER IANUS

PSEUDOUNG ER I ANUS

PSEUDOUNOER I ANUS

PS EUDOUNG ER I ANUS

PSEUDOUNGERIANUS

PSEUDOUNG ER I ANUS

PSEUDOUNS ER IANUS

Locality

Lat. Long.

NE GULF OF. MEXICO

NE GULF OF MEXICO

NE GULF OF MEXICO

NE GULF OF MEXICO

BAY OF CAMPECHE

BAY OF CAMPECHE 


\section{Publication}

14551 PFLUM FRERICHS 1976 14552 PFLUM FRERICHS 1976 14553 PFLUM FRERICHS 1976 14554 PFLUM FRERICHS 1976 14555 PFLUM FRERICHS 1976 14556 PFLUM FRERICHS 1976 14557 PFLUM FRERICHS 1976 14558 CREAGER 1958 14559 CREAGER 1958 14560 CREAGER 1958 14561 CREAGER 1958 14562 CUSHMAN 1931 14563 PARKER 1954 14564 CREAGER 1958 14565 CREAGER 1958 14566 CREAGER 1958 $\begin{array}{ll}14567 & \text { CREAGER } 1958 \\ 14568 & \text { CREAGER } 1958\end{array}$ 14568 CREAGER 1958
14569 CREAGER 1958 14570 PFLUM FRERICHS 1976 14579 PFLUM FRERICHS 1976 14572 PFLUM FRERICHS 1976 14573 PFLUM FRERICHS 1976 14574 CREAGER 1958 14575 CREAGER 1958 14576 CREAGER 1958 14577 CREAGER 1958 14578 PFLUM FRERICHS 1976 14579 PFLUM FRERICHS 1976 14580 PFLUM FRERICHS 1976 14581 PFLUM FRERICHS 1976 14582 CREAGER 1958 14583 CREAGER 1958 14584 CREAGER 1958 14585 CREAGER 1958 14586 CREAGER 1958 14587 BANDY 1956 14588 BANDY 1956 14589 BANOY 1956 14590 PFLUM FRERICHS 1976 14591 PFLUM FRERICHS 1976 14592 PFLUM FRERICHS 1976 14593 PFLUM FRERICHS 1976 14594 PHLEGER 1951A

14595 CREAGER 1958 $\begin{array}{lll}14596 & \text { PFLUM FRERICHS } & 1976 \\ 14597 & \text { PFLUM FRERICHS } & 1976\end{array}$ 14598 PFLUM FRERICHS 1976 14599 PFLUM FRERICHS 1976 14600 PFLUM FRERICHS 1976 14601 PFLUM FRERICHS 1976 14602 PFLUM FRERICHS 1976 14603 PFLUM FRERICHS 1976 14604 PFLUM FRERICHS 1976 14605 PARKER 1954 14606 PARKER 1954 14607 PARKER 1954 14608 PARKER 1954 14609 PARKER 1954 14610 PARKER 1954 14611 PARKER 1954 14612 PARKER 1954 14613 PARKER 1954 14614 PHLEGER $1951 \mathrm{~A}$ 14615 PHLEGER 1955A 14616 PHLEGER 1951A 14617 PHLEGER 1951 A 14618 PHLEGER 1951A 14619 PHLEGER 1951A 14620 PHLEGER 1951A 14621 PHLEGER 1951A 14623 PHLEGER 1951A 14624 PHLEGER 1951A 14625 PFLUM FRERICHS 1976 14626 PFLUM FRERICHS 1976 14627 PFLUM FRERICHS 1976 14628 PFLUM FRERICHS 1976 14629 PFLUM FRERICHS 1976 14630 PFLUM FRERICHS 1976 14631 PHLEGER 1955A

14632 PFLUM FRERICHS 1976 14633 PFLUM FRERICHS 1976 14634 PHLEGER 1955A 14635 PHLEGER 1955 A 14636 PHLEGER $1955 \mathrm{~A}$ 14637 PHLEGER 1955 A 14638 PFLUM FRERICHS 1976 14639 PFLUM FRERICHS 1976 14640 PFLUM FRERICHS 1976 14641 PFLUM FRERICHS 1976 14642 PFLUM FRERICHS 1976 14643 PFLUM FRERICHS 1976 14645 PFLUM FRERICHS 1976
Generic Name

Specific Name

CIBICIDES

CIBICIDES

CIBICIOES

CIBICIDES

CIBICIDES

CIBICIDES

CIBICIDES

CIBICIDES

CIBICIDES

CIBICIDES

CIBICIDES

CIBICIDES

CIBICIDES

CIBICIDES

CIBICIDES

CIBICIDES

CIBICIDES

CIBICIDES

CIBICIDES

CIBICIDES

CIBICIDES

CIBICIDES

CIBICIDES

CIBICIDES

CIBICIDES

CIBICIOES

CIBICIDES

CIBICIDES

CIBICIDES

CIBIC IDES

CIBICIDES

CIBICIDES

CIBICIOES

CIBICIDES

CIBICIDES

CIBICIDES

CIBICIDES

CIBICIDES

CIBICIDES

CIBICIDES

CIBICIDES

CIBICIDES

CIBICIDES

CIBICIDES

CIBICIDES

CIBICIDES

CIBICIDES

CIBICIDES

CIBICIDES

CIBICIDES

CIBICIDES

CIBICIDES

CI BICIDES

CIBICIDES

CIBICIDES

CIBICIDES

CI BICIDES

CIBICIDES

CIBICIDES

CIBICIDES

CIBICIDES

CIBICIDES

CIBICIDES

CIBICIDES

CIBICIDES

CIBICIDES

CIBICIDES

CIBICIDES

CIBICIDES

CIBICIDES

CIBICIDES

CI BICIDES

CIBICIDES

CIBICIDES

CIBICIDES

CIBICIDES

CI BICIDES

IBICIDES

CIBICIDES

CIBICIDES

CIBICIDES

CIBICIDES

CIBICIDES

CIBICIDES

CI BICIDES

CIBICIDES

PSEUDOUNGER I ANUS

PSEUDOUNGERIANUS

PSEUDOUNGERIANUS

PSEUDOUNGER IANUS

PSEUDOUNG ER I ANUS

PSEUDOUNG ER IANUS

RE FULGENS

RE FUL GENS

RE FUL GENS

REFULGENS

ROBERTSOVIANA

ROBERTSOVIANUS

ROBERTSOVIANUS

ROBERT SOVIANUS

ROBERTSON I ANUS

ROBERTSOVIANUS

ROBERTSOVIANUS

ROBERTSON IANUS

ROBERTSON IANUS

ROBER TSON IANUS

ROBERTSOVIANUS

ROBERTSON I ANUS

ROBERTSOVIANUS

ROBERTSOY IANUS

ROBERTS ON IANUS

ROBERTSONIANUS

ROBERT SONIANUS

ROBERTSOVIANUS

ROBERTSONIANUS

RO BERTSON IANUS

ROBERTSOY IANUS

ROBERTSON I ANUS

ROBERTSONIANUS

ROBERTSONIANUS

ROBERTSON I ANUS

ROBERTSON IANUS

ROBERTSONIANUS

ROBERT SON IANUS

ROBERTSON IANUS

ROBERTSOV I ANUS

ROBERTS ONIANUS

ROBERTSONIANUS

ROBERTSON IANUS

ROBERTS ON I ANUS

ROBERTSOVIANUS

ROBERTSON IANUS

ROBERTSONIANUS

ROBERTSON IANUS

ROBERTSONIANUS

ROBERTSONIANUS

ROBERTSON I ANUS

ROBERTSON IANUS

ROBERTSON IANUS

ROBERTSON IANUS

ROBERTS ON IANUS

ROBERTSOY IANUS

ROBERTSON IANUS

ROBERTSOVIANUS

ROEERTSON IANUS

ROBERTSON IANUS

ROBERTSON IANUS

ROBERTSONIANUS

ROBERTSON IANUS

ROEERTSONIANUS

ROBERTSON IANUS

ROBERTS ON I ANUS

ROBERTSON IANUS

ROBERTSON IANUS

ROPERTSONIANUS

ROBER TS

SON I ANUS

ROBERTSONIANUS

ROBERTS ONIANUS

ROBERTSON IANUS

ROBERTSON IANUS

ROBERTSON IANUS

ROBERTSONIANUS

ROBERTSONIANUS

ROBERTSON IANUS

ROBERTSON IANUS

ROBER TSON IANUS

ROBERTSONIANUS

ROBERTSONIANUS

ROBERTSOY IANUS

ROBERTSONIANUS

ROBERTSONIANUS

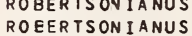

ROBERTSOVIANUS

ROBERTSON I ANUS

ROBERT SON IANUS

ROBERTSON IANUS

ROBERTSOR

ROBERTS ONIANUS
ROEERTS ON IANUS
Locality

PSEUDOUNGER I ANUS

ROBERTS ON IANUS

ROBERTS ON IANUS

CENTRAL GULF OF MEXICO CENTRAL GULF OF MEXICO CENTRAL GULF OF MEXICO CENTRAL GULF OF MEXICO CENTRAL GULF OF MEXICO CENTRAL GULF OF MEXICO CENTRAL GULF OF MEXICO 


\section{Publication}

14646. PFLUM FRERICHS 1976 14647 PFLUM FRERICHS 1976 14648 PFLUM FRERICHS 1976 14649 PFLUM FRERICHS 1976 14650 PFLUM FRERICHS 1976 14651 PFLUM FRERICHS 1976 14652 PFLUM FRERICHS 1976 14653 PFLUM FRERICHS 1976 14654 PFLUM FRERICHS 1976 14655 PFLUM FRERICHS 1976 14656 PFLUM FRERICHS 1976 14657 PARKER 1954 14658 PARKER 1954 14659 PARKER 1954 14660 PARKER 1954 14661 PARKER 1954 14662 PARKER 1954

14663 PARKER 1954

14664 PARKER 1954

14665 PHLEGER 1951A

14666 PHLEGER $1951 \mathrm{~A}$

14667 PHLEGER 1951A

14668 PFLUM FRERICHS 1976

14669 PFLUM FRERICHS 1976

14670 PARKER 1954

14671 PARKER 1954

14672 PARKER 1954

14673 PHLEGER 1955 A

14674 PHLEGER 1955 A

14675 PHLEGER $1951 \mathrm{~A}$

14676 PHLEGER $1951 \mathrm{~A}$

14678 PHLEGER 1951A

14678 PHLEGER 1951A

14680 PFLUM FRERICHS 1976

14681 PFLUM FRERICHS 1976

14682 PFLUM FRERICHS 1976

14683 PFLUM FRERICHS 1976

14684 PFLUM FRERICHS 1976

14685 PFLUM FRERICHS 1976

14686 PHLEGER $1951 \mathrm{~A}$

14687 CREAGER 1958

14688 CREAGER 1958

14689 CREAGER 1958

14690 CREAGER 1958

14691 PHLEGER 1951 A

14692 PHLEGER 1951 A

14693 PHLEGER 1951A

14694 PHLEGER 1951A

14695 PHLEGER $1951 \mathrm{~A}$

14696 CREAGER 1958

14697 CREAGER 1958

14698 CREAGER 1958

14699 PHLEGER 1951A

14700 PHLEGER $1951 \mathrm{~A}$

14701 PHLEGER 1951A

14702 PHLEGER 1951A

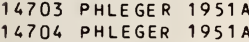

14705 PHLEGER 1951A

14706 PHLEGER 1951A

14707 PHLEGER 1951A

14708 PHLEGER 1951A

14709 CREAGER 1958

14710 CREAGER 1958

14711 CREAGER 1958

14712 CREAGER 1958

14713 PARKER 1954
14714 PARKER 1954

14714 PARKER 1954
14715 PARKER 1954

14716 PARKER 1954

14717 CREAGER 1958

14718 LUDWICK WALTON 1957

14719 PARKER 1954

14720 PARKER 1954

14721 PARKER 1954

14722 PARKEQ 1954

14723 PARKER 1954

14724 PARKER 1954

14725 PARKER 1954

14726 CREAGER 1958

14727 CREAGER 1958

14728 CREAGER 1958

14729 PARKER 1954

14730 CREAGER 1958

14731 PFLUM FRERICHS 1976

14732 PFLUM FRERICHS 1976

14733 PFLUM FRERICHS 1976

14734 PFLUM FRERICHS 1976

14735 PFLUM FRERICHS 1976

14736 PFLUM FRERICHS 1976

14737 PFLUM FRERICHS 1976

14738 PFLUM FRERICHS 1976

14739 PFLUM FRERICHS 1976

14740 PFLUM FRERICHS 1976

\section{Generic Name \\ Specific Name}

CIBICIDES

CI IICIDES

CI BICIDES

CIBICIDES

CIBICIDES

CIBICIDES
CIBICIDES

CIBICIDES

CIBICIDES

CI BICIDES

CIBICIDES

CIBICIDES

CIBICIDES

CI BICIDES

CIBICIDES

CIBICIDES

CIBICIDES

CIBICIDES

CIBICIDES

CIBICIDES

CIBICIDES

CIBICIDES

CIBICIDES

CIBICIDES

CIBICIDES

CIBICIDES

CIBICIDES

CIBICIDES

CIBICIDES

CIBICIDES

CIBICIDES

CIBICIDES

CIBICIDES

CIBICIDES

CIBICIDES

CIBICIDES

CIBICIDES

CIBICIDES

CIBICIDES

CIBICIDES

CIBICIDES

C I BICIDES

CIAICIDES

CIBICIDES

CIBICIDES

CIBICIDES

CIBICIDES

CIBICIDES

CI BICIDES

CIBICIDES

CIBICIDES

CIBICIDES

CI BICIDES

CIBICIDES

CIBICIDES

CIBICIDES

CIBICIDES

C I BICIDES

CIBICIDES

CIBICIDES

CIBICIDES

C I BICIDES

CI BICIDES

CIBICIDES

CIBICIDES

CIBICIDES

CIBICIDES

CI BICIDES

CIBICIDES

CI BICIDES

C I BICIDES

CI BICIDES

CIBICIDES

CI BICIDES

C I BICIDES

CIBICIDES

CI BIC IDES

CIBICIDES

CIBICIDES

CIBICIDES

CIBICIDES

CI BICIDES

CIBICIDES

CI BICIDES

CIBICIDES

C IBICIDES

CIBICIDES

CIBICIDES

CIBICIDES

CIBICIDES

CIBICIDES

CIBICIDES

CIBICIDES

CIBICIDES

CIBICIDES
ROBERTSONIANUS

ROBERTS ON IANUS

ROBERTSONIANUS

ROBERTSON IANUS

ROBERTSOVIANUS

ROBERTS OVIANUS

ROBERTS OVIANUS

ROEERTSON IANUS

ROBERTSON I A NUS

ROBERTSONIANUS

ROBERTSONIANUS

ROBERTSOVIANUS

ROEERTSONIANUS

ROEERTSONIANUS

ROBERTSONIANUS

ROBERTSON IANUS

ROEERTSON IANUS

ROBERTSON IANUS

ROEERTS ON IANUS

ROEERTSON IANUS

ROBERTSON I ANUS

ROBER TSOV IANUS

ROBERTS ON IANUS

ROBERTSOVIANUS

ROBERTSON IANUS

ROBERTSOVIANUS

ROBERTSONIANUS

ROBERTSON IANUS

ROBERTSOV IANUS

ROBERTSONIANUS

ROEERTSON IANUS

ROEERTSOVIANUS

ROBERTSON IANUS

ROEERTS ON IANUS

ROEERTSONIANUS

ROEERTSOV IANUS

ROEERTSON IANUS

ROBERTS ONIANUS

RO BER TSON IANUS

ROBERTS OVIANUS

ROBUSTUS

ROEUSTUS

ROBUSTUS

ROBUSTUS

ROEUSTUS

ROBUSTUS

ROEUSTUS

ROEUSTUS

ROEUSTUS

ROBUSTUS

ROBUSTUS

ROBUSTUS

ROEUSTUS

ROEUSTUS

ROBUSTUS

ROBUSTUS

ROBUSTUS

ROBUSTUS

ROEUSTUS

ROEUSTUS

ROBUSTUS

ROBUSTUS

ROBUSTUS

RUGOSA

RUGOSA

RUGOSA

RUGOSA

RUGOSA

RUGOSA

RUGOSA

RUGOSA

RUGOSA

RUGOSA

RUGOSA

RUGOSA

RUGOSA

RUGOSA

RUGOSA

RUGOSA

RUGOSA

RUGOSA

RUGOSA

RUGOSA

RUGOSA

RU GOSA

RUGOSA

RUGOSUS

RUGOSUS

RUGOSUS

RUGOSUS

RUGOSUS

RUGOSUS

RUGOSUS

RUGOSUS

RUGOSUS

Locality

Lat. Long.

NW GULF OF MEXICO

NW GULF OF MEXICO 


\section{Publication}

14741 PFLUM FRERICHS 1976 14742 PFLUM FRERICHS 1976 14743 PFLUM FRERICHS 1976 14744 PFLUM FRERICHS 1976 14745 PFLUM FRERICHS 1976 14746 PFLUM FRERICHS 1976 14747 PFLUM FRERICHS 1976 14748 PFLUM FRERICHS 1976 14749 PFLUM FRERICHS 1976 14750 PFLUM FRERICHS 1976 14751 PFLUM FRERICHS 1976 14752 PFLUM FRERICHS 1976 14753 PFLUM FPERICHS 1976 14754 PFLUM FRERICHS 1976 14755 PFLUM FRERICHS 1976 14756 PFLUM FRERICHS 1976 14757 PFLUM FRERICHS 1976 14758 PFLUM FRERICHS 1976 14759 PFLUM FRERICHS 1976 14760 PFLUM FRERICHS 1976 14761 PFLUM FRERICHS 1976 14762 PFLUM FRERICHS 1976 14763 PFLUM FRERICHS 1976 14764 DFLUM FRERICHS 1976 14765 PFLUM FRERICHS 1976 14766 PFLUM FRERICHS 1976 14767 PFLUM FRERICHS 1976 14768 PFLUM FRFRICHS 1976 14769 PFLUM FRERICHS 1976 14770 PFLUM FRERICHS 1976 14771 PFLUM FRERICHS 1976 14772 PFLUM FRERICHS 1976 14773 PFLUM FRERICHS 1976 14774 PFLUM FRERICHS 1976 14775 NORTON 1930 14776 CREAGER 1958 14777 CREAGER 1958 14778 CREAGER 1958 14779 CREAGFR 1958 14780 BOCK 1076

14781 PARKER 1054 14782 PARKER 105 14783 PFLUM FPERICHS 1976 14784 PFLUM FRERICHS 1976 14785 PFLUM FRERICHS 1976 14786 CREAGER 1958

14787 CREAGER 1958

14788 PFLUM FRERICHS 1976 14789 PFLUM FRERICHS 1976 14790 PFLUM FRERICHS 1976 14791 PFLUM FRERICHS 1976 14792 PFLUM FRERICHS 1976 14793 PFLUM FRERICHS 1976 14794 CREAGER 1958

14795 CREAGER 1959

14796 PFLUM FRERICHS 1976 14797 CREAGER 1958

14798 PFLUM FRERICHS 1976 14799 PFLUM FRERICHS 1976 14800 PFLUM FRERICHS 1976 14801 PARKER 1754

14802 PARKER 1954

14803 PARKER 1954

14804 PARKER 1954

14805 PARKER 1254

14806 PARKER 1954

14807 PFLUM FRERICHS 1976

14803 PFLUM FRERICHS 1976 14809 PHLEGER 1951A

14810 PHLEGER $1951 \mathrm{~A}$

14812 LUDWICK WALTON 1957

14813 PFLUM FRERICHS 1976

14814 PFLUM FRFRICHS 1976

14815 PFLUM FRERICHS 1976 14816 PFLUA FRERICHS 1976 14817 PFLUM FRERICHS 1976 14818 PFLUM FRERICHS 1976 14810 PFLUM FRERICHS 1976 14820 PFLUM FRERICHS 1976 14821 PFLUM FRERICHS 1976 14822 PFLUM FRERICHS 1976 14823 PARKER 1954 14824 PARKER 1954 14825 PHLEGER 1951A 14826 PHLEGER 19514 14827 PHLEGER 1951 A 14828 PHLEGER 1951A 14829 PHLEGER 1951A 14830 NORTON 1930 14831 NORTON 1930 14832 CREAGER 1958 14835 PFLUM FRERICHS 1976
Generic Name

CI 9 ICIDES

CIBICIDES

CIBICIDES

CIBICIDES

CIBICIDES

CIBICIDES

CIBICIDES

CIBICIDES

CIBICIDES

CI I ICIOES

CIBICIDES

CIBICIDES

CIBICIDES

CIBICIDES

CIBICIDES

CIRICICES

CIBICIDES

CIBICIDES

CIBICIDES

C IBICIDES

CIBICIDES

CI BICIDES

CIBICIDES

CIBICIDES

CIBICIDES

CIBICIDES

CIBICIDES

CI BICIDES

C I BICIDES

CIBICIDES

CIBICIDES

CIBICIDES

CIBICIDES

CI SICIDES

CIBICIDES

CIRICIDES

CIBICIDES

CIBICIDES

CI BICIDES

CI I I IDES

CIBICIDES

CI BICIDES

CIBICIDES

CIBICIDES

C I BICIDES

CIBICIDES

CI BICIDES

CIBICIDES

CI BICIDES

CI BICIDES

CIBICIDES

CIBICIDES

CIBICIDES

CIBICIDES

CIBICIDES

CI BICIDES

CIBICIDES

CIBICIDES

CI B I C I DES

CIBICIDES

CIBICIDES

CIBICIDES

CIBICIDES

CIBICIDES

CI I ICIDES

C I BICIDES

CIBICIDES

C IBICIDES

CIBICIDES

CIBICIDES

CIBICIDES

CIBICIDES

CI BICIDES

CIBICIDES

CIBICIDES

CIBICIDES

CIBICIDES

CIBICIDES

CIBICIDES

CI IICIDES

CIBICIDES

CIBICIDES

CIBICIDES

CIBICIDES

CIBICIDES

CIBICIDES

CI BICIDES

CIBICIDES

CI BICIDES

CIBICIDES

CIBICIDES

C IBICIDES

CIBICIDES
Specific Name

RUGOSUS

RUGOSUS

RUGOSUS

RUGOSUS

RUGOSUS

RUGOSUS

RUGOSUS

RUGOSUS

RUGOSUS

RUGOSUS

RUGOSUS

RUGOSUS

RUGOSUS

RUGOSUS

RUGOSUS

RUGOSUS

RUGOSUS

RUGOSUS

RUGOSUS

RUGOSUS

RUGOSUS

RUGOSUS

RUGOSUS

RUGOSUS

RUGOSUS

RUGOSUS

RUGOSUS

RUGOSUS

RUGOSUS

RUGOSUS

RUGOSUS

TUN I DUL A

UMBONATUS

UMBONAT US

UMBONATUS

UMBONATUS

UMBONATUS

UMBONATUS

UMBONATUS

UMBONATUS

UMBONATUS

UM EONAT US

UMEONATUS

UMBONATUS

UMEONAT US

UMEONAT US

UMBONATUS

UMEONATUS

UMBONATUS

UMBONATUS

UMBONATUS

UMBONATUS

UMEONATUS

UMEONATUS

UMBONATUS

UMBONATUS

UMBONATUS

UMEONATUS

UMBONATUS

UMEONATUS

UMEONATUS

UMEONATUS

UMBONATUS

UMEONATUS

UMEONATUS

UMBONATUS

UMEONATUS

UMEONATUS

UMBONATUS

UMEONATUS

UMBONATUS

UMEONAT US

UMBONATUS

UMBONATUS

UMEONATUS

UMEONATUS

UMBONATUS

UMEONAT US

UMBONATUS

UMBONATUS

UMEONATUS

UMEONATUS

UMEONATUS

UMEONAT US

UMEONATUS

UMBONATUS

UN GER I A NA

WUELLERST ORF

WUELLERST ORF I

WU ELLERST ORF I

WUELLERST ORF I
WUELLERST ORF I

Locality

NW GULF OF MEXICO

NW GULF OF MEXICO

NW GULF OF MEXICO

NW GULF OF MEXICO

CENTRAL GULF OF MEXICO

CENTRAL GULF OF MEXICO

CENTRAL GULF OF MEXICO 


\section{Publication}

14836 PFLUM FRERICHS 1976 14837 PARKER 1954

14838 CREAGER 1958

14839 CREAGER 1958

14840 PFLUM FRERICHS 1976

14841 PFLUM FRERICHS 1976

14842 PFLUM FRERICHS 1976

14843 PFLUM FRERICHS 1976

14844 PFLUM FRERICHS 1976

14845 PFLUM FRERICHS 1976

14846 PFLUM FRERICHS 1976

14847 PFLUM FRERICHS 1976

14848 PFLUM FRERICHS 1976

14849 PFLUM FRERICHS 1976

14850 PFLUM FRERICHS 1976

14851 PFLUM FRERICHS 1976

14852 PFLUM FRERICHS 1976

14853 PHLEGER 1955 A

14854 PHLEGER 1955 A

14855 PARKER 1954

14856 CREAGER 1958

14857 CREAGER 1958

14858 CREAGER 1958

14859 PFLUM FRERICHS 1976

14860 PFLUM FRERICHS 1976

14861 PFLUM FRERICHS 1976

14862 PFLUM FRERICHS 1976

14863 PFLUM FRERICHS 1976

14864 PFLUM FRERICHS 1976

14865 PFLUM FRERICHS 1976

14866 PFLUM FRERICHS 1976

14867 PFLUM FRERICHS 1976

14868 PFLUM FRERICHS 1976

$1486^{\circ}$ PFLUM FRERICHS 1976

14870 PFLUM FRERICHS 1976

14871 PFLUM FRERICHS 1976

14872 PFLUM FRERICHS 1976

14873 PFLUM FRERICHS 1976

14874 PFLUM FRERICHS 1976

14875 PFLUM FRERICHS 1976

14876 PFLUM FRERICHS 1976

14877 PFLUM FRERICHS 1976

14878 PFLUM FRERICHS 1976

14879 PFLUM FRERICHS 1976

14880 PFLUM FRERICHS 1976

14881 PFLUM FRERICHS 1976

14882 PFLUM FRERICHS 1976

14883 PFLUM FRERICHS 1976

14884 PFLUM FRERICHS 1976

14885 PFLUM FRERICHS 1976

14886 PARKER 1954

14887 PARKER 1954

14888 PARKER 1954

14889 PARKER 195

14890 PARKER 1954

14891 PARKER 1954

14892 PARKER 1954

14893 PARKER 1954

14894 CREAGER 1958

14895 PHLEGER 1955A

14896 PHLEGER 1955A

14897 PHLEGER 1955 A

14898 PHLEGER 1955A

14899 PHLEGER 1955A

14900 PHLEGER 195SA

14901 PFLUM FRERICHS 1976

14902 PFLUM FRERICHS 1976

14903 PARKER 1954

14904 PARKER 1954

14905 PARKER 1954

14906 PARKER 1954

14907 PFLUM FRERICHS 1976

14908 PFLUM FRERICHS 1976

14909 PFLUM FRERICHS 1976

14910 PFLUM FRERICHS 1976

14911 PFLUM FRERICHS 1976

14912 PFLUM FRERICHS 1976

14913 PARKER 1954

14914 PARKER 1954

14915 PARKER 1954

14916 PARKER 1756

14917 PFLUM FRERICHS 1976

14918 PFLUM FRERICHS 1976

14919 PFLUM FRERICHS 1976

14920 PFLUM FRERICHS 1976

14921 PFLUM FRERICHS 1976

14922 PFLUM FRERICHS 1976

14923 PFLUM FRERICHS 1976

14924 PFLUM FRERICHS 1976

14925 LUDWICK WALTON 1957

14926 PARKER PHLEGER PEIRSON 1953

14927 LUDWICK WALTON 1957

14928 PHLEGER 1954

14929 WARREN 1957

14930 PARKER PHLEGER PEIRSON 1953
Generic Name

CIBICIDES

CIBICIDES

CI IICIDES

CIBICIDES

CIBICIDES

CIBICIDES

CIBICIDES

CIBICIDES

CIBICIDES

CIBICIDES

CIBICIDES

CI BICIDES

CIBICIDES

CI BICIDES

CIBICIDES

CIBICIDES

CIBICIDES

CIBICIDES

CIBICIDES

CIBICIDES

CIBICIDES

CIBICIDES

CIBICIDES

CIBICIDES

CIBI CIDES

CIBICIDES

CIBICIDES

CIBICIDES

CI BICIDES

CIBICIDES

CIBICIDES

CIBICIDES

CIBICIDES

CIBICIDES

CIBICIDES

CIBICIDES

CIBICIDES

CIBICIDES

C I BICIDES

CIBICIDES

CIBICIDES

CIBICIDES

CIBICIDES

CIBICIDES

CI BICIDES

CIBICIDES

CIBICIDES

CIBICIDES

CIBICIDES

CIBICIDES

CIBICIDES

CIBICIDES

CIBICIDES

CIBICIDES

CIBICIDES

CIBICIDES

CI BICIDES

CIBICIDES

CIBICIDES

CIBICIDES

CIBICIDES

CIBICIDES

CIBICIDES

CIBICIDES

CIBICIDES

CIBICIDES

CIBICIDES

CIBICIDES

CIBICIDES

CIBICIDES

CIBICIDES

CIBICIDES

CIBICIDES

CIBICIDES

CIBICIDES

CIBICIDES

CIBICIDES

CIBICIDES

CIBICIDES

CIBICIDES

CIBICIDES

CIBICIDES

CIBICIDES

CIBICIDES

CIBICIDES

CIBICIDES

C IBICIDINA

CIBICIDINA

CI BICIDINA

CI BICIDINA

CIBICIDINA

CIBICIDINA
Specific Name

Locality

WUELLERST ORF I

WUELLERSIORFI

WUELLERSTORFI

WUELLERST ORF I

WUELLER ST OR F I

WUELLERST ORFI

WUELLER ST OR FI

WUELLERST ORF

WUELLERST ORFI

WUELLER STORF

WUELLER ST ORF

WUELLERST OR F

WUELLER ST ORF I

WUELERST ORF

WU ELLER ST ORF

WUELLERST ORF

WUELLERST ORF

WUELLER ST OR F

WUELLERST ORF I

WUELLERST ORF

WUELLERST ORFI

WUELLERST ORF I

WUELLERST ORF

WUELLER ST OR F

WUELLERST OR FI

WUELLER ST ORF

WUELLERST ORF I

WUELLERST ORFI

WUELLERST ORF

WU ELLERST ORF

WUELLERST ORF

WUELLER STORF

WUELLER ST OR

WU ELLER ST ORF

WUELLERST ORF

WUELLERST ORF

WUELLERST ORFI

WUELLERST ORF

WUELLERSTORFI

WUELLER ST ORFI

WUELLERSI ORF

WUELLER ST ORF

WUELLER ST OR F

WUELLERSTOR F I

WUELLERST ORF

WUELLERSTORF

WUELLER ST ORF

WUELLER ST OR F

WUELLERST OR FI

WUELLERST ORFI

WUELLERST ORFI

WUELLERSI ORFI

WUELLERSTORF

WU ELLERST ORF

WU ELLERST ORF I

WUELLERST ORF

WUELLERST ORF

WUELLERST ORF

WUELLERSTORFI

WUELLERST ORFI

WUELLER ST ORF I

WUELLERSTORFI

WUELLERST ORF I

WUELLERSTORF

WUELLERST ORFI

WUELLERST ORF

WUELLER ST ORF

WUELLER STORF

WUELLERSTORF

WUELLER ST ORF I

WUELLERSTORFI

WUELLERSI ORF

WUELLERSIORFI

WUELLER ST ORF

WUELLERSI ORFI

WUELLER ST OR FI

WU ELLER STORF I

WUELLER ST ORF

WUELLER STORF I

WUELLER STORF I

WUELLER STORF

WUELLERST ORFI

WUELLERSTORF

CONCENTRI CA

STRATTONI

STRATTON

STRATTON

STRATTON

STRATTONI

CENTRAL GULF OF MEXICO

NE GULF OF MEXICO

BAY OF CAMPECHE

BAY OF CAMPECHE 


\section{Publication}

14931 PARKER 1954

14932 PARKER PHLEGER PEIRSON 1953 14933 PARKER 1954

14934 PARKER 1954

14935 PARKER 1954

14936 PARKER 1954

14937 WARREN 1956

14938 LAMB 1972

14939 ANDERSON 1968

14940 PARKER PHLEGER PEIRSON 1953

14941 PARKER PHLEGER PEIRSON 1953

14942 PHLEGER 1954

14943 PARKER 1954

14944 PARKER 1954

14945 PARKER 1954

14946 PARKER 1954

14947 PARKER 1954

14948 PARKER 1954

14949 PARKER 1954

14950 PARKER 1954

14951 PARKER 1954

14953 PHLEGER 19558

14954 PARKER PHLEGER PEIRSON 1953

14955 SHEPARD MOORE 1955

14956 PARKER PHLEGER PEIRSON 1953

14957 LEROY HODGKINSON 1975

14958 LEROY HODGKINSON 1975

14959 LEROY HODGKINSON 1975

14960 DAVIS 1964

14961 CUSHMAN 19228

14962 CUSHMAN 19228

14963 CUSHMAN $1922 \mathrm{~B}$

14964 CUSHMAN 19228

14965 CUSHMAN 19228

14966 CUSHMAN 19228

14967 CUSHMAN $1922 \mathrm{~B}$

14968 CUSHMAN 19228

14969 PHLEGER 1965 A

14970 PHLEGER 1965 A

14971 PHLEGER 1965 A

14972 CUSHMAN 19228

14973 CUSHMAN 19228

14974 CUSHMAN $1922 \mathrm{~B}$

14975 CUSHMAN 19228

14976 CUSHMAN $1922 \mathrm{~B}$

14977 CUSHMAN 19228

14978 BOCK 1976

14979 LEROY HODGKINSON 1975

14980 CUSHMAN 1922A

14981 CUSHMAN 19228

14982 CUSHMAN 19228

14983 CUSHMAN $1922 \mathrm{~B}$

14984 CUSHMAN $1922 \mathrm{~B}$

14985 DAVIS 1964

14986 NORTON 1930

14987 CUSHMAN $1922 \mathrm{~A}$

14988 PARKER 1954

14989 PARKER 1954

14990 PARKER 1954

14991 PARKER 1954

14992 PARKER 1954

14993 PARKER 1954

14994 PFLUM FRERICHS 1976

14995 PARKER 1954

14996 PARKER 1954

14997 BOCK 1976

14998 ANDERSEN 1961

14999 BENDA PURI 1962

15000 VAUGHAN 1918

15001 NORTON 1930

15002 CREAGER 1958

15003 CREAGER 1958

15004 CUSHMAN $1922 \mathrm{~A}$

15005 WARREN 1957

15006 CREAGER 1958

15007 BENDA PURI 1962

15008 WARREN 1956

15009 ANDERSEN 1961
15010 ANDERSEN 1961

15011 LEROY HODGKINSON 1975

15012 PFLUM FRERICHS 1976

15013 PFLUM FRERICHS 1976

15014 PFLUM FRERICHS 1976

15015 PFLUM FRERICHS 1976

15016 PFLUM FRERICHS 1976

15017 PFLUM FRERICHS 1976

15018 PFLUM FRERICHS 1976

15019 PFLUM FRERICHS 1976

15020 PFLUM FRERICHS 1976

15021 PFLUM FRERICHS 1976

15022 PFLUM FRERICHS 1976

15023 PFLUM FRERICHS 1976

15024 PFLUM FRERICHS 1976

\section{Generic Name}

CIBICIDINA

CI BICIDINA

CIBICIDINA

CIBICIDINA

C IBICIDINA

CIBICIDINA

CIBICIDINA

CIBICIDINA

CIBICIDINA

CIBICIDINA

CIBICIDINA

CI BIC IDINA

CIBICIDINA

CIBICIDINA

CIBICIDINA

CIBICIDINA

CIBICIDINA

CIBICIDINA

CIBICIDINA

CIBICIDINA

CIBICIDINA

CI BIC ID INA

C I BIC IDINA

CIBICIDINA

CIBICIDOIDES

CIBICIDOIDES

CIBICIDOIDES

CLAVULINA

CLAVULINA

CLAVULINA

CLAVULINA

CLAVULINA

CLAVULINA

CLAVULINA

CLAVUL INA

CLAVUL INA

CLAVULINA

CLAVULINA

CLAVULINA

CLAVULINA

CLAVUL INA

CLAVULINA

CLAVULINA

CLAVULINA

CLAVULINA

CLAVULINA

CLAVULINA

CLAVULINA

CLAVULINA

CLAVULINA

CL AVULINA

CLAVULINA

CLAVULINA

CLAVULINA

CONORBINA

CONORBINA

CONORBINA

CONORBINA

CONORBINA

CONORBINA

CONORBINA

CONORBINA

CONORBINA

CORNULOCUL INA

CORNUSPIRA

CORNUSPIRA

CORNUSPIRA

CORNUSPIRA

CORNUSPIRA

CORNUSPIRA

CORNUSPIRA

CORNUSPIRA

CORNUSPI RA

CORNUSPIRA

C ORNUSPIRA

CORNUSPIRA

CORNUSPIRA

CORNUSPIROIDES

CORNUSPIROIDES

CORYPHOS TOMA

CORYPHOSTOMA

CORYPHOSTOMA

CORYPHOSTOMA

CORYPHOSTOMA

CORYPHOSTOMA

CORYPHOSTOMA

CORYPHOSTOMA

CORYPHOSTOMA

CORYPHOSTOMA

CORYPHOSTOMA

CORYPHOSTOMA

CORYPHOSTOMA

CORYPHOSTOMA
Specific Name

STRATTONI

STRATTONI

ST RAT TONI

STRATTONI

STRATTONI

STRATTONI

STRATTON

STRATTONI

STRATTONI

STRAT TONI

STRATTONI

STRATTONI

STRATTONI

STRATTONI

STRATTONI

STRATTONI

ST RATTONI

STRATTONI

STRATTON

STRATTONI

STRATTONI

STRATTONI

STRAT TONI

STRATTONI

STRATTONI

STRATTON

LOBATUL US

ROBER TSON I ANUS

RUGOSUS

B I CARINAT A

COMMUNIS

COMMUNIS

COMMUNIS

COMMUNIS

FL INT I ANA

FL INT IANA

FL INTIANA

FL INTIANA

GRACILIS

GRACILIS

GRACILIS

HUMIL IS EEXICANA

HUMILIS MEXICANA

HUMILIS MEXICANA

HUMILIS MEXICANA

HUMILIS YEXICANA

HUMILIS MEXICANA

MEXICANA

MEXICANA

NODOSARIA

OC CIDEN TALIS

OC CIDENTALIS

OC CIDENTALIS

TR ICARINA TA

TR ICAR INA TA

TRICARINATA

TR I CARINA TA

ORBI CULAR IS

ORBICULAR IS

ORBICUL AR IS

OR OICULAR IS

OREI CUL AR IS

OREICULAR IS

ORBI CULAR IS

OREI CUL AR IS

OREICULAR IS

INCONSTAN S

EXPANSA

IN VOL VENS

IN VOL VENS

I N VOL VENS

I N VOL VENS

IN VOL VENS

PLANORBIS

PL ANORBIS

PL ANORBIS

PLANORB IS

PLANORB IS

FOLIACEUM

FOLIACEUS

ABRUPTA

ABRUPTA

ABRUPTA

ABRUPTA

AB RUPTA

ABRUPTA

ABRUPTA

ABRUPTA

MAYORI

SPINESCEN

SP INESCEVS

SPINESCEN S

SP INESCEYS

SP INESCEVS

\section{Locality}

NE GULF OF MEXICO

TEXAS GULF COAST

NE GULF OF MEXICO 


\section{Publication}

15026 PFLUM FRERICHS 1976 15027 PFLUM FRERICHS 1976 15028 PFLUM FRERICHS 1976 15029 PFLUM FRERICHS 1976 15030 PFLUM FRERICHS 1976 15031 PFLUM FRERICHS 1976 15032 PFLUM FRERICHS 1976 15033 PFLUM FRERICHS 1976 15034 PFLUM FRERICHS 1976 15035 PFLUM FRERICHS 1976 15036 PFLUM FRERICHS 1976 15037 PFLUM FRERICHS 1976 15038 PFLUM FRERICHS 1976 15039 PFLUM FRERICHS 1976 15040 PFLUM FRERICHS 1976 15041 PFLUM FRERICHS 1976 15042 PFLUM FRERICHS 1976 15043 PFLUM FRERICHS 1976 15044 PFLUM FRERICHS 1976 15045 PFLUM FRERICHS 1976 15046 PFLUM FRERICHS 1976 15047 PFLUM FRERICHS 1970 15048 PFLUM FRERICHS 1976 5049 PFLUM FRERICHS 1976 15050 PFLUM FRERICHS 1976 15051 PFLUM FRERICHS 1976 15052 PFLUM FRERICHS 1976 15053 PFLUM FRERICHS 1976 15054 PFLUM FRERICHS 1976 15055 PFLUM FRERICHS 1976 15056 PFLUM FRERICHS 1976 15057 PFLUM FRERICHS 1976 15058 PFLUM FRERICHS 1976 15059 PFLUM FRERICHS 1976 15060 PFLUM FRERICHS 1976 15061 PFLUM FRERICHS 1976 15062 PFLUM FRERICHS 1976 15063 PFLUM FRERICHS 1976 15064 PFLUM FRERICHS 1976 15065 PFLUM FRERICHS 1976 15066 PFLUM FRERICHS 1976 15067 PFLUM FRERICHS 1976 15068 ANDERSEN 1961

15069 PFLUM FRERICHS 1976 15070 PFLUM FRERICHS 1976 15071 LEHMANN 1957

15072 PFLUM FRERICHS 1976

15073 LEHMANN 1957

15074 LEHMANN 1957

15075 WARREN 1957

15076 WARREN 1956

15077 WARREN 1956

15078 WARREN 1957

15079 PFLUM FRERICHS 1976

15080 OTVOS 1978

15081 BOCK 1976

15082 LYNTS PFISTER 1967

15083 WARREN 195

1 SO84 WARREN 1756

15085 WARREN 1956

15086 WARREN 1957

15087 WARREN 1956

15088 LEHMANN 1957

SO89 WARREN 1957

15090 LEROY HODGKINSON 1975

15091 CUSHMAN 1920

15092 CUSHMAN 1920

15093 CUSHMAN 1920

15094 CUSHMAN 1920

15095 CUSHMAN 1920

15096 PFLUM FRERICHS 1976 15097 PFLUM FRERICHS 1976 15098 PFLUM FRERICHS 1976 15099 LEROY HODGKINSON 1975

15100 PFLUM FRERICHS 1976

15101 PFLUM FRERICHS 1976

15102 PFLUM FRERICHS 1976

15103 PFLUY FRERICHS 1976

15104 PFLUM FRERICHS 1976

15105 PFLUM FRERICHS 1976

15106 PFLUM FRERICHS 1976

15107 PFLUM FRERICHS 1976

15108 PFLUM FRERICHS 1976

15109 PFLUM FRERICHS 1976

15110 PFLUM FRERICHS 1976

15111 PFLUM FRERICHS 1976

15112 PFLUM FRERICHS 1976

15113 PFLUM FRERICHS 1976

15114 PFLUM FRERICHS 1976

15115 PFLUM FRERICHS 1976

15116 PFLUM FRERICHS 1976

15117 PFLUM FRERICHS 1976

15118 PFLUM FRERICHS 1976

15119 PFLUM FRERICHS 1976
15120 PFLUM FRERICHS 1976
Generic Name

CORYPHOSTOMA

CORYPHOSTOMA

CORYPHOSTOMA

CORYPHOSTOMA

CORYPHOSTOMA

CORYPHOSTOMA

CORYPHOSTOMA

CORYPHOSTOMA

CORYPHOSTOMA

CORYPHOSTOMA

CORYPHOSTOMA

CORYPHOSTOMA

CORYPHOSTOMA

CORYPHOSTOMA

CORYPHOSTOMA

CORYPHOSTOMA

CORYPHOSTOMA

CORYPHOSTOMA

CORYPHOSTOMA

CORYPHOS TOMA

CORYPHOS TOMA

CORYPHOSTOMA

CORYPHOS TOMA

CORYPHOSTOMA

CORYPHOSTOMA

CORYPHOSTOMA

CORYPHOSTOMA

CORYPHOSTOMA

CORYPHOSTOMA

CORYPHOSTOMA

CORYPHOSTOMA

CORYPHOSTOMA

CORYPHOSTOMA

CORYPHOSTOMA

CORYPHOSTOMA

CORYPHOSTOMA

CORYPHOS TOMA

CORYPHOSTOMA

CORYPHOSTOMA

CORYPHOSTOMA

CORYPHOSTOMA

CR I BROB I GE NER INA

CRIBROEL PH I D IUM

CRIBROELPHIDIUM

CRIBROELPHI OIUM

CR IBROEL PHI DIUM

CRIBROELPH IOIUM

CR IBROELPHIDIUM

CR IBROELPHIDIUM

CRIBR OELPHI DIUM

CR IBROELPHIDIUM

CRIBROELPHI DIUM

CR IBROELPHI DIUM

CR IBROELPH I OI UM

CR IBROELPHIDIUM

CR IBROEL PH I OI UM

CRIBROELPHIDIUM

CRIBROELPHIOIUM

CR IBROEL PH I DI UM

CR IBR OELPH I OIUM

CRIBROELPHIDIUM

CR I BROELPHIDIUM

CRIBROELPHIDIUM

CR IBR OPY RGO

CR IBROST OMOIDES

CR IBR OSTOMOIDES

CR IBR OST OMOIDES

CRIBROSTOMOIDES

CRIBROSTOMOIDES

CRIBROSTOMOIDES

CRIBROSTOMOIDES

CRIBR OS TOMOIDES

CRIBROSTOMO IDES

CR IBROST OMOIDES

CR IBR OSTOMOI DES

CRIBROSTOMOI OES

CRIBROSTOMOIDES

CRIBROSTOMOIDES

CRIBROSTOMOIDES

CRIBROSTOMOIDES

CRIBROSTOMOIDES

CR IBROST OMO IDES

CRIBROSTOMOIDES

CRIBROSTOMOIDES

CR IBROSTOMOIDES

CRIBROSTOMOIDES

CR I BR OST OMOIDES

CR IBROSTOMO IDES

CR IBROSTOMOIDES

OSTOMOIDES

CRIBROSTOMOIDES

CR IBROSTOMOIDES

CR IBR OSTOMOIDES

CRIBR OSTOMOIDES
Specific Name

SPINESCEVS

SPINESCEN

SP INE SCEV S

SPINESCENS

SP INESCEN

SP INE SCEN

SPINESCENS

SP INESCEV S

SP INESCEN

SPINESCENS

SPINESCENS

PINESCEN S

SP INESCEVS

SPINESCENS

P INESCEV

SPINESCEVS

SP. INESCEN S

SP INESCENS

SUBSPINES CENS

SUBSPINES CENS

SUESPINES CENS

UBSPINES CENS

SURSPINES CENS

SUESPINES CENS

SUBSPINES CENS

SUBSPINES CENS

SUBSPINES CENS

SUBSP INES CENS

SUESPINES CENS

SUBSPINES CENS

SUBSPINES CENS

SUBSPINES CENS

SUBSPINES CENS

SUBSPINES CENS

SUESPINES CENS

SUBSPINES CENS

SU BSPINES CEN

ZANZIBARI CA

ZANZIBARI CA

ZANZIBARI CA

PARKERAE

DISCOIDALE

DISCOIDALE

DISCOIDALE

GUNTERI GALVESTONENSE

KOEBOEENS IS

KUGLERI

KUGLER I

KUGLER I

LI MOSUM

LI MOSUM

POEYANUM

POEYANUM

POEYANUM

POEYANUM

SALSUM

SALSUM

TR IN I TA TE NS IS

TR INI TA TE NSIS

VADESCENS

VADESCENS

VA DESCENS

ROEUSTA

BRADYI

BRADY

BR ADY

BRADYI

BRADY

CANARIENSIS

CANARIENSIS

CANARIENS IS

EMACIATUS

LOBATUS

LOEATUS

LOEATUS

LOBATUS

LOBATUS

LOBATUS

LOBATUS

LOBATUS

LOEATUS

LOBATUS

LOBATUS

LOBATUS

LOEATUS

LOEATUS

LOEATUS

LOBATUS

LOBATUS

LOEATUS

LOBATUS

LOBATUS

\section{Locality}

Lat. Long.

NW GULF OF MEXICO 


\section{Publication}

15121 PFLUM FRERICHS 1976 15122 PFLUM FRERICHS 1976 15123 PFLUM FRERICHS 1976 15124 PFLUM FRERICHS 1976 15125 PFLUM FRERICHS 1976 15126 PFLUM FRERICHS 1976 15127 PFLUM FRERICHS 1976 15128 PFLUM FRERICHS 1976 15129 PFLUM FRERICHS 1976 15130 PFLUM FRERICHS 1976 15131 PFLUM FRERICHS 1976 15132 PFLUM FRERICHS 1976 15133 PFLUM FRERICHS 1976 15134 PFLUM FRERICHS 1976 15135 LEROY HODGKINSON 1975 15136 PFLUM FRERICHS 1976
15137 PFLUM FRERICHS 1976 15138 PFLUM FRERICHS 1976 15139 LEROY HODGKINSON 1975 15140 PFLUM FRERICHS 1976 15141 PFLUM FRERICHS 1976 15142 PFLUM FRERICHS 1976 15143 PFLUM FRERICHS 1976 15144 PFLUM FRERICHS 1976 15145 PFLUM FRERICHS 1976 15146 PFLUM FRERICHS 1976 15147 PFLUM FRERICHS 1976 15148 PFLUM FRERICHS 1976 15149 PFLUM FRERICHS 1976 15150 PFLUM FRERICHS 1976 15151 PFLUM FRERICHS 1976 15152 PFLUM FRERICHS 1976 15153 PFLUM FRERICHS 1976 15154 PFLUM FRERICHS 1976 15155 PFLUM FRERICHS 1976 15156 PFLUM FRERICHS 1976 15157 PFLUM FRERICHS 1976 15158 PFLUM FRERICHS 1976 15159 PFLUM FRERICHS 1976 15160 PFLUM FRERICHS 1976 15161 PFLUM FRERICHS 1976 15162 PFLUM FRERICHS 1976 15163 PFLUM FRERICHS 1976 15164 PFLUM FRERICHS 1976 15165 PFLUM FRERICHS 1976 15166 PFLUM FRERICHS 1976 15167 PFLUM FRERICHS 1976 15168 PFLUM FRERICHS 1976 15:69 PFLUM FRERICHS 1976 15170 LEROY HODGKINSON 1975 15171 PFLUM FRERICHS 1976
15172 PFLUM FRERICHS 1976 15172 PFLUM FRERICHS 1976
15173 PFLUM FRERICHS 1976 15174 PFLUM FRERICHS 1976 15175 PFLUM FRERICHS 1976 15176 PFLUM FRERICHS 1976 15177 PFLUM FRERICHS 1976 15178 PFLUM FRERICHS 1976 15179 PFLUM FRERICHS 1976 15180 PFLUM FRERICHS 1976 15181 PFL UM FRERICHS 1976 15182 PFLUM FRERICHS 1976 15183 PFLUM FRERICHS 1976 15184 PFLUM FRERICHS 1976 15185 PFLUM FRERICHS 1976 15186 PFLUM FRERICHS 1976 15187 PFLUM FRERICHS 1976 15188 PFLUM FRERICHS 1976 15189 PFLUM FRERICHS 1976 15190 PFLUM FRERICHS 1976 15191 PFLUM FRERICHS 1976 15192 LEROY HODGKINSON 1975 15193 PFLUM FRERICHS 1976 15194 PFLUM FRERICHS 1976 15196 PFLUM FRERICHS 1976 15197 PFLUM FRERICHS 1976 15198 PFLUM FRERICHS 1976 15199 PFLUM FRERICHS 1976 15200 PFLUM FRERICHS 1976 15201 PFLUM FRERICHS 1976 15202 PFLUM FRERICHS 1976 15203 PFLUM FRERICHS 1976 15204 PFLUM FRERICHS 1976 5205 PFLUM FRERICHS 1976 15206 PFLUM FRERICHS 1976 15207 PFLUM FRERICHS 1976 15208 PFLUM FRERICHS 1976 15209 PFLUM FRERICHS 1976 15210 PFLUM FRERICHS 1976 15211 PFLUM FRERICHS 1976 15212 PFLUM FRERICHS 1976 15213 PFLUM FRERICHS 1976 15214
15215 PFLUM FRERICHS
1976
Generic Name

CRIBROSTOMOIDES CRIBROSTOMOIDES CRIBROSTOMOIDES CR I BR OS TOMOIDES CRIBROSTOMOIDES CRIBROSTOMOIDES CRIBROSTOMOIDES CRIBROSTOMOIDES CRIBROSTOMOIDES CRIBROSTOMOIDES CRIBROSTOMOIDES CRIBROSTOMOIDES CRIBROSTOMOIDES CRIBROSTOMOIDES CRIBROSTOMOIDES CRIBROSTOMOIDES CRIBROSTOMOIDES CRIBROSTOMOIDES CRIBROSTOMOIDES CRIBROSTOMOIDES CR IBROST OMO I DES CRIBROSTOMOIDES CRIBROSTOMOIDES CRIBROSTOMOIDES CRIBROST OMO I DES CRIBROSTOMOIDES CRIBROSTOMOIDES CRIBROSTOMO IDES CRIBROSTOMOIDES CRIBROSTOMO IDES CRIBROSTOMOIDES CR IBROSTOMOIDES CRIBROSTOMOIDES CRIBROSTOMOIDES CRI IRROSTOMOIDES CRIBROS TOMOIDES CRIBROSTOMOIDES CRIBROST OMOIDES CRIBROSTOMOIDES CRIBROSTOMOIDES CRI BROSTOMOIDES CRIBROSTOMOIDES CRIBROSTOMOIDES CRIBROSTOMO IDES CRIBROSTOMOIDES CRIBROSTOMOIDES CRIBROSTOMOIDES CRIBROST OMOIDES CRIBROSTOMOIDES CRIBROSTOMOIDES CRIBROS TOMOIDES CRIBROSTOMOIDES CRIBROSTOMOIDES CRIBROSTOMOIDES CRIBROSTOMOIDES CRIBROSTOMOIDES CRIBROSTOMOIDES CRI BROSTOMO IDES CR IBROST OMOIDES CR IBR OS TOMOIDES CR I BROSTOMOIDES CRIBROSTOMOIDES CR IBROSTOMOIDES CRIBROSTOMOIDES CRIBROSTOMOIDES CRIBROSTOMOIDES CRIBROST OMOIDES CRIBROSTOMOIDES CRIBROSTOMOIDES CRIBROSTOMOIDES CRIBROSTOMOIDES CRIBROSTOMOIDES CRIBROSTOMOIDES CR IBROSTOMOI DES CRIBROSTOMOIDES CRIBROSTOMOIDES CRIBROSTOMOIDES CR IBROS TOMOIDES CR IBROST OMOIDES CRIBROSTOMOIDES CR IBROST TMOOIDES CRIBROSTOMOIDES CRIBROSTOMOIDES CRIBROSTOMOIDES CRIBROS TOMOIDES CRIBROSTOMOIDES CRIBROSTOMOIDES CRIBROSTOMOIDES CRIBROSTOMOIDES CRIBROSTOMOIDES CRIBROSTOMOIDES CRIBROSTOMOIDES CRIBROSTOMOIDES CRIBROSTOMOIDES CRIBROSTOMOIDES
Specific Name

LOEATUS

LOEATUS

LOBATUS

LOBATUS

LOBATUS

LOBATUS

LOEATUS

LOBATUS

LOBATUS

OBATUS

LOBATUS

LOBATUS

LOBATUS

OBATUS

NITIDUS

RINGENS

RI NGENS

RI AGENS

RI NGENS

RINGENS

RINGENS

RI NGENS

RIN NGENS

RINGENS

RINGENS

RINGENS

RINGENS

RINGENS

RINGENS

RINGENS

RINGENS

RINGENS

RINGENS

RINGENS

SC I TULUS

SCITULUS

SCITULUS

SC ITULUS

SCITULUS

SCITULUS

SCITULUS

SCITULUS

SCITULUS

Sc ITULUS

SCITULUS

SCITULUS

SCITULUS

SCITULUS

SCITULUS

SCITULUS

SCITULUS

SCITULUS

SCITULUS

SCITULUS

SCITULUS

SCITULUS

SCITULUS

SCITULUS

SCITULUS

SCITULUS

SCITULUS

SCITULUS

SCITULUS

SCITULUS

SCITULUS

SUBGL OB OS US

SUBGL OBOS US

SUEGLOBOS US

SUEGLOBOSUS

SUBGL OB OS US

SUBGLOBOS US

SUBGLOBOS US

SUBGL OBOS US

SUEGL OBOS US

SUBGLOBOS US

SUBGLOB OS US

SUBGLOBOSUS

SUBGLOBOS US

SUBGL OBOSUS

SUEGLOBOS US

SUBGL OBOS US

SUBGLOBOSUS

SUBGL OBOS US

SUBGL OBOS US

SURGLOBOS US

SUEGL OBOS US

SUBGL OBOS US

SUBGLOBOS US

SUBGL OBOS US

\section{Locality}

NH GULF OF MEXICO

NW GULF OF MEXICO

NW GULF OF MEXICO

NW GULF OF MEXICO

NH GULF OF MEXICO

CENTRAL GULF OF MEXICO

NH GUL $F$ OF MEXICO 
Publication

15216 PFLUM FRERICHS 1976 15217 PFLUM FRERICHS 1976 15218 PFLUM FRERICHS 1976 15219 PFLUM FRERICHS 1976 15220 PFLUM FRERICHS 1976 15221 PFLUM FRERICHS 1976 15222 PFLUM FRERICHS 1976 15223 PFLUM FRERICHS 1976 15224 PFLUM FRERICHS 1976 15225 PFLU Y FRERICHS 1976 15226 PFLUM FRERICHS 1976 15227 PFLUM FRERICHS 1976 15228 PFLUM FRERICHS 1976 15229 PFLUM FRERICHS 1976 15230 PFLUM FRERICHS 1976 15231 PFLUM FRERICHS 1976 15232 PFLUM FRERICHS 1976 15233 PFLUM FRERICHS 1976 15234 PFLUM FRERICHS 1976 15235 PFLUM FRERICHS 1976 15236 PFLUM FRERICHS 1976 15237 PFLUM FRERICHS 1976 15238 PFLUM FRERICHS 1976 15239 PFLUM FRERICHS 1976 15240 PFLUM FRERICHS 1976 15241 PFLUM FRERICHS 1976 15242 PFLUM FRERICHS 1976 15243 PFLUM FRERICHS 1976 15244 PFLUM FRERICHS 1976 15245 PFLUM FRERICHS 1976 15246 PFLUM FRERICHS 1976 15247 PFLUM FRERICHS 1976 15248 PFLUM FRERICHS 1976 15249 PFLUM FRERICHS 1976 15250 PFLUM FRERICHS 1976 15251 PFLUM FRERICHS 1976 15252 PFLUM FRERICHS 1976 15253 PFLUM FRERICHS 1976 15254 PFLUM FRERICHS 1976 1525S PFLUM FRERICHS 1976 15256 LEROY HODGKINSON 197 15257 PFLUM FRERICHS 1976 15258 PFLUM FRERICHS 1976 15259 PFLUM FRERICHS 1976 15260 PFLUM FRERICHS 1976 15261 PFLUM FRERICHS 1976 15262 PFLUM FRERICHS 1976 15263 PFLUM FRERICHS 1976 15264 PFLUM FRERICHS 1976 15265 PFLUM FRERICHS 1976 15266 PFLUM FRERICHS 1976 15267 PFLUM FRERICHS 1976 15268 PFLUM FRERICHS 1976 15269 PFLUM FRERICHS 1976 15270 PFLUM FRERICHS 1976 15271 PFLUM FRERICHS 1976 15272 PFLUM FRERICHS 1976 15273 PFLUM FRERICHS 1976 15274 PFLUM FRERICHS 1976 15275 PFLUM FRERICHS 1976 15276 PFLUM FRERICHS 1976 15277 PFLUM FRERICHS 1976 15278 PFLUM FRERICHS 1976 15279 PFLUM FRERICHS 1976 15280 PFLUM FRERICHS 1976 15281 PFLUM FRERICHS 1976 15282 PFLUM FRERICHS 1976 15283 PFLUM FRERICHS 1976 15284 PFLUM FRERICHS 1976 15285 PFLUM FRERICHS 1976 15286 PFLUM FRERICHS 1976 15287 PFLUM FRERICHS 1976 15288 PFLUM FRERICHS 1976 15289 PFLUM FRERICHS 1976 15290 PFLUM FRERICHS 1976 15291 PFLUM FRERICHS 1976 15292 PFLUM FRERICHS 1976 15293 PFLUM FRERICHS 1976 15294 PFLUM FRERICHS 1976 15295 PFLUM FRERICHS 1976 15296 PFLUM FRERICHS 1976 15297 PFLUM FRERICHS 1976 15298 PFLUM FRERICHS 1976 15299 PFLUM FRERICHS 1976 15300 PFLUM FRERICHS 1976 15301 PFLUM FRERICHS 1976 15302 PFLUM FRERICHS 1976 15303 PFLUM FRERICHS 1976 15304 PFLUM FRERICHS 1976 15305 PFLUM FRERICHS 1976 15306 CUSHMAN 1923 15307 CUSHMAN 1923 15308 CUSHMAN 1923 15309 CUSHMAN 1923 15309 CUSHMAN 1923
15310 CUSHMAN 1923
Generic Name

Specific Name

Locality

CRIBROSTOMOIDES CRIBROSTOMOIDES CRIBKOS TOMOIDES CRIBROSTOMOIDES CR IBROSTOMOIDES CRIBROSTOMOIDES CRIBROSTOMOIDES CRIBROS TOMOIDES CRIBROSTOMOIDES CRIBROSTOMOIDES CRIBROSTOMOIDES CRIBROSTOMOIDES CRIBROSTOMOIDES CR IBR OST OMOIDES CRIBROSTOMOIDES CRIBROSTOMOIDES CR IBROSTOMOIDES CRIBROSTOMOIDES CRIBROSTOMOIDES CRIBROSTOMOIDES CRIBROST OMOIDES CRIBROSTOMOIDES CRIBROSTOMOIDES CRIBROSTOMOIDES C.RIBROSTOMOIDES CR IBROST OMOIDES CR IBROSTTMOIDES CRIBROSTOMOIDES CRIBROSTOMOIDES CRIBROSTOMOIDES CRIBROSTOMOIDES CRIBROSTOMOIDES CRIBROSTOMOIDES CRIBROSTOMOIDES CRIBROST OMOIDES CRIBROSTOMOIDES CRIBROSTOMOIDES CRIBROSTOMOIDES CRIBROSTOMOIDES CRIBROSTOMOIDES CRIBROSTOMOIDES CRIBROST OMOIDES CRIBROS TOMOIDES CRIBROSTOMOIDES CR IBROSTOMOIDES CRIBROSTOMOIDES CRIBROSTOMOIDES CRIBR OS TOMOIDES CRIBROSTOMOIDES CR IBROST OMOIDES CRIBROSTOMOIDES CRIBROSTOMOIDES CRIBROST OMOIDES CRIBROSTOMOIDES CRIBROSTOMOIDES CRIBROSTOMOIDES CRIBROSTOMOIDES CRIBROSTOMOIDES CRIBROSTOMO IDES CRIBROSTOMOIDES CR IBROSTOMOIDES

CRIBROSTOMOIDES

CRIBROSTOMOIDES CRIBROSTOMOIDES CR IBROSTOMO IDES CRIBROS TOMO I DES CR IBROSTOMO IDES CRIBROSTOMOIDES CRIBROSTOMOIDES CRIBROSTOMOIDES CRIBROSTOMOIDES CRIBROSTOMOIDES CRIBROSTOMOIDES CRIBROSTOMOIDES CRIBROSTOMOIDES CRIBROSTOMOIDES CR IBROSTOMOIDES CRIBROSTOMOIDES CRIBROSTOMOIDES CRIBROSTOMOIDES CRIBROSTOMOIDES CRIBROSTOMO IDES CRIBROSTOMOIDES CRIBROSTOMO IDES CRIBROSTOMOIDES CRIBROS TOMOIDES CRIBROSTOMOIDES CRIBROSTOMO IDES CRIBROSTOMOIDES CR IBROSTOMOIDES CRISTELLARIA

CRISTELLARIA

CRISTELLARIA

CRISTELLARIA

CRISTELLARIA
SUBGLOBOS US

SUEGLOBOSUS

SUBGL OBOS US

SUBGL OBOS US

UEGLOBOSUS

SUBGLOBOSUS

SUEGLOBOS US

SUBGL OB OS US

SUEGL OBOS US

SUEGLOBOSUS

UUGL OBOS US

UEGLOBOS US

SUGL OBOS US

SU BGL OBOS US

SUEGL OBOS US

SUEGLOBOSUS

SUBGLOBOS US

SUEGL OBOS US

SUBGLOBOS US

SUEGLOBOSUS

SUEGLOBOS US

SUBGL OBOSUS

SUBGL OBOS US

SUBGLOBOS US

UMBILICATUS

UMEILI I CAT US

UMEILICATUS

UMEILICAT US

UMEILICATUS

UMEILICAT US

UMEILI I CAT US

UMEILICATUS

UMEILICAT US

UMEILICAT US

UMEILICATUS

UMBILICATUS

UMEILI I CAT US

WI ESNER I

WI ESNER I

WIESNER I

WIESNER I

WI IESNER I

WI ESNER I

WI ESNER I

WIESNER I

WI ESNER I

WI ESNER I

WI ESNER I

WIESNER I

WIESNER I

WIESNER I

WIESNERI

WIESNER I

WI ESNER I

WI ESNER I

WIESNER I

WIESNER I

WI ESNER I

WI ESNER I

WIESNERI

WIESNER I

WI ESNER I

WIESNER I

WIESNER I

WISNER I

WIESNERI

WI ESNER I

WIESNER I

WIESNER I

WI ESNER I

WIESNER I

WIESNER I

WIESNER I

WIESNER I

WI ESNER I

WI ESNER I

WIESNERI

WIESNER

WIESNERI

WIESNER I

WIESNER I

WIESNER I

ALBATROSS

ANTILLEA

CALCAR

CALCAR

CALCAR

CENTRAL GULF OF MEXICO

CENTRAL GULF OF MEXICO CENTRAL GULF OF MEXICO CENTRAL GULF OF MEXICO CENTRAL GULF OF MEXICO CENTRAL GULF OF MEXICO CENTRAL GULF OF MEXICO NW GULF OF MEXICO NW GULF OF MEXICO 


\section{Publication}

15311 CUSHMAN 1923 15312 VAUGHAN 1919 15313 CUSHMAN 1923 15314 CUSHMAN 1923 15315 CUSHMAN 1923 15316 CUSHMAN 1923 15317 CUSHMAN 1923 15318 CUSHMAN 1923 15319 CUSHMAN 1923 15320 CUSHMAN 1923 15321 CUSHMAN 1923 15322 CUSHMAN 1923 15323 CUSHMAN 1923 15324 CUSHMAN 1923 15325 CUSHMAN 1923 15326 CUSHMAN 1923 15327 VAUGHAN 1918 15328 CUSHMAN 1923 15329 CUSHMAN 1923 15330 CUSHMAN 1923 15331 CUSHMAN 1923 15332 CUSHMAN 1923 15333 CUSHMAN 1923 15334 CUSHMAN 1923 15335 CUSHMAN 1923 15336 CUSHMAN 1923 15338 CUSHMAN 1923 15339 CUSHMAN! 1923 15340 CUSHMAN 1923 15341 CUSHMAN 1923 15342 CUSHMAN 1923 15343 CUSHMAN 1923 15344 CUSH MAN 1923 15345 CUSHMAN 1923 15346 CUSHMAN 1923 15347 CUSHMAN 1923 15348 CUSHMAN 1923 15349 CUSHMAN 1923 15350 CUSHMAN 1923 15351 CUSHMAN 1923 15353 CUSHMAN 1923 15353 CUSHMAN 1923 15355 LEROY HODGKINSON 1975 15356 PHLEGER 1951A 15357 PHLEGER 1951A 15358 CUSHMAN 1920

15359 CUSHMAN 1920

15360 CUSHMAN 1920

15361 CUSHMAN 1920

15362 CREAGER 1958

15363 CREAGER 1958

15364 CREAGER 1958

15365 CREAGER 1958

15367 PHLEGER 1951A

15368 PFLUM FRERICHS 1976 15369 PFLUM FRERICHS 1976 15370 PFLUM FRERICHS 1976 15371 PFLUM FRERICHS 1976 15372 PFLUM FRERICHS 1976 15373 PHLEGER 1951A 15374 PHLEGER $1951 \mathrm{~A}$ 15375 PHLEGER 1951A 15376 PFLUM FRERICHS 1976 15377 PFLUM FRERICHS 1976 15378 PFLUM FRERICHS 1976 15379 PHLEGER 1951A

15380 PFLUM FRERICHS 1976 15381 PFLUM FRERICHS 1976 15382 PFLUM FRERICHS 1976 15383 PFLUM FRERICHS 1976 15384 PFLUM FRERICHS 1976 15385 PFLUM FRERICHS 1976 15386 PFLUM FRERICHS 1976 15387 PFLUM FRERICHS 1976 15388 PFLUM FRERICHS 1976 15389 PFLUM FRERICHS 1976 15391 PFLUM FRERICHS 1976 15392 PFLUM FRERICHS 1976 15393 CREAGER 1958

15394 PFLUM FRERICHS 1976 15395 PFLUM FRERICHS 1976 15396 CREAGER 1958
15397 CREAGER 1958 15393 PFLUM FRERICHS 1976 15399 PFLUM FRERICHS 1976 15400 PFLUM FRERICHS 1976 15401 CREAGER 1958

15402 LEROY HOOGKINSON 1975

15403 PHLEGER 1951A

15404 PFLUM FRERICHS 1976

15405 CREAGER 1958
Generic Name

Specific Name

Locality

CRISTELLARIA CRISTELLARIA CRISTELLARIA CRISTELLARIA CR ISTELL AR I A CR ISTELLAR IA

CRISTELLARIA

CRISTELLARIA

CRISTELLARIA

CR ISTELLAR IA

CR ISTELLARIA

CRISTELLARIA

CRISTELLARIA

CRISTELL ARIA

CRISTELLARIA

CRISTELLARIA

CRISTELLARIA

CRISTELLARIA

CRISTELLARIA

CRISTELLARIA

CRISTELLARIA

CRISTELLARIA

CRISTELLARIA

CRISTELLAR I A

CRISTELLARIA

CRISTELLARIA

CR ISTELLAR I A

CRISTELLARIA

CRISTELLARIA

CRISTELLARIA

CRISTELLARIA

CRISTELLARIA

CRISTELLARIA

CRISTELLARIA

CRISTELLARIA

CRISTELLARIA

CRISTELLARIA

CRISTELLARIA

CRISTELLARIA

CRISTELLARIA

CRISTELLARIA

CRITHIONINA

CRUCILOCULI NA

CYCLAMMINA

CYCLAMMINA

CYCLAMMINA

CYCLAMMINA

CYCLAMMINA

CY CL AMMINA

CYCLAMMINA

CYCLAMM INA

CYCLAMMINA

CYCLAMMINA

CYCLAMMINA

CYCLAMMINA

CYCLAMMINA

CYCLAMMINA

CYCLAMMINA

CYCLAMMINA

CYCLAMMINA

CYCLAMMINA

CYCLAMMINA

CYCLAMMINA

CYCLAMMINA

CYCLAMMINA

CY CLAMM INA

CYCLAMMINA

CYCLAMMINA

CYCLAMM I NA

CYCLAMMINA

CYCLAMMINA

CYCLAMMINA

CYCLAMMI NA

CYCLAMMINA

CYCLAMM INA

CYCLAMMINA

CYCLAMMINA

CYCLAMMI NA

CYCLAMMINA

CYCLAMMINA

CYCLAMMINA

CYCLAMMINA

CYCLAMMINA

CYCLAMMINA

CYCLAMMINA

CYCLAMMINA

CYCLAMMI NA

CYCLAMMINA

CYCLAMMINA

CYCLAMMINA

CYCLAMMINA

CYCLAMMINA
CALCAR

CALCAR

CALCAR

CALCAR

CONVERGENS

CREPIDULA

FORMOSA

$G$ I BBA

GIEBA

$G$ I BBA

GI BBA

IO TA

I T AL I CA

IT ALICA

ITAL I CA

LATIFRONS

LI MBATA

LIMBATA

LUCIDA

MA RG I NUL I NO IDES

OC CIDENTALIS TORRIDA

OC CIDENTALIS TORRIDA

OC CIDENTALIS TORRIDA

PEREGRINA

PEREGRINA

PEREGRINA

PEREGRINA

PEREGRINA

PEREGRINA

PEREGRINA

PEREGR INA

RO TULATA

SCHOENBACHI

SC HOENBACHI

SUEACULEATA

SUEACULEATA GLABRATA

SUBACULEATA GLABRATA

SUEACULEATA GLABRATA

SUBMAMIL_ IGERA

PI SUM

TR IANGULARIS

CANCELLATA

CANCELLATA

CANCELLATA

CANCELLATA

CANCELLATA

CANCELLATA

CANCELL ATA

CANCELL ATA

CANCELLATA

CANCELLATA

CANCELL AT A

CANCELL ATA

CANCELLATA

CANCELLATA

CANCELLATA

CANCELLATA

CANCELLATA

CANCELLATA

CANCELLATA

CANCELLATA

CANCELLATA

CANCELLATA

CANCELLATA

CANCELLATA

CANCELL ATA

CANCELL ATA

CANCELLATA

CANCELLLATA

CANCELLATA

CANCELLATA

CANCELLATA

CANCELLATA

CANCELLATA

CANCELLATA

CANCELLATA

CANCELLATA

CANCELLATA

CANCELLATA

CANCELLLATA

CANCELLATA

CANCELLATA

CANCELL ATA

CANCELL ATA

CANCELLLATA

CANCELLATA

CANCELLATA

CANCELLATA

CANCELLATA

NE GULF OF MEXICO FLORIDA KEYS

NE GULF OF MEXICO NE GULF OF MEXICO NE GULF OF MEXICO NE GULF OF MEXICO NE GULF OF MEXICO NE GULF OF MEXICO NE GULF OF MEXICO NE GULF OF MEXICO NE GULF OF MEXICO NE GULF OF MEXICO 


\section{Publication}

15406 PFLUM FRERICHS 1976 15407 PFLUM FRERICHS 1976 15408 PFLUM FRERICHS 1976 15409 PFLUM FRERICHS 1976 15410 PFLUM FRERICHS 1976 15411 CREAGER 1958

15412 CREAGEP 1958

15413 CREAGER 1958 15414 PFLUM FRERICHS 1976
15415 PFLUM FRERICHS 1976 15415 PFLUM FRERICHS 1976
15416 PFLUM FRERICHS 1976 15417 PFLUM FRERICHS 1976 15418 PFLUM FRERICHS 1976 15419 PFLUM FRERICHS 1976 15420 PFLUM FRERICHS 1976 15421 PFLUM FPERICHS 1976 15422 PFLUM FRERICHS 1976 15423 PFLUM FRERICHS 1976 15424 PFLUM FRERICHS 1976 15425 PFLUM FRERICHS 1976 15426 PFLUM FRERICHS 1976 15427 PFLUM FRERICHS 1976 15428 PFLUM FRERICHS 1976 15429 PFLUM FRERICHS 1976 15430 PHLEGER $1951 \mathrm{~A}$

15431 PHLEGER 1951 A

15432 PFLUM FRERICHS 1976 15433 PHLEGER 1951A

15434 PFLUM FRERICHS 1976 15435 PFLUM FRERICHS 1976 15436 PFLUM FRERICHS 1976 15437 PFLUM FRERICHS 1976 15438 PFLUM FRERICHS 1976 15439 PFLUM FRERICHS 1976 15440 PFLUM FRERICHS 1976 15441 PFLUM FRERICHS 1976 15442 CUSHMAN 1920

15443 CUSHMAN 1920

15444 CUSHMAN 1920

$15445^{\circ}$ CUSHMAN 1920

15446 CUSHMAN 1920

15447 LEROY HODGKINSON 1975

15448 PFLUM FRERICHS 1976

15449 PFLUM FRERICHS 1976

15450 PFLUM FRERICHS 1976

15451 PFLUM FRERICHS 1976

15452 PFLUM FRERICHS 1976

15453 PFLUM FRERICHS 1976

15454 PFLUM FRERICHS 1976

15455 LEROY HODGKINSON 1975

15456 PFLUM FRERICHS 1976
15457 PFLUM FRERICHS 1376

15457 PFLUM FRER
15458 BOCK 1976

15459 BOCK 1975

15460 AYALA-CASTANARES 1963

15461 VAUGHAN 1918

15462 DAVIS 1964

15463 CUSHMAN $1922 \mathrm{~A}$

15464 DAVIS 1964

15465 BENDA PURI 1962

15466 CUSHMAN 1931

15467 BOCK 1976

15468 LYNTS PFISTER 1967

15469 NORTON 1930

15470 CUSHMAN 1931

15471 PFLUM FRERICHS 1976 15472 PFLUM FRFRICHS 1976 15473 PFLUM FRERICHS 1976 15474 PFLUM FRERICHS 1976 15476 PFLUM FRERICHS 1976 15476 PFLUM FRERICHS 1976
15477 PFLUM FRERICHS 1976

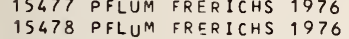
15479 PFLUM FRERICHS 1976 15480 PFLUM FRERICHS 1976 15481 PFLUM FRERICHS 1976 15482 PFLUM FRERICHS 1976 15483 PFLUM FRERICHS 1976 15484 PFLUM FRFRICHS 1976 15485 PFLUM FRERICHS 1976 15486 PFLUM FRERICHS 1976 15487 PFLUIA FRERICHS 1976 15488 PFLUM FRERICHS 1976 15489 PFLUM FRERICHS 1976 15490 ANDERSEN 1961

15491 PFLUM FRERICHS 1976 15492 PFLUM FRERICHS 1976 15493 PFLUM FRERICHS 1976 15494 PFLUM FRERICHS 1976 15495 PFLUM FRERICHS 1976 15496 PFLUM FRERICHS 1976 15497 PFLUM FRERICHS 1976 15497
15498
$15 F L U M$ 15499 PFLUM FRERICHS 1976 15500 PFLUM FRERICHS 1976
Generic Name

Specific Name

Locality

Lat. Long.

CY CLAMMINA

CYCLAMMINA

CY CL AMMINA

CY CLAMMINA

CY CLAMMINA

CYCLAMM I NA

CYCLAMMINA

CY CLAMMINA

CYCLAMM!NA
CYCLAMMINA

CY CLAMM I NA

CY CLAMM I NA

CY CLAMMINA

CY CLAMMINA

CY CLAMM I NA

CYCLAMHINA

CYCLAMMINA

CY CLAMMINA

CYCLAMMINA

CYCLAMM I NA

CY CLAMMINA

CYCLAMMINA

CY CLAMMINA

CYCLAMMINA

CYCLAMMINA

CYCLAMM I NA

CYCLAMMINA

CY CLAMM INA

CYCLAMMINA

CY CLAMMINA

CYCLAMMINA

CY CLAMM I NA

CY CLAMMINA

CYCLAMMINA

CY CLAMMINA

CYCLAMMINA

CYCLAMMINA

CYCLAMMINA

CY CLAMMI NA

CY CLAMMINA

CY CLAMM INA

CY CL AMMINA

CYCLAMMINA

CYCLAMMINA

CY CL AMM INA

CYCLAMMINA

CY CLAMMINA

CYCLAMMINA

CYCLAMMINA

CY CLAMMINA

CYCLAMMINA

CYCLAMMINA

CYCLOGYRA

CYCLOGYRA

CYCLOGYRA

CYMBAL OPORA

CYMBALOPORA

CYMBALOPORA

CYMBALOPORA

CY MBAL OPORETTA

CYMBAL OPORE TTA

CYMBAL OP ORETTA

CYMBALOPORETTA

CYMBAL OPORE TTA

CYMBAL OPORET TA

CYSTAMMINA

CYSTAMMINA

CYSTAMMINA

CY STAMMINA

CYSTAMMINA

CYSTAMMINA

CYSTAMMINA

CY STAMMINA

CY STAMMINA

CY STAMMINA

CYSTAMMINA

CY STAMMINA

CYSTAMMINA

CYSTAMMINA

CYSTAMMINA

CYSTAMMINA

CY STAMMINA

CYSTAMMINA

CYSTAMMINA

DENTALINA

DENTALINA

DENTALINA

DENTALINA

DE NT ALINA

DENTALINA

DENTALINA

DENTAL INA

DENTAL INA

DENTALINA

DENTALINA
CANCELLATA

CANCELLATA

CANCELLATA

CANCELLATA

CANCELLATA

CANCELLATA

CANCELLATA

CAACELLATA

CANCELLATA

CANCELLATA

CANCELLATA

CANCELLAT A

CANCELLAT A

CANCELLATA

CANCELLATA

CANCELLATA

CANCELLATA

CAACELLATA

CANCELLAT A

CANCELLAT A

CANCELLATA

CANCELLATA

CANCELLAT A

CANCELLATA

CANCELLAT A

CANCELLATA

CANCELLATA

CANCELLATA

CANCELLATA

CANCELLATA

CANCELLATA

CANCELLATA

CANCELLATA

PAUCILOCJLATA

PAUCILOCULATA

PAUCILOCULATA

PAUCILOCJLATA

PAUCILOCJLATA

PUSILLA

TRULLISSA TA

TRLLLISSATA

TRULLISSATA

TRLLL I SSA TA

TRLLL IS SA TA

TRLLLISSA TA

TR ULLISSATA

TRLLLISSA TA

TR ULLISSA TA

IN VOLVENS

PL ANORBIS

PLANORBIS

POEYI

SQUAMMOSA

SQLAMMOSA

BRADYI

SQUAMMO SA

SQ UAMMOSA

SQLIAMMOSA

SQLAMMOSA

SQLAMMO SA

PAUC ILO CULATA

PAUCILOCULATA

PAUCILOCULATA

PAUCILOCULATA

PAUCILOCJLATA

PAUCILOCULATA

PAUCILOCULATA

PAUCILOCULATA

PAUCILOCJLATA

PAUCILOCULATA

PAUCILOCJLATA

PAUCILOCJLATA

PAUCILOCJLATA

PAUCILOCJLATA

PAUCILOCJLATA

PAUCILOCJLATA

CALOMORPHA

COMMUNIS

COMMUNIS

CONMUNIS

COMMUNIS

COMMUNIS

COMMUNIS

COMMUNIS

COMMUNIS

COMMUNIS

COMMUNIS
PAUCILOCULATA

PAUCILOCULATA

PAUCILOCULATA

CENTRAL GULF OF MEXICO

CENTRAL GULF OF MEXICO

CENTRAL GULF OF MEXICO

CENTRAL GULF OF MEXICO

CENTRAL GULF OF MEXICO

BAY OF CAMPECHE

BAY OF CAMPECHE 


\section{Publication}

15501 PFLU 1 FRERICHS 1976 15502 PFLUM FRERICHS 1976 15503 PFLUM FRFRICHS 1976 15504 PFLUM FRERICHS 1976 15505 PFLUM FRERICHS 1976 15506 PFLUM FRFRICHS 1976 15507 PFLUM FRERICHS 1976 15508 PFLUM FRERICHS 1976 15509 KELLOUGH 1956

15510 KELLOUGH 1956
15511 PFLUM FRERICHS 1976 15512 PFLUM FRERICHS 1976 15513 BANDY 1956

15514 PFLUM FRERICHS 1976 15515 PFLUM FRFRICHS 1976 15516 PFLUM FRERICHS 1976 15517 PFLUM FRERICHS 1976 15518 KELLOUGH 1956

15519 PFLUM FRERICHS 1976 15520 PFLUM FRERICHS 1976 15521 PFLUM FRERICHS 1976 15522 PFLUM FRERICHS 1976 15523 PFLUM FRERICHS 1976 15524 PFLUM FRERICHS 1976 15525 PFLUM FRERICHS 1976 15526 PFLUM FRERICHS 1976 15527 PFLUM FRERICHS 1976 15528 PFLUM FRERICHS 1976 15529 PFLUM FRERICHS 1976 15530 PFLUM FRERICHS 1976 15531 PFLUM FRERICHS 1976 15532 BANDY 1256

15533 BOCK 1976
15534 PFLUM FRERICHS 1976 15535 PFLUM FRERICHS 1976 15536 PFLUM FRERICHS 1976 15536 PFLUM FRERICHS 1976
15537 PFLUM FRERICHS 1976 15538 PFLUM FRERICHS 1976 15539 PFLUM FREFICHS 1976 15540 PFLUM FRERICHS 1976 15541 PFLUM FRERICHS 1976 15542 PFLUM FRERICHS 1976 15543 PFLUM FRERICHS 1976 15544 PFLUM FRERICHS 1976 15545 PFLUM FRERICHS 1976 15546 PFLUM FRERICHS 1976 15547 PFLUM FRERICHS 1976 15548 PFLUM FRERICHS 1976 15549 PFLUM FRFRICHS 1976 15550 PFLUM FRERICHS 1976 15551 PFLUM FRERICHS 1976 15552 PFLUM FRERICHS 1976 15553 PFLUM FRERICHS 1976 15554 PFLUM FRERICHS 1976 15555 LEROY HDDGKINSON 1975 15556 ANDERSEN 1961

15557 BOCK 1976

15558 PFLUM FRERICHS 1976 15559 PFLUM FRERICHS 1976 15560 PFLUM FRERICHS 1976 15561 PFLUM FRERICHS 1976 15562 PFLUM FRERICHS 1976 15563 PFLUM FRERICHS 1976 15564 PFLUM FRERICHS 1976 15565 PFLUM FRERICHS 1976 15566 PFLUM FRERICHS 1976 15567 PFLUM FRERICHS 1976 15568 PFLUM FRERICHS 1976 15569 PFLUM FRERICHS 1976 15570 ANDERSEN 1961

15571 PFLUM FRERICHS 1976 15572 PFLUM FRERICHS 1376 15573 PFLUM FRERICHS 1976 15574 PFLUY FRERICHS 1976 15575 PFLUM FRERICHS 1976 15576 PFLUM FRERICHS 1976 15577 PFLU 9 FRERICHS 1976 15578 PFLUM FRERICHS 1976 15579 PFLUM FRERICHS 1976 15580 PFLUM FRERICHS 1976 15581 PFLUM FRERICHS 1976 15582 PFLUM FRERICHS 1976

15583 ANDERSEN 1951

15584 LEROY HODGKINSON 1975

15585 ANDERSEN 196

15586 VAUGHAN 1913
15587 VAUGHAN 1918

15587 VAUGHAN 1918
15588 CUSHMAN $1922 \mathrm{~A}$

15589 CUSHMAN 1931

15590 NORTON 1730

15591 CUSHMA:I 1922A

15592 CUSHMAN 1931

15593 PHLEGER $1951 \mathrm{~A}$
15594 PHLEGER $1951 \mathrm{~A}$

15595 PHLEGER $1951 \mathrm{~A}$
Generic Name

Specific Name

DENTALINA

DENTALINA

DENTALINA

DENTALINA

DENTAL INA

DENTALIIA

DE IT TLL INA

DENTALINA

DENTALINA

DENTALINA

DENTALINA

DENTALINA

DENTALINA

DENTALINA

DENTALINA

DENTALINA

DENTALINA

DENTALINA

DENTALINA

DENTAL INA

DENTALINA

DENTALINA

DENTALINA

DENTALINA

DENTALINA

DENTALINA

DENTALINA

DENTALINA

DENT ALINA

DENTALINA

DENTALINA

DENTALI NA

DENTALI NA

DENTALINA

DENTALINA

DENTALINA

DENTALINA

DENTALINA

DENTALINA

DE NTALINA

DENTALINA

DENTALINA

DENTALINA

DENTALINA

DENTALINA

DENTALINA

DENTALINA

DENTALINA

DENTALINA

DENTALINA

DENTALINA

DENTALINA

DENTAL INA

DENTALINA

DE NTALINA

DENTALINA

DENTALINA

DENTALINA

DENTALINA

DENTALINA

DENTALINA

DENTALINA

DENTAL INA

DENTALINA

DENTALINA

DENTALINA

DENTALINA

DENTALINA

DENTALINA

DENTALINA

DENTALINA

DENT AL INA

DENTALINA

DENTALINA

DENTALINA

DENTALINA

DENTALINA

DENTALINA
DISCOPULVINUL INA

DI SCORB I NA

D I SCORB INA

DISCORBIS

DI :CORBIS

DISCORBIS

DI SCORBIS

DISCORBIS

DI SCORBIS

DISCORBIS

DISCORBIS

\section{COMMUNIS}

CONMUNIS

COMMUNIS

COMMUNIS

COMMUNIS

COMMUNIS

COMMUNIS

COMMUNIS

COMMUNIS

COMMUNIS

CONMUNIS

COMMUNIS

COMMUNIS

COMMUNIS

COMMUNIS

COMMUNIS

COMMUNIS

COMMUNIS

COMMUNIS

COMMUNIS

COMMUNIS

COMMUNIS

CONMUNIS

COMMUNIS

COMMUNIS

COMMUNIS

COMMUNIS

COMMUNIS

COMMUNIS

COMMUNIS

COMMUNIS

COMMUNIS

COMMUNIS

CUVIERI

CUVIERI

CUVIERI

CUVIERI

CUVIERI

CUVIERI

CUVIERI

CUVIERI

CUVIERI

CUVIERI

CUVIERI

CUVIERI

CUVIERI

CUVIERI

CUVIERI

CUVIERI

CUVIERI

CUVIERI

CUVIERI

CUVIERI

CUVIERI

FARCIMEN

FILIFORMI S

FI LIFORMI S

IN CRNATA BRADYENSIS

INORNATA BRADYENSIS

INCRNATA BRADYENSIS

INORNATA BRADYENSIS

INORNATA BR ADYENSIS

INORNATA BRADYENS IS

IN TOR TA

IN TOR TA

IN TOR TA

INTORTA

INTORTA

IN TORTA

IN TOR TA

IN TOR TA

IN TOR TA

IN TORTA

IN TOR TA

IN TORTA

IN TORTA

IN TORTA

IN TOR TA

INTORTA

INTORTA

INTOR TA

I N TOR TA

SUBEMACIATA

SUESOLUTA

BERTHELOT I

BERTHEL OT I

VI LARDEBJ ANA

AD VEVA

AL LOMORPH INOIDES

AL $A$ A B R I I

AUBER I I

AUBER I I

BERTHEL OT I

BERTHELOT I

\section{Locality}

CENTRAL GULF OF MEXICO

CENTRAL GULF OF MEXICO

CENTRAL GULF OF MEXICO

NW GULF OF MEXICO

NW GULF OF MEXICO

NW GULF OF MEXICO

CENTRAL GULF OF MEXICO

CENTRAL GULF OF MEXICO

NW GULF OF MEXICO

NW GULF OF MEXICO 


\section{Publication}

15596 NORTON 1930

15597 PHLEGER 1951A

15598 PHLEGER 1951A

15599 PHLEGER 1951A

15600 PHLEGER 1951A

15601 PHLEGER 1951A

15602 PHLEGER 1951A

15603 PHLEGER $1951 \mathrm{~A}$

15604 PHLEGER 1951.A

15605 PHLEGER 1951A

15606 PHLEGER 1951A

15607
15608

15609 KELLOUGH 1956

15610 KELLOUGH 1956

15611 AYALA-CASTANARES 1963

15612 AYALA-CASTANARES SEGURA 1968

15613 KELLOUGH 1956

15614 PARKER 1954

15615 PARKER 1954

15616 PARKER 1954

15617 PARKER 1954

15618 PARKER 1954

15619 PARKER 1954

15620 PARKER 1954

15621 PARKER 1954

15622 PHLEGER 1956

15623 PARKER 1954

15624 PHLEGER 1956

15625 PHLEGER 1956

15626 PHLEGER 1956

15627 PARKER 1954

15628 PARKER 1954

15629 KELLOUGH 1956

15630 PARKER 1954

15631 PARKER 1954

15633 PHLEGER 1951 A

15634 CREAGER 1958

15634 CREAGER 1958
15635 PHLEGER 1951 A

15636 PHLEGER 1951A

15637 PHLEGER 1951A

15638 PHLEGER $1951 \mathrm{~A}$

15639 PHLEGER 1951 A

15640 PHLEGER 1951A

15641 PHLEGER 1951A

15642 PHLEGER 1951A

15643 PHLEGER $1951 \mathrm{~A}$

15644 PHLEGER 1951A

15645 PHLEGER 1951 A

15646
15647
$15 O R T O E R$
15648

15647 NORTON 1930

15648 CUSHMAN 1931
15649 CREAGER 1958

15650 CREAGER 1958

15651 CUSHMAN 1931

15652 PHLEGER 1951A

15653 PHLEGER $1951 \mathrm{~A}$

15654 PHLEGER 1951A

15655 PHLEGER 1951 A

15656 PHLEGER 1951A

15657 PHLEGER 1951A

15658 PHLEGER 1951A

15659 PHLEGER $1951 \mathrm{~A}$

15650 PHLEGER 1951 A

15661 PHLEGER 1951A

15662 PHLEGER 1951 A

15663 PHLEGER $1951 \mathrm{~A}$

15664 PHLEGER 1954

15665 PHLEGER 1954

15666. WALT ON 1960

15667 BANDY 1956

15668 BANDY 1956

15669 BANDY 1956

15670 BANDY 1956

15671 BANDY 1956

15672 BANDY 1956

15673 BANDY 1956

15674 BANDY 1956

15675 BANDY 1956

15676 BANDY 1956

15677 ANDERS ON 1968

15678 BENDA PURI 1962

15679 BANDY 1956

15680 BANDY 1956

15681 BANDY 1956

15682 BANDY 1956

15683 BANDY 1956

15684 BANDY 1956

15685 BANDY 1956

15686 BANDY 1956

15687 BANDY 1956

15688 BANDY 1956

15689 BANDY 1956

15690 BANDY 1956
Generic Name

DI SCORBIS

DI SCORBIS

DISCORBIS

OISCORBIS

DISCORBIS

DISCORBIS

DI SCORBIS

DISCORBIS

DISCORBIS

DISCORBIS

DISCORBIS

DISCORBIS

D ISCORBIS

D ISCORBIS

DISCORBIS

DISCORBIS

DI SCORBIS

DISCORBIS

DI SCORBIS

DISCORBIS

DI SCORBIS

DI SCORBIS

DISCORBIS

DISCORBIS

DI SCORBIS

DISCORBIS

DISCORBIS

DI SCORBIS

DI SCORBIS

DI SCORBIS

DI SCORBIS

DI SCORBIS

DISCORBIS

DISCORBIS

DI SCORBIS

DI SCORBIS

DISCORB IS

DI SCORBIS

DISCORBIS

DISCORBIS

DISCORB IS

DISCORB IS

DISCORBIS

DISCORBIS

DISCORBIS

DI SCORBIS

D I SCORBIS

DISCORBIS

DI SCORBIS

DISCORBIS

DISCORBIS

DISCORBIS

DISCORBIS

DI SCORBIS

DISCORBIS

DISCORBIS

DISCORBIS

DISCORBIS

DISCORBIS

DISCORBIS

DISCORBIS

DISCORBIS

DISCORBIS

DISCORBIS

DISCORBIS

DI SCORBIS

DI SCORBIS

DI SCORBIS

DISCORBIS

DI SCORBIS

DI SCORBIS

DISCORBIS

DISCORBIS

DI SCORBIS

DI SCORBIS

DI SCORBIS

DISCORBIS

DISCORBIS

DISCORBIS

DISCORBIS

DISCORB IS

DI SCORBIS

DISCORBIS

DISCORBIS

DISCORBIS

DISCORB IS

DISCORBIS

DISCORBIS

DISCORBIS

DISCORBIS

DISCORBIS

DISCORBIS

DISCORBIS
Specific Name

BERTHEL OT I

BERTHEL OT I

BERTHELOT I

BERTHELOT I

BERTHELOT I

BERTHELOT

BERTHEL OT

BERTHEL OT I

BE RT HEL OT I

BERTHEL OT I

BERTHELOT I

BERTHELOT I

BERTHELOT I

BULBOSA

$B \cup L B O S A$

BULBOSA

BULBOSA

BULBOSA

BULBOSA

BULBOSA

BULBOSA

BU LBOSA

BULBOSA

BULBOSA

BULBOSA

BULBOSA

BULBOSA

BULBOSA

BULBOSA

BULBOSA

BULBOSA

BULBOSA

BULBOSA

BULBOSA

BULBOSA

BULBOSA

BULBOSA

CANDE IANA

C ANDE I ANA

CANDEIANA

CANDE IANA

CANDE I ANA

C A NDE I ANA

CANDE I ANA

CANDEIANA

CANDEIANA

CA NDE I ANA

CANDEIANA

CANDE IANA

C A $\triangle D E I A N A$

C ANDEIANA

C ANDE IANA

CANDE IANA

C ANDE I ANA

CANDE IANA

C ANDEIANA

C A ADEIANA

CANDEIANA

CANDE I ANA

C ANDE I ANA

C ANDE I ANA

CANDE IANA

C ANDEI ANA

C ANDE I ANA

CA $A D E$ IANA

CANDE IANA

CANDEIANA

CANDEI ANA

C ANDEI ANA
COLUMBIENSIS

COLUMBIEVSIS

CONCINNA

CONCINNUS

COACINNUS

COACINNUS

CONCINNUS

CONCINNUS

CONCINNUS

COACINNUS

COACINNUS

COACINNUS

CONCINNUS

CONCINNUS

CONCINNUS

CONCINNUS

CONCINNUS

CONCINNUS

CONCINNUS

CONCINNUS

CONCINNUS

CONCINNUS

CONCINNUS

CONCINNUS

CONCINNUS

CONC INNUS

CONCINNUS

Locality

TORTUGAS, FLLA

$N W$ GULF OF MEXICO

NW GULF OF MEXICO

NW GULF OF MEXICO

NW GULF OF MEXICO 


\section{Publication}

15691 BANDY 1956

15692 PARKER PHLEGER PEIRSON 1953

15693 PARKER PHLEGER PEIRSON 1953

15694 PARKER PHLEGER PEIRSON 1953

15695 PARKER PHLEGER PEIRSON 1953

15696 PHLEGER 1951A

15697 PARKER PHLEGER PEIRSON 1953

15698 PHLEGER 1954

15699 PARKER PHLEGER PEIRSON 1953 15700 WARREN 1956

15701 CUSHMAN 1931

15702 WALTON 1960

15703 PARKER PHLEGER PEIRSON 1953

15704 PHLEGER 1951A

15705 WARREN 1957

15706 PHLEGER 1954

15707 SHIF FLETT 1961

15708 CUSHMAN 1922 A

15709 PHLEGER $1951 \mathrm{~A}$

15710 PHLEGER 1951A

15711 PHLEGER 1951A
15712 PHLEGER 1951A

15713 PHLEGER 1951A

15714 PHLEGER 1951 A

15715 BANDY 1954

15716 BANDY 1956

15717 BANDY 1956

15718 BANDY 1954

15719 BANDY 1954

15720 BANDY 1956

15721 KELLOUGH 1956

15722 BANDY 1956

15723 BANDY 1956

15724 BANDY 1956

15725 BANDY 1956

15726 BANDY 1956

15727 BANDY 1954

15728 BANDY 1956

15729 BANDY 1956

15730 BANDY 1956

15731 BANDY 1956

15732 BANDY 1956

15733 BANDY 1954

15734 BANDY 1956

15735 BANDY 1956

15737 BANDY 1956

15738 BANDY 1956

15739 BANDY 1956

15740 BANDY 1956

15741 BANDY 1956

15742 BANDY 1956

15743 BANDY 1956

15744 BANDY 1956

15745 BANDY 1956

15746 BANDY 1956

15747 SHIFFLETT 1961

15748 LIDZ LIDZ 1966

15749 BANDY 1956

15750 BENDA PURI 1962

15751 BANDY 1956

15752 BANDY 1956

15753 BANDY 1956

15754 CUSHMAN $1922 \mathrm{~A}$

15755 CUSHMAN 1931

15756 CUSHMAN 1931

15757 NORTON 1930

15758 CREAGER 1958

15759 SHIFFLETT 1961

15760 CUSHMAN $1922 \mathrm{~A}$

15761 CUSHMAN 1931

15762 NORTON 1930

15763 SHIFFLETT 1961

15764 NORTON 1930

15765 LYNTS PFISTER 1967

15766 NORTON 1930
15767 CUSHMAN 1931

15767 CUSHMAN 1931
15768 CUSHMAN 1922 A

15769 NORTON 1930

15770 CREAGER 1958

15771 PHLEGER 1965A

15772 LEHMANN 1957

15773 PHLEGER $1965 \mathrm{C}$

15774 SHEPARD MOORE 1955

15775 PHLEGER 1965 A

15776 PARKER PHLEGER PEIRSON 1953

15777 PHLEGER 1965 A

15778 PARKER PHLEGER PEIRSON 1953

15779 PHLEGER 1965 A

15780 PHLEGER $1965 \mathrm{~A}$

15781 PHLEGER 1965 A

15782 BENDA PURI 1962

15783 ANDERSEN 1961

15784 PFLUM FRERICHS 1976

15785 PFLUM FRERICHS 1976
Generic Name

DISCORBIS

DISCORBIS

DI SCORBIS

DI SCORBIS

I SCORBIS

DISCORBIS

DISCORBIS

DI SCORBIS

DI SCORBIS

DISCORBIS

I ISCORBIS

DISCORBIS

DISCORB IS

DI SCORBIS

DI SCORBIS

DI SCORB IS

DIS CORBIS

DI SCORB IS

DISCORBIS

DISCORB IS

DI SCORBIS

DI SCORBIS

DIS CORB IS

DI SCORBIS

DISCORBIS

DI SCORBIS

DI SCORBIS

DI SCORB IS

DI SCORBIS

DI SCORBIS

DI SCORB IS

DI SCORB IS

DISCORBIS

DISCORBIS

DISCORBIS

DIS CORBIS

DI SCORBIS

DI SCORBIS

DISCORBIS

DISCORBIS

DI SCORBIS

DI SCORB IS

DISCORBIS

DI SCORBIS

DISCORBIS

DISCORBIS

DI SCORBIS

DI SCORBI S

DI SCORBI S

DISCORBIS

DI SCORB IS

DISCORBIS

DISCORBIS

DISCORBIS

DISCORBIS

DI SCORB IS

DI SCORBIS

DISCORBIS

DISCORB IS

DI SCORBIS

DI SCORB IS

DI SCORBIS

DI SCORBIS

DISCORBIS

DISCORBIS

DI SCORBIS

DI SCORBI

DISCORB IS

DI SCORBIS

DI SCORB I S

DISCORBIS

DISCORBIS

DI SCORB IS

DI SCORB IS

DI SCORBIS

DISCORBIS

DI SCORBIS

DISCORBIS

DI SCORINOPS IS

DISCORINOPSIS

DISCORINOPS IS

DI SCORINOPS IS

DI SCOR INOPS IS

DI SCOR INOPS IS

DI SCORINOP IS

DI SCORINOPS IS

DISCORINOPSIS

DI SCORINOPSIS

DI SCORINOPS IS

DI SCOR INOPS IS

DOROTHIA

DOROTHIA

DOROTHIA
Specific Name

CONCINNUS

FL ORI DANA

FLOR I DANA

FL OR I DANA

FL ORI DANA

FL ORIDANa

FL OR I DANA

FL OR I DANA

FL ORI DANA

FL OR I DANA

FL OR I DANA

FL OR IDANA

FL ORI DANA

FL ORI DANA

FL ORI DANA

FL ORI DANA

FL ORI DANA

FL ORI DANA

FL OR I DANA

FL ORI DANA

FL OR I DANA

FL CRI DANUS

FL ORIDANUS

FL ORIDANUS

FL OR I DANUS

FL ORIDANJS

FLORI DANUS

FL ORIDANUS

FL ORI DAN'S

FLORI DANUS

FL ORIDANUS

FLORIDANUS

FL OR I DANUS

FLORIDANUS

FLOR I DANUS

FL CRIDANUS

FLORI DANUS

FL ORI DANUS

FLCRIDANUS
FLORIDANUS

FL ORI DANUS

FLORIDANUS

FLORIDANUS

FL ORIDANUS

FL ORI DANUS

FLORIDANUS

FL ORIDANUS

FLORIDANUS

FLORIDANUS

FL ORI DANU S

FLORIDANUS

FL OR I DENS IS

FL ORIDENS IS

FLORIDENS IS

FLCRIDENS IS

FLCRIDENS IS

FLORIDENS IS

FL OR I DENS IS

FLORIDENS IS

MIRA

MI RA

MIRA

MI RA

NITIDA

OREI CUL AR IS

OREI CULAR IS

ORBICULAR IS

ORBICULAR IS

PATELLIFORMIS

ROSEA

RUGOSA

SUBARAUCANA

SUBARAUCANA

SUBARAUCANA

SUEZENSIS

AGUAYOI

AGUAYOI

A GUAYOI

AGUAYOI

AGUAYOI

AGUAYOI

AGUAYOI

AGUAYOI

AGUAYOI

AGUAYOI

AGUAYOI

CARIBAEA

PSEUDOTURRIS

PSEUDOTURRIS

Locality

NE GULF OF MEXICO

TEXAS GULF COAST

TEXAS GULF COAST

TEXAS GULF COAST

TEXAS GULF COAST

NW GULF OF MEXICO

TEXAS GULF COAST

MISSISSIPPI SOUND

TEXAS GULF COAST

BURAS SE LOUISIANA 


\section{Publication}

15786 PFLUM FRERICHS 1976 15787 PFLUM FRERICHS 1976 15788 PFLUM FRERICHS 1976 15789 PFLUM FRERICHS 1976 15790 PFLUM FRERICHS 1976 15791 PFLUM FRERICHS 1976 15792 PFLUM FRERICHS 1976 15793 PFLUM FRERICHS 1976 15794 PFLUM FRERICHS 1976 15795 PFLUM FRERICHS 1976 15796 PFLUM FRERICHS 1976 15797 PFLUM FRERICHS 1976 15798 LEROY HODGKINSON 1975 15799 LEROY HODGKINSON 1975 15800 CREAGER 1958

15801 PARKER 1954

15802 PARKER 1954

15803 PARKER 1954

15804 PARKER 1954

15805 PARKER 1954

15806 PFLUM FRERICHS 1976

15807 PFLUM FRERICHS 1976

15808 PHLEGER 1951A

15809 PHLEGER 1951 A

15810 PFLUM FRERICHS 1976

15811 PFLUM FRERICHS 1976

15812 LEROY HODGKINSON 1975

15813 PHLEGER $1951 \mathrm{~A}$

15814 PHLEGER 1951A

15815 PHLEGER 1955A

15816 PHLEGER 1951A

15817 CREAGER 1958

15818 CREAGER 1958

15819 CREAGER 1958

15820 PHLEGER 1951A

15821 PHLEGER 1951A

15822 PHLEGER $1951 \mathrm{~A}$

15823 LOEP 1965

15824 LOEP 1965

15825 CREAGER 1958

15826 PARKER 1954

15827 PARKER 1954

15828 PARKER 1954

15829 PARKER 1954

15830 PFLUM FRERICHS 1976

15831 PFLUM FRERICHS 1976

15832 PFLUM FRERICHS 1976

15833 PFLUM FRERICHS 1976

15834 PFLUM FRERICHS 1976

15835 PFLUM FRERICHS 1976

15836 PFLUM FRERICHS 1976

15837 PFLUM FRERICHS 1976

15838 PFLUM FRERICHS 1976

15839 PFLUM FRERICHS 1976

15840 PFLUM FRERICHS 1976

15841 PFLUM FRERICHS 1976

15842 PFLUM FRERICHS 1976

15843 PFLUM FRERICHS 1976

15844 PFLUM FRERICHS 1976

15845 PFLUM FRERICHS 1976

15846 PFLUM FRERICHS 1976

15847 PFLUM FRERICHS 1976

15848 PFLUM FRERICHS 1976

15849 PFLUM FRERICHS 1976

15850 PFLUM FRERICHS 1976

15851 PFLUM FRERICHS 1976

15852 PFLUM FRERICHS 1976

15853 PFLUM FRERICHS 1976

15854 PFLUM FRERICHS 1976

15855 PFLUM FRERICHS 1976

15856 PFLUM FRERICHS 1976

15857 PFLUM FRERICHS 1976

15858 PFLUM FRERICHS 1976

15859 PFLUM FRERICHS 1976

15860 PFLUM FRERICHS 1976

15861 PFLUM FRERICHS 1976

15862 PHLEGER $1955 \mathrm{~A}$

15863 PHLEGER 1951 A

15864 PHLEGER 1951A

15865 PHLEGER 1951A

15866 PHLEGER 1951A

15867 PHLEGER 1955A

15868 PARKER 1954

15869 PARKER 1954

15870 PARKER 1954

15871 PARKER 1954

15872 PARKER 1954

15873 PARKER 195

15874 PARKER 1954

15875 PARKER 1954

15876 PARKER 1954

15877 PARKER 1954

15878 PARKER 1954

15880 PHLEGER 1951 A

Generic Name

Specific Name

Locality

Lat. Long.

DOROTHIA

DOROTHIA

DOROTHIA

DOROTHIA

DOROTHIA

DOROTHIA

DOROTHIA

DOROTHIA

DOROTHIA

DOROTHIA

DOROTHIA

DOROTHIA

DOROTHIA

EGGERELLA

EGGERELLA

EGGERELLA

EGGERELLA

EGGERELLA

EGGERELLA

EGGERELLA

EGGERELLA

EGGERELLA

EGGERELLA

EG GERELLA

EGGERELLA

EG GEREL LA

EGGERELLA

EGGERELLA

EG GERELLA

EGGERELLA

EGGERELLA

EGGERELLA

EGGERELLA

EGGERELLA

EGGERELLA

EGGERELLA

EG GERELLA

EG GERELLA

EG GERELLA

EGGERELLA

EGGERELLA

EGGERELLA

EGGERELLA

EGGERELLA

EGGERELLA

EGGERELLA

EGGERELLA

EGGERELLA

EGGERELLA

EGGERELLA

EGGERELLA

EGGERELLA

EG GERELLA

EGGERELLA

EG GERELLA

EGGERELLA

EGGERELLA

EGGERELLA

EG GERELLA

EGGERELLA

EGGERELLA

EGGERELLA

EGGERELLA

EGGERELLA

EG GERELLA

EG GERELLA

EGGERELLA

EGGERELLA

EGGERELLA

EGGERELLA

EGGERELLA

EGGERELLA

EGGERELLA

EGGER ELLA

EGGERELLA

EGGERELLA

EGGERELLA

EGGERELLA

EGGERELLA

EGGERELLA

EG GERELLA

EGGERELLA

EGGERELLA

EGGERELLA

EGGERELLA

EG GERELLA

EGGERELLA

EGGERELLA

EGGERELLA

EGGERELLA

EGGERELLA

EGGERELLA

EGGERELLA
PSEUDOTURRIS

PSEUDOTURRIS

PSEUDOTUR RIS

PS EUDOT UR RIS

PSEUDOTURRIS

P SEUDOTURRIS

PSEUDOTURRIS

PSEUDOTURRIS

PSEUDOTURRIS

PSEUDOTURRIS

PS EUDOTURRIS

PSEUDOTURRIS

SCABRA

AFFIXA

BRADYI

BRADYI

BRADYI

BRADYI

BRADYI

BRADYI

BRADYI

BRADYI

BRADYI

BRADYI

BRADYI

BRADYI

BR ADYI

BRADYI

BRADYI

BRADYI

BRADYI

BR ADYI

BRADYI

BRADYI

BR ADYI

BRADYI

BRADYI

BRADYI

BRADYI

BRADYI

BR ADYI

BRADYI

BR ADYI

BRADYI

BRADYI

BRADYI

BRADYI

BRADYI

BRADYI

BRADY I

BRADYI

BR ADYI

BRADYI

BR ADYI

BR ADYI

BRADYI

BRADYI

BRADYI

BR ADYI

BRADYI

BRADYI

BRADYI

BR ADYI

BRADYI

BR ADYI

BR ADYI

BRADYI

BR ADYI

BRADYI

BR ADY I

$B R A D Y I$
$B R A D Y I$

BRADYI

BRADYI

BR ADYI

BRADYI

BRADYI

BRADYI

BR ADYI

BRADYI

BR ADYI

BRADYI

BRADYI

BR ADYI

BRADYI

BRADYI

BRADYI

BRADYI

BRADYI

BRADYI

BRADYI

BRADYI

BRADYI
BRADYI

NW GULF OF MEXICO

NW GULF OF MEXICO

$N W$ GULF OF MEXICO 


\section{Publication}

15881 PHLEGER 1951A 15882 PHLEGER 1951A 15883 PHLEGER 1951A 15884 PHLEGER 1951A

15885 PHLEGER 1951 A

15886 PFLUM FRERICHS 1976 15887 PFLUM FRERICHS 1976 15888 PFLUM FRERICHS 1976 15889 PFLUM FRERICHS 1976 15890 PHLEGER 1951A

15891 PHLEGER $1951 \mathrm{~A}$

15892 PFLUM FRERICHS 1976

15893 PHLEGER 1951A

15894 CREAGER 1958

15895 CREAGER 1958

15896 CREAGER 1958

15897 PFLUM FRERICHS 1976

15898 PHLEGER 1951A

15899 PFLUM FRERICHS 1976

15900 PFLUM FRERICHS 1976

15901 PFLUM FRERICHS 1976

15902 PFLUM FRERICHS 1976

15903 PFLUM FRERICHS 1976

15904 PFLUM FRERICHS 1976

15905 PFLUM FRERICHS 1976

15906 PFLUM FRERICHS 1976

15907 PFLUM FRERICHS 1976

15908 CREAGER 1958

15909 PFLUM FRERICHS 1976 15910 PFLUM FRERICHS 1976 15911 PFLUM FRERICHS 1976 15912 PFLUM FRERICHS 1976 15913 PFLUM FRERICHS 1976 15914 PFLUM FRERICHS 1976 15915 PFLUM FRERICHS 1976 15916 PFLUM FRERICHS 1976 15917 PFLUM FRERICHS 1976 15918 PFLUM FRERICHS 1976 15919 PFLUM FRERICHS 1976 15920 PFLUM FRERICHS 1976 15921 PFLUM FRERICHS 1976 15922 PHLEGER 1951A

15923 PFLUM FRERICHS 1976 15924 PFLUM FRERICHS 1976 15925 CREAGER 1958

15926 PFLUM FRERICHS 1976 15927 PFLUM FRERICHS 1976 15928 PFLUM FRERICHS 1976 15929 PFLUM FRERICHS 1976 15930 PFLUM FRERICHS 1976 15931 PFLUM FRERICHS 1976 15932 PFLUM FRERICHS 1976 15933 CREAGER 1958

15934 CREAGER 1958

15935 LEROY HODGKINSON 1975

15936 PFLUM FRERICHS 1976 15937 PFLUM FRERICHS 1976 15938 PFLUM FRERICHS 1976 15939 PFLUM FRERICHS 1976 15940 PFLUM FRERICHS 1976 15941 PFLUM FRERICHS 1976 15942 PFLUM FRERICHS 1976 15943 PFLUM FRERICHS 1976 15944 PFLUM FRERICHS 1976 15945 PFLUM FRERICHS 1976 15946 PFLUM FRERICHS 1976 15947 PFLUM FRERICHS 1976 15948 PFLUM FRERICHS 1976 15949 PFLUM FRERICHS 1976 15950 PFLUM FRERICHS 1976 15951 PFLUM FRERICHS 1976 15952 PFLUM FRERICHS 1976 15953 PFLUM FRERICHS 1976 15954 PFLUM FRERICHS 1976 15955 PFLUM FRERICHS 1976 15956 PFLUM FRERICHS 1976 15957 PFLUM FRERICHS 1976 15958 PFLUM FRERICHS 1976 15959 PFLUM FRERICHS 1976 15960 PFLUM FRERICHS 1976 15961 PFLUM FRERICHS 1976 15962 PFLUM FRERICHS 1976 15963 PFLUM FRERICHS 1976 15964 PFLUM FRERICHS 1976 15965 PFLUM FRERICHS 1976 15966 PFLUM FRERICHS 1976 15967 PFLUM FRERICHS 1976 15968 PFLUM FRERICHS 1976 15969 PFLUM FRERICHS 1976 15970 PFLUM FRERICHS 1976 15971 PFLUM FRERICHS 1976 15972 PFLUM FRERICHS 1976 15973 PFLUM FRERICHS 1976 15974 PFLUM FRERICHS 1976 15975 PFLUM FRERICHS 1976
Generic Name Specific Name

EGGERELLA

EGGERELLA

EGGERELLA

EGGERELLA

EGGERELLA

EGGERELLA

EGGERELLA

EGGERELLA

EGGERELLA

EGGERELLA

EGGERELLA

EGGERELLA

EGGERELLA

EGGERELLA

EGGERELLA

EGGERELLA

EGGERELLA

EGGERELLA

EGGERELLA

EGGERELLA

EGGERELLA

EGGERELLA

EGGERELLA

EGGERELLA

EGGERELLA

EGGERELLA

EG GERELLA

EGGERELLA

EGGERELLA

EGGERELLA

EGGERELLA

EGGERELLA

EGGERELLA

EGGERELLA

EGGERELLA

EGGERELLA

EGGERELLA

EGGERELLA

EG GERELLA

EGGERELLA

EGGERELLA

EGGERELLA

EGGERELLA

EGGERELLA

EG GERELLA

EG GERELLA

EGGERELLA

EGGERELLA

EGGERELLA

EGGERELLA

EGGERELLA

EG GERELLA

EGGERELLA

EGGERELLA

EGGERELLA

EGGERELLA

EGGERELLA

EGGERELLA

EG GERELLA

EGGERELLA

EGGERELLA

EGGERELLA

EGGERELLA

EGGERELLA

EGGERELLA

EGGERELLA

EGGERELLA

EGGERELLA

EGGERELLA

EGGERELLA

EGGERELLA

EGGERELLA

EHRENBERGINA

EHRENBERGINA

EHRENBERGINA

EHRE NBE RGINA

EHRE NBE RGINA

EHRENBERGINA

EHRENBERGINA

EHRENBER GI N A

EHRENBERGINA

EHRENBE RGI NA

EHRE NBERGI NA

EHRENBERG I NA

EHRENBERGIN A

EHRE NBERGI NA

EHRENBE RG I NA

EHRENBERGINA

EHRE NBERGINA

EHRENBERGINA

EHRE NBER GI NA

BRADYI

BRADYI

BRADYI

BRADY

BRADYI

BR ADYI

BRADYI

BRADYI

BRADY

BRADY

BRADYI

BRADYI

BRADYI

BRADYI

BRADY

BRADYI

BRADYI

BRADYI

BRADY

BR ADYI

BRADYI

BRADYI

BRADYI

BRADYI

BRADYI

BRADYI

BRADYI

BRADYI

BRADY I

BRADYI

BRADY

BR ADYI

BRADYI

BRADYI

PR OP I NQ UA

PROPINOUA

PR OPI NQUA

PR OPINQUA

PROPI NQUA

PR OP INQUA

PROPINQUA

PROPINQUA

PR OPI NQUA

PROPINQUA

PR OPI NQUA

PROPINQUA

PROPINQUA

PR CPI NQUA

PROPINQUA

PR OPINQUA

PROPI NQUA

PROPINQUA

PROPINQUA

PROPI NQUA

PROPI NQUA

PROPINQUA

PR OP I NQUA

PROPINQUA

PROP I NQUA

PROPINQUA

PROPI NQUA

SCABRA

SCABRA

PUPA

PUPA

PUPA

PUPA

PUPA

PUPA

PUPA

PUPA

PUPA

PUPA

PUPA

PUPA

PUPA

PUPA

PUPA

PUPA

PUPA

PUPA
PUPA
BRADYI NW GULF OF MEXICO

NW GULF OF MEXICO

NW GULF OF MEXICO

NW GULF OF MEXICO

NW GULF OF MEXICO

NH GULF OF MEXICO

NH GULF OF MEXICO

NH GULF OF MEXICO

NH GULF OF MEXICO

NH GULF OF MEXICO

NW GULF OF MEXICO

NW GULF OF MEXICO

NH GULF OF MEXICO

\section{Locality}


Publication

15976 PFLUM FRERICHS 1976 15977 PFLUM FRERICHS 1976 15978 PFLUM FRERICHS 1976 15979 PFLUM FRERICHS 1976 15980 PFLUM FRERICHS 1976 15981 PFLUM FRERICHS 1976 15982 BANDY 1956

15983 PARKER 1954 15984 PARKER 1954

15985 PARKER 1954

15986 BANDY 1956

15987 PARKER 1954

15988 PFLUM FRERICHS 1976

15989 CREAGER 1958

15990 PHLEGER 1951A

15991 PFLUM FRERICHS 1976

15992 PFLUM FRERICHS 1976

15993 PFLUM FRERICHS 1976

15994 PFLUM FRERICHS 1976

15995 PFLUM FRERICHS 1976

15996 PFLUM FRERICHS 1976

15997 PFLUM FRERICHS 1976

15998 PHLEGER 1951A

15999 PHLEGER 1951A

16000 PHLEGER 1951A

16001 PHLEGER 1951A

16002 NORTON 1930

16003 WARREN 1957

16005 LIDZ LIDZ 1966

16005 LIDZ LIDZ

16006 BANDY 1956
16007 BANDY 1956

16008 BANDY 1956

16009 BANDY 1956

16010 BANDY 1956

16011 BANDY 1956

16012 BANDY 1956

16013 WALTON 1960

16014 BANDY 1956

16015 BANDY 1956

16016 BANDY 1956

16017 BANDY 1956

16018 BANDY 1956

16019 BANDY 1956

16020 BANDY 1956

16021 BANDY 1956

16022 BANDY 1956

16023 WARREN 1956

16024 AYALA-CASTANARES 1963

16025 AYALA-CASTANA

16026 WALTON 1964

16027 BENDA PURI 1962

16028 BENDA PURI 1962

16029 PHLEGER 1956

16030 PARKER 1954

16032 LEHMANN 1957

16033 PARKER 1954

16033 PARKER 1954
16034 PARXER 1954

16034
16035
$16 H L E G E R \quad 1954$

16036 PARKER 1954

16037 PARKER PHLEGER PEIRSON 1953

16038 PARKER PHLEGER PEIRSON 1953

16039 PARKER PHLEGER PEIRSON 1953

16040 PARKER PHLEGER PEIRSON 1953

16041 POST 1951

16042 PARKER PHLEGER PEIRSON 1953

16043 LUDWICK WALTON 1957

16044 PHLEGER 1954

16045 BOCK 1976

16046 PARKER PHLEGER PEIRSON 1953

16047 PHLEGER 1956

16048 PARKER 1954

16049 PARKER 1954

16050 PARKER 1954

16051 PHLEGER 1956

16052 PHLEGER 1956

16053 PARKER PHLEGER PEIRSON 1953

16054 PARKER PHLEGER PEIRSON 1953

16055 PHLEGER 1956

16056 POST 1951

16057 POST 1951

16058 LIDZ LIDZ 1966

16059 SEGURA 1963

16060 LEHMANN 1957

16061 PHLEGER 1954

16062 LANKFORD 1959

16063 PHLEGER LANKFORD 1957

16064 PHLEGER 1954

16065 PHLEGER $1965 \mathrm{C}$

16066 PHLEGER 19558

16067 WALTON 1960

16068 BENDA PURI 1962

16069 BENDA PURI 1962

16069 BENDA PURI 1962
16070 BENDA PURI 1962
Generic Name

Specific Name

EHRENBERGINA

EHRENBERGINA

EHRENBERGIN A

EHRENBERGINA

EHRENBERGINA

EHRENBER GINA

EHRENBER GINA

EHRENBERGINA

EHRENBERGINA

EHRENBERGINA

EHRENBERGINA

EHRENBERGINA

EHRENBERGINA

EHRENBER GINA

EHRENBERGINA

EHRENBERGINA

EHRENBERGINA

EHRENBERGINA

EHRENBERGIN A

EHRENBERGINA

EHRENBERGINA

EHRENBERGINA

EHRENBERG INA

EHRENBERGINA

EHRENBERGINA

EHRENBERGINA

ELPHIDIUM

ELPHIDIUM

ELPHIDIUM

ELPHIDIUM

ELPHIDIUM

ELPHIDIUM

ELPHIDIUM

ELPH IDIUM

ELPHI DIUM

ELPHIDIUM

ELPHIDIUM

ELPHIDIUM

ELPHIDIUM

ELPH I DIUM

ELPHIDIUM

ELPHIDIUM

ELPHIDIUM

ELPH ID IUM

ELPHIDIUM

ELPHIDIUM

ELPHIDIUM

ELPH I I UM

ELPHIDIUM

ELPHIDIUM

ELPHI DIUM

ELPHIDIUM

ELPHIDIUM

ELPHIDIUM

ELPHIDIUM

ELPHI DIUM

ELPHIDIUM

ELPHIDIUM

ELPHIDIUM

ELPHIDIUM

LPHIDIUM

ELPHIDIUM

ELPHIDIUM

ELPHIDIUM

ELPHIDIUM

ELPHIDIUM

ELPHIDIUM

ELPHIDIUM

ELPHIDIUM

ELPHIDIUM

ELPHIDIUM

ELPHIDIUM

ELPHI DIUM

ELPHIDIUM

ELPHIDIUM

ELPHIDIUM

ELPHIDIUM

ELPHIDIUM

ELPHIDIUM

ELPHIOIUM

ELPH I DIUM

ELPHIDIUM

LPHIDIUM

ELPHIDIUM

ELPHI DIUM

ELPHIDIUM

ELPHIDIUM

ELPHIDIUM

ELPHIDIUM

ELPHIDIUM
PUFA

PUPA

PUPA

PUPA
SPINEA

SPINEA

SPINEA

SP INEA

SPINEA

SPINEA

SP INEA

SPINEA

TRIGONA

IR IGONA

TR IGONA

TR I GONA

TR IGONA

TR IGONA

TRIGONA

TRIGONA

TRIGONA

TR IGONA

TR IGONA

TRIGONA

ADVENA

AD VENA

AD VENUM

AD VENUM

AD VENUM

ADVENUM

AD VENUM

AD VENUM

ADVENUM

ADVENUM

AD VENUM

AD VENUM

AD VENUM

AD VENUM

ADVENUM

ADVENUM

AD VENUM

AD VENUM

AD VENUM

AD VENUM

AD VENUM

ADVENUM

ADVENUM

ADVENUM

ADVENUM

AD VENUM

AD VENUM

AD VENUM

ADVENUM

AD VENUM

ADVENUM

AD VENUM

AD VENUM

AD VENUM

ADVENUM

ADVENUM

ADVENUM

ADVENUM

AD VENUM

AD VENUM

AD VENUM

ADVENUM

A D VENUM

ADVENUM

A D VENUM

ADVENUM

AD VENUM

AD VENUM

ADVENUM

$A D$ VENUM

AD VENUM

ADVENUM

AD VENUM

AD VENUM

AR I I CUL AT UM

AR I I CULAT UM

AR TI CUL AT UM

DELICATUL UM

DELICATULUM

DELI CATUL UM

DELICATUL UM

DELI CATUL UM

DELICATUL UM

DELICATUL UM

DELICATUL UM

DELICATU'UM

DELICATUL UM

DELICATUL UM

DELICATUL UM
TRIGONA

Locality

Lat. Long.

NW GULF OF MEXICO

NH GULF OF MEXICO

WW GULF OF MEXICO

NW GULF OF MEXICO

NW GULF OF MEXICO

NW GULF OF MEXICO

NE GULF OF MEXICO

NE GULF OF MEXICO 
Publication

16071 AYALA-CASTANARES SEGURA 1968 ELPHIDIUM 16072 WALTON 1964 16074 PARKER PHLEGER PEIRSON 1953 ELPHIDIUM 16075 WANTLAND 1969 PEIRH 1953 ELPHDIUM 16077 PARKER PHLEGER PEIRSON 1953 ELPHIDIUM 16078 PARKER PHLEGER PEIRSON 1953 ELPHIDIUM 16078 PARKER PHLEGER PEIRSON 1953 ELPHIDIUM

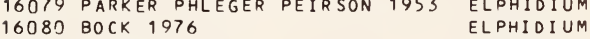
16081 PHLEGER 1956

16082 KANE 1967

16084 KANE 1967

16085 PHLEGER 1951 A

16086 PHLEGER 1951A

16087 PHLEGER 1951 A

16088 PHLEGER 1951 A

16089 PHLEGER 1951A

16090 PHLEGER 1951A

16091 PHLEGER 1951A

16092 PHLEGER 1951A

16093 PHLEGER $1951 \mathrm{~A}$

16094 PHLEGER $1951 \mathrm{~A}$

16095 PHLEGER 1951A

16096 PHLEGER 1951A

16097 PHLEGER 1951A

16098 PHLEGER $1965 \mathrm{C}$

16099 PHLEGER 1954

16100 PHLEGER LANKFORD 1957

16101 LUDWICK WALTON 1957

16102 LANKFORD 1959

16103 PHLEGER 1954

16104 WARREN 1957

16105 POAG 1976

16106 PARKER 1954

16107 PARKER 1754

16108 PARKER 1954

16109 PARKER 1954

16110 PARKER 1954

16111 PARKER 1954

16112 PARKER 1954

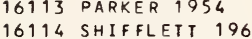

16114 SHIFFLETT 196
16115 PHLEGER 1951A

16115 PHLEGER $1951 \mathrm{~A}$
16116 PHLEGER 1951A

16117 PHLEGER 1951A

16118 PHLEGER 1951A

16119 PHLEGER 1951A

16120 PHLEGER 1951A

16121 PHLEGER 1951A

16122 PHLEGER $1951 \mathrm{~A}$

16123 PHLEGER 1951A

16124 PHLEGER 1951A

16125 PHLEGER 1956

16126 ANDERSEN 1961

16127 WALTON 1960

16128 KANE 1962

16129 PHLEGER 1951A

16130 SEGURA 1963

16131 PHLEGER 1956

16132 POAG SWEET 1972

16133 PHLEGER 1956

16134 KELLOUGH 1956

16135 KELLOUGH 1956

16136 KELLOUGH 1956

16137 BANDY 1956

16138 BENDA PURI 1962

16139 BANDY 1956

16140 BANDY 1954

16141 BANDY 1956

16142 BANDY 1956

16143 KELLOUGH 1956

16144 KELLOUGH 1956

16145 ANDERSON 1968

16146 KELLOUGH 1956

16147 KELLOUGH 1956

16148 BANDY 1956

16149 BANDY 1956

16150 BANDY 1956

16151 BANDY 1956

16153 BANOY 1956

16153 BANDY 1956
16154 BANDY 1954

16155 BANDY 1956

16156 KORNFELD 1931

16157 BANDY 1956

16158 BANDY 1956

16159 BANDY 1956

16160 BANDY 1956

16161 BANDY 1956

16162 BANDY 1956
16163 BANDY 1956

16164 BANDY 1956

16165 BANDY 1956
ELPHIDIUM

ELPHIDIUM

ELPHIDIUM

ELPHIOIUM

ELPHIDIUM

ELPHIDIUM

ELPHIOIUM

ELPHIDIUM

ELPHIDIUM

ELPHIDIUM

ELPHIDIUM

ELPHIDIUM

ELPHIDIUM

ELPHIOIUM

ELPHIDIUM

ELPHIDIUM

ELPHIOIUM

ELPHIDIUM

ELPHIDIUM

ELPHIDIUM

ELPHIOIUM

ELPHIDIUM

ELPHIDIUM

ELPHIDIUM

ELPHIDIUM

ELPHIDIUM

ELPHIDIUM

ELPHIDIUM

ELPHIDIUM

ELPHIDIUM

ELPHIDIUM

ELPHIDIUM

ELPHIDIUM

ELPHIDIUM

ELPHIDIUM

ELPHIDIUM

ELPHIOIUM

ELPHIDIUM

ELPHIDIUM

ELPHIDIUM

ELPHIDIUM

ELPHIOIUM

ELPHIDIUM

ELPHIDIUM

ELPHIDIUM

ELPHIDIUM

ELPHIDIUM

ELPHIDIUM

ELPHIDI UM

ELPHIDIUM

ELPHIDIUM

ELPHIDIUM

ELPHIOIUM

ELPHIDIUM

ELPHIOIUM

ELPHIDIUM

ELPHIDIUM

ELPHIOIUM

ELPHIDIUM

ELPHIDIUM

ELPHIDIUM

ELPHIDIUM

ELPHIDIUM

ELPHIDIUM

ELPHIDIUM

ELPHIDIUM

ELPHIDIUM

ELPHIDIUM

ELPHIDIUM

ELPHIDIUM

ELPHIDIUM

ELPHIDIUM

ELPHIDIUM

ELPHIDIUM

ELPHIDIUM

ELPHIDIUM

ELPHIDIUM

ELPHIDIUM

ELPHIDIUM
ELPHIDIUM

ELPHIDIUM
Specific Name

DELICATUL UM

DELICATUL UM

DELI CAT UL UM

DELICATUL UM

DELICAT UL UM

DE LICATULUM

DELICATULUM

DELI CATUL UM

DELICATUL UM

DELICATUL UM

DELICATUL UM

DISCOIDALE

DISCOIDALE

DISCOIDALE

DISCOIDALE

DI SCOI DALE

DISCOIDALE

DI SCOIDALE

DI SCOIDALE

DISCOIDALE

DI SCOIDALE

DISCOIDALE

DISCOIDALE

DISCOIDALE

DI SCOIDALE

DISCOIDALE

DISCOIDALE

DISCOIDALE

DI SCOIDALE

DISCOIDALE

DI SCOIDALE

DISCOIDALE

DISCOIDALE

DISCOIDALE

DISCOIDALE

DISCOIDALE

DI SCOIDALE

DISCOIDALE

DISCOIDALE

DI SCOIDALE

DISCOIDALE

DISCOIDALE

DISCOIDALE

DISCOIDALE

DISCOIDALE

DISCOIDALE

DISCOIDALE

DISCOIDALE

DISCOIDALE

DISCOIDALE

DISCOIDALE

DISCOIDALE

DI SCOIDALE

DISCOIDALE

DI SCOIDA.E

DISCOIDALE

DISCOIDALE

DI COIOALE

DISCOIDALE

DISCOIDALE

DISCOIDALE

DISCOIDALE

DISCOIDALE

DISCOIDALE

DISCOIDALE

DISCOIDALE

DISCOIDALE

DIS COIDALE

DISCOIDALE

DISCOIDALE

DISCOIDALE

DISCOIDALE

DISCOIDALE

DISCOIDALE

DISCOIDALE

DISCOIDALE

DISCOIDALE

DISCOIDALE

DI SCOIDALE

DISCOIDALE

DISCOIDALE

DISCOIDALE

DISCOIDALE

DISCOIDALE

DISCOIDALE

DISCOIDALE

DISCOIDA- E

DISCOIDALE

DISCOIDALE

DISCOIDALE

DISCOIDALE

DISCOIDALE

Locality

Lat. Long.

LAGUNA MADRE, NE TEXAS TAMPA-SARASOTA BAY, FLA.

L. DE TERMINOS, CAMPECHE

TEXAS GULF COAST

TRINITY BAY, TEXAS

TEXAS GULF COAST

TEXAS GULF COAST

TEXAS GULF COAST

NE GULF OF MEXICO

CENTRAL TEXAS BAYS

SABINE LAKE, TEXAS

TEXAS GULF COAST

SABINE LAKE, TEXAS

$\mathrm{NW}$ GULF OF MEXICO

NW UULF OF MEXICO

NW GULF OF MEXICO

NW GULF OF MEXICO

$N W$ GULF OF MEXICO

$N W$ GULF OF MEXICO

NW GULF OF MEXICO 


\section{Publication}

16166 PHLEGER 1956 16167 PARKER 1954

16168 PARKER 1954

16169 PARKER 1954

16170 BOCK 1976

16171 BOCK 1976

16172 BOCK 1976

16173 PARKER PHLEGER PEIRSON 1953

16174 PARKER PHLEGER PEIRSON 1953

16175 KORNFELD 1931

16176 KORNFELD 1931
16177 PARKER PHLEGER PEIRSON 1953

16178 KORNFELD 1931

$\begin{array}{lll}16179 & \text { KORNFELD } & 1931 \\ 16180 & \text { KORNFELD } & 1931\end{array}$

16181 PHLEGER 1956

16182 KORNFELD 1931

16183 SHENTON 1957

16184 PARKER PHLEGER PEIRSON 1953

16185 PARKER PHLEGER PEIRSON 1953

16186 PARKER PHLEGER PEIRSON 1953

16187 KORNFELD 1931

16188 BANDY 1956

16189 KORNFELD 1931

16190 PARKER PHLEGER PEIRSON 1953

16191 LOEP 1965

16192 BANDY 1956
16193 BANDY 1954

16194 BANDY 1954

16195 BANDY 1954

16196 BANDY 1956

16197 KORNFELD 1931
16198 AYALA-CASTANARES 1963

16198 AYALA-CASTAN
16199 WARREN 1956

16200 BANDY 1954

16201 LOEP 1965

16202 LOEP 1965

16203 AYALA-CASTANARES SEGURA 1968

16204 WALTON 1964

16205 NORTON 1930

16206 BENDA PURI 1962

16207 AKERS 1952

16208 AYALA-CASTANARES 1963

16209 BANDY 1954

16210 PHLEGER 1951A

16211 PHLEGER 1951A

16212 BANDY 1954

16213 BANDY 1954

16214 PHLEGER 1951A

16215 PHLEGER 1951 A

16217 BANDY 1954

16218 BANDY 1954

16219 BANDY 1954

16220 KELLOUGH 1956

16221 KELLOUGH 1956

16222 ANDERSEN 1961

16223 BOCK 1976

16224 PHLEGER 1951 A

16225 SHIFFLETT 1961

$\begin{array}{ll}16226 & \text { LEHMANN } 1957 \\ 16227 & \text { PHLEGER } 1951 \text { A }\end{array}$

16228 PHLEGER 1951A

16229 PHLEGER 1951A

16230 PHLEGER 1951A

16231 PHLEGER 1951A

16232 PHLEGER 1954

16233 LEHMANN 1957

16234 PHLEGER 1954

16235 PHLEGER LANKFORD 1957

16236 PHLEGER 1960

16237 PHLEGER 1965 A

16238 PHLEGER 1965 A

16239 PHLEGER 1965 A

16240 PHLEGER 1965 A

16241 PHLEGER 1965A

16242 AYALA-CASTANARES SEGURA 1968

16243 PHLEGER 1965 A

16244 PHLEGER $1965 \mathrm{C}$

16245 PHLEGER 19658

16246 BENDA PURI 1962

16247 PHLEGER 19658
16248 BENDA PURI 1962

16248 BENDA PURI 196
16249 PHLEGER $1965 \mathrm{~A}$

16250 BENDA PURI 1962

16251 AYALA-CASTANARES 1963

16252 OTVOS 1978

16253 SEGURA 1963

16254 PHLEGER 1956

16255 SHEPARD MOORE 1955

16256 BOCK 1976

16257 BOCK 1976

16258 WANTLAND 1969

16259 POAG 1978

16260 POAG 1978
Generic Name

ELPHIDIUM

ELPHIDIUM

ELPHIDIUM

ELPHIDIUM

ELPHIDIUM

ELPHI DIUM

ELPHIDIUM

ELPHIDIUM

ELPHIDIUM

ELPHIDIUM

ELPHIDIUM

ELPHIDIUM

ELPHI DIUM

ELPHIDIUM

ELPHIDIUM

ELPHIDIUM

ELPHIDIUM

ELPHIDIUM

ELPHIDIUM

ELPHIDIUM

ELPHIDIUM

ELPHIDIUM

ELPHIDIUM

ELPHIDIUM

ELPHIDIUM

ELPHIDIUM

LPHIDIUM

ELPHI D I UM

ELPHIDIUM

ELPHIDIUM

ELPHIDIUM

ELPHIDIUM

IUM

ELPHID IUM

ELPHIDIUM

ELPHIDIUM

ELPHIDIUM

ELPHI DIUM

ELPHIDIUM

ELPHIDIUM

ELPHIDIUM

ELPHIDIUM

ELPHIDIUM

ELPHIDIUM

ELPHIDIUM

ELPHIDIUM

ELPHIDIUM

ELPHIDIUM

ELPHIDIUM

ELPHIDIUM

ELPHIDIUM

ELPHIDIUM

ELPHIDIUM

ELPHIDIUM

ELPHIDIUM

ELPHIDIUM

ELPH I D I UM

ELPHIDIUM

ELPHIDIUM

ELPHIDIUM

ELPHIDI UM

ELPHIDIUM

ELPHIDIUM

ELPHIDIUM

ELPHIDIUM

ELPHIDIUM

ELPHIDIUM

ELPHIDIUM

ELPHIDIUM

ELPHIDIUM

ELPHIDIUM

ELPHIDI UM

ELPHIDI UM

ELPHIDI UM

ELPHIDIUM

ELPHI DI UM

ELPH I DIUM

ELPHIDIUM

ELPHIDIUM

ELPH I D I UM

ELPHIDIUM

ELPHIDIUM

ELPHIDIUM

ELPHIDIUM

ELPHIDIUM
Specific Name

DISCOIDALE

DISCOIDALE

DISCOIDALE

DISCOIDALE

DISCOIDALE

DISCOIDALE

DISCOIDALE

DISCOIDALE

DISCOIDALE

DISCOIDALE

DISCOIDALE

DI SCOIDALE

DISCOIDALE

DI SCOIDALE

DI SCOIDALE

DI SCOIDALE

DI SCOIDALE

DI SCOIDALE

DI SCOIDALE

DISCOIDALE

DISCOIDALE

DISCOIDALE

DISCOIDALE

DISCOIDALE

DISCOIDALE

DISCOIDALE

DI SCOIDALE

DISCOIDALE

DISCOIDALE

DI SCOIDALE

DI SCOIDALE

DISCOIDALE

DISCOIDALE

DI SCOIDALE

DISCOIDALE

DI SCOIDALE

DISCOIDALE

DISCOIDALE

DISCOIDAL IS

EX CAVATUM

EXCAVATUM

FI MBRI A TULUM

FI MBR IA TULUM

FI MBRIA TULUM

F I MBR I A TULUM

FI MBR I A TULUM

FI MBR I A TULUM

F I MBR I A TULUM

FI MBRIATULUM

F I MBR I A TULUM

FI MBR I A TULUM

F I MBR I A TUL UM

F I MBR I A TU LUM

FI MBR I A TULUM

F I MBR IA TULUM

i imb i tu tum

FI MBR I TULUM

F I MBRI A TULUM

FI MBR I A TULUM

F I MBR I A TULUM

F I MBR I A TULUM

F I MBR IA TULUM

F I MBR I A TULUM

GALVE ST ONEN SE

GALVESTOVEN SE

GALVESTONENSE

GALVESTONENSE

GA LVESTONENSE

GALVESTON EN SE

GALVESTON EN SE

GALVESTONEN SE

GA LVE STONEN SE

GA LVESTONENSE

GA LVEST ONENSE

GALVESTONENSE

GALVESTOVEN SE

GALVESTON ENSE

GALVESTONENSE

GA LVE ST OV EN SE

GA LVEST ON ENSE

GA LVEST ONENSE

GALVESTON ENSE

GALVESTOVENSE

GALVESTONEN SE

GALVESTONENSE

GA LVE STONENSE

GALVESTON EN SE

GALVESTON EN SE

GALVESTONENSE

GALVESTONENSE

GALVESTONENSE MEXICANUM

GALVESTONENSE TYPICUM

Locality

Lat. Long.

NW GULF OF MEXICO

NE GULF OF MEXICO

NE GULF OF MEXICO

NE GULF OF MEXICO

NE GULF OF MEXICO

NE GULF OF MEXICO

NE GULF OF MEXICO

TEXAS GULF COAST

TEXAS GULF COAST

LOUISIANA GULF COAST

LOUISIANA GULF COAST

TEXAS GULF COAST

TEXAS GULF COAST

LOUISIANA GULF COAST

TEXAS GULF COAST

NW GULF OF MEXICO

TEXAS GULE COAST 
Publication

16261 PARKER PHLEGER PEIRSON 1953 16262 PARKER PHLEGER PEIRSON 1953 16263 PARKER PHLEGER PEIRSON 1953 16264 PARKER PHLEGER PEIRSON 1953 16265 WALTON 1960

16266 PARKER PHLEGER PEIRSON 1953 16267 PARKER PHLEGER PEIRSON 1953 16268 PARKER PHLEGER PEIR SON 1953 16269 PARKER PHLEGER PEIRSON 1953 16270 PARKER PHLEGER PEIRSON 1953 16271 POAG 1975

16272 POAG 1976

16273 PARKER 1954

16274 PARKER 1954
16275 SHEPARD MOORE 1955

16276 KANE 1967

16277 LANKFORD 1959

16278 PHLEGER 1954

16279 WARREN 1957

16280 PHLEGER 1965

16281 PHLEGER 1954
16282 PHLEGER LANKFORD 1957

16282 PHLEGER LAN 16283 LOEP 1965

16284 BANDY 1956

16285 PHLEGER 1965 A

16286 LOEP 1965

16287 KANE 1962

16288 SEGURA 1963

16289 WALDRON 1963

16290 LEHMANN 1957

16291 DHLEGER 1960

16292 SHIFFLETT 1961

16293 PARKER PHLEGER PEIRSON 1953

16294 PAPKER PHLEGER PEIRSON 1953

16295 PARKER PHLEGER PEIRSON 1953

16296 WANTLAND 1969

16297 PARKER PHLEGER PEIRSON 1953

16298 PARKER PHLEGER PEIRSON 1953

16299 PARKER DHLEGER PEIRSON 1953

16300 PARKER PHLEGER PEIRSON 1953

16301 SHENTON 1957

16302 PARKER PHLEGER PEIRSON 1953

16303 BOCK 1976

16304 PARKER PHLEGER PEIRSON 1953 16305 PARKER PHLEGER PEIRSON 1953 16306 PHLEGER 1956

16307 PHLEGER 1956

16308 PHLEGER 1956

16309 PHLEGER 1956

16310 POAG SWEET 1972

16311 PHLEGER 1956

16312 PARKER 1954

16313 PARKER 1754

16314 PARKER 1954

16315 WALTON 1960

16316 PHLEGER LANKFORD 1978

16317 OTVOS 1978

16318 LIDZ LIDZ 1966

16319 PARKER 1954

16320 PARKER 1954

16321 PARKER 1954

16322 PARKER 1954

16323 PARKER 1954

16324 PHLEGER 1955 B

16326 BANDY 1956

16327 BANDY 1956

16328 BANDY 1956

16330 WARREN 1956

16330 WARREN 1956

16332 WALTON 1964

16333 AYALA-CASTANARES 1963

16334 BANDY 1956

16335 BANDY 1956

16336 BANDY 1956

16337 BANDY 1956

16338 SANDY 1956

16339 PHLEGER 1965 A

16340 PHLEGER 1965 A

16341 PHLEGER $196.5 \mathrm{~B}$

16342 ANDERSON 1968

16343 PHLEGER 1965 A

16344 PHLEGER 1965 A

16345 aENDA PURI 1962

16346 PHLEGER $1965 \mathrm{~B}$

16347 PHLEGER 1965 A

16348 PHLEGER 1965A

16349 PHLEGER 1965A

16350 BENDA PURI 1962

16351 PHLEGER 1965 A

16352 PHLEGER 1965 A

16353 POAG 1976

16354 PHLEGER $1951 \mathrm{~A}$

16355 PHLEGER 1951A
Generic Name

ELPHIDIUM

ELPHIDIUM

ELPHIDIUM

ELPHIDIUM

ELPHIDIUM

ELPHIDIUM

ELPHIDIUM

ELPHIDIUM

ELPHI DIUM

ELPHIDIUM

ELPHIDIUM

ELPHIDIUM

ELPHIDIUM

ELPHIDIUM

ELPHIDIUM

ELPHIDIUM

ELPHIDIUM

ELPHIDIUM

ELPHID I UM

ELPHIDIUM

ELPHIDIUM

ELPHIDIUM

ELPHIDIUM

ELPHIDIUM

ELPHID I UM

ELPHIDIUM

ELPHIDIUM

ELPHIDIUM

ELPHIDIUM

ELPHIDIUM

ELPHIDIUM

ELPHIDIUM

ELPHIDIUM

ELPHIDIUM

ELPHIDIUM

ELPHIDIUM

ELPHIDIUM

EL PH I D I UM

ELPHIDIUM

ELPHIDIUM

ELPHIDIUM

ELPHIDIUM

ELPHIDIUM

ELPHIDIUM

ELPHIDIUM

ELPHIDIUM

ELPHIDIUM

ELPHIDIUM

ELPHIDIUM

ELPHIDI UM

ELPHIDIUM

ELPHIDIUM

ELPHIDIUM
ELPHIDIUM

ELPHIDIUM

ELPHIDIUM

L

ELPHIDIUM

ELPHIDIUM

ELPHIDIUM

ELPHIDIUM

ELPHIDIUM

ELPHIDIUM

ELPHIDIUM

ELPHIDIUM

ELPHIDIUM

ELPHIDIUM

ELPHIDIUM

ELPHIDIUM

ELPHIDIUM

ELPHIDIUM

ELPHIDIUM

ELPHIDIUM

ELPHIDIUM

ELPHIDIUM

ELPHIDIUM

ELPHIDIUM

ELPHIDIUM

ELPHIDIUM

ELPHIDIUM

ELPHIDI UM

ELPHIDIUM
Specific Name

Locality

GALVESTOVENSIS

GALVESTOVENSIS

GALVESTONENSIS

GALVESTONENSIS

GALVESTONENSIS

GALVESTOVENSIS

GALVEST ONENSIS

GALVESTONENSIS

GA LVEST OVEN SIS

GALVESTON ENSIS

GALVESTONENSIS GALVESTONENSIS

GALVESTONENSIS KOEBOEENSE

GUNTERI

GUNTER

GUNTER

GUNTERI

GUNTERI

GUNTERI

GUNTERI

GUNTERI

GUNTER

GUNTERI

GUNTERI

GUNTERI

GUNTER

GUNTERI

GUNTERI

GUNTERI

GUNTER I

GUNTERI

GUNTERI

GUNTERI

GUNTERI

GUATER

GUNTER I

GUNTERI

GUNTERI

GUNTER I

GUNTERI

GUNTERI

GUNTERI

GUNTER I

GUNTERI

GUNTERI

GUNTERI

GUNTERI

GUNTERI

GUNTERI

GUNTERI

GUNTERI

GUNTERI

GUNTERI

GUNTERI

GUNTERI

GUNTERI

GUNTERI

GUNTERI

GUNTERI

GUNTER I

GUNTER I

GUNTERI

GUNTERI

GUNTER I

GUNTERI

GUNTERI

GUNTER I

GUNTERI

GUNTERI

GUNTER I

GUNTERI

GUNTERI

GUNTERI

GUNTERI

GUNTER I

GUNTERI

GUNTERI

GUNTERI

GUNTERI

GUNTER

GUNTERI

GUNTERI

GUNTERI

GUNTERI

GUNTERI

GUNTER I

GUNTER

GUNTERI DEL ICATULUM

GUNTERI S ALVESTONENSE

GUNTERI GALVESTONENSE

TEXAS GULF COAST

TEXAS GULF COAST

TEXAS GULF COAST

TEXAS GULF COAST

MISSISSIPPI SOUND

TEXAS GULF COAST

TEXAS GULF COAST

TEXAS GULF COAST

TEXAS GULF COAST

TEXAS GULF COAST

SAN ANTONIO B.. TEXAS

SAN ANTONIO B... TEXAS

NE GULF OF MEXICO

NE GULF OF MEXICO

CENTRAL TEXAS COAST

SABINE LAKE, TEXAS

MISSISSIPPI DELTA

$N$ GULF OF MEXICO

SE LOUISIANA

GALVESTON B., TEXAS

MISSISSIPPI SOUND

TEXAS GULF COAST 


\section{Publication}

16356 PHLEGER 1951A 16357 PHLEGER 1951A 16358 BANDY 1954 16359 BANDY 1954 16360 BANDY 1954 16361 CREAGER 1958 16362 PHLEGER 1951A 16363 PHLEGER 1951A 16364 PHLEGER 1951A 16365 PHLEGER 1951 A 16366 BANDY 1954 16367 BANDY 1954 16368 8ANDY 1954

16369 KELLOUGH 1956 16370 KELLOUGH 1956 16371 KELLOUGH 1956 16372 KELLOUGH 1956 16373 PHLEGER 1951 A 16374 PHLEGER 1951A 16375 PHLEGER 1951A 16376 PHLEGER 1951A 16377 PHLEGER 1951A 16378 PHLEGER 1951A 16379 PHLEGER 1951A 16380 PHLEGER 1951A 16381 PHLEGER 1951A 16382 LOWMAN 1949

16383 PHLEEER 1951A

16384 PHLEGER 1951A

16385 KELLOUGH 1956 16386 KELLOUGH 1956
16387 KELLOUGH 1956 16388 KORNFELD 1931 16389 KORNFELD 1931 16390 KORNFELD 1931 16391 KORNFELD 1931 16392 KORNFELD 1931 16393 KORNFELD 1931 16394 KORNFELD 1931 16395 KORNFELD 1931 16396 KORNFELD 1931 16397 KORNFELD 1931 16398 KORNFELD 1931 16399 KORNFELD 1931 16400 KORNFELD 1931 16401 KORNFELD 1931 16402 KORNFELD 1931 16403 KORNFELD 1931 16404 KORNFELD 1931 16405 POST 1951

16407 KORNFELD 1931

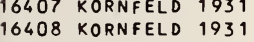
16409 KORNFELD 1931 16410 POST 1951

16411 POAG 1976

16412 POAG 1978

16413 POAG 1978

6414 POST 1951

16415 POST 1951

16416 PHLEGER 1954

16417 PHLEGER 1954

16419 ANDERSEN 1961

16420 ANDERSEN 1961

16420 ANDERSEN 1961

16421
16422 ANDERSEN 1961

6423 WANTLAND 1969

16424 PARKER PHLEGER PEIRSON 1953

16425 PARKER PHLEGER PEIRSON 1953

16426 BEN DA PURI 1962

16427 OTVOS 1978

16428 WALTON 1960
16429 KANE 1967

16429 KANE 1967

6431 PHLEGER 1965A

16432 ANDERSON 1968

16433 PHLEGER 19658

16434 KELLOUGH 1956

16435 WARREN 1956

16436 AYALA-CASTANARES SEGURA 1968

16437 KORNFELD 1931

16438 KORNFELD 1931

6439 KORNFELD 1931

16441 KORNFELD 1931

16442 KORNFELD 1931

16443 PHLEGER 1956

16444 AYALA-CASTANARES 1963

16445 PARKER PHLEGER PEIRSON 1953

16446 PARKER PHLEGER PEIRSON 1953

16447 PARKER PHLEGER PEIRSON 1953

16448 PARKER PHLEGER PEIRSON 1953

16449 PHLEGER 1956

16450 KORNFELD 1931
Generic Name

ELPHIDIUM

ELPHIDIUM

ELPHIDIUM

ELPHIDIUM

ELPHIDIUM

ELPHIDIUM

ELPHIDIUM

ELPHIDIUM

ELPHIDIUM

ELPHIDIUM

ELPHIDIUM

ELPHIDIUM

ELPHIDIUM

ELPHIDIUM

ELPHIDIUM

ELPHIDIUM

ELPHIDIUM

ELPHIDIUM

ELPHIDIUM

ELPHIDIUA

ELPHIDIUM

ELPHIDIUM

ELPHIDIUM

ELPH I DI UM

ELPHIDIUM

ELPHIDIUM

ELPHIDIUM

ELPHIDIUM

ELPHIDIUM

ELPH I DIUM

ELPHIDIUM

ELPHIDIUM

ELPHIDIUM

ELPHIDIUM

ELPHIDIUM

ELPHIDIUM

ELPHIDIUM

ELPHIDIUM

ELPHIDIUM

ELPHIDIUM

ELPH I DI UM

ELPHIDIUAM

ELPHIDIUM

ELPHIDIUM

EL PHI DI UM

ELPHIDIUM

ELPHIDIUM

ELPHIDIUM

ELPHIDIUM

ELPHIDIUM

ELPHIDIUM

ELPHI DIUM

ELPHIDIUM

ELPHIDIUM

ELPHIDIUM

ELPHIDIUM

ELPHIDIUM

ELPHIDIUM

ELPHIDIUM

ELPHIDIUM

ELPHIDIUM

ELPHIDIUM

ELPHIDIUM

ELPHIDIUM

ELPHIDIUM

ELPHIDIUM

ELPHIDIUM

ELPHIDIUM
ELPHIDIUM

ELPHIDIUM

ELPHIDIUM

ELPHIDIUM

ELPHIDIUM

ELPHIDIUM

ELPHIDIUM

ELPHIDIUM

ELPHIDIUM

ELPHIDIUM

ELPHIDIUM

ELPHIDIUM

ELPHIDIUM

ELPHIDIUM

ELPHIDIUM
Specific Name

GUNTERI GAL VESTONENSE GUNTERI GALVESTONENSE GUNTERI SALVESTONENSE GUNTERI GALVESTONENSE GUNTERI GAL VESTONENSE GUNTERI GAL VESTONENSE GUNTERI GALVESTONENSE GUNTERI GALVESTONENSE GUNTERI GALVESTONENSE GUNTERI SALVESTONENSE GUNTERI GALVESTONENSE GUNTERI GALVESTONENSE GUNTERI GALVESTONENSE GUNTERI GAL VESTONENSE GUNTERI GALVESTONENSE GUNTERI GALVESTONENSE GUNTERI GALVESTONENSE GUNTERI GALVESTONENSE GUNTERI GAL VESTONENSE GUNTERI GALVESTONENSE GUNTERI GALVESTONENSE GUNTERI GALVESTONENSE GUNTERI GALVESTONENSE GUNTERI GALVESTONENSE GUNTERI GALVESTONENSE GUNTERI GALVESTONENSE GUNTERI GALVESTONENSE GUNTERI GALVESTONENSE GUNTERI GALVESTONENSE GUNTER I GALVESTONENSE GUNTERI GAL VESTONENSE GUNTERI GALVESTONENSE GUNTERI GALVESTONENSIS GUNTERI GALVESTONEN SIS GUNTER I OALVESTONENSIS GUNTER I GAL VESTONENSIS GUNTER I GALVESTONENSIS GUNTERI GALVESTONENSIS GUNTERI GALVESTONENSIS GUNTERI GALVESTONENSIS GUNTERI GALVESTONENSIS GUNTERI SALVESTONENSIS GUNTER I GAL VESTONENS IS GUNTERI 6 AL VES TONENS IS GUNTERI SAL VESTONENSIS GUNTERI GALVESTONENSIS GUNTERI GALVESTONENSIS GUNTERI GALVESTONENSIS GUATERI GAL VESTONENSIS GUNTER I GALVESTONENSIS GUNTERI GALVESTONENSIS GUNTERI GALVESTONENSIS GUNTERI GALVESTONENSIS GUNTERI GALVESTONENSIS GUNTER I 6 AL VESTONENSIS GUNTERI G UNTERI GUNTERI SAL SUM

GUNTERI TYPICUM

IN CERTUM

IN CERTUM

IN CER TUM

IN CERTUM

IN CERTUM

IN CER TUM

IN CER TUM

IN CERTUM

IN CER TUM

INCERTUM MEXI CANA

INCERTUM MEXI CANUM

IN CER TUM MEXI CANUM IN CERTUM MEXI CANUM INCERTUM MEXI CANUM INCERTUM MEXI CANUM IN CERTUM MEXI CANUM IN CERTUM MEXI CANUM INCERTUM MEXICANUM IN CERTUM MEXICANUM IN CERTUM MEXI CANUM INCERTUM MEXICANUM INCERTUM MEXI CANUM INCERTUM MEXI CANUM
INCERTUM MEXICANUM IN CERTUM MEXI CANUM IN CERTUM MEXICANUM IN CER TUM MEXI CANUM INCER TUM MEXI CANUM INCERTUM MEXI CANUM IN CERTUM MEXI CANUM IN CERTUM MEXI CANUM
INCERTUM MEXICANUM IN CER TUM MEXI CANUM INCERTUM MEXI CANUM INCERTUM MEXICANUM INCERTUM MEXI CANUM IN CERTUM MEXI CANUM INCERTUM MEXICANUM IN CERTUM MEXI CANUM

Locality

Lat. Long.

NW GULF OF MEXICO

NU GULF OF MEXICO

NW GULF OF MEXICO

NW GULF OF MEXICO

NH GULF OF MEXICO

BAY OF CAMPECHE

$N W$ GULF OF MEXICO

NH GULF OF MEXICO

NW GULF OF MEXICO

NU GULF OF MEXICO

$N W$ GULF OF MEXICO

NW GULF OF MEXICO

NH GULF OF MEXICO

NW GULF OF MEXICO

NH GULF OF MEXICO

NW GULF OF MEXICO 


\section{Publication}

16451 PHLEGER 1951A 16452 PHLEGER $1951 \mathrm{~A}$ 16453 PHLEGER 1951A 16454 PHLEGER 1951A 16455 PHLEGER 1951 A 16456 PHLEGER 1951 A 16457 PHLEGER 1951A 16458 PHLEGER 1951A 16459 PHLEGER 1951A 16460 PHLEGER 1951 A 16461 PHLEGER 1951A 16462 PHLEGER 1951A 16463 PHLEGER 1955 16464 WALTON 1964 16465 SEGURA 1963 16466 LEHMANN 1957

16467 SHIFFLETT 1961

16468 SHEPARD MOORE 1955

16469 PHLEGER $1965 \mathrm{C}$

16470 PHLEGER LANKFORD 1957

16471 LANKFORD 1959

16472 WARPEN 1957

16473 PARKER PHLEGER PEIRSON 1953 16474 PARKER PHLEGER PEIRSON 1953 16475 BOCK 1976

16476 PHLEGER 1956

16477 AYALA-CASTANARES 1963

16478 AYALA-CASTANARES SEGURA 1968 16479 PHLEGER 1965A

16480 PHLEGER 1965 A

16481 PHLEGER 1965A

16482 PHLEGER 1965A

16483 WALTON 1960

16485 PARKER PHLEGER PEIRSON 1953

16486 PARKER PHLEGER PEIRSON 1953 16487 PARKER PHLEGER PEIRSON 1953

16488 PARKER PHLEGER PEIRSON 1953 16489 PARKER PHLEGER PEIRSON 1953 16490 PARKER PHLEGER PEIRSON 1953 16491 PARKER PHLEGER PEIRSON 1953 16492 PARKER PHLEGER PEIRSON 1953 16493 PHLEGER 1954

16494 PHLEGER LANKFORD 1957

16495 PHLEGER 1954

16496 PHLEGER 1960

16497 SEGURA 1963

16498 PARKER PHLEGER PEIRSON 1953

16499 PHLEGER 1965A

16500 PHLEGER 1965 A

16501 PHLEGER 1965A

16502 PHLEGER 1965 A

16503 WALDRON 1963

16504 NORTON 1930

16506 PHLEGER 1965 A

16507 WALTON 1960

16508 PHLEGER 1965 A

16509 PARKER PHLEGER PEIRSON 1953

16510 PHLEGER 1956

16511 PARKER PHLEGER PEIRSON 1953

16512 PARKER PHLEGER PEIRSON 1953

16513 PHLEGER 1956

16514 WALTON 1964

16515 PHLEGER 1965 A

16516 PHLEGER $1965 \mathrm{~A}$

16517 PHLEGER $1965 \mathrm{~A}$

16519 PHLEGER 1965 A

16519 PHLEGER 1965 A

16521 PHLEGER 1965 A

16522 PHLEGER 1965 B

16523 PHLEGER 1965 A

16524 BENDA PURI 1962

16525 PHLEGER 1956

16526 WANTLAND 1969

16527 PARKER PHLEGER PEIRSON 1953

16528 PARKER PHLEGER PEIRSON 1953 16529 PHLEGER 1956

16530 PARKER PHLEGER PEIRSON 1953

16531 PHLEGER 1956

16532 AYALA-CASTANARES SEGURA 1968

16533 PARKER PHLEGER PEIRSON 1953

16534 PARKER PHLEGER PEIRSON 1953

16535 LANKFORD 1959

16536 PHLEGER 1955

16537 WARREN 1957

16539 SHEPARD MOORE 1955

16540 PHLEGER LANKFORD 1957

16541 PHLEGER 1954

16542 PHLEGER $1965 \mathrm{C}$

16543 PARKER PHLEGER PEIRSON 1953

16544 PARKER PHLEGER PEIRSON 1953

16545 LEHMANN 1957

\section{Generic Name}

ELPHIDIUM

ELPHIDIUM

ELPHIDIUM

ELPHIDIUM

ELPHIDIUM

ELPHIDIUM

ELPHIDIUM

ELPHIDIUM

ELPHIDIUM

ELPHIDIUM

EL PHID I UM

ELPHIDIUM

ELPHIDIUM

ELPHIDIUM

ELPHID I UM

ELPHIDIUM

ELPHIDIUM

ELPHIDIUM

ELPHIDIUM

ELPHIDIUM

ELPHIDIUM

ELPHIDIUM

EL PHI I U UM

ELPHIDIUM

ELPHIDIUM

ELPHIDIUM

ELPHIDIUM

ELPHIDIUM

ELPHIDIUM

ELPHIDIUM

ELPHIDIUM

ELPHIDIUM

ELPHIDIUM

ELPHIDIUM

EL PHIDIUM

ELPHIDIUM

ELPHIDIUM

ELPHIDIUM

ELPHIDIUM

ELPHIDIUM

ELPHIDIUM

ELPHIDIUM

ELPHIDIUA

ELPHIDIUM

ELPHIDIUM

ELPHIDIUM

ELPHIDIUM

ELPHIDIUM

ELPHIDIUM

ELPHIDIUM

ELPHIDIUM

ELPHIDIUM

ELPHIDIUM

ELPHIDIUM

ELPHIDIUM

LLPIDIUM

ELPHIDIUM

ELPHIDIUM

ELPHIDIUM

ELPHIDIUM

ELPHIDIUM

ELPHIDIUM

ELPHIDIUM

ELPHIDIUM

ELPH IDIUM

ELPHIDIUM

ELPHIDIUM

ELPHIDIUM

ELPHIDIUM

ELPHIDIUM

ELPHIDIUM

ELPHIDIUM

ELPHIDIUM

ELPHIDIUM

ELPHIDIUM

ELPHIDIUM

ELPHIDIUM

ELPHIOIUM

ELPHIDIUM

ELPHIDIUM

ELPHIDIUM

ELPHIDIUM

ELPHIDIUM

ELPHIDIUM

ELPHIDIUM
Specific Name

IN CERTUM MEXI CANUM INCERTUM MEXICANUM IN CERTUM MEXI CANUM INCERTUM MEXICANUM INCER TUM MEXI CANUM IN CERTUM MEXI CANUM INCERTUM MEXI CANUM INCERTUM MEXICANUM INCERTUM MEXI CANUM INCERTUM MEXI CANUM INCERTUM MEXICANUM IN CERTUM MEXI CANUM INCERTUM MEXICANUM INCERTUM MEXI CANUM INCERTUM MEXICANUM INCERTUM MEXICANUM IN CER TUM MEXI CANUM IN CERTUM MEXI CANUM IN CERTUM MEXI CANUM IN CER TUM NEXICANUM INCER TUM MEXICANUM IN CER TUM MEXI CANUM IN CERTUM MEXI CANUM INCER TUM MEXI CANUM IN CERTUM MEXI I ANUM INCERTUM MEXICANUM KOEBOEENSE

KOEBOEENSE

KOEGOEENSE

KO EBOEENSE

KOEBOEENSE

KOEBOEENSE

KOEBOEENSE

KOEBOEENSE

KOEBOEENSE

KOEBOEENSE

KOEBOEENSE

KOEBOEENSE

KOEBOEENSE

KO EBOEENSE

KOEGOEENSE

KOEBOEENSE

KOEBOEENSE

KOEBOEENSE

KOESOEENSE

KO EBOEENSE

KO EBOEENSE

KOEBOEENSE

XOEBOEENSE

KOEBOEENSE

KOEBOEENSE

KOEBOEENSE

LI MOSUM

MA TAGORDA NUM

MATAGORDANUM

MATAGORDANUM

MA TAG ORDANUM

MATAGORDANUM

MATAGORDA NUM

MATAGOR DANUM

MATAGOR DANUM

MA TAGORDANUM

MATAGORDANUM

MATAGORDANUM

MA TAGORDANUM

MA TAGOR DA NUN

MA TAGORDANUM

MA TAGORDANUM

MA TAGORDANUM

MA TAGORDANUM

MA TAGORDANUM

MA TAGOR DANUM

MA TAGORDANUM

MA TAGORDANUM

MA TAGORDANUM

MATAGORDANUM

MATAG OR DANUM

MATAGORDANUM

MA TAGORDANUM

MA TAGORDANUM

MATAGORDANUM

MA TAGOR DANUM

MATAGORDANUM

MA TAG ORDANUM

MATAGORDANUM

MATAGORDANUM

MATAGORDANUM

MA TAGORDANUM

MATAGORDANUM

MA TAG OR DANUM

MATAGORDANUM

MA TAGORDANUM

MA TAGORDANUM

Locality

NW GULF OF MEXICO

NW GULF OF MEXICO

NW GULF OF MEXICO

NW GULF OF MEXICO

NW GULF OF MEXICO

NW GULF OF MEXICO

NW GULF OF MEXICO

NW GULF OF MEXICO

NW GULF OF MEXICO

NW GULF OF MEXICO

NW GULF OF MEXICO

NW GULF OF MEXICO

MISSISSIPPI DELTA

TAMPA-SARASOTA BAY, FLA. 


\section{Publication}

16546 PHLEGER 1960 16547 WALDRON 1963

16548 KANE 1962

16549 KANE 1967

16550 SEGURA 1963
16551 BANDY 1956

16552 BANDY 1956

16553 POST 1951

16554 POST 1951

16555 LEHMANN 1957

16556 NORTON 1930

16557 LIDZ LIDZ 1966

16558 PHLEGER 195
16559 BANDY 1956

16560 BANDY 1956

16561 BANDY 1956

16562 KELLOUGH 1956

16563 PHLEGER 19658

16564 ANDERSON 1968
16565 PHLEGER LANKFORD 1978

16565 PHLEGER LANK
16566 CUSHMAN 1930

16567 WARREN 1957

16568 LANKFORD 1959

16569 PHLEGER 19558

16570 POAG 1976

16571 KANE 1967

16572 SEGURA 1963

16573 PARKER 1954
16574 PARKER 1954

16575 SHIFFLETT 1961

16576 WALDRON 1963

16577 LEHMANN 1957

16578 WALDRON 1963

16579 PHLEGER 1960

16580 KANE 1962

16581 PARKER PHLEGER PEIRSON 1953

16582 PHLEGER 1956

16584 PARKER PHLEGER PEIRSON 1953

16585 PHLEGER 1956

16586 PARKER PHLEGER PEIRSON 1953

16587 PHLEGER 1954

16588 PHLEGER $1965 \mathrm{C}$

16589 PHLEGER LANKFORD 1957

16590 PARKER 1954

16591 PARKER 1954

16592 PARKER 1954
16593 PHLEGER 1965 A

16593
16594
$16 H E N T O N$

16595 PHLEGER 1965A

16596 WARREN 1956

16597 PHLEGER 1965A

16598 PHLEGER 1965 A

16599 HANTLAND 1969

16600 PARKER PHLEGER PEIRSON 1953

16601 POST 1951

16602 PARKER PHLEGER PEIRSON 1953

16603 POST 1959

16604 PARKER PHLEGER PEIRSON 1953

16605 PARKER PHLEGER PEIRSON 1953

16606 BENDA PURI 1962

16607 PARKER PHLEGER PEIRSON 1953

16608 CREAGER 1958

16609 PHLEGER 1956

16610 PHLEGER $1965 \mathrm{~B}$

16611 BENDA PURI 1962

16612 BANDY 1956

16613 BANDY 1954

16614 BANDY 1956

16615 BANDY 1954

16616 BANDY 1954

16617 BANDY 1956

16618 BANDY 1956

16619 PHLEGER 1965A

16620 KELLOUGH 1956

16621 KELLOUGH 1956

16622 KELLOUGH 1956

16623 BANDY 1956

16624 BANDY 1956

16625 BANDY 1956

16626 BANDY 1956

16627 BANDY 1956

16628 BANDY 1956

16629 BANDY 1956

16630 BANDY 1956

16631 BANDY 1956

16632 BANDY 1956

16633 BANDY 1956

16634 AKERS 1952

16635 AYALA-CASTANARES SEGURA 1968

16636 BANDY 1054

16637 BANDY 1956

16638 HALTON 1964

16639 BANDY 1956

16640 BANDY 1956
Generic Name

ELPHIDIUM

ELPHIDIUM

ELPHIDIUM

ELPHIDIUM

ELPHIDIUM

ELPHIDIUM

ELPHID I UM

ELPHIDIUM

ELPHIDIUM

ELPHIDIUM

ELPHIDIUM

ELPH I D I UM

ELPHIDIUM

ELPHIDIUM

ELPHIDIUM

ELPHIDIUM

ELPHIDIUM

ELPHIDIUM

ELPHIDIUM

ELPHIDIUM

ELPHIDIUM

ELPHIDIUM

ELPHIDIUM

ELPHIDIUM

ELPHIDIUM

ELPHIDIUM

ELPH I D I UM

ELPHIDIUM

ELPHIDIUM

ELPHIDIUM

ELPHIDIUM

ELPHI DIUM

ELPHI DIUM

ELPHIDIUM

ELPHIOIUM

ELPHIDIUM

ELPHIDIUM

ELPHIDIUM

ELPHIDIUM

ELPHIDIUM

ELPHIDIUM

ELPHIDIUM

ELPHIDIUM

ELPHIDI UM

ELPHIDIUM

ELPHIDIUM

ELPHIDIUM

ELPHIDIUM

ELPHIDIUM

ELPHIDIUM

ELPH I D IUM

ELPHIDIUM

ELPHIDIUM

ELPHI DIUM

ELPHIDIUM

ELPHIDIUM

ELPHIDIUM

ELPHIDIUM

ELPHIDIUM

ELPHIDIUM

ELPHIDIUM

ELPHIDIUM

ELPHIDIUM

ELPHIDIUM

ELPHIDIUM

ELPHIDIUM

ELPHIDIUM

ELPH I D I UM

ELPHIDIUM

ELPHIDIUM

ELPHIDIUM

ELPHIDIUM

ELPHIDIUM

ELPHIDIUM

ELPHIDIUM

ELPHIDIUM

ELPHIDIUM

ELPHIDIUM

ELPHIDIUM

ELPHIDIUM

ELPHIDIUM

ELPHIDIUM

ELPHIDIUM

ELPHIDIUM

ELPHIDIUM
Specific Name

MATAGOR DANUM

MATAGORDANUM

MATAGOR DANUM

MA TAGOR DANUM

MEXI CANUM

MEXICANUM

MORENOI

MORENOI

OCEANICU
POEYANA

POEYANUM

POEYANUM

POEYANUM

POEYANUM

POEYANUM

POEYANUM

POEYANUM

POEYANUM

POEYANUM

POEYANUM

POEYANUM

POEYANUM

POEYANUM

POEYANUM

POEYANUM

POEYANUM

POEYANUM

POEYANUM

POEYANUM

POEYANUM

POEYANUM

POEYANUM

POEYANUM

POEYANUM

POEYANUM

POEYANUM

POEYANUM

POEYANUM

POEYANUM

POEY ANUM

POEYANUM

POEYANUM

POEYANUM

POEYANUM

POEYANUM

POEYANUM

POEYANUM

POEYANUM

POEYANUM

POEYANUM

POEYANUM

POEYANUM

POEYANUM

POEYANUM

POEYANUM

POEYANUM

POEYANUM

POEYANUM

POEYANUM

POEYANUM

POEYANUM

POEYANUM

POEYANUM

POEYANUM

POEYANUM

POEYANUM

POEYANUM

POEYANUM

POEYANUM

POEYANUM

POEYANUM

POEYANUM

POEYANUM

POEYANUM

POEYANUM

POEYANUM

POEYANUM

POEYANUM

POEYANUM

POEYANUM

POEYANUM

POEYANUM

POEYANUM

POEYANUM

POEYANUM

POEYANUM

POEYANUM

POEYANUM

POEYANUM

POEYANUM

POEYANUM

POEYANUM

POEYANUM

\section{Locality}

LAGUNA MADRE, TEXAS

MISSISSIPPI DELTA

SABINE LAKE, TEXAS

SABINE LAKE, TEXAS

MATAMOROS, MEXICO

NE GULF OF MEXICO

NE GULF OF MEXICO

SOUTH TEXAS COAST

SOUTH TEXAS COAST

TEXAS GULF COAST

TORTUGAS, FLA

VERACRUZ REEFS

$N$ GULF OF MEXICO

NE GULF OF MEXICO

NE GULF OF MEXICO

NE GULF OF MEXICO

NH GULF OF MEXICO 


\section{Publication}

16641 BANDY 1956

16642 WALTON 1960

16643 BANDY 1954

16644 AYALA-CASTANARES 1963

16645 BANDY 1954

16646 BANDY 1956

16647 BANDY 1956

16648 BANDY 1956

16649 BANDY 1956

16650 BANDY 1956
16651 PHLEGER 1956

16652 PARKER PHLEGER PEIRSON 1953

16653 PARKER 1954

16654 PARKER 1954

16655 PARKER 1954

16656 PARKER 1954

16657 PARKER 1954

16658 BANDY 1956

16659 BANDY 1956

16660 BANDY 1956
16661 BANDY 1956

16661 BANDY 1956
16662 BANDY 1956

16663 BANDY 1956

16664 BANDY 1956

16665 BANDY 1956

16666 CREAGER 1958

16667 KANE 1967

16668 PHLEGER 1954

16669 POST 1951

16670 POST 1951

16671 BENDA PURI 1962

16672 ANDERSEN 1961

16673 POAG SHEET 1972

16674 PHLEGER 1956

16675 PHLEGER 1965

16676 PHLEGER 1954

16677 PARKER PHLEGER PEIRSON 1953

16678 PARKER PHLEGER PEIRSON 1953

16679 PARKER PHLEGER PEIRSON 1953

16680 PARKER PHLEGER PEIRSON 1953

16681 PARKER PHLEGER PEIRSON 1953

16682 PHLEGER 1956

16683 PARKER PHLEGER PEIRSON 1953

16684 PARKER PHLEGER PEIRSON 1953

16685 PHLEGER $1965 \mathrm{~B}$

16686 PHLEGER 1965 A

16687 PHLEGER 1965 A

16688 BENDA PURI 1962

16689 PHLEGER 1965 A

16690 PHLEGER 1965A

16691 PHLEGER $1965 \mathrm{~B}$

16692 PHLEGER 1954

16693 PHLEGER 1954

16694 LEHMANN 1957

16695 PHLEGER 1965 A

16696 PHLEGER 1965A

16697 PHLEGER 1965 A

16698 PHLEGER 1965A

16699 BENDA PURI 1962

16700 PHLEGER 1965 A

16701 ANDERSEN 1961

16702 CREAGER 1958

16703 CREAGER 1958

16704 CREAGER 1958

16705 CREAGER 1958

16706 CREAGER 1958

16707 CREAGER 1958

16708 ANDERSEN 1961

16709 PHLEGER 1955A

16710 PHLEGER 1955A

16711 PHLEGER 1955A

16712 PARKER 1954

16713 PARKER 1954

16714 PARKER 1954

16715 PARKER 1954

16716 PHLEGER 1955A

16717 PARKER 1954

16718 PARKER 1954

16719 PARKER 1954

16720 PARKER 1954

16721 PARKER 1954

16722 PARKER 1954

16723 PARKER 1954

16724 PHLEGER 1955 A

16725 PHLEGER 1955A

16726 PARKER 1954

16727 PARKER 1954

16728 PHLEGER 1955A

16729 PHLEGER 1955A

16730 PARKER 1954

16731 PARKER 1954

16732 PARKER 1954

16733 CUSHMAN 1931

16734 CUSHMAN 1931

16735 CUSHMAN 1931
Generic Name

Specific Name

ELPHIDIUM

ELPHIDIUM

ELPHIDIUM

ELPHIDIUM

ELPHIDIUM

ELPHIDIUM

ELPHIDIUM

ELPHIDIUM

ELPHIDIUM
ELPHIDIUM

ELPHIDIUM

ELPHIDIUM

ELPHIDIUM

ELPHIDIUM

ELPHIDIUM

ELPHIDIUM

ELPHIDIUM

ELPHIDIUM

ELPHIDIUM

ELPHIDIUM

ELPHIDIUM

ELPHIDIUM

ELPHIDIUM

ELPHIDIUM

ELPHIDIUM

ELPHIDIUM

ELPHIOIUM

ELPHIDIUM

ELPHIDIUM

ELPHIDI UM

ELPHIDIUM

ELPHIDIUM

ELPHIDIUM

ELPHIDIUM

ELPHIDIUM

ELPHIDIUM

ELPHIDIUM

ELPHIDIUM

ELPHIDIUM

ELPHIDIUM

ELPHIDIUM

ELPHIDIUM

ELPHIDIUM

ELPHIDIUM

ELPHIDIUM

ELPHIDIUM

ELPHIDIUM

ELPHIDIUM

ELPHIDIUM

ELPHIDIUM

ELPHIDIUM

ELPHIDIUM

ELPH I I UM

ELPHIDIUM

EN ANTI O DEN T AL INA

ENTOSOLENIA

ENTOSOLENIA

ENTOSOLENIA

ENTOSOLENIA

EN TOSOLENIA

ENTOSOLENIA

EP ISTOM INA

EP I S T OM I NELL A

EP IS TOM INELLA

EP I STOMINE LLA

EP I STOMI NELL A

EP ISTOMINELLA

EP ISTOMINELLA

EP IST OM INE LL A

EPISTOM INELLA

EP ISTOM I NELL A

EP ISTOM I NELLA

EP ISTOMI NELLA

EP ISTOMINELL A

EP ISTOM INELLA

EP ISTOMI NELLA

EP I STOM I NE LL A

EP IS TOMINELLA

EP I STOM I NELL A

EP IST OM I NELLA

EP I STOM I NELLA

EP I STOMINELLA

EPISTOMINELLA

EP ISTOMINELLA

EPISTOM I NELL LA

EP IST OMI NELLA

EP I STOMINELLA

EP IS TOM I NELLA

EP IS TOM I NELLA
POEYANUM

POEYANUM

POEYANUM

POEYANUM

POEYANUM

POEYANUM

POEYANUM

POEYANUM

POEYANUM

POEYANUM

POEYANUM

POEYANUM

POEYANUM

POEYANUM

POEYANUM

RUGULOSUM

RUGULOSUM

RUGULOS UM

RUGUL OSUM

RUGUL OSUM

RUGULOSUM

RUGUL OS UM

RUGULOSUM

SAGRUM

SELSEYENSE

TRANSLUCENS

TRANSLUCENS

TRANSLUCENS

TRANSLUCENS

TRANSLUCENS

TRANSLUCENS

TRANSLUCENS

TRANSLUCENS

TRANSLUCENS

TUPIDUM

TUNIDUM

TUPIDUM

TUMIDUM

TUMIDUM

TUMIDUM

TUPIDUM

TUNIDUM

TUMIDUM

TUMIDUM

TUMIDUM

TUMIDUM

TUMIDUM

TUPIDUM

TUMI DUM

TUMI DUM

TUMI DUM

TUMIDUM

TUNIDUM

TUMIDUM

TUMIDUM

TUMI DUM

TUMIDUM

TUNIDUM

CORMUNIS

OREIGNYANA

ORBIGNYANA

ORBIGNYANA

ORBIGNYANA

OREIGNYANA ANTILLEA

ORBIGNYANA ANTILLEA

ELEGANS

DE CORATA

DE CORATA

DE CORATA

DE CORATA

DE CORATA

DE CORATA

DE CORATA

DE CORATA

DE CORATA

DE CORATA

DE CORATA

DE CORATA

DE CORATA

DE CORATA

DE CORATA

DE CORATA

DE CORATA

DE CORATA

DE CORATA

DE CORATA

DE CORATA

DE CORATA

DE CORATA

DE CORATA

ELEGANS

ELEGANS

ELEGANS

Locality

NE GULF OF MEXICO

MISSISSIPPI SOUND

NW GULF OF MEXICO

L. DE TERMINOS, CAMPECHE

NW GULF OF MEXICO

NE GULF OF MEXICO

NE GULF OF MEXICO

NE GULF OF MEXICO

NE GULF OF MEXICO

NE GULF OF MEXICO 


\section{Publication}

16736 CUSHMAN 1931 16737 PARKER 1954

16738 LUDWICK. WALTON 1957

16739 PHLEGER 1955A

16740 PHLEGER $1955 \mathrm{~A}$

16741 PARKER 1354

16742 PARKER 1954

16743 PARKER 1954

16745 PHLEGER 1955 A

16746 PHLEGER 1955A

16747 PHLEGER 1955 A

16748 PHLEGER $1955 \mathrm{~A}$

16749 PARKER 1954

16750 PARKER 1954

16751 PARKER
1654
16752 PARKER 1954

16753 PARKER 1954

16754 PARKER 1954

16755 LANKFORD 1959

16756 PFLUM FRERICHS 1976

16757 PFLUM FRERICHS 1976

16758 PFLUM FRERICHS 1976

16759 PFLUM FRERICHS 1976

16760 PFLUM FRERICHS 1976

16761 PFLUM FRERICHS 1976

16762 PFLUM FRERICHS 1976 16763 PARKER 1054

16764 PFLUM FRERICHS 1976

16765 PFLUM FRERICHS 1976

16766 PFLUM FRERICHS 1976

16767 PFLUM FRERICHS 1976

16768 PFLUM FRERICHS 1976

16769 PFLUM FRERICHS 1976

16770 PFLUM FRERICHS 1976

16771 PFLUM FRERICHS 1976

16772 PFLUM FRERICHS 1976

16773 PFLUM FRERICHS 1976

16774 PFLUM FRERICHS 1976

16775 PFLUM FRERICHS 1976

16776 PFLUM FRERICHS 1976

16777 PFLUM FRERICHS 1976

16778 PFLUM FRERICHS 1976

16779 PFLUM FRERICHS 1976

16780 PARKER 1954

16781 PFLUM FRERICHS 1976

16782 PFLUM FRERICHS 1976 16783 PFLUM FRERICHS 1976 16784 PFLUM FRERICHS 1976 16785 PFLUM FRERICHS 1976 16786 PFLUM FRERICHS 1976 16787 PFLUM FRERICHS 1976 16788 PFLUM FRERICHS 1976 16789 PFLUM FRERICHS 1976 16790 PFLUM FRERICHS 1976 16791 PFLUM FRERICHS 1976 16792 PFLUM FRERICHS 1976 16793 PFLUM FRERICHS 1976 16794 PFLUM FRERICHS 1976 16795 PFLUM FRERICHS 1976 16796 PFLUM FRERICHS 1976 16797 PFLUM FRERICHS 1976 16798 PFLUM FRERICHS 1976 16799 PFLUM FRERICHS 1976 16800 PFLUM FRERICHS 1976 16801 PFLUM FRERICHS 1976 16802 PFLUM FRERICHS 1976 16803 PFLUM FRERICHS 1976 16804 PFLUM FRERICHS 1976 16805 PFLUM FRERICHS 1976 16806 PFLUM FRERICHS 1976 16807 PFLUM FRERICHS 1976 16808 PFLUM FRERICHS 1976 16809 PFLUM FRERICHS 1976 16810 PFLUM FRERICHS 1976 16811 PFLUM FRERICHS 1976 16812 PFLUM FRERICHS 1976 16813 PFLUM FRERICHS 1976 16814 PFLUM FRER ICHS 1976 16815 PARKER 1954 16816 PARKER 1954 16817 PARKER 1954 16818 PARKER 1954 16819 PARKER 1954 16820 PARKER 1954 16821 PHLEGER 1955 A 16822 PHLEGER $1955 \mathrm{~A}$ 16823 PARKER 1954 16824 PARKER 1954 16825 PARKER 1954 16826 PARKER 1954 16827 PARKER 1954 16827 PARKER 1954 16829 PARKER 1954 16830 PARKER 1954
Generic Name

Specific Name

EP IS TOM I NE LL A EP IS IOMINELLA EP ISTOMINELLA EP I STOMINELLA EP I ST OM I NELL $L A$ EP ISTOMINELLA EP I S TOM I NELLA EPISTOMINELLA EP ISTOMINELLA EPISTOMINELLA EPISTOMINELLA EP I ST OM I NELL $L$ EP IS TOM INELLA EP ISTOM I NELLA EP IS TOM I NELL A EP ISTOMINELLA EPISTOMINELLA EP ISTOMI NELLA EP ISTOMINELLA EP IS TOMINELLA EP IS TOM I NELL LA EP I S TOM I NEL LA EP I STOMINELLA EP I STOMI NELLA EP IS TOM I NELLA EP IS TOM I NELLA EP IS TOM I NELL A EP ISTOMINELLA EP IS TOM I NELL LA EP IST OM I NELL A EP IS TOM I NELLA EP ISTOM INELLA EP IS TOM I NELLA EPISTOMINELLA EP IS TOMI NE LLA EP IS TOMINELLA EP ISTOMINELLA EPISTOMINELLA EP IST OMINELLA EP I S TOM I NELL LA EPISTOMINELLA EPIS TOM I NELLA EP IS TOM I NELL A EP ISTOMINELLA EP ISTOMINELLA EP ISTOMINELLA EP IS TOMINELLA EP IS TOM I NE LL A EP IS TOM I NELLA EP IS TOM I NELLA EP ISTOMINELLA EP IST OMI NELLA EP IS TOM INELLA EPISTOMI NELLA EP ISTOMINELLA EP IS TOM I NE LLA EP I ST OM I NE LLA EP ISTOMINELLA EP ISTOMINELLA EPIST OM I NELLA EP IS TOMINELLA EP IS TOM I NE LLA EP IST OMI NE LLA EP ISTOM I NELL A EPISTOMINELLA EP ISTOM I NELLA EP IS TOM I NELLA EP ISTOMINELLA EP ISTOMI NELLA EP IS TOMI NELLA EP ISTOMI NELLA EP I STOMINELLA EP ISTOM INELLA EP ISTOMI NELLA EPISTOMINELLA EP IST OMI NELLA EP ISTOMINELLA EP ISTOMI NELL LA EP IST OMI NE LLA EP I STOM I NELLA EP ISTOMINELLA EP ISTOMINELLA EP ISTOMINELLA EP IS TOMI NELLA EP IST OM I NE L LA EP IST OMI NELLA EP ISTOM I NELLA EP ISTOMI NELLA EP IST OM INELLA EP ISTOM INELLA EP ISTOMINELLA EP IS T OMI NE LLA EP ISTOMI NELLA EP I STOM I NELL A EP ISTOM I NELLA
ELEGANS

EXIGUA

EXIGUA

EXIGUA

EXIGUA

EXIGUA

EXIGUA

EXIGUA

EXIGUA

EXIGUA

EXIGUA

EXIGUA

EXIGUA

EXIGUA

EXIGUA

EXIGUA

EXIGUA

EXIGUA

EXIGUA

EXIGUA

EXIGUA

EXIGUA

EXIGUA

EXIGUA

EXIGUA

EXIGUA

EXIGUA

EXIGUA

EXIGUA

EXIGUA

EXIGUA

EXIGUA

EXIGUA

EXIGUA

EXIGUA

EXIGUA

EXIGUA

EXIGUA

EXIGUA

EXIGUA

EXIGUA

EXIGUA

EXIGUA

EXIGUA

EXIGUA

EXIGUA

EXIGUA

EXIGUA

EXIGUA

EXIGUA

EXIGUA

EXIGUA

EXIGUA

EXIGUA

EXIGUA

EXIGUA

EXIGUA

EXIGUA

EXIGUA

EXIGUA

EXIGUA

EXIGUA

EXIGUA

EXIGUA

XIGUA

EXIGUA

EXIGUA

EXIGUA

EXIGUA

EXIGUA

EXIGUA

EXIGUA

EXIGUA

EXIGUA

EXIGUA

EXIGUA

EXIGUA

EXIGUA

EXIGUA

EXIGUA

EXIGUA

EXIGUA

EXIGUA

EXIGUA

EXIGUA

RUGOSA

RUGOSA

RUGOSA

RUGOSA

\section{Locality}

NE GULF OF MEXICO

NE GULF OF MEXICO

VE GULF OF MEXICO

$N$ GULF OF MEXICO 


\section{Publication}

16831 PARKER 1954 16832 PARKER 1954 16833 PARKER 1954 16834 PARKER 1754 16835 PARKER 1954 16836 PARKER 1954 16837 PARKER 1954 16838 PARKER 1954 16839 PARKER 1054 16840 PARKER 1954 16841 PARKER 1954 16842 PARKER 1954 16843 PARKER 1954 16844 PARKER 1954 16845 PARKER 1954 16846 PARKER 1754 16847 PHLEGER 1956 16848 PHLEGER 1956 16849 PARKER 1954 16850 PHLEGER 1956 16851 PARKER 1754
16852 PARKER 1954 16853 PARKER 1954 16854 PARKER 1954 16855 PARKER 1954 16856 PARKER 1954 16857 PARKER 1954 16858 PARKER 1954

16859 ANDERSEN 1961 16860 ANDERSEN 1961 16861 ANDERSEN 1961
16862 ANDERSEN 1961 16862 ANDERSEN 1961

16864 PARKER 1954

16865 PARKER 1954

16866 PARKER 1954

16867 PARKER 1954

16868 PHLEGER $1955 \mathrm{~A}$

16869 POAG 1976

16870 PHLEGER 19558

16871 LUDWICK WALTON 1957

16872 LANKFORD 1959

16873 ANDERSFN 1961

16874 ANDERSEN 1961

16875 PARKER 1954

16876 PARKER 1954

16877 PHLEGER 1956

16878 BOCK 1976

16879 PARKER PHLEGER PEIRSON 1953

16880 ANDERSEN 1961

16881 PARKER PHLEGER PEIRSON 1953

16882 WARREN 1956

16883 ANDERSEN 1961

16884 PARKER 1954

16885 ANDERSEN 1961

16886 PARKER 1054

16887 PARKER 1954

16888 PARKER 1954

16889 AYALA-CASTANARES SEGURA 1968

16890 AKERS 1952

16891 WARREN 1957

16892 PHLEGER LANKFORD 1957

16893 KANE 1962

16894 KANE 1967

16895 WARREN 1956

16896 AYALA-CASTANARES 1963

16897 POAG 1976

16898 POAG 1976

16899 PARKER 1954

16900 LUDWICK WALTON 1957

16901 PARKER 1954

16902 PARKER 1954

16903 PARKER 1954

16904 PARKER 1954

16905 PHLEGER $1951 \mathrm{~A}$

16906 PHLEGER $1951 \mathrm{~A}$

16907 PARKER 1954

16908 PARKER 1954

16909 PARKER 1954

16910 PHLEGER 1951 A

16911 PHLEGER 1951A

16912 PHLEGER 1951A

16913 PHLEGER 1951A

16914 PHLEGER $1951 \mathrm{~A}$

16915 PHLEGER $1951 \mathrm{~A}$

16916 PHLEGER 1951 A

16917 PHLEGER $1951 \mathrm{~A}$

16918 PHLEGER $1951 \mathrm{~A}$

16919 PARKER 1954

16920 PARKER 1954

16921 PHLEGER $1951 \mathrm{~A}$

16922 PHLEGER $1951 \mathrm{~A}$

16923 PHLEGER 1951A

16925 BANDY 1954

\section{Generic Name}

EPISTOM I NELL A

EPISTOMINELLA

EPISTOMINELLA

EPISTOM INELLA

EPISTOMINELLA

EPISTOMINELLA

EP IST OM I NELLA

EPISTOMINELLA

EP I STOMINELLA

EPIST OM I NELLA

EPISTOMINELLA

EP ISTOMINELLA

EPISTOMINELLA

EPISTOMINELLA

EP ISTOM I NELLA

EP ISTOM I NELLA

EPISTOMINELLA

EP IS TOM I NELLA

EPIST OMINELLA

EPISTOMINELLA

EP ISTOM I NELLA

EP I ST OMI NELLA

EPISTOMINELLA

EPISTOMINELLA

EPISTOMINELLA

EP ISTOMINELLA

EPISTOMINELLA

EPISTOMINELLA

EPISTOM INELLA

EP IST OM I NE LLA

EP ISTOM I NELLA

EP ISTOM I NELLA

EP ISTOMINELLA

EPISTOMINELLA

EPISTOMINELLA

EP ISTOMINELLA

EPIS TOMINELLA

EP IS TOMINELLA

EP ISTOMINELLA

EPISTOMINELLA

EPISTOMINELLA

EP ISTOMINELLA

EP IS TOMINELLA

EPISTOM I NE LLA

EP IS TOM I NELL A

EP ISTOM I NE LLA

EPISTOMINELLA

EP IST OMINELLA

EP IST OM INELLA

EPISTOMINELLA

EP ISTOM INE LLA

EP ISTOMINELLA

EPISTOMINELLA

EPISTOMINELLA

EPISTOMINELLA

EPONIDELLA

EPONIDELLA

EPONIDELLA

EPONIDELLA

EPONIDELLA

EPONI DELLA

EPONIDELLA

EPONIDELLA

EPONIDES

EPONIDES

EPONIDES

EPONIDES

EPONIDES

EPONIDES

EPONIDES

EPONIDES

EPONIDES

EPONIDES

EPONIDES

EPONIDES

EPONIDES

EPONIDES

EPONIDES

EPONIDES

EPONIDES

EPONIDES

EP ONIDES

EPONIDES

EPONIDES

EPONI DES

EPONIDES

EPONIDES

EPONIDES

EPONIDES

EPONIDES
Specific Name

RUGOSA

RUGOSA

RUGOSA

RUGOSA

RU GOSA

RUGOSA

RUGOSA

RUGOSA

RUGOSA

VI TREA

VI TREA

VI TREA

VI TREA

VI TREA

VI TREA

VITREA

VITREA

VI TREA

VI TREA

VI TREA

VI TREA

VITREA

VI TREA

VI TREA

VI TREA

VI TREA

VITREA

VI TREA

VI TREA

VI TREA

VI TREA

VI TREA

VI TREA

VITREA

VI TREA

VI TREA

VI TREA

VI TREA

VITREA

VITREA

VI TREA

VI TREA

VI TREA

VITREA

VI TREA

VITREA

VI TREA

VI TREA

VI TREA

VI TREA

GARDENISLANDENS IS

GARDENISL ANDENS IS

GARDENI SL ANDENSIS

GARDEN ISL ANDENS IS

GARDENI SL ANDENSIS

GARDENIS- ANDENSIS

GARDENISLANDENSIS

GARDEN I SLANDENS IS

PALMERAE GARDENISLANDENSIS

PALMERAE PALMERAE

ANTILLARUM

ANTILLARUM

ANTILLARJM

AN TILLARUM

AN TILLARUM

AN TILLARUM

AN TILLARUM

ANTILLARUM

AN TILLARUM

AN TILLARUM

AN TILLARUM

ANTILLARJM

ANTILLARUM

AN TILLARJM

ANTILLARJM

ANTILLARUM

AN TILLARUM

ANTILLARUM

AN TILLARUM

AN TILLARUM

ANTILLARUM

AN TILLARUM

AN TILLARUM

ANTILLARUM

AN TILLARUM

\section{Locality}

NE GULF OF MEXICO

NE GULF OF MEXICO

NE GULF OF MEXICO

NE GULF OF MEXICO

NE GULF OF MEXICO

NE GULF OF MEXICO

VE GULF OF MEXICO

NE GULF OF MEXICO

NE GULF OF MEXICO

NE GULF OF MEXICO

NE GULF OF MEXICO

NE GULF OF MEXICO

NE GULF OF MEXICO

NE GULF OF MEXICO 
Publication

16926 BANDY 1954 16927 BANDY 1954 16928 BANDY 1954 16929 BANDY 1956 16930 BANDY 1956 16931 BANDY 1956 16932 BANDY 1956 16933 BANDY 1956 16934 BANDY 1956 16935 KELLOUGH 1956 16936 KELLOUGH 1956 16937 KELLOUGH 1956 16938 KELLOUGH 1956 16939 KELLOUGH 1956 16940 KELLOUGH 1956 16941 PHLEGER 1951 A 16942 PHLEGER 1951A 16943 BANDY 1954

16944 BANDY 1954

16945 PHLEGER 1951 A 16946 PARKER 1954 16947 CREAGER 1958 16948 PHLEGER 1956 16949 PHLEGER 1956 16950 PHLEGER 1956

16951 BOCK 1976

16952 BOCK 1976

16953 CREAGER 1958
16954 8OCK 1976

16955 PHLEGER 1951A

16956 PHLEGER 1951A

16957 KELLOUGH 1956

16958 BANDY 1956

16959 BANDY 1956

16960 BANDY 1956

16961 BANDY 1956

16962 BANDY 1956

16963 BANDY 1956
16964 BANDY 1956

16965 CUSHMAN 1931

16966 BANDY 1956

16967 BANDY 1956

16968 BANDY 1956

16969 CUSHMAN 1931

16970 SEGURA 1963

16971 CREAGER 1958

16972 PHLEGER 19558

16973 PHLEGER 1951A

16974 PHLEGER $1951 \mathrm{~A}$

16975 PHLEGER $1951 \mathrm{~A}$

16976 PHLEGER 1951A

16977 PHLEGER 1951A

16978 PHLEGER 1951A

16979 PHLEGER 1951A

16980 PHLEGER 1951A

16981 PHLEGER $1951 \mathrm{~A}$

16983 PHLEGER 1951A

16984 PHLEGER 1951A

16985 PHLEGER 1951A

16986 PHLEGER 1951A

16987 KELLOUGH 1956

16988 KELLOUGH 1956

16989 KELLOUGH 1956

16990 KELLOUGH 1956

16991 KELLOUGH 1956

16992 PHLEGER $1951 \mathrm{~A}$

16993 PHLEGER 1951A

16994 PHLEGER 1951A

16995 PHLEGER 1954

16996 - PHLEGER 1954

16997 PHLEGER 1951A

16998 CREAGER 1958

16999 CREAGER 1958

17000 NORTON 1930

17001 CUSHMAN 1931

17002 PFLUM FRERICHS 1976

17003 PFLUM FRERICHS 1976

17004 PFLUM FRERICHS 1976

17005 PFLUM FRERICHS 1976

17006 PFLUM FRERICHS 1976

17007 PFLUM FRERICHS 1976

17008 PFLUM FRERICHS 1976

17009 PFLUM FRERICHS 1976

17010 CREAGER 1958

17011 PARKER 1954

17012 PARKER 1954

17013 PARKER 1954

17014 PARKER 1954

17015 PARKER 1954

17016 PARKER 1054

17018 PFLUM FRERICHS 1976

17019 PFLUM FRERICHS 1976

17019 PFLUM FRERICHS 1976
17020 PFLUM FRERICHS 1976
Generic Name

Specific Name

Locality

EPONIDES

EPONIDES

EPONIDES

EPONIDES

EPONIDES

EP ONIDES

EPONIDES

EPONIDES

EP ONIDES

EP ONI DES

EPONIDES

EPONIDES

EPONIDES

EPONIDES

EPONIDES

EPONIDES

EPONIDES

EPONIDES

EPONIDES

EPONIDES

EPONIDES

EPONIDES

EPONIDES

EPONIDES

EPONIDES

EP ONIDES

EPONIDES

EPONIDES

EPONIDES

EP ONI DES

EPONIDES

EPONIDES

EPONIDES

EPONIDES

EPONIDES

EPONIDES

EPONI DES

EPONIDES

EP ONIDES

EPONIDES

EPONIDES

EPONIDES

EPONI DES

EPONIDES

EPONIDES

EPONIDES

EPONIDES

EPONIDES

EPONIDES

EPONIDES

EP ONI DES

EP ONIDES

EPONIDES

EP ONIDES

EP ONIDES

EPONIDES

EPONIDES

EPONIDES

EPONIDES

EPONIDES

EPONIDES

EPONIDES

EPONIDES

EPONIDES

EP ONIDES

EPONIDES

EPONIDES

EPONI DES

EPONIDES

EPONIDES

EPONIDES

EPONIDES

EPONIDES

EPONIDES

EPONIDES

EPONIDES

EPONIDES

EPONIDES

EPONIDES

EPONIDES

EPONIDES

EPONI DES

EPONIDES

EPONIDES

EPONIDES

EPONIDES

EPONIDES

EPONI DES

EPONIDES

EPONIDES

EPONIDES

EPONIDES

EPONIDES

EPONIDES

EPONIDES
ANTILLARUM

ANTILLARUM

AN I ILLARUM

AN TILLARUM

ANTILLARUM

ANTILLARUM

AN TILLARUM

AN TILLARUM

AN TILLARUM

ANTILLARUM

ANTILLARUM

AN TILLARUM

AN TILLARUM

ANTILLARUM

AN TILLARUM

ANTILLARUM

ANTILLARUM

ANTILLARUM

ANTILLARUM

ANTILLARUM

ANTILLARUM

AN IILLARUM

AN TILLARJM

ANTILLARJM

ANTILLARUM

ANTILLAR'J M

ANTILLARUM

ANTILLARUM

AN TILLARUM

ANTILLARUM

ANTILLARJM

AN TILLARUM

AN TILLARUM

AN TILLARJM

ANTILLARUM

AN TILLARUM

AN TILLARUM

ANTILLARUM

AN TILL ARUM

ANTILLARUM

CORYELLI

GA VIOTAENSIS

HA NNAI

HANNA

HANNAI

HANNAI

HANNA I

HANNAI

HANNAI

HANNAI

HANNAI

HANNAI

HANNAI

HANNAI

HANNAI

HANNAI

HANNAI

HANNAI

HANNAI

HANNAI

HANNAI

HANNAI

HANNAI

HANNAI

HANNAI

HANNAI

HANNAI

HANNAI

HANNAI

IN CERTA

POLIUS

POLIUS

POLIUS

POLIUS

POLIUS

POLIUS

POLIUS

POLIUS

POLIUS

POLIUS

POLIUS

POLIUS

POLIUS

POLIUS

POLIUS

POLIUS

POLIUS

POLIUS
ANTILLARUM

ANTILLARUM

NW GULF OF MEXICO

NW GULF OF MEXICO

NW GULF OF MEXICO

NE GULF OF MEXICO

NE GULF OF MEXICO

NE GULF OF MEXICO

NE GULF OF MEXICO

NE GULF OF MEXICO

NE GULF OF MEXICO 


\section{Publication}

17021 PFLUM FRERICHS 1976 17022 PFLUM FRERICHS 1976 17023 PFLUM FRERICHS 1976 17024 PFLUM FRERICHS 1976 17025 PFLUM FRERICHS 1976 17026 PFLUM FRERICHS 1976 17027 PHLEGER 19518

17028 PARKER 1954

17029 LUDWICK WALTON 1957

17030 DHLEGER 1955A

17031 PHLEGER 1955A

17032 PARKER 1954

17033 PARKER 1954
17034 PARKER 1954

17035 PHLEGER 1955 A

17036 PHLEGER 1955A

17037 PFLUM FRERICHS 1976

17038 PFLUM FRERICHS 1076

17039 PFLUM FRERICHS 1976

17040 PARKER 1954

17041 PFLUM FRERICHS 1976

17042 PARKER 1954

17043 PARKER 1954

17044 PARKER 1354

17045 PHLEGER 1955 A

17046 PHLEGER 19518

17047 PARKER 1954

17048 PARKER 1954

17049 PARKER 1954

17051 PFLUM FRERICHS 1976

17052 PFLUM FRERICHS 1976

17052
17053 PFLUM FRERICHS 1976

17053 PFLUM FRERICHS 1976
17054 PFLUM FRERICHS 1976

17055 PFLUM FRERICHS 1976

17056 PFLUM FRERICHS 1976

17057 PFLUM FRERICHS 1976

17058 PFLUM FRERICHS 1976

17059 PFLUM FRERICHS 1976

17060 PFLUM FRERICHS 1976

17061 PFLUM FRERICHS 1976

17062 PFLUM FRERICHS 1976

17063 PFLUM FRERICHS 1976

17064 PFLUM FRERICHS 1976

17065 PFLUM FRERICHS 1976

17066 PFLUM FRERICHS 1976

17067 PFLUM FRERICHS 1976

17068 PFLUM FRERICHS 1976

17069 PFLUM FRERICHS 1976

17070 PFLUM FRERICHS 1976

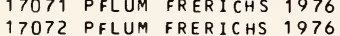

$\begin{array}{lll}17072 & \text { PFLUM FRERICHS } & 1976 \\ 17073 & \text { PFLUM FRERICHS } & 1976\end{array}$

17074 PFLUM FRERICHS 1976

17075 PFLUM FRERICHS 1976

17076 PFLUM FRERICHS 1976

17077 PFLUM FRERICHS 1976

17078 PFLUM FRERICHS 1976

17079 PFLUM FRERICHS 1976

17080 PFLUM FRERICHS 1976

17081 PFLUM FRERICHS 1976

17082 PFLUM FRERICHS 1976

17083 PFLUM FRERICHS 1976

17084 PFLUM FRERICHS 1976

17085 PFLUM FRERICHS 1976

17086 NORTON 1930

17087 CREAGER 1958

17088 CREAGER 1958

17089 LOEP 1965

17090 BOCK 1976

17091 PFLUM FRERICHS 1976

17092 PFLUM FRERICHS 1976

17093 PFLUM FRERICHS 1976

17094 PFLUM FRERICHS 1976

17095 PFLUM FRERICHS 1976

17097 PFLUM FRERICHS 1976

17098 PFLUM FRERICHS 1976

17098 PFLUM FRERICHS 1976
17099 DFLUM FRERICHS 1976

17100 PFLUM FRERICHS 1976

17101 PFLUM FRERICHS 1976

17102 PFLUM FRERICHS 1976

17103 PFLUM FRERICHS 1976

17104 PFLUM FRERICHS 1976

17105 PFLUM FRERICHS 1976

17106 PFLUM FRERICHS 1976

17107 PFLUM FRERICHS 1976

17108 PFLUM FRERICHS 1976

17109 PHLEGER $1951 \mathrm{~A}$

17110 PHLEGER 1951A

17111 PHLEGER 1951A 1976

17112 PFLUM FRERICHS 1976
17113 PFLUM FRERICHS 1976

17114 PFLUM FRERICHS 1976

17115 PFLUM FRERICHS 1976
Generic Name

EPONIDES

EPONIDES

EPONIDES

EPONIDES

EP ONIDES

EPONIDES

EPONIDES

EPONIDES

EPONIDES

EPONIDES

EDONIDES

EP ONIDES

EPONIDES

EPONIDES

EPONIDES

EPONIDES

EPONIDES

EPONIDES

EPONIDES

EPONIDES

EPONIDES

EPONIDES

EPONIDES
EPONIDES

EPONIDES

EPONIDES

EPONIDES

EPONIDES

EPONIDES

EPONIDES

EPONIDES

EPONIDES

EPONIDES

EPONIDES

EPONIDES

EPONIDES

EPONIDES

EPONIDES

EPONIDES

EPONIDES

EPONIDES

EPONIDES

EPONIDES

EPONIDES

EPONIDES

EPONIOES

EPONIDES

EPONIDES

EPONIDES

EPONIDES

EPONIDES

EPONIDES

EPONIDES

EPONIDES

EPONIDES

EPONIDES

EPONIDES

EPONIDES

EPONIDES

EPONIDES

EPONIDES

EPONIDES

EPONIDES

EPONIDES

EPONIDES

EPONIDES

EPONIDES

EPONIDES

EPONIDES

EPONIDES

EPONIDES

EPONIDES

EPONIDES

EPONIDES

EPONIDES

EPONIDES

EPONIDES

EPONIDES

EPONIDES

EPONIDES

EPONIDES

EPONIDES

EPONIDES

EPONIDES

EPONIDES

EPONIDES

EPONIDES

EPONIDES

EPONIDES

EPONIDES
Specific Name

POLIUS

POLIUS

POLIUS

POLIUS

POLIUS

POLIUS

POLIUS

POLIUS

POLIUS

POLIUS

POLIUS

POLIUS

POLIUS

POLIUS

POLIUS

POLIUS
POLIUS

POLIUS

POLIUS

Polius

POLIUS

POLIUS

POLIUS

POLIUS

POLIUS

POLIUS

POLIUS

POLIUS
POLIUS

POLIUS

POLIUS

POLIUS

POLIUS

POLIUS

POLIUS

POLIUS

POLIUS

POLIUS

POLIUS

POLIUS

POLIUS

POLIUS

POLIUS

POLIUS

POLIUS

POLIUS

POLIUS

POLIUS

POLIUS

POLIUS

POLIUS

POLIUS

POLIUS

POLIUS

Polius

POLIUS

PYGMAEA

RE GUL AR IS

RE GULAR IS

REGULARIS

RE GULAR IS

RE GULAR IS

REGULAR IS

REGULARIS

RE GULAR IS

REGULAR IS

RE GULARIS

REGULARIS

RE GULAR IS

RE GULAR IS

RE GULARIS

RE GUL AR IS

REGULARIS

RE GULAR IS

RE GULAR IS

RE GULARIS

REGULAR IS

RE GULAR IS

RE GULAR IS

RE GULAR IS

RE GULAR IS

RE GULAR IS

REGUL AR IS
RE GULAR IS

Locality

CENTRAL GULF OF MEXICO CENTRAL GULF OF MEXICO CENTRAL GULF OF MEXICO CENTRAL GULF OF MEXICO CENTRAL GULF OF MEXICO CENTRAL GULF OF MEXICO SIGSBEE DEEP

NE GULF OF MEXICO

NE GULF OF MEXICO

$N$ GULF OF MEXICO

$N$ GULF OF MEXICO

NE GULF OF MEXICO

NE GULF OF MEXICO

NE GULF OF MEXICO

$N$ GULF OF MEXICO

$N$ GULF OF MEXICO

CENTRAL GULF OF MEXICO

CENTRAL GULF OF MEXICO

NE GULF OF MEXICO

CENTRAL GULF OF MEXICO

NE GULF OF MEXICO

NE GULF OF MEXICO

NE GULF OF MEXICO

$N$ GULF OF MEXICO

SIGSBEE DEEP 


\section{Publication}

17116 PFLUM FRERICHS 1976 17117 PFLUM FRERICHS 1976 17118 PFLUM FRERICHS 1976 17119 PHLEGER 1951A

17120 PFLUM FRERICHS 1976 17121 PFLUM FRERICHS 1976 17122 PFLUM FRERICHS 1976 17123 PFLUM FRERICHS 1976 17124 PFLUM FRERICHS 1976 17125 LEHMANN 1957

17126 PHLEGER 1951A

17127 PHLEGER 1951A

17128 PHLEGER $1951 \mathrm{~A}$

17129 PHLEGER 1951A

17131 PHLEGER 1951A

17132 PARKER 1954

17133 LUDWICK WALTON 1957

17134 PHLEGER 1955 A

17135 PHLEGER $1955 \mathrm{~A}$

17136 PHLEGER $1951 \mathrm{~A}$

17137 PHLEGER 1951A

17138 PHLEGER $1951 \mathrm{~A}$

17139 PHLEGER $1951 \mathrm{~A}$

17141 PHLEGER 1951A

17142 PHLEGER $1951 \mathrm{~A}$

17143 PHLEGER $1951 \mathrm{~A}$

17144 PHLEGER $1951 \mathrm{~A}$

17145 PHLEGER 1951 A

17146 PHLEGER 1951A

17147 PHLEGER 1951A

17148 PHLEGER $1951 \mathrm{~A}$

17149 PARKER 1954

17150 PARKER 1954

17152 PARKER 1954

17153 PARKER 1954

17154 PARKER 1954

17155 PARKER 1954

17156 PARKER 1954

17157 CUSHMAN 1931

17158 NORTON 1930

17159 LUDWICK WALTON 1957

17160 PARKER 1954

17161 PARKER 1954

17162 AYALA-CASTANARES 1963

17163 PARKER 1954

17164 PARKER 1954

17165 LOEP 1965

$\begin{array}{lll}17166 & \text { PARKER } & 1954 \\ 17167 & \text { PARKER } & 1954\end{array}$

17168 PARKER 1954

17169 PARKER 1054

17170 SEGURA 1963

17171 PARKER 1954

17172 PARKER 1954

17173 LEHMANN 1957

17174 KELLOUGH 1956

17175 PARKER 1954

17176 PARKER 1954

17177 PARKER 1954

17179 DFLUM FRERICHS 1976

17180 PFLUM FRERICHS 1976

17181 PFLUM FRERICHS 1976

17182 PFLUM FRERICHS 1976

17183 PFLUM FRERICHS 1976

17184 PFLUM FRERICHS 1976

17185 PFLUM FRERICHS 1976

17186 PFLUM FRERICHS 1976

17187 PARKER 1954

17188 PARKER 1954

17189 LUDWICK WALTON 1957

17190 PHLEGER 1955A

17191 PHLEGER 1955A

17192 PHLEGER 1955A

17193 PHLEGER 19518

17194 PHLEGER 1955A

17195 PHLEGER 1951A

17196 PHLEGER 1951A

17197 PHLEGER 1951A

17198 PHLEGER 1951A

17199 PHLEGER 1951A

17200 PARKER 1954

17201 PARKER 1954

17202 BOCK 1976

17203 ANDERSEN 1961

17204 PFLUM FRERICHS 1976

17205 PFLUM FRERICHS 1976

17206 PFLUM FRERICHS 1976

17207 PFLUM FRERICHS 1976

17208 PHLEGER 1951A

17209 PHLEGER 1951A

17210 PHLEGER 1955A
Generic Name

EPONIDES

EPONIDES

EPONIDES

EPONIDES

EPONIDES

EPONIDES

EPONIDES

EPONIDES

EPONIDES

EP ONIDES

EPONIDES

EPONIDES

EPONIDES

EPONIDES

EPONIDES

EPONIDES

EPONIDES

EPONIDES

EPONIDES

EPONIDES

EPONIDES

EPONIDES

EPONIDES

EPONIDES

EPONIDES

EPONIDES

EPONIDES

EPONIDES

EPONIDES

EPON IDES

EPONIDES

EPONIDES

EPONIDES

EPONIDES

EPONIDES

EP ONIDES

EPONIDES

EPONIDES

EPONIDES

EPONIDES

EPONIDES

EPONIDES

EPONIDES

EPONIDES

EPONIDES

EPONIDES

EPONIDES

EP ON IDES

EPONIDES

EPONIDES

EPON I DES

EPONIDES

EPONIDES

EPONIDES

EPONIDES

EPONIDES

EPONIDES

EPONIDES

EPONIDES

EPONIDES

EPONIDES

EDONIDES

EPONIDES

EPONIDES

EPONIDES

EPONIDES

EPONIDES

EPONIDES

EPONIDES

EPONIDES

EPONIDES

EPON IDES

EPONIDES

EPONIDES

EPONIDES

EPONIDES

EPONIDES

EPONIDES

EP ON IDES

EPONIDES

EP ONIDES

EPONIDES

EPONIDES

EPONIDES

EPONIDES

EPONIDES

EPONIDES

EPONIDES

EPONIDES

EP ONIDES

EPONIDES

EP ONIDES

EP ONIDES

EPON IDES
EPONIDES
Specific Name

RE GULAR IS

RE GULAR IS

RE GULAR IS

RE GULAR IS

REGULARIS

RE GULAR IS

RE GULAR IS

RE GULAR IS

RE GULAR IS

REGULARIS

RE GULARIS

RE GULAR IS

RE GULAR IS

RE GULAR IS

RE GULAR IS

REGULARIS

RE GULAR IS

RE GULARIS

RE GULARIS

RE GULAR IS

REGULAR IS

RE GULAR IS

RE GULAR IS

REGULAR IS

REGULAR IS

REGULARIS

RE GULAR IS

REGULARIS

RE GULAR IS

RE GULAR IS

RE GULAR IS

REGULARIS

RE GULAR IS

REGULARIS

REGULARIS

RE GULAR IS

REGULAR IS

REGULARIS

RE GULAR IS

REPANDA

REPANDA

REPANDUS

REFANDUS

REPANDUS

REFANDUS

REPANQUS

REPANDUS

REFANDUS

REFANDUS

REPANDUS

REPANDUS

REPANDU

REPANDUS

REPANDUS

REFANDUS

REPANDUS

TENERA

TUNIDUL US

TUNIDULUS

TUNIDULUS

TUNIDULUS

TUNIDULUS

TUNIDULUS

TUNIDULUS

TUN I DUL US

TUNIDULUS

TUNIDUL US

TUNIDULUS

TUNIDULUS

TUNIDULUS

TUNI DUL US

TUNI DUL US

TUNIDULUS

TUNI DUL US

TUNIDULUS

TUN I DUL US

TUNIDUL US

IUNIDUL US

TUNI I ULUS

TUNIDULUS

UNIDULUS

TUNIDUL US

TUMIDUL US

TUNIDUL US

TUMI DULUS

TUNI DUL US

TUNI DUL US

TUNIDULUS

TUNIDULUS

TUNI DUL US

TUNIDULUS

TUNIDULUS

Locality

NW GULF OF MEXICO

NW GULF OF MEXICO

NW GULF OF MEXICO

$N W$ GULF OF MEXICO

$N W$ GULF OF MEXICO

NW GULF OF MEXICO

NW GULF OF MEXICO

NW GULF OF MEXICO 


\section{Publication}

17211 PHLEGER $1951 \mathrm{~A}$ 17212 PHLEGER 1951 A 17213 PHLEGEQ :951A 17214 PHLEGER $1951 \mathrm{~A}$ 17215 PHLEGER $1955 \mathrm{~A}$ 17216 PARKER 1954

17217 PFLUM FRERICHS 1976 17218 PFLUM FREPICHS 1976 17219 PFLUM FRERICHS 1976 17220 PFLUM FRERICCHS 1976 17221 PFLUM FRERICHS 1976 17222 PFLUM FRERICHS 1976 17223 PFLUM FRERICHS 1976 17224 PFLUM FRERICHS 1976 17225 PFLUM FRERICHS 1976 17226 PFLUM FRERICHS 1976 17227 PFLUM FRERICHS 1976 17228 PARKER 1254 17229 PARKER 1954

17230 PARKER 1754

17231 PARKER 1954

17232 PARKER 1354

17233 PFLUM FRERICHS 1976 17234 PFLUM FRERICHS 1976 17235 PHLEGER 1951 A

17236 PFLUM FRERICHS 1976 17237 PFLUM FRERICHS 1976 17238 PFLUM FRERICHS 1976 17239 PFLUM FRERICHS 1976 17240 PARKER 1954

17241 PARKER 1954

17242 PARKER 1954

17243 PFLIJM FRERICHS 1976 17244 PFLUM FRERICHS 1976 17245 PFLUM FRERICHS 1976 17246 PFLUM FRERICHS 1976 17247 PARKER 1954 17248 PARKER 1754 17249 PARKER 1954

17250 PARKER 1954

17251 PFLUM FRERICHS 1976 17252 PFLUM FRERICHS 1976 17253 PFLUM FRFRICHS 1976 17254 PFLUM FRERICHS 1976 17255 PFLUM FRERICHS 1976 17256 PFLUM FRERICHS 1976 17257 PFLUM FRERICHS 1976

17258 PARKER 1954

17259 PARKER 1954

17260 PARKER 1954

17261 PARKER 1954

17262 PFLUM FRERICHS 1976

17263 PFLUM FRERICHS 1976

17264 PFLUM FRERICHS 1976

17265 PFLUM FREFICHS 1976

17266 PHLEGER 1951 A

17267 PHLEGER $1951 \mathrm{~A}$

17268 PHLEGER $1951 \mathrm{~A}$

17269 PFLUM FRFRICHS 1976

17270 PFLUM FRERICHS 1976

17271 PFLUM FPERICHS 1976

17272 PFLUM FRERICHS 1976

17273 PFLUM FRERICHS 1976

17274 PFLUM FRERICHS 1976

17275 PFLUM FRERICHS 1976

17276 DFLUM FRERICHS 1976

17277 PHLEGER 1956

17278 PARKER 1054
17279 PFLUM FRERICHS 1976

17280 PFLUM FRERICHS 1976

17281 PFLUM FRERICHS 1976

17282 PFL'JM FRERICHS 1976

17283 PFLUM FRERICHS 1976

17284 PFLUM FRERICHS 1976

17285 PFLIJM FRERICHS 1976

17286 PFLUM FRERICHS 1976

17287 PFLUM FRERICHS 1976

17288 PFLUM FRERICHS 1976

17289 PFLUM FRERICHS 1976

17290 DFLUM FRERICHS 1976

17291 AYALA-CASTANARES 1963

17292 PARKER 1954

17293 PARKER 1754

17294 PFLUM FRERICHS 1976
17295 DFLUM FRERICHS 1976

17295 PFLUM FRERICHS 1976
17296 PFLUM FREKICHS 1976

17297 PARKER 1954

17299 PARKER 1754

17299 PHLEGER 1955A

17300 PHLEGER $1951 \mathrm{~A}$

17301 PHLEGER 1955A

17302 PHLEGER 1951 A

17303 PHLEGER $1951 \mathrm{~A}$

17304 PHLEGER 1951 A
Generic Name

EPONIDES

EPONIDES

EP ONIDES

EPONIDES

EPONIDES

EPONIDES

EPONIDES

EPONIDES

EPONIDES

EPONIDES

EPONIDES

EPONIDES

EPONIDES

EP ONIDES

EPONIDES

EPONIDES

EPONIDES

EPONIDES

EPONIDES

EPONIDES

EPONIDES

EPONIDES

EPONIDES

EPONIDES

EPONIDES

EPONIDES

EPONIDES

EPONIDES

EPONIDES

EPONIDES

EPONIDES

EPONIDES

EPONIDES

EPONIDES

EPONIDES

EPONIDES

EPONIDES

EPONIDES

EPONIDES

EPONIDES

EPONIDES

EPONIDES

EPONIDES

EPONIDES

EPONIDES

EPONIDES

EP ONIDES

EPONIDES

EPONIDES

EPONIDES

EPONIDES

EPONIDES

EPONIDES

EPONIDES

EPONIDES

EPONIDES

EPONIDES

EPONIDES

EPONIDES

EPONIDES

EPONIDES

EPONIDES

EPONIDES

EPONIDES

EPONIDES

EPONIDES

EPONIDES

EPONIDES

EPONIDES

EPONIDES

EPONIDES

EPONIDES

EPONIDES

EPONIDES

EPONIDES

EPONIDES

EPONIDES

EPONIDES

EPONIDES

EPONIDES

EPONIDES

EPONIDES

EPONIDES

EPONIDES

EPONIDES

EPONIDES

EP ONIDES

EPONIDES

EP ONIDES

EPONIDES

EPONIDES

EPONIDES

EPONIDES

EPONIDES

EPONIDES
Specific Name

TUMIDULUS

TUNIDUL US

TUNIDUL US

TUNI DULUS

TUNIDULUS

TUMIDULUS

TUMIDULUS

TUNIDULUS

TUNIDULUS

TUNIDULUS

TUNIDULUS

TUMIDULUS

TUNIDULUS

TUNI DUL US

TUMIDUL US

TUNI DUL US

TUNIDULUS

TUNI DUL US

UNIDULUS

TUNIDULUS

TUMIDUL US

TUN I DUL US

TUNIDULUS

TUNIDUL US

TUN I DUL US

TUNIDULUS

TUNIDUL US

TUNIDULUS

TURGIDUS

TURG I DUS

TURGIDUS

TURGIDUS

TURGIDUS

TURGIDUS

TURGIDUS

TURGIDUS

TURGIDUS

TURG IDUS

TURGIDUS

TURGIDUS

TURG IDUS

TURG I DUS

TURG I DUS

TURGIDUS

TURGIDUS

TURGIDUS

TURGIDUS

TURGIDUS

TURGIDUS

TURGIDUS

TURGIDUS

TURGIDUS

TURGIDUS

TURGIDUS

TURG I DUS

TURGIDUS

TURGIDUS

TURGIDUS

TURGIDUS

TURGIDUS

TURGIDUS

TURGIDUS

TURGIDUS

TURGIDUS

TURGIDUS

TURGIDUS

TURGIDUS

TURG IDUS

TURG I DUS

TURGIDUS

TURGIDUS

TURGIDUS

TURGIDUS

TURGI DUS

TURGIDUS

TURGIDUS

TURG I DUS

TURGIDUS

TURGIDUS

TURG I DUS

TURG I DUS

TURGIDUS

TURG I DUS

TURGIDUS

TURGIDUS

TURGIDUS

TURGIDUS

TURGIDUS

TURGIDUS

TURG IDUS

TURG I DUS

TURGIDUS

TURGIDUS

TURGIDUS

\section{Locality}

NW GULF OF MEXICO

NW GULF OF MEXICO

NW GULF OF MEXICO 


\section{Publication}

17306 PHLEGER 1951A 17307 PHLEGER 1951A 17308 PHLEGER 1951A 17309 PHLEGER 1951A 17310 PHLEGER 1951A 17311 PHLEGER 1951A 17312 PHLEGER $1951 \mathrm{~A}$ 17313 PHLEGER 1951A 17315 PARKER 1954

17316 PFLUM FRERICHS 1976 17316 PFLUM FRERICHS 1976 17318 PFLUM FRERICHS 1976 17319 PFLUM FRERICHS 1976 17320 PARKER 1954

17321 PARKER 1954

17322 PARKER 1754

17323 PARKER 1954

17324 PHLEGER $1955 \mathrm{~A}$

17325 PHLEGER 1951A

17326 PHLEGER 1951

17327 PARKER 1954

17328 PARKER 1954

17330 PARKER 1954

17331 PHLEGER 1955 A

17332 LUDWICK WALTON 1957

17333 PHLEGER 1955 A

17334 PFLUM FRERICHS 1976

17335 PFLUM FRERICHS 1976

17336 PHLEGER 1951A

17337 PHLEGER 1955A

17338 PHLEGER 1955 A

17339 PFLUM FRERICHS 1976

17340 PFLUM FRERICHS 1976

17341 PFLUM FRERICHS 1976

17342 PFLUM FRERICHS 1976

17343 PFLUM FRERICHS 1976

17344 PHLEGER $1951 \mathrm{~A}$

17345 PHLEGER $1951 \mathrm{~A}$

17346 PHLEGER 1951 A

17347 PHLEGER $1951 \mathrm{~A}$

17348 PHLEGER $1951 \mathrm{~A}$

17349 PHLEGER $1951 \mathrm{~A}$

17351 PFLUM FRERICHS 1976

17352 PHLEGER 1951 A

17353 PHLEGER 1951A

17354 PHLEGER 1955 A

17355 PHLEGER 1955A

17356 PHLEGER $1955 \mathrm{~A}$

17357 PHLEGER 1951A

17358 PHLEGER $1951 \mathrm{~A}$

17359 PHLEGER 1951 A

17360 PHLEGER 1951A

17361 PHLEGER $1951 \mathrm{~A}$

17362 PHLEGER $1951 \mathrm{~A}$

17363 PHLEGER 1951A

17364 PHLEGER 1951 A

17365 PHLEGER $1951 \mathrm{~A}$

17366 PARKER 1054

17367 PHLEGER $1951 \mathrm{~A}$

17368 PHLEGER $1951 \mathrm{~A}$

17360 PHLEGER $1951 \mathrm{~A}$

17370 PHLEGER 1951A

17371 CREAGER 1958

17372 PHLEGER 1951A

17373 PHLEGER $1951 \mathrm{~A}$

17374 PHLEGER $1951 \mathrm{~A}$

17375 PHLEGER $1951 \mathrm{~A}$

17376 PHLEGER 1951A

17377 PHLEGER 1951 A

17378 PHLEGER 1951A

17379 PHLEGER $1951 \mathrm{~A}$

17380 PHLEGER 1951 A

17381 PHLEGER 1951A

17382 PHLEGER 1951A

17383 PHLEGER $1951 \mathrm{~A}$

17384 PHLEGER 1951A

17385 PHLEGER 1951A

17386 PHLEGER $1951 \mathrm{~A}$

17387 CREAGER 1958

17388 CREAGER 1958

17389 PHLEGER 1956

17390 CREAGEP 1958

17391 CREAGER 1958

17392 PHLEGER 1951A

17393 PHLEGER 1951A

17394 PHLEGER $1951 \mathrm{~A}$

17395 PHLEGER 1951A

17396 PHLEGER $1951 \mathrm{~A}$

17397 PHLEGER $1951 \mathrm{~A}$

17398 PHLEGER 1951A

17399 PHLEGER $1951 \mathrm{~A}$

17400 PHLEGER 1951A
Generic Name

Specific Name

Locality

EPONIDES

EPONIDES

EPONIDES

EPONIDES

EPONIDES

EPONIDES

EPONIDES

EPONIDES

EPONIDES

EPONIDES

EPONIDES

EPONIDES

EPONIDES

EPONIDES

EPONIDES

EPONIDES

EPONIDES

EPONIDES

EPONIDES

EP ONIDES

EPONIDES

EP ONIDES

EPONIDES

EPONIDES

EPONIDES

EPONIDES

EPONIDES

EPONIDES

EPONIDES

EPONIDES

EPONIDES

EPONIDES

EPONIDES

EPONIDES

EPONIDES

EPONIDES

EPONIDES

EPONIDES

EPONIDES

EPONIDES

EPONIDES

EPONIDES

EPONIDES

EPONIDES

EPONIDES

EPONIDES

EPONIDES

EPONIDES

EPONIDES

EPONIDES

EPONIDES

EPONIDES

EPONIDES

EPONIDES

EPONIDES

EPONIDES

EPONIDES

EPONIDES

EPONIDES

EPONIDES

EPONIDES

EPONIDES

EPONIDES

EPONIDES

EPONIDES

EPONIDES

EPONIDES

EPONIDES

EPONIDES

EPONIDES

EPONIDES

EPONIDES

EPONIDES

EPONIDES

EPONIDES

EPONIDES

EPONIDES

EPONIDES

EPONIDES

EPONIDES

EPONIDES

EPONIDES

EPONIDES

EPONIDES

EPONIDES

EPONIDES

EPONIDES

EPONIDES

EPONIDES

EPONIDES

EPONIDES

EPONIDES

EPONIDES

EPONIDES

EPONIDES
TURGIDUS

TURGIDUS

TURGIDUS

TURG IDUS

TURGIDUS

TURGIDUS

TURG IDUS

TURGIDUS

TURG IDUS

TURGIDUS

TURG I DUS

TURG IDUS

TURGIDUS

TURG I DUS

TURGIDUS

TURGIDUS

TURG I DUS

TURGIDUS

TURG I DUS

TURGIDUS

TURG I DUS

TURGIDUS

TURGIDUS

TURGIDUS

TURG I DUS

TURG IDUS

TURG I DUS

TURG I DUS

TURGIDUS

TURGIDUS

TURGIDUS

TURG I DUS

TURGIDUS

TURG I DUS

TURG I DUS

TURG I OUS

TURGIDUS

TURGIDUS

TURGIDUS

TURG I DUS

TURGI DUS

TURGIDUS

TURG I DUS

TURGIDUS

TURG I DUS

TURGIDUS

TURGIDUS

TURGIDUS

TURGIDUS

TURG I DUS

TURGIDUS

TURG I DUS

TURGIDUS

TURGIDUS

TURGI DUS

TURGIDUS

TURG I DUS

TURGIDUS

TURGIDUS

TURGIDUS

TURG I DUS

UMEONATUS

UMBONATUS

UMBONATUS

UMEONATUS

UMBONATUS

UMEONATUS

UMBONATUS

UMEONATUS

UMBONATUS

UMBONATUS

UMEONATUS

UMEONATUS

UMBONATUS

UMEONATUS

UMEONATUS

UMBONATUS

UMEONATUS

UMEONATUS

UMEONATUS

UMEONATUS

UMEONATUS

UM BONATUS

UMEONATUS

UMBONATUS

UMBONATUS

UMEONATUS

UMBONATUS

UMEONATUS

UMBONATUS

UMBONATUS

UMEONATUS

UMBONATUS

Lat. Long.

NW GULF OF MEXICO

NW GULF OF MEXICO

NW GULF OF MEXICO

WW GULF OF MEXICO 


\section{Publication}

17401 PHL $\subseteq$ GER $1951 \mathrm{~A}$ 17402 PHLEGER $1951 \mathrm{~A}$ 17403 PHLEGER $1951 \mathrm{~A}$ 17404 PHLEGER 1951 A 17405 PHLEGER 1951 A 17406
17407 CREEGER 1958 17408 PHLEGER $1951 \mathrm{~A}$ 17409 PHLEGER $1951 \mathrm{~A}$ 17410 PHLEGER 1951A 17411 PHLEGER $1951 \mathrm{~A}$ 17412 PHLEGER 1951 A 17413 PHLEGER 1951A 17414 PHLEGER 1951
17415 POAG 1972

17416 CUSHMAN 1922 A 17417 PFLUM FRERICHS 1976 17418 PFLUM FRERICHS 1976 17419 PFLUM FRERICHS 1976 17420 PFLUM FRERICHS 1976 17421 DFLUM FRERICHS 1976 17422 PFLUM FRERICHS 1976 17423 PFLUM FRERICHS 1976 17424 PFLUM FRERICHS 1976 17425 PFLUM FRERICHS 1976 17426 PFLUM FRERICHS 1976 17427 PFLUM FRERICHS 1976 17428 PFLUM FRERICHS 1976 17428
17429
PFLUUM FREPICHS 1976 17430 PFLUM FRERICHS 1976 17431 BOCK 1976

17432 PFLUM FRERICHS 1976 17433 PFLIJM FRERICHS 1976 17434 DFLUM FRERICHS 1976 17435 PFLUM FRERICHS 1976 17436 PFLUM FRERICHS 1976 17437 PFLUM FRERICHS 1976 17438 PFLUM FRERICHS 1976 17439 PFLUM FRERICHS 1976 17440 PFLUM FRERICHS 1976 17441 PFLUM FRERICHS 1976 17442 PFLUM FRERICHS 1976 17443 KELLOUGH 1956

17444 KELLOUGH 1956

17445 PFLUM FRERICHS 1976 17446 PFLUM FRERICHS 1976 17447 PFLUM FRERICHS 1976 17448 PFLUM FRERICHS 1976 17449 PFLUM FRERICHS 1976 17450 PFLUM FRERICHS 1976 17451 PFLUM FRERICHS 1976 17452 PFLUM FRERICHS 1976 17453 PFLUM FRERICHS 1976 17454 PFLUM FRERICHS 1976 17455 PFLUM FRERICHS 1976 17456 PFLUM FRERICHS 1976 17457 PFLUM FRERICHS 1976 17458 PFLUM FRERICHS 1976 17459 PFLUM FRERICHS 1976 17460 PFLUM FRERICHS 1976 17461 PFLUM FRERICHS 1976 17462 PFLUM FRERICHS 1976 17463 PFLUM FRERICHS 1976 17464 POAG 1976

17465 PFLUM FRERICHS 1976 17466 PFLUM FRERICHS 1976 17467 PFLUM FRERICHS 1976 17468 PFLUM FRERICHS 1976 17469 PFLUM FRERICHS 1976 17470 PFLUM FRERICHS 1976 17471 PFLUM FRERICHS 1976 17472 PFLUM FRERICHS 1976 17473 PFLUM FRERICHS 1976 17474 PFLUM FRERICHS 1976 17475 PFLUM FRERICHS 1976 17476 PFLUM FRERICHS 1976 17477 PFLUM FRERICHS 1976 17478 PFLUM FRERICHS 1976 17479 PFLUM FRERICHS 1976 17480 PFLUM FRERICHS 1976 17481 PFLUM FRERICHS 1976 17482 PFLUM FRERICHS 1976 17483 PFLUM FRERICHS 1976 17484 PFLUM FRERICHS 1976 17485 PFLUM FRERICHS 1976 17486 PFLUM FRERICHS 1976 17487 PFLUM FRERICHS 1976 17489 PFLUM FRERICHS 1976 17490 PFLUM FRERICHS 1976 17499 PFLUM FRERICHS 1976 17492 PFLUM FRERICHS 1976 17493 BOCK 1976

17494 PFLUM FRERICHS 1976 17495 DFLUM FRERICHS 1976

\section{Generic Name}

EPONIDES

EPONIDES

EPONIDES

EPONIDES

EPONIDES

EPONIDES

EPONIDES

EPON I DES

EPONIDES

EPON I DES

EPONIDES

EPONIDES

EP ONIDES

EUUVIGERINA

FI SCHERINA

FISSURINA

FISSURINA

FISSURINA

F I SSURINA

FISSURINA

FI SSURINA

FISSURINA

F I SSURINA

FI SSURINA

FISSURINA

FISSURINA

FISSURINA

FISSURINA

FISSURINA

FISSURINA

FISSURINA

FISSURINA

FISSURINA

FI SSURINA

F I SSURINA

FISSURINA

F I SSURINA

FISSURINA

FISSURINA

FISSURINA

FISSURINA

F ISSURINA

FISSURINA

FISSURINA

FISSURINA

FISSURINA

F I SSUR INA

FISSURINA

FISSURINA

FISSURINA

FISSURINA

F I S SUR INA

FLORILUS

FLORILUS

FLORILUS

FLORILUS

FLORILUS

FLORILUS

FLORILUS

FLORILUS

FLORILUS

FLORILUS

FLORILUS

FLORILUS

FLORILUS

FLORILUS

FLORILUS

FLORILUS

FL ORILUS

FLORILUS

FLORILUS

FLORILUS

FLORILUS

FLORILUS

FLORILUS

FLORILUS

FLORILUS

FLORILUS

FL ORILUS

FLORILUS

FLORILUS

FLORILUS

FLORILUS

FLORILUS

FLORILUS

FLORILUS

FLORILUS

FLORILUS

FLORILUS

FLORILUS

\section{Specific Name}

UMBONATUS

UM EONATUS

UMEONATUS

UMEONATUS

UMEONATUS

UMEONATUS

UMEONATUS

UMBONATUS

UMEONATUS

UMBONATUS

UMEONATUS

UMEONATUS

UMEONATUS

PAFVULA

DUBIA

ARADASII

ARADASII

AR ADASII

ARADASII

ARADASII

ARADASI I

FORMOSA

FORMOSA

FORMOSA

FORMOSA

FORMOSA

F ORMOSA

FORMOSA

FORMOSA

FORMOSA

FO RMOSA

ORMOSA

F RMOSA

FORMOSA

FORMOSA

FORMOSA

FORMOSA

OREI GNYAVA

ORBIGNYAVA

PUACTATA

STRIATOPUNCTATA

TENUISSIMA

TENUISSIYA

TENUISS IMA

TENUISSIYA

TENUISSIYA

TENUISSIMA

TENUISSIMA

TENUISSIYA

TENUISSIMA

TENUISSIMA

TENU ISS IMA

TENUISSIMA

AT LANTI CJS

A T LANTICUS

AT LANTI CJS

ATLANTICJS

A T LANTI CUS

A T LANTICUS

ATLANTICUS

ATLANTICUS

A TLANTICUS

CLAVATUS

CLAVATUS

CLAVATUS

CLAVATUS

CLAVATUS

CLAVATUS

CLAVATUS

CLAVATUS

CLAVATUS

CLAVATUS

CLAVATUS

CLAVATUS

CLAVATUS

CLAVATUS

CLAVATUS

CLAVATUS

CLAVATUS

CLAVATUS

CLAVATUS

CLAVATUS

CLAVATUS

CLAVATUS

CLAVATUS

CLAVATUS

CLAVATUS

CLAVATUS

CLAVATUS

GRATELOUP

SCAPHUS

\section{Locality}

NW GULF OF MEXICO

NW GULF OF MEXICO

NW GULF OF MEXICO

$\mathrm{NW}$ GULF OF MEXICO

NW GULF OF MEXICO

NW GULF OF MEXICO

BAY OF CAMPECHE

$\mathrm{NW}$ GULF OF MEXICO

NW GULF OF MEXICO 
Publication

17496 PFLUM FRERICHS 1976 17497 PFLUM FRERICHS 1976 17498 PFLUM FRERICHS 1976 17400 PFLUM FRERICHS 1976 17500 PFLUM FRERICHS 1976 17501 PFLUM FRERICHS 1976 17502 PFLUM FRERICHS 1976 17503 PFLUM FRERICHS 1976 17504 PFLUM FRERICHS 1976 17505 PFLUM FRERICHS 1976 17506 PFLUM FRERICHS 1976 17507 PFLUM FRERICHS 1976 17508 PFLUM FRERICHS 1976 17509 PFLUM FRERICHS 1976 17510 PFLUM FRERICHS 1976 17511 ANDERSEN 1961

17512 ANDERSEN 1961 17513 PFLUM FRERICHS 1976
17514 PFLUM FRERICHS 1976 17515 BANDY 1956

17516 CREAGER 1958

17517 CUSHMAN 1923

17518 CUSHMAN 1923

17519 CUSHMAN 1923

17520 CUSHMAN 1923

17521 CUSHMAN 1923

17522 BOCK 1976

17523 BOCK 1976

17524 BOCK 1976

17525 BOCK 1976

17527 POAG 1976

17528 BOCK 1976

17529 BOCK 1976

17530 POAG 1972

17531 AYALA-CASTANARES 1963

17532 PFLUM FRERICHS 1976

17533 PFLUM FRERICHS 1976

17534 LYNTS PFISTER 1967

17535 PFLUM FRERICHS 1976

17536 PFLUM FRERICHS 1976

17537 PFLUM FRERICHS 1976

17538 PFLUM FRERICHS 1976

17539 PFLUM FRERICHS 1976

17540 PFLUM FRERICHS 1976

17541 PFLUM FRERICHS 1976

17542 PFLUM FRERICHS 1976

17543 PFLUM FRERICHS 1976

17544 PFLUM FRERICHS 1976

17545 PFLUM FRERICHS 1976

17546 PFLUM FRERICHS 1976

17547 PFLUM FRERICHS 1976

17548 PFLUM FRERICHS 1976

17549 PFLUM FRERICHS 1976

17550 PFLUM FRERICHS 1976

17551 PFLUM FRERICHS 1976

17552 PFLUM FRERICHS 1976

17553 PFLUM FRERICHS 1976

17554 PFLUM FRERICHS 1976

17555 PFLUM FRERICHS 1976

17556 PFLUM FRERICHS 1976

17557 PFLUM FRERICHS 1976

17558 PFLUM FRERICHS 1976

17559 PFLUM FRERICHS 1976

17560 PFLUM FRERICHS 1976

17561 PFLUM FRERICHS 1976

17562 PFLUM FRERICHS 1976

17563 PFLUM FRERICHS 1976

17564 PFLUM FRERICHS 1976
17565 PFLUM FRERICHS 1976

17566 PFLUM FRERICHS 1976

17567 PFLUM FRERICHS 1976

17568 PFLUM FRERICHS 1976

17569 AYALA-CASTANARES 1963

17570 SEGURA 1963

17571 BOCK 1976

17572 BANDY 1956

17573 BANDY 1956

17574 BOCK 1976

17575 ANDERSEN 1961

17576 KELLOUGH 1956

17577 BANDY 1956

17578 BANDY 1956

17579 CREAGER 1958

17580 PHLEGER 1956

17581 PARKER 1954

17582 PARKER 1954

17583 PARKER 1954

17584 BANDY 1956

17585 BANDY 1956

17586 BANDY 1956

17587 BANDY 1956

17588 PHLEGER $1951 \mathrm{~A}$

17589 BANDY 1956

17590 BANDY 1956
Generic Name

FLORILUS

FRANCES ITA

FRANCESITA

FRANCES ITA

FRANCES ITA

FRANCESITA

FRANCESITA

FRANCESITA

FRANCESITA

FRANCES ITA

FRANCES I TA

FRANCESITA

FRANCESITA

FRANCESITA

FR ONDI CULAR I A

FR ONDICULAR IA

FRONDI CULARIA

FRONDICULAR IA

FR ONDICULARIA

FR ONDI CULARIA

FR OND I CULAR I A

FR OND I CULAR IA

FR ON DICULAR IA

FR ONDICULAR IA

FR ONDI CULAR IA

FURSENK OINA

F URSE NK OINA

FURSENKOINA

FURSENKOINA

FURSENKOINA

FURSENKOINA

FURSE NKOINA

FURSENKOINA

FURSENKOINA

FURSENKOINA

FURSENKOINA

FURSENKOINA

FURSENKOINA

FURSENKOINA

FURSENKOINA

FURSE NKOINA

FURSENK OINA

FURSENKOINA

FURSENKOINA

FURSENKOINA

FURSENKOINA

FURSENKOINA

FURSENKOINA

FURSENKOINA

FURSENKOINA

FURSENK OINA

FURSENK OINA

FURSENK OINA

FURSENKOINA

FURSENKO INA

FURSENKOINA

FURSENKOINA

FURSENKOINA

FURSENKOINA

FURSENKOINA

FURSENKO INA

FURSENK OINA

FURSENKOINA

FURSENKOINA

FURSENKOINA

FURSENKOINA

FURSENKOIN A

FURSENKOINA

FURSENKO INA

FURSENKOINA

FURSENKO INA

FURSENKO INA

FURSENKOINA

FURSENK OINA

FURSE NKOINA

GAUDRYINA

GAUDRYINA

GAUDRYINA

GAUDRYINA

GAUDRYINA

GAUDRYINA

GAUDRYINA

GAUDRY INA

GAUDRYINA

GAUDRYINA

GAUDRYINA

GAUDRYINA

GAUDRYINA

GAUDRYINA

GAUDRYINA

GAUDRYINA

GAUDRYINA

GAUDRYINA

GAUDRY I NA
Specific Name

Locality

SCAPHUS

ADVENA

ADVENA

ADVENA

AD VENA

ADVENA

AD VENA

ADVENA

A D VENA

AD VENA

AD VENA

ADVENA

AD VENA

COMPRESSA

SAGITTULA

SAGITTULA

SAGITTULA

SAGITTULA

SAGITTULA

SAGITTULA

SAGITTULA LANCEOLATA

SAGITTULA LANCEOLATA

SAGITTULA LANCEOLATA

COMPLANATA

COMPRESSA

ME XICANA

PONTONI

PONTONI

PONTONI

PONTONI

PONTONI

POATON

POATONI

PONTONI

PUNCTATA

SCHRE IBER SI ANA

SC HRE IBER S I ANA

SCHRE IBER SI ANA

SC HRE I BER SI ANA

SC HRE IBER SI ANA

SC HRE I BER SI ANA

SCHRE IBER SI ANA

SCHREIBER SI ANA

SCHRE IBER SI ANA

SCHREIBER SI AN A

SC HRE IBER SI ANA

SCHRE I BER SI ANA

SCHREIBER SI ANA

SCHRE IBER S I ANA

SEFINUDA

SEMINUDA

SE MINUDA

SEMINUDA

SENINUDA

SENINUDA

SENINUDA

SE I NUDA

SENINUDA

SENINUDA

SE IINUDA

SEMINUDA

SEMINUDA

SEMINUDA

SEMINUDA

SEMINUDA

SERINUDA

SEMINUDA

SEMINUDA

SP IN I COST ATA

SPINICOSTATA

SP INICOST AT A

AE QUA

AEQUA

AE OUA

AE QUA

AE GUA

$A E$ QUA

AEQUA

AE QUA

AE QUA

AE QUA

AE QUA

AE QUA

AE QUA

AE QUA

AE QUA

AEQUA

AE QUA

AE QUA

AE QUA

NW GULF OF MEXICO

NW GULF OF MEXICO

NW GULF OF MEXICO

NW GULF OF MEXICO

CENTRAL GULF OF MEXICO

CENTRAL GULF OF MEXICO

CENTRAL GULF OF MEXICO

CENTRAL GULF OF MEXICO

CENTRAL GULF OF MEXICO 


\section{Publication}

17591 BANDY 1956

17592 PHLEGER $1951 \mathrm{~A}$

17594 PHLEGER $1951 \mathrm{~A}$

17595 PHLEGER 1951A

17596 PHLEGER 1951A

17597 PHLEGER 1951A

17598 PARKER 1954

17599 PARKER 1954

17600 PARKER 1954

17601 PARKER 1954

17603 LUDWICK WALTON 1957

17604 CREAGER 1958

17605 CREAGER 1958

17606 CREAGER 1958

17607 CUSHMAN 1922

17608 CREAGER 1958

17609 CUSHMAN 19228
17610 CREAGER 1958

17611 CUSHMAN 19228

17612 CUSHMAN $1922 \mathrm{~B}$

17613 PFLUM FRERICHS 1976

17614 CREAGER 1958

17615 CUSHMAN $1922 \mathrm{~B}$
17616 PFLUM FRERICHS 1976

17616 PFLUM FRERICHS

17618 PFLUM FRERICHS 1976

17619 PFLUM FRERICHS 1976

17620 PFLUM FRERICHS 1976

17621 PARKER 1954

17622 PARKER 1954

17623 PARKER 1954

17624 PHLEGER 1951 A

17625 PHLEGER 1951A

17626 PHLEGER 1951A

17627 PHLEGER $1951 \mathrm{~A}$

17628 PHLEGER 1951A

17629 PHLEGER 1951A

17630 PARKER 1954

17631 PARKER 1954

17632 PARKER 1954

17633 LUDWICK WALTON 1957

17634 PFLUM FRERICHS 1976

17635 PFLUM FRERICHS 1976

17636 PFLUM FRERICHS 1976

17637 CUSHMAN $1922 \mathrm{~B}$

17638 CUSHMAN 19228

17639 CUSHMAN $1922 \mathrm{~B}$

17640 CUSHMAN 19228

17641 CUSHMAN $1922 \mathrm{~B}$

17642 CUSHMAN $1922 \mathrm{~B}$

17643 CUSHMAN 19228

17644 CUSHMAN 19228

17645 CUSHMAN 19228

17646 CUSHMAN 19228

17647 CREAGER 1958

17648 PARKER PHLEGER PEIRSON 1953

17649 PARKER PHLEGER PEIRSON 1953

17650 PARKER PHLEGER PEIRSON 1953

17651 PARKER PHLEGER PEIRSON 1953

17652 PHLEGER 1954

17653 PHLEGER $1955 \mathrm{~B}$

17654 PHLEGER 1954

17655 PHLEGER 1954

17656 PHLEGER 1954

17657 PHLEGER $1965 \mathrm{C}$

17658 PHLEGER 1965 A

17659 WALTON 1964

17660 KANE 1967

17661 LEHMANN 1957

17662 WALDRON 1963

17663 LANKFORD 1959

17664 WARREN 1957

17665 PHLEGER 1954

17666 BENDA PURI 1962

17667 WALTON 1960

17668 PHLEGER $1965 \mathrm{~B}$

17669 PHLEGER 19658

17670 WARREN 1956

17671 PARKER PHLEGER PEIRSON 1953

17672 PARKER PHLEGER PEIRSON 1953

17673 PHLEGER 1956

17674 PHLEGER 1956

17675 PARKER PHLEGER PEIRSON 1953

17676 PHLEGER 1956

17677 PHLEGER 1956

17678 PHLEGER 1956

17679 CREAGER 1958

17680 PARKER 1954

17681 PFLUM FRERICHS 1976

17682 PFLUM FRERICHS 1976

17683 PARKER 1954

17684 PARKER 1954

17685 PARKER 1954

\section{Generic Name}

GAUDRYINA

GA UDRYINA

GAUDRYINA

GAUDRYINA

GAUDRYINA

GAUDRYINA

GAUDRYINA

GAUDRYINA

GAUDRYINA

GAUDRYINA

GAUDRYINA

GAUDRYINA

GAUDRYINA

GAUDRYINA

GAUDRYINA

GAUDRYINA

GAUDRYINA

GAUDRYINA

GAUDRYINA

GAUDRYINA

GAUDRYINA

GAUDRYINA

GAUDRYINA

GAUDRYINA

GAUDRYINA

GAUDRYINA

GAUDRYINA

GAUDRYINA

GAUDRYINA

GAUDRYINA

GAUDRYINA

GA UDRYINA

GAUDRYINA

GAUDRYINA

GAUDRYINA

GAUDRYINA

GAUDRYINA

GAUDRYINA

GAUDRYINA

GAUDRYINA

GAUDRYINA

GAUDRYINA

GAUDRYINA

GAUDRYINA

GAUDRYINA

GAUDRYINA

GAUDRYINA

GAUDRYINA

GAUDRYINA

GAUDRYINA

GAUDRYINA

GAUDRYINA

GAUDRYINA

GAUDRYINA

GA UDRYINA

GAUDRYINA

GAUDRYINA

GAUDRYINA

GAUDRYINA

GAUDRYINA

GAUDRYINA

GAUDRYINA

GAUDRYINA

GAUDRYINA

GAUDRYINA

GAUDRYINA

GAUDRYINA

GAUDRYINA

GAUDRYINA

GAUDRYINA

GAUDRYINA

GAUDRYINA

GAUDRYINA

GAUDRYINA

GAUDRYINA

GAUDRYINA

GAUDRYINA

GAUDRYINA

GAUDRYINA

GAUDRYINA

GAUDRYINA

GAUDRYINA

GAUDRYINA

GAUDRYINA

GAUDRYINA

GAUDRYINA

GAUDRY INA

GAUDRYINA

GAUDRYINA

GAUDRY INA

GAUDRYINA

GAUDRYINA

GAUDRYINA
Specific Name

AE QU A

AEQUA

AE QUA

AE QUA

AE QUA

AE QUA

AE QUA

AE QUA

$A E Q U A$

AE QUA

AE QUA

AE QUA

AE QUA

AP I CULARIS

APICULARIS

AP I CULARIS

APICULARIS

APICULARIS

APICULARIS

APICULARIS

API CULARIS

APICULARIS

A T LANTI CA

A T LANTI CA

A TLANTI CA

A T LANTI CA

A TLANTICA

A TLANTICA

AT LANTI CA

ATLANTICA

ATLANTICA

AT LANTI CA

ATLANTI CA

ATLANTI CA

AT LANTICA

A T LANTICA

ATLANTICA

A T LANTI CA

AT LANTICA

A T LANTI CA

BA CCATA NOVANGLIAE

BRADYI

BRADYI

BRADYI

BRADYI

BRADY I

BRADYI

BRADYI

BRADY I

CHILOSTOMA

COMPRESSA

EXILIS

EXILIS

EXILIS

EXILIS

EXILIS

EXILIS

EXILIS

EXILIS

EXILIS

EXILIS

EXILIS

EXILIS

EXILIS

EXILIS

EXILIS

EXILIS

EXILIS

EXILIS

EXILIS

ExILIS

EXILIS

EXILIS

EXILIS

EXILIS

EXILIS

EXILIS

EXILIS

EXILIS

EXILIS

FLINTII

FLINTII

FL INTII

FL INT I I

FL INTI I

FLINTII

FLINTII

Locality

NE GULF OF MEXICO NW GULF OF MEXICO NH GULF OF MEXICO NW GULF OF MEXICO NH GULF OF MEXICO NH GULF OF MEXICO NW GULF OF MEXICO NE GULF OF MEXICO NE GULF OF MEXICO 


\section{Publication}

17686 PARKER 1954

17687 PFLUM FRERICHS 1976

17688 PFLUM FRERICHS 1976

17689 PFLUM FRERICHS 1976

17690 PARKER 1954

17691 PARKER 1954

17692 PARKER 1954

17693 PARKER 1954

17694 CREAGER 1958

17695 CUSHMAN 19228

17696 CUSHMAN 19228

17697 PARKER 1954

17698 PARKER 1954

17699 PARKER 1954

17701 PFLUM FRERICHS 1976

17701 PFLUM FRERICHS 1976
17702 PFLUM FRERICHS 1976

17702 PFLUM FRERICHS 1976
17703 PFLUM FRERICHS 1976

17704 PFLUM FRERICHS 1976

17705 PARKER 1954

17706 PARKER 1954

17707 PARKER 1954

17708 PARKER 1954

17709 PARKER 1954

17710 PARKER 1954

17711 PFLUM FRERICHS 1976

17712 PARKER 1954

17713 PARKER 1954

17715 PFLUM FRERICHS 1976

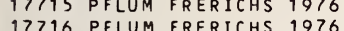

17717 PFLUM FRERICHS 1976

17718 PFLUM FRERICHS 1976

17719 PFLUM FRERICHS 1976

17720 PARKER 1954

17721 PARKER 1954

17722 PARKER 1954

17723 PARKER 1956

17724 BANDY 1956

17725 BANDY 1956

17726 BANDY 1956

17727 CUSHMAN 1918

17728 CUSHMAN 1918

17729 CUSHMAN 1918

17730 CUSHMAN 1918

17731 BANDY 1956

17732 BANDY 1956

17733 ANDERSEN 1961

17736 PFLUM FRERICHS 1976

17735 PFLUM FRERICHS 1976

17736 PFLUM FRERICHS 1976

17737 DFLUM FRERICHS 1976

17738 PFLUM FRERICHS 1976

17739 PFLUM FRERICHS 1976

17740 PFLUM FRERICHS 1976

17741 PFLUM FRERICHS 1976

17742 PFLUM FRERICHS 1976

17743 PFLUM FRERICHS 1976

17744 PFLUM FRERICHS 1976

17745 PFLUM FRERICHS 1976

17746 PFLUM FRERICHS 1976

17747 PFLUM FRERICHS 1976

17748 PFLUM FRERICHS 1976

17749 PFLUM FRERICHS 1976

17750 PFLUM FRERICHS 1976

17751 PFLUM FRERICHS 1976

17752 PARKER 1954

17753 PARKER 1954

17754 PHLEGER 1955A

17755 PHLEGER $1955 \mathrm{~A}$

17756 PFLUM FRERICHS 1976

17757 PFLUM FRERICHS 1976

17758 PFLUM FRERICHS 1976

17759 PFLUM FRERICHS 1976

17760 PFLUM FRERICHS 1976

17761 PFLUM FRERICHS 1976

17762 PFLUM FRERICHS 1976

17763 PFLUM FRERICHS 1976

17764 PFLUM FRERICHS 1976

17765 PFLUM FRERICHS 1976

17766 PFLUM FRERICHS 1976

17767 PFLUM FRERICHS 1976

17768 PARKER 1954

17769 PARKER 1954

17770 PARKER 1954

17771 PFLUM FRERICHS 1976

17772 PARKER 1954

17773 PARKER 1954

17774 PARKER 1954

17775 PARKER 1954

17776 PARKER 1954

17777 PARKER 1954

17778 LUDWICK WALTON 1957

17779 PHLEGER 1955A

17780 PHLEGER 1955A
Generic Name

Specific Name

Locality

FL IN TI I

GAUDRY INA

GAUDRYINA

GAUDRYINA

GAUDRYINA

GAUDRYINA

GAUDRYINA

GAUDRYINA

GAUDRYINA

GAUDRYINA

GAUDRYINA

GAUDRYINAA

GAUDRYINA

GAUDRYINA

GAUDRYINA

GAUDRYINA

GAUDRYINA

GAUDRYINA

GAUDRYINA

GAUDRYINA

GAUDRYINA

GAUDRYINA

GAUDRYINA

GAUDRYINA

GAUDRYINA

GAUDRYINA

GAUDRYINA

GAUDRYINA

GAUDRYINA

GAUDRYINA

GAUDRYINA

GAUDRYINA

GAUDRYINA

GAUDRYINA

GAUDRYINA

GAUDRYINA

GAUDRYINA

GAUDRYINA

GAUDRYINA

GAUDRYINA

GAUDRYINA

GI RVANELLA

GI RVANE LLA

GI RVANELLA

GI RVANELLA

GLANDULINA

GLANDUL INA

GL ANDULINA

GL ANDUL INA

GLANDUL INA

GLANDUL INA

GLANDULINA

GL ANDULINA

GL ANDUL INA

GLOBOBUL IMINA

GLOBOBUL IMINA

GL OBOBULIMINA

GL OBOBU LIMINA

GLOBOBULIMINA

GL OBOBUL IM INA

GL OBOBUL IM INA

GL OBOBUL IM INA

GL OBOBULIMINA

GLOBOBULIMINA

GL OBOBUL IMINA

GL OBOBULIMINA

GL OBOBUL IM INA

GLOBOBUL IMINA

GL OBOBULIMINA

GL OBOBUL IMINA

GLOBOBULIMINA

GLOBOBULIMINA

GL OBOBUL IM INA

GL OBOBUL IMINA

GLOBOBUL IMINA

GL OBOBUL IM I NA

GLOBOBULIMINA

GLOBOBULIMINA

GLOBOBUL IMINA

GLOBOBULIMINA

GLOBOBULIMINA

GLOBOBULIMINA

GLOBOBULIMINA

GL OBOBUL IM I NA

GLOBOBULIMINA

GLOBOBULIMINA

GLOBOBUL IMINA

GLOBOBULIMINA

GLOBOBUL IMINA

GL OBOBULIMINA

GLOBOBULIMINA

GLOBOBULIMINA

GLOBOBUL IMINA

GLOBOBULIMINA

GLOBOBULIMINA
FL INTII

FL INTII

FL INTII

FLINTII

FLINTI

FLINTII

FL INT I I

FLINTII

FLINTII

MINUTA

MINUTA

MINUTA

MINUTA

MINUTA

MI NUTA

MINUTA

MI NUTA

MINUTA

MINUTA

MINUTA

MINUTA

MI NUTA

MINUTA

MINUTA

MI NUTA

MINUTA

MINUTA

MINUTA

MI NUTA

MINUTA

MINUTA

MINUTA

MINUTA

ST AVENS IS

ST AVENS IS

ST AVENS IS

VAGANS

VAGANS

VAGANS

VAGANS

CONATULA

CONATULA

LAEVIGATA

LAEVIGATA

LAEVIGATA

LAEVIGATA

LAEVIGATA

LAEVIGATA

AFFINIS

AFFINIS

AF FINIS

AFFINIS

AFFINIS

AFFINIS

AF FINIS

AFFIN IS

AFFINIS

AFFINIS

AF FINIS

AFFINIS

AFFINIS

AF FINIS

AFFINIS

AFFINIS

AFFINIS

AF FINIS

AFFINIS

AFFINIS

AFFINIS

AFFINIS

AFFINIS

AFFINIS

AFFINIS

AF INIS

AFFINIS

AF FINIS

AF FIN IS

AF INIS

AF FINIS

AF FINIS

AF IINIS

AF FINIS

AFFINIS

AFFINIS

AFFINIS

AFFINIS

AF FIN IS

AFFINIS

NE GULF OF MEXICO

CENTRAL GULF OF MEXICO

CENTRAL GULF OF MEXICO

NW GULF OF MEXICO

NE GULF OF MEXICO

NE GULF OF MEXICO

NE GULF OF MEXICO

NE GULF OF MEXICO

BAY OF CAMPECHE 


\section{Publication}

17781 PHLEGER $1955 \mathrm{~A}$

17782 PHLEGER $1955 \mathrm{~A}$

17784 PHLEGER 19.55 A

17784 PHLEGER 19.55

17786 PARKER 1954

17787 PARKER 1954

17788 PFLUM FRERICHS 1976

17789 PFLUM FRERICHS 1976

17790 PFLUM FRERICHS 1976

17791 PFLUM FRERICHS 1976

17792 PFLUM FRERICHS 1976

17793 PFLUM FRERICHS 1976

17794 PFLUM FRERICHS 1976

17795 PFLUM FRERICHS 1976

17796 PFLUM FRERICHS 1976

17797 PFLUM FRERICHS 1976

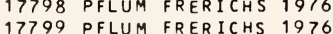

17799
17800 PFLUM FRERICHS
1976

17801 PFLUM FRERICHS 1976

17802 PFLUM FRERICHS 1976

17803 PFLUM FRERICHS 1976

17804 PFLUM FRERICHS 1976

17805 PFLUM FRERICHS 1976

17806 PFLUM FRERICHS 1976

17807 PFLUM FRERICHS 1976

17808 CREAGER 1958

17809 PFLUM FRERICHS 1976

17810 PFLUM FRERICHS 1976

17811 PFLUM FRERICHS 1976

17812 PFLUM FRERICHS 1976

17813 PARKER 1954

17814 PARKER 1954

17815 PARKER 1054

17816 PARKER 1954

17817 PARKER 1954

17818 PFLUM FRERICHS 1976

17819 PFLUM FRERICHS 1976

17820 PFLUM FRERICHS 1976

17821 PFLUM FRERICHS 1976

17822 PFLUM FRERICHS 1976

17823 PFLUM FRERICHS 1976

17824 PFLUM FRERICHS 1976

17825 PFLUM FQERICHS 1976

17826 PFLUM FRERICHS 1976

17827 PFLUM FRERICHS 1976

17828 PFLUM FRERICHS 1976

17829 LANKFORD 1959

17830 PARKER 1954

17831 PARKER 1954

17832 PARKER 1954

17833 PARKER 1954

17834 PFLUM FRERICHS 1976

17835 PFLUM FRERICHS 1976

17836 PFLUM FRERICHS 1976

17837 PFLUM FRERICHS 1976

17838 PFLUM FRERICHS 1976

17839 PFLUM FRERICHS 1976

17840 PFLUM FRERICHS 1976

17841 PFLUM FRERICHS 1976

17842 PFLUM FRERICHS 1976

17843 PFLUM FRERICHS 1976

17844 PFLUM FRERICHS 1976

17845 PFLUM FRERICHS 1976

17846 PFLUM FRERICHS 1976

17847 PFLUM FRERICHS 1976

17848 PFLUM FRERICHS 1976

17849 PFLUM FRERICHS 1976

17850 PFLUM FRERICHS 1976

17851 PFLUM FRERICHS 1976

17852 PFLUM FRERICHS 1976

17853 PFLUM FRERICHS 1976

17854 PFLUM FRERICHS 1976

17855 PFLUM FRERICHS 1976

17856 PFLUM FRERICHS 1976

17857 PFLUM FRERICHS 1976

17858 PFLUM FRERICHS 1976

17860 PFLUM FRERICHS 1976

17861 PFLUM FRERICHS 1976

17862 PFLUM FRERICHS 1976

17863 PFLUM FRERICHS 1976

17864 PFLUM FRERICHS 1976

17865 PFLUM FRERICHS 1976

17866 PFLUM FRERICHS 1976

17867 PFLUM FRERICHS 1976

17868 PFLUM FRERICHS 1976

17869 PFLUM FRERICHS 1976

17870 PFLUM FRERICHS 1976

17871 PFLUM FRERICHS 1976

17873 PFLUM FRERICHS 1976

17874 PFLUM FRERICHS 1976

17875 PFLUM FRERICHS 1976
Generic Name

Specific Name

GLOBOBULIMINA

GLOBOBULIMINA

GLOBOBULIMINA

GLOBOBUL IM INA

GLOBOBULIMINA

GLOBOBUL IMINA

GLOBOBULIMINA

GLOBOBUL IMINA

GLOBOBUL IMINA

GLOBOBUL IMINA

GLOBOBUL IMINA

GL OBOBULIMIVA

GLOBOBUL IM INA

GLOBOBULIMINA

GLOB OBUL IM I NA

GLOBOBUL IM INA

GL OBOBULIMINA

GL OBOBUL IMINA

GL OBOBUL IMINA

GL OBOBULIM INA

GL OBOBUL IMINA

GL OBOBUL IM I NA

GLOBOBUL IMINA

GLOBOBUL IMINA

GL OBOBUL IM INA

GLOBOBUL IM INA

GLOBOBUL IMI VA

GL OBOBUL IM INA

GL OBOBUL IMI VA

GL OBOBUL IM INA

GL OB OBUL IM INA

GLOBOBUL IMINA

GL OBOBUL IMINA

GLOBOBUL IMINA

GL OBOBUL I M I NA

GL OBOBUL IM INA

GL OBOBUL IMI INA

GLOBOBUL IMINA

GL OBOBUL IMINA

GLOBOBULIMINA

GL OBOBUL IM IN N

GL OBOBUL IM IN A

GL OBOBULIMINA

GL OBOBUL IM I N

GL OBOBUL IM IN A

GL OBOBUL IMINA

GLOBOBULIMINA

GLOBOBUL IM INA

GL OBOBUL IM INA

GLOBOBUL IMINA

GLOBOBULIMINA

GLOBOBUL IMINA

GLOBOBUL IM INA

GL OBOBULIMINA

GL OBOBUL IMINA

GLOBOBULIMINA

GL OBOBUL IM I NA

GLOBOBUL IMINA

GLOBOB

GL OBOBULIMI NA

GLOBOBULIMINA

GLOBOBUL IMINA

GL 0BOBUL IM INA

GLOBOBULIMINA

GLOBOBULIMINA

GLOBOBUL IM I NA

GLOBOBUL IMINA

GL OBOBULIMINA

GL OBOBUL IMINA

GLOBOBULIMINA

GL OSOBUL IM INA

GLOBOBUL

GL OBOBUL IMINA

GL OBOBUL IMINA

GLOBOBULIMINA

GLOBOBUL IM INA

GL OBOBUL IM I NA

GLOBOCASSIDULINA

GL OBOCASSIDULINA

GLOBOCASSIDULINA

GLOBOCAS SI DULINA

GLOBOCASSIDULINA

GL OBOCASSIDULINA

GL OBOCASSIDULINA

GLOBOCASSIDULINA

GL OBOCASSIDULINA

GLOBOCASSIDUL INA

GLOBO CASSI DUL INA

GL OBOCASSIDUL INA

GL OBOCASSIDULINA

GL OBOCAS SIDULINA

GLOBOCAS SIDULINA

GL OBOCAS SI DUL INA

GL OBOCAS SIDULINA

AF FINIS

AFFINIS

AFFINIS

AFFINIS

AFFINIS

AFFINIS

AFFINIS

AFFINIS

AFFINIS

AFFINIS

AFFINIS

AFFINIS

AFFINIS

AF FINIS

AFFINIS

AFFINIS

AF FINIS

AFFINIS

AFFINIS

AFFINIS

AF FINIS

AFFINIS

AFFIVIS

AF FINIS

AF FINIS

AFFINIS

AF FINIS

AFFINIS

AFFINIS

AFFINIS

AF FINIS

AFFINIS

AF FINIS

AFFINIS

AFFIN IS

AF F INIS

AFFINIS

AFFINIS

AFFINIS

AFFINIS

MI SSISSIPPIENSIS

MISSISSIPPIENSIS

MISSISSIPPIENSIS

$M I S S I S S I P P I E N S I S$

MISSISSIPPIENSIS

OVULA

OVLLA

OVLLLA

OVULA

OVULA

OVULA

OVLLA

OVULA

OVULA

OVULA

OVULA

OVLLA

OVULA

OVULA

OVULA

PYRULA SPINESCENS

PYRULA SP INESCENS

PYRULA SPINESCENS

PYRULA SOINESCENS

PYRULA SPINESCENS

PYRULA SPINESCENS

PYRULA SPINESCENS

PYRULA SPINESCENS

PYRULA S' INESCENS

CRASSA

CRASSA

CRASSA

CRASSA

CR ASSA

CR ASSA

CRASSA

RASSA

CRASSA

CRASSA

CR ASSA

CRASSA

CR ASSA

CRASSA

CRASSA

CR ASSA
Locality

Lat. Long.

$N$ GULF OF MEXICO

$N$ GULF OF MEXICO

$N$ GULF OF MEXICO

$N$ GULF OF MEXICO

NE GULF OF MEXICO

NE GULF OF MEXICO

NE GULF OF MEXICO

CENTRAL GULF OF MEXICO

CENTRAL GULF OF MEXICO

CENTRAL GULF OF MEXICO

NW GULF OF MEXICO 
Publication

17876 PFLUM FRERICHS 1976 17877 PFLUM FRERICHS 1976 17878 PFLUM FRERICHS 1976 17879 PFLUM FRERICHS 1976 17880 PFLUM FRERICHS 1976 17881 PFLUM FRERICHS 1976 17882 PFLUM FRERICHS 1976 17883 PFLUM FRERICHS 1976 17884 PFLUM FRERICHS 1976 17885 PFLUM FRERICHS 1976 17886 PFLUM FRERICHS 1976 17887 PFLUM FRERICHS 1976 17888 PFLUM FRERICHS 1976 17889 PFLUM FRERICHS 1976 17890 PFLUM FRERICHS 1976 17891 PFLUM FRERICHS 1976 17891 PFLUM FRERICHS
17892 PFLUM FRERICHS 1976 17892 PFLUM FRERICHS 1976

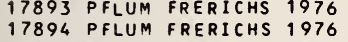
17895 PFLUM FRERICHS 1976 17896 PFLUM FRERICHS 1976 17897 PFLUM FRERICHS 1976 17898 PFLUM FRERICHS 1976 17899 PFLUM FRERICHS 1976 17899
17900 PFLUM FRERICHS
179076 17900 PFLUM FRERICHS 1976 17902 PFLUM FRERICHS 1976 17903 PFLUM FRERICHS 1976 17904 PFLUM FRERICHS 1976 17905 PFLUM FRERICHS 1976 17906 PFLUM FRERICHS 1976 17907 PFLUM FRERICHS 1976 17908 PFLUM FRERICHS 1976 17909 PFLUM FRERICHS 1976 17910 PFLUM FRERICHS 1976 17911 PFLUM FRERICHS 1976 17912 PFLUM FRERICHS 1976 17913 PFLUM FRERICHS 1976 17914 PFLUM FRERICHS 1976 17915 PFLUM FRERICHS 1976 17916 PFLUM FRERICHS 1976 17917 PFLUM FRERICHS 1976 17918 PFLUM FRERICHS 1976 17919 PFLUM FRERICHS 1976 17920 PFLUM FRERICHS 1976 17921 PFLUM FRERICHS 1976 17922 PFLUM FRERICHS 1976 17923 PFLUM FRERICHS 1976 17924 PFLUM FRERICHS 1976 17925 PFLUM FRERICHS 1976 17926 PFLUM FRERICHS 1976 17927 PFLUM FRERICHS 1976 17928 PFLUM FRERICHS 1976 17929 PFLUM FRERICHS 1976 17930 PFLUM FRERICHS 1976 17931 PFLUM FRERICHS 1976 17932 PFLUM FRERICHS 1976 17933 PFLUM FRERICHS 1976 17934 PFLUM FRERICHS 1976 17935 PFLUM FRERICHS 1976 17936 PFLUM FRERICHS 1976 17937 PFLUM FRERICHS 1976 17938 PFLUM FRERICHS 1976 17939 PFLUM FRERICHS 1976 17940 PFLUM FRERICHS 1976 17941 PFLUM FRERICHS 1976 17942 PFLUM FRERICHS 1976 17943 PFLUM FRERICHS 1976 17944 PFLUM FRERICHS 1976 17945 PFLUM FRERICHS 1976 17946 PFLUM FRERICHS 1976 17947 PFLUM FRERICHS 1976 17948 PFLUM FRERICHS 1976 17949 PFLUM FRERICHS 1976 17950 PFLUM FRERICHS 1976 17951 PFLUM FRERICHS 1976 17952 PFLUM FRERICHS 1976 17953 PFLUM FRERICHS 1976 17954 PFLUM FRERICHS 1976 17955 PFLUM FRERICHS 1976 17956 PFLUM FRERICHS 1976 17957 PFLUM FRERICHS 1976 17958 PFLUM FRERICHS 1976 17959 PFLUM FRERICHS 1976 17960 PFLUM FRERICHS 1976 17961 PFLUM FRERICHS 1976 17962 PFLUM FRERICHS 1976 17963 PFLUM FRERICHS 1976 17964 PFLUM FRERICHS 1976 17965 PFLUM FRERICHS 1976 17966 PFLUM FRERICHS 1976 17967 PFLUM FRERICHS 1976 17968 PFLUM FRERICHS 1976 17969 PFLUM FRERICHS 1976 17970 PFLUM FRERICHS 1976

Generic Name

Specific Name

Locality

Lat.

Long.

GLOBOCASSI DULINA GL OBOCAS SI DUL INA GLOBOCAS SIDULINA GLOBOCAS SI DULINA GLOBOCAS SIDULINA GLOBOCASSI DULINA GLOBOCASSIDULINA GLOBO CASSI DULINA GLOBOCAS SI DULINA GLOBOCASSIDULINA GLOBOCASSI DULINA GL OBOC AS SI DULINA GL OBOCASSI DUL INA GLOBOCASSIDULINA GL OBOCASSIDULINA GL OBOCASSIDULINA GL OBOCASSIDULINA GL OBOCAS SI DUL INA GLOBOCASSI DUL INA GL OBOCAS SIDULINA GL OBOCASSIDULINA GLOBOCAS SI DULINA GL OBO CAS SI DUL INA GL OBOCAS SI DULINA GLOBOCAS SIDULINA GL OBOCAS SIDULINA GL OBOCAS SI DULINA GL OBOCAS SI DUL INA GLOBOCASSIDULINA GLOBOCASSIDULINA GLOBOCASSIDULINA GLOBOCAS SI DULINA GLOBOCAS SI DULINA GLOBOCAS SIDULINA GLOBOCASSI DULINA GLOBOCAS SIDUL INA GL OBOCAS SIDULINA GL OBOCASSIDULINA GLOBOCASSIDULINA GLOBOCASSI DULINA GLOBOCAS SI DULINA GL OBOCASSI DULINA GLOBOCAS SIDULINA GLOBOCASSI DULINA GLOBOCASSIDULINA GLOBOCAS SI DULINA GL OBOCAS SI DUL INA GL OBOCASSIDULINA GLOBOCASSIDULINA GLOBOCAS SI DUL INA GLOBOCASSIDULINA GL OBOCASSIDULINA GL OBOCAS SI DULINA GL OBOCAS SIDULINA GL OBOCASSIDUL INA GL OBOCASSIDULINA GL OBOCASSI DULLINA GLOBOCAS SI DUL INA GL OBOCASSIDULINA GLOBOCASSIDULINA GLOBOCAS SIDULINA GL OBOCASSI DULINA GL OBOCAS SIDULINA GL OBOCASSI DULINA GLOBOCASSI DULINA GL OBOCASSI DUL INA GLOBOCAS SIDULINA GLOBOCAS SI DULINA GLOBOCAS SIDULINA GL OBOCASSIDULINA GLOBOCASSIDULINA GLOBOCAS SIDULINA GLOBOCAS SIDULINA GLOBOCA S SI DULINA GLOBOCAS SIDULINA GL OBOCASSI DULINA GLOBOCAS SIDUL INA GLOBOCASSI DULINA GLOBOCASSIDULINA GLOBOCASSI DULINA GLOBOCASSI DUL INA GLOBOCAS SI DULINA GLOBOCASSI DULINA GL OBOCAS SI DULINA GLOBOCASSIDULINA GLOBOCASSI DULINA GL OBOCASSI DULINA GL OBOCASSIDULINA GLOBOCASSIDULINA GL OBOCAS SIDULINA GL OBOCAS SIDULINA GLOBOCAS SI DULINA GLOBOCASSI DULINA GLOBOCASSIDULINA GLOBOCAS SI DULINA GLOBOCAS SI DULINA GLOBOCASSI DULINA
CRASSA

CRASSA

CRASSA

CRASSA

CRASSA

CR ASSA

CR ASSA

CRASSA

CRASSA

CRASSA

CRASSA

CR AS SA

CRASSA

CRASSA

CRASSA

CRASSA

CRASSA

CRASSA

CRASSA

CRASSA

CRASSA

CRASSA

CRASSA

CRASSA

CR ASSA

CRASSA

CRASSA

CRASSA

CRASSA

CRASSA

CRASSA

CR ASSA

GLOBULOSA

MOLUCCENS IS

MOLUCCENS IS

MOLUCCENS IS

MOLUCCENS IS

MOLUCCENS IS

MOLUCCENS IS

MOLUCCENS IS

MOLUCCENS IS

MO LUCCENS IS

MOLUCCENS IS

MOLUC CENS IS

MURRHYNA

MURRHYNA

MURRHYNA

MURRH YNA

MURRHYNA

MURRHYNA

MURRHYNA

MURRHYNA

MURRHYNA

MURRHYNA

MURRHYNA

MURRHYNA

MURRHYNA

MURRHYNA

MURRHYNA

MURRHYNA

MU RRHYNA

MURRHYNA

MURRHYNA

PACIFICA

PACIFICA

PACIFICA

PACIFICA

PACIFICA

PACIFICA

PACIFICA

PACIFICA

PACIFICA

PACIFICA

PACIFICA

PACIFICA

PACIFICA

PACIFICA

PACIFIC

PACIFICA

PACIFICA

PACIFICA

PACIFICA

PACIFICA

PACIFICA

PACIFIC

PACIFICA

NW GULF OF MEXICO

NW GULF OF MEXICO

CENTRAL GULF OF MEXICO 


\section{Publication}

17971 PFLUM FRERICHS 1976 17972 PFLUM FRERICHS 1976 17973 PFLUM FRERICHS 1976 17074 PFLUM FRERICHS 1976 17975 PFLUM FRERICHS 1976 17976 PFLUM FRERICHS 1976 17977 PFLUM FRERICHS 1976 17978 PFLUM FRERICHS 1976 17979 DFLUM FRERICHS 1976 17980 PFLUM FRERICHS 1976 17981 PFLUM FRERICHS 1976 17982 PFLUM FRERICHS 1976 17983 PFLUM FRERICHS 1976 17984 PFLUM FRERICHS 1976 17985 PFLUM FRERICHS 1976 17986 PFLUM FRERICHS 1976 17087 PFLUM FRERICHS 1976 17988 PFLUM FRERICHS 1976 17989 PFLUM FRERICHS 1976 17990 PFLUM FRERICHS 1976 17991 PFLUM FRERICHS 1976 17992 PFLUM FRERICHS 1976 17993 PFLUM FRERICHS 1976 17994 PFLUM FRERICHS 1976 17995 PFLUM FRERICHS 1976 17996 PFLUM FRERICHS 1976 17997 PFLUM FRERICHS 1976 17998 PFLUM FRERICHS 1976 17999 PFLUM FRERICHS 1976 18000 PFLUM FRERICHS 1976 18001 PFLUM FRERICHS 1976 18002 PFLUM FRERICHS 1976 18003 DFLUM FRERICHS 1976 18004 PFLUM FRERICHS 1976 18005 PFLUM FRERICHS 1976 18006 PFLUM FRERICHS 1976 18007 PFLUM FRERICHS 1976 18008 PFLUM FRERICHS 1976 18009 PFLUM FRERICHS 1976 18010 PFLUM FRERICHS 1976 18011 PFLUM FRERICHS 1976 18012 PFLUM FRERICHS 1976 18013 PFLUM FRERICHS 1976 18014 PFLUM FRERICHS 1976 18015 PFLUM FRERICHS 1976 18016 PFLUM FRERICHS 1976 18017 PFLUM FRERICHS 1976 18018 PFLUM FRERICHS 1976 18019 PFLUM FRERICHS 1976 18020 PFLUM FRERICHS 1976 18021 PFLUM FRERICHS 1976 18022 PFLUM FRERICHS 1976 18023 PFLUM FRERICHS 1976 18024 PFLUM FRERICHS 1976 18025 PFLUM FRERICHS 1976 18026 PFLUM FRERICHS 1976 18027 PFLUM FRERICHS 1976 18028 PFLUM FRERICHS 1976 18029 PFLUM FRERICHS 1976 18030 PFLUM FRERICHS 1976 18031 PFLUM FRERICHS 1976 18032 LEROY HODGKINSON 1975 18033 PFLUM FRERICHS 1976 FLUM FRERICHS 1976 18035 PFLUM FRERICHS 1976 18036 PFLUM FRERICHS 1976 18037 PFLUM FRERICHS 1976 18038 PFLUM FRERICHS 1976 18039 PFLUM FRERICHS 1976 18040 PFLUM FRERICHS 1976 18041 PFLUM FRERICHS 1976 18042 PFLUM FRERICHS 1976 18043 PFLUM FRERICHS 1976 18045 LEROY HODGKINSON 1975 18046 PARKER 1954

18047 PARKER 1954

18048 PARKER 1954

18049 PARKER 1954

18050 PARKER 1954

18051 PARKER 1954

8052 SEGURA 1963

8053 PHLEGER 1951A

18054 PHLEGER 1951A

18055 PHLEGER 1951A

18056 PHLEGER 1951 A

18057 PFLUM FRERICHS 1976 18058 PFLUM FRERICHS 1976 18059 PFLUM FRERICHS 1976 18060 DFLUM FRERICHS 1976 18061 PFLUM FRERICHS 1976 18062 PFLUM FRERICHS 1976 1951A 18064 LEROY HODGKINSON 1975 18065 PFLUM FRERICHS 1976
Generic Name

GLOBOCASSI DULINA GLOBOCASSIDULINA GL OBOCASSIDULINA GLOBOCAS SIDULINA GLOBOCASSIDULINA GL OBOCAS SIDUL INA GL OBOCASSI DULINA GLOBOCAS SIDULINA GLOBOCAS SIDULINA GLOBOCASSIDULINA GL OBOCASSI DULINA GL OBOCASSI DUL INA GL OBOCASSIDULINA GLOBOCASSIDULINA GLOBOCASSIDULINA GLOBOCASSIDULINA GLOBOCASSIDULINA GL OBOCASSIDUL INA GL OBOCAS SIDULINA GL OBOCASSI DULINA GLOBOCASSIDULINA GL OBOCASSIDULINA GLOBOCASSIDULINA GL OBOCASSI DULINA GL OBOCASSIDULINA GL OBOCASSI DUL INA GLOBOCASSIDULINA GLOBOCASSIDULINA GL OBOCASSIDULINA GL OBOCASSIDULINA GLOBOCASSIDULINA GL OBOCASSI DULINA GLOBOCASSIDULINA GLOBOCAS SIDULINA GLOBOCASSI DULINA GLOBOCASSI DULINA GLOBOCASSIDULINA GLOBOCASSI DULINA GL OBOCASSIDULINA GLOBOCASSIDULINA GL OBOCASSIDULINA GL OBOCASSI DULINA GLOBOCASSIDULINA GLOBOCASSIDULINA GL OBOCAS SIDULINA GL OBOCAS SIDULINA GLOBOCASSI DULINA GLOBOCAS SIDULINA GL OBOCASSI DULINA GLOBOCAS SIDULINA GL OBOCASSIDULINA GL OBOCASSI DUL INA GLOBOCASSIDULINA GL OBOCASSIDULINA GLOBOCAS SIDULINA GLOBOCASSIDULINA GLOBOCAS SIDULINA GLOBOCAS SIDULINA GL OBOCASSIDULINA GLOBOCAS SIDULINA GL OBOCASSI DULINA GL OBOCASSIDULINA GLOBOCASSIDULINA GL OBOCASSIDULINA GLOBOCASSIDULINA GLOBOCASSIDULINA GL OBOCASSIDULINA GL OBOCASSIDULINA GLOBOCAS SIDULINA GL OBOCAS SI DULINA GLOBOCASSIDULINA GL OBOCASSIDULINA GLOBOCASSIDULINA GLOBOTEXTULARIA GLOBOTEXTULARIA

GLOBULINA

GL OBULINA

GL OBUL INA

GLOBULINA

GL OBULINA

GLOBULINA

GL OBUL INA

GL OMOSPIRA

GLOMOSPIRA

GLOMOSPIRA

GL OMOSPIRA

GLOMOSPIRA

GL OMOSPIRA

GLOMOSPIRA

GLOMOSPIRA

GL OMOSPIRA

GL OMOSPIRA

GL OMOSPI RA

GL OMO SPIRA
Specific Name

PACIFICA

PACIFICA

PACIFICA

PACIFICA

PACIFICA

PACIFICA

SUEGL OBOSA

SUBGL OB OSA

SUBGL OBOS A

SU BGL OB OS A

SUBGL OBOSA

SUEGL OBOSA

SUBGLOBOSA

SU BGL OB OS A

SU BGL OB OSA

SU EGL OBOSA

SU EGL OBOS A

SU BGL OBOSA

SU EGL OB OSA

SU BGL OBOSA

SUEGL OB OSA

SU BGL OBOSA

SUGLOB OSA

SUBGL OBOS

SU BGL OB OSA

SUEGLOBOSA

SUEGL OBOS A

SUBGLOBOSA

SUEGL OBOS A

SUEGLOBOSA

SUEGLOBOSA

SU EGLOBOSA

SU BGL OB OSA

SU BGL OBOSA

SU EGL OBOS A

SUEGLOBOSA

SUEGLOBOSA

SUBGLOBOSA

SUEGLOBOSA

SUBGL OBOSA

SUEGL OB OSA

SUEGLOBOSA

SUBGL OB OSA

SUEGL OBOS A

SUEGLOBOSA

SUEGLOB OSA

SU EGL OBOS A

SU BGL OBOSA

SUEGLOB OSA

SUBGL OB OS A

SUEGL OBOS

SU EGLOBOS A

SUEGLOBOSA

SUEGLOBOSA

SUEGL OBOS A

SUEGLOBOSA

SUEGL OBOSA

SUEGLOBOSA

SUEGLOBOSA

SU BGL OBOSA

SU BGL OBOSA

AN CEPS

CARIBAE

CARIBAEA

CARIBAEA

CARIBAEA

$G I E B A$

CHAROIDES

CHAROIDES

CHAROIDES

CHAROIDES

CHAROIDES

CHAROIDES

CHAROIDES

CHAROIDES

CHAROIDES

CHAROIDES

CHAROIDES

CHAROIDES

Locality

NW GULF OF MEXICO

NW GULF OF MEXICO

NW GULF OF MEXICO

NW GULF OF MEXICO

NW GULF OF MEXICO

NW GULF OF MEXICO

NW GULF OF MEXICO

$N W$ GULF OF MEXICO

$N W$ GULF OF MEXICO

NW GULF OF MEXICO

NW GULF OF MEXICO

$N W$ GULF OF MEXICO

NW GULF OF MEXICO 


\section{Publication}

18066 PFLUM FRERICHS 1976 18067 PFLUM FRERICHS 1976 18068 PFLUM FRERICHS 1976 18069 PFLUM FRERICHS 1976 18070 PFLUM FRERICHS 1976 18071 PFLUM FRERICHS 1976 18072 PFLUM FRERICHS 1976 18073. PFLUM FRERICHS 1976 18074 PFLUM FRERICHS 1976 \begin{tabular}{l}
18074 \\
18075 \\
\hline
\end{tabular} \begin{tabular}{l}
18075 \\
18076 \\
\hline
\end{tabular} 18076
18077 PFLUMM FRERICHS 1976 18077 PFLUM FRERICHS 1976
18078 PFLUM FRERICHS 1976 18079 PFLUM FRERICHS 1976 18080 PFLUM FRERICHS 1976 18081 PFLUM FRERICHS 1976 18082 PFLUM FRERICHS 1976 18083 PFLUM FRERICHS 1976 18084 PFLUM FRERICHS 1976 18085 PFLUM FRERICHS 1976 18086 PFLUM FRERICHS 1976 18087 PFLUM FRERICHS 1976 18088 PFLUM FRERICHS 1976 18089 PFLUM FRERICHS 1976 18090 PFLUM FRERICHS 1976 18091 PARKER 1954

18092 PFLUM FRERICHS 1976 18093 PHLEGER 1951A

18094 PHLEGER 1951A

18095 PHLEGER 1951A

18096 PHLEGER $1951 \mathrm{~A}$

18097 PHLEGER 1951A

18098 PHLEGER 1951A

18099 PHLEGER 1951A

18100 PHLEGER 1951A

18101 PHLEGER 1951A

18102 PHLEGER 1951 A

18103 PHLEGER 1951A

18104 PHLEGER 1951A

18105 PHLEGER 1951A

18106 PHLEGER 1951A

18107 PHLEGER 1951 A

18108 PHLEGER 1951A

18109 PHLEGER $1951 \mathrm{~A}$

18110 PARKER 1954

18111 PARKER 1954

18112 PARKER 1954

18113 PARKER 1954

18114 PARKER 1954

18115 PFLUM FRERICHS 1976

18116 PARKER 1954

18117 PARKER 1954

18118 PARKER 1954

18119 PFLUM FRERICHS 1976

18120 PFLUM FRERICHS 1976

18121 PFLUM FRERICHS 1976

18122 PFLUM FRERICHS 1976

18123 PFLUM FRERICHS 1976

18124 PFLUM FRERICHS 1976

18125 LUDWICK WALTON 1957

18126 PHLEGER $1951 \mathrm{~B}$

18127 PHLEGER 1951B

18128 PHLEGER 1951A

18129 PHLEGER 1951A

18130 PHLEGER 1951A

18131 PHLEGER 1951A

18132 PHLEGER $1951 \mathrm{~A}$

18133 PARKER 1954

18135 PHLEGER 1951 A

18136 PARKER 1954

18137 PHLEGER 1951A

18138 PHLEGER 1951A

18139 PHLEGER 1951A

18140 PHLEGER 1951A

18141 PFLUM FRERICHS 1976

18142 PFLUM FRERICHS 1976

18143 PFLUM FRERICHS 1976

18144 PFLUM FRERICHS 1976

18145 PFLUM FRERICHS 1976

18146 PFLUM FRERICHS 1976

18147 PFLUM FRERICHS 1976

18148 PARKER 1954

18149 PFLUM FRERICHS 1976

18150 PFLUM FRERICHS 1976

18151 PFLUM FRERICHS 1976

18152 PFLUM FRERICHS 1976

18153 PFLUM FRERICHS 1976

18154 PFLUM FRERICHS 1976

18155 PFLUM FRERICHS 1976

18156 PARKER 1954

18157 PARKER 1954

18158 PARKER 1954

18159 PARKER 1954

18160 PARKER 1954
Generic Name

Specific Name

Locality

GL OMOSP IRA

GL OMOSPIRA

GL OMOSPIRA

GL OMOSPIRA

GL OMOSPIRA

GL OMOSP IRA

GL OMOSP I RA

GLOMOSPIRA

GLOMOSPIRA

GL OMOSPIRA

GLOMOSPIRA

GL OMOSP I RA

GL OMOSPIRA

GL OMO SPIRA

GL OMOSPIRA

GL OMOSP I RA

GLOMOSP I RA

GL OMOSPIRA

GL OMOSPIRA

GL OMOSPIRA

GL OMOSP IRA

GL OMOSPIRA

GL OMOSPIRA

GLOMOSPI RA

GL OMOSPIRA

GL OMOSP IRA

GL OMO SPIRA

GL OMOSP I RA

GLOMOSPIRA

GL OMOSPIRA

GL OMOSP IRA

GL OMOSPIRA

GL OMOSPIRA

GLOMOSPIRA

GL OMOSPIRA

GLOMOSPIRA

GL OMOSPIRA

GL OMOSP I RA

GL OMOSP IRA

GL OMO SPIRA

GL OMO SP IRA

GL OMOSPIRA

GL OMOSPIRA

GL OMOSPIRA

GL OMO SPI RA

GL OMOSPIRA

GLOMOSPI RA

GLOMOSPIRA

GL OMOSPIRA

GL OMOSPIRA

GLOMOSPIRA

GL OMOSPIRA

GLOMOSPIRA

GL OMOSPIRA

GL OMO SP I RA

GL OMOSPIRA

GL OMOSPIRA

GL OMOSP I RA

GL OMOSP I RA

GL OMOSPI RA

GL OMOSPIRA

GL OMOSPIRA

GL OMOSPIRA

GL OMOSP I RA

GLOMOSPIRA

GL OMOSPIRA

GL OMOSPIRA

GL OMOSPIRA

GL OMOSPIRA

GLOMOSPIRA

GLOMO SPIRA

GL OMOSPIRA

GL OMOSPI RA

GL OMOSPIRA

GL OMO SPIRA

GL OMOSPIRA

GLOMOSPIRA

GL OMOSP I RA

GL OMOSPIRA

GL OMO SP IRA

GL OMOSPIRA

GL OMOSPIRA

GL OMOSPIRA

GLOMOSPIRA

GL OMOSPIRA

GL OMOSP I RA

GL OMOSPI RA

GLOMO SPIRA

GL OMOSPIRA

GL OMOSPIRA

GL OMOSPIRA

GL OMOSP IRA
CHAROIDES

CHAROIDES

CHAROIDES

CHAROIDES

CHAROIDES

CHAROIDES

CHAROIDES

CHAROIDES

CHAROIDES

CHAROIDES

CHAROIOES

CHAROIDES

CHARO IOES

CHAROIDES

CHAROIDES

CHAROIDES

CHAROIDES

CHAROIDES

CHAROIDES

CHAROIDES

CHAROIDES

CHAROIDES

CHAROIDES

CHAROIDES

CHAROIDES

CHAROIDES

CHAROIDES

CHAROIDES

CHAROIDES

CHAROIDES

CHAROIDES

CHAROIOES

CHAROIDES

CHAROIDES

CHAROIDES

CHAROIDES

CHAROIDES

CHAROIDES

CHAROIDES

CHAROIDES

CHAROIDES

CHAROIDES

CHAROIDES

CHAROIDES

CHAROIDES

CHAROIDES

CHAROIDES

CHAROIDES

CHAROIDES

CHAROIDES

CHAROIDES

CHAROIDES

CHAROIDES

CHAROIDES

CHAROIDES

CHAROIDES

CHAROIDES

CHARO IDES

CHAROIDES

CHAROIDES

CHAROIDES

CHAROIDES

CHAROIDES

CHAROIDES

CHAROIDES

CHAROIDES

CHAROIOES

CHAROIDES

CHAROIOES

CHAROIDES

CHAROIDES

CHAROIDES

CHAROIDES

CHAROIDES

CHAROIDES

CHAROIDES

CHAROIDES

CHAROIDES

CHAROIDES

CHAROIOES

CHAROIDES

CHAROIDES

CHAROIDES

CHAR OIDES

CHAROIDES

CHAROIDES

CHAROIDES

CHAROIDES

CHAROIOES

CHAROIDES

CHAROIDES

CHAROIDES

CHAROIDES

CHAROIDES

CHAROIDES

NH GULF OF MEXICO

NH GULF OF MEXICO

NH GULF OF MEXICO

NH GULF OF MEXICO 


\section{Publication}

18161 PARKER 1954

18162 PARKER 1954

18163 PARKER 1954

18164 PARKER 1954

18165 PARKER 1954

18166 PFLUM FRERICHS 1976

18167 PFLUM FRERICHS 1976

18168 PFLUM FRERICHS 1976

18169 PFLUM FRERICHS

18171 PFLUM FRERICHS 1976

18171 PFLUM FRERICHS
19176
18172 PFLUM FRERICHS 1976

18173 PFLUM FRERICHS 1976

18174 PFLUM FRERICHS 1976

18175 PFLUM FRERICHS 1976

18176 PFLUM FRERICHS 1976

18177 PFLUM FRERICHS 1976

18178 PFLUM FRERICHS 1976
18179 PFLUM FRERICHS 1976

18179 PFLUM FRERICHS 1976
18180 PFLUM FRERICHS 1976

18181 PFLUM FRERICHS 1976

18182 PFLUM FRERICHS 1976

18183 PFLUM FRERICHS 1976

18184 PFLUM FRERICHS 1976

18185 PFLUM FRERICHS 1976

18186 CUSHMAN 1918

18187 CUSHMAN 1918

18188 PARKER 1954

18189 PARKER 1954

18190 PARKER 1954

18191 PARKER 1954

18192 PARKER 1954

18193 PARKER 1954

18194 PARKER 1954

18195 PFLUM FRERICHS 1976

18196 PARKER 1954

18197 PARKER 1954

18198 PARKER 1954

18199 PARKER 1954

18200 PFLUM FRERICHS 1976

18201 PFLUM FRERICHS 1976

18202 PFLUM FRERICHS 1976

18203 PFLUM FRERICHS 1976

18204 PFLUM FRERICHS 1976

18205 PFLUM FRERICHS 1976

18206 PFLUM FRERICHS 1976

18207 PFLUM FRERICHS 1976

18208 PFLUM FRERICHS 1976

18209 PFLUM FRERICHS 1976

18210 PFLUM FRERICHS 1976

18211 PARKER 1954

18212 PFLUM FRERICHS 1976

18213 PFLUM FRERICHS 1976

18214 PFLUM FRERICHS 1976

18215 PFLUM FRERICHS 1976

18216 PFLUM FRERICHS 1976

18217 PFLUM FRERICHS 1976

18218 PFLUM FRERICHS 1976

18219 PFLUM FRERICHS 1976

18220 PFLUM FRERICHS 1976

18221 PFLUM FRERICHS 1976

18222 PFLUM FRERICHS 1976

18223 PFLUM FRERICHS 1976

18224 PFLUM FRERICHS 1976

18225 PFLUM FRERICHS 1976

18226 PFLUM FRERICHS 1976

18227 PFLUM FRERICHS 1976

18228 PARKER 1954

18229 PHLEGER 1955 A

13230 PARKER 1954

18231 PARKER 1954

18232 PARKER 1954

18233 CREAGER 1958

18234 PHLEGER 1955A

18235 PHLEGER 1955A
18236 LUDWICK WALTON 1957

18237 PARKER 1954

18238 PARKER 1954

18239 PARKER 1954

18240 PARKER 1954

18241 PARKER 1954

18242 BANDY 1956

18243 WALTON 1960

18245 BANDY 1956

18246 SHIFFLETT 1961

18247 SHEPARD MOORE 1955

18248 SHEPARD MOORE 1955

18249 LEHMANN 1957

18250 PARKER 1954

18251 PARKER 1954

18252 PARKER 1954

18253 LANKFORD 1959

18254 PHLEGER 1954

18255 PHLEGER 1954
Generic Name

GL OMOSPIRA

GL OMOSPIRA

GLOMOSPIRA

GL OMOSPIRA

GL OMOSPIRA

GLOMOSPIRA

GL OMOSP I RA

GL OMOSPIRA

GLOMOSPIRA

GL OMOSPIRA

GL OMOSPIRA

GLOMOSPIRA

GL OMOSPIRA

GL OMOSP I RA

GL OMOSPIRA

GL OMOSPIRA

GLOMOSPIRA

GL OMOSPIRA

GL OMOSPIRA

GL OMOSPIRA

GL OMOSPIRA

GL OMOSPIRA

GLOMOSPIRA

GLOMOSPIRA

GL OMOSPIRA

GLOMOSP IRA

GLOMOSPIRA

GL OMOSPIRA

GL OMOSP IRA

GL OMOSP I RA

GL OMOSP IRA

GLOMOSPIRA

GLOMOSPIRA

GLOMOSPIRA

GL OMOSPIRA

GL OMOSP I RA

GL OMOSPIRA

GL OMOSPIRA

GL OMOSPIRA

GLOMOSPIRA

GLOMOSPIRA

GL OMO SP I RA

GLOMOSPIRA

GL OMOSP I RA

GL OMOSPIRA

GL OMOSPIRA

GL OMOSPIRA

GLOMOSP I RA

GL OMOSPI RA

GL OMOSP I RA

GL OMOSPI RA

GL OMOSPIRA

GL OMOSPIRA

GL OMOSPIRA

GL OMOSPI RA

GL OMOSPIRA

GLOMOSPIRA

GL OMOSPIRA

GL OMOSP I RA

GLOMOSPIRA

GL OMOSPIRA

GL OMOSPIRA

GL OMOSPIRA

GL OMOSPIRA

GLOMOSPIRA

GL OMOSPIRA

GL OMOSPIRA

GL OMOSPIRA

GOESELLA

GOESELLA

GOESELLA

GOESELLA

GOESELLA

GOESELLA

GOESELLA

GOESELLA

GOESELLA

GOESELLA

GOESELLA

GOESELLA

GOESELLA

GUTTULINA

GUTTULINA

GUTTULINA

GUTTULINA

GUTTULINA

GUTTULINA

GUTTULINA

GUTTULINA

GUTTULINA

GUTTULINA

GUTTULINA

GUTTULINA

GUTTULINA

GUTTULINA
Specific Name

CHAROIDES

CHAROIDES

CHAROIDES

CHAROIDES

GORDIAL IS

GORDIALIS

GORDIALIS

GORDIAL IS

GORDIALIS

TORDIALIS

GORDIALIS

GORDIALIS

GORDIALIS

GORDIALIS

GORDIAL IS

GORDIALIS

GORDIAL IS

GORDIALIS

GORDIALIS

GORDIAL IS

GORDI AL IS

GORDIALIS

GORDIALIS

GORDIAL IS

GORDI AL IS

GORDIAL IS

GORDIALIS

GORDIALIS

GORDIAL IS

GORDIALIS

GORDIALIS

GORDIAL IS

GORDIALIS

GORDIAL IS

GORDIALIS

GORDIALIS

GORDIAL IS

GORDIAL IS

GORDIAL IS

GORDIAL IS

GORDIAL IS

GORDIAL IS

GORDIAL IS

GORDIALIS

GORDIALIS

GORDI AL IS

GORDI AL IS

GORDIAL IS

GORDIALIS

GORDIALIS

GORDIALIS

GORDIALIS

GORDIAL IS

GORDIALIS

GORDIALIS

GORDI ALIS

GOFDIALIS

GORDIALIS

GORDIALIS

GORDIAL IS

GORDIALIS

GORDIALIS

GORDIALIS

GORDIALIS

GORDIAL IS

GORDIAL IS

MISSISSIPPIEN IS

MISSISSIPPIENSIS

MISSISSIPPIENSIS

MISSISSIPPIENSIS

MI SSISSIPPIENSIS

MISSISSIPPIENSIS

MI SSISSIPPIENSIS

MI SSISSIPPIENSIS

MI SSISSIPPIENSIS

MISSISSIPPIENSIS

MISSISSIPPIENSIS

MISSISSIPPIENSIS

MISSISSIPPIENSIS

AUSTRALIS

AUSTRALIS

AUSTRALIS

AUSTRALIS

AUSTRALIS

AU STRALIS

AU STRALIS

AUSTRALIS

AUSTRALIS

AUSTRALIS

AUSTRALIS

AUSTRALIS

AUSTRALIS

Locality

NE GULF OF MEXICO

NE GULF OF MEXICO

NE GULF OF MEXICO

NE GULF OF MEXICO

NE GULF OF MEXICO

CENTRAL GULF OF MEXICO 
Publication

18256 PARKER 1954

18257 PHENTON 1957 PARKER PHLEGER PEIRSON 1953 GUTTULINA

18259 BOCK 1976

18260 PARKER 1954

18261 PARKER 1954

18262 PARKER 1954

18263 PARKER 1954

18265 PARKER PHLEGER PEIRSON 1953

18266 ANDERSON 1968

18267 KELLOUGH 1956

18268 PARKER 1954

18269 PARKER PHLEGER PEIRSON 1953

18270 BANDY 1956

18271 BANDY 1956

18272 BANDY 1956

18273 BANDY 1956

18274 BANDY 1956

18275 BANDY 1956

18276 BANDY 1956

18277 AYALA-CASTANARES SEGURA 1968

18278 BANDY 1956

18279 BANDY 1956

18280 BANDY 1956

18281 BANDY 1956

18282 BANDY 1956

18283 BANDY 1956

18284 BANDY 1956

18285 BANDY 1956

18286 BANDY 1956

18287 BANDY 1956

18288 BOCK 1976

18289 BOCK 1976

18290 NORTON 1930

18291 SEGURA 1963
18292 NORTON 1930

18293 ANDERSEN 1961

18294 BANDY 1954

18295 BANDY 1954

18296 BANDY 1954

18297 BANDY 1954

18298 DAVIS 1964

18299 BANDY 1954

18300 BANDY 1954

18301 ANDERSEN 1961

18302 POST 1951

18303 NORTON 1930

18304 NORTON 1930

18305 BANDY 1956

18306 CUSHMAN 1931

18307 BANDY 1956

18308 BANDY 1956

18309 BANDY 1956

18310 BANDY 1956

18311 BANDY 1956

18312 BOCK 1976

18313 PARKER 1954

18314 PARKER 1954

18315 PARKER 1954

18316 BANDY 1956

18317 BANDY 1956

18318 BANDY 1956

18319 BENDA PURI 1962

18320 BANDY 1956

18321 BANDY 1956

18322 BANDY 1956

18323 CUSHMAN 1931

18324 PARKER 1954

18325 . PARKER 1954

18326 PARKER 1954

18327 LUDWICK WALTON 1957

18328 BANDY 1956

18329 BANDY 1956

18330 BANDY 1956

18331 BANDY 1956

18332 BANDY 1956

18333 BANDY 1956

18334 BANDY 1956

18335 BANDY 1956

18336 PFLUM FRERICHS 1976

18337 PFLUM FRERICHS 1976

18338 PFLUM FRERICHS 1976

18339 PFLUM FRERICHS 1976

18340 PFLUM FRERICHS 1976

18341 PFLUM FRERICHS 1976

18342 PFLUM FRERICHS 1976

18343 PFLUM FRERICHS 1976

18344 PFLUM FRERICHS 1976

18345 PFLUM FRERICHS 1976

18346 PFLUM FRERICHS 1976

18347 PFLUM FRERICHS 1976

18348 PFLUM FRERICHS 1976

18349 PFLUM FRERICHS 1976

18350 PFLUM FRERICHS 1976

GUTTULINA

GYROI DINA
Generic Name

GUTTULINA

GUTTUL INA

GUTTULINA

GUTTULINA

GUTTULINA

GUTTULINA

GUTTUL INA

GUTTUL INA

GUTTULINA

GUTTULINA

GUTTULINA

GUTTULINA

GUTTULINA

GUTTULINA

GUTTULINA

GUTTUL INA

GUTTULINA

GUTTULINA

GUTTULINA

GUTTULINA

GUTTULINA

GUTTULINA

GUTTULINA

GUTTULINA

GUTTULINA

GUTTULINA

GUTTULINA

GUTTULINA

GUTTULINA

GUTTULINA

GUTTULINA

GUTTUL INA

GUTTULINA

GUTTULINA

GUTTULINA

GUTTULINA

GUTTULINA

GUTTULINA

GYPSINA

GYPS INA

GYPS INA

GYPS INA

GYPSINA

GYPS INA

GYPS INA

GYPS INA

GYPSINA

GYPSINA

GYPSINA

GYPSINA

GYPSINA

GYPSINA

GYPS INA

GYPSINA

GYPS INA

GYPSINA

GYPS INA

GYPSINA

GYPSINA

GYPSINA

GYPS INA

GYPS INA

GYPSINA

GYPSINA

GYPSINA

GYPS INA

GYPS INA

GYPSINA

GYPSINA

GYPSINA

GYPSINA

GYROIDINA

GYROI DINA

GYROIDINA

GYROI DINA

GYROIDINA

GYROIDINA

GYROIDINA

GYROIDINA

GYROIDINA

GYROI DINA

GYROI DINA

GYROIDINA

GYROI IINA

GYROIDINA
Specific Name

Locality

Lat. Long.

AUSTRAL IS

AUSTRAL IS

AUSTRAL IS

AUSTRALIS

AUSTRALIS

AUSTRALIS

AU STRAL IS

AUSTRALIS

AU STRAL IS

AUSTRAL IS

AUSTRALIS

AU STRAL IS

AUSTRAL IS

AUSTRAL IS

AUSTRALIS

AUSTRAL IS

AU STRALIS

AUSTRALIS

AUSTRAL IS

AU STRALIS

AU STRALIS

AU STRALIS

AU STRAL IS

AUSTRAL IS

AU STRALIS

AUSTRALIS

AUSTRAL IS

AU STRALIS

AU STRAL IS

AUSTRALIS

AU STRAL IS

HI RSUT

LAEVIS

OBLONGA

PR CBLEMA

PR OBLEMA

PULCHELLA

RE GINA

REGINA

RE GINA

RE GINA

RE GINA

RE GINA

REGINA

SP I CAEF OR MI

SPICAEFORMIS AUSTRALIS

GL OBULUS

GL OBULUS

VESICULAR IS

VESICULAR IS

VE SI CULAR IS

VESICULAR IS

VESICUL AR IS

VESI CULAR IS

VESICULAR IS

VESICULAR IS

VESI CULLAR IS

VE SICULAR IS

VESI CULAR IS

VESICULAR IS

VE SI CULAR IS

VESI CUL AR IS

VE SI CUL AR IS

VE SICUL AR IS

VESI CULAR IS

VESI CULARIS

VE SI CUL AR IS

VE SI CUL AR IS

VE SICULAR IS

VESICULAR IS

VESICULAR IS

VE SI CULAR IS

VESICULAR IS

VESICULARIS

VESICULAR IS

VE SICUL AR IS

VESICULAR IS

VE SICULAR IS

VE SI CUL AR IS

ALTIFORMIS ACUTA

ALTIFORMIS ACUTA

ALTIFORMIS ACUTA

ALTIFORMIS ACUTA

AL IIFORMIS ACUTA

AL TIFORMIS ACUTA

ALTIFORMIS ACUTA

ALTIFORMIS ACUTA

ALTIFORMIS ACUTA

ALTIFORMIS ACUTA

AL TIFORMIS ACUTA

ALTIFORMIS ACUTA

ALTIFORMIS ACUTA

AL TIFORMIS ACUTA

ALTIFORMIS ACUTA

NE GULF OF MEXICO

MATAGORDA BAY, TEXAS

TEXAS GULF COAST

NE GULF OF MEXICO

NE GULF OF MEXICO

NE GULF OF MEXICO

NE GULF OF MEXICO

NE GULF OF MEXICO

NE GULF OF MEXICO

TEXAS GULF COAST 


\section{Publication}

18351 PFLUM FRERICHS 1976 18352 PFLUM FRERICHS 1976 18353 PFLUM FRERICHS 1976 18354 PFLUM FRERICHS 1976 18355 PFLUM FRERICHS 1976 18356 PFLUM FRERICHS 1976 18357 PFLUM FRERICHS 1976 18358 PFLUM FRERICHS 1976 18359 PFLUM FRERICHS 1976 18360 PFLUM FRERICHS 1976 18361 PFLUM FRERICHS 1976 18362 PFLUM FRERICHS 1976 18363 PFLUM FRERICHS 1976 18364 PFLUM FRERICHS 1976 18365 PFLUM FRERICHS 1976 18366 PFLUM FRERICHS 1976 18367 PFLUM FRERICHS 1976 18368 PFLUM FRERICHS 1976 18369 PFLUM FRERICHS 1976 18370 PFLUM FRERICHS 1976 18371 PFLUM FRERICHS 1976 18372 PFLUM FRERICHS 1976 18373 PFLUM FRERICHS 1976 18374 PFLUM FRERICHS 1976 18375 PFLUM FRERICHS 1976 18376 PFLUM FRERICHS 1976 18377 PFLUM FRERICHS 1976 18378 PFLUM FRERICHS 1976 18379 PFLUM FRERICHS 1976 18380 PFLUM FRERICHS 1976 18381 PFLUM FRERICHS 1976 18382 PFLUM FRERICHS 1976 18383 PFLUM FRERICHS 1976 18384 PFLUM FRERICHS 1976 18385 PFLUM FRERICHS 1976 18386 PFLUM FRERICHS 1976 18387 PFLUM FRERICHS 1976 18388 PFLUM FRERICHS 1976 18389 PFLUM FRERICHS 1976 18390 PFLUM FRERICHS 1976 18391 PFLUM FRERICHS 1976 18392 PFLUM FRERICHS 1976 18393 PFLUM FRERICHS 1976 18394 PFLUM FRERICHS 1976 18395 PFLUM FRERICHS 1976 18396 PFLUM FRERICHS 1976 18397 PFLUM FRERICHS 1976 18398 PFLUM FRERICHS 1976 18399 PFLUM FRERICHS 1976 18400 PFLUM FRERICHS 1976 18401 PFLUM FRERICHS 1976 18402 PFLUM FRERICHS 1976 18403 PFLUM FRERICHS 1976 18404 PFLUM FRERICHS 1976 18405 PFLUM FRERICHS 1976 18406 PFLUM FRERICHS 1976 18407 PFLUM FRERICHS 1976 18408 PFLUM FRERICHS 1976 18409 PFLUM FRERICHS 1976 18410 PFLUM FRERICHS 1976 18411 PFLUM FRERICHS 1976 18412 PFLUM FRERICHS 1976 18413 PFLUM FRERICHS 1976 18414 PFLUM FRERICHS 1976 18415 PFLUM FRERICHS 1976 18416 CREAGER 1958 18417 CREAGER 1958 18418 CREAGER 1958 CREAGER 1958 18420 CREAGER 1958 18421 CREAGER 1958 18422 CREAGER 1958 18423 CREAGER 1958 18424 CREAGER 1958 18425 PARKER 1954 18426 PARKER 1954 18427 PARKER 1954 18428 PARKER 1954 18429 PARKER 1954 8430 PARKER 1954 18432 PARKER 1954 18433 PARKER 1954 18434 PARKER 1954 18435 PHLEGER 1955 A 18437 PARKER 1954 18438 PARKER 1954 18439 PHLEGER 1951A 18440 PHLEGER 1951A 18441 PHLEGER 1955A 18442 PFLUM FRERICHS 1976 18443 PHLEGER 1955A

\section{Generic Name}

GYROI DINA GYROIDINA GYROIDINA GYROIDINA GYROIDINA GYROIDINA GYROIDINA GYROI DINA GYROI OINA GYROIDINA GYROIDINA GYROIDINA GYROI DINA GYROIDINA GYROIDINA GYROIDINA GYROI DINA GYROI DINA GYROIDINA GYROIDINA GYROIDINA GYROIDINA GYROIDINA GYROIDINA GYROIDINA GYROIDINA GYROIDINA GYROI DINA GYROIDINA GYROIDINA GYROI DINA GYROIDINA GYROIDINA GYROIDINA GYROIDINA GYROIDINA GYROIDINA GYROIDINA GYROIDINA GYROI DINA GYROI DINA GYROIOINA GYROIDINA GYROIDINA GYROIDINA GYROIDINA GYROI DINA GYROIDINA GYRO IDINA GYROIDINA GYROIDINA GYROI DINA GYROIDINA GYROI DINA GYROI DINA GYROIDINA GYROIDINA GYROIDINA GYROIDINA GYROIDINA GYROIDINA GYROIDINA GYROIDINA GYROIDINA GYROI DINA GYROIDINA GYROIDINA GYROIDINA GYROIDINA GYROIDINA GYROIDINA GYROIDINA GYROI DINA GYROI DINA GYROIDINA GYROI DINA GYROIDINA GYROIDINA GYROIDINA GYROIDINA GYROIDINA YROIDINA GYROIDINA GYROIDINA GYROIDINA GYROIDINA GYROIDINA GYROIDINA GYROIDINA GYROIDINA GYROIDINA GYROIDINA GYROIDINA GYROIDINA GYROI DINA

\section{Specific Name}

AL TIFORMIS ACUTA ALTIFORMIS ACUTA AL TIFORMIS ACUTA ALTIFORMIS ACUTA ALTIFORMIS ACUTA AL TIFORMIS ACUTA AL TIFORMIS ACUTA ALTIFORMIS ACUTA ALTIFORMIS ACUTA ALTIFORMIS ACUTA ALTIFORMIS ACUTA AL TIFORMIS ACUTA ALTIFORMIS ACUTA AL TIFORMIS ACUTA AL TIFORMIS ACUTA ALTIFORMIS CUSHMANI ALTIFORMIS CUSHMANI AL TIFORMIS CUSHMANI AL TIFORMIS CUSHMANI ALTIFORMIS CUSHMANI AL TIFORMIS CUSHMANI AL TIFORMIS CUSHMANI AL TIFORMIS CUSHMANI AL TIFORMIS CUSHMANI ALTIFORMIS CUSHMANI AL TIFORMIS CUSHMANI ALTIFORMIS CUSHMANI AL TIF ORMIS CUSHMANI AL TIFORMIS CUSHMANI ALTIFORMIS CUSHMANI ALTIFORMIS CUSHMANI ALTIFORMIS CUSHMANI ALTIFORMIS CUSHMANI AL TIFORMIS CUSHMANI AL TIFORMIS CUSHMANI ALTIFORMIS CUSHMANI ALTIFORMIS CUSHMANI ALTIFORMIS CUSHMANI ALTIFORMIS CUSHMANI AL TIFORMIS CUSHMANI ALTIFORMIS CUSHMANI AL TIFORMIS CUSHMANI ALTIFORMIS CUSHMANI ALTIFORMIS CUSHMANI AL IIFORMIS CUSHMANI AL TIFORMIS CUSHMANI AL TIFORMIS CUSHMANI ALTIFORMIS CUSHMANI AL TIFORMIS CUSHMANI AL TIFORMIS CUSHMANI ALTIFORMIS CUSHMANI AL TIFORMIS CUSHMANI ALTIFORMIS CUSHMANI AL TIFORMIS CUSHMANI ALTIFORMIS CUSHMANI ALTIFORMIS CUSHMANI ALTIFORMIS CUSHMANI ALTIFORMIS CUSHMANI AL TIFORMIS CUSHMANI AL TIFORMIS CUSHMANI ALTIFORMIS CUSHMANI
ALTIFORMIS CUSHMANI AP I CULARIS

LAMARCK IANA LAMAR CK IANA LAMARCK IA NA LANARCKIANA MAURYAE

MA URYAE

MAURYAE

MAURYAE

NE CSOLDAN II

NE OSOLDAN II

NE OSOLDANI

NE OSOL DAN II

NE OSOLOAN II

NE CSOLDAN II

NE OSOLDAN II

NE OSOLDAN II

NE OS OLDAN I

NE OSOLDAN II

NE CSOLDAN II

NE OSOLDAYII

NE OSOLDANII

OREICULAR IS

OR BI CULAR I

OREICULAR IS

OREICUL AR IS

OREI CUL AR IS

ORBICULAR IS

OREICULAR IS

\section{Locality}




\section{Publication}

18446 PHLEGER $1951 \mathrm{~A}$ 18447 PHLEGER 1951 A 18448 PHLEGER 1951A 18449 PHLEGER $1951 \mathrm{~A}$ 18450 PFLUM FRERICHS 1976 18451 PFLUM FRERICHS 1976 18452 PFLUM FRERICHS 1976 18453 PFLUM FRERICHS 1976 18454 PFLUM FRERICHS 1976 18455 PFLUM FRERICHS 1976 18456 PFLUM FRERICHS 1976 18457 PHLEGER 1951A

18458 PFLUM FRERICHS 1976 18459 PFLUM FRERICHS 1976 18460 PFLUM FRERICHS 1976 18461 PFLUM FRERICHS 1976 18462 PFLUM FRERICHS 1976 18463 PFLUM FRERICHS 1976 18464 PFLUM FRERICHS 1976 18465 PHLEGER 1951A

18466 PHLEGER 1951A

18467 PHLEGER 1951A

18468 PHLEGER 1951 A

18470 PFLUM FRERICHS 1976

18470 PFLUM FRERICHS 1976

18472 PFLUM FRERICHS 1976

18473 PHLEGER $1951 \mathrm{~A}$

18474 PHLEGER 1951A

18475 PHLEGER 1951A

18476 PHLEGER $1951 \mathrm{~A}$

18477
18478

18478 PARKER 1954
18479 PARKER 1954

18479 PARKER 1954
18480 PARKER 1954

18481 PARKER 1754

18482 PARKER 1954

18483 PHLEGER $1955 \mathrm{~A}$

18484 PFLUM FRERICHS 1976

18485 PARKER 1954

18486 PARKER 1954

18487 PARKER 1954

18488 LUDWICK WALTON 1957

18489 PHLEGER 1955A

18490 PHLEGER 1955 A

18491 PIILEGER $1955 \mathrm{~A}$

18492 PHLEGER 1955A

18493 PARKER 1954

18494 PARKER 1954

18495 PARKER 1954

18496 PHLEGER $1951 \mathrm{~A}$

18497 PARKER 1954

18498 PARKER 1954

18499 PARKER 1954

18500 PARKER 1954

18501 PHLEGER $1951 \mathrm{~A}$

18502 PHLEGER $1951 \mathrm{~A}$

18503 PHLEGER $1951 \mathrm{~A}$

18504 PHLEGER 1951 A

18505 PHLEGEF 1951A

18506 PHLEGER $1951 \mathrm{~A}$

18507 PHLEGER 1951A

18508 PFLUM FRERICHS 1976

18509 PFLUM FRERICHS 1976

18510 PFLUM FRERICHS 1976

18511 PFLUM FRERICHS 1976

18512 PFLUM FRERICHS 1976

18513 PFLUM FRERICHS 1976

18514 PFLUM FRERICHS 1976

18515 PFLUM FRERICHS 1976

18516 PFLUM FRERICHS 1976

18517 PFLUM FRERICHS 1976

18518 PARKER 1954

18519 PARKER 1954

18520 PARKER 1954

18521 PARKER 1954

18522 PFLUM FRERICHS 1976

18523 PFLUM FRERICHS 1976

18524 PFLUM FRERICHS 1976

18525 PFLUM FRERICHS 1976

18526 PFLUM FRERICHS 1976

18527 PFLUM FRERICHS 1976

18528 PFLUM FRERICHS 1976

18529 PFLUM FRERICHS 1976

18530 PFLUM FRERICHS 1976

18531 PFLUM FRERICHS 1976

18532 PFLUM FRERICHS 1976

18533 PFLUM FRERICHS 1976

18534 PFLUM FRERICHS 1976

18535 PFLUM FRERICHS
18536 PFLUM FRERICHS 1976

18536 PFLUM FRERI
18537 PARKER 1954

18538 PARKER 1954

18539 PARKER 1954

18540 PFLUM FRERICHS 1976
Generic Name

GYROIDINA

GYROIDINA

GYROIDINA

GYROIDINA

GYROIDINA

GYROIDINA

GYROIDINA

GYROIDINA

GYROIDINA

GYROIDINA

GYROIDINA

GYROIDINA

GYROIDINA

GYROIDINA

GYROIDINA

GYROIDINA

GYROIDINA

GYROIDINA

GYROIDINA

GYROIDINA

GYROIDINA

GYROIDINA

GYROIDINA

GYROIDINA

GYROIDINA

GYROIDINA

GYROIDINA

GYROIDINA

GYROIDINA

GYROIDINA

GYROIDINA

GYROIDINA

GYROIDINA

GYROIDINA

GYROIDINA

GYROIDINA

GYROIDINA

GYROIDINA

GYROIDINA

GYROIDINA

GYROIDINA

GYROIDINA

GYROIDINA

GYROIDINA

GYROIDINA

GYROIDINA

GYROIDINA

GYROIDINA

GYROIDINA

GYPOI DINA

GYROIDINA

GYROI DINA

GYROIDINA

GYROI D INA

GYROIDINA

GYROIDINA

GYROIDINA

GYROIDINA

GYROI D INA

GYROIDINA

GYRO I DINA

GYROIDINA

GYROIDINA

GYROIDINA

GYRO I D INA

GYROIDINA

GYROIDINA

GYROIDINA

GYROIDINA

GYROIDINA

GYROIDINA

GYROIDINA

GYROIDINA

GYROI DINA

GYROIDINA

GYROIDINA

GYROIDINA

GYROIDINA

GYROIDINA

GYROIDINA

GYROIDINA

GYROIDINA

GYROI DINA

GYROIDINA

GYROIDINA

GYROIDINA

GYROIDINA

GYROIDINA

GYROIDINA

GYROIDINA

GYROIDINA

GYROIDINA
Specific Name

Locality

Lat. Long.

OREICULAR IS OREICULAR IS OREICULAZ IS OREICUL AR IS OREI CULAR IS OREI CULAR IS OREI CULAR IS OREI CUL AR IS OREICULAR IS OREI CUL AR IS OREI IUL AR IS OREI CULAR IS OREICULAR IS OREI CULAR IS ORBICULAZ IS OREICULAR IS ORE I CUL AR IS OREICULAR IS OREI CULAR IS OREI CULAR IS ORE I CUL AR IS OREICULAR IS OREICULAR IS OREI CUL AR IS OREICULAR IS OREICULAR IS OREICULAR IS OREICULAR IS OR EI CUL AR IS OREICULAR IS OR BICUL AR IS ORE I CUL AR IS OREI CULAR IS OREICULAR IS OREICUL AR IS OREICULAR IS OREICUL AR IS ORE ICUL AR IS OREICULAR IS OREICULAR IS ORE I CULAR IS OREICUL AR IS OREICUL AR IS OREI CUL AR IS OREICULAR IS OREICULAR IS OREICULAR IS OREI CUL AR IS OREI CUL AR IS OREICULAR IS OREICUL AR IS OREICULAR IS ORBICULAR IS OREI CUL AR IS OREI CUL AR IS OREICULAR IS OREICULAR IS OREICULAR IS OREI CULAR IS OREICULAR IS OREICULAR IS OREICULAR IS OREICULAR IS OREICULAR IS ORE I CUL AR IS OREICULAR IS OREICULAR IS OREI CULAR IS OREICULAR IS OREICULAR IS ORE I CUL AR IS ORBI CULAR IS OREICULAR IS OREICULAR IS OREICULARIS OREI CUL AR IS OREICULAR IS OREICULAR IS OREICULAR IS OREICULAR IS ORBICULAR IS OREI CULAR IS OREICULAR IS OREICULAR IS OREICULAR IS OR BICULAR IS OR EICULAR IS OREICULAR IS OREICULAR IS OREICULAR IS OREICULAR IS OREICULAR IS OREICULAR IS ORBICULAR IS

NW GULF OF MEXICO

$N W$ GULF OF MEXICO

NW GULF OF MEXICO

NW GULF OF MEXICO

$N$ GULF OF MEXICO

NW GULF OF MEXICO 


\section{Publication}

18541 PFLUM FRERICHS 1976 18542 PFLUM FRERICHS 1976 18543 PFLUM FRERICHS 1976 18544 PFLUM FRERICHS 1976 18545 PFLUM FRERICHS 1976 18546 PFLUM FRERICHS 1976 18547 PFLUM FRERICHS 1976 18548 PFLUM FRERICHS 1976 18549 PFLUM FRERICHS 1976 18550 PFLUM FRERICHS 1976 18551 PFLUM FRERICHS 1976 18552 PFLUM FRERICHS 1976 18553 PFLUM FRERICHS 1976 18554 PFLUM FRERICHS 1976 18555 PFLUM FRERICHS 1976 18556 PFLUM FRERICHS 1976 18557 PFLUM FRERICHS 1976 18558 PFLUM FRERICHS 1976 18559 PFLUM FRERICHS 1976 18560 PFLUM FRERICHS 1976 18561 PFLUM FRERICHS 1976 18562 CUSHMAN 1931

18563 CUSHMAN 1931

18564 PFLUM FRERICHS 1976 18565 PFLUM FRERICHS 1976 18566 PFLUM FRERICHS 1976 18567 PFLUM FRERICHS 1976 18568 PFLUM FRERICHS 1976 18569 PFLUM FRERICHS 1976 18570 PFLUM FRERICHS 1976 18571 PFLUM FRERICHS 1976 18572 PFLUM FRERICHS 1976 18573 PFLUM FRERICHS 1976 18574 PHLEGER $1951 \mathrm{~A}$

18575 PARKER 1954

18576 PHLEGER 1951A

18577 PHLEGER $1951 \mathrm{~A}$

18578 PHLEGER $1951 \mathrm{~A}$

18579 PHLEGER 1951 A

18580 PHLEGER 1951A

18582 PHLEGER $1951 \mathrm{~A}$

18583 PHLEGER $1951 \mathrm{~A}$

18584 PHLEGER $1951 \mathrm{~A}$

18585 PHLEGER 1951A

18586 PHLEGER $1951 \mathrm{~A}$

18587 PHLEGER $1951 \mathrm{~A}$

18588 CREAGER 1958

18589 CREAGER 1958

18590 CREAGER 1958

18591 PHLEGER $1951 \mathrm{~A}$

18592 PHLEGER $1951 \mathrm{~A}$

18593 PHLEGER $1951 \mathrm{~A}$

18594 PHLEGER $1951 \mathrm{~A}$

18595 PHLEGER 1951 A

18596 PHLEGER $1951 \mathrm{~A}$

18598 PHLEGER $1951 \mathrm{~A}$

18599 PHLEGER $1951 \mathrm{~A}$

18600 PHLEGER 1951A

18601 CREAGER 1958

18602 CREAGER 1958

18603 CREAGER 1958

18604 CREAGER 1958

18605 CREAGER 1958

18606 CREAGER 1958

18607 PFLUM FRERICHS 1976

18608 PFLUM FRERICHS 1976

18609 PFLUM FRERICHS 1976

18610 PFLUM FRERICHS 1976

18611 PFLUM FRERICHS 1976

18612 PFLUM FRERICHS 1976

18613 PFLUM FRERICHS 1976

18614 PFLUM FRERICHS 1976

18615 PFLUM FRERICHS 1976

18616 PFLUM FRERICHS 1976

18617 PFLUM FRERICHS 1976

18618 PFLUM FRERICHS 1976

18619 PFLUM FRERICHS 1976

18620 PFLUM FRERICHS 1976

18621 PFLUM FRERICHS 1976

18622 PFLUM FRERICHS 1976

18623 PFLUM FRERICHS 1976

18624 PFLUM FRERICHS 1976

18625 PFLUM FRERICHS 1976

18626 PFLUM FRERICHS 1976

18627 PFLUM FRERICHS 1976

18628 PFLUM FRERICHS 1976

18629 PFLUM FRERICHS 1976

18630 PFLUM FRERICHS 1976

18631 PFLUM FRERICHS 1976

18632 PFLUM FRERICHS 1976

18633 PFLUM FRERICHS 1976

18634 PFLUM FRERICHS 1976
18635 PFLUM FRERICHS 1976
Generic Name

GYROI DINA

GYROI DINA

GYROIDINA

GYROIDINA

GYROIDINA

GYROIDINA

GYROIDINA

GYROIDINA

GYROI DINA

GYROIDINA

GYROI DINA

GYROIDINA

GYROI DINA

GYROIDINA

GYROIDINA

GYROI DINA

GYROIDINA

GYROIDINA

GYROIDINA

GYROIDINA

GYROIDINA

GYROI DINA

GYROIDINA

GYROIDINA

GYROIDINA

GYROIDINA

GYROIDINA

GYROIDINA

GYROIDINA

GYROIDINA

GYROIDINA

GYROIDINA

GYROIDINA

GYROIDINA

GYROIDINA

GYROIDINA

GYROIDINA

GYROIDINA

GYROIDINA

GYROIDINA

GYROIDINA

GYROIDINA

GYROIDINA

GYROIDINA

GYROIDINA

GYROIDINA

GYROIDINA

GYROIDINA

GYROIDINA

GYROIDINA

GYROIDINA

GYROIDINA

GYROIDINA

GYROIDINA

GYROIDINA

GYROIDINA

GYROIDINA

GYROIDINA

GYROIDINA

GYROIDINA

GYROI DINA

GYROIDINA

GYROIDINA

GYROIDINA

GYROIDINA

GYROIDINA

GYROIDINA

GYROIDINA

GYROIDINA

GYROIDINA

GYROIDINA

GYROIDINA

GYROI DINA

GYROI DINA

GYROIDINA

GYROIDINA

GYROIDINA

GYROIDINA

GYROIDINA

GYROIDINA

GYROIDINA

GYROIDINA

GYROIDINA

GYROIDINA

GYROIDINA

GYROIDINA

GYROIDINA

GYROIDINA

GYROIDINA

GYROIDINA

GYROIDINA

GYROIDINA

GYROIDINA

GYROI DINA

GYROIDINA

\section{Specific Name}

ORE I CUL AR IS

OREICULAR IS

OREI CULAR IS

OREI CULAR IS

OREICULAR IS

REICULAR IS

OREI CUL AR IS

OREICULAR IS

OREICUL AR I

OREICULAR IS

OREICULAR IS

OREICULAR IS

OREICULAR IS

OREICULAR IS

OREICULAR IS

OREICULAR IS

OREICULAR IS

ORBICUL AR IS

OREICULAR IS

SOLDANI I

SOLDANII

SOLDANII

SOLDANI

SOLDANI

SOLDANI I

SOLDANI

SOLDANII

SOLDANII

SOLDANI

SOLDANII ALTIFORMIS

SOLDANII ALTIFORMIS

SOLDANI I AL I IFORMIS

SOLDANI I AL IIFORMIS

SOLDANII ALTIFORMIS

SOLDANII ALTIFORMIS

SOLDANII ALTIFORMIS

SOLDANII ALTIFORMIS

SOLDANII AL TIFORMIS

SOLDANII AL IIFORMIS

SOLDANI AL IFORMIS

SOLDANII ALTIFORMIS

SOLDANII ALTIFORMIS

SOLDANII ALTIFORMIS

SOLDANII ALTIFORMIS

SOLDANII ALTIFORMIS

SOLDANII ALTIFORMIS

SOLDANII ALTIFORMIS

SOLDANII ALTIFORMIS

SOLDANII ALTIFORMIS

SOLDANII ALTIFORMIS

SOLDANI I AL TIFORMIS

SOLDANI I ALTIFORMIS

SOLDANII ALTIFORMIS

SOLDANII ALTIFORMIS

SOLDANII ALTIFORMIS

SOLDANII ALTIFORMIS

SOLDANII ALTIFORMIS

SOLDANII ALTIFORMIS

SOLDANI I AL TIFORMIS

SOLDANII AL TIFORMIS

SOLDANII ALTIFORMIS

SOLDANII ALTIFORMIS

UMBONATA

UMEONATA

UMEONATA

UMEONATA

UMEONATA

UMEONATA

UMEONAT

UMEONATA

UMEONATA

UMEONATA

UMEONATA

UMEONATA

UMEONATA

UMEONATA

UMEONATA

UMEONATA

UMEONATA

UMEONATA

UMPONATA

UMEONATA

UMEONATA

UMBONATA

UMEONATA

UMEONATA

UMEONATA

UMEONAT

UMEONATA

UMEONATA

UMEONATA

Locality

$\mathrm{NW}$ GULF OF MEXICO

Nh GULF OF MEXICO

$\mathrm{Nh}$ GULF OF MEXICO

NW GULF OF MEXICO 
Publication

18636 PFLUM FRERICHS 1976 18637 PFLUM FRERICHS 1976 18638 PFLUM FRERICHS 1976 18639 PFLUM FRERICHS 1976 18640 PFLUM FRERICHS 1976 18641 PFLUM FRERICHS 1976 18642 PFLUM FRERICHS 1976 18643 PFLUM FRERICHS 1976 18644 PFLUM FRERICHS 1976 18645 PFLUM FRERICHS 1976 18646 PFLUM FRERICHS 1976 18647 PFLUM FRERICHS 1976 18648 PFLUM FRERICHS 1976 18649 PFLUM FRERICHS 1976 18649 PFLUM FRERICHS 1976
18650 PFLUM FRERICHS 1976

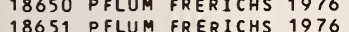
18651
18652
$18 F L U M M$ 18653 PFLUM FRERICHS 1976 18654 PFLUM FRERICHS 1976 18655 PFLUM FRERICHS 1976 18656 PFLUM FRERICHS 1976 18657 PFLUM FRERICHS 1976 18658 PARKER 1954 18659 PARKER 1954

18660 PARKER 1954

18661 PARKER 1954

18662 PARKER 1954

18663 PARKER 1954

18664 PARKER 1954

18665 PARKER 1954

18666 PARKER 1954

18667 PARKER 1954

18668 PARKER 1954

18669 PARKER 1954

18670 PARKER 1954

18671 PARKER 1954

18672 PARKER 1954

18673 CUSHMAN 1922 A

18674 LEROY HODGKINSON 1975

18675 PFLUM FRERICHS 1976

18676 PFLUM FRERICHS 1976

18677 PFLUM FRERICHS 1976

18678 PFLUM FRERICHS 1976

18679 PFLUM FRERICHS 1976

18680 PFLUM FRERICHS 1976

18681 BANDY 1956

18682 BANDY 1956

18683 PFLUM FRERICHS 1976

18684 PFLUM FRERICHS 1976

18685 PFLUM FRERICHS 1976

18686 BANDY 1956

18687 BANDY 1956

18688 BANDY 1956

18689 BANDY 1956

18690 LAMB 1972

18691 KELLOUGH 1956

18692 KELLOUGH 1956

18693 BANDY 1956

18694 BANDY 1956

18695 BANDY 1956

18696 BANDY 1956

18697 BANDY 1956

18698 BANDY 1956

18699 BANDY 1956

18700 KELLOUGH 1956

18701 KELLOUGH 1956

18702 KELLOUGH 1956

18703 BANDY 1956

18704 BANDY 1956

18705 BANDY 1956

18706 BANDY 1956

18707 ANDERSEN 1961

18708 PFLUM FRERICHS 1976

18709 PFLUM FRERICHS 1976

18710 SEGURA 1963

18711 LANKFORD 1959

18712 BANDY 1956

18713 BANDY 1956

18714 BANDY 1956

18715 BANDY 1956

18716 BANDY 1956

18717 BANDY 1956

18718 BANDY 1956

18719 AYALA-CASTANARES 1963

18720 ANDERSON 1968

18721 KELLOUGH 1956

18722 KELLOUGH 1956

18723 BANDY 1956

18725 LOEP 1965

18726 PFLUM FRERICHS 1976

18727 PFLUM FRERICHS 1976

18728 ANDERSEN 1961

18729 POAG 1976

18730 KELLOUGH 1956
Generic Name

Specific Name

GYROIDINA

GYROIDINA

GYROI DINA

GYROIDINA

GYROIDINA

GYROIDINA

GYROIDINA

GYROIOINA

GYRO I D I NA

GYROIDINA

GYROIDINA

GYROI DINA

GYROI I INA

GYROI DINA

GYROI DINA

GYROIDINA

GYROI DINA

GYROIDINA

GYROIDINA

GYROIDINOIDES

GYROIDINOIDES

GYROIDINOIDES

GYROIDINOIDES

GYROIDINOIDES

GYROIDINOI DES

GYROIDINOIDES

GYROIDINOIDES

GYROIDINOIDES

GYROIDINOIDES

GYROIDINOIDES

GYROIDINOIDES

GYROIDINOIDES

GYROIDINOIDES

GYROI DINOIDES

HALIPHY SEMA

HALYPHY SEMA

HANZ AWA IA

HANZAHAIA

HANZAUA IA

HANZAWA IA

HANZAWAIA

HANZ AWA I A

HANZAWAIA

HANZAHA IA

HANZ AWA I A

HANZAWAIA

HANZ AWA I A

HA NZ A WAI A

HANZAWAIA

HANZAWAIA

HANZAWA I A

HANZAWAIA

HANZ AWA I A

HANZ AWA I A

HANZAWAIA

HANZAWAIA

HANZAWA I A

HANZAWAI A

HANZAWA IA

HANZ AWA I A

HANZAWA I A

HANZAWAIA

HANZ AWA IA

HANZAWA I A

HANZ AWAIA

HANZ AWA I A

HANZAWAIA

HANZ AWAIA

HANZAWAIA

HANZAWA IA

HANZAWAI A

HANZ AWA I A

HANZ AWA I A

HANZ AWAIA

HA NZ AWA IA

HANZAWA IA

WA I

HANZAWAIA

HANZ AWA I A

HANZAWAIA

HANZ AWAIA

HANZAWAIA

HANZAWAIA

HANZ AWAIA

HANZAWAIA

HANZAWAIA
UMEONATA

UM EONATA

UMEONATA

UMEONATA

UMEONATA

UMEONATA

UMBONATA

UMEONATA

UMEONATA

UM BONATA

UMBONATA

UMBONATA

UMEONATA

UMEONATA

UMEONATA

UMBONATA

UM EONATA

UMEONATA

UMEONATA

SOLDANII ALTIFORMIS

SOLDANI I ALTIFORMIS

SOLDANII ALTIFORMIS

SOLDANII ALTIFORMIS

SOLDANII AL TIFORMIS

SOLDANII ALTIFORMIS

SOLDANII ALTIFORMIS

SOLDANII AL TIFORMIS

SOLDANII ALTIFORMIS

SOLDANII ALTIFORMIS

SOLDANII ALTIFORMIS

SOLDANII ALTIFORMIS

SOLDANII ALTIFORMIS

SOLDANI I ALTIFORMIS

SOLDANII ALTIFORMIS

ADVENA

TUMANOWIC ZII

BERTHELOT I

BERTHELOT I

BERTHELOT I

BE RTHEL OT I

BERTHELOT I

BERTHELOT I

BERTHELOT I

BERTHELOT I

BERTHEL OT I

BERTHEL OT I

BERTHEL OT I

CONCENTRI CA

CONCENTRI CA

CONCENTRI CA

CONCENTRI CA

CONCENTRI CA

COACENTRI CA

CONCENTRI CA

CONCENTRI CA

CONCENTRI CA

CONCENTRI CA

CONCENTRI CA

CONCENTRI CA

CONCENTRI CA

CONCENTRI CA

CONCENTRI CA

COACENTRI CA

CONCENTRI CA

CONCENTRI CA

CONCENTRI CA

CONCENTRICA

CONCENTRI CA

CONCENTRI CA

CONCENTRI CA

CONCENTRI CA

CONCENTRI CA

COACENTRI CA

CONCENTRI CA

CONCENTRI CA

CONCENTRI CA

CONCENTRI CA

C ONCENT RI CA

CONCENTRI CA

COACENTRI CA

CONCENTRI CA

COACENTRI CA

CONCENTRI CA

COACENTRI CA

COACENTRI CA

CONCENTRI CA

COACENTRI CA

CONCENTRI CA

STRATTONI

STRATTONI
UMEONATA

Locality

Lat. Long.

CENTRAL GULF OF MEXICO

CENTRAL GULF OF MEXICO

NW GULF OF MEXICO

NW GULF OF MEXICO

NW GULF OF MEXICO

NW GULF OF MEXICO

NW GULF OF MEXICO

NW GULF OF MEXICO

NW GULF OF MEXICO

NW GULF OF MEXICO

NW GULF OF MEXICO 


\section{Publication}

18731 KELLOUGH 1956

18732 BANDY 1956

18733 BANDY 1956

18734 BANDY 1956

18735 BANDY 1956

18736 BANDY 1956

18737 BANDY 1956

18738 BANDY 1956

18740 BOCK MOORE 1968

18741 WALTON 1960

18742 PHLEGER 1956

18743 PHLEGER 1956

18744 LEHMANN 1957

18745 SHIFFLETT 1961

18746 PFLUM FRER

18748 LANKFORD 1959

18749 SEGURA 1963

18750 AYALA-CASTANARES 1963

18751 BANDY 1954

18752 LOEP 1965

18753 BANDY 1956

18754 BANDY 1954

18755 BANDY 1954

18756 BANDY 1956

18757 BANDY 1956

18758 BANDY 1954

18759 BANDY 1954

18760 BANDY 1956

18762 BANDY 1956

18763 BANDY 1956

18764 BANDY 1956

18765 BANDY 1956

18766 KELLOUGH 1956

18767 KELLOUGH 1956

18768 KELLOUGH 1956

18769 KELLOUGH 1956

18770 BOCK 1976

18771 SOCK 1976

18772 BOCK 1976

18773 PHLEGER 1956

18774 PHLEGER 1956

18775 PHLEGER 1956

18776 ROCK 1976

18777 POAG SWEET 1972

18778 SANDY 1956

18779 BANDY 1956

18780 BANDY 1956

18781 BANDY 1956

18782 BANDY 1956

18783 BANDY 1956

18784 BANDY 1956

18785 KELLOUGH 1956

18786 BOCK 1976

18787 BOCK 1976

18788 CUSHMAN 1920

18789 CUSHMAN 1920

18790 CUSHMAN 1920

18791 CUSHMAN 1920

18792 PFLUM FRERICHS 1976

18793 PFLUM FRERICHS 1976

18794 PFLUM FRERICHS 1976

18795 CREAGER 1958

18796 PFLUM FRERICHS 1976 18797 PFLUM FRERICHS 1976 18798 PFLUM FRERICHS 1976
18799 PFLUM FRERICHS 1976 18800 PFLUM FRERICHS 1976 18801 PFLUM FRERICHS 1976 18801 PFLUM FRERICHS 1976
18802 PFLUM FRERICHS 1976

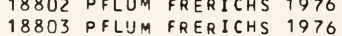
18804 PFLUM FRERICHS 1976 18805 PFLUM FRERICHS 1976 18806 PFLUM FRERICHS 1976 18807 PFLUM FRERICHS 1976

18808 CREAGER 1958

18809 CREAGER 1958

18810 PFLUM FRERICHS 1976 18811 PFLUM FRERICHS 1976 18812 PFLUM FRERICHS 1976 18813 PFLUM FRERICHS 1976 18814 PFLUM FRERICHS 1976 18815 PFLUM FRERICHS 1976 18816 PFLUM FRERICHS 1976 18817 PFLUM FRERICHS 1976 18818 PARKER 1954 18819 PARKER 1954

18820 PARKER 1954

18821 PARKER 1954

18822 PHLEGER $1955 \mathrm{~A}$

18823 PHLEGER 1951A

18824 PHLEGER $1951 \mathrm{~A}$
18825 PHLEGER $1951 \mathrm{~A}$
Generic Name

HANZAWAIA

HANZAWA I A

HANZAWAIA

HANZAWAIA

HANZ A WA I A

HANZAWAIA

HANZAWAIA

HANZAWAI A

HANZAWAIA

HANZAWAIA

HANZAWAIA

HANZAWAI A

HANZAWAI A

HANZAWAIA

HANZAWAIA

HANZAWA IA

HANZAWAIA

HANZAWAIA

HANZAWA I A

HANZAWAI A

HANZAWA IA

HANZAWAIA

HANZ AWAI A

HANZAWAI A

HANZ AWA I A

HANZAWAIA

HANZ AWA I A

HANZ AWA I A

HANZAWAIA

HANZ AWA I A

HANZAWAI A

HANZ AWA I A

HANZAWAI A

HANZAWAI A

HANZAWA I A

HANZAWAIA

HANZAWAIA

HANZ AWAI A

HANZ AWAI A

HANZAWAI A

HANZ AWAI A

HANZ AWA I A

HANZ AWA I A

HANZ AWA I A

HA VZ AWA I A

HANZAWA I A

HANZAWAI A

HANZAWAIA

HANZ AWA I A

HANZ AWAI A

HANZ AWAI A

HANZAWAIA

HANZ AWAIA

HAPLOPHRAGMIUM

HAPLOPHRAGMI UM

HAPLOPHRAGMIUM

HAPLOPHRAGMIUM

HA PLOPHRAGMOIDES

HAPLOPHRAGMOIDES

HAPLOPHRAGMOIDES

HAPLOPHRAGMOI DES

HAPLOPHRAGMOIDES

HAPLOPHRAGMOIDES

HAPLOPHRAGMOIDES

HAPL OPHRAGMOIDES

HAPLOPHRAGMOI DES

HAPLOPHRAGMOIDES

HAPLOPHRAGMOI DES

HAPLOPHRAGMOIDES

HAPLOPHRAGMOIDE

HAPLOPHRAGMO I DES

HAPLOPHRAGMOIDES

HAPLOPHRAGMOIDES

HAPLOPHRAGMOIDES

HAPLOPHRAGMOIDES

HAPLOPHRAGMOIDES

HAPLOPHRAGMOIDES

HAPLOPHRAGMOIDE

HAPLOPHRAGMOIDES

HAPLOPHRAGMOIDES

HAPLOPHRAGMOIDES

HAPLOPHRAGMOIDES

HAPLOPHRAGMOIDES

HAPLOPHRAGMOIDES

HAPLOPHRAGMOIDE

HAPLOPHRAGMOI DES

HAPLOPHRAGMOIDES

HAPLOPHRAGMOI DES

HAPL OPHRAGMOI DES

HAPLOPHRAGMOIDE

HAPLOPHRAGMOIDES
Specific Name

STRATIONI

STRATTONI

STRATTONI

STRATTONI

STRATTONI

STRATTONI

STRATTONI

STRATTON

STRATTONI

STRATTONI

STRATTONI

STRATTONI

STRATTONI

STRATTONI

STRATTONI

STRATTONI

STRAT TONI

STRATTONI

ST RAT TONI

STRATTONI

STRATTONI

STRATTONI

STRATTONI

STRATTONI

STRATTONI

STRATTON

STRATTONI

ST RATTONI

STRATTONI

STRATTONI

ST RATTONI

STRATTONI

STRATTONI

STRATTONI

STRATTONI

STRATTONI

STRATTONI

STRATTONI

STRATTONI

ST RATTONI

STRATTONI

STRATTONI

ST FATTONI

STRATTONI

STRATTONI

SIRATTONI

STRATTONI

STRATTONI

STRATTONI

STRATTONI

STRATTONI

LI TUOLI NO IDEUM

LI TUOLINO I DEUM

LI TUOLINO I DEUM

BRADYI

BRAYI

BRADYI

BRADYI

BRADYI

BRADYI

BRADYI

BRADYI

BRADYI

BRADYI

BRADYI

BRADYI

BRADYI

BRADYI

$B R A D Y$

BRADYI

BRADYI

BRADYI

BRADYI

BRADYI

BRADYI

BRADYI

BRADYI

BRADYI

BRADYI

BRADYI

BRADYI

BRADYI

Locality

NW GULF OF MEXICO

NE GULF OF MEXICO

NE GULF OF MEXICO

NE GULF OF MEXICO

NE GULF OF MEXICO

NE GULF OF MEXICO

NE GULF OF MEXICO

NE GULF OF MEXICO

NE GULF OF MEXICO

$N$ GULF OF MEXICO

MISSISSIPPI SOUND

CENTRAL TEXAS BAYS

NW GULF OF MEXICO

TEXAS GULF COAST

HEALD BANK, G. OF MEXICO

NW GULF OF MEXICO

NW GULF OF MEXICO

MISSISSIPPI DELTA

MATAMOROS, MEXICO 


\section{Publication}

18826 PHLEGER 1951A 18827 PHLEGER 1955A 18828 PHLEGER $1951 \mathrm{~A}$ 18829 PFLUM FRERICHS 1976 13830 DFLUM FRERICHS 1976 18831 PFLUM FRERICHS 1976 18832 PFLUM FRERICHS 1976 18832 PFLUM FRERICHS 1976

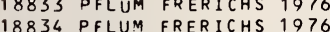
18834 PFLUM FRERICHS 1976
18835 PFLUM FRERICHS 1976 18836 PFLUM FRERICHS 1976 18837 PFLUM FRERICHS 1976 18838 BOCK 1976

18839 PARKER 1954

18840 PARKER 1954

18841 PARKER 1954

18842 PARKER 1954

18843 PARKER 1954

18844 PARKER 1954

18846 PFLUM FRERICHS 1976

18847 PFLUM FRERICHS 1976

18848 PFLUM FRERICHS 1976

18849 PFLUM FRERICHS 1976

18850 PARKER 1954

18851 PARKER 1954

18852 PARKER 1954

18853 PARKER 1954

18854 PARKER 1954

18855 PARKER 1954

8856 PARKER 1954

18857 PARKER 1954

18858 PARKER 1954

18860 PHLEGER 1955A

18861 PHLEGER 1955A

13862 PHLEGER 1955A

8863 PHLEGER 1955A

18864 PARKER 1954

18865 PARKER 1954

18866 PFLUM FRERICHS 1976

18867 PFLUM FRERICHS 1976

18868 PFLUM FRERICHS 1976 18869 PFLUM FRERICHS 1976 18870 PFLUM FRERICHS 1976 18871 PFLUM FRERICHS 1976 18872 PFLUM FRERICHS 1976 18873 PFLUM FRERICHS 1976 18874 PFLUM FRERICHS 1976 18875 PFLUM FRERICHS 1976 18876 PFLUM FRERICHS 1976 18877 PFLUM FRERICHS 1976 18878 PHLEGER 1951A

18879 PFLUM FRERICHS 1976 18880 PFLUM FRERICHS 1976 18881 PFLUM FRERICHS 1976 18882 PFLUM FRERICHS 1976 18883 PFLUM FRERICHS 1976 18884 PFLUM FRERICHS 1976 18885 PFLUM FRERICHS 1976 18886 PFLUM FRERICHS 1976 18887 PFLUM FRERICHS 1976 18888 PFLUM FRERICHS 1976 18889 PFLUM FRERICHS 1976 18890 PFLUM FRERICHS 1976 18891 PFLUM FRERICHS 1976 18892 PFLUM FRERICHS 1976 18893 PHLEGER 1951A 18894 PHLEGER $1951 \mathrm{~A}$ 18895 PHLEGER 1951 A 18896 PFLUM FRERICHS 1976 8897 PFLUM FRERICHS 1976 18898 PFLUM FRERICHS 1976 18899 PFLUM FRERICHS 1976 18900 PHLEGER 1951A 18901 PHLEGER 1951A 18902 PHLEGER 1951 A 18903 PHLEGER 1951A 18904 PHLEGER 1955 A 18905 PFLUM FRERICHS 1976 18906 PFLUM FRERICHS 1976 18907 PFLUM FRERICHS 1976 18908 PHLEGER $1951 \mathrm{~A}$ 18909 PHLEGER 1951A 18910 PHLEGER 1951A 18910 PHLEGER 1951A 18911 PHLEGER 1951 A
18912 PHLEGER $1951 \mathrm{~A}$ 18912 PHLEGER 1951A 18914 PHLEGER 1951A 18915 PHLEGER 1951A 18916 PHLEGEQ 1951A 18917 PHLEGER 1951A 18918 PHLEGER 1951A 18919 PHLEGER 1951 A 18920 PHLEGER 1951A
Generic Name

HAPLOPHRAGMOIDES HAPLOPHRAGMOI DES HAPLOPHRAGMOIDES HAPLOPHR AGMOIDES HAPLOPHRAGMOIDES HAPLOPHRAGMOI DES HAPLOPHRAGMOIDES HAPLOPHRAGMOIDES HAPLOPHRAGMOIDES HAPLOPHRAGMOIDES HAPLOPHRAGMOIDES HAPLOPHRAG MOIDES HAPL OPHRAGMOIDES HAPL OPHRAGMOIDES HAPLOPHR AGMOIDES HAPL OPHR AGMOIDES HAPLOPHRAGMOIDES HAPL OPHRAGMOI DES HAPLOPHRAGMO I DES HAPLOPHR AGMOI DES HAPLOPHR AGMOI DES HAPL OPHR AGMOIDES HAPL OPHR AGMOI DES HAPL OPHRAGMOIDES HAPLOPHR AGMOIDES HAPLOPHR AGMOIDES HAPLOPHRAGMOIDES HAPLOPHR AGMOIDES HAPLOPHRAGMOIDES HAPLOPHR AG MO I DES HAPL OPHRAGMOIDES HAPLOPHRAGMOIDES HAPL OPHR AGMOIDES HAPLOPHRAGMOIDES HAPLOPHR AGMOI DES HAPLOPHRAGMOIDES HAPLOPHR AGMOIDES HAPL OPHR AGMOI DES HAPLOPHRAGMOIDES HAPL OPHRAGMOI DES HAPL OPHRAGMOIDES HAPL OPHR AGMOI DES HAPLOPHRAGMOIDES HAPLOPHRAGMOIDES HAPLOPHRAGMOIDES HAPLOPHRAGMOIDES HAPL OPHRAGMOIDES HAPLOPHRAGMOI DES HAPLOPHRAGMOIDES HAPLOPHRAGMOIDES HAPL OPHRAGMOIDES HAPL OPHRAGMOI DES HAPLOPHRAGMOIDES HAPLOPHRAGMOIDES HAPL OPHRAGMOIDES HA PL OPHR AGMOIDES HAPLOPHRAGMOIDES HAPL OPHRAGMOIDES HAPLOPHRAGMOIDES HA PLOPHRAGMOIDES HAPLOPHR AGMO IDES HAPLOPHRAGMOIDES HAPLOPHRAGMOIDES HAPLOPHRAGMOIDES HAPLOPHRAGMOIDES HA PLOPHRAGMOIDES HAPLOPHRAGMOIDES HA PLOPHRAGMOIDES HAPLOPHRAGMOIDES HAPLOPHRAGMOIDES HAPLOPHRAGMOIDES HAPLOPHRAGMOIDES HA PLOPHRAGMOIDES HAPLOPHRAGMOI DES HAPLOPHRAGMOIDES HAPLOPHRAGMOIDES HAPL OPHRAGMOIDES HAPLOPHRAGMOIDES HAPLOPHRAGMOIDES HAPLOPHRAGMOIDES HAPL OPHRAGMOIDES HAPLOPHRAGMOIDES HAPLOPHR AGMOIDES HAPL OPHRAGMOIDES HAPLOPHRAGMOIDES HAPL OPHRAGMO I DES HAPLOPHRAGMOIDES HAPLOPHRAGMOI DES HAPLOPHRAGMOI DES HA PLOPHRAGMOIDES HAPLOPHRAGMOIDES HAPLOPHRAGMOIDES HAPL OPHRAGMOIDES
HAPLOPHRAGMOIDES HAPLOPHRAGMOIDES
Specific Name

BR ADY I

BR ADYI

BRADYI

BR ADYI

BRADYI

BRADYI

BR ADYI

BR ADYI

BRADYI

BRADYI

BRADYI

BRADYI

BR ADYI

BRADYI

BR ADYI

BRADYI

BR ADYI

BRADYI

BRADYI

BR ADYI

BRADYI
BRADYI

BRADYI

BRADYI

BR ADYI

BRADYI

BRADYI

BR ADYI

BR ADYI

BR ADYI

BR ADY I

BR ADYI

BR ADYI

BR ADYI

BRADYI

BR ADYI

BRADYI

BRADYI

BR ADYI

BRADYI

BR ADYI

BRADYI

BR ADYI

BRADYI

BRADYI

BR ADYI

BR ADYI

BRADYI

BR ADYI

BRADYI

BR ADYI

BR ADYI

BR ADYI

BRADYI

BRADYI

BRADYI

BRADYI

$B R$ ADYI

BRADYI

BR ADYI

BRADYI

BR ADYI

BRAOYI

BR ADYI

BR ADYI

BR ADYI

BR ADYI

BRADYI

BRADY I

BR ADYI

BR ADYI

BR ADYI

BR ADYI

BR ADY I

BR ADYI

BR ADYI

BR ADY I

BR ADYI

BRADYI

BRADYI

BRADYI

BRADYI

BR ADYI

BR ADY I

Locality

NW GULF OF MEXICO

$N$ GULF OF MEXICO

NW GULF OF MEXICO

CENTRAL GULF OF MEXICO

CENTRAL GULF OF MEXICO

CENTRAL GULF OF MEXICO

CENTRAL GULF OF MEXICO

CENTRAL GULF OF MEXICO

CENTRAL GULF OF MEXICO

CENTRAL GULF OF MEXICO

CENTRAL GULF OF MEXICO 


\section{Publication}

18921 PHLEGER 1951A 18922 PHLEGER 1951A 18923 PHLEGER 1951A 18924 PHLEGER 1951A 18925 PHLEGER 1951A 18926 BANOY 1954 18927 BANDY 1954 18928 BANDY 1954 18929 BANDY 1954 18931 BANDY 1954 18932 KORNFELD 1931

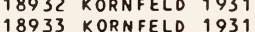
18934 KORNFELD 1931 18935 PHLEGER $1965 \mathrm{C}$ 18936 PFLUM FRERICHS 1976 18937 PFLUM FRERICHS 1976 18938 PFLUM FRERICHS 1976 18939 PFLUM FRERICHS 1976 18940 PFLUM FRERICHS 1976 18941 PFLUM FRERICHS 1976 18942 PFLUM FRERICHS 1976 18943 PFLUM FRERICHS 1976 18944 CUSHMAN 1920 18945 CUSHMAN 1920 18946 CUSHMAN 1920 18947 CUSHMAN 1920 18948 CUSHMAN 1920
18949 CUSHMAN 1920 18950 PHLEGER 1951A 18951 PHLEGER 1951 A 18952 PHLEGER 1951A 18953 PHLEGER 1951A 18954 PHLEGER 1951A 18955 PHLEGER 1951A 18956 PHLEGER 1951A 18957 PHLEGER 1951A 18958 PHLEGER 1951A 18959 PHLEGER 1951 A 18960 PHLEGER 1951A 18961 PHLEGER 1951A 18962 PHLEGER 1951A 18963 PHLEGER 1951A 18964 KANE 1962

18965 KANE 1967

18966 WARREN 1957

18967 WANTLAND 1969

18968 LANKFORD 1959

18969 WARREN 1956

18970 HALDRON 1963

18971 OTVOS 1978

18973 ANDERSEN 1952

18974 BANDY 1956

18975 BANDY 1956

18976 BANDY 1956

18977 BANDY 1956

18978 BANDY 1956

18979 CUSHMAN 1920

18980 CUSHMAN 1920

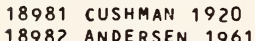

18983 CUSHMAN 1920

18984 CUSHMAN 1920

18985 CUSHMAN 1920

18986 CUSHMAN 1920

18987 CUSHMAN 1920

18988 CUSHMAN 1920

18989 CUSHMAN 1920

18990 CUSHMAN 1920

18991 PFLUM FRERICHS 1976 18992 PFLUM FRERICHS 1976 18993 PFLUM FRERICHS 1976 18994 PFLUM FRERICHS 1976 18995 PFLUM FRERICHS 1976 18996 PFLUM FRERICHS 1976 18997 PFLUM FRERICHS 1976 18998 PFLUM FRERICHS 1976 18999 PFLUM FRERICHS 1976 19000 PFLUM FRERICHS 1976 19001 PFLUM FRERICHS 1976 19002 PFLUM FRERICHS 1976 19003 PFLUM FRERICHS 1976 19004 PFLUM FRERICHS 1976 19005 PFLUM FRERICHS 1976 19006 PFLUM FRERICHS 1976 19007 PFLUM FRERICHS 1976 19008 PFLUM FRERICHS 1976 19009 PFLUM FRERICHS 1976 19010 PFLUM FRERICHS 1976 19011 PFLUM FRERICHS 1976 19012 PFLUM FRERICHS 1976 19013 PFLIJM FRERICHS 1976 19014 PFLUM FRERICHS 1976 19015 PFLUM FRERICHS 1976
Generic Name

HAPL OPHRAGMOIDES HA PLOPHRAGMOI DES HAPLOPHRAGMOIDES HAPL OPHRAGMOI DES HA PL OPHR AGMOI DES HAPL OPHRAGMOIDES HAPL OPHRAGMOI DES HAPL OPHRAGMOI DES HA PLOPHRAGMOIDES HAPL OPHRAGMOI DES HAPL OPHRAGMOIDES HAPLOPHRAGMOIDES HAPLOPHRAGMO I DES HA PL OPHRAGMOI DES HAPLOPHRAGMOI DES HAPL OPHRAGMOI DES HAPL OPHRAGMOIDES HA PL OPHRAGMOI DES HAPLOPHRAGMOIDES HAPLOPHRAGMOIDES HAPL OPHRAGMOIDES HAPLOPHRAGMOIDES HAPLOPHRAGMOIDES HAPL OPHRAGMOI DES HAPL OPHRAGMOIDES HAPLOPHRAGMOIDES HAPLOPHRAGMOIDES HAPL OPHRAGMOI DES HAPLOPHRAGMOIDES HAPL OPHRAGMOI DES HAPLOPHRAGMOIDES HAPLOPHRAGMOIDES HAPLOPHRAGMOIDES HAPL OPHRAGMOI DES HAPL OPHRAGMOIDES HAPLOPHRAGMOIDES HAPL OPHRAGMOIDES HAPLOPHRAGMOIDES HAPLOPHRAGMOIDES HAPL OPH RAGMOIDES HAPL OPHRAGMOIDES HAPL OPHRAGMOIDES HAPLOPHRAGMOIDES HA PLOPHRAGMOI DES HAPLOPHRAGMO IDES HAPL OPHRAGMOI DES HAPLOPHRAGMOI DES HAPLOPHRAGMOIDES HAPLOP HR AGMOIDES HAPLOPHRAGMOI DES H APLOPHR AGMOI DES HAPLOPHRAGMOIDES HAPLOPHRAGMOIDES HAPLOPHR AGMOI DES HAPLOPHRAGMOIDES HAPL OPHRAGMOIDES HAPLOPHRAGMOIDES HAPL OPHRAGMOI DES HAPLOPHRAGMOIDES HAPL OPHRAGM OI DES HAPL OPHRAGMOIDES HAPLOPHRAGMOIDES HAPL OPHRAGMOIDES HAPL OPHRAGMOI DES HAPLOPHRAGMOIDES HAPLOPHRAGMOIDES HAPLOPHRAGMOI DES HAPLOPHRAGMOIDES HAPLOPHRAGMOIDES HAPL OPHR AGMOI DES HAPL OPHRAGMOIDES HAPLOPHRAGMOIDES HAPLOPHRAGMOIDES HA PLOPHRAGMOIDES HAPL OPHRAGMOIDES HAPL OPHR AGMOI DES HAPLOPHRAGMOIDES HAPLOPHRAGMOIDES HAPL OPHRAGMOIDES HAPL OPHRAGMOIDES HAPL OPHRAGMOIDES HA PL OP HR AGMOI DES HAPL OPHRAGMOIDES HAPLOPHRAGMOIDES HAPLOPHRAGMO IDES HAPL OPHRAGMOIDES HAPL OPHR AGMOI DES HA PLOPHRAGMOIDES HAPL OPHR AGMOI DES HAPL OPHR AGMOI DES HAPLOPHRAGMOIDES HAPLOPHRAGMOIDES HAPL OPHRAGMOIDES HAPLOPHRAGMOIDES
Specific Name

BRADYI

BRADYI

BRADYI

BRADYI

CANARIENS IS MEXICANA

CAMARIENS IS MEXICANA

CAAARIENS IS MEXICANA

CANARIENS IS MEXICANA

CANARIENS IS MEXICANA

CANARIENS IS MEXICANA

CANARIENS IS MEXICANA

CANAR IENS IS MEXI CANA

CANARIENS IS MEXICANA

COLUMBIENSE

CORONATUS

CORONATUS

CORONATUS

CORONATUS

CORONATUS

CORONATUS

CORONATUS

CORONATUS

EMACI ATUM

EMACIATUM

EM AC I AT UM

EMACIATUM

EMAC I AT UM

EMACI ATUM

GL OMERATUM

GL OMERATUM

GL OMERATUM

GLOMERATUM

GL OMERA TU M

GL OME RA TUM

GL OMERA TUM

GL OMERA TUM

GL OMERATUM

GL OMERA TUM

GLCMERA TUM

GL OMERA TUM

GL OMERATUM

MANILAENS IS

MANILAENS IS

MANILAENS IS

MA AILAENS IS

MAAILAENS IS

MAAILAENS IS

MA A ILAENS IS

MANILAENS IS

MEXICANA

MEXICANA

ME XI CANA

ME XI CANA

MEXICANA

NITI DUM

NI TI DUM

NI TI DUM

PLANISSI4 A

RI NGENS

RINGENS

RINGENS

RI AGENS

SCITULUM

SCITULUM

SPHAERI LO CULUM

SP HAERI LO CULUS

SPHAERI LO CULUS

SP HAE R I LO CULUS

SPHAERILOCULUS

SPHAER I LO CULUS

SPHAERILJ CULUS

SPHAERILO CULUS

SPHAERILOCULUS

SPHAERILO CULUS

SPHAERILOCULUS

SPHAERILOCULUS

SPHAER ILO CULUS

SPHAER ILO CULUS

SPHAERILO CULUS

SP HAE RI LO CULUS

SPHAERILOCULUS

SPHAE RILOCULUS

SPHAERILOCULUS

SPHAERI LO CULUS

SPHAER I LO CULUS

SPHAERILO CULUS

SPHAE RI LO CULUS

SPHAERILOCULUS

SPHAERILOCULUS

SPHAERI LOCULUS

Locality

NW GULF OF MEXICO

NW GULF OF MEXICO

NH GULF OF MEXICO

NW GULF OF MEXICO

NH GULF OF MEXICO

NH GULF OF MEXICO

NH GULF OF MEXICO

NW GULF OF MEXICO 


\section{Publication}

19016 PFLUM FRERICHS 1976 19017 PFLUM FRERICHS 1976 19018 PFLUM FRERICHS 1976 19019 PFLUM FRERICHS 1976 19020 PFLUM FRERICHS 1976 19021 PFLUM FRERICHS 1976 19022 PFLUM FRERICHS 1976 9023 DFLUM FRERICHS 1976 19024 PFLUM FRERICHS 1976 19025 PFLUM FRERICHS 1976 19026 PFLUM FRERICHS 1976 19027 PFLUM FRERICHS 1976 19028 PFLUM FRERICHS 1976 19029 PFLUM FRERICHS 1976 19030 PFLUM FRERICHS 1976 9031 PFLUM FRERICHS 1976 19032 PFLUM FRERICHS 1976 19033 PFLUM FRERICHS 1976 19034 PFLUM FRERICHS 1976 19035 PFLUM FRERICHS 1976 19036 PFLUM FRERICHS 1976 9037 PFLUM FRERICHS 1976 9038 PFLUM FRERICHS 1976 9039 PFLUM FRERICHS 1976 19040 PFLUM FRERICHS 1976 19041 PFLUM FRERICHS 1976 19042 PFLUM FRERICHS 1976 19043 PFLUM FRERICHS 1976 9044 CUSHMAN 1920 19045 PHLEGER 19558 19046 PHLEGER 1954 19047 PHLEGER 1954 19048 DHLEGER 1954 19049 PHLEGER 1954 19050 PHLEGER $1965 \mathrm{C}$ 9051 WALTON 1960 9052 OTVOS 1978 19053 CUSHMAN 1920 19054 ANDERSEN 1952 19055 ANDERSEN 1952 19056 ANDERSEN 1952 19057 LANKFORD 1959 9058 WALDRON 1963 9059 KANE 1967 19060 KANE 1962 19061 WARREN 1956 19062 WANTLAND 1969 19063 PHLEGER $1965 \mathrm{C}$ 19064 WARREN 1957

19065 CUSHMAN 1920 19066 CUSHMAN 1920 19067 CUSHMAN 1920

19068 CUSHMAN 1920

9069 CUSHMAN 1922 A

19070 NORTON 1930

19071 NORTON 1930

9072 CUSHMAN $1922 \mathrm{~A}$

19073 NORTON 1930

19074 PHLEGER $1965 \mathrm{~A}$

19075 PHLEGER $1965 \mathrm{~A}$

9076 PHLEGER 1965 A

19078 PHLEGER 1965A

19078 PHLEGER 1965 A
19079 PHLEGER 1965 A

9080 PHLEGER 1965 A

19081 PFLUM FRERICHS 1976

19082 PFLUM FRERICHS 1976

19083 PFLUM FRERICHS 1976

19084 PFLUM FRERICHS 1976

19085 PFLUM FRERICHS 1976

19086 BENDA PURI 196?

19087 NORTON 1930

19088 CUSHMAN 1930

19089 CUSHMAN 1922 A

19091 PFLUM FRERICHS 1976

19091 PFLUM FRERICHS 1976
19092 PFLUM FRERICHS 1976

19093 CREAGER 1958

19094 CREAGER 1958

19095 CREAGER 1958

19096 PFLUM FRERICHS 1976 19097 PFLUM FRERICHS 1976 19098 PFLUM FRERICHS 1976 19099 PFLUM FRERICHS 1976 19100 PFLUM FRERICHS 1976 19101 PFLUM FRERICHS 1976 19102 PFLUM FRERICHS 1976 19103 PFLUM FRERICHS 1976 19104 PFLUM FRERICHS 1976 19105 PFLUM FRERICHS 1976 19106 PFLUM FRERICHS 1976 19107 BANOY 1956

19108 BANDY 1956

19109 PFLUM FRERICHS 1976

19110 PFLUM FRERICHS 1976

\section{Generic Name}

HAPLOPHRAGMOIDES HAPLOPHRAGMOIDES HAPLOPHRAGMOIDES HAPLOPHRAGMOIDES HAPLOPHRAGMOIDES HAPLOPHRAGMOIDES HAPLOPHRAGMOIDES HAPLOPHRAGMOIDES HAPLOPHRAGMOIDES HAPLOPHRAGMOIDES HAPLOPHRAGMOI DES HAPLOPHRAGMOIDES HAPLOPHRAGMOIDES HAPLOPHRAGMOIDES HAPLOPHRAGMOIDES HAPLOPHRAGMOIDES HAPLOPHRAGMOIDES HAPLOPHRAGMOIDES HAPLOPHRAGMOIDES HAPLOPHRAGMOIDES HAPLOPHRAGMOIDES HAPLOPHRAGMOIDES HAPLOPHRAGMOI DES HAPL OPHRAGMOIDES HAPLOPHRAGMOIDES HAPLOPHRAGMOIDES HAPLOPHRAGMOI DES HAPLOPHRAGMOIDES HAPLOPHRAGMOIDES HAPLOPHRAGMOIDES HAPLOPHRAGMOI DES HAPLOPHRAGMOIDES HAPLOPHRAGMOIDES HAPLOPHRAGMOIDES HAPLOPHRAGMOIDES HAPLOPHRAGMOIDES HAPLOPHRAGMOIDES HAPLOPHRAGMOI DES HAPLOPHRAGMOI DES HAPLOPHRAGMOIDES HAPLOPHRAGMOI DES HAPLOPHRAGMOIDES HAPLOPHRAG MOI DES HAPLOPHRAGMOIDES HAPLOPHRAGMOIDES HAPLOPHRAGMOIDES HAPLOPHRAGMOIDES HAPL OPHRAGMOIDES HAPLOPHRAGMOIDES HAPLOSTI ICHE HAPLOST ICHE HAPLOSTICHE HAPLOST I CHE

HAUER INA

HAUER INA

HAUER INA

HAUER INA

HAUERINA

HELENINA

HELENINA

HELEN INA

HELENINA

HELENINA

HELENINA

HELENINA

HERONALLENIA

HERONALLENI A

HE RONALLENIA

HE RONALLEN I A

HE RONALLENIA

HERONALLENIA

HETEROSTEGINA

HETEROSTEGINA

HOEGLUND INA

HOEGLUNDINA

HOEGLUNDINA

HOEGLUNDINA

HOE GL UN D INA

HOEGLUNDINA

HOEGLUNDINA

HOEGLUNDINA

HOEGLUNDINA

HOEGLUNDINA

HOEGLUNDINA

HOE GLUNDINA

HOEGLUNDINA

HOEGLUNDINA

HOEGLUNDINA

HOEGLUNDINA

HOEGLUNDINA

HOEGLUNDINA

HOEGLUNDINA

HOEGLUND INA
Specific Name

SP HAERILO CULUS

SPHAERI LO CULUS

SPHAERI LOCULUS

SPHAERILO CULUS

SPHAER I LO CULUS

SPHAERILO CULUS

SPHAERI LO CULUS

SPHAER I LOCULUS

SPHAERI LJ CULUS

SPHAERI LO CULUS

SPHAERI LJ CULUS

SPHAERI LJ CULUS

SPHAER I LJ CULUS

SPHAERI LOCULUS

SPHAERI LJ CULUS

SPHAERILO CULUS

SPHAERI LJ CULUS

SPHAER I LO CULUS

SPHAER I LO CULUS

SPHAER I LO CULUS

SPHAERI LO CULUS

SP HAERI LO CULUS

SPHAERI LO CULUS

SPHAERILJ CULUS

SPHAERI LJ CULUS

SPHAERI LOCULUS

SP HAER I LO CULUS

SP HAER I LO CULUS

SUBGL OBOS UM

SUBINVOLUTUM

SUEINVOLUTUM

SUEINVOLU TUM

SUBINVOLUTUM

SUEINVOLUTUM

SUBINVOLJTUM

SUBINVOLUTUM

SUBINVOLUTUM

TR LLL IS SA TA

W I LBERT I

WI LBERT I

WI LBERT I

WI LBERT I

WI LBERT I

WI LBERT I

WI LBERT I

W I BERT I

WI LBERTI

DUEIA

DUEIA

DUEIA

DUBIA

BRADYI

BRADY I

FRAGILISS IMA

OR NATIS SI MA

ORAATISSIMA

AN DER SENI

A N DER SENI

ANDER SENI

AN DER SENI

AN DERSENI

AN DERSENI

AN CERSENI

GEMMATA

GEMMATA

GEMMATA

GEMMATA

GE MMATA

LI AGULATA

ANTILLARJM

AN TILLARUM

AN TILLARUM

ELEGANS

ELEGANS

ELEGANS

ELEGANS

ELEGANS

ELEGANS

ELEGANS

ELEGANS

ELEGANS

EL EGANS

ELEGANS

ELEGANS

ELEGANS

ELEGANS

ELEGANS

ELEGANS

ELEGANS

ELEGANS

ELEGANS

ELEGANS

\section{Locality}

CENTRAL GULF OF MEXICO

CENTRAL GULF OF MEXICO

NW GULF OF MEXICO

$N W$ GULF OF MEXICO 


\section{Publication}

19111 BANDY 1956 19112 PFLUM FRERICHS 1976 19113 PFLUM FRERICHS 1976 19114 PFLUM FRERICHS 1976 19115 PHLEGER 1955A

19116 PFLUM FRERICHS 1976 19117 PFLUM FRERICHS 1976 19118 PFLUM FRERICHS 1976 19119 PFLUM FRERICHS 1976 19120 PFLUM FRERICHS 1976 19121 PFLUM FRERICHS 1976 19122 PFLUM FRERICHS 1976 19123 PFLUM FRERICHS 1976 19124 PFLUM FRERICHS 1976 19125 PFLUM FRERICHS 1976 19126 PFLUM FRERICHS 1976 19127 PFLUM FRERICHS 1976 19128 PFLUM FRERICHS 1976 19129 PFLUM FRERICHS 1976 19130 PFLUM FRERICHS 1976 19131 PFLUM FRERICHS 1976 19132 PFLUM FRERICHS 1976 19133 PFLUM FRERICHS 1976 19134 PFLUM FRERICHS 1976 19135 PFLUM FRERICHS 1976 19136 PFLUM FRERICHS 1976 19137 PFLUM FRERICHS 1976 19138 PFLUM FRERICHS 1976 19139 PFLUM FRERICHS 1976 19140 PFLUM FRERICHS 1976 9141 PFLUM FRERICHS 1976 1914? PFLUM FRERICHS 1976 19143 PARKER 1954

19144 PHLEGER $1951 \mathrm{~A}$

19145 PFLUM FRERICHS 1976 19146 PFLUM FRERICHS 1976 19147 PFLUM FRERICHS 1976 19148 PFLUM FRERICHS 1976 19149 PFLUM FRERICHS 1976 19150 PFLUM FRERICHS 1976 19151 PFLUM FRERICHS 1976 19152 PFLUM FRERICHS 1976 19153 PFLUM FRERICHS 1976 19154 PFLUM FRERICHS 1976 19155 PFLUM FRERICHS 1976 19156 PFLUM FRERICHS 1976 19157 PFLUM FRERICHS 1976 19158 PFLUM FRERICHS 1976 19159 PFLUM FRERICHS 1976 19160 PFLUM FRERICHS 1976 19161 PFLUM FRERICHS 1976 19162 PFLUM FRERICHS 1976 19163 PFLUM FRERICHS 1976 19164 PFLUM FRERICHS 1976 19165 PFLUM FRERICHS 1976 19166 PFLUM FRERICHS 1976 19167 PFLUM FRERICHS 1976 19168 CREAGER 1958

19169 PFLUM FRERICHS 1976 19170 PFLUM FRERICHS 1976 19171 PFLUM FRERICHS 1976 19172 PFLUM FRERICHS 1976 19173 PFLUM FRERICHS 1976 19174 PFLUM FRERICHS 1976 19175 PFLUM FRERICHS 1976 19176 PARKER 1954

19177 PHLEGER 1951A

19178 PHLEGER 1951A 19179 PHLEGER 1951A 19180 PARKER 1954

19181 PARKER 1954

19182 PARKER 1954

19183 PFLUM FRERICHS 1976

19184 PHLEGER 195SA

19185 PHLEGER 1951A

19186 PHLEGER 1951A

19187 PHLEGER 1951A

19188 PHLEGER 1951A

19189 PHLEGER 1951A

19190 PARKER 1954

19191 PARKER 1954

19192 PARKER 1954

19193 PARKER 1954

19194 PARKER 1954

19195 PARKER 1954

19196 PARKER 1954

19197 LUDWICK WALTON 1957

19198 PARKER 1954
19199 LANKFORD 1959

19200 PARKER 1954

19201 PARKER 1954

19202 CREAGER 1958

19203 CREAGER 1958

19204 PHLEGER 1951A

19205 PHLEGER 1951A
Generic Name

HOEGLUNDINA

HOEGLUNDINA

HOE GLUND INA

HOEGLUNDINA

HOEGLUNDINA

HOEGLUNDINA

HOEGLUNDINA

HOEGLUNDINA

HOEGLUNDINA

HOEGLUNDINA

HOEGLUNDINA

HOEGLUNDINA

HOEGLUNDINA

HOEGLUNDINA

HOEGLUNDINA

HOEGLUNDINA

HOEGLUNDINA

HOEGLUNDINA

HOEGLUNDINA

HOEGLUNDINA

HOEGLUNDINA

HOEGLUNDINA

HOEGLUNDINA

HOEGLUNDINA

HOEGLUNDINA

HOEGLUNDINA

HOEGLUNDINA

HOEGLUNDINA

HOEGLUNDINA

HOEGLUNDINA

HOEGLUNDINA

HOEGLUNDINA

HOEGLUNDINA

HOEGLUNDINA

HOEGLUNDINA

HOEGLUNDINA

HOEGLUNDINA

HOEGLUN DINA

HOEGLUNDINA

HOEGLUNDINA

HOEGLUND INA

HOEGLUNDINA

HOEGLUNDINA

HOEGLUNDINA

HOEGLUND INA

HOEGLUND INA

HOEGLUND INA

HOEGLUND INA

HOEGLUNDINA

HOEGLUNDINA

HOEGLUND INA

HOEGLUNDINA

HOEGLUNDINA

HOEGLUNDINA

HOEGLUNDINA

HOEGLUND INA

HOEGLUNDINA

HOE GLUNDINA

HOEGLUNDINA

HOEGLUNDINA

HOEGLUND INA

HOEGLUNDINA

HOEGLUNDINA

HOEGLUNDINA

HOEGLUNDINA

HOEGLUNDINA

HOEGLUNDINA

HOEGLUNDINA

HOEGLUNDINA

HOEGLUNDINA

HOEGLUNDINA

HOEGLUNDINA

HOEGLUNDINA

HOEGLUND INA

HOEGLUNDINA

HOEGLUNDINA

HOEGLUNDINA

HOEGLUNDINA

HOEGLUNDINA

HOEGLUNDINA

HOEGLUNDINA

HOEGLUNDINA

HOEGLUNDINA

HOEGLUNDINA

HOEGLUNDINA

HOEGLUNDINA

HOEGLUNDINA

HOEGLUNDINA

HOEGLUNDINA

HOEGLUNDINA

HOEGLUNDINA

HOEGLUNDINA
Specific Name

ELEGANS

ELEGANS

ELEGANS

ELEGANS

ELEGANS

ELEGANS

ELEGANS

ELEGANS

ELEGANS

ELEGANS

ELEGANS

ELEGANS

ELEGANS

ELEGANS

LEGANS

ELEGANS

ELEGANS

ELEGANS

ELEGANS

ELEGANS

ELEGANS

ELEGANS

ELEGANS

ELEGANS

ELEGANS

ELEGANS

ELEGANS

ELEGANS

ELEGANS

ELEGANS

ELEGANS

ELEGANS

ELEGANS

ELEGANS

ELEGANS

ELEGANS

ELEGANS

ELEGANS

ELEGANS

ELEGANS

ELEGANS

ELEGANS

ELEGANS

ELEGANS

ELEGANS

LEGANS

ELEGANS

ELEGANS

ELEGANS

ELEGANS

ELEGANS

ELEGANS

ELEGANS

ELEGANS

ELEGANS

ELEGANS

ELEGANS

ELEGANS

LLGANS

ELEGANS

ELEGANS

ELEGANS

ELEGANS

ELEGANS

ELGANS

LEGAN

ELEGANS

ELEGANS

ELEGANS

ELEGANS

ELEGANS

ELEGANS

ELEGAN

ELEGANS

ELEGANS

ELEGAN

ELEGANS

ELEGANS

ELEGANS

ELEGANS

ELEGANS

ELEGANS

ELEGAN

ELEGANS

ELEGANS

ELEGANS

ELEGANS

Locality

Lat. Long.

NE GULF OF MEXICO

NW GULF OF MEXICO

NW GULF OF MEXICO

$N W$ GULF OF MEXICO

$N$ GULF OF MEXICO

NW GULF OF MEXICO

NW GULF OF MEXICO

NW GULF OF MEXICO

NW GULF OF MEXICO

$\mathrm{NW}$ GULF OF MEXICO

NW GULF OF MEXICO 


\section{Publication}

19206 PHLEGER 1951A 19207 CREAGER 1958 19208 PARKER 1954 19209 PARKER 1954 19210 PARKER 1954 19211 PARKER 1754 19212 PARKER 1954 19213 PARKER 1954 19214 PARKER 1954 19215 PHLFGER 1951A 19216 CREAGER 1958

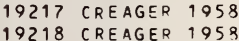
19218 CREAGER 1958 19220 CREAGER 1958 19221 CREAGER 1953 19222 CREATER 1958 19223 CREAGER 1958 9224 CREAGER 1958 19225 CREAGER 1958 19226 PHLEGER 1951 A 19227 PHLEGER 1951A 19229 PHLEGER 1951 A 19230 PHLEGER 1951A 19231 PHLEGEP 1951 A 19232 PHLEGER 1951 A 19233 PHLEGER 1951 A 19234 PHLEGER 1951 A 19235 PHLEGER 1951 A 19236 PHLEGER 1951A 19237 PHLEGER 1955A 19238. PHLEGED 1951A
19239 PHLEGER 1955A 19240 PHLEGER 1951A 19241 PHLEGER 1951A 19242 CUSHMAN $1922 \mathrm{~A}$ 19243 NORTON 1930

19244 PFLUM FRERICHS 1976 19245 LEROY HODGKINSON 1975 19246 PFLUM FRERICHS 1976 19247 PFLUM FRERICHS 1976 19248 PFLUM FRERICHS 1976 19249 PFLUM FRERICHS 1976 19250 PFLUM FRERICHS 1976 19251 FFLUM FRERICHS 1976 19252 PFLUM FRERICHS 1976 19253 PFLUM FRERICHS 1976 19254 PFLUM FRERICHS 1976 19255 PFLUM FRERICHS 1976 19256 PFLUM FRERICHS 1976 19257 PFLUM FRERICHS 1976 19258 PFLUM FRERICHS 1976 19259 PFLUM FRERICHS 1976 19260 PFLUM FRERICHS 1976 19261 PFLUM FRERICHS 1976 19262 PFLUM FRERICHS 1976 19263 PFLUM FRERICHS 1976 19264 PFLUM FRERICHS 1976 19265 PFLUM FRERICHS 1976 19266 PFLUM FRERICHS 1976 19267 PFLUM FRERICHS 1976 19268 PFLUM FRERICHS 1976 19269 PFLUM FRERICHS 1976 19270 PFLUM FRERICHS 1976 19271 PFLUM FRERICHS 1976 19272 PFLUM FRERICHS 1976 19273 PFLUM FRERICHS 1976 19274 PFLUM FRERICHS 1976 19275 PFLUM FRERICHS 1976 19276 PFLUM FRERICHS 1976 19277 PFL'JM FPERICHS 1976 19278 PFLUM FRERICHS 1976 19279 PFLUM FRERICHS 1976 19280 DFLUM FRERICHS 1976 19281 PFLUM FRERICHS 1976 19282 PFLUM FRERICHS 1976 19283 PFLUM FRERICHS 1976 19284 PFLU M FRERICHS 1976 19285 PFLUM FRERICHS 1976 19286 PFLUM FRERICHS 1976 19287 PFLUM FRERICHS 1976 19288 PFLUM FRERICHS 1976 19289 PFLUM FRERICHS 1976 19290 PFLUM FRERICHS 1976 19291 PFLUM FRERICHS 1976 19292 PFLUM FRERICHS 1976 19293 LERDY HODGKINSON 1975 19294 PFLUM FRERICH 19295 PFLUY FRERICHS 1976
19296 PFLUM FRERICHS 1976 19296 PFLUM FRERICHS 1976
19297 PFLUM FRERICHS 1976 19298 PFLUM FRERICHS 1976 19299 PFLUM FRERICHS 1976 19300 CUSHMAN 1920
Generic Name

Specific Name

Locality

Lat. Long.

HOEGLUNDINA

HOEGLUNDINA

HOEGLUNDINA
HOEGLUNDINA

HOEGLUNDINA

HOEGLUNDINA

HOEGLUNDINA

HOEGLUND INA

HOEGLUNDINA

HOEGLUNDINA

HOEGLUNDINA

HOEGLUNDINA

HOEGLUNDINA

HOEGLUNDINA

HOEGLUNDINA

HOEGLUNDINA

HOEGLUND INA

HOEGLIIN DINA

HOEGLUNDINA

HOEGLUNDINA

HOEGLUNDINA

HOEGLUND INA

HOEGLUNDINA

HOEGLUNDINA

HOEGLUNDINA

HOEGLUNDINA

HOEGLUNDINA

HOEGLUNDINA

HOEGLUNDINA

HOEGLUNDINA

HOEGLUNDINA

HOEGLUNDINA

HOEGLUNDINA

HOEGLUNDINA

HOEGLUNDINA

HOEGLUNDINA

HOMOTREMA

HORMOSINA

HORMOSINA

HORMOSINA

HORMOSINA

HORMOSINA

HORMOS INA

HORMOSINA

HORMOSINA

HORMOSINA

HORMOSINA

HORMOSINA

HORMOSINA

HORMOS INA

HORMOSINA

HORMOSINA

HORMOS INA

HORMOS INA

HORMOS INA

HORMOSINA

HORMOS INA

HORMOSINA

HORMOS INA

HORMOS INA

HORMOSINA

HORMOSINA

HORYOSINA

HORMOS INA

HORMOSINA

HORMOSINA

HORMOS INA

HORMOSINA

HORMOSINA

HORMOSINA

HORMOS INA

HORMOSINA

HORMOS INA

HORMOS INA

HORMOSINA

HORMOSINA

HORMOSINA

HORMOSINA

HORMOS INA

ORMOS INA

HO RMOS IN A

HORMOS INA

HORMOS INA

HORMOSINA

HORMOS INA

HORMOSINA

HORIAOS INA

HORMOS INA

HORMOSINA

HORMOSINA

HORMOS INA

HORMOSINA

HORMOS INA

HORMOS INA

HORMOSINA
ELEGANS

ELEGANS

ELEGANS

ELEGANS

ELEGANS

ELEGANS

ELEGANS

ELEGANS

ELEGANS

ELEGANS

ELEGANS

ELEGANS

ELEGANS

ELEGANS

ELEGANS

ELEGANS

ELEGANS

ELEGANS

ELEGANS

ELEGANS

ELEGANS

ELEGANS

ELEGANS

ELEGANS

ELEGANS

ELEGANS

ELEGANS

ELEGANS

ELEGANS

ELEGANS

ELEGANS

RUBRUM

RUBRUM

CARPENTER I

CARPENTER

CARPENTER

CARPENTER

CARPENTER I

CARPENTER I

CARPENTER I

CARPENTEP I

C A RPENTER I

CARPENTER

CARPENTER

CARPENTER I

CA RPENTEP I

CARPENTER I

C A RPENTER I

CARPENTER

CARPENTER

CARPENTER

C A RPENTER I

CARPENTER I

CARPENTER I

CARPENTER I

CARPENTEP I

CARPENTER

CARPENTER I

CARPENTER I

CA RPENTER I

DISTANS DELICATULA

DI STANS DELICATULA

DI STANS DELICATULA

DI STANS DELICATULA

DI STANS DELICATULA

DISTANS DELICATULA

DI STANS DELICATULA

DI STANS DELICATULA

GL OBULIFERA

GLOBULIFERA

GL OBULIFERA

GL CBULIF $=R A$

GL OBULIFERA

GL OBULI IFE RA

I FE RA

GL OBULIFERA

GLOBULIFERA

GL CBULI IFE RA

GLOBULIFE RA

GLOBULIFERA

GL OBULIFERA

GL OBUL IFERA

GL CBULIIFERA

GL OBULIFERA

GLOBULIFERA

GL OBUL IFERA

GL OBUL IFERA

GL CBULIFERA
NW GULF OF MEXICO

BAY OF CAMPECHE

NE GULF OF MEXICO

NE GULF OF MEXICO

NE GULF OF MEXICO

NE GULF OF MEXICO

NE GULF OF MEXICO

NE GULF OF MEXICO

NE GULF OF MEXICO 


\section{Publication}

19301 PFLUM FRERICHS 1976 19302 PFLUM FRERICHS 1976 19303 PFLUM FRERICHS 1976 19304 PFLUM FRERICHS 1976 19305 PFLUM FRERICHS 1976 19306 PFLUM FRERICHS 1976 19307 LEROY HODGKINSON 1975 19308 CUSHMAN 1920 19309 CUSHMAN 1920 19310 CUSHMAN 1920 19311 CUSHMAN 1920 19312 CUSHMAN 1920 19313 CUSHMAN 1920 19314 PFLUY FRERICHS 1976 19315 PFLUM FRERICHS 1976 19316 PFLUM FRERICHS 1976 19317 CUSHMAN 1920 19318 CUSHMAN 1920 19319 CUSHMAN 1920

19320 PFLUM FRERICHS 1976 19321 CUSHMAN 1920

19322 PFLUM FRERICHS 1976 19323 PFLUM FRERICHS 1976 19324 PFLUM FRERICHS 1976 19325 PFLUM FRERICHS 1976 19326 PFLUM FRERICHS 1976 19327 PFLUM FRERICHS 1976 19328 PFLUM FRERICHS 1976 19329 PFLUM FRERICHS 1976 19330 PFLUM FRERICHS 1976 19331 PFLUM FRERICHS 1976 19332 PFLUM FRERICHS 1976 19333 CUSHMAN 1920 19334 CUSHMAN 1920

19335 PFLUM FRERICHS 1976 19336 PFLUM FRERICHS 1976 19337 PFLUM FRERICHS 1976 19338 PFLUM FRERICHS 1976 19339 PFLUM FRERICHS 1976 19340 PFLUM FRERICHS 1976 19341 PFLUM FRERICHS 1976 19342 PFLUM FRERICHS 1976 19343 PFLUM FRERICHS 1976 19344 PFLU Y FRERICHS 1976 19345 CUSHMAN 1918 19346 CUSHMAN 1918 19347 CUSHMAN 1918

19348 PFLUM FRERICHS 1976 19349 PFLUM FRERICHS 1976 19350 CUSHMAN 1918

19351 CUSHMAN 1918

19352 PFLUM FRERICHS 1976 19353 LEROY HODGKINSON 1975 19354 CUSHMAN 1918

19355 PFLUM FRERICHS 1976 19356 PFLUM FRERICHS 1976 19357 PFLUM FRERICHS 1976 19358 PFLUM FRERICHS 1976 19359 PFLUM FRERICHS 1976 19360 PFLUM FRERICHS 1976 19361 PFLUM FRERICHS 1976 19362 PFLUM FRERICHS 1976 19363 PFLUM FRERICHS 1976 19364 PFLUM FRERICHS 1976 19365 PFLUM FRERICHS 1976 19366 PFLUM FRERICHS 1976 10367 PFLUM FRERICHS 1976 19368 PFLUM FRERICHS 1976 19369 PFLUM FRERICHS 1976 19370 PFLUM FPERICHS 1976 19371 LEROY HODGKINSON 1975 19372 PFLUM FRERICHS 1976 19373 PFLUM FRERICHS 1976 19374 PFLUM FRERICHS 1976 19375 PFLUM FRERICHS 1976 19376 CUSHMAN 1918 19377 CUSHMAN 1918

19378 PFLUM FRERICHS 1976 19379 PFLUM FRERICHS 1976 19380 PFLUM FRERICHS 1976 19381 PFLUM FRERICHS 1976 19382 PFLUM FRERICHS 1976 19383 PFLUM FRERICHS 1976 19384 PFLUY FRERICHS 1976 19385 PFLUM FRERICHS 1976 19386 PFLUM FRERICHS 1976 19387 CUSHMAN $1922 \mathrm{~A}$

19388 PFLUM FRERICHS 1976 19389 PFLUM FRERICHS 1976 19390 PHLEGER 1965 A

19391 PARKER PHLEGER PEIRSON 1953 19392 SHEPARD MOORE 1955

19393 OTVOS 1978

19394 PHLEGER LANKFORD 1978

19395 PHLEGER 1965 A
Generic Name

HORMOS INA

HORMOSINA

HORMOSINA

HORMOSINA

HORMOS INA

HORMOS INA

HORMOSINA

HORMOS INA

HORMOSINA

HORMOSINA

HORMOS INA

HORMOS INA

HORMOS INA

HORMOS INA

HORMOSINA

HORMOSINA

HORMOS INA

HORMOSINA

HORMOS INA

HORMOS INA

HORMOS INA

HORMOSINA

H.ORMOS INA

HORMOSINA

HORMOS INA

HORMOS INA

HORMOS INA

HORMOS INA

HORMOSINA

HORMOS INA

HORMOSINA

HORMOS INA

HY PERAMMINA

HYPERAMMINA

HYPERAMMIN A

HYPERAMMINA

HYPERAMMINA

HYPERAMMINA

HYDERAMMINA

HYPERAMMINA

HYPERAMMINA

HYPERAMMINA

HYPER AMMINA

HYPERAMMINA

HYPERAMMINA

HYPERAMMINA

HYPERAMMINA

HY PERAMMINA

HY PERAMMINA

HYPERAMMINA

HYPERAMMINA

HYPERAMMINA

HYPERAMMINA

HYPERAMMINA

HYPERAMMINA

HYPERAMMINA

HYPERAMMINA

HYPERAMMINA

HYPERAMMINA

HYPERAMMINA

HYPERAMMINA

HYPERAMMINA

HYPERAMMINA
HYPERAMMINA

HYPERAMMINA

HYPERAMMINA

HYPERAMMINA

HYPERAMMINA

HYPERAMMINA

HYPERAMMINA

HYPERAMMINA

HYPERAMMINA

HYPERAMMINA

HYPERAMMINA

HYPERAMMINA

HYPERAMMINA

HYPERAMMINA

HYPERAMMINA

HYPERAMMINA

HYPERAMMINA

HYPERAMMINA

HYPERAMMINA

HYPERAMMINA

IR IDIA

I SLANDIELLA

I SLANDIELL

J A DAMMINA

JADAMM I NA

JADAMMINA

J ADAMMINA

JADAMMINA
Specific Name

GL CBUL I FE RA

GL CBUL I FE RA

GL CBUL I FE RA

GL OBUL I FE RA

GL OBUL I FERA

GL CBULIFERA

MONILE

MONILE

OV AL I FORY IS

OVALIF ORM IS

OVALI FORM IS

OVALIFORM IS

OVICULA

OV I CULA

OVI CULA

OVICULA

OVICULA

OVICULA

OV I CULA

OVI CULA

OV ICULA

OV ICULA

OV I CULA

OVICULA

OVICULA

OV I CULA

OV I CULA

OVICULA

OV I CULA

OVICULA

OVICULA MEXICANA

OVICULA MEXICANA

CYLINDRICA

CYLINDRICA

CYLINDRICA

CYLINDRICA

CYLINDRICA

CYLINDRICA

CYLINDR ICA

CYLINDRIC A

CYLINDR ICA

CYLINDRICA

I STORTA

DI STORTA

EL ONGATA

FRIABILIS

FRIABIL IS

FR IAB IL IS

FR IAB IL IS

FR I AB IL IS

FRIABILIS

FRIABILIS

FR I ABIL IS

FR IABILIS

FR I ABIL IS

FR IABILIS

FR IAB IL IS

FRIABIL IS

FR IABILIS

FR IABILIS

FRIABIL IS

FRIABILIS

FRIABIL IS

FR IABILIS

FRIABILIS

FRIABILIS

FR IABILIS

FR IABIL IS

LAEVIGATA

LAEVIGATA

LAEVIGATA

LAEVIGATA

LAEVIGATA

LAEVIGATA

LAEVIGATA

LAEVIGATA

LAEVIGATA

LAEVIGATA

LAEVI GATA

LAEVIGATA

LAEVIGATA

LAEVIGATA

LAEVIGATA

LAEVIGATA

DI APHANA

NORCROSSI AUSTRALIS

NORCROSSI AUSTRALIS

POLYSTOMA

POLYSTOMA

POLYSTOMA

POLYSTOMA

POLYSTOMA

POLYSTOMA

Locality

CENTRAL GULF OF MEXICO

NW GULF OF MEXICO

$N W$ GULF OF MEXICO

$N W$ GULF OF MEXICO

NW GULF OF MEXICO 
Publication

19396 PHLEGER 1965 A

19397 PFLUM FRERICHS 1976

19398 PFLUM FRERICHS 1976

19399 PFLUM FRERICHS 1976

9400 PFLUM FRERICHS 1976

9401 PFLUM FRERICHS 1976

19402 PFLUM FRERICHS 1976

19403 PFLUM FRERICHS 1976

19404 PFLUM FRERICHS 1976

19405 PFLUM FRERICHS 1976

19406 PFLUM FRERICHS 1976

19407 PFLUM FRERICHS 1976

19408 PFLUM FRERICHS 1976

19409 PFLUM FRERICHS 1976

19410 PFLUM FRERICHS 1976

19411 PFLUM FRERICHS 1976

19412 PFLUM FRERICHS 1976

19413 PFLUM FRERICHS 1976

19414 PFLUM FRERICHS 1976

19415 PFLUM FRERICHS 1976

19416 PFLUM FRERICHS 1976

19417 PFLUM FRERICHS 1976

19418 PFLUM FRERICHS 1976

19419 PFLUM FRERICHS 1976

19420 PFLUM FRERICHS 1976

19421 PFLUM FRERICHS 1976

19422 PFLUM FRERICHS 1976

19423 PFLUM FRERICHS 1976

19424 PFLUM FRERICHS 1976

19425 PFLUM FRERICHS 1976

19426 PFLUM FRERICHS 1976

19427 PFLUM FRERICHS 1976

19428 PFLUM FRERICHS 1976

19429 PFLUM FRERICHS 1976

19430 PFLUM FRERICHS 1976

19431 PFLUM FRERICHS 1976
19432 LEROY HODGKINSON 197

19433 PFLUM FRERICHS 1976

19433
19434
PFLLUM FRERICHS 1976

19435 PFLUM FRERICHS 1976

19436 PFLUM FRERICHS 1976

19437 PFLUM FRERICHS 1976

19438 PFLUM FRERICHS 1976

19439 PFLUM FRERICHS 1976

19440 PFLUM FRERICHS 1976

19441 PFLUM FRERICHS 1976

19442 PFLUM FRERICHS 1976

19443 PFLUM FRERICHS 1976

19444 PFLUM FRERICHS 1976

19445 PFLUM FRERICHS 1976

19446 PFLUM FRERICHS 1976

19447 PFLUM FRERICHS 1976

19448 PFLUM FRERICHS 1976

19449 PFLUM FRERICHS 1976

19450 PFLUM FRERICHS 1976

19451 PFLUM FRERICHS 1976

19452 PFLUM FRERICHS 1976

19453 PFLUM FRERICHS 1976

19454 PFLUM FRERICHS 1976

19455 PFLUM FRERICHS 1976

19456 PFLUM FRERICHS 1976

19457 PFLUM FRERICHS 1976

19458 PFLUM FRERICHS 1976

19459 PFLUM FRERICHS 1976

19460 PFLUM FRERICHS 1976

19461 PARKER 1954

19462 PARKER 1954

19463 PFLUM FRERICHS 1976

19464 PFLUM FRERICHS 1976

19465 PFLUM FRERICHS 1976

19466 CREAGER 1958

19467 CREAGER 1958

19468 CREAGER 1958

19469 CREAGER 1958

19470 PARKER 1954

19471 PFLUM FRERICHS 1976

19472 PFLUM FRERICHS 1976

19473 PFLUM FRERICHS 1976

19474 PARKER 1954

19475 PARKER 1954

19476 PARKER 1954

19477 PARKER 1954

19478 PARKER 1954

19479 PFLUM FRERICHS 1976

19480 PFLUM FRERICHS 1976

19481 PFLUM FRERICHS 1976

19482 PFLUM FRERICHS 1976

19483 PFLUM FRERICHS 1976

19484 PARKER 1954

19485 PARKER 1954

19486 PARKER 1954

19487 PARKER 1954

19488 PARKER 1954 PFLUM FRERICHS 1976

19490 PFLUM FRERICHS 1976
Generic Name

J A DAMM I NA

KARRER I ELLA

KARRERIELLA

KARRER IELLA

KARRER IELLA

KARRERI ELLA

KARRERIELLA

KARRERIELLA

KARRERIELLA

KARRERIELLA

KARRERIELLA

KARRERIELLA

KARRERI ELLA

KARRERI ELLA

KARRERI ELLA

KARRERIELLA

KARRER I ELLA

KA RRERIELLA

KARRER I ELLA

KARRER I ELLA

KARRERIELLA

KARRER IELLA

KARRER I

KARRERIELLA

KARRERIELLA

KARRER I ELLA

KARRERIELLA

KARRER IELLA

KARRERIELLA

KARRERIELLA

KARRER IELLA

KARRERIELLA

KARRER IELLA

KARRER I ELLA

KARRER I ELLA

KA RRER I ELLA

KARRERIELLA

KARRERIELLA

KARRERI ELLA

KARRERIELLA

KARRERIELLA

KARRERI ELLA

KARRER IELLA

KARRERIELLA

KARRERIELLA

KARRER IELLA

KARRER I ELLA

KARRER I ELLA

KA RRER I ELL A

KARRERIELLA

KARRER IELLA

KARRERIELLA

KARRER IELLA

KARRERI ELL A

KARRER I ELL A

KA RRER IELLA

KARRER IELLA

KARRER IELLA

KARRERIELLA

KARRER I ELL A

KARRER IELLA

KARRERIELLA

KARRER IELLA

KARRERIELLA

KARRER I ELLA

KARRER I ELLA

KARRER I ELLA

KARRER I ELLA

KARRERIELLA

KARRERIELLA

KARRER I ELLA

KARRERIELLA

KARRER I ELLA

KARRERIELLA

KARRER IELLA

KARRER I ELL A

KARRERIELLA

KARRERI ELLA

KARRER I ELLA

KARRER I ELLA

KARRER IELLA

KARRERIELLA

KARRERIELLA

KARRERIELLA

KARRERIELLA

KARRERIELLA

KARRERIELLA

KARRER I ELLA

KARRER I ELLA

KARRER IELLA

KARRER IELLA

KARRER I ELLLA

KARRER I ELLA
Specific Name

Locality

Lat. Long.

POLYSTOMA

AP ICULARIS

AP I CULARIS

APICULARIS

APICULARIS

APICULARIS

APICULARIS

APICULARI

APICULARIS

AP I CULARIS

AP I CULARIS

APICULARIS

AP I CULARIS

APICULARIS

APICULARIS

APICULARIS

AP ICULARIS

APICULARIS

APICULARIS

AP I CULARIS

AP ICULARIS

AP I CULARIS

AP I CULARIS

APICULARIS

AP ICULARIS

APICULARIS

AP ICULARIS

APICULARIS

AP I CULARIS

APICULARIS

AP ICULARIS

AP ICULARIS

APICULARIS

APICULARIS

AP ICULARIS

APICULARIS

APICULARIS

APICULARIS

APICULARIS

AP ICULARIS

AP I CULARIS

APICULARIS

AP ICULARIS

APICULARIS

APICULARIS

APICULARIS

APICULARIS

APICULARIS

APICULARIS

APICULARIS

AP I CULARIS

APICULARIS

APICULARIS

APICULARIS

APICULARIS

APICULARIS

APICULARIS

APICULARIS

APICULARIS

AP ICULARI

BR ADYI

BR ADY

BRADYI

BRADYI

BRADYI

BRADYI

BRADY I

BRADYI

BRADY

BRADY

BRADYI

BRADYI

BR ADY I

BRADYI

BRADYI

BRADYI

BRADYI

BRADY

BR ADYI

BR ADYI

BRADYI

BRADYI

BRADYI

BR ADYI

BRADYI

BRADYI

BR ADY I

BRADYI

BRADYI

ALLYN'S BIGHT, TEXAS

CENTRAL GULF OF MEXICO

CENTRAL GULF OF MEXICO

CENTRAL GULF OF MEXICO

NW GULF OF MEXICO

NH GULF OF MEXICO

NW GULF OF MEXICO

CENTRAL GULF OF MEXICO

CENTRAL GULF OF MEXICO 


\section{Publication}

19491 PFLUM FRERICHS 1976 19492 PFLUM FRERICHS 1976 19493 PFLUM FRERICHS 1976 19494 PFLUM FRERICHS 1976 19495 PFLUM FRERICHS 1976 19496 PARKER 1954

19497 PFLUM FRERICHS 1976 19498 PFLUM FRERICHS 1976 19499 PFLUM FRERICHS 1976 19500 PFLUM FRERICHS 1976 19501 PFLUM FRERICHS 1976 19502 PFLUM FRERICHS 1976 19503 PFLUM FRERICHS 1976 19504 PFLUM FRERICHS 1976 19505 PFLUM FRERICHS 1976 19506 PFLUM FRERICHS 1976 19507 LEROY HODGKINSON 1975 19508 PHLEGER 1951A

19509 PHLEGER 1951A

19510 PFLUM FRERICHS 1976

19511 PFLUM FRERICHS 1976

19512 ANDERSEN 1961

19513 CREAGER 1958

19514 PFLUM FRERICHS 1976 19515 PFLUM FRERICHS 1976 19516 PFLUM FRERICHS 1976 19517 PFLUM FRERICHS 1976 19518 BANOY 1956

19519 LOEP 1965

19520 PFLUM FRERICHS 1976 19521 BANOY 1956

19522 PFLUM FRERICHS 1976 19523 PFLUM FRERICHS 1976 19524 PFLUM FRERICHS 1976 19525 PFLUM FRERICHS 1976 19526 PFLUM FRERICHS 1976 19527 PFLUM FRERICHS 1976 19528 PHLEGER 1951A

19529 PHLEGER 1951 A

19530 PHLEGER 1951A

19531 PFLUM FRERICHS 1976 19532 PFLUM FRERICHS 1976 19533 PFLUM FRERICHS 1976 19534 PFLUM FRERICHS 1976 19535 PFLUM FRERICHS 1976 19536 PHLEGER 1951A

19537 PFLUM FRERICHS 1976

19538 PARKER 1954

19539 PARKER 1954

19540 PHLEGER 1951A

19541 PHLEGER 1951A

19542 PHLEGER $1951 \mathrm{~A}$

19543 PHLEGER $1951 \mathrm{~A}$

19544 PHLEGER 1951A

19545 CUSHMAN 1923

19546 CUSHMAN 1923

19547 CUSHMAN 1923

19548 LEROY HODGKINSON 1975

19549 BOCK 1976

19550 CUSHMAN 1923

19551 CUSHMAN 1923

19552 CUSHMAN 1923

19553 CUSHMAN 1923

19554 CUSHMAN 1923

19555 CREAGER 1958

19556 CUSHMAN 1923

19557 CUSHMAN 1923

19558 CUSHMAN 1923

19560 CREAGER 1958

19561 CREAGER 1958

19562 CREAGER 1958

19563 ANDERSEN 1961

19564 ANDERSEN 1961

19565 ANDERSEN 1961

19566 ANDERSEN 1961

19567 PFLUM FRERICHS 1976

19568 PFLUM FRERICHS 1976

19569 PFLUM FRERICHS 1976

19570 PFLUM FRERICHS 1976

19571 PFLUM FRERICHS 1976

19572 PFLUM FRERICHS 1976

19573 PFLUM FRERICHS 1976

19574 PFLUM FRERICHS 1976

19575 PFLUM FRERICHS 1976

19576 PFLUM FRERICHS 1976

19577 CREAGER 1958

19578 PFLUM FRERICHS 1976 19579 PFLUM FRERICHS 1976 19580 PFLUM FRERICHS 1976 19581 PFLUM FRERICHS 1976 19582 PFLUM FRERICHS 1976 19583 PFLUM FRERICHS 1976 19584 PFLUM FRERICHS 1976 119585 PFLUM FRERICHS 1976

\section{Generic Name}

KARRERI ELL

KARRERI ELLA

KARRERIELLA

KARRERI ELLA

KARRERIELLA

KARRER I ELLA

KARRERIELLA

KA RRERI ELL

KARRER I ELLA

KARRERI ELLA

KARRERIELLA

KARRERI ELLA

KARRERIELLA

KARRERI ELLA

KARRERI ELLA

KA RRERIELLA

KARRERI ELLA

KARRERIELLA

KA RRERIELLA

KARRERIELLA

KARRERI ELLA

KARRERI ELL

KA RRERI ELLA

KARRERI ELLA

KARRER IELLA

KARRERIELLA

KARRER I ELLA

KARRERIELLA

KARRERI ELLA

KA RRER I ELLA

KA RRER I ELLA

KARRERIELLA

KARRERIELLA

KARRERI ELLA

KARRER I ELL

KARRER I ELLA

KARRER IELLA

KARRER I ELLA

KARRERIELLA

KARRERIELLA

KARRER IELL

KARRER I ELLA

KA RRERIELLA

KARRERIELLA

KARRERIELLA

KARRER I ELLA

KARRERIELL

KARRERIELLA

KARRERI ELLA

KA RRER IELL

KARRER

LAGENA

LA GENA

LAGENA

LAGENA

LA GE NA

LAGENA

LA GENA

LA GE NA

LA GENA

LA GENA

LAGENA

LA GENA

LAGENA

LAGENA

LAGENA

LAGENA

LA GENA

LAGENA

LA GENA

LA GENA

LA GENA

LA GENA

LA GENA

LA GENA

LA GENA

LA GENA

LA GENA

LAGENA

LAGENA

LA GENA

LAGENA

LAGENA

LA GENA

LA GENA

LA GENA

LAGENA

LAGENA
Specific Name

BRADYI

BRADYI

BR ADY I

BR A OYI

BRAOYI

BRADY I

BRADYI

BRADYI

BR ADYI

BRAOYY

BRADYI

BRADYI

BR ADY I

BRAOY I

BRADYI

BRADYI

BRADYI
BRADYI

BRADYI

BRADYI

BR AOY I

BRADYI

BRADYI

BRADYI

BRADYI

BRADYI

BRADYI

BRADYI

BRAOYI

BRADYI

BR ADYI

BRADYI

BR ADY I

BR AOY I

BRADYI

BRADYI

BRADYI

BRADYI

BRADYI

BRADYI

BRADYI

BRADYI
BRADYI

BRADYI

BR ADYI

BR ADYI

BRADY I

AC UTI I COSTA

A CUTICOSTA

ACUTICOSIA

AP IOPLEURA

DISTOMA

FL INTIANA

FL INT IANA

FL INT IANA

FL INT I ANA

FL INTIANA

GLOBOSA

GRACILLIMA

GRACILLIMA

GRACILLIMA

TEA O

HE XAGONA

HEXAGONA

HISPIDULA

INUSITATA

LAEVICOSTATA

LAEVIS

LAEVIS

LAEVIS

LAEVIS

LAEVIS

LAEVIS

LAEVIS

LAEVIS

LAEVIS

LAEVIS

LAEVIS

LAEVIS

LAEVIS

LAEVIS

LAEVIS

LAEVIS

LAEVIS

LAEVIS

\section{Locality}

NW GULF OF MEXICO

$N$ GULF OF MEXICO

$N W$ GULF OF MEXICO

NW GULF OF MEXICO

NW GULF OF MEXICO

NE GULF OF MEXICO

NW GULF OF MEXICO

NH GULF OF MEXICO

NW GULF OF MEXICO

NW GULF OF MEXICO

NW GULF OF MEXICO

NW GULF OF MEXICO

NW GULF OF MEXICO

NW GULF OF MEXICO

$N W$ GULF OF MEXICO 


\section{Publication}

19586 PFLUM FRERICHS 1976 19587 BENDA PURI 1962

19588 CUSHMAN 1923

19589 CUSHMAN 1923

19590 CUSHMAN 1923

19591 CUSHMAN 1923

9592 CUSHMAN 1923

19593 ANDERSEN 1961
19594 ANDERSEN 1961

19595 CUSHMAN 1923

19596 BOCK 1976

19597 ANDERSEN 1961

19598 ANDERSEN 196

19599 BOCK 1976

19600 ANDERSEN 1961

19601 CUSHMAN 1923

19602 CUSHMAN 1923

19603 PFLUM FRERICHS 1976

19604 PFLUM FRERICHS 1976

19605 PFLUM FRERICHS 1976

19606 BANDY 1954

19607 BANDY 1954

19608 BANDY 1954

9609 BANDY 195

19610 BANDY 1954

19611 PFLUM FRERICHS 1976

19612 PFLUM FRERICHS 1976

19613 LANKFORD 1959

19614 PFLUM FRERICHS 1976

19615 PFLUM FRERICHS 1976

19616 PFLUM FRERICHS 1976

19617 PFLUM FRERICHS 1976

19618 PFLUM FRERICHS 1976

19619 PFLUM FRERICHS 1976

19620 PFLUM FRERICHS 1976

19621 PFLUM FRERICHS 1976

19622 PFLUM FRERICHS 1976

19623 PFLUM FRERICHS 1976

19624 PFLUM FRERICHS 1976

19625 PFLUM FRERICHS 1976

19626 PFLUM FRERICHS 1976

19627 PFLUM FRERICHS 1976

19628 PFLUM FRERICHS 1976

19629 PFLUM FRERICHS 1976

19630 PFLUM FRERICHS 1976

19631 PFLUM FRERICHS 1976

19632 PFLUM FRERICHS 1976

19633 PFLUM FRERICHS 1976

19634 PFLUM FRERICHS 1976

19635 PFLUM FRERICHS 1976

19636 PFLUM FRERICHS 1976

19637 PFLUM FRERICHS 1976

19638 PFLUM FRERICHS 1976

19639 PFLUM FRERICHS 1976

19640 PFLUM FRERICHS 1976

19641 PFLUM FRERICHS 1976

19642 PFLUM FRERICHS 1976

19643 PFLUM FRERICHS 1976

19644 PFLUM FRERICHS 1976

19645 PFLUM FRERICHS 1976

19646 PFLUM FRERICHS 1976

19647 PFLUM FRERICHS 1976

19648 PFLUM FRERICHS 1976

19649 PFLUM FRERICHS 1976

19650 PFLUM FRERICHS 1976

19651 PFLUM FRERICHS 1976

19652 PFLUM FRERICHS 1976

19653 PFLUM FRERICHS 1976

19654 PFLUM FRERICHS 1976

19655 PFLUM FRERICHS 1976

19656 PFLUM FRERICHS 1976

19657 PFLUM FRERICHS 1976

19658 BANDY 1956

19659 BANDY 1956

19660 LEHMANN 1957

19661 PFLUM FRERICHS 1976

19662 PFLUM FRERICHS 1976

19663 PFLUM FRERICHS 1976

19664 PFLUM FRERICHS 1976

19665 PFLUM FRERICHS 1976

19666 PFLUM FRERICHS 1976

19667 PFLUM FRERICHS 1976

19668 PHLEGER 1951A

19669 PFLUM FRERICHS 1976

19670 PFLUM FRERICHS 1976

19671 PFLUM FRERICHS 1976

19672 PFLUM FRERICHS 1976

19673 PFLUM FRERICHS 1976

19674 PFLUM FRERICHS 1976

19675 PFLUM FRERICHS 1976

19676 PARKER 1954

19677 PARKER 1954

19678 PARKER 1954

19679 PARKER 1954

19680 PARKER 1954
Generic Name

LAGENA

LAGENA

LAGENA

LAGENA

LAGENA

LAGENA

LAGENA

LAGENA

LAGENA

LAGENA

LAGENA

LAGENA

LAGENA

LA GENA

AGENA

LA GENA

LAGENA

LAGENA

LAGENA

LAGENA

LAGENA
LAGENA

LA GE NAMMINA

LAGENAMMINA

LAGENAMM INA

LAGENAMMINA

LAGENAMMINA

LAGENAMMINA

LAGENAMMINA

LAGENAMM INA

LA GE NAMMINA

LAGENAMMINA

LAGE NAMMINA

LA GE NAMMINA

LAGENAMMINA

LAGENAMMINA

LAGENAMMINA

LAGENAMMINA

LAGENAMMINA

LAGENAMMINA

LAGENAMMINA

LA GENAMMINA

LAGENAMMINA

LA GENAMMINA

LA GENAMMINA

LA GE NAMMINA

LAGENAMMINA

LA GENAMMINA

LA GENAMMINA

LA GENAMMINA

LAGENAMMINA

LAGENAMMINA

LA GENAMMINA

LAGENAMMINA

LAGENAMMINA

LAGENAMMINA

LAGENAMMINA

LA GENAMMINA

LA GENAMMINA

LAGENAMMINA

LAGENAMMINA

LAGENAMMI NA

LAGENAMMINA

LAGENAMM INA

LAGENAMMINA

LAGENAMMINA

LAGENAMMINA

LAGENAMMINA

LAGENAMMINA

LAGENONODOSARIA

LAGENONO DOSAR IA

LAMARCKINA

LATICAR ININA

LATI CAR ININA

LATICAR ININA

LATI CARININA

LATICAR ININA

LATICAR ININA

LATICAR ININA

LATICAR ININA

LA TICAR ININA

LATICAR ININA

LATICARININA

LA TICAR ININA

LATICAR ININA

LATI CAR ININA

LATICAR ININA

LATICARININA

LATI CAR ININA

LATI CAR ININA

LA TI CAR ININA

LA TICAR ININA
Specific Name

Locality

Lat. Long.

LAEVIS

LAEVIS

LONG ISPINA

MARGINATA

MARG INATA

MARGINATA

ME XI CANA

NE EULOSA

OREIGNYANA CARIBAEA

SEMISTRIATA

SPICATA

SP IRATA

STRIATA

STRIATA

SUBLAGENOIDES

SULCATA

SULCATA

TENUIS

TENUIS

TENUIS

TENUIS

TE NUIS

AT LANTICA

ATLANTICA

A TLANTI CA

AT LANTI CA

ATLANTI CA

DI FFLUG IF ORMIS

DI FFLUG IF ORMIS

DI FFLUGIF ORMIS

DI FFLUG IF ORMIS

DI FFLUGIF ORMIS

DI FFLUGIF ORMIS

DI FFLUG IF ORMIS

DI FFLUG IF ORMIS

DI FFLUG IF ORMIS

DIFFLUG IF ORMIS

DI FFLUGIF ORMIS

DIFFLUGIF ORMIS

DI FFLUG IF ORMIS

DI FFLUGIF ORMIS

DI FFLUG IF ORMIS

DI FFLUG IF ORMIS

DI FFLUG IF ORMIS

DI FFLUG IF ORMIS

DI FFLUG IF ORMIS

DI FFLUG IF ORMIS

DI FFLUG IF ORMIS

DI FFLUGIF ORMIS

DI FFLUG IF ORMIS

DI FFLUG IF ORMIS

DI FFLUGIF ORMIS

DI FFLUG IF ORMIS

DI FFLUG IF ORMIS

DI FFLUG IF ORMI S

DI FFLUG IF ORMIS

DIFFLUGIF ORMIS

DI FFLUG IF ORMIS

DI FFLUG IF ORMIS

DI FFL UG IF ORMIS

DI FFLUGIF ORMIS

DI FFLUG IF ORMIS

DI FFLUGIF ORMIS

DI FFLUGIF ORMIS

DI FFLUG IF ORMIS

DI FFLUG IF ORMIS

DI FFLUG IF ORMIS

SCALARIS

SCALAR IS

ATLANTI CA

PALPERATA

PA UPERATA

PAUPERATA

PAUPERATA

PA UPERATA

PALPERATA

PAUPERATA

PAUPERATA

PA UPERATA

PALPERATA

PAUPERATA

PA UPERATA

PAUPERATA

PAUPERATA

PALPERATA

PALPERATA

PALPERATA

PAUPERATA

CENTRAL GULF OF MEXICO

CAPE ROMANO, FLA

NE GULF OF MEXICO

NE GULF OF MEXICO

NE GULF OF MEXICO

NE GULF OF MEXICO

NE GULF OF MEXICO

MISSISSIPPI DELTA

MISSISSIPPI DELTA 


\section{Publication}

19681 PARKER 1954 19682 PARKER 1954

19683 PARKER 1954

19684 LOEP 1965

19685 LOEP 1965

19686 PFLUM FRERICHS 1976

19687 PFLUM FRERICHS 1976

19688 PFLUM FRERICHS 1976

19689 PFLUM FRERICHS 1976

19690 PFLUM FRERICHS 1976

19691 PFLUM FRERICHS 1976

19692 PFLUM FRERICHS 1976

19693 PFLUM FRERICHS 1976

19694 PFLUM FRERICHS 1976

19695 PFLUM FRERICHS 1976

19696 PFLUM FRERICHS 1976

19697 PFLUM FRERICHS 1976

19698 PFLUM FRERICHS 1976

19699 PFLUM FRERICHS 1976

19700 PFLL'M FRERICHS 1976

19701 PFLUM FRERICHS 1976

19702 PFLUM FRERICHS 1976

19703 PFLUM FRERICHS 1976

19704 LERJY HODGKINSON 1975

19705 PHLEGER $1951 \mathrm{~A}$

19706 PARKER 1954

19707 CREAGER 1958

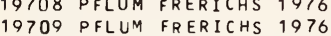

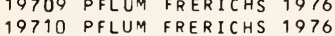

19711 PFLUM FRERICHS 1976

19712 PFLUM FRERICHS 1976

19713 PARKER 1954

19714 PARKER 1954

19715 PARKER 1954

19716 PHLEGER 1955A

19717 PFLUM FRERICHS 1976

19718 PFLUM FRERICHS 1976

19719 PFLUM FRERICHS 1976

19720 PFLUM FRERICHS 1976

19721 PHLEGER 1951A

19722 PARKER 1054

19723 PARKER 1954

19724 PARKER 1954

19725 PARKER 1954

19726 PARKER 1954

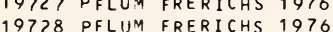

19729 PFLUM FPERICHS 1976

19730 CREAGER 1958

19731 CREAGER 1958

19732 CREAGER 1958

19733 CREAGER 1958

19734 CREAGER 1958

19735 CREAGER 1958

19736 CREAGER 1958

19737 CREAGER 1958

19738 PHLEGER 1955A

19739 PHLEGER $1955 \mathrm{~A}$

19740 PHLEGER 1951A

19741 PHLEGER 1951 A

19743 PHLEGER 1951 A

19744 PHLEGER 1951A

19745 PHLEGER 1951A

19746 PHLEGER 1951 A

19747 PHLEGER 1951A

19748 PHLEGER $1951 \mathrm{~A}$

19750 PHLEGER 1951A

19751 PHLEGER 1951A

19752 PHLEGER $1951 \mathrm{~A}$

19753 PARKER 1954

19754 PHLEGER $1951 \mathrm{~A}$

19755 PHLEGER $1951 \mathrm{~A}$

19756 PHLEGER $1951 \mathrm{~A}$

19757 PHLEGER 1955 A

19758 PHLEGER 1955A

19759 PHLEGER $1955 \mathrm{~A}$

19760 PHLEGER 1955 A

19762 PFLUM FRERICHS 1976

19763 PFLUM FRERICHS 1976

19764 PFLUM FRERICHS 1976

19765 PFLUM FRERICHS 1976

19766 PFLUM FRERICHS 1976

19767 PFLUM FRERICHS 1976

19768 PFLUM FRERICHS 1976

19769 PFLUM FRERICHS 1976

19770 PFLUM FRERICHS 1976

19771 PFLUM FRERICHS 1976

19772 PFLUM FRERICHS 1976

19773 PFLUM FRERICHS 1976

19774 PFLUM FRERICHS 1976

19775 PFLUM FRERICHS 1976

\section{Generic Name}

LATI C AR ININA

LATICAR ININA

LATI CAR ININA

LATICARININA

LATICARININA

LATICARININA

LATICARININA

A T I CARININA

LA TI CAR ININA

LA TICAR ININA

LATI CAR I NINA

LATICAR ININA

LA TICARININA

LATICARININA

LATICAR ININA

LA TICAR ININA

LATICAR ININA

LA TI CAR ININA

LATI CARININA

LA TICAR ININA

LATICARININA

LATICAR ININA

LATICARININA

LATICAR ININA

LATICAR ININA

LATICAR I NINA

LATICAR ININA

LA TI CAR ININA

LATICAR ININA

LA TICARININA

LA TI CARI NINA

LATICAR ININA

LA TICAR ININA

LATICAR ININA

LATI CAR ININA

LATICAR ININA

LA TICARININA

LA T I C AR I NINA

LATICARININA

LATICAR ININA

LA TICARININA

LATI CAR ININA

LATICARININA

LA TI CAR ININA

LATI CAR ININA

LA TICARININA

LA TI CAR IN INA

A I ICAR ININA

LATICARININA

LATI CAR ININA

LA TICAR ININA

LATICAR ININA

LA TI CAR ININA

A I ICAR ININA

LATICARININA

LATICARININA

LATICARININA

LATICARININA

LA I ICAR IN INA

LA TICAR ININA

LATICARININA

LATICAR ININA

LATICAR ININA

LATICAR ININA

LATICARININA

LATI C AR IN INA

LATICAR ININA

A TICAR IN INA

LATICAR ININA

LATICAR ININA

LATICARININA

LATICAR ININA

LA TI CAR ININA

A TICAR ININA

LATICARININA

LATI CARININA

A TICAR ININA

LA TICAR ININA

LA TI CAR ININA

LATICARININA

LA TI CAR IN INA

$\angle A T I C A R I N I N A$

A TICAR ININA

A TI CARININA

LA TICAR ININA

LATI CAR I NINA

LA TI CAR ININA

LA TICAR ININA

A IICAR ININA

A TI CARININA

LATI CAR ININA

LA TICARININA

LA TI CAR IN INA

LA TICARININA
Specific Name

PALPERATA

PALPERATA
PALPERATA

PA UPERATA

PAUPERATA

PAUPERATA

PAUPERATA

PA UPERATA

PAUPERATA

PALPERATA

PALPERATA

PAUPERATA

PALPERATA

PAUPERATA

PA UPERATA

PALPERATA

PAUPERATA

PALPERATA

PAUPERATA

PAUPERATA

PALPERATA

PALPERATA

PALPERATA

PALPERATA

PALPERATA

PALPERATA

PAUPERATA

PALPERATA

PAUPERATA

PALPERATA

PALPERATA

PAUPERATA

PALPERATA

PAUPERATA

PALPERATA

PAUPERATA

PAUPERATA

PALPERATA

PALPERATA

PALPERATA

PALPERATA

PALPERATA

PAUPERATA

PALPERATA

PALPERATA

PALPERATA

PAUPERATA

PAL'PERATA

PALPERATA

PAUPERATA

PALPERATA

PA LIPERATA

PALPERATA

PALPERATA

PALPERATA

PALPERATA

PA UPERATA

PALPERATA

PALPERATA

PALPERATA

PALPERATA

PALPERATA

PA UPE RATA

PALPERATA

PALPERATA

PALPERATA

PALPERATA

PALPERATA

PALPERATA

PALPERATA

PALPERATA

PALPERATA

PALPERATA

PALPERATA

PALPERATA

PALPERATA

PALPERATA

PALPERATA

PALPERATA

PA UPERATA

PALPERATA

PA UPERATA

\section{Locality}

NE GULF OF MEXICO

NE GULF OF MEXICO

NE GULF OF MEXICO

$N W$ GULF OF MEXICO

NW GULF OF MEXICO

CENTRAL GULF OF MEXICO

CENTRAL GULF OF MEXICO

CENTRAL GULF OF MEXICO

NW GULF OF MEXICO

NW GULF OF MEXICO

$N W$ GULF OF MEXICO

NW GULF OF MEXICO

NW GULF OF MEXICO

NW GULF OF MEXICO

NW GULF OF MEXICO

NW GULF OF MEXICO 


\section{Publication}

19776 PFLUM FRERICHS 1976 19777 PFLUM FRERICHS 1976 19778 CREAGER 1958

19779 CREAGER 1958

19780 CREAGER 1958

19781 CREAGER 1958

19782 PFLUM FRERICHS 1976

19783 PFLUM FRERICHS 1976

19784 PFLUM FRERICHS 1976

19785 PFLUM FRERICHS 1976

19786 PFLUM FRERICHS 1976

19787 PFLU:M FRERICHS 1976

19788 PFLUM FRERICHS 1976

19789 PFLUIA FRERICHS 1976

19790 CUSHMAN 1931

19791 CUSHMAN 1931

19792 CUSHMAN 1931

19793 CREAGER 1958

19794 PFLUM FRERICHS 1976

19795 CUSHMAN 1931

19796 PFLUM FRERICHS 1976

19797 CREAGER 1958

19798 LEHMANN 1957

19799 PFLUM FRERICHS 1976

19800 PFLUM FRERICHS 1976

19801 PFLUM FPERICHS 1976

19802 PFLUM FRERICHS 1976

19803 PFLUM FRERICHS 1976

19804 PFLUM FRERICHS 1976

19805 PFLUM FRERICHS 1976

19806 PFLUM FRERICHS 1976

19807 PFLUM FRERICHS 1976

19808 PFLUM FRERICHS 1976

19809 PFLUM FRERICHS 1976

19810 PFLUM FRERICHS 1976

19811 PFLIJM FRERICHS 1976

19812 BOCK 1976

19813 PFLUM FRERICHS 1976

19814 PFLUM FRERICHS 1976

19815 PFLUM FRERICHS 1976

19816 PFLUM FRERICHS 1976

19817 PFLUM FRERICHS 1976

19818 PFLUM FRERICHS 1976

19819 PFLUM FRERICHS 1976

19820 PFLUM FRERICHS 1976

19821 LEROY HODGKINSON 1975

19822 PFLUM FRERICHS 1976

19823 PFLUM FRERICHS 1976

19824 PFLUM FRERICHS 1976

19825 PFLUM FRERICHS 1976

19826 PFLUM FRERICHS 1976

19827 PFLUM FRERICHS 1976

19828 PFLUM FRERICHS 1976

19829 PFLUM FRERICHS 1976

19830 PFLUM FRERICHS 1976

19831 PFLUM FRERICHS 1976

19832 BOCK 1976

19833 PFLUM FRERICHS 1976

19834 DFLUM FRERICHS 1976

19835 PFLUM FRERICHS 1976

19836 PFLUM FRERICHS 1976

19837 PFLUM FRERICHS 1776

19838 PFLUM FRERICHS 1976

19839 PFLUM FRERICHS 1976

19840 PFLUM FRERICHS 1976

19841 PFLUM FRERICHS 1976

19842 PFLUM FRERICHS 1976

19843 PFLUM FRERICHS 1976

19844 PFLUM FRERICHS 1976

19845 PFLUM FRERICHS 1976

19846 PFLUM FPERICHS 1976

19847 PFLUM FRERICHS 1976

19848 PFLUM FPERICHS 1976

19849 PFLUM FPERICHS 1976

19850 PFLUM FRERICHS 1976

19851 BOCK 1976

19852 PFLUM FRERICHS 1976

19853 PFLUM FRERICHS 1976

19854 BOCK 1976

19855 PFLIJM FRERICHS 1976

19856 PFLUM FRERICHS 1976

19857 PFLUM FRERICHS 1976

19858 PFLUM FRERICHS 1976

19859 PFLUM FRERICHS 1976

19860 PFLUM FRERICHS 1976

19861 PFLUM FRERICHS 1976

19862 PFLUM FRERICHS 1976

19863 PFLUM FRERICHS 1976

19864 PFLUM FRERICHS 1976

19865 PFLUM FRERICHS 1976

19866 PARKER 1254

19867 PHLEGER 1956

19868 PFLUM FRERICHS 1976

19869 ANDERSEN 196

19870 BOCK 1976
Generic Name

Specific Name

Locality

LA II CAR ININA

LAT I CAR ININA

LATI CAR I NINA

LATI CAR IN INA

LATICAR ININA

LATICARININA

LATICARININA

LATICARININA

LA TI CAR I NINA

LA TICAR ININA

LA TICAR ININA

LA TICAR ININA

LATICAR ININA

LATICAR ININA

LATICAR IN INA

LATICAR ININA

LA T I CAR ININA

LA TICAR ININA

LATICAR ININA

LA TICAR ININA

LENTI CUL INA

LENT I CUL INA

LENT I CUL INA

LENT I CUL INA

LENTI CULINA

LENT I CUL INA

LENTI CUL INA

LENTI CUL INA

LENTI CULINA

LENTICUL INA

LENTI CULINA

LENTICUL INA

LENTI CUL INA

LENTI CUL INA

LENTICUL INA

LENTI CULINA

LENTICUL INA

LENT I CULINA

LENTI CUL INA

LENT I CUL INA

LENTI CUL INA

LENTI CULINA

LENT I CUL INA

LENTI CUL INA

LENTI CUL INA

LENT I CUL INA

LENT I CUL INA

LENT I CUL INA

LENTI CULINA

LENT I CUL INA

LENT I CUL INA

LENTI CUL INA

LENTI CUL INA

LENTI CUL INA

LENTI CUL INA

LENTI CUL INA

LENT I CUL INA

LENTICULINA

LENTI CUL INA

LENT I CUL INA

LENT I CUL INA

LENTI CUL INA

LE NTI CUL INA

LENTI CULINA

LENTI CUL INA

LENTICULINA

LENTI CUL INA

LENTI CUL INA

LENTICUL INA

LENT I CUL INA

LENTI CUL INA

LENTI CUL INA

LENTI CUL INA

LENT I CULINA

LENT I CUL INA

LENTICULINA

LENTI CUL INA

LENTI CUL INA

LENTI CUL INA

LENTI CUL INA

LENTICULINA

LENTICULINA

LENT I CUL INA

LENTICUL INA
LENTI CULINA

LENTI CUL INA
LENTICULINA

LENTI CUL INA

LENT I CUL INA

LENT I CUL INA

LEVI ICUL INA

LENTI CULINA

LENTI CUL INA

LENT I CUL INA

LENT I CULINA
PALPERATA

PA UPERATA

PALPERATA

PALPERATA

PAUPERATA

PALPERATA

PAUPERATA

PA UPERATA

PALPERATA

PAUPERATA

PALPERATA

PALPERATA

PAUPERATA

PA UPE RATA

PALIPERATA

PA UPERATA

PAUPERATA

PALPERATA

PALPERATA

PAUPERATA

PA UPERATA

CALCAR

CALCAR

CALCAR

CALCAR

CALCAR
CALCAR

CALCAR

CALCAR

CALCAR

CALCAR

CALCAR

CALCAR

CALCAR

CALCAR

CALCAR

CALCAR

CALCAR

CALCAR

CALCAR

CALCAR

CALCAR

CALCAR

CALCAR

CONPRESSA

$G I B B A$

GI BBA

GI $B B A$

$G I B B A$

$G$ I BBA

GI EBA

$G I B B A$

$G I B B A$

$G I B B A$

GI BBA

GI EBA

GIEBA

$G I B B A$

$G I B B A$

GI BBA

GI $B 9 A$

GIEBA

GIBBA

GIBBA

GI BBA

$G I B B A$

GIEBA

GIEBA

GIBBA

$G$ I BBA

GI BBA

$G$ I BBA

GI EBA

GI BBA

IO TA

ORPICULAR IS

OREICULAR IS

OREI CUL AR IS

OREI CULAP IS

ORBICULAR IS

OREICULAR IS

OREICULAR IS

ORE ICULAR IS

ORE ICULAR IS

ORBICULAR IS

OREICULAR IS

OREICULAZ IS

OREICULAR IS

OREICULAR IS

PE REGRINA

PEREGRINA

PEREGR INA

PEREGRINA

PE REGR I NA

CENTRAL GULF OF MEXICO

CENTRAL GULF OF MEXICO

BAY OF CAMPECHE

BAY OF CAMPECHE 


\section{Publication}

19871 PARKER 1954

19872 PARKER 1754

19873 PARKER 1954

19874 PARKER 1754

19875 PARKER 1256

19876 PFLUM FRERICHS 1976

19877 PFLUM FRERICHS 1976

19878 PFLUM FRERICHS 1976

19879 PFLUM FRERICHS 1976

19880 PFLUM FRERICHS 1976

19881 PFLUM FRERICHS 1976

19882 PHLEGER $1951 \mathrm{~A}$

19883 PHLEGER 1951 A

19884 PHLEGER 1951 A

19885 PFLUM FRERICHS 1976

19886 PFLUM CRERICHS 1976

19887 PFLUM FRERICHS 1976

19888 PFLUM FRERICHS 1976

19889 PFLUM FRERICHS 1976

19890 PFLUM FRERICHS 1976

19891 PFLUM FRERICHS 1976

19892 PFLUM FRERICHS 1976

19893 PFLUM FRERICHS 1976

19894 PFLUM FRERICHS 1976

19895 PFLUM FRERICHS 1976

19896 PFLUM FRERICHS 1976

19897 PFLUM FRERICHS 1976

19898 PFLUM FRERICHS 1976

19899 PFLUM FRERICHS 1976

19900 PFLUM FRERICHS 1976

19901 PFLUM FRERICHS 1976

19902 PFLUM FDERICHS 1976

19903 PFLUM FRERICHS 1976

19904 PFLUM FRERICHS 1976

19905 PFLUM FRERICHS 1976

19906 PFLUM FRERICHS 1976

19907 PFLUM FRERICHS 1976

19908 PHLEGER 1951A

19909 PHLEGER 1951A

19910 PFLUM FRERICHS 1976

19911 PFLUM FRERICHS 1976

19912 PFLUM FRERICHS 1976

19913 PFLUM FRERICHS 1976

19914 PFLUM FRERICHS 1976

19915 DFLUM FRERICHS 1976

19916 PHLFGER 1951A

19917 PHLEGER 1951A

19918 PFLUM FRERICHS 1976

19919 PFLUM FRERICHS 1976

19920 PFLUM FRERICHS 1976

19921 PFLUM FRERICHS 1976

19922 PHLEGER $1951 \mathrm{~A}$

19923 PHLEGER 1951A

19924 PHLEGER 1951A

19925 PHLEGER $1951 \mathrm{~A}$

19926 PHLEGER 1951A

19927 PFLIJM FRERICHS 1976

19928 PFLUM FRERICHS 1976

19929 PFLUM FRERICHS 1976

19930 PARKER 1954

19931 PARKER 1954

19932 PARKER 1954

19933 PARKER 1954

19934 PARKER 1954

19935 PARKER 1754

19936 PARKER 1954

19937 PARKER 1954

19938 PARKER 1954

19939 PARKER 1054

19940 LANKFORD 1959

19941 LUDWICK WALTON 1957

19942 PARKER 1954

19943 PHLEGER 1951A

19944 PHLEGER $1951 \mathrm{~A}$

19945 PHLEGER 1951A

19946 PHLEGER 1951 A

19947 PHLEGER 1451A

19948 PHLEGER 1951A

19949 PHLEGER 1951 A

19950 PHLEGER 1951 A

19951 PHLEGER 1951A

19952 PHLEGER $1951 \mathrm{~A}$

19953 PHLEGER 1951A

19954 PHLEGER $1951 \mathrm{~A}$

19955 PHLEGER $1951 \mathrm{~A}$

19956 PHLEGER 1951 A

19957 PHLEGER $1951 \mathrm{~A}$

19958 PHLEGER $1951 \mathrm{~A}$

19959 PHLEGER $1951 \mathrm{~A}$

19960 PHLEGER 1951 A

19961 PHLEGER 1951A

19962 PFLUM FRERICHS 1976

19963 PFLUM FPERICHS 1976

19964 PFLUM FRERICHS 1976

19965 PARKER 1954
Generic Name

LENTICUL INA

LENTICUL INA

LENTI CUL INA

LENTI CUL INA

LENTICULINA

LENTICUL INA

LENTI CUL INA

LENTI CUL INA

LENTI I ULL INA

LENTI CUL INA

LENTI C UL INA

LENTI CUL INA

LENTI CULINA

LENTI CUL INA

LENTI CULINA

LENTICUL INA

LENTI CUL INA

LENT I CULINA

LENTICULINA

LENT I CUL INA

LENTI CULINA

LENTI CULINA

LENTICULINA

LENT I CUL INA

LENT I CUL INA

LENTI CULINA

LENT ICULINA

LENTI CUL INA

LENT I CULINA

LENTICULINA

LENTICULINA

LENTICULINA

LE VTI CUL INA

LENTI CUL INA

LENT ICUL INA

LENT I CULINA

LENTI CULINA

LENTI CUL INA

LENTI CUL INA

LENT I CUL INA

LENTI CUL INA

LENTI CULINA

LENT I CULINA

LENT I CUL INA

LENTICULINA

LENTI CULINA

LENTICUL INA

LENTICULINA

LENTI CUL INA

LENTI CUL INA

LENT I CUL INA

LENTI CUL INA

LENT I CUL INA

LENTICULINA

LENTI CULINA

LENTI CULINA

LENT I CUL INA

LENTI CUL INA

LENTI CUL INA

LENTI CUL INA

LENTICULINA

LENT I CUL INA

LENT I CUL INA

LENTI CUL INA

LENTICULINA

LENTI CULINA

LENTI CULINA

LENT I CUL INA

LENTI CUL INA

LENTI CUL INA

LENTICULINA

LEVT ICULINA

LENTI CULINA

LENT I CULINA

LENTI CULINA

LENT I CUL INA

LENTICULINA

LENTI CUL INA

LENTICUL INA

LENTI CULINA

LENT I CULINA

LENT I CULINA

LENTI CUL INA

LENTI CUL INA

LENTI CUL INA

LENTI CUL INA

LENTI CULINA

LENT I CULINA

LENTI CULINA

LENTI CUL INA

LENT I CUL INA
Specific Name

PEREGRINA

PEREGRINA

PEREGRI NA

PEREGRINA

PEREGRINA

PEREGRINA

PEREGRINA

PEREGRINA

PE REGRINA

PEREGRINA

PEREGRINA

PEREGRINA

PEREGRINA

PEREGRINA

PEREGRINA

PEREGRINA

PEREGRINA

PEREGRINA

PEREGRINA

PEREGRINA

PEREGRINA

PEREGRINA

PEREGRINA

PEREGRINA

PEREGRINA

PEREGRINA

PEREGRINA

PEREGRINA

PEREGRINA

PEREGRINA

PEREGR I NA

PEREGRINA

PEREGRINA

PEREGRINA

PEREGRINA

PEREGRINA

PEREGRINA

PE REGRINA

PEREGRINA

PEREGRINA

PE REGRINA

PEREGRINA

PE REGR INA

PEREGRINA

PEREGR INA

PEREGRINA

PEREGRINA

PEREGRINA

PEREGRINA

PEREGRINA

PEREGRINA

PEREGRINA

PEREGRINA

PEREGRINA

PEREGRINA

PEREGR INA

PE REGRINA

PEREGRINA

PEREGRINA

PEREGRINA

PE RE GR INA

PEREGRINA

PE REGRINA

PEREGRINA

PE FEGRINA

PEREGRINA

PE RE GR I NA

PEREGRINA

PEREGRINA

PE REGRINA

PE REGRINA

PE REGRINA

PEREGRINA

PEREGRINA

PE REGR INA

PEREGRINA

PEREGRINA

PEREGRINA

PEREGRINA

PE REGRINA

PEREGRINA

PE REGRINA

PEREGRINA

PEREGRINA

PE FEGRINA

PEREGRINA

PEREGRINA

PEREGRINA

PE FEGRINA

PEREGRINA

\section{Locality}

NE GULF OF MEXICO

NE GULF DF MEXICO

NE GULF OF MEXICO

NE GULF OF MEXICO

NE GULF OF MEXICO 


\section{Publication}

19966 PFLUM FRERICHS 1976 19967 PFLUM FRERICHS 1976 19968 PFLUM FRERICHS 1976 19969 PFLUM FRERICHS 1976 19970 PFLUM FRERICHS 1976 19971 PFLUM FRERICHS 1976 19972 PFLUM FRERICHS 1976 19973 PFLUM FRERICHS 1976 19973 PFLUM FRERICHS 1976 19974 PFLUM FRERICHS 1976 19975 PFLUM FRERICHS 1976
19976 PFLUM FRERICHS 1976 19977 PFLUM FRERICHS 1976 19978 PFLUM FRERICHS 1976 19979 PFLUM FRERICHS 1976 19980 PFLUM FRERICHS 1976 19980 PFLUM FRERICHS 1976 19981 PFLUM FRERICHS 1976

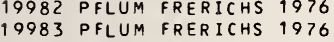
19984 PFLUM FRERICHS 1976 19985 PFLUM FRERICHS 1976 19986 BOCK 1976

19987 ANDERSEN 1961

19988 PFLUM FRERICHS 1976

19989 BANDY 1956

19990 BANDY 1956

19991 CUSHMAN 1923

19992 CUSHMAN 1923

19993 PFLUM FRERICHS 1976 19994 PFLUM FRERICHS 1976 19995 PFLUM FRERICHS 1976 19996 PFLUM FRERICHS 1976 19996 PFLUM FRERICHS 1976
19997 PFLUM FRERICHS 1976 19998 PFLUM FRERICHS 1976 19999 PFLUM FRERICHS 1976 20000 PFLUM FRERICHS 1976 20001 PFLUM FRERICHS 1976 20002 PFLUM FRERICHS 1976 20003 PFLUM FRERICHS 1976 20003 PFLUM FRERICHS 1976
20004 PFLUM FRERICHS 1976 20005 PFLUM FRERICHS 1976 20006 PFLUM FRERICHS 1976 20007 LEROY HODGKINSON 1975 20008 PFLUM FRERICHS 1976 20009 PFLUM FRERICHS 1976 20009
20010
PFLLUM FRERICHS 1976 20010
20011
PFLLUM FR FRERICHS 1976 20011 PFLUM FRERIC
20012 CUSHMAN 1920

20013 PFLUM FRERICHS 1976 20014 PFLUM FRERICHS 1976 20015 PFLUM FRERICHS 1976 20016 PFLUM FRERICHS 1976 20016 PFLUM FRERIC

20017 CUSHMAN 1920 20019 PFLUM FRERICHS 1976 20020 PFLUM FRERICHS 1976 20021 PFLUM FRERICHS 1976 20022 PARKER 1954 20023 PARKER 1954 20024 PARKER 1954 20025 PARKER 195 20026 PARKER 1954 20027 PARKER 1954 20028 PARKER 1954 20029 PARKER 1954 20030 PARKER 1954 20031 PARKER 195 20032 PARKER 1954 20033 PARKER 1954 20034 PARKER 195 20036 PARKER 1954 20036
20037
PARKER 20038 ANDERSEN 1961 20039 BANDY 1956 20040 BANDY 1956 20041 BANDY 1956 20042 BANDY 1956 20043 BANDY 1956 20043 BANDY 1956 20044 BANDY 1956 20045 BANDY 1956
20046 BANDY 1956 20047 BANDY 1956 20048 BANDY 1956 20049 BOCK 1976 20050 BANDY 1956 20051 BANDY 1956 20051 BANDY 1956 20052 BANDY 1956
20053 BANDY 1956 20054 BANDY 1956 20055 BANDY 1956 20056 BANDY 1956 20057 BANDY 1956 20058 BANDY 1956 20058 BANDY 1956 20060 BANDY 1956
Generic Name

Specific Name

Locality

LENTICULINA

LENTI CUL INA

LENTI CUL INA

LENTICUL INA

LENT I CULINA

LENT I CUL INA

LENTI CUL INA

LENTI CUL INA

LENTI CULINA

LENTI CULINA

LENT I CULINA

LENTI CULINA

LENTI CULINA

LENTI CULINA

LENTI CULINA

LENTI CULINA

LENT I CUL IN A

LENTI CULINA

LIEBUSELLA

LIEBUSELLA

LI NGUL INA

LINGUL INA

L INGUL IN A

LINGUL INA

LINGUL INA

LITUOTUBA

LI TUOTUBA

LITUOTUBA

LI TUOTUBA

LI TUOTUBA

LI TUOTUBA

LI TUOTUBA

LI TUOTUBA

LI TUOTUBA

LI TUOTUBA

LI TUOTUBA

LI TUOTUBA

LI TUOTUBA

LI TUOTUBA

LI TUOTUBA

LI TUOTUBA

LI TUOTUBA

LI TUOTUBA

LI TUOTUBA

LI TUOTUBA

LI TUOTUBA

LITUOTUBA

LI TUOTUBA

LI TUOTUBA

I TUOTUBA

LI TUOTUBA

LI TUOT TBA A

LI TUOTUBA

LOXOSTOMUM

LOXOSTOMUM

LOXOSTOMUM

OXOS TOMUM

LOXOSTOMUM

LOXOSTOMUM

LOXOSTOMUM

LOXOSTOMUM

LOXOSTOMUM

OXOS TOMUM

OXOSTOMUM

LOXOSTOMUM

LOXOSTOMUM

LOXOSTOMUM

LOXOSTOMUM

OXOSTOMUM

OXOSTOMUM

OXXSTOMUM

LOXOSTOMUM

LOXOSTOMUM

LOXOSTOMUM

LOXOSTOMUM

LOXOSTOMUM

LOXOSTOMUM

LOXOSTOMUM

LOXOSTOMUM

LOXOSTOMUM

LOXOSTOMUM

MARG INUL INA

MARG INUL INA

MARG INUL IN A

MARG INUL INA

MARG I NUL INA

MARG INUL INA

MARG INUL INA

MARG INUL INA

MARG INUL IN A

MA RG INUL INA

MARG I NUL INA
PEREGRINA

PEREGRINA

PEREGRINA

PEREGRINA

PEREGRINA

PEREGRINA

PEREGRINA

PEREGRINA

PEREGRINA

PEREGRINA

PEREGRINA

PEREGRINA

PERERINA

PEREGRINA

PEREGRI NA

PEREGRINA

PE REGRINA

RO TULATA

SOLDANI I

SOLDANI I

CARINATA

CARINATA

SENINUDA

SENINUDA

SENINUDA

LI TUIFORY IS

LI TUIFORM IS

LI TUIFORMIS

LI TUIFORY IS

LI TUIFORM IS

LI TUIFORM IS

LI TUIFORMIS

LI TUIFORM IS

LI TUIFORM IS

LI TUIFORMIS

LI TUIFORMIS

LI TUIFORM IS

LI TUI FORM IS

LI TUI FORY IS

LI TUIFORM IS

LI TUIFORY IS

LI TUIFORY IS

LI TUIFORM IS

LI TUIFORM IS

LI TUIFORM IS

LI TUIFORM IS

LI TUIFORMIS

LI TUIFORM IS

LITUIFORM IS

LI TUIFORM IS

LI TUIFORMIS

LITUIFORM IS

AB RUPTUM

ABRUPTUM

AB RUPTUM

AB RUPTUM

AB RUPTUM

AB RUPTUM

ABRUPTUM

AB RUPTUM

AB RUPTUM

ABRUPTUM

AB RUPTUM

ABRUPTUM

ABRUPTUM

ABRUPTUM

GE LB I

MA YOR I

MAYORI

MA YOR I

SUESPINES CENS

SUESPINES CENS

SURSPINES CENS

SUESPINES CENS

SUESPINES CENS

SUBSPINES CENS

SUESPINES CENS

TRLNCATUM

AD VENA

ADVENA

AD VENA

A OVENA

ADVENA

ADVENA

ADVENA

ADVENA

ADVENA

ADVENA

AD VENA

NW GULF OF MEXICO

NW GULF OF MEXICO

NW GULF OF MEXICO

NW GULF OF MEXICO

$N W$ GULF OF MEXICO

$N W$ GULF OF MEXICO

$N W$ GULF OF MEXICO 


\section{Publication}

20061 BANDY 1956

20062 BANDY 1956

20063 VAUGHAN 1918
20064 BOCK 1976

20065 ANDERSEN 1961

20066 CUSHMAN 1923

20067 PFLUM FRERICHS 1976

20068 BANDY 1956

20069 LANKFORD 1959

20070 PARKER 1954

20071 PHLEGER 1951 A

20072 PARKER 1954

20073 PARKER 1954

20074 PARKER 1954

20075 PHLEGER $1951 \mathrm{~A}$

20076
20077
PHLEGER $1951 \mathrm{~A}$

20078 PHLEGER $1951 \mathrm{~A}$

20079 PHLEGER 1951A

20080 PHLEGER $1951 \mathrm{~A}$

20081 PHLEGER 1951A

20082 PHLEGER 1951 A

20083 PHLEGER $1951 \mathrm{~A}$

20084 PHLEGER $1951 \mathrm{~A}$

20085 PHLEGER 1951A

20086 PHLEGER $1951 \mathrm{~A}$

20087 PHLEGER $1951 \mathrm{~A}$

20089 CREAGER 1958

20089 CREAGER 1958
20090 PARKER 1954

20091 PHLEGER 1951 A

20092 PHLEGER 1951A

20093 PHLEGER 1951 A

20094 PHLEGER 1951

20096 LUDWICK WALTON 1957

20096 LUDWICK WALTON

20098 ANDERSEN 1961

20099 LEROY HODGKINSON 1975

20100 ANDERSEN 1961

20101 KELLOUGH 1956

20102 KELLOUGH 1956

20103 KELLOUGH 1956

20104 PHLEGER 1951A

20105 PHLEGER $1951 \mathrm{~A}$

20106 KELLOUGH 1956

20108 PHLEGER 1951 A

20109 PHLEGER 1951A

20110 BOCK 1976

20111 CREAGER 1958

20112 PHLEGER 1951A

20113 PHLEGER 1951A

20114 PHLEGER 1951A

20116 ANDERSEN 1961

20117 CUSHMAN 1923

20118 CUSHMAN 1923

20119 CUSHMAN 1923

20120 CREAGER 1958

20121 CREAGER 1958

20122 CREAGER 1958

20123 CREAGER 1958

20124 CREAGER 1958

20125 PFLUM FRERICHS 1976

20126 PFLUM FRERICHS 1976

20127 PFLUM FRERICHS 1976

20128 PFLUM FRERICHS 1976

20129 PFLUM FRERICHS 1976

20130 PFLUM FRERICHS 1976

20131 PFLUM FRERICHS 1976

20132 ANDERSEN 1961

20133 BOCK 1976

20134 BANDY 1956

20135 ANDERSEN 1961

20136 PFLUM FRERICHS 1976

20137 PFLUM FRERICHS 1976

20138 PFLUM FRERICHS 1976

20139 PFLUM FRERICHS 1976

20140 PFLUM FRERICHS 1976

20141 BANDY 1956

20142 BANDY 1956

20143 BANDY 1956

20144 BANDY 1956

20145 PFLUM FRERICHS 1976

20146 PFLUM FRERICHS 1976

20147 PFLUM FRERICHS 1976

20148 PFLUM FRERICHS 1976

20149 PFLUM FRERICHS 1976

20150 PFLUM FRERICHS 1976

20151 PFLUM FRERICHS 1976

20152 PFLUM FRERICHS 1976

20153 ANDERSEN 1961

20154 PFLUM FRERICHS 1976
Generic Name

MARG INUL INA

MARG INUL INA

MARG I NUL INA

MARG INUL INA

MARG INUL INA

MARG INUL INA

MARG INUL INA

MARG INUL INA

MARGINUL INA

MARG I NUL INA

MARGINUL INA

MARG INUL INA

MARG INUL IN A

MARG INUL INA

MARGINUL INA

MARGI NUL INA

MARG I NUL INA

MARG INUL INA

MARG INUL INA

MARG I NUL INA

MARGINUL INA

MARG INUL INA

MARG INULINA

MARG I NUL INA

MARGINUL INA

MARG INUL INA

MARG INUL INA

MARGINUL INA

MARG I NUL INA

MARGI NUL INA

MARGINUL INA

MARG INUL INA

MARG INUL INA

MARG INUL INA

MARGINUL INA

MARGINUL INA

MARG INUL INA

MARG INUL INA

MARGINUL INA

MARG INUL INA

MARG INUL INA

MARG I NUL INA

MARG INUL INA

MARG INUL INA

MARG INUL INA

MARGINUL INA

MARGINUL INA

MARGINUL INA

MARG INUL INA

MARG INUL INA

MARG INUL INA

MARG INUL INA

MARG I NUL INA

MARGINUL INA

MARG INUL INA

MARG I NUL INA

MARG INUL INA

MARG INUL INA

MARG INUL INA

MARGINUL INA

MARGINUL INA

MARGI NUL INA

MARG INUL INA

MARG INUL INA

MARGINUL INA

MARG INUL INA

MARG INUL INA

MARG I NUL INA

MARGINUL INA

MARG I NUL INA

MARGINUL INA

MARG INULINOPS IS

MARGINUL INOPS IS

MARGINUL INOPSIS

MARG INUL INOPS IS

MARGINULINOPSIS

MARGI NUL INOPSIS

MARGINULINOPSIS

MARG INUL INOPS IS

MARGINUL INOPSIS

MARGINULINOPS IS

MARGI NUL INOPS IS

MARGINUL INOPS IS

MARGINUL INOPS IS

MARG I NUL INOPS IS

MA RG I NUL INOPS IS

MARGINUL INOPS IS

MARGINUL INOI

MARGINUL INOPSIS

MARGINULINOPSIS

MARG INUL INOPS IS

MARGINUL INOPSIS

MARG INUL INOPSIS
Specific Name

Locality

ADVENA

ADVENA

COSTATA

GL ABRA

GLABRA

GLABRA OBESA

HANTKENI

HANTKEN I

MARG INULI NOIDES

MARGINULINOIDES

MARGINULINOIDES

MARG INULI NO I DES

MARG INULI NO IDES

MA RGINUL I NOIDES

MARGINULI NOIDES

MARGINULI NOIDES

MARG INULI NO IDES

MARG I NULI NO I DE

MARGINULI NOIDES

MA RG I NUL I NO IDES

MARGINULINO IDES

MARGINULI NO IDES

MARGINULI NOIDES

MAFGINULI NO IDES

MARGINULINO IDES

MARG INULINOIDES

MARG I NULI NO IDES

MARG INULI NO I DES

MARGINULI NOIDES

MARGINULI NO IDES

MARGINULI NO IDES

MARG INULI NOIDES

MA RG I NULI NO I DE

MA RG I NULI NO IDES

MARGINULI NOIDES

MARGINULINOIDES

MARGINULI NO IDES

OBESA

OBESA

PE RPROCERA

PLANATA

PLANATA

PL ANATA

PLANATA

PLANATA

PLANATA

PL ANATA

PLANATA

PL ANATA

PLANATA

PL ANATA

PLANATA

PL ANATA

PLANATA

ST RIATULA

STRIATULA

STRIATULA

STRIATULA

SUBACULEATA GLABRATA

SUEACULEATA GLABRATA

SUEACULEATA GLABRATA

SUEACULEATA GLABRATA

SUEACULEATA GLABRATA

TENUIS

TENUIS

TENUIS

TENUIS

TENUIS

TENUIS

TENUIS

VI LLA

DENSI COST ATA

MA RGI NULI NOIDES

MA FGINUL INOIDES

MARG INULI NOIDES

MARGINULI NOIDES

MARGINULI NOIDES

MARGI NULI NO IDES

SUEACULEATA

SU BACULEA TA

SUEACULEATA

SUEACULEATA

SU BACULEATA GLABRATA

SUBACULEATA GLABRATA

SUEACULEATA GLABRATA

SUEACULEATA GLABRATA

SUEACULEATA GLABRATA

SUEACULEATA GLABRATA

SU BACULEATA GLABRATA

SUEACULEA TA GLABRATA

SUEACULEATA GLABRATA

SUBACULEATA GLABRATA

SUEACULEATA GLABRATA

NE GULF OF MEXICO

NE GULF OF MEXICO

FLORIDA KEYS

NE GULF OF MEXICO

MISSISSIPPI DELTA

NE GULF OF MEXICO

NW GULF OF MEXICO

NE GULF OF MEXICO 


\section{Publication}

20156 PFLUM FRERICHS 1976 20157 PFLUM FRERICHS 1976 20158 PFLUM FRERICHS 1976 20159 PFLUM FRERICHS 1976 20160 PFLUM FRERICHS 1976 20161 PFLUM FRERICHS 1976 20162 PFLUM FRERICHS 1976 20163 PFLUM FRERICHS 1976 20164 PFLUM FRERICHS 1976 20165 PFLUM FRERICHS 1976 20166 PFLUM FRERICHS 1976 20167 PFLUM FRERICHS 1976 20168 PFLUM FRERICHS 1976 20169 PFLUM FRERICHS 1976 20170 PFLUM FRERICHS 1976 20171 PFLUM FRERICHS 1976 20172 PFLUM FRERICHS 1976 20173 PFLUM FRERICHS 1976 20174 PFLUM FRERICHS 1976 20175 PFLUM FPERICHS 1976 20176 PFLUM FRERICHS 1976 20177 PFLUM FRERICHS 1976 20178 PFLUM FRERICHS 1976 20179 PFLUM FRERICHS 1976 20180 PFLUM FRERICHS 1976 20181 PFLUM FRERICHS 1976 20182 PFLUM FRERICHS 1976 20183 PFLUM FRERICHS 1976 20184 PFLUM FRERICHS 1976 20185 PFLUM FRERICHS 1976 20186 PFLUM FRERICHS 1976 20187 PFLUM FRERICHS 1976 20188 PFLUM FRERICHS 1976 20189 PFLUM FRERICHS 1976 20190 PFLUM FRERICHS 1976 20191 PFLUM FRERICHS 1976 20192 PFLUM FRERICHS 1976 20193 PFLUM FRERICHS 1976 20194 PFLUM FRERICHS 1976 20195 PFLUM FRERICHS 1976 20196 PFLUM FRERICHS 1976 20197 PFLUM FRERICHS 1976 20198 PFLUM FRERICHS 1976 20199 PFLUM FRERICHS 1976 20200 PFLUM FRERICHS 1976 20201 PFLUM FRERICHS 1976 20202 PFLUM FRERICHS 1976 20203 PFLUM FRERICHS 1976 20204 PFLUM FRERICHS 1976 20205 PFLUM FRERICHS 1976 20206 PFLUM FRERICHS 1976 20207 PFLUM FRERICHS 1976 20208 PFLUM FRERICHS 1976 20209 PFLUM FRERICHS 1976 20210 PFLUM FRERICHS 1976 20211 PFLUM FRERICHS 1976 20212 PFLUM FRERICHS 1976 20213 PFLUM FRERICHS 1976 20214 PFLUM FRERICHS 1976 20215 PFLUM FRERICHS 1976 20216 PFLUM FRERICHS 1976 20217 PFLUM FRERICHS 1976 20218 PFLUM FRERICHS 1976 20219 PFLUM FRERICHS 1976 20220 PFLUM FRERICHS 1976 20221 PFLUM FRERICHS 1976 20222 PFLUM FRERICHS 1976 20223 CUSHMAN 1922A

20224 NORTON 1930

20225 POST 1951

20226 NORTON 1930

20227 CUSHMAN $1922 \mathrm{~A}$

20228 DAVIS 1964

20229 SHIFFLETT 196

20230 LEHMANN 1957

20231 SHIFFLETT 1961

20233 PHLEGER LANKFORD 1957

20234 BANDY 1954

20235 BANOY 1954

20236 KORNFELO 1931

20237 PARKER PHLEGER PEIRSON 1953 20238 BANDY 1954

20239 AYALA-CASTANARES SEGURA 1968 20240 BANDY 1954

20241 PARKER PHLEGER PEIRSON 1953 20242 PARKER PHLEGER PEIRSON 1953 20243 PARKER PHLEGER PEIRSON 1953 20244 BANDY 1954

20245 KORNFELO 1931

20246 PARKER PHLEGER PEIRSON 1953 20247 POST 1951

20248 SHENTON 1957

20249 KORNFELO 1931

20250 PARKER PHLEGER PEIRSON 1953
Generic Name

MARG INUL INOP $\$$ IS MARGINUL INOPS IS MA RG INUL INOPS IS MARGINUL INOPS IS MARG INUL INOPSIS MA RGI NUL INOPSIS MA RG INUL INOPS IS MARGINUL INOPSIS MARG I NUL INOPS IS MARSIPELLA MARSIPELLA MARSI PELLA MARS IPELLA MARSIPELLA MARSI PELLA MARSIPELLA MART INOTTIELLA MARTINOTIIELLA MARTINOTTIELLA MARTINOTTIELL MARTINOTTIELLA MARTINOT TIELLA MARTINOTTI ELLA MARTINOTTIELLA MART INOTTIELLA MARTINOTTIELLA MART I NOTTIELLA MARTINOTTIELLA MARTINOTTIELLA MARTINOTTIELLA MARTINOTTIELLA MARTINOT IELLA MARTINOTTIELLA MARTINOTTIELLA MARTINOTTIELLA MARTINOTTI ELLA MARTINOTTIELLA MARTINOTTIELLA MARTINOTIIELLA MARTINOTTIELLA MART INOTTIELLA MARTINOTTIELLA MARTINOTTIELLA MART INOTTIELLA MARTINOTTIELLA MART INOTIIELLA MARTINOTTIELLA MARTINOTTIELLA MARTINOTIIELLA MARTINOTTIELLA MARTINOTIIELLA MARTINOTTIELLA MART INOT TIELLA MARTINOTTIELLA MARTINOTTIELLA MART INOTTIELLA MARTINOTTIELLA MARTINOTIIELLA MARTINOTTIELLA MARTINOTTIELLA MART INOTTIELLA MARTINOTTIELLA MARTINOTTIELLA MART INOTTIELLA MARTINOTIIELLA MARTINOTIIELLA MARTINOTTIELLA MASSILINA

MASSILINA

MASSILINA

MASSILINA

MASSILINA

MASS IL INA

MASSILINA

MASS IL INA

MASS I I NA

MASSILINA

MASS I L INA

MASSILINA

MASSILINA

MASSILINA

MASSILINA

ASS IL INA

MASSILINA

MASSILINA

MASS ILINA

MASSILINA

MASS ILINA

MASSILINA

MASSILINA

MASSILINA

MASSILINA

MASSILINA

\section{Specific Name}

SUEACULEA TA GLABRATA SUEACULEATA GLABRATA SUEACULEATA GLABRATA SUEACULEATA GLABRATA SUEACULEA TA GLABRATA SUEACULEATA GLABRATA SUEACULEATA GLABRATA SUEACULEATA GLABRATA SUEACULEATA GLABRATA

EL ONGATA

EL CNGATA

EL ONGATA

EL ONGATA

EL ONGATA

EL ONGATA

ELONGATA

COMMUNIS

CONMUNIS

OC CI DENTALIS

OC CI DENTALIS

OC CIDENTALIS

OC CI DENTALIS

OC CIDENTALIS

OC CIDEN TALIS

OC CIDENTALIS

OC CIDENTALIS

OC CIDENTALIS

OC CIDENTALIS

OC CI DEN TALIS

OC CIDENTALIS

OC CIDEN TALIS

OC CIDENTALIS

OC CIDENTALIS

OC CIDENTALIS

OC CIDENTALIS

OC CIDENTALIS

OCCIDENTALIS

OC CIDEN TALIS

OC CIDENTALIS

OC CIDENTALIS

OCCIDENTALIS

OC CIDENTALIS

OC CIDENTALIS

OCCIDENTALIS

OCCIDENTALIS

OC CIDENTALIS

OC CIDENTALIS

OC CIDENTALIS

OC CI DENTALIS

OC CIDENTALIS

OC CIDENTALIS

OC CIDENTALIS

OC CIDENTALIS

OC CIDENTALIS

OC CIDENTALIS

OC CIDENTALIS

OC CIDENTALIS

OC CIDENTALIS

OC CI DENTALIS

OC CIDENTALIS

OC CIDENTALIS

OC CIDENTALIS

OC CIDENTALIS

OC CIDENTALIS

OC CIDENTALIS

OCCIDENTALIS

AL VEOL I NI FORM IS

ANNEC TENS

CRENATA

IN AEQUALIS

IN AEQUALI

PE RUVIANA

PE RUVIANA

PERUVIANA

PE RUV IANA

PERUVIANA

PE RUVI ANA

PERUVIANA

PERUVIANA

PERUVIANA

PERUVIANA

PE RUVIANA

PERUVIANA

PERUVIANA

PERUVIANA

PE RUVIANA

PERUVIANA

PE RUVIANA

PE RUV I A NA

PERUVIANA

\section{Locality}

Lat. Long.

NW GULF OF MEXICO

NW GULF OF MEXICO

NW GULF OF MEXICO

NW GULF OF MEXICO 


\section{Publication}

20251 PHLEGER 1956 20252 PARKER PHLEGER PEIRSON 1953 20253 PHLEGER 1965 A

20254 PARKER PHLEGER PEIRSON 1953 20255 PARKER PHLEGER PEIRSON 1953 20256 PARKER PHLEGER PEIRSON 1953 20257 PHLEGER 1965A

20258 PHLEGER 1965 A

20259 PHLEGER LANKFORD 1957

20260 SEGURA 1963

20261 LEHMANN 1957

20262 PARKER PHLEGER PEIRSON 1953
20263 PARKER PHLEGER PEIRSON 1953

20263 PARKER PHLEGER PEIRSON 1953

20265 PARKER PHLEGER PEIRSON 1953

20266 SHENTON 1957

20267 ANDERSEN 1961

20268 PFLUM FRERICHS 1976

20269 PFLUM FRERICHS 1976

20270 PFLUM FRERICHS 1976

20271 PFLUM FRERICHS 1976

20272 PFLUM FRERICHS 1976

20273 PFLUM FRERICHS 1976

20274 PFLUM FRERICHS 1976

20275 PFLUM FRERICHS 1976

20276 PFLUM FRERICHS 1976

20277 PFLUM FRERICHS 1976

20278 PFLUM FRERICHS 1976

20279 PFLUM FRERICHS 1976

20280 PFLUM FRERICHS 1976

20281 PFLUM FRERICHS 1976

20282 PFLUM FRERICHS 1976

20283 PFLUM FRERICHS 1976

20284 PFLUM FRERICHS 1976

20285 PFLUM FRERICHS 1976

20286 PFLUM FRERICHS 1976

20287 PFLUM FRERICHS 1976

20288 PFLUM FRERICHS 1976

20289 PFLUM FRERICHS 1976

20290 PFLUM FRERICHS 1976

20291 PFLUM FRERICHS 1976

20292 PFLUM FRERICHS 1976

20293 PFLUM FRERICHS 1976

20294 SHEPARD MOORE 1955

20295 LANKFORD 1959

20296 PHLEGER 1955 B

20297 PHLEGER 1965 A

20298 WARREN 1957

20299 POAG 1976

20300 KANE 1967

20301 PHLEGER 1954

20302 PHLEGER 1954

20303 PHLEGER 1954

20304 PHLEGER 1954

20305 PHLEGER LANKFORD 1957

20306 PHLEGER $1965 \mathrm{C}$

20307 PHLEGER 1954

20308 KANE 1962

20309 WALDRON 1963

20310 PARKER PHLEGER PEIRSON 1953 20311 PARKER PHLEGER PEIRSON 1953 20312 PHLEGER 1956

20313 LEHMANN 1957

20314 PARKER PHLEGER PEIRSON 1953

20315 PARKER PHLEGER PEIRSON 1953

20316 WANTLAND 1969

20317 POST 1951

20318 PARKER PHLEGER PEIRSON 1953

20319 POST 1951

20320 PARKER PHLEGER PEIRSON 1953

20322 PHLEGER 1965 A

20323 PHLEGER 1965 A

20324 PHLEGER 1965 A

20325 PHLEGER 1965 A

20326 PHLEGER 1965A

20327 PHLEGER 1965 A

20328 PHLEGER 1965 A

20329 WARREN 1956

20330 BENDA PURI 1962

20331 BENDA PURI 1962

20332 LAMB 1972

20333 PHLEGER 1965 A

20334 BENDA PURI 1962

20336 PHLEGER 1965 B

20337 PHLEGER 1965 A

20338 ANDERSON 1968

20339 AYALA-CASTANARES SEGURA 1968

20340 AYALA-CASTANARES 1963

20341 PHLEGER LANKFORD 1978

20342 PARKER PHLEGER PEIRSON 1953

20343 OTVOS 1978

20345 LEROY HODGKINSON 1975
Generic Name

MASSILINA

MASSILINA

MASSILINA

MASSILINA

MASSILINA

MASSILINA

MASSILINA

MASSILINA

MASSILINA

MASSILINA

MASSILINA

MASSILINA

MASSILINA

MASS IL INA

MELONIS

MELONIS

MELONIS

MELONIS

MELONIS

MELONIS

MELONIS

MELONIS

MELONIS

MELONIS

MELONIS

MELONIS

MELONIS

MELONIS

MELONIS

MELONIS

MELONIS

MELONIS

MELONIS

MELONIS

MELON IS

MELONIS

MELONIS

MELONIS

MILI AMM INA

MI LI AMM I NA

MI LI AMM I NA

MI LI AMM I NA

MI LI AMM I NA

MILI AMM I NA

MI LI AMM I NA

MI LI AMM INA

MI LI AMM I NA

MI LI AMM I NA

MI LI AMM I NA

MI LI AMM I NA

MI LI AMM I NA

MI LI AMM I NA

MI LI AMM I NA

MI LI AMM I NA

MI LI AMM I NA

MI LI AMM I NA

MI LI AMM INA

MI L I AMM INA

MI L I AMM I NA

MILI AMM I NA

MI LI AMMINA

MI LIAMMI NA

MI LI AMMI NA

MI LI AMMI NA

MI LI AMM I NA

MI LI AMM I NA

MI LI AMM I NA

MI LI AMM I NA

MI LI AMM I NA

MI LI AMM I NA

MI L I AMM I NA

MI LI AMM I NA

MI LI AMM I NA

MI LI AMM I NA

MI LI AMM I NA

MI L I AMM I NA

MI LI AMM I NA

MI LI AMM I NA

MI LI AMM I NA

MI LI AMM I NA

MI LI AMM I NA

MILIAMMINA

MI LI AMM I NA

MI LI AMMINA

MI LI AMM I NA

MI LI AMM I NA

MI LI OL INELLA
Specific Name

PERUVIANA

PERUVI ANA

PROTEA

PROTEA

PROTEA

PROTEA

PROTEA

PROTEA

PROTEA

PROTEA

PROTEA

PROTEA

PROTEA

PROTEA

QUADRANS

BARLEEANUS

BARLEEANUS

BARLEEANUS

BARLEEANUS

BARLEEANUS

BA RLEEANUS

BARLEEANUS

BARLEEANUS

POMPILIOI DES

POMPILIOI DES

POMPILIOI DES

PONPILIOIDES

POMPILIOI DES

PONPILIOI DES

POMPILIOI DES

POMPILIOIDES

PONPILIOIDES

PONPILIOIDES

PONPILIOIDES

POMPILIOIDES

POMPILIOIDES

POMPILIOIDES

PONPILIOIDES

PONPILIOI DES

POMPILIOIDES

POMPILIOIDES

FUSCA

FUSCA

FUSCA

FU SCA

FUSCA

FUSCA

FUSCA

FUSCA

FUSCA

FUSCA
FUSCA

FUSCA

FUSCA

FUSCA

FUSCA

FUSCA

FUSCA

FUSCA

FUSCA

FUSCA

FUSCA

FUSCA

FUSCA

FUSCA

FUSCA

FUSCA

FUSCA

FUSCA

FUSCA

FUSCA

FUSCA

FUSCA

FUSCA

FUSCA

FUSCA

FUSCA

FUSCA

FU SCA

FUSCA

FUSCA

FUSCA

FUSCA

FUSCA

FUSCA

FUSCA

FUSCA

FUSCA

FUSCA

FUSCA

ANTAR CTICA

Locality

CENTRAL TEXAS BAYS

TEXAS GULF COAST

$2822 \mathrm{~N} 096 \quad 45 \mathrm{~W}$
CORPUS CHR ISTI

TEXAS $27 \quad 45 \mathrm{~N} 097 \quad 12 \mathrm{~W}$

TEXAS GULF COAST

TEXAS GULF COAST

TEXAS GULF COAST

ALLYN'S BIGHT. TEXAS

PASS CAVALLO. TEXAS

TEXAS GULF COAST

MATAMOROS, MEXICO

TEXAS GULF COAST

TEXAS GULF COAST

TEXAS GULF COAST

TEXAS GULF COAST

TEXAS GULF COAST

MATAGORDA BAY, TEXAS 
Publication

20346 OTVOS 1978

20347 PHLEGER $1965 \mathrm{~B}$

20348 POST 1951

20349 BOCK 1976

20350 BOCK 1976

20351 BOCK 1976

20352 ANDERSEN 1961

20353 PHLEGER $1965 \mathrm{~A}$

20354 PHLEGER 1965 A

20355 WARREN 1957

20356 PHLEGER 1965A

20357 PHLEGER 1965A

20358 PHLEGER 1965A

20359 PHLEGER 1965 A

20360 PHLEGER 1965 A

20361 PHLEGER 1965 A

20362 PHLEGER 1965A

20363 PHLEGER 1965 A

20364 PHLEGER 1965 A

20365 PHLEGER 1965 A

20366 PHLEGER 1965 A

20367 PHLEGER 1965 A

20368 PHLEGER 1965 A

20369 PHLEGER 1965 A

20370 AYALA-CASTANARES SEGURA 1968

20371 PHLEGER 1965A

20372 PHLEGER 1965A

20373 PFLUM FRERICHS 1976

20374 LEROY HODGKINSON 1975

20375 PFLUM FRERICHS 1976

20376 LYNTS PFISTER 1967

20377 ANDERSEN 1961

20378 CUSHMAN $1922 \mathrm{~A}$

20379 BENDA PURI 1962

20380 NORTON 1930

20381 CUSHMAN 1930

20382 ANDERSEN 1961

20383 BOCK 1976

20384 BOCK 1976

20385 BOCK 1976

20386 BOCK 1976

20387 ANDERSEN 1961

20388 AYALA-CASTANARES 1963

20389 LOEP 1965

20390 ANDERSEN 1961

20391 PFLUM FRERICHS 1976

20392 PFLUM FRERICHS 1976

20393 PFLUM FRERICHS 1976

20394 PFLUM FRERICHS 1976

20395 PFLUM FRERICHS 1976

20396 PFLUM FRERICHS 1976

20397 PFLUM FRERICHS 1976

20398 PFLUM FRERICHS 1976

20399 PFLUM FRERICHS 1976

20400 PFLUM FRERICHS 1976

20401 ANDERSEN 1961

20402 PFLUM FRERICHS 1976

20403 PFLUM FRERICHS 1976

20404 PFLUM FRERICHS 1976

20405 PFLUM FRERICHS 1976

20406 PFLUM FRERICHS 1976

20407 PFLUM FRERICHS 1976

20408 PFLUM FRERICHS 1976

20409 PFLUM FRERICHS 1976

20410 PFLUM FRERICHS 1976

20411 PFLUM FRERICHS 1976

20412 PFLUM FRERICHS 1976

20413 PFLUM FRERICHS 1976

20414 PFLUM FRERICHS 1976

20415 PFLUM FRERICHS 1976

20416 PFLUM FRERICHS 1976

20417 PFLUM FRERICHS 1976

20418 PFLUM FRERICHS 1976

20419 PFLUM FRERICHS 1976

20420 PFLUM FRERICHS 1976

20421 PFLUM FRERICHS 1976

20422 PFLUM FRERICHS 1976

20423 PFLUM FRERICHS 1976

20424 CUSHMAN 1922A

20425 BANDY 1954

20426 BANDY 1954

20427 BANDY 1956

20428 BANDY 1954

20429 BANDY 1956

20430 BANDY 1954

20431 BANDY 1954

20432 BANDY 1956

20433 BANDY 1956

20434 BANDY 1956

20435 BANDY 1956

20436 BANDY 1956

20437 BANDY 1956

20438 BANDY 1956

20439 BANDY 1956

20440 BANDY 1956
Generic Name

MILIOLINELLA

MI LI OL I NELLA

MI LIOL INELLA

MI LIOL INELLA

MI LIOL I NELLA

MI LIOL INELL

MILIOL INELLA

MILIOLINELLA

MI LIOL INELLA

MI LIOL I NELL A

MILIOLINELLA

MI LIOLINELLA

MI LI OL INELLA

MILIOL INELLA

MI LIOL INELL A

MI LIOL INELLA

MILIOLINELLA

MILIOLINELLA

MI LIOLINELLA

MILIOL INELLA

MILIOLINELLA

MILIOL INELLA

MILIOLI NELLA

I LIOL INELLA

MI LIOL INELLA

MI LI OLINELLA

MILIOLINELLA

MI LIOL I NELL A

MI LIOL INELLA

MI LIOL INELLA

MONALYSIOIUM

MONALYSIDIUM

MONALYSIDIUM

MONALYSI DIUM

NEOCONORBINA

NE OCONORBINA

NEOC ONORBINA

NE OCONORBINA

NE OCONORBINA

NE OC ONORBINA

NE OC ONORBINA

NE OEPONIDES

NE OEPON I DES

NEOEPONI DES

NE OEPONI DES

NEOEPONIDES

NE OEPONI DES

NEOEPONIDES

NE OEPONI DES

NE OEPONI DES

NE OEPONIDES

NEOEPONIDES

NE OEPONIDES

NE OEPONIDES

NODELLUM

NODELLUM

NODELLUM

NODELLUM

NODELLUM

NODELLUM

NODELLUM

NODELLUM

NODELLUM

NODELLUM

NODELLUM

NODELLUM

NODELLUM

NODELLUM

NODELLUM

NODELLUM

NODELLUM

NODELLUM

NODELLUM

NODELLUM

NODELLUM

NODELLUM

NODELLUM

NODOBACULARIA

NODOBACULARIELLA

NODOBACULARIELLA

NODOBACULARIELLA

NODOBACULARIELLA

NODOBACULARIE ULA

NODOBACULAR IELLA

NODOBAC ULARIELLA

NODOBACULARIELLA

NODOBACULARIELLA

NODOBACULARIELLA

NODOBACULARIELLA

NODOBAC ULAR IELLA

NODOBACULARIELLA

NODOBACULAR IELLA

NODOBACUL

NODOBACULARIELLA
Specific Name

Locality

Lat. Long.

CI RCULARIS

CI RCULARIS

FI CHTELIANA

LAEIOSA

LABIOSA

MI CR.OST OY A

I CROST OMA

MI CROSTOMA

I CROSTOMA

MI CROSTOMA

MI CROSTOMA

MI CROSTOMA

MI CROSTOMA

MI CROSTOMA

BLIQUINODA

OBLIQUINODA

DBLIQUINODA

OBLIQUINODA

$O B L I Q U I N O D A$

OBLI QUINODA

OBLIQUINODA

OBLIQUINJDA

OBLIQUINODA

OBLIQUINODA

SUBROTUNDA

SUBROTUNDA

SUBROTUNDA

SUEROTUNDA

WARREN I

POLITA

POLITA

POLITA

POLITUM

FL CRIDENS IS

ORBICULAR IS

OREICULAR IS

OREI CULAR IS

OREI CUL AR IS

TERQUEMI

ANTILLARUM

ANTILLARUM

ANTILLARUM
CORYELLI

CORYELLI

CORYELLI

CORYELLI

CORYELLI

CORYELLI

CORYELLI

CORYELLI

CORYELLI

CORYELLI

MENBRANACEUM

MENBRANACEUM

MENBRANAC EUM

MENBR ANAC EUM

MENBRANACEUM

MEMBRAN AC EUM

MENBRANAC EUM

MENBRANACEUM

MENBRANAC EUM

MENBRANAC EUM

MENBRANAC EUM

MENBRANACEUM

ME NBRANACEUM

MENBRAN AC EUM

MENBRANAC EUM

MENBR AN AC EUM

MENBRANAC EUM

MENBRANACEUM

MENBRANAC EUM

MENBRANACEUM

ME NBRANAC ELIM

MENBRANAC EUM

TI BIA

A TLANTICA

A TLANTICA

A TLANTI CA

A TLANTI CA

AT LANTICA

A T LANTICA

ATLANTICA

AT LANTI CA

AT LANTICA

A TLANTI CA

ATLANTICA

A TLANTICA

ATLANTICA

A I LANTICA

ATLANTICA

L. PONTCHARTRAIN, LA. WHITEWATER B.. SW FLA

SCUTH TEXAS COAST

NE GULF OF MEXICO

NE GULF OF MEXICO

NE GULF OF MEXICO 


\section{Publication}

20441 BANDY 1956 20442 BANDY 1956 20443 ANDERSEN 1961

20444 BANDY 1956

20445 BANDY 1956

20446 BANDY 1956

20447 BANDY 1956

20448 BANDY 1956

20449 BANDY 1956

20450 BANDY 1956

20451 BENDA PURI 1962

20452 KELLOUGH 1956

20453 PARKER 1954

20454 PARKER 1954

20455 BOCK 1976

20456 PARKER 1954

20457 PARKER 1954

20458 LUDWICK WALTON 1957

20459 PARKER 1954

20460 PARKER 1954

20461 PPRKER 1954

20462 PARKER 1954

20463 PARKER 1954

20464 PARKER 1954

20465 PARKER 1954

20466 PARKER 1954

20467 PARKER 1954

20468 PARKER 1954

20469 DAVIS 1964

20470 SHIFFLETT 1961

20471 ANDERSEN 1961

20472 BANDY 1956

20474 BANDY 1956

20475 BANDY 1956

2047 h CUSHMAN 1923

20477 ANDERSEN 1961

20478 ANDERSEN 196

20479 CUSHIAN 1923

20480 PFLUM FRERICHS 1976

20481 WARREN 1956

20482 WARREN 1957

20483 CUSHMAN 1923

20484 CUSHMAN 1923

20485 CUSHMAN 1923

20486 CUSHMAN 1923

20487 CUSHMAN 1923

20488 CUSHMAN 1923

20489 CUSHMAN 1923

20490 CUSHMAN 1923

20491 CUSHMAN 1923

20492 CUSHMAN 1923

20493 CUSHMAN 1923

20494 CUSHMAN 1923

20495 CUSHMAN 1923

20496 CUSHMAN 1923

20497 CUSHMAN 1923

20498 CUSHMAN 1923

20499 CUSHMAN 1923

20500 LEROY HODGKINSON 1975

20501 CUSHMAN 1923

20502 CUSHMAN 1923

20503 CUSHMAN 1923

20504 ANDERSEN 1961

20505 CUSHMAN 1923

20506 CUSHMAN 1923

20507 CREAGER 1958

20508 PARKER 1954

20510 PARKER 1954

20511 PARKER 1954

20512 PARKER 1954

20513 PARKER 1954

20514 PARKER 1954

20515 PARKER 1954

20516 PARKER 1954

20517 CREAGER 1958

20518 CUSHMAN 1923

20519 CUSHMAN 1923

20520 PFLUM FRERICHS 1976

20521 PFLUM FRERICHS 1976

20522 PFLUM FRERICHS 1976

20523 PHLEGER $1951 \mathrm{~A}$

20524 PHLEGER $1951 \mathrm{~A}$

20525 ANDERSEN 1961

20526 CUSHMAN 1923

20527 CUSHMAN 1923

20528 BOCK 1976

20529 PHLEGER $1951 \mathrm{~A}$

20530 PHLEGER $1951 \mathrm{~A}$

20531 PHLEGER $1951 \mathrm{~A}$

20532 PHLEGER $1951 \mathrm{~A}$

20533 PHLEGER $1951 \mathrm{~A}$

20535 PHLEGER $1951 \mathrm{~A}$

\section{Generic Name}

NODOBACULAR IELLA

NODOBACULARI ELLA

NODOBACULARI ELLA

NODOBACULAR IELLA

NODOBAC ULARIELLA

NODOBACULAR IELLA

NODOBA CULARIELLA

NODOBACULARIELLA

NODOBAC ULAR I ELLA

NODOBACULARIELLA

NODOBA CULARI ELLA

NO DOBACULAR I ELLA

NODOBACULAR IELLA

NODOBACULAR IELLA

NODOBACULAR IELLA

NODOBACULARIELLA

NODOBACULARI ELLA

NO DOBA CULAR IELLA

NODOBAC ULAR IELLA

NODOBACULARIELLA

NODOBACULARIELLA

NODOBAC ULAR IELLA

NODOBACULARIELLA

NODOBACULAR IELLA

NODOBAC ULARI ELLA

NO DOBACULARIELLA

NODOBACULARIELLA

NODOBACULARIELLA

NO DOBA CULAR IELLA

NODOBACULAR IELLA

NODOBACULAR I ELLA

NODOBACULARIELLA

NODOBA CULAR IELLA

NODOBACULARIELLA

NODOBACULAR IELLA

NODOSARI A

NODOSARIA

NODOSARIA

NODOSARIA

NODOSARIA

NODOSARIA

NODOSARIA

NODOSARI

NODOSARIA

NODOSARIA

NODOSAR I A

NODOSAR I A

NODOSARI A

NODOSARI A

NODOSARIA

NODOSARIA

NODOSARIA

NODOSARI A

NODOSARIA

NODOSARIA

NODOSARIA

NODOSARI A

NODOSARI A

NODOSARI A

NODOSAR IA

NODOSARIA

NODOSARIA

NODDSARI

NODOSARIA

NODOSARIA

NODOSARIA

NODOSARI

NODOSARIA

NODOSARIA

NODOSARI

NODOSARIA

NODOSARIA

NODOSARIA

NODOSARIA

NODOSARIA

NODOSARIA

NODOSARIA

NODOSARI A

NODOSARIA

NODOSARIA

NODOSARIA

NODOS

NODOSARIA

NODOSARIA

NO DOSARI

NODOSARI

NO DOSARIA

NODOSARIA

NODOSARIA

NODOSARIA

NODOSARIA

NODOSARIA

NODOSARI

NODOSARIA

NODOSARIA

NODOSARIA
Specific Name

A T LANTI CA

A TLANTICA

A T LANTI CA

ATLANTI CA

A TLANTICA

AT LANTI CA

AT LANTI CA

AT LANTI CA

A TLANTICA

AT LANTI CA

A T LAN I I C

CASSIS

CASSIS

CASS IS

CASS IS

CASS IS

CASS IS

CASSIS

CASS IS

CASSIS

CASSIS

CASSIS

CASSIS

CASSIS

CA SSIS

CASSIS

CASSIS

COAVEXIUS CULA

MEXICANA

MEXICANA

MEXICANA

MEXICANA

ADVENA

ALBATROSS I

ATLANTICA

CA LOMORPHA

CA TESBY I

CATESBYI

CONATULA

CONATULA

CONATULA

CONATULA

CONATULA

CONMUNIS

COMMUNIS

CONMUNIS

CONMUNIS

CONSOBRIVA EMACIATA

CONSOBR INA EMACIATA

CONSOBR IVA EMACIA TA

CONSOBRIVA EMACIATA

FARCIMEN

FILIFORMIS

FI LIFORMI S

FILIFORMI S

FLINTII

FLINTII

FL INTI I

FL INTII

FUSTA

HIRSUTA A CULEATA

HIRSUTA ACULEATA

HI SPI DA

HISPIDA

HI SPIDA

$H I S P I D A$

HI SPIDA

H I SPIDA

H I SPIDA

HI SPIDA

HI SPIDA

HI SP I DA

IN TER CELL UL AR IS

LAEVIGATA TORRIDA

LAEVIGATA TORRIDA

LANNULI IFERA

LANNULIFERA

LAMNULI FERA

PY FULA

PYRULA

PYRULA

PYRULA

PYRULA

PYRULA

PYRULA

PYRULA

PYFULA

PYRULA

PYRULA

PYFULA

\section{Locality}

NE GULF OF MEXICO

NE GULF OF MEXICO

MISSISSIPPI DELTA

NE GULF OF MEXICO 


\section{Publication}

20536 PHLEGER 1951A 20537 PHLEGER $1951 \mathrm{~A}$ 20538 PHLEGER $1951 \mathrm{~A}$ 20539 PHLEGER 1951A 20540 PHLEGER 1951A 20541 CUSHMAN 1923 20542 CUSHMAN 1923 20543 CUSHMAN 1923 20544 CUSHMAN 1922A 20545 CREAGER 1958 20546 PHLEGER 1951A 20547 PHLEGER 1951A 20548 CUSHMAN 1923 20549 CUSHMAN 1923 20550 CUSHMAN 1923 20551 CUS HMAN 1923 20552 CUSHMAN 1923 20553 CUSHMAN 1923 20554 PHLEGER 1951A 20555 PHLEGER 1951A 20556 PHLEGER 1951A 20557 PHLEGER 1951A 20558 PHLEGER 1951A 20559 PHLEGER 1951A 20560 PHLEGER 1951A 20561 PHLEGER 1951A 20562 PHLEGER 1951A 20563 PHLEGER 1951A 20564 PHLEGER 1951A 20565 PHLEGER 1951A 20566 PHLEGER 1951A 20567 PHLEGER 1951A 20568 PHLEGER 1951A 20569 PHLEGER 1951A 20570 PHLEGER 1951A 20571 CUSHMAN 1923 20572 CUSHMAN 1923 20573 CUSHMAN 1923 20574 KELLOUGH 1956 20575 VAUGHAN 1918 20576 CREAGER 1958 20577 CUSHMAN 1923 20578 CUSHMAN 1923 20579 CREAGER 1958 20580 CUSHMAN 1923 20581 CUSHMAN 1923 20582 BANDY 1956

20583 BANDY 1956 20584 BANDY 1956 20585 BANDY 1956 20586 BANDY 1956 20587 BANDY 1956

20588 ANDERSEN 1961 20589 CREAGER 1958 20590 CREAGER 1958 20591 CREAGER 1958 20592 SHENTON 1957 20593 CREAGER 1958 20594 KORNFELD 1931 20595 KORNFELD 1931 20596 PHLEGER 1951A 20597 PHLEGER 1951A 20598 PHLEGER 1951A 20599 PHLEGER 1951A 20600 PHLEGER 1951 A 20601 PHLEGER 1951A 20602 PHLEGER 1951A 20603 KORNFELD 1931 20604 PHLEGER 1951 A 20605 PHLEGER 1951A 20606 PHLEGER 1951A 20607 KORNFELD 1931 20608 PHLEGER 1951A 20609 PHLEGER 1951 A 20610 PHLEGER 1951A 20611 KORNFELD 1931 20612 PHLEGER 1951A 20613 BOCK 1976

20614 OTVOS 1978

20615 BOCK 1976

20616 PARKER 1954

20617 PARKER 9954

20618 PARKER 1954

20619 PARKER 1954

20620 PARKER 1954

20621 PARKER 1954

20622 PHLEGER 1956

20623 PARKER 1954

20624 PARKER 1954

20625 PARKER 1954

20626 PARKER 1954

20627 PARKER 1954

20628 PARKER 1954

20629 PARKER 1954

20630 LUDHICK WALTON 1957
Generic Name

NODOSARIA

NODOSARIA

NODOSARIA

NODOSAR I A

NODOSARIA

NODOSARIA

NODOSARIA

NODOSARIA

NODOSARIA

NODOSARIA

NODOSARIA

NODOSARIA

NODOSARIA

NODOSARIA

NODOSARIA

NODOSARIA

NODOSARIA

NODOSARIA

NODOSARIA

NODOSAR IA

NODOSARIA

NODOSARIA

NODOSARIA

NODOSARIA

NODOSARIA

NODOSARIA

NODOSARIA

NODOSARIA

NODOSARIA

NODOSARI A

NODOSARIA

NODOSARIA

NODOSARIA

NODOSARIA

NODOSARIA

NODOSARIA

NODOSARIA

NODOSARIA

NODOSARIA

NODOSARIA

NODOSAR I A

NODOSAR I A

NODOSARIA

NODOSARIA

NODOSARI A

NONION

NONI ON

NONION

NONION

NONION

NONION

NONION

NONION

NONION

NONI ON

NONION

NONION

NONI ON

NONION

NONION

NONION

NONION

NONION

NONION

NONION

NONION

NONION

NONION

NONION

NONION

NONION

NONION

NONION

NONION

NONION

NONION

NONION

NONION

NONION

NONION

NONI ON

NONION

NONION

NONION

NONION

NONION

NONION

NONION

NONION

NONION

NONION

NONION

NONION
Specific Name

PYRULA

PYRULA

PYRULA

PYRULA

PYRULA SEMIRUGOSA

PYRULA SEMIRUGOSA

PYRULA SEMIRUGOSA

ROTUNDATA

SCALARIS SEPARANS

SUBL INEAT A

SUBL INEATA

SUBLINEATA

SUEL INEAT A

SUBLINEAT A

SUBLINEATA

SUBLINEATA

SUBL I NEAT A

SUEL I NEAT A

SUBLINEATA

SUBLINEATA

SUELINEATA

SUBLINEATA

SUBLINEATA

SUELINEAT A

SUEL INE AT A

SUBLINEAT A

SUBLINEATA

SUBLINEATA

SUELINEAT A

SUEL INEAT A

SUELINEATA

SUELINEATA

SUBLINEATA

SUBLINEAT A

SUESOLUTA

SUBSOLUTA

VERTEBRAL IS

VERTEBRAL IS

VERTEBRAL IS

VERTEBRALIS ALBATROSSI

VERTEBRALIS ALBATROSSI

VERTEBRAL IS ALBATROSSI

VERTEBRAL IS ALBATROSSI

VERTEBRALIS ALBATROSSI

VERTEBRAL IS ALBATROSSI

AFFINIS

AFFINIS

AFFINIS

AFFINIS

AFFINIS

AFFIN IS

BA FLEEANUS

DEPRESSULA

DEFRESSULAA

DEPRESSULA

DEPRESSULA

DEPRESS UL A

DEFRESSULA MATAGORDANA DEPRESSULA MATAGORDANA DEPRESSUL A MATAGORDANA DEPRESSULA MATAGORDANA DEFRESSU. A MATAGORDANA DEPRESSUL A MATAGORDANA DEPRESSUL A MATAGORDANA DEPRESSULA MATAGORDDANA DEPRESSU A MATAGORDana DEPRESSULA MATAGORDANA DEPRESSUL A MATAGORDANA DEPRESSULA MATAGORDANA DEPRESSULA MATAGORDANA DEPRESSUL-A MATAGORDANA DEPRESSULA MAIAGORDANA DEPRESSULA MATAGORDANA DEPRSSULA MaTagordana DEPRESSUL A MATAGORDANA DEPRESSUL A MATAGORDANA DEPRESSULUM MATAGORDANUM DERESSULUM MATAGORDANUM

FORMOSUM

FO RMOSUM

FO RMOSUM

FORMOSUM

FORMOSUM

FORMOSUM

FORMOSUM

FORMOSUM

FORMOSUM

FO RMOSU

FORMOSUM

FO RMOSUM

FORMOSUM

FORMOSUM

EORMOSUM

Locality

NW GULF OF MEXICO 


\section{Publication}

20631 PARKER 1954 20632 PARKER 1954 20633 LEHMANN 1957 20634 LEHMANN 1957

20635 PHLEGER 1951A 20636 PHLEGER $1951 \mathrm{~A}$ 20637 PHLEGER 1951 A 20638 PHLEGER $1951 \mathrm{~A}$ 20639 PHLFGER $1951 \mathrm{~A}$ 20640 PHLEGER $1951 \mathrm{~A}$ 20641 PHLEGER $1951 \mathrm{~A}$ 20642 PHLEGER $1951 \mathrm{~A}$ 20643 PHLEGER $1951 \mathrm{~A}$ 20644 PHLEGER $1951 \mathrm{~A}$ 20645 KORNFELD 193 20646 NORTON 1930 20647 CUSHMAN 1930

20648 PHLEGER 1951 A

20649 AYALA-CASTANARES 1963 20650 BENDA PURI 1962

20651 PHLEGER $1951 \mathrm{~A}$

20652 PHLEGER $1951 \mathrm{~A}$

20653 PHLEGER 1951 A

20654 PHLEGER $1951 \mathrm{~A}$

20655 PHLEGER 1951A

20656 PHLEGER 1951A

20657 PHLEGER $1951 \mathrm{~A}$

20658 PHLEGER 1951A

20659 PHLEGER 1951 A

20660 PHLEGER 1951A

20661 PHLEGER 1951A

20662 PHLEGER $1951 \mathrm{~A}$

20663 PHLEGER 1951 A

20664 PHLEGER 1951A

20665 POST 1051

20666 LEHMANN 1957

20667 POST 195

20668 PHLEGER $1951 \mathrm{~A}$

20669 PHLEGER 1951 A

20670 PHLEGER 1951A

20671 PHLEGER $1951 \mathrm{~A}$

20672 PHLEGER 1951A

20673 PHLEGER 1951 A

20674 PHLEGER $1951 \mathrm{~A}$

20675 PHLEGER 1951 A

20676 PHLEGER 1951 A

20677 PHLEGER $1951 \mathrm{~A}$

20678 PHLEGER $1951 \mathrm{~A}$
20679 PHLEGER $1951 \mathrm{~A}$

20679 PHLEGER $1951 \mathrm{~A}$

20681 LUDWICK WALTON 1957

20682 PHLEGER $1951 \mathrm{~A}$

20683 PHLEGER 1951 A

20684 PHLEGER $1951 \mathrm{~A}$

20685 PHLEGER 1951 A

20686 PHLEGER $1951 \mathrm{~A}$

20687 PHLEGER 1951 A

20688 PHLEGER 1951A

20689 PHLEGER 1951A

20690 PHLEGER $1951 \mathrm{~A}$

20691 PHLEGER 1951 A

20692 PHLEGER $1951 \mathrm{~A}$

20693 PHLEGER 1955 A

20694 PHLEGER 1955 A

20695 PHLEGER 1955A

20696 PHLEGER $1951 \mathrm{~A}$

20697 PHLEGER 1951A

20698 PHLEGER $1951 \mathrm{~A}$

20699 PHLEGER 1951 A

20700 PARKER 1954

20701 PARKER 1954

20702 PARKER 1954

20703 PARKER 1954

20704 PHLEGER 1951 B

20705 PHLEGER $1951 \mathrm{~A}$

20706 PHLEGER $1951 \mathrm{~A}$

20707 PHLEGER 1951 A

20708 KELLOUGH 1956

20709 KELLOUGH 1956

20710 PARKER 1954

20711 DARKER 1954

20712 PARKER 1954

20713 PARKER 1954

20714 PARKER 1954

20715 CREAGER 1958

20716 NORTON 1930

20717 PHLEGER LANKFORD 1978

20718 BENDA PURI 1962

20719 CREAGER 1958

20720 CREAGER 1958

20721 OTVOS 1978

20722 PHLEGER 1956

20723 PARKER 1954

20724 PARKER PHLEGER PEIRSON 1953 20725 PARKER PHLEGER PEIRSON 1953
Generic Name

NONION

NONION

NONION

NONION

NONION

NONION

NONION

NONION

NONION

NONION

NONION

NONION

NONION

NONION

NONION

NONION

NONION

NONION

NONION

NONION

NONION

NONION

NONION

NONION

NONION

NONION

NONION

NONION

NONION

NONION

NONION

NONI ON

NONION

NONION

NONION

NONION

NONI ON

NONION

NONION

NONION

NONION

NONION

NONION

NONION

NONION

NONION

NONION

NONION

NONION

NONION

NONI ON

NONION

NONION

NONION

NONION

NONION

NONION

NONION

NONION

NONION

NONION

NONION

NONION

NONION

NONION

NONION

NONION

NONI ON

NONION

NONI ON

NONION

NONION

NONION

NONION

NONION

NONION

NONION

NONION

NONION

NONION

NOVION

NONI ON

NONION

NONION

NONION

NONION

NONIONELLA

NONI ONELLA

NONIONELLA

NONIONELLA

NONI ONELLA

NONI ONELLA

NONIONELLA

NONIONELLA
Specific Name

FO FMOSUM

FORMOSUM

GRANOSUM

GRATELOUP I

GRATEL OUP I

GRATELOU' I

GRATELOUP I

GRATELOUP I

GRATELOUP I

GRATELOUP I

GRATELOUP I

GRATELOUP I

GRATELOUP I

GRATELOUP I

GRATEL OUP I

GRATELOUP I

GRATELOUD I

GRATELOUP I

GRATELOUP I

GRATELOUP I

GRATEL OUP I

GRATELOUP I

GRATEL OUP I

GRATELOUP I

GRATELOUP I

GRATELOUP I

GRATELOUPI

GRATELOU' I

GRATELOUP I

GR ATELOUP I

GRATELOUD I

GRATELOUP I

GRATEL OUP I

PAUCILOCULUM

PAUCILOCULUM

PAUCILOCJLUM

PONPILIOIDES

PONPILIOI DES

PONPILIOIDES

PONPILIOIDES

PONPILIOIDES

PONPILIOIDES

POMPILIOIDES

PONPILIOI DES

POMPILIOI DES

PONPILIOIDES

POMPILIOI DES

POMPILIOIDES

PONPILIOIDES

PONPILIOIDES

PONPILIOIDES

PONPILIOIDES

POMPILIOIDES

PONPILIOI DES

PONPILIOI DES

POMPILIOIDES

POMPILIOIDES

PONPILIOIDES

POMPILIOI DES

POMPILIOIDES

PONPILIOI DES

POMPILIOI DES

PONPILIOI DES

PONPILIOI DES

PONPILIOIDES

POMPILIOIDES

PONPILIOIDES

PONPILIOI DES

POMPILIOIDES

PONPILIOI DES

PONPILIOI DES

PONPILIOI DES

PONPILIOIDES

PONPILIOI DES

PONPILIOIDES

PONPILIOI DES

PONPILIOIDES

PONPILIOIDES

PONPILI OI DES

POMPILIOIDES

PONPILIOIDES

PONPILIOIDES

PONPILIOIDES

POMPILIOI DES

SCAPHA

TI SBURYEVSIS

A TLANTI CA

A TLANTICA

A T LANTICA

AT LANTI CA

AT LANTI CA

A TLANI I CA

\section{Locality}

NE GULF OF MEXICO

NE GULF OF MEXICO 


\section{Publication}

20726 PHLEGER 1956 20727 PHLEGER 1956 20728 PARKER 1954

20729 PHLEGER 1956

20730 BANDY 1956

20731 BANOY 1956

20732 BANOY 1956

20733 BANDY 1956

20734 BANOY 1956

20735 PARKER 1954

20736 BANOY 1954

20737 BANOY 1956

20738 BANOY 1954

20739 WARREN 1956

20740 LOEP 1965

20741 HALTON 1964

20742 KELLOUGH 1956

20744 KELLOUGH 1956

20745 BENDA PURI 1962

20746 BANDY 1954

20747 AYALA-CASTANARES SEGURA 1968

20748 BANOY 1954

20749 BANDY 1954

20750 KELLOUGH 1956

20751 KELLOUGH 1956

20752 KELLOUGH 1956

20753 KELLOUGH 1956

20754 BANOY 1956

20755 AYALA-CASTANARES 1963

20756 BANDY 1954

20757 LOEP 1965

20758 WALTON 1960

20759 ANDERSON 1968

20760 KELLOUGH 1956

20761 PHLEGER 19658

20762 PHLEGER 1956

20763 PARKER PHLEGER PEIRSON 1953

20764 PARKER 1954

20765 PARKER 1954

20766 PARKER 1954

20767 PARKER 1954

20768 PARKER 1954

20769 PARKER 1954

20770 PARKER 1954

20771 PARKER 1954

20772 PARKER 1954

20773 PARKER 1954

20774 PHLEGER LANKFORD 1957

20775 PHLEGER 1954

20776 PHLEGER 1955 A

20777 LUDWICK WALTON 1957

20778 PHLEGER 1954

20779 PHLEGER 1955 A

NONIONELLA

20780 PARKER PHLEGER PEIRSON 1953 NONIONELLA

20781 PARKER 1954

20782 PARKER 1954
20783 PARKER 1954

20784 BOCK 1976

20785 BOCK 1976

20786 PARKER 1954

20787 PARKER 1954

20788 BOCK 1976

20789 BOCK 1976

20790 BOCK 1976

20791 PARKER PHLEGER PEIRSON 1953

20792 CREAGER 1958

20793 PHLEGER 1951A

20794 PHLEGER 1951 A

20795 PHLEGER $1951 \mathrm{~A}$

20796 PHLEGER 1951A

20797 PHLEGER 1951 A

20798 PHLEGER 1951A

20799 PHLEGER 1951A

20800 PHLEGER 1951A

20801 BANDY 1956

20802 PARKER 1954

20803 BANDY 1956

20804 BANDY 1956

20805 PHLEGER 1951 A

20806 PHLEGER 1951

20807 DAVIS 1964

20808 PHLEGER 1951A

20809 PHLEGER 1951 A

20810 PHLEGER 1951A

20811 PHLEGER 1951A

20812 PHLEGER 1951 A

20813 PHLEGER 1951 A

20814 PHLEGER 1951 A

20815 PHLEGER 1951A

20816 LANKFORD 1959

20817 BANDY 1956

20818 BANDY 1956

20819 BANDY 1956

20820 BANDY 1956

NONIONELLA

\section{Generic Name}

NONIONELLA

NONIONELLA

NONI ONELLA

NONIONELLA

NONI ONELLA

NONI ONELLA

NONIONEL LA

NONIONELLA

NONIONELLA

NONI ONELLA

NONIONELLA

NONIONELLA
NONIONELLA

NONIONELLA

NONIONELLA

NONI ONELLA

NONIONELLA

NONIONELLA

NONIONELLA

NONIONELLA

NONIONELLA

NONI ONELLA

NONIONEL LA

NONIONELLA

NONI ONELLA

NONI ONELLA

NONIONELLA

NONIONELLA

NONI ONELLA

NONI ONELLA

NONIONELL

NONI ONELLA

NONIONELLA

NONIONELLA

NONIONELLA

NONIONELLA

NONIONELLA

NONIONELLA

NONIONELLA

NONIONELLA

NONIONELLA

NONIONELLA

NONIONELLA

NONI ONELLA

NONIONELLA

NONIONELLA

NONIONELLA

NONI ONELLA

NONI ONELLA

NONIONELLA

NONI ONELLA

NONIONELLA

NONI ONELLA

NONI ONELLA

NONIONELLA

NONIONELLA

NONIONELLA

NONIONELLA

NONIONELLA

NONI ONELLA

NONI ONELLA

NONI ONELLA

NONIONELLA

NONIONELLA

NONI ONELLA

NONIONELLA

NONI ONE LLA

NONIONELLA

NONI ONELLA

NONI ONELLA

NONIONELLA

NONI ONELLA

NONIONELLA

NONIONELLA

NONIONELLA

NONI ONELLA

NONI ONELLA

NONIONELLA

NONIONELLA

NONIONELLA

NONI ONELLA

NONIONELLA

NONIONELLA

NONI ONELLA

NONIONELLA

NONIONELLA
Specific Name

A T LANTI CA

A T LANTICA

A T LAN I I CA

A T LANTI CA

ATLANTICA

A TLANTI CA

A T LANT I CA

A T LANTI CA

A T LANTI CA

A T LANTICA

A LANTICA

A T LANTICA

A T LANT I CA

AT LANTICA

ATLAN TI CA

AT LANT I CA

AT LANTICA

ATLANTICA

AT LANT I CA
AT LANTI CA

A T LANTI CA

A T LANTICA

AT LANT I CA

A T LANTI CA

AT LANTICA

A T LAN I I CA

A T LANTICA

A TLANTI CA

AT LANTICA

AT LANTICA

AT LANTI CA

AT LANTI CA

A T LANTICA

A T LANTICA

A T LANTICA

A T LANTI CA

A T LANTICA

A TLANTICA

A T LANTI CA

A T L ANTI CA

A T LANTI CA

A T LANT I CA

AT LANTI CA

AT LANTICA

A T LANTI CA

A T LANTI CA

A T LANTICA

ATLANTICA

A T LANTICA

A TLANTICA

A T LANTI CA

A T LANTI CA

A TLANTICA

AT LAN T I CA

A T LANTI CA

A T LANTICA

A TLANTI CA

A T LANTICA

AT LANT I CA

A T LANTICA

A T LANT I CA

A T LAN I I CA

AT LANTICA

A TLANTICA

ATLANTI CA

A T LANTICA

A T LANTI CA

AT LANTI CA

ATLANTICA

ATLANTICA

AT LANTICA

A T LANTI CA

ATLANTICA

A T LANTI CA

AT LANTI CA

AT LANTICA

A TLANTI CA

AT LANTICA

A T LANTI CA

AT LANTICA

A T LANTI CA

A TLANTICA

AT LANTICA

A T LANTICA

AT LANTI CA

A TLANTICA

ATLANTICA

AT LANTICA

A TLANTICA

A TLANTI CA

Locality

Lat. Long.

NW GULF OF MEXICO

CENTRAL TEXAS BAYS

NE GULF OF MEXICO

NW GULF OF MEXICO

NE GULF OF MEXICO

NE GULF OF MEXICO

NE GULF OF MEXICO

NE GULF OF MEXICO

NE GULF OF MEXICO

NE GULF OF MEXICO

NW GULF OF MEXICO

NW GULF OF MEXICO 


\section{Publication}

20821 WARREN 1957 20822 PARKER 1954 20823 PHLEGER 1951 A 20824 PHLEGER 1951 A 20825 PHLEGER 1955 20826 BANDY 1956 20827 PHLEGER 1955 B 20828 PHLEGER 1951 A 20829 KANE 1967 20830 PHLEGER 1951A 20831 PHLEGER 1951A 20832 PHLEGER 1951 A 20833 SEGURA 1963 20834
20835 PHLEGER 1951A 20836 BANDY 1956 20837 WARREN 1956 20838 ANDERSEN 1961 20839 ANDERSEN 1961 20840 ANDERSEN 1961 20841 WAREEN 1957 20842 ANDERSEN 1961 20843 ANDERSEN 1961 20844 ANDERSEN 196 20845 ANDERSEN 196 20846 ANDERSEN 1961 20847 ANDERSEN 1961 20848 BANDY 1956 20849 BANDY 1956 20850 BANDY 1956 20851 BANDY 1956 20852 BANDY 1956 20853 BANDY 1956 20854 BANDY 1956 20855 BANDY 1956 20856 DAVIS 1964 20857 BANDY 1956 20858 BANDY 1956 20859 BANDY 1956 20860 BANDY 1956 20861 BANDY 1956 20862 BANDY 1956 20863 BANDY 1956 20864 BANOY 1956 20865 PHLEGER 1951A 20866 PHLEGER $1955 \mathrm{~B}$ 20867 PHLEGER 1951A 20868 PHLEGER 1951A 20869 PHLEGER 1951A 20870 LANKFORD 1959 20871 PARKER 1954

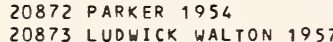
20874 PHLEGER 1954 20875 PHLEGER 1955 A

20876 PARKER 1954

20877 PARKER 1954 20878 PARKER 1954 20879 PARKER 1954 20880 PARKER 1954 20881 PARKER 1954 20882 PHLEGER 1959 A 20883 PHLEGER $1951 \mathrm{~A}$ 20884 PHLEGER 1951 20885 PHLEGER 1951A 20886 PHLEGER $1951 \mathrm{~A}$ 20887 PHLEGER 1951A 20888 PHLEGER $1951 \mathrm{~A}$ 0889 PHLEGER 1951 A 20890 PHLEGER $1951 \mathrm{~A}$ 20891 PHLEGER 1951A 20892 PHLEGER 1951 A 20893 PHLEGER 1951A 20894 PHLEGER 1951A 20895 PHLEGER $1951 \mathrm{~A}$ 20896 PHLEGER $1951 \mathrm{~A}$ 20897 PHLEGER 1951A 20898 PFLUM FRERICHS 1976 20899 PFLUM FRERICHS 1976 20900 SEGURA 1963 20901 PHLEGER $1951 \mathrm{~A}$ 20902 PHLEGER 1951 A 20903 PARKER 1954

20904 PFLUM FRERICHS 1976 20905 PARKER 1954 20906 PHLEGER 1951 A 20907 PHLEGER 1951 A 20908 PFLUM FRERICHS 1976 20909 PFLUM FRERICHS 1976 20910 PFLUM FRERICHS 1976 20911 AYALA-CASTANARES 1963 20912 BENDA PURI 1962

20913 KELLOUGH 1956

20914 KELLOUGH 1956 20915 ANDERSON 1968
Generic Name

Specific Name

NONI ONELLA

NONIONELLA

NONIONELLA

NONI ONELLA

NONI ONELLA

NONI ONELLA

NONIONELLA

NONIONELLA

NONI ONELLA

NONI ONELLA

NONIONELLA

NONIONELLA

NONI ONELLA

NONIONELLA

NONI ONELLA

NONIONELLA

NONIONELLA

NONI ONELLA

NONIONELLA

NONIONELLA

NONI ONELLA

NONIONELLA

NONIONELLA

NONI ONELLA

NONI ONELLA

NONIONELLA

NONI ONELLA

NONIONELLA

NONI ONELLA

NONI ONELLA

NONI ONELLA

NONIONELLA

NO NI ONE LLA

NONI ONELLA

NONI ONELLA

NONI ONELLA

NONIONELLA

NONIONELLA

NONIONELLA

NONI ONELLA

NONI ONELLA

NONIONELLA

NONIONELLA

NONIONELLA

NONI ONELLA

NONI ONELLA

NONIONELLA

NONIONELLA

NONI ONELLA

NONI ONELLA

NONI ONELLA

NONI ONELLA

NONI ONELLA

NONI ONELLA

NONI ONELLA

NONI ONELLA

NONI ONELLA

NONI ONELLA

NONI ONELLA

NONIONELLA

NONI ONELLA

NONI ONELLA

NONI ONE LLA

NONIONELLA

NONI ONELLA

NONI ONELLA

NONI ONELLA

NONIONE LLA

NONI ONELLA

NONI ONELLA

NONI ONELLA

NONI ONELLA

NO NI ONELLA

NONI ONELLA

NONI ONELLA

NONIONELLA

NONI ONELLA

NONI ONELLA

NONIONELLA

NONI ONELLA

NONIONELLA

NONI ONELLA

NONIONELLA

NONIONELLA

NONI ONELLA

NONIONELLA

NONI ONELLA

NONIONELLA

AT LANTI CA

A T LANTICA

A T LANTI CA

A T LANTI CA

AT LANTICA

A T LANT I CA

A T LANTI CA

AT LANTI CA

A TLANTI CA

AT LANTI CA

AT LANTICA

ATLANTICA

AT LANTI CA

A T LANTI

AURIS

AURIS

AURIS

AURIS

AURIS

AURIS

AURIS

AURIS

AURIS

BASILOBA

GRATELOUP I

GRATELOUP I

GRATELOUP I

GRATELOUD I

GRATEL OUP I

GRATELOUP I

GRATELOUP I

GRAT ELOUP I

GRAT EL OUP I

GRATELOUP I

GRATELOUP I

GRATELOUP I

GRATELOUP

GRATEL OUP I

GRATELOUP I

GRAT ELOUS I

OP IMA

OP IMA

OP IMA

OPIMA

OP IMA

OP IMA

OP IMA

OP IMA

OP IMA

OP IMA

OPIMA

OP IMA

OP IMA

OP I MA

OPIMA

OP IMA

OP IMA

OPIMA

OP IMA

OP IMA

OP IMA

OP IMA

OP IMA

OPIMA

OPIMA

OP IMA

OP I MA

OPIMA

OPIMA

OPIMA

OP IMA

OP IMA

OP IMA

OPIMA

OP IMA

OP IMA

OP I MA

OP IMA

OPIMA

OP IMA

OP I MA

OP IMA

OP IMA

OP IMA

OP IMA

OP IMA

OP IMA

OP IMA

OP IMA
ATLANTICA SE LOUISIANA

$N$ GULF OF MEXICO

Locality

NE GULF OF MEXICO

NW GULF OF MEXICO

NW GULF OF MEXICO

NE GULF OF MEXICO

MISSISSIPPI DELTA

NW GULF OF MEXICO

SABINE LAKE, TEXAS

NW GULF OF MEXICO

NW GULF OF MEXICO

NW GULF OF MEXICO

MATAMOROS, MEXICO

HEALD BANK, G. OF MEXICO

NW GULF OF MEXICO 
Publication

20916 KELLOUGH 1956

20917 PFLUM FRERICHS 1976

20918 PFLUM FRERICHS 1976

20919 PFLUM FRERICHS 1976

20920 PFLUM FRERICHS 1976

20921 PFLUM FRERICHS 1976

20922 PFLUM FRERICHS 1976

20923 PFLUM FRERICHS 1976

20924 PFLUM FRERICHS 1976

20925 PFLUM FRERICHS 1976

20926 WALTON 1960

20927 PHLEGER $1951 \mathrm{~A}$

20929 PARKER PHLEGER PEIRSON 1953

20930 PHLEGER 1956

20931 PHLEGER 1956

20932 PHLEGER 1956

20933 PHLEGER 1956

20936 POAG 1972

20935 PARKER 1954

20936 PARKER 1954

20937 PARKER 1954

20938 PARKER 1956 P 20939 PARKER PHLEGER PEIRSON 1953

20940 PARKER PHLEGER PEIRSON 1953

20941 BOCK 1976

20942 CREAGER 1958

20943 PHLEGER 1956

20944 PARKER PHLEGER PEIRSON 1953

20945 PARKER 1954

2 ก946 PARKER 1954

20947 PARKER 1954

20948 CREAGER 1958

20949 OTVOS 1978

20950 PARKER PHLEGER PEIRSON 1953

20951 BOCK 1976

20952 PARKER PHLEGER PEIRSON 1953

20953 CUSHMAN 1922 A

20956 VAUGHAN 1918

20955 VAUGHAN 1918

20956 PARKER PHLEGER PEIRSON 1953

20957 POAG SWEET 1972

20958 PHLEGER 1956

20959 PHLEGER 1956

20960 PHLEGER 1956

20961 PHLEGER 1956

20962 SHEPARO MOORE 1955

20963 PARXER 1956

20964 PARKER 1954

20965 PARKER 1954

20966 PARKER 1954

20967 PARKER 1954

20968 PARKER 1954

20969 LANKFORO 1959

20970 PHLEGER 1955

20971 BOCK 1976

20972 CUSHMAN $1922 A$

20973 BOCK 1976

20974 BOCK 1976

20975 LEROY HODGKINSON 1975

20976 PARKER 1954

20977 PARKER 1954

20978 PARKER 1954

20979 PARKER 1954

20980 PARKER 1956

20981 PARKER 1956

20982 ANDERSEN 1961

20983 BOCK 1976

20984 ANDERSEN 1961

20985 LEROY HOOGKINSON 1975

20986 PFLUM FRERICHS 1976

20987 PFLUM FRERICHS 1976

20988 PFLUM FRERICHS 1976

20989 BOCK 1976

20990 ANDERSEN 1961

20991 BENDA PURI 1962

20992 VAUGHAN 1918

20993 VAUGHAN 1918

20994 VAUGHAN 1918

20995 CUSHMAN $1922 \mathrm{~A}$

20996 VAUGHAN 1918

20997 CUSHMAN 1922A

20998 CUSHMAN 1922 A

20999 VAUGHAN 1918

21000 VAUGHAN 1918

21001 PFLUM FRERICHS 1976

21002 PFLUM FRERICHS 1976

21003 PFLUM FRERICHS 1976

21004 PFLUM FRERICHS 1976

21005 PFLUM FRERICHS 1976

21006 PFLUM FRERICHS 1976

21007 PFLUM FRERICHS 1976

21008 PFLUM FRERICHS 1976

21000 PFLUM FRERICHS 1976

21010 PFLUM FRERICHS 1976
Generic Name

Specific Name

Locality

NONIONELLA

NONIONELLA

NONIONELLA

NONIONELLA

NONIONELLA

NONI ONELLA

NONI ONEL LA

NONI ONELLA

NONI ONELLA

NONI ONELLA

NONIONELLA

NONI ONELLA

NONI ONELLA

NONI ONELLA

NONI ONELLA

NONI ONELLA

NONIONELLA

NONI ONELLA

NONIONELLA

NONIONELLA

NONIONELLA

NONIONELLA

NONIONELLA

NONIONELLA

NONIONELLA

NONIONELLA

NONI ONELLA

NONIONELLA

NONI ONELLLA

NONIONELLA

NONIONELLA

NONI ONELLA

NONIONELLA

NONI ONELLA

NONIONELLA

NONI ONELLA

NONIONELLA

NONIONINA

NONIONINA

NONIONINA

NOUR I A

NOURIA

NOUR I A

NOURIA

NOUR I A

NOUR I A

NOUR I A

NOUR I A

NOURIA

NOUR I A

NOUR IA

NOURIA

NOUR I A

NOURIA

NOUR I A

NOUR IA

NUBECULARIA

NU BECULARI A

NUBECUL INA

NUMMOLOCULI NA

NUMMOLOCUL INA

NUMMOLOCUL INA

NU MMOLOCUL INA

NU MMOL OCUL INA

NUMMOLOCULINA

NUMMOLOCUL INA

OOLINA

OOLINA

OOLINA

OOLINA

OOLINA

OOLINA

OOLINA

OOLINA

OOLINA

OPHTHALMIOIUM

ORBICULINA

ORBICULINA

ORBICULINA

ORBICULINA

ORBICULINA

ORBICULINA

ORBITOLITES

ORBITOLITES

ORQITOLITES

ORIDORSALIS

ORIDORSALIS

OR IOORSALIS

ORIOORSALIS

ORIDORSALIS

ORIDORSALIS

ORIDOR

ORIOOR

ORIOORSALIS

ORI DORSALIS
OPIMA

OP IMA

$O P$ IMA

OP IMA

$O P I M A$

OPIMA

OPIMA

OP IMA

OP IMA

OPIMA

OP IMA

OPIMA

OP IMA

$O P I M A$

OPIMA

OP IMA

OP IMA

OP IMA

OPIMA

OPIMA

$O P I M A$

OPIMA

$O P I M A$

OPIMA

OPIMA

OPIMA

OPIMA

OPIMA

$O P I M A$

OPIMA

$O P I M A$

OPIMA

OP IMA

OPIMA

OP IMA

OP IMA

OPIMA

GRATELOUP I

SCAPHA

UM B IL ICAT ULA

POLYMORPA INOI DES

POLYMORPHINOIOES

POLYMORPA INOIDES

POLYMORPA INOIDES

POLYMORPH INOIOES

POLYMORPA INOIDES

POLYMORPH INOIDES

POLYMORPY INOI OES

POLYMORPA INOIDES

POLYMORPA INOIDES

POLYMORPH INOIDES

POLYMORPA INOIOES

POLYMORPA INOIDES

POLYMORPH INOIOES

POLYMORPA INOIDES

POLYMORPAINOIDES

AN TILLAR'J M

LUCIFLUGA

OI VER I C AT

CONTRARIA

I RREGUL AR IS

I R RE GULAR IS

IR REGULAR IS

IRRE GULAR IS

IRREGULAR IS

I R RE GUL AR IS

CAUOIGERA

HEXAGONA

OONISPIVA

LONG ISPIVA

IV A

LONGISPINA

LONGISPINA

MELO

INCONSTAVS

AOLNCA

$A D L V C A$

ADUNCA

ADLNCA

COMPRESSA

CONPRESSA

OUPLEX

MARGINALIS

MARGINALIS

SIDEBOTTOMI

SI DEBOTTOMI

SI CEBOTTOMI

SI DEBOTTOMI

SI DEBOTTOMI

SI OEBOTTOMI

SI CEBOTTOMI

SI CEBOT TOM

TENER STELLATUS

NW GULF OF. MEXICO

CENTRAL GULF OF MEXICO

CENTRAL GULF OF MEXICO

CENTRAL GULF OF MEXICO 


\section{Publication}

21011 PFLUM FRERICHS 1976 21012 PFLUM FRERICHS 1976 21013 PFLIJM FRERICHS 1976 21014 PFLUM FRERICHS 1976 21015 PFLUM FRERICHS 1976 21016 PFLUM FRERICHS 1976 21017 PFLUM FRERICHS 1976 21017 PFLUM FRERICHS 1976 21019 PFLU'A FRERICHS 1976 21020 PFLUM FRERICHS 1976 21021 DFLUM FDEFICHS 1976 21022 PFLUM FRERICHS 1976 21023 PFLUM FRERICHS 1976 21024 PFLUM FRERICHS 1976 21025 PFLUM FRERICHS 1976 21026 PFLI 1 FRERICHS 1976 21027 PFLUM FRERICHS 1976 21028 PFLUM FRERICHS 1976 21029 PFLIJ ARERICHS 1976 21030 PFLUM FRERICHS 1976 21031 PFLUM FPERICHS 1976 21031 PFLUM FPERICHS 1976
21032 PFLUM FRERICHS 1976 21032 PFLUM FRERICHS 1976 21033 PFLUM FRERICHS 1976
21034 PFLUY FRFRICHS 1976 21035 PFLUM FRERICHS 1976 21036 PFLIJM FPERICHS 1976 21037 PFLUM FRERICHS 1976 21038 PFLUM FRERICHS 1976 21039 PFLU:1 FRERICHS 1976 21040 PFLUM FRERICHS 1976 21041 PFLUM FRERICHS 1976 21042 PFLUM FRERICHS 1976 21043 PFLU: FRERICHS 1976 21044 PFLUM FRERICHS 1976 21045 PFLIM FRERICHS 1976 21046 PFLUM FRERICHS 1976 21047 PFLUM FRERICHS 1976 21048 PFLUM FRERICHS 1976 21049 PFLUM FRERICHS 1976 21050 PFLUM FRERICHS 1976 21051 PFLUM FRERICHS 1976 21052 PFLUM FRERICHS 1976 21053 PFLIJY FRERICHS 1976 21054 PFLUM FRERICHS 1976 21055 PFLUM FRERICHS 1976 21056 PFLUM FRERICHS 1976 21057 PFLUM FRERICHS 1976 21058 PFLUM FRERICHS 1976 21059 PFLUM FRERICHS 1976 21060 PFLUM FRERICHS 1976 21061 PFLUM FRERICHS 1976 21062 PFLUM FRERICHS 1976 21063 PFLUM FRERICHS 1976 21064 LEROY HODGKINSON 1975 21065 PFLUM FRERICHS
21066 PFLUM FRERICHS 1976 21066
21067 PFLUM FRERICHS
21976 21067
21068 PFLUM FPERICHS
21976
21069 21069 PFLUM FRERICHS 1976 21070 PFLUM FRERICHS 1376 21071 PFLUM FRERICHS 1976 21072 DFLUM FRERICHS 1976 21073 PFLUM FRERICHS 1976 21074 PFLUM FRERICHS 1976 21075 PFLUM FPERICHS 1976 21076 PFLUM FRERICHS 1976 21077 PFLUM FRERICHS 1976 21078 PFLUM FRERICHS 1976 21079 PFLUM FRERICHS 1976 21080 PFLUA FRERICHS 1976 21081 PFLUM FRERICHS 1976 21082 PFLUM FREFICHS 1976 21083 PFLUM FRERICHS 1976 21084 PFLUM FRERICHS 1976 21085 PFLUM FPERICHS 1976 21086 PFLIJM FRERICHS 1976 21087 PFLUM FRERICHS 1976 21088 PFLUM FRERICHS 1976 21089 PFLUM FRERICHS 1976 21090 PFLUM FRFRICHS 1976 21091 PFLUY FOERICHS 1976 M FRERICHS 1976 21093 PFLUM FRERICHS 1976 21094 PFLUA FRERICHS 1976 21095 PFLUM FRERICHS 1976 21096 DFLUM FRERICHS 1976 21097 PFLUM FRERICHS 1976 21098 PFLUM FRFRICHS 1976 21099 PFLUM FRERICHS 1976 21100 PFLUM FPERICHS 1976 21101 PFLUM FRERICHS 1976 21102 PFLUM FRERICHS 1976 21103 PFLUM FRERICHS 1976 21104 PFLUM FRERICHS 1976
21105 PFLUM FRERICHS 1976
Generic Name

ORIDORSALIS ORIIDORSALIS ORIDORSALIS OR IDORSALI OR IDORSALIS OR IDORSALIS ORIDORSALIS ORI IDORSALIS ORIDORSALIS ORIDORSALIS ORIDORSALIS ORIDORSALIS ORIDORSALIS ORIDORSALIS OR I DORSALIS ORIDORSALIS OR IDORSALIS OR IDORSALIS ORIDORSALIS ORIDORSALIS ORIDORSALIS ORIDORSALIS ORIDORSALIS ORIDORSALIS ORIDORSALIS ORIDORSALIS ORIDORSALIS ORIDORSALIS ORIDORSALIS OR IDORSALIS ORIDORSALIS ORIDORSALIS ORIDORSALIS ORIDORSALIS OR IDORSALIS ORIDORSALIS ORIDORSALIS ORIDORSALIS OR IDORSALIS OR IDORSALIS ORIDORSALIS ORIDORS ALIS ORIDORSALIS ORIDORSALIS ORIDORSALIS OR IDORSALIS ORIDORSALIS ORIDORSALIS ORIDORSALIS ORIDORSALIS ORIDORSALIS ORIDORSALI ORIDORSALIS ORIDORSALIS OR IDORSALIS ORIDORSALIS ORIDORSALIS ORIDORSALIS ORIDORSALIS OR I DORSALIS ORIDORSALIS ORIDORSALIS OR IDORSALIS ORIDORSALIS ORI DORSALIS OR IDORSALIS OR IDORSALIS OR IDORSALIS OR IDORSALIS ORIDORSALIS ORIDORSALIS ORIDORSALIS ORIDORSALIS ORIDORSALIS OR IDORSALIS ORIDORSALIS ORIDORSALIS ORIDORSALIS ORIDORSALIS ORIDORSALIS ORIDORSALIS ORIDORSALIS ORIDORSALIS ORIDORSALIS ORIDORSALI IS ORIDORSALIS OR IDORSALIS ORIDORSALIS ORIDORSALIS OPIDORSALIS ORIDORSALIS ORIDORSALIS ORIDORSALIS OR IDORSALIS OR IDORSALIS

\section{Specific Name}

TENER STELLATUS

TENER STELLATUS

TENER STELLATUS

TENER STELLATUS

TENER STELLATUS

TENER STELLATUS

TENER STELLATUS

TENER STELLATUS

TENER STELLATUS

TENER STELLATUS

TENER STELLATUS

TENER STELLATUS

TEN'ER STELLATUS

TENER STELLATUS

TENER STELLATUS

TEAER STELLATUS

TENER STELLATUS

TENER STELLATUS

TENER STELLATUS

TENER STELLATUS

TEAER STELLATUS

TENER STELLATUS

TENER STELLATUS

TENER STELLATUS

TENER STELLAT US

TENER TENER

TENER TENER

TENER TEVER

TENER TENER

TENER TEVER

TENER TENER

TENER TEVER

TENER TEVER

TEAER TENER

TENER TEVER

TENER TENER

TENER TEVER

TENER TENER

TENER TEVER

TENER TEVER

TENER TENER

TEAER TEVER

TENER TENER

TENER TENER

EAER TENER

TEAER TEVER

TENER TEVER

TE AER UMBONATUS

TENER UMBONATUS

TEAER UMBONATUS

TENER UMBONATUS

TEAER UMBONATUS

TENER UMBONATUS

TEAER UMBONATUS

TENER UMBONATUS

TENER UMBONATUS

TENER UMB ONATUS

TEAER UMBONATUS

TENER UMBONATUS

TENER UMB ONATUS

TENER UMBONATUS

TENER UMBONATUS

TE NER UMBONATUS

TEAER UMBONATUS

TENER UMBONATUS

TEAER UMBONATUS

TENER UMBONATUS

TENER UMBONATUS

TENER UMBONATUS

TENER UMBONATUS

TENER UMB ONATUS

TENER UMEONATUS

TENER UMBONATUS

TENER UMBONATUS

TENER UMBONATUS

TEAER UMBONATUS

TENER UMBONATUS

TEAER UMBONATUS

TENER UMBONATUS

TENER UMBONATUS

TENER UMBONATUS

TENER UMBONATUS

TENER UMBONATUS

TENER UMBONATUS

TENER UMBONATUS

TENER UMBONATUS

TENER UMBONATUS

TENER UMB ONATUS

TENER UMBONATUS

TENER UMBONATUS

TEAER UMBONATUS

TENER UMBONATUS

\section{Locality}


Publication

21106 PFLUM FRERICHS 1976 21107 PFLUM FRERICHS 1976 21108 PFLUM FRERICHS 1976 21109 PFLUM FRERICHS 1976 21110 PFLUM FRERICHS 1976 21111 PFLUM FRERICHS 1976 21112 ANDERSEN 1961

21113 PFLUM FRERICHS 1976 21114 PFLUM FRERICHS 1976 21115 PFLUM FRERICHS 1976 21116 PFLUM FRERICHS 1976 21117 PFLUM FRERICHS 1976 21119 PFLUM FRERICHS 1976 21119 PFLUM FRERICHS 1976 21120 PFLUM FRERICHS
21121 PFLUM FRERICHS 1976 21122 PARKER 1954

21123 PFLUM FRERICHS 1976 21124 PFLUM FRERICHS 1976 21125 PFLUM FRERICHS 1976 21126 PFLUM FRERICHS 1976 21127 PFLUM FRERICHS 1976 21128 PFLUM FRERICHS 1976 21129 PFLUM FRERICHS 1976 21130 PFLUM FRERICHS 1976 21131 PFLUM FRERICHS 1976 21132 PFLUM FRERICHS 1976 21133 PFLUM FRERICHS 1976 21134 PFLUM FRERICHS 1976 21135 PFLUM FRERICHS 1976 21136 PFLUM FRERICHS 1976 21137 PFLUM FRERICHS 1976 21138 PFLUM FRERICHS 1976 21139 PFLUM FRERICHS 1976 21140 PFLUM FRERICHS 1976 21141 PFLUM FRERICHS 1976 21142 PFLUM FRERICHS 1976 21143 PFLUM FRERICHS 1976

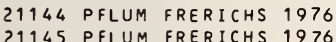
21146 LOEP 1965

21147 LOEP 1965

21148 BOCK 1976

21149 PARKER 1954

21150 PARKER 1954

21151 PARKER 1954

21152 PARKER 1954

21153 PARKER 1954

21154 PARKER 1954

21155 PARKER 1954

21156 PFLUM FRERICHS 1976 21157 PFLUM FRERICHS 1976 21158 PFLUM FRERICHS 1976 21159 PFLUM FRERICHS 1976 21160 PFLUM FRERICHS 1976 21161 PFLUM FRERICHS 1976 21162 PARKER 1954

21163 PHLEGER 1955A

21164 PARKER 1954

21165 PHLEGER 1955A

21166 PHLEGER 1955A

21167 PHLEGER 1955A

21168 PHLEGER 1955A

21160 PHLEGER $1955 \mathrm{~A}$

21170 PHLEGER 1955 A

21171 PARKER 1954

21172 PARKER 1954

21173 PARKER 1954

21174 PARKER 1954

21175 PARKER 1954

21176 PARKER 1954

21177 PARKER 1954
21178 PARKER 1954

21179 PFLUM FRERICHS 1976

21180 PFLUM FRERICHS 1976

21181 PFLUM FRERICHS 1976

21182 PFLUM FRERICHS 1976

21183 PFLUM FRERICHS 1976 21184 PFLUM FRERICHS 1976 21185 PFLUM FRERICHS 1976 21186 PFLUM FRERICHS 1976 21187 PFLUM FRERICHS 1976 21188 PFLU'A FRERICHS 1976 21189 PFLUM FRERICHS 1976 21190 PFLUM FRERICHS 1976 21191 PFLUM FRERICHS 1976 21192 PFLUM FRERICHS 1976 21193 PFLUM FRERICHS 1976 21194 PFLUM FRERICHS 1976 21195 PFLUM FRERICHS 1976 21196 PFLUM FRERICHS 1976 21197 PFLUM FRERICHS 1976 21198 PFLUM FRERICHS 1976 21199 PARKER 1954

21200 PFLUM FRERICHS 1976
Generic Name

Specific Name

Locality

ORIDORSALIS

OR IDORSALIS

ORIDORSALIS

ORIDORSALIS

ORIDORSALIS

OR IDORSALIS

ORIDORSALIS

ORTHOMORPHINA

ORTHOMORPHINA

ORTHOMORPH INA

ORTHOMORPHINA

ORTHOMORPHIVA

ORTHOMORPH INA

OR THOMORPH INA

OR THOMORPH I NA

OSANGULARIA

OS ANGULARIA

OSANGULARIA

OSANGULARIA

OS ANGULARIA

OSANGULARIA

OSANGULARIA

OSANGULARIA

OS ANGULARI A

OSANGULARIA

OSANGULARI A

OS ANGUL ARI A

OSANGULARIA

OS ANGULARIA

OSANGULARIA

OSANGULARIA

OSANGULARIA

OS ANGULARIA

OS ANGUL ARI A

OS ANGULARIA

OSANGULARIA

OSANGULARI A

OSANGUL ARIA

OS ANGULARIA

OSANGULARIA

OSANGULARIA

OSANGULARIA

OS ANGUL ARIA

OSANGULARIA

OSANGULARIA

OS ANGULARIA

OSANGULARIA

OS ANGUL ARI A

OSANGULARIA

OSANGULARIA

OSANGULARIA

OSANGULARIA

OS ANGUL AR I A

OS ANGULARIA

OSANGULARIA

OSANGULARIA

OSANGULARIA

OS ANGULARIA

OSANGULARIA

OS ANGUL ARI A

OSANGULARIA

OSANGULARIA

OSANGULARIA

OSANGULARIA

OSANGULARIA

OSANGULARI

OS ANGULARIA

OSANGULARIA

OSANGULARIA

OSANGULARIA

OS ANGUL ARI A

OSANGULARIA

OSANGUL ARI

OS ANGUL ARIA

OS ANGULARIA

OS ANGUL ARIA

OSANGULARIA

OS ANGULARIA

OSANGULARIA

OS ANGULARI A

OSANGULARIA

OSAVGULARIA

OS ANGUL ARI A

OS ANGULARIA

OSANGULARIA

OS ANGULARIA

OS ANGULARIA

OSANGULARI

OSANGULARIA

OSANGULARIA

ANGUL ARIA

OSANGULARI A

OS ANGUL ARI

OS ANGUL ARIA

OS ANGULARI A
TENER UMBONATUS

TENER UMB ONATUS

TENER UMBONATUS

TENER UMBONATUS

WE STI

GUTT IFERA

GUTTIFERA

GUTT IFERA

GU TTI FERA

GUTT IFERA

GUTTIFERA

CULTUR

CULTUR

CULTUR

CULTUR

CULTUR

CULTUR

CULTUR

CULTUR

CULTUR

CULTUR

CULTUR

CULTUR

CUITUR

CULTUR

CULTUR

CULTUR

CULTUR

CULTUR

CULTUR

CULTUR

CULTUR

CULTUR

CULTUR

CULTUR

CULTUR

CULTUR

CULTUR

CULTUR

CULTUR

CULTUR

CULTUR

CULTUR

CULTUR

CULTUR

CULTUR

CULTUR

CULTUR

CULTUR

CULTUR

CULTUR

CULTUR

CULTUR

CULTUR

CULTUR

CULTUR

CULTUR

CULTUR

CULTUR

CULTUR

CULTUR

CULTUR

CULTUR

CULTUR

CULTUR

CULTUR

CULTUR

CULTUR

CULTUR

CULTUR

CULTUR

CULTUR

CULTUR

CULTUR

CULTUR

CULTUR

CULTUR

CULTUR

CULTUR

CULTUR

CULTUR

CULTUR

CULTUR

CULTUR

CULTUR

CULTUR

ULTUR

ULTUR

ULTUR

CULTUR

CULTUR
TENER UMB ONATUS

CENTRAL GULF OF MEXICO

CENTRAL GULF OF MEXICO

CENTRAL GULF OF MEXICO

CENTRAL GULF OF MEXICO 


\section{Publication}

21201 PFLUM FRERICHS 1976 21202 PFLUM FRERICHS 1976 21203 PFLUM FRERICHS 1976 21204 PFLUM FRERICHS 1976 21205 PFLUM FRERICHS 1976 21206 PFLUM FRERICHS 1976 21207 LEROY HODGKINSON 1975 21208 PFLUM FRERICHS 1976 21209 PFLUM FRERICHS 1976 21210 PFLUM FRERICHS 1976 21211 PFLUM FRERICHS 1976 21212 PFLUM FRERICHS 1976 21213 PFLUM FRERICHS 1976 21214 PFLUM FRERICHS 1976 21215 PFLUM FRERICHS 1976 21216 PFLUM FRERICHS 1976 21217 PFLUM FRERICHS 1976 21218 PFLUM FRERICHS 1976 21219 PFLUM FRERICHS 1976 21220 PFLUM FRERICHS 1976 21221 PFLUM FRERICHS 1976 21222 PFLUM FRERICHS 1976 21223 PFLUM FRERICHS 1976 21224 PFLUM FRERICHS 1976 21225 PFLUM FRERICHS 1976 21226 PFLUM FRERICHS 1976 21227 PFLUM FRERICHS 1976 21228 PFLUM FRERICHS 1976 21229 PFLUM FRERICHS 1976 21230 PFLUM FRERICHS 1976 21231 PFLUM FRERICHS 1976 21232 PFLUM FRERICHS 1976 21233 PFLUM FRERICHS 1976 21236 PFLUM FRERICHS 1976 21235 PFLUM FRERICHS 1976 21236 PFLUM FRERICHS 1976 21237 PFLUM FRERICHS 1976 21238 PFLUM FRERICHS 1976 21239 PFLUM FRERICHS 1976 21240 PFLUM FRERICHS 1976 21241 PFLUM FRERICHS 1976 21242 PFLUM FRERICHS 1976 21243 PFLUM FRERICHS 1976 21244 PFLUM FRERICHS 1976 21245 PFLUM FRERICHS 1976 21246 PFLUM FRERICHS 1976 21247 PFLUM FRERICHS 1976 21248 OTVOS 1978

21249 WANTLAND 1969

21250 BOCK 1976

21251 LANKFORD 1959

21252 SHEPARD MOORE 1955

21253 PHLEGER 1965 A

21254 PHLEGER 1965 A

21255 PHLEGER $1965 \mathrm{~A}$

21256 PHLEGER 1965 A

21257 LEHMANN 1957

21258 PHLEGER 1960

21259 SEGURA 1763

21261 PARKER DHLEGER PEIRSON 1953

21262 PARKER PHLEGER PEIRSON 1953

21263 SHENTON 1957

21264 PARKER PHLEGER PEIRSON 1953

21265 PHLEGER 1965 A

21266 PHLEGER 1965 A

21267 PHLEGEP 1965 A

21268 PARKER PHLEGER PEIRSON 1953

21269 PARKER PHLEGER PEIRSON 1953

21270 AYALA-CASTANARES 1963

21271 AYALA-CASTANARES SEGURA 1968 21272 PHLEGER 1956

21273 PARKER PHLEGER PEIRSON 1953

21274 PARKER PHLEGER PEIRSON 1953

21275 PHLEGER 1965 A

21276 POAG 1978

21277 POAG 1978

21278 ANDERSEN 1961

21279 PFLUM FRERICHS 1976

21280 PFLUM FRERICHS 1976

21281 PFLUM FRERICHS 1976

21282 PFLUM FRERICHS 1976

21283 PFLUM FRERICHS 1976

21284 PFLUM FRERICHS 1976

21285 PFLUM FRERICHS 1976

21286 PFLUM FRERICHS 1976

21287 CREAGER 1959

21288 CREAGER 1958

21289 CREAGER 1958

21290 CREAGER 1958

21291 PHLEGER 1951A

21292 PHLEGER $1951 \mathrm{~A}$

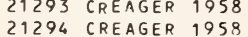

21295 CREAGER 1958
Generic Name

OS ANGULARI A

OS ANGUL ARI A

OS ANGULLARI A

OS ANGUL AR I A

OS ANGULARI A

OS ANGUL ARI A

OS ANGULARI A

OS ANGULARI A

OS ANGUL ARI A

OSANGULARIA

OSANGULARIA

OS ANGUL ARI A

OS ANGUL ARI A

OSANGULARI A

OS ANGULARI A

OSANGULARI A

OS ANGULARIA

OS ANGUL ARI A

OS ANGUL ARI A

OSANGULARI A

OS ANGULARIA

OS ANGUL ARIA

OSANGULARI A

OS ANGULARI A

OSANGULARIA

OS ANGUL ARIA

OS ANGUL AR I A

OS ANGUL ARI A

OS ANGUL ARI A

OS ANGULARIA

OS ANGULARIA

OS ANGUL ARIA

OS ANGUL ARI A

OS ANGUL ARI A

OS ANGUL ARI A

OSANGULARI A

OSANGUL ARI A

OSANGULARIA

OSANGULARIA

OS ANGUL ARI A

OSANGUL ARI A

OS ANGULARIA

OS ANGULARI A

OS ANGULARIA

OSANGULARIA

OS ANGULARIA

OSANGULARIA

PALMER I NELLA

PALMERINELLA

PALMER INELLA

PALMER INELLA

PALMER INELLA

PALMER INELLA

PALMERINELLA

PALMER I NELLA

PALMERINELLA

PALMERINELLA

PALMERINELLA

PALMER I NELLA

PALMER I NELL A

PALMER INELLA

PALMER INELLA

PALMERI NELLA

PALMER INELLA

PALMER I NELL

PALMER INELLA

PALMER INELLA

ALMERINELLA

PALMER INELLA

PALMER INELLA

PALMERI NELLA

PALMERINELLA

PALMER I NELL A

PALMER INELLA

PALMERINELLA

PARAF IS SUR I INA

PARAFISSURINA

PARAFISSURINA

PARAF ISSURINA

PARAFISSUR INA

PARAFIS SUR I VA

PARAF ISSURINA

PARAF IS SUR INA

PARAF ISSURINA

PARRELLA

PARRELLA

PARRELLA

PARRELLA

PARRELLA

PARRELLA

PARRELLA

PARRELLA
Specific Name

CULTUR

CULTUR

CULTUR

CULTUR

CULTUR

CULTUR

RUGOSA

$R \cup G O S A$

RUGOSA

RUGOSA

RUGOSA

RUGOSA

$R \cup G O S A$

RUGOSA

RUGOSA

RUGOSA

RUGOSA

RUGOSA

RUGOSA

$R \cup \in O S A$

RUGOSA

$R \cup \in O S A$

RUGOSA

RUGOSA

$R \cup \in O S A$

$R \cup G O S A$

RUGOSA

RUGOSA

$R \cup \in O S A$

$R \cup \in O S A$

RUGOSA

RUGOSA

RUGOSA

$R \cup G O S A$

$R \cup G O S A$

RUEOSA

RUGOSA

RUGOSA

$R \cup \in O S A$

$R \cup G O S A$

RUGOSA

$R \cup \in O S A$

RUGOSA

RUGOSA

RUGOSA

GARDENISL ANDENSIS

GAFDENISLANDENSIS

GARDENISL ANDENSIS

GARDENISLANDENS IS

PALMERAE

PALMERAE

PALMERAE

PALMERAE

PALMERAE

PALMERAE

PALMERAE

PALMERAE

PALMERAE

PALMERAE

PALMERAE

PALMERAE

PALMERAE

PALMERAE

PALMERAE

PALMERAE

PALMERAE

PALMERAE

PALMERAE

PALMERAE

PALMERAE

PALMERAE

PALMERAE GARDENISLANDENSIS

PALMERAE TYPICA

LATERAL IS

LATERALIS

LATERALIS

LATERALIS

LATERAL IS

LATERALIS

LATERALIS

LATERALIS

LATERALIS

CULTUR

CULTUR

CULTUR

CULTUR

CULTUR

CULTUR

CULTUR

CULTUR

Locality

$N W$ GULF OF MEXICO

NW GULF OF MEXICO

NW GULF OF MEXICO

NW GULF OF MEXICO

NW GULF OF MEXICO

NW GULF OF MEXICO

$N$ GULF OF MEXICO

NW GULF OF MEXICO

NW GULF OF MEXICO 


\section{Publication}

21296 CREAGER 1958 21297 CREAGER 1958 21298 PHLEGER 1951A 21299 PHLEGER 1951A 21300 PHLEGER 1951A 21301 PHLEGER 1951A 21302 PHLEGER 1951A 21303 PHLEGER 1951A 21304 PHLEGER $1951 \mathrm{~A}$ 21305 PHLEGER 1951A 21306 PHLEGER 1951A 21307 PHLEGER 1951 A 21308 PHLEGER 1951A
21309 PHLEGER 1951A 21309
21310 PHLEGER $1951 \mathrm{~A}$
$2 \mathrm{H}$ EGER $1951 \mathrm{~A}$ 21311 CREAGER 1958 21312 CREAGER 1958 21313 PHLEGER 1951A 21314 PHLEGER 1951A 21315 CREAGER 1958 21316 PHLEGER 1951A 21317 PHLEGER 1951A 21318 PHLEGER $1951 \mathrm{~A}$ 21319 CREAGER 1958 21320 CREAGER 1958 21321 PHLEGER 1951A 21322 PHLEGER 1951A
21323 ANDERSEN 1961 21324 BOCK 1976

21325 PFLUM FRERICHS 1976

21326 BANDY 1956

21327 BANDY 1956

21328 BANDY 1956

21329 LUDWICK WALTON 1957

21330 BANDY 1956

21331 BANDY 1956

21332 BANDY 1956

21333 ANDERSEN 1961

21334 CUSHMAN 1918

21335 CUSHMAN 1918

21336 CUSHMAN 1918

21337 CUSHMAN 1918

21338 CUSHMAN 1922A

21339 NORTON 1930

21340 BOCK 1976

21341 CUSHMAN 1930

21342 CUSHMAN 1930

21343 NORTON 1930

21344 CUSHMAN $1922 \mathrm{~A}$

21345 BOCK 1976

21346 SEGURA 1963

21348 CUSHMAN 1922A

21348 CUSHMAN 1922 A

21350 KELLOUGH 1956

21351 CUSHMAN 1922A

21352 NORTON 1930

21353 VAUGHAN 1918

21355 DAVIS 1964

21356 BENDA PURI 1962

21357 BOCK 1976

21358 CUSHMAN 1930

21359 NORTON 1930

21360 CUSHMAN 1922A

21361 BOCK 1976

21362 CREAGER 1958

21363 DAVIS 1964

21364 BANDY 1956
21365 CUSHMAN 1922

21366 BANDY 1956

21367 BANDY 1956

21368 BANDY 1956

21369 BANDY 1956

21370 BANDY 1956

21371 BANDY 1956

21372 BANDY 1956

21373 BANDY 1956

21374 WALTON 1960

21375 CUSHMAN 1930

21376 NORTON 1930

21377 BANDY 1956
21378 BANDY 1956

21379 BANDY 1956

21380 BANOY 1956

21381 BANDY 1956

21382 BANDY 1956

21383 BANDY 1956

21384 CUSHMAN 1920

21385 CUSHMAN $1922 \mathrm{~A}$

21386 NORTON 1930

21387 DAVIS 1964
21388 CUSHMAN 193

21389 BENDA PURI 1962

21390 NORTON 1930
Generic Name

$\begin{array}{ll}\text { PARRELLA } & \text { CULTUR } \\ \text { PARRELLA } & \text { CULTUR } \\ \text { PARRELLA } & \text { CULTUR } \\ \text { PARRELLA } & \text { CULTUR } \\ \text { PARRELLA } & \text { CULTUR } \\ \text { PARRELLA } & \text { CULTUR } \\ \text { PARRELLA } & \text { CULTUR }\end{array}$

PARRELLA

PARRELLA

PARRELLA

PARRELLA

PARRELLA

PARRELLA

PARRELLA

PARRELLA

PARRELLA

PARRELLA

PARRELLA

PARRELLA

PARRELLA

PARRELLA

PARRELLA

PARRELLA

PARRELLA

PARRELLA

PARRELLA

PARRELLA

PATELLINA

PA VONINA

PAVONINA

PAVONINA

PAVONINA

PAVONINA

PAVONINA

PAVONINA

PA VONINA

PAVONINA

PELOSINA

PELOSINA

PELOSINA

PELOSINA

PENEROPLIS

PENEROPLIS

PENEROPLIS

PENER OP L IS

PENEROPL IS

PENEROPLIS

PENEROPLIS

PENEROPLIS

PENEROPLIS

PENER OPL IS

PENER OPL IS

PENEROPL IS

PENEROPLIS

PENEROPLIS

PENEROPL IS

PENEROPLIS

PENEROPLIS

PENEROPLIS

PENEROPLIS

PENEROPLIS

PENEROPLIS

PENEROPL IS

PENEROPLIS

PENEROPLIS

PE NEROPL IS

PENEROPL IS

PENEROPL IS

PENEROPLIS

PENEROPLIS

PENEROPLIS

PENEROPL IS

PENEROPL IS

PENEROPLIS

PENEROPLIS

PENEROPLIS

PENER OPL IS

PENEROPLIS

PENEROPLIS

PENEROPLIS

PENEROPLIS

PENEROPLIS

PE NEROPL IS

PENEROPLIS

PENEROPLIS

PENEROPL IS

PENEROPL IS

PLACOPSILINA

PLANISPIRINA

PL AN ISPIRINA

PLANORBULINA

PLANORBULINA

PLANOR BULINA

PLANORBULINA
Locality

BAY OF CAMPECHE BAY OF CAMPECHE

NW GULF OF MEXICO

NW GULF OF MEXICO

NW GULF OF MEXICO

NW GULF OF MEXICO

NW GULF OF MEXICO

NW GULF OF MEXICO

NW GULF OF MEXICO

NH GULF OF MEXICO

NW GULF OF MEXICO

NW GULF OF MEXICO

NW GULF OF MEXICO

$N W$ GULF OF MEXICO

NW GULF OF MEXICO

BAY OF CAMPECHE

NW GULF OF MEXICO

NW GULF OF MEXICO

BAY OF CAMPECHE

NW GULF OF MEXICO

NW GULF OF MEXICO

NW GULF OF MEXICO

BAY OF CAMPECHE

OF CAMPECHE

NW GULF OF MEXICO

NW GULF OF MEXICO

MISSISSIPPI DELTA

NE GULF OF MEXICO

NW GULF OF MEXICO

NE GULF OF MEXICO

NE GULF OF MEXICO

NE GULF OF MEXICO

NE GULF OF MEXICO

NE GULF OF MEXICO

NE GULF OF MEXICO

NE GULF OF MEXICO

MISSISSIPPI DELTA

NE GULF OF MEXICO

NE GULF OF MEXICO

NE GULF OF MEXICO

NE GULF OF MEXICO

TOR TUGAS

TORTUGAS, FLA

NE GULF OF MEXICO

TORTUGAS, FLA

TORTUGAS, FLA

TORTUGAS, FLA

TORTUGAS

NE GULF OF MEXICO

MATAMOROS, MEXICO

NE GULF OF MEXICO

TOR TUGAS

TORTUGAS, FLA

NH GULF OF MEXICO

TORTUGAS

TORTUGAS, FLA

DRY TORTUGA

CAMPEC HE BANK, MEXICO

CAPE ROMANO, FLA.

NE GULF OF MEXICO

TORTUGAS, FLA

TORTUGAS, FLA

TORTUGAS

NE GULF OF MEXICO

BAY OF CAMPECHE

CAMPECHE BANK, MEXICO

NE GULF OF MEXICO

TORTUGAS

NE GULF OF MEXICO

NE GULF OF MEXICO

NE GULF OF MEXICO

NE GULF OF MEXICO

NE GULF OF MEXICO

NE GULF OF MEXICO

NE GULF OF MEXICO

NE GULF OF MEXICO

MISSISSIPPI SOUND

TORTUGAS, FLA

TORTUGAS, FLA

NE GULF OF MEXICO

NE GULF OF MEXICO

NE GULF OF MEXICO

NE GULF OF MEXICO

NE GULF OF MEXICO

NE GULF OF MEXICO

NE GULF OF MEXICO

NE GULF OF MEXICO

TOR TUGAS

TORTUGAS, FLA

CAMPECHE BANK, MEXICO

TORTUGAS, FLA

CAPE ROMANO, FLA.

TORTUGAS, FLA

Lat. Long.

$2 \mathrm{C} 10 \mathrm{~N} 094 \quad 15 \mathrm{~W}$ $2007 N \quad 093 \quad 17 \mathrm{H}$ $2747 \mathrm{~N} 09155 \mathrm{~W}$ $2705 \mathrm{~N} 09210 \mathrm{~W}$ $2806 \mathrm{~N} 09407 \mathrm{~W}$ $2729 \mathrm{~N} 09355 \mathrm{~W}$ $2704 \mathrm{~N} 09401 \mathrm{~W}$ $2709 \mathrm{~N} 094 \quad 17 \mathrm{~W}$ $2742 \mathrm{~N} 09426 \mathrm{~W}$ $5 \mathrm{~N} 09447 \mathrm{~N}$ $2732 \mathrm{~N} 093$ O5W $2751 \mathrm{~N} 09033 \mathrm{~W}$ $2716 \mathrm{~N} 09021 \mathrm{~W}$ $2647 \mathrm{~N} 09556 \mathrm{~W}$ $2 \mathrm{C} 50 \mathrm{~N} 09325 \mathrm{~W}$ $2037 \mathrm{~N} 092 \quad 25 \mathrm{~W}$ 
Publication

21391 CUSHMAN 1922A

21392 BANDY 1956

21393 BANDY 1956

21394 BANDY 1956

21396 BANDY 1956

21397 BANDY 1956

21398 KELLOUGH 1956

21399 KELLOUGH 1956

21400 KELLOUGH 1956

21401 KELLOUGH 1956

21402 KELLOUGH 1956

21403 BANDY 1954

21404 BANDY 1956

21405 BANDY 1954

21406 LOEP 1965
21407 KELLOUGH 1956

21408 BANDY 1956

21409 BANDY 1956

21410 BANDY 1956

21411 BANDY 1956

21412 BANDY 1956

21413 BANDY 1956

21414 BANDY 1956

21416 BANDY 1956

21417 BANDY 1956

21418 BANDY 1954

21419 BANDY 1956

21420 BANDY 1956

21421 PARKER 1954
21422 PARKER 1954

21423 LUDWICK WALTON 1957

21424 PARKER 1954

21425 PARKER 1954

21426 PARKER 1954

21427 BANDY 1956

21428 ANDERSEN 1961

21429 CUSHMAN 1931

21431 BOCK 1976

21432 BOCK 1976

21433 BOCK 1976

21434 PARKER 1954

21435 BANDY 1956

21436 BANDY 1956

21437 PARKER 1954

21438 PARKER 1954
21439 PARKER 1954

21440 PHLEGER 1951A

21441 PHLEGER 1951A

21442 PHLEGER 1951A

21443 PHLEGER $1951 \mathrm{~A}$

21444 PHLEGER $1951 \mathrm{~A}$

214446 PHLEGER $1951 \mathrm{~A}$

21447 PHLEGER $1951 \mathrm{~A}$

21448 PHLEGER 1951A

21449 PHLEGER 1951A

21450 PHLEGER 1951 A

21452 PARKER 1954

21453 PARKER 1954

21454 PARKER 1954

21455 CUSHMAN $1922 \mathrm{~A}$

21456 NORTON 1930

21457 PARKER 1954

21458 PHLEGER 1951A

21460 PFLUM FRERICHS 1976

21461 PFLUM FRERICHS 1976 21462 PFLUM FRERICHS 1976 21463 PFLUM FRERICHS 1976 21464 CREAGER 1958

21465 PARKER 1954

21466 PARKER 1954

21467 PARKER 1954

21468 PARKER 1954

21469 PARKER 1954

21470 PHLEGER $1951 \mathrm{~A}$

21471 PHLEGER $1951 \mathrm{~A}$

21472 PHLEGER 1951A

21474 PHLEGER 1951A

21475 PHLEGER 1951 A

21476 PHLEGER 1951 A

21477 PHLEGER 1951 A

21470 PHLEGER 1951A

21480 PFLUM FRERICHS 1976

21481 PFLUM FRERICHS 1976

21482 PFLUM FRERICHS 1976

21483 PFLUM FRERICHS 1976

21484 PFLUM FRERICHS 1976

21485 AYALA-CASTANARES 1963
Generic Name

Specific Name

PLANORBULINA

PLANORBULINA

PLANORBULINA

PLANORBULINA

PLANORBULINA

PLANORBULINA

PLANORBULINA

PLANORBULINA

PLANORBULINA

PL ANORBULINA

PLANORBULINA

PLANORBULINA

PLANORBULINA

PLANORBULINA

PLANORBULINA

PLANORBULINA

PLANORBULINA

PLANORBULINA

PLANORBULINA

PLANORBULINA

PLANORBULINA

PLANORBULINA

PLANORBULINA

PLANORBULINA

PLANORBULINA

PLANORBULINA

PLANORBULINA

PLANORBULINA

PLANORBULINA

PLANORBULINA

PLANORBULINA

PLANORBULINA

PLANORBULINA

PLANORBULINA

PLANORBULINA

PLANORBULINA

PLANORBULINA

PLANORBULINA

PLANORBULINA

PLANORBULINA

PLANORBULINA

PLANORBULINA

PLANORBULINA

PLANORBULINA

PLANORBULIN

PLANORBULINA

PLANORBULINA

PLANORBULINA

PL ANORBULINA

PLANORBULINA

PLANORBULINA

PL ANORBULINA

PLANORBULINA

PLANORBULINA

PLANORBULINA

PLANORBULINA

PLANORBULINA

PLANORBULINA

PLANORBULINA

PLANORBULINA

PLANORBULINA

PLANORBULINA

PLANORBULINA

PLANORBULINA

PLANORBULINELLA

PLANULINA

PLANUL INA

PLANUL I NA

PLANULINA

PLANULINA

PLANULINA

PLANULINA

PLANULINA

PLANULINA

PLANUL INA

PL ANULI INA

PLANUL INA

PLANULINA

PL ANULI INA

PLANULINA

PLANULINA

PLANULINa

PLANULINA

PLANULINA

PLANULIINA

PLANULINA

PLANULINA

PLANULINA

PLANULINA

PLANULINA

PLANULINA

PLANULINA

PLANULINA

PLANULINA
ACERVALIS

MEDITERRANENS IS

ME DITERRANENS IS

ME DITERRANENS I S

ME CITERRANENS IS

ME CITERRANENSIS

MEDITERRANENS IS

MEDITERRANENSIS

MEDITERRANENS IS

ME DITERRANENS IS

ME IITERRANENS IS

ME DITERRA NENS IS

ME DITERRANENSIS

MEDITERRANENSIS

MEDITERRANENSIS

MEDITERRANENS IS

MEDITERRANENS IS

ME DITERRANENSIS

ME DITERRA NENS IS

MEDITERRA NE

MEDITERRANE

ME DITERRANENS IS

ME OITERRANENS IS

ME DITERRANENS IS

ME DITERRANENS IS

MEDITERRA NEI

TERANENSIS

MEDIT ER

TERA NENS IS

MEDITERRANENSIS

MECITERRANENS IS

MEDITERRANENS IS

MEDITERRANENS IS

MEDITERRANENS IS

ME DITERRANENS IS

ME CITERRA NENS IS

MECITERRANENS IS

MEDITERRANENS IS

MEDITERRANENS IS

MEDITERRANENS IS

ME DITER RA NENS I

ME DITERRANENS IS

ME DITERRANENS IS

ME DITERRA NE NS IS

MEDITERRANENSIS

MEDITERRANENS IS

MEDITERRANENS IS

MECITERRANENS IS

ME DITERRANENS IS

MEDITERRANENS IS

MEDITERRANENS IS

MEDITERRANENSIS

MEDITERRANENS IS

MEDITERRANENS IS

ME D ITERRA NENSIS

MEDITERRANENS IS

$M E$ DITERRANENS IS

MEDITERRANENSIS

MECITERPANENSIS

MEDITERRANENS IS

MED ITERRA NENS I S

LARVATA

A RIMINENS IS

AR IMINENS IS

AR IMINENS IS

AR IMINE NS IS

AR IMINENS IS

AR IMINENS IS

AR IMINENS IS

A R IMINENS IS

AR IMINENS IS

AR IMINENS IS

AR IMINENS IS

AR IMINENS IS

AR IMINENS IS

AR IMINENS IS

AR IMINE NS IS

ARIMINENS IS

ARIMINENS IS

AR IMINENS IS

AR IMINENS IS

AR IMINENS IS

ARIMINENS IS

O IMINENS IS

ARIMINENS IS

AR IMIS SNS IS

AR IMINENS IS

ARIMINENS IS

AR IMINENS IS
ME OITERRANENS IS

Locality

Lat. Long.

TOR TUG AS

NE GULF OF MEXICO

NE GULF OF MEXICO

NE GULF OF MEXICO

NE GULF OF MEXICO

NE GULF OF MEXICO

TAMPA BAY, FLA.

NW GULF OF MEXICO

NH GULF OF MEXICO

NH GULF OF MEXICO

NW GULF OF MEXICO

NW GULF OF MEXICO

NH GULF OF MEXICO 


\section{Publication}

21486 PARKER 1954 21487 PHLEGER 1951 A

21488 PFLUM FRERICHS 1976 21489 PFLUM FRERICHS 1976

21490 PARKER 1954

21491 PFLUM FRERICHS 1976

21492 PFLUM FRERICHS 1976

21493 PFLUM FRERICHS 1976

21494 PFLUM FRERICHS 1976

21495 PFLUM FRERICHS 1976

21496 PFLUM FRERICHS 1976

21497 PARKER 1954

21498 PARKER 1954

21499 PARKER 1954

21500 BOCK 1976

21501 PFLLM FRERICHS 1976

21502 PFLUM FRERICHS 1976

21503 PHLEGER 1951A

21504 PARKER 1954

21505 LUOWICK WALTON 1957

21506 PARKER 1954

21507 PHLEGER 1956

21508 PHLEGER 1956

21509 PHLEGER 1956

21510 BOCK 1976

21511 BOCK 1976

21512 BOCK 1976

21513 PHLEGER 1956

21514 PARKER 1954
21515 PARKER 1954

21516 PARKER 1954

21517 PARKER 1954

21518 AYALA-CASTANARES 1963

21519 KELLOUGH 1956

21520 KELLOUGH 1956

21521 KELLOUGH 1956

21522 KELLOUGH 1956

21523 KELLOUGH 1956

21524 KELLOUGH 1956

21525 CREAGER 1953

21526 CREAGER 1958

21527 PHLEGER 1951A

21528 PHLEGER 1951A

21529 PHLEGER $1951 \mathrm{~A}$

21530 PARKER 1954

21531 PARKER 1954

21532 PARKER 1954

21533 PHLEGER 1951A

21534 PHLEGER $1951 \mathrm{~A}$

21535 PHLEGER 1951A

21536 PHLEGER 1951A

21537 PHLEGER 1951A

21538 PHLEGER $1951 \mathrm{~A}$

21539 PHLEGER $1951 \mathrm{~A}$

21540 PHLEGER 1951A

21541 PHLEGER 1951A

21542 PHLEGER $1951 \mathrm{~A}$

21543 PARKER 1954

21544 PARKER 1954

21545 PARKER 1954

21546 PARKER 1954

21547 PARKER 1954

21548 PARKER 1954
21549 PHLEGER 1951 A

21549 PHLEGER 1951 A

21551 PHLEGER $1951 \mathrm{~A}$

21552 PHLEGER $1951 \mathrm{~A}$

21553 PHLEGER 1951A

21554 PFLUM FRERICHS 1976

21555 ANDERSEN 1961

21556 PHLEGER $1951 \mathrm{~A}$

21557 PHLEGER 1951A

21558 PHLEGER 1951A

21559 PHLEGER 1951A

21560 PHLEGER 1951A

21561 PHLEGER 1951 A

21562 PFLUM FRERICHS 1976

21563 PHLEGER $1951 \mathrm{~A}$

21564 LUDWICK WALTON 1957

21565 PARKER 1954

21566 PFLUM FRERICHS 1976

21567 PFLUM FRERICHS 1976

21568 PFLUM FRERICHS 1976

21569 LOEP 1965

21570 BANDY 1956

21571 BANDY 1956

21572 BANDY 1956

21573 CREAGER 1958

21574 CREAGER 1958

21575 CUSHMAN 1931

21576 PARKER 1954

21577 PARKER 1954

21578 PARKER 1954

21579 PHLEGER 1951A

21580 PHLEGER 1951A

\section{Generic Name}

PLANULINA

PL ANULINA

PL ANUL INA

PL ANULINA

PLANUL INA

PLANUL I NA

PLANULINA

PL ANULINA

PL ANUL INA

PLANULINA

PLANULINA

PL ANUL INA

PLANULINA

PLANULINA

PL ANUL INA

PL ANULINA

PLANULINA

PL ANULIINA

PLANULINA

PL ANULINA

PLANULINA

PLANUL INA

PLANULINA

PLANUL INA

PL ANULINA

PL ANUL INA

PL ANUL INA

PLANULINA

PLANULINA

PLANULINA

PLANULINA

PLANUL INA

PL ANUL INA

PLANUL INA

PLANULINA

PLANULINA

PLANULINA

PLANUL INA

PL ANUL INA

PLANULINA

PLANUL INA

PLANULINA

PL ANUL INA

PLANULINA

PLANULINA

PLANULINA
PLANULINA

PLANULINA

PLANULINA

PLANUL INA

PLANULINA

PLANULINA

PL ANUL INA

PLANULINA

PLANULINA

PL ANUL INA

PLANULINA

PLANUL INA

PLANUL INA

PL ANUL INA

PLANUL INA

PLANULINA

PLANUL INA

PLANUL INA

PL ANUL INA

PLANULINA

PLANULINA

PLANUL INA

PLANULINA

PLANULINA

PLANUL INA

PLANUL INA

PLANUL INA

PL ANULINA

PLANUL INA

PL ANUL INA

PLANULINA

PLANUL INA

PLANULINA

PLANULINA

PLANULINA

PLANULINA

PLANULI INA

PLANUL INA

PLANULINA

PLANULINA

PL ANUL INA

PLANUL INA

PLANULINA

PLANULINA

PLANUL INA

PLANUL INA

PLANUL INA
Specific Name

AR IMINENS IS

AR IMINENS IS

AR IMINENS IS

AR IMINENS IS

AR IMINENS IS

AR IMINENS IS

AR IMINENS IS

AR IMINENS IS

$A R$ IMINENS IS

AR IMINENS IS

AR IMINENS IS

AR IMINENS IS

AR IMINENS IS

AR IMINENS IS

AR IMINENS IS

AR IMINENS IS

EXXRNA

EXORNA

EXCRNA

EXCRNA

EXORNA

EXCRNA

EXORNA

EXORNA

EXORNA

EXCRNA

EXORNA

EXORNA

EXORNA

EXORNA

EXCRNA

EX CRNA

EXORNA

EXORNA

EXCRNA

EXCRNA

EXORNA

EXCRNA

EX ORNA

EXCRNA

EXORNA

EXORNA

EXORNA

EXCRNA

EXORNA

EXORNA

EXCRNA

EXCRNA

EX ORNA

EXORNA

EXORNA

EXCRNA

EXCRNA

EXCRNA

EXORNA

EXORNA

EXCRNA

EXORNA

EXCRNA

EXCRNA

EXCRNA

EXORNA

EXCRNA

FOVEOLATA

FO VEOLATA

FOVEOLATA

FOVEOLATA

FOVEOLATA

F OVEOLATA

FOVEOLATA

FOVEOLATA

FOUEOLATA

FO VEOLATA

FOVEOLATA

FOVEOLATA

F OVEOLATA

FOVEOLATA

FOUEOLATA

FOVEOLATA

FOVEOLATA

FOVEOLATA

FOVEOLATA

FOVEOLATA

FOVEOLATA

FOVEOLATA

FOVEOLATA

FOVEOLATA

FO VEOLATA

FOVEOLATA

FOVEOLATA

F OVEOLATA

FOVEOLATA

\section{Locality}

NE GULF OF MEXICO

NW GULF OF MEXICO

$N W$ GULF OF MEXICO

$N W$ GULF OF MEXICO

NE GULF OF MEXICO 


\section{Publication}

21581 CREAGER 1958 21582 PARKER 1954

21583 PHLEGER 1955 A

21584 CUSHMAN 1931

21585 PARKER 1954

21587 PARKER 1954

21588 PARKER 1954

21589 PFLUM FRERICHS 1976

21590 PFLUM FRERICHS 1976

21591 PFLUM FRERICHS 1976

21592 PFLUM FRERICHS 1976

21593 PFLUM FRERICHS 1976

21594 ANDERSEN 1961

21595 BANDY 1956

21596 BANDY 1956

21597 BANDY 1956

21598 BANDY 1956

21599 BANDY 1956

21600 BANDY 1956

21601 BANDY 1956

21602 BANDY 1956

21603 BANDY 1956

21604 BANDY 1956

21605 BANDY 1956

21606 BANDY 1956

21607 BANDY 1956

21608 BANDY 1956

21609 BANDY 1956

21610 BANDY 1956

21611 BANDY 1956

21612 BANDY 1956

21613 BANDY 1954

21614 BANDY 1954

21615 BANDY 1954

21616 LIDZ LIDZ 1966

21617 BANDY 1954

21618 BANDY 1956

21619 BANDY 1956

21620 PHLEGER 1951A

21621 PHLEGER 1951A

21622 PHLEGER 1951A

21623 PHLEGER 1951A

21624 PHLEGER $1951 \mathrm{~B}$

21625 PHLEGER 1951B

21626 PHLEGER 1951 A

21627 PHLEGER 1951A

21628 PHLEGER 1951A

21629 PHLEGER 1951A

21630 PHLEGER 1951A

21631 PHLEGER 1951A

21632 PHLEGER 1951A

21633 PHLEGER $1951 \mathrm{~A}$

21634 PHLEGER $1951 \mathrm{~A}$

21635 PHLEGER 1951A

21636 PARKER 1954

21637 PARKER 1954

21638 PARKER 1954

21639 PARKER 1954

21640 PARKER 1954

21641 PHLEGER 1955A

21642 PHLEGER 1955A

21643 PARKER 1954

21644 PARKER 1954

21645 PARKER 1954

21646 PARKER 1954

21647 PARKER 1954

21648 PARKER 195

21649 PARKER 1954

21650 PARKER 1954

21651 PARKER 1954

21652 PHLEGER 1955 A

21653 PARKER 1954

21654 PARKER 1954

21655 PARKER 1954

21656 CREAGER 1958

21657 PARKER 1954

21658 PARKER 1954

21659 PFLUM FRERICHS 1976

21660 PFLUM FRERICHS 1976 21661 PFLUM FRERICHS 1976 21662 PFLUM FRERICHS 1976 21663 PFLUM FRERICHS 1976 21664 PFLUM FRERICHS 1976 21665 PFLUM FRERICHS 1976 21666 PFLUM FRERICHS 1976 21667 PFLUM FRERICHS 1976 21668 PFLUM FRERICHS 1976 21669 PFLUM FRERICHS 1976 21670 PFLUM FRERICHS 1976 21671 PFLUM FRERICHS 1976 21672 PFLUM FRERICHS 1976 21673 PFLUM FRERICHS 1976 21674 PFLUM FRERICHS 1976 21675 CUSHMAN 1923
Generic Name

PLANULINA

PLANULINA

PLANULINA

PL ANULINA

PLANULINA

PL ANULINA

PLANULINA

PLANULINA

PLANULINA

PLANULINA

PLANULINA

PLANULINA

PLANUL INA

PLANULINA

PLANULINA

PL ANULINA

PLANULINA

PLANULINA

PLANULI NA

PL ANULINA

PLANULINA

PL ANUL INA

PLANULINA

PLANULINA

PLANULINA

PLANULINA

PLANULINA

PL ANUL INA

PLANULINA

PLANULINA

PL ANULINA

PLANULINA

PL ANUL INA

PLANULINA

PLANULINA

PLANULINA

PLANULINA

PLANULINA

PLANULINA

PLANULINA

PLANULINA

PLANULINA

PLANULINA

PLANULINA

PL ANULINA

PLANUL INA

PL ANULINA

PLANULINA

PLANULINA

PLANUL INA

PLANULINA

PLANULINA

PLANUL INA

PLANULINA

PLANUL INA

PLECTINA

PLECIINA

PLECTINA

PLECTINA

PLECTINA

PLECTINA

PLECTINA

PLECTINA

PLECTINA

PLECTINA

PLECTINA

PLECTINA

PLECTINA

PLECTINA

PLECTINA

PLECTINA

PLECTINA

PLECTINA

PLECTINA

PLECTINA

PLECTINA

PLECTINA

PLEUROSTOMELLA

PLEUROSTOMELLA

PLEUROSTOMELLA

PLEUROST OMELLA

PLEUROSTOMELLA

PLEUROSTOMELLA

PLEUROSTOME

PLEUROSTOMELLA

PLEUROSTOMELLA

PLEUROSTOMELLA

PLEUROSTOMELLA

PLEUROSTOMELLA

PLEUROSTOME LLA

PLEUROSTOMELLA

PLEUROSTOMELLA

PLEUROSTOMELLA

POLYMORPHINA
Specific Name

FOVEOLATA

FOVEOLATA

FOVEOLATA

FOVEOLATA

FO VEOLATA

FOVEOLATA

FOVEOLATA

FOVEOLATA

FOVEOLATA

F OVEOLATA

F OVEOLATA

ME RA

OR NATA

ORNATA

OR NATA

OR AATA

ORNATA

ORNATA

ORNATA

ORNATA

ORNATA

ORNATA

ORNATA

ORNATA

ORNATA

ORNATA

ORNATA

ORNATA

OR NATA

OR NATA

OR AATA

OR AATA

OR NATA

OR NATA

OR A AT

WUELLER ST ORF

WUELLER ST ORF

WUELLERST ORF

WUELLER ST ORF

WUELLER ST ORFI

WUELLER STORF

WUELLER ST ORF

WUELLER ST ORF

WUELLER ST OR F

WUELLER ST OR F

WUELLER ST ORF

WUELLER ST OR F

LER ST ORF I

WUELLER ST OR F

WU ELLER ST ORF

AP ICULARIS

APICULARIS

AP I CULARIS

AP I CULARIS

APICULARIS

AP I CULARIS

AP ICULARIS

AP I CULARIS

AP I CULARIS

APICULARIS

API CULARIS

APICULARIS

API CULARI

AP I CULARI S

AP ICULARIS

AP ICULARIS

APICULARIS

APICULARIS

AP I CULARI

API.CULARIS

APICULARI S

APICULARIS

AP ICULARIS

BOLIVINOI DES

BOLIVINOI DES

BOLIVINOI DES

BOLIVINOI DES

BOLIVINOI DES

BOLIVINOI DES

BOLIVINOI DES

BOLIVINOI DES

BOLIVINOIDES

BOLIVINOI DES

BOLIVINOI DES

BOLIVINOI DES

BOLIVINOI DES

BOLIVINOI DES

BOLIVINOI DES

BOLIVINOIDES

EQUALIS

Locality

BAY OF CAMPECHE

NE GULF OF MEXICO

$N$ GULF OF MEXICO

NE GULF OF MEXICO

NE GULF OF MEXICO

NE GULF OF MEXICO

NE GULF OF MEXICO 


\section{Publication}

21676 CUSHMAN $1922 \mathrm{~A}$

21677 CUSHMAN $1922 \mathrm{~A}$

21678 NORTON 1930

21679 BANDY 1956

21680 BANDY 1956

21681 BANDY 1956

21683 BANDY 1956

21683 BANDY 1956
21684 BANDY 1956

21684 BANDY 1956
21685 BANDY 1956

21686 BANDY 1956

21687 BANDY 1956

21688 CUSHMAN $1922 \mathrm{~A}$

21689 NORTON 1930

21690 CUSHMAN 1922 A

21691 VAUGHAN 1918

21692 CUSHMAN $1922 \mathrm{~A}$

21693 CUSHMAN $1922 \mathrm{~A}$

21694 CUSHMAN $1922 \mathrm{~A}$

21695 VAUGHAN 1918

21696 VAUGHAN 1918

21697 VAUGHAN 1918

21698 VAUGHAN 1918

21699 BANDY 1956

21700 BANDY 1956

21701 SANDY 1956

21702 BANDY 1956

21703 BANDY 1956

21704 BANDY 1956

21705 BANDY 1956

21706 SANDY 1956

21707 BANDY 1956

21708 BANDY 1956

21709 BANDY 1956

21710 BANDY 1956

21711 BANDY 1956

21712 BANDY 1956

21713 BANDY 1954

21714 BOCK 1976

21715 LEHMANN 1957

21716 BANDY 1954

21718 BANDY 1954

21719 KELLOUGH 1956

21720 KELLOUGH 1956

21721 LOEP 1965

21722 BENDA PURI 1962

21723 ANDERS $\subseteq N 1961$

21724 BANDY 1954

21725 KELLOUGH 1956

21726 BANDY 1954

21727 BANDY 1954

21728 BANDY 1954

21729 KELLOUGH 1956

21730 ANDERSEN 1961

21731 BENDA PURI 1962

21732 POAG 1976

21733 PARKER 1954

21734 PARKER 1954

21735 LANKFORD 1959

21736
21737 PARKER 1954

21737 PARKER 1954

21738 BANDY 1954

21739 BANDY 1956

21740 BANDY 1954

21741 BANDY 1954

21742 BANDY 1954

21743 PARKER 1954
21744 PARKER 1954

21745 PARKER 1954

21746 PARKER 1954

21747 PARKER 1954

21748 PHLEGER 1954

21749 PARKER 1954

21750 LUDWICK WALTON 1957

21751 BANDY 1956

21752 BOCK 1976

21753 PHLEGER 1956

21754 PHLEGER 1956

21755 PHLEGER 1956

21756 PHLEGER 1956

21757 PARKER PHLEGER PEIRSON 1953

21758 PARKER 1954

21759 BANDY 1954

21760 BANDY 1956

21761 BANDY 1954

21762 BANDY 1956

21763 BANDY 1956

21764 PARKER 1954

21765 BANDY 1956

21766 PHLEGER 19558

21767 SHIFFLETT 1961

21768 PHLEGER 1951A

21769 PHLEGER $1951 \mathrm{~A}$

21770 PHLEGER 1951A
Generic Name

POLYMORPHINA

POLYMORPHINA

POLYMORPHINA

POLYMORPHINA

POLYMORPHINA

POLYMORPHINA

POLYMORPHINA

POLYMORPHINA

POLYMORPHINA

POLYMORPHINA

POLYMORPHINA

POLYMORPHINA

POLYMORPHINA

POLYMORPHINA

POLYSTOMELLA

POLYSTOMELLA

POLYSTOMELLA

POLYSTOMELLA

POLYSTOMELLA

POLYSTOMELLA

POLYSTOMELLA

POLYSTOMELLA

POLYSTOMELLA

POROEPONIDES

POROEPONIDES

POROEPONIDES

POROEPONIDES

POROEPONIDES

POROEPONIDES

POROEPONIDES

POROEPONIDES

POROEPONIDES

POROEPONIDES

POROEPONIDES

POROEPONIDES

POROEPONIDES

POROEPONIDES

POROEPONIDES

POROEPONIDES

POROEPONIDES

POROEPONIDES

POROEPONIDES

POROEPONIDES

POROEPONIDES

POROEPONIDES

POROEPONIDES

POROEPON IDES

POROEPONIDES

POROEPONIDES

POROEPONIDES

PRAESORITES

PRAESORITES

PRAESORITES

PRAESORITES

PRAESORITES

PRAESORI TES

PR OT ELPHIDIUM

PROTEONINA

PROTEONINA

PR OTEONINA

PR OT EONINA

PROTEONINA

PROTEONINA

PROTEONINA

PROTEONINA

PROTEONINA

PROTEONINA

PROTEON INA

PROTEON INA

PROTEONINA

PROTEONINA

PROTEONINA

PROTEONINA

PROTEONINA

PROTEONINA

PROTEONINA

PROT EON INA

PR OTEONINA

PROTEONINA

PROTEONINA

PROTEONINA

PROTEONINA

PROTEONINA

PROTEONINA

PROTEONINA

PR OTEON INA

PROTEONINA

PROTEONINA

PR OTEONINA

PROTEONINA

PROTEONINA

PROTEON INA

PROTEONINA

PROTEONINA

PR OTEON INA
PROTEONINA
Specific Name

Locality

Lat. Long.

GI BBA

LALTEA

PULCHELLA

PULCHELLA

PULCHELLA

PULCHELLA

PULCHELLA

PULCHELLA

PULCHELLA

PULCHELLA

PULCHELLA

RE GINA

ADVENA

CRISPA

DI SCOIDAL IS

MACELLA

ST RIATOPJ NCTATA

ST FIATOPUNCTATA

ST FI ATOPUNCTATA

ST RIATOPJ NCTATA

CR IBROR EP ANDUS

CR IBROREP ANDUS

CRIBROREPANDUS

CR IBROREP AN DUS

CRIBROREPANDUS

CRIBROREP AN DUS

CR IBROREP ANDUS

CR IBROREP ANDUS

CRIBROREPAN DUS

CRIBROREPANDUS

CRIBROREP AN DUS

CRIBROREPANDUS

CR IBROREPANDUS

CR IBR OR EP AN DUS

LATERAL IS

LATER AL IS

LATER AL IS

LA TERAL IS

LATERAL IS

LATERALIS

LATERALIS

LATERALIS

LATERAL IS

LA TER ALIS

LATERAL IS

LATERALIS

OREITOLITOIDES

ORBITOL ITOIDES

ORBITOL IT OI DES

ORBITOLIT OIDES

OREITOL II OIDES

OREITOL IT OIDES

MATAGORDA NUM

AT LANTICA

AT LANTI CA

A T LANTI CA

A T LANTI CA

ATLANTI CA

A T LANTI CA

A TLANTICA

AT LANTI CA

A T LANTI CA

AT LANTI CA

AT LANTI CA

AT LANTI CA

AT LANTICA

AT LANTI CA

A TLANTI CA

A T LANTI CA

A T LANTI CA

A T LANTI CA

A TLANTICA

ATLANTICA

AT LANTICA

A TLANTI CA

AT LANTI CA

A T LANTI CA

AT LANTI CA

A TLANTI CA

ATLANTICA

AT LANTI CA

AT LANT I CA

A TLANTICA

ATLAVTICA

ATLANTI CA

ATLANTIC

CONPRIMA

CONPRIMA

TORTUGAS

TORTUGAS

TORTUGAS, FLA

NE GULF OF MEXICO

NE GULF OF MEXICO

NE GULF OF MEXICO

TORTUGAS

NE GULF OF MEXICO

NE GULF OF MEXICO 


\section{Publication}

21771 PHLEGER 1951A 21772 PHLEGER $1951 \mathrm{~A}$ 21773 PHLEGER $1951 \mathrm{~A}$ 21774 PHLEGER 1951 A 21775 PHLEGER $1951 \mathrm{~A}$ 21776 PHLEGER $1951 \mathrm{~A}$ 21.777 PHLEGER $1951 \mathrm{~A}$ 21778 PHLEGER $1951 \mathrm{~A}$ 21779 PHLEGER $1951 \mathrm{~A}$ 21780 PHLEGER 1951A 21781 PHLEGER $1951 \mathrm{~A}$ 21782 PHLEGEP 1951 21783 PHLEGER 1951 A 21784 PHLEGER 1951 A 21785 PHLEGER 1951A 21786 PHLEGER $1951 \mathrm{~A}$ 21787 PHLEGER $1951 \mathrm{~A}$ 21788 PHLEGER $1951 \mathrm{~A}$ 21789 PHLEGER 1951A 21790 PARKER 1954 21791 PARKER 1954 21792 PARKER 1954 21793 PHLEGER $1951 \mathrm{~A}$ 21794 PARKER 1954

21796 KELLOUGH 1956 21797 KELLOUGH 1956 21798 CUSHMAN 1918 21799 CUSHMAN 1918 21800 PHLEGER 1951A 21801 PHLEGER $1951 \mathrm{~A}$ 21802 PHLEGER $1951 \mathrm{~A}$ 21803 PHLEGER 1951A 21804 PARKER 1954 21805 PARKER 1954 21806 PARKER 1954 21807 KELLOUGH 1956 21808 PHLEGER $1951 \mathrm{~A}$ 21809 PHLEGER 1951 A 21810 PHLEGER 1951A 21811 PHLEGER $1951 \mathrm{~A}$ 21812 PHLEGER 1951A 21813 PHLEGER $1951 \mathrm{~A}$ 21814 PHLEGER $1951 \mathrm{~A}$ 21815 PHLEGER 1951 A 21816 PHLEGER 1951A 21817 PHLEGER 1951A 21818 PHLEGER 1951A 21819 PHLEGER 1951A 21820 PHLEGER $1951 \mathrm{~A}$ 21821 PHLEGER $1951 \mathrm{~A}$ 21822 PHLEGER 1951 A 21823 PHLEGER 1951A 21824 PHLEGER $1951 \mathrm{~A}$
21825 PHLEGER $1951 \mathrm{~A}$ 21826 PHLEGER $1951 \mathrm{~A}$ 21827 PHLEGER $1951 \mathrm{~A}$ 21828 PHLEGER $1951 \mathrm{~A}$ 21829 PARKER 1954

21830 PARKER 1954

21831 PARKER 1954

21832 PARKER 1954

21833 PARKER 1954

21834 PHLEGER 1951A

21835 PHLEGER 1951A

21836 PHLEGER 1951 A

21837 PARKER 1954

21838 PARKER 1954
21839 PHLEGER $1951 \mathrm{~A}$

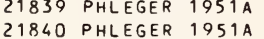

21841 PARKER 1954

21842 PHLEGER $1951 \mathrm{~A}$

21843 PHLEGER 1951 A

21844 PHLEGER 1951 A

21845 PHLEGER 1951A

21846 PHLEGER 1951A

21847 PHLEGER 1951 A

21848 PHLEGEP $1951 \mathrm{~A}$

21849 PARKER 1954

21850 PARKER 1954

21851 PARKER 1954

21852 PARKER 1954

21853 PARKER 1954

21854 PARKER 1954

21855 PARKER 1954

21856 PARKER 1354

21857 PHLEGER 1954

21859 PARKER PHLEGER PEIRSON 1953

21860 PHLEGER 1954

21861 PARKER PHLEGER PEIRSON 1953

21862 PHLEGER 1954

21863 SHEPARD MOORE 1955

21864 OTVOS 1978

21865 PARKER PHLEGER PEIRSON 1953
Generic Name

PROTEONINA

PROTEON INA

PROTEONINA

PROTEON INA

PROTEON I NA

PR OTEONINA

PROTEONINA

PROTEONINA

PROTEONINA

PROTEONINA

PROTEONINA

PROTEONINA

PROTEONINA

PROTEONINA

PROTEONINA

PROTEONINA

PROTEONINA

PR OTEONINA

PROTEONINA

PROTEONINA

PR OTE ON I NA

PROTEON INA

PROTEON INA

PR OTEON INA

PROTEONINA

PROTEONINA

PROTEONINA

PROTEONINA

PROTEONINA

PROTEONINA

PROTEONINA

PROTEONINA

PROTEON INA

PROTEONINA

PR OTEONINA

PROTEON I NA

PROTEONINA

PROTEONINA

PROTEONINA

PR OTEONINA

PROTEONINA

PROTEONINA

PROTEONINA

PROTEONINA

PROTEONINA

PROTEONINA

PROTEONINA

PROTEONINA

PROTEON INA

PR OTE ON INA

PROTEON INA

PROTEONINA

PROTEONINA

PROTEONINA

PROTEONINA

PROT EON I NA

PR OTEONINA

PROTEONINA

PROTEONINA

PROTEONINA

PR OT EON INA

PROTEON I NA

PROTEONINA

PROTEONINA

PROTEONINA

PROTEONINA

PROTEON I NA

PROTEONINA

PR OTEON I NA

PR OTEONINA

PROTEON INA

PROTEONINA

PROTEONINA

PROTEON I NA

PROTEONI NA

PR OTEONINA

PROTEON I NA

PROTEON INA

PROTEONINA

PROTEONINA

PROTEONINA

PROTEONINA

PROTEONINA

PR OTEONINA

PROTEONINA

PROTEONINA

PROTEONI NA PROTEONINA PROTEONINA PROTEONINA PROTEONINA

PR OT E ON I NA
Specific Name

CONPRIMA

CONPRIMA

CONPR IMA

CONPR IMA

CONPRIMA

CONPRIMA

CONPR IMA

CONPRIMA

CONPR IMA

CONPRIMA

CONPR IMA

CONPRIMA

DIFFLUGIF ORMIS

DI FFLUG IF ORMI S

DI FFLUG IF ORMIS

DI FFLUG IF ORMIS

DIFFLUGIF ORMIS

DI FFLUGIF ORMIS

DI FFLUGIF ORMIS

DI FFLUGIF ORMIS

DI FFLUG IF ORMIS

DI FFLUG IF ORMIS

DI FFLUGIF ORMIS

DI FFLUGIF ORMIS

DIFFLUGIF ORMIS

DI FFLUGIF ORMIS

DI FFLUGIF ORMIS

DI FFLUGIF ORMIS

DI FFLUGIF ORMIS

DI FFLUGIF ORMIS

DI FFLUGIF ORMIS

DIFFLUGIF ORMIS

DI FFLUG IF ORMIS

DI FFLUG IF ORMIS

DI FFLUG IF ORMIS

DI FFLUG IF ORMIS

DIFFLUGIF ORMIS

DIFFLUGIF ORMIS

DI FFLUGIF ORMIS

DI FFLUG IF ORMIS

DI FFLUG IF ORMI S

DI FFLUGIF ORMIS

DI FFLUG IF ORMIS

DI FFLUGIF ORMIS

DIFFLUG IF ORMIS

DI FFLUGIF ORMIS

DI FFLUG IF ORMIS

DI FFLUG IF ORMIS

DI FFLUG IF ORMIS

DIFFLUG IF ORMIS

DIFFLUGIFORMIS

DIFFLUGIF ORMIS

DIFFLUGIF ORMIS

OI FFLUGIF ORMIS

DIFFLUG IF ORMIS

DI FFLUG IF ORMIS

DIFFLUGIF ORMIS

DIFFLUG IF ORMIS

DI FFLUGIF ORMIS

DI FFLUGIF ORMIS

DI FFLUG IF ORMIS

DI FFLUG IF ORMIS

DI FFLUG IF ORMIS

DI FFLUG IF ORMIS

DI FFLUG IF ORMIS

DIFFLUG IF ORMIS

DI FFLUGIF ORMIS

DIFFLUGIF ORMIS

DI FFLUGIF ORMIS

DI FFLUGIF ORMIS

DIFFLUG IF ORMIS

DIFFLUG IF ORMIS

DI FFLUG IF ORMIS

DI FFLUG IF ORMIS

DI FFLUGIF ORMIS

DI FFLUG IF ORMIS

DIFFLUG IF ORMIS

DI FFLUGIF ORMIS

DI FFLUGIF ORMIS

OI FFLUG IF ORMIS

DI FFLUGIF ORMIS

DI FFLUGIF ORMIS

DI FFLUG IF ORMIS

LAGENAR IA

LA GENAR IA

LAGENARIA

LA GENARIA

LAGENARIA

LAGENARIA

LAGENARIA

LAGENAR IA

LAGENAR IA

\section{Locality}

$\mathrm{Nh}$ GULF OF MEXICO

NW GULF OF MEXICO

NW GULF OF MEXICO

NW GULF OF MEXICO

NW GULF OF MEXICO

NW GULF OF MEXICO

NW GULF OF MEXICO 


\section{Publication}

21866 CUSHMAN 1918 21867 CUSHMAN 1918 21868 PHLEGER 1965A 21869 PHLEGER 1965A 21870 CUSHMAN 1918 21871 CUSHMAN 1918 21872 BANDY 1956 21873 BANDY 1956 21874 WARREN 1956 21875 WARREN 1957

21876 PARKER PHLEGER PEIRSON 1953 21877 SHEPARD MOORE 1955

21878 LANKFORD 1959 21879 PHLEGER 1951A 21880 PHLEGER 1951 21881 PARKER 1956 21882 PARKER 1954 21883 PHLEGER 1951A 21884 PHLEGER 1951A 21885 PHLEGER 1951A 21885 PHLEGER 1951A 21886 PHLEGER 1951A 21887 PHLEGER 1951A 21889 PHLEGER 1951A 21890 PHLEGER 1951A 21891 PHLEGER 1951A 21892 PHLEGER 1951A 21893 PHLEGER 1951A 21894 PHLEGER 1951A 21895 PHLEGER 1951A 21896 PHLEGER 1951A 21897 PFLUM FRERICHS 1976 21898 CREAGER 1958 21899 CREAGER 1958 21900 CREAGER 1958

21901 PFLUM FRERICHS 1976 21902 PFLUM FRERICHS 1976 21903 PFLUM FRERICHS 1976 21904 PFLUM FRERICHS 1976 21905 PFLUM FRERICHS 1976 21906 PFLUM FRERICHS 1976 21906 PFLUM FRERICHS 1976 21907
21908 PFLUM FRERICHS 1976 21909 PFLUM FRERICHS 1976 21910 PHLEGER 1951 A

21911 PHLEGER 1951

21912 PARKER 1954

21913 CREAGER 1958

21914 PARKER 1954

21915 PHLEGER $1951 \mathrm{~A}$

21916 PFLUM FRERICHS 1976 21917 PFLUM FRERICHS 1976 21918 PFLUM FRERICHS 1976 21919 PFLUM FRERICHS 1976 21920 PFLUM FRERICHS 1976 21921 PFLUM FRERICHS 1976 21922 CREAGER 1958

21923 PARKER 1954

21924 PARKER 1954

21925 PFLUM FRERICHS 1976

21926 PARKER 1954

21927 PARKER 1954

21928 PARKER 1954

21929 PHLEGER $1951 \mathrm{~A}$

21930 PHLEGER 1951A

21931 PARKER 1954

21932 KELLOUGH 1956

21933 KELLOUGH 1956

21934 KELLOUGH 1956

21935 KELLOUGH 1956

21936 ANDERSEN 1961

21937 PFLUM FRERICHS 1976

21938 PFLUM FRERICHS 1976

21939 PARKER 1954

21940 PARKER 1954

21941 CREAGER 1958

21942 PARKER 1954

21943 CREAGER 1958

21944 PARKER 1954

21945 PARKER 1954

21946 PARKER 1954

21947 LUDWICK WALTON 1957

21948 PARKER 1954

21949 WARREN 1957

21950 PHLEGER 1955A

21951 LUDWICK WALTON 1957

21952 PARKER 1954

21953 LANKFORD 1959

21954 PARKER 1954

21955 PARKER 1954

21956 PARKER 195

21957 PARKER 1954

21958 PARKER 1954

21959 PARKER 195

21960 PARKER 1954
Generic Name

PR OTEONINA

PROTEONINA

PROTOSCHISTA

PROTOSCHISTA

PSAMMOSPHAERA

PS EUDOCLAVUL INA

PSEUDOCLAVULINA

PSEUDOCLAVULINA

PSEUDOCLAVUL INA

PSEUDOCL AVUL INA

PSEUDOCLAVULINA

PSEUDOCLAVULINA

PSEUDOCL AVUL INA

PSEUDOCLAVULINA

PSEUDOCLAVULINA

PSEUDOCLAVULINA

PSEUDOCLAVULINA

PSEUDOCLAVULINA

PSEUDOCL AVULINA

PSEUDOCLAVULINA

PSEUDOCLAVULINA

PSEUDOCLAVULINA

PSEUDOCLAVULINA

PSEUDOCLAVULINA

PSEUDOCLAVULINA

PSEUDOC LAVULINA

PSEUDOCLAVULINA

PSEUDOCLAVULINA

PSEUDOCLAVULINA

PSEUDOCLAVULINA

PSEUDOCLAVULINA

PSEUDOCLAVULINA

PSEUDOCLAVULINA

PSEUDOCL AVUL INA

PSEUDOCLAVULINA

PSEUDOCLAVULINA

PSEUDOCLAVULINA

PSEUDOCLAVULINA

PSEUDOCLAVUL INA

PSEUDOCLAVULINA

PSEUDOCLAVULINA

PSEUDOCLAVULINA

PSEUDOCLAVULINA

PSEUDOCLAVULINA

PSEUDOCLAVULINA

PSEUDOCLAVULINA

PSEUDOCLAVUL INA

PSEUDOCLAVULINA

PSEUDOCLAVULINA

PSEUDOCLAVUL INA

PSEUDOC LAVUL INA

PSEUDOCLAVULINA

PSEUDOCLAVULINA

PSEUDOCLAVULINA

PSEUDOCLAVULINA

PSEUDOCLAVULINA

PSEUDOCLAVULINA

PSEUDOCLAVULINA

PSEUDOCLAVULINA

PSEUDOCLAVULINA

PSEUDOCLAVULINA

PSEUDOCLAVULINA

PSEUDOCLAVULINA

PSEUDOCLAVULINA

PSEUDOCLAVULINA

PSEUDOCLAVULINA

PSEUDOCLAVULINA

PSEUDOCLAVUL INA

PSEUDOCLAVULINA

PSEUDOCLAVULINA

PSEUDOCLAVULINA

PSEUDOCLAVULINA

PSEUDOCLAVULINA

PSEUDOCLAVULINA

PSEUDOCLAVULINA

PSEUDOCLAVULINA

PSEUDOCLAVULINA

PSEUDOCLAVULINA

PSEUDOCLAVULINA

PSEUDOCLAVUL INA

PSEUDOCLAVULINA

PSEUDOCLAVULINA

PSEUDOEPON IDES

PSEUDOEPONIDES

PSEUDOEPONIDES

PSEUDOEPONIDES

PSEUDOEPONIDES

PSEUDOEPONIDES

PSEUDOEPONIDES

PS EUDOEPONI DES

PSEUDOEPONIDES

PS EUDOEPONIDES

PSEUDOEPONIDES

PSEUDOEPONIDES
Specific Name

TESTACEA

TESTACEA

I NDENS

PARVA

PARVA

CONSTANS

CONSTANS

GRACILIS

GRACILIS

GRACILIS

GRACILIS

MEXICANA

MEXI CANA

MEXICANA

MEXICANA

MEXI CANA

MEXICANA

MEXICANA

MEXICANA

MEXICANA

MEXICANA

MEXI CANA

MEXI CANA

MEXICANA

MEXICANA

MEXICANA

MEXICANA

MEXICANA

MEXICANA

EEIICANA

MEXI CANA

EXICANA

MEXI CANA

MEXICANA

MEXICANA

MEXI CANA

MEXICANA

MEXICANA

MEXICANA

MEXICANA

MEXICANA

MEXICANA

MEXICANA

MEXICANA

MEXI CANA

MEXICANA

MEXI CANA

MEXICANA

MEXICANA

MEXICANA

MEXICANA

MEXI CANA

MEXICANA

MEXICANA

MEXICANA

MEXICANA

MEXICANA

MEXICANA

MEXICANA

MEXICANA

MEXI CANA
MEXICANA

MEXICANA

MEXICANA

MEXI CANA

NOVANGLIAE

NO VANGLIAE

NOVANGLIAE

NOVANGLIAE

NO VANGL IAE

NOVANGLIAE

NOVANGLIAE

NOVANGLIAE

NOVANGL IAE

NOVANGLIAE

AN OER SENI

UMEONATUS

UMBONATUS

UMEONATUS

UMBONATUS

UMEONATUS

UMEONAT US

UMEONATUS

UMEONATUS

UMBONATUS

UMBONATUS

UMEONATUS

\section{Locality}

NE GULF OF MEXICO

NE GULF OF MEXICO

PASS CAVALLO, TEXAS

PORT ALTO, TEXAS

NE GULF OF MEXICO

NE GULF OF MEXICO

NE GULF OF MEXICO

NE GULF OF MEXICO 


\section{Publication}

21961 PARKER 1954 21962 PARKER 1954 21963 PARKER 1954 21964 PHLEGER 1955 21966 PHLEGER 1955 A 21967 PHLEGER 1955 A 21968 CREAGER 1958 21969 CREAGER 1958 21970 CREAGER 1958 21971 CREAGER 1958 21972 CREAGER 1958 21973 CREAGER 1958 21974 PARKER 1954 21975 PARKER 1954 21976 PHLEGER 1955A 21977 PHLEGER 1955 A 21978 PARKER 1954 21979 PARKER 1954 21980 PARKER 1954 21981 PARKER 1954 21982 PARKER 1954 21983 PARKER 1954 21984 PHLEGER $1955 \mathrm{~A}$ 21985 PARKER 1954 21986 CREAGER 1958 21987 CREAGER 1958 21988 CREAGER 1958 21989 CREAGER 1958 21990 CREAGER 1958 21991 PARKER 1954 21992 PARKER 1954 21993 PARKER 1954 21994 LOEP 1965 21995 CREAGER 1958 21996 PARKER 1954 21997 PARKER 1954 21998 PARKER 1954 21999 CREAGER 1958 22000 LUDHICK WALTON 1957 22001 PARKER 1954 22002 CREAGER 1958 22003 CREAGER 1958 22004 PHLEGER 1951A 22005 PARKER 1954 22006 PARKER 1954 22007 LOEP 1965 22008 PHLEGER 1951A 22009 PARKER 1954 22010 PHLEGER 1951A 22011 PHLEGER 1951A 22012 PHLEGER 1951A 22013 PHLEGER 1951A 22014 PHLEGER 1951A 22015 PHLEGER $1951 \mathrm{~A}$ 22016 PFLUM FRERICHS 1976 22017 PFLUM FRERICHS 1976 22018 PFLUM FRERICHS 1976 22019 ANDERSEN 1961 22020 PFLUM FRERICHS 1976 22021 BOCK 1976

22022 BOCK 1976

22023 LEROY HODGKINSON 1975 22024 ANDERSEN 1961 22025 ANDERSEN 1961 22026 ANDERSEN 1961 22027 PHLEGER 1951 A 22028 PHLEGER 1951A 22029 PHLEGER 1951A 22030 PHLEGER 1951A 22031 PHLEGER 1951日 22032 PHLEGER 1951A 22033 PHLEGER 1951A 22034 PHLEGER 1951A 22035 PHLEGER 1951 A 22036 PHLEGER 1951A 22037 PHLEGER 1951 A 22038 PHLEGER 1951A 22039 PHLEGER 1951A 22040 DAVIS 1964 22041 PHLEGER 1951 A 22042 PHLEGER 1951A 22043 PHLEGER 1951A 22044 PHLEGER 1951 A 22045 PHLEGER 1951A 22046 PHLEGER 1951A 22047 PHLEGER $1951 \mathrm{~A}$ 22048 PHLEGER $1951 \mathrm{~A}$ 22049 PHLEGER $1951 \mathrm{~A}$ 22050 PHLEGER 1951A 22051 PHLEGER 1951A 22052 PHLEGER 1951A 22053 PHLEGER 1951A 22054 PHLEGER 1951A 22055 PHLEGER 1951A
Generic Name

Specific Name

Locality

PSEUDOEPONIDES

PSEUDOEPONIDES

PSEUDOEPONI DES

PSEUDOEPONIDES

PSEUDOEPON IDES

PSEUDOEPONI DES

PSEUDOEP ONIDES

PSEUDOEPONIDES

PSEUDOEPONIDES

PSEUDOEPONIDES

PSEUDOEPONIDES

PSEUDOEP ONIDES

PSEUDOEPONIDES

PSEUDOEPONIDES

PSEUDOEPONIDES

PSEUDOEPONIDES

PSEUDOEP ONIDES

PSEUDOEPONIDES

PSEUDOEPONIDES

PSEUDOEPONIDES

PSEUDOEP ONIDES

PSEUDOEPONIDES

PSEUDOEPONIDES

PSEUDOEPONIDES

PSEUDOEPONIDES

PSEUDOEPONIDES

PSEUDOEPONI DES

PSEUDOEPONI DES

PSEUDOEPONIDES

PSEUDOEP ONIDES

PSEUDOEPONIDES

PSEUDOEPONIDES

PSEUDOEPONIDES

PSEUDOGLANDUL INA

PSEUDOGLANDULINA

PSEUDOGLANDULINA

PSEUDOGLANDUL INA

PSEUDOGL AN DULINA

PSEUDOGL ANDUL INA

PSEUDOGLANDULINA

PSEUDOGL ANDUL INA

PSEUDOGLANDUL INA

PSEUDOGLANDULINA

PSEUDOGLANDULINA

SEUDOGL AN DUL INA

PSEUDOGLANDULINA

PSEUDOGLANDULINA

PSEUDOGLANDULINA

PSEUDOGLANDUL INA

PSEUDOGL ANDULINA

PSEUDOGLANDULINA

PSEUDOGLANDULINA

PSEUDOGLANDULINA

PSEUDOGLANDUL INA

PSEU DOGL ANDUL INA

PSEUDONODOSARIA

PSEUDONODOSARIA

PSEUDONODOSARIA

PSEUDONODOSAR IA

PSEUDONODOSARIA

PSEUDONODOSARIA

PSEUDONODOSARIA

PSEUDONODOSARIA

PSEUDONONION

PSEUDONONION

PSEUDONONION

PSEUDOPARRELLA

PSEUDOPARRELLA

PSEUDOPARRELLA

PSEUDOPARRELLA

PSEUDOPARRELLA

PSEUDOPARRELLA

PSEUDOPARRELLA

PSEUDOPARRELLA

PSEUDOPARRELLA

PSEUDOPARRELLA

PSEUDOPARRELLA

PS EUDOPARRELLA

PSEUDOPARRELLA

PSEUDOPARRELLA

PSEUDOPARRELLA

PSEUDOPARRELLA

PSEUDOPARRELLA

PSEUDOPARRELLA

PS EUDOPARRELLA

PSEUDOPARRELLA

PSEUDOPARRELLA

PSEUDOPARRELLA

PSEUDOPARRELLA

PSEUDOPARRELLA

PSEUDOPARRELLA

PSEUDOPARRELLA

PSEUDOPARRELLA

PSEUDOPARRE LLA

PSEUDOPARRELLA
UMBONATUS

UMEONATUS

UMEONATUS

UMBONATUS

UMBONATUS

UMEONATUS

UMBONATUS

UMBONATUS

UMEONATUS

UMEONATUS

UMBONATUS

UMBONATUS

UMBONATUS

UMEONATUS

UMEONATUS

UMBONATUS

UMEONATUS

UMBONATUS

UMBONATUS

UMEONAT US

UMBONATUS

UMBONATUS

UMBONATUS

UM BONATUS

UMEONATUS

UMEONATUS

UMBONATUS

UMBONATUS

UMBONATUS

UMBONATUS

UMEONATUS

UM EONATUS

UMBONATUS

COMATULA

COMATULA

CONATULA

CONATULA

CONATULA

COMATULA

COMATULA

COMATULA

COMATULA

CONATULA

COMATULA

COMATULA

CORATULA

COMATULA

CONATULA

CONATULA

CONATULA

COMATULA

CONATULA

CONATULA

CORATULA

COMATULA

COMATULA

COMATULA

CONATULA

CONATULA

CONATULA

MAYOR I

PORRECTA

TORRIDA

ATLANTI CUS

GRATEL OUP I

DE CORATA

DE CORATA

DE CORATA

DE CORATA

DE CORATA

DE CORATA

DE CORATA

DE CORATA

DE CORATA

DE CORATA

DE CORATA

DE CORATA

DE CORATA

DE CORATA

EXIGUA

EXIGUA

EXIGUA

EXIGUA

EXIGUA

EXIGUA

EXIGUA

$X I G \cup A$

EXIGUA

EXIGUA

EXIGUA

EXIGUA

EXIGUA

NE GULF OF MEXICO

NE GULF OF MEXICO

NE GULF OF MEXICO 


\section{Publication}

22056 PHLEGER 1951A 22057 PHLEGER 1951A 22058 PHLEGER 1951A 22059 PHLEGER 1951A 22060 PHLEGER 1951A 22061 PHLEGER 1951A 22062 PHLEGER 1951A 22063 PHLEGER 1951A 22064 PHLEGER 1951A 22065 PHLEGER 1951A 22066 PHLEGER 1951A 22067 PHLEGER $1951 \mathrm{~A}$ 22068 PHLEGER 1951A 22069 PHLEGER $1951 \mathrm{~A}$ 22070 PHLEGER 1951A 22071 PHLEGER $1951 \mathrm{~A}$ 22072 PHLEGER 1951A 22073 PHLEGER 1951A 22075 PHLEGER 1951A 22076 PHLEGER 1951A 22077 PHLEGER $1951 \mathrm{~A}$ 22078 PHLEGER 1951A 22079 PHLEGER 1951A 22080 CREAGER 1958 22081 CREAGER 1958 22082 CREAGER 1958
22083 PHLEGER 1951A 22084 PHLEGER 1951A 22085 PHLEGER 1951 A 22086 PHLEGER 1951A 22087 PHLEGER 1951A 22088 PHLEGER 1951A 22089 PHLEGER $1951 \mathrm{~A}$ 22090 PHLEGER 1951A 22091 PHLEGER 1951A 22093 PHLEGER 1951A 22094 PHLEGER 1951A 22095 PHLEGER $1951 \mathrm{~A}$ 22096 PHLEGER 1951A 22097 PHLEGER 1951A 22098 PHLEGER $1951 \mathrm{~A}$ 22099 PHLEGER 1951A 22100 PHLEGER 1951A 22101 PHLEGER 1951 A 22102 PHLEGER 1951A 22103 PHLEGER 1951A 22104 PHLEGER $1951 \mathrm{~A}$

22106 PFLUM FRERICHS 1976 22107 PFLUM FRERICHS 1976 22108 FRER ICHS 1969

22109 PFLUM FRERICHS 1976 22110 PFLUM FRERICHS 1976 22111 PFLUM FRERICHS 1976 22112 PFLUM FRERICHS 1976 22113 PFLUM FRERICHS 1976 22114 PFLUM FRERICHS 1976 22115
22116 PFLUM FRERICHS 1976 22117 PFLUM FRERICHS 1976 22118 FRERICHS 1969

22119 PFLUM FRERICHS 1976 22120 PFLUM FRERICHS 1976 22121 PFLUM FRERICHS 1976 22122 PFLUM FRERICHS 1976 22123 PFLUM FRERICHS 1976 22124 PFLUM FRERICHS 1976 22125 PFLUM FRERICHS 1976 22126-PFLUM FRERICHS 1976 22127 PFLUM FRERICHS 1976 22128 PFLUY FRERICHS 1976 22129 PFLUM FRERICHS 1976 22130 PFLUM FRERICHS 1976 22131 PFLUM FRERICHS 1976 22132 PFLUM FRERICHS 1976 22133 PFLUM FRERICHS 1976 22134 PFLUM FRERICHS 1976 22135 PFLUM FRERICHS 1976 22136 PFLUM FRERICHS 1976 22137 PFLUM FRERICHS 1976 22138 PFLUM FRERICHS 1976 22139 PFLUM FRERICHS 1976 22140 PHLEGER 1951A

22141 PFLUM FRERICHS 1976

22142 PHLEGER 1951A

22143 PHLEGER 1951A

22144 PHLEGER 1951A

22145 PHLEGER 1951A

22146 PHLEGER 1951A

22147 PHLEGER 1951A

22148 PHLEGER $1951 \mathrm{~A}$

22150 PHLEGER 1951A
Generic Name

Specific Name

Locality

Lat. Long.

PSEUDOPARRELLA

EXIGUA

EXIGUA

PSEUDOPARRELLA

PSEUDOPARRELLA

PSEUDOPARRELLA

PSEUDOPARRELLA

PSEUDOPARRELLA

PSEUDOPARRELLA

PSEUDOPARRELLA

PSEUDOPARRELLA

PSEUDOPARRELLA

PSEUDOPARRELLA

PSEUDOPARRELLA

PSEUDOPARRELLA

PSEUDOPARRELLA

PSEUDOPARRELLA

PSEUDOPARRELLA

PSEUDOPARRELLA

PSEUDOPARRELLA

SEUDOPARRELLA

PSEUDOPARRELLA

PSEUDOPARRELLA

PSEUDOPARRELLA

PSEUDOPARRELLA

PSEUDOPARRELLA

PSEUDOPARRELLA

SEUDOPARRE LLA

PSEUDOPARRELLA

PSEUDOPARRELLA

PSEUDOPARRELLA

PSEUDOPARRELLA

PSEUDOPARRELLA

PSEUDOPARRELLA

PSEUDOPARRELLA

PSEUDOPARRELLA

PSEUDOPARRELLA

PSEUDOPARRELLA

PSEUDOPARRELLA

PSEUDOPARRELLA

PSEUDOPARRELLA

PSEUDOPARRELLA

PSEUDOPARRELLA

PSEUDOPARRELLA

PSEUDOPARRELLA

PSEUDOPARRELLA

PSEUDOPARRELLA

PSEUDOPARRELLA

PSEUDOPARRELLA

PSEUDOPARRELLA

PSEUDOT ROCHAMMINA

PSEUDOTROCHAMMINA

PSEUDOTROCHAMMINA

PSEUD OTR OCHAMMINA

PSEUDOTROCHAMMINA

PSEUDOTROCHAMMINA

PSEUDOTROCHAMMINA

PSEUDOTROCHAMMINA

PSEUDOTROCHAMMINA

PSEUDOTROCHAMMINA

PSEUDOTROCHAMMINA

PSEUDOTROCHAMMINA

PSEUDOTROCHAMMINA

PSEUDOTROCHAMMINA

PSEUDOTROC HAMMINA

PSEUDOTROCHAMMINA

PSEUDOTROCHAMMINA

PSEUDOTROCHAMMINA

PSEUDOTROCHAMMINA

PSEUDOTROCHAMMINA

PSEUDOTROCHAMMINA

PS EUDOTROCHAMMINA

PSEUDOTROC HAMMINA

PSEUDOTROCHAMMINA

PSEUDOTROCHAMMINA

PSEUDOTROCHAMMINA

PSEUDOTROCHAMMINA

PSEUDOTROCHAMMINA

PSEUDOTROCHAMMINA

PSEUDOTROCHAMMINA

PSEUDOTROCHAMMINA

PULLENIA

PULLENIA

PULLENIA

PULLENIA

PULLENIA

PULLENIA

PULLENIA

PULLENIA

PULLEN I A

PULLENIA

PULLENIA

PULLENIA

PULLENIA

PULLENIA
NW GULF OF MEXICO

NW GULF OF MEXICO

NW GULF OF MEXICO

NW GULF OF MEXICO

NW GULF OF MEXICO

NW GULF OF MEXICO

NW GULF OF MEXICO

NW GULF OF MEXICO

NW GULF OF MEXICO

NW GULF OF MEXICO

NW GULF OF MEXICO

NW GULF OF MEXICO

NW GULF OF MEXICO

NW GULF OF MEXICO

NW GULF OF MEXICO

NW GULF OF MEXICO

NW GULF OF MEXICO

NW GULF OF MEXICO

NW GULF OF MEXICO

NW GULF OF MEXICO

$N W$ GULF OF MEXICO

$N W$ GULF OF MEXICO

NW GULF OF MEXICO

BAY OF CAMPECHE

BAY OF CAMPECHE

BAY OF CAMPECH

NW GULF OF MEXICO

NW GULF OF MEXICO

NW GULF OF MEXICO

NW GULF OF MEXICO

$N W$ GULF OF MEXICO

NW GULF OF MEXICO

NW GULF OF MEXICO

$N W$ GULF OF MEXICO

$N W$ GULF OF MEXICO

NW GULF OF MEXI 50

NW GULF OF MEXICO

NW GULF OF MEXICO

NW GULF OF MEXICO

NW GULF OF MEXICO

$\mathrm{NW}$ GULF OF MEXICO

NW GULF OF MEXICO

NW GULF OF MEXICO

$\mathrm{NW}$ GULF OF MEXICO

NW GULF OF MEXICO

$N W$ GULF OF MEXICO

CENTRAL GULF OF MEXICO

CENTRAL GULF OF MEXICO

CENTRAL G. OF MEXICO

NW GULF OF MEXICO

NW GULF OF MEXICO

$N W$ GULF OF MEXICO

$\mathrm{NW}$ GULF OF MEXICO

NW GULF OF MEXICO

NW GULF OF MEXICO

NW GULF OF MEXICO

NW GULF OF MEXICO

CENTRAL G. OF MEXICO

NW GULF OF MEXICO

CENTRAL GULF OF MEXICO

CENTRAL GULF OF MEXICO

NW GULF OF MEXICO

$\mathrm{NW}$ GULF OF MEXICO

NW GULLF OF MEXICO

$N W$ GULF OF MEXICO

$N W$ GULF OF MEXICO

NW GULF OF MEXICO

NW GULF OF MEXICO

$N$ GULF OF MEXICO

NW GULF OF MEXICO

NW GULF OF MEXICO

NW GULF OF MEXICO

NW GULF OF MEXICO

NW GULF OF MEXICO

NW GULF OF MEXICO

NW GULF OF MEXICO

NW GULF OF MEXICO

NW GULF OF MEXICO

NW GULF OF MEXICO

NW GULF OF MEXICO

NW GULF OF MEXICO

NW GULF OF MEXICO

NW GULF OF MEXICO

NW GULF OF MEXICO

NW GULF OF MEXICO

NW GULF OF MEXICO

$N$ GULF OF MEXIC

NW GULF OF MEXIC

NW GULF OF MEXICO

NW GULF OF MEXICO
NW GULF OF MEXICO

CENTRAL GULF OF MEXICO

$2718 \mathrm{~N} 09014 \mathrm{~W}$ $2659 \mathrm{~N} 09611 \mathrm{~W}$ $2730 \mathrm{~N} 09510 \mathrm{~W}$ $2633 \mathrm{~N} 09440 \mathrm{H}$ $2 t 58 \mathrm{~N} 09557$ 27 $10 \mathrm{~N} 09622 \mathrm{~W}$ $2825 \mathrm{~N} 091 \quad 49 \mathrm{~W}$ $2825 \mathrm{~N} 09053 \mathrm{~W}$ 


\section{Publication}

22151 PHLEGER 1951A 22152 PHLEGER 1951A 22153 PHLEGER 1951A 22154 PHLEGER $1951 \mathrm{~A}$ 22155 PHLEGER 1951A 22156 LUDWICK WALTON 1957 22157 PARKER 1954 22158 PARKER 1954 22159 PHLEGER 1951A 22160 PHLEGER 1951A 22161 PHLEGER 1951A

22162 PFLUM FRERICHS 1976 22163 PFLUM FRERICHS 1976 22164 PFLUM FRERICHS 1976 22165 PFLUM FRERICHS 1976 22166 PFLUM FRERICHS 1976 22167 PHLEGER 1951A 22168 PHLEGER 1951 A 22170 PFLUM FRERICHS 1976 22170 PFLUM FRERICHS
22171 PHLEGER 1951A

22172 PFLUM FRERICHS 1976 22173 PFLUM FRERICHS 1976 22174 PFLUM FRERICHS 1976 22176 PFLUM FRERICHS 1976 22177 PFLUM FRERICHS 1976 22178 PFLUM FRERICHS 1976 22179 PFLUM FRERICHS 1976 22180 PFLUM FRERICHS 1976 22181 PFLUM FRERICHS 1976 22182 PFLUM FRERICHS 1976 22183 PFLUM FRERICHS 1976 22184 PFLUM FRERICHS 1976 22185 PFLUM FRERICHS 1976 22186 PFLUM FRERICHS 1976 22187 PFLUM FRERICHS 1976 22188 PFLUM FRERICHS 1976 22189 PFLUM FRERICHS 1976 22190 PFLUM FRERICHS 1976 22191 PFLUM FRERICHS 1976 22192 PFLUM FRERICHS 1976 22193 PFLUM FRERICHS 1976 22194 PFLUM FRERICHS 1976 22195 PHLEGER 1951A

22196 PHLEGER 1951A 1976 22197 PFLUM FRERICHS 1976 22198 PHLEGER 1951A

22199 PFLUM FRERICHS 1976 22200 PFLUM FRERICHS 1976
22201 PFLUM FRERICHS 1976 22202 PFLUM FRERICHS 1976 22203 PHLEGER 1951 A

22204 PFLUM FRERICHS 1976 22205 PFLUM FRERICHS 1976 22206 PARKER 1954

22207 PARKER 1954

22208 PFLUM FRERICHS 1976 22209 PFLUM FRERICHS 1976 22210 PFLUM FRERICHS 1976 22211 ANDERSEN 1961

22212 LOEP 1965

22213 LOEP 1965

22214 PFLUM FRERICHS 1976 22215 PFLUM FPERICHS 1976 22216 PFLUM FRERICHS 1976 22217 PHLEGER 1951A

22218 PFLUM FRERICHS 1976 22219 PFLUM FRERICHS 1976 22220 PFLUM FRERICHS 1976 22221 CREAGER 1958

22222 PARKER 1954

22223 PARKER 1954

22224 CREAGER 1958

22225 CREAGER 1958

22226 CREAGER 1958

22227 CREAGER 1958

$\begin{array}{lll}22228 & \text { CREAGER } & 1958 \\ 22229 & \text { CREAGER } & 1958\end{array}$

22230 PARKER 1954

22231 PARKER 1954

22232 PARKER 1954

22233 PARKER 1954

22234 PARKER 1954

22235 PARKER 1954

22236 PARKER 1954

22237 PARKER 1954

22239 PARKER 1954

22240 PFLUM FRERICHS 1976

22241 PARKER 1954

22242 PARKER 1954

22243 PARKER 1954

22244 PARKER 1954

22245 PARKER 1954

\section{Generic Name}

PULLENIA

PULLENIA

PULLENIA

PULLENIA

PULLENIA

PULLENIA

PULLENIA

PULLENIA

PULLENI A

PULLENIA

PULLENIA

PULLENIA

PULLENIA

PULLENIA

PULLEN I A

PULLENIA

PULLENIA

PULLENIA

PULLEN I A

PULLEN I A

PULLEN I A

PULLENIA

PULLEN I A

PULLENIA

PULLENIA

PULLENIA

PULLENIA

PULLENIA

PULLENIA

PULLENIA

PULLENIA

PULLENIA

PULLENIA

PULLEN I A

PULLENIA

PULLENIA

PULLENI A

PULLENIA

PULLENIA

PULLENIA

PULLENIA

PULLENIA

PULLENIA

PULLENIA

PULLENIA

PULLENIA

PULLENIA

PULLENIA

PULLENIA

PULLENIA

PULLENI A

PULLEN I A

PULLENIA

PULLENIA

PULLENIA

PULLENIA

PULLENIA

PULLENIA

PULLENIA

PULLEN I A

PULLENIA

PULLENIA

PULLEN I A

PULLENIA

PULLENIA

PULLENIA

PULLENIA

PULLENIA

PULLENIA

PULLENIA

PULLEN I A

PULLENI A

PULLENIA

PULLENIA

PULLENIA

PULLENIA

PULLENIA

PULLENI A

PULLENIA

PULLENI A

PULLENIA

PULLENIA

PULLENI A

PULLENIA

PULLEN I A

PULLENI A

PULLENIA
Specific Name

BULLOIDES

BULLOIDES

BULLOIDES

BULLOIDES

BULLOIDES

BULLOIDES

BULLOIDES

BULLOIDES

BULLOIDES

BULLOIDES

BULLOIDES

BULLOIDES

BULLOIDES

BULLOIDES

BULLOIDES

BULLOIDES

BULLOIOES

BULLOIDES

BULLOIDES

BULLOIDES

BULLOIDES

BULLOIDES

BULLOIDES

BULLOIDES

BULLOIDES

BULLOIDES

BULLOIDES

BULLOIDES

BULLOIDES

BULLOIDES

BULLOIDES

BULLOIDES

BULLOIOES

BULLOIDES

BULLOIDES

BULLOIDES

BULLOIDES

BULLOIDES

BULLOIDES

BULLOIDES

BULLOIDES

BULLOIDES

BULLOIDES

BULLOIDES

BULLOIDES

BULLOIDES

BULLOIDES

BULLOIDES

BULLOIDES

BULLOIDES

BULLOIDES

BULLOIDES

BULLOIDES

BULLOIDES

BULLOIDES

BULLOIDES

BULLOIDES

BULLOIDES

BULLOIDES

BULLOIDES

BULLOIDES

BULLOIDES

BULLOIDES

BULLOIDES

BULLOIDES

BULLOIDES

BULLOIDES

BULLOIDES

BULLOIDES

BULLOIDES

BULLOIDES

BULLOIDES

BULLOIDES

BULLOIDES

BULLOIDES

BULLOIDES

BULLOIDES

BULLOIDES

BULLOIDES

BULLOIDES

BULLOIDES

BULLOIDES

BULLOIDES

BULLOIDES

BULLOIDES

EULLOIDES

BULLOIDES

BULLOIDES

BULLOIDES

\section{Locality}

NW GULF OF MEXICO

NW GULF OF MEXICO

NW GULF OF MEXICO

NW GULF OF MEXICO

NW GULF OF MEXICO

NE GULF OF MEXICO

NE GULF OF MEXICO

NE GULF OF MEXICO

NW GULF OF MEXICO

NW GULF OF MEXICO

$N W$ GULF OF MEXICO

NW GULF OF MEXICO

NW GULF OF MEXICO

NW GULF OF MEXICO

NW GULF OF MEXICO

NW GULF OF MEXICO

NW GULF OF MEXICO 


\section{Publication}

22246 PARKER 1954

\section{PARKER 1954}

22248 PFLUM FRERICHS 1976

22249 PARKER 1954

22250 PFLUM FRERICHS 1976 22251 PFLUM FRERICHS 1976 22252 PFLUM FRERICHS 1976 22253 PFLUM FRERICHS 1976 22254 PFLUM FRERICHS 1976 22255 PFLUM FRERICHS 1976 22256 PFLUM FRERICHS 1976 22257 PFLUM FRERICHS 1976 22258 PFLUM FRERICHS 1976 22259 PFLUM FRERICHS 1976 22260 PFLUM FRERICHS 1976 22261 PFLUM FRERICHS 1976 22262 PFLUM FRERICHS 1976 22263 PFLUM FRERICHS 1976 22264 PFLUM FRERICHS 1976

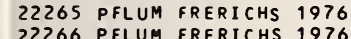
22266 PFLUM FRERICHS 1976

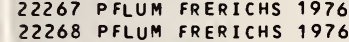
22269 PFLUM FRERICHS 1976 22270 PFLUM FRERICHS 1976 22270
22271
PFLLUM FRERICHS 1976 22272 PFLUM FRERICHS 1976 22273 PFLUM FRERICHS 1976 22274 PFLUM FRERICHS 1976 22275 PFLUM FRERICHS 1976 22276 PFLUM FRERICHS 1976 22277 PFLUM FRERICHS 1976 22278 PFLUM FRERICHS 1976 22279 PHLEGER 1951A

22280 PHLEGER 1951A

22281 PFLUM FRERICHS 1976

22282 PFLUM FRERICHS 1976

22283 PFLUM FRERICHS 1976

22284 PFLUM FRERICHS 1976 22285 PFLUM FRERICHS 1976 22286 PFLUM FRERICHS 1976 22287 PFLUM FRERICHS 1976 22288 PFLUM FRERICHS 1976 22289 PFLUM FRERICHS 1976 22290 PFLUM FRERICHS 1976 22291 PFLUM FRERICHS 1976 22292 PFLUM FRERICHS 1976 22293 PFLUM FRERICHS 1976 22294 PFLUM FRERICHS 1976 22295 PFLUM FRERICHS 1976

22296 PFLUM FRERICHS 1976

22297 PARKER 1954

22298 PARKER 1954

22299 PARKER 1954

22300 PARKER 1954

22301 PARKER 1954

22303 PFLUM FRERICHS 1976

22304 PARKER 1954

22305 PARKER 1954

22306 PARKER 1954

22307 PARKER 1954

22308 PARKER 1954

22309 PARKER 195

22310 PARKER 1954

22311 PHLEGER 1951A

22312 PHLEGER 1951A

22313 PHLEGER 1951A

22314 PHLEGER 1951A

22315 PHLEGER 1951A

22316 PHLEGER 1951A

22317 PHLEGER 1951A

22318 PHLEGER 1951A

22319 PHLEGER 1951A

22320 PHLEGER 1951A

22321 PHLEGER 1951A

22322 PHLEGER 1951A

22323 PHLEGER 1951A

22324 PHLEGER 1951A

22325 PHLEGER 1951A

22326 PHLEGER 1951A

22327 PHLEGER 1951A

22328 PHLEGER 1951A

22329 PARKER 1954

22330 PARKER 1954

22331 PARKER 1954

22332 PHLEGER 1951A

22333 PHLEGER 1951A

22334 PFLUM FRERICHS 1976

22335 PFLUM FRERICHS 1976

22336 PFLUM FRERICHS 1976

22337 PFLUM FRERICHS 1976

22338 PFLUM FRERICHS 1976

22339 PFLUM FRERICHS 1976

22340 PFLUM FRERICHS 1976
Generic Name

Specific Name

Locality

Lat. Long.

PULLENIA

PULLENIA

PULLENIA

PULLENIA

PULLENI A

PULLENIA

PULLENIA

PULLENIA

PULLENIA

PULLENIA

PULLENIA

PULLENIA

PULLENIA

PULLENIA

PULLENIA

PULLENIA

PULLENIA

PULLENIA

PULLENIA

PULLENIA

PULLENIA

PULLENIA

PULLENIA

PULLENIA

PULlenia

PULLENI A

PULLENIA

PULLENIA

PULLENIA

PULLENIA

PULLENI A

PULLENIA

PULLENIA

PULLENIA

PULLENIA

PULLENIA

PULLENIA

PULLENIA

PULLENIA

PULLENIA

PULLENIA

PULLENI A

PULLENIA

PULLENIA

PULLENI A

PULLENIA

PULLENIA

PULLENI A

PULLENIA

PULLENIA

PULLENIA

PULLENIA

PULLENIA

PULLENIA

PULLENIA

PULLENIA

PULLENIA

PULLENIA

PULLENIA

PULLENIA

PULLENIA

PULLENIA

PULLENIA

PULLENIA

PULLENIA

PULLENIA

PULLENIA

PULLENIA

PULLENIA

PULLENIA

PULLENIA

PULLENIA

PULLENIA

PULLENIA

PULLENI A

PULLENIA

PULLENIA

PULLENIA

PULLENIA

PULLENIA

PULLENIA

PULLENIA

PULLENIA

PULLENIA

PULLENIA

PULLENIA

PULLENIA

PULLENIA

PULLENIA

PULLENIA

PULLENIA

PULLENIA
BULLOIDES

OULLOIDES

BULLOIDES

BULLOIDES

OS LOENS IS

OS LOENSIS

OSLOENSIS

OS LOENSIS

OS LOENS IS

OSLOENSIS

OSLOENS IS

OSLOENS IS

OSLOENSIS

OS LOENS IS

OS LOENSIS

OS LOENS IS

OSLOENSIS

OS LOENSIS

OSLOENSIS

OSLOENS IS

OS LOENS IS

SLEN IS

OSLOENSIS

OSLOENSIS

OS LOENS IS

OSLOENS IS

OSLOENSIS

OSLOENSIS

OSLOENSIS

OSLOENSIS

QU INQUELJBA

QU INQUE LOBA

QU INQUELOBA

QU I NQUE LOBA

QU INQUE LJ BA

QU I NQUE LOBA

QU INQUE LOBA

QU INQUE LOBA

QU INQUE LOBA

QU INQUE LO BA

QUINQUELOBA

QU INQUE LO BA

QU INQUELOBA

QU INQUE LOBA

QU INQUELO BA

QUINQUELOBA

QU INQUE LOBA

QU INQUE LOBA

QU INQUE LO BA

QU INQUE LO BA

QUINQUELOBA

QU INQUE LJBA

QU INQUE LOBA

QU INQUELOBA

QU I NQUE LO BA

QU INQUE $L O B A$

QU INQUELJBA

QUINQUELOBA

QU I NQUE LOBA

QU INQUELOBA

QU INQUELOBA

QU INQUELJ BA

QU INQUE L BA

QU INQUE LO BA

QU INQUE LOBA

QU INQUE LOBA

QU INQUELOBA

QU INQUELOBA

QU INQUE LOBA

QU INQUE LOBA

QUINQUELOBA

QU INQUELOBA

QU INQUELOBA

QU INQUELOBA

QU INQUE LOBA

QU INQUELOBA

QU INQUELOBA

QU INQUE LOBA

QU INQUELOBA

QU INQUE LOBA

QU INQUELOBA

QU INQUELO BA

QU INQUE LOBA

QU INQUE LOBA

QU INQUE LOBA

QU INQUE LO BA

QU INQUE LOBA

QU INQUE LOBA

QU INQUELOBA

QU INQUELOBA

QU INQUE LOBA

QU INQUELOBA

QU INQUELOBA
QU INQUELOBA

NE GULF OF MEXICO

NE GULF OF MEXICO

CENTRAL GULF OF MEXICO

NE GULF OF MEXICO 


\section{Publication}

22341 PFLUM FRERICHS 1976 22342 PFLUM FRERICHS 1976

22343 PHLEGER 1951A

22344 PHLEGER $1951 \mathrm{~A}$

22345 PHLEGER 1951 A

22346 LEROY HODGKINSON 1975

22347 PHLEGER $1951 \mathrm{~A}$

22348 PHLEGER $1951 \mathrm{~A}$

22350 PHLEGER 1951 A

22351 PHLEGER 1951A

22352 PHLEGER 1951A

22353 PHLEGER 1951A

22354 PHLEGER 1951A

22355 PHLEGER 1951A

22356 PHLEGER 1951A

22357 PHLEGER 1951A

22359 PFLUM FRERICHS 1976

22360 PFLUM FRERICHS 1976

22361 PFLUM FRERICHS 1976

22362 PFLUM FRERICHS 1976

22363 PFLUM FRERICHS 1976

22364 PFLUM FRERICHS 1976

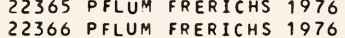

22366 PFLUM FRERICHS 1976
22367 PFLUM FRERICHS 1976

22368 PFLUM FRERICHS 1976

22369 PFLUM FRERICHS 1976

22370 PFLUM FRERICHS 1976

22371 PFLUM FRERICHS 1976

22372 PFLUM FRERICHS 1976

22373 PFLUM FRERICHS 1976

22374 PFLUM FRERICHS 1976

22375 PARKER 1954

22376 CREAGER 1958

22377 CREAGER 1958

22378 CREAGER 1958

22379 BOCK 1976

22380 CREAGER 1958

22381 PFLIJM FRERICHS 1976

22382 PFLUM FRERICHS 1976

22383 BANDY 1956

22384 CREAGER 1958

22385 CREAGER 1958

22386 CREAGER 1958

22387 PARKER 1954

22388 PHLEGER 1956

22389 PARKER 1954

22390 PARKER 1954

22391 PARKER 1954

22392 PARKER 1954

22393 PARKER 1954

22394 PARKER 1954

22395 PARKER 1954

22396 PARKER 1954

22397 PFLUM FRERICHS 1976

22398 PFLUM FRERICHS 1976

22399 PFLUM FRERICHS 1976

22400 PFLUM FRERICHS 1976

22401 PFLUM FRERICHS 1976

22402 PFLUM FRERICHS 1976

22403 PFLUM FRERICHS 1976

22404 PFLUM FRERICHS 1976

22405 PFLUM FRERICHS 1976

22406 PFLUM FRERICHS 1976

22407 PFLUM FRERICHS 1976

22408 PFLUM FRERICHS 1976

22409 PFLUM FRERICHS 1976

22410 PFLUM FRERICHS 1976

22411 PFLUM FRERICHS 1976

22412 PFLUM FRERICHS 1976

22413 PFLUM FRERICHS 1976

22414 PFLUM FRERICHS 1976

22415 PFLUM FRERICHS 1976

22416 PFLUM FRERICHS 1976

22417 PFLUM FRERICHS 1976

22418 PFLUM FRERICHS 1976

22419 PFLUM FRERICHS 1976

22420 ANDERSEN 1961

22421 PFLUM FRERICHS 1976

22422 PFLUM FRERICHS 1976

22423 PFLUM FRERICHS 1976

22424 PFLUM FRERICHS 1976

22425 PFLUM FRERICHS 1976

22426 PFLUM FRERICHS 1976

22427 PFLUM FRERICHS 1976

22428 PFLUM FRERICHS 1976

22429 PFLUM FRERICHS 1976

22430 PFLUM FRERICHS 1976

PRERICHS 1976

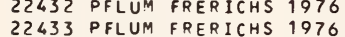

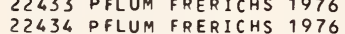

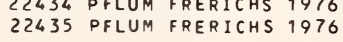

Generic Name

PULLENIA

PULLENIA

PULLENIA

PULLENIA

PULLENIA

PULLENIA

PULLENIA

PULLENIA

PULLENIA

PULLENIA

PULLENIA

PULLENIA

PULLENIA

PULLEN I A

PULLENIA

PULLENIA

PULLENIA

PULLENIA

PULLENIA

PULLENIA

PULLENIA

PULLENIA

PULLENIA
PULLEN IA

PULLENIA

PULLENIA

PULLENIA

PULLEN I A

PULLENIA

PULLENIA

PULLENIA

PULLENIA

PULLENIA

PULLENIA

PULLENIA

PULLENIA

PULLENI A

PULLENIA

PULLENIA

PULLENIA

PULLENIA

PULLENIA

PULLENIA

PULLEN I A

PULLENIA

PULLENIA

PULLENIA

PULLENIA

PULLENIA

PULLENIA

PULLENIA

PULLEN IA

PULLENIA

PULLENIA

PULLENIA

PULLENIA

PULLEN IA

PULLENIA

PULLENIA

PULLENIA

PULLENIA

PULLENIA

PULLENIA

PULLENI A

PULLENIA

PULLENIA

PULLENIA

PULLEN I A

PULLENIA

PULLENIA

PULLENIA

PULLENIA

PULLENIA

PULLENIA

PULLENIA

PULLENIA

PULLENIA

PULLENIA

PULLEN I A

PULLENIA

PULLENIA

PULLENIA

PULLENIA

PULLENIA

PULLENIA

PULLEN I A

PULLENIA

PULLENIA

PULLENIA

PULLENIA

PULLENIA

PULLENIA

PULLENIA
Specific Name

QU INQUELOBA

QU INQUE LJ BA

QU INQUELOBA

QU INQUELJ BA

QU INQUE LOBA

QU INQUE LOBA

QU INQUELOBA

QU INQUELOBA

QU INQUE LOBA

QU INQUE LOBA

QU INQUE LOBA

QUINQUE LOBA

QU INQUE LOBA

QU INQUELOBA

QU INQUELOBA

QU INQUE LOBA

QU INQUELOBA

QU INQUELOBA

QU INQUE LOBA

QU INQUELOBA

QUINQUELOBA

QU INQUELJ BA

QU INQUELLBA

QU INQUELOBA

QU INQUELOBA

QU INQUELOBA

QU INQUELOBA

QU INQUE LOBA

QU INQUE LOBA

QU INQUELOBA

QU INQUELOBA

QU INQUELOBA

QUINQUELJ BA

QU INQUELOBA

QU INQUELOBA

QUINQUELOBA

QU INQUELOBA

QU INQUE LOBA

QUINQUELOBA

QU INQUELO BA

QU INQUELOBA

QU INQUELOBA

QU INQUE LOBA

QU INQUELPBA

QUINQUELOBA

QU INQUELOBA

QU INQ UELJ BA

QU INQUELOBA

QU INQUE LOBA

QU INQUE LOBA

QU INQUELOBA

QU INQUELJ BA

QUINQUELOBA

QU INQUELOBA

QU INQUELOBA

QUINQUELJ BA

QU INQUE LO BA

QU INQUELOBA

QU INQUELOBA

QU INQUELOBA

QU INQUELJBA

QU INQ UE LO BA

QU INQUELJBA

QU INQUELOBA

QU INQUELOBA

QUINQUELOBA

QU INQUELOBA

QU INQ UE LOBA

QU INQUELOBA

QUINQUELOBA

QUINQUELOBA

QUINQ UELOBA

QU INQUELOBA

QUINQUELOBA

QU INQUELOBA

QU INQUELOBA

QU INQUE L BAA

QU INOUELOBA

QU INQUE LOBA

SU BCAR INATA

SUESPHAER I CA

SUBSPHAER ICA

SUESPHAER I CA

SUESPHAER I CA

SUESPHAER ICA

SUESPHAER ICA

SUESPHAER ICA

SUBSPHAER ICA

SUESPHAER I CA

SUESPHAER ICA

SUESPHAER I CA

SUEPHAER ICA

SUESPHAER ICA

SUBSPHAER ICA

SUESPHAER ICA

Locality

NW GULF OF MEXICO

NW GULF OF MEXICO

NH GULF OF MEXICO

NW GULF OF MEXICO

NH GULF OF MEXICO

$N$ GULF OF MEXICO

NW GULF OF MEXICO 


\section{Publication}

22436 PFLUM FRERICHS 1976 22437 PFLUM FRERICHS 1976 22438 PFLUM FRERICHS 1976 22439 PFLUM FREPICHS 1976 22440 PFLUM FRERICHS 1976 22441 PFLUM FRERICHS 1976 22442 PFLUM FRERICHS 1976 22443 PFLUM FRERICHS 1976 22444 PFLUM FRERICHS 1976 22445 PFLUM FRERICHS 1976 22446 PFLUM FRERICHS 1976 22447 PFLUM FRERICHS 1976 22447
22448 PFLUUM FRERICHS 1976 22449 PFLUM FRERICHS 1976 22449
22450 PFLUM FRERICHS 1976 22451 PFLUM FRERICHS 1976 22452 PFLUM FRERICHS 1976 22453 PFLUM FRERICHS 1976 22454 PFLUM FRERICHS 1976 22455 PFLUM FRERICHS 1976 22456 PFLUM FRERICHS 1976 22457 LEROY HODGKINSON 1975 22458 PFLUM FRERICHS 1976 22459 PFLUM FRERICHS 1976 22461 PFLUM FRERICHS 1976 22462 PFLUM FRERICHS 1976 22463 PFLUM FRERICHS 1976 22463 PFLUM FRERICHS 1976 22465 PFLUM FRERICHS 1976 22466 PFLUM FRERICHS 1976 22467 PFLUM FRERICHS 1976 22468 PFLUM FRERICHS 1976 22469 PFLUM FRERICHS 1976 22470 PFLUM FRERICHS 1976 22471 PFLUM FRERICHS 1976 22472 PFLUM FRERICHS 1976 22473 PFLUM FRERICHS 1976 22474 PFLUM FRERICHS 1976 22475 PFLUM FRERICHS 1976 22476 PFLUM FRERICHS 1976 22477 PFLUM FRERICHS 1976 22478 PFLUM FRERICHS 1976 22479 PFLUM FRERICHS 1976 22480 PFLUM FRERICHS 1976 22481 PFLUM FRERICHS 1976 22482 PFLUM FRERICHS 1976 22483 PFLUM FRERICHS 1976 22484 PFLUM FRERICHS 1976 22484
22485
PFLUUM FRERICHS 1976 22486 PFLUM FRERICHS 1976 22487 PFLUM FRERICHS 1976 22488 PFLUM FRERICHS 1976 22489 PFLUM FRERICHS 1976 22490 PFLUM FRERICHS 1976 22491 PFLUM FRERICHS 1976 22492 PFLUH FRERICHS 1976 22493 PFLUM FRERICHS 1976 22494 PFLUM FRERICHS 1976 22495 PFLUM FRERICHS 1976 22496 PFLUM FRERICHS 1976 22497 PFLUM FRERICHS 1976 22498 PFLUM FRERICHS 1976 22499 PFLUM FRERICHS 1976 22500 PFLUM FRERICHS 1976 22501 PFLUM FRERICHS 1976 22502 PFLUM FRERICHS 1976 22503 PFLUM FRERICHS 1976 22504 VAUGHAN 1918 22505 VAUGHAN 1918 22506 DAVIS 1964 22507 ANDERSEN 1961 22508 NORTON 1930 22509 ANDERSEN 1961 22510 BANDY 1954 22511 BANDY 1954 22512 BANDY 1954 22513 DAVIS 1964 22514 BANDY 1954 22515 BANDY 1954 22516 BANDY 1954 22517 BANDY 1954 22518 LEROY HODGKINSON 1975 22519 KELLOUGH 1956 22520 BANDY 1956 22521 BANDY 1956 22522 BANDY 1956 22523 BOCK 1976 22524 BANDY 1956 22525 BANDY 1954 22526 BANDY 1954 22527 BANDY 1954 22528 BANDY 1956 22529 LANKFORD 195 22530 NORTON 1930
Generic Name

PULLENIA PULLENIA

PULLENIA

PULLENIA

PULLENI A

PULLENIA

PULLENIA

PULLENIA

PULLENIA

PULLNIA

PULLENIA

PULLENI A

PULLENIA

PULLENIA

PULLENIA

PULLENIA

PULLENIA

PULLENIA

PULLENIA

PULLENIA

PULLENIA

PULLENIA

PULLENIA

PULLENIA

PULLENIA

PULLENIA

PULLENIA

PULLENIA

PULLENIA

PULLENIA

PULLENIA

PULLENIA

PULLENIA

PULLENIA

PULLENIA

PULLENIA

PULLENIA

PULLENIA

PULLENIA

PULLENIA

PULLENIA

PULLENIA

ULLENIA

PULLENI

PULLENI A

PULLENIA

PULLENIA

PULLENIA

PULLENIA

PULLENIA

PULLENIA

PULLENIA

PULLENIA

PULLENIA

PULLENIA

PULLENIA

PULLENIA

PULLENIA

PULLENIA

PULLENIA

PULLENIA

PULLENIA

PULLENIA

PULVINULINA

PULVINULINA

PULVINULINA

PUTEOL INA

PYRGO

PYRGO

PYRGO

PYRGO

PYRGO

PYRGO

PYRGO

PYPGO

PYRGO

PYRGO

PYRGO

PYRGO

PYRGO

PYRGO

PYRGO

PYRGO

PYRGO

PYRGO

PYRGO

PYRGO

PYRGO

\section{Specific Name}

SUESPHAER ICA

SUESPHAER ICA

SUESPHAER ICA

SUESPHAER ICA

SUESPHAER I CA

SUESPHAER ICA

SUESPHAER ICA

SUESPHAER I CA

SUESPHAER ICA

SUESPHAER ICA

SUESPHAER ICA

SUESPHAER I CA

SUESPHAER ICA

SUESPHAEP ICA

SUESPHAER ICA

SUESPHAER ICA

SUESPHAER ICA

SUESPHAER ICA

SUESPHAER ICA

SUESPHAER ICA

SUESPHAER ICA

SU ESPHAER ICA

SUESPHAER ICA

SUESPHAER ICA

SUESPHAER ICA

SUESPHAER ICA

SUESPHAER ICA

SUESPHAER ICA

SUESPHAER ICA

TR INI TA TENS IS

TR IN I TA TE NS IS

TR INITATENS IS

TR INITATENS IS

TR INITATENS IS

TR INITATENS IS

TR IN I TA TENS IS

TR INI TA TENS IS

TR INITATENS IS

TR IN I TATENS IS

TR IN I TATENS IS

TR INITATENS IS

TR INITATENS I

TR IN I TATENS IS

TR IN I TATE NS IS

TR INITATENS I

TR INITATENS IS

TR INI TATENS IS

TR INITATENS IS

TR IN I TATENS I

TR INITATENS IS

TR INITATENS IS

TR INITATENS IS

TR INI TA TENS IS

TR INITATENS IS

TR INITATENS IS

TR IN I TATENS IS

TR INITA TENS IS

TR IN I TA TENS IS

TR IN I TA TENS IS

TR IN I TATENS IS

TR INITATENS IS

TR INITATENS IS

TR IN I TATENS I S

TR INI TATENS IS

TR INITATENSIS

TR IN ITATENS IS

AURI CULA

ELEGANS

IN CERATA

PROTEA

ANCMALA

CLYPEATA

CL YPEATA

CL YPEATA

CLYPEATA

CL YPEATA

CONATA

CONATA

CONATA

CONATA

CONATA

CONATA

CONATA

CONATA

CONATA

CONATA

CONATA

CONATA

CONATA

CONATA

COMATUS

DENTICULATA

\section{Locality}

NW GULF OF MEXICO

$\mathrm{NW}$ GULF OF MEXICO

$N W$ GULF OF MEXICO

NW GULF OF MEXICO

NW GULF OF MEXICO

NW GULF OF MEXICO

CENTRAL GULF OF MEXICO

CENTRAL GULF OF MEXICO

CENTRAL GULF OF MEXICO 


\section{Publication}

22531 SOCK 1976

22532 CUSHIAAN 1929

22533 PFLUM FRERICHS 1976

22534 CREAGER 1958

22535 PFLUMM FRERICHS 1976 22536 PFLUM FRERICHS 1976 22537 PFLUM FRERICHS 1976 22538 PFLUM FRERICHS 1976 22539 PFLUM FRERICHS 1976 22540 CUSHMAN 1929

22541 PFLUM FRERICHS 1976 22542 PFLUM FRERICHS 1976 22543 PFLUM FRERICHS 1976 22544 PFLUM FRERICHS 1976 22545 PFLUM FRERICHS 1976 22546 PFLUM FRERICHS 1976 22547 BOCK 1976

22548 LEROY HODGKINSON 1975 22549 PFLUM FRERICHS 1976 22550 PFLUM FRERICHS 1976 22551 PFLUM FRERICHS 1976 22552 PFLUM FRERICHS 1976 22553 PFLUM FRERICHS 1976 22554 PFLUM FRERICHS 1976 22555 PFLUM FRERICHS 1976 22556 PFLUM FRERICHS 1976 22557 PFLUM FRERICHS 1976 22558 LEROY HODGKINSON 1975 22559 BOCK 1976

22560 PFLUM FRERICHS 1976 22561 PFLUM FRERICHS 1976 22562 PFLUM FRERICHS 1976 22563 PFLUM FRERICHS 1976 22564 PFLUM FRERICHS 1976 22565 PFLUM FRERICHS 1976 22566 BOCK 1976

22567 PFLUM FRERICHS 1976 22568 PFLUM FRERICHS 1976 22569 PFLUM FRERICHS 1976 22570 PFLUM FRERICHS 1976 22571 PFLUM FRERICHS 1976 22572 PFLUM FRERICHS 1976 22573 PFLUM FRERICHS 1976 22574 PFLUM FRERICHS 1976 22575 PFLUM FRERICHS 1976 22576 PFLUM FRERICHS 1976 22577 PFLUM FRERICHS 1976 22578 PFLUM FRERICHS 1976 22579 PFLUM FRERICHS 1976 22580 PFLUM FRERICHS 1976 22581 PFLUM FRERICHS 1976 22582 NORTON 1930

22583 LEROY HODGKINSON 1975 22584 PFLUM FRERICHS 1976 22585 PFLUM FRERICHS 1976 22586 NORTON 1930 22587 CREAGER 1958
22588 PFLUM FRERICHS 1976 22589 PARKER 1954
22590 PFLUM FRERICHS 1976 22591 PFLUM FRERICHS 1976 22592 PFLUM FRERICHS 1976 22593 PFLUM FRERICHS 1976 22594 PFLUM FRERICHS 1976 22595 PFLUM FRERICHS 1976 22596 PFLUM FRERICHS 1976 22597 PFLUM FRERICHS 1976 22598 PFLUM FRERICHS 1976 22600 PFLUM FRERICHS 1976 22601 PFLUM FRERICHS 1976

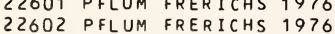
22602
22603 PFLUM FRERICHS
22976 22604 PFLUM FRERICHS 1976 22605 PFLUM FRERICHS 1976 22606 PFLUM FRERICHS 1976 22607 PFLUM FRERICHS 1976 22608 PFLUM FRERICHS 1976 22609 PARKER 1954 22610 PARKER 1954 22611 PARKER 1954 22612 PARKER 1954 22613 PARKER 1954 22614 PARKER 1954 22615 PARKER 1954 22616 PARKER 1954

22617 PFLUM FRERICHS 1976 22618 PFLUM FRERICHS 1976 22619 PFLUM FRERICHS 1976 22620 PFLUM FRERICHS 1976 22621 PFLUM FRERICHS 1976 22622 PFLUM FRERICHS 1976 22623 PFLUM FRERICHS 1976 22624 PFLUM FRERICHS 1976
22625 PFLUM FRERICHS 1976
Generic Name

PYRGO

PYRGO

PYRGO

PYRGO

PYRGO

PYRGO

PYRGO

PYRGO

PYRGO

PYRGO

PYRGO

PYRGO

PYRGO

PYRGO

PYRGO

PYRGO

PYRGO

PYRGO

PYRGO

PYRGO

PYRGO

PYRGO

PYRGO

PYRGO

PYRGO

PYRGO

PYRGO

PYRGO

PYRGO

PYRGO

PYRGO

PYRGO

PYRGO

PYRGO

PYRGO

PYRGO

PYRGO

PYRGO

PYRGO

PYRGO

PYRGO

PYRGO

PYRGO

PYRGO

PYRGO

PYRGO

PYRGO

PYRGO

PYRGO

PYRGO

PYRGO

PYRGO

PYRGO

PYRGO

PYRGO

PYRGO

PYRGO

PYRGO

PYRGO

PYRGO
PYRGO

PYRGO

PYRGO

PYRGO

PYRGO

PYRGO

PYRGO

PYRGO

PYRGO

PYRGO

PYRGO

PYRGO

PYRGO

PYRGO

PYRGO

PYRGO

PYRGO

PYRGO

PYRGO

PYRGO

PYRGO

PYRGO

PYRGO

PYRGO

PYRGO

PYRGO

PYRGO

PYRGO

PYRGO
Specific Name

DEATI CULATA

DEPRESSA

DEFRESSA

DEPRESSA

DEPRESSA

DEPRESSA

DEFRESSA

DEPRESSA

DEPRESSA

DEPRESSA

DEFRES

DEFRESSA

DEPRESSA

DEFRESSA

DE PRESSA

DEPRESSA

DEPRESS

DEFRESSA

DE FRESSA

EL CNGATA

EL CNGATA

EL CNGATA

ELONGATA

EL ONGATA

EL ONGATA

EL CNGATA

ELCNGATA

EL CNGATA

EL ONGATA

EL ONGATA

ELCNGATA

ELONGATA

FO RNASINI I

LUCERNULA

LU CERNULA

LU CERNULA

LUCERNULA

LU CERNULA

LUCERNULA

LUCERNULA

LUCERNULA

LUCERNULA

LU CERNULA

LU CERNULA

LUCERNULA

LUCERNULA

LU CERNULA

LUCERNULA

LUCERNULA

LU CERNULA

LUCERNULA

LUCERNULA

MI LLETT I

MURRH INA

MURRH IN A

MURRHINA

MURRH INA

MURRHINA

MU RRH INA

MURRHINA

MU RRH INA

MURRHINA

MURRH INA

MU RRHINA

MURRHINA

MURRHINA

MURRHINA

MU RRH INA

MURRH INA

MURRH INA

MURRHINA

MURRHINA

MURRH INA

MU RRH INA

MURRHINA

MU RRH INA

MURRHINA

MURRH INA

MURRH INA

MURRHINA

MURRHINA

MURRHINA

MURRHINA

MURRH INA

MURRH INA

MURRH INA

MURRH INA

MURRHINA

MURRHINA

MURRHINA

Locality

NE GULF OF MEXICO

NE GULF OF MEXICO

CENTRAL GULF OF MEXICO

BAY OF CAMPECHE

NW GULF OF MEXICO

NW GULF OF MEXICO

$N$ W GULF OF MEXICO

NW GULF OF MEXICO

NW GULF OF MEXICO

NE GULF OF MEXICO

CENTRAL GULF OF MEXICO 
Publication

22626 PFLUM FRERICHS 1976 22627 PFLUM FRERICHS 1976 22628 PFLUM FRERICHS 1976 22629 PFLUM FRERICHS 1976 22630 PFLUM FRERICHS 1976

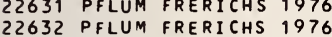
22632 PFLUM FRERICHS 1976
22633 PFLUM FRERICHS 1976 22634 PFLUM FRERICHS 1976 22635 PFLUM FRERICHS 1976 22636 PFLUM FRERICHS 1976 22637 PFLUM FRERICHS 1976 22638 PFLUM FRERICHS 1976 22639 PFLUM FRERICHS 1976 22640 PFLUM FRERICHS 1976 22641 PFLUM FRERICHS 1976 22642 PFLUM FRERICHS 1976 22643 PFLUM FRERICHS 1976 22644 CREAGER 1958

22645 CUSHMAN 1929

22646 CUSHMAN 1929

22647 CUSHMAN 1929

22648 PFLUM FRERICHS 1976

22649 PHLEGER 1951 A

22650 PHLEGER $1955 \mathrm{~A}$

22651 PHLEGER 1951A

22652 PHLEGER 1951A

22653 PHLEGER 1951A

22654 PHLEGER $1951 \mathrm{~A}$

22655 PHLEGER 1951A

22656 PFLUM FRERICHS 1976

22657 PFLUM FRERICHS 1976

22658 PHLEGER 1951A

22659 PHLEGER 1951A

22660 PHLEGER $1951 \mathrm{~A}$

22661 PHLEGER 1951A

22662 PHLEGER 1951A

22663 PHLEGER 1951A

22664 PFLUM FRERICHS 1976

22665 PHLEGER 1951A

22666 PHLEGER 1951A

22667 PHLEGER 1951 A

22668 PFLUM FRERICHS 1976

22669 PFLUM FRERICHS 1976

22670 PFLUM FRERICHS 1976

22671 PFLUM FRERICHS 1976

22672 PFLUM FRERICHS 1976

22673 PFLUM FRERICHS 1976

22674 LEROY HODGKINSON 1975

22675 PHLEGER 1951 A

22676 PHLEGER $1951 \mathrm{~A}$

22677 PARKER 1954

22678 PFLUM FRERICHS 1976

22679 PFLUM FRERICHS 1976

22680 PFLUM FRERICHS 1976

22681 LUDWICK WALTON 1957

22682 PARKER 1954

22683 PARKER 1954

22684 PARKER 1954

22685 PARKER 1954

22687 PARKER 1954

22688 PARKER 1954

22689 PARKER 1954

22690 PARKER 1954

22691 PARKER 1954

22692 PARKER 1954

22693 BANDY 1956

22694 BANDY 1956

22695 BANDY 1956

22696 ANDERSEN 1961

22697 BANDY 1956

22698 BANDY 1956

22699 KELLOUGH 1956

22700 CREAGER 1958

22701 KELLOUGH 1956

22702 KELLOUGH 1956

22703 KELLOUGH 1956

22704 PHLEGER $1951 \mathrm{~A}$

22705 CREAGER 1958

22706 BOCK 1976

22707 PARKER 1954

22708 PARKER 1954

22709 CREAGER 1958

22710 CREAGER 1958

22711 PARKER 1954

22712 PARKER 1954

22713 PARKER 1954

22714 PARKER 1954

22715 PARKER 1954

22716 PARKER 1954

22717 LUDHICK WALTON 1957

22718 PARKER 1954

22719 PARKER 1954
22720 PARKER 1954
Generic Name Specific Name Locality

PYRGO MURRHINA NW GULF OF MEXICO

PYRGO MURRHINA CENTRAL GULF OF MEXICO

PYRGO MURRHINA

PYRGO MURRHINA

PYRGO MURRHINA

MURRH INA

MURRHINA

MURRHINA

MURRH INA

MURRHINA

MURRHINA

MURRHINA

MURRHINA

MURRHINA

MURRH INA

MURRHINA

MURRHINA

MURRH INA

MURRHINA

MURRHINA

MURRH INA

MURRH IN A

MURRHINA

MURRHINA

MURRHINA

MURRHINA

MURRHINA

MURRH INA

MURRH INA

MURRH INA

MURRH INA

MURRHINA

MURRH INA

MURRHINA

MURRHINA

MURRHINA

MURRH INA

MURRH INA

MURRH INA

MURRHINA

MURRH INA

MURRHINA

MURRHINA

MURRH INA

MURRHINA

MURRH INA

MURRH INA

MURRH INA

MURRHINA

MURRHINA

MURRHINA

MURRHINA

MURRHINA

MURRHINA

MURRH INA

MURRH INA

MURRH INA

MURRHINA

MURRH INA

MURRHINA

MURRH INA

MURRHINA

MURRHINA

MURRH IN

NA SUTA

NASUTA

NASUTA

NASUTA

NASUTA

NASUTA

NASUTUS

NASUTUS

NA SUTUS

NA SUTUS

NASUTUS

NASUTUS

NASUTUS

NASUTUS

NA SUTUS

NASUTUS

NASUTUS

NASUTUS

NA SUTUS

NASUTUS

NA SUTUS

NASUTUS

NA SUTUS

NA SUTUS

NASUTUS

NASUTUS

NASUTUS
CENTRAL GULF OF MEXICO

CENTRAL GULF OF MEXICO

CENTRAL GULF OF MEXICO

CENTRAL GULF OF MEXICO

CENTRAL GULF OF MEXICO

CENTRAL GULF OF MEXICO

CENTRAL GULF OF MEXICO

CENTRAL GULF OF MEXICO

CENTRAL GULF OF MEXICO

CENTRAL GULF OF MEXICO

CENTRAL GULF OF MEXICO

CENTRAL GULF OF MEXICO

CENTRAL GULF OF MEXICO

CENTRAL GULF OF MEXICO

CENTRAL GULF OF MEXICO

$N W$ GULF OF MEXICO

BAY OF CAMPECHE

NE GULF OF MEXICO

NE GULF OF MEXICO

NE GULF OF MEXICO

CENTRAL GULF OF MEXICO

$N$ GULF OF MEXICO

$N$ G GULF OF MEXICO

NW GULF OF MEXICO

NH GULF OF MEXICO

NW GULF OF MEXICO

$N$ WULF OF MEXICO

NW GULF OF MEXICO

NH GULF OF MEXICO

NH GULF OF MEXICO

$N$ W GULF OF MEXICO

$N$ WULF OF MEXICO

$N W$ GULF OF MEXICO

NW GULF OF MEXICO

NW GULF OF MEXICO

CENTRAL GULF OF MEXICO

NW GULF OF MEXICO

$N$ G GULF OF MEXICO

NH GULF OF MEXICO

$N$ GULF OF MEXICO

NW GULF OF MEXICO

NW GULF OF MEXICO

$N$ GULF OF MEXICO

$N$ GULF OF MEXICO

$N$ WULF OF MEXICO

$N$ GULF OF MEXICO

NW GULF OF MEXICO

NW GULF OF MEXICO

NE GULF OF MEXICO

NH GULF OF MEXICO

NW GULF OF MEXICO

NW GULF OF MEXICO

NE GULF OF MEXICO

NE GULF OF MEXICO

NE GULF OF MEXICO

NE GULF OF MEXICO

NE GULF OF MEXICO

NE GULF OF MEXICO

NE GULF OF MEXICO

NE GULF OF MEXICO

NE GULF OF MEXICO

NE GULF OF MEXICO

NE GULF OF MEXICO

NE GULF OF MEXICO

NE GULF OF MEXICO

NE GULF OF MEXICO

NE GULF OF MEXICO

MISSISSIPPI DELTA

NE GULF OF MEXICO

NE GULF OF MEXICO

NW GULF OF MEXICO

BAY OF CAMPECHE

$N W$ GULF OF MEXICO

NU GULF OF MEXICO

NW GULF OF MEXICO

$N W$ GULF OF MEXICO

BAY OF CAMPECHE

NE GULF OF MEXICO

NE GULF OF MEXICO

NE GULI

BAY OF CAMPECHE

BAY OF CAMPECHE

NE GULF OF MEXICO

NE GULF OF MEXICO

NE GULF OF MEXICO

NE GULF OF MEXICO

NE GULF OF MEXICO

NE GULF OF MEXICO

NE GULF OF MEXICO

NE GULF OF MEXICO

NE GULF OF MEXICO

NE GULF OF MEXICO
$N W$ GULF OF MEXICO

Lat. Long.

$2734 \mathrm{~N} 09213 \mathrm{~W}$ $27 \quad 48 \mathrm{~N} 088 \quad 44 \mathrm{~W}$ $2742 \mathrm{~N} 088 \quad 41 \mathrm{~W}$ $2755 \mathrm{~N} 088 \quad 50 \mathrm{~W}$ $27 \quad 42 \mathrm{~N} 088 \quad 39 \mathrm{~W}$ $2810 N 08857 W$ $2803 N 088 \quad 52 W$ $2755 \mathrm{~N} 088 \quad 50 \mathrm{H}$ $2812 \mathrm{~N} 088 \quad 58 \mathrm{~W}$ $2816 N 08901 \mathrm{~W}$ 


\section{Publication}

22721 PARKER 1954 22722 PARKER 1954 22724 PARKER 1954 22725 LANKFORD 1959 22726 PHLEGER 1951 A 22727 PHLEGER $1951 \mathrm{~A}$ 22728 PHLEGER $1951 \mathrm{~A}$ 22729 PHLEGER $1951 \mathrm{~A}$ 22730 PHLEGER 1951A 22731 PHLEGER 1951 A 22732 PHLEGER 1951 A 22733 PHLEGER 1951 A 22734 PHLEGER 1951A 22735 PHLEGER 1951A 22736 PHLEGER 1951 A 22737 PHLEGER 1951 A 22738 PHLEGER 1951A 22739 PHLEGER $1951 \mathrm{~A}$ 22740 PHLEGER 1951A 22741 PHLEGER 1951A 22742 PHLEGER $1951 \mathrm{~A}$ 22743 PHLEGER $1951 \mathrm{~A}$ 22744 PHLEGER 1951A 22745 PHLEGER 1951A 22746 CREAGER 1958 22747 CREAGER 1958 $2274 \%$ PHLEGER 1956 22749 PARKER 1954 22750 PARKER 1954 22751 PARKER 1954 22753 BANDY 1956 22754 BANDY 1956 22755 BANDY 1956 22756 BANDY 1956 22757 BANDY 1956 22758 BANDY 1956 22759 BANDY 1956 22760 BANDY 1956 22761 BANOY 1956 22762 BANDY 1956 22763 ANDERSEN 1961

22764 PFLUM FRERICHS 1976 22765 PFLUM FRERICHS 1976 22766 PFLUM FRERICHS 1976 22767 PFLUM FRERICHS 1976 22768 PFLUM FRERICHS 1976 22769 PFLUM FRERICHS 1976 22770 PFLUM FRERICHS 1976 22771 PFLUM FRERICHS 1976 22772 PFLUM FRERICHS 1976 22773 PFLUM FRERICHS 1976 22774 PFLUM FRERICHS 1976 22775 PFLUM FRERICHS 1976 22776 PFLUM FRERICHS 1976 22777 PFLUM FRERICHS 1976 22778 PFLUM FRERICHS 1976 22779 PFLUM FRERICHS 1976 22780 PFLUM FRERICHS 1976 22781 DFLUM FRERICHS 1976 22782 PFLUM FRERICHS 1976 22783 PFLUM FRERICHS 1976 22784 CUSHMAN 1929

22785 CUSHMAN 1929 22786 PFLUM FRERICHS 1976
22787 PFLUM FRERICHS 1976 22788 PFLUM FRERICHS 1976 22789 CREAGER 1958

22790 SHIFFLETT 196

22791 NORTON 1930

22792 BENDA PURI 1962

22793 BOCK 1976

22794 PFLUM FRERICHS 1976 22795 CREAGER 1958

22796 CREAGER 1958

22798 PFLUM FRERICHS 1976

22799 PFLUM FRERICHS 1976

22800 ANDERSEN 1961

22801 PFLUM FRERICHS 1976

22802 PFLUM FRERICHS 1976 22803 PFLUM FRERICHS 1976 22804 PFLUM FRERICHS 1976 22805 PFLUM FRERICHS 1976 22806 PFLUM FRERICHS 1976 22807 PFLUM FRERICHS 1976 22808 PFLUM FRERICHS 1976 22809 PFLUM FRERICHS 1976 22810 LEROY HOOGKINSON 1975 22811 PFLUM FRERICHS 1976 22812 NORT ON 1930

22813 NORTON 1930

22814 BANDY 1956

22815 BANOY 1956

\section{Generic Name}

PYRGO

PYRGO

PYRGO

PYRGO

PYRGO

PYRGO

PYRGO

PYRGO

PYRGO

PYRGO

PYRGO

PYRGO

PYRGO

PYRGO

PYRGO

PYRGO

PYRGO

PYRGO

PYRGO

PYRGO

PYRGO

PYRGO

PYRGO

PYRGO

PYRGO

PYRGO

PYRGO

PYRGO

PYRGO

PYRGO

PYRGO

PYRGO

PYRGO

PYRGO

PYRGO

PYRGO

PYRGO

PYRGO

PYRGO

PYRGO

PYRGO

PYRGO

PYRGO

PYRGO

PYRGO

PYRGO

PYRGO

PYRGO

PYRGO

PYRGO

PYRGO

PYRGO

PYRGO

PYRGO

PYRGO

PYRGO

PYRGO

PYRGO

PYRGO

PYRGO

PYRGO

PYRGO

PYRGO

PYRGO

PYRGO

PYRGO

PYRGO

PYRGO

PYRGO

PYRGO

PYRGO

PYRGO

PYRGOELLA

PYRGOELLA

PYRGOELLA

PYRGOELLA

PYRGOELLA

PYRGOELLA

PYRGOELLA

PYRGOELLA

PYRGOELLA

PYRGOELLA

PYRG OELLA

PYRGOELLA

PYRGOELLA

PYRGOELLA

PYRULINELLA

PYRULINELLA

QUINQUELOCUL INA
Specific Name

NASUTUS

NA SUTUS

NA SUTUS

NA SUTUS

NA SUTUS

NA SUTUS

NA SUTUS

NA SUTUS

NASUTUS

NASUTUS

NASUTUS

NASUTUS

NA SUTUS

NA SUTUS

NASUTUS

NA SUTUS

NASUTUS

NASUTUS

NASUTUS

NASUTUS

NASUTUS

NA SUTUS

NASUTUS

NASUTUS

NASUTUS

NA SUTUS

NA SUTUS

NA SUTUS

OBLONGA

PE RUVIANA

PERUVIANA

PERUVIANA

PERUVIANA

PERUVIANA

PERUVIANA

PE RUVI ANA

PERUVIANA

PERUVIANA

PERUV I ANA

PHLEGER I

SARSII

SARS I I

SARSII

SARSII

SARS I I

SARSII

SARSII

SARSII

SARSII

SARSII

SARSII

SERRATA

SERRATA

SERRATA

SERRATA

SERRATA

SERRATA

SERRATA

SERRATA

SERRATA

SERRATA

SERRATA

SERRATA

SERRATA

SERRATA

SERRATA

SUESPHAER ICA

SUESPHAER ICA

SUESPHAER ICA

SUESPHAER ICA

SUESPHAER ICA

TUEULOSA

TUEULOSA

VE SPER T IL I 0

SPHAERA

SP HAERA

SP HAERA

SPHAERA

SPHAERA

SPHAERA

SP HAERA

SP HAERA

SP HAERA

SPHAERA

SP HAERA

SPHAERA

SPHAERA

SPHAERA

LACTEA

AGGLUTINANS

A G GLUTINANS

Locality

NE GULF OF MEXICO

NE GULF OF MEXICO

NE GULF OF MEXICO

NE GULF OF MEXICO

MISSISSIPPI DELTA

NW GULF OF MEXICO

NW GULF OF MEXICO

NW GULF OF MEXICO

NW GULF OF MEXICO

$\mathrm{NW}$ GULF OF MEXICO

$N W$ GULF OF MEXICO

NW GULF OF MEXICO

NW GULF OF MEXICO 


\section{Publication}

22816 BANDY 1956

22817 BANDY 1956

22818 NORTON 1930

22819 LIDZ LIDZ 1966

22820 VAUGHAN 1918

22821 VAUGHAN 1918

22823 CUSHMAN 1922 A

22824 DAVIS 1964

22825 BANDY 1956

22826 BANDY 1956

22827 BANDY 1956

22828 BENDA PURI 1962

22829 BANDY 1956

22830 BANDY 1956

22831 BANDY 1956

22832 BANDY 1956

22833 BANDY 1956

22834 BANDY 1956

22835 LIDZ LIDZ 1966

22836 BANDY 1956

22837 BANDY 1956

22838 BANDY 1956

22839 BANDY 1956

22840 BANDY 1956

22841 CUSHMAN 1922A

22842 NORTON 1930

22844 KORNFELD 1931

22844 KORNFELD 1931

22846 KORNFELD 1931

22847 KORNFELD 1931

22848 NORTON 1930

22849 KORNFELD 1931

22850 BOCK 1976

22851 BOCK 1976

22852 PARKER 1954

22853 BANOY 1956

22854 LEHMANN 1957

22855 BANDY 1956

22856 BANDY 1956

22857 BANDY 1956

22858 PHLEGER 1951A

22859 PHLEGER 1951A

22860 PHLEGER 1951A

22861 PHLEGER 1951A

22862 PHLEGER 1951A

22863 PHLEGER 1951

22865 PARKER 1954

22866 PARKER 1954

22867 ANDERSEN 1961

22868 PARKER 1954

22869 PARKER 1954

22870 PARKER 1954

22871 PARKER 1954

22872 PHLEGER 1951A

22873 PARKER 1954

22874 BANDY 1956

22875 BANDY 1956

22876 BANDY 1956

22877 BANDY 1956

22878 BANDY 1956

22879 BANDY 1956

22880 BANDY 1956

22881 DAVIS 1964

22882 BANDY 1956

22883 BANDY 1956

22884 BANDY 1956

22885. BANDY 1956

22886 LOEP 1965

22887 BENDA PURI 1962

22888 KELLOUGH 1956

22889 KELLOUGH 1956

22890 KELLOUGH 1956

22891 KELLOUGH 1956

22892 KELLOUGH 1956

22893 AYALA-CASTANARES 1963

22894 BANDY 1956

22895 BANDY 1956

22896 BANDY 1956

22897 POST 1951

22898 CUSHMAN 1922 A

22899 NORTON 1930

22900 NORTON 1930

22901 BANDY 1956

22902 BANDY 1956

22903 BANDY 1956

22904 BENDA PURI 1962

22905 BANDY 1956

22906 BENDA PURI 1962

22907 BANDY 1956

22908 BANDY 1956

22909 BANDY 1956

22910 BANDY 1956
Generic Name

QUINQUEL OCULINA QUINQUELOCUL INA QUINQUELOCUL INA QUINQUELOCULINA QUINQUELOCULINA QUINQUELOCULINA QUINQUE LOCUL INA QUINQUELOCULINA QUINQUE LOCULINA QUINQUELOCUIINA QUINQUE LOCULINA QUINQUEL OCULINA QUINQUEL OCULINA QUINQUELOCULINA QUINQUE LOCULINA QUINQUEL OCULINA QUINQUEL OCUL INA QUINQUE LOCULINA QUINQUEL OCULINA QUINQUEL OCULINA QUINQUEL LCULINA QUINQUEL OCUL INA QUINQUE LOCUL INA QUINQUELOCULINA QUINQUELOCUL INA QUINQUE LOC ULINA QU INQUEL LOCULINA QUINQUELOCULINA QUINQUEL LCUL INA QUINQUEL OCULINA QUINQUEL OCULINA QUINQUEL LCULINA QUINQUEL OCULINA QUINQUEL OCULINA QUINQUEL LCULINA QUINQUEL OCULINA QUINQUELOCULINA QUINQUELOCULINA QUINQUELOCULINA QUINQUELOCULINA QUINQUEL OCULINA QU INQUELOCULINA QUINQUELOCULINA QU INQUE LOCULINA QUINQUEL OCUL INA QU INQUEL LCULINA QU INQUEL LCULINA QUINQUELOCULINA QU INQUEL LCULINA QUINQUEL OCULINA QUINQUEL OCULINA QUINQUEL OCULINA QUINQUEL OCULINA QUINQUE LOCULINA QU INQUE LOCULINA QUINQUEL OCULINA QU INQUE LOCULINA QUINQUEL OCULINA QUINQUEL OCULINA QUINQUEL OCULINA QUINQUE LOC UL INA QUINQUELOCULINA QUINQUE LOCULINA QUINQUELOCUL INA QUINQUELOCULINA QUINQUE LOCULINA QUINQUELOCULINA QUINQUELOCUL INA QUINQUEL OCUL INA QUINQUELOCULINA QUINQUE LOCUL INA QUINQUELOCUL INA QUINQUE LOCULINA QUINQUELOCULINA QUINQUELOCULINA QUINQUEL OCUL INA QUINQUEL OCULINA QUINQUEL OCUL INA QUINQUEL OC ULINA QUINQUE LOCULINA QUINQUE LOCULINA QUINQUELOCUL INA QUINQUELOCUL INA QUINQUEL OCUL INA QUINQUE LOCULINA QUINQUEL OC ULINA QU INQUEL OC ULINA QUINQUEL OCULINA QUINQUELOCULINA QUINQUEL OCUL INA QUINQUEL OCULINA QUINQUELOCULINA QUINQUE L OCUL INA QUINQUEL OC UL INA QUINQUELOCULINA
Specific Name

AGGLUTINANS

AGGLUTINANS

AGGLUTINANS

AGGLUTINANS

AG GLUTI INANS

AGGLUTINANS

AG GLUTINANS

AG GLUTI INANS

AGGLUTINANS

A GGLUTI INANS

AG GLUTI NANS

AG GLUTI INANS

AG GLUTINANS

AG GLUT I NANS

AG GLUTINANS

AKNER I ANA

AKNERI ANA

AKAERIANA

AKNER I ANA

AKNERIANA

AK NER I ANA

AK AER I ANA

AKNER I ANA

AKAERIANA

AKNER I A NA

AL VEOLINI FORMIS

ANTILLARJM

ANT ILL A RUM M

AU EERIANA

AUEER IANA

AUBERIANA

AUBERIANA

AUEERIANA

AUEERIANA

BI CARINATA

BI COSTATA

B I costata

B I costata

BI COSTATA

BI COSTATA

BI COSTATA

BI costata

Bi costata

BI costata

Bi costata

BI costata

B I costata

BI COSTATA

o i costata

Bi costata

B I COSTATA

BI costata

BI COSTATA

B I costata

BI costata

B I costata

BI COSTATA

B I COSTATA

o I costata

BI COSTATA

BI COSTATA

B I COSTATA

BI CosTATA

B I COSTATA

BI costata

BI COSTATA

B I COSTATA

BI COSTATA

BI COSTATA

BI costata

BI costata

BI COSTATA

BI costata

B I COSTATA

BI COSTATA

B I costata

B I COSTATA

BI CENTATa

BI DENTATA

BONEANA

BOSCIANA

BOSCIANA

BO SCIANA

BOSCIANA

BOSCIANA

BOSCIANA

BOSCIANA

BOSCIANA

BO SCIANA
BOSCIANA

Locality

NE GULF OF MEXICO

NE GULF OF MEXICO

TORTUGAS, FLA

$\checkmark E R A C R U Z$ REEFS

FLORIDA KEYS

ORY TORTUGAS

IORTUGAS

CAMPECHE BANK, MEXICO

NE GULF OF MEXICO 


\section{Publication}

22911 BANDY 1956 22912 BANDY 1956 22913 BANDY 1956 22914 BANDY 1956 22915 BOCK 1975 22916 PFLUM FRERICHS 1976 22917 BANDY 1956 22918 BANDY 1956 22919 BANDY 1956 22920 BANDY 1956 22921 BANDY 1956 22922 BANDY 1956 22923 BANDY 1956 22924 BANDY 1956 22925 BANDY 1956 22926 BANDY 1956 22927 BANDY 1956 22928 BANOY 1956 22929 NORTON 1930 22930 CUSHMAN 1922 22931 NORTON 1930 22933 LEHMANN 1957 22934 POST 1951 22935 POST 1951 22936 CUSHMAN $1922 \mathrm{~A}$ 22937 BENDA PURI 1962 22938 CUSHMAN 1922 A 22939 KANE 1967 22940 PARKER 1954 22941 PARKER 1954 22942 KANE 196 ? 22943 SEGURA 1963 22944 PARKER 1954 22945 PARKER 1954

22947 SHEPARD MOORE 1955

22948 SHIFFLETT 1961 22949 PARKER 1954 22950 PARKER 1954 22951 PARKER 1954 22952 PHLEGER $1951 \mathrm{~A}$ 22953 PHLEGER 1951A 22954 PHLEGER 1951A 22955 PHLEGER 1951A 22956 PHLEGER 1951A 22957 PHLEGER 1951A 22958 PHLEGER 1951 A 22959 SHENTON 1957

22960 PARKER PHLEGER PEIRSON 1953 22961 BANDY 1956

22962 PARKER 1954

22963 PARKER 1954

22964 PARKER PHLEGER PEIRSON 1953 22965 PARKER PHLEGER PEIRSON 1953 22966 PHLEGER 1956

22967 PARKER PHLEGER PEIRSON 1953 22968 PHLEGER 1951 A 22969 PARKER 1954 22970 LANKFORD 1959 22971 PHLEGER 1956 22972 PHLEGER 1956 22973 PHLEGER 1956 22974 BOCK 1976

22975 KELLOUGH 1956 22976 KELLOUGH 1956 22977 KELLOUGH 1956 22978 KELLOUGH 1956 22979 BANDY 1954

22980 AYALA-CASTANAPES 1963

22981 LOEP 1965

22982 AYALA-CASTANARES SEGURA 1969 22983 BANDY 1954 22984 DAVIS 1964

22985 BENDA PURI 1962

22986 WALTON 1964

22987 PHLEGER $1951 \mathrm{~A}$

22983 PHLEGER 1955 B

22989 PHLEGER 1951A

22990 BANOY 1956 22991 BANDY 1954 22992 BANDY 1954 22993 BANDY 1956 22994 BANDY 1954 22995 BANDY 1954 22996 BANDY 1956 22997 BANDY 1956 22998 BANDY 1956 22999 BANDY 1956 23000 BANDY 1956 23001 BANDY 1956 23002 BANDY 1956

23003 WALTON 1960 23004 BANDY 1956
23005 OTVOS 1978
Generic Name

QU INQUELOCULINA QUINQUE LOCUL INA QUINQUELOCULINA QUINQUEL OCULINA QUINQUELOCULINA QU INQUELOCULI INA QU INQUELOCULINA QU INQUELOLULINA QU INQUE LOCULINA QUINQUELOCUL INA QU INQUEL OCULINA QU INQUE LOCULINA QUINQUELOCULINA QUINQUELOCULINA QU INQUEL OCULINA QU INQUELOCULINA QUINQUEL OCULINA QU INQUELOCULINA QU INQUELOCULINA QU INQUELOCUL INA QU INQUEL OCUL I NA QUINQUEL OCUL INA QU INQUE L OC UL I NA QU INQUE LOC UL INA QU INQUEL OCUL INA QU INQUELOCULINA QUINQUELOCULINA QU INQUELOCULINA QU INQUE LOCUL INA QUINQUEL OCULINA QU INQUELOCULINA QU INQUEL OCULINA QUINQUELOCUL INA QU INQUELOCULINA QUINQUE LOC ULINA QUINQUELOCULINA QU INQUELOCULINA QUINQUEL OCULINA QUINQUE LOC UL I NA QUINQUE LOCULINA QUINQUEL OCUL INA QU INQUE LOCUL INA QU INQUELOCULI NA QUINQUELOCULINA QUINQUELOCULINA QU INQUEL OC ULI INA QUINQUELOCULINA QU INQUE LOCULINA QU INQUELOCUL INA QU INQUEL OCULINA QU INQUEL OCULI INA QUINQUE LOC ULINA QUINQUELOCUL INA QU INQUELOCULINA QUINQUELOCULINA QU INQUEL OC UL I NA QUINQUELOCULINA QUINQUELOCUL INA QUINQUELOCUL INA QU INQUELOCULINA QUINQUELOCULINA QUINQUELOCULINA QUINQUE LOCULINA QUINQUEL OC UL INA QUINQUE L OC UL INA QU INQUEL OCULI INA QU INQUEL OC UL INA QUINQUELOCUL INA QU INQUE LOCUL INA QU INQUE LOCUL INA QUINQUEL OCULI INA QU INQUE LOCUL INA QUINQUEL OCUI. I NA QU INQUEL OCULINA QU INQUE LOCULINA QU INQUEL OC UL INA QU INQUE LOCULINA QUINQUELOCULINA QUINQUEL OCULINA QU INQUELOCULINA QUINQUELOCUL INA QUINQUEL OCULINA QU INQUEL OCUL INA QU INQUE LOC ULINA QUINQUEL OCUL INA QUINQUEL OCUL INA QU INQUEL OCULI INA QU INQUELOCULINA QU INQUE L OC UL INA QUINQUELOCULINA QUINQUELOCULINA QUINQUE LOC UL INA QU INQUEL OCULINA QU INQUELOCULINA QUINQUEL OCULI INA
Specific Name

Locality

Lat. Long.

BOSCIANA

BOSCIANA

BOSCIANA

BOSCIANA

BOSCIANA

BOSCIANA

BOSCIANA

BOSCIANA

BO SCI ANA

BO SCIANA

BOSCIANA

BO SCI ANA

BOSCIANA

BOSCIANA

BOSCIANA

BRADYANA

BRADYANA

CA ADE I ANA

CA $A D E I A N A$

C A NDE I ANA

C A N DE IANA

CA $A D E I A N A$

CA TALINENSIS

COLLUMNOSA

CONPTA

CONPTA

CONPTA

CONPTA

CONPTA

CONPTA

CONPTA

CONPTA

CONPTA

CONPTA

CONPTA

CONPTA

COMPTA

CONPTA

CONPTA

CONPTA

CONPTA

CONPTA

CONPTA

CONPTA

COMPTA

CONPTA

CONPTA

CONPTA

CONPTA

CONPTA

CONPTA

CONPTA

COMPTA

CONPTA

CONPTA

CONPTA

CONPTA

CONPTA

CONPTA

COMPTA

CONPTA

CONPTA

CONPTA

COMPTA

CONPTA.

COMPTA

CONPTA

CONPTA

CONPTA

COMPTA

CONPTA

CONPTA

CONPTA

CONPTA

CONPTA

CONPTA

CONPTA

COMPTA

CONPTA

COMPTA

CONPTA

CONPTA

NE GULF OF MEXICO

NE GULF OF MEXICO

NE GULF OF MEXICO

NE GULF OF MEXICO

NE GULF OF MEXICO

NW GULF OF MEXICO

CALOOSAHATCHEE R.. FLA.

NE GULF OF MEXICO

NE GULF OF MEXICO

NE GULF OF MEXICO 


\section{Publication}

23006 BANDY 1956 23007 BANDY 1956

23008 BANDY 1956

23009 BANDY 1956

23010 BANOY 1956

23011 BANDY 1956

23012 BANOY 1956

23013 BANOY 1956

23014 BANOY 1956

23015 BANDY 1956

23016 ANDERSEN 196

23018 KORNFELO 193

23019 LEHMANN 1957

23020 SEGURA 1963

23021 CUSHMAN $1922 \mathrm{~A}$

23022 KORNFELD 1931

23023 KORNFELD 1931

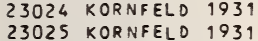

23026 KORNFELD 1931

23027 KORNFELD 1931

23028 POST 1951

23028 POST 1951

23030 NORTON 1930

23031 LANKFORD 1959

23032 KANE 1967

23033 PARKER PHLEGER PEIRSON 1953

23034 PARKER PHLEGER PEIRSON 1953

23035 PARKER PHLEGER PEIRSON 1953

23036 PARKER PHLEGER PEIRSON 1953

23037 PARKER PHLEGER PEIRSON 1953

23038 PHLEGER 1956

23039 BENDA PURI 1962

23040 PARKER PHLEGER PEIRSON 1953

23041 BOCK 1976

23042 PARKER PHLEGER PEIRSON 1953

23043 NORTON 1930

23044 WALTON 1960

23045 PHLEGER LANKFORD 1957

23046 SEGURA 1963

23047 LEHMANN 1957

23049 DAVIS 1964

23050 NORTON 1930

23051 LEHMANN 1957
23052 BENDA PURI 196

23053 BANDY 1956

23054 BANDY 1956

23055 BANDY 1956

23056 BANDY 1956

23057 BOCK 1976

23058 BANDY 1956

23059 BANDY 1956

23060 BANDY 1956

23061 DAVIS 1964

23062 PARKER PHLEGER PEIRSON 1953

23063 AYALA-CASTANARES SEGURA 1968

23064 AYALA-CASTANARES 1963

23065 NORTON 1930

23066 PARKER PHLEGER PEIRSON 1953

23067 PARKER PHLEGER PEIRSON 1953

23068 PHLEGER 1956

23069 PARKER PHLEGER PEIRSON 1953

23070 PARKER PHLEGER PEIRSON 1953

23071 PARKER PHLEGER PEIRSON 1953

23072 PARKER PHLEGER PEIRSON 1953

23073 PARKER PHLEGER PEIRSON 1953

23074 CUSHMAN 1922 A

23075 PHLEGER LANKFORD 1957

23076. LANKFORD 1959

23077 LEHMANN 1957

23078 KANE 1967

23079 KANE 1962

23080 PHLEGER 1960

23081 SEGURA 1963

23083 PHLEGER 1955

23084 ANDERSEN 1961

23085 NORTON 1930

23086 BOCK 1976

23087 BOCK 1976

23088 PARXER 1954

23089 PARKER 1954

23090 LOEP 1965

23091 BANDY 1956

23092 BENDA PURI 1962

23093 PARKER 1954

23094 BANOY 1950

23095 BANDY 1956

23096 BANDY 1956

23097 KELLOUGH 1956

23098 SEGURA 1963

23099 LANKFORD 195

23100 BANOY 1956
Generic Name

QUINQUEL LOCUL INA QUINQUEL OCULINA QU INQUELOCULINA QUINQUEL OC UL INA QUINQUELOCULINA QUINQUEL OCULINA QU INQUE LOCUL INA QU INQUEL OCULINA QUINQUE LOC ULI INA QUINQUEL OCULINA QU INQUEL OCULINA QUINQUELOC ULINA QUINQUELOCULINA QUINQUEL OCULINA QUINQUEL OCULINA QU INQUEL LCULINA QUINQUELOCULINA QUINQUELOCULINA QUINQUELOCULINA QUINQUEL OCULINA QUINQUEL OCULI INA QUINQUEL OCULINA QUINQUEL OCULINA QUINQUEL OC UL INA QU INQUE LOCULINA QU INQUEL OCULINA QU INQUE L OCULIINA QUINQUEL OCULINA QU INQUEL OCULINA QUINQUE LOCULIINA QUINQUEL OCUL INA QUINQUEL OCULINA QUINQUEL OCULINA QUINQUEL OCULINA QU INQUEL OC UL INA QU INQUEL LCUL INA QUINQUEL OCULINA QUINQUELOCULINA QUINQUE LOCUL I NA QUINQUEL OCUL INA QUINQUE LOCULINA QUINQUEL LOCULINA QUINQUELOCULINA QUINQUEL OCULINA QUINQUELOCULINA QUINQUELOCULINA QU INQUEL OCULINA QUINQUEL OCUL INA QUINQUE LOC ULINA QU INQUE LOCULINA QUINQUE LOCULINA QUINQUELOCULINA QU INQUE L OC UL I NA QU INQUEL OC UL INA QUINQUELOCULINA QU INQUE LOCUL INA QU INQUELOCUL INA QU INQUEL OC UL INA QUINQUEL OCULINA QU INQUEL OCUL INA QU INQUE LOCUL INA QU INQUELOCUL INA QU INQUEL OCUL INA QUINQUELOCULINA QUINQUELOCULINA QU INQUELOCULINA QUINQUELOCULINA QU INQUE LOCUL INA QUINQUELOCULINA QUINQUE LOC ULINA QUINQUE LOCULI NA QUINQUE LOCULINA QU INQUEL OCULINA QUINQUELOCULINA QU INQUEL OCUL INA QUINQUEL OC ULINA QUINQUE LOCULINA QUINQUE LOCUL I NA QUINQUEL OCULINA QUINQUE L OCUL I NA QU INQUE LOCUL INA QU INQUELOCULI INA QUINQUELOCULINA QUINQUELOCUL INA QU INQUE LOCULI NA QUINQUELOCULINA QUINQUEL LCULINA QU INQUE LOCULI INA QUINQUEL LC UL I NA QU INQUEL OCULI INA QUINQUEL OC ULINA

Specific Name

Locality

Lat. Long.

COMPTA

COPPTA

CONPTA

CONPTA

CONPTA

CONPTA

CONPTA

COMPTA

CONPTA

COMPTA

COSTATA

COSTATA

COSTATA

COSTATA

COSTATA

COSTATA

COSTATA

COSTATA

COSTATA

CULTRATA

CULTRATA

CULTRATA

CULTRATA

CULTRATA

CULTRATA

CULTRATA

CULTRATA

CULTRATA

CULTRATA

CULTRATA

CULTRATA

CULTRATA

CULTRATA

CULTRATA

CUVIERIAVA

CUVIERIANA

OURRAND II

DUTEMPLEI

DU TEMPLEI

DU TEMPLEI

DUTEMPLEI

DU TEMPLEI

DUTEMPLEI

DU TEMPLEI

DU TEMPLEI

DU TEMPLEI

EL ONGATA

FUNAFUTIENS IS

FUNAFUT IENS IS

FUNAFUTIENSIS

FUNAFUTIENS IS

FUNAFUT IENS IS

FUNAFUTIENSIS

FUNAFUT IENS IS

FUMAFUTIENSIS

FUNAFUTIENSIS

FUNAFUT IENS IS

FUNAFUTIENS IS

FUNAFUT IENS IS

FUNAFUT IENS IS

FUNAFUTIENSIS

FUNAFUTIENSIS

FUNAFUTIENS IS

FUNAFUT IENSIS

FUNAFUTIENSIS

FU AAFUTIENS IS

FUMAFUTIENSIS

FUNAFUTIENS IS

FUNAFUTIENS IS

GARRETTII

GLABRATA

GRACILIS

HORRIDA

HORRIDA

HORR I DA

HORRIDA

HORRIDA

HORRI DA

HORR I DA

HORRIDA

HORRIDA

HORRIDA

HORRIDA

HORRIDA

HORRIDA

HORRIDA

NE GULF OF MEXICO

NE GULF OF MEXICO

NE GULF OF MEXICO

NE GULF OF MEXICO

NE GULF OF MEXICO

NE GULF OF MEXICO

NE GULF OF MEXICO

NE GULF OF MEXICO

NE GULF OF MEXICO

NE GULF OF MEXICO

MISSISSIPPI DELTA

NE GULF OF MEXICO

TEXAS GULF COAST 


\section{Publication}

23101 BANDY 1956 23102 BANDY 1956

23103 SANDY 1956

23104 AYALA-CASTANARES 1963

23105 BANDY 1956

23106 BANDY 1956

23107 KELLOUGH 1956

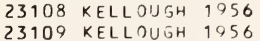

23110 KELLOUS,H 1956

23111 LUDWICK WALTON 1957

23112 PARKER 1054

23113 PARKER 1954

23114 PAPKEQ 1954

23115 PARKER 1954
23116 PARKER 1954

23116 PARKER 1754

23118 PHLEGE? 1951 A

23119 PHLEGER 195? A

23120 PHLEGED $1951 \mathrm{~A}$

23121 PHLEGER 1951A

23122 PHLEGER 1951A

23123 PHLEGER 1951A

23124 PHLEGER 1951A

23125 PHLEGEP $1951 \mathrm{~A}$

23127 PHLEGER 1951A

23128 PHLEGER 1951 A

23129 PHLEGER $1951 \mathrm{~A}$

23130 PARKER 1954

23131 PARKER 1954

23132 PARKER 1954

23133 PARKER 1754

23134
23135
$2 H L E G E R$

23136 PHLEGER 1951 A

23137 BANDY 1756

23138 BANDY 1956

23139 BANDY 1956

23140 BANDY 1956
23141 BENDA PURI 1962

23142 BANDY 1956

23143 BANDY 1956

23144 BANDY 1956

23145 BANDY 1956

23146 BANDY 1956

23147 BANDY 1956

23148 BANDY 1956

23149 BANDY 1956
23150 CUSHMAN 1922 A

23151 BOCK 1975

23152 LYNTS PFISTER 1967

23153 PHLEGER 19653

23154 NORTON 1930

23155 PHLEGER 19658

23156 BOCK 1976

23157 BOCK 1976

23158 BOCK 1976

23159 PARKER PHLEGER PEIRSON 1953

23160 PHLEGEP 1951A

23161 PHLEGER $1951 \mathrm{~A}$

23162 PHLEGER 1951A

23163 PHLEGER $1951 \mathrm{~A}$

23164 PHLEGER 1951 A

23165 PHLEGER 1951A

23166 PHLEGER 1951A

23167 PHLEGER 1951A

23169 PHLEGER 1951 A

23170 PHLEGER 1951A

23171 PHLEGER 1951A

23172 SHEPARD MOORE 1955

23173 PHLEGER $1951 \mathrm{~A}$

23175 BANDY 1954

23176 KELLOUGH 1956

23177 KELLOUGH 1956

23178 KELLOUGH 1956

23179 KELLOUGH 1956

23180 KELLOUGH 1956

23181 BENDA PUQI 1962

23182 WALTON 1764

23183 LOEP 1765

23184 9ANDY 1956

23185 PARKER 1954

23186 NORTON 1930

23187 WALTON 196 ?

23188 KELLOUSH 1956

23189 KELLOUGH 1956
23190 PHLEGER 19658

23190 PHLEGER 1965
23191 BANDY 1954

23191 BANDY 1954

23192 BANDY 1956
23193 AYALA-CASTANARES 1963

23194 BANDY 1954

23195 BANDY 1954
Generic Name

QU INQUE LOCULINA QU INQUE LOCULINA QUINQUELOCULINA QU INQUELOCULINA QU INQUEL OCULINA IU INQUEL OC UL INA QU INQUE LOCUL INA QU INQUE L OC UL INA QUINQUEL OCULINA QU INQUF LOCULINA QU INQUE LOC ULI INA QU INQUE L OCUL INA QU INQUE LOCUL INA QU INQUE L OC UL I NA QU INQUE LOCUL INA QU INQUE LOCULINA QUINQUELOCUL INA QUINQUELOCULINA QUINQUEL OCULINA QUINQUELOCULINA QUINQUELOCULINA QU INQUFLOCULINA QUINQUELOCUL INA QU INQUE LOCULINA QU INQUE LOCUL INA QU INQUEL OCULINA QU INQUE L OCUL INA QU INQUE LOCULINA QU INQUELOCULINA QU INQUE LOCUL INA QU INQUELOC UL INA QU INQUEL OCULINA QU INQUELOCULINA QU INQUEL OC ULI INA QU INQUE LOCUL INA QU INQUEL OCULINA QU INQUEL OC UL INA QU INQUEL OCULINA QU INQUE LOCULINA QU INQUEL OCUL INA QUINQUEL OCUL INA QU INOUFL OC ULINA QUINQUE. L OC ULI INA QU INQUEL OCUL INA QU INQUELOCULINA QU INQUE L OC ULI INA QU INQUE L OCUL I NA QUINQUELOCULINA QU INQUE L OC UL I NA QU INQUE LOCULINA QU INQUELOCULINA QU INQUEL OC UL INA QU INQUE LOCUL INA QUINQUE L OCUL INA QU INQUE LOCUL I NA QU INQUELOCULINA QU INQUEL OCUL INA QUINQUELOCUL INA QU INQUE LOCULINA QU INQUE LOCUL I NA QU INQUE LOCUL INA QUINQUEL LC UL I NA QU INQUE LOCULINA QU INQUE LOC ULI INA QU INQUE LOCULINA QU INQUE LOC UL I NA QUINQUE LOCUL INA QU INQUEL OCUL INA QU INQUE LOCUL INA QU INQUE LOCUL INA QU INQUE L OCULI INA QU INQUEL OC UL INA QU INQUE LOCULINA QU INQUE LOCULINA QU INQUE L OCUL INA QU INQUE LOCUL INA QU INQUELOCULINA QU INQUELOCULINA QU INQUE LOC UL I NA QU INQUE LOC ULINA QU INQUEL OCUL INA QUINQUE LOCUL INA QU INQUELOCULINA QU INQUELOCULINA QUINQUELOCULINA QU INQUELOCULINA QU INQUE LOCULINA QU INQUE LOCUL I NA QU INQUELOCULINA QU INQUE LOCULI INA QU INQUE LOCUL INA QU INQUE LOCUL INA QUINQUELOC ULINA QU INQUE LOCUL INA QU INQUE LOCUL INA
Specific Name

HORRIDA

HORRIDA

HORRIDA

HORR IDA

HORRIOA

HORRI DA

HORR I DA

HORRIDA

HORRI DA

HORRIDA

HORRI DA

HORRIDA

HORRIDA

HORRIDA

HORRI DA

HORRIDA

HORR IDA

HORR I DA

HORR IDA

HORR I DA

HORRIDA

HORR IDA

HORRIDA

HORRIDA

HORRI DA

HORRIDA

HORRIDA

ORRIDA

HORRI DA

HORRIDA

HORRIDA

HORRIDA

JUGOSA

$J \cup G O S A$

$\cup \operatorname{COSA}$

JUGOSA

JU GOSA

JUGOSA

JUGOSA

$J \cup \operatorname{COSA}$

$J \cup G O S A$

JU GOSA

KERIMBATI CA PHILIPPINENSIS

LAEVIGATA

LAEVIGATA

LAEVIGATA

LAEVIGATA

LAEVIGATA

LANARCKIANA

LAMARCKIANA

LANARCKIANA

LANARCKIANA

LANARCKIANA

LANARCKIANA

LANARCKIANA

LANARCK IANA

LANARCKIANA

LANARCKIANA

LANARCKIANA

LANARCKIANA

LANARCKIANA

ANARCKIANA

LANARCKIANA

LANARCKIANA

LANARCK IANA

LANARCKIANA

LANARCKIANA

LANARCKIANA

LANARCKIANA

LANARCKIANA

LANARCKIANA

LANARCKIANA

A MARCK IANA

A NARCKIANA

LANARCKIANA

LANARCKIANA

LANARCKIANA

LANARCKIANA

LANARCKIANA

LANARCK IANA

LANARCKIANA

LANARCKIANA

LANARCKIANA

ANAR CK IANA

LANARCKIANA

Locality

NE GULF OF MEXICO

NE GULF OF MEXICO

NE GULF OF MEXICO

L. DE TERMINOS, CAMPECHE

NE GULF OF MEXICO

NE GULF OF MEXICO

NW GULF OF MEXICO

NW GULF OF MEXICO

NW GULF OF MEXICO

NW GULF OF MEXICO

NE GULF OF MEXICO

NE GULF OF MEXICO

NE GULF OF MEXICO

NE GULF OF MEXICO

NE GULF OF MEXICO 
Publication

23196 BANDY 1954

Generic Name

QUINQUELOCULINA QUINQUE L OCUL INA

23198 AYALA-CASTANARES SEGURA 1968 QUINQUELOCULINA 23199 BANDY 1956 23200 BANDY 1956 23201 BANDY 1956 23202 BANDY 1956 23203 BANDY 1956 23204 BANDY 1956 23205 BANDY 1956 23206 BANDY 1956 23206 BANDY 1956 23208 BANDY 1956 23209 PARKER 1954 23210 PHLEGER 1951A

23211 PARKER PHLEGER PEIRSON 1953 23212 PHLEGER 1956

23213 PARKER PHLEGER PEIRSON 1953 23214 PARKER PHLEGER PEIRSON 1953 23215 BANDY 1956 23216 BANDY 1956 23217 BANDY 1956 23218 BANDY 1956 23219 ANDERSEN 1961

23220 BANDY 1956

23221 BANDY 1956

23222 BANDY 1956

23223 PARKER 1954
23224 PARKER 1954

23225 PARKER 1954

23226 PARKER PHLEGER PEIRSON 1953

23227 PHLEGER 1956

23228 LYNTS PFISTER 1967

23220 PHLEGER 1956

23230 BOCK 1976

23231 BOCK 1976

23232 BANDY 1956

23233 BANDY 1956

23234 BANDY 1956

23235 BANDY 1956

23236 BANDY 1956

23237 BANDY 1956
23238 KANE 1967

23238 KANE 1967
23239 WALDRON 1963

23240 CUSHMAN $1922 \mathrm{~A}$

23241 SEGURA 1963

23242 BANDY 1956

23243 BANDY 1956

23244 BANDY 1956

23245 KANE 1962

23246 PHLEGER $1951 \mathrm{~A}$

23247 PHLEGER 1951A

23248 PHLEGER $1951 \mathrm{~A}$

23249 SHIFFLETT 1961
23250 PHLEGER LANKFORD 1957

23250 PHLEGER LANKF

23252 PARKER 1954

23253 LANKFORD 1959

23254 PARKER 1954

23255 PARKER 1954

23256 PARKER 1954

23257 PARKER 1954

23258 PARKER 1954

23259 PARKER 195

23260 PARKER 1954

23261 PARKER 1954

23262 PARKER 1954

23263 DAVIS 1964

23264 PARKER 1954

23265 LIDZ LIDZ 1966

23266 NORTON 1930

23267 NORTON 1930

23268 CUSHMAN 1922A

23269 SHEPARD MOORE 1955

23270 BANDY 1956

23271 CUSHMAN 1922A

23272 SEGURA 1963

23273 LEHMANN 1957

23274 PHLEGER $1965 \mathrm{~B}$

23275 PHLEGER 1965 A

23276 PHLEGER 1965A

23277 BOCK 1976

23278 PARKER PHLEGER PEIRSON 1953

23279 BENDA PURI 1962

23280 PHLEGER 1965 A

23281 ANDERSON 1968

23282 PHLEGER 1965 A

23283 PHLEGER 1965 A

23284 PHLEGER 1965 B

23285 PHLEGER 1965 A

23286 PARKER PHLEGER PEIRSON 1953

23287 PARKER PHLEGER PEIRSON 1953

23288 BANDY 1956

23289 BANDY 1956

23290 PHLEGER LANKFORD 1957
Specific Name

Locality

Lat. Long.

LANARCKIANA

LANARCKIANA

ANARCKIANA

ANARCKIANA

LANARCKIANA

LANARCKIANA
LANARCKIANA

LANARCKIANA

LANARCKIANA

LAMARCKIANA

LANARCKIANA

LANARCKIANA

LANARCKIANA

LAMARCKIANA

LANARCKIANA

LANAR CKIANA

LANARCKIANA

LANARCKIANA

LANARCKIANA

LANARCKIANA

LANARCKIANA

LANAR CKIANA

LANARCKIANA

LANARCKIANA

LANARCKIANA

LANARCKIANA

LANARCKIANA

LANARCKIANA

LANARCKIANA

LANARCKIANA

LANARCKIANA

LANARCK IANA

LANARCKIANA

LANARCKIANA

LANARCKIANA

LANARCKIANA

LAMAR CKIANA

LANARCKIANA

LANARCK IANA

LANARCKIANA

LANARCKIANA

LANARCKIANA

LANARCKIANA

LANARCKIANA

LANARCK IANA

LANARCKIANA

LANARCKIANA

LANARCKIANA

LANARCKIANA

LANARCKIANA

LANARCK IANA

LANARCKIANA

LANARCK IANA

LANARCKIANA

LANAR CKIANA

LANARCKIANA

LANARCKIANA

LANARCKIANA

LANARCKIANA

LANARCKIANA

LANARCK IANA

LANARCKIANA

LANARCKIANA

LANARCKIANA

LAMARCKIANA

LANARCKIANA

LANARCKIANA

LANARCKIANA INFLATA

LINBATA

PAFKERAE OCCIDENTAL IS

PARKERI OCCIDENTALIS

POEYANA

POEYANA

POEYANA

POEYANA

POEYANA

POEYANA

POEYANA

POEYANA

POEYANA

POEYANA

POEYANA

POEYANA

POEYANA

POEYANA

POEYANA

POEYANA

POEYANA

POEYANA

POEYANA

POEYANA

POEYANA

POEYANA
NW GULF OF MEXICO

NW GULF OF MEXICO

LAGUNA MADRE, NE TEXAS

NE GULF OF MEXICO

NE GULF OF MEXICO

NE GULF OF MEXICO

NE GULF OF MEXICO

NE GULF OF MEXICO

NE GULF OF MEXICO

NE GULF OF MEXICO

NE GULF OF MEXICO

NE GULF OF MEXICO

NE GULF OF MEXICO

NE GULF OF MEXICO

NW GULF OF MEXICO

TEXAS GULF COAST

NW GULF OF MEXICO

TEXAS GULF COAST

TEXAS GULF COAST

NE GULF OF MEXICO

NE GULF OF MEXICO

NE GULF OF MEXICO

NE GULF OF MEXICO

MISSISSIPPI DELTA

TAMPA BAY, FLA.

PINE IS. SOUND, FLA

NE GULF OF MEXICO

NE GULF OF MEXICO

NE GULF OF MEXICO

TEXAS GULF COAST

DRY TORTUGAS

NW GULF OF MEXICO

NE GULF OF MEXICO

NE GULF OF MEXICO

NE GULF OF MEXICO

NE UULF OF MEXICO

NE GULF OF MEXICO

NE GULF OF MEXICO

NE GULF OF MEXICO

SAB INE LAKE, TEXAS

MISSISSIPPI DELTA

TORTUG AS

MATAMOROS, MEXICO

NE GULF OF MEXICO

TAMPA GAY, FLA.

NE GULF OF MEXICO

SABINE LAKE, TEXA

NW GULF OF MEXICO

NW GULF OF MEXICO

NW GULF OF MEXICO

HEALD BANK, G. OF MEXICO

TEXAS GULF COAST

NE GULF OF MEXICO

NE GULF OF MEXICO

MISSISSIPPI DELTA

NE GULF OF MEXICO

NE GULF OF MEXICO

NE GULF OF MEXICO

NE GULF OF MEXICO

NE GULF OF MEXICO

NE GULF OF MEXICO

NE GULF OF MEXICO

NE GULF OF MEXICO

NE GULF OF MEXIC

CAMPECHE BANK, MEXICO

NE GULF OF MEXICO

VERACRUZ REEFS

TORTUGAS, FLA

TORTUGAS, FLA

TORTUGAS

CENTRAL TEXAS COAST

IAMPA BAY, FLA.

TOR TUG AS

MATAMOROS, MEXICO

TEXAS GULF COAST

TEN THUUSAND IS. . SW FLA.

COPANO BAY, TEXAS

AVACA HAY, TEXAS

NE GULF OF MEXICO

IEXAS GULF COAST

CAPE ROMANO, FLA.

MUSTANG LAKE, TEXAS

MISSISSIPPI SOUND

PASS CAVALLO, TEXAS

OLORADO R. DELTA, TEXAS

WHITEWATER B.. SW FLA.

PORT ALTO TEXAS

TEXAS GULF COAST

IEXAS GULF COASI

INE IS. SOUND, FLA.

CHARLOTTE HARBOUR, FLA.

TEXAS GULF COAS
NE GULF OF MEXICO

CHARLOTTE HARBOUR, FLA.

$2 \varepsilon 50 \mathrm{~N} 09320 \mathrm{~W}$

$2530 \mathrm{~N} 093$ OOW

$2510 \mathrm{~N} 09737 \mathrm{~W}$

$29 \quad 17 \mathrm{~N} 085 \quad 46 \mathrm{~W}$ 


\section{Publication}

23291 DAVIS 1964

23292 NORTON 1930

23293 WALTON 1960

23294 BANDY 1956

23295 BANDY 1956

23296 PARKER PHLEGER PEIRSON 1953

23297 PHLEGER 1965A

23298 BENDA PURI 1962

23299 PHLEGER 1965

23300 WALTON 1964

23301 BANDY 1956

23302 BANOY 1956

23303 BANDY 1956

23304 BANDY 1956

23305 BANDY 1956
23306 AYALA-CASTANARES 1963

23307 AYALA-CASTANARES SEGURA 1968 23308 PHLEGER 1965 A

23309 BANDY 1956

23310 BANDY 1956

23311 PARKER PHLEGER PEIRSON 1953 23312 PARKER PHLEGER PEIRSON 1953 23313 PHLEGER 1956

23314 PARKER PHLEGER PEIRSON 1953 23315 SHENTON 1957

23316 PARKER PHLEGER PEIRSON 1953 23317 PHLEGER 1960

23318 PARKER 1954

23319 PARKER 1954

23320 PARKER 1954

23321 PARKER 1954

23322 PARKER 1954

23323 PARKER 1954

23324 WALTON 1964

23326 PARKER 1954

23327 AYALA-CASTANARES 1963

23328 BANDY 1956

23329 PFLUM FRERICHS 1976

23330 NORTON 1930

23331 PARKER 1954

23332 PARKER 1954

23333 PARKER 1954

23334 CUSHMAN 1922 A

23335 LEHMANN 1957

23336 PFLUM FRERICHS 1976

23337 DAVIS 1964

23338 PARKER 1954

23339 SEGURA 1963

23340 VAUGHAN 1918

23341 WALTON 1960

23342 AYALA-CASTANARES 1963

23363 AYALA-CASTANARES SEGURA 1968

23344 PARKFR PHLEGER PEIRSON 1953

23345 PARKER PHL

23346 BANDY 1956
23347 BANDY 1956

23348 PARKER PHLEGER PEIRSON 1953

23349 BANDY 1956

23350 PHLEGER 1956

23351 BANDY 1956

23352 PARKER PHLEGER PEIRSON 1953 23353 PARKER PHLEGER PEIRSON 1953 23354 PARKER PHLEGER PEIRSON 1953 23355 PHLEGER 1960

23356 PARKER PHLEGER PEIRSON 1953 23357 PARKER PHLEGER PEIR SON 1953 23358 PARKER PHLEGER PEIRSON 1953 23359 PHLEGER 19558

23360 SEGURA 1963

23361 SHEPARD MOORE 1955

23362 LEHMANN 1957

23363 PHLEGER LANKFORD 1957

23364 WALDRON 1963

23365 PARKER 1954

23367 LIDZ LIDZ 1966

23368 ANDERSEN 1961

23369 WALTON 1964

23370 PARKER 1954

23371 PARKER 1954

23372 PARKER 1954

23373 BOCK 1976

23374 PARKER 1954

23375 WALTON 1960

23376 NORTON 1930

23377 LIDZ LIDZ 1966

23378 LEHMANN 1957

23380 WALTON 1960

23381 POST 1951

23382 KORNFELD 1931

23383 KORNFELD 1931

23384 KORNFELD 1931
Generic Name

QUINQUELOCULINA QU INQUELOCUL INA QU INQUELOCULINA QUINQUELOCULINA QU INQUEL OC UL INA QUINQUE LOCULINA QUINQUELOC UL INA QU INQUEL OCULINA QUINQUE LOCULINA QU INQUELOC UL INA QU INQUELOCUL INA QUINQUELOCUL INA QU INQUELOCULINA QU INQUELOCULINA QUINQUELOCULINA QUINQUELOCULINA QUINQUELOCUL INA QU INQUEL OCULINA QUINQUEL OCULINA QU INQUELOCULINA QU INQUELOCULINA QU INQUELOCUL INA QU INQUELOCULINA QUINQUE LOCULINA QU INQUELOCULINA QUINQUELOCULINA QU INQUELOCULINA QUINQUEL OC ULINA QU INQUE LOC UL INA QU INQUEL OCUL INA QU INQUEL OCULINA QU INQUELOC UL INA QUINQUELOCULINA QU INQUELOCULINA QUINQUELOCULINA QU INQUEL OCUL INA QUINQUELOCULINA QUINQUELOCULINA QU INQUELOCULINA QUINQUELOCULINA QUINQUEL OCULINA QU INQUEL OC UL INA QU INQUELOCULINA QU INQUELOCULINA QUINQUELOCULINA QU INQUE LOCULINA QUINQUELOCULINA QUINQUELOCULINA QU INQUE LOCUL INA QUINQUELOCULINA QUINQUEL OCUL INA QU INQUELOC ULINA QU INQUEL OCULINA QUINQUE LOCUL INA QU INQUE LOC ULINA QU INQUE LOCULINA QU INQUEL OC ULINA QUINQUELOCULINA QU INQUEL OCUL INA QU INQUELOCULINA QU INQUEL OCUL INA QUINQUE LOCUL INA QUINQUELOCULINA QU INQUELOCULINA QUINQUELOCULINA QUINQUEL OC UL INA QU INQUELOCULINA QU INQUELOCULINA QUINQUELOCULINA QU INQUELOCULINA QU INQUELOCULINA QU INQUELOCULINA QUINQUELOCULINA QUINQUE LOCUL INA QU INQUE L OC UL INA QUINQUELOCULINA QU INQUE LOCULINA QU INQUELOCULINA QUINQUELOCULINA QUINQUELOCULINA QUINQUELOCULINA QU INQUE LOCULINA QU INQUELOCULINA QUINQUELOCULINA QU INQUELOCULINA QUINQUELOCUL INA QUINQUE LOCULINA QUINQUE LOCULINA QUINQUELOCULINA QU INQUELOCUL INA QUINQUELOCULINA QUINQUELOCUL INA QU INQUELOCULINA QU INQUE LOCULI INA QUINQUELOCULINA
Specific Name

Locality

Lat.

Long.

POEYANA

POEYANA

POEYANA

POEYANA

POEYANA

POEYANA

POEYANA

POEYANA

POEYANA

POEYANA

POEYANA

POEYANA

POEYANA

POEYANA

POEYANA

POEYANA

POEYANA

POEYANA

POEYANA

POEYANA

POEYANA

POEYANA

POEYANUM

POLYGONA

POLYGONA

POLYGONA

POLYGONA

POLYGONA

POLYGONA

POLYGONA

POLYGONA

POLYGONA

POLYGONA

POLYGONA

POLYGONA

POLYGONA

POLYGONA

POLYGONA

POLYGONA

POLYGONA

POLYGONA

POLYGONA

POLYGONA

POLYGONA

PULCHELLA

RETI CULATA

RHCDIENSIS

RHCDIENSI

RHCDIENSIS

RHCDIENSIS

RHCDIENSIS

RHCDIENSIS

RHCDIENSIS

RHCDIENSIS

RHCDIEN SI

RHCDIENSIS

RHCDIENSIS

RHCDIENSIS

RHCDIENSIS

RHCDIENSIS

RHCDIENSI

RHCDIENSI S

RHCDIENSIS

RHODIENSIS

RHCDIENSIS

RHCDIENSIS

RHCDIENSIS

RHCDIENSI

RHCDIENSIS

RHCDIENSI

SAEULOSA

SAEULOSA

SAEULOSA

SAEULOSA

SAELLOSA

SAEULOSA

SAEULOSA

SAEULOSA

SA EULOSA

SANOAENSI

SANOAENSI

SA WANENSIS

SC FOB I CUL AT A

SENINULA

SENINULA

SENINULA

SENINULA

SEN INULA

CAMPECHE BATK, MEXICO

TORTUGAS, FLA

MISSISSIPPI SOUND

NE GULF OF MEXICO

NE GULF OF MEXICO

TEXAS GULF COAST

ALLYN'S BIGHT, TEXAS

CAPE ROMANO, FLA.

COPANO BAY TEXAS

TAMPA-SARASOTA BAY, FLA. 
Publication

23386 K.ORNFELD 1931 23387 KORNFELD 1931

23388 SHIFFLETT 1961

23389 KORNFELD 1931

23390 KORNFELD 1931

23391 KORVFELD 1931

23392 LEHMANN 195

23393 KANE 1 ग6?
23394 KANE 196 ?

23395 PARKER PHLEGER PEIRSON 1953

23396 PARKER PHLEGER PEIRSON 1953

23397 SHEPAR D MOORE 1955

23398 PFLUM FRERICHS 1976

23399 PHLEGER 1965 A

23400 PHLFGED 1965 A

23401 SEGURA 1963

23402 PHLEGEP LANKFORD 1957

23403 PHLEGER 1956

23404 PARKER PHLEGER PEIRSON 1953

23405 PARKER DIHEGER PEIRSON 1953

23406 PARKER PHLEGER PEIRSON 1953

23407 PFLUM FRERICHS 1976

23408 PFLUM FRERICHS 1976

23409 PARKER PHLEGER PEIRSON 1953

23410 PHLEGER 1956

23411 PHLEGER 1956

23412 PHLEGER 1956

23413 PARKER PHLEG

23415 PARKER PHLEGER PEIRSON 1953

23416 BOCK 1976

23417 WALTON 1964

23418 PHLEGER 1965 A

23419 BENDA PURI 1962

23420 BENDA PURI 1962

23421 PHLEGER 1965 A

23422 P HLEGER 1965A

23423 ANDERSON 1968

23424 PHLEGER 1965 A

23425 PHLEGER 1965 A

23426 AYALA-CASTANARES 1963

23427 AYALA-CASTANARES SEGURA 1968

23428 LEHMANN 1957

23429 NORTON 1930

23430 CUSHMAN 1922 A

23432 LEHMANN 1957

23433 POST 1951

23434 CUSHMAN 1922 A

23435 NORTON 1930

23436 AYALA-CASTANARES 1963

23437 BOCK 1976

23438 BANDY 1956

23439 BANDY 1954

23440 BANDY 1954

23441 BANDY 1956

23442 BANOY 1954

23443 PHLEGER 1965 A

23444 PHLEGER 1965

23445 PHLEGER $1905 \mathrm{~A}$

23446 PHLEGER 1965A

23447 PHLEGER 1965 A

23448 PHLEGER 1965 A

23449 PHLEGER $1965 \mathrm{~A}$

23450 BOCK 1976

23451 ANDERSEN 196

23452 NORTON 1930

23453 CUSHMAN 1922 A

23454 SEGURA 1963

23455 DAVIS 1964
23456 NORTON 1930

23457 PFLUM FRERICHS 1976

23458 PFLUM FRERICHS 1976

23459 PARKER 1954

23460 PARKER 1954

23461 PFLUM FRERICHS 1976

23462 PFLUM FRERICHS 1976

23463 PARKER 1754

23464 PARKER 1954

23465 PFLUM FRERICHS 1976

23466 PFLUM FRERICHS 1976

23467 PFLUM FRERICHS 1976

23468 PFLUM FRERICHS 1976

23469 PFLUM FRERICHS 1976

23470 PFLUM FRERICHS 1976

23471 PFLUM FRERICHS 1976

23472 PFLUM FRERICHS 1976

23473 PFLUM FRERICHS 1976

23474 PFLUM FRERICHS 1976

23475 PFLUM FRERICHS 1976

23476 DFLUM FRERICHS 1976

23477 PARKER 1754

23478 PARKER 1954

23479 PFLUM FRERICHS 1976

23480 PFLUM FRERICHS 1976
Generic Name

QUINQUE L OCUL INA QUINQUEL OCULINA QUINQUELOCULINA QU INQUE LOCUL INA QU INQUELOCUL INA QU INQUE L OCUL INA QU INQUE L OCUL INA QUINQUEL LCULI INA QU INQUELOCULINA QU INGUE LOCULI INA QU INQUE LOCULINA QUINQUELOCULINA QU INQUE LOCUL INA QU INQUEL OCUL INA QUINQUEL OCULINA QU INQUE LOCUL INA QUINQUE LOCUL INA QUINQUELOCULINA QU INQUELOCUL INA QU INQUEL OCULI INA QU INQUELOCUL INA QUINQUE LOCULI INA QU I NQUEL OCUL I NA QU INQUE LOCULINA QUINQUEL OCUL INA QUINQUEL OCULINA QUINQUE LOCUL INA QU INQUEL OCUL I NA QU INQUELOCUL INA QU INQUELOCULINA QUINQUEL OCUL INA QUI NQUELOC UL INA QUINQUE L OC UL INA QU INQUEL OCUL INA QUINQUE LOCULINA QUINQUEL OCULINA QU INQUELOCULINA QUINQUELOCULI INA QUINQUELOCULINA QU INQUEL OCUL INA QU INQUE LOCULI INA QUINQUELOCULINA QUINQUEL OC UL INA QU INQUELOCUL INA QU INQUELOCUL INA QU INQUELOCUL INA QU INQUE LOC UL INA QUINQUE LOCULINA QUINQUEL OCULINA QU INQUELOCULINA QU I VQUE LOCUL INA QUINQUEL OC UL INA QUINQUELOCULINA QU INQUE LOCUL INA QUINQUELOCULINA QU INQUEL OCUL INA QU INQUE LOC UL I NA QUINQUEL OCULINA QU INQUELOCUL INA QUINQUELOCULINA QUINQUELOCULINA QU INQUELOCULINA QUINQUEL OC UL INA QUINQUEL OCULIINA QUINQUELOCUL INA QU INQUE LOCUL INA QUINQUEL OC UL INA QUINQUELOCULINA QUINQUELOCUL INA QUINQUELOCULINA QUINQUELOCULINA QUINQUELOCUL INA QUINQUELOCULINA QUINQUELOCULINA QU INQUE LOCUL INA QUINQUEL OCULINA QU INQUEL OCULI INA QU INQUE LOCUL INA QU INQUELOCULINA QUINQUE LOC ULINA QUINQUELOCULINA QUINQUELOCULINA QUINQUELOCUL INA QUINQUEL OCUL INA QUINQUEL OCUL INA QU INQUELOCULINA QU INQUEL OCUL INA QU INQUELOCULINA QU INQUELOCULINA QUINQUEL OCUL INA QUINQUELOCULINA QU INQUEL OCUL INA
Specific Name

SENINULA

SENINULA

SENINULA

SENINULA

SENINULA

SENINULA

SENINULUM

SENINULUM

SENINULUM

SENINULUY

SENINULUA

SENINULUM

SENINULUM

SENINULUM

SENINUL UM

SENINULUM

SEN.INULUM

SENINULUM

SENINULUM

SENINULUM

SENINULUM

SENINULUM

SENINULUM

SENINULUM

SENINULUY

SENINULUM

SENINULUM

SENINULUM

SENINULUM

SENINULUM

SENINUL UM

SENINULUM

SENINULUY

SENINULUM

SENINULUM

SENINULUM

SENINUL UM

SENINUL UM

SENINULUM

SENINULUM JUGOSA

STRIATA

STRIATA

SUEARENAR IA

SUECARINATA

SUEPOEYANA

SUEPOEYAVA

SUEPOEYAVA

SUBPOEYANA

SUEPOEYANA

SUEQUADRA

SUBQUADRA

SUEQUADRA

SUEQUADRA

SUEQUADRA

TE AAGOS

TENAGOS

TEAAGOS

TEAAGOS

TEAAGOS

TENAGOS

TE^AGOS

TEAAGOS

TIFSWORDI

TR I CAR I NA TA

TR I CAR INA TA

TR ICARINA TA

TR I CAR INATA

UN DOSA

VENUSTA

VEAUSTA

VEAUSTA

VEAUSTA

VENUSTA

VENUSTA

VEAUSTA

VENUSTA

VENUSTA

VENUSTA

VENUSTA

VENUSTA

VEAUSTA

VENUSTA

VEAUSTA

VENUSTA

VENUSTA

VEAUSTA

VENUSTA

VENUSTA

VEAUSTA

VE AUSTA

VENUSTA

VENUSTA

Locality

Lat. Long.

TEXAS GULF COAST

TEXAS GULF COAST

HEALD BANK, G. OF MEXICO

TEXAS GULF COAST

TEXAS GULF COAST

LOUISI ANA GULF COAST

TEXAS GULF COAST

SABINE LAKE, TEXAS

SABINE LAKE. TEXAS

TEXAS GULF COAST 


\section{Publication}

23481 PARKER 1954

23482 PARKER 1954

23483 SHIFFLETT 1961

23484 PFLUM FRERICHS 1976

23485 PFLUM FRERICHS 1976

23486 PFLUM FRERICHS 1976

23487 PFLIJM FRERICHS 1976

23488 PFLUM FRERICHS 1976

23489 PFLUM FRERICHS 1976

23490 NORTON 1930

23491 PFLUM FRERICHS 1976 23492 PFLUM FRERICHS 1976 23493 PFLUM FRERICHS 1976 23494 PFLUM FRERICHS 1976 23495 SEGURA 1963

23496 PFLUM FRERICHS 1976 23497 PFLUM FRERICHS 1976 23498 PFLUM FRERICHS 1976 23499 PFLIJM FRERICHS 1976 23500 PFLUM FRERICHS 1976 23501 PFLUM FRERICHS 1976 23502 PFLUM FRERICHS 1976 23503 PFLUM FRERICHS 1976 23504 PFLUM FRERICHS 1976 23505 PFLUM FRERICHS 1976 23506 PFLUM FRERICHS 1976 23507 PFLUM FRERICHS 1976 23508 PFLUM FRERICHS 1976 23509 PFLUM FRERICHS 1976 23510 PFLUM FRERICHS 1976 23511 PFLUM FRERICHS 1976 23512 PARKER PHLEGER PEIRSON 1953 23513 PARKER PHLEGER PEIRSON 1953 23514 PARKER PHLEGER PEIRSON 1953 23515 LEHMANN 1957

23516 PARKER PHLEGER PEIRSON 1953 23517 PHLEGER LANKFORD 1957

23518 PHLEGER 1960

23519 SEGURA 1963

23520 PARKER PHLEGER PEIRSON 1953 23521 AYALA-CASTANARES 1963

23522 PARKER PHLEGER PEIRSON 1953 23523 PARKER PHLEGER PEIRSON 1953 23524 PARKER PHLEGER PEIRSON 1953 23525 PHLEGER 1965 B

23526 ANDERSEN 1961

23527 LEROY HODGKINSON 1975

23528 PFLUM FRERICHS 1976

23529 PFLUM FRERICHS 1976

23530 SEGURA 1963

23531 PARKER 1954

23532 PARKER 1954

23533 PARKER 1954

23534 LUDWICK WALTON 1957

23535 WARREN 1957

23536 LANKFORD 1959

23537 PARKER 1954

23538 SHEPARD MOORE 1955

23539 PARKER 1954

23540 PARKER 1954

23542 PARKER 1954

23543 PARKER 1954

23544 BANDY 1956

23545 BANDY 1956

23546 BANDY 1956

23547 BANDY 1956

23548 BANDY 1956

23549 BANDY 1956

23550 PARKER 1954

23551 BANDY 1956
23552 ANDERSEN 196

23553 BANDY 1956

23554 BANDY 1956

23555 BANDY 1954

23556 BANDY 1954

23557 BANDY 1956

23559 PARKER 195

23560 PARKER 1954

23561 PHLEGER 1956

23562 PARKER 1954

23563 PHLEGER 1956

23564 PARKER 1954

23566 BANDY 1954

23567 WARREN 1956

23568 LOEP 1965

23569 SANDY 1954

23570 BANDY 1954

23571 BOCK 1976

23572 PARKER PHLEGER PEIRSON 1953 23573 PHLEGER 1956

23574 PHLEGER 1956

23575 PARKER 1954
Generic Name

QU INQUELOCULINA QU INQUE LOCUL INA QUINQUELOCULINA QU INQUELOCUL INA QU INQUEL OCUL INA QUINQUEL OCUL INA QUINQUEL OCUL INA QU INQUE L OCUL INA QU INQUELOCUL INA QU INQUELOCUL INA QU INQUE LOC UL I NA QUINQUELOCULINA QU INQUELOC UL INA QUINQUE LOCULINA QU INQUEL OCULINA QUINQUEL OC UL INA QUINQUEL OCUL INA QU INQUELOCUL INA QUINQUELOCUL INA QU INQUELOCUL INA QU INQUE LOCULINA QU INQUE LOCULINA QU INQUELOCULINA QUINQUELOCULINA QUINQUELOC ULIINA QU INQUEL OCUL INA QU INQUELOCULINA QUINQUEL OCULINA QUINQUEL OC ULINA QUINQUEL OCULINA QUINQUE LOCULINA QU INQUE LOC ULINA QU INQUE LOCUL INA QUINQUELOCULINA QUINQUE LOCUL INA QU INQUE LOCUL INA QU INQUE LOCUL INA QU INQUEL OCUL INA QU INQUELOCUL INA QU INQUE LOCUL INA QU INQUE LOC ULI INA QUINQUELOCULINA QUINQUEL OCUL INA QU INQUE L OCULINA QU INQUELOC UL INA RA MUL IN A RA MUL INA

RAMULINA

RECTOBOLIVINA

RECTOBOL IV INA

RECTOBOLIVINA

RECTOBOLIVINA

RECTOBOLIVINA

RECTOBOL IVINA

RECTOBOLIVINA

RECTOBOL IVINA

RECTOBOLIVINA

RECTOBOLIVINA

RECTOBOLIVINA

RECTOBOLIVINA

RECTOBOLIVINA

RECTOBOL IVINA

RECTOBOLIVINA

RECTOBOLIVINA

RECTOBOLIVINA

RECTOBOLIVINA

RECTOBOL IVINA

RECTOBOL IVINA

RECTOBOLIVINA

RECTOBOL IVINA

RECTOBOLIVINA

RECTOBOLIVINA

RECTOBOLIVINA

RECTOBOLIVINA

RECTOBOL IVINA

RECTOBOLIVINA

RECTOBOLIVINA

RECTOBOLIVINA

RECTOBOL IV INA

RECTOBOL IV INA

RECTOBOL IVINA

RECTOBOL IVINA

RECTOBOL IV I IA

RECTOBOLIVINA

RECTOBOLIVINA

RECTOBOL IV INA

RECTOBOLIVINA

RECTOBOLIVINA

RECTOBOL IVINA

RECTOBOL IVINA

RECTOBOLIV INA

RECTOBOLIVINA

RECTOBOLIVINA RECTOBOLIVINA

RECTOBOLIVINA
Specific Name

Localitv

Lat. Long.

VEAUSTA

VEAUSTA

VULGARIS

VULGARIS

VULGARIS

VULGARIS

VULGARI

VULGARIS

VULGARIS

VULGARIS

VULGARIS

VULGARIS

VULGARIS

VULGARIS

VULGARIS

VULGARIS

VULGARIS

VULGARIS

VULGARIS

WE AVER I

WEAVERI

WE AVERI

WEAVER I

WE AVERI

WE AVER I

WE AVERI

WE AVER I

WI ESNER I

WI ESNER

WI ESNER I

WI ESNER I

WIESNER I

WI ESNERI

WI ESNER

WI ESNER

WIESNER

WI ESNER

WI ESNER

W I ESNER I

$W I$ IESNER I

GL OBUL I FERA

GL CBULIFERA

AD VENA

AD VENA

AD VENA

AD VENA

A D VENA

ADVENA

AD VENA

ADVENA

AD VENA

ADVENA

ADVENA

ADVENA

AD VENA

AD VENA

ADVENA

ADVENA

A DVENA

ADVENA

$A D V E N A$

ADVENA

ADVENA

ADVENA

AD VENA

AD VENA

ADVENA

ADVENA

AD VENA

ADVENA

AD VENA

ADVENA

ADVENA

ADVENA

ADVENA

ADVENA

ADVENA

AD VENA

AD VENA

ADVENA

ADVENA

ADVENA

ADVENA

ADVENA

A D VENA

ADVENA

AD VENA

ADVENA

DINORPHA

NE GULF OF MEXICO

NE GULF OF MEXICO

HEALD BANK, G. OF MEXICO

$N W$ GULF OF MEXICO

CENTRAL GULF OF MEXICO

CENTRAL GULF OF MEXICO

CENTRAL GULF OF MEXICO

NW GULF OF MEXICO 


\section{Publication}

23576 PFLUM FRERICHS 1976 23577 PFLUM FRERICHS 1976 23578 PFLUM FRERICHS 1976 23579 PARKER 1954

23580 PARKER 1954

23581 PARKER 1954

23582 PARKER 1954

23583 PARKER 1954

23584 PFLUM FRERICHS 1976

23585 PFLUM FRERICHS 1976

23586 PFLUM FRERICHS 1976

23587 PFLUM FRERICHS 1976

23588 PFLUM FRERICHS 1976

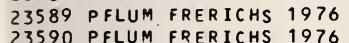
23590 PFLUM FRERICHS 1976
23591 PFLUM FRERICHS 1976 23592 PFLUM FRERICHS 1976 23593 PFLUM FRERICHS 1976 23594 PFLUM FRERICHS 1976 23595 PFLUM FRERICHS 1976 23596 PFLUM FRERICHS 1976 23597 LANKFORD 1959

23598 LEROY HODGKINSON 1975 23599 PFLUM FRERICHS 1976 23600 PFLUM FRERICHS 1976 23601 PFLUM FRERICHS 1976 23602 PFLUM FRERICHS 1976 23603 PFLUM FRERICHS 1976 23604 PFLUM FRERICHS 1976 23605 PFLUM FRERICHS 1976 23606 PFLUM FRERICHS 1976 23607 PFLUM FRERICHS 1976 23608 PFLUM FRERICHS 1976 23609 PFLUM FRERICHS 1976 23610 PFLUM FRERICHS 1976 23611 PFLUM FRERICHS 1976 23612 PFLUM FRERICHS 1976 23613 PFLUM FRERICHS 1976 23614 PFLUM FRERICHS 1976 23615 PFLUM FRERICHS 1976 23616 PFLUM FRERICHS 1976 23617 PFLUM FRERICHS 1976 23618 PFLUM FRERICHS 1976 23619 PFLUM FRERICHS 1976 23620 PFLUM FRERICHS 1976 23621 PFLUM FRERICHS 1976 23622 PFLUM FRERICHS 1976 23623 PFLUM FRERICHS 1976 23624 PFLUM FRERICHS 1976 23625 PFLUM FRERICHS 1976 23626 PFLUM FRERICHS 1976 23627 PFLUM FRERICHS 1976 23628 PFLUM FRERICHS 1976 23629 PFLUM FRERICHS 1976 23630 PFLUM FRERICHS 1976 23631 PFLUM FRERICHS 1976 23632 PFLUM FRERICHS 1976 23633 PFLUM FRERICHS 1976 23634 PFLUM FRERICHS 1976 23635 PFLUM FRERICHS 1976 23636 PFLUM FRERICHS 1976 23637 PFLUM FRERICHS 1976 23638 PFLUM FRERICHS 1976 23639 PFLUM FRERICHS 1976 23640 CUSHMAN 1920

23641 CUSHMAN 1920
23642 LEROY HODGKINSON 1975

23642 LEROY HODGKINSON 197
23643 PFLUM FRERICHS 1976

23644 PARKER 1954

23645 PARKER 1954

23646 LUDWICK HALTON 1957

23647 PARKER 1954

23648 PARKER 1954

23649 PARKER 1954

23650 PARKER 1954

23651 PARKER 1954

23652 PARKER 1954

23653 PARKER 1954

23654 PARKER 1954

23655 PARKER 1954

23656 CUSHMAN 1920

23657 CUSHMAN 1920
23658 CUSHMAN 1920

23658 CUSHMAN 1920
23659 PFLUM FRERICHS 1976

23660 PFLUM FRERICHS 1976

23661 PHLEGER 1951A

23662 PHLEGER 1951 A

23663 PHLEGER 1951 A

23664 PFLUM FRERICHS 1976

23665 PHLEGER 1951A

23666 PHLEGER 1951A

23667 PHLEGER 1951A

23668 PHLEGER 1951A

23669 PHLEGER 1951 A
23670 PFLUM FRERICHS 1976
Generic Name

RECTOBOLIVINA

RECTOBOLIVINA

RECTOBOLIVINA

RECTOBOLIVINA

RECTOBOL IVINA

RECTOBOL IVINA

RECTOBOLIVINA

RECTOBOL IV INA

RECTOBOLIVINA

RECTOBOLIVINA

RECTOBOL IVINA

RECTOBOLIVINA

RECTOBOLIVINA

RECTOBOLIVINA

RECTOBOLIVINA

RECTOBOLIVINA

RECTOBOLIVINA

RECTOBOL IVINA

RECTOBOLIVINA

RECTOBOLIVINA

RECTOBOLIVINA

RECTUVIGERINA

RECUR VOI DES

RECUR VOIDES

RECUR VOIDES

RE CURVOIDES

RE CURVOIDES

RECUR VOIDES

RECURVOIDES

RE CUR VOIDES

RE CUR VOIDES

RECURVOIDES

RECUR VOIDES

RECURVOIDES

RE CUR VOIDES

RECURVOIDES

RE CUR VOIDES

RE CURV OIDES

RECURVOI DES

RE CUR VOIDES

RECURVOIDES

RECUR VOIDES

RE CURVOIDES

RECURVOIDES

RECURVOIDES

RE CUR VOIDES

RECURVOIDES

RE CURVOIDES

RECURVOIDES

RE CURVOIDES

RECURVOIDES

RE CURVOIDES

RECURVOIDES

RECURVOIDES

RE CUR VOIDES

RECURVOIDES

RECURVOIDES

RECURVOIDES

RECURVOIDES

RE CUR VOIDES

RECURVOIDES

RE CURVOI DES

RECUR VOIDES

RECURVOIDES

RE OPHAX

REOPHAX

REOPHAX

RE OPHAX

RE OPHAX

RE OPHAX

RE OPHAX

RE OPHAX

RE OPHAX

REOPHAX

RE OPHAX

RE OPHAX

REOPHAX

RE OPHAX

RE OPHAX

RE OPHAX

RE OPHAX

RE OPHAX

RE OPHAX

RE OPHAX

RE OPHAX

RE OPHAX

REOPHAX

RE OPHAX

RE OPHAX

RE OPHAX

REOPHAX

RE OPHAX

RE OPHAX

RE OPHAX

RE OPHAX

Specific Name

Locality

Lat. Long.

DI MORPHA

DI MORPHA

DI MORPHA

DI MORPHA

DI NORPHA

DI MORPHA

DI NORPHA

DI MORPHA

DI NORPHA

DINORPHA

DI FORPHA

DI MORPHA

DI MORPHA

DI NORPHA

DINORPHA

DI MORPHA

DI MORPHA

DI NORPHA

NI COLI

CONTORTUS

CONTORTUS SCITULUS

CONTORTUS SCITULUS

CONTORTUS SCITULUS

CONTORTUS SCITULUS

CONTORTUS SCITULUS

CONTORTUS SCITULUS

CONTORTUS SCIJULUS

CONTORTUS SCITULUS

CONTORTUS SCITULUS

CONTORTUS SCITULUS

CONTORTUS SCITULUS

CONTORTUS SCITULUS

COATORTUS SCITULUS

CONTORTUS SCITULUS

CONTORTUS SCITULUS

CONTORTUS SCITULUS

CONTORTUS SUBGLOBOSUS

CONTORTUS SUBGLOBOSUS

CONTORTUS SUBGLOBOSUS

CONTORTUS SUBGLOBOSUS

COATORTUS SUBGLOBOSUS

CONTORTUS SUBGLOBOSUS

CONTORTUS SUBGLOBOSUS

CONTORTUS SUBGLOBOSUS

CONTORTUS SUBGLOBOSUS

CONTORTUS SUBGLOBOSUS

CONTORTUS SUBGLOBOSUS

CONTORTUS SUBGLOBOSUS

CONTORTUS SUBGLOBOSUS

CONTORTUS SUBGLOBOSUS

CONTORTUS SUBGLOBOSUS

CONTORTUS SUBGLOBOSUS

CONTORTUS SUBGLOBOSUS

CONTORTUS SUBGLOBOSUS

CONTORTUS SUBGLOBOSUS

CONTORTUS SUBGLOBOSUS

CONTORTUS SUBGLOBOSUS

CONTORTUS SUBGLOBOSUS

CONTORTUS SUBGLOBOSUS

CONTORTUS SUBGLOBOSUS

CONTORTUS SUBGLOBOSUS

ADLNCUS

ADUNCUS

AGGLUTINATUS

BACILLARIS

BILOCULAR IS

BI LOCULAR IS

BI LOCULAR IS

B I LOCULAR IS

BI LOCUL AR IS

BILOCULAR IS

BILOCULAR IS

BI LOCUL AR IS

B I LOCULAR IS

B I LOCULAR IS

BI LOCULAR IS

BI LOCULAR IS

BILOCULAR IS

DENTALINI FORMIS

DENTALINI FORMIS

DEATALINI FORMIS

DENTALINI FORMIS

DEATALINI FORMIS

DENTALINI FORMIS

DENTALINI FORMIS

DENTALINI FORMIS

DE ATALI NI FORMIS

DENTALINI FORMI

DENTALINI FORM I

DE ATALINI FORMI S

DEATALINI FORMIS

$N$ GULF OF MEXICO

NH GULF OF MEXICO

NW GULF OF MEXICO

NE GULF OF MEXICO

NE GULF OF MEXICO

NE GULF OF MEXICO 
Publication

23671 PHLEGER $1951 \mathrm{~A}$ 23672 PHLEGER $1951 \mathrm{~A}$ 23673 PHLEGER 1951A 23674 PHLEGER 1951A 23675 PHLEGER 1951 A 23676 PHLEGER 1951A 23677 PHLEGER $1951 \mathrm{~A}$ 23678 PHLEGER 1951 A 23679 PHLEGEP 1951A 23680 PHLEGER $1951 \mathrm{~A}$ 23681 PFLUM FRERICHS 1776 23682 PFLUM FRERICHS 1976 23683 PFLUM FRERICHS 1976 23684 PFLUM FRERICHS 1976 23685 PFLUM FRERICHS 1976 23686 PFLUM FRERICHS 1976 23687 PFLUM FRERICHS 1976 23688 PFLUM FRERICHS 1976

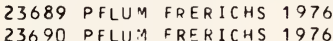
23690 PFLUA FRERICHS

23692 PFLUM FRERICHS 1976 23693 PFLUM FRERICHS 1976 23694 PFLUM FRERICHS 1976 23695 PHLEGER 1951A

23696 PFLUM FRERICHS 1976 23697 PFLUM FRERICHS 1976 23698 PFLUM FRERICHS 1976 23699 PFLUM FRERICHS 1976 23700 PFLUM FRERICHS 1976 23701 PFLUM FRERICHS 1976 23702 PFLUM FRERICHS 1976 23703 PFLUM FRERICHS 1976 23704 PHLEGER 1951A

23705 PFLUM FRERICHS 1976 23706 PFLUM FRERICHS 1976 23707 PFLUM FRERICHS 1976 23708 PFLUM FRERICHS 1976 23709 PFLUM FRERICHS 1976 23710 PFLUM FRERICHS 1976 23711 PFLUM FRERICHS 1976 23712 PFLUM FRERICHS 1976 23713 PFLUM FRERICHS 1976 23714 PFLUM FRERICHS 1976 23715 PFLUM FRERICHS 1976 23716 PFLUM FRERICHS 1976 23717 PFLUM FRERICHS 1976 23718 PFLUM FRERICHS 1976 23719 PFLUM FRERICHS 1976 23720 PFLUM FRERICHS 1976 23721 PFLUM FRERICHS 1976 23722 PFLUM FRERICHS 1976 23723 PFLUM FRERICHS 1976 23724 PFLUM FRERICHS 1976 23725 PFLUM FRERICHS 1976 23726 PFLUM FRERICHS 1976 23727 PFLUM FRERICHS 1976 23728 PFLUM FRERICHS 1976 23729 PFLUM FRERICHS 1976

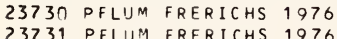
23731 PFLUM FRERICHS 1976 23733 PFLUM FRERICHS 1976 23734 PFLUM FRERICHS 1976 23735 PFLUM FRERICHS 1976 23736 PFLUM FRERICHS 1976 23737 PFLUM FRERICHS 1976 23738 PFLUM FRERICHS 1976 23739 PFLUM FPERICHS 1976 23740 PFLUM FRERICHS 1976 23741 PFLUM FRERICHS 1976 23742 PFLUM FRERICHS 1976 23743 PFLUM FRERICHS 1976 23744 PFLUM FRERICHS 1976 23745 PFLU 1 FRERICHS 1976 23746 PFLUM FRERICHS 1976 23748 PFLUM FRERICHS 1976 23749 PFLUM FRERICHS 1976 23750 PFLU:1 FRERICHS 1976 23751 PFLUM FRERICHS 1976
23752 PFLUM FRERICHS 1976 23753 PARKER 1954

23754 PARKER 1954 23756 PFLUM FRERICHS 1976 23757 PARKER 1954
23758 PARKER 1954

23759 PARKER 1954

23760 PARKER 1954

23761 DARKER 1954

23762 PARKER 1954

23763 PARKER 1954

23765 PFLUM FRERICHS 1976
Generic Name

Specific Name

DEATALINI FORM IS

DE ATALINI FORMIS

DEATALINI FORMIS

DEATALINIFORMIS

DEATALINI FORMI

DEATALINI FORMIS

DENTALINI FORMIS

DERTALINI FORMIS

DEATALINI FORMIS

DENTALINI FORMIS

DENTALINIFORMIS

DENTALINI FORMIS

DEATALINI FORMIS

DEATALINI FORMIS

DERTALINI FORMIS

DEATALINI FORMIS

DENTALINI FORMIS

DENTALINI FORMIS

DE ATALINI FORMIS

DEATALINI FORMIS

DEATALINI FORMIS

DEATALINI FORMIS

DEATALINI FORMIS

DEATALINIFORMIS

DEATALINI FORMIS

DENTALINI FORMIS

DEATALINI FORMIS

DENTALINI FORMIS

DEATALINI FORMIS

DEATALINI FORMIS

DEATALINIFORMIS

DEATALINIFORMIS

DEATALINI FORMIS

DEATALINI FORMIS

DENTALINI FORMIS

DE ATALINI FORMIS

DEATALINI FORMIS

DEATALINIFORMIS

DEATALINI FORMIS

DEATALINI FORMIS

DEATALINI FORMIS

DEATALINI FORMIS

DE $A$ TALINI FORMIS

DEATALINIFORMIS

DENTALINI FORMIS

DI STANS

DI STANS

DI STANS

I STANS

DI STANS

DI STANS

DI STANS

DI STANS

DI STANS

I STANS

DI STANS

DI STANS DELICATULUS

DI STANS DELICATULUS DI STANS DELICATULUS DI STANS DELICATULUS DISTANS DEL ICATULUS DI STANS DELICATULUS DI STANS DELICATULUS DI STANS DELICATULUS DI STANS DEL ICATULUS DI STANS DELICATULUS DI STANS DELICATULUS DI STANS DELICATULUS DI STANS DELICATULUS DI STANS DELICATULUS DI STANS DEL ICATULUS DI STANS DELICATULUS DI STANS DELICATULUS DI STANS DEL ICATULUS DI STANS DELICATULUS DI STANS DELICATULUS DI STANS , EL ICATULUS DISTANS DEL ICATULUS DI STANS DELICATULUS DISTANS DEL ICATULUS DISTANS DELICATULUS DI STANS DELICATULUS DI STANS DEL ICATULUS DISTANS , ELICATULUS DI STANS DEL ICATULUS DI STANS JELICATULUS DISTANS DEL ICATULUS DISTANS DELICATULUS DISTANS DELICATULUS DI STANS DELICATULUS DI STANS DELICATULUS DI STANS DELICATULUS DI STANS DELICATULUS DISTANS DELICATULUS
Locality

Lat. Long.

$N$ W GULF OF MEXICO

NW GULF OF MEXICO

NW GULF OF MEXICO

NW GULF OF MEXICO

NW GULF OF MEXICO

NW GULF OF MEXICO

NW GULF OF MEXICO

$\mathrm{NW}$ GULF OF MEXICO

NW GULF OF MEXICO

NW GULF OF MEXICO

NW GULF OF MEXICO

NW GULF OF MEXICO

NW GULF OF MEXICO

NW GULF OF MEXICO

$N W$ GULF OF MEXICO

NW GULF OF MEXICO

NW GULF OF MEXICO

NW GULF OF MEXICO

NW GULF OF MEXICO

$N W$ GULF OF MEXICO

NW GULF OF MEXICO

NW GULF OF MEXICO

$N W$ GULF OF MEXICO

NW GULF OF MEXICO

NW GULF OF MEXICO

NW GULF OF MEXICO

$N W$ GULF OF MEXICO

$N W$ GULF OF MEXICO

NW GULF OF MEXICO

$N W$ GULF OF MEXICO

NW GULF OF MEXICO

NW GULF OF MEXICO

NW GULF OF MEXICO

$N W$ GULF OF MEXICO

NW GULF OF MEXICO

CENTRAL GULF OF MEXICO

CENTRAL GULF OF MEXICO

CENTRAL GULF OF MEXICO

CENTRAL GULF OF MEXICO

CENTRAL GULF OF MEXICO

NW GULF OF MEXICO

$N W$ GULF OF MEXICO

$N W$ GULF OF MEXICO

NW GULF OF MEXICO

NW GULF OF MEXICO

NW GULF OF MEXICO

NW GULF OF MEXICO

$N W$ GULF OF MEXICO

NW GULF OF MEXICO

NW GULF OF MEXICO

NW GULF OF MEXICO

NW GULF OF MEXICO

NW GULF OF MEXICO

NW GULF OF MEXICO

$N W$ GULF OF MEXICO

NW GULF OF MEXICO

NW GULF OF MEXICO

NW GULF OF MEXICO

NW GULF OF MEXICO

NW GULF OF MEXICO

NW GULF OF MEXICO

NW GULF OF MEXICO

NW GULF OF MEXICO

NW GULF OF MEXICO

NW GULF OF MEXICO

$N W$ GULF OF MEXICO

NW GULF OF MEXICO

NW GULF OF MEXICO

NW GULF OF MEXICO

NW GULF OF MEXICO

NW GULF OF MEXICO

NW GULF OF MEXICO

NW GULF OF MEXICO

$\mathrm{NW}$ GULF OF MEXICO

NW GULF OF MEXICO

NW GULF OF MEXICO

NW GULF OF MEXICO

NW GULF OF MEXICO

NW GULF OF MEXICO

$N W$ GULF OF MEXICO

NW GULF OF MEXICO

NW GULF OF MEXICO

NE GULF OF MEXICO

NE GULF OF MEXICO

CENTRAL GULF OF MEXICO

CENTRAL GULF OF MEXICO

NE GULF OF MEXICO

NE GULF OF MEXICO

NE GULF OF MEXICO

NE GULF OF MEXICO

NE GULF OF MEXICO

NE GULF OF MEXICO

NE GULF OF MEXICO

NE GULF OF MEXICO

CENTRAL GULF OF MEXICO

$2755 \mathrm{~N} 09620 \mathrm{~W}$ $2710 \mathrm{~N} 09622 \mathrm{~W}$ $26 \quad 45 \mathrm{~N} 094 \mathrm{O} 6 \mathrm{~W}$ $2750 \mathrm{~N} 093 \quad 05 \mathrm{~W}$ $2751 \mathrm{~N} 09033 \mathrm{~W}$ $2705 \mathrm{~N} 09210 \mathrm{~W}$ $2509 N 08824 W$ $2825 \mathrm{~N} 09149 \mathrm{~W}$ 
Publication

23766 PFLUM FRERICHS 1976 23767 PFLUM FRERICHS 1976 23768 PFLUM FRERICHS 1976 23769 PARKER 1954 23770 PARKER 1954

23771 PARKER 1954
23772 PFLUM FRERICHS 1976 23773 PFLUM FRERICHS 1976 23774 PFLUM FRERICHS 1976 23775 PFLUM FRERICHS 1976 23776 PFLUM FRERICHS 1976 23776 PFLUM FRERICH

23778 PFLUM FRERICHS 1976 23779 PFLUM FRERICHS 1976 23780 PFLUM FRERICHS 1976 23781 PFLUM FRERICHS 1976 23782 PFLUM FRERICHS 1976 23783 LUDWICK WALTON 1957 23784 PARKER 1954 23785 PARKER 1954 23786 PARKER 1954 23787 PARKER 1954 23788 PARKER 1954 23789 PARKER 1954 23790 PARKER 1954 23791 PARKER 1954 23792 PARKER 1954 23793 PARKER 1954 23794 PARKER 1954 23795 LUDWICK WALTON 1957 23796 PARKER 1954 23797 PARKER 1954 23798 PARKER 1954 23799 PARKER 1954 23800 PARKER 1954 23801 PARKER 1954 23802 PARKER 1954 23803 PARKER 1954 23804 PARKER 1954 23805 PARKER 1954 23806 PARKER 1954 23807 PARKER 1954 23808 PARKER 1954 23809 PARKER 1954 23810 PARKER 1954 23811 PARKER 1954 23812 PARKER 1954 23813 PARKER 1954 23814 LUDWICK WALTON 1957 23815 PARKER 1954 23816 PARKER 195 23817 BOCK 1976 23818 PARKER 1954 23819 PARKER 1954 23820 PARKER 1954 23821 PARKER 1954 23822 PARKER 195

23823 PHLEGER LANKFORD 1957

23824 LANKFOPD 1959

23825 PHLEGER 1955 B

23826 BOCK 1976

23827 SEGURA 1963

23828 WALTON 1960
23829 PHLEGER $1965 \mathrm{C}$

23830 PHLEGER LANKFORD 1978

23831 PARKER PHLEGER PEIRSON 1953 23832 PARKER PHLEGER PEIRSON 1953 23833 PHLEGER 1965 A

23834 WALTON 1964

23835 BENDA PURI 1962

23836 PHLEGER $1965 \mathrm{~B}$

23837 PHLEGER 1965 A

23838 PHLEGER 19658

23839 PARKER PHLEGER PEIRSON 1953

23840 PARKER PHLEGER PEIRSON 1953

23841 PARKER PHLEGER PEIRSON 1953

23842 PARKER PHLEGER PEIRSON 1953

23843 PFLUM FRERICHS 1976

23844 PFLUM FRERICHS 1976

23845 PFLUM FRERICHS 1976

23846 PFLUM FRERICHS 1976

23847 PFLUM FRERICHS 1976

23848 CUSHMAN 1920

23849 BOCK 1976

23850 LEROY HODGKINSON 1975

23851 CUSHMAN 1920

23852 CUSHMAN 1920

23853 NORTON 1930

23854 PFLUM FRERICHS 1976

23855 PFLUM FRERICHS 1976

23856 PFLUM FRERICHS 1976

23857 PFLUM FRERICHS 1976

23858 PFLUM FRERICHS 1976

23859 PFLUM FRERICHS 1976

23860 PFLUM FRERICHS 1976
Generic Name Specific Name

RE OPHAX

REOPHAX

REOPHAX

RE OPHAX

REOPHAX

REOPHAX

REOPHAX

REOPHAX

RE OPHAX

REOPHAX

REOPHAX

RE OPHAX

RE OPHAX

REOPHAX

RE OPHAX

RE OPHAX

REOPHAX

REOPHAX

RE OPHAX

REOPHAX

REOPHAX

REOPHAX

RE OPHAX

REOPHAX

RE OPHAX

REOPHAX

RE OPHAX

REOPHAX

REOPHAX

RE OPHAX

REOPHAX

REOPHAX

RE OPHAX

RE OPHAX

RE OPHAX

REOPHAX

REOPHAX

REOPHAX

RE OPHAX

REOPHAX

REOPHAX

REOPHAX

RE OPHAX

REOPHAX

RE OPHAX

REOPHAX

RE OPHAX

RE OPHAX

REOPHAX

REOPHAX

RE OPHAX

RE OPHAX

RE OPHAX

REOPHAX

REOPHAX

EOPHAX

RE OPHAX

RE OPHAX

REOPHAX

RE OPHAX

RE OPHAX

RE OPHAX

RE OPHAX

RE OPHAX

REOPHAX

RE OPHAX

RE OPHAX

RE OPHAX

RE OPHAX

RE OPHAX

RE OPHAX

RE OPHAX

REOPHAX

RE OPHAX

REOPHAX

RE OPHAX

RE OPHAX

RE OPHAX

RE OPHAX

REOPHAX

RE OPHAX

REOPHAX

RE OPHAX

RE OPHAX

RE OPHAX

RE OPHAX

REOPHAX

RE OPHAX

RE OPHAX

RE OPHAX
DI STANS DELICATULUS DI STANS DELICATULUS DI STANS DELICATULUS DI STANS DELICATULUS DI STANS DELICATULUS DI STANS DELICATULUS DI STANS DELICATULUS DI STANS DELICATULUS DI STANS DELICATULUS DI STANS DELICATULUS DI STANS DELICATULUS GUTTIFER

GUTTIFER

GUTTIFER

GUTTIFER

GUTTIFER

GUTTIFERA

GUTTIFERA

GUTTIFERA

GUTTIFERA

GUTTIFERA

GUTTIFERA

H I SPIDULU S

HISPIDULUS

H I SPI DULUS

HISPIDULUS

HISPIDULJS

HISPIDULUS

HISPIDULUS

HISPIDULUS

HISPIDULUS

HISPIDULUS

HISPIDULUS

HISPIDULUS

HISPIDULUS

HISPIDULUS

HISPIDULUS

HISPIDULUS

HI SPIDULJS

HI SPIDULUS

HISPIDULUS

HISPIDULUS

HISPIDULUS

HISPIDULUS

I RREGULAP IS

IR REGULAR IS

I R REGULAR IS

I R REGULAR IS

IRREGULAR IS

I R FEGULAR IS

IRREGULAR IS

IRREGULAR IS

IR RE GUL AR IS

IR RE GUL AR IS

NANA

NANA

NANA

NANA

NANA

NANA

NAAA

NANA

NANA

NANA

NANA

NA^A

NA^A

NANA

NANA

NANA

NANA

NODUL OSA

NODULOSA

NO CULOSA

NO CULOSA

NODULOSA

NO DULOSUS

NODULOSUS

NODULOSUS

NO CULOSUS

NO DULOSUS

NODULOSUS

PI LULIFER

PI LUL IFER

PI LUL IFER

PI LULIFER

PI LULIFER

PILULIFER

Locality

Lat. Long.

CENTRAL GULF OF MEXICO CENTRAL GULF OF MEXICO NW GULF OF MEXICO NE GULF OF MEXICO NE GULF OF MEXICO NE GULF OF MEXICO CENTRAL GULF OF MEXICO CENTRAL GULF OF MEXICO CENTRAL GULF OF MEXICO CENTRAL GULF OF MEXICO CENTRAL GULF OF MEXICO 


\section{Publication}

23861 PFLUM FRERICHS 1976 23862 PFLUM FRERICHS 1976 23863 PFLUM FRERICHS 1976 23864 PFLUM FRERICHS 1976 23865 PFLUM FRERICHS 1976 23866 PFLUM FRERICHS 1976 23867 CUSHMAN 1920

23868 CUSHMAN 1920 - 23869 PFLUM FRERICHS 1976 23869 PFLUM FRERICHS 1976
23870 PFLUM FRERICHS 1976 23870 PFLUM FRERICHS 1976 23872 PFLUM FRERICHS 1976 23873 PFLUM FRERICHS 1976 23874 PFLUM FRERICHS 1976 23875 PFLUM FRERICHS 1976 23876 PFLUM FRERICHS 1976 23877 PFLUM FRERICHS 1976 23878 PFLUM FRERICHS 1976 23879 PFLUM FRERICHS 1976 23880 PFLUM FRERICHS 1976 23881 PFLUM FRERICHS 1976 23882 PFLUM FRERICHS 1976 23883 PFLUM FRERICHS 1976 23884 PFLUM FRERICHS 1976 23885 PHLEGER 1951A

23886 PFLUM FRERICHS 1976

23887 PHLEGER 1951A

23888 PHLEGER 1951A

23889 PHLEGER 1951A

23890 PHLEGER 1951A

23891 PHLEGER 1951 A

23892 PHLEGER 1951A

23893 PARKER 1954

23894 PARKER 1954

23895 PHLEGER 1951 A

23896 PFLUM FRERICHS 1976

23898 PFLUM FRERICHS 1976 23899 PFLUM FRERICHS 1976 23900 PFLUM FRERICHS 1976 23901 PFLUM FRERICHS 1976 23902 PFLUM FRERICHS 1976 23903 PFLUM FRERICHS 1976 23904 PFLUM FRERICHS 1976 23905 PFLUM FRERICHS 1976 23906 PFLUM FRERICHS 1976 23907 PFLUM FRERICHS 1976 23908 PFLUM FRERICHS 1976 23909 PHLEGER 1951 A

23910 PHLEGER 1951A

23911 PFLUM FRERICHS 1976 23912 PARKER 1954

23913 PARKER 1954

23914 PARKER 1954

23915 PFLUM FRERICHS 1976 23916 PFLUM FRERICHS 1976 23917 PFLUM FRERICHS 1976 23918 PFLUM FRERICHS 1976 23919 PFLUM FRERICHS 1976 23920 PFLUM FRERICHS 1976 23921 PFLUM FRERICHS 1976 23922 PFLUM FRERICHS 1976 23923 PFLUM FRERICHS 1976 23924 PFLUM FRERICHS 1976 23925 PFLUM FRERICHS 1976 23926 PFLUM FRERICHS 1976 23927 PFLUM FRERICHS 1976 23928 PFLUM FRERICHS 1976 23929 PFLUM FRERICHS 1976 23930 PFLUM FRERICHS 1976 23931 PFLUM FRERICHS 1976 23932 PARKER 1954

23933 PFLUM FRERICHS 1976 23934 PFLUM FRERICHS 1976 23935 PFLUM FRERICHS 1976 23936 PFLUM FRERICHS 1976 23937 PFLUM FRERICHS 1976 23938 PFLUM FRERICHS 1976 23930 PHLEGER $1951 \mathrm{~A}$

23940 PARKER 1954

23941 PHLEGER 1951 A

23942 PHLEGER 1951A

23943 PHLEGER 1951A

23944 PHLEGER 1951A
23945 LUDWICK WALTON 1957

23946 PARKER 1954

23947 PARKER 1954

23949 PHLEGER 1951 A

23950 PHLEGER 1951A

23951 PHLEGER 1951A

23952 PHLEGER 1951 A

23953 PFLUM FRERICHS 1976

23954 PFLUM FRERICHS 1976
23955 PFLUM FRERICHS 1976
Generic Name

REOPHAX

RE OPHAX

REOPHAX

RE OPHAX

REOPHAX

RE OPHAX

RE OPHAX

RE OPHAX
RE OPHAX

RE OPHAX
RE OPHAX

REOPHAX

REOPHAX

RE OPHAX

REOPHAX

RE OPHAX

RE OPHAX

RE OPHAX

RE OPHAX

REOPHAX

REOPHAX

REOPHAX

RE OPHAX

REOPHAX

RE OPHAX

RE OPHAX

REOPHAX

REOPHAX

REOPHAX

REOPHAX

REOPHAX

REOPHAX

RE OPHAX

RE OPHAX

RE OPHAX

RE OPHAX

RE OPHAX

RE OPHAX

RE OPHAX

RE OPHAX

REOPHAX

RE OPHAX

REOPHAX

REOPHAX

RE OPHAX

REOPHAX

REOPHAX

RE OPHAX
REOPHAX

REOPHAX

RE OPHAX

REOPHAX

REOPHAX

REOPHAX

REOPHAX

RE OPHAX

REOPHAX

REOPHAX

RE OPHAX

REOPHAX

REOPHAX

REOPHAX

RE OPHAX

REOPHAX

REOPHAX

RE OPHAX

REOPHAX

REOPHAX

REOPHAX

REOPHAX

RE OPHAX

RE OPHAX

RE OPHAX

RE OPHAX

RE OPHAX

RE OPHAX

RE OPHAX

RE OPHAX

REOPHAX

RE OPHAX

RE OPHAX

REOPHAX

REOPHAX

RE OPHAX

RE OPHAX

RE OPHAX

REOPHAX

REOPHAX

RE OPHAX

RE OPHAX

RE OPHAX

REOPHAX

RE OPHAX
Specific Name

PILULIFER

PI LUL IFER

PI LUL IFER
PILULIFER

PILULIFER

PILULIFER

PILULIFER

PILULIFER

PI LUL IFER

PILULIFER

PILULIFER

PILULIFER

PILULIFER

PILULIFER

PILULIFER

PI UULIFER

PI LULIFER

PI LUL IFER

PILULIFER

PI LULIFER

PILULIFER

PILULIFER

PILULIFER

PILULIFER

SCCRPIURJS

SC CRPIURJS

SCCRPIURUS

SCCRPIURUS

SCCRPIURUS

SCCRPIURJS

SC CRPIURJS

SC CRPIURUS

SCCRPIURUS

SCCRPIURUS

SCCRPIURUS

SCCRPIURJS

SCCRPIURUS

SCCRPIURUS

SCCRPIURUS

SCCRPIURJS

SCCRPIURUS

SCCRPIURUS

SCCRPIURJS

SCORPIURUS

SCCRPIURJS

SC CRPIURUS

SCCRPIURUS

SCORPIURUS

SCORPIURUS

SCCRPIURUS

SCCRPIURUS

SC CRPIURUS

SCCRPIURUS

SC CRPIURUS

SC CRPIURUS

SCORPIURUS

SCCRPIURUS

SCCRPIURUS

SC CRPIURJS

SC CRPIURUS

SCCRPIURUS

SCCRPIURUS

SC CRPIURUS

SC CRPIURUS

SC CRPIURUS

SCCRPIURUS

SCCRPIURUS

SCCRPIURUS

SCCRPIURUS

SCCRPIURJS

SC CRPIURUS

SCCRPIURUS

SCCRPIURJS

SCCRPIURUS

SCCRPIURUS

SCCRPIURUS

SCCRPIURUS

SCCRPIURUS

SCCRPIURUS

SC CRPIURUS

SC CRPIURUS

SC CRPIURUS

SCCRPIURUS

SC CRPIURUS

SCCRPIURJS

SC CRPIURUS

SCCRPIURJS

SCCRPIURUS

SCORPIURJS

SC CRPIURUS

SCCRPIURUS

SCCRPIURUS

SCCRPIURUS

SCCRPIURUS

\section{Locality}

NW GULF OF MEXICO

NW GULF OF MEXICD

$\mathrm{NW}$ GULF OF MEXICO

NW GULF OF MEXICO

NW GULF OF MEXICO

NW GULF OF MEXICO

NE GULF OF MEXICO

NE GULF OF MEXICO

CENTRAL GULF OF MEXICO 
Publication

23956 PFLUM FRERICHS 1976 23957 PFLUM FRERICHS 1976 23958 PFLUM FRERICHS 1976 23959 PFLUM FRERICHS 1976 23960 BANDY 1956

23961 PFLUM FRERICHS 1976 23962 PHLEGER $1951 \mathrm{~A}$

23963 PHLEGER 1951A

23964 PHLEGER 1951 A

23965 PFLUM FRERICHS 1976 23966 PFLUM FRERICHS 1976 23967 PFLUM FRERICHS 1976 23968 VAUGHAN 1918

23969 BOCK 1976

23970 PHLEGER 1956

23971 PARKER 1954

23972 PFLUM FRERICHS 1976

23973 PHLEGER 1951A

23974 PHLEGER 1951A

23975 PHLEGER 1951 A

23976 PHLEGER $1951 \mathrm{~A}$

23977 PHLEGER 1951A

23978 PHLEGER 1951A

23979 PHLEGER 1951A

23980 PHLEGER 1951A

23981 LUDWICK WALTON 1957

23982 LEROY HODGKINSON 1975

23983 PFLUM FRERICHS 1976

23984 PFLUM FRERICHS 1976

23985 PFLUM FRERICHS 1976

23986 PFLUM FRERICHS 1976

23987 PFLUM FRERICHS 1976

23988 PFLUM FRERICHS 1976

23989 PFLUM FRERICHS 1976

23990 PFLUM FRERICHS 1976

23991 PFLUM FRERICHS 1976

23992 PFLUM FRERICHS 1976

23993 PFLUM FRERICHS 1976

23994 PFLUM FRERICHS 1976

23995 PFLUM FRERICHS 1976

23996 PFLUM FRERICHS 1976

23997 PFLUM FRERICHS 1976

23998 PFLUM FRERICHS 1976

23999 PFLUM FRERICHS 1976

24000 PFLUM FRERICHS 1976

24001 PFLUM FRERICHS 1976

24002 PFLUM FRERICHS 1976

24003 PFLUM FRERICHS 1976

24004 PFLUM FRERICHS 1976

24005 PFLUM FRERICHS 1976

24006 PFLUM FRERICHS 1976

24007 PFLUM FRERICHS 1976

24008 PFLUM FRERICHS 1976

24009 BANDY 1956

24010 BANDY 1956

24011 PARKER 1954

24012 BANDY 1956

24013 PARKER 1954

24014 BANDY 1956

24015 BANDY 1956

24016 BANDY 1956

24017 BANDY 1956

24018 BANDY 1956

24019 BANDY 1956

24020 BANDY 1956

24021 CREAGER 1958

24022 WALTON 1960

24023 PHLEGER 1956

24025 PHLEGER 1956

24026 PARKER PHLEGER PEIRSON 1953

24027 PARKER PHLEGER PEIRSON 1953

24028 PHLEGER 1956

24029 PARKER 1954

24030 PARKER 1954

24031 PARKER 1954

24032 PHLEGER 1951A

24033 PHLEGER $1951 \mathrm{~A}$

24034 DAVIS 1964

24035 PHLEGER $1951 \mathrm{~A}$

24036 PHLEGER 1951 A

24037 BANDY 1956

24038 BANDY 1954

24039 BANDY 1956

24040 BANDY 1954

24041 BANDY 1954

24042 BANDY 1956

24043 BANDY 1954

24044 BANDY 1954

24045 KELLOUGH 1956

24046 WARREN 1956

24047 LOEP 1965

24048 BANDY 1956

24049 AYALA-CASTANARES 1963

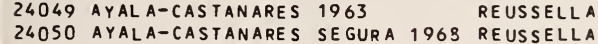

RE US SELLA

Generic Name

Specific Name

Locality

Lat. Long.

RE OPHAX

RE OPHAX

RE OPHAX

RE OPHAX

REOPHAX

REOPHAX

REOPHAX

RE OPHAX

REOPHAX

REOPHAX

RE OPHAX

RE OPHAX

RE OPHAX

RE OPHAX

RE OPHAX

RE OPHAX

RE OPHAX

REOPHAX

RE OPHAX

RE OPHAX

RE OPHAX

REOPHAX

RE OPHAX

RE OPHAX

RETICULOPHR AGMIUM

RETICUL OPHRAGMIUM

RE TI CUL OPHRAG MIUM

RETI CUL OPHRAGMIUM

RETICULOPHR AGMIUM

RETI CULOPHR AGMIUM

RETI I UL OPHR AGMIUM

RETI CUL OPHR AGMIUM

RETI CUL OPHR AGMIUM

RE TI CUL OPHRAGMIUM

RETI CUL OPHRAGMIUM

RE TI CUL OPHR AGMIUM

RE TI CULOPHRAGMIUM

RE TI CUL OPHRAGMIUM

RETI CUL OPHR AGMIUM

RETI CUL OPHR AGMI UM

RETICUL OPHR AGMIUM

RETICULOPHR AGMIUM

RETI CUL OPHRAGMIUM

RETICUL OPHR AGMIUM

RETI CUL OPHR A GMIUM

RETICULOPHRAGMIUM

RET ICUL OPHR AGMIUM

RETICULOPHRAGMIUM

RE USSELLA

RE USSELLA

REUSSELLA

REUSSELLA

RE US SELLA

REUSSELLA

REUSSELLA

REUSSELLA

RE US SELLA

RE US SELLA

RE US SELLA

REUSSELLA

REUSSELLA

REUSSELLA

RE USSELLA

REUSSELLA

RE USSELLA

REUSSELLA

RE US SELLA

REUSSELLA

RE USSELLA

REUSSELLA

REUSSELLA

RE US SELLA

RE US SELLA

RE USSELLA

REUSSELLA

RE USSELLA

RE USSELLA

REUS SELLA

REUSSELLA

RE US SELLA

RE US SELLA

REUSSELLA

RE USSELLA

REUSSELLA

RE USSELLA

RE USSELLA
SC CRPIURUS

SC CRPIURUS

SC CRPIURUS

SC CRPIURUS

SC CRPIURUS

SCCRPIURJ S

SCCRPIURU S

SC CRPIURUS

SC CRPIURU S

SCORPIURUS

SCORPIURUS

SC CRPIURU S

SCCRPIURUS

SCORPIURUS

SC ORPIURUS

SC CRPIURUS

SCORPIURUS

SC CRPIURUS

SC ORP IURU S

SC CRPIURUS

SC ORPIURUS

SC CRPIURUS

SC CRPIURUS

SC CRPIURUS

SC CRPIUR'J

VENEZUELANUM

VE NEZUELANUM

VEAEZUELANUM

VENEZUELA NUM

VENEZUELA NUM

VENEZUELANUM

VENE Z UELA NUM

VENEZUELANUM

VENEZUELANUM

VENEZUELANUM

VE NE ZUELANUM

VENEZUELANUM

VENEZUELA NUM

VEAEZUELANUM

VEAEZUELANUM

VENEZUELANUM

VENEZUELANUM

VENEZUELA NUM

VENEZUELANUM

VE NE ZUE LA NUM

VENEZUELANUM

VEAEZUELANUM

VEAEZUELANUM

ATLANTI CA

ATLANTICA

ATLANTICA

AT LANTI CA

AT LANTI CA

AT LANTI CA

AT LANTI CA

ATLANTICA

AT LANTI CA

A T LANTI CA

AT LANTI CA

LANTI CA

AT LANTI CA

AT LANTI CA

AT LANT I CA

ATLANTI CA

A T LANTICA

A T LANTICA

ATLANTICA

ATLANTICA

ATLANTICA

ATLANTICA

ATLANTICA

ATLANTICA

ATLANTICA

AT LANTICA

A T LANTI CA

ATLANTICA

AT LANTICA

AT LANTI CA

AT LANTI CA

ATLANTICA

A TLANTICA

A TLANTI CA

ATLANTICA

AT LANTICA

ATLANTICA

ATLANTICA

AT LANTI CA

AT LANTICA

A T LANTICA

CENTRAL GULF OF MEXICO

CENTRAL GULF OF MEXICO

CENTRAL GULF OF MEXICO

CENTRAL GULF OF MEXICO

NE GULF OF MEXICO

CENTRAL GULF OF MEXICO

NW GULF OF MEXICO

NW GULF OF MEXICO

NW GULF OF MEXICO

CENTRAL GULF OF MEXICO 


\section{Publication}

24051 BANDY 1956

24052 BANDY 1956

24053 BANDY 1954

24054 KELLOUGH 1956

24056 KELLOUGH 1956

24057 BANDY 1956

24058 BANDY 1956

24059 BANDY 1956

24060 BANDY 1956

24061 BANDY 1956

24062 BANDY 1956

24063 KELLOUGH 1956

24064 KELLOUGH 1956

24065 PHLEGER 1956

24066 SHIFFLETT 196

24067 PHLEGER $1951 \mathrm{~A}$

24068 SEGURA 1963

24069 PHLEGER $1951 \mathrm{~A}$
24070 PHLEGER $1951 \mathrm{~A}$

24071 PHLEGER 1951 A

24072 LUDWICK WALTON 1957

24073 PHLEGER 1956

24074 WARREN 1957

24075 SHEPARD MOORE 1955

24076 PFLUM FRERICHS 1976

24077 PFLUM FRERICHS 1976

24078 BOCK 1976

24079 PARKER PHLEGER PEIRSON 1953

24080 BOCK 1976

24082 PARKER 1954

24083 PARKER 1954

24084 PARKER 1954

24085 PHLEGER 1954

24086 LANKFORD 1959

24087 PARKER 1054

24088 PARKER 1954

24089 PARKER 1954

24090 PARKER 1954

24091 PARKER 1954

24092 PARKER 1954

24093 PARKER 1954

24094 PHLEGER 1951A

24095 PHLEGER 1951A

24096 PHLEGER 1951A

24097 PHLEGER 1951A

24098 PHLEGER $1951 \mathrm{~A}$

24099 PHLEGER $1951 \mathrm{~A}$

24100 PHLEGER 1951A

24101 PHLEGER 1951 A

24102 PHLEGER 1951A

24103 PHLEGER 1951A

24104 PHLEGER 1951A

24105 PHLEGER 1951A

24106 PHLEGER 1951 A

24107 PHLEGER $1951 \mathrm{~A}$

24108 PHLEGER 195? A

24109 PHLEGER 1951 A

24110 PARKER PHLEGER PEIRSON 1953

24111 BOCK 1976

24112 ANDERSEN 1961

24113 NORTON 1930

24114 CUSHMAN 1918

24115 PFLUM FRERICHS

24117 PFLUM FRERICHS 1976

24118 PFLUM FRERICHS 1976
24119 PFLUM FRERICHS 1976

24120 PFLUM FRERICHS 1976

24121 PFLUM FRERICHS 1976

24122 PFLUM FRERICHS 1976

24123 PFLUM FRERICHS 1976

24124 PFLUM FRERICHS 1976

24125 PFLUM FRERICHS 1976

24126 PFLUM FRERICHS 1976

24127 PFLUM FRERICHS 1976

24128 PFLUM FRERICHS 1976

24129 PFLUM FRERICHS 1976

24130 PFLUM FRERICHS 1976

24132 PFLUM FRERICHS 1976

24133 PFLUM FRERIC 4 S 1976

24134 PFLUM FRERICHS 1976

24135 PFLUM FRERICHS 1976

24136 PFLUM FRERICHS 1976

24137 PFLUM FRERICHS 1976

24138 PFLUM FRERICHS 1976

24139 PFLUM FRERICHS 1976

24140 PFLUM FRERICHS 1976

24141 PFLUM FRERICHS 1976

24142 PFLUM FRERICHS 1976

24144 PFLUM

24145 PFLUM FRERICHS 1976
Generic Name

RE USSELLA

REUSSELLA

REUSSELLA

REUS SELLA

RE USSELLA

RE USSELLA

RE USSELLA

REUS SELLA

REUSSELLA

REUSSELLA

REUSSELLA

RE USSELLA

REUSSELLA

RE US SELLA

REUSSELLA

RE US SELLA

REUSSELLA

REUSSELLA

RE US SELLA

RE USSELLA

REUSSELLA

RE USSELLA

REUSSELLA

RE USSELLA

RE USSELLA

RE USSELLA

RE USSELLA

REUSSELLA

RE US SELLA

RE USSELLA

RE USSELLA

RE USSELLA

REUSSELLA

REUSSELLA

RE USSELLA

RE USSELLA

REUSSELLA

RE USSELLA

RE USSELLA

RE USSELLA

RE USSELLA

REUSSELLA

RE USSELLA

RE USSELLA

RE USSELLA

RE USSELLA

RE USSELLA

RE USSELLA

RE USSELLA

RE USSELLA

RE USSELLA

REUSSELLA

REUSSELLA

RE USSELLA

REUSSELLA

REUSSELLA

RE USSELLA

REUSSELLA

REUSSELLA

RE USSIA

RHABDAMMINA

RHABDAMMINA

RHABDAMMINA

RHABDAMM INA

RHABDAMMIN

RHABDAMMINA

RHABDAMMINA

RHABDAMMINA

RHABDAMMINA

RHABDAMMINA

RHABDAMMINA

RHABDAMMINA

RHABDAMMIN

RHABDAMMINA

RHABDAMMINA

RHABDAMMINA

RHABDAMMINA

RHABDAMMINA

RHABDAMMIN A

RHABDAMMINA

RHABDAMMINA

RHABDAMMINA

RHABDAMMINA

RHABDAMMINA

RHABDAMMINA

RHABDAMMINA

RHABDAMMINA

RHABDAMMINA

RHABDAMMINA

RHABDAMMINA

RHABDAMMINA

RHABDAMMINA
Specific Name

Locality

A T LANTICA

A TLANTICA

AT LANTI CA

AT LANTI CA

A TLANTICA

AT LANTI CA

A T LANTI CA

A T LANTICA

ATLANTICA

ATLANTICA

ATLANTICA

A TLANTI CA

ATLANTI CA

AT LANTI CA

A TLANTI CA

A TLANTI CA

A TLANTICA

AT LANTICA

A T LANTI CA

AT LANTICA

AT LANTICA

ATLANIICA

AT LANTI CA

A TLANTI CA

A T LANTI CA

A T LANTICA

ATLANTICA

AT LANTICA

AT LANTI CA

A TLANTI CA

AT LANTICA

A T LANTICA

AT LANTI CA

AT LANTI CA

AT LANTICA

AT LANTI CA

AT LANTICA

A TLANTI CA

ATLANTICA

ATLANTI CA

ATLANTICA

A T LANTICA

A T LANTI CA

A TLANTI CA

A T LAN TICA

ATLANTICA

A T LANTICA

AT LANTICA

AT LANTI CA

A TLANTICA

A T LANTI CA

ATLANTICA

A T LANTICA

A TLANTI CA

ATLANTICA

MI CCENICA

SP INULOSA

ABYSSORUM

$A B Y S S O R U M$

ABYSSORUM

AB YSSORUY

ABYSSORUM

$A B$ YSSORUM

ABYSSORUM

$A B Y S S O R U M$

ABYSSORUM

ABYSSORUM

ABYSSORUM

ABYSSORUM

$A B Y S S O R U M$

ABYSSORUM

ABYSSORUM

AB YS SORUM

ABYSSORUM

$A B$ YSSORUM

$A B$ YSSORUM

ABYSSORUM

ABYSSORUM

ABYSSORUM

$A B$ YSSORUM

AB YSSORUY

ABYSSORUM

ABYSSORUY

$A B Y S S O R U Y$

ABYSSORUM

ABYSSORUM

AB YS SORUM

NE GULF OF MEXICO

NE GULF OF MEXICO

NW GULF OF MEXICO

NW GULF OF MEXICO

NW GULF OF MEXICO

NW GULF OF MEXICO

NE GULF OF MEXICO

NE GULF OF MEXICO

NSE GULF OF MEXICO

NE GULF OF MEXICO

NE GULF OF MEXICO

NE GULF OF MEXICO

NW GULF OF MEXICO

NW GULF OF MEXICO

NW GULF OF MEXICO

HEALD BANK, G. OF MEXICO 


\section{Publication}

24146 LEROY HODGKINSON 1975 24147 PFLUM FRERICHS 1976 24148 PFLUM FRERICHS 1976 24149 PFLUM FRERICHS 1976 24150 PFLUM FRERICHS 1976 24151 PFLUM FRERICHS 1976 24152 PFLUM FRERICHS 1976 24953 PFLUM FRERICHS 1976 24154 PFLUM FRERICHS 1976 24155 PFLUM FRERICHS 1976 24156 PFLUM FRERICHS 1976 24157 PFLUM FRERICHS 1976 24158 PFLUM FRERICHS 1976 24159 CUSHMAN 1918

24160 PFLUM FRERICHS 1976 24161 PFLUM FRERICHS 1976 24162 CUSHMAN 1918 24163 CUSHMAN 1918 24164 CUSHMAN 1918 24165 LEROY HODGKINSON 1975 24166 CUSHMAN 1918

24167 PFLUM FRERICHS 1976 24168 LEROY HODGKINSON 1975 24169 PFLUM FRERICHS 1976 24170 PFLUM FRERICHS 1976 24171 PFLUM FRERICHS 1976 24172 PFLUM FRERICHS 1976 24173 PFLUM FRERICHS 1976 24174 PFLUM FRERICHS 1976 24175 PFLUM FRERICHS 1976 24176 PFLUM FRERICHS 1976 24177 PFLUM FRERICHS 1976 24178 PFLUM FRERICHS 1976 24179 PFLUM FRERICHS 1976 24180 PFLUM FRERICHS 1976 24181 PFLUM FRERICHS 1976 24182 PFLUM FRERICHS 1976 24183 PFLUM FRERICHS 1976 24184 PFLUM FRERICHS 1976 24185 PFLUM FRERICHS 1976 24186 PFLUM FRERICHS 1976 24187 PFLUM FRERICHS 1976 24188 CUSHMAN 1918

24189 CUSHMAN 1918

24190 PFLUM FRERICHS 1976 24191 PFLUM FRERICHS 1976 24192 PFLUM FRERICHS 1976 24193 PFLUM FRERICHS 1976 24194 PFLUM FRERICHS 1976 24195 PFLUM FRERICHS 1976 24196 PFLUM FRERICHS 1976 24197 CUSHMAN 1918 24198 CUSHMAN 1918 24199 PFLUM FRERICHS 1976 24200 PFLUM FRERICHS 1976 24201 PFLUM FRERICHS 1976 24202 PFLUM FRERICHS 1976 24203 PFLUM FRERICHS 1976 24204 PFLUM FRERICHS 1976 24205 PFLUM FRERICHS 1976 24206 PFLUM FRERICHS 1976 24207 PFLUM FRERICHS 1976 24208 PFLUM FRERICHS 1976 24209 PFLUM FRERICHS 1976 24210 PFLUM FRERICHS 1976 24211 PFLUM FRERICHS 1976 24212 PFLUM FRERICHS 1976 24213 PFLUM FRERICHS 1976 24214 PFLUM FRERICHS 1976 24215 PFLUM FRERICHS 1976 24216 PFLUM FRERICHS 1976 24217 PFLUM FRERICHS 1976 24218 PFLUM FRERICHS 1976 24219 NORTON 1930

24220 PFLUM FRERICHS 1976 24221 PFLUM FRERICHS 1976 24222 PFLUM FRERICHS 1976 24223 PFLUM FRERICHS 1976 24224 PFLUM FRERICHS 1976 24225 PFLUM FRERICHS 1976 24226 PFLUM FRERICHS 1976 24227 PFLUM FRERICHS 1976 24228 PFLUM FRERICHS 1976 24229 PFLUM FRERICHS 1976 24230 PFLUM FRERICHS 1976 24231 PFLUM FRERICHS 1976 24232 PFLUM FRERICHS 1976 24233 PFLUM FRERICHS 1976 24234 PFLUM FRERICHS 1976 24235 PFLUM FRERICHS 1976 24236 PFLUM FRERICHS 1976 24237 PFLUM FRERICHS 1976 24238 PFLUM FRERICHS 1976 24239 PFLUM FRERICHS 1976
24240 PFLUM FRERICHS 1976
Generic Name

RHABDAMMINA RH ABDAMM INA RHABDAMMINA RHABDAMMINA RHABDAMMINA RHABDAMMINA RHABDAMMINA RHABDAMMINA RHABDAMMINA RHABDAMMINA RHABDAMMINA RHABDAMMINA RH ABDAMMINA RHABDAMMINA RHABDAMMINA RHABDAMMINA RHABDAMMINA RHABDAMMINA RHABDAMMINA RHABDAMMINA RHABD AMMINA RHABDAMMINA RHABDAMMINA RH ABDAMMINA RHABDAMM INA RH ABDAMMINA RHABDAMMINA RHABDAMMINA RHABDAMMINA RH ABDAMMINA RHABDAMMINA RHABDAMMINA RHABDAMMINA RHABDAMMINA RHAB DAMMINA RHABDAMMINA RHABDAMMINA RHABDAMMINA RHABDAMMINA RHABDAMMIN RHABDAMMINA RHABDAMMINA RHABDAMMINA RHABDAMMINA RHABDAMMIN A RHABDAMMIN A RH ABDAMMIN A RHABDAMMINA RHABDAMMINA RHABDAMMINA RHABDAMMINA RHABDAMMINA RHABDAMMINA RHABDAMMINA RHABDAMMINA RHABDAMMINA RHABDAMMINA RHABDAMMINA RHABDAMMINA RHABDAMM INA RH ABDAMMINA RHABDAMMINA RHABDAMMINA RHABDAMMINA RHABDAMMINA RHABDAMMIN A RH ABDAMMINA RHABDAMMINA RHABDAMMINA RHABDAMMINA RHIZAMMI NA RH I ZAMMINA RHIZAMMINA RHIZ AMMINA RHIZ AMMINA RHIZ AMMI NA RH IZ AMMINA RHIZAMMINA RH IZ AMM INA RH IZ AMM I NA RHIZ AMM I NA RH IZ AMM I NA RHIZ AMMINA RHIZAMMINA RHIZAMMINA RHIZ AMM I NA RH IZ AMMINA RHIZ AMM I NA RHIZ AMM INA RH IZ AMM INA RHIZ AMMINA RHIZ AMMINA RH IZ AMM I NA RH IZ AMM I NA
Specific Name

ABYSSORUM ABYSSORUM ABYSSORUM ABYSSORUM ABYSSORUM ABYSSORUM ABYSSORUA ABYSSORUM ABYSSORUM ABYSSORUM AB YS SORUM ABYSSORUM ABYSSORUM AB YSSORUM ABYSSORUM ABYSSORUM RADIATA DI SCRETA DI SCRETA OI SCRETA

OISCRETA

INEARIS

LI AEARIS

LI AEARIS

LINEARIS

LINEARIS

LINEARIS

LINEARIS

LINEARIS

LINEARIS

LINEAR IS

LINEAR IS

LI AEARIS

I NEARIS

I NEARIS

LINEARIS

LINEARIS

LI NEARIS

LINEARIS

LINEARIS

LINEAR IS

LINEARIS

LINEARIS

LI AEARIS

LI AEARIS

LINEARIS

LINEARIS

LINEARIS

LIAEARIS

LI AEARIS

LI NEARIS

LINEARIS

LINEARIS

LI AEARIS

LI AEARIS

LINEARIS

LIAEARIS

LINEARIS

LIAEARIS

LI AEARIS

LINEARIS

I NEARIS

LINEAR IS

LIAEARIS

AL GAEFORY IS

AL GAEFORY IS

AL GAEFORM IS

AL GAEFORM IS

AL GAEFORM IS

AL GAEFORM IS

AL GAEFORM IS

AL GAEFORM IS

AL GAEFORMIS

AL G AEFORM IS

AL GAEFORM IS

ALGAEFORMIS

AL GAEFORM IS

AL GAEFORMIS

AL GAE FORMIIS

AL GAEF ORM IS

ALGAEFORM IS

AL GAEF ORMIS

AL GAEF O ORM IS

AL GAEFORM IS

AL GAEFORM IS

AL GAEFORMIS

AL EAEFORM IS

\section{Locality}

Lat. Long.

$N$ GULF OF MEXICO

NU GULF OF MEXICO

NW GULF OF MEXICO

NW GULF OF MEXICO

NW GULF OF MEXICO

CENTRAL GULF OF MEXICO

CENTRAL GULF OF MEXICO

CENTRAL GULF OF MEXICO 


\section{Publication}

24241 PFLUM FRERICHS 1976 24242 PFLUM FRERICHS 1976 24243 CUSHMAN 1918

24244 PARKER 1954
24245 LUDWICK WALTON 1957

24246 PARKER 1954
24247 PARKER 1954

24248 PARKER 1954

24249 PARKER 1954

24250 PARKER 1954

24251 PARKER 1954

24252 PARKER 1954

24253 PARKER 1954

24254 PARKER 1954

24255 PFLUM FRERICHS 1976

24256 PFLUM FRERICHS 1976

24257 PFLUM FRERICHS 1976

24258 PFLUM FRERICHS 1976 24259 PFLUM FRERICHS 1976 24260 PFLUM FRERICHS 1976 24261 PFLUM FRERICHS 1976 24262 PFLUM FRERICHS 1976 24263 PFLUM FRERICHS 1976 24264 PFLUM FRERICHS 1976 24265 PFLUM FRERICHS 1976 24266 PFLUM FRERICHS 1976 24267 PFLUM FRERICHS 1976 24268 PFLUM FRERICHS 1976 24269 PFLUM FRERICHS 1976 24270 PFLUM FRERICHS 1976 24271 PFLUM FRERICHS 1976 24272 PFLUM FRERICHS 1976 24273 PFLUM FRERICHS 1976 24274 PFLUM FRERICHS 1976 24275 PFLUM FRERICHS 1976 24276 PFLUM FRERICHS 1976 24277 PFLUM FRERICHS 1976 24278 PFLUM FRERICHS 1976 24279 ANDERSEN 1961

24280 BOCK 1976

24281 PFLUM FRERICHS 1976

24282 ANDERSEN 1961

24283 BANDY 1956

24284 ANDERSEN 1961

24285 BANDY 1956

24286 BANDY 1956

24287 NORTON 1930
24288 LANKFORD 1959

24289 BANDY 1956

24290 BANDY 1956

24291 BANDY 1956

24292 BANDY 1956

24293 BANDY 1956

24294 ANDERSEN 1961

24295 ANDERSEN 1961

24296 ANDERSEN 1961

24297 ANDERSEN 1961

24298 ANDERSEN 1961

24299 BANDY 1956

24300 BANDY 1956

24301 BANDY 1956

24302 BANDY 1956

24303 BANDY 1956

24304 BANDY 1956

24305 SEGURA 1963

24306 LEHMANN 1957

24307 BOCK 1976

24308 PARKER
243094
PARKER 1954

24310 PARKER 1954

24311 PARKER 1954

24312 PARKER 1954

24313 LUDWICK WALTON 1957

24314 PARKER 1954

24315 PARKER 1954

24316 PARKER 1954

24317 PARKER 1954

24318 PARKER 1954

24319 PARKER 1954

24320 PARKER 1954

24321 PARKER 1954

24322 BOCK 1976

24323 BOCK 1976

24324 BOCK 1976

24325 BOCK 1976

24326 BOCK 1976

24327 BOCK 1976

24328 BOCK 1976

24329 PARKER 1954

24330 PARKER 1954

24331 PARKER 1954

24332 PARKER 1954

24333 PARKER 1954

24334 PARKER 1954
24335 PARKER 1954
Generic Name

RHIZ AMMINA

RH IZ AMMI NA

RHIZAMMINA

ROBERT INA

ROBERTINA

ROBERT INA

ROBERTINA

ROBERTINA

ROBERT INA

ROBERT INA

ROBERTINA

ROBERTINA

ROBERTINA.

ROBERT INA

ROBERTINA

ROBERTINOIDES

ROBERTINOIDES

ROBERTINOIDES

ROBERTINOIDES

ROBERTINOIDES

ROBERTINOIDES

ROBERTINOIDES

ROBERTINOIDES

ROBERTINOIDES

ROBER I INOIDES

ROBERTINOIDES

ROBERIINOIDES

ROBERTINOIDES

ROBERTINOIDES

ROBERTINOI DES

ROBER I INOIDES

ROBERTINOIDES

ROBERTINOIDES

ROBERTINOI DES

ROBERTINOIDES

ROBERT INOIDES

ROBERTINOIDES

ROBERTINOIDES

ROBERTINOIDES

ROBULUS

ROBULUS

ROBULUS

ROBULUS

ROBULUS

ROBULUS

ROBULUS

ROBULUS

ROBULUS

ROBULUS

ROBULUS

ROBULUS

ROBULUS

ROBULUS

ROBULUS

ROBULUS

ROBULUS

ROBULUS

ROBULUS

ROBULUS

ROBULUS

ROBULUS

ROBUL US

ROLSHAUSENIA

ROLSHAUSENIA

ROSALINA

ROSALINA

ROSALINA

ROSALINA

ROSALINA

ROSALINA

ROSALINA

ROSALINA

ROSALINA

ROSALINA

ROSALINA

ROSALINA

ROSALINA

ROSALINA

ROSALINA

ROSALINA

ROSALINA

ROSALINA

ROSALINA

ROSALINA

ROSALINA

ROSALINA

ROSALINA

ROSALINA

ROSALINA

ROSAL INA

ROSALINA

ROSALINA

ROSALINA
Specific Name

AL GAEFORY IS

AL GAE FORM IS

IN DIVISA

BRADYI

BRADYI

BRADYI

BRADYI

BRADY I

BRADYI

BRADYI

BRADY I

BR ADYI

BRADYI

BRADYI

OCEANICA

OC EANICA

BRADYI

BRADYI

BRADYI

BRADYI

BRADYI

BRADY

BRADYI

BRADYI

BRADYI

BRADYI

BRADYI

BRADYI

BRADY

BRADY

BRADYI

BRADYI

BRADYI

BRADYI

BRADYI

BRADY

BRADYI

BRADYI

BRADYI

BRADYI

BOWDENENS IS

CALCAR

CALCAR

CALCAR

CALCAR

CALCAR

CALCAR

CALCAR

CALCAR

CALCAR

CALCAR

COAVERGEVS

CULTRATUS

FALCIFER

I O TUS

LOWMANI

SERPENS

ST EPHENSONI

STEPHENSON

ST EPHEN SONI

ST EPHEN SON

SUEORB I CULARIS

SUEORBICJLARIS

ROLSHAUSENI

ROLSHAUSENI

BAHAMAENS IS

BERTHELOI I

BERTHELOT I

BERTHELOT I

BE RTHELOT I

BERTHELOT I

BEFTHEL OT I

BERTHEL OT I

BERTHELOTI

BERTHELOT I

BERTHELOT I

BEFTHELOT I

BERTHELOT I

BERTHELOTI

BERTHELOT I

BU LBOSA

COLUMBIEVSI S

COLUMBIENSIS

COLUMBIENSIS

COLUMBIEVSI

COLUMBIEVSIS

COLUMBIENSIS

COACINNA

CONCINNA

CONCINNA

CONCINNA

CONCINNA

CONCINNA

CONCINNA

Locality

NW GULF OF MEXICO

NW GULF OF MEXICO

NE GULF OF MEXICO

NE GULF OF MEXICO

NE GULF OF MEXICO

NE GULF OF MEXICO

NE GULF OF MEXICO 
Publication

24336 PARKER 1954 24337 PARKER 1954 24338 PARKER 1954 24339 PARKER 1954 24340 PARKER 1954 24341 LUDWICK WALTON 1957 24342 PARKER 1954 24343 PARKER 1954

24344 SEGURA 1963

24345 KELLOUGH 1956

24346 PARKER 1954
24347 AYALA-CASTANARES 1963

24347 AYALA-CASTANA
24348 PARKER 1954

24349 PARKER 1954

24350 PARKER 1954

24351 PHLEGER 1956

24352 PHLEGER 1956

24353 PARKER 1954

24354 PHLEGER 1956

24355 PHLEGER 1956

24356 PARKER 1954
24357 PARKER 1954

24358 BOCK 1976

24359 SEGURA 1963

24360 PHLEGER LANKFORD 1957

24361 PARKER 1954

24362 LUDWICK WALTON 1957

24363 PARKER 1954

24364 PARKER 1954

24365 PHLEGER $1965 \mathrm{~B}$

24367 BENDA PURI 1962

24367 BENDA PURI
24368 WALTON 1964

24369 AYALA-CASTANARES SEGURA 1968

24370 AYALA-CASTANARES 1963

24371 PHLEGER 1956

24372 PHLEGER 1956

24373 PARKER 1954
24374 PHLEGER $1965 A$

24374 PHLEGER 1965
24375 PARKER 1954

24376 PARKER 1954

24377 PARKER 1954

24378 PARKER 1954

24379 PARKER 1954

24380 PARKER 1954

24381 BOCK 1976

24382 PARKER 1954

24383 PARKER 1954
24384 PARKER 1954

24385 PARKER 1954

24386 PARKER 1954

24387 PHLEGER 1956

24388 PHLEGER 1956

24389 PHLEGER 1956

24390 BOCK 1976

24391 PARKER 1954

24392 PARKER 1954

24394 LUDHICK WALTON 1957

24395 PARKER 1954

24396 PARKER 1954

24397 PARKER 1954

24398 PARKER 1954

24399 PARKER 1954

24400 PARKER 1954

24401 PARKER 1954

24402 PARKER 1954

24403 WALTON 1964

24404 PARKER 1954

24405 PARKER 1954

24406 PARKER 1954

24407 PARKER 1954

24408 PARKER 1954

24409 PARKER 1954

24410 PARKER 1954

24411 PARKER 1954

24412 PARKER 1954

24413 PARKER 1954

24414 PARKER 1954

24415 PARKER 1954

24416 PARKER 1954

24417 PARKER 1954

24418 PARKER 1954

24419 PARKER 1954

24420 PARKER 1954

24421 PARKER 1954

24422 LUDWICK WALTON 1957

24423 PARKER 1954

24424 ANDERSEN 1961

24425 PARKER 1954

24426 PARKER 1954

24427 LUDWICK WALTON 1957

24428 PARKER 1954

24429 PARKER 1954

24430 PARKER 1954
Generic Name

ROSALINA

RO SALINA

ROSALINA

ROSALINA

ROSALINA

ROSAL INA

ROSALINA

ROSALINA

ROSALINA

ROSALINA

ROSALINA

ROSALINA

ROSALINA

ROSALINA

ROSALINA

ROSALINA

ROSALINA

RO SAL INA

ROSALINA

ROSALINA

ROSALINA

ROSALINA

ROSALINA

ROSALINA

ROSALINA

ROSALINA

ROSALINA

ROSALINA

ROSALINA

ROSALINA

ROSALINA

ROSA LINA

ROSALINA

ROSALINA

ROSALINA

ROSALINA

ROSALINA

ROSALINA

ROSALINA

ROSALINA

ROSALINA

ROSALINA

ROSALINA

ROSALINA

ROSALINA

ROSALINA

ROSALINA

ROSALINA

ROSALINA

ROSALINA

ROSALINA

ROSALINA

ROSALINA

ROSALINA

ROSALINA

ROSALINA

ROSALINA

ROSALINA

ROSALINA

ROSALINA

ROSALINA

ROSALINA

ROSALINA

ROSALINA

ROSALINA

ROSALINA

ROSALINA

ROSALINA

ROSALINA

ROSALINA

ROSALINA

ROSALINA

ROSALINA

ROSALINA

ROSALINA

ROSALINA

ROSALINA

ROSALINA

ROSALINA

ROSALINA

ROSALINA

ROSALINA

ROSALINA

ROSALINA

ROSALINA

ROSALINA

ROSALINA

ROSALINA

Specific Name

Locality

Lat. Long.

CONCINNA

CONCINNA

COACINNA

CONCINNA

CONCINNA

CONCINNA

CONCINNA

CONCINNA

CONCINNA

CONCINNA

COACINNA

COACINNA

CONCINNA

CONCINNA

CONCINNA

CONCINNA

COACINNA

CONCINNA

CONCINNA

CONCINNA

CONCINNA

FL CR I DANA

FLORIDANA

FL OR I DANA

FL ORI DANA

FL ORI DANA

FLOR I DANA

FLCRIDANA

FL CR IDANA

FL OR IDANA

FLOR I DANA

FLCRIDANA

FL CR I DANA

FL CRIDANA

FL ORI DANA

FL CR I DANA

FL ORI DANA

FL CR I DANA

FL CRI DANA

FL CRIDANA

FL CRIDANA

FL CR IDANA

FL CR IDANA

FL OR IDANA

FL CRIDANA

FL OR I DANA

FLOR I DANA

FL OR I DANA

FLCRIDANA

FL CRIDANA

FL CRIDANA

FLCR IDENS IS

FLCRIDENS IS

FLORIDENS IS

FL CRIDENS IS

FL CR IDENS IS

FLCRIDENS IS

FL ORIDENS IS

FLORIDENS IS

FL OR I DENS IS

FL ORI DENS IS

PARKERAE

PARKERAE

PARKERAE

PARKERAE

PARKERAE

PARKERAE

PARKERAE

PARKERAE

PARKERAE

PARKERAE

PARKERAE

PARKERAE

PARKERAE

PARKERAE

PAFKERAE

PARKERAE

PARKERAE

PARKERAE

PARKERAE

PARKERAE

PARKERAE

PARKERAE

PARKERAE

PARKERAE

SUEZENS IS

SUEZENSIS

SUEZENSIS

SUEZENS IS

SUEZENS IS

SUEZENS IS

SUEZENSIS

NE GULF OF MEXICO

NE GULF OF MEXICO

NE GULF OF MEXICO

NE GULF OF MEXICO

NE GULF OF MEXICO

NE GULF OF MEXICO

NE GULF OF MEXICO

NE GULF OF MEXICO

MAT AMOROS, MEXICO

NW GULF OF MEXICO

NE GULF OF MEXICO

L. DE TERMINOS. CAMPECHE

NE GULF OF MEXICO

NE GULF OF MEXICO 


\section{Publication}

24431 PARKER 1954

24432 PARKER 1954

24433 PARKER 195

24434 PFLUM FRERICHS 1976

24435 PFLUM FRERICHS 1976

24436 PFLUM FRERICHS 1976

24437 PFLUM FRERICHS 1976

24430 PARKER 1954

24440 PHLEGER 1956

24441 PHLEGER 1956

24442 PARKER 1954

24443 PHLEGER 1956

24444 BOCK 1976

24445 PARKER 1054

24446 PARKER 1954

24447 PARKER 1954

24448 PARKER 1954

24449 PARKER 1954

24450 PARKER 1954

24451 PARKER 1954

PARKER 1954

24453 PARKER 1954
24454 PARKER 1954

24455 PHLEGER 1954

24456 LUDWICK WALTON 1957

24457 PARKER PHLEGER PEIRSON 1953

24458 SHENTON 1957

24459 PARKER PHLEGER PEIRSON 1953 24460 PHLEGER 1956

24461 PHLEGER 1954

24462 PARKER 1954

24464 PARKER 1054

24465 POST 1951

24466 PARKER 1954

24467 PARKER 1954

24468 PHLEGER $1955 \mathrm{~B}$

24469 CUSHMAN $1922 \mathrm{~A}$

24470 SHEPARD MOORE 1955

24471 CREAGER 1958

24472 CREAGER 1958

24473 POST 1951

24474 KELLOUGH 1956

24475 KELLOUGH 1956

24476 KELLOUGH 1956

24478 NORTON 1930

24479 PARKER 1954

24480 PARKER 1954

24481 PARKER 1954

24482 PHLEGER 1956

24483 PHLEGER 1956

84 PHLEGER 1956

24485 PHLEGER 1956
24486 PARKER PHLEGER PEIRSON 1933

24487 PARKER PHLEGER PEIRSON 1953 24488 PARKER PHLEGER PEIRSON 1953 24489 PARKER PHLEGER PEIRSON 1953 24490 PARKER PHLEGER PEIRSON 1953 24491 PARKER PHLEGER PEIRSON 1953 24492 PARKER PHLEGER PEIRSON 1953 24493 PARKER 1954

\section{WALTON 1964}

24495 KELLOUGH 1956

24496 KELLOUGH 1956

24497 KORNFELD 1931

24498 KORNFELD 1931

\begin{tabular}{l}
24499 \\
24500 KORNFELD \\
24531 \\
\hline
\end{tabular}

24501 KORNFELD 1931

24502 WARREN 1956

24503 PHLEGER $1951 \mathrm{~A}$

24504 PHLEGER 1951A

24505 PHLEGER 1951A

24506 PHLEGER $1951 \mathrm{~A}$

24507 PHLEGER 1951A

24508 PHLEGER 1951A

24509 PHLEGER $1951 \mathrm{~A}$

24510 PHLEGER 1951A

24512 KORNFELD 1931

24513 KORNFELD 1931

24514 KORNFELD 1931

24515 KORNFELD 1931

24516 KORNFELD 1931

24517 KORNFELD 1931

24519 KORNFELD 1931

24520 KORNFELD 1931

24521 KORNFELD 1931

24522 PHLEGER 1951A

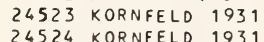

24525 KORNFELD 1931
Generic Name

ROSALINA

ROSALINA

ROSALINA

ROSAL INA

OSALINA

ROSALINA

ROSALINA

ROSALINA

ROSALINA

ROSALINA

ROSALINA

ROSALINA

ROSALINA

ROSALINA

ROSALINA

ROSALINA

ROSALINA

ROSALINA

ROSALINA

ROTALIA

ROTALIA

ROTALIA

ROTALIA

ROTALIA

ROTALIA

ROTALIA

ROTALIA

ROTALIA

ROTALIA

ROTALIA

ROTALIA

ROTALIA

ROTALIA

ROTALIA

ROTALIA

ROTALIA

ROTALIA

ROTALIA

ROTALIA

ROTALIA

ROTALIA

ROTALIA

ROTALIA

ROTALIA

ROTALIA

ROTALIA

ROTALIA

ROTALIA

ROTALIA

ROTALIA

ROTALIA

ROTALIA

ROTALIA

ROTALIA

ROTALIA

ROTALIA

ROTALIA

ROTALIA

ROTALIA

ROTALIA

ROTALIA

ROTALIA

ROTALIA

ROTALIA

ROTALIA

ROTALIA

ROTALIA

ROTALIA

ROTALIA

ROTALIA

ROTALIA

ROTALIA

ROTALIA

ROTALIA

ROTALIA

ROTALIA

ROTALIA

ROTALIA

ROTALIA

ROTALIA

ROTALIA

ROTALIA

ROTALIA

ROTALIA

ROTALIA

ROTALIA

ROTALIA

ROTALIA

ROTALIA

ROTALIA

ROTALIA

ROTALIA

\section{Specific Name}

SUEZENSIS

SUEZENSIS

SUEZENSIS

SUEZENSIS

SUEZENSIS

SUEZENS IS

SUEZENSIS

SUEZENS IS

SUEZENS IS

SUEZENSIS

SUEZENSIS

SUEZENSIS

SUEZENSIS

SUEZENSIS

SUEZENSIS

SUEZENSIS

SUEZENSIS

BECCARII

BECCARII

BECCARII

BECCARII

BECCAR I I

BE CCARI

BECCARII

BECCARI I

BECCARI I

BECCARII

BECCAR I I

BECCARII

BECCARII

BE CCAR I I

BE CCAR I I

BECCARII

BECCARII

BECCARII

BECCARII

BE CCARI I

BECCARI I

BECCARI I

BECCARII

BECCARI

BECCARI

BECCARI

BECCARI I

BE CCAR I I

BECCARII

BECCARII

BECCARII

BECCARI I

BECCARII

BECCARII

BE CCAR I I

BECCARII

BECCARII

BECCARI I

BECCARII

BE CCARII

BECCARI I PARKINSONIANA

BECCARI PARKINSONIANA

BECCARI I PARKINSONIANA

BECCARII PARKINSONIANA

BECCARII PARKINSONIANA

BECCARI I PARKINSONIANA

BECCARII PARK INSONIANA

BECCARII PARKINSONIANA

BECCARI I PARKINSONIANA

BECCARI I PARKINSONIANA

BE CCARII PARKINSONIANA

BECCARII PARKINSONIANA

BECCARI I PARKINSONIANA

BECCARI I PARK INSONIANA

BECCARI I PARKINSONIANA

BECCARII PARKINSONIANA

BECCARI I PARKINSONIANA

BECCARII PARK INSONIANA

BECCARII PARKINSONIANA

BE CCARII PARKINSONIANA

BECCARII PARKINSONIANA

BE CCARII PARKINSONIANA

BECCARII PARKINSONIANA

BECCARII PARKINSONIANA

BECCARI I PARKINSONIANA

BECCARII PARKINSONIANA

BECCARI I PARKINSONIANA

BECCARI I PARKINSONIANA

\section{Locality}

Lat. Long.

NE GULF OF MEXICO

NE GULF OF MEXICO

NE GULF OF MEXICO

$N W$ GULF OF MEXICO

NW GULF OF MEXICO

CENTRAL GULF OF MEXICO

CENTRAL GULF OF MEXICO

LE TERMINOS, CAMPECHE

NE GULF OF MEXICO

$N W$ GULF OF MEXICO

NW GULF OF MEXICO

NE GULF OF MEXICO

NW GULF OF MEXICO

NE GULF OF MEXICO

NE GULF OF MEXICO 
Publication

24526 PHLEGER 1951A 24527 PHLEGER 1951 A 24528 PHLEGER 1951A 24529 KORNFELD 1931 24530 PHLEGER $1951 \mathrm{~A}$ 24531 PHLEGER $1951 \mathrm{~A}$ 24532 PHLEGER $1951 \mathrm{~A}$ 24533 PHLEGER 1951A 24534 KORNFELD 1931 24534 KORNFELD 1931 24536 PHLEGER 1951A 24537 PHLEGER 1951 24538 WARREN 1957 24539 SHIFFLETT 1961 24540 PHLEGER $1951 \mathrm{~A}$ 24541 PHLEGER $1951 \mathrm{~A}$ 24542 PHLEGER $1951 \mathrm{~A}$ 24543 SHIFFLETT 1961 24544 PHLEGER 1951 A 24545 PHLEGER $1951 \mathrm{~A}$ 24546 LOWMAN 1949
24547 WARREN 1957

24548 PHLEGER 1951A 24549 PHLEGER $1951 \mathrm{~A}$ 24550 PHLEGER $1951 \mathrm{~A}$ 24551 PHLEGER 1951A 24552 PHLEGER $1951 \mathrm{~A}$ 24553 PHLEGER 1951 A 24554 PHLEGER $1951 \mathrm{~A}$ 24555 PHLEGER 1951A 24556 PHLEGER 1951 A 24557 PHLEGER $1951 \mathrm{~A}$ 24558 PHLEGER 1951A 24559 PHLEGER $1951 \mathrm{~A}$ 24560 WARREN 1956

24561 CUSHMAN 1931

24562 PHLEGER $1951 \mathrm{~A}$

24563 POST 1951

24564 POST 1951

24565 KORNFELD 1931

24566 KORNFELD 1931

24567 KORNFELD 1931

24569 KORNFELD 1931

24570 KORNFELD 1931

24571 PHLEGER 1956

24572 PARKER PHLEGER PEIRSON 1953

24573 PHLEGER 1951A

24574 PHLEGER $1951 \mathrm{~A}$

24575 PHLEGER 1951A

24576 PHLEGER 1956

24577 PHLEGER 1956

24578 PHLEGER 1956

24579 SHENTON 1957

24580 PARKER PHLEGER PEIRSON 1953

24581 PHLEGER $1951 \mathrm{~A}$

24582 PHLEGER 1951 A

24583 WARREN 1957
24584 PHLEGER 1951 A

24585 PHLEGER 1951A

24586 PHLEGER 1951A

24587 PHLEGER $1951 \mathrm{~A}$

24588 WARREN 1956

24589 PHLEGER 1951A

24590 PHLEGER 1951A

24591 PHLEGER $1951 \mathrm{~A}$

24592 KELLOUGH 1956

24593 PHLEGER $1951 \mathrm{~A}$

24594 PHLEGER $1951 \mathrm{~A}$

24595 PHLEGER $1951 \mathrm{~A}$

24596 CREAGER 1958

24597 PHLEGER 1956

24598 PHLEGER 1956

24599 PARKER PHLEGER PEIRSON 1953

24600 PHLEGER 1956

24601 PHLEGER 1951A

24602 PHLEGER 1956

24603 PARKER PHLEGER PEIRSON 1953

24604 LOEP 1965

24605 WARREN 1956

24606 PHLEGER 1951A

24607 PHLEGER 1951A

24608 PHLEGER $1951 \mathrm{~A}$

24609 WARREN 1957

24610 PHLEGER 1954

24611 PHLEGER 19558

24612 PHLEGER 1951A

24613 SHIFFLETT 1961

24614 SHEPARD MOORE 1955

24615 PARKER PHLEGER PEIRSON 1953

24616 PARKER PHLEGER PEIRSON 1953

24617 PARKER PHLEGER PEIRSON 1953

24618 CUSHMAN 1931

24619 NORTON 1930

24620 CREAGER 1958
Generic Name

ROIALIA

RO TALIA

ROTALIA

ROTALIA

ROTALIA

ROTALIA

ROTALIA

ROTALIA

ROTALIA

ROTALIA

ROTALIA

ROTALIA

ROTALIA

ROTALIA

ROTALIA

ROTALIA

ROTALIA

ROTALIA

ROTALIA

ROTALIA

ROTALIA

ROTALIA

ROTALIA

ROTALIA

ROTALIA

ROTALIA

ROTALIA

ROTALIA

ROTALIA

ROTALIA

ROTALIA

ROTALIA

ROTALIA

ROTALIA

ROTALIA

ROTALIA

ROTALIA

ROTALIA

ROTALIA

ROTALIA

ROTALIA

ROTALIA

ROTALIA

ROTALIA

ROTALIA

ROTALIA

ROTALIA

ROTALIA

ROTALIA

ROTALIA

ROTALIA

ROTALIA

ROTALIA

ROTALIA

ROTALIA

ROTALIA

ROTALIA

ROTALIA

ROTALIA

ROTALIA

ROTALIA

ROTALIA

ROTALIA

ROTALIA

ROTALIA

ROTALIA

ROTALIA

ROTALIA

ROTALIA

ROTALIA

ROTALIA

ROTALIA

ROTALIA

ROTALIA

ROTALIA

ROTALIA

ROTALIA

ROTALIA

ROTALIA

ROTALIA

ROTALIA

ROTALIA

ROTALIA

ROTALIA

ROTALIA

ROTALIA

ROTALIA

ROTALIA

ROTALIA

ROTALIA

ROTALIA

ROTALIA

ROTALIA
Specific Name

BECCARII PARKINSONIANA

BECCARI I PARKINSONIANA BECCARI I PARKINSONIANA BECCARI I PARKINSONIANA BE CCARII PARKINSONIANA BECCARII PARKINSONIANA BECCARI I PARKINSONIANA BE CCARII PARKINSONIANA BECCARI I PARKINSONIANA BECCARI I PARK INSONIANA BECCARI I PARK INSONIANA BECCARII PARKINSONIANA BECCARII PARKINSONIANA BECCARII PARKINSONIANA BECCARII TEPIDA BECCARII TEPIDA BECCARI I TEPIDA BECCARII TEPIDA BECCARII TEPIDA BECCARII TEPIDA BECCARII TEPIDA BECCARII TEPIDA BE CCARII TEPI DA BECCARII TEPIDA BECCARI I TEPIDA BECCARI I TEPIDA BECCARII TEPIDA BECCARI I TEPIDA BECCARII TEPIDA BECCARII TEPIDA BECCARI I TEPIDA BE CCARII TEPI DA BECCARII TEPIDA BECCARII TEPIDA BECCARII TEPIDA BECCARII TEPIDA BECCARI I TEPIDA BECCARI I TEPIDA BECCARII TEPIDA BECCARII TEPIDA BECCARII TEPIDA BECCARII TEPIDA BE CCARI I TEPIDA BECCARII TEPIDA BECCARII TEPIDA

PAUCILOCULATA

PAUCILOCULATA

PAUCILOCULATA

PAUCILOCULATA

PAUCILOCULATA

PAUCILOCULATA

PAUCILOCULATA

PAUCILOCULATA

PAUCILOCULATA

PAUCILOCULATA

PALCILOCULATA

PALCILOCULATA

PAUCILOCULATA

PAUCILOCULATA

PAUCILOCJLATA

PAUCILOCULATA

PALCILOCULATA

PAUCILOCULATA

PAUCILOCULATA

PAUCILOCULATA

PAUCILOCJLATA

PALCILOCULATA

PAUCILOCULATA

PAUCILOCULATA

PAUCILOCULATA

PR AE GER I

ROLSHAUSEN I

ROLSHAUSENI

ROLSHAUSEN

ROLSHAU SEN

ROLSHAUSEN I

ROLSHAUSENI

ROLSHAUSEN

ROLSHAUSE N I

ROLSHAU SEN

ROLSHAU SEN

ROLSHAUSEN

ROLSHAUSE NI

ROLSHAUSEN

ROLSHAUSENI

ROLSHAUSEN I

ROLSHAUSEN

ROLSHAUSEN

ROLSHAUSEN

ROLSHAUSEN

ROLSHAUSEN

RO LSHAUSE NI

ROSEA

ROSEA

TRANSLUCENS

Locality

NW GULF OF MEXICO

NH GULF OF MEXICO

NW GULF OF MEXICO

TEXAS GULF COAST

NW GULF OF MEXICO 


\section{Publication}

24621 PARKER 1954 24622 PARKER 1954 24623 PHLEGER 1955 A 24624 PHLEGER 1955 A 24625 PHLEGER 1951A 24626 PHLEGER $1951 \mathrm{~A}$ 24627 PHLEGER 1951A 24628 PHLEGER 1951A 24629 PHLEGER 1955 A 24630 PARKER 1954 24631 PARKER 1954 24632 PARKER 1954 24633 PARKER 1954 24634 PARKER 1954 24635 PARKER 1954 24636 PARKER 1954 24637 PARKER 1954 24638 PARKER 1954 24639 PARKER 1954 24640 PARKER 1954 24641 PARKER 1954 24642 PHLEGER $1951 \mathrm{~A}$ 24643 PHLEGER $1951 \mathrm{~A}$ 24644 PHLEGER $1951 \mathrm{~A}$ 24645 PHLEGER 1951A 24646 CREAGER 1958 24647 CREAGER 1958 24648 PHLEGER 1951A 24649 PHLEGER 1951A 24650 PHLEGER $1951 \mathrm{~A}$ 24651 PHLEGER 1951A 24652 PHLEGER 1951A 24653 PHLEGER $1951 \mathrm{~A}$ 24654 PHLEGER $1951 \mathrm{~A}$ 24655 PHLEGER 1951 A 24656 PARKER 1954
24657 PARKER 1954 24658 CREAGER 1958 24659 CREAGER 1958 24660 PARKER 1954 24661 PARKER 1954 24662 PARKER 1954 24663 PARKER 1954 24664 PARKER 1954 24665 PHLEGER 1955A 24666 PHLEGER 1951A 24667 PHLEGER 1951A 24668 PHLEGER 1951A 24669 PHLEGER 1951A 24670 PHLEGER 1951A 24671 PHLEGER $1951 \mathrm{~A}$ 24672 PHLEGER 1955A 24673 PHLEGER 1955 A 24674 PARKER 1954 24675 PARKER 1954 24676 PHLEGER $1951 \mathrm{~A}$
24677 PHLEGER $1951 \mathrm{~A}$ 24677 PHLEGER 1951A
24678 ANDERSEN 1961 24679 PARKER 1954 24680 PARKER 1954 24681 PARKER 1954 24682 PARKER 1954 24683 PARKER 1954 24684 PARKER 1954 24685 PARKER 1954 24686 PARKER 1954 24687 PARKER 1954 24688 PARKER 1954 24689 PARKER 1954 24690 PARKER 1954 24691 LUDWICK WALTON 1957 24692 PHLEGER 1955A 24693 PHLEGER 1955A 24694 PARKER 1954 24695 PARKER 1954 24696 PARKER 1954 24697 PARKER 1954 24698 PARKER 1954 24699 PARKER 1954 24700 PARKER 1954 24701 PARKER 1954

24702 PFLUM FRERICHS 1976 24703 PFLUM FRERICHS 1976 24704 PFLUM FRERICHS 1976 24705 BANDY 1956 24706 BANDY 1956 24707 AYALA-CASTANARES 1963 24708 BANDY 1956 24709 BANDY 1956 24710 BANDY 1956 24711 PFLUM FRERICHS 1976 24712 BENDA PURI 1962 24713 POAG 1972 24714 LIDZ LIDZ 1966 24715 PFLUM FRERICHS 1976
Generic Name

ROTALIA

ROTALIA

ROTALIA

RO TALIA

RO TALIA

ROTALIA

ROTALIA

ROTALIA

ROTALIA

ROTALIA

ROTALIA

ROTALIA

ROTALIA

ROTALIA

ROTALIA

ROTALIA

ROTALIA

RO TAL IA

ROTALIA

ROTALIA

ROTALIA

ROTALIA

ROTALIA

ROTALIA

ROTALIA

ROTALIA

ROTALIA

ROTALIA

ROTALIA

ROTALIA

ROTALIA

OTALIA

ROTALIA

ROTALIA

ROTALIA

RO TALIA

ROTALIA

ROTALIA

ROTALIA

ROTALIA

ROTALIA

ROTALIA

ROTALIA

ROTALIA

ROTALIA

ROTALIA

ROTALIA

RO YALIA

RO TALIA

ROTALIA

ROTAMORPHINA

RO TAMORPHINA

RO TAMORPHINA

ROTAMORPHINA

ROTAMORPHINA

ROTAMORPHINA

ROTAMORPHINA

ROTAMORPHINA

RO TAMORPHINA

ROTAMORPHINA

ROTAMORPHINA

ROTAMORPHINA

ROTAMORPHINA

RO TAMORPHINA

ROTAMORPHINA

ROTAMORPHINA

ROTAMORPHINA

ROTAMORPHINA

ROTAMORPHINA

ROTAMO

ROTAMORPHINA

ROTAMORPHINA

ROTAMORPHINA

ROTAMORPHINA

ROTAMORPHINA

ROTORBINELLA

ROTORBINELLA

ROTORBINELLA

ROTORB I NELLA

ROTORBINELLA

ROTORBINELLA

ROTORBINELL A

RO TORBINELLA

RO TORB INELL A

RO TORB INELLA

RO IORBINELLA

ROTORBINELL A

ROTORBINELLA

ROTORB INELLA
Specific Name

Locality

Lat. Long.

TRANSLUCENS

TRANSLUCENS

TRANSLUCENS

TRANSLUCENS

TRANSLUCENS

TRANSLUCENS

TRANSLUCENS

TRANSLUCENS

TRANSLUCENS

TRANSLUCENS

TRANSLUCENS

TRANSLUCENS

TRANSLUCENS

TR ANSLUCENS

TRANSLUCENS

TRANSLUCENS

TRANSLUCENS

TRANSLUCENS

TR ANSLUCENS

TRANSLUCENS

TRANSLUCENS

TRANSLUCENS

TRANSLUCENS

TRANSLUCENS

TRANSLUCENS

TRANSLUCENS

TRANSLUCENS

TRANSLUCENS

TRANSLUCENS

TRANSLUCENS

TRANSLUCENS

TRANSLUCENS

TRANSLUCENS

TRANSLUCENS

TRANSLUCENS

TRANSLUCENS

TRANSLUCENS

TRANSLUCENS

TRANSLUCENS

TRANSLUCENS

TR ANSLUCENS

TRANSLUCENS

TRANSLUCENS

TRANSLUCENS

TRANSLUCENS

TRANSLUCENS

TRANSLUCENS

TRANSLUCENS

TRANSLUCENS

TRANSLUCENS

TRANSLUCENS

TRANSLUCENS

TRANSLUCENS

TRANSLUCE NS

TRANSLUCENS

TRANSLUCENS

TRANSLUCENS

GL ABRA

LAEVIGATA

LAEVIGATA

LAEVIGATA

LAEVIGATA

LAEVIGATA

LAEVIGATA

LAEVIGATA

LAEVIGATA

LAEVIGATA

LAEVIGATA

LAEVIGATA

LAEVIGATA

LAEVIGATA

LAEVIGATA

LAEVIGATA

LAEVIGATA

LAEVIGATA

LAEVIGATA

LAEVIGATA

LAEVIGATA

LAEVIGATA

LAEVIGATA

LAEVIGATA

BA SILICA

BASILICA

BASILICA

BASILICA

BA SILICA

BASILICA

BA SILICA

BASILICA

BA SILICA

ROSACEA

ROSEA

RO SEA

TRANSLUCENS

NE GULF OF MEXICO

NE GULF OF MEXICO

$N$ GULF OF MEXICO

$N$ GULF OF MEXICO

NH GULF OF MEXICO

$N W$ GULF OF MEXICO 


\section{Publication}

24716 PFLUM FRERICHS 1976 24717 PFLUM FRERICHS 1976 24718 PFLUM FRERICHS 1976 24719 PFLUM FRERICHS 1976 24720 PFLUM FRERICHS 1976 24721 PFLUM FRERICHS 1976 24722 PFLUM FRERICHS 1976 24723 PFLUM FRERICHS 1976 24724 PFLUM FRERICHS 1976 24725 PFLUM FRERICHS 1976 24726 PFLUM FRERICHS 1976 24727 PFLUM FRERICHS 1976 24728 PFLUM FRERICHS 1976 24729 PFLUM FRERICHS 1976 24730 PFLUM FRERICHS 1976 24731 PFLUM FRERICHS 1976 24732 PFLUM FRERICHS 1976 24733 PFLUM FRERICHS 1976 24734 PFLUM FRERICHS 1976 24335 PFLUM FRERICHS 1976 24336 PFLUM FRERICHS 1976

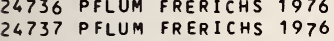
24738 PFLUM FRERICHS 1976 24739 PFLUM FRERICHS 1976 24740 PFLUM FRERICHS 1976 24741 PFLUM FRERICHS 1976 24742 PFLUM FRERICHS 1976 24743 PFLUM FRERICHS 1976 24744 PFLUM FRERICHS 1976 24745 PFLUM FRERICHS 1976 24746 PFLUM FRERICHS 1976 24747 PFLUM FRERICHS 1976 24748 PFLUM FRERICHS 1976 24749 PFLUM FRERICHS 1976 24750 PFLUM FRERICHS 1976 24751 PFLUM FRERICHS 1976 24752 PFLUM FRERICHS 1976 24753 PFLUM FRERICHS 1976 24754 PFLUM FRERICHS 1976 24755 PFLUM FRERICHS 1976 24756 PFLUM FRERICHS 1976 24757 PFLUM FRERICHS 1976 24758 PFLUM FRERICHS 1976 24759 PFLUM FRERICHS 1976 24760 PFLUM FRERICHS 1976 24761 PFLUM FRERICHS 1976 24762 PFLUM FRERICHS 1976

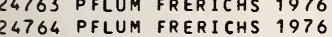
24765 PFLUM FRERICHS 1976 24766 PFLUM FRERICHS 1976 24767 PFLUM FRERICHS 1976 24768 PFLUM FRERICHS 1976 24770 PFLUM FRERICHS 1976 24771 PFLUM FRERICHS 1976 24772 PFLUM FRERICHS 1976 24773 PFLUM FRERICHS 1976 24774 PFLUM FRERICHS 1976 24775 PFLUM FRERICHS 1976 24776 LEROY HODGKINSON 1975 24777 PFLUM FRERICHS 1976 24778 PFLUM FRERICHS 1976 24779 CUSHMAN 1918 24780 CUS HMAN 1918 24781 VAUGHAN 1918 24782 CUSHMAN 1918 24783 CUSHMAN 1918 24785 PFLUM FRERICHS 1976 24786 PFLUM FRERICHS 1976 24787 PFLUM FRERICHS 1976 24788 PFLUM FRERICHS 1976 24789 PFLUM FRERICHS 1976 24790 PFLUM FRERICHS 1976 24791 PFLUM FRERICHS 1976 24792 PFLUM FRERICHS 1976 24793 PFLUM FRERICHS 1976 24794 PFLUM FRERICHS 1976 24795 PFLUM FRERICHS 1976 24796 PFLUM FRERICHS 1976 24797 PFLUM FRERICHS 1976 24798 PFLUM FRERICHS 1976 24799 PFLUM FRERICHS 1976 24800 PFLUM FRERICHS 1976 24801 PFLUM FRERICHS 1976 24802 PFLUM FRERICHS 1976 24803 PFLUM FRERICHS 1976 24804 PFLUM FRERICHS 1976 24805 PFLUM FRERICHS 1976 24806 PFLUM FRERICHS 1976 24807 PFLUM FRERICHS 1976 24808 PFLUM FRERICHS 1976 24809 PFLUM FRERICHS 1976 24810 PFLUM FRERICHS 1976
Generic Name

ROTORBINELLA ROTORBINELLA ROTORBINELLA ROTORBINELLA ROTORBI NELL A ROTORBINELL A ROTORBINELL A ROTORBI NELL A ROTORBINELL A ROTORBI NELL A ROTORBINELLA ROTORBINELLA ROTORBI NELLLA ROTORB INELLA ROTORB I NELL LA ROTORBI NELLA RO TORBINELLA ROTORBINELLA ROTORBINELL A RO TORBINELLA RO TORBINELLA RO TORB NELLA RO TORBI NELLA ROTORBINELLA RO TORBI NELLA ROTORBINELLA RO TORB I NELL LA ROTORB INELLLA RO TORBINELL A ROTORBI NELLA ROTORBINELLA ROTORBINELL A ROTORBINELLA ROTORBINELLA ROTORBI NELLA ROTORBINELL A RO TORB INELLA ROTORB I NELL A

ROTORBI NELL A

ROTORBI NELL A

ROTORB I NELL LA

ROTORBINELL A

ROTORB I NELLLA

ROTORBI NELL A

ROTORBI NELL A

ROTORB I NELL A

ROTORBINELLA

ROTORBINELLA

ROTORBI NELLA

ROTORBINELL A

ROTORBINELL A

ROTORBINELLLA

ROTORBINELLA

ROTORBINELLA

ROTORBI NELL A

ROTORB I NELL A

SACCAMMINA

SACCAMMINA

SACCAMMINA

SACCAMMINA

SACCAMMI NA

SACCAMMINA

SACC AMM I NA

SACCAMMINA

SACCAMMINA

SACCORHIZA

SACCORHIZA

SACCORHIZA

SACCORHIZA

SACCORHIZA

SACCORHIZA

SACCORHIZA

SA.CCORHIZA

SACCORHIZA

SACCORHIZA

SACCORHIZA

SACCORHIZA

SACCORHIZA

SACCORHIZA

SACCORHIZA

SACCORHIZA

SACCORHIZA

SACCORHIZA

SACCORHIZA

SACCORHIZA

SACCORHIZA

SACCORHIZA

SACCORHIZA

SACCORHIZA

SACCORHIZA

SACCORHIZA

SACCORHIZA

SACCORHIZA

SACCORHI ZA
Specific Name

Locality

Lat.

Long.

TR ANSLUCENS

TRANSLUCENS

TRANSLUCENS

TRANSLUCENS

TRANSLUCENS

TRANSLUCENS

TRANSLUCENS

TRANSLUCE NS

TRANS LUCENS

TRANSLUCENS

TRANSLUCENS

TRANSLUCENS

TRANSLUCENS

TRANSLUCENS

TRANSLUCENS

TR ANSLUCENS

TRANSLUCENS

TRANSL UCENS

TRANSLUCENS

TRANS LUCENS

TR ANS LUCENS

TRANSLUCENS

TRANSLUCENS

TRANSLUCENS

TR ANSLUCENS

TRANS LUCENS

TR ANSLUCENS

TR ANSLUCENS

TRANS LUCENS

TR ANSLUCENS

TR ANSLUCENS

TR ANSLUCE NS

TR ANSLUCENS

TRANS LUCENS

TR ANS LU CENS

TR ANSLU CENS

TR ANSLUCENS

TRANSLUCE NS

TRANSL UCENS

TR ANS LU CENS

TRANSLUCENS

TRANSLUCENS

TRANSLUCENS

TR ANSLUCENS

TR ANSLU CENS

TR ANSLUCE NS

TRANSLUCENS

TRANSLUCENS

TR ANS LUCENS

TRANSLUCENS

TRANSLUCENS

TRANSLUCENS

TR ANS LUCENS

TRANSLUCENS

TRANSLUCENS

TR ANSLUCENS

TRANSLUCENS

SOCIALIS

SOCIALIS

SOCIALIS

SOCIALIS

SOCIALIS

SOCIALIS

SPHAERICA

SPHAERICA

RAMOSA

RAMOSA

RAMOSA

RAMOSA

RANOSA

RAMOSA

RANOSA

RAMOSA

RAMOSA

RAMOSA

RAMOSA

RANOSA

RA NOSA

RAMOSA

RAMOSA
RAMOSA

RAMOSA

RANOSA

RAMOSA

RAMOSA

RAMOSA

RANOSA

RAMOSA

RAMOSA

RAMOSA

RAMOSA

CENTRAL GULF OF MEXICO NW GULF OF MEXICO NH GULF OF MEXICO NH GULF OF MEXICO NW GULF OF MEXICO 


\section{Publication}

24811 PFLUM FRERICHS 1976 24812 PFLUM FRERICHS 1976 24813 PFLUM FRERICHS 1976 24814 PFLUM FRERICHS 1976 24815 PFLUM FRERICHS 1976 24816 PFLUM FRERICHS 1976 24817 PFLUM FRERICHS 1976 24818 PFLUM FRERICHS 1976 24819 PFLUM FRERICHS 1976 24820 PFLUM FRERICHS 1976 24821 PFLUM FRERICHS 1976 24822 PFLUM FRERICHS 1976 24823 PFLU'A FRERICHS 1976 24824 PFLUM FRERICHS 1976 24825 PFLUM FRERICHS 1976 24826 PFLUM FRERICHS 1976 24827 PFLUM FRERICHS 1976 24828 PFLUM FRERICHS 1976 24829 PFLUM FRERICHS 1976 24830 PFLUM FRERICHS 1976 24831 PFLUM FRERICHS 1976 24832 PFLUM FRERICHS 1976 24833 PFLUM FRERICHS 1976 24834 PFLUM FRERICHS 1976 24836 PFLUM FRERICHS 1976 24837 PFLUM FRERICHS 1976 24838 PFLUM FRERICHS 1976 24839 PFLIJM FRERICHS 1976 24840 PFLUM FRERICHS 1976 24841 PFLUM FRERICHS 1976 24842 PFLUM FRERICHS 1976 24843 CUSH MAN 1918

24844 PFLUM FRERICHS 1976 24845 PFLUM FRERICHS 1976 24846 PFLUM FRERICHS 1976 24847 PFLUM FRERICHS 1976 24848 PFLIJM FRERICHS 1976 24849 PFLUM FRERICHS 1976 24850 PFLUM FRERICHS 1976 24851 CUSHMAN 1918

24852 BOCK 1976

24853 BANOY 1956

24854 BANDY 1956

24855 ANDERSEN 1961

24856 SOCK 1976

24857 PFLUM FRERICHS 1976

24858 ANDERSEN 1961

24859 ANDERSEN 196

24860 BOCK 1976

24861 ANDERSEN 1961

24862 CREAGER 1958

24863 CREAGER 1958

24864 CREAGER 1958

24865 CREAGER 1958

24866 CREAGER 1958

24867 CREAGER 1958

24868 CREAGER 1958

24869 CREAGER 1958

24870 NORTON 1930

24871 PHLEGER 1956

24872 PARKER 1954

24873 PHLEGER 1956

24874 PARKER 1954

24876 PARKER 1954

24877 PARKER 1954

24878 PARKER 1954
24879 PARKER 1954

24880 PARKER 1954

24881 PARKER 1954

24882 PARKER 1954

24883 PARKER 1954

24884 PARKER 1954

24885 PARKER 1954

24886 PARKER 1954

24887 PARKER 1954

24888 PARKER 1254

24889 PARKER 1954

24890 BANDY 1954

24891 BANOY 1954

24892 BANDY 1954

24893 BANDY 1954

24894 BENDA PURI 1962

24895 BANDY 1954

24897 ANDERSFN 1961

24897 ANDERSEN 1961
24898 PHLEGER 1951 A

24899 PHLEGER 1951 A

24900 PHLEGER $1951 \mathrm{~A}$

24901 ANDERSEN 1961

24902 PHLEGER $1951 \mathrm{~A}$

24903 PHLEGER $1951 \mathrm{~A}$

24904 PHLEGER 1951A

24905 PHLEGER 1951A
Generic Name

SACCORHIZA

SACCORHIZA

SACCORHIZA

SACCORHIZA

SACCORHIZA

SACCORHIZA

SACCORHIZA

SACCORHIZA

SACCORHIZA

SACCORHIZA

SACCORHIZA

SACCORHIZA

SACCORHIZA

SACCORHIZA

SACCORHIZA

SACCORHIZA

SACCORHIZA

SACCORHIZA

SACCORHIZA

SACCORHIZA

SACCORHIZA

SACCORHIZA

SACCORHIZA

SACCORHIZA

SACCORHIZA

SACCORHIZA

SACCORHIZA

SACCORHIZA

SACCORHIZA

SACCORHIZA

SACCORHIZA

SACCORHIZA

SACCORHIZA

SACCORHIZA

SAC CORHIZA

SACCORHIZA

SACCORHIZA

SACCORHIZA

SAGRINA

SARACENARIA

SARACENARI A

SARACENARIA

SARACENAR I A

SARACENARIA

SARACENARI A

SARACENARI A

SARACENARI A

SCRACNARIA

SCHENCKIELLA

SCHENCK IELLA

SCHENCKIELLA

SCHENCK IELLA

SCHENCK IELLA

SC HENCK I ELLA

SCHENCK IELLA

SC HLUMBERGERINA

SEABROOKIA

SEABROOKIA

SEABROOKIA

SEABROOKIA

SEABROOKIA

SEABROOKIA

SEABROOKIA

SEABROOKIA

SEABROOKIA

SEABROOKIA

SEABROOKIA

SEABROOK IA

SEABROOKIA

SEABROOKIA

SEABROOKIA

SEABROOKI

SEABROOKIA

SEABROOKIA

SEABROOK IA

S I GMOIL INA

SI GMOIL I NA

SI GMOILINA

SI GMOIL INA

SI GMOILINA

SI GMOIL INA

SIGMOIL INA

SI GMOILINA

SI GMOILINA

SI GMO IL INA

SI GMOIL INA

SI GMOIL INA

SI GMOIL INA

SIGMOIL INA

SI GMOIL INA

SI GMOIL I NA
Specific Name

Locality

RANOSA

RANOSA

RAMOSA

RANOSA

RANOSA

RANOSA

RANOSA

RANOSA

RANOSA

RANOSA

RAMOSA

RAMOSA

RANOSA

RANOSA

RA NOSA

RANOSA

RANOSA

RA NOSA

RAMOSA

RANOSA

RANOSA

RANOSA

RANOSA

RANOSA

RANOSA

RANOSA

RANOSA

RANOSA

RA NOSA

RANOSA

RANOSA

RANOSA

RAMOSA

RANOSA

PULCHELLA PRIMITIVA

AMFLA

AMFLA

IT AL I CA

I TAL I CA

LAMPTONI

LATIFORMIS JAMAICENSIS

LATIFRONS

OC CIDENTALIS

OCCIDENTALIS

OC CIDENTALIS

OC CIDENTALIS

OC CIDENTALIS

OC CIDENTA LIS

OC CIDENTALIS

OC CIDENTALIS

AL VEOL INI FORMIS

EARLANDI

EA RLANDI

EA RLANDI

EARLANDI

EARLAND I

EARLANDI

EA RLANOI

EARLANDI

EARLANDI

EARLANDI

EARLANDI

EARLANDI

EARLANDI

EARLANDI

EARLANDI

EARLANDI

EARLANDI

EARLANOI

AN TILLARJM

ANTILLARJM

ANTILLARUM

ANTILLARJM

ANTILLARUM

AN TILLARUM

ANTILLARUM

DI STORTA

DI STORTA

DI STORTA

DI STORTA

OI STORTA

DI STORTA

DI STORTA

DISTORTA

DISTORTA

NW GULF OF MEXICO

NW GULF OF MEXICO

$N W$ GULF OF MEXICO

NW GULF OF MEXICO

$N W$ GULF OF MEXICO

$N W$ GULF OF MEXICO

NW GULF OF MEXICO

NW GULF OF MEXICO

NW GULF OF MEXICO

$N W$ GULF OF MEXICO

NW GULF OF MEXICO

NW GULF OF MEXICO

NW GULF OF MEXICO 


\section{Publication}

24906 PHLEGER 1951A 24907 PHLEGER 1951A 24908 PHLEGER 1951A 24909 PHLEGER $1951 \mathrm{~A}$ 24910 PHLEGER 1951A 24911 PHLEGER 1951A 24912 PHLEGER 1951A 24913 PHLEGER $1951 \mathrm{~A}$ 24914 PHLEGER 1951 A 24915 PARKER 1954 24916 PHLEGER 1951A 24917 PHLEGER $1951 \mathrm{~A}$ 24918 PHLEGER 1951A
24919 PHLEGER 1951 A 24919 PHLEGER $1951 \mathrm{~A}$
24920 PHLEGER $1951 \mathrm{~A}$ 24921 PHLEGER $1951 \mathrm{~A}$ 24922 PHLEGER $1951 \mathrm{~A}$ 24923 PHLEGER 1951A 24924 PHLEGER 1951A 24925 BOCK 1976

24926 PARKER 1954

24927 PARKER 1954

24928 PARKER 1954

24929 PARKER 1954

24931 LUDWICK WALTON 1957

24932 LANKFORD 1959

24933 PARKER 1954

24934 PARKER 1954

24935 PARKER 1954

24936 PARKER 1954

24937 PHLEGER 1951A

24938 PHLEGER 1951A

24939 PHLEGER 1951A

24940 PHLEGER $1951 \mathrm{~A}$

24941 PARKER 1954

24942 PARKER 1954

24943 PARKER 1954

24944 PARKER 1954

24946 PHLEGER 1956

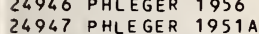

24948 PHLEGER 1951A

24949 PHLEGER 1951A

24950 PHLEGER $1951 \mathrm{~A}$

24951 PHILEGER 1951 A

24952 PHLEGER 1951 A

24953 PHLEGER $1951 \mathrm{~A}$

24954 PHLEGER 1951A

24955 PFLUM FRERICHS 1976

24956 PHLEGER 1951A

24958 PHLEGER $1951 \mathrm{~A}$

24959 PHLEGER 1951A

24960 PHLEGER 1951A

24961 PHLEGER 1951 A

24962 PHLEGER 1951A

24963 PHLEGER 1951A

24964 PHLEGER 1951A

24965 PHLEGER $1951 \mathrm{~A}$

24966 PHLEGER 1951 A

24967 PHLEGER $1951 \mathrm{~A}$

24968 PHLEGER 1951A

24969 PHLEGER $1951 \mathrm{~A}$

24970 PHLEGER 1951A

24971 PHLEGER 1951A

24972 PHLEGER 1951A

24973 PHLEGER $1951 \mathrm{~A}$

24974 PARKER 1954

24975 CUSHMAN 1929

24976 CUSHMAN 1929

24977 BENDA PURI 1962

24978 PFLUM FRERICHS 1976

24979 CUSHMAN 1929

24980 CUSHMAN 1929

24981 PARKER 1954

24982 PARKER 1954

24983 PHLEGER 1955 A

24984 PARKER 1954

24985 PARKER 1954

24986 PARKER 1954

24987 PARKER 1954

24988 PARKER 1954
24989 PARKER 1954

24990 PARKER 1954

24991 PARKER 1954

24992 PARKER 1954

24993 PARKER 1954

24994 PHLEGER 1951A

24995 PHLEGER 1955 A

24996 PARKER 1954

24997 PARKER 1954
24998 PARKER 1954

24998 PARKER 1954
24999 PFLUM FRERICHS 1976

25000 PFLUM FRERICHS 1976
Generic Name

SIGMOILINA

SI GMOIL I NA

SI GMOIL INA

SI GMO IL INA

SI GMOIL INA

SI GMOIL INA

S I GMOIL INA

SI GMO IL I NA

S I GMOIL INA

S I GMOIL INA

SI GMOIL INA

SI GMOIL INA

SI GMOIL INA

S I GMO I L I NA

SI GMOILINA

SIGMOIL INA

SIGMOILINA

SIGMOILINA

S I GMOIL I NA

SI GMOI L INA

SI GMO IL I NA

S I GMOIL I NA

SI GMO IL INA

S I GMOIL INA

I GMOILINA

SI GMOIL I NA

SI GMOILINA

S I GMOIL I NA

S I GMOIL I NA

SI GMOIL INA

SI GMOILINA

SIGMOIL INA

SI GMOIL INA

S I GMOIL I NA

S I GMO IL I NA

SI GMOILINA

SI GMOIL INA

S I GMOIL INA

S I GMO IL I NA

SIGMOILINA

SI GMOIL INA

SI GMO IL I NA

SI GMOIL INA

SI GMOIL INA

SIGMOIL INA

SI GMOIL INA

SI GMO IL INA

S I GMOILINA

SI GMO IL I NA

SI GMOIL INA

SI GMOIL I NA

SI GMOIL INA

SI GMOIL INA

SI GMOIL INA

S I GMOIL INA

S I GMO I L INA

SI GMO IL INA

SI GMO IL I NA

SI GMOIL INA

SI GMO IL INA

SI GMOIL INA

S I GMO IL I NA

SI GMOIL INA

SI GMO IL INA

SI GMOIL INA

SI GMOIL INA

SI GMOILINA

SI GMOIL INA

S I GMO I L I NA

SI GMO IL I NA

SI GMOIL INA

SI GMOIL I NA

SI GMOIL INA

SI GMO IL INA

SI GMOIL I NA

S I GMO IL I NA

S I GMO IL INA

SI GMOILINA

SI GMO IL I NA

SI GMOIL INA

SI GMOIL INA

SI GMOILINA

SI GMOIL INA

S I GMOIL I NA

S I GMOIL INA

S I GMO IL INA

SI GMOIL INA

SI GMOIL INA

SIGMOIL INA

S I GMO IL INA

SI GMOIL INA

S I GMO IL INA

SI GMO IL INA

SI GMO IL INA
Specific Name

Locality

Lat. Long.

DISTORTA

DI STORTA

DI STORTA

DISTORTA

DISTORTA

DISTORTA

DI STORTA

DISTORTA

DI STORTA

DI STORTA

DISTORTA

DI STORTA

DISTORTA

DISTORTA

DI STORTA

DI STORTA

DI STORTA

DISTORTA

DI STORTA

DI STORTA

DI STORTA

DISTORTA

DI STORTA

DISTORTA

DI STORTA

DI STORTA

DI STORTA

DI STORTA

DI STORTA

DI STORTA

DISTORTA

DI STORTA

DI STORTA

DI STORTA

SC HLUMBER GER I

SC LLUMBER GERI

SC HLUMBER GE R I

SC HLUMBER GERI

SC HLUMBER GERI

SC HLUMBER GER

SC HLUMBERGERI

SC HLUMBER GERI

SC HLUMBER GERI

SC HLUMBER GER I

SC HLUMBER GER I

SC HLUMBER GE RI

SC HLUMBER GER I

SCHLUMBER GERI

SC HLUMBER GERI

SCHLUMBER GERI

SCHLUMBER GER I

SC HLUMBER GER I

SCHLUMBER GER

ER GE R I

SC HLUMBER GER I

SC HLUMBER GERI

SC HLUMBEP GERI

SC HLUMBER GE RI

SC HLUMBER GERI

SCHLUMBER GER

SCHLUMBER GERI

SCHLUMBER GERI

SCHLUMBERGERI

SC HLUMBER GERI

SC FLUMBER GE RI

SC HLUMBER GE RI

SCHLUMBER GERI

SC

SC HLUMBER GERI

SCHLUMBER GER I

SCHLUMBER GERI

SCHLUMBER GERI

SC HLUMBER GER I

SC HLUMBER GE RI

SCHLUMBER GERI

C CHLUMBER GER I

SC

SCHLUMBER GERI

SC HLUMBER GERI

SC HLUMBER GE R I

SCHLUMBER GE R I

SCHLUMBER GERI

SC HLUMBER GER I

SCHLUMBERGERI

SC HLUMBER GERI

SC HLUMBER GE R I

SC HLUMBER GERI

SI GMOIDEA

S I GMOIDEA

NW GULF OF MEXICO

NW GULF OF MEXICO

NW GULF OF MEXICO

NW GULF OF MEXICO

NW GULF OF MEXICO

NW GULF OF MEXICO

WW GULF OF MEXICO 


\section{Publication}

25001 PFLUM FRERICHS 1976 25002 BANDY 1956 25003 BENDA PURI 1962

25004 BANDY 1956

25005 BANDY 1956

25006 BANDY 1956

25007 BANDY 1956

25008 BANDY 1956

25009 BANDY 1956

25010 BANDY 1956

25011 BANDY 1956

25012 BANDY 1956

25013 BANDY 1956
25014 PARKER 1954

25014 PARKER 1954
25015 BANDY 1956

25016 PARKER 1954

25017 BANDY 1956

25018 BENDA PURI 1962

25019 PARKER 1954

25020 PARKER 1954

25021 PARKER 1954

25022 PARKER 1954
25023 PARKER 1954

25024 PARKER 1954

25025 BOCK 1976

25026 PARKER 1954

25027 PARKER 1954

25028 PARKER 1954

25029 PARKER 1954

25030 PARKER 1054
25031 ANDERSEN 1961

25032 LEROY HODGKINSON 1975

25033 PFLUM FRERICHS 1976

25034 PFLUM FRERICHS 1976

25035 ANDERSEN 1961

25036 PFLUM FRERICHS 1976

25037 PFLUM FRERICHS 1976

25038 PFLUA FRERICHS 1976

25039 PFLUM FRERICHS 1976

25040 PFLUM FRERICHS 1976

25041 PFLUM FRERICHS 1976

25042 PFLUM FRERICHS 1976

25043 PFLUM FRERICHS 1976

25044 PFLUM FRERICHS 1976

25045 PFLUM FRERICHS 1976

25046
25047
PFLUUM

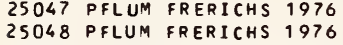

25049 PFLUM FRERICHS 1976

25050 PFLUM FRERICHS 1976

25051 PFLUM FRERICHS 1976

25053 PFLUM FRERICHS 1976

25054 PFLUM FRERICHS 1976

25055 PFLUM FRERICHS 1976

25056 PFLUM FRERICHS 1976

25057 PFLUM FRERICHS 1976

25058 PFLUM FRERICHS 1976

25059 PFLUM FRERICHS 1976

25060 PFLUM FRERICHS 1976

25061 PFLUM FRERICHS 1976

25062 PFLUM FRERICHS 1976

25063 PFLUM FRERICHS 1976

25064 PFLUM FRERICHS 1976

25065 PFLUM FRERICHS 1976

25066 PFLUM FRERICHS 1976

25067 PFLUM FRERICHS 1976

25068 PFLUM FRERICHS 1976

25069 PFLUM FRERICHS 1976

25070 PFLUM FRERICHS 1976

25071 PFLUM FRERICHS 1976

25072 PFLUM FRERICHS 1976

25073 PFLUM FRERICHS 1976

25074 PFLUM FRERICHS 1976

25075 PFLUM FRERICHS 1976

25076 PFLUM FRERICHS 1976

25077 PFLUM FRERICHS 1976

25078 PFLUM FRERICHS 1976

25079 PFLUM FRERICHS 1976

25080 PFLUM FRERICHS 1976
25081 PFLUM FRERICHS 1976

$\begin{array}{lll}25081 & \text { PFLUM FRERICHS } & 1976 \\ 25082 & \text { PFLUM FRERICHS } & 1976\end{array}$

25083 PFLUM FRERICHS 1976

25084 PFLUM FRERICHS 1976

25085 PFLUM FRERICHS 1976

25086 PFLUM FRERICHS 1976

25087 PFLUM FRERICHS 1976

25088 PFLUM FRERICHS 1976

25089 PFLUM FRERICHS 1976

25090 PFLUM FRERICHS 1976

25091 PFLUM FRERICHS 1976

25093 PFLUM FRERICHS 1976

25094 PFLUM FRERICHS 1976

25095 PFLUM FRERICHS 1976
Generic Name

SIGMOIL INA

SI GMOIL I NA

SI GMOILINA

SI GMOIL INA

SI GMOIL INA

SI GMOILINA

SI GMOIL I NA

SI GMOIL INA

SI GMOIL I NA

SI GMO IL INA

SI GMO IL INA

SI GMO IL INA

SI GMOIL I NA

SI GMOIL INA

SI GMOIL INA

SI GMOIL INA

SI GMO IL INA

SI GMOIL INA

SI GMOI L INA

SI GMOIL INA

SI GMOIL INA

SI GMOIL INA

SI GMOIL I NA

SI GMOIL INA

SI GMOIL INA

SI GMOIL I NA

SI GMOIL INA

SI GMO IL INA

SI GMOILINA

SI GMOILINA

S I GMO IL OPS IS

S I GMOIL OPS I S

SI GMOIL OPS IS

SI GMOIL OPS IS

SIGMOILOPSIS

SI GMOILOPS IS

SI GMOIL OPS IS

SI GMOILOPS I S

SI GMOIL OPS IS

SI GMOILOPS IS

SIGMOIL OPS IS

SI GMOILOPS IS

SI GMOILOPS IS

SI GMOIL OPS IS

SI GMOILOPS IS

SIGMOIL OPS IS

SIGMOIL OPS IS

SI GMOILOPS IS

SI GMOILOPS IS

SI GMOILOPS IS

SI GMOIL OPS I S

SI GMOILOPSIS

SI GMOILOPSIS

SI GMOILOPSIS

SI GMOIL OPS IS

SI GMOILOPS IS

SI GMOILOPSIS

SI GMOILOPSIS

SI GMOILOPSIS

SI GMOIL OPS IS

SI GMOILOPS IS

SI GMOILOPS IS

SI GMOIL OPS I S

SI GMOIL OPSI S

SI GMOILOPSIS

SI GMOILOPSIS

SI GMOILOPS IS

SI GMOILOPS IS

SI GMOILOPS I S

S I GMOIL OPS IS

SI GMOILOPS IS

SI GMOILOPSIS

SI GMOILOPS IS

SI GMOIL OPS IS

SI GMOILOPS IS

S I GMOIL OPS IS

SI GMOIL OPS IS

SI GMOILOPS I S

SI GMOILOPSIS

SI GMOIL OPSI S

SI GMOIL OPS IS

SI GMOILOPS IS

SI GMOILOPS IS

SI GMOILOPS IS

SI GMOIL OPS I S

SI GMOILOPS IS

SI GMOILOPS IS

SI GMOIL OPS IS

S I GMO IL OPS I S

SI GMOILOPSIS

SI GMOIL OPSIS

SI GMOILOPS IS

SI GMOILOPS IS

SI GMOILOPS IS

SI GMOILOPS IS
Specific Name

SI GMOIDEA

SUEPOEYAYA

SUBPOEYANA

SUEPOEYANA

SUEPOEYANA

SUEPOEYANA

SUEPOEYANA

SUBPOEYANA

SUEPOEYANA

SUBPOEYANA

SUEPOEY ANA

TENUIS

TENUIS

TENUIS

TENUIS

TENUIS

TENUIS

TENUIS

TENUIS

TENUIS

TENUIS

TE NUIS

TENUIS

TENUIS

TENUIS

TENUIS

FL INT I I

$S C$ HL UMBER GE R I

SC HLUMBER GE R I

SC HLUMBER GERI

SCHLUMBER GER

SC HLUMBER GER I

SC HLUMBER GER

SC HL UMBER GER I

SC HLUMBER GER

SCHLUMBER GER

SCHLUMBER GERI

SC HLUMBER GER I

SC HLUMBER GER I

SC HL UMBER GERI

SC HLUMBER GER

SCHLUMBER GER

SC HLUMBER GER

SCHLUMBER GERI

SC HLUMBER GER I

SC HLUMBER GE R I

SC HLUMBER GER I

SC HL UMB ER GER I

SC HLUMBER GER

SCHLUMBER GERI

$S$ C HLUMBER GER I

SC HLUMBER GE R I

S C HLUMB ER GE R I

S C HLUMBER GERI

SC HLUMBER GERI

SC HLUMBER GER I

SC HLUMBER GER I

SC HLUMBER GERI

SC HLUMBER GER I

SCHLUMBER GER I

SC HLUMBER GER I

SCHLUMBER GER

SCHLUMBER GE RI

S C HLUMBER GER

S C HLUMBER GER

S C HLUMBER GE RI

SC HLUMBER GER I

SC HLUMBER GE RI

SCHLUMBEF

$S$ CHLUMBER GERI

SC HLUMBER GERI

SC HLUMBER GER I

SC HLUMBER GER I

SC HLUMBER GER I

SC HLUMBER GER I

SCHLUMBER GER

SCHLUMBER GERI

SC HLUMBER GERI

SC HLUMBER GER I

S C HLUMBER GE R I

SC HLUMB ER GER I

SC HLUMBER GERI

SC HLUMBER GER I

SCHLUMBER GERI

SC HLUMBER GERI

SCHLUMBER GERI

S C HLUMBER GER I

SCHLUMBER GER I

SC HLUMBER GER

SC HLUMBER GERI

Locality

NH GULF OF MEXICO

NE GULF OF MEXICO

CAPE ROMANO, FLA.

NE GULF OF MEXICO

NE GULF OF MEXICO

NE GULF OF MEXICO

NE GULF OF MEXICO

NE GULF OF MEXICO

NE GULF OF MEXICO

NE GULF OF MEXICO 


\section{Publication}

25096 PFLUM FRERICHS 1976 5097 PFLUM FRERICHS 1976 25098 PFLUM FRERICHS 1976 25099 PFLUM FRERICHS 1976 25100 PFLUM FRERICHS 1976 25101 PFLUM FRERICHS 1976 25101 PFLUM FRERICHS 1976 25103 PFLUM FRERICHS 1976 25104 PFLUM FRERICHS 1976 25105 PFLUM FRERICHS 1976 25106 PFLUM FRERICHS 1976 25107 NORTON 1930

25108 CUSHMAN 1922A

25109 CUSHMAN 1922 A 1976

25110 PFLUM FRERICHS 1976
25111 PHLEGER 1951A

25112 PFLUM FRERICHS 1976

25113 CREAGER 1958

25114 CREAGER 1958

25115 CREAGER 1958

25117 CREAGER 1958

25118 PHLEGER 1956

25119 PARKER 1954

25120 PARKER 1954

25121 PARKER 1954

25123 PFLUM FRERICHS 1976

25124 PFLUM FRERICHS 1976

25125 PFLUM FRERICHS 1976

25126 PFLUM FRERICHS 1976

25127 PFLUM FRERICHS 1976

25128 BANDY 1956

5130 PFLUM FRERICHS 1976

25130 PFLUM FRERI

25132 PARKER 1954

25133 PARKER 1954

25134 LANKFORD 1959

25135 PHLEGER $1951 \mathrm{~A}$

25137 PFLUM FRERICHS 1976

25137 PFLUM FRERICHS 1976

25139 PFLUM FRERICHS 1976

25140 PFLUM FRERICHS 1976

25141 PF'UM FRERICHS 1976

25142 PFLUM FRERICHS 1976

25143 PFLUM FRERICHS 1976

25144 PFLUM FRERICHS 1976

25145 PFLUM FRERICHS 1976

25146 PFLUM FRERICHS 1976

25147 PARKER 1954

25148 PARKER 1954

25149 BOCK 1976

25150 CREAGER 1958

25151 CREAGER 1958

25152 CREAGER 1958

25153 BANDY 1956

25154 BANDY 1956

25155 BANDY 1956

25156 BANDY 1956

25157 BANDY 1956

25158 BANDY 1956

25159 BANDY 1956

25160 CREAGER 1958

25161 BANDY 1956

25163 PHLEGER $1951 \mathrm{~A}$

25164 PHLEGER $1951 \mathrm{~A}$

25165 PHLEGER 1951A

25166 PHLEGER $1951 \mathrm{~A}$

25167 PHLEGER 1951A

25168 PHLEGER $1951 \mathrm{~A}$

25169 PHLEGER 1951A

25170 PHLEGER $1951 \mathrm{~A}$

25172 PHLEGER 1951A

25173 PHLEGER $1951 \mathrm{~A}$

25174 PHLEGER 1951A

25175 PHLEGER 1951A

25176 PHLEGER 1951A

25177 PHLEGER 1951A

25178 DAVIS 1964

25179 PFLUM FRERICHS 1976

25180 PFLUM FRERICHS 1976

25181 CREAGER 1958

25182 CREAGER 1958

25183 CREAGER 1958

25184 NORTON 1930

25185 CUSHMAN 1931

25186 KELLOUGH 1956

25187 KELLOUGH 1956

$25188 \mathrm{KELLOUGH} 1956$

25189 KELLOUGH 1956

25190 KELLOUGH 1956

\section{Generic Name}

SI GMOILOPSIS

S I GMOIL OPS I S

SI GMOIL OPS I

SI GMOIL OPSIS

SI GMOILOPSIS

SI GMOILOPSIS

SI GMOILOPSIS

SI GMOILOPSIS

SIGMOILOPSIS

SI GMOILOPS IS

SI GMOIL OPSI S

SI PHOGENER I NA

SI PHOGE NER INA

SI PHOGE NER I NA

SI PHONINA

SI PHONINA

SIPHONINA

SI PHONINA

SI PHONINA

SI PHONINA

SI PHONINA

SI PHONINA

SI PHONINA

SI PHON I NA

SI PHONINA

SI PHONI NA

SI PHONINA

SI PHONINA

SI PHONI NA

SI PHONINA

SI PHONI NA

SI PHONINA

SI PHONINA

SI PHONINA

SI PHONINA

SI PHONI NA

SI PHON I NA

SI PHONINA

SI PHONINA

SIPHONINA

SI PHONINA

SI PHONINA

SI PHON INA

SI PHON I NA

SI PHONI NA

SIPHONI NA

SI PHONINA

SIPHONINA

SI PHONI NA

SI PHONINA

SI PHONINA

SI PHONINA

SI PHONINA

SI PHONI NA

SIPHONINA

SI PHON I NA

SI PHONINA

SI PHONINA

SI PHONINA

SIPHONINA

SI PHONINA

SI PHONINA

SI PHONI NA

SI PHONINA

SI PHONI NA

SI PHON I NA

SI PHONINA

SI PHONI NA

SI PHON I NA

SI PHONINA

SI PHONI NA

SI PHON I NA

SI PHONINA

SI PHONI NA

SI PHON I NA

SI PHONINA

SI PHONI NA

SI PHON I NA

SI PHONI NA

SI PHONINA

SI PHONINA

SI PHONINA

SIPHONINA

SI PHONINA

SI PHON I NA

SI PHON I NA

SI PHONI NA

SI PHONINA

SI PHONINA

SI PHONINA

SI PHONINA

SI PHONINA

SI PHONINA

SI PHONINA
Specific Name

SC HLUMBER GE R I

SC HLUMBER GE RI

S.CHLUMBER GE RI

SCHLUMBER GERI

SCHLUMBER GERI

SC HLUMBER GE RI

SC HLUMBER GE R I

SCHLUMBER GERI

SCHLUMBER GERI

SCHLUMBER GERI

SC HLUMBER GER I

ADVENA

RAPHANUS

BRPDYANA

BR ADYANA

BR ADYANA

BR ADYANA

BR ADYANA

BRADYANA

BRADYANA

BRADYANA

BRADYANA

BRADYANA

BRADYANA

BRADYANA

BRADYANA

BRADYANA

BR ADYANA

BRADYANA

BR ADYANA

BR ADYANA

BR ADYANA

BRADYANA

BRADYANA

BRADYANA

BR ADYANA

BR ADYANA

BRADYANA

BR ADYANA

BR ADYANA

BR ADYANA

BR ADYANA

BRADYANA

BRADYANA

BRADYANA

BRADYANA

BR ADYANA

BR ADYANA

BRADYANA

BR ADYANA

BR ADYANA

BR ADYANA

BR ADYANA

BR ADYANA

BRADYANA

BRADYANA

BRADYANA

BRADYANA

BR ADYANA

BR ADYANA

BRADYANA

BR ADYANA

BRADYANA

BRADYANA

BR ADYANA

BR ADYANA

BRADYANA

BRADYANA

BRADYANA

BR ADYANA

BRADYANA

BR ADYANA

BR ADYANA

BRADYANA

BR ADYANA

BRADYANA

BR ADYANA

BRADYANA

BRADYANA

BRADYANA

BRADYANA

PULCHRA

PULCHRA

PULCHRA

PULCHRA

PULCHRA

PULCHRA

PULCHRA

PULCHRA

PULCHRA

PULCHRA

PULCHRA

\section{Locality}

CENTRAL GULF OF MEXICO

CENTRAL GULF OF MEXICO

CENTRAL GULF OF MEXICO

CENTRAL GULF OF MEXICO

CENTRAL GULF OF MEXICO

CENTRAL GULF OF MEXICO

CENTRAL GULF OF MEXICO

CENTRAL GULF OF MEXICO

CENTRAL GULF OF MEXICO 


\section{Publication}

25191 KELLOUGH 1956 25192 ANDERSEN 1961 25193 PFLUM FRERICHS 1976 25194 CREAGER 1958

25195 LOEP 1965

25196 KELLOUGH 1956

25197 BOCK 1976

25198 PHLEGER $1951 \mathrm{~A}$ 25199 PFLUM FRERICHS 1976 25200 PFLUM FRERICHS 1976

25201 PHLEGER $1951 \mathrm{~A}$

25202 PHLEGER 1951A

25203 PHLEGER 1951A

25204 PHLEGER 1951 A

25205 PHLEGER 1951A

25206 PHLEGER 1951A

25207 PHLEGER 1951 A

25208 PHLEGER $1951 \mathrm{~A}$

25209 PARKER 1954

25210 LUDWICK WALTON 1957

25211 PARKER 1954

25212 PHLEGER 1951A

25213 PHLEGER 1951A

25214 PHLEGER $1951 \mathrm{~A}$

25216 PHLEGER 1951A

25217 PARKER 1954

25218 PARKER 1954

25219 PARKER 1954

25220 PARKER 1954

25222 PHLEGER 1951 A

25223 PHLEGER 1951A

25224 PHLEGER 1951 A

25225 CUSHMAN 1922A

25226 PHLEGER 1951A

25227 PARKER 1954

25228 CREAGER 1958

25229 PHLEGER $1951 \mathrm{~A}$

25230 PARKER 1954

25231 PFLUM FRERICHS 1976

25232 PFLUM FRERICHS 1976

25233 PFLUM FRERICHS 1976

25234 PHLEGER 1951A

25235 PARKER 1954

25236 PARKER 1954

25237 PHLEGER 1956

25238 PHLEGER 1951A

25239 PHLEGER 1951 A

25240 PHLEGER $1955 \mathrm{~A}$

25242 DAVIS 1964

25243 PHLEGER 1951 A

25244 PARKER 1954

25245 PHLEGER $1951 \mathrm{~A}$

25246 PARKER 1954

25247 PARKER 1954

5248 PARKER 1954

25249 PARKER 1954 25250 PFLUM FRERICHS 1976

25251 PFLUM FRERICHS 1976

25252 PFLUM FRERICHS 1976

25253 ANDERSEN 1961

25254 CREAGER 1958

25255 PFLUM FRERICHS 1976

25256 PFLUM FRERICHS 1976

25257 PFLUM FRERICHS 1976

25258 PFLUM FRERICHS 1976

25259 PFLUM FRERICHS 1976

25260 ANDERSEN 1961

25261 PARKER 1954

25262 PFLUM FRERICHS 1976

25263 PFLUM FRERICHS 1976

25264 PARKER 1954

25265 PARKER 1954

25266 PARKER 195

25267 LUDWICK WALTON 1957

25268 PARKER 1954

25269 PFLUM FRERICHS 1976

25270 PFLUM FRERICHS 1976

25271 PFLUM FRERICHS 1976

25272 PFLUM FRERICHS 1976

25273 PARKER 1954

25274 LEROY HODGKINSON 1975

25275 PARKER 1954

25276 BANDY 1956

25277 PFLUM FRERICHS 1976

25278 PFLUM FRERICHS 1976

25279 PFLUM FRERICHS 1976

25280 PFLUM FRERICHS 1976

25281 PFLUM FRERICHS 1976

25282 PFLUM FRERICHS 1976

25283 PFLUM FRERICHS 1976

25284 PFLUM FRERICHS 1976

25285 PFLUM FRERICHS 1976

\section{Generic Name}

SI PHONINA

SIPHONINA

SI PHONINA

SI PHONINA

SIPHONINA

SI PHONINA

SIPHON INA

SI PHONINA

SI PHONINA

SI PHON IN A

SI PHON INA

SI PHON INA

SI PHONINA

SIPHONINA

SI PHON INA

SI PHONINA

SI PHONINA

SI PHONINA

SI PHONINA

SI PHON I NA

SI PHON INA

SI PHONINA

SIPHONINA

SI PHONINA

SI PHONINA

SI PHON INA

SI PHON INA

SIPHONINA

SI PHONINA

SI PHONINA

SI PHONINA

SI PHONINA

SI PHON INA

SI PHONINA

SI PHONINA

SIPHONINA

SIPHONINA

SIPHONINA

SI PHON INA

SI PHONINA

SI PHONINA

SI PHONINA

SI PHONINA

SIPHONINA

SI PHONINA

SI PHONINA

SIPHONINA

SI PHONINA

SI PHONINA

SIPHONINA

SI PHONINA

SI PHON INA

SI PHONINA

SI PHONINA

I PHONINA

SI PHONINA

SIPHOTEXTULARIA

SIPHOTEXTUIARIA

SIPHOTEX TULAR IA

SIPHOTEXTULARIA

SI PHOTEX TULAR IA

SI PHOTEXTULARIA

SI PHOTEXTULARIA

SIPHOTEXTULARIA

SIPHOTEXTULARIA

SIPHOTEXTULARIA

SI PHOTEX TUL ARIA

SIPHOTEXTULARIA

SI PHOTEXTULARIA

SIPHOTEXTUL AR IA

SIPHOTEXTULARIA

SIPHOTEXTULARIA

SI PHOTEX TULARI

SIPHOTEXTULARIA

SIPHOTEXTULARIA

SIPHOTEXTULARIA

SIPHOTEXTULARIA

SI PHOTEXTULAR IA

SIPHOTEXTULARIA

SI PHOTEXTUL AR I

SIPHOTEXTULAR IA

SIPHOTEXIULARIA

SIPHOTEXTUL AR IA

SIPHOTEX TULAR IA

SI PHOTEX TULAR IA

SI PHOTEXTULAR I

SIPHOTE XTULARIA

SI PHOTEXTULARIA

SIPHOTEXTULARIA

SI PHOTEXTULAR IA

SI PHOTEXTULARIA
Specific Name

Locality

Lat. Long.

PULCHRA

PULCHRA

PULCHRA

PULCHRA

PULCHRA

PULCHRA

PULCHRA

PULCHRA

PULCHRA

PULCHRA

PULCHRA

PULCHRA

PULCHRA

PULCHRA

PULCHRA

ULCHRA

PULCHRA

PULCHRA

PULCHRA

PULCHRA

PULCHRA

PULCHRA

PULCHRA

PULCHRA

PULCHRA

PULCHRA

PULCHRA

PULCHRA

PULCHRA

PULCHRA

PULCHRA

PULCHRA

PULCHRA

PULCHRA

PULCHRA

PULCHRA

PULCHRA

PULCHRA

PULCHRA

PULCHRA

PULCHRA

PULCHRA

PULCHRA

PULCHRA

PULCHRA

ULCHRA

PULCHRA

PULCHRA

PULCHRA

PULCHRA

PULCHRA

PULCHRA

PULCHRA

AFFINIS

AFFINIS

AF FIN IS

A F F INIS

AFFINIS

AFFINIS

AFFINIS

AFFIN IS

AFFINIS

AF FIN IS

OACAVA

U URTA

CURTA

CURTA

CURTA

CURTA

CURTA

CURTA

CURTA

CURTA

CURTA

CURTA

CURTA

CURTA

CURTA

OL IANAENS IS

ROLSHAUSENI

ROLSHAUSEN I

ROLSHAUSENI

ROLSHAUSEN

ROLSHAUSEN

ROLSHAUSENI

ROLSHAUSÉN

ROLSHAU

ROLSHAUSENI

NH GULF OF MEXICO

MISSISSIPPI DELTA

NW GULF OF MEXICO

BAY OF CAMPECHE

$\mathrm{NW}$ GULF OF MEXICO

NH GULF OF MEXICO

NE GULF OF MEXICO

NW GULF OF MEXICO

NW GULF OF MEXICO

NW GULF OF MEXICO

NW GULF OF MEXICO 


\section{Publication}

25286 PFLUM FRERICHS 1976 25287 PFLIJM FRERICHS 1976 25288 PFLUM FRERICHS 1976 25289 PFLUM FRERICHS 1976 25290 PFLUM FRERICHS 1976 25291 PFLUM FRERICHS 1976 25292 PFLUM FRERICHS 1976 25293 PFLUM FRERICHS 1976 25294 PARKER 1954 25295 PARKER 1754

25296 PARKER 1954

25297 PARKER 1954

25298 PHLEGER 1955A

25299 PFLUM FRERICHS 1976

25300 PFLUM FRERICHS 1976

25301 PFLUM FRERICHS 1976

25302 PHLEGER $1955 \mathrm{~A}$

25303 PFLUM FRERICHS 1976

25304 PFLUM FRERICHS 1976

25305 PFLUM FRERICHS 1976

25306 PFLUM FRERICHS 1976

25308 PARKER 1954

25309 PARKER 1954

25309
25310
PARKER 1954

25311 PARKER 1954

25312 PARKER 1054

25313 CREAGER 1958

25314 BOCK 1976

25315 PARKER 1954

25316 PARKER 1954

$\begin{array}{lll}25317 & \text { PFLUM FRERICHS } & 1976 \\ 25318 & \text { PFLUM FRERICHS } & 1976\end{array}$

25319 ANDERSEN 1961

25320 PFLUM FRERICHS 1976

25321 PFLUM FRERICHS 1976

25322 PFLUM FRERICHS 1976

25323 PFLUM FRERICHS 1976

25324 PFLUM FRERICHS 1976

25325 PFLUM FRERICHS 1976

25326 PFLUM FRERICHS 1976

25327 PFLUM FRERICHS 1976

25328 PFLUM FRERICHS 1976

25329 PFLUM FRERICHS 1976

25330 PFLUM FRERICHS 1976

25331 PFLUM FRERICHS 1976

25332 PFLIJM FRERICHS 1976

25333 PFLUM FRERICHS 1976

25334 PFLUM FRERICHS 1976

25335 PFLUM FRERICHS 1976

25336 PFLIJM FRERICHS 1976

25337 PFLUM FRERICHS 1976

25338 PFLUM FRERICHS 1976

25339 PFLUP FRERICHS 1976

25340 PFLUM FRERICHS 1976

25341 PFLUM FRERICHS 1976

25343 BOCK 1976

25344 NORTON 1930

25345 CUSHMAN 1930

25346 BANDY 1956

25347 BANDY 1956

25348 BANDY 1956

25349 BANDY 1956

25351 BANDY 1956

25352 BANDY 1956

25353 BANDY 1956

25354 BANDY 1956

25355 PANDY 1956

25356 BANDY 1056

25357 BANDY 1956

25358 BANDY 1956

25359 BANDY 1956

25360 BANDY 1956

25361 BANDY 1956

25362 BANDY 1956

25363 BANDY 1956

25364 BANDY 1956

25365 BANDY 1956

25366 BANDY 1956

25367 BANDY 1956

25368 BANDY 1956

25369
25370 CREAGER 1958

25371 PFLUM FRERICHS 1976

25372 CREAGER 1958

25373 CREAGER 1958

25374 CREAGER 1958

25375 CREAGER 1958

25376 CREAGER 1958

25377 CREAGER 1958

25378 CREAGER 1958

25379 PARKER 1954

25380 PARKER 1954
Generic Name

SI PHOTEXTULARIA

SIPHOTEXTULARIA

SIPHOTEXTULARIA

SI PHOTEX TULARIA

SIPHOTEXTULARIA

SIPHOTEXTULARIA

SI PHOTEXTULAR I A

SIPHOTEXTULARIA

SI PHOTEXTUL AR IA

SI PHOTEXTULARIA

SIPHOTEXTULARIA

SI PHOTEXTULARIA

SI PHOTEXTULARIA

SIPHOTEXTUL AR IA

SI PHOTEXTUL AR IA

SI PHOTEXTULARIA

SIPHOTE XTULARIA

SIPHOTEXIULAR IA

SI PHOTE XTULARIA

SI PHOTEXTULAR IA

SI PHOTEX TUL AR I A

SIPHOTEXTULARIA

SI PHOTEXTUL ARIA

SIPHOTEXTULAR IA

SI PHOTEXTULARIA

SI PHOTEXTULAR IA

SIPHOTEXTULAR IA

SI PHOTE X TULAR IA

SI PHOTEXTULARIA

SIPHOTE XTULARIA

SI PHOTEXTUL AR IA

SI PHOTEXTULAR IA

SIPHOTE XTULAR IA

SIPHOTEXTULARIA

SIPHOTROCHAMMINA

SI PHOTROCHAMMINA

SI PHOTR OCHAMMINA

SI PHOTR OCHAMMINA

SI PHOTROCHAMMINA

SI PHOTR OCH AMMINA

SIPHOTROCHAMMINA

SI PHOTROCHAMMINA

SI PHOTR OCHA MMINA

SI PHOTROCHAMMINA

SI PHOTR OCHAMMINA

SI PHOTR OCHAMMINA

SI PHOTR OCHAMMINA

S I PHOTROCHAMMINA

SI PHOTR OCHAMM INA

SI PHOTROCHAMMINA

SIPHOTR OCHAMM INA

SI PHOTR OCHAMM INA

SIPHOTROCHAMMINA

SI PHOTROCHAMMINA

SI PHOTR OCHA YMINA

SI PHOTR OCHAMMINA

SI PHOTR OCHAMMINA

SORITES

SORITES

SORITES

SORITES

SORITES

SORITES

SORITES

SORITES

SORITES

SORITES

SORITES

SORITES

SORITES

SORITES

SORITES

SORITES

SORITES

SORITES

SORITES

SORITES

SORITES

SORITES

SORITES

SORITES

SORITES

SPHAEROIDINA

SPHAERO I DINA

SPHAEROIDINA

SPHAEROIDINA

SPHAEROIDINA

SPHAEROIDINA

SPHAEROI DINA

SPHAEROIDINA

SPHAEROIDINA

SPHAEROIDINA

SPHAEROIDINA

SPHAEROIDINA

SPHAEROIDINA
Specific Name

Locality

ROLSHAUSEN I

ROLSHAUSENI

RO LSHAUSENI

ROLSHAUSENI

ROLSHAUSENI

ROLSHAUSEN

ROLSHAUSEN

ROLSHAUSENI

ROLSHAUSENI

ROLSHAUSENI

ROLSHAUSENI

ROLSHAUSENI

ROLSHAUSENI

ROLSHAUSEN

ROLSHAUSEN I

OLSHAUSENI

ROLSHAUSENI

ROLSHAUSENI

ROLSHAUSENI

ROLSHAUSENI

ROLSHAUSENI

RO LSHAUSENI

ROLSHAUSENI

ROLSHAUSENI

ROLSHAUSE NI

ROLSHAUSENI

ROLSHAUSENI

ROLSHAUSENI

ROLSHAUSENI

ROLSHAUSE NI

ROLSHAUSENI

ROLSHAUSENI

ROLSHAUSEN I

SAUL CYANA

SQUAMATA

SQUAMATA

SQLAMATA

SQLAMATA

SQLAMATA

SQLAMATA

SQLAMATA

SQLAMATA

SQLAMATA

SQUAMATA

SQLAMATA

SQLAMATA

SQLAMATA

SQLAMATA

SQLAMATA

QLAMATA

QLAMATA

SQUAMATA

SQLAMATA

SQLAMATA

SQLAMATA

SQLAMATA

HOFKERI

MARGINALIS

MARGINALIS

OREITOLITOIDES

OREITOL IT OI DES

OREITOLITOIDES

OREITOL IT OI DES

OREITOLITOIDES

OREITOLITOIDES

OREITOL ITOIDES

OREITOLITOIDES

OREITOLITOIDES

OREITOLITOI DES

ORBITOL IT OI DES

ORE ITOLITOI DE

OREITOLITO

OREITOLITOIDES

ORBITOLITOIDES

OREITOLITOI DES

OREITOL ITOIDES

OREITOLITOIDES

OREITOLITOIDES

OREITOL ITOIDES

OREITOLITOIDES

ORBITOLITOIDES

OREITOLITOIDES

BULLOIDES

BULLOIDES

BULLOIDES

BULLOIDES

BULLOIDES

BULLOIDES

BULLOIDES

BULLOIDES

BULLOIDES

BULLOIDES

BULLOIDES

BULLOIDES

NW GIJLF OF MEXICO

$N W$ GULF OF MEXICO

NW GULF OF MEXICO

NW GULF OF MEXICO 


\section{Publication}

25381 PARKER 1954 25382
25383
PARKER 1954
$192 K R$ 25384 PFLUM FRERICHS 1976 25385 PFLUM FRERICHS 1976 25386 PFLUM FRERICHS 1976 25387 PFLUM FRERICHS 1976 25388 PFLUM FRERICHS 1976 25389 PFLUM FRERICHS 1976 25390 PFLUM FRERICHS 1976 25391 PFLUM FRERICHS 1976 25392 PFLUM FRERICHS 1976 25393 PFLUM FRERICHS 1976 25394 PFLUM FRERICHS 1976 25395 PFLUM FRERICHS 1976 25396 PFLUM FRERICHS 1976 25397 PFLUM FRERICHS 1976 25398 PFLUM FRERICHS 1976 25399 PFLUM FRERICHS 1976 25400 PHLEGER 1955 A

25401 LIJOWICK WALTON 1957 25402 PHLEGER 1955 A

25403 PARKER 1954

25404 PARKER 1954

25405 PARKER 1954

25406 PHLEGER 1955 A

25407 PFLUM FRERICHS 1976 25408 PFLUM FRERICHS 1976 25409 PFLUM FRERICHS 1976 25410 PFLUM FRERICHS 1976 25411 PFLUM FRERICHS 1976 25412 PFLUM FRERICHS 1976 25413 PFLUM FRERICHS 1976 25414 PFLUM FRERICHS 1976 25415 PFLUM FRERICHS 1976 25416 PARKER 1954 25417 PARKER 1954 25418 PARKER 1954

25419 PARKER 1954

25420 CREAGER 1958

25421 CREAGER 1958

25422 CREAGER 1958

25423 PFLUM FRERICHS 1976 25424 PFLUM FRERICHS 1976 25425 PFLUM FRERICHS 1976 25426 PFLUM FRERICHS 1976

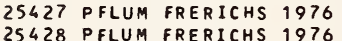
$\begin{array}{lll}25428 & \text { PFLUM FRERICHS } & 1976 \\ 25429 & \text { PFLUM FRERICHS } & 1976\end{array}$ 25429 PFLUM FRERICHS 1976
25430 PFLUM FRERICHS 1976 25431 PFLUM FRERICHS 1976 25432 PFLUM FRERICHS 1976 25433 PFLUM FRERICHS 1976 25434 PFLUM FRERICHS 1976 25435 PFLUM FRERICHS 1976 25436 PFLUM FRERICHS 1976 25437 PFLUM FRERICHS 1976 25438 PFLUM FRERICHS 1976 25439 PFLUM FRERICHS 1976 25440 PFLUM FRERICHS 1976 25441 PFLUM FRERICHS 1976 25442 PFLUM FRERICHS 1976 25443 PFLUM FRERICHS 1976 25444 PARKER 1954

25445 PFLUM FRERICHS 1976 25446 PFLUM FRERICHS 1976 25447 PFLUM FRERICHS 1976 25448 PFLUM FRERICHS 1976 25449 PFLUM FRERICHS 1976
25450 PFLUM FRERICHS 1976 25451 PFLUM FRERICHS 1976 25452 PFLUM FRERICHS 1976 25453 PFLUM FRERICHS 1976 25454 PFLUM FRERICHS 1976 25455 PFLUM FRERICHS 1976 25456 PFLUM FRERICHS 1976 25457 CREAGER 1958 25458 CREAGER 1958

25459 CREAGER 1958

25460 CREAGER 1958

25461 LOEP 1965

25462 LOEP 1965

25463 ANDERSEN 1961

25464 PFLUM FRERICHS 1976 25465 CREAGER 1958

25466 PARKER 1954

25467 PHLEGER 1956

25468 PARKER 1954

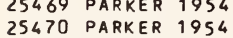

25471 PARKER 1954

25472 PARKER 1954

25473 PARKER 1954

25474 PFLUM FRERICHS 1976 25475 PFLUM FRERICHS 1976
Generic Name

SPHAEROI DINA SPHAEROIDINA SPHAEROI DINA SPHAEROIDINA SPHAEROIDINA SPHAEROI DINA SPHAEROI DINA SPHAEROI DINA SPHAEROI DINA SPHAEROIDINA SPHAEROI DINA SPHAEROI DINA SPHAEROI DINA SPHAEROI DINA SPHAEROI DINA SPHAEROI DINA SPHAEROI DINA SPHAEROI DINA SPHAEROI DINA SPHAEROI OINA SPHAEROIOINA SPHAEROI DINA SPHAEROI DINA SPHAEROIDINA SPHAEROI DINA SPHAEROI DINA SPHAEROI DINA SPHAEROIDINA SPHAEROI OINA SPHAEROI DINA SPHAEROIDINA SPHAEROIDINA SPHAEROIDINA SPHAEROIDINA SPHAEROIDINA SPHAEROIDINA SPHAEROI DINA SPHAEROIOINA SPHAEROI DINA SPHAEROIDINA SPHAEROIDINA SPHAEROI DINA SPHAER OIDINA SPHAEROIDINA SPHAEROIDINA SPHAEROIDINA SPHAEROIOINA SPHAEROIDINA SPHAEROIDINA SPHAEROI DINA SPHAEROIDINA SPHAEROIDINA SPHAEROIDINA SPHAEROI OINA SPHAEROI DINA SP HAEROI DINA SPHAEROI DINA SPHAEROI DINA SPHAEROIDINA SPHAEROIDINA SPHAEROI DINA SPHAEROIDINA SPHAEROI DINA SPHAEROIOINA SPHAEROI DINA SPHAEROIDINA SPHAEROI OINA SPHAEROIDINA SPHAEROIOINA SPHAEROIDINA SPHAEROI DINA SPHAEROI DINA SPHAEROI DINA SPHAEROIDINA SPHAEROIDINA SPHAEROI DINA SPHAEROI DINA SPHAEROIDINA SPHAEROIDINA SPHAEROIDINA SPHAEROI DINA SPHAEROIOINA SPHAEROI DINA SPHAEROIDINA SPHAEROI DINA SPHAEROIDINA SPHAEROI DINA SPHAEROI DINA SPHAEROIDINA SPHAEROI DINA SPHAEROI DINA SPHAEROIDINA SPHAEROI DINA SPHAEROIDINA
Specific Name

Locality

NE GULF OF MEXICO NE GULF OF MEXICO NE GULF OF MEXICO NW GULF OF MEXICO NW GULF OF MEXICO NW GULF OF MEXICO NW GULF OF MEXICO NW GULF OF MEXICO NW GULF OF MEXICO NW GULF OF MEXICO NH GULF OF MEXICO NW GULF OF MEXICO $N W$ GULF OF MEXICO NW GULF OF MEXICO NW GULF OF MEXICO NH GULF OF MEXICO $N W$ GULF OF MEXICO NW GULF OF MEXICO $N W$ GULF OF MEXICO $N$ GULF OF MEXICO NE GULF OF MEXICO $N$ GULF OF MEXICO NE GULF OF MEXICO NE GULF OF MEXICO NE GULF OF MEXICO $N$ GULF OF MEXICO NW GULF OF MEXICO NH GULF OF MEXICO NW GULF OF MEXICO NW GULF OF MEXICO NW GULF OF MEXICO NW GULF OF MEXICO NW GULF OF MEXICO NW GULF OF MEXICO NW GULF OF MEXICO NE GULF OF MEXICO NE GULF OF MEXICO NE GULF OF MEXICO NE GULF OF MEXICO BAY OF CAMPECHE BAY OF CAMPECHE BAY OF CAMPECHE CENTRAL GULF OF MEXICO CENTRAL GULF OF MEXICO CENTRAL GULF OF MEXICO CENTRAL GULF OF MEXICO CENTRAL GULF OF MEXICO CENTRAL GULF OF MEXICO CENTRAL GULF OF MEXICO NW GULF OF MEXICO NH GULF OF MEXICO NW GULF OF MEXICO NH GULF OF MEXICO NW GULF OF MEXICO NW GULF OF MEXICO NW GULF OF MEXICO NW GULF OF MEXICO NW GULF OF MEXICO NW GULF OF MEXICO NW GULF OF MEXICO NW GULF OF MEXICO NW GULF OF MEXICO NW GULF OF MEXICO NE GULF OF MEXIr CENTRAL GULF OF MEXICO CENTRAL GULF OF MEXICO CENTRAL GULF OF MEXICO CENTRAL GULF OF MEXICO NU GULF OF MEXICO

NW GULF OF MEXICO CENTRAL GULF OF MEXICO CENTRAL GULF OF MEXICO CENTRAL GULF OF MEXICO CENTRAL GULF OF MEXICO CENTRAL GULF OF MEXICO CENTRAL GULF OF MEXICO BAY OF CAMPECHE BAY OF CAMPECHE BAY OF CAMPECHE BAY OF CAMPECHE NW GULF OF MEXICO NW GULF OF MEXICO MISSISSIPPI DELTA CENTRAL GULF OF MEXICO BAY OF CAMPECHE NE GULF OF MEXICO NW GULF OF MEXICO NE GULF OF MEXICO NE GULF OF MEXICO NE GULF OF MEXICO NE GULF OF MEXICO NE GULF OF MEXICO NE GULF OF MEXICO CENTRAL GULF OF MEXICO CENTRAL GULF OF MEXICO

Lat. Long.

$\begin{array}{lllllllll}28 & 14 N & 087 & 04 W\end{array}$ $2738 \mathrm{~N} 08634 \mathrm{~W}$ $2822 \mathrm{~N} 086 \quad 14 \mathrm{~W}$ 


\section{Publication}

25476 PFLUM FRERICHS 1976 25477 PFLUM FRERICHS 1976 25478 PFLUM FRERICHS 1976 25479 PFLUM FRERICHS 1976 25480 CREAGER 1958

25481 PARKER 1954

25482 PARKER 1954

25483 PARKER 1954

25484 PARKER 1954

25485 PARKER 1954

25486 PARKER 1954

25487 PARKER 1954

25488 PARKER 1954

25489 PARKER 1954

25490 CREAGER 1958

25491 SHIFFLETT
25492 BOCK 1976

25493 BOCK 1976

25494 BOCK 1976

25495 KORNFELD 1931

25496 DAVIS 1964

25498 PARKER 1954

25499 PARKER 1954

25500 PARKER 1954

25501 PARKER 1954

25502 PARKER 1954

25503 PFLUM FRERICHS 1976

25504 LUDWICK WALTON 1957

25505 PARKER 1954

25506 PARKER 1954

25507 CUSHMAN $1922 \mathrm{~A}$

25508 PARKER 1954

25509 PARKER 1954

25510 ANDERSEN 1961

25511 WALTON 1964

25512 AYALA-CASTANARES 1963

25513 LEHMANN 1957

25514 CUSHMAN 1931

25515 PFLUM FRERICHS 1976

25516 NORTON 1930

25517 PARKER 1954

25518 PARKER 1954

25519 DAVIS 1964

25520 CUSHMAN 1930

25521 CUSHMAN 1930

25522 NORTON 1930

25523 CUSHMAN 1922A

25525 KELLOUGH 1956

25526 ANDERSEN 1961

25527 PFLUM FRERICHS 1976

25528 AYALA-CASTANARES 1963

25529 KELLOUGH 1956

25530 NORTON 1930

25531 LANKFORD 1959

25532 NORTON 1930

25533 BOCK 1976

25534 CUSHMAN 1922 A

25535 VAUGHAN 1918

25536 BOCK 1976

25537 CUSHMAN $1922 \mathrm{~A}$

25538 NORTON 1930

25539 CUSHMAN $1922 \mathrm{~A}$

25540 NORTON 1930

25541 ANDERSEN 1961

25542 ANDERSEN 1961

25543 BENDA PURI 1962
25544 BENDA PURI 1962

25545 AYALA-CASTANARES 1963

25546 BANDY 1956

25547 BANDY 1956

25548 BANDY 1956

25549 BANDY 1956

25550 BANDY 1956

25551 BANDY 1956

25552 BANDY 1956

25553 BANDY 1956

25554 BANDY 1956

25555 DAVIS 1964

25556 BANDY 1956

25557 BANDY 1956

25558 BENDA PURI 1962

25559 BENDA PURI 1962

25560 CUSHMAN 1922 A

25561 PARKER 1954

25562 PARKER 1954

25563 PARKER 1954

25564 PARKER 1954

25565 PARKER 1954

25566 PARKER 1954

25567 VAUGHAN 1918

25568 WALTON 1960

25569 LUDWICK WALTON 1957

25570 PARKER 1954
Generic Name

SPHAEROIDINA

SPHAEROI DINA

SPHAEROIDINA

SPHAEROIDINA

SPHAEROIDINA

SPHAEROI DINA

SPHAEROI DINA

SPHAEROIDINA

SPHAEROIDINA

SPHAEROIDINA

SPHAEROIDINA

SPHAEROIDINA

SPHAEROI DINA

SPHAEROIDINA

SPIR ILLINA

SPIRILLINA

SPIRILLINA

SPIRILLINA

SPIRILLINA

SPIRILLINA

SPIRILLINA

SPIRILLINA

SPIRILLINA

SPIR ILL INA

SPIRILL INA

SPIRILLINA

SPIRILL INA

SPIRILLINA

SPIR I LL INA

SPIRILLINA

SPIRILLINA

SPIR ILL INA

SPIRILL INA

SPIRILL INA

SPIRILLINA

SPIR ILL INA

SP IR ILL INA

SPIRILLINA

SPIRILLINA

SPIRILLINA

SPIRILLINA

SPIRILLINA

SPIRILL INA

SPIROLINA

SPIROLINA

SPIROLINA

SPIROL INA

SPIROLOCUL INA

SPIROLOCUL INA

SP IROL OCUL INA

SPIROLOCULINA

SPIROL OCUL INA

SPIROLOCUL INA

SP IROLOCUL INA

SP IROLOC UL INA

SPIROL OCUL INA

SP IROLOCUL INA

SPIROLOCULINA

SPIROL OCUL INA

SPIROLOCULINA

SPIROLOCUL INA

SPIROLOCULINA

SPIROLOCULINA

SPIROL CULINA

SPIROL OCUL INA

SP IROL OC UL INA

SPIROLOCULINA

SPIROLOCULINA

SPIROLOCULINA

SPIROLOCUL INA

SPIROLOCULINA

SPIROLOCUL INA

SPIROL OCUL INA

SPIROL OCULI INA

SPIROL OCUL INA

SPIROL OCUL INA

SPIR OL OCUL IVA

SPIROLOCUL INA

SPIROLOCULINA

SPIROLOCULINA

SPIROL OCUL INA

SPIROL OCUL INA

SPIROLOCUL INA

SPIROLOCULINA

SPIROLOCULINA

SPIROLOCUL INA

SPIROLOCUL INA

SPIROLOCULINA

SPIROL OCUL INA

SP IROLOCUL INA

SPIROLOCUL INA

SPIROLOCULINA

SPIROLOCULINA

SPIROLOCUL INA

SPIROLOCUL INA
SPIROLOCULINA
Specific Name

Locality

Lat. Long.

BULLOIDES

BULLOIDES

BULLOIDES

BULLOIDES

BULLOIDES

CONPACTA

COMPACTA

COMPACTA

CONPACTA

CONPACTA

CONPACTA

CONPACTA

CONPACTA

CONPACTA

DE CORATA

DE CORATA

DE CORATA

DENTI CULA TA

OR A ATA

VIVIPARA

VI VIPARA

VI VIPARA

VI VIPARA

VIVIPARA

VI VIPARA

VIVIPARA

VI VIPARA

VI VIPARA

VIVIPARA

VI VIPARA

VI VIPARA

VIVIPARA

VI VIPARA

VI VIPARA

II VIPARA

VI VIPARA

VI VIPARA

VI VIPARA

VIVIPARA

VIVIPARA

VI VIPARA

I VIPARA

$A R$ IE TINA

AR IE TINUS

AR IETINUS

CYLINDRACEUS

AN TILLARJM

ANTILLARUM

ANTILLARJM

AN TILLARUM

AN TILLARUM

AN TILLARUM

ANTILLARJM

AN TILLARUM

ANTILLARUM

AN TILLARUM ANGULATA

ANTILLARUM ANGULATA

AN TILLARUM ANGULATA

ARENARIA

AR ENATA

AR ENATA

ARENATA

CACUCA

CA DUCA

DENTATA

DENTATA

DE NTATA

DENTATA

DENTATA

DEPRESSA

DEFRESSA

DE PRESSA

DEPRESSA

DEFRESSA

DEPRESSA

DEPRESSA

DEPRESSA

DEPRESSA

DEPRESSA

DEFRESSA

DEFRESSA

DEPRESSA

DEPRESSA

EXIMIA

GRATA

GRATA

GRATA

GR ATA

GRATA

GR ATA

GRATA

GRATA

GRATA

CENTRAL GULF OF MEXICO

CENTRAL GULF OF MEXICO

CENTRAL GULF OF MEXICO 


\section{Publication}

25571 PARKER 1954 25572 BOCK 1976 25573 PARKER 1954 25574 PARKER 1954 25575 PARKER 1954 25576 CUSHMAN 1922 25577 NORTON 1930
25578 POST 1951 25579 LEHMANN 1957 25580 CUSHMAN 1922A 25581 NORTON 1930 25582 CUSHMAN 1922A 25583 NORTON 1930 25584 PARKER 1954 25585 PARKER 1954 25586 BOCK 1976 25587 LUDHICK HALTON 1957 25588 PARKER 1954 25589 PARKER 1954 25590 PARKER 1954 25591 PARKER 1954
25592 PARKER 1954 25593 PARKER 1954 25594 PARKER 1954 25595 PARKER 1954 25596 PARKER 1954 25597 PARKER 1954 25599 BANDY 1956 25600 BANDY 1956 25601 PARKER 1954 25602 PARKER 1954 25604 LUDHICK WALTON 1957 25605 PARKER 1954 25606 PARKER 1954 25607 PHLEGER 1951A 25608 PARKER 1954 25609 PARKER 1954 25610 PARKER 1954 25611 BOCK 1976 25612 CREAGER 1958 25613 BANDY 1956 25614 BANDY 1956 25616 BANDY 1956 25617 BANDY 1956 25618 BANDY 1956 25619 NORT ON 1930 25620 PFLUM FRERICHS 1976 25621 PFLUM FRERICHS 1976 25622 PFLUM FRERICHS 1976 25623 PFLUM FRERICHS 1976 25624 PFLUM FRERICHS 1976 25625
25626 PFLUUM FRERICHS 1976 25627 PFLUM FRERICHS 1976 25628 PFLUM FRERICHS 1976 25629 PFLUM FRERICHS 1976 25630 PFLUM FRERICHS 1976 25631 PFLUM FRERICHS 1976 25632 PFLUM FRERICHS 1976 25633 PFLUM FRERICHS 1976
25634 PFLUM FRERICHS 1976 25635 PFLUM FRERICHS 1976 25636 PFLUM FRERICHS 1976 25637 PFLUM FRERICHS 1976 25638 PFLUM FRERICHS 1976 25639 PFLUM FRERICHS 1976 25640 PFLUM FRERICHS 1976 25641 PFLUM FRERICHS 1976 25642 PFLUM FRERICHS 1976 25643 PFLUM FRERICHS 1976 25644 PFLUM FRERICHS 1976 25645 PFLUM FRERICHS 1976 25646 PFLUM FRERICHS 1976 25647 PFLUM FRERICHS 1976 25648 PFLUM FRERICHS 1976 25649 PFLUM FRERICHS 1976 25650 PFLUM FRERICHS 1976 25651 PFLUM FRERICHS 1976 25652 PFLUM FRERICHS 1976 25653 PFLUM FRERICHS 1976 25654 PFLUM FRERICHS 1976 25655 PFLUM FRERICHS 1976 25657 PFLUM FRERICHS 1976 25658 PFLUM FRERICHS 1976 25659 PFLUM FRERICHS 1976 25660 PFLUM FRERICHS 1976 25661 PFLUM FRERICHS 1976 25662 PFLUM FRERICHS 1976 25663 PFLUM FRERICHS 1976 25664 PFLUM FRERICHS 1976 25665 PFLUM FRERICHS 1976

\section{Generic Name}

SPIROL OCUL INA SPIROLOCUL INA SPIROLOCUL INA SPIROLOCULINA SP IROLOC UL INA SPIROLOCULINA SPIROLOCUL INA SPIROL OCUL INA SPIROL OC UL INA SP IROL OCUL INA SPIR OL OCULINA SPIROLOCUL INA SPIROLOCUL INA SPIR OL OCUL INA SPIR OL OC UL INA SPIROLOCUL INA SP IROLOCUL INA SPIROL OCUL INA SPIROL OCULINA SPIROL OCULINA SPIROL OCUL INA SPIROLOCUL INA SPIROLOCULINA SPIROL OCUL INA SP IROL OCUL INA SPIROL OCULINA SPIROL OCUL INA SPIROL OCUL INA SPIR OPLECTAMMINA SP IR OPLECT AMMINA SPIROPLECTAMMINA SP IROPLE CTAMMINA SPIROPLECTAMMINA SPIROPLECTAMMINA SPIROPLE CTAMMINA SP IROPL ECT AMM INA SPIROPL ECTAMMINA SP IROPL ECTAMM INA SPIROPLECT AMMINA SPIROPLECTAMMINA SPIROPLE CT AMM INA SPIROPLECTAMM INA SPIR OPL ECT AMM INA SPIROPLECTAMM INA SPIROPLECTAMMINA SPIROPLECTAMMINA SPIROPLECTAMM INA SPIROPLECTAMMINA SPIROPLECTAMMINA SPIROSIGMOIL INA SP IROSIGMO IL INA SPIROSIGMOIL INA SPIROSIGMOI LINA SPIROS I GMOIL INA SPIROSIGMOIL INA SPIROSIGMOILINA SPIROSIGMOILINA SPIR OS I GMOIL INA SP IROS I GMO I LINA SPIROSIGMOILINA SPIROSIGMOI L INA SPIROSIGMOILINA SP IROSIGMO I L INA SPIROSIGMOIL INA SPIROSIGMOIL INA SPIROSIGMOILINA SPIROSIGMOIL INA SPIROSIGMOIL INA SPIROSIGMOILINA SPIROS IGMOILINA SPIROSIGMOI L INA SPIROSIGMOIL INA SPIROSIGMOIL INA SP IROSIGMOIL INA SPIR OSIGMOIL INA SPIROSI GMOILINA SPIROSIGMOIL INA SPIROSIGMOILINA SPIROSI GMOIL I NA SPIROSIGMOIL INA SPIROSIGMOIL INA SPIROSI GMOIL INA SPIROSI GMOILINA SP IR OS I GMOIL INA SP IROSI GMOIL INA SP IROSIGMOI LINA SP IROSIGMO IL INA SPIROSIGMOIL INA SPIROSI GMOILINA SPIROSIGMOIL INA SPIROS I GMOI L I NA SPIROSI GMOIL INA SPIROS IGMOILINA SPIROSIGMOILINA SPIROSIGMOILINA
Specific Name

GRATA

GRATA

GRATA

GR ATA

GRATA

GRATEL OUP I

GRATEL OUP I

MANIFESTA

MANIFEST

OR NATA

ORNATA

PLANULATA

PLANULATA

SOLDANII

SOLDANII

SOLDANII

SOLDANI

SOLDANI

SOLDANI

SOLDANII

SOLDANI I

SOLDANI I

SOLDANI

SOLDANI

SOLDANII

SOLDANII

SOLDANI I

SOLDANII

FL ORI DANA

FL CRI DANA

FL OR I DANA

FL CRIDANA

FL OR I DANA

FL OR I DANA

FL CR I DANA

FL CRIDANA

FL ORI DANA

FL ORI DANA

FL ORI DANA

FL ORI DANA

FL CRI DANA

FL OR I DANA

FL OR I DANA

FL CRI DANA

FL OR I DANA

FLRIDANA

FL ORI DANA

WR IGH TI

DISTORTA

DISTORTA

DISTORTA

DISTORTA

DI STORTA

DI STORTA

DISTORTA

DI STORTA

DISTORTA

DI STORTA

DISTORTA

DI STORTA

DI STORTA

OI STORTA

DISTORTA

DI STORTA

DI STORTA

DI STORTA

DISTORTA

DI STORTA

DI STORTA

DI STORTA

DISTORTA

DISTORTA

DI STORTA

DI STORTA

DI STORTA

DISTORTA

DISTORTA

DISTORTA

DI STORTA

DI STORTA

DI STORTA

DI STORTA

DI STORTA

DISTORTA

DISTORTA

DI STORTA

DI STORTA

DISTORTA

DI STORTA

DI STORTA

DI STORTA

DISTORTA

DI STORTA

DI STORTA

\section{Locality}

NE GULF OF MEXICO NE GULF OF MEXICO NE GULF OF MEXICO NE GULF OF MEXICO NE GULF OF MEXICO TOR TUGAS

TORTUGAS, FLA 


\section{Publication}

25666 PFLUM FRERICHS 1976 25667 PFLUM FRERICHS 1976 25668 PFLUM FRERICHS 1976 25669 PFLUM FRERICHS 1976 25670 PFLUM FRERICHS 1976 25671 PFLUM FRERICHS 1976 25672 PFLUM FRERICHS 1976 25673 PFLUM FRERICHS 1976 25673 PFLUM FRERICHS 1976
25674 PFLUM FRERICHS 1976

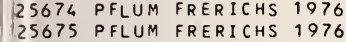
25676 PFLUM FRERICHS 1976 25677 PFLUM FRERICHS 1976 25678 PFLUM FRERICHS 1976 25679 PFLUM FRERICHS 1976 25679 PFLUM FRERICHS 1976
25680 PFLUM FRERICHS 1976 25680
25681
PFLUM FRERICHS 1976 25681 PFLUM FRERICHS 1976
25682 PFLUM FRERICHS 1976 25683 PFLUM FRERICHS 1976 25684 PFLUM FRERICHS 1976 25685 PFLUM FRERICHS 1976 25686 PFLUM FRERICHS 1976 25686 PFLUM FRERICHS 1976 25687
25688
2 25689 PFLUM FRERICHS 1976 25690 PFLUM FRERICHS 1976 25691 PFLUM FRERICHS 1976 25692 PFLUM FRERICHS 1976 25693 PFLUM FRERICHS 1976 25694 PFLUM FRERICHS 1976 25694 PFLUM FRERICHS 1976
25695 PFLUM FRERICHS 1976 25696 PFLUM FRERICHS 1976 25697 PFLUM FRERICHS 1976 25698 PFLUM FRERICHS 1976 25699 PFLUM FRERICHS 1976 25700 PFLUM FRERICHS 1976 25701 PFLUM FRERICHS 1976 25701 PFLUM FRERICHS 1976
25702 PFLUM FRERICHS 1976 25703 PFLUM FRERICHS 1976 25704 PHLEGER 1956

25705 PARKER 1954

25706 PARKER 1954

25707 PARKER 1954

25708 PARKER 1954

25709 PHLEGER 1956

25710 PARKER 1954

25711 PARKER 1954

25712 PARKER 1954

25713 PARKER 1954

25714 PHLEGER 1956

25715 PARKER 1954

25716 PARKER 1054

25717 PARKER 1954

25718 PHLEGER 1956

25710 PARKER 1954

25720 PARKER 1954

25721 PARKER 1954

25722 PARKER 1954

25723 PARKER 1954

25724 PARKER 1954

25725 PARKER 195

25726 PARKER 1954

25727 PARKER 1954

25728 PARKER 1954

25729 PARKER 1954

25730 PARKER 195

25731 BANDY 1956

25732 ANDERSEN 1961

25733 BANDY 1956

25734 PFLUM FRERICHS 1976

25735 LUDWICK WALTON 1957

25736 CUSHMAN 1918

25737 CUSHMAN 1918

25738 BENDA PURI 1962

25739 LEHMANN 1957

25740 LANKFORD 1959

25741 KANE 1967

25742 WALTON 1960

25743 PHLEGER LANKFORD 1957

25744 PHLEGER 1960

25745 KANE 1962

25746 BANDY 1954

25747 BANDY 1954

25748 BANDY 1954

25749 BENDA PURI 1962

25750 BENDA PURI 1962

25751 BANDY 1954

25752 BANDY 1954

25753 BENDA PURI 1962

25754 BANDY 1954

25755 BENDA PURI 1962

25756 ANDERSEN 1961

25757 ANDERSEN 1961

25758 ANDERSEN 1961

25759 BENDA PURI 1962

25760 AKERS 1952

\section{Generic Name}

SPIROS I GMOILINA

SP IROS I GMO I L INA

SPIROS I GMO I L INA

SPIROSI GMO IL INA

SPIROSI GMO IL I NA

SPIROS I GMOIL INA

SPIROSIGMOIL INA

SPIROS I GMO I L INA

SPIROSIGMOILINA

ST AINFORTHIA

ST AINFORTHIA

STA INFORTHIA

STAINFORTHIA

STAINFORTHIA

TAINFORTHIA

STAINFORTHIA

STAINFORTHIA

ST AINFORTHIA

STAINFORTHIA

ST A INF ORTHIA

STAINFORTHIA

STAINFORTHIA

STA INFORTHIA

STAINFORTHI A

STAINF ORTHIA

STAINF ORTHIA

STAINF ORTHIA

ST AINFORTHIA

STAINFORTHIA

STAINFORTHIA

STA INFORTHIA

STAINFORTHIA

STAINFORTHIA

STAINFORTHIA

ST AINFORTHIA

STAINFORTHIA

ST A INFORTHIA

STAINFORTHIA

STETSON IA

STETSONIA

STETSON IA

STETSONIA

STETSONIA

STETSONI A

STET SONIA

STET SON I A

STETSON I A

STETSONIA

STETSONIA

STET SON I A

STETSON I A

STETSONIA

STETSONIA

STETSONIA

STETSONIA

STET SON I A

STET SON I A

STETSONIA

STETSONIA

STETSONIA

STETSONIA

STETSONIA

STETSONIA

STET SONIA

ST OMATORBINA

STOMATORBINA

ST OMATORBINA

ST OMATORBINA

ST OMATOREINA

ST ORTHOSPHAERA

STORTHOSPHAERA

STREBLUS

STREBLUS

STREBLUS

STREBLUS

STREBLUS

STREBLUS

STREBLUS

STREBLUS

STREBLUS

STREBLUS

STREBLUS

STREBLUS

STREBLUS

STREBLUS

STREBLUS

STREBLUS

STREBLUS

STREBLUS

STREBLUS

ST REBLUS

STREBLUS

STREBLUS

STREBL US
Specific Name

Locality

Lat. Long.

DISTORTA

DISTORTA

DI STORTA

DI STORTA

DI STORTA

DI STORTA

DISTORTA

DISTORTA

DI STORTA

CONPLANAT A

COMPLANAT A

CONPLANAT A

CONPLANAT A

CONPLANAT A

CONPLANAT A

CONPLANAT A

CONPLANAT A

CONPLANAT A

CONPLANAT A

CONPL ANAT A

CONPLANATA

CONPLANATA

COMPLANAT A

CONPLANAT A

CONPLANAT A

COMPLANAT A

COMPLANATA

CONPLANATA

COMPLANAT A

CONPLANAT A

CONPLANAT A

COMPLANATA

COMPLANATA

CONPLANAT A

CONPLANATA

MI NUTA

MI NUTA

MI NUTA

MINUTA

MINUTA

MI NUTA

MINUTA

MINUTA

MINUTA

MINUTA

MI NUTA

MI NUTA

MINUTA

MINUTA

MINUTA

MINUTA

MI NUTA

MINUTA

MINUTA

MI NUTA

MI NUTA

MI NUTA

MINUTA

MINUTA

CONCENTRI CA

CONCENTRI CA

COACENTRI CA

CONCENTRI CA

CONCENTRI CA

ALEIDA

ALEIDA

BECCAR I I

BECCARII

BECCARII

BECCARII

BE CCARII

BECCARI I

BECCARII

BECCARII PARKINSONIANA

BECCARII SOBR INA

BECCARII SOBRINA

BECCARII SOBRINA

BECCARII SOBRINA

BECCARII SOBRINA

BECCARII SOBRINA

BECCARII SOBRINA

BECCARII SOBRINA

BECCARII SOBRINA

BECCARII TEPIDA

BECCARII TEPIDA

BECCARII TEPIDA

BECCARII TEPIDA

BECCARII TEPIDA

BECCARII TEPIDA

NW GULF OF MEXICO

NW GULF OF MEXICO

NW GULF OF MEXICO 


\section{Publication}

25761 ANDERSEN 1961 25762 ANDERSEN 1961

25763 ANDERSEN 1961 25764 ANDERSEN 1961 25765 ANDERSEN 1961 25766 KANE 1962

25767 BRADSHAW 1957

25768 BENDA PURI 1962

25769 WALDRON 1963

25770 KANE 1967

25771 KANE 1962

25772 LEHMANN 1957

25773 BENDA PURI 1962

25774 BANDY 1954

25775 BANDY 1954

25776 BANDY 1954

25778 BANDY 1954

25779 KANE 1967

25780 KANE 1962

25781 BANDY 1954

25782 BANDY 1956

25783 BANDY 1956

25784 BANDY 1956

25786 BANDY 1956

25787 BANDY 1956

25788 BANDY 1956

25789 BANDY 1956

25790 BANDY 1956

25792 ARNAL 1955

25793 WALDRON 1963

25794 BANDY 1956

25795 BANDY 1956

25796 ARNAL 1955

25797 ARNAL 1955

25798 BANDY 1956

25799 BANDY 1956

25801 BANDY 1956

25802 BANDY 1956

25803 BANDY 1956

25804 BANDY 1956

25805 BANDY 1956

25806 BANDY 1956

25807 BANDY 1956

25808 BANDY 1956

25809 BANDY 1956

25810 BANDY 1956

25811 BANDY 1956

25813 LANKFORD 1959

25814 PFLUM FRERICHS 1976

25815 VAUGHAN 1918

25816 NORTON 1930

25817 KELLOUGH 1956

25818 CUSHMAN 19228

25819 LEHMANN 1957

25820 CREAGER 1958

25821 OTVOS 1978

25822 KORNFELD 1931

25823 KORNFELD 1931

25824 BOCK 1976

25825 BOCK 1976

25826 DAVIS 1964

25827 SEGURA 1963

25828 CUSHMAN 1922 A

25829 CREAGER 1958

25830 CREAGER 1958

25831 LEROY HODGKINSON 1975

25832 LEHMANN 1957

25833 CUSHMAN 19228

25834 CREAGER 1958

25835 VAUGHAN 1918

25836 CREAGER 1958

25837 CUSHMAN 19228

25838 CUSHMAN 19228

25839 ANDERSEN 1961

25840 ANDERSEN 1961

25841 PARKER 1954

25842 PARKER 1954

25843 PARKER 1954

25844 PFLUM FRERICHS 1976

25845 BANDY 1956

25846 BANDY 1956

25847 BANDY 1956

25848 BANDY 1956

25849 BANDY 1956

25850 BANDY 1956

25851 BANDY 1956

25852 KELLOUGH 1956

25853 KELLOUGH 1956

25854 KELLOUGH 1956

25855 PARKER 1954

\section{Generic Name}

STREBLUS

STREBLUS

STREBLUS

STREBLUS

STREBLUS

STREBLUS

STREBLUS

STREBLUS

STREBLUS

STREBLUS

STREBLUS

STREBLUS

STREBLUS

STREBLUS

STREBLUS

STREBLUS

STREBLUS

STREBLUS

STREBLUS

STREBLUS

STREBLUS

STREBLUS

STREBLUS

STREBLUS

STREBLUS

STREBLUS

STREBLUS

STREBLUS

STREBLUS

STREBLUS

STREBLUS

STREBLUS

STREBLUS

STREBLUS

STREBLUS

STREBLUS

STREBLUS

STREBLUS

STREBLUS

STREBLUS

STREBLUS

STREBLUS

STREBLUS

STREBLUS

STREBLUS

STREBLUS

STREBLUS

STREBLUS

STREBLUS

SULCOPHAX

SULCOPHAX

TE CHNITELLA

TEXTULARIA

TEXTULARIA

TEXTULARIA

TEXTULARIA

TEXTULARIA

TEXTULARIA

TEXTULARIA

TEXTULARIA

TEXTULARIA

TEXTULARIA

TEXTULARIA

TEXTULARIA

TEXTULARIA

TEXTULARIA

TEXTULARIA

TEXTULARIA

TEXTULARIA

TEXTULARIA

TE XTULARIA

TEXTULARIA

TEXTULARIA

TEXTULARIA

TEXTULARIA

TEXTULARIA

TEXTULARIA

TEXTULARIA

TEXTULARIA

TEXTULARIA

TEXTULARIA

TEXTULARIA

TEXTULARIA

TEXTULARIA

TEXTULARIA

TEXTULARIA

TEXTULARIA

TEXTULARIA

TEXTULARIA

TEXTULARIA

TEXTULARIA

TEXTULARIA

TEXTULARIA
Specific Name

BECCARII TEPIDA

BECCARII TEPIDA

BE CCARII TEPIDA

BECCARII TEPIDA

BE CCARII TEPIDA

BECCARII TEPIDA

BECCARII TEPIDA

BECCARII TEPIDA

PARKINS OVIANA

PAUCILOCULATA

PAUCIL OCULATUS

PAUCILOCJLATUS

ROLSHAU SENI

ROLSHAUSENI

ROLSHAUSEN I

ROLSHAUSENI

ROLSHAUSEN I

ROLSHAUSENI

ROLSHAUSENI

ROLSHAUSE

SOERINUS

SOERINUS

SOBRINUS

SOBRINUS

SOBRINUS

SOBRINUS

SOBRINUS

SOBRINUS

SOBRINUS

SOERINUS

TEPIDA

TEFIDUS

TEPIDUS

TEPIDUS

TEPIDUS

TEPIDUS

TEPIOUS

TEFIDUS

TEPIDUS

TEPIDUS

TEPIDUS

TEPIDUS

TEPIDUS

TEPIDUS

TEPIDUS

TEPIDUS

TEPIDUS

TEPIDUS

TEFIDUS

PALUSTRIS

PALUSTRIS

LE GUMEN

AG GLUTINANS

AGGLUTINANS

AG GLUTINANS

AGGLUTINANS

AGGLUTI NANS

AG GLUTINANS

AG GLUTINANS

A G GLUTINANS

AGGLUT I NANS

AGGLUTINANS

AGGLUT INANS

AG GLUTINANS

AG GLUTI NANS

AG GLUTINANS

AL BATROSS I

ALBATROSSI

AS PERA

AURA

BARRETTII

BARRETTII

BARRETTI

BARRETTII

BARRETTII

BA RRETTII

CALVA

CA NDE I ANA

CANDEIANA

CANDE I ANA

CA NDE I ANA

CA D DE I ANA

CA DDE IANA

CA DDE IANA

CANDE I ANA

CANDEIANA

CA NDE I ANA

CANDE I ANA

CAADE I ANA

CA ADE I ANA

CANDEIANA

CANDEIANA

CANDEIANA

Locality

Lat. Long.

MISSISSIPPI DELTA

MISSISSIPPI DELTA

MISSISSIPPI DELTA

MISSISSIPPI DELTA

MISSISSIPPI DELTA

SABINE LAKE. TEXAS

SAN ANTONIO B.. TEXAS 


\section{Publication}

25856 PARKER 1954 25857 PARKER 1954

25858 PARKER 1954

25859 PARKER 1954

25860 PARKER 1954
25861 SHIFFLETT 1961

25862 PFLUM FRERICHS 1976

25863 CUSHMAN $1922 \mathrm{~A}$

25864 LUDWICK WALTON 1957

25865 KELLOUGH 1956

25866 KELLOUGH 1956

25867 BENDA PUR I 1962

25868 WALTON 1964

25869 BANDY 1956

25870 BANDY 1956

25871 BANDY 1956

25872 BANDY 1956

25873 KELLOUGH 1956

25874 BANOY 1956

25875 BANOY 1956

25876 BANDY 1956

25877 BANOY 1956

25878 NORTON 1930

25879 LIDZ LIDZ 1966

25880 BOCK 1976

25881 BANDY 1954

25882 BANDY 1954

25883 BANDY 1954

25884 BANOY 1956

25885 BANDY 1956

25886 BANOY 1956

25887 BANOY 1954

25888 BANDY 1954

25889 PARKER 1954

25890 PARKER 1954

25891 PARKER 1954

25892 PARKER 1954

25893 PARKER 1954

25894 BANOY 1954

25895 NORTON 1930

25896 CUSHMAN 19228

25897 BANDY 1956

25898 BANOY 1956

25899 BANOY 1956

25900 BANDY 1956

25901 BANDY 1956

25902 BANDY 1956

25903 SANDY 1956

25904 BANDY 1956

25905 BANDY 1956

25906 BANDY 1956

25907 CUSHMAN $1922 \mathrm{~A}$

25908 BANDY 1956

25909 BANOY 1956

25910 LUDWICK WALTON 1957

25911 DAVIS 1964

25912 BANDY 1956

25913 BANDY $195 \mathrm{C}$

25914 BANOY 195

25915 ANDERSEN 1961

25916 BANDY 1956

25917 PARXER 1954

25918 PARKER 1954

25919 PARKER 1954

25920 PARKER 1954

25921 CREAGER 19

25922 BOCK 1976

25924 PARKER 1954

25925 PARKER 1954

25926 PARKER 1954

25927 PARKER 1954

25928 PARKER 1954

25929 PARKER 1954

25930 PARKER 1954

25931 LEHMANN 1957

25932 LANKFORD 1959

25933 PHLEGER $1965 \mathrm{E}$

25934 PARKER 1954

25935 PFLUM FRERICHS 1976

25936 PFLUM FRERICHS 1976

25937 PFLUM FRERICHS 1976

25938 PFLUM FRERICHS 1976

25939 PFLUM FRERICHS 1976

25940 PARKER 1954

25941 PARKER 1954

25942 PARKER 1954

25943 PARKER 1954

25944 PARKER 1954

25945 PARKER 1954

25945 PARKER 19

25947 PFLUM FRERICHS 1976

25948 PFLUM FRERICHS 1976

25949 PHLEGER $1965 \mathrm{~A}$
25950 PHLEGER $1965 \mathrm{~A}$
Generic Name

TEXTULARIA

TEXTULARIA

TEXTULARIA

TEXTULARIA

TEXTULARIA

TEXTULARIA

TEXTULARIA

TEXTULARIA

TEXTULARIA

TEXTULARIA

TEXTULARIA

TEXTULARIA

TEXTULARIA

TEXTULARIA

TEXTULARIA

TEXTULARIA

TEXTULARIA

TEXTULARIA

TEXTULAR IA

TEXTULARIA

TEXTULARIA

TEXTULARIA

TEXTULARIA

TEXTULARIA

TEXTULARIA

TEXTULARIA

TEXTULARIA

TEXTULAR IA

TEXTULAR IA

TEXTULARIA

TEXTULARIA

TEXTULARIA

TEXTULARIA

TEXTULARIA

TEXTULARIA

TEXTULARIA

TEXTULARIA

TEXTULARIA

TEXTULARIA

TEXTULARIA

TEXTULARIA

TEXTULARIA

TEXIULARIA

TEXTULARIA

TEXTULARIA

TEXTULARIA

TEXTULARIA

TEXTULAR IA

TEXTULARIA

TEXTULARIA

TEXTULARIA

TEXTULARIA

TEXTULARIA

TEXTULARIA

TEXTULARIA

TEXTULARIA

TEXTULARIA

TEXTULARIA

TEXTULARIA

TEXTULARIA

TEXTULARIA

TEXTULARIA

TEXTULARIA

TEXTULARIA

TEXTULARIA

TEXTULARIA

TEXTULARIA

TEXTULARIA

TEXTULARIA

TEXTULARIA

TEXTULARIA

TEXTULARIA

TEXTULARIA

TEXTULARIA

TEXTULARIA

TEXTULARIA

TEXTULARIA

TEXTULARIA

TEXTULARIA

TEXTULARIA

TEXTULARIA

TEXTULARIA

TEXTULARIA

TEXTULARIA

TEXTULARIA

TEXTULAR IA

TEXTULARIA

TEXTULARIA

TEXTULARIA

TEXTULARIA
Specific Name

CANDEIANA

CANDEIANA

CANDEIANA

CANDEIANA

CANDEIANA

CANDEIANA
CANDEIANA

CANDEIIANA

CANDE I ANA

CANDEIANA

CANDEIANA

CA NDE IANA

CANDE I ANA

C A $\triangle$ DE I ANA

CANDEIANA

CANDEI I NA

CANDEIANA

CANDEIANA

CANDEIANA

CA D DE I ANA

CANDEIIANA

CANDEIANA

CANDEI I NA

CANDEIANA

CAADEI I NA

CANDEIANA

CANDE IANA

CANDE I ANA

CANDEIANA

CANDE IANA

CA DDE I ANA

CANDE IANA

CANDEIANA

CANDE IANA

CANDEIANA
CANDEIANA

CANDEI ANA

CA D EEIANA

CANDEIANA

CONICA

CONICA

CONICA

CONICA

CONICA

CONICA

CONICA

CONICA

CONICA

CONICA

CONICA

CONICA

CONICA

CONICA

CONICA

CONICA

CONICA

CONICA
CONICA
CONICA

CONICA

CONICA

CONICA

CONICA

CONICA

CONICA

CONICA

CONICA

CONICA

CONICA

CONICA

CONICA

CONICA

CONICA

CONICA

CONICA

CONICA

CONICA

CONICA

EARLANDI

EARLANDI

EARLANDI

EARLAND I

EARLANDI

EARLANDI

EARLANO I

EARLANDI

EARLANDI

EARLANDI

EAFLANDI

EARLANDI

EARLANDI

EARLANDI

EARLANDI

EARLANDI

EARLANDI

Locality

NE GULF OF MEXICO

NE GULF OF MEXICO

NE GULF OF MEXICO

NE GULF OF MEXICO

NE GULF OF MEXICO

HEALD BANK, G. OF MEXICO

NW GULF OF MEXICO

TORTUGAS

NE GULF OF MEXICO

NW GULF OF MEXICO 
Publication

25951 PHLEGER 1965B 25952 PFLUM FRERICHS 1976

25953 LEHMANN 1957

25954 SHIFFLETT 1961

25955 PFLUM FRERICHS

25957 PHLEGER 1955A

25958 PARKER 1954

25959 PHLEGER $1955 \mathrm{~A}$

25960 PHLEGER 1955A

25961 CUSHMAN 19228

25962 NORTON 1930

25963 CUSHMAN 19228

25965 PHLEGER 1951A

25966 PHLEGER 1951A

25967 PHLEGER 1951A

25968 PHLEGER 1951A

25969 PHLEGER 1951A

25970 PHLEGER 1951A

25971 PARKER 1954

25972 PARKER 1954

25974 PHLEGER 1951A

25975 PHLEGER 1951A

25976 PHLEGER 1951A

25977 PHLEGER 1951A

25978 PHLEGER 1951A

25979 PARKER 1954

25980 PARKER 1954

25981 PARKER 1954 25 S 1976

25982 PFLUM FRERICHS 1976
25983 PFLUM FRERICHS 1976

25984 BANDY 1956

25985 BANDY 1956

25986 BANDY 1956

25987 CREAGER 1958

25988 PARKER 1954

25989 PARKER 1954

25990 BANDY 1956

25991 PARKER 1954

25992 PHLEGER 1951 A

25993 CUSHMAN 19228

25994 CUSHMAN 1922

25995 BANDY 1956

25996 BANDY 1956

25998 BANDY 1956

25999 BANDY 1956

26000 BANDY 1956

26001 PARKER 1954

26002 LUDHICK WALTON 1957

26003 PARKER 1954

26004 PARKER 1954

26005 BOCK 1976

26006 CREAGER 1958

26007 BENDA PURI 1962

26008 NORTON 1930

26009 VAUGHAN 1918

26010 NORTON 1930

26011 ANDERSEN 1961

26012 CREAGER 1958

26013 SHIFFLETT 1961

26014 LIDZ LIDZ 1966

26015 PHLEGER 1951A

26016 SEGURA 1963

26017 PHLEGER 1951A

26018 CUSHMAN 1922A

26020 PHLEGER 1951A

26021 PHLEGER 1951A

26022 PHLEGER 1951A

26023 CREAGER 1958

26024 CREAGER 1958

26025 LIDZ LIDZ 1966

26026 PHLEGER 1951A

26027 PHLEGER 1951 A

26028 PHLEGER 1951A

26029 PHLEGER 1951A

26030 PHLEGER 1951A

26031 PHLEGER 1951A

26032 CREAGER 1958

26033 PARKER 1954

26034 PARKER 1954

26035 PARKER 1954

26036 PARKER 1954

26037 PARKER 1954

26038 PARKER 1954

26039 PHLEGER 1951 A

26041 BANDY 1956

26042 BANDY 1956

26043 NORTON 1930

26044 BANDY 1956

26045 BANDY 1956
Generic Name

TEXTULAR IA

TEXTULARIA

TEXTULARIA

TEXTULARIA

TEXTULAR IA

TEXTULARIA

TEXTULARIA

TEXTULARIA

TEXTULARIA

TEXTULARIA

TEXTULARIA

TEXTULARIA

TEXTULARIA

TEXTULARIA

TEXTULARIA

TEXTULARIA

TEXTULARIA

TEXTULARIA

TEXTULARIA

TEXTULARIA

TEXTULARIA

TE XTULARIA

TEXTULARIA

TEXTULARIA

TEXTULARIA

TEXTULARIA

TEXTULARIA

TEXTULARIA

TEXTULARIA

TEXTULARIA

TEXTULARIA

TEXTULARIA

TEXTULARIA

TEXTULARIA

TEXTULARIA

TEXTULARIA

TEXTULARIA

TEXTULARIA

TEXTULARIA

TEXTULARIA

TEXTULARIA

TEXTULARIA

TEXTULARIA

TEXTULARIA

TEXTULARIA

TEXTULARIA

TEXTULARIA

TEXTULARIA

TEXTULARIA

TEXTULARIA

TEXTUL AR IA

TEXTULARIA

TEXTULAR IA

TEXTULARIA

TEXTULARIA

TEXTULARIA

TEXTULARIA

TEXTULARIA

TEXTULARIA

TEXTULARIA

TEXTULARIA

TEXTULARIA

TEXTULARIA

TEXTULARIA

TEXTULARIA

TEXTULARIA

TEXTULAR IA

TEXTULARIA

TEXTULARIA

TEXTULARIA

TEXTULARIA

TEXTULARIA

TEXTULAR IA

TEXTULARIA

TEXTULARIA

TEXTULARIA

TEXTULARIA

TEXTULAR IA

TEXTULARIA

TEXTULARIA

TEXTULAR IA

TEXTULARIA

TEXTULARIA

TEXTULARIA

TEXTULAR IA

TEXTULARIA

TEXTULARIA

TEXTULARIA

TEXTULARIA

TEXTULARIA

TEXTULARIA
Specific Name

EARLANDI

EARLANDI

EARLANDI

EARLANDI

EARLANDI

EARLANDI

EARLANDI

EARLANDI

FL INTII CURTA

FL ORIDANA

FL CRIDANA

FL ORI DANA

FOLIACEA OCCIDENTALIS

FOLIACEA OCCIDENTALIS

FOLIACEA OCCIDENTALIS

FOLIACEA OCCIDENTALIS

FOLIACEA OCCIDENTALIS

FOLIACEA OCCIDENTAL IS

FOLIACEA OCCIDENTALIS

FOLIACEA OCCIDENTALIS

FOLIACEA OCCIDENTALIS

FOLIACEA OCCIDENTALIS

FOLIACEA OCCIDENTALIS

FOLIACEA OCCIDENTALIS

FOLIACEA OCCIDENTALIS

FOLIACEA OCCIDENTALIS

FOLIACEA OCCIDENTALIS

FOLIACEA OCCIDENTALIS

FOLIACEA OCCIDENTALIS

FOLIACEA OCCIDENTALIS

FOLIACEA OCCIDENTAL IS

FOLIACEA OCCIDENTALIS

FOLIACEA OCCIDENTALIS

FOLIACEA OCCIDENTALIS

FOLIACEA OCCIDENTALIS

FOLIACEA OCCIDENTAL IS

FOLIACEA OCCIDENTALIS

FOLIACEA OCCIOENTALIS

FOLIACEA OCCIDENTALIS

FOLIACEA OCCIDENTALIS

FOLIACEA OCCIDENTALIS

FOLIACEA OCCIDENTALIS

FOLIACEA OCCIDENTAL IS

FOLIACEA OCCIDENTALIS

FOLIACEA OCCIDENTALIS

FOLIACEA OCCIDENTALIS

FOLIACEA OCCIDENTALIS

FOLIACEA OCCIDENTALIS

FOLIACEA OCCIDENTALIS

FOLIACEA OCCIDENTAL IS

FOLIACEA OCCIDENTALIS

FOLIACEA OCCIDENTALIS

FOLIACEA OCCIDENTAL IS

GOESII

GR AMEN

GRAMEN

GRAMEN

HAUERII

KERIMBAEVSIS

MAURYAE

MA YOR I

MAYORI

MA YOR I

MAYORI

MAYORI

MAYORI

MAYORI

MAYORI

MAYOR I

MAYORI

MAYORI

MAYORI

MA YORI

MAYOR I

MAYORI

MAYORI

MAYORI

MAYOR I

MAYORI

MAYORI

MAYOR I

MAYORI

MAYORI

MA YOR I

MAYORI

MA YOR I

MAYORI

MAYORI

MAYORI

MA YORI

Locality

Lat. Long.

WHITEWATER B.. SW FLA.

CENTRAL GULF OF

HEALD BANK, G. OF MEXICO

NH GULF OF MEXICO

$N$ GULF OF MEXICO

$N$ GULF OF MEXICO

NE GULF OF MEXICO

$N$ GULF OF MEXICO

$N$ GULF OF MEXICO

NE GULF OF MEXICO

TORTUGAS, FLA

NE GULF OF MEXICO

TORTUGAS

NW GULF OF MEXICO

NW GULF OF MEXICO 


\section{Publication}

26046 BANDY 1956

26047 WALTON 1960

26048 ANDERSEN 1961

26049 BANDY 1956

26050 BANDY 1954

26051 BANDY 1956

26052 BANDY 1954

26053 BANDY 1956

26054 BANDY 1954

26055 BANDY 1954

26056 BANDY 1956

26057 BANDY 1954

26058 PARKER 1954

26059 PARKER 1954

26061 PARKER PHLEGER PEIRSON 1953

26062 PARKER PHLEGER PEIRSON 1953

26063 PARKER PHLEGER PEIRSON 1953

26064 PARKER PHLEGER PEIRSON 1953

26065 PHLEGER 1956

26066 PHLEGER 1956

26067 PHLEGER 1956

26068 PHLEGER 1956

26069 CREAGER 1958

26070 BOCK 1976

26071 CREAGER 1958

26072 BOCK 1976

26073 BOCK 1976

26074 LUDWICK WALTON 1957

26075 PHLEGER 1954

26076 WARREN 1957

26077 LANK FORD 1959

26078 PARKER 1954

26079 PARKER 1954

26080 PARKER 1954

26081 BANDY 1954
26082 BANDY 1956

26083 BANDY 1956

26084 BANDY 1956

26085 BANDY 1956

26086 BANDY 1956

26087 BENDA PURI 1962

26088 LOEP 1965

26089 KELLOUGH 1956

26090 KELLOUGH 1956

26091 KELLOUGH 1956

26092 KELLOUGH 1956

26093 KELLOUGH 1956

26094 BANDY 1956

26095 KELLOUGH 1956

26096 KELLOUGH 1956

26097 BANDY 1956

26098 BANDY 1956

26099 LOEP 1965

26100 WARREN 1956

26101 PFLUM FRERICHS 1976

26102 PHLEGER 1951A

26103 PFLUM FRERICHS 1976

26104 PFLUM FRERICHS 1976

26105 PHLEGER 1951A

26106 PHLEGER 1951A

26107 PHLEGER 1951A

26108 PHLEGER 1951A

26109 PHLEGER $1951 \mathrm{~A}$

26110 PFLUM FRERICHS 1976

26111 PFLUM FRERICHS 1976

26112 CUSHMAN 19228

26113 CUSHMAN 19228

26114 CUSHMAN 19228

26115 CUSHIAAN 19228

26116 PHLEGER 1951A

26117 PFLUM FRERICHS 1976

26118 PFLUM FRERICHS 1976

26119 CREAGER 1958

26120 CREAGER 1958

26121 CREAGER 1958

26122 ANDERSEN 1961

26123 PHLEGER 1951A

26124 PHLEGER 1951A

26125 LUDWICK WALTON 1957

26126 ANDERSEN 1961

26127 LANKFORD 195

26128 WARREN 1957

26129 ANDERSEN 1961

26130 CUSHMAN 19228

26131 BANDY 1956

26132 BANDY 1956

26133 BANDY 1956

26134 CUSHMAN 19228

26135 CUSHMAN $1922 \mathrm{~A}$

26136 VAUGHAN 1918

26137 BANDY 1956

26138 BANDY 1956

26139 BANDY 1956

26140 BANDY 1956
Generic Name

Specific Name

Locality

Lat. Long.

TEXTULARIA

TEXTULARIA

TEXTULARIA

TEXTULARIA

TEXTULARIA

TEXTULARIA
TEXTULARIA

TEXTULARIA

TEXTULARIA

TEXTULARIA

TEXTULARIA

TEXTULARIA

TEXTULARIA

TEXTULAR IA

TEXTULARIA

TEXTULARIA

TEXTULARIA

TEXTULARIA

TEXTULAR IA

TEXTULARIA

TEXTULARIA

TEXTULAR IA

TEXTULARIA

TEXTULARIA

TEXTULARIA

TEXTULARIA

TEXTULARIA

TEXTULARIA

TEXTULARIA

TEXTULARIA

TEXTULARIA

TEXTULARIA

TEXTULARIA

TEXTULARIA

TEXTULARIA

TEXTULARIA

TEXTULARIA

TEXTULARIA

TEXTULARIA

TEXTULARIA

TEXTULARIA

TEXTULARIA

TEXTULARIA

TEXTULARIA

TEXTULARIA

TEXTULARIA

TEXTULARIA

TEXTULARIA

TEXTULARIA

TEXTULARIA

TEXTULARIA

TEXTULARIA

TEXTULARIA

TEXTULAR IA

TEXTULARIA

TEXTULARIA

TEXTULARIA

TEXTULARIA

TEXTULARIA

TEXTULAR IA

TEXTULARIA

TEXTULARIA

TEXTULARIA

TEXTULARIA

TEXTULARIA

TEXTULARIA

TEXTULARIA

TEXTULARIA

TEXTULARIA

TEXTULARIA

TEXTULARIA

TEXTULAR IA

TEXTULARIA

TEXTULARIA

TEXTULAR IA

TEXTULARIA

TEXTULARIA

TEXTULAR IA

TEXTULARIA

TEXTULARIA

TEXTULARIA

TEXTULARIA

TEXTULARIA

TEXTULARIA

TEXTULARIA

TEXTULARIA

TEXTULARIA

TEXTULAR IA
MA YOR I

MA YOR I

MAYOR I

MA YOR I

MAYORI

MA YORI

MA YOR I

MA YORI

MA YOR I

MA YOR I

MA YOR I

MA YOR I

MAYORI

MAYOR I

MA YOR I

MA YOR I

$M A Y O R I$

MA YOR I

MA YOR I

MA YOR I

MA YOR I

MA YOR I

MA YOR I

MA YORI

MA YOR I

MA YOR I

MAYORI

MA YOR I

MA YOR I

MA YOR I

MA YOR I

MA YORI

MA YOR I

MAYORI

MA YOR I

MA YOR I

MA YOR I

MA YOR I

MA YOR I

MA YOR I

MA YOR I

MA YORI

MA YOR I

MA YOR I

MA YOR I

MA YOR I

MA YOR I

MA YOR I

MA YOR I

MEXICANA

MEXICANA

ME XI CANA

MEXICANA

MEXI CANA

MEXICANA

MEXICANA

MEXICANA

MEXI CANA

MEXICANA

MEXICANA

MEXI CANA

MEXICANA

MEXI CANA

MEXICANA

MEXICANA

MEXI CANA

MEXICANA

ME XICANA

MEXI CANA

MEXI CANA

MEXICANA

MEXI CANA

MEXI CANA

OC CIDENTALIS

PALUSTR IS

PALUSTRIS

PALUSTRIS

PARVULA

PS EUDOTRJ CHUS

PSEUDOTRJ CHUS

PSEUDOTRJ CHUS

PSEUDOTRJ CHUS

RUGOSA

SAGITTULA

SECASENSI S

SECASENSI S

SECASENSI S

SECASENSI S
NE GULF OF MEXICO

MISSISSIPPI SOUND MISSISSIPPI DELTA

NE GULF OF MEXICO

$N \backsim$ GULF OF MEXICO

NE GULF OF MEXICO

NW GULF OF MEXICO

NE GULF OF MEXICO

NW GULF OF MEXICO

NW GULF OF MEXICO

NE GULF OF MEXICO

NW GULF OF MEXICO

NE GULF OF MEXICO

NE GULF OF MEXICO

NE GULF OF MEXICO

TEXAS GULF COAST 


\section{Publication}

26141 BANDY 1956

26142 BANDY 1956

26143 BANDY 1956

26144 BANDY 1956

26145 BANDY 1956

26146 BANDY 1956

26148 ANDERSEN 1961

26149 VAUGHAN 1918

26150 ANDERSEN 1961

26151 BANDY 1956

26152 BANDY 1956

26154 KELLOUGH 1956

26155 LOEP 1965
26156 PFLUM FRERICHS 1976

26156 PFLUM FRER

26158 BANDY 1956

26159 BANDY 1956

26160 BANDY 1956

26162 KELLOUGH 1956

26163 CREAGER 1958

26164 CUSHMAN 1919

26165 CUSHMAN 1918

26166 PFLUM FRERICHS 1976

26167 PFLUM FRERICHS 1976

26168 PFLUM FRERICHS 1976

26169 PFLUM FRERICHS 1976

26170 PFLUM FRERICHS 1976

26171 PFLUM FRERICHS 1976

26172 LEROY HODGKINSON 1975

26173 PFLUM FRERICHS 1976

26174 PFLUM FRERICHS 1976

26175 PFLUM FRERICHS 1976

26176 PFLUM FRERICHS 1976

26177 PFLUM FRERICHS 1976

26178 PFLUM FRERICHS 1976

26179 PFLUM FRERICHS 1976

26180 PFLUM FRERICHS 1976

26181 PFLUM FRERICHS 1976

26182 PFLUM FRERICHS 1976

26184 PFLUM FRERICHS 1976

26185 PFLUM FRERICHS 1976

26186 PFLUM FRERICHS 1976

26187 PFLUY FRERICHS 1976

26188 PFLU A FRERICHS 1976

26189 PFLUM FRERICHS 1976

26190 LEROY HODGKINSON 1975

26191 LEROY HODGKINSON 1975

26192 OTVOS 1978

26193 WANTLAND 1969

26194 PHLEGER 1965 A

26195 PHLEGER 1965 A

26196 PHLEGER $1905 \mathrm{~A}$

26197 PHLEGER 1965 A

26198 PHLEGER $1965 \mathrm{C}$

26199 PARKER 1954

26200 PARKER 1954

26201 PARKER 1954

26202 PARKER 1954

26203 PARKER 1954

26204 PARKER 1954

26205 PFLUM FRFRICHS 1976

26206 PARKER 1954

26207 PFLUM FRERICHS 1976

26208 PFLUM FRERICHS 1976

26209 PFLUM FRERICHS 1976

26210 PFLUM FRERICHS 1976

26211 PFLUM FRERICHS 1976

26212 PFLUM FRERICHS 1976

26213 PFLUM FRERICHS 1976

26214 PFLUM FRERICHS 1976

26215 PFLUM FPERICHS 1976

26216 PFLUM FRERICHS 1976

26217 PFLUM FRERICHS 1976

26218 PFLUM FRERICHS 1976

26219 PFLUM FRFRICHS 1976

26220 PFLUM FRERICHS 1976

26221 LEROY HODGKINSON 1975

26222 PFLU iी FRERICHS 1976

26223 PFLUM FRERICHS 1976

26224 PFLUM FRERICHS 1976

26225 PFLUM FRERICHS 1976

26226 PARKER 1954

26227 PFLUM FRERICHS 1976

26228 PFLUM FRERICHS 1976

26229 LUDWICK WALTON 1957

26230 PFLUM FRERICHS 1976

26231 PARKER 1054

26232 PARKER 1954

26233 PARKER 1954

26234 PARKER 1954

26235 PFLUM FRERICHS 1976
Generic Name

Specific Name

Locality

Lat. Long.

TEXTULARIA

TEXTULARIA

TEXTULARIA

TEXTULARIA

TEXTULAR IA

TEXTULARIA

TEXTULARIA

TEXTULARIA

TEXTULARIELLA

TEXTULARIELLA

TE XTULARIELLA

TEXTULARIELLA

TEXTULARIELLA

TEXTULARIELLA

TEXTULARIELLA

TEXTULARIELLA

TEXTULARIELLA

TEXTULARIELLA

TE XTULAR IELLA

TEXTULAR IELLA

TEXTULAR IELLA

TEXTULAR IELLA

THURAMMI NA

THUR AMMI NA

THURAMMINA

THURAMM I NA

THURAMM I NA

THURAMMI NA

THURAMMINA

THUR AMM I NA

THURAMM INA

THURAMMINA

THURAMM I NA

THURAMMINA
THURAMMINA

THUR AMMI NA

THUR AMM I NA

THUR AMM I NA

THURAMM I NA

THURAMMINA

THURAMMI NA

THURAMMI NA

THURAMMI NA

THURAMMINA

THURAMMINA

THURAMM I NA

THURAMMINA

TI PHOTROCHA

TIPHOTROCHA

TIPHOTROCHA

TI PHOTROCHA

TI PHOTROCHA

TI PHOTROCHA

TI PHOTROCHA

TOLYPAMMINA

TOLYPAMMINA

TOL YPAMMINA

TOLYPAMMINA

TOLYPAMMINA

IOLYPAMMINA

TOLYPAMMINA

TOLYPAMM INA

TOLYPAMMINA

TOLYPAMMINA

TOLYPAMMINA

TOLYPAMMINA

TOLYPAMMINA

TOLYPAMMINA

TOLYPAMMINA

TOLYPAMMINA

TOLYPAMMINA

TOLYPAMMINA

TOLYPAMMINA

TOLYPAMMINA

TOLYPAMMINA

TOLYPAMMIN

TOLYPAMMINA

TOLYPAMMINA

TOLYPAMMINA

TOLYPAMMINA

TOLYPAMMINA

TOLYPAMN INA

TOLYPAMMINA

TOLYPAMMINA

TOLYPAMMINA

TOL YPAMMINA

TOLYPAMMINA

TOLYPAMMINA

TOL YPAMMINA

TOLYPAMMINA

TOLYPAMMINA
SECASENSIS

SECASENSIS

SECASENSIS

SECASENSI S

SECASENSIS

SE RAN

SI CA

BROCHUS

BARRETTII

SARRETTII

BARRETTII

A RRETTII

BARRETTII

BARRETTII

BARRETTII

BARRETTII

BARRETTII

BARRETTI

CONICA

TRCCHUS

$F A \cup O S A$

FA VOSA

PAPILLATA

AFILLATA

PAFILLATA

PAFILLATA

PAPILLATA

PAPILLATA

PAPILLATA

PAPILLATA

PAPILLATA

PAPILLATA

PAFILLATA

PAILLATA

PAFILLATA

PAPILLATA

PAPILLATA

PAFILLATA

PAFILLATA

AFILLATA

PAFILLATA

PAPILLATA CARIOSA

PAPILLATA CASTANEA

CONPR IMAT A

CONPR IMAT A

CONPRIMAT

ONPRIMAT A

CONPRIMAT A

CONPRIMAT A

CONPRIMATA

SCHAUDINN I

SCHAUDINN I

SC HAUDINN I

SC HAUDINN I

SCHAUDINNI

SCHAUDINN I

SCHAUDINVI

SCHAUDINN I

SCHAUD INN I

SCHAUDINN I

SC HAUDINN I

SCHAUDINN I

SCHAUDINV

SCHAUDINN

SCHAUDINN I

SC LAUDINN I

SCHAUDINVI

SCHAUDINV

SCHAUDINN

SC HAUDINN

SCHAUDINN I

SC HAUDINN

SCHAUDINN I

SCHAUDINN

SCHAUDINN

SCHAUDINN

SCHAUDINV

SC MAUDINN

SCHAUDINV I

SC HAUDINN I

SCHAUDINN I

SCHAUDINN I

SC HAUDINV

SC HAUDINV I

SCHAUDINN
SC HAUDINN
SECASENSI S

TAMPA BAY, FLA.

TAMPA BAY, FLA

NE GULF OF MEXICO

NE GULF OF MEXICO

NE GULF OF MEXICO

NE GULF OF MEXICO

TEXAS GULF COAST

MISSISSIPPI DELTA

FLORIDA KEYS

MISSISSIPPI DELTA

NE GULF OF MEXICO

NE GULF OF MEXICO

NW GULF OF MEXICO

NW GULF OF MEXICO 


\section{Publication}

26236 PFLUM FRERICHS 1976 26237 PFLUM FRERICHS 1976 26238 PFLUM FRERICHS 1976 26239 LEROY HODGKINSON 1975 26240 PFLU M FRERICHS 1976 26241 PFLUM FRERICHS 1976 26242 PFLUM FRERICHS 1976 26243 PFLUM FRERICHS 1976 26244 PFLUM FRERICHS 1976 26245 PFLUM FRERICHS 1976 26246 PFLUM FRERICHS 1976 26247 PFLUM FRERICHS 1976 26248 PFLUM FRERICHS 1976 26249 PFLUM FRERICHS 1976 26250 PFLUM FRERICHS 1976 26251 PFLUM FRERICHS 1976 26252 PFLUM FRERICHS 1976 26253 PFLUM FRERICHS 1976 26254 PFLUM FRERICHS 1976 26255 PFLUM FRERICHS 1976 26256 PFLUM FRERICHS 1976 26257 PFLUM $M$ FRERICHS 1976 26258 PFLUM FRERICHS 1976 26259 PFLUM FRERICHS 1976 26260 PFLUM FRERICHS 1976 26261 PFLUM FRERICHS 1976 26262 PFLUM FRERICHS 1976 26263 PFLUM FRERICHS 1976 26264 KELLOUGH 1956 26265 KELLOUGH 1956

26266 ANDERSEN 1961

26267 CUSHMAN 1922A

26268 BOCK 1976

26269 BOCK 1976

26270 POAG 1972

26271 PARKER 1954

26272 PARKER 1954

26273 PFLUM FRERICHS 1976 26274 PFLUM FRERICHS 1976 26275 PARKER 1954

26276 PHLEGER 1956

26277 PARKER 1954

26278 PARKER 1954

26279 PARKER 1954

26280 PARKER 1954

26281 PHLEGER $1951 \mathrm{~A}$

26282 FHLEGER $1951 \mathrm{~A}$

26283 CUSHMAN 1923

26284 CUSHMAN 1923

26285 CUSHMAN 1923

26286 PHLEGER 1951A

26287 PARKER 1954

26288 PARKER 1954

26289 PFLUM FRERICHS 1976

26290 PFLUM FRERICHS 1976

26291 PFLUM FRERICHS 1976 26292 PFLUM FRERICHS 1976 26293 PFLUM FRERICHS 1976 26294 PFLUM FRERICHS 1976 26295 PFLUM FRERICHS 1976 26296 PARKER 1954

26297 PHLEGER 1951 A

26298 PHLEGER 1951 A

26299 PFLUM FRERICHS 1976

26300 PFLUM FRERICHS 1976 26301 PFLUM FRERICHS 1976 26302 PFLUM FRERICHS 1976 26303 PFLUM FRERICHS 1976 26304 PFLUM FRERICHS 1976 26305 PFLUM FRERICHS 1976 26306 PFLUM FRERICHS 1976 26306 PFLUM FRERICHS 1976 26308 PFLUM FRERICHS 1976 26309 PFLUM FRERICHS 1976 26310 PFLUM FRERICHS 1976 26311 PFLUM FRERICHS 1976 26312 PFLUM FRERICHS 1976 26313 PFLUM FRERICHS 1976 26314 PFLUM FRERICHS 1976 20315 PARKER 1954

26316 BOCK 1976

26317 PARKER 1954

26318 PARKER 1954

26319 PFLUM FRERICHS 1976 26320 PFLUM FRERICHS 1976 26321 PFLUM FRERICHS 1976 26322 PFLUM FRERICHS 1976 26323 PHLEGER 1951A 26324 PHLEGER $1951 \mathrm{~A}$ 26325 PHLEGER 1951A 26326 PHLEGER $1951 \mathrm{~A}$ 26327 PHLEGER $1951 \mathrm{~A}$ 26328 PARKER 1954 26328 PARKER 1954 26330 PARKER 1954
Generic Name

TOLYPAMMINA

TOLYPAMMINA

TOLYPAMMINA

TOLYPAMMINA

TOSAIA

TOSAIA

TOSAIA

TOSAIA

TOSAIA

TOSAIA

TOSAIA

TOSAIA

TOSAIA

TOSAIA

TOSAIA

TOSAIA

TOSAIA

TOSAIA

TOSAIA

TOSAIA

TOSAIA

TOSAIA

TOSAIA

TOSAIA

TOSAIA

TRET OMPHALUS

TRET OMPHALUS

TRETOMPHALUS

TRETOMPHALUS

TRETOMPHALUS

TR IFARINA

TR IFAR INA

TRIFAR INA

TR IFAR INA

TRIFAR INA

TR IFAR I NA

TR IFARINA

TR IFAR INA

TR IFARINA

TR IFAR INA

TR IFARINA

TR IFARINA

TR IFAR I NA

TR IFAR INA

TR IFAR INA

TRIFARINA

TR IFAR I NA

TR IFARI NA

TR IF ARINA

TR I FAR I NA

TR IFAR INA

TR IFAR I NA

TR IFARINA

TR IFAR INA

TR IFARINA

TR I FAR INA

TR IFAR INA

TR IFAR I NA

TR IFAR INA

TR IFAR I NA

TR IFAR INA

TR IFAR I NA

TR IFAR INA

TR IF AR I NA

TR IFAR I N A

TR IFARINA

TR I F AR INA

TR IFAR INA

TR IFAR I NA

TR IFAR I NA

TR IFAR INA

IR IFAR INA

TR I F ARIN A

TR I FAR I NA

TR IFAR I NA

TR IFAR I NA

TR IF AR INA

TR IF AR INA

TR IFAR INA

TR IFARINA

TRIFARINA

TR I FAR INA

TRIFARINA

TR IF AR INA

TR IF A R INA

TR IFAR I NA

TR IFAR INA

TR IFAR INA

TR IFAR I NA

TR IFAR I NA
Specific Name

SCHAUDINV I

SCHAUDINN I

$S C$ HAUDINN I

VAEANS

WE AVER I

WE AVERI

WEAVER I

WEAVERI

WEAVERI

WE AVER I

WE AVER I

WE AVERI

WE AVER I

WE A VER I

WEAVERI

WEAVERI

WEA VER I

WEAVER I

WE AVER I

WE AVER I

WEAVER

WE AVER

WE AVER

WE AVER I

WE AVER

E AVERI

A T LANTI CUS

AT LANT I CUS

AT LANTI CUS

BULLOIDES

PL ANUS

BELLA

BELLA

BR ADY

BRADYI

RADYI

BRADYI
BRADYI

BRADYI

BRADYI

BRADYI

BRADYI

BR ADYI

BRADYI

BR ADYI

BRADYI

BRADYI

BRADYI

BRADYI

BRADYI

BRADYI

BRADYI

BRADYI

BRADYI

BRADYI

BRADYI

BRADYI

BR ADYI

BR ADY I

BRADYI

BRADYI

BRADYI

BRADYI

BRADYI

BRADYI

BRADYI

BRADYI

BRADYI

BRADYI

BRADYI

BR ADYI

BR ADYI

BR ADYI

BRADYI

BRADYI

BRADYI

BRADYI

BRADYI

BR ADYI

BRADYI

BRADYI

BI ADYI

BRADYI

BRADYI

BR ADY I

ORADYI

BRADYI

BRADYI

BR ADYI

BRADYI

BRADYI

BRADYI

BR ADY I

\section{Locality}

$N W$ GULF OF MEXICO

NW GULF OF MEXICO

CENTRAL GULF OF MEXICO

$N$ GULF OF MEXICO

NW GULF OF MEXICO

NW GULF OF MEXICO 
Publication

26331 PHLEGER $1951 \mathrm{~A}$ 26332 PHLEGER 1951 A 26333 PHLEGER $1951 \mathrm{~A}$ 26334 PHLEGER 1951 A 26335 PHLEGER $1951 \mathrm{~A}$
26336 PHLEGER $1951 \mathrm{~A}$ 26337 PHLEGER $1951 \mathrm{~A}$ 26338 PHLEGER $1951 \mathrm{~A}$ 26339 PHLFSER 1951 A 26340 DHLEGER $1951 \mathrm{~A}$
26341 PHLEGER $1951 \mathrm{~A}$

26342 LUOWICK WALTON 1957

26363 PHLEGER 1951A

26344 PHLESER 1951 A
26345 LEROY HODGXINSON 1975

26346 90CK 1976

26347 QQE

26348 AANDY 1950

26349 BANDY 1956

26350 BANDY 1950

2635 ? CUSHMAV 1922A

26353 NORTON $193 \mathrm{C}$

26354 PARKEP 1954

26355 PARKER 1754

26356 PARKER 1754
26357 PARKER 1954

26357
26358
2 PARKER 1954

26359 PARKER 1754

26360 PARKER 1954

26361 WALTON 1964

26362 BOCK 1975

26363 PARKER 1954

26364 PARKER 1954

26365 PARKER 1954

26366 PARKER 1754

26368 LUDWICK NALTON 1957

26369 PARKER 1254

26370 PARKER 1954
26371 LANKFORD 1959

26372 DAVIS 1704

26373 NORTOV 1930

26374 CUSHMAN $1922 \mathrm{~A}$

26375 BENDA PURI 1962

26376 KELLOUGH 1956

26377 SEGURA 1063

26378 NORTON 173

26379 KELLOUGH 1956

26381 KELLOUGH 1956

26382 CUSHMAN 1922 A

26383 LEHMANN 1957

26384 NORTON 1930

26385 DAVIS 1964

26386 CUSHMAV 1922 A

26387 DAVIS 1964

26388 NORTON 1930

26389 BENDA PURI 1962

26390 PARKER PHLEGER PEIRSON 1953

26391 PARKER PHLEGER PEIRSON 1953
26392 PARKER PHLEGER PEIRSON 1953

26393 SOCK 1976

26394 CUSHMA'N $1922 \mathrm{~A}$

26395 BOCK 1976

26396 ANDERSEN 1961

26397 NORTON 1930
26398 CUSHMAN 1922

26398 CUSHMAN 1922 A
26399 DAVIS 1964

26400 NORTON 1230

26401 DAVIS 1964

26402 NORTON 1930

26403 VAUGHAN 1918

26404 VAUGHAN 1918

26405 CUSHMAN 1922 A

26406 POST 1951

26407 BENDA PURI 1962

26408 BANDY 1956

26409 BANDY 1956

26410 BANDY 1956

26411 BANDY 1956

26412 BOCK 1975

26413 BANDY 1956

26414 KORNFELD 1931

26415 DAVIS 1064

26416 WARREN 1957

26417 KORVFELD 1931

26418 KORNFELD 1931

26419 SEGURA 1263

26420 CUSHMAN 1922 A

26421 PHLEGER 1960

26422 SHIFFLETT 1961

26423 BENDA PURI 1962

26424 BENDA PURI 1962

26425 NORTON 1930
Generic Name

TR IFARINA

TR IFAR INA

TR IFAR INA

TRIFARINA

TRIFARINA

TRIFAR INA

TRIFAR INA

TR IFAR INA

TR IFARINA

TR IFARINA

IRIFARINA

TRIFAR INA

TRIFARINA

TRIFARINA

TR ILOCULINA

TRILOCULINA

TR ILOCULINA

TRILOCULINA

TRILOCULINA

TR ILOCULINA

TR ILOCULINA

TRILOCULINA

TRILOCULINA

TRILOCULINA

TRILOCULINA

TRILOCULINA

TR ILOCULINA

TRILOCULINA

TR ILOCULINA

TRILOCULINA

TRILOCULINA

TR ILOCULINA

TRILCCULINA

TRILOCULINA

TRILOCULINA

TRILOCUL INA

TRILOCULINA

TRILOCULINA

TRILOCULINA

TR ILOCUL INA

TR ILOCULINA

TR ILOCULINA

TRILOCULINA

IR ILOCULINA

TRILOCULINA

TRILOCULINA

TRILOCULINA

TRILOCULINA

TR ILOCULINA

TRILOCULINA

IRILOCULINA

TRILOCULINA

TRILOCULINA

TRILOCULINA

TRILOCULINA

TRILOCULINA

TRILOCULINA

TRILOCULINA

TRILOCUL INA

TRILOCULINA

TRILOCULINA

TR ILOCULINA

TRIL OCULINA

TRILOCULINA

TRILOCULINA

TRILOCULINA

TRILOCULINA

TRILOCUL INA

TRILOCUL INA

TR ILOCULINA

TR ILOCULINA

TR ILOCULINA

TRILOCULINA

TR IL OCUL INA

TRILOCULINA

TR I LOCULINA

TR ILOCUL INA

TRILOCUL INA

TRILOCULINA

TRILOCULINA

TRILOCULINA

TR IL OCULINA

TRILOCULINA

TR I L OCULINA

TRILOCULINA

TRILOCULINA

TRILOCULINA

TRILCCULINA

TRILOCULINA

TR ILOCULINA

TRILOCULINA

TR ILOCUL INA

TRILOCULINA
Specific Name

Locality

Lat. Long.

BRADYI

BRADYI

BRADYI

BRADY

BRADYI

BRADY

BRADYI

BRAOY

BRAOY

BRAOYI

BRADYI

BRADYI

CARINATA BRADYANA

JANAI CENS IS

AFFINIS

AFFINIS

AF FINIS

BELLATULA

BE RMUDE ZI

BI CARINAT A

BI CARINATA

BREVIDENT ATA

BREVIDENT ATA

BREVIDENT ATA

BREVIDENT ATA

BREVIDENI ATA

BREVIDENT ATA

BREVIDENTAT A

BREVIDENT ATA

BREVIDENT ATA

BREVIDENT ATA

BREVIDENI ATA

BREVIDENTATA

BREVIDENT ATA

BREVIDENTATA

BREVIDENT ATA

GREVIDENI ATA

BREVIDENTAIA

BREVIDENTATA

CANDEIANA

CARINATA

CARINATA

CARINATA

CI RCULARIS

CIRCULARIS

CIRCULARIS

CI RCULARIS

CIRCULARIS

CI RCULARIS

CI RCU

CI RCULARI

CUNEATA

DENTATA

FI CHTELIANA

FI CHTELIANA

FI CHTEL IANA

F I TERRE I

F I TERREI MENINGOI

FI TERREI MENINGOI

FI TERREI MENINGOI

FI TERRE I MENINGOI

GRACILIS

IN $\subseteq$ IGNIS

INSIGNIS

IN SI GNIS

LAEIOSA

LAEIOSA

LAEIOSA

LINNE I ANA

LI NNE I ANA

LI NNE I ANA

LI NNE I ANA

LI NNE I ANA

LI NNE I ANA

LI ANE I ANA

LINNEIANA COMIS

LIANEIANA COMIS

LINNEIANA COMIS

LINNEIANA COMIS

LINNEI ANA COMIS

LINNEIANA COMIS

OBLONGA

$O B L O N G A$

OBLONGA

OBLONGA

OBLONGA

OBLONGA

$O B L O N G A$

OB LONGA

OBLONGA

OBLONGA

OBLONGA

OBLONGA

NW GULF OF MEXICO

NW GULF OF MEXICO

$N W$ GULF OF MEXICO

NW GULF OF MEXICO

NW GULF OF MEXICO

NW GULF OF MEXICO

NW GULF OF MEXICO

NW GULF OF MEXICO

NW GULF OF MEXICO

NW GULF OF MEXICO

NE GULF OF MEXICO

NW GULF OF MEXICO

$N W$ GULF OF MEXICO

$N$ GULF OF MEXICO 


\section{Publication}

26426 POST 1951

26427 KORNFELD 1931

26428 CUSHMAN $1922 \mathrm{~A}$

26429 NORTON 1930
26430 DAVIS 1964

26430 DAVIS 1964
26431 CUSHMAN $1922 \mathrm{~A}$

26432 NORTON 1930

26433 BOCK 1976

26434 CUSHMAN 1922 A

26435 NORTON 1930

26436 LEHMANN 1957

26437
$26 H L E G E R$
26438
LANKFORD 19558

26439 PARKER PHLEGER PEIRSON 1953

26440 PHLEGER LANKFORD 1957

26441 KANE 1967

26442 KANE 1962

26443 PARKER PHLEGER PEIRSON 1953

26444 PARKER PHLEGER PEIRSON 1953 26445 PARKER PHLEGER PEIRSON 1953 26446 PARKER PHLEGER PEIRSON 1953 26447 PHLEGER 1956

26448 PARKER PHLEGER PEIRSON 1953 26449 PHLEGER 1965A

26450 PHLEGER 1965 A

26451 ANDERSON 1968

26452 BENDA PURI 1962

26453 PHLEGER $1965 \mathrm{~A}$

26454 PHLEGER $1965 \mathrm{~A}$

26455 PHLEGER 1965 A

26456 PARKER PHLEGER PEIRSON 1953

26457 PARKER PHLEGER PEIRSON 1953

26458 PARKER PHLEGER PEIRSON 1953

26459 OTVOS 1978

26460 WALTON 1960

26461 WALTON 1964

26462 PHLEGER 1965 A

26463 DAVIS 1964

26464 BANDY 1954

26465 BANDY 1954

26466 BANDY 1954

26467 BANDY 1954

26468 BANDY 1954

26469 BANOY 1954

26470 SHIFFLETT 1961

26471 BENDA PURI 1962

26472 SEGURA 1963

26473 SHIFFLETT 1961

26474 NORTON 1930

26475 CUSHMAN 1922 A

26476 NORTON 1930

26477 PFLUM FRERICHS 1976

26478 PFLUM FRERICHS 1976

26479 PFLUM FRERICHS 1976

26480 CUSHMAN $1922 \mathrm{~A}$

26481 SEGURA 1963

26482 PARKER 1954

26483 PHLEGER $1955 \mathrm{~A}$

26484 PARKER 1954

26485 PARKER 1954

26486 LANKFORD 1959

26487 PFLUM FRERICHS 1976

26488 PFLUM FRERICHS 1976

26489 PFLUM FRERICHS 1976

26490 PFLUM FRERICHS 1976

26491 PFLUM FRERICHS 1976

26492 PFLUM FRERICHS 1976

26493 PFLUM FRERICHS 1976

26494 PFLUM FRERICHS 1976

26495 PARKER 1954

26496 PARKER 1954

26497 PARKER 1954

26498 PARKER 1954

26499 PARKER 1954

26500 PARKER 1954

26501 BOCK 1976

26502 PFLUM FRERICHS 1976

26503 PFLUM FRERICHS 1976

26504 ANDERSEN 1961

26505 PFLUM FRERICHS 1976

26506 PFLUM FRERICHS 1976

26507 PFLUM FRERICHS 1976

26508 PARKER 1954

26509 PFLUM FRERICHS 1976

26510 PARKER 1954

26511 PARKER 1954

26512 PARKER 1954

26513 PARKER 1954

26514 PFLUM FRERICHS 1976

26515 PHLEGER $1955 \mathrm{~A}$

26516 PHLEGER $1955 \mathrm{~A}$

26517 PFLUM FRERICHS 1976

26518 BANDY 1956

26519 WALTON 1964

26520 BANDY 1956
Generic Name

Specific Name

Locality

Lat. Long.

TR ILOCUL INA

TR ILOCULINA

TR ILOCULINA

TR ILOCULINA

TR ILOCUL INA

TRILOCUL INA

TRILOCUL INA

TR I LOCUL INA

TRILOCULINA

TR ILOCUL INA

TR ILOCULINA

TR ILOCULINA

TRILOCULINA

TRILOCULINA

TR ILOC UL INA

TR IL OCULINA

TRILOCULINA
TRILOCULINA

TR ILOCULINA

TRILOCULINA

TR I LOCUL INA

TR ILOCUL INA

TRILOCULINA

TRILOCULINA

TR ILOCULINA

TRILOCUL INA

TRILOCUL INA

TRILOCULINA

TRILOCULINA

TR ILOCULINA

TRILOCULINA

TRILOCUL INA

TRILOCULINA

TRILOCUL INA

TRILOCULINA

TRILOCUL INA

TRILOCULINA

TR ILOCULINA

TR ILOCULINA

TR ILOCULINA

TR ILOCULINA

TRILOCULINA

TRILOCULINA

TR IL OCULINA

TRILOCULINA

TR I LOCULINA

TRILOCULINA

TR ILOCUL INA

TR ILOCUL INA

TRILOCUL INA

TRILOCULINA

TRILOCULINA

TRILOCULINA

TRILOCULINA

TRILOCULINA

TRILOCULINA

TR I LOCULINA

TR I LOCULINA

TRILOCULINA

TR ILOCUL INA

TR ILOCUL INA

TRILOCULINA

TR ILOCULINA

TRILOCULINA

TRILOCULINA

TRILOCULINA

TRILOCULINA

TR I LOCULINA

TRILOCULINA

TR ILOCULINA

TR I LOCULINA

TR I LOCUL INA

TR I LOCUL INA

TRILOCULINA

TRILOCULINA

TRILOCULINA

TR ILOCULINA

TRILOCULINA

TRILOCUL INA

TR I LOCULINA

TRILOCULINA

TR I LOCULINA

TR IL OCULINA

TRILOCUL INA

TR I LOCUL INA

TR I LOCULINA

TR ILOCULINA

TR ILOCUL INA

TR ILOCULINA

TRILOCULINA

TRILOCULINA

TRILOCULINA

TRILOCULINA

TRILOCULINA
OB LONGA

PLANCIANA

PL ANCI ANA

PLANCIANA

QUADR ILATERALIS

QUADRILAI ERALIS

ROTUNDA

RO TUNDA

RO TUNDA

SI CEBOTTOMI

SI DEBOTTOMI

SI CEBOT TOMI

SI DEBOT TOMI

SI DEBOT TOMI

SI CEBOTTOMI

SI DEBOT TOMI

SI DEBOTTOMI

SI DEBOTTOMI

SI DEBOT TOMI

SI DEBOT TOMI

SI LEBOT TOMI

SI DEBOTTOMI

SI DEBOT TOMI

SI OEBOT TOMI

SI DEBOTTOMI

SI DEB OT TOMI

SI DEB OT TOMI

SI DEBOTTOMI

SI DEBOT TOMI

SI LEBOTTOMI

SI DEBOT TOMI

SI DEBOT TOMI

SI DEBOTTOMI

SI DEBOTTOMI

SI DEBOT TOMI

SI DEBOTTONI

SQLAMOSA

SQLAMOSA

SQLAMOSA

SQ LAMOSA

SQLAMOSA

SQLAMOSA

SQLAMOSA

SQLAMOSA

STRIATOTR IGONULA

SUEORBI CULARIS

SUBORBICJLARI

TRANSVERSESTRIATA

IRANSVERSESTR IATA

TR ICARINA TA

TR ICARINATA

TR ICARINATA

TR ICAR INATA

TR ICARINA TA

TR ICAR INA TA

TR ICAR INA TA

TR ICARINA TA

TR ICARINATA

TR I CAR I NA TA

TR I CAR I NA TA

TR ICAR INA TA

TR ICARINA TA

TR ICARINA TA

TR ICAR INA TA

TR ICARINA TA

TR ICARINA TA

TR ICAR INATA

TR ICAR INA TA

TR ICARINA TA

TR I CARINA TA

TR ICAR INA TA

TR ICAR INA TA

TR I CAR INA TA

TR ICARINA TA

TR ICARINA TA

TR ICARINATA

TR ICARINA TA

TR ICARINA TA

TR ICAR INATA

TR I CARINA TA

TR I CARINATA

TR I CAR I NA TA

TR ICAR INATA

TR I CAR INA TA

TR ICAR INA TA

TR ICARINA TA

TR ICARINA TA

TR ICARINA TA

TR ICAR INA TA

TR ICAR INA TA

TR IGONULA

TR IGONULA

TR I GONULA
SOUTH TEXAS COAST

LOUISIANA GULF COAST

TORTUGAS

TORTUGAS, FLA 
Publication

26521 BENDA PURI 1962

26522 BANDY 1956

26523 BANDY 1956

26524 BANDY 1956

26525 BANDY 1956

26526 NORTON 1930

26527 BANDY 1956

26528 PFLUM FRERICHS 1976

26529 PFLUM FRERICHS 1976

26530 BANDY 1956

26531 BANDY 1956

26532 BANDY 1956

26533 PFLUM FRERICHS 1976

26534 PFLUM FRERICHS 1976

26535 SHIFFLETT 1961

26536 SEGURA 1963

26537 CUSHMAN 1922 A

26538 BOCK 1976

26539 BANDY 1956

26540 BANDY 1956

26541 BANDY 1956

26542 BANDY 1956

26543 PFLUM FRERICHS 1976

26544 PFLUM FRERICHS 1976

26545 PFLUM FRERICHS 1976

26546 PFLUM FRERICHS 1976

26547 PFLUM FRERICHS 1976

26548 PFLUM FRERICHS 1976

26549 PFLUM FRERICHS 1976

26550 ANDERSEN 1961

26551 BANDY 1954

26552 BANDY 1956

26553 BANDY 1956

26554 BANDY 1954

26555 AYALA-CASTANARES 1963

26556 BANDY 1954

26557 BANDY 1956

26558 PFLUM FRERICHS 1976

26559 BANDY 1956

26560 BANDY 1956

26561 PARKER PHLEGER PEIRSON 1953 26562 PARKER PHLEGER PEIRSON 1953 26563 POST 1951

26564 KELLOUGH 1956

26565 ANDERSON 1968

26566 BANDY 1956

26567 BANDY 1956

26568 BANDY 1954

26569 BANDY 1954

26570 BANDY 1956

26571 BANDY 1956

26572 BANDY 1954

26573 KANE 1967

26574 PHLEGER 19658

26575 PARKER PHLEGER PEIRSON 1953 26576 PHLEGER 1956

26577 KANE 1962

26578 SEGURA 1963

26579 PARKER PHLEGER PEIRSON 1953

26580 PHLEGER 1960

26581 PARKER PHLEGER PEIRSON 1953 26582 BENDA PURI 1962

26583 BENDA PURI 1962

26584 BENDA PURI 1962

26585 PARKER PHLEGER PEIRSON 1953

26586 PHLEGER 19658

26587 PARKER PHLEGER PEIRSON 1953 $\begin{array}{llll}26588 & \text { PARKER PHLEGER } & \text { PEIRSON } & 1953 \\ 26589 & \text { PARKER PHLEGER PEIRSON } & 1953\end{array}$ 26590 PFLUM FRERICHS 1976

26591 PFLUM FRERICHS 1976

26592 PFLUM FRERICHS 1976

26593 PFLUM FRERICHS 1976

26594 PFLUM FRERICHS 1976

26595 PFLUM FRERICHS 1976

26596 PFLUM FRERICHS 1976

26597 PFLUM FRERICHS 1976

26598 PFLUM FRERICHS 1976

26599 PFLUM FRERICHS 1976

26600 PFLUM FRERICHS 1976

26601 BOCK 1976

26602 PFLUM FRERICHS 1976

26603 PFLUM FRERICHS 1976

26604 PFLUM FRERICHS 1976

26605 PFLUM FRERICHS 1976

26606 PFLUM FRERICHS

26607 CREAGER 1958
26608 PFLUM FRERICHS 1976

26609 PFLUM FRERICHS 1976

26610 PHLEGER 1951A

26611 PHLEGER 1951A

26612 NORTON 1930

26613 PHLEGER $1951 \mathrm{~A}$

26614
26615
Generic Name

TRILOCULINA

TRILOCULINA

TRILOCUL INA

TRILOCULINA

TRILOCULINA

TRILOCULINA

TRILOCULINA

TR IL OCUL INA

TRILOCULINA

TRI LOCUL INA

TRILOCULINA

TRILOCULINA

TRILOCULINA

TRILOCULINA

TRILOCUL INA

TR ILOCULINA

TRILOCULINA

TRILOCUL INA

TRILOCULINA

TRILOCULINA

TRILOCULINA

TRILOCULINA

TRILOCULINA

TRILOCUL INA

TRILOCULINA

TRILOCULINA

TRILOCULINA

TRILOCULINA

TR ILOCULINA

TR I LOCUL INA

TRILOCULINA

TRILOCULINA

TRILOCULINA

IRILOCULINA

TR ILOCULINA

TRILOCULINA

TRILOCULINA

TRILOCULINA

TRILOCULINA

TRILOCULINA

TRILOCULINA

TRILOCULINA

TRILOCULINA

TRILOCUL INA

TRILOCUL INA

TRILOCULINA

TRILOCULINA

TRILOCULINA

TRILOCULINA

TRI LOCULINA

TRILOCULINA

TRILOCULINA

TRILOCULINELLA

TR ILOCULINELLA

TR ILOCULINELLA

TRILOCULINELLA

TRILOCULINELLA

TRILOCULINELLA

TRILOCUL INELLA

TR ILOCULINELLA

TRILOCULINELLA

TRILOCULINELLA

TRILOCULINELLA

TR I L OCULINELLA

TRILOCULINELLA

TRILOCULINELLA

TR I LOCULINELLA

TRILOCULINELLA

TRILOCULINELLA

TRITAXIS

TRITAXIS

TRITAXIS

TRITAXIS

TRITAXIS

TRITAXIS

TRITAXIS

TRITAXIS

TRITAXIS

TRITAXIS

TROCHAMMINA

TROCHAMMINA

TROCHAMMINA

TROCHAMMINA

TROCHAMMINA

TROCHAMMINA

TROCHAMMINA

TROCHAMMINA

IROCHAMMINA

TROCHAMMINA

TROCHAMMINA

TROCHAMMINA

TROCHAMMINA

TROCHAMMINA

TROCHAMMINA

TROCHAMMINA
Specific Name

TR IGONULA

TR IGONULA

TR IGONULA

TRIGONULA

TR IGONULA

TR IGONULA

TR IGONULA

TR I GONULA

TR IGONULA

TR I GONULA

TR I GONULA

TR I GONULA

TR I GONULA

TR I GONULA

TR IGONULA

TR I GONULA

TRIGONULA

TR IGONULA

TR I GONULA

TF IGONULA

TR I GONULA

TR I GONULA

TRIGONULA

TRIGONULA

TR I GONULA

TR IGONULA

TR IGONULA

TR I GONULA

TR IGONULA

TR IGONULA

TR IGONULA

TR I GONULA

TR I GONULA

TR I GONULA

TR IGONULA

TR I GONULA

TR IGONULA

TR IGONULA

TR I GONULA

TR IGONULA

TR I GONULA

TR I GONULA

TR I GONULA

TR I GONULA

TR IGONULA

TR IGONULA

TR I GONULA

TR IGONULA

TR I GONULA

TRIGONULA

TR IGONULA

OBLIQUINODA

OBLIQUINODA

OBLIQUINODA

OBLIQUINODA

$O B$ LI QU INO DA

OBLIQUINJ DA

OBLIQUINODA

OB LIQUINODA

OBLIQUINJ DA

$O B L I Q U I N O D A$

OB LIQUINODA

OBLIQUINJ DA

OB LI QUINO DA

OBLIQUINJ DA

BLIQUINO DA

OB LI QUI NO DA

OBLIQUINODA

CONICA

CONICA

COAICA

CONICA

CONICA

FUSCA

FUSCA

FUSCA

FUSCA

FUSCA

ACVENA

ADVENA

ADVENA

ADVENA

AD VENA

A DVENA

ADVENA

AD VENA

ADVENA

ADVENA

AD VENA

ADVENA

$A D V E N A$

ADVNA

AD VENA

ADVENA

Locality

Lat. Long.

CAPE ROMANO, FLA.

CALOOSAHATCHEE R.. FLA.

NE GULF OF MEXICO 
Publication

26616 PHLEGER 1951A 26617 PHLEGER 1951A 26618 PHLEGER 1951 A 26619 PHLEGER 1951A 26620 PHLEGER 1951A 26621 PHLEGER 1951A 26622 PHLEGER 1951A 26623 PHLEGER 1951 A 26624 PARKER 1954

26625 PHLEGER 1951A 26626 PHLEGER 1951A 26627 PHLEGER 1951A 26628 PHLEGER $1951 \mathrm{~A}$ 26629 PARKER 1954

26630 PARKER 1954

26631 PARKER 1954

26632 PARKER 1954

26633 PARKER 1954

26634 LUDWICK WALTON 1957

26635 PFLUM FRERICHS 1976

26636 CUSHMAN 1922 A

26637 PHLEGER 1951A A 1976

26639 PHLEGER 1954

26639 PHLEGER 1954

26640 PHLEGER 195
26641 KANE 1967

26642 KANE 1967

26643 SHEPARD MOORE 1955

26644 WALDRON 1963

26645 WARREN 1956
26646 PARKER PHLEGER PEIRSON 1953

26647
26648
PHLEGER

26649 WARREN 1957

26650 PHLEGER 1954

26651 PFLUM FRERICHS 1976

26652 PFLUM FRERICHS 1976

26653 LEROY HODGKINSON 1975

26654 CUSHMAN 1920

26655 CUSHMAN 1920

26656 CUSHMAN 1920

26658 CUSHMAN 1920

26659 PFLUM FRERICHS 1976

26659 PFLUM FRERICHS 1976

26661 PFLUM FRERICHS 1976

26662 CUSHMAN 1920

26663 CUSHMAN 1920

26664 CUSHMAN 1920

26665 PFLUM FRERICHS 1976

26666 PFLUM FRERICHS 1976

26667 PFLUM FRERICHS 1976

26668 PFLUM FRERICHS 1976

26669 PFLUM FRERICHS 1976

26670 PFLUM FRERICHS 1976

26671 PFLUM FRERICHS 1976

26672 PFLUM FRERICHS 1976

26673 PFLUM FRERICHS 1976

26674 PFLUM FRERICHS 1976

26675 PFLUM FRERICHS 1976

26676 PFLUM FRERICHS 1976

26677 PARKER 1954

26678 PARKER 1954

26679 CUSHMAN 1920

26680 PFLUM FRERICHS 1976

26681 PFLUM FRERICHS 1976

26682 PFLUM FRERICHS 1976

26683 PARKER 1954

26684 PARKER 1954 CHS 1976

26686 PFLUM FRERICHS 1976

26687 PFLUM FRERICHS 1976

26688 PFLUM FRERICHS 1976

26689 PFLUM FRERICHS 1976

26690 PFLUM FRERICHS 1976

26691 PFLUM FRERICHS 1976

26692 PFLUM FRERICHS 1976

26693 PFLUM FRERICHS 1976

26694 PFLUM FRERICHS 1976

26695 PFLUM FRERICHS 1976

26696 PFLUM FRERICHS 1976

26697 PFLUM FRERICHS 1976

26698 PFLUM FRERICHS 1976

26699 PFLUM FRERICHS 1976

26700 PFLUM FRERICHS 1976

26701 PFLUM FRERICHS 1976

26702 PFLUM FRERICHS 1976

26703 PFLUM FRERICHS 1976
26704 PFLUM FRERICHS 1976

26704 PFLUM FRERI
26705 PARKER 1954

26706 PARKER 1954

26707 PARKER 1954

26708 PARKER 1954

26709 PFLUM FRERICHS 1976

26710 PFLUM FRERICHS 1976

Generic Name

Specific Name

Locality

Lat. Long.

TR OCHAMMINA

TROCHAMMINA

TROCH AMMINA

TR OCHAMM INA

TR OCH AMMINA

TROCHAMMINA

TROCHAMMINA

TROCHAMMINA

TROCHAMMINA

TROCHAMMINA

TROCHAMMINA

TROCHAMMINA

TROCHAMMINA

TROCHAMMINA

TROCHAMMINA

TROCHAMMINA

TROCHAMMINA

TROCHAMMINA

TR OCHAMMINA

TROCHAMMINA

TROCHAMMINA

TR OCHAMMINA

TROCH AMM INA

TROCHAMMINA

TROCH AMMINA

TROCHAMMINA

TROCHAMM INA

TROCH AMM INA

TROCHAMMINA

TR OCHAMMINA

TROCHAMMINA

TROCHAMMINA

TROCHAMMINA

TROCHAMMINA

TROCHAMMINA

TROCHAMMINA

TROCHAMMINA

TROCHAMMINA

TROCHAMMINA

TROCHAMMINA

TROCHAMMINA

TROCHAMMINA

TROCHAMMINA

TROCHAMMINA

TROCHAMMINA

TROCHAMMINA

TROCHAMMINA

TROCHAMMINA

TROCHAMMINA

TROCHAMMINA

TROCH AMM INA

TROCHAMMINA

TROCHAMMINA

TROCH AMMINA

TROCHAMMINA

TROCHAMMINA

TROCHAMM INA

TR OCHAMMINA

TROCH AMM INA

TROCHAMM INA

TROCHAMMINA

TR OCHAMMINA

TROCHAMMINA

TR OCHAMMINA

TROCHAMMINA

TROCHAMMINA

TR OCHAMMINA

TROCHAMMINA

TR OCHAMMINA

TR OCHAMMINA

TROCHAMM INA

TROCHAMMINA

TROCHAMM INA

TROCHAMM INA

TROCHAMMINA

TROCHAMMINA

TROCHAMMINA

TROCHAMMINA

TROCHAMMINA

TROCHAMMINA

TROCHAMMINA

TROCHAMM INA

TROCHAMMINA

IR OCHAMMINA

TROCHAMMINA

TROCHAMMINA

TROCHAMMINA

TROCHAMMINA

TR OCHAMMINA

TROCH AMM INA

TROCHAMMINA

TROCHAMMINA

TROCHAMMINA

TR OCHAMMIN A

TROCHAMMINA
ADVENA

ADVENA

AD VENA

ADVENA

ADVENA

AD VENA

AD VENA

AD VENA

ADVENA

ADVENA

ADVENA

AD VENA

ADVENA

$A D V E N A$

ADVENA

AD VENA

ADVENA

ADVENA

AD VENA

ADVENA

AD VENA

CONPRIMAT A

COMPRIMATA

COMPRIMATA

COMPRIMATA

CONPRIMATA

COMPRIMAT A

COMPRIMATA

COMPRIMATA

COMPRIMATA

COMPRIMATA

COMPR IMAT A

COMPRIMATA

CONGLOBATA

CONGLOBAT A

GLOBIGERINIF ORMIS

GLOBIGERINIFORMIS

GL OBI GE RI NIF ORMIS

GLOBIGERINI FORMIS

GL CBI GERI NI FORMIS

GL OBUL OSA

GLCBULOSA

GL OBUL OSA

GL OBULOSA

GL OBUL OSA

GL CBUL OSA

GL OBULOSA

GL OBULOSA

GL OBUL OSA

GL OBULOSA

GL OBULOSA

GL OBULOSA

GL OBULOSA

GL OBULOSA

GL OBUL OSA

GL OBULOSA

GL OBULOSA

GL CBUL OSA

GL OBULOSA

GL CBUL OSA

GL OBULOSA

GL OBULOSA

GL CBUL OSA

GL OBUL OSA

GL CBULOSA

GL OBUL OSA

GL CBUL OSA

GL OBULOSA

GL OBULOSA

GLOBULOSA

GL CBUL OSA

GL OBULOSA

GL OBUL OSA

GL OBUL OSA

GL OBULOSA

GL CBUL OSA

GL CBULOSA

GL OBULOSA

GL OBUL OSA

GL OBUL OSA

GLCBULOSA

GL CBULOSA

GL OBULOSA

GLOBULOSA

GL OBUL OSA

GL OBULLOSA

GL OBULOSA

GL CBULOSA

GL CBUL OSA

GL OBULOSA

GL BBULOSA

GL CBULOSA

GL CBULOSA

NW GULF OF MEXICO

$\mathrm{NW}$ GULF OF MEXICO NW GULF OF MEXICO NW GULF OF MEXICO

NW GULF OF MEXICO

NH GULF OF MEXICO 
Publication

26711 PFLUM FRERICHS 1976 26712 PFLUM FRFRICHS 1976 26713 PFLUM FRERICHS 1976 26714 PFLUM FRERICHS 1976 26715 PARKER 1954

26717 PFLUM FRERICHS 1976 26718 PFLUM FRERICHS 1976 26719 PARKER 1954

26720 PARKER 1954

26721 PARKER 1954

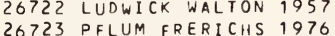
26724 PARKER 1954

26725 SHEPARD MOORE 1955

26726 LEHMANN 1957

26727 PHLEGER $1965 \mathrm{C}$

26728 PHLEGER 1954

26729 LANKFORD 1959

26730 WALDRON 1963

26731 PHLEGER $1965 \mathrm{~A}$

26732 PHLEGER 1965 A

26733 PHLEGER 1965 A

26735 PHLEGER 1965 A

26736 PHLEGER 1965 A

26737 PHLEGER 1965 A

26738 CUSHMAN 1920

26739 OTVOS 1978

26740 PHLEGER LANKFORD 1978

26741 POST 1951

26742 KANE 1967

26744 PHLEGER 1954

26745 PHLEGER 1954

26746 PHLEGER 1954

26747 LOEP 1965

26748 PHLEGER 1965 A

26749 WARREN 1957

26750 PHLEGER $1955 \mathrm{~B}$

26751 PARKER PHLEGER PEIRSON 1953 26752 PARKER PHLEGER PEIRSON 1953 26753 BOCK 1976

26754 BENDA PURI 1962

26755 WARREN 1956

26756 KORNFELD 1931

26757 KORNFELD 1931

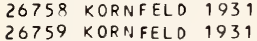

26760 KORNFELD 1931

26761 KORNFELD 1931

26762 KORNFELD 1931

26763 PARKER 1954

26764 PARKER 1954
26765 PFLUM FRERICHS 1976 26766 PFLUM FRERICHS 1976 26767 PFLUM FRERICHS 1976 26768 PFLUM FRERICHS 1976 26769 PARKER 1954

26770 PARKER 1954

26771 PFLUM FRERICHS 1976 26772 PFLUM FRERICHS 1976 26773 PFLUM FRERICHS 1976 26774 PFLUM FRERICHS 1976 26775 PARKER 1954

26776 PARKER 1954
26777 PFLUM FRERICHS 1976 26778 PFLUM FRERICHS 1976 26779 PFLUM FRERICHS 1976 26780 PARKER 1954

26781 PFLUM FRERICHS 1976 26782 PFLUM FRERICHS 1976 26783 PFLUM FRERICHS 1976 26784 PARKER 1954

26785 PARKER 1954

26786 PARKER 1954

26787 PARKER 1954

26788 PARKER 1954

26789 PARKER 1954

26790 PARKER 1954
26791 PFLUM FRERICHS 1976

26792 PARKER 1954

26793 PFLUM FRERICHS 1976

26794 PFLUM FRERICHS 1976

26795 PFLUM FRERICHS 1976

26796 PFLUM FRERICHS 1976

26797 PFLUM FRERICHS 1976

26798 PFLUM FRERICHS 1976

26799 PFLUM FRERICHS 1976 26800 PFLUM FRERICHS 1976 26801 PFLUM FRERICHS 1976 26802 PFLUM FRERICHS 1976 26803 PFLUM FRERICHS 1976 26804 PFLUM FRERICHS 1976 26805 PFLUM FRERICHS 1976
Generic Name

TROCHAMMINA TROCHAMMINA TROCHAMMINA TROCHAMMINA TROCHAMMINA TROCHAMMINA
TROCHAMMINA TROCHAMMINA
TROCHAMMINA TROCHAMMINA TROCHAMMINA TROCHAMMINA TROCHAMMINA TROCHAMMINA TROCHAMMINA TROCHAMMINA TROCHAMMINA TROCHAMMINA TROCHAMMINA TROCHAMMINA TROCHAMMINA TROCHAMMINA TR OCHAMMINA TROCHAMMINA TROCHAMMINA TROCHAMMINA TROCHAMMINA TROCHAMMINA TROCHAMMINA T ROCHAMMINA TROCHAMMINA TROCHAMMINA TROCHAMMINA TROCHAMMINA TROCHAMMINA TROCHAMM INA TROCHAMMINA TROCHAMM INA TROCHAMMINA TR OCHAMMINA TROCHAMMINA TROCHAMMINA TROCHAMMINA TROCHAMMINA TROCHAMMINA TROCHAMM INA TROCHAMMINA TROCHAMMINA TROCHAMMINA TROCHAMM INA TROCHAMMINA TROCHAMMINA TROCHAMMINA TROCHAMMINA TROCHAMMINA TROCHAMMINA TROCHAMMINA TROCHAMMINA TROCHAMMINA TROCHAMMINA TROCHAMMINA IROCHAMMINA TR OCHAMMINA TROCHAMMINA TROCHAMMINA TROCHAMMINA TR OCHAMMINA I ROCHAMMINA TROCHAMMINA TROCHAMMINA TROCHAMMINA TROCHAMMINA TROCHAMMINA TROCHAMMINA TROCHAMMINA IROCHAMMINA TROCHAMMINA TROCHAMMINA TROCHAMMINA TROCHAMMINA TROCHAMMINA TROCHAMMINA TROCHAMMINA TROCHAMMINA TROCHAMMINA TROCHAMMINA TROCHAMMINA TROCHAMMINA TROCHAMMINA TROCHAMMINA TROCHAMMINA TROCHAMMINA TROCHAMMINA TROCHAMM INA TROCHAMMINA TROCHAMMINA TROCHAMMINA
Specific Name

GL CBULOSA

GL CBULOSA

GL CBULOSA

GL CBULOSA

GL OBULOSA

GL OBULOSA

GL CBULOSA

GL CBUL OSA

GLCBULOSA

GL CBULOSA

GL CBULOSA

GL CBULOSA

I N FLA TA

INFLATA

INFLATA

NFLATA

IN FLATA

IN FL ATA

IN FLATA

IN FLATA

IN FLATA

NFLAT

IN FL A TA

IN FLATA

IN FLATA

IN FLATA

IN FLAT A

IN FLATA

IN FLATA

N FLATA

IN FLATA

INFLATA

INFLATA

IN FLATA

IN FLATA

IN FLATA

IN FLATA

IN FLATA

IN FLATA

IN FLATA MEXICANA

INFIATA MEXICANA

IN FLATA YEXICANA

IN FLATA MEXICANA

IN FLATA MEXICANA

INFLATA MEXICANA

INFLATA MEXICANA

JAPONICA

JAFONICA

JAPONICA

JAPONICA

JAFONICA

JAPONICA

JAFON ICA

JAFONICA

JAPONICA

JAPONICA

JAPONICA

JAPONICA

JAFONICA

JAFONICA

JAPONICA

JAPONICA

JAFONICA

JAFONICA

JAFONICA

JAPONICA

JAPONICA

JAPONICA

JAFONICA

JAFONICA

JAPONICA

JAPONICA

JAPONICA

JAFONICA

JAFONICA

JAPONICA

JAFONICA

JAPONICA

JAPONICA

JAFONICA

JAFONICA

JAPONICA

JAPONICA

JAPONICA

JAFONICA

JAPONICA

JAFONICA

JAFONICA

JAPONICA

Locality

Lat. Long.

$N W$ GULF OF MEXICO

NW GULF OF MEXICO

$\mathrm{NW}$ GULF OF MEXICO

$N W$ GULF OF MEXICO

NE GULF OF MEXICO

NE GULF OF MEXICO

$\mathrm{NW}$ GULF OF MEXICO

$N W$ GULF OF MEXICO

NE GULF OF MEXICO

NE GULF OF MEXICO

NE GULF

NW GULF

NE GULF OF MEXICO

CENTRAL TEXAS COAST 


\section{Publication}

26806 PFLUM FRERICHS 1976 26807 PFLUM FRERICHS 1976 26808 PFLUM FRERICHS 1976 26809 PFLUM FRERICHS 1976 26809 PFLUM FRERICHS 1976 26811 PFLUM FRERICHS 1976 26811 PFLUM FRERICHS 1976
26812 PFLUM FRERICHS 1976 26813 PFLUM FRERICHS 1976 26814 PFLUM FRERICHS 1976 26815 PFLUM FRERICHS 1976 26816 PFLUM FRERICHS 1976 26817 PFLUM ERERICHS 1976 26818 PFLUM FRERICHS 1976 26819 PFLUM FRERICHS 1976 26820 PFLUM FRERICHS 1976 26821 PFLUM FRERICHS 1976 26822 BANDY 1956

26823 PHLEGER 1954

26824 PHLEGER 1954

26825 WARREN 1957

26826 SEGURA 196

26827 WALTON 1960

26828 WARREN 1956

26829 LANKFORD 1959

26830 KANE 1967

26831 KANE 1962

26832 LEHMANN 1957

26833 WALDRON 1963

26834 WARREN 1957

26835 WANTLAND 1969

26836 PHLEGER 1954

26837 PHLEGER 1954

26839 PARKER PHLEGER PEIRSON 1953

26840 PARKER PHLEGER PEIRSON 1953

26841 PHLEGER $1965 \mathrm{C}$

26842 PHLEGER 19558

26843 WALTON 1960

26844 WARREN 1956

26845 PHLEGER 1965 A

26846 PHLEGER 1965A

26847 PARKER PHLEGER PEIRSON 1953 26848 LANKFORD 1959

26849 PHLEGER 1954

26850 WALTON 1964

26851 WALTON 1960

26852 PARKER 1954

26853 PARKER 1954

26854 PARKER 1954

26855 PARKER 1954

26857 LUDWICK WALTON 1957

26858 PARKER 1954

26858 PARKER 1954
26859 PARKER 1954

26859 PARKER 1954
26860 WALTON 1964

26861 BANDY 1956

26862 NORTON 1930

26863 BENDA PURI 1962

26864 BENDA PURI 1962

26865 PARKER 1954

26866 PARKER 1954

26867 PARKER 1954

26868 PARKER 1954

26869 PARKER 1954

26870 PARKER 1954

26871 PARKER 1954

26872 PARKER 1954

26873 PARKER 1954

26874 PARKER 1954

26875 LUDWICK WALTON 1957

26876 PARKER 1954

26877 LEROY HODGKINSON 1975

26878 PFLUM FRERICHS 1976

26879 PFLUM FRERICHS 1976

26880 PFLUM FRERICHS 1976

26881 CUSHMAN 1920

26882 PFLUM FRERICHS 1976

26883 PFLUM FRERICHS 1976

26884 PFLUM FRERICHS 1976

26885 PFLUM FRERICHS 1976

26886 PFLUM FRERICHS 1976

26887 PARKER 1954

26888 PFLUM FRERICHS 1976

26889 PFLUM FRERICHS 1976

26890 PFLUM FRERICHS 1976

26891 PFLUM FRERICHS 1976

26892 PFLUM FRERICHS 1976

26893 PFLUM FRERICHS 1976

26894 PFLUM FRERICHS 1976

26895 PFLUM FRERICHS 1976

26896 PFLUM FRERICHS 1976

26897 PFLUM FRERICHS 1976

26898 PFLUM FRERICHS 1976

26899 PFLUM FRERICHS 1976

26900 PFLUM FRERICHS 1976
Generic Name

TR OCHAMMINA

TROCHAMMINA

TROCHAMMINA

TROCHAMMINA

TROCHAMMINA

TR OCHAMM INA

TROCHAMMINA

TROCHAMMINA

TR OCHAMM INA

TROCHAMMINA

TR OCHAMMINA

TROCHAMMINA

TROCHAMMINA

TROCHAMMINA

TROCHAMMINA

TROCHAMMINA

TROCHAMMINA

TR OCHAMMINA

TROCHAMMINA

TR OCHAMMINA

TR OCHAMMINA

TROCHAMMINA

TROCHAMMINA

TROCHAMMINA

TR OC HAMMINA

TROCHAMMINA

TROCHAMMINA

TROCHAMMINA

TROCHAMMINA

TR OCHAMMINA

TROCHAMMINA

TROCHAMMINA

TROCHAMMINA

TR OCHAMMINA

TROCHAMMINA

TR OCHAMMINA

TROCHAMMINA

TROCHAMMINA

TROCHAMMINA

TR OCHAMMINA

TROCHAMMINA

TROCHAMMINA

TROCHAMMINA

TROCHAMMINA

TROCHAMMINA

TROCHAMMINA

TROCHAMMINA

TR OCHAMMINA

TROCHAMMINA

TROCHAMMINA

TROCHAMMINA

TR OCHAMMINA

TROCHAMMINA

TROCHAMMINA

TROCHAMMINA

TR OCHAMMINA

TROCHAMMINA

TR OCHAMMINA

TROCHAMMINA

TROCHAMMINA

TR OCHAMMINA

TROCHAMMINA

TROCHAMMINA

TROCHAMMINA

TR OCHAMM INA

TR OCHAMMINA

TROCHAMMINA

TR OCHAMMINA

TROCHAMMINA

TR OCHAMMINA

TR OCHAMMINA

TROCHAMMINA

TR OCHAMMINA

TROCHAMMINA

TROCHAMMINA

TROCHAMMIN A

TROCHAMMINA

TROCHAMNINA

TR OCHAMMINA

TR OCHAMMINA

TROCHAMMINA

TR OCHAMMINA

TR OCHAMMINA

TROCHAMMINA

TROCHAMMINA

TROCHAMMINA

TROCHAMMINA

TROCHAMMIN

TROCHAMMINA

TROCHAMMINA

TROCHAMMINA

TROCHAMMINA

TROCHAMMINA

TROCHAMMINA

TR OCHAMMINA
Specific Name

Locality

Lat. Long.

JAPONICA

JAPONICA

JAPONICA

JAFONICA

JAFONICA

JAPONICA

JAPONICA

JAPONICA

JAPONICA

JAPONICA

JAPON ICA

JAPON I CA

JAPON ICA

JAPONICA

LAEVIGATA

LOEATA

LOEATA

LOEATA

LOEATA

LOEATA

MACRESCEN S

MACRESCENS

MACRESCENS

MACRESCEN S

MACRESCEN S

MACRESCEN S

MACRESCEN S

MACRESCENS

MACRESCEN S

MACRESCEN S

MACRESCENS

MA CRESCEN S

MACRESCENS

MACRESCENS

MACRESCENS

MACRESCEN S

MACRESCEN S

MACRESCEN S

MACRESCEN S

MACRESCEN S

MULTILOCULATA

OCHRACEA

QUADRILOSA

QUADRILOBA

QUADRILOBA

QUADR ILOBA

QUADRILOBA

QUADRILOBA

QUADRILOBA

QUADR ILOBA

ROTALIF OR MIS

SI MPLISSIMA

SQUAMATA

SQLAMATA

SQLAMATA

SQLAMATA

SQLAMATA

SQLAMATA

SQUAMATA

SQUAMATA

SQLAMATA

SQLAMATA

SQUAMATA

SQUAMATA

SQLAMATA

SQUAMATA

SUEGLABRA

SUBGLABRA

SUBTURB INATA

SUBTURB INATA

SUETURBINATA

SUETURB INATA

SUBTURBINATA

TA SMANI CA

TA SMANI CA

TA SMANI CA

TA SMANI CA

TA SMANI CA

TA SMANI CA

TA SMANI CA

TA SMANI CA

TA SMANICA

TA SMANI CA

TA SMANICA

TA SMANICA

TA SMANI CA

TA SMANI CA

NW GULF OF MEXICO

$N W$ GULF OF MEXICO

NW GULF OF MEXICO

$N W$ GULF OF MEXICO

NW GULF OF MEXICO

NW GULF OF MEXICO 


\section{Publication}

26901 PFLUM FRERICHS 1976 26902 PFLUM FRERICHS 1976 26903 PFLUM FRERICHS 1976 26904 PFLUM FRERICHS 1976 26905 PFLUM FRERICHS 1976 26906 PARKER 1954 26907 PARKER 1954 26908 PARKER 1954 26909 PARKER 1954 26910 PFLUM FRERICHS 1976 26911 PFLUM FRERICHS 1976 26912 PFLUM FRERICHS 1976 26913 PFLUM FRERICHS 1976 26914 PFLUM FRERICHS 1976 26915 PFLUM FRERICHS 1976 26916 PFLUM FRERICHS 1976 26917 PARKER 1954

26918 PFLUM FRERICHS 1976 26919 PARKER 1954

26920 PARKER 1954

26921 PARKER 1954

26922 PARKER 1954

26923 PFLUM FRERICHS 1976 26924 PFLUM FRERICHS 1976 26925 PARKER 1954

26926 PARKER 1954

26927 CUSHMAN 1920

26928 KANE 1962

26929 KANE 1967

26930 HARREN 1956
26931 HANTLAND 1969

26932 WARREN 1957

26933 WANTLAND 1969

26934 CUSHMAN 1920

26935 CUSHMAN 1920

26936 LEROY HODGKINSON 1975

26937 CUSHMAN 1920

26938 CUSHMAN 1922 A

26939 CUSHMAN 192

26940 DAVIS 1964

26941 CUSHMAN 1922 A

26942 CUSHMAN 1922 A

26943 VAUGHAN 1918
26944 CUSHMAN 1922 A

26944 CUSHMAN $1922 \mathrm{~A}$
26945 PFLUM FRERICHS 1976

26946 PFLUM FRERICHS 1976

26947 PFLUM FRERICHS 1976

26948 PFLUM FRERICHS 1976

26949 PFLUM FRERICHS 1976

26950 PFLUM FRERICHS 1976

26951 PFLUM FRERICHS 1976

26952 PFLUM FRERICHS 1976

26953 CUSHMAN 1923

26954 PFLUM FRERICHS 1976 26955 PFLUM FRERICHS 1976 26956 PFLUM FRERICHS 1976 26957 PFLUM FRERICHS 1976 26958 CUSHMAN 1922 A

26959 PFLUM FRERICHS 1976 26960 PFLUM FRERICHS 1976 26961 PFLUM FRERICHS 1976 26962 PFLUM FRERICHS 1976 26963 PFLUM FRERICHS 1976 26964 PFLUM FRERICHS 1976 26965 PARKER 1954

26966 PARKER 1954

26967 PARKER 1954

26968 PARKER 1954

26969 PFLUM FRERICHS 1976 26970 PFLUM FRERICHS 1976 26971 PFLUM FRERICHS 1976 26972 PFLUM FRERICHS 1976 26973 PFLUM FRERICHS 1976 26974 PARKER 1954

26975 PFLUM FRERICHS 1976 26976 PARKER 1954

26977 PFLUM FRERICHS 1976 26978 PFLUM FRERICHS 1976 26979 PFLUM FRERICHS 1976 26980 PFLUM FRERICHS 1976 26981 PFLUM FRERICHS 1976 26982 PFLUM FRERICHS 1976 26983 PFLUM FRERICHS 1976 26984 PFLUM FRERICHS 1976 26985 PARKER 1954

26986 PFLUM FRERICHS 1976 26987 PARKER 1954

26988 PARKER 1954

26989 PARKER 1954

26990 PARKER 195

26991 PARKER 1954

26992 PARKER 1954

26993 CREAGER 1958

26994 CREAGER 1958

26995 LOEP 1965

\section{Generic Name \\ Specific Name}

TROCHAMMINA

TROCHAMMINA

TROCHAMMINA

TROCHAMMINA

TR OCHAMMINA

TROCHAMMINA

TROCHAMMINA

TROCHAMMINA

TR OCHAMMINA

TROCHAMMINA

TROCHAMMINA

TROCHAMMINA

TROCHAMMINA

TROCHAMMINA

TR OCH AMMINA

TROCHAMMINA

TROCHAMMINA

TROCHAMMINA

TROCHAMMINA

TROCHAMMINA

TROCHAMMINA

TR OCHAMMINA

TROCHAMMINA

TROCHAMMINA

TROCHAMMINA

TROCHAMMINA

TROCHAMMINITA

TROCHAMMINI TA

TROCHAMMIN I TA

TROCHAMMINITA

TROCHAMMIN I TA

TR OCHAMMIN I TA

TROCHAMMINOI DES

TROCHAMMINO IDES

TROCHAMMINOIDES

TROCHAMMINOIDES

TRUNCATULINA

TR UNCATULINA

TRUNCATULINA

TRUNCATULINA

TRUNCATULINA

TRUNCATULINA

TRUNCATULINA

UV IGER I NA

UV IGER I NA

UV IGERINA

UV IGER I NA

UV I GER INA

UVIGER INA

UVIGER INA

UVIGERINA

UV IGER INA

UV IGERINA

UVIGERINA

UVIGERINA

UV IGERINA

UV IGER INA

UV IGERINA

UV IGER INA

UV I GER INA

UV IGER I NA

UVIGER INA

UV IGER I NA

UVIGERINA

UVIGERINA

UVIGERINA

UV IGERINA

UV IGERINA

UV IGERINA

UVIGERINA

UV I GER INA

UV IGERINA

UV IGER INA

UV I GER INA

UVIGERINA

UV IGER INA

UV IGER INA

UVIGER INA

UV IGER INA

UV IGER INA

UVIGERINA

UV IGER INA

UV IGER INA

UVIGERINA

UV IGERINA

UV IGERINA

UV IGERINA

UVIGERINA

UVIGERINA

UV IGER INA

UVIGERINA

UV I GER INA

UVIGERINA

UVIGERINA
TA SMANI CA

TA SMANI CA

TA SMANI CA

TA SMANI CA

TA SMANI CA

TA SMANI CA

TA SMANI CA

T A SMAN I CA

TA SMANI CA

TA SMANI CA

TA SMAN I CA

TA SMANI CA

TA SMANI CA

T A SMA NI CA

TA SMANI CA

A SMANI CA

TASMANI CA

TA SMANI CA

TA SMANI CA

TA SMANI CA

TA SMANI CA

A SMANI CA

TURBINATA

IRREGULAR IS

IRREGULAR IS

RREG ULAR IS

IRREGULAR IS

SALSUS

SALSUS

TEUS

ROTEUS

PRCTEUS

ADVENA

ANTILLARUM

CANDEIANA

CORA

ROSEA

ROSEA

AMPULLACEA

AMPULLACEA

AMPULLACE A

AMFULLACEA

AMPULLACEA

AM FULLACE

AMPULLACE A

A MPULLACE A

AMPULLACE A

AMFULLACEA

AMPULLACEA

AMPULLACEA

AM PULLACE

AN GULOSA

AUEER I ANA

AUEER I ANA

AUEERIANA

AUEERIANA

AUEER I ANA

AUEER I ANA

AU EER IANA

AU BER I ANA

AUEER I ANA

AUEERI ANA

AU RER I ANA

AUEER I ANA

AUEER I ANA

AUBERIANA

AUEER I ANA

AU EER I A NA

AUEERI ANA

AUEER I ANA

AUEERIANA

A UEE R I A NA

AUBER I ANA

UEER I ANA

AUEER I ANA

AUEERI ANA

AU EER I ANA

U EER IANA

AUEERI ANA

AUEERI ANA

AUEERIANA LAEVIS

AUEERIANA LAEVIS

AUEERIANA LAEVIS

Locality

NW GULF OF MEXICO

$N W$ GULF OF MEXICO

NW GULF OF MEXICO

NW GULF OF MEXICO

CENTRAL GULF OF MEXICO

NE GULF OF MEXICO

NE GULF OF MEXICO

NE GULF OF MEXICO

NE GULF OF MEXICO

NW GULF OF MEXICO

NW GULF OF MEXICO 


\section{Publication}

26996 CUSHMAN 1923

26997 CUSHMAN 1923
26998 CREAGER 1958

26999 PHLEGER 1951 A

27000 PHLEGER $1951 \mathrm{~A}$

27001 PHLEGER 1951A

27002 PHLEGER 1951A

27003 PHLEGER $1951 \mathrm{~A}$

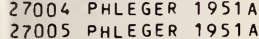

27006 LOEP 1965

27007 PHLEGER $1951 \mathrm{~A}$

27008 PHLEGER $1951 \mathrm{~A}$

27009 PHLEGER 1951A

27010 PHLEGER $1951 \mathrm{~A}$

27011 PHLEGER $1951 \mathrm{~A}$

27012 PHLEGER $1951 \mathrm{~A}$

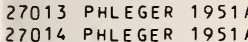

27015 PHLEGER 1951A

27016 PHLEGER 1951A

27017 PHLEGER $1951 \mathrm{~A}$

27018 PHLEGER 1951A

27019 PHLEGER $1951 \mathrm{~A}$

27020 PHLEGER $1951 \mathrm{~A}$

27021 PHLEGER $1951 \mathrm{~A}$

27022 PHLEGER $1951 \mathrm{~A}$

27023 PHLEGER 1951A

27024 PHLEGER $1951 \mathrm{~A}$

27025 PHLEGER $1951 \mathrm{~A}$

27026 PHLEGER $1951 \mathrm{~A}$

27027 PHLEGER 1951A

27028 PHLEGER $1951 \mathrm{~A}$

27029 ANDERSEN 1961

27031 BENDA PURI 1962

27032 BANDY 1956

27033 PHLEGER $1951 \mathrm{~A}$

27034 PHLEGER $1951 \mathrm{~A}$

27035 BANDY 1956

27033 PFLUM FRERICHS 1976

27037 PHLEGER $1951 \mathrm{~A}$

27038 PHLEGER $1951 \mathrm{~A}$

27039 BANDY 1956

27040 ANDERSEN 1961

27041 CREAGER 1958

27042 CREAGER 1958

27043 CREAGER 1958

27044 BOCK 1976

27045 CREAGER 1958

27046 PARKER 1954

27047 PARKER 1954

27048 PARKER 1954

27049 PHLEGER $1951 \mathrm{~A}$

27050 PHLEGER 1951 A

27051 PHLEGER $1951 \mathrm{~A}$

27052 PARKER 1954

27053 PHLEGER 1951 A
27054 PARKER 1954

27055 LUOWICK WALTON 1957

27056 PARKER 1954

27057 PARKER 1954

27058 LEROY HODGKINSON 1975

27059 PFLUM FRERICHS 1976

27060 PFLUM FRERICHS 1976

27061 PFLUM FRERICHS 1976

27062 PFLUM FRERICHS 1976

27063 PFLUM FRERICHS 1976

27064 PFLUM FRERICHS 1976

27065 PFLUM FRERICHS 1976

27066 PFLUM FRERICHS 1976

27067 PFLUM FRERICHS 1976

27068 PFLUM FRERICHS 1976

27069 PFLUM FRERICHS 1976

27070 PFLUM FRERICHS 1976

27071 PFLUM FRERICHS 1976

27072 PFLUM FRERICHS 1976

27073 PFLUM FRERICHS 1976

27074 PFLUM FRERICHS 1976

27075 BANDY 1956

27076 BENDA PURI 1962

27077 BANDY 1956

27078 KELLOUGH 1956

27079 KELLOUGH 1956

27080 LOEP 1965

27081 BANDY 1956

27082 BANDY 1956

27083 CREAGER 1958

27084 CREAGER 1958

27085 CREAGER 1958

27086 CREAGER 1958

27087 PHLEGER $1951 \mathrm{~A}$

27088 PARKER 1954

27089 PHLEGER 1951

27090 PARKER 1954

\section{Generic Name \\ Specific Name}

UV IGERI NA

UVIGER INA

UVIGERINA

UV IGER INA

UV IGERINA

UVIGERINA

UVIGERINA

UV IGERINA

UVIGERINA

UVIGERINA

UV IGER INA

UV I GER INA

UV IGER INA

UV IGER INA

UV IGER INA

UV IGERINA

UVIGERINA

UVIGER I NA

UV IGER INA

UVIGER INA

UVIGER INA

UV IGERINA

UV IGER INA

UVIGERINA

UV IGERINA

UV IGER INA

UV IGERINA

UV IGERINA

UV IGER I NA

UV IGERINA

UV I GER INA

UVIGERINA

UVIGER INA

UV IGER INA

UVIGERINA

UVIGERINA

UVIGERINA

UV I GER INA

UVIGERINA

UV IGER INA

UV IGER INA

UVIGERINA

UVIGERINA

UVIGERINA

UVIGERINA

UVIGER INA

UVIGERINA

UV IGERINA

UV IGERINA

UVIGERINA

UVIGERINA

UV IGERINA

UV IGER INA

UV IGER INA

UV IGER INA

UVIGERINA

UV IGERINA

UV IGERI NA

UV IGERINA

UV IGER INA

UV IGERINA

UVIGERINA

UVIGER INA

UVIGERINA

UVIGERINA

UV IGER INA

UV IGER INA

UV IGERINA

UV IGER INA

UVIGERINA

UV IGERINA

UV IGERINA

UV I GERINA

UV IGER INA

UVIGER INA

UV IGER I NA

UVIGER INA

UVIGERINA

UVIGERINA

UV I GER I NA

UVIGERINA

UV IGER INA

UV IGERINA

UVIGERINA

UV IGERINA

UV IGER I NA

UVIGERINA

UV IGERINA

UV IGER INA

UV IGER INA

UVIGERINA

UVIGERINA

UV IGER I NA

UVIGERI NA
AUEERIANA LAEVIS

AUEERIANA LAEVIS

AUEERIANA LAEVIS

AUEERIANA LAEVIS

AUEERIANA LAEVIS

AUEER I ANA LAEVIS

AUEER I ANA LAEVIS

AUEERIANA LAEVIS

AUEER IANA LAEVIS

AUEERIANA LAEVIS

AUEERIANA LAEVIS

AUEERIANA LAEVIS

AUEERIANA LAEVIS

AUEERIANA LAEVIS

AUEERIANA LAEVIS

AUEERIANA LAEVIS

AUEERIANA LAEVIS

AUEERIANA LAEVIS

AUEERIANA LAEVIS

AUEER IANA LAEVIS

AUEER IANA LAEVIS

AUEERIANA LAEVIS

AUEERIANA LAEVIS

AUEERIANA LAEVIS

AUEERIANA LAEVIS

AUEERIANA LAEVIS

AUEERIANA LAEVIS

AUEERIANA LAEVIS

AUEERIANA LAEVIS

AUEER IANA LAEVIS

AUEERIANA LAEVIS

AUEERIANA LAEVIS

BE LLULA

BELLULA

BELLULA

FL INT I I

FL INT I I

FL INT I I

FL INT I I

LL INTI I

FL INTII

FL INTII

FLINTII

FL INT I I

FL INTII

LL INT II

FL INTII

FL INT II

FL INTII

FL INT I I

FL INTI I

FL INT I I

L INTI I

FL INT I I

FL INTII

FL INT I I

FL INT I I

FL INTI I

L INT I I

FL IN T I I

FL INT I I

HI SPIDA

HI SPIDA

HI SPIDA

H I SPIDA

HI SPIDA

I SPIDA

HI SPIDA

HI SPIDA

H I SPIDA

$H I S P I D A$

HI SPIDA

HI SPIDA

HI SP I DA

HI SP IDA

HI SPIDA

H I SPIDA

HI SPIDOCOSTATA

HI SPIDOCOSTATA

HI SPIDOCOSTATA

HI SPIDOCOSTATA

HISPIDOCOSTATA

H I SPIDOCOSTATA

HISPIDOCOSTATA

HI SPIDOCOSTATA

HI SPIDOCOSTATA

H I SPIDOCOSTATA

HI SPIDOCOSTATA

HI SPIDOCOSTAT

H I SPIDOCDSTATA

H I SPIDOCOSTATA

HI SPIDOCJ STATA

H I SPIDOCOSTATA
AUEER IANA LAEVIS

Locality

Lat. Long.

NE GULF OF MEXICO

NE GULF OF MEXICO

BAY OF CAMPECHE

NW GULF OF MEXICO

NW GULF OF MEXICO 


\section{Publication}

27091 PHLEGER $1951 \mathrm{~A}$ 27092 PHLEGER 1951A 27093 PARKER 1954 27094 PARKER 1954 27095 CREAGER 1958 27096 CREAGER 1958 27097 CREAGER 1958 27098 CREAGER 1958 27099 CREAGER 1958

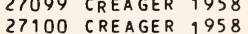
27101 CREAGER 1958 27102 CREAGER 1958 27103 CREAGER 1958 27104 CREAGER 1958 27105 PHLEGER 1951A 27106 PHLEGER 1951A 27107 PHLEGER 1951A 27108 PARKER 1954 27109 CREAGER 1958 27110 CREAGER 1958 27111 CREAGER 1958 27112 CREAGER 1958 27113 CREAGER 1958 27114 CREAGER 1958 27115 CREAGER 1958 27116 PARKER 1954 27117 PHLEGER 1951 A 27118 PHLEGER $1951 \mathrm{~A}$ 27119 PHLEGER $1951 \mathrm{~A}$ 27120 PHLEGER $1951 \mathrm{~A}$ 27121 PHLEGER 1951A
27122 PHLEGER 1951A 27123 PARKER 1954 27124 PARKER 1954 27125 PARKER 1954 27126 PARKER 1954 27127 PARKER 1954 27128 PARKER 1954 27129 LUDWICK WALTON 1957 27130 PARKER 1954 27131 BOCK 1976 27132 PARKER 1954 27133 PARKER 1954 27134 PARKER 1954 27135 PARKER 1954 27136 PARKER 1954 27137 PARKER 1954 27138 PARKER 1954 27139 PARKER 1954 27140 PHLEGER 1956 27141 PARKER 1954 27142 CUSHMAN 1923 27143 CREAGER 1958 27144 CREAGER 1958 27145 ANDERSEN 1961 27146 PHLEGER 1956 27147 PARKER 1954 27148 PHLEGER 1956 27149 CREAGER 1958 27150 PARKER 1954 27151 PARKER 1954 27152 PARKER 1954 27153 PARKER 1954
27154 PHLEGER 1956 27154 PHLEGER 1956
27155 PARKER 1954 27156 PARKER 1954 27157 PARKER 1954 27158 PARKER 1954 27159 PARKER 1954 27160 PARKER 1954
27161 PARKER 1954 27162 LUDHICK WALTON 1957 27163 LANKFORD 1959 27164 PARKER 1954 27165 PARKER 1954 27166 PARKER 1954 27167 CREAGER 1958 27168 CREAGER 1958 27169 CREAGER 1958 27170 PARKER 1954 27171 PARKER 1954 27172 PARKER 1954 27173 PARKER 1954 27174 PARKER 1954 27175 PARKER 1954 27176 HARREN 1957 27177 PHLEGER 1955 A 27178 PARKER 1954 27179 PARKER 1954 27180 PARKER 1954

27181 PARKER 1954

27182 PARKER 1954

27183 PHLEGER 1951A

27184 PARKER 1954 27185 PHLEGER 1951A
Generic Name

Specific Name

Locality

UV I GER I NA UVIGER INA UV IGERINA UV I GER I NA UV IGER INA UVIGERINA UVIGERINA UV IGER I NA UVIGERINA UVIGERINA UV IGERINA UVIGERINA UVIGERINA UV I GER I NA UV IGER INA UV IGERINA UV IGER I NA UV I GER INA UVIGER INA UV IGERINA UVIGERINA UVIGERINA UVIGERINA UVIGER INA UVIGER INA UVI GER I NA UV IGERINA UV IGER INA UVIGER I NA UVIGERINA UV I GER IN A UV IGER INA UVIGER INA UV IGE RINA UVIGERINA UVIGER INA UVIGERINA UVIGERINA UVIGERINA UV IGER I NA UVIGER INA UV IGER INA UV IGER INA UV IGERINA UV IGERINA UV IGER I N UVIGER INA UV I GER INA UVIGERINA UV IGER IN A UV IGERINA UVIGERINA UVIGERINA UV IGERINA UVIGERINA UVIGERINA UVIGERINA UV IGERINA UVIGER INA UVIGERINA UV I GER INA UVIGERINA UVIGERINA UV IGER INA UV I GER INA UV IGER INA UVIGER INA UVIGERINA UVIGER IN UVIGERINA UVIGERINA UV IGER I NA UVIGER INA UV I GER I NA UVIGER INA UV IGERINA UVIGER INA UVIGERINA UVIGER INA UV IGER INA UV IGER I NA UV IGER I NA UV IGER INA UVIGERINA UV I GER I NA UVIGER I NA UV I GER I NA UV IGER INA UV IGER INA UVIGERINA UV IGER INA UV I GERINA UV IGER INA UV IGERINA UV IGER INA
HISPIDOCOSTATA HISPIDOCOSTATA HISPIDOCS STATA HI SPIDOCOSTATA HI SPIDOCOSTATA HISPIDOCOSTATA HISPIDOCOSTATA HI SPIDOCOSTATA HI SPIDOCOSTATA HI SPIDOCOSTATA HI SPIDOCOSTATA HI SPIDOCOSTATA HI SPIDOCOSTATA HISPIDOCOSTATA HISPIDOCOSTATA HI SPIDOCOSTATA HI SPIDOCOSTATA HISPIDOCJ STATA H I SPIDOCOSTATA HISPIDOCS STATA HI SPIDOCOSTATA HI SPIDOCOSTATA HI SPIDOCOSTATA HI SPIDOCDSTATA HI SPIDOCOSTATA H I SPI DOCOSTATA HISPIDOCOSTATA HI SPIDOCJ STATA H I SPIDOCO STATA HI SPIDOCS STATA HI SPIDOCOSTATA HI SPI DO COSTATA LAEVIS

LAEVIS

LAEVIS

LAEVIS

LAEVIS

LAEVIS

LAEVIS

LAEVIS

LAEVIS

LAEVIS

LAEVIS

LAEVIS

LAEVIS

LAEVIS

LAEVIS

LAEVIS

LAEVIS

LAEVIS

LAEVIS

OC CIDENTALIS

PARVULA

PARVULA

PARVULA

PARVULA

PARVULA

PARVULA

PARVULA

PARVULA

PARVULA

PARVULA

PARVULA

PARVULA

PARVULA

PARVULA

PARVULA

PARVULA

PARVULA

PARVULA

PARVULA

PARVULA

PARVULA

PARVULA

PARVULA

PARVULA

PARVULA

PARVULA

PARVULA

PE REGRINA

PE REGRINA

PE FEGRINA

PEREGR INA

PEREGR INA

PEREGRINA

PEREGRINA

PEREGRINA

PEREGRINA

PEREGRINA

PE REGR I NA

PEREGR I NA

PEREGR I NA

PEREGRINA

PE REGR INA

NW GULF OF MEXICO

NW GULF OF MEXICO

NE GULF OF MEXICO

NE GULF OF MEXICO 


\section{Publication}

27186 PHLEGER 1951 A 27187 PHLEGER 1951A 27188 PHLEGER $1951 \mathrm{~A}$ 27189 PHLEGER $1951 \mathrm{~A}$ 27190 OHLEGER 1951A 27191 PHLEGER 1951A 27192 PHLEGER $1951 \mathrm{~A}$ 27193 PHLEGER 1951A 27194 PHLFGER $1951 \mathrm{~A}$ 27195 PHLEGER 1951A 27196 PHLEGER 1951A 27197 PHLEGER 1951A 27198 PHLEGER 1951A 27109 PHLEGER 1951A 27200 PHLEGER 1951A 27201 PHLEGER 1951A 27202 PHLEGER $1951 \mathrm{~A}$ 27203 PHLEGER 1951A 27204 PHLEGER 1951A 27205 PHLEGER 1951 A 27206 PHLEGER $1951 \mathrm{~A}$ 27207 PHLEGER 1955A 27208 PHLEGER 1955 A 27210 PFLUM FRERICHS 1976 27210
27211
PFLLUM FRERICHS 1976 27212 PFLUM FRERICHS 1976 27213 PHLEGER 1951A

27214 PHLEGER 1951A

27215 PFLIJM FRFRICHS 1976

27216 PFLUM FRERICHS 1976

27217 PHLEGER 1951A

27218 PHLEGER $1955 \mathrm{~A}$

27219 PHLEGER 1955 A

27220 PHLEGER 1955A

27222 PHLEGER 1955A

27223 PHLEGER 1951A

27224 PHLEGER $1951 \mathrm{~A}$

27225 CREAGER 1958

27226 CREAGER 1958

27227 CREAGER 1958

27228 PARKER 1954

27229 PARKER 1954

27230 PARKER 1954

27231 PARKER 1954
27232 PARKER 1954

27233 PARKER 1954

27234 PHLEGER $1951 \mathrm{~A}$

27235 PHLEGER $1951 \mathrm{~A}$

27237 PFLUA FRERICHS 1976

27238 PHLEGER $1951 \mathrm{~A}$

27239 PHLEGER $1951 \mathrm{~A}$

27240 PHLEGER 1951A

27241 PHLEGER 1955A

27242 PHLEGER 1955 A

27243 PHLEGER 1955 A

27244 PHLEGER 1951 A

27245 PFLUM FRERICHS 1976

27246 PFLUM FRERICHS 1976

27247 WARREN 1956

27248 PFLUM FRERICHS 1976

27249 LOEP 1965

27250 LOEP 1965

27251 PFLUM FRERICHS 1976

27252 LOEP 1965

27253 PFLUM FRERICHS 1976

27254 PFLUM FRERICHS 1976

27255 CREAGER 1958

27256 CREAGER 1958

27257 CREAGER 1958

27258 CREAGER 1958

27259 CREAGER 1958

27260 CREAGER 1958

27261 CUSHMAN 1923

27262 PFLUM FRERICHS 1976

27263 PFLUM FRERICHS 1976

27264 CREAGER 1958

27265 CREAGER 1958

27266 PFLUM FRERICHS 1976

27267 PFLUM FRERICHS 1976

27268 PFLUM FRERICHS 1976

27269 PFLUM FRERICHS 1976

27270 PFLUM FRERICHS 1976

27271 PFLUM FRERICHS 1976

27272 PFLUM FRERICHS 1976

27273 PFLUM FRERICHS 1976

27274 PFLUM FRERICHS 1976

27275 PFLUM FRERICHS 1976

27276 PFLUM FRERICHS 1976

27277 PFLUM FRERICHS 1976

27278 PFLUM FRERICHS $19 \% 6$

27279 PFLUM FRERICHS 1976

27280 PFLUM FRERICHS 1976
Generic Name

Specific Name

Locality

Lat. Long.

UVIGERINA

UVIGERINA

UVIGERINA

UVIGERINA

UV IGER INA

UVIGERINA

UVIGERINA

UV I GER I NA

UV IGERINA

UV IGER I NA

UVIGERINA

UVIGERINA

UVIGERINA

UVIGERINA

UVIGERINA

UVIGERINA

UV IGER I NA

UVIGERINA

UVI GERINA

UVIGERINA

UVIGERINA

UVIGERINA

UVIGERINA

UV IGER I NA

UVIGER INA

UVIGER INA

UVIGERINA

UVIGERINA

UVIGERINA

UV IGERINA

UV I GER INA

UVIGERINA

UV IGER INA

UVIGERINA

UVIGERINA

UVIGERINA

UVIGERINA

UVIGER INA

UVIGERINA

UVIGERINA

UV IGER INA

UVIGERINA

UVIGERINA

UVIGERINA

UVIGER INA

UVIGER I NA

UV IGERINA

UVIGER INA

UVIGERINA

UVIGERINA

UVI GERINA

UVIGERINA

UV IGER INA

UVIGER I NA

UVIGERINA

UVIGER INA

UV I GER I NA

UV IGER INA

UV IGER INA

UVIGERINA

UVIGERINA

UVIGERINA

UVIGER INA

UVIGER INA

UV I GER INA

UVIGER I NA

UVIGERINA

UVIGER INA

UV IGER INA

UV IGERINA

UVIGERINA

UVIGER INA

UV IGER INA

UVIGERINA

UV IGER INA

UV IGER INA

UV IGER INA

UV I GER INA

UVIGERINA

UVIGER INA

UV I GER I NA

UVIGERINA

UV I GER INA

UVIGERINA

UVIGER INA

UV IGER INA

UVIGERINA

UV IGER I NA

UVIGERINA

UV IGER INA

UV IGER INA

UV IGER INA
PEREGRINA

PE REGRINA

PEREGRINA

PE REGRINA

PEREGR I NA

PEREGR INA

PEREGRINA

PEREGRINA

PEREGRINA

PEREGRINA

PE REGR INA

PEREGR INA

PEFEGR INA

PEREGRINA

PEREGRINA

PEREGRINA

PEREGRINA

PEREGRINA

PE REGR I NA

PE REGR I NA

PEREGR INA

PEREGRINA

PE REGRINA

PEREGRINA

PEREGR INA

PE FEGRINA

PEREGRINA

PEREGRINA

PEREGRINA

PE REGR INA

PE REGRINA

PEREGRINA

PEREGRINA

PEREGRINA

PEREGRINA

PEREGRINA

PEREGRINA

PEFEGRINA

PEREGRINA

PEREGR INA

PE REGRINA

PEREGRINA

PEREGRINA

PE FEGRINA

PE REGRINA

PEREGRINA

PE REGRINA

PEREGRINA

PEREGR I NA

PEREGRINA

PE REGRINA

PEREGRINA

PE REGRINA

PEREGRINA

PEREGRINA

PE REGR I NA

PEFEGRINA

PEREGRINA

PEREGRINA

PEREGRINA

PEREGRINA

PEREGRINA

PEREGRINA

PEREGRINA

PE REGRINA

PEREGRINA

PEREGRINA

PEREGRINA

PEREGRI NA

PEREGRINA

PE REGRI NA

PEREGRINA

PEREGRINA

PEREGRINA

PEREGRINA

PEREGRINA

PEREGR INA

PEREGRINA

PE REGRINA

PE FEGRINA

PEREGRINA

PEREGRINA DIRUPTA

PEREGRINA DIRUPTA

PEREGRINA DIRUPTA

PEFEGRINA DIRUPTA

PE REGRINA DIRUPTA

PEREGRINA OIRUPTA

PEREGRINA OIRUPTA

PEREGRINA DIRUPTA

PEREGRINA DIRUPTA

PEREGRINA DIRUPTA

PEREGRINA DIRUPTA

PEREGRINA DIRUPTA

PEREGRINA DIRUPTA

PEREGRINA DIRUPTA

PEREGRINA DIRUPTA
NW GULF OF MEXICO

NW GULF OF MEXICO

NW GULF OF MEXICO

NW GULF OF MEXICO

NW GULF OF MEXICO 


\section{Publication}

27281 PFLUM FRERICHS 1976 27282 PFLUM FRERICHS 1976 27283 PFLUM FRERICHS 1976 27284 PFLUM FRERICHS 1976 27285 PFLUM FRERICHS 1976 27286 PFLUM FRERICHS 1976 27287 PFLUM FRERICHS 1976 27288 PFLUM FRERICHS 1976 27289 PFLUM FRERICHS 1976 27290 PFLUM FRERICHS 1976 27291 PFLUM FRERICHS 1976 27292 PFLUM FRERICHS 1976 27293 PFLUM FRERICHS 1976 27294 PFLUM FRERICHS 1976 27295 PFLUM FRERICHS 1976 27296 PFLUM FRERICHS 1976 27297 PFLUM FRERICHS 1976 27298 PFLUM FRERICHS 1976 27299 PFLUM FRERICHS 1976 27300 PFLUM FRERICHS 1976 27301 PFLUM FRERICHS 1976 27302 PFLUM FRERICHS 1976 27303 PFLUM FRERICHS 1976 27304 PFLUM FRERICHS 1976 27305 PFLUM FRERICHS 1976 27306 PFLUM FRERICHS 1976 27307 PFLUM FRERICHS 1976 27303 PFLUM FRERICHS 1976 27309 PFLUM FRERICHS 1976 27310 PFLUM FRERICHS 1976 27311 PFLUM FRERICHS 1976 27312 PFLUM FRERICHS 1976 27313 PFLUM FRERICHS 1976 27314 PFLUM FRERICHS 1976 27315 PFLUM FRERICHS 1976 27316 PFLUM FRERICHS 1976 27317 PFLUM FRERICHS 1976 27318 PFLUM FRERICHS 1976 27319 PFLUM FRERICHS 1976 27320 PFLUM FRERICHS 1976 27321 PFLUM FRERICHS 1976 27322 PFLUM FRERICHS 1976 27323 PFLUM FRERICHS 1976 27324 PFLUM FRERICHS 1976 27325 PFLUM FRERICHS 1976 27326 PFLUM FRERICHS 1976 27327 PFLUM FRERICHS 1976 27328 PFLUM FRERICHS 1976 27329 PFLUM FRERICHS 1976 27330 PFLUM FRERICHS 1976 27331 PFLUM FRERICHS 1976 27332 PFLUM FRERICHS 1976 27333 PFLUM FRERICHS 1976

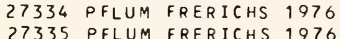
27335 PFLUM FRERICHS 1976
27336 PFLUM FRERICHS 1976 27337 PFLUM FRERICHS 1976 27338 PFLUM FRERICHS 1976 27339 PFLUM FRERICHS 1976 27340 PFLUM FRERICHS 1976 27341 PFLUM FRERICHS 1976 27342 PFLUM FRERICHS 1976 27343 PFLUM FRERICHS 1976 27344 PFLUM FRERICHS 1976 27345 PFLUM FRERICHS 1976 27346 PFLUM FRERICHS 1976 27347 PFLUM FRERICHS 1976 27348 PFLUM FRERICHS 1976 27349 PFLUM FRERICHS 1976 27350 PFLUM FRERICHS 1976 27351 PFLUM FRERICHS 1976 27353 PFLUM FRERICHS 1976 27354 PFLUM FRERICHS 1976 27355 PFLUM FRERICHS 1976 27356 PFLUM FRERICHS 1976 27358 PFLUM FRERICHS 1976 27359 PFLUM FRERICHS 1976 27360 PHLEGER $1951 \mathrm{~A}$ 27361 PHLEGER $1951 \mathrm{~A}$ 27362 PHLEGER 1951 A 27363 PHLEGER 1951 A 27365 PHLEGER 1951A 27366 PHLEGER $1951 \mathrm{~A}$ 27367 PHLEGER $1951 \mathrm{~A}$ 27368 PHLEGER 1951A 27369 PHLEGER $1951 \mathrm{~A}$ 27370 PHLEGER 1951A 27371 PHLEGER $1951 \mathrm{~A}$ 27372 PHLEGER $1951 \mathrm{~A}$ 27373 PHLEGER $1951 \mathrm{~A}$ 27374
27375 PHLEGER $1951 \mathrm{~A}$
Generic Name

UV IGER INA UV IGER INA UVIGERINA UVIGERINA UVIGERINA UVIGERINA UV IGERINA UV IGERINA UVIGERINA UV IGERINA UVIGERINA UV IGER INA UVIGERINA UVIGER INA UVIGERINA UVIGERINA UVIGERINA UVIGER INA UVIGERINA UVIGERINA UVIGERINA UVIGERINA UVIGERINA UVIGERI UVIGERINA UVIGERINA UVIGERINA UV IGERINA UVIGERINA UV IGER INA UV IGER I NA UVIGERINA UV IGER INA UVIGERINA UV I GER I NA UVIGERINA UVIGER INA UV IGER INA UV IGER INA UVIGER I NA UVIGERINA UVIGERINA UVIGER INA UV IGERINA UVIGERINA UVIGERINA UV IGER INA UV IGER INA UVIGERINA UV IGER I NA UVIGER I NA UV I GER INA UV IGERINA UV IGER INA UVIGER INA UVIGERINA UVIGERINA UVIGERINA UVIGERINA UV IGER I NA UV IGER INA UV IGER INA UV IGERINA UV IGERINA UVIGERINA UVIGER INA UV IGER INA UVIGERINA UV IGER INA UV IGERINA UVIGERINA UVIGERINA UV IGER INA
UV IGER INA UVIGER INA UV I GER INA UV IGER INA UVIGER I NA UV IGER INA UVIGERINA UVIGERINA UV IGER INA UVIGER INA UVIGERINA UVIGERINA UVIGERINA UV IGER INA UV IGER INA UV I GER I NA UVIGERINA UVIGERINA
Specific Name

PEREGRINA DIRUPTA PEREGR INA DIRUPTA PEREGRI NA DIRUPTA PEREGRINA DIRUPTA PEFEGRINA DIRUPTA PEREGRINA DIRUPTA PEREGRINA DIRUPTA PEREGRINA DIRUPTA PEREGRINA DIRUPTA PEREGRINA DIRUPTA PEREGRINA DIRUPTA PEREGRINA DIRUPTA PEREGRINA DIRUPIA PEREGRINA DIRUPTA PEREGRINA DIRUPTA PEREGRINA DIRUPTA PEREGRINA DIRUPTA PEREGRINA DIRUPTA PEREGRINA DIRUPTA PEREGRINA DIRUPTA PEREGRINA DIRUPTA PEREGRINA DIRUPTA PEREGR INA DIRUPTA PEREGRINA DIRUPTA PEREGRINA DIRUPTA PEREGRINA DIRUPTA PEREGRINA DIRUPTA PEREGRINA DIRUPTA PEREGRINA DIRUPTA PEREGRINA DIRUPTA PEREGRINA DIRUPTA PEREGRINA DIRUPTA PEREGRINA DIRUPTA PEREGRINA DIRUPTA PEREGRINA DIRUPTA PEREGRINA DIRUPTA PEREGRINA DIRUPTA PEREGRINA DIRUPTA PEREGRINA DIRUPIA PEREGRINA DIRUPTA PEREGRINA DIRUPTA PEREGRINA DIRUPTA PEREGRINA OIRUPTA PEREGRINA DIRUPTA PEREGRINA DIRUPTA PEREGRINA DIRUPTA PEREGRINA DIRUPTA PEREGRINA DIRUPTA PEREGRINA DIRUPTA PEREGRINA DIRUPTA PEREGRINA DIRUPTA PEREGRINA DIRUPIA PEREGRINA DIRUPTA PEREGRINA DIRUPTA PEREGRINA DIRUPT PEREGRINA DIRUPTA PEFEGRINA DIRUPTA PEREGRINA DIRUPTA PEREGRINA DIRUPTA PEFEGRINA OIRUPTA PEREGRINA MEDITERRANEA PEREGRINA MEDITERRANEA PEREGRINA MEDITERRANEA PEREGRINA MEDITERRANEA PEREGRINA MEDITERRANEA PEREGR INA MEOITERRANEA PEREGRINA MEOITERRANEA PEREGRINA MEDITERRANEA PEREGRINA MEDITERRANEA PEREGRINA MEDITERRANEA PEFEGRINA MEDITERRANEA PEREGRINA MEDITERRANEA PEREGRINA MEDITERRANEA PEREGRINA MEDITERRANEA PEREGRINA MEDITERRANEA PEREGRINA MEDITERRANEA PEREGRINA MEDITERRANEA PEREGRINA MEDITERRANEA PEREGRINA MEDITERRANEA PEREGRINA PARVULA PEREGRINA PARVULA PEREGRINA PARVULA PEREGRINA PARVULA PEREGRINA PAR VULA PEREGRINA PARVULA PEREGRINA PAR VULA PEREGRINA PARVULA PEREGRINA PARVULA PEREGRINA PAR VULA PEREGRINA PARVULA PEREGRINA PARVULA PEREGRINA PARVULA PEFEGRINA PARVULA PEREGRINA PARVULA PEREGRINA PARVULA

Locality

Lat. Long.

GULF OF MEXICO CENTRAL GULF OF MEXICO CENTRAL GULF OF MEXICO CENTRAL GULF OF MEXICO CENTRAL GULF OF MEXICO 


\section{Publication}

27376 PHLEGER 1951A 27377 PHLEGER 1951A 27378 PHLEGER 1951A 27379 PHLEGER 1951A 27380 PHLEGER 1951A 27381 CUSHMAN 1923 27382 CUSHMAN 1923 27383 CUSHMAN 1923 27384 CUSHMAN 1923 27385 CUSHMAN 1923 27386 CUSHMAN 1923 27387 PHLEGER 1951A 27388 CUSHMAN 1923 27389 CUSHMAN 1923 27390 CUSHYAN 1923 27391 PHLEGER 1951 27392 CUSHMAN 1923 27393 CUSHMAN 1923
27394 CUSHMAN 1923

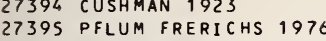
27396 PFLUM FRERICHS 1976 27397 PHLEGER $1951 \mathrm{~A}$ 27398 PHLEGER 1951A 27399 PFLUM FRERICHS 1976 27400 PFLUM FRERICHS 1976 27401 PFLUM FRERICHS 1976

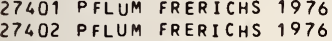
27403 PFLUM FRERICHS 1976 27404 ANDERSEN 1961

27405 PFLUM FRERICHS 1976 27406 PFLUM FRERICHS 1976 27407 PFLUM FRERICHS 1976 27408 PFLUM FRERICHS 1976 27409 PFLUM FRERICHS 1976 27410 PFLUM FRERICHS 1976 27411 PFLUM FRERICHS 1976 27412 PFLUM FRERICHS 1976 27413 PFLUM FRERICHS 1976 27414 PFLUM FRERICHS 1976 27415 PFLUM FRERICHS 1976 27416 PFLUM FRERICHS 1976 27417 PFLUM FRERICHS 1976 27418 PFLUM FRERICHS 1976 27419 PFLUM FRERICHS 1976 27420 PFLUM FRERICHS 1976 27421 PFLUM FRERICHS 1976 27422 LEROY HODGKINSON 1975 27423 PFLUM FRERICHS 1976 27424 PFLUM FRERICHS 1976 27425 PFLUM FRERICHS 1976 27426 PFLUM FRERICHS 1976 27427 PFLUM FRERICHS 1976 27428 PFLUM FRERICHS 1976 27428 PFLUM FRERICHS 1976
27429 PFLUM FRERICHS 1976 27430 PFLUM FRERICHS 1976 27431 PFLUM FRERICHS 1976 27432 PFLUM FRERICHS 1976 27433 PFLUM FRERICHS 1976 27434 PFLUM FRERICHS 1976 27435 PFLUM FRERICHS 1976 27436 PFLUM FRERICHS 1976 27437 PFLUM FRERICHS 1976 27438 PFLUM FRERICHS 1976 27439 PFLUM FRERICHS 1976 27440 PFLUM FRERICHS 1976 27441 PFLUM FRERICHS 1976 27442 PFLUM FRERICHS 1976 27443 PFLUM FRERICHS 1976 27444 PFLUM FRERICHS 1976 27445 PFLUM FRERICHS 1976 27446 PFLUM FRERICHS 1976 27447 VAUGHAN 1918 27448 CUSHMAN 1923

27449 CUSHMAN 1923

27450 LEROY HODGKINSON 1975 27451 NORTON 1930

27452 ANDERSEN 1961

27453 LOEP 1965

27454 CUSHMAN 19228

27455 CUSHMAN 19228

27456 CUSHMAN $1922 \mathrm{~B}$

27457 CUSHMAN $1922 \mathrm{~A}$

27458 CUSHMAN 19228

27459 DAVIS 1964

27460 NORTON 1930

27461 PFLUM FRERICHS 1976

27462 PFLUM FRERICHS 1976

27463 PFLUM FRERICHS 1976 27464 PFLUM FRERICHS 1976 27465 PFLUM FRERICHS 1976 27466 PFLUM FRERICHS 1976 27467 PFLUM FRERICHS 1976 27468 PFLUM FRERICHS 1976 27469 PFLUM FRERICHS 1976 27470 PFLUM FRERICHS 1976
Generic Name Specific Name

UVI GERINA

UVIGERINA

UVIGERINA

UVIGERINA

UVIGERINA

UVIGERINA

UV IGERINA

UVIGERINA

UVIGERINA

UV IGER INA

UVIGERINA

UVIGER INA

UV IGER I NA

UV IGERINA

UV IGER I NA

UVIGER INA

UVIGER INA

UVIGERINA

UV IGER I NA

UV IGER I NA

UVIGER I NA

UV IGER INA

UV IGER I NA

UVIGERINA

UV IGER INA

UV IGER INA

UVIGER INA

UVIGERINA

UV IGER I NA

UV IGERINA

UV IGERINA

UVIGER INA

UVIGER INA

UV IGER INA

UVIGERINA

UV IGERINA

UV IGER INA

UVIGERINA

UVIGERINA

UVIGERINA

UVIGERI NA

UV IGER INA

UVIGERINA

UV I GER I NA

UVIGERINA

UVIGERINA

UVIGERINA

UVIGERINA

UVIGERINA

UV IGER INA

UVIGER I NA

UVIGERINA

UV IGER I NA

UV IGERINA

UVIGERINA

UV IGER INA

UV I GER INA

UVIGER INA

UV IGERINA

UVIGERINA

UV I GER I NA

UVIGERINA

UVIGER INA

UVIGERINA

UVIGER I NA

UV IGER INA

UV IGER I NA

UV IGER I NA

UV IGER I NA

UV I GER INA

UV IGER INA

VAGINUL INA

VAGINUL I NA

VAGINUL INA

VAGINUL INA

VAGINUL INOPSIS

VAGINUL INOPSIS

VALVULINA

VALVULINA

VALVULINA

VALVULINA

VALVULINA

VALVULINA

VALVULINA

VALVULINER I A

VALVUL INER IA

VAL VULINER I A

VALVULINERIA

VALVUL INER I A

VALVULINERIA

VALVULI NER I A

VALVULINER IA

VALUULINER IA

VALVULI NER I A
PEREGRINA PARVIJLA

PEREGRINA PARVULA

PEREGRINA PARVULA

PEREGRINA PARVULA

PEREGRINA PARVULA

PEREGRINA PARVULA

PEREGRINA PARVULA

PEREGRINA PARVULA

PEREGRINA PARVULA

PEREGRINA PAR VULA

PEREGR INA PARVULA

PEREGRINA PAR VULA

PEREGRINA PAR VULA

PEREGRINA PARVULA

PEREGRINA PARVULA

PEREGRINA PARVULA

PEREGRINA PARVULA

PEREGRINA PARVULA

PEREGRINA PARVULA

PEREGRINA PARVULA

PEREGRINA PARVULA

PEREGRINA PARVULA

PEREGRINA PARVULA

PEREGRINA PEREGRINA

PEREGRINA PEREGRINA

PEREGRINA PEREGRINA

PEREGRINA PEREGRINA

PEREGRINA PEREGRINA

SELSEYENS IS

SENTICOSA

SENTI COSA

SENTI COSA

SENTI COSA

SENTI COSA

SENTI COSA

SENTI COSA

SENTI COSA

SENTI COSA

SENTI COSA

SENTI COSA

SENII COSA

SENTI COSA

SPINICOST ATA

SPINICOSTATA

SPINICOSTATA

SPINI COST ATA

SP INI COST ATA

SPINICOST ATA

SPINICOSTATA

SPINICOSTATA

SP INI COST ATA

SP INICOST ATA

SPINI COST ATA

SPINICOSTATA

SPINI COSTATA

SP INI COST ATA

SPINICOST ATA

SP INI COST ATA

SPINICOST ATA

SPINI COSTATA

SP INI COST ATA

SP IN I COST AT A

SP INI COSTATA

SP INI COST AT A

SPINICOSTATA

SP INI COST ATA

SPINICOST AT A

SPINI COST ATA

SP INICOSTATA

SPINICOSTATA

SPINICOST ATA

TE NUISTRI ATA

LE GUMEN

LE GUMEN

LEGUMEN

LINEARIS

PL ANATA

PL ANATA

CONICA

CONICA

CONICA

OVIEDOIAVA

OV IEDOIAVA

OVIEDOI AN A

OVIEDOI AVA

COMPLANATA

COMPLANATA

COMPLANAT A

COMPLANATA

CONPLANAT A

CONPLANAT A

CONPLANATA

CONPLANAT A

CONPLANAT A

CONPLANATA

Locality

Lat. Long.

W GULF OF MEXICO

$N W$ GULF OF MEXICO 


\section{Publication}

27471 PFLUM FRERICHS 1976 27472 PFLUM FRERICHS 1976 27473 PFLUM FRERICHS 1976 27474 PFLUM FRERICHS 1976 27475 PFLUM FRERICHS 1976 27476 PFLUM FRERICHS 1976 27477 PFLUM FRERICHS 1976 27478 PFLUM FRERICHS 1976 27479 PFLUM FRERICHS 1976 27480 PFLJM FRERICHS 1976 27481 PFLUM FRERICHS 1976 27482 PFLUM FRERICHS 1976 27483 PFLUM FRERICHS 1976 27484 PFLUM FRERICHS 1976 27485 PFLUM FRERICHS 1976 27486 PFLUM FRERICHS 1976 27487 PHLEGER $1951 \mathrm{~A}$

27488 PHLEGER $1951 \mathrm{~A}$

27489 PFLUM FRERICHS 1976

27490 PFLUM FRERICHS 1976

27491 PFLUM FRERICHS 1976

27492 PHLEGER $1951 \mathrm{~A}$

27493 PHLEGER 1951A

27494 PHLEGER $1951 \mathrm{~A}$

27495 PHLEGER $1951 \mathrm{~A}$

27496 PHLEGER 1951A
27497 PFLUM FRERICHS 1976

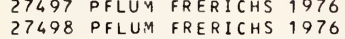
27499 PFLUM FRERICHS 1976 27500 PFLUM FRERICHS 1976 27501 PFLUM FRERICHS 1976 27502 PFLUM FRERICHS 1976 27503 PFLUM FRERICHS 1976 27504 PHLEGER $1951 \mathrm{~A}$ 27505 PHLEGER 1951A 27506 PFLUM FRERICHS 1976 27507 PFLUM FRERICHS 1976 27508 PFLUM FRERICHS 1976 27509 PFLUM FRERICHS 1976 27510 PFLUM FRERICHS 1976 27511 PFLUM FRERICHS 1976 27512 PFLUM FRERICHS 1976 27513 PFLUM FRERICHS 1976 27514 PFLUM FRERICHS 1976 27515 PFLUM FRERICHS 1976 27516 PFLUM FRERICHS 1976 27517 PHLEGER 1951A 27518 PHLEGER 1951A 27519 PHLEGER $1951 \mathrm{~A}$ 27520 PHLEGER $1951 \mathrm{~A}$ 27521 PHLEGER 1951A

27523 PFLUM FRERICHS 1976 27523
27524 PFLUM FRERICHS 1976 27525 PFLUM FRERICHS 1976 27526 PHLEGER $1951 \mathrm{~A}$ 27527 PHLEGER 1951 A 27528 PHLEGER $1951 \mathrm{~A}$ 27529 PHLEGER $1951 \mathrm{~A}$ 27530 PHLEGER $1951 \mathrm{~A}$ 27531 PFLUM FRERICHS 1976 27532 PFLUM FRERICHS 1976 27533 PFLUM FRERICHS 1976 27534 PFLUM FRERICHS 1976 27535 PFLUM FRERICHS 1976 27536 PFLUM FRERICHS 1976 27537 PFLUM FRERICHS 1976

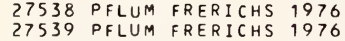
27540 PFLUM FRERICHS 1976 27541 PFLUM FRERICHS 1976 27542 PFLUM FRERICHS 1976 27543 PFLUM FRERICHS 1976 27544 PFLUM FRERICHS 1976 27545 PFLUM FRERICHS 1976 27546 PFLIJM FRERICHS 1976 27547 PHLEGER $1951 \mathrm{~A}$ 27548 PHLEGER 1951A
27549 PFLUM FRERICHS 1976 27550 PHLEGER 1951A 27550
27551 PHLEGER 1951 A A 27552 PHLEGER 1951 A 27553 PFLUM FRERICHS 1976 27554 PHLEGER 1955 A 27556 PHLEGER 1955A 27557 PARKER 1954 27558 PARKER 1954 27559 PARKER 1954 27560 BOCK 1976 27561 PARKER 1954 27562 ANDERSEN 1961 27563 PARKER 1954 27564 PHLEGER 1955 A 27565 PHLEGER 1955 A
Generic Name

VALVUL INER I A VALVULINER I A VALVUL I NER I A VALVUL INER I A VALVUL INER IA VALVULINER I A VALVULINER I A VALVULINERIA VALVULINER I A VALVULINER IA VALVUL INERIA VALVUL I NER I A VALVUL I NER I A VALVULINER I A VALVULINER I A VALVULINER I A VALVULI NER I A VALVUL INER I A VALVULINER I A VALVULINER I A VALVULINER I A VALVULINER I A VALVUL INER I A VALVUL I NER I A VALVULINER I A VALVUL I NER I A VALVULI NER IA VALVULI NER I A VALVULINER I A VALVUL I NER I A VALVULINER I A VALVUL INER I A VALVUL I NER I A VALVULINER I A $\checkmark A L V U L$ INER I A VALVUL I NER I A VALVUL INER I A VALVUL I NER I A VALVULINER I A VALVUL INER IA VALVUL INER I A VALVULINER I A VALVULINER I A VALVUL INERIA VALVUL INER I A VALVUL INER I A VALVULINER IA VALVULI NER I A VALVULINER I A VALVUL I NER I A VALVULINER I A VALVULINER IA VALVULINER IA VALVUL INER I A VALVULI NER I A VALVUL I NER I A VALVUL I NER I A VALVUL I NER I A VALVUL INER I A VALVUL I NER I A VALVUL INER I A $\checkmark A L V U L I N E R$ I A VALVULINER I A VALVUL INER I A VALVUL INER I A VALVULINER I A VALVUL INER I A $\checkmark A L V U L I N E R$ I A $\checkmark A L V U L I N E R$ I A VALVULINER I A VALVUL INER I A VALVULINER I A VALVULINER IA VALVUL INER I A $\checkmark A L V U L I N E R I A$ VALVULI INER I A VALVULINER I A VALVULINER I A VALVUL INER I A VALVULINER IA VALVULINER I A VALVULINER I A VALVULI NER I A VALVULINERI A VALVULINER I A VALVULINER I A VALVULINER IA VALVULI NER I A VALVULINER I A $\checkmark A L V U L I N E R$ I A VALVULINER I A VALVULINER I A VALVULINER I A VALVUL INER I A VALVULINER I A
Specific Name

CONPLANATA

CONPLANAT A

CONPLANAT

CONPLANAT

CONPLANAT A

CONPLANAT A

CONPLANAT A

CONPLANAT A

CONPLANAT A

CONPLANAT A

CONPLANAT A

CONPLANATA

LAEVIGATA

LAEVIGATA

LAEVIGATA

LAEVIGATA

LAEVIGATA

LAEVIGATA

LAEVIGATA

LAEVIGATA

LAEVIGATA

LAEVIGATA

LAEVIGATA

LAEVI GATA

LAEVIGATA

LAEVIGATA

LAEVIGATA

LAEVIGATA

LAEVIGATA

LAEVIGATA

LAEVIGATA

LAEVIGATA

LAEVIGATA

LAEVIGATA

LAEVIGATA

LAEVIGATA

LAEVIGATA

LAEVIGATA

LAEVIGATA

LAEVIGATA

LAEVIGATA

LAEVIGATA

LAEVIGATA

LAEVIGATA

LAEVIGATA

LAEVIGATA

LAEVIGATA

LAEVIGATA

LAEVIGATA

LAEVIGATA

LAEVIGATA

LAEVIGATA

LAEVIGATA

LAEVIGATA

LAEVIGATA

LAEVIGATA

LAEVIGATA

LAEVIGATA

LAEVIGATA

LAEVIGATA

LAEVIGATA

LAEVIGATA

LAEVIGATA

LAEVIGATA

LAEVIGATA

LAEVIGATA

LAEVIGATA

LAEVIGATA

LAEVIGATA

LAEVIGATA

LAEVIGATA

LAEVIGATA

LAEVIGATA

LAEVIGATA

LAEVIGATA

LAEVIGATA

MEXICANA

MEXICANA

MEXICANA

MEXI CANA

MEXICANA

MEXICANA

MEXICANA

MEXICANA

MEXICANA

\section{Locality}

CENTRAL GULF OF MEXICO CENTRAL GULF OF MEXICO CENTRAL GULF OF MEXICO CENTRAL GULF OF MEXICO CENTRAL GULF OF MEXICO CENTRAL GULF OF MEXICO CENTRAL GULF OF MEXICO CENTRAL GULF OF MEXICO CENTRAL GULF OF MEXICO CENTRAL GULF OF MEXICO CENTRAL GULF OF MEXICO CENTRAL GULF OF MEXICO 


\section{Publication}

27566 PARKER 1954 27567 PARKER 1954 27568 PHLEGER $1955 \mathrm{~A}$ 27570 PARKER 1954 27570 PARKER 1954

27572 LANKFORD 1959

27573 CREAGER 1958

27574 PFLUM FRERICHS 1976 27575 PFLUM FRERICHS 1976 27576 PFLUM FRERICHS 1976 27577 CREAGER 1958 27578 CREAGER 1958 27579 PFLUM FRERICHS 1976 27580 PFLUM FRERICHS 1976 27581 PFLUM FRERICHS 1976 27582 PFLUM FRERICHS 1976 27583 PFLUM FRERICHS 1976 27584 PFLUM FRERICHS 1976 27585 PFLUM FRERICHS 1976 27586 PFLUM FRERICHS 1976 27586 PFLUM FRERICHS 1976 27588 PFLUM FRERICHS 1976 27589 PFLUM FRERICHS 1976 27590 PFLUM FRERICHS 1976 27591 PARKER 1954 27592 PARKER 1954 27593 PARKER 1954 27594 PARKER 1754 27595 PARKER 1954 27596 PARKER 1954 27597 LUDWICK WALTON 1957 27598 PARKER 1954 27599 PARKER 1754 27599
27600
PARKER 27601 PARKER 1954

27602 PFLUM FRERICHS 1976 27603 PFLUM FRERICHS 1976 27604 PFLUM FRERICHS 1976 27605 PFLUM FRERICHS 1976 27606 PFLUM FRERICHS 1976 27607 PARKER 1954

27608 PARKER 1954

27609 CREAGER 1958

27610 PFLUM FRERICHS 1976 27611 PFLUM FRERICHS 1976 27612 PFLUM FRERICHS 1976 27613 PFLUM FRERICHS 1976 27614 PFLUM FRERICHS 1976 27615 PFLUM FRERICHS 1976 27616 PARKER 1754

27617 PFLUM FRERICHS 1976 27618 PFLUM FRERICHS 1976 27619 PFLUM FRERICHS 1976 27620 PFLUM FRERICHS 1976 27621 PFLUM FRERICHS 1976 27622 PFLUM FRERICHS 1976 27623 PFLUM FRERICHS 1976 27624 PFLUM FRERICHS 1976

27625 CREAGER 1958

27626 CREAGER 1958

27627 PARKER 1754

27628 PHLEGER 1956

27629 PARKER 1954

27630 PARKER 1954

27631 PFLUM FRERICHS 1976 27632 PFLUM FRERICHS 1976 27633 PARKER 1954

27634 PFLUM FRERICHS 1976

27635 PFLUM FRERICHS 1976 27636. PFLUM FRERICHS 1976 27637 PFLUM FRERICHS 1976 27638 PFLUM FRERICHS 1976 27639 PFLUM FRERICHS 1976 27640 PFLUM FRERICHS 1976 27641 PARKER 1954

27642 PARKER 1954

27643 PARKER 1754

27644 PFLUM FRERICHS 1976

27645 PFLUM FRERICHS 1976

27646 PFLUM FRERICHS 1976

27647 PFLUM FRERICHS 1976

27648 PFLUM FRERICHS 1976 27649 PFLUM FRERICHS 1976 27650 PFLUM FRERICHS 1976 27651 PFLUM FRERICHS 1976 27652 PFLUM FRERICHS 1976 27653 PFLUM FRERICHS 1976 27654 PFLUM FRERICHS 1976 27655 PFLUM FRERICHS 1976 27656 PFLUM FRERICHS 1976 27657 PFLUM FRERICHS 1976 27658 PFLUM FRERICHS 1976 27659 PFLUM FRERICHS 1976
27660 PFLUM FRERICHS 1976
Generic Name

Specific Name

VALVUL INER I A

VALVULINERIA VALVULINER IA VALVULINERI A

VALVULINERIA

VALVULINERI A

VALVUL INER I A

VALVULINERIA

VALVULINER I A

VALVULINER I A

VALVUL INER I A

VAL VUL INER I A

VALVULINER I A

VAL VULINER IA

VALVULINER IA

VALVULINERI A

VALVULI NER I A

VALVUL I NER I A

VALVUL INER I A

VALVULINER I A

VALVULINERIA

VALVULINER I A

VALVUL INER I A

VALVUL INER IA

VA LVUL I NER I A

VALVULINER I A

VALVULI NER I A

VALLVLI INER I A

VAL VUL INER IA

VALVUL INER I A

VALVULINERI A

VALVULINER IA

VALLULINERIA

VALVULINER IA

VALVUL INER I A

VALVULINER I A

VALVULINER I A

VALVULINER I A

VALVUL INER I A

VALVUL INER I A

VALVULINER I A

VALVULINER I A

VALVUL INER I A

VALVULINER IA

VALVUL I NER I A

VALVULINER I A

VALVULINER I A

VALVUL INER I A

VALVUL INER I A

VALVULINER IA

VALVULINER I A

VALVUL I NER I A

VALVULINER I A

VALVULINER IA

VALVULINER IA

VALVULINERIA

VALVULINER I A

VALVULINER I A

VAL VUL I NER I A

VALVULINER I A

VALVULINERIA

VALVULINER IA

VALVULINER I A

VALVULINERIA

VALVUL INER IA

VALVULINER IA

VALVULINER I A

VALVUL INER I A

VALVUL INER I A

VALVULINER I A

VALVUL I NER I A

VALVUL I NER I A

VALVUL INER I A

VALVULINER IA

VALVUL INER I A

VALVULINER IA

VALVULINER I A

VALVUL I NER I A

VALVULINER I A

VALVULINERIA

VALVUL I NER I A

VALVULINER I A

VALVULINER IA

VALVUL INER I A

VALVUL INER I A

VALVULINER I

VALLUL INER I A

VALVULINER I A

VALVULI

VALVUL I NER I A

VALVUL INER I

VAL VUL I NER I

VALVULINER I A

VALVULINER I A

VALVUL I NER I A

VALVUL INER I A
MEXICANA

MEXICANA

MEXICANA

ME XI CANA

MEXI CANA

MEXICANA

MI NUTA

MI UUTA

MI NUTA

MI NUTA

MINUTA

MI UUTA

MI NUTA

MINUTA

MINUTA

MINUTA

MINUTA

MINUTA

MINUTA

MINUTA

MI NUTA

MINUTA

MI NUTA

MI AUTA

MI AUTA

MI NUTA

MINUTA

MINUTA

MINUTA

MI NUTA

MINUTA

MI AUTA

MINUTA

MI NUTA

MI NUTA

MINUTA

MI NUTA

MINUTA

MI NUTA

MI NUTA

MI NUTA

MINUTA

MINUTA

MINUTA

MI NUTA

MINUTA

MI NUTA

MI AUTA

MI NUTA

MINUTA

MINUTA

MI NUTA

MI AUTA

MI NUTA

MINUTA

MINUTA

MI NUTA

MI UUTA

MI NUTA

MI NUTA

MINUTA

MI NUTA

MI NUTA

MINUTA

MINUTA

MI UUTA

MI NUTA

OPIMA

OP IMA

OP IMA

$O P I M A$

OP IMA

OP IMA

OP IMA

OP IMA

OP IMA

$O P I M A$

OPIMA

OP IMA

OP IMA

OP IMA

OP IMA

OPIMA

OP IMA

\section{Locality}

Lat. Long.

NE GULF OF MEXICO

NE GULF OF MEXICO

$N$ GULF OF MEXICO

$N$ GULF OF MEXICO

NE GULF OF MEXICO 


\section{Publication}

27661 PFLUM FRERICHS 1976 27662 PFLUM FRERICHS 1976 27663 NORTON 1930

27664 CUSHMAN 19228

27665 CUSHMAN 19228 27666 CUSHMAN 19228 27667 CUSHMAN 19228 27668 CUSHMAN 19228 27669 CUSHMAN $1922 \mathrm{~B}$ 27670 CUSHMAN 19228 27671 CUSHMAN 19223 27672 CUSHMAN 1922 B 27673 CUSHMAN 19223 27674 KELLOUGH 1956 27675 CUSHMAN $1922 \mathrm{~A}$ 27676 DAVIS 1964 27677 NORTON 1930 27678 NORTON 1930 27679 CUSHMAN $1922 \mathrm{~A}$ 27680 NORTON 1930 27681 PARKER 1954 27682 PARKER 1954 27683 PARKER 9954 27684 PARKER 1954 27685 PARKER 1954 27686 PARKER 1954 27687 PARKER 1954 27688 PARKER 1954 27689 PARKER 1954 27690 PHLEGER 1955A 27691 PHLEGER $1955 \mathrm{~A}$ 27692 PARKER 1954 27693 PARKER 1954 27694 PHLEGER 1956 27695 PHLEGER 1956 27696 PARKER 1954

27697 PARKER 1954 27698 PHLEGER 1951A 27699 PHLEGER 1951A 27700 PHLEGER $1951 \mathrm{~A}$ 27701 PHLEGER $1951 \mathrm{~A}$ 27702 PARKER 1954 27703 PARKER 1954 27704 PARKER 1954 27705 PARKER 1954 27706 PARKER 1954 27707 CREAGER 1958 27708 PARKER 1954 27709 PARKER 1954 27710 PARKER 1954 27711 KELLOUSH 1956 27712 ANDERSEN 1961 27713 PHLEGER $1951 \mathrm{~A}$ 27714 PARKER 1954 27715 PHLEGER 1956 27716 PHLEGER 1956 27717 PARKER 1954 27718 LUDWICK WALTON 1957 27719 LANKFORD 1959 27?20 PARKER 1954 27721 PARKER 1954 27722 PARKER 1954 27723 PARKER 1954 27724 PARKER 1954 27725 PARKER 1954 27726 PARKER 1954 27727 PARKER 1954 27728 PARKER 1954 27730 PARKER 1954 27731 PARKER 1954 27732 PARKER 1954 27733 PARKER 1954
27734 PARKER 1954 27735 PHLEGER 1955 A 27736 PHLEGER 1955A 27737 PHLEGER 1955A 27738 PHLEGER 1955 A 27739 PHLEGER $1951 \mathrm{~A}$ 27740 PHLEGER 1951A 27741 PHLEGER 1951 A 27742 PHLEGER $1951 \mathrm{~A}$ 27743 PHLEGER 1951A 27744 PHLEGER $1951 \mathrm{~A}$ 27745 PHLEGER 1951 A 27746 PHLEGER 1951A 27747 PHLEGER $1951 \mathrm{~A}$ 27748 PHLEGER 1951A 27740 PHLEGER 1951A 27750 PHLEGER $1951 \mathrm{~A}$ 27751 PHLEGER $1951 \mathrm{~A}$ 27752 PHLEGER 1951 A 27753 PHLEGER $1951 \mathrm{~A}$ 27754 PHLEGER $1951 \mathrm{~A}$
27755 PHLEGER $1951 \mathrm{~A}$
Generic Name

VALVULINER I A

VALVULINER I A

VALVULINERIA

VERNEUILINA

VERVEUILINA

VERNEUIL INA

VERNEUILINA

VERNEUILINA

VERNEUI LINA

VERNEUILINA

VERNEUILINA

VERNEUILINA

VERNEUI LINA

VERNEUILINA

VERTEBR AL INA

VERTEBRALINA

VERTEBRALINA

VERT EBRALINA

VERTEBR ALINA

VIRGULINA

VI RGULI NA

VI RGUL INA

VIRGULINA

VIRGULINA

VI RGULINA

VI RGULI NA

VI RGULINA

VI RGULINA

VIRGULINA

VI RGUL I NA

VI RGUL INA

VIRGULINA

VI RGULINA

VI RGULINA

VIRGULINA

VI RGULINA

VI RGUL I NA

VIRGULINA

VIRGULINA

VIRGULINA

VI RGUL INA

VIRGULINA

VI RGUL INA

VI RGULINA

VI RGUL INA

VI RGUL INA

VI RGULINA

VI RGULINA

VI RGULINA

VI RGUL INA

VI RGULINA

VI RGULINA

VIRGULINA

VIRGULINA

VI RGULINA

VI RGUL INA

VIRGULINA

VIRGULINA

VIRGULINA

VIRGULINA

VI RGUL I NA

VI RGULINA

VI RGULINA

VIRGULINA

VI RGULINA

VI RGULINA

VI RGULINA

VI RGULINA

VIRGULINA

VI RGULINA

VIRGULINA

VI RGULINA

VIRGULINA

VI RGULINA

VIRGULINA

VI RGUL INA

VIRGULINA

VI RGULINA

VI RGULINA

VI RGUL INA

VIRGULINA

VI RGUL I NA

VIRGULINA

VI RGULINA

VI RGULI INA

VI RGULINA

VIRGULINA

VIRGULINA

VIRGULINA

VI RGUL INA

VI RGUL INA

VI RGULINA

VI RGULINA

VI RGULINA
Specific Name

Locality

OP IMA

VI LARDEBOANA

AF FIXA

AFFIXA

AFFIXA

AFFIXA

BRADYI

BRADYI

BRADYI

BRADYI

PR CPINQUA

PR CPINQUA

CASSIS

CASSIS

CASSIS MJCRONATA

CASSIS MJCRONATA

STRIATA

ADVENA

ADVENA

ADVENA

AD VENA

ADVENA

ADVENA

ADVENA

ADVENA

ADVENA

ADUENA

ADVENA

CONPLANAT

CONPLANAT A

CONPLANATA

CONPLANAT A

CONPLANAT A

CONPLANATA

COMPLANATA

CONPLANATA

CONPLANAT A

CONPLANATA

CONPLANAT A

CONPLANAT A

CONPLANATA

CONPLANATA

CONPLANAT A

CONPL ANAT A

CONPL ANAT A

CONPLANATA

CONPLANAT A

CONPLANATA

CONPLANATA

CONPLANAT A

CONPLANAT A

CONPLANAT A

CONPLANAT A

CONPLANATA

CONPLANAT A

CONPLANAT A

CONPLANATA

CONPLANAT A

CONPLANATA

CONPLANATA

CONPLANATA

CONPLANATA

CONPLANATA

CONPLANATA

ONPLANAT A

CONPLANATA

CONPLANATA

CONPLANAT A

CONPLANAT A

CONPLANAT A

CONPLANAT A

CONPLANAT A

CONPLANATA

COMPLANATA

CONPLANAT A

CONPLANAT A

COMPL ANAT A

CONPLANAT A

CONPLANAT A

CONPLANATA

CONPLANATA

CONPLANAT A

CONPLANAT A

CONPLANATA

CONPLANAT A

CONPLANAT A

CONPLANATA

CONPLANATA

CONPLANAT A

NW GULF OF MEXICO

NW GULF DF MEXICO

TORTUGAS, FLA

VE GULF OF MEXICO

NE GULF OF MEXICO

NE GULF OF MEXICO

NE GULF OF MEXICO

NE GULF OF MEXICO

NE GULF OF MEXICO 


\section{Publication}

27756 PHLEGER 1951A 27757 PHLEGER 1951A 27758 PHLEGER $1951 \mathrm{~A}$ 27759 PHLEGER $1951 \mathrm{~A}$ 27760 PHLEGER 1951A 27761 PHLEGER 1951A 27762 PHLEGER $1951 \mathrm{~A}$ 27763 PHLEGER $1951 \mathrm{~A}$ 27764 PHLEGER 1951A 27765 PHLEGER 1951A 27766 PHLEGER 1951A 27767 PHLEGER $1951 \mathrm{~A}$ 27768 PHLEGER 1951A 27769 PHLEGER 1951A 27770 CUSHMAN 19228 27771 CREAGER 1958 27772 CREAGER 1958 27773 PARKER 1954

27774 PARKER 1954

27775 CUSHMAN 19228

27776 ANDERSEN 1961

27777 PARKER 1954

27778 PARKER 1954

27779 PARKER 1954
27780 CUSHMAN 19228

27780 CUSHMAN $1922 \mathrm{~B}$
27781 PHLEGER 1951A

27782 PHLEGER 1951A

27783 PHLEGER $1951 \mathrm{~A}$

27784 PHLEGER $1951 \mathrm{~A}$

27785 PHLEGER 1951A

27786 PHLEGER 1951A

27788 PHLEGER 1951A

27789 PHLEGER $1951 \mathrm{~A}$

27790 PHLEGER $1951 \mathrm{~A}$

27794 PARKER 1954

27792 PARKER 1954

27793 PARKER 1954

27794 PHLEGER 1955A

27795 PHLEGER 1955 A
27796 PARKER 1954

27797 PARKER 1954

27798 PHLEGER 1951A

27799 PHLEGER 1955 A

27800 PHLEGER 1951 A

27801 PHLEGER $1951 \mathrm{~A}$

27802 PHLEGER 1951A

27803 PHLEGER 1951A

27804 PHLEGER $1951 \mathrm{~A}$

27805 PHLEGER $1951 \mathrm{~A}$

27806 PHLEGER 1951

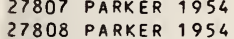

27809 LANKFORD 1959

27810 PARKER 1954

27812 LUDWICK WALTON 1957

27813 LANKFORD 1959

27814 PHLEGER 1954

27815 PHLEGER 1954

27816 PARKER 1954

27817 PHLEGER 1951A

27818 PHLEGER 1951A

27819 PHLEGER 1951 A

27820 PHLEGER 1951A
27821 PHLEGER 1951A

27822 PHLEGER 1951A

27823 LANKFORD 1959

27824 LUDWICK WALTON 1957

27825 WARREN 1957

27826 PARKER 1954

27827 PARKER 1954

27828 PARKER 1954

27829 PARKER 1954

27830 PARKER 1954

27831 PHLEGER 1951A

27832 PHLEGER $1951 \mathrm{~A}$

27833 PHLEGER 1951A

27834 PHLEGER 1951A

27835 PHLEGER 1951A

27836 PARKER 1954

27837 PARKER 1954

27838 PARKER 1954

27839 PARKER 1954

27840 WALTON 1960

27841 PARKER 1954

27842 PARKER 1954

27843 PARKER PHLEGER PEIRSON 1953

27844 CREAGER 1958

27845 CREAGER 1958

27846 KELLOUGH 1956

27847 PHLEGER 1956

27848 PHLEGER 1956

27849 PHLEGER 1956

27850 PARKER 1954
Generic Name

Specific Name

Locality

Lat. Long.

VI RGUL INA

VI RGUL INA

VI RGUL INA

VIRG UL INA

VIRGULINA

VIRGULINA

VI RGUL I NA

VIRGULINA

VIRGULINA

VI RGULI NA

VIRGULINA

VI RGULINA

VI RGULINA

VIRGULINA

VI RGULINA

VI RGUL I NA

VI RGUL I NA

VI RGULINA

VI RGUL INA

VI RGULINA

VI RGULINA

VI RGULINA

VI RGUL INA

VI RGUL INA

VI RGUL I NA

VIRGULINA

VI RGULINA

VIRGULINA

VI RGULINA

VI RGUL INA

VI RGULINA

VI RGULINA

VIRGULINA

VIRGULINA

VI RGULINA

VI RGUL I NA

VI RGUL I NA

VI RGULINA

VIRGULINA

VI RGUL INA

VI RGULI NA

VIRGULINA

VIRGULINA

VIRGULINA

VI RGUL INA

VI RGULINA

VI RGUL INA

VIRGULINA

VIRGULINA

VIRGUL INA

VIRGULINA

VI RGUL INA

VI RGULINA

VI RGUL I NA

VIRGUL INA

VIRGULINA

VI RGULI NA

VI RG UL INA

VI RGUL I NA

VI RGULINA

VI RGUL I NA

VI RGULINA

VI RGUL INA

VIRGULINA

VI RGULINA

VI RGULINA

VI RGULI NA

VIRGULINA

VI RGUL I NA

VI RGUL INA

VI RGUL I NA

VIRGULINA

VI RGULINA

VI RGULI NA

VIRGUL INA

VIRGUL INA

VI RGUL INA

VIRGULINA

VIRGULINA

VI RGUL I NA

VI RGUL I NA

VI RGULINA

VI RGULI NA

VIRGUL INA

VI RGUL INA

VIRGULINA

VIRGULINA

VI RGUL INA

VIRGUL I NA

VI RGULINA

VI RGUL I NA

VI RGULINA

VI RGUL INA

VIRGUL INA

VIRGULINA

VI RGULINA

VIRGULINA
COMPLANAT A

COMPLANAT A

CONPLANATA

COMPL ANAT A

COMPLANAT A

CONPLANAYA

CONPLANAT A

CONPLANAT A

COMPLANAT A

COMPL ANAT A

COMPLANAT A

COMPLANATA

CONPLANATA

CONPLANAT A

COMPRESSA

COMPRESSA

MEXI CANA

MEXI CANA

ME XICANA

MEXI CANA

MEXI CANA

MEXICANA

MEXI CANA

MEXICANA

MEXICANA

MEXICANA

ME XI CANA

MEXICANA

MEXICANA

MEXICANA

MEXI CANA

MEXI CANA

MEXICANA

MEXI CANA

MEXICANA

MEXI CANA

MEXI CANA

MEXI CANA

MEXI CANA

MEXICANA

MEXI CANA

E XICANA

ME XICANA

MEXI CANA

MEXICANA

MEXICANA

MEXICANA

MEXICANA

MEXICANA

MEXICANA

MEXI CANA

MEXI CANA

MEXICANA

PERTUSA

PONTONI

POATONI

PONTONI

PONTONI

PONTONI

POATONI

PONTONI

POATONI

POATONI

POATONI

POATONI

PONTONI

PONTONI

PONTONI

POATONI

POATONI

PONTONI

PONTONI

PONTONI

POATONI

POATONI

POATONI

POATONI

PONTONI

POATONI

POATI

POATONI

POATONI

POATONI

POATONI

POATONI

PONTONI

PONTONI

POATONI

OTONI

PONTONI
NW GULF OF MEXICO

NW GULF OF MEXICO

NW GULF OF MEXICO

NW GULF OF MEXICO

$N W$ GULF OF MEXICO

NW GULF OF MEXICO

NW GULF OF MEXICO 
Publication

27851 PHLEGER 1956

27852 PARKER PHLEGER PEIRSON 1953 27853 PARKER PHLEGER PEIRSON 1953 27854 PARKER PHLEGER PEIRSON 1953 27855 KELLOUGH 1956 27856 KELLOUGH 1956
27857 KELLOUGH 1956 27857 KELLOUGH 1956 27859 PHLEGER 1951 A 27860 PHLEGER 1951 A 27861 PHLEGER $1951 \mathrm{~A}$ 27862 PHLEGER $1951 \mathrm{~A}$ 27863 PHLEGER $1951 \mathrm{~A}$ 27864 PHLEGER 1951A 27865 KELLOUGH 1956 27866 LOEP 1965

27867 WARREN 1956

27868 PHLEGER $1951 \mathrm{~A}$

27869 PHLEGER $1951 \mathrm{~A}$
27870 PHLEGER $1951 \mathrm{~A}$ 27870 PHLEGER $1951 \mathrm{~A}$
27871 PHLEGER $1951 \mathrm{~A}$ 27872 PHLEGER 1951A 27873 ANDERSEN 1961 27874 ANDERSEN 1961 27874 ANDERSEN 1961 1955

27876 KELLOUGH 1956 27877 PHLEGER 1951A 27878 PHLEGER $1951 \mathrm{~A}$ 27879 PHLEGER $1951 \mathrm{~A}$ 27880 PHLEGER $1951 \mathrm{~A}$ 27881 PHLEGER 1951A 27882 PHLEGER 19558 27883 PHLEGER $1951 \mathrm{~A}$ 27884 PHLEGER 1951A 27885 PARKER 1954 27886 PARKER 1954 27887 PARKER 1954 27888 PARKER 1954 27889 PARKER 1954 27890 PARKER 1954 27891 PARKER 1954 27892 PARKER 1954

27893 LUDWICK WALTON 1957 27894 PARKER 1954

27895 ANDERSEN 1961

27896 ANDERSEN 1961 27897 CUSHMAN $1922 \mathrm{~A}$ 27899 DAVIS 1964 27900 PARKER 1954 27901 PARKER 1954 27902 PARKER 1954 27903 PARKER 1954 27904 NORTON 1930 27905 BENDA PURI 1962 27906 PARKER 1954 27907 PARKER 1954 27908 PARKER 1954 27909 PARKER 1754 27910 PARKER 1954 27911 BANDY 1956 27912 BANDY 1956 27913 BANDY 1956 27914 BANDY 1956 27915 BANDY 1956 27916 BANDY 1956 27917 BANDY 1954 27918 BANDY 1956 27920 BANDY 1956 27921 BANDY 1956 27922 BANDY 1956 27923 BANDY 1954 27924 BANDY 1954 27925 BANDY 1956 27926 BANDY 1956 27927 BANDY 1954 27928 BENDA PURI 1962 27929 BANDY 1956 27930 BANDY 1956 27931 BANDY 1956 27933 BANDY 1954 27934 BANDY 1954 27935 CREAGER 1958 27936 PHLEGER 1956 27937 PHLEGER 1956 27938 KELLOUGH 1956 27939 PHLEGER $1951 \mathrm{~A}$ 27940 PHLEGER $1951 \mathrm{~A}$ 27941 PHLEGER $1951 \mathrm{~A}$ 27942 PHLEGER $1951 \mathrm{~A}$ 27943 PHLEGER 1951 A
27944 PHLEGER 1956 27945 PHLEGER 1956
Generic Name

VIRGULINA

VI RGULINA

VIRGULINA

VIRGULINA

VIRGULINA

VIRGULINA

VI RGULINA

VI RGULINA

VI RGULINA

VIRGULINA

VIRGULINA

VI RGULINA

VIRGULINA

VIRGULINA

VI RGULINA

VIRGULINA

VIRGULI NA

VIRG UL INA

VI RGULINA

VIRGULINA

VI RGULINA

VI RGULINA

VIRGULINA

VIRGULINA

VI RGULINA

VI RGULINA

VI RGULINA

VIRGUL INA

VIRGUL INA

VIRGULINA

VIRGULINA

VI RGUL I NA

VI RGUL INA

VIRGUL INA

VIRGULINA

VIRGUL INA

VIRGULINA

VIRGULINA

VI RGUL INA

VI RGUL INA

VIRGULINA

VI RGUL INA

VIRGULINA

VIRGULINA

VI RGUL INA

VI RG ULINA

VIRGULINA

VIRGULINA

VI RGUL INA

VI RGULINA

VIRGULINA

VI RGULINA

VIRGULINA

VI RGULINA

VIRGULINA

VIRGUL INA

VIRGULINA

VI RGULINA

VI RGULINA

VIRGULINA

VIRGULINA

VI RGULINA

VI RGULINA

VIRGUL INA

VI RGUL INA

VI RGULINA

VI RGULINA

VIRGULINA

VIRGULINA

VIRGULINA

VI RGULINA

VIRGULINA

VIRGULINA

VIRGULINA

VIRGULINA

VI RGUL INA

VI RGULINA

VIRGULINA

VIRGULINA

VIRGULINA

VIRGULINA

VI RGULINA

VIRGUL INA

VIRGULINA

VIRGULINA

VIRGULINA

VIRGULINA

VI RGULINA

VIRGULINA

VIRGULINA

VI RGUL INA

VIRGULI NA

VI RGULINA

VIRGULINA
VIRGULINA
Specific Name

POATONI

PONTONI

POATONI

POATONI

PONTONI

POATONI

PONTONI

POATONI

POATONI

PONTONI

POATONI

POATONI

POATONI

POATONI

POATONI

PONTONI

POATONI

PONTONI

POATONI

POATONI

POATONI

POATONI

POATONI

POATONI

PONTONI

PONTONI

POATONI

PONTONI

PONTONI

PUNCTATA

PUACTATA

PUNCTATA

PUACTATA

PUNCTATA

PUNCTATA

PUNCTATA

PUACTATA

PUACTATA

PUACTATA

PUACTATA

PUACTATA

PUACTATA

PUACTATA

PUNCTATA

PUNCTATA

PUNCTATA

PUACTATA

PUACTATA

PUACTATA

PUACTATA

PUACTATA

SCIRE IBER SI ANA

SCIRE IBER SI AN A

SC RRE IBER S I AN A

SCHRE I BER S I ANA

SC HRE IBER SI ANA

SCHRE IBER SI ANA

SC HRE IBER S I ANA

SC HRE IBER SI ANA

SCIREIBER SIANA

SCFRE IBER S I ANA

SCHREIBER SIANA

SC HRE IBER SI AN A

SC HRE IBER SI ANA

SC HRE IBER SI ANA

SC HRE IBER SI ANA

SCFRE I BER SI ANA

SCHRE IBER SI ANA

SC HRE IBER SI ANA

SCHRE IBER SI ANA

SC HRE IBER SI AN A

SC HRE IBER SI ANA

SC HRE I BER S I ANA

SCHRE IBER S I ANA

SC HREIBER SI ANA

SP INICOST ATA

SPINI COST ATA

SP INI COST ATA

SP INI COST AT A

SPINI COSTATA

SPINICOSTATA

SPINICOSTATA

SP INICOSTATA

SP INICOSTATA

SPINI COSTATA

SP INICOST AT A

Locality

Lat. Long.

NW GULF OF MEXICO

TEXAS GULF COAST

TEXAS GULF COAST

TEXAS GULF COAST

$N W$ GULF OF MEXICO

NW GULF OF MEXICO

NW GULF OF MEXICO

$\mathrm{NW}$ GULF OF MEXICO

$N W$ GULF OF MEXICO

$N W$ GULF OF MEXICO

NW GULF OF MEXICO

NW GULF OF MEXICO

NW GULF OF MEXICO

$N W$ GULF OF MEXICO 


\section{Publication}

27946 PARKER PHLEGER PEIRSON 1953 27947 PHLEGER 1951A

27948 PHLEGER 1951A

27949 PHLEGER $1951 \mathrm{~A}$

27950 PHLEGER 1951A

27951 PHLEGER 1951A

27952 PHLEGER 1951A

27953 PHLEGER $1951 \mathrm{~A}$

27954 PHLEGER $1951 \mathrm{~A}$

27955 PHLEGER 1951A

27956 SHEPARD MOORE 1955

27957 PHLEGER 1951A

27958 PHLEGER 1951A

27959 PHLEGER 1951A

27960 VAUGHAN 1918

27961 PHLEGER $1951 \mathrm{~A}$

27962 PARKER 1954

27963 PARKER 1954

27964 PARKER 1954

27965 PHLEGER $1951 \mathrm{~A}$

27966 PHLEGER $1951 \mathrm{~A}$

27967 PHLEGER 1951A

27968 PHLEGER 1955 A

27969 PHLEGER $1951 \mathrm{~A}$

27970 PARKER 1954

27971 PARKER 1954

27972 PHLEGER $1951 \mathrm{~A}$

27973 PARKER 1954

27974 PARKER 1954

27975 PARKER 1954

27976 PHLEGER 1955 A

27977 PARKER 1954

27978 PARKER 1954

27979 PHLEGER 1951 A

27980 PARKER 1954

27981 PHLEGER $1951 \mathrm{~A}$

27982 PHLEGER 1951A

27983 PHLEGER $1951 \mathrm{~A}$

27984 PHLEGER $1951 \mathrm{~A}$

27985 PHLEGER 1951A

27986 BENDA PURI 1962

27987 BANDY 1956

27988 BANDY 1956

27989 ANDERSEN 1961

27990 BANDY 1956

27991 SHIFFLETT 1961

27992 PARKER 1954

27993 PARKER 1954

27994 PARKER 1954

27995 PARKER 1954

27996 PARKER 1954

27997 PARKER 1954

27998 PARKER 1954

27999 PARKER 1954

28000 PARKER 1954

28001 PARKER 1954

28002 PARKER 1954

28003 PARKER 1954

28004 BOCK 1976

28005 WALTON 1960

28006 BANDY 1956

28007 PARKER 1954

\section{Generic Name}

VI RGULINA

VI RGULINA

VI RGULINA

VI RGULINA

VIRGULI INA

VI RGULINA

VI RGULINA

VI RGULINA

VI RGULINA

VI RGULINA

VI RGULINA

VI RGULINA

VI RGUL INA

VI RGULINA

VI RGULINA

VI RGUL I NA

VIRGULINA

VIRGULINA

VIRGULINA

VI RGULINA

VI RGULINA

VI RGULINA

VIRGULINA

VI RGULINA

VI RGULINA

VIRGUL INA

VI RGUL INA

VIRGUL INA

VIRGULINA

VI RGULINA

VI RGUL I NA

VI RGULINA

VIRGULINA

VI RGULI NA

VIRGULINA

VI RGULINA

VI RGUL INA

VI RGULINA

VIRGULINA

VI RGULINA

WI ESNERELLA

WIESNERELLA

WIESNERELLA

WIESNERELLA

WIESNERELLA

WIESNERELLA

WIESNERELLA

WIESNERELLA

WIESNERELLA

WI ESNERELLA

WIESNERELLA

WI ESNERELLA

WI ESNERELLA

WIESNEREILLA

WI ESNERELLA

WI ESNERELLA

WIESNERELLA

WI ESNERELLA

WI ESNERELLA

WIESNERELLA

WI ESNERELLA

WIESNERELLA
Specific Name

SP INI COST AT A

SPINICOST ATA

SP INI COST ATA

SP INI COSTATA

SP INI COST ATA

SP INI COSTATA

SPINICOSTATA

SPINICOSIATA

SP INI COSTATA

SP INI COSI AT A

SP INICOSTATA

SP INICOSTATA

SP INI COSTATA

SPINI COSI AT A

SQLAMOSA

TE SSELLAT A

TE SSELLAT A

TE SSELLAT A

TESSELLAT A

TE SSELLAT A

TE SSELLAT A

TE SSELLATA

TE SSELLATA

TESSELLAT A

TE SSELLAT A

TE SSELLAT A

TE SSELLATA

TE SSELLATA

TE SSELLAT A

TE SSELLAT A

TE SSELLAT A

TE SSELLAT A

TE SSELLAT A

TE SSELLATA

TESSELLAT A

TESSELLAT A

TE SSELLAT A

TE SSELLAT A

TE SSELLAT A

TE SSELLAT A

AURI CUL AT A

AURICULATA

AURI CULATA

AURI CULATA

AURI CULAT A

AURI CULLATA

AURICULAT A

AU RI CUL AT A

AURICULATA

AURICULAT A

AURI CULATA

AURI CULAIA

AU RI CULAT A

AURICULAT A

AURICULAT A

AURICULATA

AURI CULAT A

AURI CULAT A

AURI CULAI A

AURICULATA

AURICULATA

AURI CULAT A
Locality

TEXAS GULF COAST

$N$ W GULF OF MEXICO

NW GULF OF MEXICO

NW GULF OF MEXICO

NH GULF OF MEXICO

NH GULF OF MEXICO

NW GULF OF MEXICO

NW GULF OF MEXICO

NW GULF OF MEXICO

NW GULF OF MEXICO

CENTRAL TEXAS COAST

NW GULF OF MEXICO

NW GULF OF MEXICO

NW GULF OF MEXICO

DRY TORTUGAS

NW GULF OF MEXICO

NE GULF OF MEXICO

NE GULF OF MEXICO

NE GULF OF MEXICO

NW GULF OF MEXICO

NH GULF OF MEXICO

NW GULF OF MEXICO

$N$ GULF OF MEXICO

NW GULF OF MEXICO

NE GULF OF MEXICO

NE GULF OF MEXICO

NW GULF OF MEXICO

NE GULF OF MEXICO

NE GULF OF MEXICO

NE GULF OF MEXICO

$N$ GULF OF MEXICO

NE GULF OF MEXICO

NE GULF OF MEXICO

NW GULF OF MEXICO

NE GULF OF MEXICO

NH GULF OF MEXICO

NW GULF OF MEXICO

NW GULF OF MEXICO

NW GULF OF MEXICO

NW GULF OF MEXICO

CAPE ROMANO FLA.

NE GULF OF MEXICO

NE GULF OF MEXICO

MISSISSIPPI DELTA

NE GULF OF MEXICO

HEALD BANK, G. OF MEXICO

NE GULF OF MEXICO

NE GULF OF MEXICO

NE GULF OF MEXICO

NE GULF OF MEXICO

NE GULF OF MEXICO

NE GULF OF MEXICO

NE GULF OF MEXICO

NE GULF OF MEXICO

NE GULF OF MEXICO

NE GULF OF MEXICO

NE GULF OF MEXICO

NE GULF OF MEXICO

NE GULF OF MEXICO

MISSISSIPPI SOUND

NE GULF OF MEXICO

NE GULF OF MEXICO

Lat. Long.

$2810 \mathrm{~N} 09635 \mathrm{~W}$ $2806 \mathrm{~N} 09407 \mathrm{~W}$ $2852 \mathrm{~N} 094 \quad 42 \mathrm{~W}$ $2853 \mathrm{~N} 09245 \mathrm{~W}$ $2820 \mathrm{~N} 095 \mathrm{0} 4 \mathrm{H}$ $2746 \mathrm{~N} 09447 \mathrm{~W}$ $2820 \mathrm{~N} 09519 \mathrm{~W}$ $2755 \mathrm{~N} 096 \quad 20 \mathrm{~W}$ $2759 \mathrm{~N} 09606 \mathrm{~W}$ $2718 \mathrm{~N} 09614 \mathrm{~W}$ $2800 \mathrm{~N} 09640 \mathrm{~W}$ $2622 \mathrm{~N} 09640 \mathrm{~W}$ $2730 \mathrm{~N} 09642 \mathrm{~W}$ $2710 \mathrm{~N} 096 \quad 22 \mathrm{~W}$ $2434 \mathrm{~N} 08250 \mathrm{~W}$ $2647 \mathrm{~N} 095$ 56W $2848 \mathrm{~N} 08925 \mathrm{~W}$ $\begin{array}{llll}2 \varepsilon & 25 \mathrm{~N} 088 \quad 20 \mathrm{~W}\end{array}$ $2858 \mathrm{~N} 08847 \mathrm{~W}$ $2729 \mathrm{~N} 093 \quad 55 \mathrm{~W}$ $2742 \mathrm{~N} 09426 \mathrm{H}$ 27) $05 \mathrm{~N} 092 \mathrm{~N}$ $2818 \mathrm{~N} 089 \quad 20 \mathrm{~W}$ $2732 \mathrm{~N} 093 \mathrm{OSW}$ $2802 \mathrm{~N} 08520 \mathrm{~W}$ $2530 \mathrm{~N} 08459 \mathrm{~W}$ $2710 \mathrm{~N} 096 \quad 22 \mathrm{~W}$ $2915 \mathrm{~N} 08755 \mathrm{~W}$ $2850 \mathrm{~N} 08736 \mathrm{~W}$ $2744 \mathrm{~N} 08916 \mathrm{~W}$ $2802 \mathrm{~N} 08919 \mathrm{~W}$ $2900 \mathrm{~N} 08654 \mathrm{~W}$ $2822 \mathrm{~N} 08614 \mathrm{~W}$ 


\section{Catalog 2}

\section{Synonymized Species with Publication and Location}

\section{Publication}

10001 PFLUM FRERICHS 1976 10002 PFLUM FRFRICHS 1976 10003 PFLUM FRERICHS 1976 10004 PFLUM FRERICHS 1976 10005 PFLUM FRERICHS 1976 10006 PFLUM FRERICHS 1976 10007 PFLUM FRERICHS 1976 10008 PFLUM FRERICHS 1976 10009 PFLUM FRERICHS 1976 10010 PFLUM FRERICHS 1976 10011 PFLUM FRERICHS 1976 10012 PFLUM FRERICHS 1976 10013 PFLUM FRERICHS 1976 10014 PFLUM FRERICHS 1976 10015 PFLUM FRERICHS 1976 10016 PFLUM FRERICHS 1976 10017 PFLUM FRERICHS 1976 10018 PFLUM FREPICHS 1976 10019 PFLUM FDEPICHS 1976 10020 PFLUM FRERICHS 1976 10021 PFLUM FRERICHS 1976 10022 PFLUM FRERICHS 1976 10023 PFLUM FRERICHS 1976 10024 PFLUM FRERICHS 1976 10025 PFLUM FRERICHS 1976 10026 PFLUM FRERICHS 1976 10027 PARKER 1754 10028 PAPKER 1954 10029 PFLUM FRERICHS 1976 10030 PFLUM FRERICHS 1976 10031 PARKER 1954 10032 PARKER 1954 10033 PARKER 1754 10034 PARKER 1054 10035 PARKER 1954 10036 PARKER 1954 0037 PARKER 1954

10039 PFLUPA FRERICHS 1976

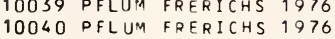
10041 PFLUM FRERICHS 1976 10042 PFLUM FRERICHS 1976 10043 PFLUM FRERICHS 1976 10044 PFLUM FRERICHS 1976 10045 PFLUM FRERICHS 1976 10046 PFLUM FRFRICHS 1976 10047 PFLUM FRERICHS 1976 10048 PFLUM FRERICHS 1976 10049 PFLUM FRERICHS 1976 10050 PFLUM FRERICHS 1976 10051 PFLUM FDERICHS 1976 10052 PFLUM FRERICHS 1976 10053 PFLUM FRERICHS 1976 10054 PFLUM FRERICHS 1976 10055 PFLUM FRERICHS 1976 10056 PFLUM FRERICHS 1976 10057 PFLUM FRERICHS 1976 10058 PFLUM FRERICHS 1976 10059 PFLUM FDERICHS 1976 10060 PFLUM FRERICHS 1976 10061 PFLUM FRERICHS 1976 10062 PFLUM FRERICHS 1976 10063 PFLUM FRERICHS 1976 10064 PFLUM FRERICHS 1976 10065 PFLUM FRERICHS 1976 10066 PFLUM FRERICHS 1976 10067 PFLUIM FRERICHS 1976 10068 PFLUM FRERICHS 1976 10069 PARKER $195 \%$ 10070 PARKER 1954 10071 PARKER 1954 10073 PARKER 1954 10073 PARKER 1954
10074 DARKER 1954 10074
10075 PARKER
1754
10076 PARKER 1754 10076 PARKER 1954 10077 PARKER 1954 10078 PARKER 1354

10079 PFLUM FRERICHS 1976 10080 PFLUM FRERICHS 1976 10081 PFLUM FRERICHS 1976 10081 PFLIJM FRERICHS 1976
10082 PFLUM FRERICHS 1976

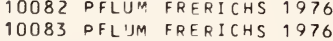
10084 PFLU A FRERICHS 1976 10085 DFLUM FREFICHS 1976
Generic Name

Specific Name

A DERCOTRYMA

ADERCOTRYMA

ADERCOTRYMA

ADERCOTRYMA

ADERCOTRYMA

ADERCOTRYMA

ADERCOTRYMA

A DERCOTRYMA

ADERCOTRYMA

A DERCOTRYMA

ADERCOTRYMA

ADERCOTRYMA

ADERCOTRYMA

ADERCOTRYMA

ADERCOTRYMA

A DERCOTRYMA

ADERCOTRYMA

ADERCOTRYMA

ADERCOTRYMA

ADERCOTRYMA

A DERCOTRYMA

ADERCOTRYMA

A DERCOTRYMA

A DERCOTRYMA

A DERCOTRYMA

ADERCOTRYMA

A DERCOTRYMA

ADERCOTRYMA

ADERCOTRYMA

ADERCOTRYMA

ADERCOTRYMA

A DERCOTRYMA

ADERCOTRYMA

ADERCOTRYMA

ADERCOTRYMA

ADERCOTRYMA

ADERCOTRYMA

A DERCOTRYMA

ADERCOTRYMA

ADERCOTRYMA

A DERCOTRYMA

A DERCOTRYMA

ADERCOTRYMA

ADERCOTRYMA

ADERCOTRYMA

A DERCOTRYMA

A DERCOTRYMA

ADERCOTRYMA

A DERCOTRYMA

A DERCOTRYMA

ADERCOTRYMA

ADERCOTRYMA

A DERCOTRYMA

ADER COTRYMA

ADERCOTRYMA

A DERCOTRYMA

ADERCOTRYMA

A DER COTRYMA

ADERCOTRYMA

A DERCOTRYMA

A DERCOTRYMA

A DERCO TRYM

ADERCOTRYMA

ADERCOTRYMA

A DERCOTRYMA

ADERCOTRYMA

A DERC OTR YMA

A DERCOTRYMA

A DERCOTRYMA

A DERCOTRYMA

A DERCOTRYMA

A DER COTRYMA

A DERCOTRYMA

ADERCOTRYMA

AL ABAMIN

ALABAMINA

AL ABA II NA

AL ABAMINA

ALABAMINA
GLOMERATA

GL OMERATA

GL OMERATA

GLOMERATA

GL OMERATA

GL OMERATA

GL OMERATA

GL OMERATA

GL OMERATA

GL OMERATA

GL OMERATA

GL OMERATA

GL CMERATA

GL CMERATA

GL OMERATA

GL OMERATA

GL OMERATA

GLOMERATA

GL OMERATA

GL OMERATA

GL OMERATA

GLOMERATA

GLOMERATA

GL OMERATA

GL OMERATA

GL OMERATA

GLOMERATA

GLOMERATA

GL OMERATA

GL OMERATA

GLOMERATA

GL OMERATA

GL OMERATA

GLOMERATA

GL OMERATA

GL OMERATA

GL CMERATA

GL OMERATA

GL OMERATA

GL OMERATA

GLOMERATA

GL OMERATA

GL CMERATA

GL CMERATA

GL CMERATA

GLOMERATA

GLOMERATA

GL OMERATA

GL OMERATA

GL CMERATA

GL OMERATA

GLOMERATA

GL CMERATA

GL OMERATA

GLOMERATA

GL OMERATA

GLOMERATA

GLOMERATA

GL OMERATA

GL OMERATA

GL CMERATA

GL OMERATA

GLOMERATA

GL CMERATA

GLOMERATA

GLOMERATA

GL CMERATA

GLOMERATA

GL CMERATA

GLOMERATA

GL OMERATA

GL OMERATA

GL OMERATA

GL OMERATA

GLOMERATA

GL OMERATA

GL OMERATA

GL OMERATA

DE CORATA

DE CORATA

DE CORATA

DE CORATA

DE CORATA

DE CORATA

\section{Locality}

CENTRAL GULF OF MEXICO CENTRAL GULF OF MEXICO CENTRAL GULF OF MEXICO CENTRAL GULF OF MEXICO CENTRAL GULF OF MEXICO CENTRAL GULF OF MEXICO CENTRAL GULF DF MEXICO CENTRAL GULF OF MEXICO CENTRAL GULF OF MEXICO CENTRAL GULF OF MEXICO CENTRAL GULF OF MEXICO CENTRAL GULF OF MEXICO CENTRAL GULF OF MEXICO CENTRAL GULF OF MEXICO CENTRAL GULF OF MEXICO CENTRAL GULF OF MEXICO CENTRAL GULF OF MEXICO CENTRAL GULF OF MEXICO CENTRAL GULF OF MEXICO CENTRAL GULF OF MEXICO CENTRAL GULF OF MEXICO CENTRAL GULF OF MEXICO CENTRAL GULF OF MEXICO CENTRAL GULF OF MEXICO CENTRAL GULF OF MEXICO CENTRAL GULF OF MEXICO NE GULF OF MEXICO NE GULF OF MEXICO $\mathrm{Nh}$ GULF OF MEXICO NW GULF OF MEXICO NE GULF OF MEXICO NE GULF OF MEXICO NE GULF OF MEXICO NE GULF OF MEXICO NE GULF OF MEXICO NE GULF OF MEXICO 
Publication

10086 PFLUM FRERICHS 1976 10087 PFLUM FRERICHS 1976 10088 PFLUM FRERICHS 1976 10089 PFLUM FRERICHS 1976 10090 PFLUM FRERICHS 1976 10091 PFLUM FRERICHS 1976 10092 PFLUM FRERICHS 1976 10093 PFLUM FRERICHS 1976 10094 PFLUM FRERICHS 1976 10095 PFLUM FRERICHS 1976 10096 PFLUM FRERICHS 1976 10097 PFLUM FRERICHS 1976 10098 PFLUM FRERICHS 1976 10099 PFLUM FRERICHS 1976 10100 PFLUM FRERICHS 1976 10101 PFLUM FRERICHS 1976 10102 PFLUM FRERICHS 1976 10103 PFLUM FRERICHS 1976 10104 PFLUM FRERICHS 1976 10105 PFLUM FRERICHS 1976 10106 PFLUM FRERICHS 1976 10107 PFLUM FRERICHS 1976 10108 PFLUM FRERICHS 1976 10109 PFLUM FRERICHS 1976 10110 PFLUM FRERICHS 1976 10111 PFLUM FRERICHS 1976 10112 PFLUM FRERICHS 1976 10113 PFLUM FRERICHS 1976 10114 PFLUM FRERICHS 1976 10115 ANDERSEN 1961

10116 ARNOLD 1953

10117 PFLUM FRERICHS 1976

10118 CUSHMAN 1922A

10119 PARKER 1954

10120 PARKER 1954

10121 CREAGER 1958

10122 PARKER 1954

10124 PARKER 1954

10125 PARKER 1954

10126 PARKER 1954

10127 PARKER 1954

10128 PARKER 1954

10129 PARKER 1954

10130 PARKER 1954

10131 CREAGER 1958

10132 CREAGER 1958

10133 PARKER 1954

10134 PARKER 1954

10135 PARKER 1954

10136 PARKER 1954

10138 PARKER 1954

10139 PARKER 1954

10140 PARKER 1954

10141 PARKER 1954

10142 PARKER 1954

10143 PARKER 1954

10144 PARKER 1954

10145 PARKER 1954

10146 PARKER 1954

10147 PARKER 1954

10148 PARKER 1954

10149 PARKER 1954

10150 PARKER 1954

10151 PARKER 1954

10152 PARKER 1954

10153 PARKER 1954

10155 PARKER 1954

10156 PARKER 1954

10157 PARKER 1956

10158 PARKER 1954

10159 PARKER 1954

10160 PARKER 1954

10161 PARKER 1954

10162 PARKER 1954

10163 PARKER 1954

10164 PARKER 1954

10165 PARKER 1954

10166 CREAGER 1959

10167 CREAGER 1958

10168 PARKER 1054

10169 PARKER 1954

10170 PARKER 1954

10171 PARKER 1954

10172 PARKER 1954

10174 PARKER 1354

10175 LUDWICK WALTON 1957

10176 PARKER 1954

10177 PARKER 1954

10178 PARKER 1954

10179 PARKER 1954
Generic Name

AL ABAMINA

ALABAMINA

AL ABAMINA

AL ABAM INA

ALABAMINA

AL ABAMI INA

AL ABAMINA
ALABAMINA

ALABAMINA

ALABAMINA

ALABAMINA

AL ABAMINA

AL ABAMINA

AL ABAMINA

ALABAMINA

ALABAMINA

AL ABAMINA

ALABAMINA

ALABAMINA

ALABAMINA

AL ABAMINA

ALABAMINA

ALABAMINA

AL ABAMINA

ALABAMINA

ALABAMINA

ALFRED OSILVESTRIS

ALLOGROMIA

ALLOMORPHINA

BORELIS

CRIBROSTOMOIDES

CRIBROSTOMOIDES

CRIBROSTOMOIDES

CRIBROSTOMOIDES

CRIBROSTOMOIDES

CRIBROSTOMOIDES

CRIBROSTOMOIDES

CRIBROSTOMOIDES

CRIBROSTOMOIDES

CRIBROSTOMOIDES

CRIBROSTOMOIDES

CRIBROSTOMOIDES

CRIBROSTOMOIDES

CRIBROSTOMOIDES

CRIBROSTOMOIDES

CRIBROSTOMOIDES

CRIBROST OMOIDES

CRIBROSTOMOIDES

CRIBROST OMOIDES

CRIBROSTOMOIDES

CRIBROSTOMOIDES

CRIBROSTOMOIDES

CR IBROST OMO IDES

HAPLOPHRAGMOI DES

HAPLOPHRAGMOI DE

HAPLOPHRAGMOIDES

HAPLOPHRAGMOI DES

HAPLOPHRAGMOIDES

HAPLOPHRAGMOIDES

HAPLOPHRAGMOIDES

HAPLOPHRAGMOIDES

HAPLOPHRAGMOIDES

HAPLOPHRAGMOIDES

HAPLOPHRAGMOIDES

HAPLOPHRAGMOIDES

HAPLOPHRAGMOIDES

HAPL OPHRAGMOIDES

HAPL OPHRAGMOI DES

HAPLOPHRAGMOIDES

HAPLOPHRAGMOIDES

CR IBROS TOMO IDES

CR IBROSTOMO IDES

CR IBROSTOMO IDES

CRIBROSTOMOIDES

CR IBROSTOMOIDES

CRIBROSTOMOIDES

CR IBROSTOMOIDES

CRIBROSTOMO IDES

CRIBROSTOMOIDES

CRIBROSTOMO IDES

CRIBROST OMOIDES

CR IBROS TOMO IDES

CRIBROSTOMO IDES

CRIBROSTOMOIDES

CRIBROSTOMOIDES

CRIBROSTOMOIDES

CR IBROSTOMOIDES

CRIBROSTOMOIDES

CRIBROSTOMOIDES

CR IBROS TOMO IDES

CRIBROSTOMOIDES

CRIBROSTOMOIDES
Specific Name

DE CORATA

DE CORATA

DE CORATA

DE CORATA

DE CORATA

DE CORATA

DE CORATA

DE CORATA

DE CORATA

E CORATA

DE CORATA

DE CORATA

DE CORATA

DE CORATA

DE CORATA

DE CORATA

DE CORATA

DE CORATA

DE CORATA

DE CORATA

DE CORATA

DE CORATA

DE CORATA

DE CORATA

DE CORATA

DE CORATA

DE CORATA

LEVINSONI

I I COLLARIS

RIGONA

PULCHRA

TI DUM

NI TI DUM

NI TI DUM

NI TIDUM

NITIDUM

NI TI DUM

NI TI DUM

NITIDUM

NI TIDUM

NI TI DUM

NI TIDUM

NI TIDUM

NITI DUM

NITIDUM

NI TIDUM

NI TIDUM

NI TIDUM

NI TIDUM

NI T I DUM

NI TI DUM

NI TI DUM

NI TIDUM

NI TIDUM

RI NGENS

RI NGENS

RINGENS

RI NGENS

RINGENS

RI NGENS

SCITULUM

SC I TULUM

SC I TULUM

SCITULUM

SC I TULUM

SCITULUM

SCITULUM

SC ITULUM

SCITULUM

SU EGL OBOSUM

SUBGLOBOSUM

SUEGLOBOSUM

SUEGLOBOSUM

SUEGLOBOSUM

SUEGLOBOSUM

SUEGL OBOS UM

SUEGLOBOSUM

SUEGL OBOSUM

SUEGL OBOSUM

SUBGL OBOSUM

SUEGLOBOSUM

SU BGL OBOSUM

SUEGL OBOSUM

SUEGL OBOSUM

SUBGLOBOSUM

WI ESNER I

WI ESNER I

WI ESNERI

WI ESNER I

I ESNER I

Locality

NW GULF OF MEXICO

$N W$ GULF OF MEXICO

NW GULF OF MEXICO

NW GULF OF MEXICO

NW GULF OF MEXICO

NW GULF OF MEXICO

NW GULF OF MEXICO

$N W$ GULF OF MEXICO

NW GULF OF MEXICO

$N W$ GULF OF MEXICO

$\mathrm{NW}$ GULF OF MEXICO

CENTRAL GULF OF MEXICO

CENTRAL GULF OF MEXICO 


\section{Publication}

10181 PARKER 1954 10182 PARKER 1954

10183 PARKER 1954

10184 PARKER 1954

10185 PARKER 1954

10186 PARKER 1954

10187 PFLUM FRERICHS 1976

10188 PFLUM FRERICHS 1976

10189 PFLUM FRERICHS 1976

10190 PHLEGER 1965A

10191 WANTLAND 1969

10192 PHLEGER 1965 A

10193 PHLEGER 1954

10194 PHLEGER LANKFOP D 1978

10195 OTVOS 1978

10196 WALTON 1960

10197 ?HLEGER $1955 \mathrm{~B}$

10198 POAG 1976

10199 KANE 1967

10200 KANE 1962

10201 LEHMANN 1957

10202 SHEPARD MOORE 1955

10203 PARKER PHLEGER PEIRSON 1953

10204 PARKER PHLEGER PEIRSON 1953

10205 PARKER PHLEGER PEIRSON 1953

10206 LANKFORD 1959

10207 PHLEGER $1965 \mathrm{C}$

10208 PHLEGER 1954

10209 PHLEGER 1954

10210 KANE 1967

10211 WARREN 1957

10212 WARREN 1956

10213 WALDRON 1963

10214 PFLUM FRERICHS 1976

10215 PFLUM FRERICHS 1976

10216 PFLUM FRERICHS 1976

10217 PFLUM FRERICHS 1976

10218 PFLUM FRERICHS 1976

10219 PFLUM FRERICHS 1976

10220 PFLUM FRERICHS 1976

10221 PFLUM FRERICHS 1976

10222 PFLUM FRERICHS 1976

10223 PFLUM FRERICHS 1976

10224 PFLUM FRERICHS 1976

10225 PFLUM FRERICHS 1976

10226 PFLUM FRERICHS 1976

10227 PFLUM FRERICHS 1976

10228 CUSHMAN 1920

10229 CUSHMAN 1920

10230 CUSHMAN 1920

10231 PFLUM FRERICHS 1976

10232 PFLUM FRERICHS 1976

10233 PFLUM FRERICHS 1976

10234 PFLUM FRERICHS 1976

10235 PFLUM FRERICHS 1976

10236 PFLUM FRERICHS 1976

10237 PFLUM FRERICHS 1976

10238 PFLUM FRERICHS 1976

10239 PFLUM FRERICHS 1976

10240 PFLUM FRERICHS 1976

10241 PFLUM FRERICHS 1976

10242 PFLUM FRERICHS 1976

10243 PFLUM FRERICHS 1976

10245 PFLUM FRERICHS 1976

10246 PFLUM FRERICHS 1976

10247 PFLUM FRERICHS 1976

10248 PFLUM FRERICHS 1976

10249 PFLUM FRERICHS 1976

10250 PFLUM FRERICHS 1976

10251 PFLUM FRERICHS 1976

10252 PFLUM FRERICHS 1976

10253 PFLUM FRERICHS 1976

10254 LEHMANN 1957

10255 WARREN 1957

10256 WANTLAND 1969

10257 WALDRON 1963

10258 PFLUM FRERICHS 1976

10259 WALTON 1964

10260 WALTON 1960

10261 PHLEGER LANKFORD 1957

10262 PHLEGER $1965 \mathrm{C}$

10263 WARREN 1956

10264 AYALA-CASTANARES SEGURA 1968

10265 PARKER PHLEGER PEIRSON 1953

10266 PARKER PHLEGER PEIRSON 1953

10267 PHLEGER 1954
10268 LEHMANN 1957

10268 LEHMANN 1957
10269 PHLEGER $1955 \mathrm{~B}$

10270 POST 1951

10271 PARKER PHLEGER PEIRSON 1953 10272 POST 1951

10273 PARKER PHLEGER PEIRSON 1953

10274 PARKER PHLEGER PEIRSON 1953

10275 PARKER PHLEGER PEIRSON 1953
Generic Name

CRIBROSTOMOIDES

CRIBROSTOMOIDES

CRIBROSTOMOIDES

CRIBROSTOMOIDES

CR IBROS TOMO IDES

CRIBROSTOMOIDES

AL VEOVALVUL INELL A

ALVEOVALVULINELL A

A LVE OVALVUL INELL A

AMMOASTUTA

AMMOASTUTA

AMMOASTUTA

AMMOASTUTA

AMMOASTUTA

AMMOASTUTA

AMMOASTUTA

AMMOASTUTA

AMMOASTUTA

AMMOASTUTA

AMMOASTUTA

AMMOASTUTA

AMMOASTUTA

AMMOASTUTA

AMMOASTUTA

AMMOASTUTA

AMMOASTUTA

AMMOASTUTA

AMMOASTUTA

AMMOAS

AMMOASTUTA

AMMOBACULITES

AMMOBACULITE

AMMOBACULITES

AMMOBACULITES

AMMOBACULITES

AMMOBACULITES

AMMOBACULITES

AMMOBACULITES

AMMOBACULITES

AMMOBACULITES

AMMOBACULITES

AMMOBACULITES

AMMOBACULITES

AMMOBACULITES

AMMOBACULITES

AMMOBACULITE

AMMOBACULITES

AMMOBACULITES

AMMOBACULITES

AMMOBACULITES

AMMOBACULITES

AMMOBACULITES

AMMOBACULITES

AMMOBACULITES

AMMOBACULITES

AMMOBACULITES

A MMOBACULITES

AMMOBACULITES

AMMOBACULITES

AMMOBACULITES

AMMOBACULITES

AMMOBACULITES

AMMOBACULITES

AMMOBACULITES

AMMOBACULITES

AMMOBACULITES

AMMOBACULITES

AMMOBACULITES

AMMOBACULITES

AMMOBACULITES

AMMOBACULITES

AMMOBACULITES

AMMOBACULITES

AMMOBACULITES

AMMOBACULITES

AMMOBACULITES

AMMOBACULITES

AMMOBACULITES

AMMOBACULITES

AMMOBACULITES

AMMOBACULITES

AMMOBACULITES

AMMOBACULITES

AMMOBACULITES

AMMOBACULITES

A MMOBACULITES

AMMOBACULITES

AMMOBACULITES

AMMOBACULITES

AMMOBACULITES

AMMOBACULITES

AMMOBACULITES
Specific Name

WI ESNER I

I IESNER I

I ESNER I

WI ESNERI

I IESNER I

POZONENSIS

POZONENSIS

INEPT A

INEPTA

INEPTA

INEPTA

IN EP TA

I NEPT A

IN EPT A

INEPTA

I NEPTA

I NEPT A

I NEPTA

I NEP TA

IN EP TA

INEPTA

INEPT A

INEPT A

I NEPTA

I N EPT A

I NEPT A

I NEPTA

SALSA

SALSA

SALSA

A GGLUTINANS

AGGLUT INANS

A G GLUT I NANS

AG GLUTI INANS

AGGLUTINANS

A GGLUTINANS

AG GLUTINANS

A GGLUTINANS

AGGLUTINANS

AG GLUTINANS

AGGLUTINANS

A GGLUTINANS

AGGLUIINANS

A GGLUTINANS

A G GLUTINANS

AG GLUTINANS

A G GLUTI NANS

A GGLUT INANS

AGGLUTINANS

AGGLUTINANS

A GGLUTINANS

A GGLUTINANS

AGGLUTINANS

AG GLUTINANS

AGGLUTINANS

AGGLUTINANS

AGGLUTINANS

AM ER I C ANU S

AMERI CANUS

AMERI CANUS

AMERI CANUS

AMERI CANUS

AMERI CANUS

AMERI CANUS

AMERI CANUS

AMERI CANUS

AMER I CANUS

AMERICANUS

AMERI CANUS

AMERICANUS

ARENARIUS

CRASSUS

CRASSUS

CRAS SUS

CYLINDROIDES

EXIGUUS

EXIGUUS

EXIGUUS

EXIGUUS

EXIGUUS

EXIGUUS

EXIGUUS

EXIGUUS

EXIGUUS

EXIGUUS

EXIGUUS

EXIGUUS

EXIGUUS

EXIGUUS

EXIGUUS

EXIGUUS

EXIGUUS

Locality

NE GULF OF MEXICO

NE GULF OF MEXICO

NE GULF OF MEXICO

NE GULF OF MEXICO

NE GULF OF MEXICO

NE GULF OF MEXICO

CENTRAL GULF OF MEXICO

CENTRAL GULF OF MEXICO 


\section{Publication}

10276 PARKER PHLEGER PEIRSON 1953 10277 PARKER PHLEGER PEIRSON 1953 10278 PHLEGER 1956

10279 PHLEGER 1956

10280 PHLEGER 1956

10281 PHLEGER 1956

10282 WARREN 1957

10283 PHLEGER 1954

10284 PHLEGER 1954

10285 PHLEGER 1954

10286 PHLEGER 1954

10287 WALTON 1960

10288 PHLEGER 1954

10289 PHLEGER 1954

10290 PHLEGER 1954

10291 WALTON 1960

10292 OTVOS 1978

10293 WALTON 1964

10294 BENDA PURI 1962

10295 PHLEGER 1965 A

10296 PHLEGER 1965 B

10297 PHLEGER 19658

10298 BENDA PURI 1962

10299 BANDY 1956

10300 BANDY 1956

10301 BANDY 1956

10302 BANDY 1956

10303 BANDY 1956

10304 BANDY 1956

10305 BANDY 1956

10306 PHLEGER 1956

10307 PHLEGER 1956

10308 PHLEGER 1956

10309 PHLEGER 1956

10310 PHLEGER 1956

10311 PARKER PHLEGER PEIRSON 1953

10312 PARKER PHLEGER PEIRSON 1953

10313 PARKER PHLEGER PEIRSON 1953

10314 BOCK 1976

10315 SEGURA 1363

10316 PHLEGER 19558

10317 LANKFORD 1959

10318 PHLEGER 1954

10319 PHLEGER $1965 \mathrm{C}$

10320 PHLEGER 1954

10321 PHLEGER 1954

10322 PHLEGER 1954

10323 OTVOS 1978

10324 WALTON 1960

10325 PHLEGER 1954

10326 PHLEGER 1954

10327 PHLEGER 1954

10328 WANTLAND 1969

10329 BANDY 1956

10330 PFLUM FRERICHS 1976

10331 PFLUM FRERICHS 1976

10332 PFLUM FRERICHS 1976

10333 PFLUM FRERICHS 1976

10334 PFLUM FRERICHS 1976

10335 PFLUM FRERICHS 1976

10336 KORNFELD 1931

10337 KORNFELD 1931

10338 KORNFELD 1931

10339 KORNFELD 1931

10340 KORNFELD 1931

10341 KORNFELO 1931

10342 PHLEGER $1951 \mathrm{~A}$

10343 CUSHMAN 1920

10344 PHLEGER 1951 A

10345 PHLEGER 1951A

10346 PHLEGER 1951A

10347 PHLEGER $1951 \mathrm{~A}$

10348 PHLEGER $1951 \mathrm{~A}$

10349 PHLEGER 1951A

10350 PHLEGER 1951A

10351 PHLEGER 1951A

10352 PHLEGER 1951A

10353 PHLEGER 1951A

10354 PHLEGER $1951 \mathrm{~A}$

10355 PHLEGER 1951 A

10356 PHLEGER 1951A

10357 PHLEGER 1951A

10358 PHLEGER 1951A

10359 PHLEGER 1951 A

10360 PHLEGER 1951A

10361 PHLEGER 1951A

10362 PHLEGER 1951A

10363 PHLEGER 1951A

10364 PHLEGER 1951A

10365 PHLEGER $1951 \mathrm{~A}$

10366 NORTON 1930

10367 CUSHMAN 1922A

10368 ANDERSON 1968

10369 BANDY 1956

10370 BANDY 1956
Generic Name

AMMOBACULITES

AMMOBACULITES

AMMOBACULITES

AMMOBACULITES

AMMOBACULITES

AMMOBACULITES

AMMOBACULITES

AMMOBACULITES

AMMOBACULITES

AMMOBACULITES

AMMOBACULITES

AMMOBACULITES

AMMOBACULITES

AMMOBACULITES

AMMOBACULITES

AMMOBACULITES

AMMOBACULITES

AMMOBACULITES

AMMOBACULITES

AMMOBACULITES

AMMOBACULITES

AMMOBACULITES

AMMOBACULITES

AMMOBACULITES

AMMOBACULITES

AMMOBACULITES

AMMOBACULITES

AMMOBACULITES

AMMOBACULITES

AMMOBACULITES

AMMOBACULITES

AMMOBACULITES

AMMOBACULITES

AMMOBACULITES

AMMOBACULITES

AMMOBACULITES

AMMOBACULITES

AMMOBACULITES

AMMOBACULITES

AMMOBACULITES

AMMOBACULITES

AMMOBACULITES

AMMOBACULITES

AMMOBACULITES

AMMOBACULITES

AMMOBACULITES

AMMOBACULITES

AMMOBACULITES

AMMOBACULITES

AMMOBACULITES

AMMOBACULITES

AMMOBACULITES

AMMOBACULITES

AMMOBACULITES

AMMOBACULITES

AMMOBACULITES

AMMOBACULITES

AMMOBACULITES

AMMOBACULITES

AMMOBACULITES

AMMOMARG INUL INA

AMMOMARG INUL I NA

AMMOMARG INUL I NA

AMMOMAR G INUL INA

AMMOMAR G INUL I NA

AMMOMAR GINUL INA

AMMOMARG INUL INA

AMMOMAR G INUL INA

AMMOMARG INUL INA

AMMOMARG INUL INA

AMMOM AR GI NUL INA

AMMOMARG INUL INA

AMMOMARG INUL INA

AMMOMAR G INUL I NA

AMMOMAR G INUL I NA

AMMOMARG INUL I NA

AMMOMAR G INUL INA

AMMOMARG INUL INA

AMMOMARG INUL I NA

AM MO MARG INUL INA

AMMOMAR GINUL INA

AMMOMARG INUL INA

AMMOMARGINUL INA

AMMOMARG INUL INA

AMMOMAR GINUL INA

AMMOMARG INUL INA

AMMOMAR G INUL INA

AMMOMARG INUL INA

AMMOMAR GINUL INA

AMMOMARG INUL INA

AMMOBACULITES

AMMOBACULITES

AMMOTI UM

AMMOT IUM

AMMO IUM
Specific Name

EXIGUUS

EXIGUUS

EXIGUUS

EXIGUUS

EXIGUUS

EXIGUUS

EXIGUUS

EXIGUUS

EXIGUUS

EXIGUUS

DI VERSUS

EXIGUUS

EXIGUUS

EXIGUUS

EXIGUUS

EXIGUUS

EXIGUUS

EXIGUUS

EXIGUUS

EXIGUUS

EXIGUUS

EXIGUUS

EXIGUUS

EXIGUUS

EXIGUUS

EXIGUUS

EXIGUUS

EXIGUUS

EXIGUUS

EXIGUUS

EXIGUUS

EXIGUUS

EXIGUUS

EXIGUUS

EXIGUUS

EXIGUUS

EXIGUUS

EXIGUUS

EXIGUUS

EXIGUUS

EXIGUUS

EXIGUUS

EXIGUUS

EXIGUUS

EXIGUUS

EXIGUUS

EXIGUUS

EXIGUUS

EXIGUUS

EXIGUUS

EXIGUUS

FILIFORMIS

F I LIFORMI

FILIFORMIS

FI LIFORMIS

FILIFORMIS

F I LI F ORMI S

FOLIACEA

FOLIACEA

FOLIACEA

FOLIACEA

FOLIACEA

FOLIACEA

FOLIACEA

FOLIACEA

FOLIACEA

FOLIACEA

FOLIACEA

FOLIACEA

FOLIACEA

FOLIACEA

FOLIACEA

FOLIACEA

FOLIACEA

FOLIACEA

FOLIACEA

FOLIACEA

FOLIACEA

FOLIACEA

FOLIACEA

FOLIACEA

FOLIACEA

FOLIACEA

FOLIACEA

FOLIACEA

RE OPHACIF ORMIS

RE OPHAC IF ORMIS

SALSUM

SALSUM

Locality

TEXAS GULF COAST

TEXAS GULF COAST

NW GULF OF MEXICO

NW GULF OF MEXICO

NW GULF OF MEXICO 


\section{Publication}

10371 PHLEGER LANKFORD 1957 10372 PHLEGER 19558

10373 WALTON 196

10374 BANDY 1956

10375 BANDY 1956

10376 BANDY 1956

10377 PHLEGER 19658

10378 PHLEGER 19658

10379 WALTON 1964

10380 LAMB 1972

10381 PHLEGER 1956

10382 PARKER PHLEGER PEIRSON 1953 10383 PARKER PHLEGER PEIRSON 1953 10384 PARKER PHLEGER PEIRSON 1953 10385 PARKER PHLEGER PEIR SON 1953 10387 PARKER PHLEGER PEIRSON 1953 10388 PARKER PHLEGER PEIRSON 1953 10389 PARKER PHLEGER PEIR SON 1953 $\begin{array}{lll}10389 & \text { PARKER PHLEGER PEIR SON } & 1953 \\ 10390 & \text { PARKER PHLEGER PEIRSON } & 1953\end{array}$ 10391 LEHMANN 1957

10392 SHEPARD MOORE 1955

10393 PHLEGER 1954

10394 PHLEGER 1954

10395 PHLEGER 1954

10396 PHLEGER 1954

10397 PHLEGER 1954

10398 PHLEGER 1954

10399 POST 1951

10400 WALDRON 1963

10401 WARREN 1957

10402 CUSHMAN 1920

10403 PFLUM FRERICHS 1976

10404 LEROY HODGKINSON 1975

10405 PFLUM FRERICHS 1976

10406 PFLUM FRERICHS 1976

10407 PFLUM FRERICHS 1976

10408 PFLUM FRERICHS 1976

10409 PFLUM FRERICHS 1976

10410 PFLUM FRERICHS 1976

10411 PFLUM FRERICHS 1976

10412 PFLUM FRERICHS 1976

10413 PFLUM FRERICHS 1976

10414 PFLUM FRERICHS 1976

10415 PFLUM FRERICHS 1976

10416 PFLUM FRERICHS 1976

10417 CUSHMAN 1998

10418 CUSHMAN 1918

10419 PFLUM FRERICHS 1976

10420 PFLUM FRERICHS 1976

10421 PFLUM FRERICHS 1976

10422 PFLUM FRERICHS 1976

10423 PFLUM FRERICHS 1976

10424 PFLUM FRERICHS 1976

10425 PFLUM FRERICHS 1976

10426 PFLUM FRERICHS 1976

10427 PFLUM FRERICHS 1976

10428 PFLUM FRERICHS 1976

10429 PFLUM FRERICHS 1976

10430 PFLUM FRERICHS 1976

10431 PFLUM FRERICHS 1976

10432 PFLUM FRERICHS 1976

10433 PFLUM FRERICHS 1976

10434 PFLUM FRERICHS 1976

10435 PFLUM FRERICHS 1976

10436 CUSHMAN 1918

10437 CUSHMAN 1918

10438 CUSHMAN 1918

10439 CUSHMAN 1918

10440 CUSHMAN 1918

10441 PFLUM FRERICHS 1976

10442 BOCK 1976

10443 CUSHMAN 1918

10444 CUSHMAN 1918

10445 PFLUM FRERICHS 1976

10446 PFLUM FRERICHS 1976

10447 PFLUM FRERICHS 1976

10448 PFLUM FRERICHS 1976

10449 PFLUM FRERICHS 1976

10450 PFLUM FRERICHS 1976 10451 PFLUM FRERICHS 1976 10452 PFLUM FRERICHS 1976 10453 PFLUM FRERICHS 1976 10454 PFLUM FRERICHS 1976 10455 PFLUM FRERICHS 1976 10456 PFLUM FRERICHS 1976 10457 PFLUM FRERICHS 1976 10458 PFLUM FRERICHS 1976 10459 PFLUM FRERICHS 1976 10460 PFLUM FRERICHS 1976 10461 PFLUM FRERICHS 1976 10462 PFLUM FRERICHS 1976 10463 PFLUM FRERICHS 1976 10464 PFLUM FRERICHS 1976 10465 PFLUM FRERICHS 1976
Generic Name

AMMOT IUM

AMMOT IUM

AMMOTIUM

AMMO TIUM

AMMOT I UM

A MMOT IUM

A MMOTIUM

AMMO TI UM

AMMOTIUM

AMMO TI UM

A MMOTIUM

A MMO TIUM

AMMOT IUM

AMMOTIUM

AMMOT IUM

AMMOT I UM

AMMOTIUM

AMMOTIUM

AMMOT IUM

AMMOTIUM

AMMOTIUM

A MMOT IUM

AMMOT IUM

AMMOBACULITES

AMMOBACULITES

AMMO SCALAR IA

AMMODISCOIDES

AMMODISCOIDES

AMMODISCOIDES

AMMODISCOIDES

AMMODISCOIDES

AMMODISCOIDES

AMMODISCOIDES

AMMODISCOIDES

AMMODISCOIDES

AMMODISCOIDES

AMMODISCOIDES

AMMODISCOIDES

AMMODISCOIDES

AMMODISCOIDES

AMMODISCOIDES

AMMODISCOIDES

AMMODISCOIDES

AMMOD ISCOIDES

AMMODISCOIDES

AMMODISCOIDES

AMMODISCOIDES

AMMODISCOIDES

AMMODISCOIDES

AMMODISCOIDES

AMMODISCOIDES

AMMODISCOIDES

AMMODISCOIDES

AMMODISCOIDES

AMMODISCOIDES

AMMODISCOIDES

AMMODISCOIDES

AMMODISCOIDES

AMMODISCOIDES

AMMODISCOIDES

AMMODISCOIDE

AMMODI SCOIDES

AMMODISCOIDE

AMMODISCOIDES

AMMODISCOIDES

AMMODI SCUS

AMMODISCUS

AMMODISC US

AMMODISC US

AMMODISCUS

AMMODISCUS

AMMODISCUS

AMMOD ISC US

AMMOD ISCUS

AMMODI SCUS

AMMODISCUS

AMMODISCUS

AMMODI SCUS

AMMODISCUS

AMMODISCUS

AMMODIS CUS

AMMOD ISCUS

AMMOD I SCUS

AMMODISCUS

AMMODISCUS

AMMODISCUS

AMMODISCUS

AMMODISCUS
Specific Name

SALSUM

SALSUM

SALSUM

ALSUM

SALSUM

SALSUM

SALSUM

SALSUM

SALSUM

SALSUM

SALSUM

SALSUM

SALSUM

SALSUM

SALSUM

SALS UM

SALSUM

SALSUM

SALSUM

SALSUM

SALSUM

SALSUM

SALSUM

SALSUM

EXIGUUS

EXIGUUS

TE NU I MARGO

TURBINATUS

TURBINATUS

TURBINATUS

TURBINATUS

TURBINATUS

TURBINATUS

TURBINATUS

TURBINATUS

TURBINATUS

TURBINATUS

TURBINATUS

TURBINATUS

TURBINATUS

TURBINATUS

TURBINATUS

TURBINATUS

TURB INATUS

TURBINATUS

TURBINATUS

TURBINATUS

TURBINATUS

TURBINATUS

TURBINATUS

TURBINATUS

TURB INATUS

TURB INATUS

TURBINATUS

TURBINATUS

TURBINATUS

TURBINATUS

URB INATUS

TURBINATUS

TURBINATUS

TURBINATUS

TURBINATUS

TURB INATUS

TURBINATUS

AN GUILLAE

I N CERTUS

IN CERTUS

PL ANORBIS

PLANORB IS

PLANORB IS

PL ANORBIS

PL ANORBIS

PLANORBIS

PL ANORBIS

PLANORBIS

PLANORBIS

PLANORBIS

PLANORBIS

PL ANORB IS

PLANORBIS

PL ANORBIS

PL ANORB IS

PLANORBIS

PLANORBIS

PLANORBIS

PLANORBIS

PL ANORBIS

PLANORBIS

Locality

Lat. Long.

TEXAS GULF COAST

MISSISSIPPI SOUND

PEACE R.. FLA.

MYAKKA R.. FLA.

CHARLOTTE HARBOUR, FLA.

TEN THOUSAND IS., SW FLA. WHITEWATER B.. SW FLA. TAMPA- SARASOTA BAY, FLA.

MOBILE BAY, AL.

CENTRAL TEXAS BAYS

TEXAS GULF COAST 


\section{Publication}

10466 PFLUM FRERICHS 1976 10467 PFLUM FRERICHS 1976 10468 PFLUM FRERICHS 1976 10469 PFLUM FRERICHS 1976 10470 PFLUM SRERICHS 1976 10471 PFLUM FRERICHS 1976 10472 PFLUM FRERICHS 1976 10473 PFLUM FRERICHS 1976 10474 PFLUM FRERICHS 1976 10475 PFLUM FRERICHS 1976 10476 PFLUM FRERICHS 1976 10477 PFLUM FRERICHS 1976 10478 PFLUM FRERICHS 1976 10479 PFLUM FRERICHS 1976 10480 DFLUM FRERICHS 1976 10481 PFLUM FRERICHS 1976 10482 PFLUM FRERICHS 1976 10483 PFLUM FRERICHS 1976 10484 PFLUM FRERICHS 1976
10485 LEROY HODGKINSON 1975 10486 PFLUM FRERICHS 1976 10487 PFLUM FRERICHS 1976 10488 PFLUM FRERICHS 1976 10489 PFLUM FRERICHS 1976 10490 PFLUM FRERICHS 1976 10491 PFLUM FRERICHS 1976 10492 PFLUM FRERICHS 1976 10493 PFLUM FRERICHS 1976 10494 PFLUM FRERICHS 1976 10495 PFLUM FRERICHS 1976 10496 PFLUY FRERICHS 1976 10497 PFLUM FRERICHS 1976 10498 LEROY HODGKINSON 1975 10499 PFLUM FRERICHS 1976 10500 PFLUM FRERICHS 1976 10501 PFLUM FRERICHS 1976 10502 PFLUM FRERICHS 1976 10503 PFLUM FRERICHS 1976 10504 PFLUM FRERICHS 1976 10505 PFLUM FRERICHS 1976 10506 FRERICHS 1969

10507 PFLUM FRERICHS 1976 10508 PFLUM FRERICHS 1976 10509 PFLUM FRERICHS 1976 10510 PFLUM FRERICHS 1976 10511 PFLUM FRERICHS 1976 10512 PFLUM FRERICHS 1976 10513 PFLUM FRERICHS 1976 10514 PFLUM FRERICHS 1976 10515 PFLUM FRERICHS 1976 10516 PFLUM FRERICHS 1976 10517 PFLUM FRERICHS 1976 10518 PFLUM FRERICHS 1976 10519 PFLUM FRERICHS 1976 10520 PFLUM FRERICHS 1976 10521 PFLUM FRERICHS 1976 10522 PFLUM FRERICHS 1976 10523 PFLUM FRERICHS 1976 10524 PFLUM FRERICHS 1976 10525 PFLUM FRERICHS 1976 10526 CUSHMAN 1918

10527 CUSHMAN 1918

10528 PFLUM FRERICHS 1976 10529 PFLUM FRERICHS 1976 10530 PFLUM FRERICHS 1976 10531 PFLUM FRERICHS 1976 10532 DFLUM FRERICHS 1976 10533 PFLUM FRERICHS 1976 10534 PFLUM FRERICHS 1976 10535 PFLUM FRERICHS 1976 10536 PFLUM FRERICHS 1976 10537 PFLUM FRERICHS 1976 10538 LEROY HODGKINSON 1975 10539 PFLUM FRERICHS 1976 10540 PFLUM FRERICHS 1976 10541 PFLUM FRERICHS 1976 10542 PFLUM FRERICHS 1976 10543 PFLUM FRERICHS 1976 10544 PFLUM FRERICHS 1976 10545 PFLUM FRERICHS 1976 10546 PFLUM FRERICHS 1976 10547 PFLUM FRERICHS 1976 10548 PFLUM FRERICHS 1976 10549 DFLUM FRERICHS 1976 10550 PFLUM FRERICHS 1976 10551 CUSHMAN 1918

10552 CUSHMAN 1918

10553 PFLUM FRERICHS 1976 10554 PFLUM FRERICHS 1976 10555 PFLUM FRERICHS 1976 10556 PFLUM FRERICHS 1976 10557 PFLUM FRERICHS 1976 10558 PFLUM FPERICHS 1976 10559 PFLUM FRERICHS 1976 10560 PFLUM FRERICHS 1976
Generic Name

AMMODISCUS

AMMODISCUS

AMMODISCUS

AMMODISCUS

AMMODISCUS

AMMODISCUS

AM MODISCUS

AMMODISC US

AMMODISCUS

AMMODISCUS

A $M$ YOD I SCUS

AMMODISCUS

AMMODISCUS

AMMODISCUS

AM:10DISCUS

AMMODISCUS

AM YOD ISCUS

AMMODISCUS

AMMOD I SC US

AMMODISCUS

AMMODISC US

AMMODISCUS

AMMODISCUS

AMMODISCUS

AMMODISCUS

AMMODIS CUS

A MMODISCUS

AMMODISCUS

AMMODISCUS

AM.MO FL INT INA

AMMOGLOBIGERINOIDES DEHISCENS

AMMOGLOBIGERINOI DES DEHISCENS

AMMOGLOBIGERINOIDES DEHISCENS

AM YOG LOBIGERINOI DES DEHISCENS

AMYOGLOBIGERINOI DES DEHISCENS

AM YOGLOBIGERINOI DES DEHISCENS

AMMOGLOBIGERINOI DES DEHISCEN

AMMOGLOBIGERINOI DES DEHISCENS

AMMOGLOBIGERINOI DES DEHISCENS

AMMOGLOBIGER INOIDES DEHISCENS

AMYOGLOBIGERINOIDES DEKISCENS

AMMOGLOBIGERINOI DES DEHISCENS

AMMOGLOBIGERINOI DES DEHISCENS

AMMOGLOBIGER INOIDES DEHISCENS

AMMOGLOBIGERINOIDES DEHISCENS

AMMOGLOBIGERINOI DES DEHISCENS

AMMOGLOBIGERINOI DES DEHISCENS

AMMOGLOBIGERINOI DES DEHISCENS

AMMOGLOBIGERINOI DES DEHISCENS

AMMOGLOBIGER INOIDES DEHISCENS

AMMOGLOBIGERINOI DES DEHISCEN

AMMOGLOBIGERINOI DES OEHISCENS

AMMOGLOBIGERINOI DES DEHISCENS

AMMOGLOBIGERINOI DES DEKISCENS

AMMOLAGENA

AMMOLAGEN

AMMOLAGENA

AM MO L A GENA

A MMOL A GENA

AMMOL AGENA

AMMOL L GENA

AMMOL AGENA

AMMOL AGENA

A MMOL A GEN

A M MOL L GEN

A M YOL L GENA

AMMOL A GENA

A YMOL $A G E N A$

AMMOL AGENA

A MMOLAGENA

AMMOL A GENA

AMMOLAGENA

AMMOL A GENA

AMMOL AGENA

A MMO LAGENA

AMMOLAGENA

AMMOL A GENA

AMMOL AGENA

A MMOL A GEN

AMMOLAGENA

AMMOL AGENA

AMMOLAGENA

AMMOL L GENA

AMMOL A GEN

A MMOL AGENA

AM YOL A GEN

AMMOLAGENA

AMMOL AGENA

AMMOLAGENA

AMMOLAGENA

AMMOLAGENA
CLAVATA

CLAVATA

CLAVATA

CLAVATA

CLAVATA

CLAVATA

CL AVATA

CLAVATA

CLAVATA

CL AVATA

CLAVATA

CL AVATA

CL AVATA

CLAVATA

CLAVATA

CLAVATA

CL AVATA

CLAVATA

CL AVATA

CLAVATA

CLAVATA

CL AVATA

CL AVATA

CLAVATA

CLAVATA

CL AVATA

CLAVATA

CL AVATA

CLAVATA

CLAVATA

CLAVATA

CLAVATA

\section{Locality}

NW GULF OF MEXICO

NW GULF OF MEXICO

NW GULF OF MEXICO

NW GULF OF MEXICO

NW GULF OF MEXICO

NW GULF OF MEXICO

VW GULF OF MEXICO

NW GULF OF MEXICO

NW GULF OF MEXICO

$N$ GULF OF MEXICO

CENTRAL GULF OF MEXICO

CENTRAL GULF OF MEXICO

NW GULF OF MEXICO

NW GULF OF MEXICO

NW GULF OF MEXICO

CENTRAL GULF OF MEXICO

CENTRAL GULF OF MEXICO

CENTRAL GULF OF MEXICO

CENTRAL GULF OF MEXICO

$N$ GULF OF MEXICO

NW GULF OF MEXICO

NW GULF OF MEXICO

NW GULF OF MEXICO

CENTRAL GULF OF MEXICO

CENTRAL GULF OF MEXICO

CENTRAL GULF OF MEXICO

CENTRAL GULF OF MEXICO

CENTRAL GULF OF MEXICO

CENTRAL GULF OF MEXICO

CENTRAL GULF OF MEXICO

CENTRAL GULF OF MEXICO

$N$ GULF OF MEXICO

NW GULF OF MEXICO

NW GULF OF MEXICO

CENTRAL GULF OF MEXICO

CENTRAL GULF OF MEXICO

CENTRAL GULF OF MEXICO

NW GULF OF MEXICO

CENTRAL GULF OF MEXICO

CENTRAL G. OF MEXICO

CENTRAL GULF OF MEXICO

NW GULF OF MEXICO

$N W$ GULF OF MEXICO

NW GULF OF MEXICO

NW GULF OF MEXICO

NW GULF OF MEXICO

$N$ WULF OF MEXICO

$N$ WULF OF MEXICO

$N W$ GULF OF MEXICO

NW GULF OF MEXICO

NW GULF OF MEXICO

NW GULF OF MEXICO

NW GULF OF MEXICO

NW GULF OF MEXICO

CENTRAL GULF OF MEXICO

CENTRAL GULF OF MEXICO

CENTRAL GULF OF MEXICO

CENTRAL GULF OF MEXICO

CENTRAL GULF OF YEXICO

NE GULF OF MEXICO

CENTRAL GULF OF MEXICO

NW GULF OF MEXICO

NW GULF OF MEXICO

NW GULF OF MEXICO

CENTRAL GULF OF MEXICO

CENTRAL GULF OF MEXICO 


\section{Publication}

10561 PFLUM FRERICHS 1976 10562 PFLUM FRERICHS 1976 10563 PFLUM FRERICHS 1976 10564 PFLUM FRERICHS 1976 10565 PFLUM FRERICHS 1976 10566 PFLUM FRERICHS 1976 10567 PFLUM FRERICHS 1976 10568 PFLUM FRERICHS 1976 10569 PFLIIM FRERICHS 1976 $105 ? 0$ DFLUM FRERICHS 1976 10571 PFLUM FRERICHS 1976 10572 PFLUM FRERICHS 1976 10573 PFLUM FRERICHS 1976

10574 PHLEGER 19658

10575 ANDERSON 1968 10576 PHLEGER 1965 A 10577 PHLEGER $1965 \mathrm{C}$ 10578 PHLEGER 1965 A

1058 P

10581 PFLUM FRERICHS 1976

10582 AYALA-CASTANARES 1963

10583 LAMB 1972

10584 AYALA-CASTANARES SEGURA 1968 10585 PHLEGER 1965 A

10586 PHLEGER 1965 A

10587 PHLEGER 1965 A

10588 PHLEGER 1965 PHEGER 1965 A

10590 PHLEGER 1965A

10591 PHLEGER $1965 \mathrm{~A}$

10592 PHLEGER 1965 A

10593 LIDZ LIDZ 1966

10594 PHLEGER LANKFOR
10595 WANTLAND 1969

10596 SEGURA 1963

10597 LOEP 1965

10598 BOCK 1976

10599 BOCK 1976

10600 POAG 1976

10601 OTVOS 1978

10602 LOEP 1965

10603 OTVOS 1978

10604 OTVOS 1978

10605 LOEP 1965 RICHS 1976

10607 PFLUM FRERICHS 1976

10608 LOEP 1965

10609 BOCK 1976

10610 BOCK 1976

10611 POAG 1978

10612 POAG 1978

10613 AYALA-CASTANARES SEGURA 1968

10614 BOCK 1976

10615 PHLEGER 1954

0616 PHLEGER 195

10617 PHLEGER 195

10618 PHLEGER 1954

10619 PHLEGER 1955A

10620 LANKFORD 1959

10621 BENDA PURI 1962

10622 BENDA PURI 1962

10623 OTVOS 1978

10624 PHLEGER 1955 A

10626 PARKER 1954

10627 PARKER 1954

10627 PARKER 1954

10629 PARKER 1754

10630 PARKER 1954

10631 SHIFFLETT 1961

10632 PARKER PHLEGER PEIRSON 1953

10633 PARKER PHLEGER PEIRSON 1953

10634 BENDA PURI 1962

10635 PHLEGER 1956

10636 PARKER 1954

10637 PARKER PHLEGER PEIRSON 1953 10638 PARKER PHLEGER PEIRSON 1953 10639 PARKER PHLEGER PEIRSON 1953

10640 PARKER PHLEGER PEIRSON 1953 10641 PARKER PHLEGER PEIRSON 1953 10642 PHLEGER 1956

10643 PHLEGER 1956

10644 PARKER 1954

10645 PARKER 1954

10646 PARKER 1954

10647 PARKER 1954

10648 PHLEGER LANKFORD 1957

10649 PARKER 1954

10650 PHLEGER 19558

10651 PHLEGER 1956

10652 PHLEGER 1956

10653 PARKER 1954

10654 PARKER 1954
Generic Name

A MIMOL AGENA

AMMOL AGENA

A MMOL L GENA

AMMOLAGENA

A MMOL L GENA

AMMOLAGENA

AMMOL AGENA

A MMOMAR G INUL INA

AMMOMARG INUL I NA

AMMOMARG INUL INA

A M MO MAR GINUL I NA

AMMOMAR GINUL INA

A MMOMAR G INUL INA

AMMON I A

AMMONIA

AMMONIA

AMMONIA

AMMONI A

A MMONIA

AMMONIA

AMMONIA

A MMON I A

AMMONIA

AMMONIA

AMMONIA

AMMON IA

AMMONIA

AMMONIA

AMMONIA

AMMON IA

AMMONI A

A MMONIA

AMMON I A

AMMONI A

AMMONI A

AMMONIA

A MMONIA

AMMON IA

AMMONIA

AMMONIA

AMMONIA

AMMON I A

AMMONIA

A MMON I A

AMMON IA

AMMON I A

AMMONI A

A MMON I A

AMMONIA

AMMONIA

AMMON I A

AMMONIA

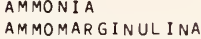

AMMOMARGINUL INA

AMMOMAR G INUL INA

AMMOMAR GINUL INA

AMMOS CAL AR I A

AMMOSCAL AR I A

AMMOSCALAR IA

AMMOSCALARI

AMMOS CALARI A

AMMOSCAL AR I A

AMMOS CAL AR I A

AMMOSCAL AR I A

AMMOSCALARIA

AMMOSCALAR I A

AMMOSC AL AR I

AMMOSCAL AR I A

AMMOSCALAR I A

AMMOS CAL AR IA

AMMOS CAL AR I A

AMMOSCAL AR I A

AMMOS CAL AR I A

AMMOSCALAR I A

AMMOS CALARIA

AMMOS CAL AR IA

AMMOSCALAR I A

AMMOSCAL AR I A

AM MOS CAL AR I A

AMMOS CAL AR I A

AMMOSCALAR I A

AMMOS CAL AR I A

AMMOS CALAR I

AMMOS CALAR I A

A MMO S CAL AR I A

AMMOS CALAR I A

AMMOS CAL AR IA

AMMOSCAL AR I A

AMMOS CALAR I

AMMOSCALAR IA
Specific Name

\section{CLAVATA}

CL AVATA

CL AVATA

CLAVATA

CLAVATA

CL AVATA

FOLIACEA

FOLIACEA

FOLIACEA

FOLIACEA

FOLIACEA

BECCARII

BECCARII

BECCARII

BECCARI

BECCARI

BECCARII

BECCARII

BECCARI I

BECCARII

BECCARII

BECCARI

BECCARII

BECCARI I

BECCARII

BECCARI

BECCARII

BECCARI I

BE CCARI

BECCARI I

BECCARI

BECCARII

BECCARII

BECCARII

BECCARI

BECCARII

BECCARI

BECCARII

BECCARI

BECCARII

BECCARII

BE CCAR I I

BECCARI

BECCARII

BECCARII

BECCARII

BECCARII

BECCARI

ROLSHAUSENI

TRANSLUCENS

FLLVIALIS

FL UVIAL IS

FLLVIALIS

FLUVIALIS

PSEUDOSPIRALIS

PSEUDOSPIRALIS

PSEUDOSPIRALIS

PSEUDOSPIRALIS

PSEUDOSPIRALIS

PSEUDOSPIRALIS

PSEUDOSPIRALIS

PSEUDOSPIRALIS

PSEUDOSPIRALIS

PS EUDOSPI RALIS

PSEUDOSPIRALIS

PSEUDOSPIRALIS

PSEUDOSPI RALIS

PSEUDOSPIRALIS

PSEUDOSPI RALIS

PSEUDOSPIRALIS

PSEUDOSPIRALIS

SEUDOSPIRALIS

PSEUDOSPIRALIS

PSEUDOSPIRALIS

PSEUDOSPIRALI

PSEUDOSPI RALIS

PSEUDOSPIRALIS

PSEUDOSPIRALIS

PSEUDOSPIRALIS

PSEUDOSPIRALIS

PSEUDOSPI RALIS

PSEUDOSPIRALIS

PSEUDOSPIRALIS

PSEUDOSPIRALIS

PSEUDOSPIRALIS

PSEUDOSPIRALIS

PSEUDOSPIRALIS

PSEUDOSPIRALIS

TENUIMARG $O$

TENUIMARGO

IENUIMARGO

\section{Locality}

$\mathrm{NW}$ GULF OF MEXICO

NW GULF OF MEXICO

NW GULF OF MEXICO

NW GULF OF MEXICO

NW GULF OF MEXICO

NW GULF OF MEXICO

$N W$ GULF OF MEXICO

NW GULF OF MEXICO

NH GULF OF MEXICO 


\section{Publication}

10656 PARKER 1954

10657 PARKER 1954

10658 PARKER 1954

10659 PARKER 1954

10660 PARKER 1954

10661 PARKER 1954

10662 PARKER 195

10663 PARKER 1954

10664 CUSHMAN 1920

10665 PFLUM FRERICHS 1976

10666 PHLEGER $1965 \mathrm{~A}$

10667 PHLEGER 1965 A

10668 PHLEGER 1965A

10669 PHLEGER $1965 \mathrm{~A}$

10670 PHLEGER 1965 A

10671 PHLEGER 1965A

10672 WALDRON 1963

10673 PHLEGER 1965 A

10674 WARREN 1957

10675 WALDRON 1963

10676 WARREN 1957

10677 WARREN 1957

10678 WARREN 1957

10679 WARREN 1956

10680 AYALA-CASTANARES 1963

10681 PHLEGER 1965A

10682 WARREN 1956

10683 PHLEGER $1965 \mathrm{C}$

10684 WARREN 1957

10685 LANKFORD 1959

10686 PHLEGER 1960

10687 WALDRON 1963

10688 AYALA-CASTANARES SEGURA 1968

10689 BENDA PURI 1962

10690 PHLEGER 1965 A

10691 BOCK 1976

10692 PHLEGER 1965 A

10693 PHLEGER $1965 \mathrm{~A}$

10694 PHLEGER 1965 A

10695 PHLEGER $1965 \mathrm{~A}$

10696 WANTLAND 1969

10697 BENDA PURI 1962

10698 PHLEGER 1965 A

10699 PHLEGER LANKFORD 1978

10700 OTVOS 1978

10701 BENDA PURI 1962

10702 PHLEGER $1965 \mathrm{~A}$

10703 PHLEGER 1965 A

10704 PHLEGER 1965A

10705 POAG 1976

10706 POAG 1978

10707 POAG 1976

10708 POAG 1978

10709 WARREN 1957

10710 ANDERSEN 1961

10711 PFLUM FRERICHS 1976

10712 PFLUM FRERICHS 1976 10713 PFLUM FRERICHS 1976 10714 PFLUM FRERICHS 1976 10715 PFLUM FRERICHS 1976 10716 PFLUM FRERICHS 1976 10717 PFLUM FRERICHS 1976 10718 PFLUM FRERICHS 1976 10719 PFLUM FRERICHS 1976 10720 PFLUM FRERICHS 1976 10721 PFLUM FRERICHS 1976 10722 PFLUM FRERICHS 1976 10723 PFLUM FRERICHS 1976 10724 ANDERSEN 1961

10725 BOCK 1976

$10726-80 C K \quad 1976$

10727 PFLUM FRERICHS 1976 10728 PFLUM FRERICHS 1976 10729 PFLUM FRERICHS 1976 10730 PFLUM FRERICHS 1976 10731 PFLUM FRERICHS 1976 10732 PFLUM FRERICHS 1976 10733 PFLUM FRERICHS 1976 10736 PFLUM FRERICHS 1976 10735 PFLUM FRERICHS 1976 10736 PFLUM FRERICHS 1976 10737 PFLUM FRERICHS 1976 10738 PFLUM FRERICHS 1976 10739 PFLUM FRERICHS 1976 10740 PFLUM FRERICHS 1976 10741 PFLUM FRERICHS 1976 10742 PFLUM FRERICHS 1976 10743 PFLUM FRERICHS 1976 10744 NORTON 1930

10745 CUSHMAN 1930

10766 CUSHMAN 1930

10747 POAG SWEET 1972

10748 POAG 1972

10749 POAG 1972

\section{Generic Name \\ Specific Name}

AMMOSCALAR I A

AMMOSCALAR IA

AMMOS CALARIA

AMMOS CALAR I A

AMMOSCALARIA

AMMOS CALAR I A

AMMOSCALARIA

AMMOSCALARIA

AMMOSPHAERO IDINA

AMMOSPHAEROIDINA

AMMOBACULITES

AMMOBACULITES

AMMOBACULITES

AMMOBACULITES

AMMOBACULITES

AMMOBACULITES

AMMOBACULITES

AMMOOACULITES

AMMOT IUM

A MMOTIUM

AMMOTIUM

AMMOTIUM

A MMO TI UM

AMMOTIUM

AMMOTIUM

AMMOT IUM

AMMOT IUM

AMMOTIUM

AMMOTIUM

AMMOT IUM

AMMOTIUM

AMMOT I UM

AMMOTIUM

AMMOTIUM

AMMOTIUM

AMMOTIUM

AMMOTIUM

AMMOTIUM

AMMOTIUM

AMMOTIUM

AMMOTIUM

AMMOTIUM

AMMOTI UM

AMMOTIUM

AMMOTIUM

AMMOTIUM

A MMO TI UM

AMMOTIUM

AMMOT IUM

AMMOTI UM

AMMOTIUM

AMMOTIUM

AMMOTIUM

AMPHICORYNA

AMPH I CORYNA

AMPHI CORYNA

AMPH I CORYN

AMPH I CORYNA

AMPHICORYNA

AMPHICORYNA

AMPHICORYNA

AMPHICORYNA

AMPH I CORYNA

AMPHICORYNA

AMPH I CORYNA

AMPH I CORYNA

AMPH I CORYNA

AMPH I CORYNA

AMPHICORYNA

AMPHICORYN

AMPHICORYNA

AMPHI CORYNA

AMPH I CORYNA

AMPH I CORYNA

AMPHICORYNA

AMPHICORYNA

AMPH I CORYN

AMPHICORYNA

AMPHICORYNA

AMPHI CORYNA

AMPHI CORYNA

AMPHICORYNA

AMPHI CORYNA

AMPHICORYNA

AMPHICORYNA

AMPHI CORYNA

AMPHICORYNA

AMPHISORUS

AMPHISORUS

AMPHISORUS

AMPHISTEG IN A

AMPHISTEGINA

AMPH ISTEGINA

AMPHISTEGINA
TENUI MARGO

TENUIMARGO

TENUI MARGO

TE NUIMARGO

TE NUIMARGO

TENUIMARGO

TENUIMARGO

TE NUI MARGO

SPHAEROID INIFORMIS

SPHAEROIDIN IFORMIS

EXIGUUS

EXIGUUS

EXIGUUS

EXIGUUS

EXIGUUS

EXIGUUS

EXIGUUS

SALSUM

SALSUM

MULTILOCULA TUM

SALSUM

CASS IS

SALSUM

SALSUM

SALSUM

SALSUM

SALSUM

SALSUM

SALSUM

SALSUM

SALSUM

SALSUM

SALSUM

SALSUM

SALSUM

SALSUM

SALSUM

SALSUM

SALSUM

SALSUM

SALSUM

SALSUM

SALSUM

SALSUM

SALSUM

SALSUM

SALSUM

SALSUM

SALSUM

SUEDIRECTUM

CAMACHOI

HI SPIDA

HISPIDA

HISPIDA

HI SP I DA

HI SPIDA

HISPIDA

HI SPIDA

$H$ I SPIDA

$H$ I SPIDA

HISPIDA

H I SP IDA

HISPIDA

HI SPIDA

ROEDERERI

SCALARIS

SEPARANS

SU EL INEATA

SU BLINEATA

SU BLINEATA

SUEL INEAT A

SU BLINEAT A

SUBLINEATA

SUEL INEATA

SU BLINEATA

SU BLINEATA

SUPLINEATA

SUBLINEATA

SUBL INEAJ A

SU OL INEATA

SUBLINEAT A

SUELINEATA

SU BL INEATA

SUOLINEATA

HEMPR ICH I I

HEMPRICH I

HE NPR I CHI I

GI EOOSA

GI EOOSA

GI BOOSA

GI BBOSA

\section{Locality}

Lat. Long.

NE GULF OF MEXICO

NE GULF OF MEXICO

NE GULF OF MEXICO 
Publication

10751 воск 1976

10752 BOCK 1976

10754 ANDERSEN 1961

10755 POAG 1972

10756 BANDY 1956

10757 VAUGHAN 1918

10758 PHLEGER 1951A

10759 LUDWICK WALTON 1957

10760 DAVIS 1964

10761 CUSHMAN 1922 A

0762 VAUGHAN 1918

10763 NORTON 1930
10764 CUSHMAN 1931

10765 CUSHMAN 1931

10766 CUSHMAN 1931

10767 LOEP 1965

10768 BANDY 1956

10769 KELLOUGH 1956

10770 KELLOUGH 1956

10771 BANDY 1956

10772 BANDY 1956

10774 BANDY 1956

10775 LYNTS PFISTER 1967

10776 BANDY 1956

10777 BANDY 1956

10778 BANDY 1956

10779 BANDY 1956

10780 BANDY 1956

10781 ANDERSEN 1961

10782 ANDERSEN 1961

10783 PFLUM FRERICHS 1976

10784 PFLUM FRERICHS 1976

10785 PFLUM FRERICHS 1976

10786 PFLUM FRERICHS 1976

10787 HALTON 1964

10788 PFLUM FRERICHS 1976

10789 PFLUM FRERICHS 1976

10790 PFLUM FRERICHS 1976

10791 PFLUM FRERICHS 1976

10792 PFLUM FRERICHS 1976

10793 BANDY 1956

10794 AYALA-CASTANARES 1963

10795 BANOY 1956

10796 LOEP 1965

10797 BANDY 1956

10798 BANDY 1956

10799 KELLOUGH 1956

10800 KELLOUGH 1956

10801 KELLOUGH 1956

10802 KELLOUGH 1956

10803 KELLOUGH 1956

१0804 PFLUM FRERICHS 1976

10805 PARKER 1954

10806 PARKER 1954

10807 PHLEGER 1956

10808 PARKER 1954

10809 PHLEGER 1956

10810 PARKER 1954

10811 PHLEGER 1951 A

10812 PHLEGER 1951A

10813 PHLEGER 1951 A

10814 PHLEGER $1951 \mathrm{~A}$

10815 BANDY 1956

10816 BANOY 1956

10817 BANDY 1956

10818 BANDY 1956

10319 BANDY 1956

10820 BANOY 1956

10821 ANDERSEN 1961

10823 CREAGER 1958

10824 BANDY 1956

10825 KELLOUGH 1956

10826 BANDY 1956

10827 PHLEGER $1951 \mathrm{~A}$

10828 PHLEGER 1951A

10829 PHLEGER 1951A

10830 PHLEGER 1951A

10831 PHLEGER 1951A

10832 PFLUM FRERICHS 1976

10833 PFLUM FRERICHS 1976

10834 PHLEGER 1951 A

10835 PARKER 1954

10836 PARKER 1954

I0837 PARKER 1954

10838 PARKER 1954

10839 PFLUM FRERICHS 1976

10840 PFLUM FRERICHS 1976

10841 PFLUM FRERICHS 1976

10842 LANKFORD 1959

10843 PHLEGER 1951 A

10844 PHLEGER 1951A

10845 PHLEGER 1951 A
Generic Name

AMPHISTEGINA

AMPHISTEGINA

AMPHISTEGINA

AMPHISTEGINA

AMPHISTEGINA

AMPHISTEGINA

A MPH I STEGINA

AMPHISTEGINA

AMPHISTEGINA

AMPHISTEGINA

AMPHISTEGINA

AMPHISTEGINA

AMPHISTEGINA

AMPHISTEGINA

AMPHISTEGINA

AMPHISTEGINA

AMPHISTEGINA

AMPHISTEGINA

AMPHISTEGINA

AMPHISTEGINA

AMPH ISTEGINA

AMPHISTEGINA

AMPHISTEGINA

AMPHISTEGINA

AMPHISTEGINA

AMPHISTEGINA

AMPHISTEGINA

AMPH ISTEGINA

AMPHISTEGINA

LAGENA

LAGENA

TR IFAR INA

TR I FAR INA

TR IFAR INA

TR I FAR I NA

TRIFARINA

TRIFAR INA

TR IFAR INA

TR IFARINA

TRIFARINA

TRIFARINA

TR IFAR I NA

TRIFARINA

TR IFAR INA

TR IFAR INA

TRIFARINA

TR IFARINA

TR IFAR INA

TRIFARINA

TR IFAR INA

TR IFARINA

TRIFARINA

IRI FAR INA

TR IFAR INA

TR IFAR INA

TRIFARINA

TR IFAR I NA

TRIFARINA

TRI FAR INA

TR I FAR INA

TR IF AR I N A

TR IFAR INA

TRIFAR INA

TR IFAR INA

TR IFAR INA

TRIFAR INA

TRI FARINA

TRIFARINA

TR IF AR IN A

TRIFARINA

TRIFAR INA

TRIFARINA

TRIFARINA

TR IF AR IN A

TR IFARINA

TRIFAR INA

TR IFAR I NA

TRIFARINA

TRIFARINA

TR IFAR INA

TR IFAR INA

TR IFARINA

TRI FAR INA

TRIFAR INA

TRIFAR INA

TR IFAR INA

TR I FAR I NA

TRI FAR I NA

TRIFARINA

TR I FAR INA

TR I FAR INA

TR IFAR INA

TR I FAR INA

TR IFAR INA
Specific Name

GI BBOSA

$G I$ BBOSA

GI BBOSA

GI BBOSA

GI BBOSA

GI EBOSA

GI BBOSA

GI B8OSA

GI $8 B O S A$

GI BBOSA

GI EBOSA

GI EBOSA

GI BBOSA

GI BBOSA

$G I$ BBOSA

$G$ I BBOSA

GI EBOSA

GI BBOSA

GI BBOSA

GI $880 S A$

$G$ I BBOSA

GI EBOSA

GI EBOSA

$G I$ BBOSA

GI BBOSA

$G$ I BBOSA

GI BBOSA

GI EBOSA

$G$ I EBOSA

GI BBOSA

GRAC ILIS

PURII

ANGULOSA

AN GULOSA

AN GULOSA

AN GULOSA

AN GULOSA

ANGULOSA

AN GUL OSA

AN GUL OSA

AN GULOSA

AN GULOS

BELLA

BE LLA

BELLA

BELLA

BELLA

BELLA

BELLA

BELLA

BELLA

BE LLA

BELLA

BELLA

BELLLA

BELLA

BELLA

BE LLA

BELLA

BE LLA

BELLA

BELLA

BELLA

BELLA

BELLA

BELLA

BELLA

BELLA

BELLA

BELLA

BELLA

BELLA

BELLA

BELLA

BELLA

BELLA

BE LLA

BELLA

BELLA

BELLA

BELLA

SELLA

BELLA

BELLA

SE LLA

3ELLA

BELLA

BELLA

BE LLA

BELLA

BELLA

BELLA

Locality

NE GULF OF MEXICO NE GULF OF MEXICO

NE GULF OF MEXICO

MISSISSIPPI DELTA

* FLOUER GARDEN B.

NE GULF OF MEXICO

DRY TORTUGAS 


\section{Publication}

10846 PHLEGER 1951A

10847 PHLEGER $1951 \mathrm{~A}$

10848 PHLEGER $19.51 \mathrm{~A}$

10849 PHLEGER 1951 A

10850 PHLEGER $1951 \mathrm{~A}$

10851 PHLEGER 1951A

10852 PHLEGER 1951A

10853 PHLEGER 1951A

10854 PHLEGER 1951

10855 PARKER 1954

10856 PARKER 1954

10857 PARKER 1954

10858 PARKER 1954

10859 PARKER 1954
10860 PARKER 1954

10860 PARKER 1954
10861 PARKER 1954

10862 PARKER 1954

10863 PARKER 1954

10864 PARKER 1954

10865 PARKER 1954

10866 PARKER 1954

10867 PARKER 1954

10868 PARKER 1954

10869 PARKER 1954

10870 PARKER 1954

10871 LUOHICK WALTON 1957

10872 PARKER 1954

10873 PARKER 1954

10874 PARKER 1954

10875 PARKER 1954

10876 PARKER 1954

10877 CREAGER 1958

10878 CREAGER 1958

10879 CREAGER 1958

10880 ANDERSEN 1961

10881 CUSHMAN $1922 \mathrm{~A}$

10882 NORTON 1930

10883 NORTON 1930

10884 PFLUM FRERICHS 1976

10885 PFLUM FRERICHS 1976

10886 PFLUM FRERICHS 1976

10887 PFLUM FRERICHS 1976

10888 PFLUM FRERICHS 1976

10889 PFLUM FRERICHS 1976

10890 PFLUM FRERICHS 1976

10891 PFLUM FRERICHS 1976

10892 PFLUM FRERICHS 1976

10893 PFLUM FRERICHS 1976

10894 PFLUM FRERICHS 1976

10895 PFLUM FRERICHS 1976

10896 PFLUM FRERICHS 1976

10897 PFLUM FRERICHS 1976

10898 PFLUM FRERICHS 1976

10899 PFLUM FRERICHS 1976

10900 DFLUM FRERICHS 1976

10901 PFLUM FRERICHS 1976

10902 PFLUM FRERICHS 1976

10903 PFLUM FRERICHS 1976

10904 PFLUM FRERICHS 1976

10905 PFLUM FRERICHS 1976

10906 PFLUM FRERICHS 1976

10907 PFLUM FRERICHS 1976

10908 PFLUM FRERICHS 1976

10909 PFLUM FRERICHS 1976

10910 PFLUM FRERICHS 1976

10911 PFLUM FRERICHS 1976

10912 PFLUM FRERICHS 1976

10913 PFLUM FRERICHS 1976

10914 PFLUM FRERICHS 1976

10915 PFLUM FRERICHS 1976

10916 PFLUM FRERICHS 1976

10917 PFLUM FRERICHS 1976

10918 PFLUM FRERICHS 1976

10919 PFLUM FRERICHS 1976

10920 PFLUM FRERICHS 1976

10921 PFLUM FRERICHS 1976

10922 PFLUM FRERICHS 1976

10923 PFLUM FRERICHS 1976

10924 PFLUM FRERICHS 1976

10925 PFLUM FRERICHS 1976

10926 PFLUM FRERICHS 1976

10927 PFLUM FRERICHS 1976

10928 PFLUM FRERICHS 1976

10929 PFLUM FRERICHS 1976

10930 PFLUM FRERICHS 1976

10931 PFLUM FRERICHS 1976

10932 CUSHMAN 1931

10933 CUSHMAN 1922

10934 NORTON 1930

10935 NORTON 1930

10936 PFLUM FRERICHS 1976

10937 PFLUM FRERICHS 1976

10938 PFLUM FRERICHS 1976

10939 PFLUM FRERICHS 1976

10940 NORTON 1930
Generic Name

TR IFAR INA

TR IFAR INA

TR IFAR INA

TR IFAR INA

TR IFARINA

TR IFARINA

TR IFAR IN A

TR IFARINA

TR IFAR INA

TR IFAR INA

TRIFARINA

TR IFAR INA

TRIFARINA

TPIFARINA

TR IFAR INA

TR IFAR I NA

TR IFAR INA

TR IFARINA

TRIFARINA

TRIFARINA

TR IFAR INA

TR IFAR I NA

TR IFARINA

TR I FAR I N A

TRIFAR INA

TR IFAR I NA

TR IFAR INA

TR IFAR INA

TRIFARINA

TR IFAR I NA

TR IFAR INA

ANOMALINA

AN OMAL INA

ANOMALINA

CIBICIDES

C IBICIDES

CIBICIDES

CIBICIDES

CIBICIDES

CI $B I C I D E S$

CIBICIDES

CIBICIDES

CIBICIDES

CI BICIDES

CIBICIDES

CIBICIDES

CIBICIDES

CIBICIDES

CIBICIDES

CIBICIDES

CIBICIDES

CIBICIDES

CIBICIDES

CIBICIDES

CIBICIDES

C IBICIDES

CIBICIDES

CIBICIDES

CIBICIDES

CIBICIDES

CIBICIDES

CI BICIDES

CIBICIDES

CIBICIDES

CIBICIDES

CI BICIDES

CIBICIDES

CI BICIDES

C I BICIDES

C IBICIOES

CIBICIDES

CIBICIDES

CIBICIDES

CIBICIDES

CIBICIDES

CIBICIOES

CIBICIDES

CIBICIDES

CIBICIDES

CIBICIDES

CIBICIDES

CIBICIDES

PLANULINA

PLANULINA

PLANULINA

PLANULINA

AN OMALINA

A NOMALINA

ANOMALINA

ANOMALINA

ANOMALINA
Specific Name

Locality

Lat. Long.

BELLA

$B E L L$

BELLA

BELLA

BELLA

BELLA

BELLA

BELLA

$B E L L A$

BELLA

BELLA

JANAICENSIS

JAMAICENSIS

JANAICENSIS

JANAI IENS IS

JANA I CENS IS

JANAICENS IS

JANAICENS IS

JAMAICENS IS

JANAI CENSIS

JANAI CENS IS

JAMAICENS IS

JAMAICENSIS

JAMAICENS IS

JANAI CENS IS

JANAICENSIS

JANAICENSIS

JAMAICENS IS

JANA I CENS IS

JAMAICENS IS

OCCIOENTALIS

AMMONOIDES

AMNONOIDES

CORONATA

CORPULENTUS

CORPULENTUS

CORPULENTUS

CORPULENTUS

CORPULENTUS

CORPULENTUS

CORPULENTUS

CORPULENTUS

CORPULENTUS

CORPULENTUS

CORPULENTUS

CORPULENTUS

CORPULENTUS

CORPULENTUS

CORPULENTUS

CORPULENTUS

CORPULENTUS

CORPULENTUS

CORPULENTUS

CORPULENTUS

CORPULENTUS

CORPULENTUS

CORPULENTUS

CORPULENTUS

CORPULENTUS

CORPULENTUS

CORPULENTUS

CORPULENTUS

CORPULENTUS

CORPULENTUS

CORPULENT

CORPULENTUS

CORPULENTUS

CORPULENTUS

CORPULENTUS

CORPULENTUS

CORPULENTUS

CORPULENTUS

CORPULENTUS

CORPULENTUS

CORPULENTUS

CORPULENTUS

CORPULENTUS

CORPULENTUS

CORPULENTUS

CORPULENTUS

CORPULENTUS

CORPULENTUS

EOWARDSIANA

EDWARDSIANA

EDWARDSIANA

FOVEOLATA

GL OBULOSA

GL OBULOSA

GLOBULOSA

GL CBULOSA

GL OBULOSA

NH GULF OF MEXICO

NW GULF OF MEXICO

NW GULF OF MEXICO

$N W$ GULF OF MEXICO

NW GULF OF MEXICO 


\section{Publication}

10941 BANDY 1956

10942 BANDY 1956

10943 BANDY 1956

10944 BANDY 1956

10945 BANOY 1956

10946 ANDERSEN 1961

10947 BANDY 1956

10948 BANDY 1956

10949 PFLUM FRERICHS 1976

10950 PFLUM FRERICHS 1976

10951 PFLUM FRERICHS 1976

10952 PFLUM FRERICHS 1976

10953 PFLUM FRERICHS 1976

10954 PFLUM FRERICHS 1976

10955 PFLUM FRERICHS 1976

10956 PFLUM FRERICHS 1976

10957 PFLUM FRERICHS 1976

10958 PFLUM FRERICHS 1976

10959 PFLUM FRERICHS 1976

10960 PFLUM FRERICHS 1976

10961 PFLUM FRERICHS 1976

10962 PFLUM FRERICHS 1976

10963 PFLUM FRERICHS 1976

10964 PFLUM FRERICHS 1976

10965 PFLUM FRERICHS 1976

10966 PFLUM FRERICHS 1976

10967 PFLUM FRERICHS 1976

10968 PFLUM FRERICHS 1976

10969 PFLUM FRERICHS 1976

10970 PFLUM FRERICHS 1976

10971 PFLUM FRERICHS 1976

10972 PFLUM FRERICHS 1976

10973 PFLUM FRERICHS 1976

10974 PFLUM FRERICHS 1976

10975 LEROY HODGKINSON 1975

10976 PHLEGER 1955 A

10977 PARKER 1954

10978 PARKER 1954

10979 PARKER 1954

10980 PARKER 1954

10981 PARKER 1954

10982 PARKER 1954

10983 PARKER 1954

10984 PARKER 1954

10985 PARKER 1954

10986 PARKER 1954

10987 PARKER 1954

10988 PARKER 1954

10989 PARKER 1954

10900 PARKER 1054

10991 PFLUM FRERICHS 1976

10992 PFLUM FRERICHS 1976

10993 PFLUM FRERICHS 1976

10994 PFLUM FRERICHS 1976

10995 PFLUM FRERICHS 1976

10996 PFLUM FRERICHS 1976

10997 PFLUM FRERICHS 1976

10998 PFLUM FRERICHS 1976

10999 DFLUM FRERICHS 1976

11000 PFLUM FRERICHS 1976

11001 PFLUM FRERICHS 1976

11002 PFLUM FRERICHS 1976

11003 PFLUM FRERICHS 1976

11004 PFLUM FRERICHS 1976

11005 PFLUM FRERICHS 1976

11006 PFLUM FRERICHS 1976

11007 PFLUM FRERICHS 1976

11008 PFLUM FRERICHS 1976

11009 PFLUM FRERICHS 1976

11011 PFLUM FRERICHS 1976

11012 PFLUM FRERICHS 1976

11013 NORTON 1930

11014 CUSHMAN 1930

11015 BANDY 1956

11016 CUSHMAN 1930

11017 BANDY 1956

11018 BENDA PURI 1962

11019 BANDY 1956

11020 BANDY 1956

11021 DAVIS 1964

11022 BANDY 1956

11023 BANDY 1956

11024 BANDY 1956

11025 BANDY 1956

11026 BANDY 1956

11027 BANDY 1956

11028 BANDY 1956

11029 LYNTS PFISTER 1967

11030 BOCK 1976

11031 NORTON 1930

11032 BENDA PURI 1962

11033 PHLEGER 1951A

11034 CUSHMAN 1930
Generic Name

CI BICIDES

CIBICIDES

CIBICIDES

CI 3 ICIDES

CIBICIDES

CIBICIDES

CIBICIDES

CIBICIDES

ANOMALINOIDES

AN OMALINOIDES

ANOMALINOIDES

A NOMALINOIDES

ANOMALINOIDES

ANOIMALINOIDES

ANOMALINOIDES

ANOMALINOIDES

ANOMALINOIDES

ANOMALINOIDES

ANOMALINOIDES

ANOMALINOIDES

ANOMALINOIDES

ANOMALINOIDES

ANOMALINOIDES

ANOMALINOIDES

ANOMALINOIDES

ANOMALINOIDES

ANOMALINOIDES

ANOMAL INOIDES

ANOMALINOIDES

ANOMALINOIDES

ANOMAL INOIDES

ANOMALINOIDES

ANOMAL INOI DES

AN OMAL INOIDES

CIBICIDES

ANOMALINOIDES

ANOMALINOIDES

ANOMALINOIDES

ANOMALINOIDES

ANOMALINOIDES

ANOMALINOIDES

ANOMALINOIDES

ANOMALINOIDES

ANOMALINOIDES

ANOMALINOIDES

A NOMALINOIDES

A NOMA L I NOIDES

A NOMALINOIDES

ANOMALINOIDES

ANOMAL INOIDES

PYRULINA

PYRULINA

PYRULINA

PYRULINA

PYRULINA

PYRULINA

PYRULINA

PYRULINA

PYRULINA

PYRULINA

PYRULINA

PYRULINA

PYRULINA

PYRULINA

PYRULINA

PYRULINA

PYRULINA

PYRULINA

PYRULINA

PYRULINA

PYRULINA

PYRULINA

ARCHAIAS

ARCHAIAS

ARCHAIAS

ARCHAIAS

ARCHAIAS

AR CHAIAS

ARCHAIAS

ARCHAIAS

ARCHAIAS

ARCHAIAS

ARCHAIAS

ARCHAIAS

ARCHAIAS

ARCHAIAS

ARCHAIAS

ARCHAIAS

ARCHAIAS

ARCHAIAS

ARCHAIAS

ARCHAIAS

ARCHAIAS

ARCHAIAS

ARCHAIAS
Specific Name

10

10

I 0

10

10

MEXICANA

MEXICANA

ME XI CANA

MEXI CANA

MEXICANA

MEXICANA

MEXI C ANA

MEXI CANA

MEXICANA

MEXICANA

MEXICANA

MEXICANA

MEXICANA

MEXICANA

MEXI CANA

MEXI CANA

MEXI CANA

MEXICANA

MEXICANA

MEXICANA

MEXICANA

CORPULENTUS

MEXICANA

MEXICANA

MEXICANA

MEXICANA

MEXI CANA

MEXI CANA

MEXICANA

MEXI CANA

MEXICANA

MEXICANA

ME XI I ANA

MEXICANA

MEXICANA

MEXICANA

MEXI CANA

ANGUSTA

ANGUSTA

AN GUSTA

AN GUSTA

ANGUSTA

AN GUSTA

EXTENSA

EXTENSA

EX TENSA

EXTENSA

EXTENSA

EXTENSA

EXTENSA

EXTENSA

EXTENSA

EXTENSA

EXTENSA

EXTENSA

EXTENSA

EXTENSA

ANGULATUS

ANGULATUS

ANGULA

ANGULATUS

ANGULATUS

ANGULATUS

ANGULATUS

AN GULATUS

AN GULATUS

AN EULATUS

ANGULATUS

ANGULATUS

AN GULATUS

AN GULATUS

AN GULATUS

AN GULATUS

ANGULATUS

CONPRESSUS

COMPRESSUS

CONPRESSUS

CONPRESSUS

Locality

NE GULF OF MEXICO

NE GULF OF MEXICO

NE GULF OF MEXICO

NE GULF OF MEXICO

NE GULF OF MEXICO

MISSISSIPPI DELTA

NE GULF OF MEXICO

NE GULF OF MEXICO

NW GULF OF MEXICO

NW GULF OF MEXICO

$N W$ GULF OF MEXICO 


\section{Publication}

11036 LOEP 1965

11037 PHLEGER 19558

11038 ANDERSEN 1951 A

11039 ANDERSEN $1951 \mathrm{~B}$

11040 ANDERSEN 1951 A

11041 PHLEGER 1965 A

11042 ANDERSEN 1951 A
11043 WARREN 1956

11044 AYALA-CASTANARES 1963

11045 PHLEGER 1954

11046 PHLEGER 1965A

11047 PHLEGER 1965 A

11048 PHLEGER 1965A

11049 BENDA PURI 1962

11050 PHLEGER 1965A

11051 PHLEGER 1965 A

11052 PHLEGER 1965 A

11053 PHLEGER 1965 A

11054 OTVOS 1978

11055 PHLEGER LANKFORD 1978

11056 WAL TON 1960

11057 WANTLAND 1969

11058 PARKER PHLEGER PEIRSON 1953

11059 PARKER PHLEGER PEIRSON 1953

11060 PARKER PHLEGER PEIRSON 1953

11061 WARREN 1957

11062 KANE 1962

11063 PHLEGER 1954

11064 PHLEGER $1965 \mathrm{C}$

11065 PHLEGER 1954

11066 LANKFORD 1959

11067 PHLEGER 1954

11068 SHEPARD MOORE 1955

11069 WALDRON 1963

11070 LEHMANN 195

11071 KANE 1967

11072 CUSHMAN $1922 \mathrm{~A}$

11073 NORTON 1930

11074 CUSHMAN 1922 A

11075 BOCK 1976

11076 ANDERSEN 1961

11078 DAVIS 1964

11079 NORTON 1930

11080 NORTON 1930

11081 KELLOUGH 1956

11082 CUSHMAN 1922A

11083 BOCK 1976

11084 BENDA PURI 1962

11085 BOCK 1976

11086 BOCK 1976

11087 CUSHMAN 1922A

11088 VAUGHAN 1918

11089 NORTON 1930

11090 BOCK 1976

11091 NORTON 1930

11092 PFLUM FRERICHS 1976

11093 PFLUM FRERICHS 1976

11094 PFLUM FRERICHS 1976

11095 PFLUM FRERICHS 1976

11096 BOCK 1976

11097 BANDY 1956

11098 BANDY 1956

11099 BANDY 1956

11100 BANDY 1956

11101 BANDY 1956

11102 PHLEGER $1951 \mathrm{~A}$

11103 BOCK 1976

11104 PARKER 1954

11105 PARKER 1954

11106 PARKER 1954

11107 SHIFFLETT 1961

11108 CUSHMAN 1922A

11109 PHLEGER 1951A

11110 PHLEGER 1951A

11111 PARKER 1954

11112 PARKER 1954

11113 PARKER 1954

11114 PARKER 1954

11115 CREAGER 1958

11116 CREAGER 1958

11117 PHLEGER 1954

11118 PHLEGER 1954

11119 LUDWICK WALTON 1957

11120 DAVIS 1964

11121 PARKER 1954

11122 PARKER 1954

11123 PARKER 1954

11124 PARKER 1954

11125 BOCK 1976

11126 LYNTS PFISTER 1967

11127 PARKER 1954

11128 BOCK 1976

11129 BANDY 1956

11130 BANDY 1956
Generic Name

ARCHAIAS

ARENOPARRELLA

ARENOPARRELLA

AR ENOPARRELLA

ARENOPARRELLA

ARENOPARRELLA

AR ENOPARRELLA

AREN OPARRELLA

ARENOPARRELLA

ARENOPARRELLA

ARENOPARRELLA

ARENOPARRELLA

ARENOPARRELLA

ARENOPARRELLA

ARENOPARRELLA

ARENOPAR RELLA

ARENOPARRELLA

ARENOPARRELLA

ARENOPARRELLA

ARENOPARRELLA

ARENOPARRELLA

ARENOPARRELLA

ARENOPARRELLA

ARENOPARRELLA

ARENOPARRELLA

ARENOPARRELLA

AR ENOPARRELLA

ARENOPARRELLA

ARENOPARRELLA

ARENOPARRELLA

ARENOPARRELLA

ARENOPARRELLA

ARENOPARRELLA

ARENOPARRELLA

AR ENOPARRELLA

ARENOPARRELLA

ARTICULINA

ART I CULINA

ARTICUL INA

AR TICULINA

ARTICULINA

ARTICULINA

ARTICULINA

ARTICULINA

NODOBACULARIELLA

NODOBACULAR IELLA

NODOBACULARIELLA

NODOBACULARIELLA

ARTICULINA

ARTICULINA

AR TI CUL INA

ARTICULINA

AR TICUL INA

ARTI CUL INA

AR I I CUL INA

ART I CUL INA

ASCHEMONELLA

ASCHEMONELLA

A SCHEMONELLA

A S CHEMONELLA

ASTACOLUS

ASTACOLUS

ASTACOLUS

ASTACOLUS

ASTER I GERINA

ASTER IGERINA

ASTERIGERINA

AS TERI GERINA

ASTERIGERINA

A S TER IGERINA

ASTERIGERINA

ASTER I GERINA

ASTER I GERINA

ASTER IGERINA

ASTER I GERINA

ASTERIGERINA

ASTER IGERINA

ASTERIGERINA

ASTERI GERINA

AS TER I GERINA

ASTER I GER INA

AS TER I GERINA

AS TER IGERINA

AS TER I GERINA

ASTER IGERINA

ASTERIGERINA

ASTERIGERINA

ASTER I GERINA

AS TER I GER I NA

ASTER I GERINA

A S TER IGER INA

ASTERIGER INA

ASTERIGERINA

A STER IGERINA

ASTERIGERINA
Specific Name

COMPRESSUS

MEXI CANA

MEXI CANA

MEXI CANA

MEXI CANA

MEXICANA

MEXICANA

MEXICANA

MEXI CANA

MEXI CANA

MEXICANA

MEXICANA

ME XI CANA

MEXICANA

MEXICANA

MEXI CANA

ME XI CANA

MEXICANA

MEXICANA

MEXI CANA

MEXICANA

MEXI CANA

ME XICANA

ME XICANA

MEXI CANA

MEXICANA

MEXICANA

ME XICANA

MEXICANA

ME XICANA

MEXICANA

MEXI CANA

ME XICANA

MEXI CANA

AN TILL ARU M

CONICO-AR TI CUL ATA

LINEATA

LI NEATA

MA YORI

MA YOR I

MAYORI

MAYOR I

MEXICANA

EXICANA

MEXICANA

MEXI C ANA

MU CRONATA

MU CRONATA

PACIFICA

SAGRA

SAGRA

SAGRA

SAGRA

SULCATA

RA MUL I F ORMIS

RA MUL IF ORMIS

RA MUL I FORMIS

SC ABR A

CREPIDULUS

OVATUS

OVATUS

CARINATA

CARINATA

CARINATA

CARINATA

CARINATA

CARINATA

CARINATA

CARINATA

CARINATA

CARINATA

CARINATA

CARINATA

CARINATA

CARINATA

CARINATA

CARINATA

CARINATA

CARINATA

CARINATA

CARINATA

CARINATA

CARINATA

CARINATA

CARINATA

CARINATA

CARINATA

CARINATA

CARINATA

CARINATA

CARINATA

CARINATA

Locality

Lat. Long.

NH GULF OF MEXICO

MISSISSIPPI DELTA

MISSISSIPPI DELTA

MISSISSIPPI DELTA 


\section{Publication}

11131 BANDY 1954 11132 BANDY 1956 11133 BANDY 1956 11134 BANDY 1956 11135 BANDY 1954 11136 BANDY 1954 11137 KELLOUGH 1956 11138 BANDY 1956 11139 CUSHMAN 1931 11140 WALTON 1960 11141 CUSHMAN 1931 11142 CUSHMAN 1931 11143 NORTON 1930 11144 CREAGER 1958 11145 BANDY 1956 11146 BANDY 1956 11147 BANDY 1956 11148 BANDY 1956 11149 BANDY 1956 11150 BANDY 1956 11151 BANDY 1956 11152 BANDY 1954 11153 BANDY 1956 11154 BANDY 1956 11155 BANDY 1956 11156 BANDY 1956 11157 BANDY 1956 11158 PARKER 1954 11159 PARKER 1954 11160 PARKER 1954 11161 PARKER 1954 11162 PARKER 1954 11163 PFLUM FRERICHS 1976 11164 PFLUM FRERICHS 1976 11165 PFLUM FRERICHS 1976 11166 PFLUM FRERICHS 1976 11167 PFLUM FRERICHS 1976 11168 PFLUM FRERICHS 1976 11169 PFLUM FRERICHS 1976 11170 PFLUM FRERICHS 1976 11171 PFLUM FRERICHS 1976 11172 PFLUM FRERICHS 1976 11173 PFLUM FRERICHS 1976 11174 PFLUM FRERICHS 1976 11175 PARKER 1954 11176 PARKER 1954

11177 PFLUM FRERICHS 1976 11178 PFLUM FRERICHS 1976 11179 PARKER 1954

11180 CUSHMAN 1918

11181 CUSHMAN 1918

11182 PFLUM FRERICHS 1976 11183 PFLUM FRERICHS 1976 11184 PFLUM FRERICHS 1976 11185 PFLUM FRERICHS 1976 11186 PFLUM FRERICHS 1976 11187 PFLUM FRERICHS 1976 11188 PFLUM FRERICHS 1976 11189 PFLUM FRERICHS 1976 11190 PFLUM FRERICHS 1976 11191 PFLUM FRERICHS 1976 11192 PFLUM FRERICHS 1976 11193 PFLUM FRERICHS 1976 11194 PFLUM FRERICHS 1976 11195 PFLUM FRERICHS 1976 11196 PFLUM FRERICHS 1976 11197 PFLUM FRERICHS 1976 11198 PFLUM FRERICHS 1976 11199 PFLUM FRERICHS 1976 11200 PFLUM FRERICHS 1976 11201 PFLUM FRERICHS 1976 11202 LEROY HODGKINSON 1975 11203 CUSHMAN 1918 11204 CREAGER 1958 11205 KELLOUGH 1956 11206 KELLOUGH 1956 11207 KELLOUGH 1956 11208 KELLOUGH 1956 11209 PHLEGER 1951 A 11210 PHLEGER 1951A 11211 PHLEGER 1951A 11212 PHLEGER 1951A 11213 PHLEGER $1951 \mathrm{~A}$ 11214 PHLEGER 1951A 11215 PHLEGER 1951 A 11216 PHLEGER 1951A 11217 PHLEGER $1951 \mathrm{~A}$ 11218 PHLEGER 1951 A 11220 PHLEGER 1951A 11221 KELLOUGH 1956 11222 KELLOUGH 1956 11223 PHLEGER 1951A 11224 PHLEGER 1951A 11225 KELLOUGH 1956
Generic Name

Specific Name

A STERIGERINA

A STER IGERINA A STERIGERINA

A STERIGERINA

A STER IGERINA

A STERIGERINA

A STER I GERINA

A STER IGERINA

A STERIGERINA

ASTER I GERINA

A STERIGERINA

A S TER I GERI NA

ASTERIGERINA

ASTERIGERINA

A STERIGERINA

ASTERIGERINA

ASTERIGERINA

A S TER I GER IN A

A S TER IGERINA

ASTERIGERINA

ASTERIGERINA

ASTER IGERINA

ASTER IGERINA

AS TER I GERIN A

AS TER I GERINA

ASTRONONION

ASTRONONION

ASTRONONION

AS TRONONION

ASTRONONION

A STRONONI ON

ASTRONONION

ASTRONONION

ASTRONONION

ASTRONONION

A S TRONON ION

ASTRONONION

AS TRONON ION

ASTRONONION

ASTRONONION

AS TRONONION

AS TRONONION

A STRONONION

ASTRONONION

ASTRONONION

ASTRONONION

ASTRONONION

A S TRORHIZA

A STRORHIZA

BATHYSIPHON

BATHYSI PHON

BATHY SIPHON

BA THYSIPHON

BATHYSI PHON

BATHYSIPHON

BATHYSIPHON

BATHYSIPHON

BA THYSIPHON

BATHYSIPHON

BATHYSI PHON

BATHYSIPHON

BA THYSI PHON

BATHYSIPHON

BA THY SIPHON

BATHYSIPHON

BATHYSIPHON

BATHYSIPHON

BATHYSIPHON

BATHYSI PHON

BATHYSIPHON

RECTOBOL IV INA

RECTOBOLIVINA

RECTOBOLIVINA

RECTOBOLIVINA

RECTOBOLIV INA

RECTOBOLIVINA

RECTOBOLIVINA

RE CTOBOL IVINA

RECTOBOLIVINA

RECTOBOL IVINA

RECTOBOLIVINA

RECTOBOLIVINA

RECTOBOL IVINA

RECTOBOLIVINA

RECTOBOL IVINA

RECTOBOLIVINA

RECTOBOL IV INA

RECTOBOLIVINA

RECTOBOLIVINA

RECTOBOLIVINA

RECTOBOL IVINA

CARINATA

CARINATA

CARINATA

CARINATA

CARINATA

CARINATA

CARINATA

CARINATA

CARINATA

CARINATA

CARINATA

CARINATA

CARINATA

CARINATA

CARINATA

CARINATA

CARINATA

CARINATA

CARINATA

CARINATA

CARINATA

CARINATA

UMIDUM

TUNIDUM

TUNIDUM

TUNIDUM

TUNIDUM

TUMIDUM

TUNIDUM

TUPIDUM

TUMIDUM

TUMIDUM

TUNIDUM

TUNIDUM

TUMIDUM

TUMIDUM

TUMIDUM

UMIDUM

TUNIDUM

TUNIDUM

TUMIDUM

TUMIDUM

VERMI FORMIS

VERMI FORMIS

FILIFORMIS

F I LI FORMIS

FILIFORMIS

FILIFORMIS

FILIFORMIS

FILIFORMIS

FILIFORMIS

FI LIF ORMIS

FILIFORMIS

FILIFORMIS

FILIFORMIS

FILIFORMIS

FILIFORMIS

FILIFORMIS

F ILIFORMIS

FI I I FORMIS

FILIFORMIS

FI II FORMI S

F ILIFORMIS

FILIFORMIS

RUFUS

RUFUS

AD VENA

ADVENA

ADVENA

AD VENA

ADVENA

ADVENA

AD VENA

AD VENA

ADVENA

ADVENA

ADVENA

AD VENA

ADVENA

AD VENA

AD VENA

AD VENA

AD VENA

A D VENA

ADVENA

AD VENA

AD VENA

AD VENA
Locality

Lat. Long.

NE GULF OF MEXICO

$2850 N 093$ 03: $2949 N 08544 W$ $\begin{array}{llll}30 & 06 N & 085 & 44 \mathrm{~W} \\ 29 & 17 N & 085 & 46 \mathrm{~W}\end{array}$ 28 SON $09345 \mathrm{~W}$ $2930 \mathrm{~N} 09345 \mathrm{~W}$ $2840 N 094 \quad 33 W$ $2732 \mathrm{~N} 082 \quad 52 \mathrm{~W}$ $2438 \mathrm{~N} 08255 \mathrm{~W}$ $3018 \mathrm{~N} 08640 \mathrm{~W}$ 


\section{Publication}

11226 PHLEGER 1951 A 11227 PHLEGER 1951A 11228 PHLEGER 1951A 11229 PHLEGER 1951A 11230 PHLEGER $1951 \mathrm{~A}$ 11231 PHLEGER 1951 A 11232 PHLEGER 1951A 11233 PHLEGER 1951A 11234 PHLEGER 1951A 11235 PHLEGER 1951A 11236 PHLEGER 1951A 11237 PHLEGER 1951A

11238 DAVIS 1964

11239 PHLEGER 1955B

11240 PHLEGER 1954

11241 PHLEGER 1951A

11242 PHLEGER 1951A

11243 PHLEGER 1951 A

11244 PHLEGER $1951 \mathrm{~A}$

11245 PHLEGER 1951A A

11246 PHLEGER $1951 \mathrm{~A}$

11247 PHLEGER 1951A
11248 LUDWICK WALTON 1957

11249 PHLEGER 1951A

11250 PHLEGER 1951A

11251 PHLEGER 1951 A

11252 PHLEGER 1951A

11253 PHLEGER 1951A

11254 PHLEGER 1951A

11255 PARKER 1954

11256 PARKER 1954

11257 PARKER 1954

11259 PARKER 1954

11260 PARKER 1954

11261 PARKER 1954

11262 PARKER 1954

11263 PARKER PHLEGER PEIRSON 1953

11264 PARKER PHLEGER PEIRSON 1953

11265 BANDY 1954

11266 BANDY 1956

11267 BANDY 1954

11268 BANDY 1956

11269 BANDY 1956

11270 BANDY 1954

11271 SHEPARD MOORE 1955

11272 SHIFFLETT 1961

11273 KELLOUGH 1956

11274 PHLEGER 1954

11275 AYALA-CASTANARES 1963

11276 LOEP 1065

11277 LANKFORD 1959

11278 WARREN 1957

11279 PHLEGER 1951A

11280 PHLEGER 1951A

11281 KELLOUGH 1956

11282 KELLOUGH 1956

11283 KELLOUGH 1956

11284 KELLOUGH 1956

11285 KELLOUGH 1956

11286 LOEP 1965

11287 WARREN 1956

11288 LOEP 1965

11289 BANDY 1954

11290 BANDY 1954

11291 BENDA PURI 1962

11292 BANDY 1954

11294 BANDY 1956

11295 PARKER 1954

11296 PARKER 1954

11297 PARKER 1954

11298 POAG SWEET 1972

11299 PHLEGER 1956

11300 PHLEGER 1956

11301 PHLEGER 1956

11302 BANOY 1956

11303 BANDY 1956

11304 BANDY 1956

11305 ANDERSEN 1961

11306 CREAGER 1958

11307 CREAGER 1958

11308 WALTON 1960

11309 PHLEGER 1956

11310 PARKER 1954

11311 BOCK 1976

11312 BOCK 1976

11313 BOCK 1976

11314 BOCK 1976

11315 CREAGER 1958
11316 PARKER PHLEGER PEIRSON 1953

11317 PARKER PHLEGER PEIRSON 1953

11318 BANDY 1956

11319 PARKER PHLEGER PEIRSON 1953

11320 PARKER PHLEGER PEIRSON 1953
Generic Name

RECTOBOL IVINA

RECTOBOLIVINA

RECTOBOLIVINA

RECTOBOLIVINA

RECTOBOLIVINA

RECTOBOLIVINA

RECTOBOLIVINA

RECTOBOLIVINA

B I GENER INA

BI GENERINA

B I GENERINA

BI GENERINA

BI GENER INA

BIGENER INA

BIGENERINA

BI GENER I NA

BI GENER I NA

BI GENERINA

BI GENERINA

B I GENER I NA

BI GENERINA

BI GENER INA

BIGENERINA

BI GENERINA

BIGENERINA

BI GENERINA

BI GENERINA

BI GENERINA

BI GENER INA

BI GENERINA

BI GENERINA

B IGENERINA

BI GENERINA

BI GENERINA

BIGENERINA

BI GENERINA

BIGENER INA

BI GENERINA

BI GENERINA

BI GENER INA

BI GENER INA

B I GENER I NA

BI GENER INA

B I GENER I NA

BI GENER INA

BI GENERINA

BI GENER INA

BI GENERINA

BI GENERINA

BI GENER I NA

BI GENER INA

BI GENERINA

BI GENERINA

BIGENERINA

BIGENERINA

BI GENERINA

BIGENERINA

BI GENER INA

BI GENER INA

BIGENERINA

BI GENER INA

BI GENER I NA

BIGENERINA

BI GENERINA

BI GENER INA

B I GENER INA

BI GENERINA

BI GENERINA

BI GENER INA

BI GENERINA

BI GENERINA

BI GENER INA

B IGENER INA

BI GENER INA

BI GENER INA

BI GENERINA

BI GENER INA

BI GENER I NA

BI GENER I NA

BI GENER I NA

BI GENER INA

BI GENER INA

BI GENER INA

B I GENER INA

BI GENER INA

BI GENER I NA

BI GENER I NA

BI GENERINA

BI GENERINA

BIGENER INA

BIGENERINA
Specific Name

AD VENA

ADVENA

ADVENA

ADVENA

ADVENA

ADVENA

ADVENA

IRREGULAR IS

IRREGULAR IS

IRREGULARIS

IRREGULAR IS

IRREGULARIS

IRREGULAR IS

IRREGULAR IS

I RREGULAR IS

IRREGULAR IS

IRREGULARIS

IRREGULAR IS

IRREGULAR IS

IRREGULAR IS

IRREGULAR IS

IRREGULARIS

IRREGULAR IS

IRREGULARIS

IRREGULAR IS

IRREGULAR IS

IRREGULAR IS

IRREGULAR IS

IRREGULAR IS

IRREGULARIS

IRREGULAR IS

IRREGULAR IS

I RREGULAR IS

IRREGULAR IS

I RREGULAR IS

IRREGULAR IS

IRREGULAR IS

IRREGULAR IS

IRREGULARIS

IRREGULAR IS

IRREGULAR IS

IRREGULARIS

IRREGULAR IS

IRREGULAR IS

IRREGULARIS

IRREGULAR IS

IRREGULAR IS

IRREGULARIS

IRREGULAR IS

I RREGULAR IS

IRREGULARIS

IRREGULAR IS

IRREGULAR IS

IRREGULARIS

IRREGULAR IS

IR REGULAR IS

IRREGULARIS

IRREGULARIS

IRREGULARIS

IR REGULARIS

IRREGULARIS

I RREGULARIS

IRREGULAR IS

IRRE GULARIS

IRREGULAR IS

IRREGULARIS

IRREGULARIS

IRREGULAR IS

I RREGULAR IS

I RREGULAR IS

IRREGULAR IS

I RREGULAR IS

IRREGULAR IS

IRREGULAR IS

IRREGULAR IS

IRREGULAR IS

IRREGULAR IS

IRREGULAR IS

IRREGULAR IS

IRREGULAR IS

IRREGULARIS

IRREGULARIS

IRREGULAR IS

I R REGULAR IS

IRREGULARIS

IRREGULAR IS

IRREGULAR IS

IR REGULAR IS

IRREGULAR IS

IRREGULAR IS

IRREGULAR IS

IR REGULAR IS

IRREGULARIS

Locality

NW GULF OF MEXICO

NW GULF OF MEXICO

NW GULF OF MEXICO

NW GULF OF MEXICO

NW GULF OF MEXICO

NW GULF OF MEXICO

$N$ W GULF OF MEXICO

NW GULF OF MEXICO

$N W$ GULF OF MEXICO

NW GULF OF MEXICO 


\section{Publication}

11321 PARKER PHLEGER PEIRSON 1953 11322 BANDY 1956 11323 BANDY 1956 11324 BANDY 1956 11325 BANDY 1956 11326 BANDY 1956 11327 BANDY 1956 11328 BANDY 1956 11329 BANDY 1956 11330 BANDY 1956 11331 BANDY 1956 11332 BANDY 1956 11333 BANDY 1956 11334 BANDY 1956 11335 SEGURA 1963 11336 KELLOUGH 1956 11337 NORTON 1930 11338 CUSHMAN 1922A 11339 VAUGHAN 1918 11341 BENDA PURI 1962 11342 CUSHMAN 19228 11343 NORTON 1930 11344 CUSHMAN $1922 \mathrm{~B}$ 11345 CUSHMAN 19228 11346 CUSHMAN 19228 11347 NORTON 1930 11348 PARKER 1954 11349 PARKER 1954 11350 PARKER 1954 11351 PARKER 1954 11352 PARKER 1954 11353 PARKER 1954 11354 PARKER 1954 11356 PARKER 1954 11357 LUDWICK WALTON 1957 11358 LANKFORD 1959 11359 PARKER 1954 11360 PARKER 1954

11361 CUSHMAN $1922 \mathrm{~A}$ 11362 CUSHMAN 1922A 11363 CUSHMAN 1922A 11364 ANDERSEN 1961 11365 ANDERSEN 1961
11366 ANDERSEN 1951 A 11366 ANDERSEN 1951 A 11367 ANDERSEN 1951
11368 WARREN 1957 11369 ANDERSEN 1951 A 11369 ANDERSEN 195 11370 WARREN 1956
11371 PHLEGER 1955A 11372 PFLUM FRERICHS 1976 11373 PFLUM FRERICHS 1976 11374 PFLUM FRERICHS 1976 11375 PFLUM FRERICHS 1976 11376 PHLEGER 1955A 11377 PHLEGER $1955 \mathrm{~A}$ 11378 PFLUM FRERICHS 1976 11379 PFLUM FRERICHS 1976 11380 ANDERSEN 1961

11381 PFLUM FRERICHS 1976 11382 PFLUM FRERICHS 1976 11383 PFLUM FRERICHS 1976 11384 PFLUM FRERICHS 1976 11385 PFLUM FRERICHS 1976 11386 PFLUM FRERICHS 1976 11387 PFLUM FRERICHS 1976 11388 PFLUM FRERICHS 1976 11389 PFLUM FRERICHS 1976 11390 PFLUM FRERICHS 1976 11391 PFLUM FRERICHS 1976 11392 PFLUM FRERICHS 1976 11393 PFLUM FRERICHS 1976 11394 PFLUM FRERICHS 1976 11395 PFLUM FRERICHS 1976 11396 PFLUM FRERICHS 1976 11397 PFLUM FRERICHS 1976 11398 PFLUM FRERICHS 1976 11399 PFLUM FRERICHS 1976 11400 PFLUM FRERICHS 1976 11401 PARKER 1954 11402 PARKER 1954 11403 PARKER 1954

11404 PARKER 1954

11405 PARKER 1954

11406 PARKER 1954

11407 PARKER 1954

11409 PFLUM FRERICHS 1976 11410 PFLUM FRERICHS 1976

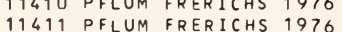
11412 PFLUM FRERICHS 1976 11413 PFLUM FRERICHS 1976

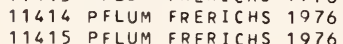

Generic Name

BI GENER INA B I GENER I NA B I GENER INA BI GENER INA BI GENERINA B I GENER INA BI GENER INA B I GENER INA B I GENER INA B I GENER I NA B I GENER INA B I GENERINA BI GENER INA B I GENER INA B I GENERINA B I GENER INA B I GENERINA B I GENER INA BI GENER INA BI GENERINA B I GENER INA B I GENER I NA B I GENER INA B I GENER I NA B I GENER I NA B I GENER I NA B I GENER I NA B I GENERI NA B I GENER I NA B I GENER INA BI GENERINA B I GENER I NA B I GENER I NA B I GENER I NA B I GENER INA B I GENER I NA BI GENER INA B I GENER I NA B I GENER INA B I GENER I NA PYRGO

PYRGO

PYRGO

B I LOCULINELLA B I LOCULINELLA B ISACCIUM B I SACCIUM BI SACCIUM BISACCIUM BI SACCIUM BOLIVINA BOLIVINA

BOLIVINA

BOLIVINA

BOLIVINA

BOLIVINA

BOLIVINA

BOLIVINA

BOLIVINA

BOLIVINA

BOLIVINA

BOLIVINA

BOLIVINA

BOLIVINA

BOLIVINA

BOLIVINA

BOLIVINA

BOLIVINA

BOLIVINA

BO LIVINA

BOLIVINA

BOLIVINA

BOLIVINA

BOLIVINA

BOLIVINA

BOLIVINA

BOLIVINA

BOLIVINA

BOLIVINA

BOLIVINA

BOLIVINA

BOLIVINA

BOLIVINA

BOLIVINA

BOLIVINA

BOLIVINA

BOLIVINA

BOLIVINA

BOLIVINA
BOLIVINA

BOLIVINA

BOLIVINA
Specific Name

I RREGULAR IS

I RREGULAR IS

I RRE GULAR IS

I RREGULAR IS

IRRE GULAR IS

I RREGULAR IS

IR REGULARIS

IRREGULAR IS

IRRE GULAR IS

IRREGULAR IS

IRREGULAR IS

I RFEGULARIS

I RRE GULAR IS

I RREGULARIS

IRREGULAR IS

I R RE GULAR IS

IRREGULAR IS

IRREGULAR IS

IRRE GULAR IS

I RRE GULAR IS

I RRE GULAR IS

TEXTULARI OIDEA

TE XTULARI OIDEA

TE XTULARI OI DEA

TE XTULARI OIDEA

PEANATULA

RO EUSTA

TE XTULARIOIDEA

TEXTULARIOIDEA

TE XTULARI OIDEA

TEXTULARI OI DEA

TE XTULARI OI DEA

TE XTULARI OIDEA

TEXTULARI OI DEA

TEXT

TE XTULARI OI DEA

TE XTULARI OIDEA

TEXTULARIOIDEA

DENTI CULATA STRIOLATA

MI LLETT I I

SUESPHAER ICA

LAEIATA

TODDAE

IMER I CA TUM

IMER I CATUM

IMERI CATUM

IM ER I CATUM

I MERI CATUM

AL ATA

AL ATA

AL ATA

ALATA

ALATA

AL ATA

AL ATA

AL ATA

ALATA

AL ATA

AL ATA

AL ATA

AL ATA

ALEATROSSI

ALBATROSSI

ALEATROSS I

ALEATROSS I

AL BATROSS I

AL BATROSS

ALEATROSS

AL BATROSS

ALEATROSS I

ALEATROSS I

ALEATROSSI

AL BATROSSI

AL BATROSS I

ALBATROSS I

ALEA.TROSS I

ALEATROSS I

AL BATROSSI

ALEATROSSI

AL BATROSSI

ALEATROSS I

ALEATROSS

ALBATROSSI

AL BATROSSI

ALBATROSSI

AL BATROSS I

ALEATROSS

AL BATROSS

AL BATROSS

AL BATROSS I

Locality

TEXAS GULF COAST

NE GULF OF MEXIC

NE GULF OF MEXICO

NE GULF OF MEXICO

NE GULF OF MEXICO

NE GULF OF MEXICO

NE GULF OF MEXICO

NE GULF OF MEXICO

NE GULF OF MEXICO

NE GULF OF MEXICO

NE GULF OF MEXICO 


\section{Publication}

11416 PFLUM FRERICHS 1976 11417 PFLUM FRERICHS 1976 11418 ANDERSEN 1961

11419 LOEP 1965

11420 LOEP 1965

11621 PARKER 1954

11422 PARKER 1954

11423 PARKER 1954

11426 PARKER 1954

11426 CUSHMAN $1922 \mathrm{~B}$

11427 CREAGER 1958

11428 CREAGER 1958

11429 CREAGER 1958

11430 CREAGER 1958

11431 CREAGER 1958

11432 CREAGER 1958

11433 PARKER 1954

11434 PHLEGER 1951A
11435 PHLEGER 1951A

11436 PFLUM FRERICHS 1976

11437 PFLUM FRERICHS 1976

11438 PFLUM FRERICHS 1976

11439 PHLEGER 19S1A

11440 PFLUM FRERICHS 1976

11441 PFLUM FRERICHS 1976

11442 PFLUM FRERICHS 1976

11443 PFLUM FRERICHS 1976

11444 PFLUM FRERICHS 1976

11445 PFLUM FRERICHS 1976

11446 PFLUM FRERICHS 1976

11447 PFLUM FRERICHS 1976

11448 PFLUM FRERICHS 1976

11449 PFLUM FRERICHS 1976

11450 PFLUM FRERICHS 1976

11451 PFLUM FRERICHS 1976

11452 PFLUM FRERICHS 1976

11453 PFLUM FRERICHS 1976

11454 PFLUM FRERICHS 1976

11455 PFLUM FRERICHS 1976

11456 PFLUM FRERICHS 1976

11457 PFLUM FRERICHS 1976

11458 PFLUM FRERICHS 1976

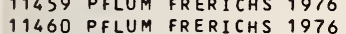

11460 PFLUM FRERICHS 1976
11461 PFLUM FRERICHS 1976

11462 PFLUM FRERICHS 1976

11463 PFLUM FRERICHS 1976

11464 PFLUM FRERICHS 1976

11465 PFLUM FRERICHS 1976

11466 PARKER 1954

11467 PARKER 1954

11468 LEROY HODGKINSON 1975

11469 PFLUM FRERICHS 1976

11470 PFLUM FRERICHS 1976

11471 PFLUM FRERICHS 1976

11472 PFLUM FRERICHS 1976

11473 PARKER 1954

11474 PFLUM FRERICHS 1976

11475 PFLUM FRERICHS 1976

11476 PFLUM FRERICHS 1976

11477 PFLUM FRERICHS 1976

11478 PFLUM FRERICHS 1976

11479 PFLUM FRERICHS 1776

11480 PFLUM FRERICHS 1976

11481 PFLUM FRERICHS 1976

11482 PFLUM FRERICHS 1976

11483 PFLUM FRERICHS 1976

11484 PFLUM FRERICHS 1976

11485 PFLUM FRERICHS 1976

11486 PFLUM FRERICHS

11488 PHLEGER 1955 A

11489 PHLEGER 1955A

11490 PHLEGER $1955 \mathrm{~A}$

11491 PHLEGER 1955A

11492 PHLEGER 195SA

11493 PHLEGER $1955 \mathrm{~A}$
11494 PHLEGER $1955 \mathrm{~A}$

11494 PHLEGER 1955A
11495 LUDWICK WALTON 1957

11496 PARKER 1954

11497 PHLEGER 1951A

11498 PHLEGER 1951A

11499 PHLEGER 1951A

11500 PHLEGER 1951A

11501 PHLEGER 1951A

11502 PHLEGER 1951 A

11503 PHLEGER 1951A

11504 PHLEGER $1951 \mathrm{~A}$

11505 PHLEGER 1951A

11506 PHLEGER 1951A

11507 PHLEGER 1951A

11508 PHLEGER 1951A

11509 PHLEGER 1951A

11510 PHLEGER 1951A
Generic Name

Specific Name

BOLIVINA

BOLIVINA

BOLIVINA

BOLIVINA

BOLIVINA

BOLIVINA

BOLIVINA

BOLIVINA

BOLIVINA

BOLIVINA

BOLIVINA

BOLIVINA

BOLIVINA

BOLIVINA

BOLIVINA

BOLIVINA

BOLIVINA

BOLIVINA

BOLIVINA

BOLIVINA

BOLIVINA

BOLIVINA

BOLIVINA

BOLIVINA

BOLIVINA

BOLIVINA

BOLIVINA

BOLIVINA

BOLIVINA

BOLIVINA

BOLIVINA

BOLIVINA

BOLIVINA

BOLIVINA

BOLIVINA

BOLIVINA

BOLIVINA

BOLIVINA

BOLIVINA

BOLIVINA

BOLIVINA

BOLIVINA

BOLIVINA

BOLIVINA

BOLIVINA

BOLIVINA

BOLIVINA

BOLIVINA

BOLIVINA

BOLIVINA

BOLIVINA

BOLIVINA

BOLIVINA

BOLIVINA

BOLIVINA

BOLIVINA

BOLIVINA

BOLIVINA

BOLIVINA

BOLIVINA

BOLIVINA

BOLIVINA

BOLIVINA

BOLIVINA

BOLIVINA

BOLIVINA

BOLIVINA

BOLIVINA

BOLIVINA

BOLIVINA

BOLIVINA

BOLIVINA

BOLIVINA

BOLIVINA

BOLIVINA

BOLIVINA

BOLIVINA

BOLIVINA

BOLIVINA

BOLIVINA

BOLIVINA

BOLIVINA

BOLIVINA

BOLIVINA

BOLIVINA

BOLIVINA

BOLIVINA

BOLIVINA

BOLIVINA

BOLIVINA

BOLIVINA

BOLIVINA
ALBATROSS I

ALBATROSS I

ALEATROSSI

ALBATROSSI

ALBATROSSI

ALEATROSS I

ALBATROSS I

ALEATROSS I

ALEATROSSI

AL BATROSSI

ALBATROSS I

ALBATROSS

ALBATROSS I

ALBATROSS I

ALBATROSSI

AL BATROSS I

ALEATROSS I

AL EATROSS I

AL BATROSSI

AL BATROSSI

ALBATROSSI

ALBATROSSI

ALEATROSS I

ALEATROSS I

AL BATROSSI

AL BATROSSI

ALBATROSSI

ALBATROSSI

ALBATROSS I

ALBATROSS I

ALBATROSS I

ALBATROSSI

ALEATROSSI

AL BATROSSI

ALBATROSS I

ALBATROSSI

AL BATROSS I

AL BATROSS I

AL EATROSSI

AL BATROSS I

ALEATROSSI

ALEATROSS I

AL BATROSSI

ALBATROSS I

AL BATROSSI

AL BATROSS I

AL BATROSS I

ALEATROSS I

ALBATROSS

AL BATROSS I

AL BATROSSI

AL BATROSS I

AL BATROSS I

AL BATROSS I

ALBATROSSI

AL BATROSS I

AL BATROSS I

ALBATROSS I

AL BATROSSI

ALBATROSSI

ALEATROSS I

ALBATROSS I

AL BATROSS I

AL BATROSS

AL BATROSS I

ALBATROSS I

ALBATROSS I

AL EATROSS I

ALEATROSS I

ALEATROSS I

ALBATROSS

ALBATROSS I

ALBATROSS I

ALBATROSSI

AL EATROSS I

ALBATROSSI

ALBATROSSI

ALBATROSS I

AL BATROSS I

AL EATROSSI

ALBATROSSI

ALBATROSSI

ALBATROSSI

ALBATROSS I

ALBATROSSI

ALBATROSS I

ALBATROSSI
ALBATROSS I

AL EATROSS I

ALEATROSS

Locality

Lat. Long.

CENTRAL GULF OF MEXICO

CENTRAL GULF OF MEXICO

MISSISSIPPI DELTA

NW GULF OF MEXICO

NW GULF OF MEXICO

NE GULF OF MEXICO

NE GULF OF MEXICO

NE GULF OF MEXICO

NE GULF OF MEXICO 


\section{Publication}

11511 PHLEGER 1951A 11512 PHLEGER $1951 \mathrm{~A}$ 11513 PHLEGER $1951 \mathrm{~A}$ 11514 PHLEGER $1951 \mathrm{~A}$ 11515 PHLEGER 1951 A 11516 PHLEGER $1951 \mathrm{~A}$ 11517 PHLEGER $1951 \mathrm{~A}$ 11518 PHLEGER 1951A 11519 PHLEGER 1951A 11520 PHLEGER 1951A 11521 PHLEGEF 1951A 11522 PARKER 1954 11523 PARKER 1954

11524 PARKER 1954

11525 PARKER 1754 11526 PHLEGER
19514
11527 11528 PHLEGED 1951A 11529 PHLEGER 1951A 11530 PHLEGEQ 1951A 11531 PHLEGER 1951A 11532 PHLEGER 1451A 11533 PHLEGER 1951A 11535 PHLEGER $1951 \mathrm{~A}$ 11536 PHLEGER 195:A 11537 PHLEGEP 1951A 11538 PHLEGER $1951 \mathrm{~A}$ 11540 PARKER 1254 11541 PHLEGER 1951A 11542 PHLEGER 1951A 11543 PHLEGER 1951A 11544 PARKER 1954

11545 PFLUM FRERICHS 1976 11546 PARKER 1954

11547 PFLUM FRERICHS 1976 11548 PHLEGER $1951 \mathrm{~A}$ 11549 PFLUM FRERICHS 1976 11550 PFLIJM FRERICHS 1976 11551 PFLIJM FRERICHS 1976 11552 PARKER 1254

11553 PHLEGE 1951A 11554 PHLEGER 1951A 11555 PHLEGER 1951A 11556 PHLEGER 1951A 11557 PARKER 1954

11558 PARKER 1754

11559 PARKER 1954

11560 PARKER 1954

11561 PHLEGER 1951A

11562 PHLEGER 1951A

11563 PHLEGER 195SA

11564 PFLUM FRERICHS 1976

11565 LUDWICK WALTON 1957

11566 PFLUM FRERICHS 1976

11567 LANKFORD 1959

11568 PHLESER 1951 A

11569 PFLUM FRERICHS 1976 11570 PFLIJM FRERICHS 1976 11571 PFLUM FRERICHS 1976 11572 CREAGER 1958

11573 PFLUM FRERICHS 1976 11574 PFLUM FRERICHS 1976 11575 ANDERSEN 1961

11576 PFLUM FRERICHS 1976 11577 ANDERSEN 1961

11578 PFLUM FRERICHS 1976 11579 PFLUM FRERICHS 1976 11580 PFLUM FRERICHS 1976 11581 PFLUM FRERICHS 1976 11582 PFLUM FRERICHS 1776 11583 CUSHMAN $1922 \mathrm{~B}$

11584 CUSHMAN $1922 \mathrm{~A}$

11585 BANDY 1956

11586 BANDY 1956 11587 BANDY 1956

11588 BANDY 1056

11589 BANDY 1956

11590 BANDY 1056

11591 PHLEGEP 1956

11593 PHLEGER 1956

11594 BANDY 1956

11595 PARKER 1254

11596 PARKER 1954

11597 PARKER 1954

11598 PAPKER 1954

11599 ANDERSFN 1951

11600 CREAGER 195

11601 CREAGER 1958

11603 PFLUM FRERICHS 1976

11604 LUDWICK WALTON 1957 11605 PARKER 1754
Generic Name

BOLIVINA

BOLIVINA

BOLIVINA

BOLIVINA

BOLIVINA

BOLIVINA

BOLIVINA

BOLIVINA

BOLIVINA

BOLIVINA

BOLIVINA

BOLIVINA

BOLIVINA

BOLIVINA

BOLIVINA

BOLIVINA

BOLIVINA

BOLIVINA

BOLIVINA

BOLIVINA

BOLIVINA

BOLIVINA

BOLIVINA

3 OLIVINA

BOLIVINA

BOLIVINA

BOLIVINA

BOLIVINA

BOLIVINA

BOLIVINA

BOLIVINA

BOLIVINA

BOLIVINA

BOLIVINA

BOLIVINA

BOLIVINA

BOLIVINA

BOLIVINA

BOLIVINA

BOLIVINA

BOLIVINA

BOLIVINA

BOLIVINA

BOLIVINA

BOLIVINA

BOLIVINA

BOLIVINA

BOLIVINA

BOLIVINA

BOLIVINA

BOLIVINA

BOLIVINA

BOLIVINA

BOLIVINA

BOLIVINA

BOLIVINA

BOLIVINA

BOLIVINA

BOLIVINA

BOLIVINA

BOLIVINA

BOLIVINA

BOLIVINA

BOLIVINA

BOLIVINA

BOLIVINA

BOLIVINA

BOLIVINA

BOLIVINA

BOLIVINA

BOLIVINA

BOLIVINA

BOLIVINA

BOLIVINA

BOLIVINA

BOLIVINA

BOLIVINA

BOLIVINA

BOLIVINA

BOLIVINA

BOLIVINA

BOLIVINA

BOLIVINA

BOLIVINA

BOLIVINA

BOLIVINA

BOLIVINA

BOLIVINA

BOLIVINA

BOLIVINA

BOLIVINA
Specific Name

AL BATROSSI

AL BATROSS

ALBATROSSI

AL EATROSS

ALEATROSS

ALEATROSS

AL BATROSS

ALBATROSS

ALEATROSS:

ALEATROSS

ALBATROSSI

ALEATROSS

AL BATROSS

AL EATROSSI

ALEATROSS

AL BATROSS

BARBATA

BARBATA

BARBATA

BARBATA

BARBATA

BARBATA

BARBATA

BA RBATA

BARBATA

BA B BATA

BARBATA

BARBATA

BARBATA

BARBATA

BARBATA

BARBATA

BARBATA

BA RBATA

BARBATA

BAFBATA

BARBATA

BARBATA

BARBATA

BA RB ATA

BARBATA

BARBATA

BARBATA

BARBATA

BA RBATA

BA RBATA

BARBATA

BARBATA

BARAATA

BARBATA

BARBATA

BARBATA

BARBATA

BARBATA

BARBATA

BARBATA

BARBATA

BAFBATA

BARBATA

BARBATA

BAKBATA

BA RBATA

BARBATA

BARBATA

BARBATA

BARBATA

BA RBATA

AL ATA

COMPACTA

DAGGARIUS

DAGGARIUS

DAGGARIUS

DAGGARIUS

DAGGARIUS

DAGGARIUS

FR AGILIS

AGILIS

FRAGILIS

FRAGILIS

FRAG ILIS

FRAGILIS

FRAGILIS

FRAGILIS

FRAG ILIS

FRAGILIS

FRAGILIS

FRAGILIS

FRAGILIS

FRAGILIS

Locality

Lat. Long.

$N W$ GULF OF MEXICO

NW GULF OF MEXICO

NW GULF OF MEXICO

NW GULF OF MEXICO

$N W$ GULF OF MEXICO

$N W$ GULF OF MEXICO

NW GULF OF MEXICO

$N W$ GULF OF MEXICO

$N W$ GULF OF MEXICO

NH GULF OF MEXICO

NW GULF OF MEXICO

NE GULF OF MEXICO

NE GULF OF MEXICO 
Publication

11606. PARKER 1754

11607 PARKER 1954

11608 PARKER 1954

11609 PARKER 1954

11610 PARKER 1954

11611 PHLEGER 1912 PHLEGER 1951A

11612 PHLEGER $1951 \mathrm{~A}$

11614 BANDY 1956

11615 LOEP 1965

1161.6 LOEP 1965

11617 KELLOUGH 1956

11618 KELLOUGH 1956

11619 PHLEGER 1951A

11620 PHLEGER 1951A

11621 PHLEGER 1951A

11622 PHLEGER 1951A

11623 PHLEGER 1951A

11624 PHLEGER $1951 \mathrm{~A}$

11625 PHLEGER 1951 A

11626 PHLEGER 1951A

11627 PHLEGER 1951A

11628 PHLEGEP 1951A

11629 PHLEGER 1951 A

11630 PHLEGER $1951 \mathrm{~A}$

11631 PHLEGER 1951A

11633 PFLUM FRERICHS 1976

11634 PFLUM FRERICHS 1976

11635 PHLEGER 1951 A

11636 PHLEGER $1951 \mathrm{~A}$

11637 PHLEGER $1951 \mathrm{~A}$

11638 PHLEGER 1951 A

11639 PHLEGER 1951A

11640 PHLEGER 1951A

11641 PHLEGER 1951A

11642 PHLEGER $1951 \mathrm{~A}$

11643 PHLEGER 1951

11644 PARKER 1954

11645 PHLEGER $1951 \mathrm{~A}$

11646 LUDWICK WALTON 1957

11647 PHLEGER 1951A

11648 PHLEGER 1951 A

11649 PARKER 1954

11650 PFLUM FRERICHS 1976

11651 PFLUM FRERICHS 1976

11652 PFLUM FRERICHS 1976

11653 PARKER 1954

11654 PARKER 1954

11655 PARKER 1954

11656 PARKER 1954

11657 PARKER 1954

11658 BANOY 1956

11659 BANDY 1956

11660 BANDY 1956

11661 BANDY 1956

11662 PFLUM FRERICHS 1976

11663 PHLEGER $1951 \mathrm{~A}$

11664 BENDA PURI 1962

11665 PHLEGER $1951 \mathrm{~A}$

11666 PHLEGER 1951 A

11667 PHLEGER 1951A

11668 PHLEGER 1951A

11669 PHLEGER 1951A

11670 PHLEGER 1951A

11671 PHLEGEP $1951 \mathrm{~A}$

11672 PHLEGER $1951 \mathrm{~A}$

11673 BENOA PURI 1962

11674 PFLUM FRERICHS 1976

11675 PFLUM FRERICHS 1976

11676 PFLUM FRERICHS 1976

11677 PFLUM FRERICHS 1976

11678 PFLUM FRERICHS 1976

11679 PFLUM FRERICHS 1976

11680 PFLUM FRERICHS 1976

11681 PARKER 1954

11682 PARKER 1954

11683 PFLUM FRERICHS 1976

11684 PFLUM FRERICHS 1976

11685 PFLUM FRERICHS 1976

11686 PARKER 1954

11687 PARKER 1954

11688 PARKER 1954

11689 PARKER 1954

11690 PARKER 1954

11691 LUDWICK WALTON 1957

11692 PARKER 1354

11693 PARKER 1354

11694 PARKER 1954

11695 PARKER 1954

11696 PARKER 1954

11696 PARKER
11697 PARKER 1954

11698 PARKER 1954

11699 SHIFFLETT 1961

11700 NORTON 1930
Generic Name Specific Name

FRAG ILIS

FRAGILIS

FRAGILIS

FRAGILIS

FRAGILIS

FRAGILIS

FRAGILIS

FRAGILIS

FRAG ILIS

FRAGILIS

FRAGILIS

FRAGILIS

FRAGILIS

FRAGILIS

FRAGILIS

FRAGILIS

FRAG ILIS

F.RAGILIS

FRAG ILIS

FRAGILIS

FRAGILIS

FRAGILIS

FRAGILIS

FRAGILIS

FRAG ILIS

FRAG ILIS

FRAGILIS

FRAGILIS

FRAGILIS

FRAGILIS

FRAGILIS

FRAG ILIS

FRAG ILIS

FRAGILIS

FRAGILIS

FRAGILIS

FRAGILIS

FRAGILIS

GOESI I

GOES I I

GOES I I

GOESII

GOESI I

GOES I I

GOESI I

GOES I I

GOESI I

GOESII

GOESII

GOESI I

GOESI I

GOESII

GOESII

GOESII

GOESII

GOESI I

GOESI I

HASTATA

HASTATA

HASTATA

HA STATA

HASTATA

HA STAIA

HASTATA

HASTATA

HASTATA

IN FLATA

OAGGARIUS

DAGGARIUS

DAGGARIUS

DAGGARIUS

DAGGARIUS

DAGGARIUS

DAGGARIUS

OAGGARIUS

DAGGARIUS

DAGGARIUS

DAGGARIUS

DAGGARIUS

DAGGARIUS

DAGGARIUS

DAGGARIUS

DAGGARIUS

DAGGARIUS

DAGGARIUS

DAGGARIUS

OAGGARIUS

OAGGARIUS

DAGGARIUS

DAGGARIUS

DAGGARIUS

DAGGARIUS

LINBATA

RECTOBOLIVINA

LINBATA
Locality

Lat. Long.

NE GULF OF MEXICO

NE GULF OF MEXICO

NE GULF OF MEXICO

NE GULF OF MEXICO

NE GULF OF MEXICO

NW GULF OF MEXICO

NW GULF OF MEXICO

NW GULF OF MEXICO

NE GULF OF MEXICO

NW GULF OF MEXICO

NW GULF OF MEXICO

NW GULF OF MEXICO

NW GULF OF MEXICO

NW GULF OF MEXICO

NW GULF OF MEXICO

NW GULF OF MEXICO

NW GULF OF MEXICO

$N W$ GULF OF MEXICO

NW GULF OF MEXICO

NW GULF OF MEXICO

NW GULF OF MEXICO

NW GULF OF MEXICO

NW GULF OF MEXICO

NW GULF OF MEXICO

$N W$ GULF OF MEXICO

NW GULF OF MEXICO

NW GULF OF MEXICO

$N W$ GULF OF MEXICO

NW GULF OF MEXICO

NW GULF OF MEXICO

NW GULF OF MEXICO

NW GULF OF MEXICO

NW GULF OF MEXICO

NW GULF OF MEXICO

NW GULF OF MEXICO

$N W$ GULF OF MEXICO

NW GULF OF MEXICO

NW GULF OF MEXICO

NE GULF OF MEXICO

$N W$ GULF OF MEXICO

NE GULF OF MEXICO

$N$ GULF OF MEXICO

NW GULF OF MEXICO

NE GULF OF MEXICO

$N$ GULF OF MEXICO

NW GULF OF MEXICO

NW GULF OF MEXICO

NE GULF OF MEXICO

NE GULF OF MEXICO

NE GULF OF MEXICO

NE GULF OF MEXICO

NE GULF OF MEXICO

NE GULF OF MEXICO

NE GULF OF MEXICO

NE GULF OF MEXICO

NE GULF OF MEXICO

NW GULF OF MEXICO

$N W$ GULF OF MEXICO

CAPE ROMANO, FLA.

NW GULF OF MEXICO

NW GULF OF MEXICO

NW GULF OF MEX

NW GULF OF MEXICO

NW GULF OF MEXICO

NW GULF OF MEXICO

NW GULF OF MEXICO

NW GULF OF MEXICO

CAPE ROMANO, FLA.

CENTRAL GULF OF MEXICO

NW GULF OF MEXICO

NW GULF OF MEXICO

$N W$ GULF OF MEXICO

CENTRAL GULF OF MEXICO

CENTRAL GULF OF MEXICO

NE GULF OF MEXICO

NE GULF OF MEXICO

CENTRAL GULF OF MEXICO

NW GULF OF MEXICO

NW GULF OF MEXICO

NE GULF OF MEXICO

NE GULF OF MEXICO

NE GULF OF MEXICO

NE GULF OF MEXICO

NE GULF OF MEXICO

NE GULF OF MEXICO

NE GULF OF MEXICO

NE GULF OF MEXICO

NE GULF OF MEXICO

NE GULF OF MEXICO

NE GULF OF MEXICO

NE GULF OF MEXICO

HEALD BANK, G. OF MEXICO

TORTUGAS, FLA

$2915 \mathrm{~N} 08755 \mathrm{~W}$

$28 \quad 57 \mathrm{~N} 085 \quad 54 \mathrm{~W}$ 


\section{Publication}

11701 CUSHMAN 1922A 11702 PHLEGER 1951A 11703 PHLEGER 1951A 11704 PHLEGER 1951 A
11705 PHLEGER 1951 A 11706 PHLEGER 1951 A 11707 PHLEGER 1951A 11708 PHLEGER $1951 \mathrm{~A}$ 11709 PHLEGER 1951A 11710 PHLEGER 1951 A 11711 PHLEGER 1951A 11712 PHLEGER $1951 \mathrm{~A}$ 11713 PHLEGER 1951A 11714 PHLEGER $1951 \mathrm{~A}$ 11715 PHLEGER 1951A 11716 PHLEGER 1951A 11717 PHLEGER 1951A 11718 PHLEGER 1951A 11719 PHLEGER 1951A 11720 PHLEGER 1951A 11721 PHLEGER 1951A 11722 PHLEGER 1951 A 11723 PHLEGER 1951 A 11724 PHLEGER $1951 \mathrm{~A}$ 11725 PHLEGER 1951A 11726 PHLEGER $1951 \mathrm{~A}$ 11727 PHLEGED 1951A 11728 PHLEGER $1951 \mathrm{~A}$ 11729 PHLEGER $1951 \mathrm{~A}$ 11730 PHLEGER 1951A 11731 PHLEGER 1951A 11732 PHLEGER 1951A 11733 PHLEGER 1951A 11734 PHLEGER 1951A 11735 PHLEGER 1951 A 11736 PHLEGER 1951A 11737 PHLEGER 1951A 11738 PHLEGER $1951 \mathrm{~A}$ 11739 PHLEGER 1951A 11740 PHLEGER 1951A 11741 PHLEGER $1951 \mathrm{~A}$ 11742 PARKER 1954

11744 PHLEGER $1951 \mathrm{~A}$ 11744 PHLEGER $1951 \mathrm{~A}$
11745 PHLEGER $1951 \mathrm{~A}$ 11746 PARKER 1954 11747 PARKER 1954 11748 PARKER 1954 11749 PARKEP 1954 11750 PARKER 1954 11751 PARKER 1954

11752 PARKER 1954

11753 PARKER PHLEGER PEIRSON 1953 11754 PARKER PHLEGER PEIRSON 1953 11755 PARKER PHLEGER PEIRSON 1953 11756 PHLEGER 1951A

11758 PARKER 1954

11760 PARKER 1954

11761 PARKER 1954

11762 PHLEGER 1956

11763 PARKER 1954

11764 PARKER 1954

11765 LUDWICK WALTON 1957

11766 PHLEGER 1954

11767 WARREN 1957

11768 LANKFORD 1959

11769 PHLEGER 1954

11770 PHLEGER 1955A

11771 PHLEGER 1955B

11772 PHLEGER LANKFORD 1957

11773 PHLEGER $1955 \mathrm{~A}$

11774 PHLEGER 1955A

11775 PHLEGER 1955 A

11776 PHLEGER 1955 A

11777 PHLEGER 1955 A

11778 PHLEGER 1955 A

11779 PARKER 1954

11780 PARKER 1954

11781 DARKER 1954

11782 PAPKER 1954

11783 PARKER 1954

11784 PARKER 1954

11785 PHLEGER 1956

11786 PARKER 1954

11787 PHLEGER 1956

11788 PARKER 1954

11789 PARKER 1954

11790 PARKER 1954

11791 PARKER 1954

11792 PARKER 1954

11793 PARKER 1954

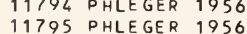

Generic Name

RECTOBOLIVINA

$B O L I V I N A$

BOLIVINA

BOLIVINA

BOLIVINA
BOLIVINA

BOLIVINA

BOLIVINA

BOLIVINA

BOLIVINA

BOLIVINA

BOLIVINA

BOLIVINA

BOLIVINA

BOLIVINA

BOLIVINA

BOLIVINA

BOLIVINA

BOLIVINA

BOLIVINA

BOLIVINA

BOLIVINA

BOLIVINA

BOLIVINA

BOLIVINA

BOLIVINA

BOLIVINA

BOLIVINA

BOLIVINA

BOLIVINA

BOLIVINA

BOLIVINA

BOLIVINA

BOLIVINA

BOLIVINA

BOLIVINA

BOLIVINA

BOLIVINA

BOLIVINA

BOLIVINA

BOLIVINA

BOLIVINA

BOLIVINA

BOLIVINA

BOLIVINA

BOLIVINA

BOLIVINA

BOLIVINA

BOLIVINA

BOLIVINA

BOLIVINA

BOLIVINA

BOLIVINA

BOLIVINA

BOLIVINA

BOLIVINA

BOLIVINA

BOLIVINA

BOLIVINA

BOLIVINA

BOLIVINA

BOLIVINA

BOLIVINA

BOLIVINA

BOLIVINA

BOLIVINA

BOLIVINA

BOLIVINA

BOLIVINA

BOLIVINA

BOLIVINA

BOLIVINA

BOLIVINA

BOLIVINA

BOLIVINA

BOLIVINA

BOLIVINA

BOLIVINA

BOLIVINA

BOLIVINA

BOLIVINA

BOLIVINA

BOLIVINA

BOLIVINA

BOLIVINA

BOLIVINA

BOLIVINA

BOLIVINA
Specific Name

LIMBATA

LOWMANI

LOWMANI

LOWMAN I

LOWMANI

LOWMANI

LOWMANI

LOWMANI

LOWMANI

LO WMANI

LOWMANI

LOWMANI

LOWMANI

LOWMAN

LOWMANI

LOWMANI

LOWMANI

LOWMAN

LOLMAN

LOWMANI

LO WMAN I

LOWMANI

LOWMAN I

LOWMANI

LOWMANI

LOWMAN

LOWMAN I

LOWMANI

LOWMANI

LO WMANI

LOWMANI

LOWMAN I

LOWMANI

LOWMANI

LOWMANI

LOWMAN I

LOWMANI

LOWMANI

LOWMANI

LOWMAN I

LOWMAN I

LOWMAN I

LOWMANI

LOWMANI

LO WMANI

LO WMANZ

LOWMANI

LOWMAN I

LO WMANI

LOWMAN

LO WMAN I

LOWMANI

LO WMANI

LOWMANI

LOWMANI

LOWMANI

LOWMAN I

LO WMAN I

LOWMANI

LO WMAN I

LO WMANI

LO WMANI

LOWMANI

LO WMANI

LOWMAN I

LO WMANI

LO WMANI

LOWMANI

LOWMANI

LOWMANI

LOWMANI

LO WMANI

LOWMANI

LOWMANI

LO WMANI

LOWMANI

LO WMANI

LOWMANI

LO WMANI

LO WMAN I

LOWMAN I

LOWMANI

LOWMANI

LOWMAN I

LOWMANI

Locality

TORTUGAS

NW GULF OF MEXICO

NW GULF OF MEXICO

NW GULF OF MEXICO

NW GULF OF MEXICO

NW GULF OF MEXICO

$N W$ GULF OF MEXICO

NW GULF OF MEXICO

$\mathrm{NW}$ GULF OF MEXICO

$N W$ GULF OF MEXICO

$N W$ GULF OF MEXICO

NW GULF OF MEXICO

$N W$ GULF OF MEXICO

$N W$ GULF OF MEXICO

$\mathrm{NW}$ GULF OF MEXICO

$N W$ GULF OF MEXICO

NW GULF OF MEXICO

$N W$ GULF OF MEXICO

$N W$ GULF OF MEXICO

$N W$ GULF OF MEXICO

NW GULF OF MEXICO

NW GULF OF MEXICO 


\section{Publication}

11796 PHLEGER 1955 A 11797 PARKER 1954 11798 PHLEGER $1951 \mathrm{~A}$ 11799 PHLEGER 1951A 11800 SEGURA 1963 11801 PARKER 1954 11802 PARKER 1954 11803 PARKER 1954 11804 KANE 1962
11805 PARKER 1954 11806 PHLEGER 1965 A 11807 PHLEGER 1965A 11808 HALTON 1964 11810 AYALA-CASTANARES SEGURA 1968 11810 AYALA-CASTANARES SEG 11812 PHLE GER $1951 \mathrm{~A}$ 11813 PHLEGER 1951A 11814 KANE 1967

11815 WALTON 1960

11816 ANDERSEN 1961

11817 ANDERSEN 1961

11818 ANDERSEN 1961

11819 ANDERSEN 1961

11820 CUSHMAN $1922 \mathrm{~A}$

11821 ANDERSEN 1961

11822 PFLUM FRERICHS 1976

11823 PFLUM FRERICHS 1976

11824 PARKER 1954

11825 PARKER 1954

11826 PARKER 1954

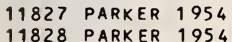

11829 PFLUM FRERICHS 1976

11830 PFLUM FRERICHS 1976 11831 PFLUM FRERICHS 1976

11832 PFLUM FRERICHS 1976

11833 PFLUM FRERICHS 1976

11834 PFLUM FRERICHS 1976

11835 PARKER 1954

11836 PARKER 1954

11837 PFLUM FRERICHS 1976

11838 PFLUM FRERICHS 1976

11839 PHLEGER $1951 \mathrm{~A}$

11840 PARKER 1954

11841 PARKER 1954

11842 PARKER 1954

11843 PARKER 1954

11844 PARKER 1954

11845 PARKER 1954

11846 PHLEGER 1951A

11847 PHLEGER 1951A

11848 PFLUM FRERICHS 1976

11849 PFLUM FRERICHS 1976

11850 PFLUM FRERICHS 1976

11851 LUOWICK WALTON 1957

11852 PHLEGER 1951A

11853 PHLEGER 1951A

11854 PARKER 1954

11855 PHLEGER 1951A

11856 PHLEGER 1951A

11858 PHLEGER 1951A

11859 PHLEGER 1951A

11860 PHLEGER 1951A

11861 PHLEGER 1951A

11862 PHLEGER 1951A

11863 PHLEGER $1951 \mathrm{~A}$

11865 PARKER 1954

11866 PARKER 1954

11867 PARKER 1954

11868 PARKER 1954

11869 PARKER 1954

11870 PFLUM FRERICHS 1976

11871 PFLUM FRERICHS 1976

11872 PARKER 1954

11873 PARKER 1954

11874 PARKER 1954

11875 PARKER 1954

11876 PARKER 1954

11877 PARKER 1954

11878 PARKER 1954

11879 PARKER 1954

11880 PARKER 1954

11881 PARKER 1954

11882 PFLUM FRERICHS 1976

11883 PFLUM FRERICHS 1976

11884 PFLUM FRERICHS 1976

11885 PFLUM FRERICHS 1976

11886 PFLUM FRERICHS 1976

11887 PFLUM FRERICHS 1976

11888 PFLUM FRERICHS 1976

$\begin{array}{ll}11889 & \text { PFLUM FRERICHS } 1976 \\ 11890 \text { PFLUM FRERICHS } & 1976\end{array}$
Generic Name

BOLIVINA

BOLIVINA

BOLIVINA

BOLIVINA
BOLIVINA

BOLIVINA

BOLIVINA

BOLIVINA

BOLIVINA

BOLIVINA

BOLIVINA

BOLIVINA

BOLIVINA

BOLIVINA

BOLIVINA

BOLIVINA

BOLIVINA

BOLIVINA

BOLIVINA

BOLIVINA

BOLIVINA

BOLIVINA
RECTOBOLIVINA

BOLIVINA

BOLIVINA

BOLIVINA

BOLIVINA

BOLIVINA

BOLIVINA

BOLIVINA

BOLIVINA

BOLIVINA

BOLIVINA

BOLIVINA

BOLIVINA

BOLIVINA

BOLIVINA

BOLIVINA

BOLIVINA

BOLIVINA

BOLIVINA

BOLIVINA

BOLIVINA

BOLIVINA

BOLIVINA

BOLIVINA

BOLIVINA

BOLIVINA

BOLIVINA

BOLIVINA

BOLIVINA

BOLIVINA

BOLIVINA

BOLIVINA

BOLIVINA

BOLIVINA

BOLIVINA

BOLIVINA

BOLIVINA

BOLIVINA

BOLIVINA

BOLIVINA

BOLIVINA

BOLIVINA

BOLIVINA

BOLIVINA

BOLIVINA

BOLIVINA

BOLIVINA

BOLIVINA

BOLIVINA

BOLIVINA

BOLIVINA

BOLIVINA

BOLIVINA

BOLIVINA

BOLIVINA

BOLIVINA

BOLIVINA

BOLIVINA

BOLIVINA

BOLIVINA

BOLIVINA

BOLIVINA

BOLIVINA

BOLIVINA

BOLIVINA

BOLIVINA

BOLIVINA

BOLIVINA

BOLIVINA

BOLIVINA
Specific Name

LOWMANI
LOWMANI
LOWMANI
LOWMANI
LOWMANI
LOWMANI
LOWMANI
LOWMANI
LOWMANI
LOWMANI
LOWMANI
LOWMANI
LOUMANI
LOWMANI
LOWMANI
LOWMANI
LOWMANI
LOWMANI
LOWMANI
LOWMANI
LOWMANI
LOWMANI
LOWMANI
LOWMANI
MAYORI
SU BAENARI ENSIS MEXICANA
MINIMA

MI NIMA

MINIMA

MINIMA

MINIMA

MI I IMA

MI IIMA

MINIMA

MINIMA

MINIMA

MINIMA

MINIMA

MINIMA

MINIMA

MINIMA

MINIMA

MINIMA

MI N IMA

MINIMA

MINIMA

MINIMA

MINIMA

MINIMA

MINIMA

MINIMA

MINIMA

MINIMA

MINIMA

MINIMA

MINIMA

MINIMA

MINIMA

MIAIMA

MINIMA

MINIMA

MINIMA

MINIMA

MINIMA

MINIMA

MINIMA

MINIMA

OR DINARIA

ORDINARIA

ORDINARIA

ORCINARIA

OR DINARIA

ORDINARIA

OR DINARIA

ORDINARIA

OR DINARIA

OR IINARIA

ORDINARIA

ORDINARIA

OR DINARIA

ORDINARIA

ORDINARIA

ORDINARIA

ORDINARIA

OR DINARIA

ORDINARIA

ORDINARIA

ORDINARIA

ORDINARIA

OR DINARIA

OR DINARIA

ORDINARIA

OR DINARIA

Locality

Lat. Long.

$N$ GULF OF MEXICO

NE GULF OF MEXICO

NU GULF OF MEXICO

NW GULF OF MEXICO

MATAMOROS, MEXICO

NE GULF OF MEXICO

NE GULF OF MEXICO

SABINE LAKE. TEXAS

NE GULF OF MEXICO

PASS CAVALLO. TEXAS

COLORADO R. DELTA. TEXAS

TAMPA-SARA SOTA BAY, FLA.

BURAS SE LOUISIANA

LAGUNA MADRE, NE TEXAS

L. DE TERMINOS, CAMPECHE

NH GULF OF MEXICO

NH GULF OF MEXICO

SAB INE LAKE, TEXAS

$M I S S I S S I P P I$ SOUND

MISSISSIPPI DELTA

MISSISSIPPI DELTA

MISSISSIPPI DELTA

MISSISSIPPI DELTA

TORTUGAS

MISSISSIPPI DELTA

CENTRAL GULF OF MEXICO

CENTRAL GULF OF MEXICO

NE GULF OF MEXICO

NE GULF OF MEXICO

NE GULF OF MEXICO

NE GULF OF MEXICO

NE GULF OF MEXICO

NW GULF OF MEXICO

NW GULF OF MEXICO

NY GULF OF MEXICO

NW GULF OF MEXICO

NW GULF OF MEXICO 


\section{Publication}

11891 PFLUM FRERICHS 1976 11892 PFLUM FRERICHS 1976 11893 PFLUM FRERICHS 1976 11894 PFLUM FRERICHS 1976 11895 PFLUM FRERICHS 1976 11896 PFLUM FRERICHS 1976 11897 PFLUM FRERICHS 1976 11898 PFLUM FRERICHS 1976 11899 PFLUM FRERICHS 1976 11900 PFLUM FRERICHS 1976 11901 PFLUM FRERICHS 1976 11902 PFLUM FRERICHS 1976 11903 PFLUM FRERICHS 1976 11904 PFLUM FRERICHS 1976 11905 PFLUM FRERICHS 1976 11906 PFLUM FRERICHS 1976 11907 PARKER 1954

11908 PARKER 1954

11909 PARKER 1954

11910 PARKER 1954

11911 PHLEGER 1955A

11912 PARKER 1954

11913 PHLEGER 1955A

11914 PHLEGER 195SA

11915 PFLUM FRERICHS 1976

11916 PARKER 1954

11917 PARKER 1954

11918 PARKER 1954

11919 PARKER 1954

11920 PARKER 1954

1921 PARKER 1954

11922 PARKER 1954

11923 PHLEGER 1955 A

11924 PHLEGER 1955 A

11925 PARKER 1954

11926 PARKER 1954

11927 PARKER 1954

11928 PARKER 1954

11929 PARKER 1954

11930 PFLUM FRERICHS 1976

11931 PHLEGER 19658

11932 PHLEGER 19658

1933 PFLUM FRERICHS 1976

11934 PFLUM FRERICHS 1976

11935 AYALA-CASTANARES 1963

11936 WALTON 1960

11937 NORTON 1930

11938 CUSHMAN $1922 \mathrm{~A}$

11939 SEGURA 1963

11940 PARKER 1954

11941 PHLEGER 1951A

11942 PHLEGER 1955A

11943 PHLEGER 1951A

11944 PARKER 1954

11945 PARKER 1954

11946 PARKER 1954

11947 PARKER 1954

11948 LUDHICK WALTON 1957

11949 PHLEGER 1954

11950 PARKER 1954

11951 PARKER 1954

11952 PARKER 1954

11953 PARKER 1954

11954 PARKER 1954

11955 PHLEGER 1951A

11956 PHLEGER 1955A

11957 PHLEGER 1955 A

11958 PHLEGER 1954

11959 LANKFORD 1959

11960 PHLEGER 1955A

11961 PHLEGER 1951A

11962 PARKER 1954

11963 PARKER 1954

11964 PHLEGER 1956

11965 PHLEGER 1956

11966 PARKER 1954

11967 PARKER 1954

11968 BENDA PURI 1962

11969 KELLOUGH 1956

11970 BANDY 1956

11971 BANDY 1956

11972 PHLEGER 1951A

11973 PHLEGER 1951A

11974 PHLEGER 1951A

11975 PHLEGER 1951A

11976 PHLEGER 1951A

11977 PHLEGER 1951A

11978 PHLEGER 1951A

11979 AYALA-CASTANARES 1963

11980 PARKER PHLEGER PEIRSON 1953

11981 PHLEGER 1951A

11982 PHLEGER 1951A

11983 PHLEGER 1951A

11984 PHLEGER 1951A
11985 PHLEGER $1951 \mathrm{~A}$
Generic Name

BOLIVINA

BOLIVINA

BOLIVINA

BOLIVINA

BOLIVINA

BOLIVINA

BOLIVINA

BOLIVINA

BOLIVINA

BOLIVINA

BOLIVINA

BOLIVINA

BOLIVINA

BOLIVINA

BOLIVINA

BOLIVINA

BOLIVINA

BOLIVINA

BOLIVINA

BOLIVINA

BOLIVINA

BOLIVINA

BOLIVINA

BOLIVINA

BOLIVINA

BOLIVINA

BOLIVINA

BOLIVINA

BOLIVINA

BOLIVINA

BOLIVINA

BOLIVINA

BOLIVINA

BOLIVINA

BOLIVINA

BOLIVINA

BOLIVINA

BOLIVINA

BOLIVINA

BOLIVINA

SAGRINA

SAGRINA

SAGRINA

SAGRINA

SA GR INA

SAGRINA

SAGR INA

SAGR INA

SAGRINA

SAGR INA

SAGR INA

SAGR INA

SAGRINA

SAGRINA

SAGRINA

SAGRINA

SAGRINA

SAGRINA

SAGRINA

SAGR INA

SAGR INA

SAGR INA

SAGR INA

SAGR INA

SAGR INA

SAGRINA

SAGRINA

SAGR INA

SAGR INA

SAGR INA

SAGRINA

SAGRINA

SAGR INA

SAGR INA

SAGRINA

SAGRINA

SAGR INA

SAGRINA

SAGRINA

SAGRINA

SAGRINA

SAGR INA

SAGR INA

SAGRINA

SAGRINA

SAGR INA

SAGRINA

SAGRINA
Specific Name

OR DINARIA

OR DINARIA

ORDINARIA

ORDINARIA

OR DINAR IA

OR DINARIA

OR DINARIA

OR CINARIA

OR DINAR I A

ORDINARIA

OR DINAR I A

ORDINARIA

OR DINARIA

OR DINARIA

ORDINARIA

OR DINARIA

ORDINARIA

ORDINARIA

OR DINAR I A

OR OINARIA

OR DINARIA

ORDINARIA

OR DINARIA

OR DINARIA

PAULA

PAULA

PAULA

PAULA

PAULA

PAULA

PAULA

PAULA

PAULA

PAULA

PAULA

PAULA

PAULA

PSEUDOPLICATA

PS EUDOPLICATA

PSEUDOPLICATA

PSEUDOPLICATA

PS EUDOPL I CATA

PSEUDOPLICATA

PULCHELLA

PULCHELLA

PULCHELLA

PULCHELLA

PULCHELLA

PULCHELLA

PULCHELLA

PULCHELLA

PULCHELLA

PULCHELLA

PULCHELLA

PULCHELLA

PULCHELLA

PULCHELLA

PULCHELLA

PULCHELLA

PULCHELLA

PULCHELLA

PULCHELLA

PU LCHELLA

PULCHELLA

PULCHELLA

PULCHELLA

PULCHELLA

PULCHELLA

PULCHELLA

PULCHELLA

PULCHELLA

PULCHELLA

PULCHELLA

PULCHELLA

PULCHELLA

PULCHELLA

PULCHELLA

PULCHELLA

PULCHELLA

PULCHELLA

PULCHELLA

PULCHELLA

PULCHELLA

PULCHELLA

PULCHELLA

PULCHELLA

PULCHELLA

HELLA

PULCHELLA

PULCHELLA

PULCHELLA

Locality

NH GULF OF MEXICO

NW GULF OF MEXICO

CENTRAL GULF OF MEXICO

CENTRAL GULF OF MEXICO

CENTRAL GULF OF MEXICO

CENTRAL GULF OF MEXICO

NW GULF OF MEXICO

NW GULF OF MEXICO

NW GULF OF MEXICO

NW GULF OF MEXICO 
Publication

11986 PHLEGER 1951A

11987 PHLEGEQ 1951 A

11988 PHLEGER 1951A

11989 PHLEGER 1951 A

11990 PHLEGER 1956

11991 PHLEGER 1956

11992 PARKER 1954

11993 PARKER 1954

11994 PARKER 1954

11995 PARKER 1954

11996 PARKER 1954

11997 PARKER 1954

11998 CUSHMAN 19228

11999 DAVIS 1964

12000 PARKER 1054

12001 PARKER 1954

12002 PFLUM FRERICHS 1976
12003 PFLUM FRERICHS 1976

$\begin{array}{lll}12003 & \text { PFLUM FRERICHS } & 1976 \\ 12004 & \text { PFLUM FRERICHS } & 1976\end{array}$

12004 PFLUM FRERI
12005 PARKER 1354

12006 PFLUM FRERICHS 1976

12007 PFLUM FRERICHS 1976

12008 PFLUM FRERICHS 1976

12009 PARKER 1954

12010 PARKER 1954

12011 PARKER 1954

12012 PFLUM FRERICHS 1976

12013 PFLU Y FRERICHS 1976

12014 PFLUM FRERICHS 1976

12015 PFLUM FRERICHS 1976

12016 PFI.UM FRERICHS 1976

12017 PFLUM FRERICHS 1976

12018 PFLUM FRERICHS 1976

12019 PFLUM FRERICHS 1976

12020 PFLUM FRERICHS 1976

12021 PFLUM FRERICHS 1976

12022 PFLUM FRERICHS 1976

12023 PARKER 1954

12024 PARKER 1954

12025 PARKER 1954

12026 PARKER 1954

12027 PARKER 1954

12028 PARKER 1954

12030 PFLUM FRERICHS 1976

12031 PFLUM FRERICHS 1976

12032 PFLUM FRERICHS 1976

12033 PFLUM FRERICHS 1976

12034 PFLUM FRERICHS 1976

12035 PFLUM FRERICHS 1976

12036 PFLUM FRERICHS 1976

12037 PFLUM FRERICHS 1976

12038 PFLUM FRERICHS 1976

12039 PFLUM FRERICHS 1976

12040 PFLUM FRERICHS 1976

12041 PFLUM FRERICHS 1976

12042 PFLUM FRERICHS 1976

12043 PFLUM FRERICHS 1976

12044 PFLUM FRERICHS 1976

12045 PFLUM FRERICHS 1976

12046 PFLUM FRERICHS 1976

12047 PFLUM FRERICHS 1976

12048 PFLUM FRERICHS

12050 PFLUM FRERICHS 1976

12051 PFLUM FRERICHS 1976

12052 PHLEGER $1951 \mathrm{~A}$

12053 PHLEGER 1951A

12054 PHLEGER 1951 A

12055 PHLEGER 1951A

12056 PHLEGER $1951 \mathrm{~A}$

12057 PHLEGER 1951A

12058 PHLEGER 1951A

12059 PHLEGER 1951 A

12060 PHLEGER 1951A

12061 PHLEGER 1951A

12062 PHLEGER $1951 \mathrm{~A}$

12063 PHLEGER 1951 A

12064 PHLEGER $1951 \mathrm{~A}$

12065 PHLEGER 1951A

12066 PHLEGER 1951A

12067 PHLEGER 1951A

12068 PHLEGER 1951A

12069 PHLEGER 1951A

12070 PHLEGER 1951A

12071 PHLEGER 1951A

12072 PHLEGER 1951A

12073 PHLEGER $1951 \mathrm{~A}$

12074 PHLEGER 1951A

12075 PHLEGER 1951A

12076 PHLEGER 1951A

12077 PHLEGER 1951A

12078 PHLEGER 1951A

12079 BENDA PURI 1962
12080 CREAGER 1958
Generic Name Specific Name

PULCHELLA

SAGRINA

SAGRINA

SAGRINA

SAGR INA

SAGRINA

SAGRINA

SAGR INA

SAGRINA

SAGR INA

SA GRINA

SAGRINA

BOLIVINA

BOLIVINA

BOLIVINA

BOLIVINA

BOLIVINA

BOLIVINA

BOLIVINA

BOLIVINA

BOLIVINA

BOLIVINA

BOLIVINA

BOLIVINA

BOLIVINA

BOLIVINA

BOLIVINA

BOLIVINA

BOLIVINA

BOLIVINA

BOLIVINA

BOLIVINA

BOLIVINA

BOLIVINA

BOLIVINA

BOLIVINA

BOLIVINA

BOLIVINA

BOLIVINA

BOLIVINA

BOLIVINA

BOLIVINA

BOLIVINA

BOLIVINA

BOLIVINA

BOLIVINA

BOLIVINA

BOLIVINA

BOLIVINA

BOLIVINA

BOLIVINA

BOLIVINA

BOLIVINA

BOLIVINA

BOLIVINA

BOLIVINA

BOLIVINA

BOLIVINA

BOLIVINA

BOLIVINA

BOLIVINA

BOLIVINITA

BOLIVINA

BOLIVINA

BOLIVINA

BOLIVINA

BOLIVINA

BOLIVINA

BOLIVINA

BOLIVINA

BOLIVINA

BOLIVINA

BOLIVINA

BOLIVINA

BOLIVINA

BOLIVINA

BOLIVINA

BOLIVINA

BOLIVINA

BOLIVINA

BOLIVINA

BOLIVINA

BOLIVINA

BOLIVINA

BOLIVINA

BOLIVINA

BOLIVINA

BOLIVINA

BOLIVINA

BOLIVINA

BOLIVINA

BOLIVINA

BOLIVINA
Locality

Lat. Long.

WW GULF OF MEXICO

NW GULF OF MEXICO

NW GULF OF MEXICO

NW GULF OF MEXICO

NW GULF OF MEXICO

NW GULF OF MEXICO

NE GULF OF MEXICO

NE GULF OF MEXICO

NE GULF OF MEXICO

NE GULF OF MEXICO

NE GULF OF MEXICO

NE GULF OF MEXICO

NE GULF OF MEXICO

CAMPECHE BANK, MEXICO

NE GULF OF MEXICO

NE GULF OF MEXICO

NW GULF OF MEXICO

NW GULF OF MEXICO

NW GULF OF MEXICO

NE GULF OF MEXICO

CENTRAL GULF OF MEXICO

CENTRAL GULF OF MEXICO

CENTRAL GULF OF MEXICO

NE GULF OF MEXICO

NE GULF OF MEXICO

NE GULF OF MEXICO

$N W$ GULF OF MEXICO

NW GULF OF MEXICO

$N W$ GULF OF MEXICO.

NW GULF OF MEXICO

NW GULF OF MEXICO

NW GULF OF MEXICO

NW GULF OF MEXICO

NW GULF OF MEXICO

NW GULF OF MEXICO

$N W$ GULF OF MEXICO

CENTRAL GULF OF MEXICO

NE GULF OF MEXICO

NE GULF OF MEXICO

NE GULF OF MEXICO

NE GULF OF MEXICO

NE GULF OF MEXICO

NE GULF OF MEXICO

NE GULF OF MEXICO

CENTRAL GULF OF MEXICO

CENTRAL GULF OF MEXICO

CENTRAL GULF OF MEXICO

CENTRAL GULF OF MEXICO

CENTRAL GULF OF MEX

$\mathrm{NW}$ GULF OF MEXICO

NW GULF OF MEXICO

CENTRAL GULF OF MEXICO

NW GULF OF MEXICO

CENTRAL GULF OF MEXICO

NW GULF OF MEXICO

NW GULF OF MEXICO

NW GULF OF MEXICO

NW GULF OF MEXICO

CENTRAL GULF OF MEXICO

CENTRAL GULF OF MEXICO

NW GULF OF MEXICO

TOR TUG AS

NW GULF OF MEXICO

NW GULF OF MEXICO

NW GULF OF MEXICO

NW GULF OF MEXIC

NW GULF OF MEXICO

NW GULF OF MEXICO

NW GULF OF MEXICO

NU GULF OF MEXICO

NW GULF OF MEXICO

NW GULF OF MEXICO

NW GULF OF MEXICO

NW GULF OF MEXICO

NW GULF OF MEXICO

NW GULF OF MEXICO

NW GULF OF MEXICO

V. GULF OF MEXICO

NW GULF OF MEXICO

NW GULF OF MEXICO

NW GULF OF MEXICO

NW GULF OF MEXICO

$N$ GULF OF MEXICO

NW GULF OF MEXICO

NW GULF OF MEXICO

$N W$ GULF OF MEXICO

NW GULF OF MEXICO

$\mathrm{NW}$ GULF OF MEXICO

NW GULF OF MEXICO

NW GULF OF MEXICO

NW GULF OF MEXICO

CAPE ROMANO, FLA.

BAY OF CAMPECHE

$\begin{array}{lllll}28 & 06 N & 094 & J 7 W\end{array}$ $2814 \mathrm{~N} 09438 \mathrm{H}$ $2740 \mathrm{~N} 094$ 00W $2800 N 096 \quad 40 \mathrm{~W}$ $2753 \mathrm{~N} 096$ 50W $2630 \mathrm{~N} 08456 \mathrm{~W}$ 


\section{Publication}

12081 CREAGER 1958 12082 CREAGER 1958 12083 ANDERSEN 1961 12084 ANDERSEN 1961 12085 CREAGER 1958 12086 CREAGER 1958 12087 CREAGER 1958 12088 CREAGER 1958 12089 CREAGER 1958 12090 WALTON 1960

12091 AYALA-CASTANARES SEGURA 1968 12092 AYALA-CASTANARES 1963

12093 WALTON 1964

12094 NORTON 1930

12096 PARKER PHLEGER PEIRSON 1953 12097 PARKER PHLEGER PEIRSON 1953 12098 WARREN 1957

12099 LANKFORD 1959

12100 PHLEGER 1955B

12101 PHLEGER LANKFORD 1957

12102 WARREN 1956

12103 PHLEGER 1956

12104 PHLEGER 1956

12105 PHLEGER 1956

12106 PHLEGER 1956

12107 PARKER PHLEGER PEIRSON 1953

12108 PARKER PHLEGER PEIRSON 1953

12109 PARKER PHLEGER PEIRSON 1953

12110 PARKER PHLEGER PEIRSON 1953

12111 PARKER PHLEGER PEIRSON 1953

12112 BANDY 1954

12113 BANDY 1954

12114 BANDY 1954

12115 KELLOUGH 1956

12116 BANDY 1954

12117 PARKER PHLEGER PEIRSON 1953 12118 POST 1951

12119 PHLEGER 1956

12120 CUSHMAN 1922A

12121 PHLEGER 1965A

12122 BENDA PURI 1962

12123 PHLEGER $1965 \mathrm{~A}$

12124 BANDY 1956

12125 LEHMANN 1957
12126 WALDRON 1963

12127 PHLEGER 1960

12128 KANE 1962

12129 KANE 1967

12130 SEGURA 1963

12131 PHLEGER 1965 B

12132 PHLEGER $1965 \mathrm{~B}$

12133 PHLEGER 1951A

12134 LANKFORD 1959

12135 PHLEGER $1951 \mathrm{~A}$

12137 PFLUM FRERICHS 1976

12138 PFLUM FRERICHS 1976

12139 PARKER 1954

12140 PARKER 1954

12141 PHLEGER 1954

12143 PARKER 1954

12144 PARKER 1954

12145 PARKER 1954

12146 PHLEGER $1951 \mathrm{~A}$

12147 WARREN 1957

12148 PARKER 1954

12149 PARKER 1954

12150 CREAGER 1958

12151 CREAGER 1958

12152 PHLEGER 1951 A

12153 PHLEGER 1951A

12154 PHLEGER 1951A

12155 PHLEGER $1951 \mathrm{~A}$

12157 PHLEGER 1951A

12158 PHLEGER 1951A

12159 PHLEGER 1951A

12160 PARKER 1954

12161 PHLEGER 1951A

12163 PHLEGER 1951A

12164 PARKER 1954

12165 PHLEGER 1951A

12166 CREAGER 1958

12167 WARREN 1956

12168 KELLOUGH 1956

12169 LOEP 1965

12170 PHLEGER 1956

12171 PHLEGER 1956

12172 PARKER 1954

12173 KELLOUGH 1956

12174 PHLEGER $1951 \mathrm{~A}$
12175 PHLEGER $1951 \mathrm{~A}$
Generic Name

BOLIVIN

BOLIVINA

BOLIVINA

BOLIVINA

BOLIVINA

BOLIVINA

BOLIVINA

BOLIVINA

BOLIVINA

BOLIVINA

BOLIVINA

BOLIVINA

BOLIVINA

BOLIVINA

BOLIVINA

BOLIVINA

BOLIVINA

BOLIVINA

BOLIVINA

BOLIVINA

BOLIVINA

BOLIVINA

BOLIVINA

BOLIVINA

BOLIVINA

BOLIVINA

BOLIVINA

BOLIVINA

BOLIVINA

BOLIVINA

BOLIVINA

BOLIVINA

BOLIVINA

BOLIVINA

BOLIVINA

BOLIVINA

BOLIVINA

BOLIVINA

BOLIVINA

BOLIVINA

BOLIVINA

BOLIVINA

BOLIVINA

BOLIVINA

BOLIVINA

BOLIVINA

BOLIVINA

BOLIVINA

BOLIVINA

BOLIVINA

BOLIVINA

BOLIVINA

BOLIVINA

BOLIVINA

BOLIVINA

BOLIVINA

BOLIVINA

BOLIVINA

BOLIVINA

BOLIVINA

BOLIVINA

BOLIVINA

BOLIVINA

BOLIVINA

BOLIVINA

BOLIVINA

BOLIVINA

BOLIVINA

BOLIVINA

BOLIVINA

BOLIVINA

BOLIVINA

BOLIVINA

BOLIVINA

BOLIVINA

BOLIVINA

BOLIVINA

BOLIVINA

BOLIVINA

BOLIVINA

BOLIVINA

BOLIVINA

BOLIVINA

BOLIVINA

BOLIVINA

BOLIVINA

BOLIVINA
Specific Name

SPICATA

STRIATULA SPINATA

STRIATULA SPINATA

SU BAENARIENSIS MEXI CANA

SUEAENARIENSIS MEXICANA

SUEAENARIENSIS MEXICANA

SU BAENARIENSIS MEXI CANA

SUEAENARIENSIS MEXI CANA

STRIATULA

STRIATULA

STRIATULA

STRIATULA

STRIATULA

STRIATULA

STRIATULA

STRIATULA

STRIATULA

STRIATULA

ST RIATULA

STRIATULA

STRIATULA

STRIATULA

STRIATULA

STRIATULA

STRIATULA

STRIATULA

STRIATULA

STRIATULA

STRIATULA

STRIATULA

STRIATULA

STRIATULA

STRIATULA

STRIATULA

STRIATULA

STRIATULA

STRIATULA

STRIATULA

STRIATULA

STRIATULA

STRI ATULA

STRIATULA

STRIATULA

STRIATULA

STRIATULA

STRIATULA

STRIATULA

STRIATULA

STRIATULA

STRIATULA

STRIATULA

STRIATULA SPINATA

STRIATULA SPINATA

STRIATULA SPINATA

STRIATULA SPINATA

STRIATULA SPINATA

STRIATULA SPINATA

STRIATULA SPINATA

STRIATULA SPINATA

STRIATULA SPINATA

STRIATULA SPINATA

STRIATULA SPINATA

STRIATULA SPINATA

STRIATULA SPINATA

STRIATULA SPINATA

STRIATULA SPINATA

STRIATULA SPINATA

STRIATULA SPINATA

STRIATULA SPINATA

STRIATULA SPINATA

STRIATULA SPINATA

STRIATULA SPINATA

STRIATULA SPINATA

STRIATULA SPINATA

STRIATULA SPINATA

STRIATULA SPINATA

STRIATULA SPINATA

STRIATULA SPINATA

STRIATULA SPINATA

STRIATULA SPINATA

STRIATULA SPINATA

STRIATULA SPINATA

STRIATULA SPINATA

STRIATULA SPINATA

STRIATULA SPINATA

STRIATULA SPINATA

STRIATULA SPINATA

STRIATULA SPINATA

STRIATULA SPINATA

STRIATULA SPINATA

STRIATULA SPINATA

STRIATULA SPINATA

STRIATULA SPINATA

STRIATULA SPINATA

Locality

Lat. Long.

BAY OF CAMPECHE

BAY OF CAMPECHE

MISSISSIPPI DELTA

MISSISSIPPI DELTA

BAY OF CAMPECHE

BAY OF CAMPECHE

BAY OF CAMPECHE

BAY OF CAMPECHE

BAY OF CAMPECHE

LAGUNA MADRE, NE TEXAS

L. DE TERMINOS, CAMPECHE

TAMPA-SARASOTA BAY, FLA.

TORTUGAS, FLA

SOUTH TEXAS COAST 
Publication

12176 PHLEGER 1951A 12177 PHLEGER 19.51 A 12178 PHLEGER 19.51 A 12179 PHLEGER 1951A

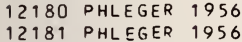
12182 PHLEGER $1951 \mathrm{~A}$ 12183 PHLEGER 1951A 12184 PHLEGER 1951A 12185 PHLEGER 1951A 12186 PHLEGER $1951 \mathrm{~A}$ 12187 PHLEGER $1951 \mathrm{~A}$ 12188 PARKER 1954 12189 PHLEGER 1951 A 12190 PHLEGER 1951A 12191 PFLUM FRERICHS 1976 12192 PARKER 1954 12193 PARKER 1954 12194 PARKER 1954 12195 PARKER 1954 12196 PARKER 1754 12197 PFLUM FRERICHS 1976 12198 PFLUM FRERICHS 1976 12199 PARKER 1954 12200 PARKER 1954

12201 PFLUM FRERICHS 1976 12202 PFLUM FRERICHS 1976 12203 PFLUM FRERICHS 1976 12204 PFLUM FRERICHS 1976 12205 PFLUM FRERICHS 1976 12206 PFLUM FRERICHS 1976 12207 PFLUM FRERICHS 1976 12208 PFLUM FRERICHS 1976 12209 PARKER 1954

12210 PARKER 1954

12211 PARKER 1954

12212 PARKER 1954

12213 PFLUM FRERICHS 1976

12214 PFLUM FRERICHS 1976 12215 PFLUM FRERICHS 1976 12216 PFLUM FRERICHS 1976 12217 PFLUM FRERICHS 1976 12218 PFLUM FRERICHS 1976 12219 PFLUM FRERICHS 1976 12220 PFLUM FRERICHS 1976 12221 PFLUM FRERICHS 1976 12222 PFLUM FRERICHS 1976 12223 PFLUM FRERICHS 1976 12224 PFLUM FRERICHS 1976 12225 PARKER 1954 12226 PARKER 1954 12227 PARKER 1954 12228 PARKER 1954 12229 PHLEGER $1951 \mathrm{~A}$ 12230 PHLEGER $1951 \mathrm{~A}$ 12231 PFLUM FRERICHS 1976 12232 PFLUM FRERICHS 1976 12233 PFLUM FRERICHS 1976 12234 PFLUM FRERICHS 1976 12235 PFLUM FRERICHS 1976 12236 PHLEGER 1951A 12237 PFLUM FRERICHS 1976 12238 PFLUM FRERICHS 1976 12239 PFLUM FRERICHS 1976 12240 PFLUM FRERICHS 1976 12241 PARKER 1954

12242 PHLEGER 1955A

12243 PARKER 1954

12244 PHLEGER $1951 \mathrm{~A}$

12245 PHLEGER $1951 \mathrm{~A}$

12247 -LUDWICK WALTON 1957

12248 PHLEGER 1951 A

12249 PHLEGER 1951A 12250 PHLEGER 1951A 12251 PHLEGER 1955A 12252 PHLEGER 1951 A 12253 PHLEGER 1955A 12254 PHLEGER $1951 \mathrm{~A}$ 12255 PHLEGER 1951A 12256 CUSHMAN 1922B 12257 CUSHMAN 19228 12258 CUSHMAN 19228 12250 CUSHMAN 19228

12260 LOEP 1965

12261 LOEP 1965

12262 BANDY 1956

12263 KELLOUGH 1956

12264 BANDY 1956

12265 PFLUM FRERICHS 1976

12266 PHLEGER $1951 \mathrm{~A}$

12267 PHLEGER 1951 A

12268 PHLEGER 1951A

12269 PHLEGER 1951A

12270 PHLEGER 1951A
Generic Name

Specific Name

BOLIVINA

BOLIVINA

BOLIVINA

BOLIVINA

BOLIVINA

BOLIVINA

BOLIVINA

BOLIVINA

BOLIVINA

BOLIVINA

BOLIVINA

BOLIVINA

BOLIVINA

BOL IV INA

BOLIVINA

BOLIVINA

BOLIVINA

BOLIVINA

BOLIVINA

BOLIVINA

BOLIVINA

BOLIVINA

BOLIVINA

BOLIVINA

BOLIVINA

BOLIVINA

BOLIVINA

BOLIVINA

BOLIVINA

BOLIVINA

BOLIVINA

BOLIVINA

BOLIVINA

BOLIVINA

BOLIVINA

BOLIVINA

BOLIVINA

BOLIVINA

BOLIVINA

BOLIVINA

BOLIVINA

BOLIVINA

BOLIVINA

BOLIVINA

BOLIVINA

BOLIVINA

BOLIVINA

BOLIVINA

BOLIVINA

BOLIVINA

BOLIVINA

BOLIVINA

BOLIVINA

BOLIVINA

BOLIVINA

BOLIVINA

BOLIVINA

BOLIVINA

BOLIVINA

BOLIVINA

BOLIVINA

BOLIVINA

BOLIVINA

BOLIVINA

BOLIVINA

BOLIVINA

BOLIVINA

BOLIVINA

BOLIVINA

BOLIVINA

BOLIVINA

BOLIVINA

BOLIVINA

BOLIVINA

BOLIVINA

BOLIVINA

BOLIVINA

BOLIVINA

BOLIVINA

BOLIVINA

BOLIVINA

BOLIVINA

BOLIVINA

BOLIVINA

BOLIVINA

BOLIVINA

BOLIVINA

BOLIVINA

BOLIVINA

BOLIVINA

BOLIVINA
STRIATULA SPINATA

STRIATULA SPINATA

STRIATULA SPINATA

STRIATULA SPINATA

STRIATULA SPINATA

STRIATULA SPINATA

STRIATULA SPINATA

STRIATULA SPINATA

STRIATULA SPINATA

STRIATULA SFINATA

STRIATULA SPINATA

SUEAENARI ENSIS

SUEAENARIENSIS MEXICANA

SUEAENARIENSIS

SUEAENARI ENSIS

SUEAENARIENSIS MEXICANA

SUEAENARIENSIS MEXICANA

SUEAENARIENSIS MEXI CANA

SUBAENARIENSIS MEXICANA

SUEAENARIENSIS MEXICANA

SUEAENARIENSIS MEXI CANA

SUBAENARIENSIS MEXICANA

SUEAENARI ENSIS MEXI CANA

SUEAENARIENSIS MEXICANA

SUEAENARIENSIS MEXI CANA

SUBAENARIENSIS MEXICANA

SUEAENARIENSIS MEXICANA

SUEAENARIENSIS MEXICANA

SUEAENARIENSIS MEXICANA

SUBAENARIENSIS MEXICANA

SUEAENARIENSIS MEXICANA

SUBAENARIENSIS MEXICANA

SUEAENARIENSIS MEXICANA

SUEAENARIENSIS MEXICANA

SUEAENARIENSIS MEXICANA

SUEAENARIENSIS MEXICANA

SUEAENARIENSIS MEXICANA

SUEAENARIENSIS MEXICANA

SUEAENARIENSIS MEXI CANA

SUEAENARIENSIS MEXI CANA

SUEAENARIENSIS MEXICANA

SUEAENARIENSIS MEXICANA

SU BAENARIENSIS MEXICANA

SUEAENARIENSIS MEXICANA

SUEAENARIENSIS MEXI CANA

SUBAENARIENSIS MEXICAVA

SUEAENARIENSIS MEXICANA

SUEAENARIENSIS MEXI CANA

SUBAENARIENSIS MEXICANA

SUEAENARIENSIS MEXICANA

SUEAENARIENSIS MEXICANA

SUBAENARIENSIS MEXICANA

SUBAENARIENSIS MEXICANA

SUEAENARIENSIS MEXICANA

SUEAENARIENSIS MEXI CANA

SUEAENARIENSIS MEXICANA

SUEAENARIENSIS MEXICANA

SUEAENARIENSIS MEXICANA

SUEAENARIENSIS MEXI CANA

SUEAENARIENSIS MEXICANA

SUEAENARIENSIS MEXICANA

SUEAENARIENSIS MEXICANA

SUEAENARIENSIS MEXI CANA

SUBAENARIENSIS MEXICANA

SUEAENARIENSIS MEXI CANA

SUEAENARIENSIS MEXICANA

SUEAENARIENSIS MEXI CANA

SUBAENARIENSIS MEXICANA

SUEAENARIENSIS MEXI CANA

SUEAENARIENSIS MEXI CANA

SUEAENARIENSIS MEXICANA

SUEAENARIENSIS MEXICANA

SUEAENARIENSIS MEXICANA

SUEAENARIENSIS MEXICANA

SUEAENARIENSIS MEXICANA

SUBAENARIENSIS MEXI CANA

SUEAENARIENSIS MEXICANA

SUEAENARIENSIS MEXICANA

SUEAENARIENSIS MEXI CANA

SUEAENARIENSIS MEXICANA

SUEAENARIENSIS MEXI CANA

SUBAENARIENSIS MEXICANA

SUEAENARIENSIS MEXI CANA

SUEAENARIENSIS MEXICANA SUBAENARIENSIS MEXICANA SUBAENARIENSIS MEXICANA SURAENARIENSIS MEXICANA SUEAENARIENSIS MEXICANA SUEAENARIENSIS MEXICANA SUEAENARIENSIS MEXI CANA SUEAENARIENSIS MEXICANA SUEAENARIENSIS MEXICANA SUEAENARIENSIS MEXICANA SUEAENARIENSIS MEXICANA

Locality

Lat. Long.

NW GULF OF MEXICO

NW GULF

NW GULF OF MEXICO

NW GULF OF MEXICO

NW GULF OF MEXICO

NW GULF OF MEXICO

NW GULF OF MEXICO 


\section{Publication}

12271 PHLEGER 1951A 12272 CREAGER 1958 12273 CREAGER 1958 12274 CREAGER 1958 12275 CREAGER 1958 12276 CREAGER 1958 12277 CREAGER 1958 12278 BENDA PURI 1962 12279 PARKER 1954

12280 LOEP 1965

12281 PHLEGER $1951 \mathrm{~A}$

12282 PARKER 1954

12284 PARKER 1954

12285 PHLEGER 1956

12286 PARKER 1954

12287 PARKER 1954

12288 PARKER 1954

12289 PARKER 1954

12290 PARKER 1954

12291 PHLEGER 1955 A

12292 PHLEGER 1955 A

12294 PHLEGER $1951 \mathrm{~A}$

12295 PHLEGER 1951 A

12296 PHLEGER 1951A

12297 PHLEGER 1951 A

12298 PHLEGER 1951A

12299 PHLEGER $1955 \mathrm{~A}$

12300 PHLEGER $1955 \mathrm{~A}$

12301 PHLEGER $1955 \mathrm{~A}$

12302
12303 PHLEGER

12304 PHLEGER $1951 \mathrm{~A}$

12305 PHLEGER 1951A

12306 PHLEGER 1951A

12307 PHLEGER 1951A

12308 PHLEGER 1951A

12309 PHLEGER 1951A

12310 PHLEGER 1951 A

12311 PHLEGER 1951A

12312 PHLEGER 1951A

12313 DHLEGER 1951A

12314 PHLEGER 1951A

12316 PHLEGER 1951A

12317 PHLEGER 1951A

12318 PHLEGER 1951A

12319 PHLEGER 1951A

12320 PHLEGER 1951A

12321 PHLEGER $1951 \mathrm{~A}$

12322 PHLEGER 1951 A 12323 PARKER 1954

12324 PARKER 1954

12325 PHLEGER 1951A
12326 PHLEGER $1951 \mathrm{~A}$

12327 PHLEGER 1951A

12328 PHLEGER 1951A

12329 PARKER 1954

12330 PARKER 1954
12331 KELLOUGH 1956

12331 KELLOUGH 1956
12332 KELLOUGH 1956

12333 KELLOUGH 1956

12334 KELLOUGH 1956

12335 CREAGER 1958

12336 CUSHMAN 19228

12337 CREAGER 1958

12338 LUDWICK WALTON 1957

12339 PHLEGER 1955 A

12340 PHLEGER 1955A

12341 PARKER 1954

12342 PARKER 1954

12343 PARKER 1954

12344 PARKER 1954

12345 PARKER 1954

12346 PARKER 1954

12347 PARKER 1954

12348 PARKER 1954

12349 PARKER 1954

12350 PARKER 1954

12351 PARKER 1954

12352 PHLEGER 1956

12353 PARKER 1954

12354 PHLEGER $1951 \mathrm{~A}$

12356 PARKER 1954

12357 PARKER 1954

12358 PARKER 1954

12359 PARKER 1954

12360 PHLEGER 1951A

12361 PHLEGER $1951 \mathrm{~A}$

12362 PHLEGER 1951A

12364 PHLEGER 1951 A

12365 PHLEGER 1951 A

\section{Generic Name}

BOLIVINA

BOLIVINA

BOLIVINA

BOLIVINA

BOLIVINA

BOLIVINA

BOLIVINA

BOLIVINA

BOLIVINA

BOLIVINA

BOLIVINA

BOLIVINA

BOLIVINA

BOLIVINA

BOLIVINA

BOLIVINA

BOLIVINA

BOLIVINA

BOLIVINA

BOLIVINA

BOLIVINA

BOLIVINA

BOLIVINA

BOLIVINA

BOLIVINA

BOLIVINA

BOLIVINA

BOLIVINA

BOLIVINA

BOLIVINA

BOLIVINA

BOLIVINA

BOLIVINA

BOLIVINA

BOLIVINA

BOLIVINA

BOLIVINA

BOLIVINA

BOLIVINA

BOLIVINA

BOLIVINA

BOL IVINA

BOLIVINA

BOLIVINA

BOLIVINA

BOLIVINA

BOLIVINA

BOLIVINA

BOLIVINA

BOLIVINA

BOLIVINA

BOLIVINA

BOLIVINA

BOLIVINA

BOLIVINA

BOLIVINA

BOLIVINA

BOLIVINA

BOLIVINA

BOLIVINA

BOLIVINA

BOLIVINA

BOLIVINA

BOLIVINA

BOLIVINA

BOLIVINA

BOLIVINA

BOLIVINA

BOLIVINA

BOLIVINA

BOLIVINA

BOLIVINA

BOLIVINA

BOLIVINA

BOLIVINA

BOLIVINA

BOLIVINA

BOLIVINA

BOLIVINA

BOLIVINA

BOLIVINA

BOLIVINA

BOLIVINA

BOLIVINA

BOLIVINA

BOLIVINA

BOLIVINA

BOLIVINA

BOLIVINA

BOLIVINA

BOLIVINA
BOLIVINA

\section{Specific Name}

SUEAENARIENSIS MEXICANA SUBAENARIENSIS MEXICANA SUEAENARIENSIS MEXI CANA

SUEAENARIENSIS MEXI CANA SUBAENARIENSIS MEXICANA SUEAENARIENSIS MEXI CANA SUEAENARIENSIS MEXICANA SUEEXCAVATA

SUESPINESCENS

SUBSPINESCENS

SUESPINESCENS

SUBSPINESCENS

SUBSPINES CENS

SUESPINES CENS

SUBSPINESCENS

SUBSPINES CENS

SUESPINESCENS

SUBSPINES CENS

SUESPINESCENS

SUESPINESCENS

SUBSPINES CENS

SUBSPINES CENS

SUBSPINES CENS

SUBSPINESCENS

SUESPINESCENS

SUESPINES CENS

SUBSPINESCENS

SUBSPINES CENS

SUESP INES CENS

SUBSPINES CENS

SUESPINESCENS

SUESPINESCENS

SUBSPINESCENS

SUESPINESCENS

SUBSPINESCENS

SUESPINES CENS

SUESPINESCENS

SUBSPINES CENS

SUBSPINESCENS

SUESPINESCENS

SUBSPINESCENS

SUESPINESCENS

SUESPINES CENS

SUBSPINESCENS

SUBSPINES CENS

SUESPINESCENS

SUESPINES CENS

SUESPINES CENS

SUBSPINESCENS

SUBSPINESCENS

SUESPINES CENS

SUBSPINES CENS

SUBSPINESCENS

SUBSPINESCENS

SUESPINES CENS

SUBSPINESCENS

SUBSPINESCENS

SUESPINESCENS

SUBSPINESCENS

SUBSPINESCENS

SUBSPINES CENS

SUESPINES CENS

SUESPINES CENS

SUESPINES CENS

SUUSPINESCENS

SUESPINES CENS

SUBSPINES CENS

SUBSPINESCENS

SUESPINES CENS

SUBSPINESCENS

SUESPINESCENS

SUESPINESCENS

SUBSPINES CENS

SUBSPINESCENS

SUBSPINESCENS

SUESPINES CENS

SUESPINESCENS

SUESPINES CENS

SUBSPINESCENS

SUESPINESCENS

SUESPINES CENS

SUBSPINESCENS

SUESPINES CEN

SUESPINES CENS

SUESPINES CENS

SUESPINES CENS

SUBSPINES CENS

SUESPINES CENS

SUBSPINES CENS

TRANSLUCENS

TRANSLUCENS

TRANSLUCENS

TRANSLUCENS

TRANSLUCENS

TRANSLUCENS

Locality

NW GULF OF MEXICO

BAY OF CAMPECHE

BAY OF CAMPECHE

BAY OF CAMPECHE

BAY OF CAMPECHE

BAY OF CAMPECHE

BAY OF CAMPECHE

CAPE RO:AANO, FLA.

NE GULF OF MEXICO

NW GULF OF MEXICO 
Publication

12366 PHLEGER $1951 \mathrm{~A}$

12367 P PHLEGER 1951A

12368 PHLEGER 1951A

12370 PFLUM FRERICHS 1976

12371 PFLUM FRERICHS 1976

12372 PFLUM FRERICHS 1976

12373 PARKER 1954

12374 PARKER 1954

12375 PARKER 1954

12376 PARKER 1954

12378 PFLUM FRERICHS 1976

12379 PFLUM FRERICHS 1976

12380 PFLUM FRERICHS 1976

12381 PFLUM FRERICHS 1976

12382 PFLUM FRERICHS 1976

12383 PFLUM FRERICHS 1976

12384 PFLUM FRERICHS 1976

12385 PFLUM FRERICHS 1976

12386 PFLUM FRERICHS 1976

$\begin{array}{lll}12387 & \text { PFLUM FRERICHS } & 1976 \\ 12388 & \text { PFLUM FRERICHS } & 1976\end{array}$

12389 PFLUM FRERICHS 1976 12390 PFLUM FRERICHS 1976 12391 PFLUM FRERICHS 1976 12392 PARKER 1954

12393 PARKER 1954

$\begin{array}{lll}12394 & \text { PFLUM FRERICHS } & 1976 \\ 12395 & \text { PFLUM FRERICHS } & 1976\end{array}$

12396 PHLEGER 1951A

12397 PHLEGER 1951 A

12398 PHLEGER $1951 \mathrm{~A}$

12399 PFLUM FRER 12400 PARKER 1954

12401 PARKER 1954

12403 PARKER 1954

12404 PARKER 1954

12406 PFLUM FRERICHS 1976

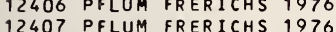

12408 PFLUM FRERICHS 1976

12409 PFLUM FRERICHS 1976

12410 PFLUM FRERICHS 1976

12411 PFLUM FRERICHS 1976

12412 PHLEGER 1951A

12413 PFLUM FRERICHS 1976

12414 PFLUM FRERICHS 1976

12415 PHLEGER 1951A

12416 PARKER 1954

12417 PHLEGER 1951A

12419 PARKER 1954

12420 PARKER 1954

12421 PHLEGER 19658

12422 PHLEGER 19658

12423 PFLUM FRERICHS 1976

12424 BOCK 1976

12425 CUSHMAN 1930

12426 DAVIS 1964

12427 NORTON 1930

12428 BOCK 1976

12429 BOCK 1976

12430 BOCK 1976

12431 BOCK 1976

12432 BOCK 1976

12433 POAG 1976

12435 BOCK 1976

12436 BOCK 1976

12437 BOCK 1976

12438 BOCK 1976

12439 POAG 1976

12440 POAG 1972

12441 POAG 1976

12442 BOCK 1976

12443 BOCK 1976

12444 BOCK 1976

12445 PHLEGER 1956

12446 PARKER 1954

12447 WALTON 1960

12448 ANDERSEN 1961

12449 PHLEGER 1965 A
12450 BANDY 1956

12451 BANDY 1956

12452 BANDY 1956

12453 WARREN 1956

12454 PHLEGER 1956

12455 PHLEGER 1956

12456 PHLEGER 1956

12457 PARKER 1954

12458 LUDWICK WALTON 1957

12459 LANKFORD 1959

12460 PHLEGER 19558
Generic Name

BOLIVINA

BOLIVINA

BOLIVINA

BOLIVINA

BOLIVINA

BOLIVINA

BOLIVINA

BOLIVINA

BOLIVINA

BOLIVINA

BOLIVINA

BOLIVINA

BOLIVINA

BOLIVINA

BOLIVINA

BOLIVINA

BOLIVINA

BOLIVINA

BOLIVINA

BOLIVINA

BOLIVINA

BOLIVINA

BOLIVINA

BOLIVINA

BOLIVINA

BOLIVINA

BOLIVINA

BOLIVINA

BOLIVINA

BOLIVINA

BOLIVINA

BOLIVINA

BOLIVINA

BOLIVINA

BOLIVINA

BOLIVINA

BOLIVINA

BOLIVINA

BOLIVINA

BOLIVINA

BOLIVINA

BOLIVINA

BOLIVINA

BOLIVINA

BOLIVINA

BOLIVINA

BOLIVINA

BOLIVINA

BOLIVINA

BOLIVINA

BOLIVINA

BOLIVINA

BOLIVINA

BOLIVINA

BOLIVINA

BOLIVINA

BOLIVINITA

BORELIS

BORELIS

BORELIS

BOLIVINA

BOLIVINA

BOLIVINA

BOLIVINA

BOLIVINA

BOLIVINA

BOLIVINA

BOLIVINA

BOLIVINA

BOLIVINA

BOLIVINA

SAGR INA

BOLIVINA

BOLIVINA

BOLIVINA

BOLIVINA

BUCCELLA

BUCCELLA

BUCCELLA

BUCCELLA

BUCCELLA

BUCCELLA

BUCCELLA

BUCCELLA

BUCCELLA

BUCCELLA

BUCCELLA

BUCCELLA

BUCCELLA

BUCCELLA

BUCCELLA

BUCCELLA

BUCCELLA
Specific Name

TRANSLUCENS

TR ANS LUCENS

TRANSLUCENS
TRANSLUCENS

TR ANSLUCENS

TR ANSLUCENS

TRANSLUCENS

TRANSLUCENS

IRANSLUCENS

TRANSLUCENS

TRANSLUCENS

TRANSLUCENS

TRANSLUCENS

TRANSLUCENS

IRANSLUCENS

TRANSLUCENS

TRANSLUCENS

TRANSLUCENS

TR ANSLUCENS

TRANSLUCENS

TRANSLUCENS

TRANSLUCENS

TRANSLUCENS

TRANSLUCENS

TRANSLUCENS

TRANSLUCENS

TRANSLUCENS

TRANSLUCENS

TRANSLUCENS

TRANSLUCENS

TRANSLUCENS

TRANSLUCENS

TRANSLUCENS

TRANSLUCENS

TRANSLUCENS

TRANSLUCENS

TRANSLUCENS

TRANSLUCENS

TR ANSLUCENS

TRANSLUCENS

TRANSLUCENS

TRANSLUCENS

TRANSLLUCENS

TRANSLUCENS

TRANSLUCENS

TRANSLUCENS

TRANSLUCENS

TRANSLUCENS

TR ANS LUCENS

TRANSLUCENS

TRANSLUCENS

TRANSLUCENS

TRANSLUCENS

TRANSLUCENS

VARIABILIS

VARIABILIS

QUADRILAT ERATA

RHOMBOIDALIS

PULCHRA

PULCHRA

PULCHRA

BARBATA

FRAGILIS

GOESII

HASTATA

DAGGARIUS

LOWMANI

LOWMANI

LOWMANI

LOUMANI

MINIMA

PAULA

PULCHELLA

STRIATULA SPINATA

STRIATULA

STRIATULA

SUBSPINESCENS

HANNAI

HANNAI

HANNAI

HANNAI

HANNAI

HANNAI

HANNAI

HANNAI

HANNAI

HANNAI

HANNAI

HAMNAI

HANNAI

HANNAI

HANNAI

HANNAI

HANNAI

Locality

Lat. Long.

NW GULF OF MEXICO

NH GULF OF MEXICO

$N W$ GULF OF MEXICO

NW GULF OF MEXICO

NW GULF OF MEXICO

NW GULF OF MEXICO

$N$ W GULF OF MEXICO

NE GULF OF MEXICO

NE GULF OF MEXICO

NE GULF OF MEXICO

NE GULF OF MEXICO

NE GULF OF MEXICO 


\section{Publication}

12461 PARKER 1954

12462 PARKER 1954

12463 PARKER 1954

12464 PARKER 1954

12466 PARKER 1954

12467 PARKER 1954

12468 PARKER 1954

12469 BANDY 1956

12470 BANDY 1956

12471 BANDY 1956

12472 BANDY 1956

12473 BANDY 1956

12474 WARREN 1957

12475 BANDY 1956

12476 SEGURA 1963

12477 BANDY 1956

12478 BANDY 1956

12479 BANDY 1956

12480 KANE 1967

12481 KANE 1962

12482 PARKER 1954

12483 PFLUM FRERICHS 1976

12484 PFLUM FRERICHS 1976

12485 PFLUM FRERICHS 1976

12486 PFLUM FRERICHS 1976

12487 PHLEGER $1951 \mathrm{~A}$

12488 PFLUM FRERICHS 1976

12489 LEROY HODGKINSON 1975

12490 PFLUM FRERICHS 1976

12491 PHLEGER 1951A

12492 PFLUM FRERICHS 1976

12493 PFLIJM FRERICHS 1976

12494 PFLUM FRERICHS 1976

12495 PFLUM FRERICHS 1976

12496 PARKER 1954

12497 PARKER 1954

12498 PARKER 1954

12500 PFLUM FRERICHS 1976

12500 PFLUM FRERI
12501 PARKER 1954

12502 PARKER 1954

12503 PFLUM FRERICHS 1976

12504 PFLUM FRERICHS 1976

12505 PFLUM FRERICHS 1976

12506 PFLUM FRERICHS 1976

12507 PFLUM FRERICHS 1976

12508 PARKER 1954

12509 PARKER 1954

12510 PARKER 1954

12511 PARKER
12512 PARKER 1954

12513 PARKER 1954

12514 PARKER 1954

12515 PFLUM FRERICHS 1976

12516 PFLUM FRERICHS 1976 12517 PFLUM FRERICHS 1976 12518 PFLUM FRERICHS 1976 12519 PFLUM FRERICHS 1976 12520 PFLUM FRERICHS 1976 12521 PFLUM FRERICHS 1976 12522 PFLUM FRERICHS 1976 12523 PFLUM FRERICHS 1976 12524 PFLUM FRERICHS 1976 12525 PFLUM FRERICHS 1976 12526 PFLUM FRERICHS 1976 12527 PFLUM FRERICHS 1976 12528 PFLUM FRERICHS 1976 12529 PFLUM FRERICHS 1976 12530 PFLUM FRERICHS 1976 12531 PFLUM FRERICHS 1976 12532 PFLUM FRERICHS 1976 12533 PFLUM FRERICHS 1976 12534 PFLUM FRERICHS 1976 12535 PFLUM FRERICHS 1976 12536 PFLUM FRERICHS 1976 12537 PFLUM FRERICHS 1976 12538 PFLUM FRERICHS 1976 12539 PFLUM FRERICHS 1976 12540 PARKER 1354

12541 PHLEGER 1955 A

12542 PARKER 1954

12543 PHLEGER 1955 A

12544 PARKER 1954

12545 PHLEGER $1955 \mathrm{~A}$

12546 PHLEGER $1955 \mathrm{~A}$

12547 PHLEGER 1955A

12549 PHLEGER 1951A

12550 LUDWICK WALTON 1957

12551 PHLEGER 1951A

12552 PHLEGER $1951 \mathrm{~A}$

12553 PHLEGER 1951A

12555 PFLUM FRERICHS 1976
Generic Name

BUCCELLA

BUCCELLA

BUCCELLA

BUCCELLA

BUCCELLA

BUCCELLA

BUCCELLA

BUCCELLA

BUCCELLA

BUCCELLA

BUCCELLA

BUCCELLA

BUCCELLA

BUCCELLA

BUCCELLA

BUCCELLA

BUCCELLA

BUCCELLA

BUCCELLA

BUCCELLA

BUCCELLA

BULIMINA

BULIMINA

BULIMINA

BULIMINA

BULIMINA

BULIMINA

BULIMINA

BULIMINA

BULIMINA

BULIMINA

BULIMINA

BULIMINA

BULIMINA

BULIMINA

BULIMINA

BULIMINA

BULIMINA

BULIMINA

BULIMINA

BULIMINA

BULIMINA

BULIMINA

BULIMINA

BULIMINA

BULIMINA

BULIMINA

BULIMINA

BUL IMINA

BULIMINA

BULIMINA

BULIMINA

BULIMINA

BULIMINA

BULIMINA

BULIMINA

BULIMINA

BULIMINA

BULIMINA

BULIMINA

BULIMINA

BULIMINA

BULIMINA

BULIMINA

BULIMINA

BULIMINA

BULIMINA

BULIMINA

BULIMINA

BULIMINA

BUL IMINA

BULIMINA

BULIMINA

BULIMINA

BULIMINA

BULIMINA

BULIMINA

BULIMINA

BULIMINA

BULIMINA

BULIMINA

BULIMINA

BULIMINA

BULIMINA

BULIMINA

I MINA

BULIMINA

BULIMINA

BULIMINA

BULIMINA

BULIMINA
Specific Name

HANNAI

HANNAI
HANNAI

HAANAI

HANNAI

HANNAI

HANNAI

HANNAI

HANNAI

HANNAI

HANNAI

HANNAI

HANNAI

HANNAI

HANNAI

HANNA I

HANNA I

HANNAI

HANNAI

HANNAI

AC LLEATA

AC LLEATA

ACULEAT

ACLLEATA

ACLLEATA

ACLLEATA

ACLLEATA

ACLLEATA

ACLLEATA

ACULEATA

AC ULEATA

AC ULEATA

AC LLEATA

AC LLEATA

AC ULEATA

AC LLEATA

ACLLEATA

AC ULEATA

AC LLEATA

ACULEATA

AC ULEATA

ACLLEATA

AC ULEATA

ACLLEATA

AC LLEATA

AC LLEATA

AC ULEATA

AC LLEATA

AC ULEATA

AC LLEATA

ACLLEATA

ACLLEATA

AC ULEATA

ACLLEATA

AC ULEATA

AC LLEATA

ACLLEATA

AC ULEATA

AC ULEATA

AC LLEATA

ACLLEATA

ACLLEATA

AC ULEATA

AC LLEATA

ACULEATA

AC LLEATA

ACULEATA

ACLLEATA

AC ULEATA

ACULEATA

AC LLEATA

ACLLEATA

AC LLEATA

AC ULEATA

AC LLEATA

AC LLEATA

ACLLEATA

AC LLEATA

ACLLEATA

AC LLEATA

AC LLEATA

ACULEATA

ACLLEATA

ACLLEATA

AC LLEATA

AC LLEATA

ACLLEATA

AC ULEATA

ACLLEATA

AC ULEATA

Locality

Lat. Long.

NE GULF OF MEXICO

NE GULF OF MEXICO NE GULF OF MEXICO NE GULF OF MEXICO NE GULF OF MEXICO NE GULF OF MEXICO NE GULF OF MEXICO NE GULF OF MEXICO NE GULF OF MEXICO NE GULF OF MEXICO NE GULF OF MEXICO NE GULF OF MEXICO NE GULF OF MEXICO 


\section{Publication}

12556 PFLUM FRERICHS 1976 12557 PFLUM FRERICHS 1976 12558 PFLUM FRERICHS 1976 12559 PFLUM FRERICHS 1976 12560 PHLEGER 1951A 12561 PHLEGER 1951A 12562 PHLEGER 1951A 12563 PHLEGER 1951A 12564 PHLEGER 1951A 12565 PARKER 1954

12566 PARKER 1954

12568 PHLEGER 1955A 12569 PHLEGER 1955 A 12570 PHLEGER 1951A 12571 CREAGER 1958 12572 PARKER 1954

12573 PHLEGER 1951A 12574 PHLEGER 1951A 12575 PHLEGER 1951A 12576
12577 PHLEGER 1951 A A 12578 PHLEGER 1951A 12579 PARKER 1954

12580 PHLEGER 1951 A

12581 CREAGER 1958

12582 CREAGER 1958

12583 CREAGER 1958

12584 CREAGER 1958

12585 CREAGER 1958

12586 CREAGER 1958

12587 CREAGER 1958

12588 PARKER 1954

12590 PHLEGER 1951A

12591 PHLEGER 1951A

12592 PHLEGER 1951A

12593 PHLEGER 1951 A

12594 LOEP 1965

12595 LOEP 1965

12596 LOEP 1965

12597 PFLUM FRERICHS 1976 12598 PFLUM FRERICHS 1976 12599 PFLUM FRERICHS 1976 12600 PFLUM FRERICHS 1976 12601 PFLUM FRERICHS 1976 12602 PFLUM FRERICHS 1976 12603 PFLUM FRERICHS 1976 12604 PFLUM FRERICHS 1976 12605 PFLUM FRERICHS 1976 12606 PFLUM FRERICHS 1976 12607 PFLUM FRERICHS 1976 12608 PFLUM FRERICHS 1976 12609 PFLUM FRERICHS 1976 12610 PFLUM FRERICHS 1976 12611 PFLUM FRERICHS 1976 12612 PFLUM FRERICHS 1976 12613 PFLUM FRERICHS 1976 12614 PFLUM FRERICHS 1976 12615 PFLUM FRERICHS 1976 12616 PFLUM FRERICHS 1976 12617 PFLUM FRERICHS 1976 12618 CUSHMAN 19228 12619 CUSHMAN 19228 12620 CUSHMAN 19228 12621 CUSHMAN 19228 12622 CUSHMAN 19228 12623 CUSHMAN 19228 12624 CUSHMAN 19228 12625 CUSHMAN 19228 12626 CUSHMAN 19228 12627 CUSHMAN $1922 \mathrm{~B}$ 12628 CREAGER 1958 12629 CREAGER 1958 12630 CREAGER 1958

12631 CUSHMAN 19228 12632 CUSHMAN 19228 12633 CUSHMAN 19228 12634 ANDERSEN 1961 12635 LOEP 1965 12636 LOEP 1965

12637 CUSHMAN 19228 12638 CREAGER 1958 12639 LOEP 1965 12640 LOEP 1965 12641 PARKER 1954 12642 PARKER 1954 12643 PHLEGER 1951A 12644 PHLEGER 1955A 12645 PARKER 1954 12646 PARKER 1954 12647 PARKER 1954 12648 PARKER 1954 12649 PARKER 1954 12650 PARKER 1954
Generic Name

BULIMINA

BULIMINA

BULIMINA

BULIMINA

BULIMINA

BULIMINA

BULIMINA

BULIMINA

BULIMINA

BULIMINA

BULIMINA

BULIMINA

BULIMINA

BULIMINA

BULIMINA

BULIMINA

BULIMINA

BULIMINA

BULIMINA

BUL IMINA

BULIMINA

BULIMINA

BULIMINA

BULIMINA

BULIMINA

BULIMINA

BULIMINA

BULIMINA

BULIMINA

BULIMINA

BULIMINA

BULIMINA

BULIMINA

BULIMINA

BULIMINA

BULIMINA

BULIMINA

BULIMINA

BULIMINA

BULIMINA

BULIMINA

BULIMINA

BULIMINA

BULIMINA

BULIMINA

BULIMINA

BULIMINA

BULIMINA

BULIMINA

BULIMINA

BULIMINA

BULIMINA

BULIMINA

BULIMINA

BULIMINA

BULIMINA

BULIMINA

BULIMINA

BULIMINA

BULIMINA

BULIMINA

BULIMINA

BULIMINA

BULIMINA

BULIMINA

BULIMINA

BULIMINA

BULIMINA

BULIMINA

BULIMINA

BULIMINA

BULIMINA

BULIMINA

BULIMINA

BULIMINA

BULIMINA

BULIMINA

BULIMINA

BULIMINA

BULIMINA

BULIMINA

BULIM INA

BULIMINA

BULIMINA

BULIMINA

BULIMINA

BULIMINA

BULIMINA

BULIMINA

BULIMINA

BULIMINA
Specific Name

AC ULEATA

AC LLEATA

AC LLEATA

AC ULEATA

ACULEATA

ACLLEATA

ACULEATA

A C ULEATA

ACULEATA

ACULEATA

ACLLEATA

ACULEATA

AC ULEATA

ACULEATA

ACULEATA

ACLLEATA

ACLLEATA

ACLLEATA

A CULEATA

ACULEATA

ACULEATA

ACULEATA

A C ULEATA

AC ULEATA

AC ULEATA

AC LLEATA

ACLLEATA

AC ULEATA

AC ULEATA

AC ULEATA

ACLLEATA

AC ULEATA

A CULEATA

AC ULEATA

ACULEATA

A CULEATA

AC ULEATA

AC ULEATA

AC ULEATA

ACULEATA

ACULEATA

AC ULEATA

AC ULEATA

ACULEATA

ACLLEATA

ACULEATA

AC ULE ATA

AC ULEATA

ACULEATA

AC ULEATA

ACULEATA

A ULEATA

AC ULEATA

ACULEATA

AC ULEATA

AC ULEATA

AC ULEATA

AC ULEATA

ACULEATA

ACULEATA

AC ULEATA

AC ULEATA

AC ULEATA

AC LLEATA

AC LLEATA

AC ULEATA

AC LLEATA

ACULEATA

AC ULEATA

AC LLEATA

ACULEATA

AFFINIS

AF FINIS

AF FINIS

AFFINIS

AFFINIS

AFFINIS

AF FIN IS

AL AZANENS IS

AL AZANENS IS

AL AZ ANENS IS

AL AZANENS IS

AL AZANENS IS

AL AZANENS IS

ALAZANENS IS

AL AZANENS IS

AL AZANENS IS

AL AZ ANENS IS

AL AZANENS IS

AL AZ ANENS IS

ALAZANENS IS

\section{Locality}

CENTRAL GULF OF MEXICO CENTRAL GULF OF MEXICO CENTRAL GULF OF MEXICO CENTRAL GULF OF MEXICO $N W$ GULF OF MEXICO NH GULF OF MEXICO NW GULF OF MEXICO NW GULF OF MEXICO NW GULF OF MEXICO 


\section{Publication}

12651 PARKER 1956 12652 CREAGER 1958 12653 CREAGER 1958 12654 CREAGER 1958 12655 CREAGER 1958 12656 PHLEGER 1955 12658 PHLEGER 1955 A 12658 PHLEGER 1955 A 12659 PARKER 1954

12660 PHLEGER $1951 \mathrm{~A}$ 12661 PHLEGER 1951A 12662 PHLEGER 1951A 12663 PARKER 1954 12664 PARKER 1954 12665 PARKER 1956 12666 PARKER 1956 12667 PARKER 1954 12668 PARKER 1954 12669 PARKER 1954 12670 PARKER 1954 12671 PARKER 1954 12672 CREAGER 1958 12673 CREAGER 1958

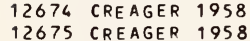
12676 PHLEGER 1951 A 12677 PHLEGER 1951A 12678 CREAGER 1958 12679 PHLEGER $1951 \mathrm{~A}$ 12680 PHLEGER 1951 A 12681 PHLEGER 1951A 12682 PHLEGER 1951A 12683 PHLEGER 1951A 12686 PHLEGER 1951 A 12685 PHLEGER 1951A 12686 PHLEGER 1959A 12687 PHLEGER 1951A 12688 PHLEGER 1951A 12689 PHLEGER $1951 \mathrm{~A}$ 12690 PHLEGER 1951A 12691 PHLEGER 1951A 12692 PHLEGER 1951A 12693 PHLEGER 1951A 12694 PHLEGER 1951A 12695 LEROY HODGKINSJN 1975 12696 PHLEGER 1951A 12697 PHLEGER 1951A 12698 PFLUM TRERICHS 1976 12699 PFLUM FRERICHS 1976 12700 PHLEGER 1951A 12701 CUSHMAN $1922 B$
12702 CUSHMAN 19228 12703 CUSHMAN 19228 12704 CUSHMAN 19228 12705 CUSHMAN 19228 12706 CUSHMAN 19228 12707 CUSHMAN 19228 12708 CUSHMAN 19228 12709 CREAGER 1958 12710 PHLEGER 1951A 12711 PHLEGER 1951A 12712 BOCK 1976

12713 PHLEGER 1951 A 12716 PHLEGER 1956 12715 PFLUM FRERICHS 1976 12716 PFLUM FRERICHS 1976 12717 PFLUM FRERICHS 1976 12718 PFLUM FRERICHS 1976 12719 LOEP 1965

12720 AYALA-CASTANARES 1963 12721 WARREN 1956

12722 PHLEGER 1965 B

12723 BENDA PURI 1962

12724 PHLEGER 19658

12725 KELL OUGH 1956

12726 KELLOUGH 1956

12727 BANDY 1956

12728 PHLEGER 1956

12729 PHLEGER 1956

12730 PHLEGER 1956

12731 CREAGER 1958

12732 CREAGER 1958

12733 PFLUM FRERICHS 1976 12734 PFLUM FRERICHS 1976 12735 PFLUM FRERICHS 1976 12736 ANDERSEN 1961

12737 PFLUM FRERICHS 1976 12738 PFLUM FRERICHS 1976

12739 CUSHMAN 19228

12740 CUSHMAN 19228

12749 VAUGHAN 1918

12742 PHLEGER 1951A

12743 PHLEGER 1951A

12745 PHLEGER 1951A
Generic Name

Specific Name

BULIMINA

BULIMINA

BULIMINA

BULIMINA

BULIMINA

BULIMINA

BULIMINA

BULIMINA

BULIMINA
BULIMINA

BULIMINA

BULIMINA

BULIMINA

BULIMINA

BULIMINA

BULIMINA

BULIMINA

BULIMINA

BULIMINA

BULIMINA

BULIMINA

BULIMINA

BULIMINA

BULIMINA

BULIMINA

BULIMINA

BULIMINA

BULIMINA

BULIMINA

BULIMINA

BULIMINA

BULIMINA

BULIMINA

BULIMINA

BULIMINA

BULIMINA

BULIMINA

BULIMINA

BULIMINA

BULIMINA

BULIMINA

BULIMINA

BULIMINA

BULIMINA

BULIMINA

BULIMINA

BUL IMINELLA

BULIMINA

BULIMINA

BULIMINA

BULIMINA

BULIMINA

BULIMINA

BULIMINA

BULIMINA

BULIMINA

BULIMINA

BULIMINA

BULIMINA

BULIMINA

BULIMINA

BULIMINA

BU LIMINA

BULIMINA

BULIMINA

BULIMINA

BULIMINA

BULIMINA

BULIMINA

BULIMINA

BULIMINA

BULIMINA

BULIMINA

BULIMINA

BULIMINA

BULIMINA

BULIMINA

BULIMINA

BULIMINA

BULIMINA

BULIMINA

BULIMINA

BULIMINA

BULIMINA

BULIMINA

BULIMINA

BULIMINA

BULIMINA

AL AZANENSIS

AL AZANENSIS

ALAZANENS IS

AL AZANENSIS

AL AZANENSIS

$A L A Z$ ANENS IS

AL AZANENSIS

AL AZANENS IS

AL AZANENSIS

AL A ZANENSIS

AL AZ ANENS IS

AL AZANENSIS

AL AZANENS IS

ALAZANENS IS

AL AZANENS IS

AL AZANENSIS

AL AZ ANENSIS

AL AZ ANENS IS

AL AZ ANENS IS

ALAZANENSIS

ALAZANENS IS

ALAZANENSIS

ALAZANENSIS

AL AZANENS IS

AL AZANENS IS

ALAZ ANENSIS

ALAZANENS IS

AL AZANENS IS

AL AZANENSIS

AL AZANENS IS

AL AZ ANENSIS

AL AZANENSIS

AL AZ ANENS IS

AL AZ ANENS IS

AL AZ ANENS IS

AL AZ ANENS IS

AL AZANENSIS

AL AZANENS IS

AL AZANENS IS

AL AZANENS IS

AL AZ ANENS IS

AL AZ ANENSIS

AL AZ ANENSIS

AL AZANENS IS

AL AZ ANENSIS

BA RBATA

BARBATA

BASSENDOR FENSIS

BUCHIANA

BUCHIANA

INFLATA MEXICANA

INFLATA MEXICANA

IN FLATA MEXI CANA

INFLATA MEXICANA

IN FLATA MEXICANA

MARGINATA

MARG INATA

MARGINATA

MARG I NATA

MARGINATA

MARG INATA

MARGINATA

MARGINATA

MARG INATA

MARGINATA

MARG INATA

MARGINATA

MARG INATA

MARGINATA

MARGINATA

MARGINATA

MARGINATA

MARG INATA

MARG INATA

MARG INATA

MARGINATA

MARGINATA

MARG I NATA

MARGINATA

MARG INATA

MARGINATA

MARG INATA

MARG INATA

MARG INATA

MARGINATA

MARGINATA

MARGINATA
Locality

Lat. Long.

IN FLATA MEXI CANA

MARG INATA

NE GULF OF MEXICO

BAY OF CAMPECHE

BAY of CAMPECHE

BAY OF CAMPECHE

BAY OF CAMPECHE

$N$ GULF OF MEXICO

NE GULF OF MEXICO

$N$ GULF OF MEXICO

NE GULF OF MEXICO

NH GULF OF MEXICO

NW GULF OF MEXICO

NW GULF OF MEXICO

NE GULF OF MEXICO

NE GULF OF MEXICO

NE GULF OF MEXICO

NE GULF OF MEXICO 


\section{Publication}

12746 PHLEGER 1951A 12747 PHLEGER $1951 \mathrm{~A}$ 12748 PHLEGER $1951 \mathrm{~A}$ 12749 PHLEGER 1951A 12750 PHLEGER 1951A 12751 PHLEGER 1951 A 12752 PHLEGER $1951 \mathrm{~A}$ 12753 PHLEGER $1951 \mathrm{~A}$ 12754 PHLEGER 1951A 12755 PHLEGER 1951 A 12756 PHLEGER 1951A 12757 PFLUM FRERICHS 1976 12758 PFLUM FRERICHS 1976 12759 PFLUM FRERICHS 1976 12760 PFLUM FRERICHS 1976 12761 PFLUM FRERICHS 1976 12762 PFLUM FRERICHS 1976 12763 PFLUM FRERICHS 1976 12764 PFLUM FRERICHS 1976 12765 PFLUM FRERICHS 1976 12766 PFLUM FRERICHS 1976 12767 PFLUM FRERICHS 1976 12768 PHLEGER 1951A 12769 PHLEGER 1951A 12770 PHLEGER 1951A 12771 PHLEGER 1951A 12772 SEGURA 1963

12773 LANKFORD 1959 12774 PHLEGER $1951 \mathrm{~A}$ 12775 PARKER 1954 12776 PARKER 1954
12777 PARKER 1954 12778 PARKER 1954 12779 PARKER 1954 12780 PARKER 1954 12781 PARKER 1954 12782 PARKER 1954 12783 PARKER 1954 12784 PARKER 1954 12785 PARKER 1954 12786 PARKER 1954 12787 PARKER 1954 12789 WARREN 1957 12790 LUDWICK WALTON 1957 12791 PHLEGER 1951A 12792 PHLEGER 1951 A 12793 CUSHMAN 19228 12794 CUSHMAN 19228 12795 CUSHMAN 19228 12796 CUSHMAN 19228
12797 CUSHMAN 19228 12798 CUSHMAN 19228 12799 CUSHMAN 19228 12800 CUSHMAN 19228 12801 CUSHMAN 19228 12802 CUSHMAN 19228 12803 CUSHMAN 19228 12804 PFLUM FRERICHS 1976 12805 PFLUM FRERICHS 1976 12806 PFLUM FRERICHS 1976 12807 PFLUM FRERICHS 1976 12808 PFLUM FRERICHS 1976 12809 PFLUM FRERICHS 1976 12810 PFLUM FRERICHS 1976 12811 PFLUM FRERICHS 1976 12812 PFLUM FRERICHS 1976 12813 PFLUM FRERICHS 1976 12815 PFLUM FRERICHS 1976 12816 PFLUM FRERICHS 1976 12817 PFLUM FRERICHS 1976 12818 PFLUM FRERICHS 1976 12819 PFLUM FRERICHS 1976 12820 PFLUM FRERICHS 1976 12821 PFLUM FRERICHS 1976 12822 PFLUM FRERICHS 1976

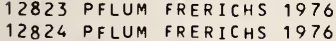
12825 PFLUM FRERICHS 1976 12826 PFLUM FRERICHS 1976 12827 PFLUM FRERICHS 1976 12828 PFLUM FRERICHS 1976 12829 PFLUM FRERICHS 1976 12830 PFLUM FRERICHS 1976 12831 PFLUM FRERICHS 1976 12832 PFLUM FRERICHS 1976 12833 PFLUM FRERICHS 1976 12834 PFLUM FRERICHS 1976 12835 PFLUM FRERICHS 1976 12836 PFLUM FRERICHS 1976 12837 PFLUM FRERICHS 1976 12838 PFLUM FRERICHS 1976 12839 PFLUM FRERICHS 1976 12840 PFLUM FRERICHS 1976

Generic Name

Specific Name

Locality

Lat.

Long. BULIMINA

BULIMIN

BULIMINA

BULIMINA

BULIMINA

BULIMINA

BUL IMINA

BULIMINA

BULIMINA

BULIMINA

BULIMINA

BULIMINA

BUL IMINA

BULIMINA

OULIMINA

BULIMINA

BULIMINA

BULIMINA

BULIMINA

BULIMINA

BULIMINA

BULIMINA

BULIMINA

OULIMINA

BULIMINA

BULIMINA

BULIMINA

BULIMINA

OULIMINA

BULIMINA

BULIMINA

BUL IMINA

BULIMINA

BULIMINA

BULIMINA

UUIMINA

BULIMINA

BULIMINA

BULIMINA

BULIMINA

UUIMINA

BULIMINA

BULIMINA

BULIMINA

BULIMINA

BULIMINA

BULIMINA

BULIMINA

BULIMINA

BULIMINA

BULIMINA

BULIMINA

BULIMINA

BULIMINA

BULIMINA

ULIMINA

BULIMINA

BULIMINA

BULIMINA

BULIMINA

BUL IMINA

BULIMINA

BULIMINA

BULIMINA

OULIMINA

BUL IMINA

BULIMINA

BULIMINA

BULIMINA

BULIMINA

BULIMINA

BULIMINA

BUL IMINA

BULIMINA

BULIMINA

BULIMINA

BULIMINA

BULIMINA

BULIMINA

BUL IMINA

BULIMINA

BULIMINA

BULIMINA

BUL IMINA

BULIMINA

BULIMINA

BULIMINA
MARG INATA

MARGINATA

MARGINATA

MARG INATA

MARG INATA

MARGINATA

MA RG INATA

MARG INATA

MARGINATA

MARGINATA

MARGINATA

MARG INATA

MARG INATA

MARGINATA

MARG INATA

MARG INATA

MARGINATA

MARG INATA

MARG INATA

ARG INATA

ARG INATA

MARGINATA

MARG INATA

MARG INATA

MAFG INATA

MARG INATA

MARG INATA

MARG INATA

MARG INATA

MARG INATA

MARG INATA

MARG INATA

MARG INA TA

MARG INATA

MARGINATA

MARG INATA

MARG INATA

MARG INATA

MARG INATA

MARGINATA

MARG INATA

MARG INATA

MARGINATA

ARG INATA

OVATA

OVATA

OVATA

OVATA

PUPOIDES

PYRULA SPINESCENS

YRULA SPINESCENS

AL AZ ANENS IS

ALAZANENS IS

AL AZ ANENS IS

AL AZ ANENS IS

ALAZANENSIS

AL AZANENS IS

AL AZ ANENS IS

AL AZ ANENSIS

ALAZANENS IS

AL AZ ANENS IS

AL AZ ANENS IS

AL AZ ANENS IS

AL AZ ANENSIS

AL AZANENS IS

AL AZANENS IS

AL AZ ANENS IS

AL AZANENS IS

AL AZANENS IS

ALAZANENS IS

AL AZANENSIS

AL AZANENS IS

AL AZ ANENSIS

AL ANENS IS

ALAZANENS IS

ALAZ ANENS IS

AL AZ ANENS IS

AL AZ ANENS IS

AL AZANENSIS

ALAZANENS IS

ALAZANENSIS

AL AZANENSIS

AL AZANENSIS

AL AZANENS IS

AL AZ ANENS IS

AL AZANENSIS

NW GULF OF MEXICO

NW GULF OF MEXICO

NW GULF OF MEXICO

NW GULF OF MEXICO

NW GULF OF MEXICO

NW GULF OF MEXICO

NW GULF OF MEXICO

NW GULF OF MEXICO

$N W$ GULF OF MEXICO

NW GULF OF MEXICO

$N W$ GULF OF MEXICO

NW GULF OF MEXICO

$N W$ GULF OF MEXICO 


\section{Publication}

12841 PFLUM FRERICHS 1976 12842 PFLUM FRERICHS 1976 12843 PFLUM FRERICHS 1976 12844 PFLUM FRERICHS 1976 12845 PFLU'A FRERICHS 1976 12846 PFLUM FRERICHS 1976 12848 PFLUM FRERICHS 1976 12848 PFLUM FRERICHS 1976 12849 PFLUM FRERICHS 1976
12850 PFLUM FRERICHS 1976 12851 PFLUM FRERICHS 1976 12852 PFLUM FRERICHS 1976 12853 PFLUM FRERICHS 1976 12854 PFLUM FRFRICHS 1976 12855 PFLUM FREFICHS 1976 12856 PFLUM FRFRICHS 1976 12857 PFLUM FRERICHS 1976 12858 PFLUM FRERICHS 1976 12859 PFLUM FRERICHS 1976 12860 PFLUM FRERICHS 1976 12861 PFLUM FRERICHS 1976 12862 PFLUM FRERICHS 1976 12864 PFLUM FRERICHS 1976 12865 PFLUM FRERICHS 1976 12866 PFLUM FRERICHS 1976 12868 PFLUM FRERICHS 1976 12869 PFLUM FRERICHS 1076 12870 PARKER 1954

12871 PARKER 1954

12872 PFLUM FRERICHS 1976 12873 PFLUM FRERICHS 1976 12874 PFLUM FRERICHS 1976 12875 PFLUM FRERICHS 1976 12876 PFLUM FRERICHS 1976 12877 PFLUM FRERICHS 1976 12878 PHLEGER 1951A 12879 PHLEGER 1951 A

12880 PFLUM FRERICHS 1976 12881 DFLUM FRERICHS 1976 12882 PFLUM FRERICHS 1976 12883 PFLIJM FRERICHS 1976 12884 PARKER 1254 12885 PARKER 1754

12886 PARKER 1954

12887 PARKER 1954

12888 PARKER 1754

12889 PARKER 1054

12890 PARKER 1954

12891 PARKER 1954

12892 PFLUM FRERICHS 1976 12893 PFLUM FRERICHS 1976

12894 PFLUM FRERICHS 1976

12895 PFLUM FRERICHS 1776 12896 PFLU:1 FRERICHS 1976 12897 PFLUM FRERICHS 1976 12898 PFLUM FRERICHS 1976 12899 PFLUM FRERICHS 1976 12900 PFLUM FRERICHS 1976 12901 PFLUM FRERICHS 1976 12902 PARKER 1754

12903 PFLUM FRERICHS 1976 12904 PFLUM FRERICHS 1976 12905 PFLUM FRERICHS 1976 12906 PFLUM FRERICHS 1976 12907 PFLUM FRERICHS 1976 12908 PFLUM FRERICHS 1976 12909 PFLUM FRERICHS 1976 12910 PARKER 1954

12911 PFLUM FRERICHS 1976 12912 PFLUM FRERICHS 1976 12913 PFLUM FRFRICHS 1976 12914 PFLUM FRERICHS 1976 12915 PFLUM FPERICHS 1976 12916 PFLUM FRERICHS 1976 12917 PFLUM FRERICHS 1776 12918 PFLUM FRERICHS 1976 12919 PARKER 1954

12920 PHLEGER 1951A 12921 PHLEGER 1951A 12922 PHLEGER 1951A 12923 PHLEGER 1951A 12924 PHLEGER 1951 A 12925 PHLEGER 1951A 12926 PHLEGER 1951A 12927 PHLEGER 1951A 12928 PHLEGER 1951A 12929 PHLEGER 1951A 12930 PHLEGER 1951A 12931 PHLEGER 1951A 12932 PHLEGER 1951 A 12933 PHLEGER 1951A 12934 PHLEGER $1951 \mathrm{~A}$ 12935 PHLEGER 1951A

\section{Generic Name}

BULIMINA

BULIMINA

BULIMINA

BULIMINA

BULIMINA

BULIMINA

BULIMINA

BULIMINA

BULIMINA

BULIMINA

BULIMINA

BULIMINA

BULIMINA

BULIMINA

BULIMINA

BULIMINA

BULIMINA

BULIMINA

BULIMINA

BULIMINA

BULIMINA

BULIMINA

BULIMINA

BULIMINA

BULIMINA

BULIMINA

BULIMINA

BULIMINA

BULIMINA

BULIMINA

BULIMINA

BULIMINA

BULIMINA

BULIMINA

BULIMINA

BULIMINA

BULIMINA

BULIMINA

BULIMINA

BULIMINA

BULIMINA

BULIMINA

BULIMINA

BULIMINA

BULIMINA

BULIMINA

BULIMINA

BULIMINA

BULIMINA

BULIMINA

BULIMINA

BULIMINA

BULIMINA

BULIMINA

BULIMINA

BULIMINA

BULIMINA

BULIMINA

BULIMINA

BULIMINA

BULIMINA

BULIMINA

BULIMINA

BULIMINA

BULIMINA

BULIMINA

BULIMINA

BULIMINA

BULIMINA

BULIMINA

BULIMINA

BULIMINA

BULIMINA

BULIMINA

BULIMINA

BULIMINA

BULIMINA

BULIMINA

BULIMINA

BULIMINA

BULIMINA

BULIMINA

BULIMINA

BULIMINA

BULIMINA

BULIMINA

BULIMINA

BULIMINA

BULIMINA
Specific Name

AL AZ ANENS IS

AL AZANENSIS

ALAZANENS IS

AL AZANENS IS

AL AZANENS IS

AL AZ ANENS IS

AL AZANENS IS

AL AZANENS IS

AL AZANENS IS

AL AZANENS IS

AL AZANENS IS

ALAZANENSIS

AL AZANENSIS

AL AZANENSIS

AL AZANENS IS

AL AZANENS IS

AL AZANENS IS

AL AZ ANENS IS

AL AZANENS IS

ALAZANENS IS

AL AZANENS IS

AL AZ ANENS IS

AL AZANENS IS

AL AZANENS IS

AL AZANENS IS

AL AZANENSIS

SP ICATA

SPICATA

SPICATA

SPICATA

SPICATA

SPICATA

SPICATA

SPICATA

SPICATA

SPICATA

SPICATA

SPICATA

SPICATA

SP ICATA

SPICATA

SP I CA TA

SPICATA

SPICATA

SP ICATA

SPICATA

SPICATA

SPICATA

SPICATA

SPICATA

SPICATA

SPICATA

SPICATA

SPICATA

SPICATA

SPICATA

SPICATA

SP ICATA

SPICATA

SPICATA

SPICATA

SP ICATA

SP ICATA

SPICATA

SPICATA

SPICATA

SPICATA

SP ICATA

SPICATA

SPICATA

SPICATA

SPICATA

SPICA IA

SP ICATA

SPICATA

SPICATA

SPICATA

SP ICATA

SP ICATA

SPICATA

SPICATA

SPICATA

SPICATA

SPICATA

SPICATA

SP ICATA

SP ICATA

SPICATA

SPICATA

SPICATA

SPICATA

SP ICATA

\section{Locality}

NW GULF OF MEXICO

$\mathrm{NW}$ GULF OF MEXICO

NW GULF OF MEXICO

NW GULF OF MEXICO

NW GULF OF MEXICO

NW GULF OF MEXICO

NW GULF OF MEXICO

NW GULF OF MEXICO

NW GULF OF MEXICO 


\section{Publication}

12936 PHLEGER 1951 A 12937 PHLEGER 1951A 12938 PHLEGER $1951 \mathrm{~A}$ 12939 PHLEGER 1951 A 12940 PHLEGER $1951 \mathrm{~A}$ 12941 PHLEGER 1951A 12942 PHLEGER 1951 A 12944 LEROY HODGKINSON 1975 12945 PHLEGER 1951 A 12946 PFLUM FRERICHS 1976 12947 PFLUM FRERICHS 1976 12948 PFLUM FRERICHS 1976 12949 PFLUM FRERICHS 1976 12950 PFLUM FRERICHS 1976 12951 PFLUM FRERICHS 1976 12952 PFLUM FRERICHS 1976 12953 PFLUM FRERICHS 1976 12954 PFLUM FRERICHS 1976 12955 PARKER 1954

12956 PARKER 1954

12957 PARKER 1954

12958 PARKER 1954

12959 PFLUM FRERICHS 1976
12960 PFLUM FRERICHS 1976

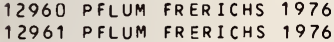
12962 LUOWICK WALTON 1957 12963 PHLEGER $1955 \mathrm{~A}$

12964 PHLEGER 1955A

12965 PHLEGER 1955 A

12966 PHLEGER 1955A

12967 PHLEGER 1955A

12968 PHLEGER 1955A

12969 PHLEGER 1955A

12970 PARKER 1954

12971 PARKER 1954

12972 PARKER 1954

12973 PARKER 1954

12974 PARKER 1954
12975 PHLEGER 1951 A

12976 PHLEGER 1951 A

12977 CREAGER 1958

12978 CREAGER 1958

12979 CREAGER 1958

12980 CREAGER 1958

12981 CREAGER 1958

12982 BOCK 1976

12983 PHLEGER 1956

12984 PFLUM FRERICHS 1976

12985 PFLUM FRERICHS 1976

12986 PFLUM FRERICHS 1976

12987 PFLUM FRERICHS 1976

12988 PFLUM FRERICHS 1976 12989 PFLUM FRERICHS 1976 12990 PFLUM FRERICHS 1976 12991 PFLUM FRERICHS 1976 12992 PFLUM FRERICHS 1976 12993 PFLUM FRERICHS 1976 12994 PFLUM FRERICHS 1976 12995 PFLUM FRERICHS 1976 12996 PFLUM FRERICHS 1976 12997 LOEP 1965

12998 LOEP 1965

12999 CREAGER 1958

13000 CREAGER 1958

13001 CREAGER 1958

13002 PFLUM FRERICHS 1976 13003 PFLUM FRERICHS 1976 13004 PFLUM FRERICHS 1976 13005 PFLUM FRERICHS 1976 13006 PFLUM FRERICHS 1976 13007 PFLUM FRERICHS 1976 13008 PFLUM FRERICHS 1976 13009 PFLUM FRERICHS 1976 13010 PFLUM FRERICHS 1976 13011 PFLUM FRERICHS 1976 13012 PFLUM FRERICHS 1976 13013 PFLUM FRERICHS 1976 13014 PFLUM FRERICHS 1976 13015 PFLUM FRERICHS 1976 13016 PFLUM FRERICHS 1976 13017 PFLUM FRERICHS 1976 13018 PFLUM FRERICHS 1976 13019 PARKER 1954

13020 LOEP 1965

13021 PFLUM FRERICHS 1976 13022 PFLUM FRERICHS 1976 13023 PFLUM FRERICHS 1976 13024 PFLUM FRERICHS 1976 13025 PFLUM FRERICHS 1976 13026 PFLUM FRERICHS 1976 13027 PFLUM FRERICHS 1976 13028 PFLUM FRERICHS 1976 13029 PFLUM FRERICHS 1976 13030 PFLUM FRERICHS 1976
Generic Name

Specific Name

Locality

Lat. Long.

OULIMINA

BULIMINA

BULIMINA

BULIMINA

BULIMINA

BULIMINA

BULIMINA

BULIMINA

BULIMINA

BULIMINA

BULIMINA

BULIMINA

BULIMINA

BULIMINA

BULIMINA

BULIMINA

BULIMINA

BULIMINA

BULIMINA

BULIMINA

BULIMINA

BULIMINA

BULIMINA

BUL IMINA

BULIMINA

BULIMINA

BULIMINA

BULIMINA

BULIMINA

BULIMINA

BULIMINA

BULIMINA

BULIMINA

BULIMINA

BULIMINA

BULIMINA

BULIMINA

BULIMINA

BULIMINA

BULIMINA

BULIMINA

BULIMINA

BULIMINA

BULIMINA

BULIMINA

BULIMINA

BULIMINA

BULIMINA

BULIMINA

BULIMINA

BULIMINA

BULIMINA

BULIMINA

BULIMINA

BULIMINA

BULIMINA

BULIMINA

BULIMINA

BULIMINA

BULIMINA

BULIMINA

BULIMINA

BULIMINA

BULIMINA

BULIMINA

BULIMINA

BULIMINA

BULIMINA

BULIMINA

BULIMINA

BULIMINA

BULIMINA

BULIMINA

BULIMINA

BULIMINA

BULIMINA

BULIMINA

BULIMINA

BULIMINA

BULIMINA

BULIMINA

BULIMINA

BULIMINA

BULIMINA

BULIMINA

BULIMINA

BULIMINA

BULIMINA

BULIMINA

BULIMINA

BULIMINA

BULIMINA
BULIMINA
SPICATA

SPILATA

SPICATA

SPICATA

SPICATA

SPICATA

SPICATA

SPICATA

SPICATA

SP ICATA

SPICATA

SPICATA

SPICATA

SPICATA

SPICATA

SPICATA

SPICATA

SPICATA

SPICATA

SPICATA

SPICATA

SPICATA

SPICATA

SPICATA

SPICATA

SPICATA

SPICATA

SP ICATA

SPICATA

SPICATA

SPICATA

SPICATA

SPICATA

SPICATA

SPICATA

SPICATA

SPICATA

SPICATA

SPICATA

SPICATA

SPICATA

SP I CATA

SPICATA

SPICATA

SPICATA

SPICATA

SPICATA

P ICATA

SPICATA

SPICATA

SPICATA

SPICATA

SPICATA

SPICATA

PICATA

SPICATA

SPICATA

SPICATA

SPICATA

SPICATA

SPICATA

IN FLATA MEXICANA

N FLATA MEXICANA

INFLATA MEXICANA

INFLATA MEXICANA INFLATA MEXICANA INFLATA MEXICANA INFLATA MEXICANA INFLATA MEXICANA INFLATA MEXICANA INFLATA MEXICANA INFLATA MEXICANA INFLATA MEXICANA INFLATA MEXICANA INFLATA MEXICANA INFLATA MEXICANA INFLATA MEXICANA INFLATA MEXICANA INFLATA MEXICANA IN FLATA MEXICANA INFLATA MEXICANA INFLATA MEXICANA INFLATA MEXICANA INFLATA MEXICANA INFLATA MEXICANA INFLATA MEXICANA INFLATA MEXICANA INFLATA MEXICANA INFLATA MEXICANA INFLATA MEXICANA
NW GULF OF MEXICO NW GULF OF MEXICO $\mathrm{NW}$ GULF OF MEXICO NW GULF OF MEXICO NW GULF OF MEXICO NW GULF OF MEXICO NW GULF OF MEXICO NW GULF OF MEXICO 


\section{Publication}

13031 PFLUM FRERICHS 1976 13032 PFLUM FRERICHS 1976 13033 PFLUM FREHICHS 1976 13034 PFLUM FRERICHS 1976 13035 PARKER 1954
13036 PARKER 1954

13037 PARKER 1354

13038 PARKER 1954

13039 PARKER 1954

13040 PARKER 1954

13041 PFLUM FRERICHS 1976

13042 LOEP 1965

13043 LOEP 1965

13045 CREAGER 1958

13046 CREAGER 1958

13047 CREAGER 1958

13048 CREAGER 1958
13049 PHLEGER $1951 \mathrm{~A}$

13050 PHLEGEP $1951 \mathrm{~A}$

13051 PHLEGER 1951A

13052 PHLEGER 1951A

13053 PHLEGER 1951A

13054 PHLEGER 1951A

13055 PHLEGER 1951A

13056 PHLEGER $1951 \mathrm{~A}$

13057 PHLEGED $1951 \mathrm{~A}$

13058 PHLEGER $1951 \mathrm{~A}$

13059 PHLEGER 1951A

13061 PHLEGER 1951A

13062 PHLEGER 1951 A

13063 PHLEGER 1951A

13064 PHLEGER 1951A

13065 PHLEGER $1951 \mathrm{~A}$

13066 PHLEGER 1951 A

13067 PHLEGER 1951A

13068 PHLEGER 1951A

13069 PHLEGER 1951A

13070 PHLEGER 1951A

13072 PHLEGER 1951A

13073 PFL'JM FRERICHS 1976

13074 PHLEGER 1951 A

13075 PHLEGER $1951 \mathrm{~A}$

13076 PHLEGER 1951A

13077 PFLUM FRERICHS 1976

13078 PFLUM FREKICHS 1976

13079 PHLEGER 1951A

13080 PHLEGER 1951A

13081 PARKER 1954

13082 PARKER 1954

13083 PARKER 1954

13084 PARKER 1954

13085 PARKER 1954

13086 PARKER 1954

13087 PARKER 1954

13088 PARKER 1954

13089 PARKER 1954

13090 PARKER 1954

13091 PARKER 1954

13092 CREAGER 1958

13093 PARKER 1954

13094 PARKER 1954

13096 PHLEGER 1955A

13097 PHLEGER 1955A

13098 PHLEGER 1955A

13099 PHLEGER 1955A

13100 PHLEGER 1955A

13101 PHLEGE? $1955 \mathrm{~A}$

13102 PHLEGER 1955A

13103 PHLEGER 1955A

13104 LUDWICK WALTON 1957

13105 PFLUM FRERICHS 1976

13106 PFLUM FRERICHS 1976

13107 PFLUM FRERICHS 1976

13108 PFLUM FRERICHS 1976

13109 PFLIJM FRERICHS 1976

13110 PFLUM FRERICHS 1976

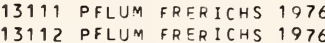

13113 PFLUM FRERICHS 1976

13114 PFLUM FRERICHS 1976

13115 PFLUM FRERICHS 1976

13116 PFLUM FRERICHS 1976

13117 PFLUM FRERICHS 1976

13119 PFLUM FRERICHS 1976

13120 PFLUM FRERICHS 1976

13121 PFLUM FRERICHS 1976

13122 PFLUA FRERICHS 1976

13123 PFLUM FRERICHS 1976

13124 PFLUM FRERICHS 1976
13125 PFLUM FRERICHS 1976
Generic Name

BULIMINA

BULIMINA

BULIMINA

BULIMINA

BULIMINA

BULIMINA

BULIMINA

BULIMINA

BULIMINA

BULIMINA

BULIIINA

BULIMINA

BULIMINA

BULIMINA

BULIMINA

BULIMINA

BUL IMINA

BULIMIN A

BULIMINA

BULIMINA

BULIMINA

BULIMINA

BULIMINA

BULIMINA

BULIMINA

BULIMINA

BULIMINA

BULIMINA

BULIMINA

BULIMINA

BULIMINA

RULIMINA

BULIMINA

BULIMINA

BULIMINA

BULIMINA

BULIMINA

BULIMINA

BULIMINA

BULIMINA

BULIMINA

BULIMINA

BULIMINA

BULIMINA

BULIMINA

BULIMINA
BULIMINA

BULIMINA

BULIMINA

BULIMINA

BULIMINA

BULIMINA

BULIMINA

BULIMINA

BULIMINA

BULIMINA

BULIMINA

BULIMINA

BULIMINA

BULIMINA

BULIMINA

BULIMINA

BULIMINA

BULIMINA

BULIMINA

BULIMINA

BULIMINA

BULIMINA

BULIMINA

BULIMINA

BULIMINA

BULIMINA

BULIMINA

BULIMINA

BULIMINA

BULIMINA

BULIMINA

BULIMINA

BULIMINA

BULIMINA

BULIMINA

BULIMINA

BULIMINA

BULIMINA

BULIMINA

BULIMINA

BULIMINA

BULIMINA
Specific Name

IN FLATA MEXICANA IN FLATA MEXICANA INFLATA MEXICANA INFLATA MEXICANA IN FLATA MEXICANA INFLATA MEXICANA IN FLATA MEXICANA IN FLATA MEXICANA IN FLATA MEXIICANA INFLATA MEXICANA INFLATA MEXICANA IN FLATA MEXICANA INFLATA MEXICANA INFLATA MEXICANA IN FLATA MEXICANA IN FLATA MEX ICANA INFLATA MEXICANA IN FLATA MEXICANA IN FLATA MEXICANA INFLATA MEXICANA IN FLATA MEX ICANA INFLATA MEXICANA INFLATA MEXICANA IN FLATA MEXICANA IN FLATA MEXICANA IN FLATA MEXICANA INFLATA MEXICANA INFLATA MEXICANA IN FLATA MEX I CANA INFLATA MEXICANA IN FLATA MEXICANA INFLATA MEXICANA INFLATA MEXICANA INFLATA MEXICANA IN FL ATA MEX ICANA IN FLATA MEXICANA IN FLATA MEXICANA IN FLATA MEXICANA INFLATA MEXICANA INFLATA MEXICANA IN FLATA MEXICANA IN FLATA MEXICANA IN FLATA MEXICANA INFLATA MEXICANA IN FLATA MEXICANA INFLATA MEXICANA INFLATA MEXICANA IN FLATA MEXICANA IN FLATA MEX I CANA INFLATA MEXICANA INFLATA MEX ICANA IN FLATA MEXICANA IN FLATA MEXICANA INFLATA MEXICANA IN FLATA MEXICANA INFLATA MEXICANA IN FLATA MEXICANA IN FLATA MEXICANA IN FLATA MEXICANA INFLATA MEXICANA IN FLATA MEXICANA IN FLATA MEX ICANA IN FL ATA MEXICANA INFLATA MEXICANA IN FLATA MEXICANA INFLATA MEXICANA INFLATA MEXICANA IN FLATA MEXICANA IN FLATA MEXICANA IN FLATA MEX ICANA INFLATA MEXICANA IN FLATA MEXICANA IN FLATA MEXICANA INFLATA MEXICANA IN FLATA MEX ICANA INFLATA MEXICANA INFLATA MEXICANA INFLATA MEXICANA INFLATA MEXICANA INFLATA MEXICANA IN FLATA MEXICANA INFLATA MEXICANA IN FLATA MEXICANA INFLATA MEXICANA IN FLATA MEXICANA IN FLATA MEXICANA INFLATA MEXICANA IN FLATA MEXICANA IN FLATA MEXICANA IN FLATA MEX ICANA INFLATA MEXICANA INFLATA $M$ INFLATA MEXICANA INFLATA MEXICANA IN FLATA MEXICANA

Locality

NW GULF OF MEXICO

NW GULF OF MEXICO

NH GULF OF MEXICO

NW GULF OF MEXICO

NE GULF OF MEXICO

NE GULF OF MEXICO

NE GULF OF MEXICO

NE GULF OF MEXICO

NE GULF OF MEXICO

NE GULF OF MEXICO

CENTRAL GULF OF MEXICO

$\mathrm{NW}$ GULF OF MEXICO

NW GULF OF MEXICO

BAY OF CAMPECHE

BAY OF CAMPECHE 


\section{Publication}

13126 PFLUM FRERICHS 1976 13127 DFLUM FRERICHS 1976 13128 PFLUM FRERICHS 1976 13129 PFLUM FRERICHS 1976 13130 PFLUM FRERICHS 1976 13131 PFLUM FRERICHS 1976 13132 PFLUM FRERICHS 1976 13133 PFLUM FRERICHS 1376 13134 PFLUM FRERICHS 1976 13135 PFLUM FRERICHS 1976 13136 PFLUM FRERICHS 1976 13137 PFLUM FRERICHS 1976 13138 PFLUM FRERICHS 1976 13139 PFLUM FRERICHS 1976 13140 PFLUM FRERICHS 1976 13141 PFLUM FRERICHS 1976 13142 PFLUM FRERICHS 1976 13143 PFLUM FRERICHS 1976 13144 PHLEGER 1956

13145 PHLEGER 1951 A

13146 PHLEGER 1951 A 13147 PHLEGE P 1951A

13148 PHLEGER 1951A 13149 PHLEGER $1951 \mathrm{~A}$ 13150 PHLEGER $1951 \mathrm{~A}$ 13152 PHLEGER 1951 A 13153 KELLOUGH 1956 13154 KELLOUGH 1956 13155 KELLOUGH 1956 13156 ANDERSEN 1961 13157 PHLEGER $1951 \mathrm{~A}$ 13158 PHLEGER $1951 \mathrm{~A}$ 13159 PHLEGER $1951 \mathrm{~A}$ 13160 PHLEGER 1951A 13161 PHLEGER 1951A 13162 PHLEGER 1951A 13163 PHLEGER 1951A 13164 PHLEGER 1951A 13166 PHLEGER 1951A 13167 PHLEGER 1951A 13168 PHLEGER $1951 \mathrm{~A}$ 13169 PHLEGER 1956 13170 KELLOUGH 1956 13171 PFLUM FRERICHS 1976 13172 WALTON 1960

13173 PHLEGER 1965A

13174 AYALA-CASTANARES 1963

13175 WARREN 1956

13176 WALTON 1964

13177 PARKER PHLEGER PEIRSON 1953

13178 PHLEGER $1951 \mathrm{~A}$

13179 PHLEGER 1951A

13180 PHLEGER 1951A

13181 PHLEGER 1951 A

13182 PHLEGER 1951A

13183 PHLEGER 1951 A

13184 PHLEGER $1951 \mathrm{~A}$

13185 PHLEGER 1951 A

13186 PHLEGER 1951A

13187 PHLEGER 1951A

13188 PARKER PHLEGER PEIRSON 1953

13189 PHLEGER 1956

13190 PHLEGER 1956

13191 PHLEGER 1956

13192 PHLEGER 1956

13193 PHLEGER 1956

13194 BOCK 1976

13195 PHLEGER 19558

13196 PHLEGER 1951 A

13197 PHLEGER 1951A

13198 PHLEGER $1951 \mathrm{~A}$

13199 PHLEGER $1951 \mathrm{~A}$

13200 PHLEGER $1951 \mathrm{~A}$

13201 LANKFORD 1959

13202 PHLEGER 1954

13203 PHLEGER 1954
13204 PARKER 1954

13204 PARKER 1954
13205 WARREN 1957

13206 PHLEGER 1955A

13207 PARKER 1954

13208 PARKER 1954

13209 PARKER 1954

13210 PARKER 1954

13211 PARKER 1954

13212 PARKER 1954

13213 PARKER 1954

13214 PARKER 1954

13215 PARKER 1954

13216 PARKER 1954

13217 PARKER 1354

13218 SEGURA 1963
13219 PHLEGER 1951 A

13219 PHLEGER $1951 \mathrm{~A}$
13220 PHLEGER $1951 \mathrm{~A}$
Generic Name

BULIMINA

BULIMINA
BULIMINA

BULIMINA

BULIMINA

BULIMINA

BULIMINA

BULIMINA

BULIMINA

BULIMINA

BULIMINA

BULIMINA

BULIMINA

BULIMINA

BULIMINA

BULIMINA

BULIMINA

BULIMINA

BULIMINA

BULIMINA

BULIMINA

BULIMINA

BULIMINA

BULIMINA

BULIMINA

BULIMINA

BULIMINA

BULIMINA

BULIMINA

BULIMINA

BULIMINA

BULIMINA

BULIMINA

BULIMINA

BULIMINA

BULIMINA

BULIMINA

BULIMINA

BULIMINA

BULIMINA

BULIMINA

BULIMINA

BULIMINA

BULIMINA

BULIMINA

BULIMINELLA

BULIMINELLA

BULIMINELLA

BULIMINELLA

BULIMINELLA

BULIMINELLA

BULIMINELLA

BULIMINELLA

BUL IMINELLA

BULIMINELLA

BUL IMINELLA

BULIMINELLA

BULIMINELLA

BULIMINELLA

BULIMINELLA

BU LIMINELLA

BULIMINELLA

BULIMINELLA

BULIMINELLA

BULIMINELLA

BULIMINELLA

BULIMINELLA

BULIMINELLA

BULIMINELLA

BULIMINELLA

BULIMINELLA

BULIMINELLA

BULIMINELLA

BULIMINELLA

BULIMINELLA

BULIMINELLA

BULIMINELLA

BULIMINELLA

BULIMINELLA

BULIMINELLA

BULIMINELLA

BULIMINELLA

BULIMINELLA

BULIMINELLA

BULIMINELLA

BUL IMINELLA

BULI I IN ELL A

BULIMINELL A

BULIMINELLA

BULIMINELLA

BULIMINELLA

BULIMINELLA

BULIMINELLA

BULIMINELL A

BULIMINELLA
Specific Name

INFLATA MEXICANA

INFLATA MEXICANA

IN FLATA MEXICANA

INFLATA MEXICANA

INFLATA MEXICANA

INELATA MEX ICANA

INFLATA MEXICANA

IN FLATA MEXICANA

IN FLATA MEXICANA

IN FLATA MEXICANA

IN FLATA MEXICANA

INFLATA MEXICANA

INFLATA MEXI I ANA

INFLATA MEXICANA

INFLATA MEXICANA

INFLATA MEXICANA

IN FLATA MEXICANA

TENUIS

TENUIS

TENUIS

TENUIS

TENUIS

TENUIS

TENUIS

TENUIS

TENUIS

TENUIS

TENUIS

TENUIS

TE NUIS

TENUIS

TENUIS

TENUIS

TENUIS

TE AUIS

TENUIS

TENUIS

TENUIS

TENUIS

TENUIS

TENUIS

TENUIS

TENUIS

TENUIS

BA SSENDOR FENSIS

BA SSENDORFENSIS

BA SSENDORFENSIS

BA SSENDORFENSIS

BASSENDORFENSIS

BASSENDORFENSIS

BA SSENDORFENSI

BASSENDOR FENS I

BASSENDORFENSIS

BA SSENDORFENSI

BASSENDORFENS IS

BASSENDORFENSIS

BASSENDOR FENSIS

BA SSENDORFENS I

BASSENDORFENSIS

BASSENDORFENS IS

BASSEN

BASSENDORFENS I S

BASSENDORFENSIS

BASSENDORFENSIS

BA SSENDOR FENSI

BASSENDOR FENSIS

BASSENDORFENS IS

BASSENDOR ENS IS

BASSENDORFENSIS

BASSENDORFENSIS

BASSENDOR FENSI

BASSEND OR FENS IS

BASSENDORFENSIS

BASSENDORFENSIS

BASSENDORFENSIS

BASSENDORFENSIS

BA SSENDORFENSI

BASSENDOR FENSIS

BASSENDORFENS IS

BA SSENDOR FENS IS

BASSENDORFENSIS

BASSENDORFENSIS

BASSENDORFENSIS

BASSENDORFENSIS

BASSENDORFENSIS

BA SSENDOR FENSIS

BASSENDORFENSI

BASSENDORFENSIS

BASSENDOH FE

BASSENDORFENSIS

BASSENDORFENSIS

BASSENDORFENSIS

BASSEND OR FENSIS

\section{Locality}

NW GULF OF MEXICO

CENTRAL GULF OF MEXICO

CENTRAL GULF OF MEXICO

NW GULF OF MEXICO

NW GULF OF MEXICO 


\section{Publication}

13221 PHLEGER 1951A

13222 PHLEGER 1951A

13223 PHLEGER 1951

13224 KANE 1962
13225 KANE 1967

13226 PHLEGER 1951A

13227 PHLEGER 1951A

13228 PHLEGER 1951 A

13229 PHLEGER 1951A

13230 KANE 1962

13231 SEGURA 1963

13232 KANE 196 ?

13233 PHLEGER 1960

13234 BENDA PURI 1962

13235 BENDA PURI 1962

13236 PHLEGER 1951A

13237 POAG 1976

13238 LANKFORD 1959

13239 PHLEGER 1951 A

13241 PHLEGFR LANKFORD 1957

13242 PHLEGER 1954

13243 PHLEGER 1965A

13244 BANDY 1956

13245 PHLEGER 1954

13246 PHLEGER $1951 \mathrm{~A}$

13248 PHLEGER 1955 B

13248 PHLEGER 19558
13249 PHLEGER 1951 A

13250 PHLEGER 1951A

13251 PHLEGER 1965 A

13252 PHLEGER 1965 A

13254 WALTON 1964

13255 AYALA-CASTANARES SEGURA 1968

13256 AYALA-CASTANARES 1963

13257 PHLEGER 19658

13258 PHLEGER 1956

13259 PHLEGER 1956

13260 PHLEGER 1956

13261 PHLEGER 1956

13262 PARKER PHLEGER PEIRSON 1953

13263 WALTON 1960

13264 OTVOS 1978

13265 ANDERSEN 1961

13266 BANDY 1956

13267 PHLEGER 1951A

13268 PHLEGER 1951A

13269 PHLEGER 1951A

13270 PHLEGER 1951A

13271 PHLEGER 1951A

13272 PHLEGER 1951A

13273 PHLEGER $1951 \mathrm{~A}$

13274 PHLEGER 1951 A

13275 PARKER PHLEGER PEIRSON 1953

13276 POST 1951

13277 PARKER PHLEGER PEIRSON 1953

13278 PARKER PHLEGER PEIRSON 1953

13279 POST 1951

13280 PARKER PHLEGER PEIRSON 1953

13281 BOCK 1376

13282 BANDY 1956

13283 BANDY 1956

13284 SANDY 1956

13285 PFLUM FRERICHS 1976
13286 PFLUM FRERICHS 1976

13287 ANDERSEN 1961

13288 ANDERSFV 1961

13289 ANDERSEN 1961

13290 ANDERSEN 1961

13291 ANDERSEN 1961

13292 ANDERSEN 1961

13293 ANDERSEN 1961

13295 CUSHMAN 19228

13296 NORTON 1930

13297 CUSHMAN 19?2A

13298 PFLUM FRERICHS 1976

13299 PFLUM FRERICHS 1976

13300 PFLUM FRERICHS 1976

13301 PFLUM FRERICHS 1976

13302 PFLUM FRERICHS 1976

13303 PFLUM FRERICHS 1976

13304 PHLEGER 1951A

13305 PHLEGER 1951A

13306 PHLEGER 1951 A

13307 PHLEGER 1951A

13308 PHLEGER 1951A

13309 PHLEGER 1951A
13310 PHLEGEP $1951 \mathrm{~A}$

13311 PARKER 1954

13312 PARKER 1354

13313 PARKER 1354
13314 PARKER 1954

13315 KELLOUGH 1956
Generic Name

BULIMINELLA

BULIMINELLA

BULIMINELLA

BULIMINELLA

BULIMINELLA

BIJLIMINELLA

BULIMINELLA

BULIMINELLA

BULIMINELLA

BULIMINELLA

BULIMINELLA

SULIMINELLA

BULIMINELLA

BULIMINELLA

BULIMINELLA

BULIMINELLA

BULIMINELLA

BULIMINELLA

BULIMINELLA

BUL IMINELLA

BULIMINELLA

BULIMINELLA

BULIMINELLA

BULIMINELLA

BULIMINELLA

BULIMINELLA

BULIMINELLA

BULIMINELLA

BULIMINELLA

BULIMINELLA

BULIMINELLA

BULIMINELLA

BULIMINELLA

BULIMINELL

BU LIMINELLA

BUL IMINELLA

BULIMINELLA

BULIMINELLA

BULIMINELLA

BULIMINELLA

BULIMINELLA

BULIMINELLA

BULIMINELLA

BULIMINELLA

BULIMINELLA

BULIMINELLA

BULIMINELLA

BULIMINELLA

BULIMINELLA

BUL IMINELLA

BULIMINELLA

BULIMINELLA

BULIMINELLA

BULIMINELLA

BULIMINELLA

BULIMINELLA

BULIMINELLA

BULIMINELLA

BULIMINELLA

BULIMINELLA

BULIMINELLA

BULIMINA

SULIMINA

BULIMINELLA

BULIMINELLA

BULIMINELLA

BULIMINELLA

BUL IMINELLA

BUL IMINELLA

BULIMINELLA

BULIMINELLA

BUL I MI NELLA

BULIMINELLA

BULIMINOIDES

CANCRIS

CANCRIS

CANCRIS

CANCRIS

CANCRIS

CANCRIS

CANCRIS

CANCRI

CANCRIS

CANCRIS

CANCRIS

CANCRIS

CANCRIS

CANCRIS

CANCRI

CANCRIS

CANCRIS

CANCRIS
Specific Name

BA SSENDORFENSIS

BASSENDORFENSIS

BASSENDORFENSIS

BASSENDORFENSIS

BASSENDOR FENSIS

BASSENDOR FENS IS

BASSENDOR FENSIS

BASSENDOR FENSIS

BA SSENDOR FENS IS

ELEGANT IS S IMA

ELEGANTISS I MA

ELEGANT IS SIMA

ELEGANTISSIMA

ELEGANT IS S I MA

ELEGANT IS SIMA

EL EGANT IS SIMA

ELEGANT IS S IMA

ELEGANT IS SIMA

ELEGANT IS SIMA

ELEGANT IS SI MA

ELEGANT IS SIMA

ELEGANT IS SIMA

ELEGANT IS SIMA

ELEGANT ISSIMA

ELEGANT IS SIMA

ELEGANT IS SIMA

ELEGANTIS SIMA

ELEGANT IS SIMA

ELEGANT IS SIMA

ELEGANTISSIMA

ELEGANT ISSIMA

ELEGANT IS S IMA

ELEGANTIS SIMA

ELEGANT ISSIMA

ELEGANTIS SIMA

ELEGANT IS SIMA

ELEGANT IS I MA

EL EGANTISSIMA

ELEGANT IS SIMA

ELEGANT IS SIMA

ELEGANT I S SIMA

ELEGANT IS S IMA

ELEGANT IS SIMA

EL EGANT IS SIMA

ELEGANTIS SIMA

ELEGANT I S I MA

ELEGANT IS SIMA

ELEGANT IS SIMA

ELEGANT ISSIMA

ELEGANT IS S IMA

ELEGANT IS SIMA

ELEGANT ISSIMA

ELEGANT IS SIMA

ELEGANT ISSIMA

ELEGANT IS SIMA

EL EGANT IS SIMA

EL EGANT IS SIMA

ELEGANT IS SIMA

ELEGANT IS SIMA

ELEGANT IS SIMA

ELEGANT IS SIMA

ELEGANT ISSIMA

ELEGANTISSIMA

EL EGANT ISS IMA

EXILIS

BASSENDOR FENSIS

BASSENDORFENSIS

BASSENDORFENSIS

BASSENDORFENSIS

BASSENDOR FENSIS

BA SSENDORFENSIS

BASSENDOR FENSIS

BA SSENDORFENSIS

SUBTERES

SUBTERES

WI LLI AMSONI ANA

AURI CULA

AURI CULA A

AURICULA

AURICULA

AURI CULA

OBLONGA

OB LONGA

OBLONGA

OB LONGA

OBLONGA

OBLONGA

OB LONGA

OBLONGA

OB LONGA

OBLONGA

OB LONGA

OB LONGA

Locality

Lat. Long.

NW GULF OF MEXICO

$N W$ GULF OF MEXICO

NW GULF OF MEXICO

SABINE LAKE, TEXAS

SABINE LAKE, TEXAS

NW GULF OF MEXICO

NW GULF OF MEXICO

NW GULF OF MEXIC

SABINE LAKE, TEXAS 


\section{Publication}

13316 KELLOUGH 1956 13317 KELL OUGH 1956 13318 PARKER 1954

13319 PARKER 1954
13320 LANKFORD 1959

13321 LUDWICK WALTON 1957

13322 PARKER 1954

13323 PARKER 1954

13324 PARKER 1954

13325 PARKER 1954

13327 PHLEGER 1951 A

13328 PHLEGER 1951A

13329 PHLEGER $1951 \mathrm{~A}$

13330 PHLEGER 1951A

13331 PHLEGER 1951A

13332 PHLEGER 1951A

13333 PHLEGER 1951A

13335 PHLEGER 1951A

13336 PHLEGER 1951A

13337 PHLEGER 1951A

13338 PHLEGER 1951A

13339 PHLEGER 1951A

13340 PHLEGER 1951A

13341 PHLEGER 1951A

13342 PHLEGER 1951A

13344 PHLEGER 1951A

13345 PHLEGER $1951 \mathrm{~A}$

13346 PARKER 1954

13347 PARKER 1954

13348 PARKER 1954

13349 CREAGER 1958

13350 CREAGER 1958

13351 PHLEGER 1956

13352 PHLEGER 1956

13353 PHLEGER 1956

13354 PARKER 1954

13356 PARKER 1954

13357 PARKER 1954

13358 BOCK 1976

13359 CREAGER 1958

13360 KELLOUGH 1956

13361 KELLOUGH 1956

13362 KELLOUGH 1956

13363 CREAGER 195

13364 BOCK 1976

13365 WARREN 1956

13366 BANDY 1954

13367 BANDY 1956

13368 BANDY 1954

13370 POAG SWEET 1972

13371 CUSHMAN 1931

13372 KELLOUGH 1956

13373 BANDY 1954

13374 BANDY 1954

13375 BANDY 1956

13376 BANDY 1956

13377 BANDY 1956

13378 BANDY 1956
13379 BANDY 1956

13379 BANDY 1956
13380 BANDY 1954

13381 BANDY 1956

13382 BANDY 1956

13383 BANDY 1956

13385 ANDERSEN 1961

13386 DAVIS 1964

13387 WARREN 1957

13388 BANDY 1956

13389 BANDY 1954

13390 BANDY 1956

13391 BOCK 1976

13392 CUSHMAN $1922 \mathrm{~A}$

13393 PARKER 1954

13394 PARKER 1954

13395 PARKER 1954

13396 PARKER 1954

13397 PARKER 1954

13398 PARKER 1954

13399 PARKER 1954

13400 PARKER 1954

13401 PARKER 1954

13402 PARKER 195

13403 PARKER 1954

13404 PARKER 1954

13405 PARKER 1954

13400 PARKER 1954

13407 PARKER 1954

13408 PARKER 1954

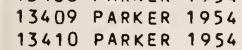

Generic Name Specific Name

Locality

Lat. Long.

CANCRIS

CANCRIS
CANCRIS

$\begin{array}{ll}\text { CANCRIS } & \text { OBLONGA } \\ \text { OBLONGA }\end{array}$

CANCRIS OBLONGA

CANCRIS OBLONGA

CANCRIS OBLONGA

CANCRIS OBLONGA

CAVCRIS OBLONGA

CANCRIS OBLONGA

OBLONGA

CANCRIS OBLONGA

CANCRIS OBLONGA

CANCRIS OBLONGA

CANCRIS 1 OBLONGA

CANCRIS OBLONGA

CANCRIS OBLONGA

CANCRIS OBLONGA

CANCRIS OBLONGA

CANCRIS OBLONGA

$\begin{array}{ll}\text { CANCRIS } & \text { OBLONGA } \\ \text { CANCRIS } & \text { OBLONGA }\end{array}$

CANCRIS OBLONGA

CANCRIS

CANCRIS OBLONGA

CANCRIS OBLONGA

CANCRIS OBLONGA

CANCRIS OBLONGA

CANCRIS OBLONGA

OBLONGA

CANCRIS OBLONGA

CANCRIS OBLONGA

CANCRIS

CANCRIS OBLONGA

CANCRIS

OBLONGA

$\begin{array}{ll}\text { CANCRIS } & \text { OBLONGA } \\ \text { CANCRIS } & \text { OBLONGA }\end{array}$

CANCRIS OBLONGA

CANCRIS OBLONGA

CANCRIS OBLONGA

CANCRIS

CANCRIS

CANCRIS

CANCRIS

CANCRIS

CANCRIS

CANCRIS

CANCRIS

CANCRIS

CANCRIS

CANCRIS

CANCRIS

CANCRIS

CANCRIS

CANCRIS

CANCRIS

CANCRIS

CANCRIS

CANCRIS

CANCRIS

CANCRIS

CANCRIS

CANCRIS

CANCRIS
CANCRIS

CANCRIS

CANCRIS

CANCRIS

CANCRIS

CARTERINA

CARTERINA

CASSI DUL INA

CASSIDULINA

CASSIDULINA

CASSIDULINA

CASSIDULINA

CASSIDULINA

CASSIDULINA

CASSIDULINA

CASSIDUL INA

CASSIDULINA

CASSIDULINA

CASSIDULINA

CASSIDULINA

CASSIDULINA

CASSI DULINA

CASSIDULINA

CASSIDULINA

CASSIDULINA
NW GULF OF MEXICO

NW GULF OF MEXICO

NE GULF OF MEXICO

NE GULF OF MEXICO

MISSISSIPPI DELTA

NE GULF OF MEXICO

NE GULF OF MEXICO

NE GULF OF MEXICO

NE GULF OF MEXICO

NE GULF OF MEXICO

NE GULF OF MEXICO

NW GULF OF MEXICO

NW GULF OF MEXICO

NW GULF OF MEXICO

NW GULF OF MEXICO

NW GULF OF MEXICO

NW GULF OF MEXICO

NW GULF OF MEXICO

NW GULF OF MEXICO

NW GULF OF MEXICO

NW GULF OF MEXICO

NW GULF OF MEXICO

NW GULF OF MEXICO

$N$ W GULF OF MEXICO

NW GULF OF MEXICO

NW GULF OF MEXICO

NW GULF OF MEXICO

NW GULF OF MEXICO

$N W$ GULF OF MEXICO

NE GULF OF MEXICO

NE GULF OF MEXICO

NE GULF OF MEXICO

BAY OF CAMPECHE

NW GULF OF MEXICO

NW GULF OF MEXICO

NW GULF OF MEXICO

NE GULF OF MEXICO

NE GULF OF MEXICO

NE GULF OF MEXICO

NE GULF OF MEXICO

NE GULF OF MEXICO

BAY OF CAMPECHE

NW GULF OF MEXICO

NW GULF OF MEXICO

NW GULF OF MEXICO

BAY OF CAMPECHE
NE GULF OF MEXICO

BURAS SE LOUISIANA

NW GULF OF MEXICO

NE GULF OF MEXICO

NW GULF OF MEXICO

TAMPICO BANK

CLAYPILE BANK

TORTUGAS, FLA

NW GULF OF MEXICO

NW GULF OF MEXICO

NW GULF OF MEXICO

NE GULF OF MEXICO

NE GULF OF MEXICO

NE GULF OF MEXICO

NE GULF OF MEXICO

NE GULF OF MEXICO

NW GULF OF MEXICO

NE GULF OF MEXICO

NE GULF OF MEXICO

NE GULF OF MEXICO

NE GULF OF MEXICO

MISSISSIPPI DELTA

CAMPECHE BANK. MEXICO

SE LOUISIANA

NE GULF OF MEXICO

NW GULF OF MEXICO

NE GULF OF MEXICO

NE GULF OF MEXICO

TORTUGAS

NE GULF OF MEXICO

NE GULF OF MEXICO

NE GULF OF MEXICO

NE GULF OF MEXICO

NE GULF OF MEXICO

NE GULF OF MEXICO

NE GULF OF MEXICO

NE GULF OF MEXICO

NE GULF OF MEXICO

NE GULF OF MEXICO

NE GULF OF MEXICO

NE GULF OF MEXICO

NE GULF OF MEXICO

NE GULF OF MEXICO

NE GULF OF MEXICO

NE GULF OF MEXICO

NE GULF OF MEXICO

NE GULF OF MEXICO
BAY OF CAMPECHE

$\begin{array}{llll}28 & 10 N \quad 094 \quad 17 W\end{array}$

$28 \quad 10 \mathrm{~N} 094 \quad 18 \mathrm{~W}$ $2934 \mathrm{~N} 088$ 01W $2952 \mathrm{~N} 088 \quad 15 \mathrm{~W}$ $2920 \mathrm{~N} 089$ 10W $2920 \mathrm{~N} 08746 \mathrm{~W}$ $2844 \mathrm{~N} 08939 \mathrm{~W}$ $2944 \mathrm{~N} 08649 \mathrm{~W}$ $2909 \mathrm{~N} 086 \quad 34 \mathrm{~W}$ $2920 \mathrm{~N} 08536 \mathrm{~W}$ $2857 \mathrm{~N} 08554 \mathrm{~W}$ $2820 \mathrm{~N} 095 \quad 19 \mathrm{~W}$ $2759 \mathrm{~N} 096$ 06 $2738 \mathrm{~N} 09547 \mathrm{~W}$ $2633 \mathrm{~N} 09620 \mathrm{~W}$ $27 \quad 30 \mathrm{~N} 096 \quad 42 \mathrm{~W}$ $\begin{array}{llll}27 & 55 \mathrm{~N} 096 & 20 \mathrm{~W} \\ 27 & 18 \mathrm{~N} 096 & 14 \mathrm{~d}\end{array}$ 


\section{Publication}

13411 PARKER 1954

13412 PARKER 1954

13413 PARKER 1954

13414 PHLEGER $1951 \mathrm{~A}$

13415 PHLEGER 1951A

13416 PARKER 1954

13417 PARKER 1954

13418 PARKER 1954

13419 PARKER 1954

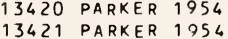

13422 PHLEGER $1951 \mathrm{~A}$

13423 PHLEGER 1951A

13424 PHLEGER $1951 \mathrm{~A}$

13425 PHLEGER 19519

13426
13427 PARKER
1954

13428 PARKER 1954

13429 LUDWICK WALTON 1957

13430 PHLEGER $1951 \mathrm{~A}$

13431 PHLEGER $1951 \mathrm{~A}$

13432 PHLEGER $1951 \mathrm{~A}$

13433 PHLEGER 1951A

13434 PHLEGER 1951 A

13436 PHLEGER $1951 \mathrm{~A}$

13437 PHLEGER 1951A

13438 PHLEGER $1951 \mathrm{~A}$

13439 PHLEGER $1951 \mathrm{~A}$

13440 PARKER 1954

13441 PHLEGER 1951A

13442 PHLEGER $1951 \mathrm{~A}$

13443 PHLEGER 1951A

13444 PHLEGER $1951 \mathrm{~A}$

13445 LOEP 1965

13446 LOEP 1965

13447 CUSHMAN 19228

13448 CREAGER 1958

13449 CREAGER 1958

13450 CREAGER 1958

13451 PHLEGER $1951 \mathrm{~A}$

13453 AYALA-CASTANARES 1963

13454 PARKER 1954

13455 BOCK 1976

13456 PARKER 1954

13457 PARKER 1954

13458 PARKER 1954

13459 PARKER 1954

13460 PARKER 1954

13461 CREAGER 1958

13462 PFLUM FRERICHS 1976

13463 CREAGER 1958

13464 BANDY 1956

13465 PFLIJM FRERICHS 1976

13466 PFLUM FRERICHS 1976

13467 PFLUM FRERICHS 1976

13468 PARKER 1954

13469 PARKER 1954

13470 PARKER 1954

13471 PARKER 1954

13472 PARKER 1954

13473 CREAGER 1958

13474 CREAGER 1958

13475 CREAGER 1958

13476 CREAGER 1958

13477 BANDY 1956

13478 BANDY 1956

13479 BANDY 1956

13480 BANDY 1956

13481 BANDY 1956

13482 BANDY 1956

13483 BANDY 1956

13484 PFLUM FRERICHS 1976

13485 ANDERSEN 1961

13486 BOCK 1976

13487 BOCK 1976

13488 BOCK 1976

13489 CREAGER 1958

13490 PARKER 1954

13491 PARKER 1954

13492 PARKER 1954

13493 PARKER 1954

13494 PARKER 1954

13495 PARKER 1954

13496 PARKER 1954

13497 PHLEGER 1956

13499 PHLEGER $1951 \mathrm{~A}$

13500 PHLEGER 1951A

13501 PFLUM FRERICHS 1976

13502 PFLUM FRERICHS 1976

13503 PFLUM FRERICHS 1976

13504 PFLUM FRERICHS 1976

13505 PFLUM FRERICHS 1976
Generic Name

CASSI DULINA

CASSIDULINA

CASSI DUL INA

CASS I DULINA

CASSIDULINA

CASS I DULINA

CASSI DUL INA

CASSIDULINA

CASSI DUL INA

CASSIDULINA

CASSIDULINA

CASSIDULINA

CASSIDULINA

CASSIDULINA

CASSIDULINA

CASSIDULINA

CASSIDULINA

CASSI DULINA

CASSIDULINA

CASSI DULINA

CASSIDULINA

CASSIDULINA

CASSIDULINA

CASSIDULINA

CASSIDULINA

CASSIDULINA

CASSIDULINA

CASSIDULINA

CASSIDUL INA

CASS IDUL INA

CASS IDUL INA

CASSIDUL INA

CASSI DUL INA

CASSIDUL INA

CASSIDULINA

CASSIDUL INA

CASS IDUL INA

CASSIDULINA

CASSIDULINA

CASSIDULINA

CASS IDUL INA

CASSIDULINA

CASSIDULINA

CASSIDULINA

CASSI DULINA

CASSIDULINA

CASS I DULINA

CASS IDUL INA

CASSIDULINA

CASSIDULINA

CASSI DUL INA

CASS I DUL INA

CASS IDULINA

CASSI DULINA

CASS IDULINA

CASSI DULINA

CASSIDUL INA

CASSIDULINA

CASSIDULINA

CASSIDULINA

CASS I DULINA

CASSI DULINA

CASS I DULINA

CASSIDULINA

CASSIDUL INA

CASS IDUL INA

CASS I DUL INA

CASSIDULINA

CASSIDULINA

CASSIDULINA

CASSIDULINA

CASS IDULINA

CASSI DULINA

CASS I DUL INA

CASSI DULINA

CASSIDULINA

CASS I DUL INA

CASSIDUL INA

CASSIDULINA

CASSI DULINA

CASSIDULINA

CASSI DULINA

CASSIDULINA

CASS IDUL INA

CASSI DUL INA

CASSIDULINA

CASSI DUL INA

CASSIDULINA

CASSIDULINA

CASS IDULINA

CASSIDULINA

CASSIDULINA

CASSIDULINA

CASSIDUL INA

CASSIDULINA
Specific Name

CARINATA

CARINATA

CR ASSA

CRASSA

CR ASSA

CR ASSA

CRASSA

CRASSA

CRASSA

CR ASSA

CR ASSA

CRASSA

CRASSA

CRASSA

CR ASSA

CRASSA

CR ASSA

CRASSA

CR ASSA

CRASSA

CRASSA

CRASSA

CRASSA

CRASSA

CR ASSA

CRASSA

CRASSA

CRASSA

CR ASSA

CR ASSA

CRASSA

CRASSA

CRASSA

CRASSA

CRASSA

CRASSA

CRASSA

CRASSA

CR ASSA

CRASSA

CR ASSA

CR ASSA

CRASSA

CR ASSA

CR ASSA

CRASSA

CR ASSA

CRASSA

CR ASSA

CURVATA

CURVATA

CURVATA

CURVATA

CURVATA

CURVATA

CURVATA

CURVATA

CURVATA

CURVATA

CURVATA

CURVATA

CURVATA

CURVATA

CURVATA

CURVATA

CURVATA

CURVATA

CURVATA

CURVATA

CURVATA

CURVATA

CURVATA

CURVATA

CURVATA

CURVATA

CURVATA

CURVATA

CURVATA

CURVATA

CURVATA

CURVATA

CURVATA

CURVATA

CURVATA

CURVATA

CURVATA

CURVATA

CURVATA

CURVATA

CURVATA

CURVATA

CURVATA

CURVATA

CURVATA

Locality

NE GULF OF MEXICO

NE GULF OF MEXICO

NE GULF OF MEXICO

NW GULF OF MEXICO

NW GULF OF MEXICO

NE GULF OF MEXICO 


\section{Publication}

13506 PFLUM FRERICHS 1976 13507 PFLUM FRERICHS 1976 13508 PFLU'1 FRERICHS 1976 13509 PFLUM FRERICHS 1976 13510 PFLIJM FRERICHS 1976 13511 PFLUM FRERICHS 1976 13512 PFLUM FRERICHS 1976 13513 PFLUM FRERICHS 1976 13514 PFLUM FRERICHS 1976 13515 PFLUM FRERICHS 1976 13516 PFLUM FREKICHS 1976 13517 PFLUM FRERICHS 1976 13518 PFLUM FRERICHS 1976 13519 PFLUM FPERICHS 1976

13520 PHLEGER $1951 \mathrm{~A}$

13521 PHLEGER 1951 A

13522 PHLEGEF 1951A

13523 PHLEGER $1951 \mathrm{~A}$

13526 PHLEGER $1951 \mathrm{~A}$

13525 PHLEGEP 1951A

13526 PHLEGEQ 1951 A

13527 PHLEGER $1951 \mathrm{~A}$

13528 PHLEGER 1951A
13529 PHLEGEP $1951 \mathrm{~A}$

3530 PHLEGEF $1951 \mathrm{~A}$

13531 PHLEGER $1951 \mathrm{~A}$

13532 PHLEGEP 1951A

13533 PHLEGER 1951A

13534 PHLEGER $1951 \mathrm{~A}$

13535 PHLEGER $1951 \mathrm{~A}$
13536 PHLEGER $1951 \mathrm{~A}$

13537 PHLEGED 1951A

13538 PHLEGER 1951 A

13539 PHLEGER 1951 A 1957

13540 LUDWICK WALTON
13541 PHLEGER 1955 A

13542 PHLEGER 1955A

13543 PARKER 1954

13544 PARKER 1954

13545 PARKER 1954

13546 PARKER 105

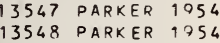

13548 PARKER
13549
1354

13550 PARKER 1954

13551 PARKER 1954

13553 LUDWICK WALTON 1957

13554 PHLEGER 1951 A

13555 PARKER 1954

13556 PARKER 1354

13557 PARKER 1954

13558 PARKER 1754

13559 CREAGEP 1958

13560 PARKER 1954

13561 PARKER 1954

13562 PARKER 1954
13563 BANDY 1956

13564 BANDY 1956

13565 BANDY 1956

13566 BANDY 1056

13567 BANDY 1056

13568 CREAGER 1958

13569 BANDY 1956
13570 BANDY 1956

13571 BANDY 1956

13572 CREAGER 1958

13573 CREAGER 1958

13574 CREAGER 1958

13575 CREAGER 9958

13576 CREAGER 1958

13577 CREAGEP 1958

13578 CREAGEP 1958

13579 CREAGER :958

13580 CREAGER 1958

13581 PHLEGER 1951A

13582 CREAGER 1958

13583 PHLEGER $1951 \mathrm{~A}$
13584 PHLEGER $1951 \mathrm{~A}$

13585 PHLEGER 1951A

13586 PHLEGER 1951A

13587 PHLEGER 1951A

13588 CUSHMAN 19228

13589 PHLEGER 1951A

13590 PHLEGER 1951 A

13591 KELLOUGH 1956

13592 CUSH'AAN 19228

13593 PHLEGEO 1951 A

13594 PHLEGER 1951A

13595 PHLEGER 1951A

13596 PHLEGER 1951A

13597 PHLEGER 1951A

13598 PHLEGER 1951 A

13599 PHLEGEP 1951A

1360 P PLEGER 1951A
Generic Name Specific Name

CURVATA

CASSIDULINA

CASSIDULINA

CASSIDULINA

CASSIDULINA

CASSIDULINA

CASSIDULINA

CASSIDULINA

CASSIDULINA

CASS IDULINA

CASSIDULINA

CASSIDULINA

CASSIDULINA

CASSIDULINA

CASSIDULINA

CASSIDULINA

CASSIDULINA

CASSIDULINA

CASSIDULINA

CASSIDULINA

CASSIDULINA

CASSIDULINA

CASSIDULINA

CASSIDULINA

CASSIDULINA

CASSIDULINA

CASSIDULINA

CASSIDULINA

CASSIDULINA

CASSIDULINA

CASSIDULINA

CASSI DULINA

CASSIDULINA

CASSIDULINA

CASSIDULINA

CASSIDULINA

CASSIDULINA

CASSIDULINA

CASSIDULINA

CASSIDULINA

CASS IDULINA

CASSIDULINA

CASSIDULINA

CASSIDULINA

CASSIDULINA

CASSIDULINA

CASSIDULINA

CASSIDULINA

CASSIDULINA

CASSIDULINA

CASSI DULINA

CASSIDULINA

CASSIDULINA

CASSIDULINA

CASSIDULINA

CASSIDULINA

CASSI DULINA

CASSIDULINA

CASSIDULINA

CASSIDULINA

CASSIDULINA

CASSIDULINA

CASSIDULINA

CASS IDULINA

CASSIDULINA

CASSIDULINA

CASSIDULINA

CASSIDULINA

CASS IDULINA

CASSIDULINA

CASSIDULINA

CASSIDULINA

CASSIDULINA

CASSIDULINA

CASSI DULINA

CASSIDULINA

CASSIDULINA

CASSIDULINA

CASS I DUL INA

CASS IDULINA

CASSIDULINA

CASSIDULINA

CASSIDULINA

CASSIDULINA

CASSIDULINA

CASSIDULINA

CASSIDULINA

CASSIDULINA

CASSI DUL INA

CASS IDULINA

CASSIDULINA
CURVATA

CURVATA

CURVATA

CURVATA

CURVATA

CURVATA

CURVATA

CURVATA

CURVATA

CURVATA

CURVATA

CUFVATA

CURVATA

CURVATA

CURVATA

CURVATA

CURVATA

CURVATA

CURVATA

CURVATA

CURVATA

CURVATA

CURVATA

CURVATA

CURVATA

CURVATA

CURVATA

CURVATA

CURVATA

CURVATA

CURVATA

CURVATA

CURVATA

CURVATA

CURVATA

CURVATA

CURVATA

CURVATA

CURVATA

CURVATA

LAEVIGATA

LAEVIGATA

LAEVIGATA

LAEVIGATA

LAEVIGATA

LAEVIGATA

LAEVIGATA

LAEVIGATA

LAEVIGATA

LAEVIGATA

LAEVIGATA

LAEVIGATA

LAEVIGATA

LAEVIGATA

LAEVIGATA

LAEVIGATA

LAEVIGATA

LAEVIGATA

LAEVIGATA

LAEVIGATA

LAEVIGATA

LAEVIGATA

LAEVIGATA

LAEVIGATA

LAEVIGATA

LAEVIGATA

NECCARINATA

NECCARINATA

NECCARINATA

NEOCAR INATA

NEOCAR INATA

NECCARINATA

NECCARINATA

NECCARINAT

NE CCAR INATA

NECCARINATA

NE OCARINATA

NE CCAR INATA

NECCAR INATA

NE CCARIUATA

NE OCARINATA

NECCARINATA

NE CCARINATA

NECCARINATA

NE CCARINATA

NE CCARI NATA

NE CCARINATA

NEOCARINATA

NE CCARINATA

NECCARINATA

NE OCAR INATA

NECCAR INA TA

NECCARINATA

Locality

NW GULF OF MEXICO

NW GULF OF MEXICO

NW GULF OF MEXICO

NW GULF OF MEXICO

$N H$ GULF OF MEXICO

NH GULF OF MEXICO

NW GULF OF MEXICO

$N W$ GULF OF MEXICO

NW GULF OF MEXICO

NW GULF OF MEXICO

NW GULF OF MEXICO

NW GULF OF MEXICO

NW GULF OF MEXICO

NW GULF OF MEXICO

NW GULF OF MEXICO 


\section{Publication}

13601 PHLEGER 1951A 13602 PHLEGER $1951 \mathrm{~A}$ 13603 PHLEGER 1951A 13604 PHLEGER 1951A 13605 PHLEGER $1951 \mathrm{~A}$ 13606 PHLEGER 1951 A 13607 PHLEGER 1951A 13608 PHLEGER 1951A 13609 PHLEGER $1951 \mathrm{~A}$

13610 PFLUM FRERICHS 1976 13611 PFLUM FRERICHS 1976 13612 PFLUM FRERICHS 1976 13613 PFLUM FRERICHS 1976 13614 PFLUM FRERICHS 1976 13615 PFLUM FRERICHS 1976 13617 PFLUM FRERICHS 1976 13618 PFLUM FRERICHS 1976 13619 PFLUM FRERICHS 1976 13620 PFLUM FRERICHS 1976 13621 PFLUM FRERICHS 1976 13622 PFLUM FRERICHS 1976 13623 PFLUM FRERICHS 1976 13624 PARKER 1954

13625 PARKER 1954 13626 PFLUM FRERICHS 1976
13627 PFLUM FRERICHS 1976 13628 PFLUM FRERICHS 1976 13629 PFLUM FRERICHS 1976 13630 PFLUM FRERICHS 1976 13631 PFLUM FRERICHS 1976 13632 PFLUM FRERICHS 1976 13633 PFLUM FRERICHS 1976 13634 PARKER 1954

13635 PFLUM FRERICHS 1976 13636 PARKER 1954

13637 PFLUM FRERICHS 1976 13638 PFLUM FRERICHS 1976 13639 PFLUM FRERICHS 1976 13640 PFLUM FRERICHS 1976 13641 PARKER 1954

13642 PARKER 1954

13643 PHLEGER 1955A

13644 PHLEGER 1955A

13645 PHLEGER 1955 A

13646 PARKER 1954

13647 PFLUM FRERICHS 1976 13648 PFLUM FRERICHS 1976 13649 PFLUM FRERICHS 1976 13650 PARKER 1954

13651 PARKER 1954

13652 PARKER 1954

13653 PFLUM FRERICHS 1976 13654 LUDHICK HALTON 1957 13655 PFLUM FRERICHS 1976 13656 PFLUM FRERICHS 1976 13657 PFLUM FRERICHS 1976 13658 PFLUM FRERICHS 1976 13659 PFLUM FRERICHS 1976 13660 PFLUM FRERICHS 1976 13661 PFLUM FRERICHS 1976 $13662^{\prime}$ PARKER 1954

13663 PARKER 1954

13664 PARKER 1954

13665 PFLUM FRERICHS 1976 13666 PFLUM FRERICHS 1976 13667 PFLUM FRERICHS 1976 13668 PFLUM FRERICHS 1976 13669 PFLUM FRERICHS 1976 13670 PARKER 1954

13671 PARKER 1954

13672 PARKER 1954

13673 PFLUM FRERICHS 1976

13674 ANDERSEN 1961

13675 PFLUM FRERICHS 1976 13676 PFLUM FRERICHS 1976 13677 PFLUM FRERICHS 1976

13678 PARKER 1954

13679 PARKER 1954

13680 PARKER 1954

13681 PHLEGER 1951A

13682 PHLEGER $1951 \mathrm{~A}$

13683 PHLEGER 1951 A

13684 PHLEGER $1951 \mathrm{~A}$

13685 PHLEGER 1951A

13686 PHLEGER $1951 \mathrm{~A}$

13687 PHLEGER 1951 A

13688 PHLEGER $1951 \mathrm{~A}$

13689 PHLEGER $1951 \mathrm{~A}$

13690 PHLEGER $1951 \mathrm{~A}$

13691 PHLEGER $1951 \mathrm{~A}$

13692 PHLEGER 1951 A

13693 PHLEGER 1951 A

13694
13695
$13 H L E G E R$
PHLER $1951 \mathrm{~A}$
Generic Name

Specific Name

NE OCARI NATA

NE OCARINA TA

NE OCARINATA

NECCARINATA

NECCARINATA

NE CCARINATA

NE OCARINATA

NECCARINATA

NECCARINATA

NECCARINATA

NE OCARINATA

NE OCAR INA TA

NE OCARINATA

NE OCARINA TA

NE OCARINATA

NEOCARINATA

NE OCARINATA

NE OCARINATA

NE OCARINATA

NEOCAR INATA

NE OCARINATA

NE OCARINATA

NE OCARINATA

NE OCARINATA

NE CCARINATA

NECCARINATA

NE OCARINATA

NE OCARINATA

NEOCARINATA

NE OCAR INATA

NE OCARINATA

NE CCARI NATA

NE OC ARINATA

NE OCARINATA

NEOCARINATA

NE OCARINATA

NE OCARINATA

NE OCARINATA

NE OCARINATA

NECCARINATA

NECCARINATA

NE OCAR INATA

NE OCAR I NATA

NECCARINATA

NE OCARINATA

NEOCARINATA

NEOCARINATA

NE OCAR INA TA

NEOCARINATA

NECCARINATA

NECCAR INATA

NE CCARINATA

NEOCAR INATA

NE OCAR I NATA

NE OCAR INATA

NE CCARINATA

NE OCARINATA

NE CCARINATA

NE OCARINATA

NE CCAR INATA

NE OCARINATA

NE OCARINATA

NECCARINATA

NE OCARINATA

NE OCAR INATA

NECCARINATA

NE OCARINATA

NE OCARINATA

NE OCARINATA

NE OCAR INATA

NE OCAR INATA

NE CCARINATA

NE OCARINAT

NORCROSSI AUSTRALIS

NORCROSSI AUSTRALIS

NORCROSSI AUSTRALIS

NORCROSSI AUSTRALIS

NORCROSSI AUSTRALIS

NORCROSSI AUSTRALIS NORCROSSI AUSTRALI NORCROSSI AUSTRALIS NORCROSSI AUSTRALIS NORCROSSI AUSTRALIS NORCROSSI AUSTRALIS NORCROSSI AUSTRALIS NORCR OSSI AU SU BGLOBOSA

SU BGL OBOSA

\section{Locality}

NH GULF OF MEXICO NW GULF OF MEXICO NW GULF OF MEXICO NH GULF OF MEXICO NW GULF OF MEXICO $N W$ GULF OF MEXICO NH GULF OF MEXICO NH GULF OF MEXICO NH GULF OF MEXICO NW GULF OF MEXICO $N W$ GULF OF MEXICO NH GULF OF MEXICO NW GULF OF MEXICO NW GULF OF MEXICO NW GULF OF MEXICO $\mathrm{NW}$ GULF OF MEXICO $N W$ GULF OF MEXICO NH GULF OF MEXICO NW GULF OF MEXICO NH GULF OF MEXICO NW GULF OF MEXICO NH GULF OF MEXICO NW GULF OF MEXICO NE GULF OF MEXICO NE GULF OF MEXICO NH GULF OF MEXICO NW GULF OF MEXICO NW GULF OF MEXICO NW GULF OF MEXICO $N$ GULF OF MEXICO NW GULF OF MEXICO NH GULF OF MEXICO NW GULF OF MEXICO NE GULF OF MEXICO NH GULF OF MEXICO NE GULF OF MEXICO NH GULF OF MEXICO NW GULF OF MEXICO NH GULF OF MEXICO NH GULF OF MEXICO NE GULF OF MEXICO NE GULF OF MEXICO

$N$ GULF OF MEXICO

$N$ GULF OF MEXICO

$N$ GULF OF MEXICO

NE GULF OF MEXICO CENTRAL GULF OF MEXICO CENTRAL GULF OF MEXICO CENTRAL GULF OF MEXICO NE GULF OF MEXICO NE GULF OF MEXICO NE GULF OF MEXICO NW GULF OF MEXICO NE GULF OF MEXICO CENTRAL GULF OF MEXICO CENTRAL GULF OF MEXICO CENTRAL GULF OF MEXICO CENTRAL GULF OF MEXICO CENTRAL GULF OF MEXICO CENTRAL GULF OF MEXICO CENTRAL GULF OF MEXICO NE GULF OF MEXICO NE GULF OF MEXICO NE GULF OF MEXICO CENTRAL GULF OF MEXICO CENTRAL GULF OF MEXICO CENTRAL GULF OF MEXICO CENTRAL GULF OF MEXICO CENTRAL GULF OF MEXICO NE GULF OF MEXICO NE GULF OF MEXICO NE GULF OF MEXICO CENTRAL GULF OF MEXICO MISSISSIPPI DELTA CENTRAL GULF OF MEXICO CENTRAL GULF OF MEXICO CENTRAL GULF OF MEXICO NE GULF OF MEXICO NE GULF OF MEXICO NE GULF OF MEXICO NW GULF OF MEXICO NH GULF OF MEXICO NH GULF OF MEXICO $N W$ GULF OF MEXICO NW GULF OF MEXICO NH GULF OF MEXICO NH GULF OF MEXICO NH GULF OF MEXICO NW GULF OF MEXICO NW GULF OF MEXICO NH GULF OF MEXICO NH GULF OF MEXICO NH GULF OF MEXICO NH GULF OF MEXICO NH GULF OF MEXICO

Lat. Long.

$2759 \mathrm{~N} 096$ 06W $2820 \mathrm{~N} 09519 \mathrm{~W}$ $2622 \mathrm{~N} 096$ $40 \mathrm{~W}$ $2539 \mathrm{~N} 096 \quad 18 W$ $2718 \mathrm{~N} 09616 \mathrm{~W}$ 


\section{Publication}

13696 PHLEGER 1951 A 13697 PHLEGER $1951 \mathrm{~A}$ 13698 PHLEGER $1951 \mathrm{~A}$ 13699 PHLEGER 195.1A 13700 PHLEGER 1951A 13701 PHLEGER 1951A 13702 PARKER 1954

13703 PHLEGER 1951A 13704 PHLEGER 1951 A 13705 PHLEGER 1951A 13706 PHLEGER 1951A 13707 PHLEGER 1955 A 13708 PHLEGER 1951A 13709 PHLEGER 1951A 13710 PHLEGER $1951 \mathrm{~A}$ 13711 PHLEGER 1951 A 13712 PHLEGER $1951 \mathrm{~A}$ 13713 PHLEGER 1951A 13714 PHLEGER $1951 \mathrm{~A}$ 13715 PHLEGER 1951A 13716 PHLEGER 1951A 13717 PHLEGER $1951 \mathrm{~A}$ 13718 PHLEGER 1955A 13719 PARKER 1954

13720 PARKER 1954

13721 PARKER 1954

13722 PHLEGER 1951 A

13723 PHLEGER 1951A

13724 PHLEGER 1951A

13725 PHLEGER $1951 \mathrm{~A}$

13726 PHLEGER $1951 \mathrm{~A}$

13727 PHLEGER 1951A

13728 PHLEGER 1951A

13729 PHLEGER $1951 \mathrm{~A}$

13730 PHLEGER 1951A

13731 PHLEGER 1951A

13732 PHLEGER $1951 \mathrm{~A}$

13733 PHLEGER $1951 \mathrm{~A}$

13734 PHLEGER $1951 \mathrm{~A}$

13735 PHLEGER $1951 \mathrm{~A}$

13736 PHLEGER $1951 \mathrm{~A}$

13738 PARKER 1954

13739 PARKER 1954

13740 PARKER 1954

13741 PARKER 1954

13742 PAFKER 195

13743 PARKER 195

13744 PARKER 1954

13745 PARKER 1954

13746 PARKER 1954

13747 PARKER 1954

13748 PARKER 1954

13749 PARKER 195

13750 PHLEGER 1955 A

13751 WALTON 1964

13752 CUSHMAN 19228

13753 CREAGER 1958

13754 PARKER 1954

13755 PARKER 1954

13756 PARKER 195

13757 PHLEGER 1955A

13758 PHLEGER 1955A

13759 LANKFORD 1959

13760 LUDWICK WALTON 1957

13761 PHLEGER 1955 A

13762 PHLEGER 1955

13763 PARKER 195

13764 PARKER 1954

13765 PARKER 1954

13766 PARKER 1954

13767 PARKER 1954

13768 PHLEGER 1955 A

13769 PARKER 1954

13770 PHLEGER $1955 \mathrm{~A}$

13771 PHLEGER 1951A

13772 PARKER 1954

13773 PARKER 1954

13774 PARKER 1954

13775 PARKER 1954

13776 PARKER 1954

13777 PARKER 1954

13778 PARKER 1954

13779 PHLEGER 1956

13780 PHLEGER 1951A

13781 PHLEGER 1951A

13782 PHLEGER $1951 \mathrm{~A}$

13783 KELLOUGH 1956

13784 KELLOUGH 1956

13785 CREAGER 1958

13786 CREAGER 1958

13787 CREAGER 1958

13788 CREAGER 1958

13789 CREAGER 1958

13790 PHLEGER 1956
Generic Name

CASSIDULINA

CASSIDULINA

CASS IDULINA

CASSIDULINA

CASSIDULINA

CASSIDULINA

CASS I DUL INA

CASSIDULINA

CASSIDULINA

CASSIDULINA

CASSIDULINA

CASSIDULINA

CASSIDULINA

CASSIDULINA

CASSIDULINA

CASSIDULINA

CASSIDULINA

CASSIDULINA

CASSIDULINA

CASSIDULINA

CASSIDULINA

CASSIDULINA

CASSIDULINA

CASSIDULINA

CASSIDULINA

CASSIDULINA

CASSIDULINA

CASSIDULINA

CASSIDULINA

CASS IDULINA

CASSIDULINA

CASSIDULINA

CASSIDULINA

CASSIDULINA

CASSIDULINA

CASSIDULINA

CASSIDULINA

CASSIDULINA

CASSIDULINA

CASSIDULINA

CASSIDUL INA

CASSIDULINA

CASSIDULINA

CASSIDULINA

CASSIDULINA

CASSIDULINA

CASSIDULINA

CASSIDULINA

CASSIDULINA

CASSIDULINA

CASSIDULINA

CASSIDULINA

CASSIDULINA

CASSIDULINA

CASSIDULINA

CASSIDULINA

CASS I DULINA

CASSIDULINA

CASSIDULINA

CASSIDULINA

CASSIDULINA

CASSIDULINA

CASSIDULINA

CASSIDULINA

CASSIDULINA

CASSIDULINA

CASSIDULINA

CASSIDULINA

CASSIDULINA

CASSIDULINA

CASSIDULINA

CASSIDULINA

CASSIDULINA

CASSIDULINA

CASSIDULINA

CASSIDULINA

CASSIDULINA

CASSIDULINA

CASSIDULINA

CASSIDULINA

CASSIDULINA

CASSIDULINA

CASSIDUL INA

CASSIDULINA

CASSIDULINA

CASSIDULINA

CASSIDULINA

CASSIDULINA

CASSIDULINA

CASSIDULINA

CASSIDULINA

CASS I DULINA

CASSIDULINA

CASSIDULINA

CASSIDULINA
Specific Name

Locality

Lat. Long.

SUEGLOBOSA

SUEGLOBOSA

SU

SU EGL OBOSA

SU BGL OBOSA

SUBGLOBOSA

SU EGL OBOSA

SUEGLOBOSA

SUBGLOBOSA

SU BGL OBOSA

SU BGL OBOSA

SUEGLOBOSA

SUEGLOBOSA

SUEGLOBOSA

SUBGLOBOSA

SUBGL OBOSA

SUBGL OBOSA

SUEGLOBOSA

SU EGLOBOS A

SUBGL OBOSA

SUEGLOBOSA

SU BGL OBOSA

SUEGL OBOSA

SUEGLOBOSA

SUBGL OBOSA

SUEGLOBOSA

SU BGL OBOSA

SUBGL OBOSA

SUEGLOBOSA

SUEGLOBOSA

SU BGL OBOSA

SUEGL OBOSA

SUBGLOBOSA

SU EGL OBOSA

SUEGLOBOSA

SUEGL OBOSA

SU EGL OB OSA

SUEGL OBOSA

SU BGL OBOSA

SUEGLOBOSA

SUEGL OBOSA

SUEGLOBOSA

SU EGL OBOSA

SUEGL OBOSA

SU BGL OBOSA

SUBGL OBOSA

SUEGLOBOSA

SUBGL OBOSA

SUEGL OBOSA

SUEGLOBOSA

SU BGL OBOS A

SUEGLOBOSA

SUEGLOBOSA

SUBGLOBOSA

SUEGLOBOSA

SUEGL OBOSA

SU BGL OBOSA

SUEGLOBOS A

SUEGLOBOSA

SUEGL OBOSA

SUEGL OBOSA

SU BGLOBOSA

SUBGL OBOSA

SU EGL OBOSA

SUEGLOBOSA

SUEGLOBOSA

SUBGL OBOSA

SUEGLOBOSA

SUEGL OBOSA

SUEGL OBOSA

SUBGLOBOSA

SU BGL OBOSA

SU BGL OBOSA

SUEGLOBOSA

SU EGL OBOSA

SUEGLOBOSA

SUEGL OBOSA

SUEGLOBOSA

SUEGLOBOSA

SUEGL OBOSA

SU EGLOBOSA

SUEGL OBOS

SUEGLOBOSA

SU BGL OBOSA

SUEGLOBOSA

SU EGLOBOSA

SU BGL OBOSA

SUBGL OBOSA

SUEGLOBOSA

SUEGL OB OSA

SU BGL OBOSA

NW GULF OF MEXICO

NW GULF OF MEXICO 


\section{Publication}

13791 PHLEGER 1456 13792 PHLEGER 1956 13793 CREAGER 1958 13794 BOCK 1976 13795 BOCK 1076 13796 CREAGER 1958 13797 BOCK 1776 13798 ROCK 1976

13799 ANDERSEN 1961

13800 PFLUM FRERICHS 1976 13801 CREAGER 1958

13802 CREAGER 1958

13803 CREAGER 1958

13804 CREAGER 1958

13805 CREAGER 1958

13806 CREAGER 1958

13807 CREAGER 1958

13808 CREAGER 1958

13809 CREAGER 1958

13810 CREAGER 1958

13811 CREAGER 1958

13812 CREAGER 1958

13813 CREAGER 1958

13814 CREAGER 1958

13815 PFLIIM FRERICHS 1976

13816 PFLUM FREFICHS 1976

13817 PFLUM FRERICHS 1976

13818 PFLUM FRERICHS 1976

13819 PFLUM FRERICHS 1976

13820 PFLUM FRERICHS 1976

13821 PFLUM FRERICHS 1976

13822 ANDERSEN 1961

13823 PFLUM FRERICHS 1976 13824 PFLUM FRERICHS 1976 13825 PFLUM FRERICHS 1976 13826 PFLUM FRERICHS 1976 13827 PFLUM FRERICHS 197 13828 PFLUM FRERICHS 1976 13829 PFLUM FRERICHS 1976 13830 PFLUM FRERICHS 1976 13831 PFLUM FRERICHS 1976 13832 PFLUM FRERICHS 1976 13833 PFLUM FRERICHS 1976 13834 PFLUM FRERICHS 1976 13835 PFLUM FRERICHS 1976 13836 PFLUM FRERICHS 1976 13837 PFLUM FRERICHS 1976 13838 PFLUM FRERICHS 1976 13839 PFLUM FRERICHS 1976 13840 PFLUM FRERICHS 1976 13841 PFLUM FRFRICHS 1976 13842 PFLUM FRERICHS 1976 13843 PFLUM FRERICHS 1976 13844 PFLUM FRERICHS 1976 13845 PFLUM FRERICHS 1976 13846 PFLUM FRERICHS 1976 13847 PFLUM FRERICHS 1976 13848 PFLUM FRERICHS 1976 13849 PFLUM FRERICHS 1976 13850 PFLUM FRERICHS 1976 13851 PFLUM FRERICHS 1976 13852 PFLUM FRERICHS 1976 13853 PFLUM FRERICHS 1976 13854 PFLUM FRERICHS 1976 13855 PFLU⿻ FRERICHS 1976 13856 PFLUM FRERICHS 1976 13857 PFLUM FRERICHS 1976 13858 PFLUM FRERICHS 1976 13859 PFLUM FRERICHS 1976 13860 PFLUM FRERICHS 1976 13861 PFLUM FRFRICHS 1976 13862 PFLUM FREKICHS 1976 13863 PFLUM FRERICHS 1976 13864 PFLUM FRFRICHS 1976 13865 PFLUM FRERICHS 1976 13866 PFLUM FRERICHS 1976 13867 PFLUM FRERICHS 1976 13868 PFLUM FRERICHS 1976 13869 PFLUM FRERICHS 1976 13870 PARKER 1354

13871 PFLUM FRERICHS 1976

13872 PARKER 1954

13873 PARKER 1254

13874 PARKER 1354
13875 PARKER 1354

13875 PARKER 1954
13876 PHLEGER 1955 A

13877 PARKER 1754

13878 PARKER 1754

13879 PARKER 1354

13880 PARKER 1954 13881 PFLU'A FRERICHS 1976
13882 PFLUM FRERICHS 1976 13883 PFLUM FRERICHS 1976 13884 PFLU'A FRERICHS 1976 13885 PFLUM FRERICHS 1976
Generic Name

CASSIDULINA

CASSIDULINA

CASSIDULINA

CASSIDULINA

CASSIDULINA

CASS I DULINA

CASSIDULINA

CASSIDULINA

CASSIDULINA

CASSIDULINA

CASSIDULINA

CASSI DUL INA

CASSIDULINA

CASSIDULINA

CASSIDULINA

CASSI DULINA

CASSIDULINA

CASSI DUL INA

CASSIDULINA

CASSIDULINA

CASSIDULINA

CASS I DULINA

CASSIDULINA

CASSIDULINOIDES

CASSIDULINOIDES

CASSIDULINOIDES

CASSIDULINOIDES

CASSIDULINOIDES

CASSIDULINOIDES

CASSI DULINOIDES

CASSIDUL INOIDES

CASSI DULINOIDES

CASSIDULINOIDES

CASSIDULINOIDES

CASSIDULINOIDES

CASSIDULINOIDES

CASSIDULINOIDES

CASSIDULINOIDES

CASSIDULINOIDES

CASSIDULINOIDES

CASSIDULINOIDES

CASSIDULINOIDES

CASSI DULINOIDES

CASSIDULINOIDES

CASS I DULINOIDES

CASSIDULINOIDES

CASSIDULINOIDES

CASSIDULINOIDES

CASSIDULINOIDES

CASSIDULINOIDES

CASSIDULINOIDES

CASSIDULINOIDES

CASSIDULINOIDES

CASSIDULINOIDES

CASSIDULINOIDES

CASSIDULINOIDES

CASSIDULINOIDES

CASSIDUL INOIDES

CASS I DULINOIDES

CASSIDULINOIDES

CASSIDULINOIDES

CASSIDULINOIDES

CASSIDULINOIDES

CASSIDULINOIDES

CASS IDULINOIDES

CASSIDULINOIDES

CASSIDULINOIDES

CASSIDULINOIDES

CASSIDULINOIDES

CASSIDULINOIDES

CASS IDULINOIDES

CASSIDULINOIDES

CASSIDULINOIDES

CASSIDULINOIDES

CASSIDULINOIDES

CASSIDULINOIDES

CASSIDULINOIDES

CASSIDULINOIDES

CASSIDULINOIDES

CASSIDULINOIDES

CASSIDULINOIDES

CASSIDULINOIDES

CASSIDULINOIDES

CASSIDULINOIDES

CASS I DULINOIDES

CASSIDULINOIDES

CASSIDULINOIDES

CASSIDULINOIDES

CASSIDULINOIDES

CASSIDULINOIDES

CASSIDULINOIDES

CASSIDULINOIDES

CASSIDULINOIDES

CASSIDULINOIDES
Specific Name

Locality

SUEGL OBOS A

SUEGL OBOSA

SUEGLOBOSA

SU BGL OBOSA

SUBGL OBOSA

SUEGL OBOSA

SUEGL OBOSA

SUEGL OBOSA

SUEGL OBOSA

SUBGL OBOSA

SUEGLOBOSA

SUEGLOBOSA

SUEGL OBOSA

SUEGL OBOSA

SUEGLOBOSA

SUEGLOBOSA

SUEGLOBOSA

SUEGLOBOSA

SUEGLOBOSA

SUBGLOBOSA

SUEGLOBOSA

SU BGL OBOSA

SUBGL OBOSA

SUEGL OBOSA

BRADYI

BRADY

-1
$-B R A D Y I$

BRADYI

BRADY I

BRADYI

BRADYI

MEXICANUS

MEXICANUS

MEXICANUS

MEXICANUS

MEXI CANUS

MEXICANUS

MEXICANUS

MEXICANUS

MEXICANUS

MEXICANUS

MEXICANUS

MEXICANUS

MEXICANUS

MEXICANUS

MEXICANUS

MEXICANUS

MEXI CANUS

MEXICANUS

MEXI CANUS

MEXICANU

MEXICANUS

MEXICANUS

MEXICANUS

MEXICANUS

ME XI CANUS

MEXI CANUS

MEXI CANUS

MEXICANUS

MEXICANUS

MEXICANUS

MEXICANUS

MEXICANUS

MEXICANUS

MEXICANUS

MEXICANUS

MEXICANUS

MEXICANUS

MEXICANUS

MEXICANUS

ME XI CANUS

PARKERIANUS

PARKERIANUS

PARKERI ANUS

PARKERIANUS

PARKERIANUS

PARKERI ANUS

PARKERIANUS

TENUIS

TENUIS

TENUIS

TENUIS

TENUIS

TENUIS

TENUIS

TENUIS

TENUIS

TENUIS

TE NUIS

TENUIS

TENUIS

TENUIS

TENUIS

TENUIS

NW GULF OF MEXICO

NW GULF OF MEXICO

BAY OF CAMPECHE 


\section{Publication}

13886 PFLUM FRERICHS 1976 13887 PFLUM FRERICHS 1976 13888 PFLUM FRERICHS 1976 13889 PFLUM FRERICHS 1976 13890 PFLUM FRERICHS 1976 13891 PFLUM FRERICHS 1976 13892 PARKER 1954

13893 PHLEGER $1955 \mathrm{~A}$

13894 PARKER 1954

13895 PFLUM FRERICHS 1976

13896 PFLUM FRERICHS 1976

13897 LANKFORD 1959

13898 LUDWICK WALTON 1957

13899 PHLEGER 1951A

13900 PHLEGER 1951A

13901 PHLEGER 1951A

13902 PHLEGER $1951 \mathrm{~A}$

13903 PHLEGER $1951 \mathrm{~A}$

13904 PFLUM FRERICHS 1976

13905 PFLUM FRERICHS 1976

13906 PFLUM FRERICHS 1976

13907 PFLUM FRERICHS 1976

13908 PFLUM FRERICHS 1976

13909 PHLEGER $1951 \mathrm{~A}$

13910 PHLEGER 1951A

13911 PHLEGER 1951A

13912 PHLEGER 1951A

13913 PHLEGER 1951A

13914 PHLEGER 1951A

13915 PHLEGER 1951A

13916 PHLEGER 1951 A

13917 PHLEGER 1951A

13918 PHLEGER 1951A

13919 PHLEGER 1951 A

13920 PFLUM FRERICHS 1976

13921 PFLUM FRERICHS 1976

13922 PFLUM FRERICHS 1976

13923 PFLUM FRERICHS 1976

13924 PFLUM FRERICHS 1976

13925 PFLUM FRERICHS 1976

13926 PFLUM FRERICHS 1976

13927 PFLUM FRERICHS 1976

13928 PHLEGER 1951 A

13929 PARKER 1954

13930 PARKER 1954

13931 PARKER 1954

13932 PARKER 1954

13933 PARKER 1954

13934 PARKER 1954

13935 PARKER 1954

13936 PARKER 1954

13937 PARKER 1954

13938 PARKER 1954

13939 PARKER 1954

13940 PARKER 1954

13941 PARKER 1954

13942 PHLEGER $1955 A$

13943 LUDWICK WALTON 1957 13944 PFLUM FRERICHS 1976 13945 PFLUM FRERICHS 1976 13946 PFLUM FRERICHS 1976 13947 PFLUM FRERICHS 1976 13948 PFLUM FRERICHS 1976 13949 PFLUM FRERICHS 1976 13950 PFLUM FRERICHS 1976 13951 PFLUM FRERICHS 1976 13952 PFLUM FRERICHS 1976 13953 PFLUM FRERICHS 1976 13954 ANDERSEN 1961

13955 PFLUM FRERICHS 1976 13956 PFLUM FRERICHS 1976 13957 PFLUM FRERICHS 1976 13958 PFLUM FRERICHS 1976 13959 PFLUM FRERICHS 1976 13960 PFLUM FRERICHS 1976 13961 PFLUM FRERICHS 1976 13962 PFLUM FRERICHS 1976 13963 PFLUM FRERICHS 1976 13964 PFLUM FRERICHS 1976 13965 PFLUM FRERICHS 1976 13966 PFLUM FRERICHS 1976 13967 PFLUM FRERICHS 1976 13968 PFLUM FRERICHS 1976 13969 PFLUM FRERICHS 1976 13970 PFLUM FRERICHS 1976 13971 PFLUM FRERICHS 1976 13972 PHLEGER 1951A

13973 PHLEGER 1951 A

13974 PARKER 1954

13975 PARKER 1954

13976 PARKER 1954

13977 PFLUM FRERICHS 1976 13978 PFLUM FRERICHS 1976 13979 PFLUM FRERICHS 1976 13980 PFLUM FRERICHS 1976
Generic Name

CASSIDJLINOIDES CASSIDULINOIDES CASSIDULINOIDES CASSI DULINOIDES CASSI DULINOIDES CASSIDULINOIDES CASSIDULINOIDES CASSIDULINOIDES CASSIDULINOIDES CASSIDULINOIDES CASSIDULINOIDES CASS IDULINOIDES CASSIDUL INOIDES CHILOSTOMELLA CHILOSTOMELLA CHILOSTOMELLA CHILOSTOMELLA CHILOSTOMELLA CHILOSTOMELLA CHILOSTOMELLA

CHILOSTOMELLA CHILOSTOMELLA CHILOSTOMELLA CHILOSTOMELLA CHILOSTOMELLA CHILOSTOMELLA CH ILOSTOMELLA CHILOSTOMELLA CHILOSTOMELLA CHILOSTOMELLA CHILOSTOMELLA CHILOSTOMELLA CHILOSTOMELLA CH ILOSTOMELLA CH ILOSTOMEL LA CHILOSTOMELLA CHILOSTOMELLA CH ILOSTOMELLA CHILOSTOMELLA CHILOSTOMELLA CHILOSTOMELLA CH ILOSTOMELLA CHILOST OMELLA CHILOSTOMELLA CHILOSTOMELLA CH I LOST OME LLA CHILOSTOMELLA CHILOSTOMELLA CHILOSTOMELLA CHILOSTOMELLA CH ILOSTOMELLA CHILOSTOMELLA CHILOSTOMELLA CHILOSTOMELLA CHILOSTOMELLA CH ILOSTOMEL LA CH ILOSTOMELLA CHILOSTOMELLA CHILOSTOMELLA CH ILOSTOMELLA CH ILOST OMELLA CHILOSTOMELLA CHILOSTOMELLA CHILOSTOMELLA CHILOSTOMELLA CHILOSTOMELLA CHILOSTOMELLA CHILOSTOMELLA CHILOSTOMELLA CHILOSTOMELLA CH ILOSTOMELLA CHILOS TOMELLA CHILOSTOMELLA CHILOSTOMELLA CHILOST OMELLA CH ILOSTOMELLA CH I LOSTOMELLA CH ILOSTOMELLA CHILOSTOMELLA CHILOSTOMELLA CHILOSTOMELLA CH ILOSTOMELLA CHILOSTOMELLA CHILOSTOMELLA CHILOSTOMELLA CHILOSTOMELLA CH ILOSTOMELLA CH ILOSTOMELLA CHILOSTOMELLA CHILOSTOMELLA CHILOSTOMELLA CHILOSTOMELLA CHILOSTOMELLA CHILOSTOMELLA CHILOSTOMELLA
Specific Name

TENUIS

TENUIS

TENUIS

TENUIS

TENUIS

TENUIS

TENUIS

TENUIS

TENUIS

TENUIS

TENUIS

TENUIS

TENUIS

OOLINA

OOLINA

OOLINA

OOLINA

OO LINA

OOLINA

OOLINA

OOLINA

OOLINA

OOLINA

OOLINA

OOLINA

OOLINA

OOLINA

OOLINA

OOLINA

OOLINA

OOLINA

OOLINA

OOLINA

OOLINA

OOLINA

OOLINA

OOLINA

OO LINA

OOLINA

OOLINA

OOLINA

OOLINA

OOLINA

OOLINA

OOLINA

OOLINA

OOLINA

OOLINA

OOLINA

OOLINA

OOLINA

OOLINA

OOLINA

OOLINA

DO LINA

OOLINA

OOLINA

OOLINA

OOLINA

OOLINA

OOLINA

OOLINA

OOLINA

OOLINA

OOLINA

OOLINA

OOLINA

OOLINA

OO LINA

OOLINA

OOLINA

OOLINA

OOLINA

OOLINA

OOLINA

OOLINA

OOLINA

OOLINA

OOLINA

OOLINA

OOLINA

OOLINA

OOLINA

OOLINA

OOLINA

OOLINA

OOLINA

OOLINA

OOLINA

OOLINA

OOLINA

OOLINA

OOLINA

\section{Locality}




\section{Publication}

13981 PFLUM FRERICHS 1976 13982 PFLUM FRERICHS 1976 13983 PFLUM FRERICHS 1976 13984 PFLUM FRERICHS 1976 13985 PFLUM FRERICHS 1976 13986 PFLUM FRERICHS 1976 13987 PFLUM FRERICHS 1976 13988 PFLUM FRERICHS 1976 13989 PFLUM FRERICHS 1976 13990 CUSHMAN 1924

13991 SOCK 1976

13992 ANDERSEN 1961

13993 NORTON 1930

13994 KORNFELD 1931

13995 KORNFELD 1931

13996 KORNFELD 1931

13997 KORNFELD 1931

13998 KORNFELD 1931

13999 NORTON 1930

14000 PFLUM FRERICHS 1976

14001 PFLUM FRERICHS 1976

14002 PFLUM FRERICHS 1976

14003 PFLUM FRERICHS 1976 14004 PFLUM FRERICHS 1976 14005 PFLUM FRERICHS 1976 14006 PFLUM FRERICHS 1976 14007 PFLUM FRERICHS 1976 14007 PFLUM FRERICHS 1976 14009 PFLUM FRERICHS 1976 14010 PFLUM FRERICHS 1976 14011 PFLUM FRERICHS 1976 14012 PFLUM FRERICHS 1976 14013 PFLUM FRERICHS 1976 14014 PFLUM FRERICHS 1976 14015 PFLUM FRERICHS 1976 14016 PFLUM FRERICHS 1976 14017 PFLUM FRERICHS 1976 14018 PFLUM FRERICHS 1976 14019 PFLUM FRERICHS 1976 14020 PFLUM FRERICHS 1976 14021 PFLUM FRERICHS 1976 14022 PFLUM FRERICHS 1976 14023 PFLUM FRERICHS 1976 14024 PFLUM FRERICHS 1976 14025 PFLUM FRERICHS 1976 14026 PFLUM FRERICHS 1976 14027 PFLUM FRERICHS 1976 14028 PFLUM FRERICHS 1976 14029 PFLUM FRERICHS 1976 14030 PFLUM FRERICHS 1976 14031 PFLUM FRERICHS 1976 14032 PFLUM FRERICHS 1976 14033 PFLUM FRERICHS 1976 14034 PFLUM FRERICHS 1976 14035 PFLUM FRERICHS 1976 14036 PFLUM FRERICHS 1976 14037 PFLUM FRERICHS 1976 14038 PFLUM FRERICHS 1976 14039 PFLUM FRERICHS 1976 14040 PFLUM FRERICHS 1976 14041 PFLUM FRERICHS 1976 14042 PFLUM FRERICHS 1976 14043 PFLUM FRERICHS 1976 14044 PFLUM FRERICHS 1976 14045 PFLUM FRERICHS 1976 14046 PFLUM FRERICHS 1976 14047 PFLUM FRERICHS 1976 14048 PFLUM FRERICHS 1976 14049 PFLUM FRERICHS 1976 14050 PFLUM FRERICHS 1976 14051 PFLUM FRERICHS 1976 14053 PFLUM FRERICHS 1976 14054 PFLUM FRERICHS 1976 14055 PFLUM FRERICHS 1976 14056 PFLUM FRERICHS 1976 14057 PFLUM FRERICHS 1976 14058 PFLUM FRERICHS 1976 14059 PFLUM FRERICHS 1976 14060 PFLUM FRERICHS 1976 14061 PFLUM FRERICHS 1976 14062 PFLUM FRERICHS 1976 14063 PFLUM FRERICHS 1976 14064 PFLUM FRERICHS 1976 14065 PFLUM FRERICHS 1976 14066 PFLUM FRERICHS 1976 14067 PFLUM FRERICHS 1976 14068 PFLUM FRERICHS 1976 14069 PFLUM FRERICHS 1976 14070 PFLUM FRERICHS 1976 14071 PFLUM FRERICHS 1976 14072 PFLUM FRERICHS 1976 14073 PFLUM FRERICHS 1976 14074 PFLUM FRERICHS 1976 14075 PFLUM FRERICHS 1976

\section{Generic Name}

CHILOSTOME LLA

CHILOSTOMELLA

CHILOSTOMELLA

CHILOSTOMELLA

CHILOSTOMELLA

CHILOSTOMELLA

CHILOSTOMELLA

CHILOSTOMELLA

CH ILOSTOMELLA

CHILOSTOMELLA

CHRYSAL IDINELLA

CIBICIDES

HANZAWAIA

HANZ AWA IA

HANZ AWA I A

HANZ AWA IA

CIBICIDES

CIBICIDES

CIBICIDES

CIBICIDES

CISICIDES

CIBICIDES

CIBICIDES

CIBICIDES

CIBICIDES

CIBICIDES

CI BICIDES

CIBICIDES

CI AICIDES

CIBICIDES

CIBICIDES

CIBICIDES

CIBICIDES

CIBICIDES

CIBICIDES

CIBICIDES

CIBICIDES

C I BICIDES

CIBICIDES

CIBICIDES

CIBICIDES

CI BICIDES

CI BICIDES

CIBICIDES

CIBICIDES

CIBICIDES

CIBICIDES

CIBICIDES

CIBICIDES

CIBICIDES

CIBICIDES

CIBICIDES

CIBICIDES

C I I CIDES

CIBICIDES

CIBICIDES

CIBICIDES

CIBICIDES

CIBICIDES

CI BICIDES

CIBICIDES

CIBICIDES

CI BICIDES

CIBICIDES

CIBICIDES

CIBICIDES

CIAICIDES

CIBICIDES

CI BICIDES

CIBICIDES

CIBICIDES

CI BICIDES

CIBICIDES

CI BICIDES

CIBICIDES

C I BICIDES

CIBICIDES

CIBICIDES

C I B I CIDES

CIBICIDES

CI BICIDES

CIBICIDES

CIBICIDES

CIBICIDES

CIBICIDES

CIBICIDES

CIBICIDES

CIBICIDES

CIBICIDES

CIBICIDES

CIBICIDES

CIBICIDES
CIBICIDES
Specific Name

OOLINA

OOLINA
OOLINA

OOLINA

OOLINA

OOLINA

OOLINA

OOLINA

OOLINA

OV CIDEA

POFEI

ADVENUM

STRATTONI

STRATTONI

STRATTON I

STRATTONI

ANTILLARUM

GANTAMENS IS

BANTAMENSIS

BAATAMENS IS

BANTAMENS IS

BANTAMENS IS

BANT AMENS IS

BANTAMENS IS

BANTAMENSIS

BANTAMENS IS

BA ATAMENS IS

BA $\triangle$ TAMENS IS

BANTAMENS IS

BANTAMENS IS

BANTAMENS IS

BANTAMENSIS

BAATAMENS IS

BANTAMENS IS

BANT AMENS IS

BANTAMENS IS

BRADYI

BRADYI

BRADYI

BR ADYI

BRADYI

BRADYI

BRADYI

BRADYI

BRADYI

BRADYI

BRADYI

BRADYI

BRADYI

BRADYI

BRADYI

BRADYI

BR ADYI

BRADYI

BRADYI

BRADYI

BRADY I

BRADYI

BRADYI

BRADYI

BRADYI

BR ADYI

BRADYI

BRADYI

$B R A D Y I$

BRADYI

BRADYI

BRADYI

BR ADYI

BR ADYI

BRADYI

BRADY

BRADYI

BRADYI

$B R A D Y I$

BR ADYI

BRADYI

BR ADYI

BRADYI

BRADYI

BRADYI

BRADY I

BR ADYI

BRADYI

BRADYI

\section{Locality}

NW GULF OF MEXICO

NW GULF OF MEXICO

$N W$ GULF OF MEXICO

NW GULF OF MEXICO

CENTRAL GULF OF MEXICO

CENTRAL GULF OF MEXICO

CENTRAL GULF OF MEXICO

CENTRAL GULF OF MEXICO

CENTRAL GULF OF MEXICO 


\section{Publication}

14076 PFLUM FRERICHS 1976 14077 PFLUM FRERICHS 1976 14078 PFLUM FRERICHS 1976 14079 PFLUM FRERICHS 1976 14080 PFLUM FRERICHS 1976 14081 PFLUM FRERICHS 1976 14082 PFLUM FRERICHS 1976 14083 PFLUM FRERICHS 1976 14084 CUSHMAN 1931

14085 CUSHMAN 1931

14086 PHLEGER 1951A

14087 CREAGER 1958

14088 CREAGER 1958

14090 PHLEGER $1951 \mathrm{~A}$

14091 PHLEGER 1951 A

14092 PHLEGER 1951A

14093 PHLEGER 1951A

14094 PHLEGER 1951A

14095 PHLEGER $1951 \mathrm{~A}$

14096 PHLEGER 1951A

14097 PHLEGER 1951A

14098 PHLEGER $1951 \mathrm{~A}$

14099 PHLEGER 1951A

14100 PHLEGER 1951A

14101 PHLEGER 1951A

14102 PHLEGER 1951 A

14103 PHLEGER 1951A

14104 PHLEGER 1951 A

14105 PHLEGER 1951A

14106 PHLEGER 1951A

14107 PHLEGER 1951A

14108 PHLEGER 1951A

14109 PHLEGER $1951 \mathrm{~A}$

14110 PHLEGER 1951A

14111 PHLEGER 1951

14113 PHLEGER 1951 A

14114 PHLEGER 1951A

14115 PHLEGER 1951A

14116 PHLEGER 1951 A

14117 PHLEGER 1951A

14118 CREAGER 1958
14119 CREAGER 1958

14119 CREAGER
14120 CREAGER 1958

14121 POST 1951

14122 NORTON 1930

14123 FARKER 1954

14124 PARKER 1954
14125 ANDERSEN 1961

14126 PARKER 1954

14127 PARKER 1954

14128 PARKER 1954

14129 PARKER 1954

14130 PARKER 1954

14131 PARKER 1954

14132 PARKER 1954

\begin{tabular}{l}
14133 PAKKER \\
14134 \\
1454 \\
\hline
\end{tabular}

14135 PARKER 1954

14136 PARKER 1954

14137 PARKER 195

14138 PARKER 1954

14140 LUDWICK WALTON 1957

14141 PARKER 1954

14142 PARKER 1954

14143 DAVIS 1964

14145 PARKER 1954

14146 PARKER 1954

14147 PHLEGER 1951A

14148 PARKER 1954

14149 PARKER 1954

14150 PARKER 1954

14151 PARKER 1954

14152 PARKER 1954

14153 PARKER 1954

14154 LUDWICK WALTON 1957

14155 PHLEGER 1951A

14156 AYALA-CASTANARES 1963

14157 BANDY 1956

14158 BANDY 1956

14159 BANDY 1956

14160 CREAGER 1958

14161 CREAGER 1958

14162 PHLEGER 1956

14163 CREAGER 1958

14164 CREAGER 1958

14165 PFLUM FRERICHS 1976

14166 PFLUM FRERICHS 1976

14167 PARKER 1954

14168 PARKER 1954

14169 PARKER 1954

14170 PARKER 1954
Generic Name

Specific Name

Locality

Lat. Long.

CIBICIDES

CIBICIDES

CIBICIDES

CIBICIDES

CIBICIDES

CIBICIDES

CIBICIDES

HANZAWAIA

HANZ AWA I A

HANZAWAIA

HANZAWAIA

HANZ AWA IA

HANZAWAIA

HANZAWAIA
HANZAWAIA

HANZAWAIA

HANZAWA I A

HANZAWAIA

HANZAWAIA

HANZ AWAI A

HANZ AWAIA

HANZ AWA I A

HANZAWAIA

HANZAWAIA

HANZAWAIA

HANZAWA A IA
HANZAWA IA

HANZAWAI A

HANZ AWA I A

HANZ AW I I A

HANZ AWA I A

TA ANZAWAIA

HANZAWAIA

HANZAWAI I A

HANZ AWA I A

HANZ AWA I A

HANZ AWA I A

HANZAWAIA

HANZAWAIA
HANZAHAIA

HANZAWAI A

HANZ AWA I A

HANZ AWA I A

HANZAWA I A

CIBICIDES

CIBICIDES

CIBICIDES

CIBICIDES

CIBICIDES

CIBICIDES

CIBICIDES

CIBICIDES

CIBICIDES

CIBICIDES

CIBICIDES

CIBICIDES

CIBICIDES

CIBICIDES

CIBICIDES

CIBICIDES

CIBICIDES

CIBICIDES

CIBICIDES

CIBICIDES

CIBICIDES

CIBICIDES

CIBICIDES

CIBICIDES

CIBICIDES

CIBICIDES

CIBICIDES

CIBICIDES

CIBICIDES

CIBICIDES

CIBICIDES

CIBICIDES

CIBICIDES

CIBICIDES

CIBICIDES

CIBICIDES

CIBICIDES

CIBICIDES

CIBICIDES

CIBICIDES

CIBICIDES

CIBICIDES

CIBICIDES

CIBICIDES

CIBICIDES

CIBICIDES

CIBICIDES
BRADYI

BRADYI

BRADYI

BRADYI

BRADYI

BRADYI

CONCENTRICA

CONCENTRICA

CONCENTRI CA

CONCENTRI CA

CONCENTRI CA

CONCENTRI CA

CONCENTRI CA

CONCENTRI CA

CONCENTRI CA

CONCENTRI CA

CONCENTRICA

CONCENTRICA

CONCENTRI CA

CONCENTRI CA

CONCENTRI CA

CONCENTRI CA

CONCENTRI CA

CONCENTRI CA

CONCENTRICA

CONCENTRI CA

CONCENTRI CA

CONCENTRICA

CONCENTRI CA

CONCENTRICA

CONCENTRI CA

CONCENTRI CA

CONCENTRICA

CONCENTRI CA

CONCENTRI CA

CONCENTRI CA

CONCENTRI CA

CONCENTRICA

CONCENTRI CA

CONCENTRI CA

CONCENTRI CA

CONCENTRICA

CONCENTRI CA

CONCENTRI CA

CORA

CORPULENTUS

CORPULENTUS

CORPULENTUS

CORPULENTUS

CORPULENTUS

CORPULENTUS

CORPULENTUS

CORPULENTUS

CORPULENTUS

CORPULENTUS

CORPULENTUS

CORPULENTUS

CORPULENTUS

CORPULENTUS

CORPULENTUS

CORPULENTUS

CORPULENTUS

CORPULENT US

DEPRIMUS

DEPRIMUS

DEPRIMUS

DEPRIMUS

DEFRIMUS

DEPRIMUS

DEPRIMUS

DEPRIMUS

DEPRIMUS

DEPEIMUS

DEPRIMUS

DEPRIMUS

DEPRIMUS

DEPRIMUS

DE PRI MUS

DEFRIMUS

DEPRIMUS

DEPRIMUS

DEPRIMUS

DEFRIMUS

DEPRIMUS

DEPRIMUS

DEPRIMUS

DEPRIMUS

DEPRIMUS

DEPRIMUS

DEPRIMUS

DEPRIMUS

DEPRIMUS

DEPRIMUS
CENTRAL GULF OF MEXICO

NW GULF OF MEXICO

NH GULF OF MEXICO

NW GULF OF MEXICO

NW GULF OF MEXICO

NW GULF OF MEXICO

NW GULF OF MEXICO

NW GULF OF MEXICO

TORTUGAS, FLA

NE GULF OF MEXICO

NW GULF OF MEXICO

BAY OF CAMPECHE

BAY OF CAMPECHE

BAY OF CAMPECHE 


\section{Publication}

14171 PARKER 1954 14172 PARKER 1954

14173 PARKER 1954

14174 PARKER 1954

14175 PHLEGER 1951A

14176 PHLEGER 1951A

14177 PFLUM FRERICHS 1976

14178 PFLUM FRERICHS 1976

14179 PFLUM FRERICHS 1976

14180 PFLUM FRERICHS 1976

14181 PFLUM FRERICHS 1976

14182 PFLUM FRERICHS 1976

14183 PHLEGER 1951A

14184 PHLEGER 1951A

14185 PHLEGER 1951A

14186 PHLEGER 1951A

14187 CUSHMAN 1931

14188 PHLEGER 1951A

14189 PHLEGER 1951A

14190 PHLEGER 1951A

14191 PHLEGER 1951A

14192 PHLEGER 1951A

14193 PHLEGER 1951A

14194 PHLEGER 1951A

14195 PHLEGER 1951A

14196 PHLEGER 1951A

14197 PHLEGER 1951A

14198 PHLEGER 1951A

14199 PHLEGER 1951A

14200 PHLEGER 1951A

14202 PHLEGER 1951A

14203 PARKER 1954

14204 PARKER 1954

14205 PARKER 1954

14206 PARKER 1954

14207 PARKER 1954

14208 PARKER 1954

14209 PHLEGER $1951 \mathrm{~A}$

14210 PHLEGER $1951 \mathrm{~A}$

14211 PARKER 1954

14212 PARKER 1954

14214 PARKER 1954

14215 PARKER 1954

14216 PARKER 1954

14217 PARKER 1954

14218 PHLEGER 1951 A

14219 PARKER 1954

14220 PARKER 1954

14221 PHLEGER 1951A

14222 PHLEGER 1951A

14223 PHLEGER 1951A

14224 PHLEGER 1951A

14225 PHLEGER 1951 A

14226 LANKFORD 1959
14227 LUDWICK WALTON 1957

14228 PHLEGER 1955A

14228 PHLEGER 1955 A

14230 PHLEGER 1955A

14231 PHLEGER 1955A

16232 PHLEGER $1951 \mathrm{~B}$

14233 PHLEGER $1955 \mathrm{~A}$

14234 PHLEGER 1955A

14235 CREAGER 1958

14236 CREAGER 1958

14237 BOCK 1976

14238 BOCK 1976
14239 BOCK 1976

14239 BOCK 1976

14240 BOCK 1976

14242 CREAGER 1958

14243 BOCK 1976

14244 PHLEGER 1956

14245 PARKER 1956

14246 PARKER 1954

14247 PARKER 1954

14248 PARKER 1954

14249 PARKER 1954

14250 CREAGER 1958

14251 CREAGER 1958

14252 CREAGER 1958

16253 PHLEGER 1951A

14254 PHLEGER 1951A

14255 PHLEGER 1951A

14256 PHLEGER $1951 \mathrm{~A}$
14257 PHLEGER $1951 \mathrm{~A}$

14257 PHLEGER 1951A
14258 PHLEGER $1951 \mathrm{~A}$

14259 PHLEGER 1951A

14260 CREAGER 1958

14261 KELLOUGH 1956

14262 KELLOUGH 1956

14263 KELLOUGH 1956

14266 PFLUM FRERICHS 1976

14265 CREAGER 1958
Generic Name

CIBICIDES

CIBICIDES

CIBICIDES

CIBICIDES

CIBICIDES

CIBICIDES

CIBICIDES

CIBICIDES

CIBICIDES

CIBICIDES

CIBICIDES

CIBICIDES

CIBICIDES

CIBICIDES

CIBICIDES

CIBICIDES

CIBICIDES

CIBICIDES

CIBICIDES

CIBICIDES

CIBICIDES

CIBICIDES

CIBICIDES

CIBICIDES

CIBICIDES

CIBICIDES

CIBICIDES

CI BICIDES

CIBICIDES

CIBICIDES

CIBICIDES

CI BICIDES

CIBICIDES

CIBICIDES

CIBICIDES

CIBICIDES

CIBICIDES

CIBICIDES

CIBICIDES

CIBICIDES

C I B ICIDES

CIBICIDES

CIBICIDES

CIBICIDES

CIBICIDES

CIBICIDES

CI BICIDES

CIBICIDES

CIBICIDES

CIBICIDES

CIBICIDES

CIBICIDES

CIBICIDES

CIBICIDES

CIBICIDES

CIBICIDES

CIBICIDES

CIBICIDES

CIBICIDES

CIBICIDES

CIBICIDES

CIBICIDES

CIBICIDES

CIBICIDES

CIBICIDES

CIBICIDES

CI BICIDES

CIBICIDES

CIBICIDES

CI BICIDES

CIBICIDES

CIBICIDES

CIBICIDES

CIBICIDES

CIBICIDES

CIBICIDES

CIBICIDES

CI BICIDES

CIBICIDES

CIBICIDES

CIBICIDES

CIBICIDES

CIBICIDES

CIBICIDES

CIBICIDES

CIBICIDES

CIBICIDES

CIBICIDES

CIBICIDES

CIBICIDES

CIBICIDES

CIBICIDES

CIBICIDES

CIBICIDES

CIBICIDES
Specific Name

DEPRIMUS

DEPRIMUS

DEPRIMUS

DEPRIMUS

DE PRI MUS

DE PRI MUS

DEPRIMUS

DEPRIMUS

DEPRIMUS

DEFRIMUS

DEPRIMUS

DEPRIMUS

DEPRIMUS

DEPRIMUS

DEPRIMUS

FLCRIDANUS

FLORIDANUS

FLORIDANUS

FLCRIDANUS

FL CRIDANUS

FLCRIDANUS

FLORIDANUS

FLORIDANUS

FLORIDANUS

FLCRIDANUS

FL ORI DANUS

FLORIDANUS

FLCRI DANUS

FLCRIDANUS

FLORIDANUS

FLCRIDANUS

FLORIDANUS

FLORIDANUS

FLORI DANUS

FLORIDANUS

FLORIDANUS

FL ORIDANUS

FL ORIDANUS

FL ORI DANUS

FL ORI DANUS

FL ORI DANUS

FLCRIDANUS

FLORIDANUS

FLORIDANUS

FL CR I DANUS

FL ORIDANUS

FL CRI DANUS

FLORIDANUS

FL ORIDANUS

FL ORI DANUS

FLORIDANUS

FLCRIDANUS

FL CRI DANUS

FLORIDANUS

FL ORI DANUS

FL ORIDANUS

FLORIDANUS

FLCRIDANUS

FLCRIDANUS

FL ORIDANUS

FL ORI DANUS

FLORIDANUS

FLCR IDANUS

FLCRI DANUS

FL ORIDANUS

FL ORI DANUS

FLORIDANUS

FLORIDANUS

FLORI DANUS

FL ORIDANUS

FLORIDANUS

FL ORI DANUS

FL ORIDANUS

FLCRIDANUS

FLCRIDANUS

FLCRIDANUS

FL ORI DANUS

FLCRIDANUS

FL ORI DANUS

FL CRIDANUS

FL ORIDANUS

FLCRI DANUS

FLCRIDANUS

FLORIDANUS

FLCRIDANUS

FLCRIDANUS

FL OR I DANUS

FLORIDANUS

FLCRI DANUS

FL CRIDANUS

FLORIDANUS

FL ORI DANUS

FLCRIDANUS

FL ORI DANUS

Locality

NE GULF OF MEXICO

NE GULF OF MEXICO

NE GULF OF MEXICO

NE GULF OF MEXICO

NH GULF OF MEXICO

NW GULF OF MEXICO 


\section{Publication}

14266 CREAGER $195 \%$ 14267 CREAGER 1958 14268 ANDERSEN 1961 14269 PHLEGER 1951 A 14270 PHLEGER 1951A 14271 PHLEGER 1951 A 14272 PHLEGER 1951A 14273 PHLEGER 1951A 14274 PHLEGER 1951A 14275 PHLEGER 1951A 16276 PHLEGER 1951A 14277 PHLEGER 1951 A 14278 PARKER 1954

16279 PFLUM FRERICHS 1976 14280 PFLUM FRERICHS 1976 14281 PHLEGER 1951 A 14282 PARKER 1954 14283 CREAGER 1958 14284 CREAGER 1958 14285 CREAGER 1958 14286 CREAGER 1958 14287 CREAGER 1958

14288 CREAGER 1958 14289 CREAGEP 1953 14290 CREAGER 1958

14291 LOEP 1965

14292 KELLOUGH 1956

14293 KELLOUGH 1956

16296 KELLOUGH 1956

14295 PHLEGER 1951

14296 PARKER 1954

14297 PHLEGER 1951 A

14298 PHLEGER 1951 A

14299 PHLEGER 1951A

14300 PHLEGER 1951 A

14302 LUDWICK WALTON 1957

14303 PHLEGER 1951A

14304 PHLEGER 1951 A

14305 PHLEGER 1951A

14306 PHLEGER 1951A

14307 PHLEGER 1951A

14308 PHLEGER 1951A

14309 PHLEGER 1951 A

14310 PHLEGER 1951A

14311 PHLEGER 1951A

14312 PHLEGER 1951A

14313 PHLEGER 1951A

14314 PARKER 1954

14315 PARKER 19
14316 BOCK 1976

14316 BOCK 1976
14317 PHLEGEP 1951A

14318 PARKER 1954

14319 PARKER 1954

14320 PARKER 1954

14321 PARKER 1954

14322 PARKER 1954

14323 PARKER 1954

14324 PARKER 1954

14325 CREAGER 1958

14326 CREAGER 1958

14327 PARKER 1954

14328 PARKER 1954

4329 PARKER 1954

14330 PFLUM FRERICHS 1976 14331 PFLUM FRERICHS 1976 14332 PFLUM FRERICHS 1976 14333 PFLUM FRERICHS 1976 14334 CREAGER 1958

14335 CREAGER 1958

14336 CREAGER 1958

14337 CREAGER 1958

14338 PFLUM FRERICHS 1976 14339 PFLUM FRERICHS 1976 14360 PFLUM FRERICHS 1976 14341 PFLUM FRERICHS 1976 14342 PFLUM FRERICHS 1976 14343 PFLUM FRERICHS 1976 14344 PFLUM FRERICHS 1976 14345 PFLUM FRERICHS 1976 14346 PFLUM FRERICHS 1976 14347 PFLUM FRERICHS 1976 14348 PFLUM FRERICHS 1976 14349 PARKER 1954

14350 PARKER 1954

14351 PARKER 195

14352 PFLUM FRERICHS 1976 14353 PARKER 1954

14354 PARKER 1956

14355 PFLUM FRERICHS 1976 14356 PFLUM FRERICHS 1976 14357 PFLUM FRERICHS 1976 14358 PFLUM FRERICHS 1976 14359 PFLUM FRERICHS 1976
14360 PFLUM FRERICHS 1976
Generic Name

Specific Name

CI BICIDES

CIBICIDES

CIBICIDES

CIBICIDES

CIBICIDES

CI BICIDES

CI 3ICIDES

CIBICIDES

CIBICIDES

CIBICIDES

CIBICIDES

CIBICIDES

CIBICIDES

CIBICIDES

CIBICIDES

CI BICIDES

CIBICIDES

CIBICIDES

CIBICIDES

CIBICIDES

CIBICIDES

CIBICIDES

CIBICIDES

CIBICIDES

CIBICIDES

CIBICIDES

CIBICIDES

CIBICIDES

CIBICIDES

CIBICIDES

CIBICIDES

CIBICIDES

CIBICIDES

CIBICIDES

CIBICIDES

CIBICIDES

CIBICIDES

CIBICIDES

CIBICIDES

CI BICIDES

I BICIDES

CIBICIDES
CIBICIDES

CIBICIDES

CIBICIDES

CIBICIDES

CIBICIDES

CIBICIDES

CIBICIDES

CIBICIDES

CIBICIDES

CIBICIDES

CI BICIDES

CIBICIDES

CIBICIDES

CIBICIDES

CIBICIDES

CIBICIDES

CIBICIDES

CIBICIDES

CI BICIDES

CIBICIDES

CIBICIDES

CIBICIDES

CIBICIDES

CIBICIDES

CIBICIDES

CIBICIDES

CI BICIDES

CIBICIDES

CIBICIDES

CI BICIDES

CIBICIDES

CIBICIDES

CI BI CIDES

CI BICIDES

CIBICIDES

CIBICIDES

CIBICIDES

CI BICIDES

CIBICIDES

CIBICIDES

CIBICIDES

CIBICIDES

CIBICIDES

CIBICIDES

CIBICIDES

CIRICIDES

CIBICIDES

CIBICIDES

CIBICIDES

CIBICIDES

CIBICIDES

CIBICIDES

FL ORI DANUS

FLCRIDANUS

FLORIDANUS

FLORIDANUS

FLCRIDANUS

FLCRIDANUS

FLCRIDANUS

FLORIDANUS

FLCRIDANUS

FLCRIDANUS

FL ORIDANUS

FLCRIDANUS

FL ORI DANUS

FLORIDANUS

FLCRIDANUS

FLCRI DANUS

FLCRIDANUS

FLORIDANUS

FLCRIDANUS

FLCRIDANUS

FLCRIDANUS

FLCRIDANUS

FL CRIDANUS

FL ORIDANUS

FLORIDANUS

FLORIDANUS

FLCRIDANUS

FLORIDANUS

I $O$

I 0

10

I 0

I0

I 0

I0

10

I0

10

I 0

10
10

10

10

10

10

I 0

I 0

I 0

I0

I0

IO

KULLENBERGI

KULLENBERGI

KULLENBER GI

KULLENBERGI

KULLENBER GI

KULLENBERGI

KULLENBERGI

KULLENBERGI

KULLENBERGI

KULLENBER G I

KULLENBERG I

KULLENBERGI

KULLENBER GI

KULLENBERGI

KULLENBERGI

KULLENBER GI

XULLENBERG I

KULLENBER GI

KULLEN

KULLENBERGI

KULLENBER I I

KULLENBERGI

KULLENBER GI

KULLENBER GI

KULLENBER GI

KULLENBERGI

KULLENBERGI

KULLENAERGI

KULLENBER GI

KULLENNBER GI

XULLENBERGI

KULLENBERG I

KULLENBERGI

KULLENBER I I

KULLENBER I I

KULLENBER GI

KULLENBERGI
Locality

Lat. Long.

BAY OF CAMPECHE BAY OF CAMPECHE MISSISSIPPI DELTA NW GULF OF MEXICO NW GULF OF MEXICO NW GULF OF MEXICO

NW GULF OF MEXICO

NW GULF OF MEXICO

NW GULF OF MEXICO

NW GULF OF MEXICO

NW GULF OF MEXICO 


\section{Publication}

14361 CREAGEF 1958 14362 PFLUM FRERICHS 1976 14363 CREAGEP 1958 14364 CREAGER 1958 14365 CPEAGER 1958 14366 CREAGER 1958 14367 CREAGER 1958 14368 PFLUM FRERICHS 1976 14369 PFLUM FRERICHS 1976 14370 PFLUM FRERICHS 1976 14371 PFLUM FRERICHS 1976 14372 PFLUM FRERICHS 1976 14373 PFLUM FRERICHS 1976 14374 CREAGER 1958 14375 CREAGER 1958 14376 CREAGER 1958 14377 CREAGER 1958 14378 PFLUM FRERICHS 1976 14379 PFLUM FRERICHS 1976 14380 PHLEGER 1955 A 14381 PFLUM FRERICHS 1976 14382 PFLUM FRERICHS 1976 14383 PFLUM FRERICHS 1976 14384 PFLUM FRERICHS 1976 14385 PARKER 1954 14386 PARKER 1954 14387 PARKER 1954 14389 PARKER 1954

14389 PFLUM FRERICHS 1976 14390 PFLUM FRERICHS 1976 14391 PFLUM FRERICHS 1976 14392 PFLUM FRERICHS 1976 14393 PFLUM FRERICHS 1976 14394 NORTON 1930 14395 CREAGER 1958 14396 CREAGER 1958 14397 BENDA PURI 1962 14398 CREAGER 1958 14399 PFLUM FRERICHS 1976 14400 PFLUM FRERICHS 1976 14401 PARKER 1954 14402 PARKER 1954 14403 PARKER 1954 14404 PARKER 1954 14405 PHLEGER $1951 \mathrm{~A}$ 14406 PHLEGER 1951A 14407 PHLEGER $1951 \mathrm{~A}$ 14408 PHLEGER 1951 A 14409 PHLEGER 1951A 14410 PHLEGER 1951A 14411 PHLEGER 1951A 14412 PHLEGER $1951 \mathrm{~A}$ 14413 PHLEGER 1951A 14414 PHLEGER $1951 \mathrm{~A}$ 14415 PHLEGER $1951 \mathrm{~A}$ 14416 PHLEGER $1951 \mathrm{~A}$ 14417 PFLUM FRERICHS 1976 14418 PHLEGER $1951 \mathrm{~A}$ 14419 PHLEGER $1951 \mathrm{~A}$ 14420 PARKER 1954 14421 LUDWICK WALTON 1957 14422 LANKFORD 1959 14423 PHLEGER 1951A 14424 PHLEGER $1951 \mathrm{~A}$ 14425 BOCK 1976 14426 PARKER 1954 14427 PHLEGER 1956 14428 PARKER 1954

14430 PFLUM FRERICHS 1976 14431 CREAGER 1958 14432 CREAGER 1958 14433 CREAGER 1958 14434 PHLEGER $1951 \mathrm{~A}$ 14435 PHLEGER $1951 \mathrm{~A}$ 14436 PHLEGER 1951A 14437 PHLEGER 1951A 14438 PHLEGER 1951 A 14439 PARKER 1954 14440 PARKER 1954 14441 PARKER 1954 14442 PARKER 1954 14443 PARKER 1954 14444 PARKER 1954 14445 PARKER 1954 14446 PARKER 1954 14447 PARKER 1954 14448 PARKER 1954 14449 PARKER 1954 14450 PARKER 1954 14451 PARKER 1954 14452 PARKER 1954 14453 PARKER 1954 14454 PARKER 1954
14455 PARKER 1954
Generic Name

CIBICIDES

CIBICIDES

CIBICIDES

CIBICIDES

CIBICIDES

CIBICIDES

C IBICIDES

CIBICIDES

CIBICIDES

CIBICIDES

CIBICIDES

CI BICIDES

CIBICIDES

CIBICIDES

CI BICIDES

CIBICIDES

CIBICIDES

CI BICIDES

CIBICIDES

CIBICIDES

CIBICIDES

CI BICIDES

CIBICIDES

CIBICIDES

CIBICIDES

C I BICIDES

CI I C IDES

CISICIDES

CI BICIDES

CIBICIDES

CIBICIDES

CIBICIDES

CIBICIDES

CI BICIDES

CI BICIDES

CIBICIDES

CIBICIDES

CIBICIDES

CI IICIDES

CIBICIDES

CI BICIDES

CIBICIDES

CIBICIDES

CIBICIDES

CIBICIDES

CIBICIDES

CIBICIDES

C I BICIDES

CIBICIDES

CI IICIDES

CIBICIDES

CI BI CIDES

CI II CIDES

CIBICIDES

CIBICIDES

CIBICIDES

CI IICIDES

CIBICIDES

CIBICIDES

CIBICIDES

CIBICIDES

CI BICIDES

CIBICIDES

CIBICIDES

C I BI CIDES

CI IICIDES

CIBICIDES

CIBICIDES

CIBICIDES

CIBICIDES

CIBICIDES

CI BICIDES

CI BICIDES

CI BICIDES

CIBICIDES

CI IICIDES

CIAICIDES

CIBICIDES

CI BICIDES

CIBICIDES

CIBICIDES

CIBICIDES

CIBICIDES

CI IICIDES

CIBICIDES

CI I I I DES

CIBICIDES

CIBICIDES

CIBICIDES

CIBICIDES

CIBICIDES

CIBICIDES

CIBICIDES

CIBICIDES
Specific Name

KULLENBER GI

KULLENRERG I

KULLENBER GI

KULLENBER GI

KULLENGER GI

KULLENBERGI

KULLENBER GI

KULLENBERGI

KULLENBER I I

KULLENBERGI

KULLENBER GI

KULLENBERG I

KULLENBER GI

KULLENBERGI

KULLENBERGI

KULLENBERGI

KULLENBER GI

KULLENBER G I

KULLENBER G I

KULLENBERG I

KULLENBERGI

KULLENBERGI

KULLENBER GI

KULLENBER GI

KULLENBER GI

$K U L L E N B E R G I$

KULLENBER GI

KULLENBER GI

KULLENBER GI

KULLENBER G I

LOEATULUS

LOEATULUS

LOEATULUS

LOBATULUS

LOBATULUS

LOBATULUS

LOEATULUS

MOLLIS

MOLLIS

MOLLIS

MOLLIS

MOLLIS

MOLLIS

MOLLIS

MOLLIS

MOLLIS

MOLLIS

MOLLIS

MOLLIS

MOLLIS

MOLLIS

MOLLIS

MOLLIS

MOLLIS

MOLLIS

MOLLIS

NOLLIS

MOLLIS

MOLLIS

MOLLIS

MOLLIS

MOLLIS

MOLLIS

MOLLIS

MOLLI

MOLLIS

MOLLIS

MOLLIS

MOLLIS

MOLLIS

MOLLIS

MOLLIS

MOLLIS

MOLLIS

MOLLIS

MOLLIS

MOLLIS

PRCTUBERANS

PR OTUBERANS

PR CTUBERANS

PR CTUBERANS

PROTUBERANS

PR CTUBERANS

PROTUBERANS

PR CTUBERANS

PRCTUBERANS

PRCTUBERANS

PR OTUBERANS

PRCTUBERANS

PROTUBERANS

PRCTUBERANS

PR OTUBERANS

Locality

BAY OF CAMPECHE

NW GULF OF MEXICO

BAY OF CAMPECHE

BAY OF CAMPECHE

BAY OF CAMPECHE 


\section{Publication}

14456 PARKER 1954

14457 BOCK 1976
14458 LUDWICK WALTON 1957

14459 CUSHMAN 1931

14460 CREAGER 1958

14461 CREAGER 1958

4462 CREAGER 1958

14464 CREAGER 1958

14465 CREAGER 1958

14466 CREAGER 1958

14467 CREAGER 1958

14468 CUSHMAN 1931

14469 CUSHMAN 1931

14471 CUSHMAN 1931

14472 CUSHMAN 193

14473 CUSHMAN 1931

14474 CUSHMAN 1931

14476 CUSHMAN 1931

4477 CUSHMAN 1931

14478 PFLUM FRERICHS 1976

14479 PFLUM FRERICHS 1976

14480 PFLUM FRERICHS 1976

14481 PFLUM FRERICHS 1976

14482 PFLUM FRERICHS 1976

14483 PFLUM FRERICHS 1976

14485 PFLUM FRERICHS 1976

14486 PFLUM FRERICHS 1976

14487 PFLUM FRERICHS 1976

14488 PFLUM FRERICHS 1976

14489 PFLUM FRERICHS 1976

14490 PFLUM FRERICHS 1976

14491 PFLUM FRERICHS 1976

14492 PFLUM FRERICHS 1976

14493 PFLUM FRERICHS 1976

14494 PFLUM FRERICHS 1976

14495 PFLUM FRERICHS 1976

14496 PFLUM FRERICHS 1976

14497 PFLUM FRERICHS 1976

14498 PFLUM FRERICHS 1976

14500 PFLUM FRERICHS 1976

14501 PFLUM FRERICHS 1976

14502 PFLUM FRERICHS 1976

4504 BANDY 1956

14505 PFLUM FRERICHS 1976

14506 PFLUM FRERICHS 1976

14507 PFLUM FRERICHS 1976

14508 PFLUM FRERICHS 1976

14509 PFLUM FRERICHS 1976

14510 PFLUM FRERICHS 1976

14511 PFLUM FRERICHS 1976

14512 PFLUM FRERICHS 1976

14513 AYALA-CASTANARES 1963

14514 BANDY 1956

14515 BANDY 1956

14516 BANDY 1956

14517 PFLUM FRERICHS 1976

14518 PFLUM FRERICHS 1976

14519 BANDY 1956

14520 BANDY 1956

14521 BANDY 1956

14522 BANDY 1956

14523 BANDY 1956

14525 BANDY 1956

14526 BANDY 1956

14527 P-FLUM FRERICHS 1976

14528 PFLUM FRERICHS 1976

14529 PFLUM FRERICHS 1976

14530 PFLUM FRERICHS 1976

14531 PFLUM FRERICHS 1976

14532 PFLUM FRERICHS 1976

14533 PFLUM FRERICHS 1976

14534 PFLUM FRERICHS 1976

14535 PFLUM FRERICHS 1976

14536 PFLUM FRERICHS 1976

14537 PFLUM FRERICHS 1976

14538 PFLUM FRERICHS 1976

14539 PFLUM FRERICHS 1976

14540 PFLUM FRERICHS 1976

14541 PFLUM FRERICHS 1976

14542 PFLUM FRERICHS 1976

14543 PFLUM FRERICHS 1976

14544 PFLUM FRERICHS 1976

14545 PFLUM FRERICHS 1976

14546 PFLUM FRERICHS 1976

14547 PFLUM FRERICHS 1976

14548 PFLUM FRERICHS 1976

14549 CREAGER 1958

14550 PFLUM FRERICHS 1976
Generic Name Specific Name

PR OTUBERANS

PR CTUBERANS

PSEUDOUNGERIANUS

PSEUDOUNG ER I ANUS

PSEUDOUNG ER I ANUS

PS EUDOUNGER IANUS

PSEUDOUNGERIANUS

PS EUDOUNGER I ANUS

PSEUDOUNGERIANUS

PS EUDOUNGERIANUS

PS EUDOUNGER I ANUS

PSEUDOUNGER IANUS

I 0

CIBICIDES

CIBICIDES

CIBICIDES

CIBICIDES

CIBICIDES

CIBICIDES

CIBICIDES

CIBICIDES

CIBICIDES

CIBICIDES

CIBICIDES

CIBICIDES

CIBICIDES

CIBICIDES

CIBICIDES

CIBICIDES

CIBICIDES

CIBICIDES

CIBICIDES

CIBICIDES

CIBICIDES

CIBICIDES

CIBICIDES

CIBICIDES

CIBICIDES

CIBICIDES

CIBICIDES

CIBICIDES

CIBICIDES

CIBICIDES

CIBICIDES

CIBICIDES

CIBICIDES

CIBICIDES

CIBICIDES

CIBICIDES

CIBICIDES

CIBICIDES

CIBICIDES

CIBICIDES

CIBICIDES

CIBICIDES

CIBICIDES

CIBICIDES

CIBICIDES

CIBICIDES

CIBICIDES

CI BICIDES

CIBICIDES

CIBICIDES

CIBICIDES

CIBICIDES

CIBICIDES

CI BICIDES

CIBICIDES

CIBICIDES

CI BICIDES

CIBICIDES

CIBICIDES

CIBICIDES

CIBICIDES

CIBICIDES

CI BICIDES

CIBICIDES

CIBICIDES

CIBICIDES

CIBICIDES

CIBICIDES

CIBICIDES

CIBICIDES

CIBICIDES

CIBICIDES

CIBICIDES

CIBICIDES

CIBICIDES

CIBICIDES

CIBICIDES

CIBICIDES

CIBIC ID

CI BICIDES

CIBICIDES

CIBICIDES

CIBICIDES
Locality

Lat. Long.

NE GULF OF MEXICO NE GULF OF MEXICO NE GULF OF MEXICO NE GULF OF MEXICO BAY OF CAMPECHE BAY OF CAMPECHE BAY OF CAMPECHE BAY OF CAMPECHE BAY OF CAMPECHE BAY OF CAMPECHE BAY OF CAMPECHE BAY OF CAMPECHE NE GULF OF MEXICO NE GULF OF MEXICO NE GULF OF MEXICO NE GULF OF MEXICO NE GULF OF MEXICO NE GULF OF MEXICO NE GULF OF MEXICO NE GULF OF MEXICO NE GULF OF MEXICO NE GULF OF MEXICO NW GULF OF MEXICO NW GULF OF MEXICO NW GULF OF MEXICO NW GULF OF MEXICO NW GULF OF MEXICO NW GULF OF MEXICO NW GULF OF MEXICO $N W$ GULF OF MEXICO NH GULF OF MEXICO NH GULF OF MEXICO NW GULF OF MEXICO NW GULF OF MEXICO NW GULF OF MEXICO NW GULF OF MEXICO NW GULF OF MEXICO NW GULF OF MEXICO NW GULF OF MEXICO NW GULF OF MEXICO NW GULF OF MEXICO NW GULF OF MEXICO NW GULF OF MEXICO NU GULF OF MEXICO NW GULF OF MEXICO NW GULF OF MEXICO NW GULF OF MEXICO NW GULF OF MEXICO NE GULF OF MEXICO NW GULF OF MEXICO NH GULF OF MEXICO NH GULF OF MEXICO NW GULF OF MEXICO NW GULF OF MEXICO NH GULF OF MEXICO CENTRAL GULF OF MEXICO CENTRAL GULF OF MEXICO DE TERMINOS, CAMPECHE NE GULF OF MEXICO NE GULF OF MEXICO NE GULF OF MEXICO NW GULF OF MEXICO NH GULF OF MEXICO NE GULF OF MEXICO NE GULF OF MEXICO NE GULF OF MEXICO NE GULF OF MEXICO NE GULF OF MEXICO NE GULF OF MEXICO NE GULF OF MEXICO NE GULF OF MEXICO NH GULF OF MEXICO NW GULF OF MEXICO NW GULF OF MEXICO NW GULF OF MEXICO NW GULF OF MEXICO NH GULF OF $M$ $N W$ GULF OF MEXICO NW GULF OF. MEXICO CENTRAL GULF OF MEXICO CENTRAL GULF OF MEXICO CENTRAL GULF OF MEXICO CENTRAL GULF OF MEXICO CENTRAL GULF OF MEXIC CENTRAL GULF OF MEXICO CENTRAL GULF OF MEXICO CENTRAL GULF OF MEXIC CENTRAL GULF OF MEXICO CENTRAL GULF OF MEXICO CENTRAL GULF OF MEXICO CENTRAL GULF OF MEX CENTRAL GULF OF MEXICO CENTRAL GULF OF MEXICO BAY OF CAMPECHE

CENTRAL GULF OF MEXICO

$2546 \mathrm{~N} 084 \quad 12 W$ 29 OON $085^{\circ} \mathrm{OOH}$ $2920 \mathrm{~N} 08746 \mathrm{~W}$ $2836 \mathrm{~N} 08650 \mathrm{~W}$ $1904 \mathrm{~N} 094$ 06W $1906 \mathrm{~N} 09437 \mathrm{~W}$ 


\section{Publication}

14551 PFLUM FRERICHS 1976 14552 PFLUM FRERICHS 1976 14553 PFLUM FRERICHS 1976 14554 PFLUM FRERICHS 1976 14555 PFLUM FRERICHS 1976 14556 PFLUM FRERICHS 1976 14557 PFLUM FRERICHS 1976 14558 CREAGER 1958

14559 CREAGER 1958

14560 CREAGER 1958

14561 CREAGER 1958

14562 CUSHMAN 193

14563 PARKER 1954

14564 CREAGER 1958

14566 CREAGER 1958

14566 CREAGER
14567 CREAGER 1958

14568 CREAGER 1958

14569 CREAGER 1958

14570 PFLUM FRERICHS 1976

14571 PFLUM FRERICHS 1976

14572 PFLUM FRERICHS 1976

14573 PFLUM FRERICHS 1976

14574 CREAGER 1958

14575 CREAGER 1958

14576 CREAGER 1958

14577 CREAGER 1958

14578 PFLUM FRERICHS 1976

14579 PFLUM FRERICHS 1976

14580 PFLUM FRERICHS 1976

14581 PFLUM FRERICHS 1976

14582 CREAGER 1958

14583 CREAGER 1958

14584 CREAGER 1958

14585 CREAGER 1958

14586 CREAGER 1958

14587 BANDY 1956

14588 BANDY 1956

14589 BANDY 1956

14590 PFLUM FRERICHS 1976

14591 PFLUM FRERICHS 1976

14592 PFLUM FRERICHS 1976

14593 PFLUM FRERICHS 1976

14594 PHLEGER $1951 \mathrm{~A}$

14595 CREAGER 1958

14596 PFLUM FRERICHS 1976 14597 PFLUM FRERICHS 1976 14598 PFLUM FRERICHS 1976 14599 PFLUM FRERICHS 1976 14600 PFLUM FRERICHS 1976 14601 PFLUM FRERICHS 1976 14602 PFLUM FRERICHS 1976 14603 PFLUM FRERICHS 1976 14604 PFLUM FRERICHS 1976 14605 PARKER 1954

14606 PARKER 1954

14607 PARKER 1954

14608 PARKER 1954

14609 PARKER 1954

14610 PARKER 1954

14611 PARKER 1954

14612 PARKER 1954

14613 PARKER 1954

14614 PHLEGER 1951 A

14615 PHLEGER 1955A

14616 PHLEGER 1951A

14617 PHLEGER 1951A

14618 PHLEGER 1951A

14619 PHLEGER 1951A

14620 PHLEGER 1951A

14621 PHLEGER 1951A

14622 PHLEGER 1951A

14623 PHLEGER 1951A

14624 PHLEGER 1951A

14625 PFLUM FRERICHS 1976

14626 PFLUM FRERICHS 1976

14627 PFLUM FRERICHS 1976

14628 PFLUM FRERICHS 1976

14629 PFLUM FRERICHS 1976

14630 PFLUM FRERICHS 1976

14631 PHLEGER $1955 \mathrm{~A}$

14632 PFLUM FRERICHS 1976

14633 PFLUM FRERICHS 1976

14634 PHLEGER 1955A

14635 PHLEGEP 1955 A

14636 PHLEGER 1955A

14637 PHLEGER $1955 \mathrm{~A}$

14638 PFLUM FRERICHS 1976

14639 PFLUM FRERICHS 1976

14640 PFLUM FRERICHS 1976

14641 PFLUM FRERICHS 1976

14642 PFLUM FRERICHS 1976

14643 PFLUM FRERICHS 1976

14644 PFLUM FRERICHS 1976

14645 PFLUM FRERICHS 1976
Generic Name

CI BICIDES

CIBICIDES

CIBICIDES

CIBICIDES

CIBICIDES

CIBICIDES

CIBICIDES

CIBICIDES

CIBICIDES

CIBICIDES

CIBICIDES

CIBICIDES

CIBICIDES

CIBICIDES

CIBICIDES

CIBICIDES

CIBICIDES

CI BICIDES

CIBICIDES

CIBICIDES

CIBICIDES

CIBICIDES

CIBICIDES

CIBICIDES

CIBICIDES

CIBICIDES

CIBICIDES

CIBICIDES

CIBICIDES

CIBICIDES

CIBICIDES

CIBICIDES

CIBICIDES

CIBICIDES

CIBICIDES

CIBICIDES

CIBICIDES

CIBICIDES

CIBICIDES

CIBICIDES

CIBICIDES

CIBICIDES

CI BICIDES

CIBICIDES

CIBICIDES

CIBICIDES

CIBICIDES

CIBICIDES

CIBICIDES

CIBICIDES

CIBICIDES

CI BICIDES

CIBICIDES

CI BICIDES

CIBICIDES

CIBICIDES

CIBICIDES

CIBICIDES

CI BICIDES

CIBICIDES

CIBICIDES

CIBICIDES

CIBICIDES

CIBICIDES

CI BICIDES

CIBICIDES

CIBICIDES

CIBICIDES

CIBICIDES

CIBICIDES

CIBICIDES

CIBICIDES

CIBICIDES

CIBICIDES

CIBICIDES

CIBICIDES

CIBICIDES

CIBICIDES

CIBICIDES

CIBICIDES

CIBICIDES

CI BICIDES

CIBICIDES

CIBICIDES

CIBICIDES

CIBICIDES

CI BI CIDES

CIBICIDES

CIBICIDES

CIBICIDES

CIBICIDES

CIBICIDES

CIBICIDES

CIBICIDES

CIBICIDES
Specific Name

PSEUDOUNGERIANUS PSEUDOUNGER I ANUS PSEUDOUNGER I ANUS PS EUDOUNGER IANUS PSEUDOUNGER I ANUS PSEUDOUNGERIANUS RE FULGENS

RE FULGENS

RE FUL GENS

RE FULGENS

ROEER TSONI ANUS

ROBERTSONIANUS

ROEERTSON IANUS

ROEERTSONIANUS

ROBERTSONIANUS

ROBERTSON IANUS

ROBERTSONIANUS

ROBERTSONIANUS

ROBERTSON I ANUS

ROBERTSONIANUS

ROBERTSONI ANUS

ROEERTSONIANUS

ROBERTSONIANUS

ROBERTSONIANUS

ROEERTSONIANUS

ROEERTSONIANUS

ROBERTSONIANUS

ROEERTSONIANUS

ROBERTSON IANUS

ROBERTSONIANUS

ROEERTSONIANUS

ROEERTSONIANUS

ROBERTSONIANUS

ROBERTSONIANUS

ROBERTSONIANUS

ROBERTSONIANUS

ROEERTSONIANUS

ROBER TSONIANUS

ROBERTS ON IANUS

ROBERTSONIANUS

ROBERTSONIANUS

ROEERTSON IANUS

ROBERTSONIANUS

ROEERTSONIANUS

O OBER TSONIANUS

ROBERTSONIANUS

ROEERTSONIANUS

ROBERTSONIANUS

ROBERTSONIANUS

ROBERTSONIANUS

ROBERTSONIANUS

ROEERTSONIANUS

ROEERTSONIANUS

ROBERTSONIANUS

ROBERTSONIANUS

ROBERTSONIANUS

ROBERTSONIANUS

ROEERTSONIANUS

ROBERTSON IANUS

ROBERTSONIANUS

ROBERTSON IANUS

ROBERTSONIANUS

ROEERTSONIANUS

ROEERTSONIANUS

ROBERTSONIANUS

RO BER TSONIANUS

ROBERTS ONIANUS

ROBERTSONIANUS

ROEERTSON I ANUS

ROBERTSONIANUS

ROBERTSONIANUS

ROBERTSON I ANU

ROBERTSONIANUS

ROBERTSON I ANUS

ROEERTSONIANUS

ROBER TSON IANUS

ROBERT SON IANUS

ROBERTSONIANUS

ROEERTSONIANUS

ROBERTSONIANUS

ROBERTSONIANUS

ROBERTSONIANUS

ROEERTSON IANUS

ROBERTSONIANUS

ROBERTSONIANUS

ROBERTSON IANUS

ROBERTSONIANUS

ROBERTSON IANUS

ROEER TSONIANUS

ROBERTSONIANUS

ROBERTSONIANUS

ROEERTSONIANUS

Locality

Lat. Long.

CENTRAL GULF OF MEXICO 


\section{Publication}

14646 PFLUM FRERICHS 1976 14647 PFLUM FRERICHS 1976 14648 PFLUM FRERICHS 1976 14649 PFLUM FRERICHS 1976 $\begin{array}{lll}14650 & \text { PFLUM } & \text { FRERICHS } \\ 14651 & \text { PFLUM FRERICHS } & 1976\end{array}$ 14651 PFLUM FRERICHS 1976
14652 PFLUM FRERICHS 1976 14653 PFLUM FRERICHS 1976 14654 PFLUM FRERICHS 1976 14655 PFLUM FRERICHS 1976 14656 PFLUM FRERICHS 1976 14657 PARKER 1954

14658 PARKER 1954
14659 PARKER 1954

14660 PARKER 1954

14661 PARKER 1954

14662 PARKER 1954

14663 PARKER 1954

14664 PARKER 1954

14665 PHLEGER $1951 \mathrm{~A}$

14666 PHLEGER $1951 \mathrm{~A}$

14667 PHLEGER 1951A

14668 PFLUM FRERICHS 1976

14669 PFLUM FRERICHS 1976

14670 PARKER 1954

14671 PARKER 1954

14672 PARKER 1954

14673 PHLEGER 1955A

14674 PHLEGER $1955 \mathrm{~A}$

14675 PHLEGER $1951 \mathrm{~A}$

14676 PHLEGER $1951 \mathrm{~A}$

14677 PHLEGER $1951 \mathrm{~A}$

14679 PHLEGER 1951A

14680 PFLUM FRERICHS 1976

14681 PFLUM FRERICHS 1976

14682 PFLUM FRERICHS 1976

14683 PFLUM FRERICHS 1976

14684 PFLUM FRERICHS 1976
14685 PFLUM FRERICHS 1976

14685 PFLUM FRERI CHS
14686 PHLEGER $1951 \mathrm{~A}$

14686 PHLEGER $1951 \mathrm{~A}$
14687 CREAGER 1958

14688 CREAGER 1958

14689 CREAGER 1958

14690 CREAGER 1958

14691 PHLEGER 1951A

14692 PHLEGER $1951 \mathrm{~A}$

14693 PHLEGER $1951 \mathrm{~A}$

14694 PHLEGER $1951 \mathrm{~A}$

14695 PHLEGER $1951 \mathrm{~A}$

14696 CREAGER 1958

14697 CREAGER 1958

14698 CREAGER 1958

14699 PHLEGER 1951A

14700 PHLEGER 1951A

14701 PHLEGER 1951 A

14702 PHLEGER $1951 \mathrm{~A}$

14703 PHLEGER 1951A

14704 PHLEGER 1951A

14705 PHLEGER 1951 A

14706 PHLEGER 1951A

14707 PHLEGER 1951A

14708 PHLEGER 1951A

14709 CREAGER 1958

14710 CREAGER 1958

14711 CREAGER 1958

14712 CREAGER 1958

14713 PARKER 1954

14714 PARKER 1954
14715 PARKER 1954

14716 PARKER 1954

14717 CREAGER 1958

14718 LUDWICK WALTON 1957

14719 PARKER 1954

14720 PARKER 1954

14721 PARKER 1954

14722 PARKER 1954

14723 PARKER 1954

14724 PARKER 1954

14725 PARKER 1954

14726 CREAGER 1958

14727 CREAGER 1958

14728 CREAGER 1958

14729 PARKER 1954

14730 CREAGER 1958

14731 PFLUM FRERICHS 1976

14732 PFLUM FRERICHS 1976

14733 PFLUM FRERICHS 1976
14734 PFLUM FRERICHS 1976

14735 PFLUM FRERICHS 1976

14736 PFLUM FRERICHS 1976

14737 PFLUM FRERICHS 1976

14738 PFLUM FRERICHS 1976

14739 PFLUM FRERICHS 1976

14740 PFLUM FRERICHS 1976
Generic Name

CIBICIDES

CIBICIDES

CIBICIDES

CIBICIDES

CIBICIDES

CIBICIDES

CIBICIDES

CIBICIDES

CIBICIDES

CIBICIDES

CIBICIDES

CIBICIDES

CIBICIDES

CIBICIDES

CIBICIDES

CIBICIDES

CIBICIDES

CIBICIDES

CIBICIDES

CIBICIDES

CIBICIDES

CIBICIDES

CIBICIDES

CIBICIDES

CIBICIDES

CIBICIDES

CIBICIDES

CIBICIDES

CIBICIDES

CIBICIDES

CIBICIDES

CIBICIDES

CIBICIDES

CIBICIDES

CI IICIDES

CIBICIDES

CIBICIDES

CIBICIDES
CIBICIDES

CIBICIDES

CIBICIDES

CIBICIDES

CIBICIDES

CIBICIDES

CIBICIDES

CIBICIDES

CIBICIDES

CIBICIDES

CIBICIDES

CIBICIDES

CIBICIDES

CIBICIDES

CIBICIDES

CIBICIDES

CIBICIDES

CIBICIDES

CIBICIDES

CIBICIDES

CIBICIDES

CIBICIDES

CIBICIDES

CIBICIDES

CIBICIDES

CIBICIDES

CIBICIDES

CIBICIDES

CIBICIDES

CIBICIDES

CIBICIDES

CIBICIDES

CIBICIDES

CIBICIDES

CIBICIDES

CIBICIDES

CIBICIDES

CIBICIDES

CIBICIDES

CIBICIDES

CIBICIDES
CIBICIDES

CIBICIDES

CIBICIDES

CIBICIDES

CIBICIDES

CIBICIDES

CIBICIDES

CIBICIDES

CIBICIDES

CIBICIDES

CIBICIDES

CIBICIDES

CIBICIDES

CIBICIDES
Specific Name

Locality

Lat. Long.

ROEERTSONIANUS

ROBERTSON IANUS

ROBERTSON IANUS

ROEERISON IANUS

ROEERTSON I ANUS

ROBERTSONIANUS

ROBERTSONIANUS

ROBERTSONIANUS

ROBERTSONIANUS

ROEERTSON IANUS

ROEERTSONIANUS

ROBERTSONIANUS

ROBERTSONIANUS

ROBERTSONIANUS

ROBERTSONIANUS

ROEERTSONIANUS

ROEERTSONIANUS

ROBERTSONIANUS

ROBERTSON IANUS

ROBERTSONIANUS

ROEERTSON IANUS

ROEERTSONIANUS

ROEERTSONIANUS

ROBERTSONIANUS

ROEERTSONIANUS

ROBERTSONIANUS

ROEERTSON IANUS

ROEERTSONIANUS

ROBERTSONIANUS

ROBERTSONIANUS

ROBERTSON IANUS

ROBERTSON IANUS

ROEERTSONIANUS

ROEERTSONIANUS

ROEERTSONIANUS

ROEERTSONIANUS

ROEERTSON I ANUS

ROEERTSONIANUS

ROBERTSON IANUS

CORPULENTUS

CORPULENTUS

CORPULENTUS

CORPULENTUS

CORPULENTUS

CORPULENTUS

CORPULENT US

CORPULENTUS

CORPULENTUS

CORPULENTUS

CORPULENTUS

CORPULENTUS

CORPULENTUS

CORPULENTUS

CORPULENTUS

CORPULENTUS

CORPULENTUS

CORPULENTUS

CORPULENTUS

CORPULENTUS

CORPULENTUS

CORPULENTUS

CORPULENTUS

RUGOSUS

RUGOSUS

RUGOSUS

RUGOSUS

RUGOSUS

RUGOSUS

RUGOSUS

RUGOSUS

RUGOSUS

RUGOSUS

RUGOSUS

RUGOSUS

RUGOSUS

RUEOSUS

RUGOSUS

RUGOSUS

RUGOSUS

RUGOSUS

RUGOSUS

RUGOSUS

RUGOSUS

RUGOSUS

RUGOSUS

CORPULENTUS

CORPULENTUS

CORPULENTUS

CORPULENTUS

CORPULENTUS

CORPULENT US

CORPULENTUS

CORPULENTUS

CORPULENTUS

NW GULF OF MEXICO

WW GULF OF MEXICO

NW GULF OF MEXICO

NW GULF OF MEXICO

NW GULF OF MEXICO

NW GULF OF MEXICO

NW GULF OF MEXICO

$N$ GULF OF MEXICO

NW GULF OF MEXICO 


\section{Publication}

14741 PFLUM FRERICHS 1976 14742 PFLUM FRERICHS 1976 14743 PFLUM FRERICHS 1976 14744 PFLUM FRERICHS 1976 14745 PFLUM FRERICHS 1976 14746 PFLUM FRERICHS 1976 14747 PFLUM FRERICHS 1976 14748 PFLUM FRERICHS 1976 14749 PFLUM FRERICHS 1976 14750 PFLUM FRERICHS 1976 14751 PFLUM FRERICHS 1976 14752 PFLUM FRERICHS 1976 14753 PFLUM FRERICHS 1976 14754 PFLUM FRERICHS 1976 14755 PFLUM FRERICHS 1976 14756 PFLUM FRERICHS 1976 14757 PFLUM FRERICHS 1976 14758 PFLUM FRERICHS 1976 14759 PFLUM FRERICHS 1976 14760 PFLUM FRERICHS 1976 14761 PFLUM FRERICHS 1976 14762 PFLUM FRERICHS 1976 14763 PFLUM FRERICHS 1976 14764 PFLUM FRERICHS 1976 14765 PFLUM FRERICHS 1976 14766 PFLUM FRERICHS 1976 14767 PFLUM FRERICHS 1976 14768 PFLUM FRERICHS 1976 14769 PFLUM FRERICHS 1976 14770 PFLUM FRERICHS 1976 14771 PFLUM FRERICHS 1976 14772 PFLUM FRERICHS 1976 14773 PFLUM FRERICHS 1976 14774 PFLUM FRERICHS 1976 14775 NORTON 1930

14776 CREAGER 1958

14777 CREAGER 1958

14778 CREAGER 1958

14779 CREAGER 1958

14780 BOCK 1976

14781 PARKER 1954

14782 PARKER 1954 CHS 1976

14783 PFLUM FRERICHS 1976

14785 PFLUM FRERICHS 1976

14786 CREAGER 1958

14787 CREAGER 1958

14788 PFL UM FRERICHS 1976 14789 PFLUM FRERICHS 1976 14790 PFLUM FRERICHS 1976 14791 PFLUM FRERICHS 1976 14792 PFLUM FRERICHS 1976 14793 PFLUM FRERICHS 1976 14794 CREAGER 1958 14795 CREAGER 1958

14796 PFLUM FRERICHS 1976 14797 CREAGER 1958

14798 PFLUM FRERICHS 1976 14799 PFLUM FRERICHS 1976 14800 PFLUM FRERICHS 1976 14801 PARKER 1954 14802 PARKER 1954 14803 PARKER 1954 14804 PARKER 1954 14805 PARKER 1954 14806 PARKER 1954 14807 PFLUM FRERICHS 1976 14808 PFLUM FRERICHS 1976 14809 PHLEGER 1951A

14810 PHLEGER 1951A

14811 PHLEGER $1951 \mathrm{~A}$

14812 LUDWICK WALTON 1957 14813 PFLUM FRERICHS 1976 14814 PFLUM FRERICHS 1976 14815 PFLUM FRERICHS 1976 14816 PFLUM FRERICHS 1976 14817 PFLUM FRERICHS 1976 14818 PFLUM FRERICHS 1976 14819 PFLUM FRERICHS 1976 14820 PFLUM FRERICHS 1976 14821 PFLUM FRERICHS 1976 14823 PARKER 1954

14823 PARKER 1954

14825 PHLEGER 1951 A

14826 PHLEGER $1951 \mathrm{~A}$

14827 PHLEGER 1951 A

14828 PHLEGER $1951 \mathrm{~A}$

14829 PHLEGER 1951

14830 NORTON 1930

14831 NORTON 1930

14832 CREAGER 1958

14833 CREAGER 1958

14834 PFLUM FRERICHS 1976

14835 PFLUM FRERICHS 1976
Generic Name

CI BICIDES

CIBICIDES

CI BICIDES

CIBICIDES

C IBICIDES

CIBICIDES

CIBICIDES

CIBICIDES

CIBICIDES

CIBICIDES

CIBICIDES

CI BICIDES

CIBICIDES

CIBICIDES

CIBICIDES

CI IICIDES

CI BICIDES

CIBICIDES

CI BICIDES

CIBICIDES

CI BICIDES

CI BICIDES

CIBICIDES

CIBICIDES

CIBICIDES

CIBICIDES

CIBICIDES

CIBICIDES

CIBICIDES

CIBICIDES

CIBICIDES

CI BICIDES

CIBICIDES

CI BICIDES

EP ONIDES

CIBICIDES

CIBICIDES

CIBICIDES

CIBICIDES

CIBICIDES

CIBICIDES

CIBICIDES

CIBICIDES

CIBICIDES

CI BICIDES

CIBICIDES

CIBICIDES

CIBICIDES

CIBICIDES

CIBICIDES

CIBICIDES

CI BICIDES

CIBICIDES

CIBICIDES

CIBICIDES

CIBICIDES

CIBICIDES

CIBICIDES

CIBICIDES

CI BI CIDES

CI BICIDES

CI BICIDES

CIBICIDES

CIBICIDES

CIBICIDES

CI BICIDES

CIBICIDES

CI BICIDES

CIBICIDES

CIBICIDES

CIBICIDES

CI BICIDES

CIBICIDES

CIBICIDES

CIBICIDES

CIBICIDES

CIBICIDES

CIBICIDES

CIBICIDE

CIBICIDES

CIBICIDES

C I I ICIDES

CIBICIDES

CI IICIDES

CIBICIDES

CI BICIDES

CIBICIDES

CIBICIDES

CIBICIDES

PL ANULINA

PLANULINA

PLANULINA

PLANULI INA

PLANULINA
Specific Name

CORPULENTUS

CORPULENTUS

CORPULENTUS

CORPULENTUS

CORPULENTUS

CORPULENT US

CORPULENTUS

CORPULENTUS

CORPULENTUS

CORPULENTUS

CORPULENTUS

CORPULENTUS

CORPULENTUS

CORPULENTUS

RUGOSUS

RUGOSUS

RUGOSUS

RUGOSUS

RUGOSUS

RUGOSUS

RUGOSUS

RUGOSUS

RUGOSUS

RUGOSUS

RUGOSUS

RUGOSUS

RUGOSUS

RUGOSUS

RUGOSUS

RUGOSUS

RUGOSUS

RUGOSUS

RUGOSUS

RUGOSUS

TUNIDULUS

UMEONATUS

UM EONATUS

UMBONATUS

UMBONATUS

UMBONATUS

UMBONATUS

UMEONATUS

UM EONATUS

UMEONATUS

UMEONATUS

UMBONATUS

UMEONATUS

UMEONATUS

UMBONATUS

UMBONATUS

UMBONATUS

UMEONATUS

UMEONATUS

UMEONATUS

UMBONATUS

LMBONATUS

UMEONATUS

UMEONATUS

UMEONATUS

UMBONAT US

UM EONATUS

UMEONATUS

UMEONATUS

UMBONATUS

UMBONATUS

UMEONATUS

LIMBONATUS

UMEONATUS

UMEONATUS

UMEONATUS

UM BONATUS

UMEONATUS

UMEONATUS

UMEONATUS

UMEONATUS

UMBONATUS

UMBONATUS

UMBONATUS

UMEONATUS

UMEONATUS

UMEONATUS

UMEONATUS

UMBONATUS

UMEONATUS

UMEONATUS

UMEONATUS

UMBONATUS

UMEONAT US

UMBONATUS

PSEUD OUNGERI ANUS

WUELLERSTORF I

WUELLERSTORFI

WUELLER STORFI

WUELLERSTORF I

WUELLERSTORFI

Locality

Lat. Long.

NW GULF OF MEXICO 


\section{Publication}

14836 PFLUM FRERICHS 1976 14837 PARKER 1954

14838 CREAGER 1958

14839 CREAGER 1958

14841 PFLUM FRERICHS 1976

14841 PFLUM FRERICHS 1976
14842 PFLUM FRERICHS 1976

14842 PFLUM FRERICHS 1976

14844 PFLUM FRERICHS 1976

14845 PFLUM FRERICHS 1976

14846 PFLUM FRERICHS 1976

14847 PFLUM FRERICHS 1976

14848 PFLUM FRERICHS 1976

14849 PFLUM FRERICHS 1976

14850 PFLUM FRERICHS 1976

14851 PFLUM FRERICHS 1976

14852 PFLUM FRERICHS 1976

14853 PHLEGER $1955 \mathrm{~A}$

14854 PHLEGER 1955 A

14855 PARKER 1954

14856 CREAGER 1958

14857 CREAGER 1959

14858 CREAGER 1958

14859 PFLUM FRERICHS 1976

14860 PFLUM FRERICHS 1976

14861 PFLUM FRERICHS 1976

14862 PFLUM FRERICHS 1976

14863 PFLUM FRERICHS 1976

14864 PFLUM FRERICHS 1976

14865 PFLUM FRERICHS 1976

14866 PFLUM FRERICHS 1976

14867 PFLUM FRERICHS 1976

14868 PFLUM FRERICHS 1976

14869 PFLUM FRERICHS 1976

14870 PFLUM FRERICHS 1976

14871 PFLUY FRERICHS 1976

14872 PFLUM FRERICHS 1976

14873 PFLUM FRERICHS 1976

14874 PFLUM FRERICHS 1976

14875 P FL UM FRERICHS 1976

14876 PFLUM FRERICHS 1976

14877 PFLUM FRERICHS 1976

14878 PFLUM FRERICHS 1976

14879 PFLUM FRERICHS 1976

14880 PFLUM FRERICHS 1976

14881 PFLUM FRERICHS 1976

14882 PFLUM FRERICHS 1976

14883 PFLUM FRERICHS 1976

14884 PFLUM FRERICHS 1976

14885 PFLUM FRERICHS 1976

14886 PARKER 1954

14887 PARKER 1954

14888 PARKER 1954

14889 PARKER 1954

14890 PARKER 1954

14891 PARKER 1954

14892 PARKER 1954

14893 PARKER 1954

14894 CREAGER 1958

14895 PHLEGER 1955A

14896 PHLEGER 1955A

14897 PHLEGER 1955 A

14898 PHLEGER $1955 \mathrm{~A}$

14899 PHLEGER $1955 \mathrm{~A}$

14900 PHLEGER $1955 \mathrm{~A}$

14901 PFLUM FRERICHS 1976

14902 PFLUM FRERICHS 1976

14903 PARKER 1954

14904 PARKER 1954

14905 PARKER 1954

4906 PARKER 1954

14907 PFLUM FRERICHS 1976

14908 PFLUM FRERICHS 1976

14909 PFLUM FRERICHS 1976

14910 PFLUM FRERICHS 1976

14911 PFLUM FRERICHS 1976

14912 PFLUM FRERICHS 1976

14913 PARKER 1954

14914 PARKER 1954

14915 PARKER 1954

14916 PARKER 1954

14917 PFLUM FRERICHS 1976

14918 PFLUM FRERICHS 1976

14919 PFLUM FRERICHS 1976

14920 PFLUM FRERICHS 1976

14921 PFLUM FRERICHS 1976

14922 PFLUM FRERICHS 1976

14923 PFLUM FRERICHS 1976

14924 PFLUM FRERICHS 1976

14925 LUDWICK WALTON 1957

14926 PARKER PHLEGER PEIRSON 1953

14927 LUDWICK WALTON 1957

14928 PHLEGER 1954

14929 WARREN 1957

14930 PARKER PHLEGER PEIRSON 1953
Generic Name Specific Name

WUELLERSTORFI

PLANUL INA

PLANULINA

PLANULINA

PLANUL INA

PLANULINA

PLANUL INA

PLANUL INA

PLANUL I NA

PLANUL INA

PLANULINA

PLANULINA

PLANULINA

PL ANUL INA

PLANULI INA

PLANULINA

PLANULINA

PLANULINA

PLANUL INA

PL ANUL INA

PL ANQUL INA

PLANULINA

PLANULI INA

PLANUL INA

PLANULINA

PLANULINA

PL ANUL INA

PLANUL INA

PLANULINA

PLANULINA

PLANUL INA

PL ANULI INA

PL ANULINA

PLANULINA

PL ANUL INA

PLANULINA

PLANUL INA

PLANULINA

PLANUL INA

PLANULI NA

PLANUL INA

PLANULINA

PLANULINA

PLANUL INA

PL ANULI INA

PL ANUL INA

PLANUL I NA

PL ANUL INA

PL ANUL INA

PL ANULINA

PL ANUL INA

PLANULINA

PL ANUL INA

PL ANUL INA

PL ANUL I NA

PLANUL INA

PL ANULI INA

PL ANUL I NA

PL ANUL I NA

PLANUL INA

PLANULI INA

PLANUL INA

PLANUL INA

PLANUL I NA

PLANUL INA

PLANUL I NA

PLANUL INA

PL ANULI INA

PL ANULI INA

PL ANUL I NA

PL ANUL INA

PLANULINA

PLANULINA

PLANULINA

PLANULINA

PLANULINA

PLANULINA

PL ANUL INA

PLANUL INA

PLANULINA

PLANULINA

PL ANUL INA

PL ANULI INA

PLANUL INA

PL ANUL I NA

PL ANUL INA

HANZAWAIA

HANZAWAIA

HANZ AWAIA

HANZ AWAI A

HANZ AWA I A
WUELLERSTORFI

WUELLERSTORFI

WU ELLERSTORF I

WUELLERSTOR FI

\UELLERSTORFI

WUELLERSTORFI

WUELLERSTORFI

WUELLERSTORFI

WU ELLERSTORF I

WUELLERSTORFI

WUELLERSTORFI

WUELLERSTORFI

WUELLERSTORFI

WUELLERSTORFI

WU ELLERSTORFI

WUELLERSTORFI

WUELLERSTOR F I

WUELLERSTORF I

WUELLERSTORF

WUELLERSTORFI

WUELLERSTORFI

WUELLERSTORFI

WUELLERSTORF I

WUELLERSTOR F I

WUELLERSTORFI

WUELLERSTORFI

WU ELLERSTORFI

WUELLERSTORFI

WUELLERSTORFI

WUELLERSTORFI

WUELLERSTORFI

WUELLERSTORFI

WUELLERSTORFI

WUELLERSTORFI

WU ELLERSTOR F I

WUELLERSTOR F I

WUELLERSTORFI

WUELLER STORFI

WUELLERSTORFI

WUELLERSTORFI

WUELLERSTORFI

WUELLERSTORFI

WUELLERSTORFI

WUELLERSTORFI

WUELLERSTORF I

WUELLERSTORFI

WUELLERSTORF I

WUELLERSTORF

WUELLERSTORFI

WUELLERSTORF I

$\checkmark U E L L E R S T O R F I$

WUELLERSTORFI

WUELLERSTORF

WU ELLERSTORFI

WUELLERSTORFI

WUELLERSTORFI

WUELLERSTORFI

WULLERSTORFI

WUELLERSTORFI

WUELLERSTORF

WUELLERSTORFI

WUELLERSTORFI

WUELLERSTORF I

WUELLERSTORFI

WUELLERSTORFI

WUELLERSTORFI

WUELLERSTORF I

WUELLERSTORFI

WUELLERSTORFI

WUELLERSTORF

WUELLERSTORF

WUELLERSTORFI

WUELLERSTORF

WUELLERSTORFI

WUELLERSTORFI

WUELLERSTORF

WUELLERSTORF

WUELLERSTORFI

WUELLERSTORFI

WU EL LERSTORF I

\ULLLERSTORFI

JUELLERSTORF

CONCENTRICA

ST RATTONI

STRATTON

STRATTON I

STRATTONI

STRATTONI
WUELLERSTORF

WUELLERSTORFI

WUELLERSTORF I

WUELLERSTORFI

Locality

Lat. Long.

CENTRAL GULF OF MEXICO

NE GULF OF MEXICO

BAY OF CAMPECHE

$N \leadsto$ GULF OF MEXICO

NW GULF OF MEXICO

NW GULF OF MEXICO 


\section{Publication}

14931 PARKER 1954

14932 PARKER PHLEGER PEIRSON 1953

14933 PARKER 1954

14934 PARKER 1954

14935 PARKER 1954

14936 PARKER 1954

14937 WARREN 1956

14938 LAMB 1972

14939. ANDERSON 1968

14940 PARKER PHLEGER PEIRSON 1953

14941 PARKER PHLEGER PEIRSON 1953

14942 PHLEGER 1954

14943 PARKER 1954

14944 PARKER 1954

14945 PARKER 1954

14946 PARKER 1954

14947 PARKER 1954

14948 PARKER 1954

14949 PARKER 1954

14950 PARKER 1954

14951 PARKER 1954

14952 PARKER 1954

14953 PHLEGER 19558

14954 PARKER PHLEGER PEIRSON 1953

14955 SHEPARD MOORE 1955

14956 PARKER PHLEGER PEIRSON 1953

14957 LEROY HODGKINSON 1975

14958 LEROY HODGKINSON 1975

14959 LEROY HODGKINSON 1975

14960 DAVIS 1964

14961 CUSHMAN 19228

14962 CUSHMAN $1922 \mathrm{~B}$

14963 CUSHMAN 19228

14964 CUSHMAN 19228

14965 CUSHMAN $1922 \mathrm{~B}$

14966 CUSHMAN $1922 \mathrm{~B}$

14967 CUSHMAN 19228

14968 CUSHMAN $1922 \mathrm{~B}$

14969 PHLEGER 1965 A

14970 PHLEGER 1965 A

14971 PHLEGER 1965A

14972 CUSHMAN $1922 \mathrm{~B}$

14973 CUSHMAN 1922B

14974 CUSHMAN $1922 \mathrm{~B}$

14975 CUSHMAN 19228

14976 CUSHMAN $1922 \mathrm{~B}$

14977 CUSHMAN $1922 \mathrm{~B}$

14978 BOCK 1976

14979 LEROY HODGKINSON 1975

14980 CUSHMAN 1922 A

14981 CUSHMAN $1922 B$

14982 CUSHMAN 19228

14983 CUSHMAN $1922 \mathrm{~B}$
14984 CUSHMAN $1922 \mathrm{~B}$

14985 DAVIS 1964

14986 NORTON 1930

14987 CUSHMAN 1922A

14988 PARKER 1954

14989 PARKER 1954

14990 PARKER 1954

14991 PARKER 1954

14992 PARKER 1954

14993 PARKER 1954

14904 PFLUM FRERICHS 1976

14995 PARKER 1954

14996 PARKER 1954

14997 BOCK 1976

14998 ANDERSEN 1961

14999 BENDA PURI 1962

15000 VAUGHAN 1918

15001 NORTON 1930

15002 CREAGER 1958

15003 CREAGER 1958

15004 CUSHMAN 1922 A

15005 WARREN 1957

15006 CREAGER 1958

15007 BENDA PURI 1962

15008 WARREN 1956

15009 ANDERSEN 1961

15010 ANDERSEN 1961

15011 LEROY HODGKINSON 1975

15012 PFLUM FRERICHS 1976

15013 PFLUM FRERICHS 1976

15014 PFLUM FRERICHS 1976

15015 PFLUM FRERICHS 1976

15016 PFLUM FRERICHS 1976

15017 PFLUM FRERICHS 1976

15018 PFLUM FRERICHS 1976

15019 PFLUM FRERICHS 1976

15020 PFLUM FRERICHS 1976

15021 PFLUM FRERICHS 1976

15022 PFLUM FRERICHS 1976

15023 PFLUM FRERICHS 1976

15024 PFLUM FRERICHS 1976

15025 PFLUM FRERICHS 1976
Generic Name

HANZ AWAI A

HANZAWAI A

HANZ AWAIA

HANZ AWA I A

HANZAWAIA

HANZ AWA IA

HANZAWA IA

HANZAWAIA

HANZAWAIA

HANZ AWA IA

HANZAWA IA

HANZAWAIA

HANZ AWA I A

HANZ AWA I A

HANZ AWA I A

HANZAWA IA

HANZ AWA I A

HANZAWA IA

HANZ AWA I A

HANZAWAIA

HANZ AWA I A

HANZ AWA IA

HANZ AWAIA

HANZAWAIA

CIBICIDES

CIBICIDES

CIBICIDES

CLAVULINA

CLAVULINA

CLAVULINA

CL AVUL INA

CL AVUL INA

CLAVULINA

CLAVULINA

CLAVUL INA

CLAVULINA

CLAVULINA

CLAVULINA

CLAVULINA

CLAVULINA

CLAVULINA

CLAVULINA

CLAVUL INA

CLAVULINA

CLAVULINA

CL AVULINA

CLAVULINA

B I GENER I NA

CL AVUL INA

CLAVUL INA

CLAVULINA

CLAVULINA

CL AVULINA

CLAVULINA

CLAVUL INA

NE OC ONORBINA

NEOCONORBINA

NEOCONORBINA

NE OCONORBINA

NEOCONORBINA

NEOCONORBINA

NE OCONORBINA

NEOCONORBINA

NEOCONORBINA

CORNUL OCUL INA

CORNUSPIROIDES

CYCLOGYRA

CYCLOGYRA

CYCLOGYRA

CYCLOGYRA

CYCLOGYRA

CYCLOGYRA

CYCLOGYRA

CYCLOGYRA

CYCLOGYRA

CYCLOGYRA

CYCLOGYRA

CORNUSPIROIDES

CORNUSPIROIDES

RECTOBOLIVINA

RECTOBOL IVINA

RECTOBOLIVINA

RECTOBOL IV INA

RECTOBOL IV INA

RECTOBOLIVINA

RECTOBOLIVINA

RECTOBOLIVINA

RECTOBOLIVINA

CORYPHOS TOMA

CORYPHOSTOMA

CORYPHOSTOMA

CORYPHOSTOMA

CORYPHOSTOMA
Specific Name

STRATTONI

STRATTONI

ST FATTONI

STRATTONI

STRATTONI

STRATTONI

STRATTONI

STRATTONI

STRATTONI

STRATTONI

STRATTONI

STRAT TON I

STRAT TON I

STRATTONI

STRATTONI

STRATTONI

STRATTONI

STRATTONI

STRATTONI

STRATTONI

STRATTONI

STRATTONI

STRATTON I

LOBATULUS

ROEERTSONIANUS

RUGOSUS

BI CARINATA

COMMUNIS

COMMUNIS

COMMUNIS

COMMUNIS

FLINTIANA

FL INTIANA

FL INT IANA

GRACILIS

GRACILIS

GRACILIS

MEXICANA

MEXICANA

MEXICANA

MEXICANA

MEXICANA

MEXICANA

MEXICANA

MEXI CANA

IRREGULAR IS

OC CIDENTALIS

OC CIDENTALIS

OC CIDENTALIS

TR ICARINATA

TR I CARINATA

TR ICARINATA

TR ICARINATA

TERQUEM I

TERQUEMI

TERQUEM I

TE RQUEM I

TERQUEM I

TERQUEMI

TE RQUEMI

TERQUEM I

TERQUEMI

IN CONSTANS

FOLIACEA

I N CER TA

IN VOLVENS

IN VOLVENS

IN VOL VENS

IN VOL VENS

IN VOL VENS

PL ANORBIS

PLANORBIS

PLANORBIS

PLANORBIS

PL ANORBIS

FOLIACEA

FOLIACEA

AB RUPTA

AB RUPT

AB RUPTA

AB RUPTA

ABRUPT

ABRUPTA

ABRUPT

ABRUPTA

MA YOR I

SPINESCENS

SPINESCEN

SPINESCEN

SPINESCENS

SP INESCENS

Locality

NE GULF OF MEXICO

TEXAS GULF COAST

NE GULF OF MEXICO

NE GULF OF MEXICO

NE GULF OF MEXICO

NE GULF OF MEXICO

BURAS SE LOUISIANA 
Publication

15026 PFLUM FRERICHS 1976 15027 PFLUM FRERICHS 1976 15028 PFLUM FRERICHS 1976 15029 PFLUM FRERICHS 1976 15030 PFLUM FRERICHS 1976 15031 PFLUM FRERICHS 1976 15032 PFLUM FRERICHS 1976 15033 PFLUM FRERICHS 1976 15033 PFLUM FRERICHS 1976 15034 PFLUM FRERICHS 1976 15036 PFLUM FRERICHS 1976 15037 PFLUM FRERICHS 1976 15038 PFLUM FRERICHS 1976 15039 PFLUM FRERICHS 1976 15040 PFLUM FRERICHS 1976 15041 PFLUM FRERICHS 1976 15042 PFLUM FRERICHS 1976 15043 PFLUM FRERICHS 1976 15044 PFLUM FRERICHS 1976 15045 PFLUM FRERICHS 1976 15046 PFLUM FRERICHS 1976 15047 PFLUM ERERICHS 1976 15048 PFLUM FRERICHS 1976 15049 PFLUM FRERICHS 1976 15050 PFLUM FRERICHS 1976 15051 PFLUM FRERICHS 1976 15052 PFLUM FRERICHS 1976 15053 PFLUM FRERICHS 1976 15054 PFLUM FRERICHS 1976 15055 PFLUM FRERICHS 1976 15056 PFLUM FRERICHS 1976 15057 PFLUM FRERICHS 1976 15058 PFLUM FRERICHS 1976 15059 PFLUM FRERICHS 1976 15060 PFLUM FRERICHS 1976 15061 PFLUM FRERICHS 1976 15062 PFLUM FRERICHS 1976 15063 PFLUM FRERICHS 1976 15064 PFLUM FRERICHS 1976 15065 PFLUM FRERICHS 1976 15066 PFLUM FRERICHS 1976 15067 PFLUM FRERICHS 1976 15068 ANDERSEN 1961

15069 PFLUM FRERICHS 1976 15070 PFLUM FRERICHS 1976 15071 LEHMANN 1957

15072 FFLUM FRERICHS 1976

15073 LEHMANN 1957

15074 LEHMANN 1957

15075 WARREN 1957

15076 WARREN 1956

15077 WARREN 1956

15078 WARREN 1957

15079 PFLUM FRERICHS 1976

15080 OTVOS 1978

15081 BOCK 1976

15082 LYNTS PFISTER 1967

15083 WARREN 1957

15084 WARREN 1956

15085 WARREN 1956

15086 WARREN 1957

15087 WARREN 1756

15088 LEHMANN 1957

15089 WARREN 1957

15090 LEROY HODGKINSON 1975

15091 CUSHMAN 1920

15092 CUSHMAN 1920

15093 CUSHMAN 1920

15094 CUSHMAN 1920

15095 CUSHMAN 1920

15096 PFLUM FRERICHS 1976 15097 PFLUM FRERICHS 1976 15098 PFLUM FRERICHS 1976 15099 LEROY HODGKINSON 1975 15100 PFLUM FRERICHS 1976 15101 PFLUM FRERICHS 1976 1510 ? PFLUM FRERICHS 1976 15103 PFLUM FRERICHS 1976 15104 PFLUM FRERICHS 1976 15105 PFLUM FRERICHS 1976 15106 PFLUM FRERICHS 1976 15107 PFLUM FRERICHS 1976 15108 PFLUM FRERICHS 1976 15109 PFLUM FRERICHS 1976 15110 PFLUM FRERICHS 1976 15111 PFLUM FRERICHS 1976 15112 PFLUM FRERICHS 1976 15113 PFLUM FRERICHS 1976 15114 PFLUM FRERICHS 1976 15115 PFLUM FRERICHS 1976 15116 PFLUM FRFRICHS 1976

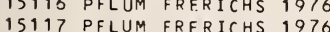
15117
15118 PFLUM 15118 PFLUM FRERICHS 1976
15119 PFLUM FRERICHS 1976 15120 PFLUM FRERICHS 1976
Generic Name CORYPHOSTOMA CORYPHOSTOMA

CORYPHOSTOMA CORYPHOSTOMA CORYPHOSTOMA CORYPHOSTOMA CORYPHOSTOMA CORYPHOSTOMA CORYPHOSTOMA CORYPHOSTOMA CORYPHOSTOMA CORYPHOSTIOMA CORYPHOSTOMA CORYPHOSTOMA CORYPHOSTOMA CORYPHOSTOMA CORYPHOS TOMA CORYPHOSTOMA CORYPHOSTOMA

BOLIVINA BOLIVINA BOLIVINA BOLIVINA BOLIVINA BOLIVINA BOLIVINA BOLIVINA BOLIVINA BOLIVINA BOLIVINA BOLIVINA BOLIVINA BOLIVINA BOLIVINA BOLIVINA BOLIVINA BOLIVINA BOLIVINA

CORYPHOSTOMA

CORYPHOSTOMA

CR IBROB I GENER INA ELPHIDIUM ELPHIDIUM ELPHIDIUM

ELPHIDIUM

ELPHIDIUM

ELPHIDIUM

ELPHIDIUM

ELPHIDIUM

ELPHIDIUM

ELPHID I UM

ELPHIDIUM

ELPHIDIUM

ELPHIDIUM

ELPH ID I UM

ELPHIDIUM

ELPHIDIUM

ELPHIDIUM

ELPHIDIUM

ELPHIDIUM

ELPHIDIUM

CRIBROPYRGO

CR IBROST OMOI DES

CRIBROSTOMOIDES

CRIBROSTOMOIDES CRIBROSTOMOIDES

CR IBROSTOMOIDES

HAPLOPHRAGMOIDES HAPLOPHRAGMOIDES HAPLOPHRAGMOIDES HAPLOPHRAGMOIDES CRIBROS TOMOIDES CRIBROSTOMOIDES CRIBROSTOMOI DES CRIBROSTOMOIDES CRIBROSTOMOIDES CRIBROSTOMOIDES CR IBROSTOMOIDES CRIBROSTOMOIDES CRIBROSTOMOIDES CRIBROSTOMOIDES CRIBROSTOMOIDES CRIBROS TOMOIDES CR IBROSTOMOI DES CR IBROS TOMOIDES CR IBROSTOMOIDES CR IBROSTOMOIDES CR IBROSTOMOIDES CRIBROS TOMOIDES CRIBROSTOMOIDES CRIBROSTOMOIDES CR IBROSTOMOIDES CRIBROSTOMOIDES
Specific Name

Locality

Lat. Long.

SPINESCENS

SPINESCENS

SP INESCENS

SPINESCENS

SPINESCENS

SPINESCENS

SPINESCENS

SPINESCEN

SPINESCENS

SPINESCENS

SPINESCENS

SP INESCENS

SPINESCENS

SP INESCENS

SPINESCENS

SPINESCENS

SPINESCENS

SP INESCENS

SUESPINES CENS

SUESPINES CENS

SURSPINESCENS

SUESPINESCENS

SUBSPINES CENS

SUESPINES CENS

SUESPINES CENS

SUESPINES CENS

SUESPINES CENS

SUESPINES CENS

SUBSPINES CEN

SUESPINESCENS

SUSPINESCENS

SUESPINESCENS

U USPINES CENS

SUESPINESCENS

SUESPINES CENS

ZANZIBARI CA

ZA IZI BARI CA

Z A NZ IBARI CA

PARKERAE

DI SCOIDALE

DI SCOIDALE

DI SCOIDALE

GALVEST ONENSE

KOEBOEENSE

KUGLERI

KUGLER

KU GLERI

EX CAVATUM

EXCAVATUM

POEYANUM

POEYANUM

POEYANUM

EX CAVATUM

EXCAVATUM

EX CAVATUM

EXCAVATUM

EXCAVATUM

EX CAVATUM

EX CAVATUV

ROEUSTA

SUEGLOBOSUM

SUEGL OBOSUM

SUEGLOBOSUM

SUEGL OBOS UM

SUEGLOBOSUM

CANARIENSIS

CA AARIENSIS

CA AARIENS IS

EMACIATUM

LOBATUS

LOBATUS

LOEATUS

LOEATUS

LOEATUS

LOEATUS

LOEATUS

LOEATUS

LOEATUS

LOBATUS

LOEATUS

LOEATUS

LOEATUS

LOEATUS

LOEATUS

LOEATUS

LOBATUS

LOBATUS

LOEATUS

LOEATUS

LOEATUS

NW GULF OF MEXICO

NW GULF OF MEXICO

CENTRAL GULF OF MEXICO

NW GULF OF MEXICO 


\section{Publication}

15121 PFLUM FRERICHS 1976 15122 PFLUM FRERICHS 1976 15123 PFLUM FRERICHS 1976 15124 PFLUM FRERICHS 1976 15125 PFLUM FRERICHS 1976 15126 PFLUM FRERICHS 1976 15127 PFLUM FRERICHS 1976 15128 PFLUM FRERICHS 1976 15129 PFLUM FRERICHS 1976 15130 PFLUM FRERICHS 1976 15131 PFLUM FRERICHS 1976 15132 PFLUM FRERICHS 1976 15133 PFLUM FRERICHS 1976 15134 PFLUM FRERICHS 1976 15135 LEROY HODGKINSON 1975 15136 PFLUM FRERICHS 1976 15137 PFLUM FRERICHS 1976 15138 PFLUM FRERICHS 1976 15139 LEROY HODGKINSON 1975 15140 PFLUM FRERICHS 1976 15141 PFLUM FRERICHS 1976 15142 PFLUM FRERICHS 1976 15143 PFLUM FRERICHS 1976 15144 PFLUM FRERICHS 1976 15145 PFLUM FRERICHS 1976 15146 PFLUM FRERICHS 1976 15147 PFLUM FRERICHS 1976 15148 PFLUM FRERICHS 1976 15149 PFLUM FRERICHS 1976 15150 PFLUM FRERICHS 1976 15151 PFLUM FRERICHS 1976 15152 PFLUM FRERICHS 1976 15153 PFLUM FRERICHS 1976 15154 PFLUM FRERICHS 1976 15155 PFLUM FRERICHS 1976 15156 PFLUM FRERICHS 1976 15157 PFLUM FRERICHS 1976 15158 PFLUM FRERICHS 1976 15159 PFLUM FRERICHS 1976 15160 PFLUM FRERICHS 1976 15161 PFLUM FRERICHS 1976 15162 PFLUM FRERICHS 1976 15163 PFLUM FRERICHS 1976 15164 PFLUM FRERICHS 1976 15165 PFLUM FRERICHS 1976 15166 PFLUM FRERICHS 1976 15167 PFLUM FRERICHS 1976 15168 PFLUM FRERICHS 1976 15169 PFLUM FRERICHS 1976 15170 LEROY HODGKINSON 1975 15171 PFLUM FRERICHS 1976 15172 PFLUM FRERICHS 1976 15173 PFLUM FRERICHS 1976 15174 PFLUM FRERICHS 1976 15175 PFLUM FRERICHS 1976 15176 PFLUM FRERICHS 1976 15177 PFLUM FRERICHS 1976 15178 PFLUM FRERICHS 1976 15179 PFLUM FRERICHS 1976 15180 PFLUM FRERICHS 1976 15181 PFLUM FRERICHS 1976 15182 PFLUM FRERICHS 1976 15183 PFLUM FRERICHS 1976 15184 PFLUM FRERICHS 1976 15185 PFLUM FRERICHS 1976 15186 PFLUM FRERICHS 1976 15187 PFLUM FRERICHS 1976 15188 PFLUM FRERICHS 1976 15189 PFLUM FRERICHS 1976 15190 PFLUM FRERICHS 1976 15191 PFLUM FRERICHS 1976 15192 LEROY HODGKINSON 1975 15193 PFLUM FRERICHS 1976 15194 PFLUM FRERICHS 1976 15195 PFLUM FRERICHS 1976 15196 PFLUM FRERICHS 1976 15197 PFLUM FRERICHS 1976 15198 PFLUM FRERICHS 1976 15199 PFLUM FRERICHS 1976 15200 PFLUM FRERICHS 1976 15201 PFLUM FRERICHS 1976 15202 PFLUM FRERICHS 1976 15203 PFLUM FRERICHS 1976 15204 PFLUM FRERICHS 1976 15205 PFLUM FRERICHS 1976 15206 PFLUM FRERICHS 1976 15207 PFLUM FRERICHS 1976 15208 PFLUM FRERICHS 1976 15209 PFLUM FRERICHS 1976 15210 PFLUM FRERICHS 1976 15211 PFLUM FRERICHS 1976 15212 PFLUM FRERICHS 1976 15214 PFLUM FRERICHS 1976 15215 PFLUM FRERICHS 1976

\section{Generic Name}

CRIBROSTOMOIDES CRIBROSTOMOIDES CRIBROSTOMOIDES CRIBROSTOMOIDES CRIBROSTOMOIDES CRIBROSTOMOIDES CRIBROSTOMOIDES CRIBROSTOMOIDES CRIBROSTOMOIDES CRIBROSTOMOIDES CRIBROSTOMOIDES CRIBROSTOMOIDES CRIBROSTOMOIDES CRIBROS TOMOIDES CRIBROSTOMOIDES HAPLOPHRAGMOI DES HAPLOPHRAGMOI DES HAPLOPHRAGMOIDES HAPLOPHRAGMOIDES HAPLOPHRAGMOIDES HAPLOPHRAGMOIDES HAPLOPHRAGMOIDES HAPLOPHRAGMOIDES HAPLOPHRAGMOI DES HAPLOPHRAGMOIDES HAPLOPHRAGMOIDES HAPLOPHRAGMOIDES HAPLOPHRAGMOIDES HAPL OPHRAGMOIDES HAPLOPHRAGMOIDES HAPLOPHRAGMOIDES HAPLOPHRAGMOIDES HAPLOPHRAGMOIDES HAPLOPHRAGMOIDES HAPLOPHRAGMOIDES HAPLOPHRAGMOIDES HAPLOPHRAGMOIDES HAPLOPHRAGMOIDES HAPLOPHRAGMOIDES HAPLOPHRAGMOIDES HAPLOPHRAGMOIDES HAPLOPHRAGMOIDES HAPLOPHRAGMOIDES HAPLOPHRAGMOIDES HAPLOPHRAGMOIDES HAPLOPHRAGMOIDES HAPL OPHRAGMOIDES HAPLOPHRAGMOIDES HAPLOPHRAGMOI DES HAPLOPHRAGMOI DES HAPLOPHRAGMOI DES HAPLOPHRAGMOI DES HAPLOPHRAGMOI DES HAPLOPHRAGMOIDES HAPL OPHRAGMOIDES HAPLOPHRAGMOIDES HAPLOPHRAGMOIDES HAPLOPHRAGMOI DES HAPLOPHRAGMOIDES HAPLOPHRAGMOIDES HAPLOPHRAGMOIDES HAPLOPHRAGMOIDES HAPLOPHRAGMOIDES HAPLOPHRAGMOIDES HAPLOPHRAGMOIDES HAPLOPHRAGMOIDES HAPLOPHRAGMOIDES HAPLOPHRAGMOIDES HAPLOPHRAGMOIDES HAPLOPHRAGMOIDES HAPLOPHRAGMOIDES CRIBROSTOMOIDES CRIBROSTOMOIDES CRIBROS TOMOIDES CRIBROSTOMOIDES CRIBROSTOMOIDES CRIBROSTOMOIDES CRIBROS TOMO IDES CRIBROSTOMOIDES CR IBROSTOMOIDES CR IBROS TOMOIDES CRIBROSTOMOIDES CRIBROSTOMOIDES CRIBROSTOMOIDES CR IBROSTOMOIDES CRIBROSTOMOI DES CRIBROSTOMOIDES CRIBROSTOMOIDES CRIBROSTOMOIDES CR IBROS TOMOIDES CR IBROSTOMOIDES CRIBROS TOMOIDES CRIBROS IOMOIDES CRIBROSTOMOIDES
Specific Name

Locality

LOEATUS

LOEATUS

LOEATUS

LOEATUS

LOBATUS

LOEATUS

LOEATUS

LOBATUS

LOEATUS

LOBATUS

LOEATUS

LOEATUS

LOBATUS

NI TIDUM

RINGENS

RINGENS

RINGENS

RI AGENS

RI $\wedge$ GENS

R I NGENS

RINGENS

I I GENS

RINGENS

RI AGENS

RI NGENS

RINGENS

I NGENS

RI AGENS

RI AGENS

RI AGENS

RI NGENS

RI NGENS

RIAGENS

SCITULUM

SC I TULUM

SC ITULUM

SCITULUM

SC I TULUM

SC ITULUM

SC ITULUM

SCITULUM

SCI TULUM

SC I TULUM

SC ITULUM

SCITULUM

SCITULUM

SC I TULUM

SC I TULUM

SC I TULUM

SC ITULUM

SCITULUM

SC I TULUM

SC I TULUM

SCITULUM

SC I TULUM

SC ITULUM

SCITULUM

SC I TULUM

SC ITULUM

SC ITULUM

SCITULUM

SC ITULUM

SC ITULUM

SC I TULUM

SU BGL OB OS UM

SUBGL OB OSUM

SUEGL OBOSUM

SUEGLOBOSUM

SUBGL OBOS UM

SUEGLOBOSUM

SUEGLOBOS UM

SUBGL OBOSUM

SUEGL OBOSUM

SU BGLOBOSUM

SUBGLOBOSUM

SUEGL OBOSUM

SUEGLOBOSUM

SUEGL OB OS UM

SUEGL OBOSUM

SU BGL OBOS UM

SUEGLOBOS UM

SUBGL OBOSUM

SUEGL OBOSUM

SU BGL OBOS UM

SUBGL OBOSUM

SUBGL OBOS UM

SUEGL OBOSUM

SUBGLOBOSUM

NW GULF OF MEXICO

NW GULF OF MEXICO

$N W$ GULF OF MEXICO

$N W$ GULF OF MEXICO

NW GULF OF MEXICO

CENTRAL GULF OF MEXICO 


\section{Publication}

15216 PFLUM FRERICHS 1976 15217 PFLUM FRERICHS 1976 15218 PFLUM FRERICHS 1976 15219 PFLUM FRERICHS 1976 15220 PFLUM FRERICHS 1976 15221 PFLUM FRERICHS 1976 15222 PFLUM FRERICHS 1976 15223 PFLUM FRERICHS 1976 15224 PFLUM FRERICHS 1976 15225 PFLUM FRERICHS 1976 15226 PFLUM FRERICHS 1976 15227 PFLUM FRERICHS 1976 15228 PFLUM FRERICHS 1976 15229 PFLUM FRERICHS 1976 15230 PFLUM FRERICHS 1976 15231 PFLUM FRERICHS 1976 15232 PFLUM FRERICHS 1976 15233 PFLUM FRERICHS 1976 15234 PFLUM FRERICHS 1976 15235 PFLUM FRERICHS 1976 15236 PFLUM FRERICHS 1976 15237 PFLUM FRERICHS 1976 15238 PFLUM FRERICHS 1976 15239 PFLUM FRERICHS 1976 15240 PFLUM FRERICHS 1976 15241 PFLUM FRERICHS 1976 15242 PFLUM FRERICHS 1976 15243 PFLUM FRERICHS 1976 15244 PFLUM FRERICHS 1976 15245 PFLUM FRERICHS 1976 15246 PFLUM FRERICHS 1976 15247 PFLUM FRERICHS 1976
15248 PFLUM FRERICHS 1976 15248 PFLUM FRERICHS 1976
15249 PFLUM FRERICHS 1976 15250 PFLUM FRERICHS 1976 15251 PFLUM FRERICHS 1976 15252 PFLUM FRERICHS 1976 15253 PFLUM FRERICHS 1976 15254 PFLUM FRERICHS 1976 15255 PFLUM FRERICHS 1976 15256 LEROY HODGKINSON 1975 15257 PFLUM FRERICHS 1976 15258 PFLUM FRERICHS 1976 15259 PFLUM FRERICHS 1976

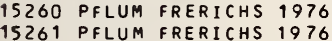
15261 PFLUM FRERICHS 1976
15262 PFLUM FRERICHS 1976 15262 PFLUM FRERICHS 1976
15263 PFLUM FRERICHS 1976 15264 PFLUM FRERICHS 1976 15265 PFLUM FRERICHS 1976 15266 PFLUM FRERICHS 1976 15267 PFLUM FRERICHS 1976 15268 PFLUM FRERICHS 1976 15269 PFLUM FRERICHS 1976 15270 PFLUM FRERICHS 1976 15271 PFLUM FRERICHS 1976 15272 PFLUM FRERICHS 1976 15273 PFLUM FRERICHS 1976 15274 PFLUM FRERICHS 1976 15275 PFLUM FRERICHS 1976 15276 PFLUM FRERICHS 1976 15277 PFLUM FRERICHS 1976 15278 PFLUM FRERICHS 1976 15279 PFLUM FRERICHS 1976 15280 PFLUM FRERICHS 1976 15281 PFLUM FRERICHS 1976 15282 PFLUM FRERICHS 1976 15283 PFLUM FRERICHS 1976 15284 PFLUM FRERICHS 1976 15285 PFLUM FRERICHS 1976 15286 PFLUM FRERICHS 1976 15287 PFLUM FRERICHS 1976 15288 PFLUM FRERICHS 1976 15289 PFLUM FRERICHS 1976 15290 PFLUM FRERICHS 1976 15291 PFLUM FRERICHS 1976 15292 PFLUM FRERICHS 1976 15293 PFLUM FRERICHS 1976 15294 PFLUM FRERICHS 1976 15295 PFLUM FRERICHS 1976 15296 PFLUM FRERICHS 1976 15297 PFLUM FRERICHS 1976 15298 PFLUM FRERICHS 1976 15299 PFLUM FRERICHS 1976 15300 PFLUM FRERICHS 1976 15301 PFLUM FRERICHS 1976 15302 PFLUM FRERICHS 1976 15303 PFLUM FRERICHS 1976

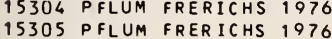
15306 CUSHMAN 1923

15307 CUSHMAN 1923

15308 CUSHMAN 1923

15309 CUSHMAN 1923

15310 CUSHMAN 1923
Generic Name

CRIBROS TOMOI DES CRIBROSTOMOIDES CRIBROSTOMOIDES CR IBROSTOMOI DES CRIBROSTOMOIDES CRIBROSTOMOIDES CR IBROSTOMOI DES CRIBROSTOMOIDES CRIBROSTOMOIDES CR IBROSTOMOIDES CRIBROSTOMOIDES CR IBROSTOMOIDES CR IBROSTOMOIDES CRIBROSTOMOIDES CRIBROSTOMOIDES CR IBROSTOMOIDES CRIBROSTOMOIDES CRIBROSTOMOIDES CRIBROSTOMOIDES CRIBROSTOMOIDES CRIBROSTOMOIDES CRIBROSTOMOIDES CRIBROSTOMOIDES CRIBROSTOMOIDES CRIBROSTOMOIDES CRIBROSTOMOIDES CR IBROSTOMOI DES CRIBROSTOMOIDES CRIBROS TOMOIDES CRIBROSTOMOIDES CRIBROSTOMOIDES CR IBROSTOMOIDES CRIBROSTOMOIDES CRIBROS TOMOIDES CRIBROSTOMOIDES CR IBROSTOMOIDES CRIBROSTOMOIDES CRIBROSTOMOIDES CRIBROSTOMOIDES CRIBROSTOMOIDES CRIBROSTOMOIDES CRIBROSTOMOIDES CR IBROSTOMOI DES CR IBROSTOMOIDES CRIBROSTOMOIDES CRIBROSTOMOIDES CRIBROSTOMOIDES CRIBROSTOMOIDES CRIBROSTOMOIDES CRIBROSTOMOIDES CRIBROSTOMOIDES CR I BROSTOMOIDES CRIBROS TOMOI DES CRIBROS TOMOI DES CR IBROST OMOIDES CRIBROSTOMOIDES CRIBROSTOMOIDES CR IBROST OMOI DES CRIBROSTOMOIDES CRIBROSTOMOIDES CRIBROSTOMO IDES CRIBROSTOMOI DES CRIBROSTOMOI DES CRIBROSTOMOI DES CRIBROSTOMO I DES CRIBROSTOMOIDES CR IBROS TOMOIDES CR IBROSTOMOIDES CRIBROSTOMOIDES CRIBROSTOMOIDES CRIBROSTOMOIDES CRIBROSTOMOIDES CR IBROSTOMOIDES CRIBROSTOMOIDES CRIBROSTOMOIDES CRIBROS TOMOIDES CRIBROSTOMOIDES CRIBROSTOMO I DES CRIBROSTOMOI DES CRIBROSTOMOIDES CRIBROSTOMOIDES CRIBROSTOMOIDES CRIBROSTOMOIDES CR IBR OSTOMO I DES CR IBROS TOMOIDES CRIBROSTOMOIDES CRIBROSTOMOIDES CRIBROSTOMOIDES CR IBROSTOMO IDES CRIBROSTOMOIDES CRIBROS TOMOIDES CRIBROSTOMOIDES ASTACOLUS

LENTI CULINA

LENTI CUL INA

LENTI CULINA

LENTI CULINA
Specific Name

SUEGLOBOSUM

SUEGLOBOSUM

SUEGL OBOSUM

SU BGLOBOSUM

SUEGLOBOSUM

SUEGLOBOSUM

SUEGL OBOSUM

SU BGL OBOS UM

SUEGL OBOS UM

SUBGL OBOSUM

SUBGL OBOSUM

SUEGLOBOSUM

SUBGL OB OSUM

SUEGL OBOSUM

SUBGL OBOSUM

SUBGLOBOSUM

SUEGL OBOSUM

SUEGLOBOSUM

SU BGL OBOSUM

SUBGL OBOSUM

SUBGL OBOS UM

SUBGL OBOSUM

SUEGL OBOS UM

SU BGL OBOSUM

UMBILICATUS

UMEILICATUS

UMBILICATUS

UMEILICATUS

UMEILICATUS

UMBILICATUS

UMBILICATUS

UMBILICATUS

UMEILICATUS

UMEILICATUS

UMEILICATUS

UMEILICATUS

WIESNERI

$W I E S N E R I$
$W I E S N E R I$

WIESNERI

WIESNER I

$W I$ ESNER I

WIESNER I

WI ESNERI

WIESNER I

WIESNER I

WIESNER I

WI ESNER I

WIESNER I

WIESNER I

WI ESNER I

WI ESNER I

WI ESNER I

WI ESNER I

WIESNERI

WIESNERI

WIESNER I

WIESNER I

WI ESNER I

WIESNER I

WI ESNERI

$W I$ ESNER I

WIESNER I
WIESNER I

WIESNERI

WIESNERI

$W I$ ESNER I

WIESNERI

WIESNERI

WIESNER I

WIESNERI

WI ESNER I

WI ESNERI

WIESNER I

WIESNERI

WIESNERI

WI ESNER I

WI ESNER I

WIESNERI

WIESNERI

WIESNERI

WIESNER I

$W$ IESNER I

WI ESNER I

ANTILLEA

CALCAR

CALCAR

CALCAR

Locality

CENTRAL GULF OF MEXICO CENTRAL GULF, OF MEXICO CENTRAL GULF OF MEXICO CENTRAL GULF OF MEXICO CENTRAL GULF OF MEXICO CENTRAL GULF OF MEXICO CENTRAL GULF OF MEXICO $N W$ GULF OF MEXICO $N W$ GULF OF MEXICO $N W$ GULF OF MEXICO 


\section{Publication}

15311 CUSHMAN 1923 15312 VAUGHAN 1918 15313 CUSHMAN 1923 15314 CUSHMAN 1923 15315 CUSHMAN 1923 15316 CUSHMAN 1923 15317 CUSHMAN 1923 15318 CUSHMAN 1923 15319 CUSHMAN 1923 15320 CUSHMAN 1923 15321 CUSHMAN 1923 15322 CUSHMAN 1923 15323 CUSHMAN 1923 15324 CUSHMAN 1923 15325 CUSHMAN 1923 15326 CUSHMAN 1923
15327 VAUGHAN 1918 15328 CUSHMAN 1923 15329 CUSHMAN 1923 15330 CUSHMAN 1923 15331 CUSHMAN 1923 15332 CUSHMAN 1923 15333 CUSHMAN 1923 15334 CUSHMAN 1923 15335 CUSHMAN 1923 15337 CUSHMAN 1923 15337 CUSHMAN 1923 15339 CUSHMAN 1923 15340 CUSHMAN 1923 15349 CUSHMAN 1923 15342 CUSHMAN 1923 15343 CUSHMAN 1923 15344 CUSHMAN 1923 15345 CUSHMAN 1923 15346 CUSHMAN 1923 15347 CUSHMAN 1923 15348 CUSHMAN 1923 15349 CUSHMAN 1923 15350 CUSHMAN 1923 15352 CUSHMAN 1923 15353 CUSHMAN 1923 15354 CUSHMAN 1918

15355 LEROY HODGKINSON 1975 15356 PHLEGER 1951A 15357 PHLEGER 1951A 15358 CUSHMAN 1920 15359 CUSHMAN 1920 15360 CUSHMAN 1920 15361 CUSHMAN 1920 15362 CREAGER 1958 15363 CREAGER 1958 15364 CREAGER 1958 15365 CREAGER 1958 15366 PHLEGER 1951A 15367 PHLEGER 1951A

15368 PFLUM FRERICHS 1976 15369 PFLUM FRERICHS 1976 15370 PFLUM FRERICHS 1976 15371 PFLUM FRERICHS 1976 15372 PFLUM FRERICHS 1976 15373 PHLEGER 1951 A 15374 PHLEGER 1951 A 15376 PFLUM FRERICHS 1976 \begin{tabular}{l}
15376 \\
15377 PFLUUM FRERICHS 1976 \\
15378 \\
\hline
\end{tabular} 15378 PFLUM FRERICHS 1976 15379 PHLEGER 1951A

15380 PFLUM FRERICHS 1976 15381 PFLUM FRERICHS 1976 15382 PFLUM FRERICHS 1976 15383 PFLUM FRERICHS 1976 15384 PFLUM FRERICHS 1976 15385 PFLUM FRERICHS 1976 15386 PFLUM FRERICHS 1976 15387 PFLUM FRERICHS 1976 15388 PFLUM FRERICHS 1976 15389 PFLUM FRERICHS 1976 15390 PFLUM FRERICHS 1976 15391 PFLUM FRERICHS 1976 15392 PFLUM FRERICHS 1976 15393 CREAGER 1958

15394 PFLUM FRERICHS 1976 15395 PFLUM FRERICHS 1976 15396 CREAGER 1958

15397
15398 CREAGER 1958 15399 PFLUM FRERICHS 1976 15400 PFLUM FRERICHS 1976 15401 CREAGER 1958

15402 LEROY HODGKINSON 1975 15403 PHLEGER 1951A

15404 PFLUM FRERICHS 1976

15405 CREAGER 1958
Generic Name

Specific Name

Locality

Lat.

Long.

LENTI CULINA

LENTI CULINA

LENTI I ULINA

LENTI CULINA

LENTI CULINA

LENT I CULINA

ASTACOLUS

ASTACOLUS

LENTI CULINA

LENT I CULINA

LENTI CULINA

LENTI C ULINA

LENT I CULINA

LENT I CULINA

SARACENARIA

SARACENARIA

SARACENARIA

ASTACOLUS

ASTACOLUS

ASTACOLUS

MARGINULINOPSIS

LENTICULINA

LENTICULINA

LENTI CULINA

LENT I CULINA

LENTI CUL INA

LENTI CUL INA

LENTI CULINA

LENT I CULINA

LENT I CULINA

LENTI CULINA

LENTI CULINA

LENTI CUL INA

LENTI CULINA

LENTI CUL INA

ASTACOL US

MARGINUL INOPSIS

MARG I NUL INOPS IS

MARGINULINOPS IS

MARGINULINOPSIS

LENT I CULINA

CRITHIONINA

CRUCILOCUL INA

CYCLAMMINA

CYCLAMMINA

CYCLAMMINA

CYCLAMM INA

CrCLAMM INA

Cr CLAMMINA

CYCL AMMINA

Cr CLAMMINA

CYCLAMM INA

CrCL AMM I NA

Cr CLAMMINA

CYCLAMM I NA

CrCLAMM I NA

Cr CLAMM I NA

CYCLAMMINA

CrCL AMM I NA

CrCLAMM INA

CY CLAMMINA

CrCLAMMINA

CrCL AMM I NA

CYCL AMMINA

CY CL AMM INA

Cr CLAMMINA

CrCLAMMINA

Cr CL AMM I NA

CYCLAMMINA

CYCL AMM I NA

CYCLAMMINA

CY CLAMMINA

CrCL AMM I NA

Cr CL AMM I NA

CY CL AMMINA

CY CL AMM INA

CY CL AMMINA

CYCL AMMINA

CYCLAMM INA

CrCLAMMINA

CYCL AMM INA

CrCLAMMINA

CY CLAMMINA

Cr CL AMMINA

CY CLAMMINA

CYCLAMMINA

Cr CL AMM I NA

CYCLAMM I NA

CY CL AMM I NA

CY CLAMMINA

CrCL AMM I NA

CYCL AMM I NA

CY CL AMM I NA
CALCAR

CALCAR

CALCAR

CALCAR

CALCAR

CONVERGENS

CREPIDULUS

CREPIDULUS

ORMOSA

$G I E B A$

$G I B B A$

$G I B B A$

$G I B B A$

IOTA

I TALICA

IT AL ICA

IT ALICA

LATIFRONS

LIMBATA

LUCIDA

MARGINUL INOIDES

TORR IDA

TORRIDA

TORRIDA

PE RE GR INA

PEREGRINA

PEREGRINA

PEREGRINA

PEREGR INA

PEREGRINA

PEREGRINA

RO TULATA

RO TULATA

SC HOENBACH I

CHOENBACHI

SUEACULEATA GLABRATA

SUEACULEATA GLABRATA

SUEACULEATA GLABRATA

SUEACULEATA GLABRATA

SUEMAMILL IGERA.

PI SUM

TR IANGULARIS

CANCELLATA

CANCELLATA

CAACELLATA

CANCELLATA

CANCELLATA

CANCELLATA

CANCELLATA

CANCELLATA

CANCELLATA

CANCELLATA

CANCELLATA

CANCELLATA

CANCELLATA

CANCELLATA

CANCELLATA

CANCELLATA

CANCELLATA

CANCELLATA

CAACELLATA

CANCELLATA

CANCELLLATA

CANCELLATA

CANCELLLATA

CANCELLATA

CANCELLATA

CANCELLATA

CANCELLATA

CANCELLLATA

CANCELLATA

CANCELLATA

CAACELLATA

CANCELLATA

CANCELLATA

CANCELLATA

CANCELLATA

CANCELLATA

CAACELLATA

CANCELLATA

CANCELLATA

CANCELLATA
CANCELLATA

CANCELLATA

CANCELLATA

CANCELLATA

CANCELLATA

CANCELLATA A

CANCELLATA

CANCELL ATA A

CANCELLATA
CANCELLATA

NE GULF OF MEXICO

FLORIDA KEYS

NE GULF OF MEXICO NE GULF OF MEXICO NE GULF OF MEXICO NE GULF OF MEXICO NE GULF OF MEXICO 


\section{Publication}

15406 PFLUM FRERICHS 1976 15407 PFLUM FRERICHS 1976 15408 PFLUM FRERICHS 1976 15409 PFLUM FRERICHS 1976 15410 PFLUM FRERICHS 1976 15411 CREAGER 1958 15412 CREAGER 1958 15413 CREAGER 1958 15414 PFLUM FRERICHS 1976 15415 PFLUM FRERICHS 1976 15416 PFLUM FRERICHS 1976 15417 PFLUM FRERICHS 1976 15418 PFLUM FRERICHS 1976 15419 PFLUM FRERICHS 1976 15420 PFLUM FRERICHS 1976 15421 PFLUM FRERICHS 1976 15422 PFLUM FRERICHS 1976 15423 PFLUM FRERICHS 1976 15424 PFLUM FRERICHS 1976 15425 PFLUM FRERICHS 1976 15426 PFLUM FRERICHS 1976 15427 PFLUM FRERICHS 1976 15428 PFLUM FRERICHS 1976 15429 PFLUM FRERICHS 1976 15430 PHLEGER 1951A 15431 PHLEGER $1951 \mathrm{~A}$
15432 PFLUM FRERICHS 1976 15433 PHLEGER 1951A

15434 PFLUM FRERICHS 1976 15435 PFLUM FRERICHS 1976 15436 PFLUM FRERICHS 1976 15437 PFLUM FRERICHS 1976 15438
15439 PFLUM FRERICHS 1976 15439
15440
PFLLUM FRERICHS 1976 15441 PFLUM FRERICHS 1976 15442 CUS HMAN 1920

15443 CUSHMAN 1920

15444 CUS HMAN 1920

15445 CUSHMAN 1920

15446 CUSHMAN 1920

15447 LEROY HODGKINSON 1975

15448 PFLUM FRERICHS 1976

15449 PFLUM FRERICHS 1976

15450 PFLUM FRERICHS 1976

15451 PFLUM FRERICHS 1976

15452 PFLUM FRERICHS 1976

15453 PFLUM FRERICHS 1976

15454 PFLUM FRERICHS 1976

15455 LEROY HODGKINSON 1975

15456 PFLUM FRERICHS 1976

15457 PFLUM FRERICHS 1976

15458 BOCK 1976

15459 BOCK 1976

15460 AYALA-CASTANARES 1963

15461 VAUGHAN 1918

15462 DAVIS 1964

15463 CUSHMAN $1922 \mathrm{~A}$

15464 DAVIS 1964

15465 BENDA PURI 1962

15466 CUSHMAN 1931
15467 BOCK 1976

15467 BOCK 1976

15468 LYNTS PFISTER 1967

15469 NORTON 1930

15470 CUSHMAN 1931

15471 PFLUM FRERICHS 1976

15472 PFLUM FRERICHS 1976

15473 PFLUM FRERICHS 1976 15474 PFLUM FRERICHS 1976 15475 PFLUM FRERICHS 1976 15476 PFLUM FRERICHS 1976 15477 PFLUM FRERICHS 1976 15478 PFLUM FRERICHS 1976 15479 PFLUM FRERICHS 1976 15480 PFLUM FRERICHS 1976 15481 PFLUM FRERICHS 1976 15482 PFLUM FRERICHS 1976 15483 PFLUM FRERICHS 1976 15484 PFLUM FRERICHS 1976 15485 PFLUM FRERICHS 1976

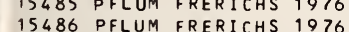
15487 PFLUM FRERICHS 1976 15488 PFLUM FRERICHS 1976 15489 PFLUM FRERICHS 1976 15490 ANDERSEN 1961

15491 PFLUM FRERICHS 1976 15492 PFLUM FRERICHS 1976 15493 PFLUM FRERICHS 1976 15494 PFLUM FRERICHS 1976 15495 PFLUM FRERICHS 1976 15496 PFLUM FRERICHS 1976 15497 PFLUM FRERICHS 1976 15498 PFLUM FRERICHS 1976 15499 PFLUM FRERICHS 1976 15500 PFLUM FRERICHS 1976
Generic Name

Specific Name

Locality

CY CLAMMINA

CY CLAMMINA

CY CLAMMINA

CYCLAMMINA

CY CLAMMINA

CYCLAMMINA

CYCLAMMINA

CY CLAMMINA

CYCLAMMINA

CYCLAMM I NA

CYCLAMMINA

CYCLAMM I NA

CY CLAMM I NA
CYCLAMMI NA

CYCLAMM I NA

CY CLAMM INA

CYCLAMMINA

CY CLAMMINA

CY CLAMM INA

CYCLAMMINA

CY CLAMM INA

CYCLAMMINA

CYCLAMM INA

CYCLAMMINA

CYCLAMMINA

CYCLAMMINA

CYCLAMMINA

CY CLAMMINA

CY CLAMMINA

CY CLAMMI NA

CY CLAMM I NA

CY CLAMMINA

CY CLAMMINA

CY CL AMM INA

CY CLAMMINA

CYCLAMMINA

CYCLAMM INA

CY CLAMMINA

CY CL AMMI NA

CY CL AMMI NA

HA PLOPHRAGMOIDE

HAPLOPHRAGMOI DES

HAPLOPHRAGMOIDES

HAPL OPHRAGMOIDES

HA PL OPHRAGMO IDES

HAPLOPHRAGMOIDES

HAPLOPHRAGMOIDES

HAPLOPHRAGMOI DES

HAPLOPHRAGMOIDES

HAPLOPHRAGMOI DES

CYCLOGYRA

CYCLOGYRA

CYCLOGYRA

CYMBALOPORA

CYMBAL OPORETT

CYMBALOPORETTA

CYMBALOPORET TA

CYMBAL OPORETTA

CYMBALOPORETTA

CYMBAL OPORET TA

CYMB AL OPORE TT A

CYMBALOPORETTA

CYSTAMMINA

CYSTAMMINA

CYSTAMMINA

CY STAMMINA

CYSTAMMINA

CY STAMMINA

CYST AMM INA

CY STAMM INA

CYSTAMMINA

CYSTAMM INA

CYSTAMMI NA

CY STAMMINA

CYSTAMMINA

CYSTAMM INA

CY STAMMINA

CYSTAMMINA

CY STAMMINA

CY ST AMMINA

CYSTAMMINA

DENTALINA

DENTAL INA

DENTAL INA

DENT AL INA

DENT AL INA

DENTAL INA

DENTALINA

DENT AL I NA

DE NT AL INA

DENTALINA

DENTALINA
CANCELLATA

CANCELLATA

CANCELLATA

CANCELLATA

CANCELLATA

CAACELLATA

CANCELLATA

CANCELLATA

CANCELLATA

CANCELLATA

CANCELLATA

CANCELLATA

CANCELLATA

CANCELLATA

CANCELLATA

CANCELLATA

CANCELLATA

CANCELLATA

CANCELLATA

CANCELLATA

CANCELLATA

CANCELLATA

CANCELLAT A

CANCELLATA

CANCELLATA

CANCELLATA

CANCELLATA

CANCELLATA

CANCELLATA

CANCELLATA

CANCELLATA

CANCELLATA

CAACELLATA

CAACELLATA

PAUCILOCULATA

PAUCILOCULATA

PAUCILOCULATA

PAUCILOCULATA

PALCILOCULATA

PUSILLA

TRULLISSATA

TRULLISSATA

TRULL ISSATA

TRLLLISSATA

TRULLISSATA

TRULLISSATA

TRLLLISSATA

TRULLISSATA

TRLLLISSATA

TRLLLISSATA

IN VOLVENS

PLANORB IS

PL ANORBIS

POEYI

SQLAMMOSA

SQUAMMOSA

BRADYI

SQUAMMOSA

SQUAMMOSA

SQLAMMOSA

SQLAMMOSA

PAUCILOCULATA

PAUCILOCULATA

PAUCILOCULATA

PAUCILOCULATA

PAUCILOCULATA

PAUCILOCULATA

PAUCILOCULATA

PAUCILOCULATA

PAUCILOCULATA

PAUCILOCULATA

PAUCILOCULATA

PAUCI LOCULATA

PAUCILOCULATA

PAUCILOCULATA

PAUCILOCULATA

PAUCILOCULATA

PAUCILOCULATA

PAUCILOCULATA

PAUCILOCULATA

CONMUNIS

CONMUNIS

COMMUNIS

COMMUN IS

CONMUNIS

COMMUNIS

COMMUNIS

COMMUNIS

COMMUNIS

CENTRAL GULF OF MEXICO

CENTRAL GULF OF MEXICO CENTRAL GULF OF MEXICO CENTRAL GULF OF MEXICO CENTRAL GULF OF MEXICO

BAY OF CAMPECHE

BAY OF CAMPECHE

BAY OF CAMPECHE

NW GULF OF MEXICO 


\section{Publication}

15501 PFLUM FRERICHS 1976 15502 PFLUM FRERICHS 1976 15503 PFLUM FRERICHS 1976 15504 PFLIJM FRERICHS 1976 15505 PFLUM FRERICHS 1976 15506 PFLUM FRERICHS 1976 15507 PFLUM FRERICHS 1976 15508 PFLUM FRERICHS 1976 15509 KELLOUGH 1956

15510 KELLOUGH 1956

15511 PFLUM FRERICHS 1976 15512 PFLUM FRERICHS 1976 15513 BANDY 1956

15514 PFLUM FRERICHS 1976 15515 PFLUM FRERICHS 1976 15516 PFLUM FRERICHS 1976 15517 PFLUM FRERICHS 1976 15518 KELLOUGH 1956 15519 PFLUM FRERICHS 1976 15520 PFLUM FRERICHS 1976 15521 PFLUM FRERICHS 1976 15522 PFLUM FRERICHS 1976 15523 PFLUM FRERICHS 1976 15524 PFLUM FRERICHS 1976 15525 PFLUM FRERICHS 1976 15526 PFLUM FRERICHS 1976 15527 PFLUM FRERICHS 1976 15528 PFLUM FRERICHS 1976 15529 PFLUM FRERICHS 1976 15530 PFLUM FRERICHS 1976 15531 PFLUM FRERICHS 1976 15532 BANDY 1956

15533 BOCK 1976

15534 PFLUM FRERICHS 1976 15535 PFLUM FRERICHS 1976 15536 PFLUM FRERICHS 1976 15537 PFLUM FRERICHS 1976 15538 PFLUM FRERICHS 1976 15539 PFLUM FRERICHS 1976 15540 PFLUM FRERICHS 1976 15541 PFLUM FRERICHS 1976 15542 PFLUM FRERICHS 1976 15543 PFLUM FRERICHS 1976 15544 PFLUM FRERICHS 1976 15545 PFLUM FRERICHS 1976 15546 PFLUM FRERICHS 1976 15547 PFLUM FRERICHS 1976 15548 PFLUM FRERICHS 1976 15549 PFLUM FRERICHS 1976 15550 PFLUM FRERICHS 1976 15551 PFLUM FRERICHS 1976 15552 PFLUM FRERICHS 1976 15553 PFLUM FRERICHS 1976 15555 LEROY HODGKINSON 1975 15556 ANDERSEN 1961

15557 BOCK 1976

15558 PFLUM FRERICHS 1976 15559 PFLUM FRERICHS 1976 15560 PFLUM FRERICHS 1976 15561 PFLUM FRERICHS 1976 15562 PFLUM FRERICHS 1976 15563 PFLUM FRERICHS 1976 15564 PFLUM FRERICHS 1976 15565 PFLUM FRERICHS 1976 15566 PFLUM FRERICHS 1976 15567 PFLUM FRERICHS 1976 15563 PFLUM FRERICHS 1976 15569 PFLUM FRERICHS 1976 15570 ANDERSEN 1961

15571 PFLUM FRERICHS 1976 15572 PFLUM FRERICHS 1976 15573 PFLUM FRERICHS 1976 15574 PFLUM FRERICHS 1976 15575 PFLUM FRERICHS 1976 15576 PFLUM FRERICHS 1976 15577 PFLUM FRERICHS 1976 15578 PFLUM FRERICHS 1976 15579 PFLUM FRERICHS 1976 15580 PFLUM FRERICHS 1976 15581 PFLUM FRERICHS 1076 15582 PFLUM FRERICHS 1976 15583 ANDERSEN 1961

15584 LEROY HODGKINSON 1975 15585 ANDERSEN 1961

15586 VAUGHAN 1918

15587 VAUGHAN 1918

15588 CUSHMAN 1922A

15589 CUSHMAN 1931

15590 NORTON 1930

15591 CUSHMAN $1922 \mathrm{~A}$

15592 CUSHMAN 1931

15593 PHLEGER $1951 \mathrm{~A}$

15595 PHLEGER 1951A
Generic Name

Specific Name

Locality

DENTALINA

DENTALINA

DENTALINA

DENTALINA

DENTALINA

DENTALINA

DENTALINA

DENTALINA

DENTALINA

DENTALINA

DENTALINA

DE VTALINA

DENTALINA

DENTALINA

DENTALINA

DENTALINA

DENTALINA

DENTALINA

DENTALINA

DENTALINA

DENTALINA

DENTALINA

DENTALINA

DENTALINA

DE NT AL I NA

DENTALINA

DENTALINA

DENTALINA

DENTALINA

DENTALI NA

DENTALINA

DENTAL INA

DENTALINA

DENTALINA

DENTALINA

DENTALINA

DENTALINA

DENTALINA

DENTALINA

DENTAL INA

DENTALINA

DENTALINA

DENTAL INA

DENTALINA

DENTALINA

DENTALINA

DENTALINA

DENTALINA

DENTALINA

DENTALI NA

DENTAL INA

DENTA LINA

DENTALINA

NODOSAR IA

DENTALINA

DENTALINA

DENTALINA

DENTALINA

DENTALINA

DENTALINA

DENT ALINA

DENTALINA

DENTAL INA

DENTALINA

DENTAL INA

DENTAL INA

DENTALINA

DENTALINA

DENTALINA

DENTALINA

DENTAL INA

DENTALINA

DENTALINA

DENTALINA

DENTALINA

DENTALINA

DENTALINA

DENTALINA

DENTALINA

DENTALINA

DENTALINA

DENTALINA

DENTALINA

DI SCORBINELLA

D I SCORB I NELL

VALVUL INER IA

ROSALINA

ROSALINA

VALVULINER I A

DISCORBIS

DI SCORBIS

DI SCORB INELL A

DI SCORB INELLA

D I SCORB INE LLA
CONMUNIS

COMMUNIS

COMMUN IS

COMMUNIS

CONMUNIS

COMMUNIS

CONMUNIS

COMMUNIS

CONMUNIS

COMMUNIS

CONMUNIS

CONMUNI

CONMUNIS

COMMUNIS

CONMUNIS

CORMUNIS

COMMUNIS

COMMUNIS

COMMUNIS

CONMUNIS

CONMUNIS

COMMUNIS

CONMUN IS

COMMUNIS

COMMUNIS

CONMUNIS

CONMUNIS

COMMUNIS

COMMUNIS

COMMUNIS

CONMUNIS

COMMUNIS

CUVIERI

CUVIERI

CUVIERI

CUVIERI

CUVIERI

CUVIERI

CUVIERI

CUVIERI

CUVIERI

CUVIERI

CUVIERI

CUVIERI

CUVIERI

CUVIERI

CUVIER I

CUVIERI

CUVIERI

CUVIERI

CUVIERI

CUVIERI

FARCIMEN

F I LI FORMIS

F ILIFORMIS

IN CRNATA BRADYENS IS

INORNATA BRADYENS IS

INORNATA BRADYENS IS

INCRNATA BRADYENSIS

INCRNATA BRADYENS IS

INORNATA BRADYENSIS

IN TORTA

I N TOR TA

INTORTA

IN TORTA

IN TOR TA

IN TOR TA

IN TOR TA

IN TORTA

I N TOR TA

IN TOR TA

IN TORTA

INTORTA

IN TOR TA

IN TORTA

IN TORTA

IN TOR TA

INTORTA

IN TORTA

INTORTA

SUEEMACIATA

SUBSOLUTA

BERTHELOTI

BERTHELOT I

II LARDEBOANA

ADVENA

ADVENA

BRADYI

A UBER I I

AURERII

BERTHELOT I

DTHELOTI

CENTRAL GULF OF AEXICO CENTRAL GULF OF MEXICO CENTRAL GULF OF MEXICO

$N W$ GULF OF MEXICO 


\section{Publication}

15596 NORTON 1930 15597 PHLEGER 1951 A 15598 PHLEGER 1951A 15599 PHLEGER 1951A 15600 PHLEGER 1951 A 15601 PHLEGER 1951A 15602 PHLEGER 1951A 15603 PHLEGER 1951A 15604 PHLEGER 1951A 15605 PHLEGER 1951A 15606 PHLEGER 1951A 15607 PHLEGER 1951A 15608 PHLEGER 1951A 15609 KELLOUGH 1956
15610 KELLOUGH 1956

15611 AYALA-CASTANARES 1963 15612 AYALA-CASTANARES SEGURA 1968 15613 KELLOUGH 1956

15614 PARKER 1954

15615 PARKER 1954

15616 PARKER 1954

15617 PARKER 1954

15618 PARKER 1954

15619 PARKER 1954

15620 PARKER 1954

15621 PARKER 1954

15622 PHLEGER 1956

15623 PARKER 1954

15624 PHLEGER 1956

15625 PHLEGER 1956

15626 PHLEGER 1956

15627 PARKER 1954

15628 PARKER 1954
15629 KELLOUGH 1956

15629 KELLOUGH 1956

15631 PARKER 1954

15632 PARKER 1954

15633 PHLEGER $1951 \mathrm{~A}$

15634 CREAGER 1958

15635 PHLEGER 1951A

15636 PHLEGER 1951A

15637 PHLEGER 1951A

15638 PHLEGER 1951A

15639 PHLEGER 1951A

15640 PHLEGER 1951A

15641 PHLEGER 1951A

15642 PHLEGER 1951A

15643 PHLEGER $1951 \mathrm{~A}$

15644 PHLEGER 1951A

IS645 PHLEGER $1951 \mathrm{~A}$

15646 PHLEGER 1951A

15647 NORTON 1930

15648 CUSHMAN 1731

15649 CREAGER 1958

15650 CREAGER 1958

15651 CUSHMAN 1931

15652 PHLEGER 1951A

15653 PHLEGER 1951 A

15654 PHLEGER 1951A

15655 PHLEGER 1951A

15656 PHLEGER 1951A

15657 PHLEGER 1951A

15658 PHLEGER 1951A

15659 PHLEGER 1951A

15660 PHLEGER 1951A

15661 PHLEGER 1951A

15662 PHLEGER 1951A

15663 PHLEGER 1951A

15664 PHLEGER 1954

15665 PHLEGER 1954

15666 WALTON 1960

15667 BANDY 1956

15668 BANDY 1956

15669 BANDY 1956

15670 BANDY 1956

15671 BANDY 1956

15672 BANDY 1956

15673 BANDY 1956

15674 BANDY 1956

15575 BANDY 1956

15676 BANDY 1956

15677 ANDERSON 1968

15678 BENDA PURI 1962

15679 BANDY 1956

15680 BANDY 1956

15681 BANDY 1956

15682 BANDY 1956

15683 BANDY 1956

15684 BANDY 1956

15685 BANDY 1956

15686 BANDY 1956

15687 BANDY 1956

15688 BANDY 1956

15689 BANDY 1956

15690 BANDY 1956
Generic Name

DI SCORBI NELLA

DI SCORB I NELL A

DI SCORBINELLA

DI SCORBINELLA

DI SCORB I NELL A

DI SCORBINELLA

DI SCORBINELLA

DI SCORB I NELLA

DI SCORBI NELL LA

DI SCORBINELLA

DI S CORB INELL A

DI SCORBINELLA

DI SCORBINELLA

ROSALINA

ROSALINA

ROSALINA

ROSALINA

ROSALINA

ROSALINA

ROSALINA

ROSALINA

ROSALINA

ROSAL INA

ROSALINA

ROSALINA

ROSALINA

ROSALINA

ROSALINA

ROSALINA

ROSALINA

ROSAL INA

ROSALINA

ROSAL INA

ROSALINA

ROSALINA

ROSAL INA

ROSALINA

ROSALINA

ROSALINA

ROSALINA

ROSALINA

ROSALINA

ROSALINA

ROSALINA

ROSALINA

ROSAL INA

ROSAL INA

ROSAL INA

ROSAL INA

ROSALINA

ROSALINA

ROSAL INA

ROSALINA

ROSALINA

ROSAL INA

ROSALINA

ROSALINA

ROSALINA

ROSALINA

ROSALINA

ROSAL INA

ROSALINA

ROSALINA

ROSALINA

ROSALINA

ROSALINA

ROSALINA

ROSAL INA

ROSAL INA

ROSAL INA

ROSALINA

ROSALINA

ROSALINA

ROSAL INA

ROSALINA

ROSALINA

ROSALINA

ROSALINA

ROSALINA

ROSALINA

ROSALINA

ROSALINA

ROSALINA

ROSALINA

ROSALINA

ROSAL INA

ROSALINA

ROSALINA

ROSALINA

ROSALINA

ROSALINA

ROSALINA

ROSAL INA
Specific Name

BERTHELOT I

BERTHELOTI

BERTHELOT I

BERTHEL OT I

ERTHELOT

BERTHELOTI

BERTHELOTI

BERTHELOTI

BERTHELOT I

BERTHELOTI

BERTHELOTI

BERTHELOT

BULBOSA

BULBOSA

BULBOSA

BULBOSA

BULBOSA

BULBOSA

BULBOSA

BULBOSA

BULBOSA

BULBOSA

BULBOSA

BULBOSA

BULBOSA

BULBOSA

BULBOSA

BULBOSA

BULBOSA

BULBOSA

BULBOSA

BULBOSA

BULBOSA

BULBOSA

BULBOSA

BULBOSA

SUEZENS IS

C ANDE IANA

SUEZENS IS

SUEZENSIS

SUEZENSIS

SUEZENS IS

SUEZENSIS

SUEZENSIS

SUEZENSIS

SUEZENSIS

SUEZENSIS

SUEZENSIS

SUEZENS IS

C ANDE I ANA

CANDE IANA

CA DDEIANA

CANDE IANA

CANDE I ANA

SUEZENSIS

SUEZENSIS

SUEZENSIS

SUEZENSIS

SUEZENSIS

SUEZENSIS

SUEZENSIS

SUEZENSIS

SUEZENSIS

SUEZENSIS

SUEZENSIS

SUEZENSIS

L OR I DANA

FLORI DANA

CONCINNA

CONCINNA

CONCINNA

CONCINNA

CONCINNA

CONCINNA

CONCINNA

CONCINNA

CONCINNA

CONCINNA

CONCINNA

COACINNA

CONCINNA

CONCINNA

CONCINNA

CONCINNA

CONCINNA

CONCINNA

CONCINNA

CONCINNA

CONCINNA

CONCINNA

CONCINNA

CONCINNA

\section{Locality}

Lat. Long.

TORTUGAS, FLA

NW GULF OF MEXICO

NW GULF OF MEXICO

NW GULF OF MEXICO 
Publication

15691 BANDY 1956

15692 PARKER PHLEGER PEIRSON 1953

15693 PARKER PHLEGER PEIRSON 1953

15694 PARKER PHLEGER PEIRSON 1953

15695 PARKER PHLEGER PEIRSON 1953

15696 PHLEGER 1951 A

15697 PARKER PHLEGER PEIRSON 1953

15698 PHLEGER 1954

15699 PARKER PHLEGER PEIRSON 1953

15700 WARREN 1956

15701 CUSHMAN 1931

15702 WALTON 1960

15703 PARKER PHLEGER PEIRSON 1953

15704 PHLEGER 1951A

15705 WARREN 1957

15706 PHLEGER 1954

15707 SHIFFLETT 1961

15708 CUSHMAN $1922 \mathrm{~A}$

15709 PHLEGER $1951 \mathrm{~A}$

15710 PHLEGER 1951 A

15711 PHLEGER 1951A

15712 PHLEGER $1951 \mathrm{~A}$

15713 PHLEGER 1951A

15714 PHLEGER 1951A

15715 BANDY 1954

15716 BANDY 1956

15717 BANDY 1956

15718 BANDY 1954

15719 BANDY 1954

15720 BANDY 1956

15721 KELLOUGH 1956

15722 BANDY 1956

15723 BANDY 1956

15724 BANDY 1956

15725 BANDY 1956

15726 BANDY 1956

15727 BANDY 1954

15728 BANDY 1956

15729 BANDY 1956

15730 BANDY 1956

15731 BANDY 1956

15732 BANDY 1956

15733 BANDY 1954

15734 BANDY 1956

15735 BANDY 1956

15736 BANDY 1954

15737 BANDY 1956

15738 BANDY 1956

15739 BANDY 1956

15740 BANDY 1956

15741 BANDY 1956

15742 BANDY 1956

15743 BANDY 1956

15744 BANDY 1956

15745 BANDY 1956

15746 BANDY 1956

15747 SHIFFLETT 1961

15748 LIDZ LIDZ 1966

15749 BANDY 1956

15750 BENDA PURI 1962

15751 BANDY 1956

15752 BANDY 1956

15753 BANDY 1956

15754 CUSHMAN 1922 A

15755 CUSHMAN 1931

15756 CUSHMAN 1931

15757 NORTON 1930

15758 CREAGER 1958

15759 SHIFFLETT 1961

15760 CUSHMAN 1922 A

15761 CUSHMAN 1931

15762 NORTON 1930

15763 SHIFFLETT 1961

15764 NORTON 1930

15765 LYNTS PFISTER 1967

15766 NORTON 1930

15767 CUSHMAN 1931

15768 CUSHMAN 1922 A

15769 NORTON 1930

15770 CREAGER 1958

15771 PHLEGER 1965 A

15772 LEHMANN 1957

15773 PHLEGER $1965 \mathrm{C}$

15774 SHEPARD MOORE 1955

15775 PHLEGER 1965 A

15776 PARKER PHLEGER PEIRSON 1953

15777 PHLEGER 1965 A

15778 PARKER PHLEGER PEIRSON 1953

15779 PHLEGER $1965 \mathrm{~A}$

15780 PHLEGER $1965 \mathrm{~A}$

15781 PHLEGER 1965 A

15782 BENDA PURI 1962

15783 ANDERSEN 1961

15784 PFLUM FRERICHS 1976

15785 PFLUM FRERICHS 1976
Generic Name

ROSALINA

ROSALINA

ROSALINA

ROSALINA

ROSALINA

ROSALINA

ROSALINA

ROSALINA

ROSALINA

ROSALINA

ROSALINA

ROSALINA

ROSALINA

ROSALINA

ROSALINA

ROSALINA

ROSALINA

POSALINA

ROSALINA

ROSALINA

ROSALINA

ROSALINA

ROSALINA

ROSALINA

ROSALINA

ROSALINA

ROSALINA

ROSAL INA

ROSALINA

ROSALINA

ROSALINA

ROSALINA

ROSALINA

ROSALINA

ROSALINA

ROSALINA

ROSALINA

ROSALINA

ROSALINA

ROSALINA

ROSAL INA

ROSALINA

RO SALINA

ROSALINA

ROSALINA

ROSALINA

ROSALINA

ROSALINA

ROSALINA

ROSALINA

ROSALINA

ROSALINA

ROSALINA

ROSALINA

ROSALINA

ROSALINA

ROSALINA

ROSALINA

ROSALINA

DISCORBIS

DISCORBIS

DI SCORBIS

DI SCORB IS

ROSALINA

ROSALINA

NE OCONORBINA

NE OCONORBINA

NEOCONORBINA

NE OCONORBINA

GLABRATELLA

DI SCORB IS

DI SCORBIS

ROSALINA

ROSALINA

ROSALINA

ROSALINA

DISCORINOPSIS

DI SCORINOPSIS

DISCORINOPS IS

DISCORINOPSIS

DI SCOR INOPSIS

DISCORINOPS IS

DI SCOR I NOPS IS

DISCORINOPSIS

DISCORINOPSIS

DISCOR INOPSIS

DISCORINOPSIS

DISCORINOPS IS

DOROTHIA

DOROTHIA

DOROTHIA
Specific Name

CONCINNA

FLCRI DANA

FL OR I DANA

FL ORI DANA

FL ORI DANA

FLOR I DANA

FLORI DANA

FLORI DANA

FLOR I DANA

FLCRI DANA

FLCRI DANA

FL ORI DANA

FLORIDANA

FL CRI DANA

FLORIDANA

FLORI DANA

FL OR I DANA

FLCRIDANA

FL CRI DANA

FLCRI DANA

FL ORI DANA

FL OR I DANA

FL ORI DANA

FL CR I DANA

FL ORI DANA

FL OR I DANA

FL ORI DANA

FL ORI DANA

FLORI DANA

FLCRI DANA

FL ORI DANA

FL CR I DANA

FL OR I DANA

FL ORI DANA

FLORI DANA

FLORI DANA

FL ORI DANA

FL ORI DANA

FLCRIDANA

FLORI DANA

FL OR I DANA

FL ORI DANA

FL ORI DANA

FL ORI DANA

FLCRIDANA

FL CR I DANA

FLCRIDANA

FLORIDENSIS

FLCRI DENS IS

FLORIDENS IS

FL ORIDENS IS

FL ORIDENSIS

FL ORIDENS IS

FL CRIDENS IS

MIRA

MIRA

MI RA

MIRA

WI LLI AMSONI

WI LLI AMSONI

TERQUEM I

TERQUEMI

T E RQUEM I

TERQUEMI

PATELLIFORMIS

ROSEA

SU BARAUCANA

SUEARAUCANA

SUEARAUCANA

SUEZENSIS

AGUAYOI

AGUAYOI

A GUAYOI

AGUAYOI

AGUAYOI

AGUAYOI

AGUAYOI

AGUAYOI

AGUAYOI

AG UAYOI

AGUAYOI

A GUAYOI

CARIBAEA

PSEUDOTURRIS

PSEUDOTURRIS

Locality

Lat. Long.

NE GULF OF MEXICO

TEXAS GULF COAST

TEXAS GULF COAST

TEXAS GULF COAST

TEXAS GULF COAST

$N W$ GULF OF MEXICO

TEXAS GULF COAST

MISSISSIPPI SOUND

TEXAS GULF COAST

BURAS SE LOUISIANA

TORTUGAS, FLA 


\section{Publication}

15786 PFLUM FRERICHS 1976 15787 P.FLUM FRERICHS 1976 15788 PFLUM FRERICHS 1976 15789 PFLUM FRERIEHS 1976 15790 PFLIJM FRERICHS 1976 15791 PFLUM FRERICHS 1976 15792 PFLUM FRERICHS 1976 15793 PFL JMM FRERICHS 1976 15794 PFLUM FRERICHS 1976 15795 PFLUM FRERICHS 1976 15796 PFLUM FRERICHS 1976 15797 PFLUM FRERICHS 1976 15798 LEROY HODGKINSON 1975 15799 LEROY HODGKINSON 1975 15800 CREAGER 1958

15801 PARKER 1954

15802 PARKER 1954

15803 PARKER 1354

15804 PARKER 1954

15805 PARKER 1954

15806 PFLUM FRERICHS 1976

15807 PFLUM FRERICHS 1976

15808 PHLEGER $1951 \mathrm{~A}$

15809 PHLEGER $1951 \mathrm{~A}$

15811 PFLUM FRERICHS 1976

15811 PFLUM FRERICHS 1976
15812 LEROY HODGKINSON 1975

15813 PHLEGER 1951A

15814 PHLEGEQ 1951A

15815 PHLEGER $1955 \mathrm{~A}$

15816 PHLEGER 1951 A

15817 CREAGER 1958

15818 CREAGER 1958

15819 CREAGER 1958

15820 PHLEGER $1951 \mathrm{~A}$

15821 PHLEGER $1951 \mathrm{~A}$
15822 PHLEGEP $1951 \mathrm{~A}$

15823 LOEP 1965

15824 LOEP 1965

15825 CREAGER 1958

15826 PARKER 1954

15827 PARKER 1954

15828 PARKER 1954

15829 PARKER 1954

15831 PFLUM FRERICHS 1976

15832 PFLUM FRERICHS 1976

15833 PFLUM FRERICHS 1976

15834 PFLUM FRERICHS 1976

15835 PFLUM FRERICHS 1976

15836 PFLUM FRERICHS 1976

15837 PFLUM FRERICHS 1976

15838 PFLUM FRERICHS 1976

15839 PFLUM FRERICHS 1976

15840 PFLUM FRERICHS 1976

15841 PFLUM FRERICHS 1976

15842 PFLUM FRERICHS 1976

15843 PFLUM FRERICHS 1976

15844 PFLUM FRERICHS 1976

15845 PFLUM FRERICHS 1976

15846 PFLUM FRERICHS 1976

15847 PFLUM FRERICHS 1976

15848 PFLUM FRERICHS 1976

15849 PFLUM FRERICHS 1976

15850 PFLUM FRERICHS 1976

15851 PFLUM FRERICHS 1976

15852 PFLUM FRERICHS 1976

15853 PFLUM FRERICHS 1976

$\begin{array}{lll}15854 & \text { PFLUM FRERICHS } & 1976 \\ 15855 & \text { PFLUM FRERICHS } & 1776\end{array}$

15856 PFLUM FRERICHS 1976

15857 PFLUM FRERICHS 1976

15858 PFLUM FRERICHS 1976

15859 PFLUM FRERICHS 1976

15860 PFLUM FRERICHS 1976

15861 PFLUM FRERICHS 1976

15862 PHLEGER 1955A

15863 PHLEGER $1951 \mathrm{~A}$

15864 PHLEGER $1951 \mathrm{~A}$

15865 PHLEGER 1951A

15866 PHLEGER 1951A

15867 PHLEGER 1955 A

15868 PARKER 1954

15869 PARKER 1954

15870 PARKER 1954

15871 PARKER 1954

15872 PARKER 1954

15873 PARKER 1754

15874 PARKER 1954

15875 PARKER 1954

15876 PARKER 1954

15877 PARKER 1954

15878 PARKER 1954

15879 PARKER 1354

15880 PHLEGER 1951A

\section{Generic Name}

DOROTHIA

DOROTHIA

DOROTHIA

DOROTHIA

DOROTHIA

DOROTHIA

DOROTHIA

DOROTHIA

DOROTHIA

DOROTHIA

DOROTHIA

DOROTHIA

EG GERELLA

EGGERELLA

EGGERELLA

EGGERELLA

EG GERELLA

EGGERELLA

EGGERELLA

EGGERELLA

EGGERELLA

EGGERELLA

EGGERELLA

EGGERELLA

EGGERELLA

EGGERELLA

EGGERELLA

EGGERELLA

EGGERELLA

EGGERELLA

EGGERELLA

EGGERELLA

EGGERELLA

EGGERELLA

EGGERELLA

EG GERELLA

EGGERELLA

EGGERELLA

EGGERELLA

EGGERELLA

EGGERELLA

EGGERELLA

EGGERELLA

EGJERELLA

EGGERELLA

EGGERELLA

EGGERELLA

EG GERELLA

EGGERELLA

EGGERELLA

EGGERELLA

EGGERELLA

EGGERELLA

EGGERELLA

EGGERELLA

EGGERELLA

EGGERELLA

EGGERELLA

EGGERELLA

EGGERELLA

EGGERELLA

EGGERELLA

EGGERELLA

EGGERELLA

EGGERELLA

EGGERELLA

EGGERELLA

EGGERELLA

EGGERELLA

EGGERELLA

EGGERELLA

EGGERELLA

EG GERELLA

EGGERELLA

EGGERELLA

EG GERELLA

EGGERELLA

EGGERELLA

EG GERELLA

EGGERELLA

EGGERELLA

EGGERELLA

EGGERELLA

EGGERELLA

EGGERELLA
Specific Name

PSEUDOTURRIS

PSEUDOTURRIS

PSEUDOTURRIS

PSEUDOTURRIS

PSEUDOTURRIS

PSEUDOTURRIS

PSEUDOTURRIS

PSEUDOTURRIS

PSEUDOTURRIS

PSEUDOTUFRIS

PSEUDOTURRIS

SCABRA

AFFIXA

BRADYI

BRADYI

BRADYI

BRADYI

BRADY

BRADYI

BRADY

BRADY

BR ADYI

BRADY

BRADY

BRADY

BR ADYI
BRADY

BRADYI

BRADYI

BR ADY

BRADY

BRADY

BRADY I

BRADYI

BRADYI

BRADY

BRADYI

BR ADYI

BRADYI

BRADYI

BRADYI

BRADYI

BRADYI

BRADYI

BRADYI

BRADYI

BRADYI

BRADYI

BRADY I

BRADYI

BRADY

BRADYI

BRADY

BRADYI

BRADY

BRADYI

BRADYI

BRADYI

BRADYI

BRADYI

BRADYI

BRADY

BRADYI

BR ADYI

BRADYI

BRADYI

BRADYI

BRADYI

BRADYI

BRADYI

BRADYI

BRADYI

BRADYI

BRADYI

BRADY

BRADYI

BRADYI

BRADY I

BRADYI

BRADYI

BRADYI

BRADYI

BRADYI

BRADY I

BR ADYI

BRADYI

BR ADYI

BRADYI

BRADYI

\section{Locality}

NW GULF OF MEXICO

NW GULF OF MEXICO

$N W$ GULF OF MEXICO

$N W$ GULF OF MEXICO

NW GULF OF MEXICO

NW GULF OF MEXICO

NW GULF OF MEXICO

NW GULF OF MEXICO

NW GULF OF MEXICO

CENTRAL GULF OF MEXICO

NW GULF OF MEXICO

NW GULF OF MEXICO

$N$ GULF OF MEXICO

$N$ GULF OF MEXICO

BAY OF CAMPECHE

NE GULF OF MEXICO

NE GULF OF MEXICO

NE GULF OF MEXICO

NE GULF OF MEXICO 
Publication

15881 PHLEGER 1951A 15882 PHLEGER 1951A 15883 PHLEGER 1951A 15884 PHLEGER 1951A 15885 PHLEGER 1951A 15886 PFLUM FRERICHS 1976 15887 PFLUM FRERICHS 1976 15888 PFLUM FRERICHS 1976 15889 PFLUM FRERICHS 1976 15890 PHLEGER 1951A

15891 PHLEGER 1951A

15892 PFLUM FRERICHS 1976 15893 PHLEGER 1951A

15894 CREAGER 1958

15895 CREAGER 1958

15896 CREAGER 1958

15897 PFLUM FRERICHS 1976

15898 PHLEGER 1951A

15899 PFLUM FRERICHS 1976 15900 PFLUM FRERICHS 1976 15901 PFLUM FRERICHS 1976 15902 PFLUM FRERICHS 1976 15903 PFLUM FRERICHS 1976 15903
15904 PFLUM FRERICHS
1976 15905 PFLUM FRERICHS 1976 15906 PFLUM FRERICHS 1976 15907 PFLUM FRERICHS 1976 15908 CREAGER 1958

15909 PFLUM FRERICHS 1976 15910 PFLUM FRERICHS 1976 15911 PFLUM FRERICHS 1976 15912 PFLUM FRERICHS 1976 15913 PFLUM FRERICHS 1976 15914 PFLUM FRERICHS 1976 15915 PFLUM FRERICHS 1976 15916 PFLUM FRERICHS 1976 15917 PFLUM FRERICHS 1976 15918 PFLUM FRERICHS 1976 15919 PFLUM FRERICHS 1976 15920 PFLUM FRERICHS 1976 15921 PFLUM FRERICHS 1976 15922 PHLEGER 1951A

15923 PFLUM FRERICHS 1976 15924 PFLUM FRERICHS 1976 15925 CREAGER 1958 15926 PFLUM FRERICHS 1976 15927 PFLUM FRERICHS 1976 15928 PFLUM FRERICHS 1976 15929 PFLUM FRERICHS 1976 15930 PFLUM FRERICHS 1976 15931 PFLUM FRERICHS 1976 15932 PFLUM FRERICHS 1976 15933 CREAGER 1958

15934 CREAGER 1958

15935 LEROY HODGKINSON 1975 15936 PFLUM FRERICHS 1976 15937 PFLUM FRERICHS 1976 15938 PFLUM FRERICHS 1976 15939 PFLUM FRERICHS 1976 15940 PFLUM FRERICHS 1976 15941 PFLUM FRERICHS 1976 15942 PFLUM FRERICHS 1976 15943 PFLUM FRERICHS 1976 15944 PFLUM FRERICHS 1976 15945 PFLUM FRERICHS 1976 15946 PFLUM FRERICHS 1976 15947 PFLUM FRERICHS 1976 15948 PFLUM FRERICHS 1976 15949 PFLUM FRERICHS 1976 15950 PFLUM FRERICHS 1976 15951 PFLUM FRERICHS 1976 15952 PFLUM FRERICHS 1976 15953 PFLUM FRERICHS 1976 15954 PFLUM FRERICHS 1976 15955 PFLUM FRERICHS 1976 15956 PFLUM FRERICHS 1976 15957 PFLUM FRERICHS 1976 15958 PFLUM FRERICHS 1976 15959 PFLUM FRERICHS 1976 15960 PFLUM FRERICHS 1976 15961 PFLUM FRERICHS 1976 15962 PFLUM FRERICHS 1976 15963 PFLUM FRERICHS 1976 15964 PFLUM FRERICHS 1976 15965 PFLUM FRERICHS 1976 15966 PFLUM FRERICHS 1976 15967 PFLUM FRERICHS 1976 15968 PFLUM FRERICHS 1976 15969 PFLUM FRERICHS 1976 15970 PFLUM FRERICHS 1976 15971 PFLUM FRERICHS 1976 15972 PFLUM FRERICHS 1976 15973 PFLUM FRERICHS 1976 15974 PFLUM FRERICHS 1976 15975 PFLUM FRERICHS 1976
Generic Name

Specific Name

EG GERELL

EGGERELLA

EGGERELLA

EG GERELLA

EGGERELLA

EG GERELLA

EGGERELLA

EGGERELLA

EGGERELLA

EGGERELLA

EGGERELLA

EGGERELLA

EGGERELLA

EGGERELLA

EGGERELLA

EGGERELLA

EGGERELLA

EGGERELLA

EGGERELLA

EGGERELLA

EGGERELLA

EGGERELLA

EGGERELLA

EGGERELLA

EG GERELLA

EGGERELLA

EG GERELLA

EG GERELLA

EGGERELLA

EG GERELLA

EGGERELLA

EGGERELLA

EG GERELLA

EGGERELL

EGGERELLA

EGGERELLA

EGGERELLA

EGGERELLA

EGGERELLA

EGGERELLA

EGGERELLA

EGGERELLA

EGGERELLA

EGGERELLA

EGGERELLA

EGGERELLA

EGGERELLA

EGGERELLA

EGGERELLA

EG GERELLA

EGGERELLA

EGGERELLA

EGGERELLA

EGGERELLA

EGGERELLA

EGGERELLA

EGGERELLA

EGGERELLA

EGGERELLA

EGGERELLA

EGGERELLA

EGGERELLA

EGGERELLA

EGGERELLA

EGGERELLA

EGGERELLA

EG GERELLA

EGGERELLA

EG GERELLA

EG GERELLA

EGGERELLA

EG GERELLA

DOROTHIA

DOROTHIA

EHRENBERGINA

EHRENBERGINA

EHRENBERGINA

EHRENBERGINA

EHRENBERGINA

EHRENBERGINA

EHRENBER GINA

EHRENBERGINA

EHRENBERGINA

EHRENBER GINA

EHRENBERGINA

EHRENBERGINA

EHRENBERGINA

EHRENBERGINA

EHRENBERGINA

EHRENBERGINA

EHRENBERG I NA

EHRENBERGINA

EHRENBERGINA
BRADYI

BRAOY I

BRADYI

BRADYI

BRADYI

BRADYI

BRADYI

BRADYI

BRADY I

BRADYI

BRADYI

BRADYI

BRADY

BR ADYI

BRADYI

BRADY

BRADY

-
$B R A D Y I$

BRADY

BRADYI

BRADY I

BRADY I

BRADY

BRADYI

BRADYI

BRADYI

BRADY

BRADY

BRADYI

BRADYI

BRADY

BRADYI

BRADY

BRADY

BRADYI

PRCPINQUA

PRCPINQUA

PROPINQUA

PROPINQUA

PROPINQUA

PROPINQUA

PR CPINQUA

PRCPINQUA

PROPINQUA

PROP INQUA

PROPINQUA

PROPINQUA

PRCPINQUA

PR CPINQUA

PROPINQUA

PROPINQUA

PROPINQUA

PRCPINQUA

PROPINQUA

PROPINQUA

PROPINQUA

PROPINQUA

PROPINQUA

PROPINQUA

PROPINQUA

PROPINQUA

PROPINQUA

PROPINQUA

PROPI NQUA

PRCPINQUA

SCABRA

PUPA

PUPA

PUPA

PUFA

PUPA

PUPA

PUPA

PUPA

PUPA

PUPA

$P U P A$

PUFA

PUFA

PUPA

PUPA

PUPA

Locality

NW GULF OF MEXICO

NW GULF OF MEXICO

NW GULF OF MEXICO

NW GULF OF MEXICO

NW GULF OF MEXICO

NW GULF OF MEXICO

NW GULF OF MEXICO

NW GULF OF MEXICO

NW GULF OF MEXICO

NW GULF OF MEXICO

NW GULF OF MEXICO

NW GULF OF MEXICO 
Publication

15976 PFLUM FRERICHS 1976 15977 PFLUM FRERICHS 1976 15978 PFLUM FRERICHS 1976 15979 PFLU M FRERICHS 1976 15980 PFLUM FRERICHS 1976 15981 PFLUM FRERICHS 1976 15982 BANDY 1956

15983 PARKER 1954

15984 PARKER 1954

15985 PARKER 1954

15986
$159 N D$
15987
PARKER 1956

15987 PARKER 1954

15989 CREAGER 1958

15090 PHLEGER 1951 A

15991 PFLUM FRERICHS 1976

15992 PFLUM FRERICHS 1976

15993 PFLUM FRERICHS 1976

15994 PFLUM FRERICHS 1976

15995 PFLUM FRERICHS 1976

15996 PFLUM FRERICHS 1976

15997 PFLUM FRERICHS 1976

15998 PHLEGER $1951 \mathrm{~A}$

15999 PHLEGER $1951 \mathrm{~A}$

16000 PHLEGER 1951A

16001 PHLEGER 1951A

16002 NORTON 1930

16003 WARREN 1957

16004 BANDY 1956

16005 LIDZ LIDZ 1966

16006 BANDY 1956

16007 BANDY 1956

16008 BANDY 1956

16009 BANDY 1956

16010 BANDY 1956

16012 BANDY 1956

16013 WALTON 1960

16014 BANDY 1956

16015 BANDY 1956

16016 BANDY 1956

16018 BANDY 1956

16018 BANDY 1956
16019 BANDY 1956

16020 BANDY 1956

16021 BANDY 1956

16022 BANDY 1956

16024 AYALA-CASTANARES 1963

16025 AYALA-CASTANARES SEGURA 1968 16026 WALTON 1964

16027 BENDA PURI 1962

16028 BENDA PURI 1962

16029 PHLEGER 1956

16030 PARKER 1954

16031 SEGURA 1963

16032 LEHMANN 1957

16033 PARKER 1954

16034 PARKER 1954

16035 PHLEGER 1954

16036 PARKER 1954

16037 PARKER PHLEGER PEIRSON 1953

16038 PARKER PHLEGER PEIRSON 1953

16039 PARKER PHLEGER PEIRSON 1953

16040 PARKER PHLEGER PEIRSON 1953

16041 POST 1951

16042 PARKER PHLEGER PEIRSON 1953

16043 LUDWICK WALTON 1957

16044 PHLEGER 1954

16045 BOCK 1976

16046 PARKER PHLEGER PEIRSON 1953

16047 PHLEGER 1956

16048 PARKER 1954

16049 PARKER 1954

16050 PARKER 1954

16051 PHLEGER 1956

16052 PHLEGER 1956

16053 PARKER PHLEGER PEIRSON 1953

16054 PARKER PHLEGER PEIRSON 1953

16055 PHLEGER 1956

16056 POST 1951

16057 POST 1951

16058 LIDZ LIDZ 1966

16059 SEGURA 1963

16060 LEHMANN 1957

16061 PHLEGER 1954

16062 LANKFORD 1959

16063 PHLEGER LANKFORD 1957

16064 PHLEGER 1954

16065 PHLEGER $1965 \mathrm{C}$

16066 PHLEGER 19558

16067 WALTON 1960

16068 BENDA PURI 1962

16069 BENDA PURI 1962

16070 BENDA PURI 1962
Generic Name

Specific Name

EHRENBERGINA

EHRENBERGINA

EHRENBERGINA

EHRENBERGINA

EHRENBERGINA

EHRENBERGINA

EHRENBERGINA

EHRENBERGINA

EHRENBERGINA

EHRENBERGINA

EHRENBERGINA

EHRENBERGINA

EHRENBERGINA

EHRENBERGINA

EHRENBERGINA

EHRENBER GINA

EHRENBERGINA

EHRENBE RGINA

EHRENBERGINA

EHRENBERGINA

EHRENBERGINA

EHRENBERGINA

EHRENBERGINA

EHRENBERGINA

EHRENBERGINA

ELPHIDIUM

ELPHIDIUM

ELPHIDIUM

ELPHIDIUM

ELPHIDIUM

ELPHIDIUM

ELPHIDIUM

ELPHI DIUM

ELPHIDIUM

ELPHIDIUM

ELPHIDIUM

ELPHIDIUM

ELPHID I UM

ELPHIDIUM

ELPHIDIUM

ELPHIDIUM

ELPHIDIUM

ELPHIDIUM

ELPHIDIUM

ELPHIDIUM

ELPHIDIUM

ELPHIDIUM

ELPHIDIUM

ELPHIDIUM

ELPHIDI UM

ELPHIDIUM

ELPHIDIUM

ELPHIDIUM

ELPHIDIUM

ELPHIDIUM

ELPHIDIUM

ELPHIDIUM

ELPHIDIUM

ELPHIDIUM

ELPH I D I UM

ELPHIDIUM

ELPHIDIUM

ELPHIDIUM

ELPHIDIUM

ELPHIDIUM

ELPHIDIUM
ELPHIDIUM

ELPHIDIUM

ELPHIDIUM

ELPHIDI UM

ELPHIDIUM

ELPHIDIUM

ELPHIDIUM

ELPHIDIUM

ELPHIDIUM

ELPHIDIUM

ELPHIDIUM

ELPHIDIUM

ELPHIDI UM

ELPHIDIUM

ELPHIDIUM

ELPHIDIUM

ELPHIDIUM

ELPHIDIUM

ELPHIDIUM

ELPHIDIUM

ELPHIDIUM

ELPHIDIUM

ELPHIDIUM

ELPHIDIUM

ELPHIDIUM
PUPA

PUPA

PUFA

SP INEA

SPINEA

SP INEA

SPINEA

SP INEA

SP INEA

SP INEA

SP INEA

TR IGONA

TR I GONA

TR IGONA

TR I GONA

TR IGONA

TR I GONA

TR I GONA

TR IGONA

TR IGONA

TR IGONA

TR IGONA

TR IGONA

TR IGONA

TR I GONA

ADVENUM

A D VENUM

ADVENUM

A D VENUM

ADVENUM

A DVENUM

ADVENUM

A D VENUM

A D VENUM

A D VENUM

A D VENUM

A D VENUM

A D VENUM

A D VENUM

A D VENUM

AD VENUM

ADVENUM

AD VENUM

ADVENUM

A D VENUM

AD VENUM

ADVENUM

A DVENUM

ADVENUM

AD VENUM

A D VENUM

A D VENUM

AD VENUM

AD VENUM

ADVENUM

ME XI C ANUM

ADVENUM

A D VENUM

A D VENUM

ADVENUM

AD VENUM

AD VENUM

AD VENUM

ADVENUM

AD VENUM

A D VENUM

A D VENUM

ADVENUM

A D VENUM

A D VENUM

ADVENUM

A D VENUM

ADVENUM

A D VENUM

ADVENUM

ADVENUM

AD VENUM

A D VENUM

AD VENUM

ARTI CULATUM

AR II CUL AT UM

AR TICULAT UM

DELICATUL UM

DELICATULUM

DELICATULUM

DELICATUL UM

DELICATUL UM

DELICATULUM

DE LICATUL UM

DELICATUL UM

DELICATULUM

DELICATULUM

DELICATUL UM

DELICATULUM

Locality

Lat. Long.

NW GULF OF MEXICO

$N W$ GULF OF MEXICO

$N$ GULF OF MEXICO

NW GULF OF MEXICO

NW GULF OF MEXICO

NW GULF OF MEXICO

NE GULF OF MEXICO

NE GULF OF MEXICO

NE GULF OF MEXICO 


\section{Publication}

16071 AYALA-CAS

16072 HALT

ELPHIDIUM

16073 AYALA-CASTANARES 1963

16074 PARKER PHLEGER PEIRSON 1953 ELPHIDIUM

16075 WANTLAND 1969

ELPH I DI UM

ELPHIDIUM

ELPHIDIUM

ELPHIDIUM

ELPHIDIUM

ELPHIDIUM

ELPHIDIUM

ELPHIDIUM

ELPHIDIUM

ELPHIDIUM

ELPHIDIUM

ELPHIDIUM

ELPHIDIUM

EL PH I D I UM

ELPHIDIUM

ELPHIDIUM

ELPHIDIUM

ELPHIDIUM

ELPHIDIUM

ELPH IDIUM

ELPHIDI UM

ELPHIDIUM

ELPH IDIUM

ELPHIDIUM

ELPHIDIUM

ELPHIDIUM

ELPHIDIUM

ELPHIDIUM

ELPHIDTUM

ELPHIDIUM

ELPHIDIUM

ELPHIDIUM

ELPHIDIUM

ELPHID I UM

ELPHIDIUM

ELPHIDIUM

ELPHIDIUM

ELPHIDIUM

ELPHIDIUM

ELPHIDI UM

ELPHIDIUM

ELPHIDIUM

ELPHIDIUM

ELPHIDIUM

ELPHIDIUM

EL PHIDI UM

ELPHID I UM

ELPHID IUM

ELPHIDIUM

ELPHIDIUM

ELPHIDI UM

ELPHIDI UM

ELPHIDIUM

ELPHIDIUM

ELPHIDIUM

ELPHIDIUM

ELPHIDI UM

ELPHIDIUM

ELPHIDIUM

ELPHIDIUM

ELPHIDI UM

ELPHIDIUM

ELPHIDIUM

ELPHIDIUM

ELPHIDIUM

ELPH I I UM

ELPH I D I UM

ELPHIDIUM

ELPHIDIUM

ELPHIDIUM

ELPHIDIUM

ELPHIDIUM

ELPH ID I UM

ELPHIDIUM

ELPHIDIUM

ELPHIDIUM

ELPHIDIUM

ELPH I D I UM

ELPHIDIUM

ELPH I I UM

ELPHIDIUM

ELPHIDIUM

ELPHIDIUM

ELPHIDIUM

ELPHIDIUM

ELPHIDIUM

ELPHIDIUM
Specific Name

DELI CATULUM

DELICATUL UM

DELICATULUM

KUGLERI

DELICATULUM

KUGLER I

KUGLERI

KUGLERI

KUGLER

DELICATULUM

DELI CATUL UM

DELI CATULUM

DI SCOIDALE

DI SCOIDALE

DISCOIDALE

DI SCOIDALE

DI SCOIDALE

DI SCOIDALE

DI SCOIDALE

DISCOIDALE

DI SCOIDALE

DI SCOIDALE

DI SCOIDALE

DI SCOIDALE

DISCOIDALE

DI SCOIDALE

DISCOIDALE

DI SCOIDALE

DI SCOIDALE

DI SCOIDALE

DISCOIDALE

DI SCOIDALE

DI SCOIDALE

DISCOIDALE

DISCOIDALE

DI SCOIDALE

DI SCOIDALE

DISCOIDALE

DISCOIDALE

DI SCOIDALE

DI SCOIDALE

DI SCOIDALE

DI SCOIDALE

DISCOIDALE

DI SCOIDALE

DI SCOIDALE

DI SCOIDALE

DI SCOIDALE

DI SCOIDALE

DI SCOIDALE

DI SCOIDALE

DI SCOIDALE

DISCOIDALE

DI SCOIDALE

DI SCOIDALE

DI SCOIDALE

DI SCOIDALE

DI SCOIDALE

DI SCOIDALE

DISCOIDALE

DISCOIDALE

DI SCOIDALE

DISCOIDALE

DISCOIDALE

DISCOIDALE

DISCOIDALE

DISCOIDALE

DI SCOIDALE

DISCOIDALE

DI SCOIDALE

DI SCOIDALE

DI SCOIDALE

DISCOIDALE

DI SCOIDALE

DISCOIDALE

DI SCOIDALE

DISCOIDALE

DI SCOIDALE

DI SCOIDALE

DISCOIDALE

DI SCOIDALE

DI SCOIDALE

DISCOIDALE

DI SCOIDALE

DISCOIDALE

DISCOIDALE

DI SCOIDALE

DISCOIDALE

DISCOIDALE

DI SCOIDALE

DI SCOIDALE

DI SCOIDALE

DI SCOIDALE

DI SCOIDALE
Locality

LAGUNA MADRE, NE TEXAS

TAMPA-SARASOTA BAY, FLA.

. DE TERMINOS. CAMPECHE

TEXAS GULF COAST

TRINITY BAY, TEXAS
TEXAS GULF COAST

TEXAS GULF COAST

TEXAS GULF COAST

TEXAS GULF COAST

NE GULF OF MEXICO

CENTRAL TEXAS BAYS

SABINE LAKE, TEXAS

TEXAS GULF COAST

SABINE LAKE, TEXAS

NW GULF OF MEXICO

NW GULF OF MEXICO

NW GULF OF MEXICO

NW GULF OF MEXICO

NW GULF OF MEXICO

NW GULF OF MEXICO

NW GULF OF MEXICO

NW GULF OF MEXICO

NW GULF OF MEXICO

NH GULF OF MEXICO

NW GULF OF MEXICO

NW GULF OF MEXICO

NW GULF OF MEXICO

GALVESTON B.. TEXAS

MISSISSIPPI SOUND

TEXAS GULF COAST

NE GULF OF MEXICO

MISSISSIPPI DELTA

$N$ GULF OF MEXICO

SE LOUISIANA

SAN ANTONIO B. TEXAS

NE GULF OF MEXICO

NE GULF OF MEXICO

NE GULF OF MEXICO

NE GULF OF MEXICO

NE GULF OF MEXICO

NE GULF OF MEXICO

NE GULF OF MEXICO

NE GULF OF MEXICO

HEALD BANK, G. OF MEXICO

NW GULF OF MEXICO

NW GULF OF MEXICO

NW GULF OF MEXICO

$N W$ GULF OF MEXICO

$N W$ GULF OF MEXICO

NH GULF OF MEXICO

NW GULF OF MEXICO

NW GULF OF MEXICO

$N W$ GULF OF MEXICO

NW GULF OF MEXICO

NW GULF OF MEXICO

MISSISSIPPI DELTA

MISSISSIPPI SOUND

SABINE LAKE, TEXAS

NW GULF OF MEXICO

MATAMOROS, MEXICO

CENTRAL TEXAS BAYS

CLAYPILE BANK

NW GULF OF MEXICO

NW GULF OF MEXICO

NW GULF OF MEXICO

NW GULF OF MEXICO

NE GULF OF MEXICO

CAPE ROMANO, FLA.

NE GULF OF MEXICO

NH GULF OF MEXICO

NE GULF OF MEXICO

$N E$ GULF OF MEXICO

$N W$ GULF OF MEXICO

NW GULF OF MEXICO

MISSISSIPPI SOUND

NW GULF OF MEXICO

NW GULF OF MEXICO

NE GULF OF MEXICO

NE GULF OF MEXICO

NE GULF OF MEXICO

NE GULF OF MEXICO

NE GULF OF MEXICO

NE GULF OF MEXICO

NH GULF OF MEXICO

NE GULF OF MEXICO

LOUISIANA GULF COAST

NE GULF OF MEXICO

NE GULF OF MEXICO

CHARLOTTE HARBOUR, FLA.

NE GULF OF MEXICO

NE GULF OF MEXICO

NE GULF OF MEXICO

NE GULF OF MEXICO

NE GULF OF MEXICO

NE GULF OF MEXICO

Lat. Long.

$2510 N \quad 097 \quad 37 W$

$27 \quad 45 \mathrm{~N} 082 \quad 35 \mathrm{~W}$

$1840 \mathrm{~N} 09130 \mathrm{~W}$ 


\section{Publication}

16166 PHLEGER 1956

16167 PARKER 1954

16169 PARKER 1954

16170 BOCK 1976

16171 BOCK 1976

16172 BOCK 1976

16173 PARKER PHLEGER PEIRSON 1953

6174 PARKER PHLEGER PEIRSON 1953

16175 KORNFELD 1931

16176 KORNFELD 1931

16177 PARKER PHLEGER PEIRSON 1953

16178 KORNFELD 1931

16179 KORNFELD 1931

16180 KORNFELD 1931

16181 PHLEGER 1956

16182 KORNFELD 1931

16183 SHENTON 1957

16184 PARKER PHLEGER PEIRSON 1953

16185 PARKER PHLEGER PEIRSON 1953

16186 PARKER PHLEGER PEIRSON 1953

16187 KORNFELD 1931

16188 BANDY 1956

16189 KORNFELD 1931

16190 PARKER PHLEGER PEIRSON 1953

16191 LOEP 1965

16192 BANDY 1956

16193 BANDY 1954

16194 BANDY 1954

16195 BANDY 1954

16196 BANDY 1956

16198 AYALA-CASTANARES 1963

16199 WARREN 1956

16200 BANDY 1954

16201 LOEP 1965

16202 LOEP 1965

16203 AYALA-CASTANARES SEGURA 1968

16204 WALTON 1964

16205 NORTON 1930

16206 BENDA PURI 1962

16207 AKERS 1952

16208 AYALA-CASTANARES 1963

16209 BANDY 1954

16210 PHLEGER 1951A

16211 PHLEGER 1951A

16212 BANDY 1954

16213 BANDY 1954

16214 PHLEGER $1951 \mathrm{~A}$

16215 PHLEGER 1951A

16216 AYALA-CASTANARES SEGURA 1968 ELPHIDIUM 16217 BANDY 1954

16218 BANDY 1954

16219 BANDY 1954

16220 KELLOUGH 1956

16221 KELLOUGH 1956

16222 ANDERSEN 196

16223 BOCK 1976

16224 PHLEGER 1951A

16225 SHIFFLETT 1961

16226 LEHMANN 1957

16227 PHLEGER 1951 A

16228 PHLEGER $1951 \mathrm{~A}$

16229 PHLEGER 1951A

16230 PHLEGER 1951A

16231 PHLEGER 1951A

16232 PHLEGER 1954

16233 LEHMANN 1957

16234 PHLEGER 1954

16235 PHLEGER LANKFORD 1957

16236 PHLEGER 1960

16237 PHLEGER 1965 A

16238 PHLEGER $1965 \mathrm{~A}$

16239 PHLEGER 1965 A

6240 PHLEGER 1965 A

16241 PHLEGER 1965 A

16243 PHLEGER 1965 A

16244 PHLEGER $1965 \mathrm{C}$

16245 PHLEGER 19658

16246 BENDA PURI 1962

16247 PHLEGER 19658

16248 BENDA PURI 1962

16249 PHLEGER 1965 A

16250 BENDA PURI 1962

16251 AYALA-CASTANARES 1963

16252 OTVOS 1978

16253 SEGURA 1963

16254 PHLEGER 1956

16255 SHEPARD MOORE 1955

16256 BOCK 1976

16257 BOCK 1976

16258 WANTLAND 1969

16259 POAG 1978

16260 POAG 1978
Generic Name Specific Name

DISCOIDALE

DISCOIDALE

DI SCOIDALE

DI SCOIDALE

DISCOIDALE

DISCOIDALE

DISCOIDALE

DISCOIDALE

DISCOIDALE

DI SCOIDALE

DISCOIDALE

DI SCOIDALE

DISCOIDALE

DI SCOIDALE

DISCOIDALE

DI SCOIDALE

DISCOIDALE

DISCOIDALE

DISCOIDALE

DISCOIDALE

DISCOIDALE

DISCOIDALE

DISCOIDALE

DISCOIDALE

DISCOIDALE

DISCOIDALE

DISCOIDALE

DISCOIDALE

DISCOIDALE

DISCOIDALE

DISCOIDALE

DI SCOIDALE

DISCOIDALE

DISCOIDALE

DISCOIDALE

DISCOIDALE

DISCOIDALE

EXCAVATUM

EXCAVATUM

F I NBR I A TULUM

FINBRIATULUM

FINBRIATULUM

F INBRIA TULUM

F INBRI A TULUM

FI MBRIATULUM

FI NBR I A TULUM

F I NBR I A TULUM

F I MBR I A TULUM

F I MBR I A TULUM

FI NBRIA TULUM

FI NBR I A TULUM

FI INBR I A TULUM

FINBRIATULUM

FINBRIATULUM

F I NBRIA TULUM

FI NBRIA TULUM

FI NBRIATULUM

FIMBRIATULUM

F I NBRI A TULUM

FI NBRIATULUM

FINBRIATULUM

FINBRI A TULUM

GALVESTONENSE

GALVESTONENS

GALVE ST ONENSE

GALVESTONENSE

GALVESTONENSE

GALVESTONENSE

GALVESTONENSE

GALVEST ONENSE

GALVESTONENSE

GA LVESTONEN SE

GALVESTONENSE

GALVESTONENSE

GALVESTONENSE

GALVEST ONEN SE

GALVEST ONEN SE

GALVESTONEN SE

GA LVESTONENSE

GALVESTONENSE

GALVESTONENSE

GUATERI

GALVESTONENSE

GALVESTONENSE

GALVESTONENSE

GALVESTONENSE

GALVESTONENSE

GALVESTONENSE

GALVESTONENSE

MEXICANUM

GALVESTONENSE
Locality

Lat. Long.

NW GULF OF MEXICO

NE GULF OF MEXICO

NE GULF OF MEXICO

NE GULF OF MEXICO

NE GULF OF MEXICO

NE GULF OF MEXICO

NE GULF OF MEXICO

TEXAS GULF COAST

LOUISIANA GULF COAST

LOUISIANA GULF COAST

TEXAS GULF COAST

TEXAS GULF COAST

LOUISIANA GULF COAST

TEXAS GULF COAST

NW GULF OF MEXICO

TEXAS GULF COAST

MAT AGORDA BAY, TEXAS

TEXAS GULF COAST

TEXAS GULF COAST

TEXAS GULF COAST

TEXAS GULF COAST

NE GULF OF MEXICO

TEXAS GULF COAST

TEXAS GULF COAST

NW GULF OF MEXICO

NE GULF OF MEXICO

NW GULF OF MEXICO

NW GULF OF MEXICO

$N W$ GULF OF MEXICO

NE GULF OF MEXICO

IEXAS GULF COAST

L. DE TERMINOS, CAMPECHE

BURAS SE LOUISIANA

NW GULF OF MEXICO

NW GULF OF MEXICO

NW GULF OF MEXICO

LAGUNA MADRE, NE TEXAS

TAMPA- SARASOTA BAY, FLA.

TORTUGAS, FLA

CAPE ROMANO, FLA.

GARDEN ISLAND BAY, LA .

L. DE TERMINOS, CAMPECHE

$N W$ GULF OF MEXICO

NW GULF OF MEXICO

NW GULF OF MEXICO

$N W$ GULF OF MEXICO

NW GULF OF MEXICO

NW GULF OF MEXICO

NW GULF OF MEXICO

LAGUNA MADRE, NE TEXAS

NW GULF OF MEXICO

NW GULF OF MEXICO

$N W$ GULF OF MEXICO

NW GULF OF MEXICO

NW GULF OF MEXICO

MISS ISSIPPI DELTA

NE GULF OF MEXICO

$N W$ GULF OF MEXICO

HEALD BANK, G. OF MEXICO

TEXAS GULF COAST

NW GULF OF MEXICO

NW GULF OF MEXICO

NW GULF OF MEXICO

NW GULF OF MEXICO

NW GULF OF MEXICO

MISSISSIPPI SOUND

TEXAS GULF COAST

N GULF OF MEXICO

TEXAS GULF COAST

LAGUNA MADRE, TEXAS

PASS CAVALLO, TEXAS

ALLYN'S BIGHT, TEXAS

COLORADO R. DELTA. TEXAS

GOOSE IS.. TEXAS

CORPUS CHRISTI BAY, TEXAS

AGUNA MADRE, NE TEXAS

COPANO BAY, TEXAS

GALVESTON B. TEXAS

IEN THOUSAND IS., SW FLA.

CAPE ROMANO, FLA.

WHITEWATER B. S SW FLA.

CAPE ROMANO, FLA.

PORT ALTO, TEXAS

CAPE ROMANO FLA.

L. DE TERMINOS, CAMPECHE

PONTCHARTRAIN, LA.

MATAMUROS, MEXICO

CENTRAL TEXAS BAYS

CENTRAL TEXAS COAST

NE GULF OF MEXICO

NE GULF OF MEXICO

TRIVITY BAY, TEXAS

SAN AVTONIO BAY, TEXAS

SAN ANTONIO BAY, TEXAS

$2740 \mathrm{~N} 096.20 \mathrm{~W}^{\circ}$

$2849 \mathrm{~N} 08340 \mathrm{~W}$

$2802 \mathrm{~N} 08520 \mathrm{~W}$

$2827 \mathrm{~N} 08430 \mathrm{~W}$

$2900 N 085$ OOW

$2955 \mathrm{~N} 08830 \mathrm{~W}$

$2950 N 086 \quad 10 \mathrm{~W}$ 


\section{Publication}

16261 PARKER PHLEGER PEIRSON 1953 16262 PARKER PHLEGER PEIRSON 1953 16263 PARKER PHLEGER PEIRSON 1953 6264 PARKER PHLEGER

16265 WALTON 1960

$\begin{array}{lll}16266 & \text { PARKER PHLEGER PEIRSON } & 1953 \\ 16267 & \text { PARKER PHLEGER PEIRSON } & 1953\end{array}$ 16268 PARKER PHLEGER PEIRSON 1953 16269
16270 PARKER PHLEGER PEIRSON 1953
16271 16271 POAG 1976

16272 POAG 1976

16273 PARKER 1954

16274 PARKER 1954

16275 SHEPARD MOORE 1955

16276 KANE 1967

16277 LANKFORD 1959

16278 PHLEGER 1954

16279 WARREN 1957

16280 PHLEGER $1965 \mathrm{C}$

16281 PHLEGER 1954
16282 PHLEGER LANKFORD 1957

16283 LOEP 1965

16284 BANDY 1956

16285 PHLEGER 1965 A

16286 LOEP 1965

16287 KANE 1962

16288 SEGURA 1963

16289 WALDRON 1963

16290 LEHMANN 195

16291 PHLEGER 1960

16292 SHIFFLETT 1961

16293 PARKER PHLEGER PEIRSON 1953

16294 PARKER PHLEGER PEIRSON 1953

16295 PARKER PHLEGER PEIRSON 1953

16296 WANTLAND 1969

16297 PARKER PHLEGER PEIRSON 1953 16298 PARKER PHLEGER PEIRSON 1953

16299 PARKER PHLEGER PEIRSON 1953

16300 PARKER PHLEGER PEIRSON 1953 16301 SHENTON 1957

16302 PARKER PHLEGER PEIRSON 1953 16303 BOCK 1976

16304 PARKER PHLEGER PEIRSON 1953 16305 PARKER PHLEGER PEIRSON 1953 16306 PHLEGER 1956

16307 PHLEGER 1956

16308 PHLEGER 1956

16309 PHLEGER 1956

16310 POAG SWEET 1972

16311 PHLEGER 1956

16312 PARKER 1954

16313 PARKER 1954

16314 PARKER 1954
16315 WALTON 1960

16316 PHLEGER LANKFORD 1978

16317 OTVOS 1978

16318 LIDZ LIDZ 1966

16319 PARKER 1954

16320 PARKER 1954

16321 PARKER 1954

16322 PARKER 1954

16323 PARKER 1954

16324 PHLEGER 1955 B

16325 AYALA-CASTANARES SEGURA 1968

16326 BANDY 1956

16327 BANDY 1956

16328 BANDY 1956

16329 BANDY 1956

16330 WARREN 1956

16331 LAMB 1972

16332 WALTON 1964

16333 AYALA-CASTANARES 1963

16334 BANDY 1956

16335 BANDY 1956

16336 BANDY 1956

16337 BANDY 1956

16338 BANDY 1956

16339 PHLEGER 1965 A

16340 PHLEGER 1965 A

16341 PHLEGER 19658

16342 ANDERSON 1968

16343 PHLEGER 1965 A

16344 PHLEGER $1965 \mathrm{~A}$

16345 BENDA PURI 1962

16346 PHLEGER $1965 \mathrm{~B}$

16347 PHLEGER $1965 \mathrm{~A}$

16348 PHLEGER $1965 \mathrm{~A}$

16349 PHLEGER $1965 \mathrm{~A}$

16350 BENDA PURI 1962

16351 PHLEGER 1965A

16352 PHLEGER 1965 A

16353 POAG 1976

16354 PHLEGER 1951A

16355 PHLEGER 1951A
Generic Name

ELPHIDIUM

ELPHIDIUM

ELPHIDIUM

ELPHIDIUM

ELPHIDIUM

ELPHIDIUM

ELPHIDIUM

ELPHIDIUM

ELPHIDIUM

ELPHIDIUM

ELPHIDIUM

ELPHIDIUM

ELPHID I UM

ELPHIDIUM

ELPH IDIUM

ELPHIDIUM

ELPHIDI UM

ELPHID I UM

ELPHIDI UM

ELPHIDI UM

ELPHIDIUM

ELPHID I UM

ELPH I D UM

ELPHIDIUM

ELPHIDIUM

ELPHIDIUM

ELPHIDIUM

ELPHIDIUM

ELPHIDIUM

ELPHIDIUM

ELPHID I UM

ELPH I D I UM

ELPHIDIUM

ELPHIDIUM

ELPHIDIUM

ELPHIDIUM

ELPHIDIUM

ELPHIDIUM

ELPHIDIUM

ELPHIDIUM

ELPHIDIUM

ELPHIDIUM

ELPHID IUM

ELPHIDIUM

ELPHIDIUM

ELPHIDIUM

ELPHIDIUM

ELPHID I UM

ELPHIDIUM

ELPHIDIUM

ELPHIDIUM

ELPHIDIUM

ELPHIDIUM

ELPHIDIUM

ELPHIDIUM

ELPHIDIUM

ELPHIDIUM

ELPHIDIUM

ELPHIDIUM

ELPHIDIUM

ELPH IDIUM

ELPHIDIUM

ELPHIDIUM

ELPHIDIUM

ELPHIDIUM

ELPHIDIUM

ELPHIDIUM

ELPHIDIUM

ELPHIDIUM

ELPHIDIUM

ELPHIDIUM

ELPHIDIUM

ELPH ID I UM

ELPHIDIUM

ELPHID I UM

ELPHIDIUM

ELPHIDIUM

ELPHIDIUM

ELPHIDIUM

ELPHIDIUM

ELPHIDIUM

ELPH IDIUM

ELPHIDIUM

ELPHIDIUM

ELPHIDIUM

ELPHIDIUM

ELPHIDIUM

ELPHIDIUM

ELPHIDIUM

ELPHIDIUM
Specific Name

GALVESTONENSE

GALVESTONENSE

GALVESTONENSE

GALVESTONEN SE

GALVESTONENSE

GALVEST ONENSE

GALVESTONEN SE

GALVESTONENSE

GALVESTONENSE

GALVESTONENSE

KOEBOEENSE

GUNTERI

GUNTERI

GUNTERI

GUNTERI

GUNTERI

GUNTERI

GUNTERI

GUNTERI

GUNTERI

GUNTERI

GUNTERI

GUNTER

GUNTER

GUNTERI

GUATERI

GUATERI

GUNTERI

GUNTERI

GUNTERI

GUNTERI

GUNTERI

GUNTERI

GUNTERI

GUATERI

GUNTERI

GUNTERI

GUNTERI

GUNTER

GUNTERI

GUNTERI

GUNTERI

GUNTERI

GUNTERI

GUNTERI

GUNTER

GUNTERI

GUNTER

GUNTER

GUNTERI

GUNTERI

GUNTERI

GUNTERI

GUNTERI

GUNTERI

GUNTERI

GUNTERI

GUNTERI

GUNTER I

GUNTERI

GUNTERI

GUNTERI

GUNTERI

GUNTERI

GUNTER

GUNTERI

GUNTERI

GUNTERI

GUNTERI

GUNTERI

GUNTERI

GUNTER

GUNTER I

GUNTER I

GUNTERI

GUNTER I

GUNTERI

GUATERI

GUATERI

GUNTERI

GUNTER I

GUNTERI

GUNTERI

GUNTER

GUNTERI

GUNTERI

GUNTERI

GUNTER

GUNTER I

DELICATULUM

GUNTER

GUNTERI

Locality

Lat. Long.

TEXAS GULF COAST

TEXAS GULF COAST

TEXAS GULF COAST

TEXAS GULF COAST

MISSISSIPPI SOUND

TEXAS GULF COAST

TEXAS GULF COAST

TEXAS GULF COAST

TEXAS GULF COAST

TEXAS GULF COAST

SAN ANTONIO B.., TEXAS 


\section{Publication}

16356 PHLEGER 1951A 16357 PHLEGER 1951A

16358 BANDY 1954

16359 BANDY 1954

16360 BANDY 1954

16361 CREAGER 1958

16363 PHLEGER 1951A

16364 PHLEGER 1951A

16365 PHLEGER 1951A

16366 BANDY 1954

16367 BANDY 1954

16368 BANDY 1954

16369 KELLOUGH 1956

16370 KELLOUGH 1956

16371 KELLOUGH 1956

16372 KELLOUGH 1956

6373 PHLEGER $1951 \mathrm{~A}$

16374
16375
PHLEGER $1951 \mathrm{~A}$
16376

6376 PHLEGER 1951A

16377 PHLEGER 1951 A

16378 PHLEGER 1951A

16379 PHLEGER 1951A

16380 PHLEGER 1951A

16381 PHLEGER 1951A

16382 LOWMAN 1949

16383 PHLEGER 1951A

16384 PHLEGER 1951A

16385 KELLOUGH 1956

16386 KELLOUGH 1956

16387 KELLOUGH 1956
16388 KORNFELD 1931

16389 KORNFELD 1931

16390 KORNFELD 1931

16391 KORNFELD 1931

16392 KORNFELD 1931

16393 KORNFELD 1931

16394 KORNFELD 1931

16395 KORNFELD 1931

16396 KORNFELD 1931

16397 KORNFELD 1931

16398 KORNFELD 1931

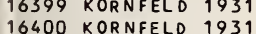

16401 KORNFELD 1931

16402 KORNFELD 1931

16403 KORNFELD 1931

16404 KORNFELD 1931

16405 KORNFELD 1931

16406 POST 1951

16407 KORNFELD 1931

16408 KORNFELD 1931

16409 KORNFELD 1931

16410 POST 1951

16411 POAG 1976

16412 POAG 1978

16413 POAG 1978

16414 POST 1951

16415 POST 1951

16416 PHLEGER 1954

16417 PHLEGER 1954

16418 SEGURA 1963

16419 ANDERSEN 1961

16420 ANDERSEN 1961

16421 ANDERSEN 1961

16422 ANDERSEN 1961

16423 WANTLAND 1969

6424 PARKER PHLEGER PEIRSON 1953

16425 PARKER PHLEGER PEIR SON 1953

16426 BENDA PURI 1962

16427 OTVOS 1978

16428 WALTON 1960

16429 KANE 1967

16430 PHLEGER $1965 \mathrm{~B}$

16431 PHLEGER 1965 A

16432 ANDERSON 1968

16433 PHLEGER 19658

16434 KELLOUGH 1956

16435 WARREN 1956

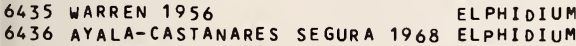

16437 KORNFELD 1931

16438 KORNFELD 1931

16439 KORNFELD 1931

16440 PHLEGER 1956

16441 KORNFELD 1931

16442 KORNFELD 1931

16443 PHLEGER 1956

16444 AYALA-CASTANARES 1963

16445 PARKER PHLEGER PEIRSON 1953

16447 PARKER PHLEGER PEIRSON 1953

16447 PARKER PHLEGER PEIRSON 1953

16448 PARKER PHLEGER PEIRSON 1953

16449 PHLEGER 1956
16450 KORNFELD 1931
Generic Name

ELPHIDIUM

ELPHIDIUM

ELPHIDIUM

ELPHIDIUM

ELPHIDIUM

ELPHIDI UM

ELPHIDIUM

ELPHIDIUM

ELPH I DI UM

ELPHIDIUM

ELPHIDIUM

ELPH I D I UM

ELPHIDIUM

ELPHID IUM

ELPHIDIUM

ELPHIDIUM

ELPHIDIUM

ELPHIDIUM

ELPHIDIUM

ELPH I D I UM

ELPHIDIUM

ELPHIDIUM

ELPHIDIUM

ELPHIDIUM

ELPHIDIUM

ELPHIDIUM

ELPHIDIUM

ELPHIDIUM

ELPHIDIUM

ELPHIDIUM

ELPHIDIUM

ELPHIDIUM

ELPHIDIUM

ELPH I D I UM

ELPHIDIUM

ELPHIDIUM

ELPHIDIUM

ELPHI D IUM

ELPHIDIUM

ELPHIDIUM

ELPHIDIUM

ELPHIDIUM

ELPH IDIUM

ELPHIDIUM

ELPHIDIUM

ELPHIDIUM

ELPHIDIUM

ELPHIDIUM

ELPHIDIUM

ELPH I I UM

ELPHI DIUM

ELPHID I UM

ELPHIDIUM

ELPHIDIUM

ELPHI DI UM

ELPHIDIUM

ELPH I D I UM

ELPH I D I UM

ELPHID I UM

ELPHIDIUM

ELPHIDIUM

ELPHIDIUM

ELPHIDIUM

ELPHIDI UM

ELPHIDIUM

ELPH I D I UM

ELPHIDIUM

ELPHIDIUM

ELPHIDIUM

ELPHIDIUM

ELPHIDIUM

ELPHIDIUM

ELPHIDI UM

ELPHIDIUM

ELPHI DIUM

ELPHIDIUM

ELPHIDIUM

ELPHI DI UM

ELPHIDIUM

ELPHIDIUM

ELPHIDI UM

ELPHIDI UM

ELPH I D U M

ELPH I D I UM

ELPH I D I UM

ELPHIDI UM

ELPHIDI UM

ELPHIDIUM

ELPHIDIUM
Specific Name

Locality

Lat. Long.

GUNTER

GUNTERI

GUNTERI

GUNTERI

GALVEST ONEN SE

GUATERI

GUNTERI

GUNTERI

GUNTER I

GUNTER I

GUNTERI

GALVEST ONENSE

GALVESTONENSE

GALVESTONENSE

GALVEST ONENSE

GUNTER I

GUNTER

GUNTERI

GUNTERI

GUNTERI

GUNTER I

GUNTERI

GUNTERI

GUATERI

GALVESTONENSE

GUNTER I

GALVESTONENSE

GALVESTONENSE

GALVESTONEN SE

GALVESTONENSE

GALVESTONEN SE

GALVESTONEN SE

GALVESTONENSE

GALVEST ONEN SE

GALVESTONENSE

GALVEST ONEN SE

GALVESTONEN SE

GALVESTONENSE

GALVESTON EN SE

GALVEST ONENSE

GALVESTONEN SE

GALVEST ONEN SE

GALVESTONENSE

GALVESTONENSE

GA LVESTONENSE

GALVESTONEN SE

GALVESTONEN SE

GUNTER I

GUNTERI

GUNTERI

GUNTER I

GUNTERI

GUNTER

EX CAVATUM

GUNTERI

EXCAVATUM

EXCAVATUM

EXCAVATUM

EXCAVATUM

EX CAVATUM

DELICATULUM

DELICATUL UM

DELICATULUM

DELICATUL UM

ME XI C AN UM

MEXICANUM

MEXICANUM

ME XIC ANUM

MEXI CANUM

MEXI CANUM

MEXICANUM

MEXICANUM

ME XI CANUM

MEXI CANUM

MEXI CANUM

MEXICANUM

MEXI CANUM

MEXICANUM

MEXI CANUM

MEXICANUM

MEXICANUM

MEXICANUM

MEXICANUM

MEXICANUM

MEXICANUM

MEXI CANUM

MEXICANUM

MEXICANUM

MEXICANUM

MEXICANUM

MEXI CANUM

NH GULF OF MEXICO

NW GULF OF MEXICO

NW GULF OF MEXICO

NW GULF OF MEXICO

NW GULF OF MEXICO

BAY OF CAMPECHE

NW GULF OF MEXICO

NW GULF OF MEXICO

$N W$ GULF OF MEXICO

$N$ GULF OF MEXICO 


\section{Publication}

16451 PHLEGER 1951A 16452 PHLEGER 1951 A 16453 PHLEGER 1951A 16454 PHLEGER 1951 A 16455 PHLEGER 1951 A 16456 PHLEGER 1951 A 16457 PHLEGER 1951A 16458 PHLEGER $1951 \mathrm{~A}$ 16459 PHLEGER 1951 A 16460 PHLEGER 1951A 16461 PHLEGER 1951A 16462 PHLEGER 1951A 16463 PHLEGER 1955 B 16464 WALTON 1964 16465 SEGURA 1963

16466 LEHMANN 1957

16467 SHIFFLETT 1961

16468 SHEPARD MOORE 1955

16469 PHLEGER 1965

16470 PHLEGER LANKFORD 1957

16471 LANKFORD 1959

16472 HARREN 1957

16473 PARKER PHLEGER PEIRSON 1953

16474 PARKER PHLEGER PEIRSON 1953 16475 BOCK 1976

16476 PHLEGER 1956

16477 AYALA-CASTANARES 1963

16478 AYALA-CASTANARES SEGURA 1968 16479 PHLEGER 1965 A

16480 PHLEGER $1965 \mathrm{~A}$

16481 PHLEGER 1965A

16482 PHLEGER 1965 A

16483 WALTON 1960

16484 PHLEGER 1956

16485 PARKER PHLEGER PEIRSON 1953

16486 PARKER PHLEGER PEIRSON 1953

16487 PARKER PHLEGER PEIRSON 1953

16488 PARKER PHLEGER PEIRSON 1953

16489 PARKER PHLEGER PEIRSON 1953

16491 PARKER PHLEGER PEIRSON 1953

16492 PARKER PHLEGER PEIRSON 1953

16493 PHLEGER 1954

16494 PHLEGER LANKFORD 1957

16495 PHLEGER 1954

16496 PHLEGER 1960

16497 SEGURA 1963

16498 PARKER PHLEGER PEIRSON 1953

16499 PHLEGER 1965 A

16500 PHLEGER 1965A

16501 PHLEGER 1965 A

16502 PHLEGER 1965A

16503 HALDRON 1963

16504 NORTON 1930

16505 WARREN 1956

16506 PHLEGER 1965 A

16507 WALTON 1960

16508 PHLEGER 1965 A

16509 PARKER PHLEGER PEIRSON 1953

16510 PHLEGER 1956

16511 PARKER PHLEGER PEIRSON 1953

16512 PARKER PHLEGER PEIRSON 1953

16513 PHLEGER 1956

16514 WALTON 1964

16515 PHLEGER 1965 A

16516 PHLEGER 1965A

16517 PHLEGER 1965 A

16518 PHLEGER 1965 A

16519 PHLEGER 1965 A

16520 PHLEGER 19658

16521 PHLEGER $1965 \mathrm{~A}$

16522 PHLEGER 19658

16523 PHLEGER 1965A

16524 BENDA PURI 1962

16525 PHLEGER 1956

16526 WANTLAND 1969

16527 PARKER PHLEGER PEIRSON 1953

16528 PARKER PHLEGER PEIRSON 1953

16529 PHLEGER 1956

16530 PARKER PHLEGER PEIRSON 1953

16531 PHLEGER 1956

HAYNESINA

AYALA-CASTANARES SEGURA 1968 HAYNESINA

16533 PARKER PHLEGER PEIRSON 1953 HAYNESINA

16534 PARKER PHLEGER PEIRSON 1953 HAYNESINA

16535 LANKFORD 1959

16536 PHLEGER 1955

16537 WARREN 1957

16538 PHLEGER 1954

16539 SHEPARD MOORE 1955

16540 PHLEGER LANKFORD 1957

16541 PHLEGER 1954

16542 PHLEGER $1965 \mathrm{C}$

16544 PARKER PHLEGER PEIRSON 1953 HAYNESINA

16545 LEHMANN 1957
Generic Name

ELPHIDIUM

ELPHIDIUM

ELPHIDIUM

ELPHIDIUM

ELPHIDIUM

ELPHIDIUM

ELPH I D IUM

ELPHI D I UM

ELPHIDIUM

ELPHIDIUM

ELPHIDIUM

ELPHIDIUM

ELPHIDIUM

ELPHIDIUM

ELPHIDIUM

ELPHIDIUM

ELPHIDI UM

ELPHIDIUM

ELPHIDIUM

ELPHIDIUM

ELPHIDIUM

ELPHIDIUM

LPH I D I UM

ELPHIDIUM

ELPHIDIUM

ELPHIDIUM

LLPHIDIUM

ELPHIDIUM

ELPHIDIUM

ELPHIDIUM

ELPHIDIUM

ELPHIOIUM

ELPHIDIUM

ELPHIDIUM

ELPH I D I UM

ELPHIDIUM

ELPHIDIUM

HAYNESINA

HAYNES INA

HAYNES INA

YNE SINA

HAYNESINA

HA YNESINA

HA YNE SINA

AYNES INA

HAYNESINA

HAYNESINA

HAYNES INA

HA YNESINA

HAYNES INA

HA YNES I NA

HAYNES I NA

A YNES INA

AY NES I NA

HAYNES I NA

HAYNESINA

HAYNES INA

HA YNE SI NA

HA YNES I NA

HAYNESINA

HAYNESINA

HAYNESINA

HAYNESINA

HAYNE SINA
Specific Name

MEXICANUM

MEXI CANUM

MEXI CANUM

MEXI CANUM

MEXI CANUM

MEXI CANUM

MEXI CANUM

MEXICANUM

MEXI CANUM

MEXI CANUM

MEXICANUM

MEXI CANUM

MEXI CANUM

ME XI C ANUM

MEXI CANUM

MEXI CANUM

MEXI CANUM

MEXI CANUM

MEXI CANUM

MEXICANUM

MEXICANUM

MEXI CANUM

MEXI CANUM

MEXI CANUM

MEXI CANUM

KOEBOEENSE

KOEBOEENSE

KOEBOEENSE

KOEBOEENSE

KOEBOEENSE

KO EBOEENSE

KOEBOEENSE

KOEBOEENSE

ME XI CANUM

MEXI CANUM

MEXI CANUM

ME XI CANUM

MEXI CANUM

MEXICANUM

MEXI CANUM

KOEBOEENSE

KOEBOEENSE

KOEBOEENSE

KOEBOEENSE

MEXICANUM

KOEBOEENSE

KOEBOEENSE

KOEBOEENSE

KOEBOEENSE

EX CAVATUM

MACELLUM

GERMANICA

GE RMANI CA

GE RMAN I CA

GERMANI CA

GERMAN I CA

GE RMAN I CA

GERMANICA

GERMANICA

GERMANI CA

GE RMAN I CA

GERMAN I CA

GE RMANICA

GERMANI CA

GERMANI CA

GE RMANI CA

GERMAN I CA

GE RMAN I CA

GERMANI CA

GERMANI CA

GE RMANI CA

GE RMANI CA

GE RMAN I CA

GE RMAN I CA

GERMANI CA

GERMANICA

GERMAN I CA

GERMANI

GE RMAN I CA

GERMANI CA

GERMAN I CA

GE RMAN I CA

GERMANI CA

GE RMAN I CA

GERMANICA

GE RMANI CA

GE RMAN I CA

GE RMANI CA

GERMANI CA

GERMANI CA

GE RMANI CA

GE RMANI CA

Locality

$\mathrm{NH}$ GULF OF MEXICO

NH GULF OF MEXICO

$N W$ GULF OF MEXICO

NW GULF OF MEXICO

NW GULF OF MEXICO

NW GULF OF MEXICO

NH GULF OF MEXICO

NH GULF OF MEXICO

NW GULF OF MEXICO

NW GULF OF MEXICO

$N W$ GULF OF MEXICO

NW GULF OF MEXICO

MISSISSIPPI DELTA

TAMPA-SARASOTA BAY, FLA.

MATAMOROS, MEXICO

TEXAS GULF COAST

HEALD BANK, G. OF MEXICO

CENTRAL TEXAS COAST

GALVESTON B.. TEXAS

TEXAS GULF COAST

MISSISSIPPI DELTA

SE LOU IS IANA

TEXAS GULF COAST

TEXAS GULF COAST

NE GULF OF MEXICO

NW GULF OF MEXICO

L. DE TERMINOS, CAMPECHE

LAGUNA MADRE, NE TEXAS

COLORADO R. DELTA. TEXAS

LAVACA BAY, TEXAS

CORPUS CHRISTI BAY, TEXAS

ALLYN'S BIGHT, TEXAS

MISSISSIPPI SOUND 


\section{Publication}

16546 PHLEGER 1960 16547 WALDRON 1963 16548 KANE 1962

16549 KANE 1967

16550 SEGURA 1963

16551 BANDY 1956

16552 BANDY 1956

16553 POST 1951

16554 POST 1951

16555 LEHMANN 1957

16556 NOR TON 1930

16557 LIDZ LIDZ 1966

16558 PHLEGER 1954

16559 BANDY 1956

16560 BANDY 1956

16561 BANDY 1956

16562 KELLOUGH 1956

16563 PHLEGER $1965 \mathrm{~B}$

16565 PHLEGER LANKFORD 1978

16566 CUSHMAN 1930

16567 WARREN 1957

16568 LANKFORD 1959

16569 PHLEGER $1955 \mathrm{~B}$

16570 POAG 1976

16571 KANE 1967

16572 SEGURA 1963

16573 PARKER 1954

16574 PARKER 1954

16575 SHIFFLETT 1961

16576 WALDRON 1963

16577 LEHMANN 1957

16578 WALDRON 1963

16579 PHLEGER 1960

16580 KANE 1962

16581 PARKER PHLEGER PEIRSON 1953 ELPHIDIUM

16582 PHLEGER 1956

16584 PARKER PHLEGER PEIRSON 1953

16585 PHLEGER 1956

16586 PARKER PHLEGER PEIRSON 1953 ELPHIDIUM

16587 PHLEGER 1954

16588 PHLEGER $1965 \mathrm{C}$

16589 PHLEGER LANKFORD 1957

16590 PARKER 1954

16591 PARKER 1954

16592 PARKER 1954

16593 PHLEGER 1965 A

16594 SHENTON 1957

16595 PHLEGER 1965 A

16596 WARREN 1956

16597 PHLEGER $1965 \mathrm{~A}$

16598 PHLEGER 1965 A

16599 WANTLAND 1969

16600 PARKER PHLEGER PEIRSON 1953

16601 POST 1951

16602 PARKER PHLEGER PEIRSON 1953

16603 POST 195

16605 PARKER PHLEGER PEIRSON 1953

16606 BENDA PURI 1962

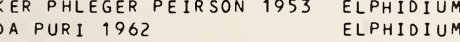

16607 PARKER PHLEGER PEIRSON 1953 ELPHIDIUM

16608 CREAGER 1958

16609 PHLEGER 1956

16610 PHLEGER $1965 \mathrm{~B}$

16611 BENDA PURI 1962

16612 BANDY 1956

16613 BANDY 1954

16614 BANDY 1956

16615 BANDY 1954

16616 BANDY 1954

16617 BANDY 1956

16618 BANDY 1956

16619 PHLEGER 1965 A

16620 KELLOUGH 1956

16621 KELLOUGH 1956

16622 KELLOUGH 1956

16623 BANDY 1956

16624 BANDY 1956

16625 BANDY 1956

16626 BANDY 1956

16627 BANDY 1956

16628 BANDY 1956

16629 BANDY 1956

16630 BANDY 1956

16631 BANDY 1956

16632 BANDY 1956

16633 BANDY 1956

16634 AKERS 1952

16635 AYALA-CASTANARES SEGURA 1968

16636 BANDY 1954

16637 BANDY 1956

16638 WALTON 1964

16639 BANDY 1956

16640 BANDY 1956
Generic Name

HAYNESINA

HAYNESINA

HAYNESINA

ELPHIDIUM

ELPHIDIUM

ELPHIDIUM

L

ELPIDIUM

LLHIDIUM

ELPHIDIUM

ELPHIDIUM

ELPHIDIUM

ELPHIDIUM

ELPHIDIUM

ELPH IDIUM

促

ELPHIDIUM

ELPHIDIUM

ELPHIDIUM

ELPHIDIUM

ELPHIDIUM

ELPHIDIUM

ELPHIDIUM

ELPHIDIUM

ELPHIDIUM

ELPHI DIUM

ELPHIDIUM

ELPHIDIUM

ELPHIDIUM

ELPHIDIUM

ELPHIDIUM

ELPHIDIUM

ELPHIDIUM

ELPHIDIUM

ELPHIDIUM

ELPHIDIUM

ELPH IDIUM

ELPHIDIUM

ELPHIDIUM

ELPHIDIUM

ELPHIDIUM

ELPHIDIUM

ELPHIDIUM

ELPH ID I UM

ELPHIDIUM

ELPHIDIUM

ELPHIDIUM

ELPHIDIUM

ELPHIDIUM

ELPH IDIUM

ELPHIDIUM

ELPHIDIUM

ELPH IDIUM

ELPHIDIUM

ELPHIDI UM

ELPHIDIUM

ELPHIDIUM

ELPHIDIUM

ELPHIDIUM

ELPHIDIUM

ELPHIDIUM

ELPHIDIUM

ELPHIDIUM

ELPHIDIUM

ELPHIDIUM

ELPHIDIUM

ELPH I D I UM

ELPHIDIUM

ELPHIDIUM
Specific Name

GERMANI CA

GERMANI CA

GERMANICA

GERMANICA

GERMANICA

MEXICANUM

MEXICANUM

MORENOI

EXCAVATUM

POEYANUM

POEYANUM

POEYANUM

POEYANUM

POEYANUM

POEYANUM

POEYANUM

POEYANUM

POEYANUM

POEYANUM

POEYANUM

POEYANUM

POEYANUM

POEYANUM

POEYANUM

POEYANUM

POEYANUM

POEYANUM

POEYANUM

POEYANUM

POEYANUM

POEYANUM

POEYANUM

POEYANUM

POEYANUM

POEYANUM

POEYANUM

POEYANUM

POEYANUM

POEYANUM

POEYANUM

POEYANUM

POEYANUM

POEYANUM

POEYANUM

POEYANUM

POEYANUM

POEYANUM

POEYANUM

POEYANUM

POEYANUM

POEYANUM

POEYANUM

POEYANUM

POEYANUM

POEYANUM

POEYANUM

POEYANUM

POEYANUM

POEYANUM

POEYANUM

POEYANUM

POEYANUM

POEYANUM

POEYANUM

POEYANUM

POEYANUM

POEYANUM

POEYANUM

POEYANUM

POEYANUM

POEYANUM

POEYANUM

POEYANUM

POEYANUM

POEYANUM

POEYANUM

POEYANUM

POEYANUM

POEYANUM

POEYANUM

POEYANUM

POEYANUM

POEYANUM

POEYANUM

POEYANUM

POEYANUM

POEYANUM

POEYANUM

POEYANUM

POEYANUM

POEYANUM

POEYANUM

Locality

LAGUNA MADRE, TEXAS

MISSISSIPPI DELTA

SABINE LAKE, TEXAS

SABINE LAKE, TEXAS

MATAMOROS, MEXICO

NE GULF OF MEXICO

NE GULF OF MEXICO

SOUTH TEXAS COAST

SOUTH TEXAS COAST

TEXAS GULF COAST

TORTUGAS, FLA

N GULF OF MEXICO

NE GULF OF MEXICO

NE GULF OF MEXICO

NE GULF OF MEXICO

$N W$ GULF OF MEXICO

WHITEWATER B.. SW FLA.

MISSISSIPPI SOUND

ALVARADO, MEXICO

TORTUGAS, FLA

SE LOUISIANA

MISSISSIPPI DELTA

MISSISSIPPI DELTA

SAN ANTONIO B., TEXAS 


\section{Publication}

16641 SANDY 1956

1664 ? WALTON 1960

16643 BANDY 1954

16644 AYALA-CASTANARES 1963

16645 BANOY 1954

16646 SANDY 1956

16647 BANDY 1956

16648 BANDY 1956

16649 BANDY 1956

16650 BANDY 1956

16651 PHLEGER 1956

16652 PARKER PHLEGER PEIRSON 1953

16653 PARKER 1754

16654 PARKER 1954

16655 PARKER 1954

16656 PARKER 1954

16657 PARKER 1954

16658 BANDY 1956

16659 BANDY 1956

16660 BANDY 1956

16661 BANDY 1956

16662 BANOY 1956

16663 BANDY 1956

16664 BANDY 1956

16665 BANDY 1956

16666 CREAGER 1958

16667 KANE 1967

16668 PHLEGER 1954

16669 POST 1951

16670 POST 195

16671 BENDA PURI 1962

16672 ANDERSEN 1961

16673 POAG SWEET 1972

16674 PHLEGER 1956

16675 PHLEGER $1965 \mathrm{C}$

16676 PHLEGER 1954

16677 PARKER PHLEGER PEIRSON 1953

16678 PARKER PHLEGER PEIRSON 1953

16679 PARKER PHLEGER PEIRSON 1953

16680 PARKER PHLEGER PEIRSON 1953

16681 PARKER PHLEGER PEIRSON 1953

16682 PHLEGER 1956

16683 PARKER PHLEGER PEIRSON 1953

16684 PARKER PHLEGER PEIRSON 1953

16685 PHLEGER 19658

16686 PHLEGER 1965 A

16687 PHLEGER 1965 A

16688 BENDA PURI 1962

16689 PHLEGER 1965 A

16690 PHLEGER 1965 A

16691 PHLEGER 19658

16692 PHLEGER 1954

16693 PHLEGER 1954

16694 LEHMANN 1957

16695 PHLEGER 1965 A

16696 PHLEGER 1965 A

16697 PHLEGER 1965 A

16698 PHLEGER 1965 A

16699 BENDA PURI 1962

16700 PHLEGER 1965 A

16701 ANDERSEN 1961

16702 CREAGER 1958

16703 CPEAGER 1958

16704 CREAGER 1958

16705 CREAGER 1958

16706 CREAGER 1958

16707 CREAGER 1958

16708 ANDERSEN 1961

16709 PHLEGER 1955 A

16710 PHLEGER 1955A

16711 PHLEGER 1955 A

16712 PARKER 1954

16713 PAPKER 1954

16714 PARKER 1954

16715 PARKER 1954

16716 PHLEGER 1955 A

16717 PARKER 1954

16718 PARKER 1954

16719 PARKER 1954

16720 PARKER 1954

16721 PARKER 1954

16722 PARKER 1954

16723 PARKER 1954

16724 PHLEGER 1955A

16726 PARKER 1954

16727 PARKER 1954

16728 PHLEGER $1955 \mathrm{~A}$

16729 PHLEGER 1955A

16730 PARKER 1954

16731 PARKER 1954

16732 PARKER 1954

16733 CUSHMAN 1931

16734 CUSHMAN 1931

\section{Generic Name}

ELPHIDIUM

ELPHIDIUM

ELPHIDIUM

ELPHIDIUM

ELPHIDIUM

ELPHIDIUM

ELPHIDIUM

ELPHIDIUM

ELPHIDIUM

ELPHIDIUM

ELPHIDIUM

ELPHIDIUM

ELPHIDIUM

ELPHIDIUM

ELPHIDI UM

ELPHIDIUM

ELPHIDIUM

ELPHIOIUM

ELPHIDIUM

ELPHIDIUM

ELPHIDIUM

ELPHIDIUM

ELPHIOIUM

ELPHIDIUM

ELPH I DI UM

ELPHIDIUM

ELPHIDIUM

ELPHIDIUM

ELPHIDIUM

ELPHIDIUM

ELPHIDIUM

ELPHIDIUN

ELPHIDIUM

ELPH IDIUM

ELPHIDIUM

ELPHIDIUM

ELPHIDIUM

ELPHIDIUM

ELPHIDIUM

ELPH IDI UM

ELPHIDIUM

ELPHIDIUM

ELPHIDIUM

ELPHIDIUM

ELPHIDIUM

ELPHIDIUM

ELPHIDIUM

ELPHIDIUM

ELPHIDIUM

ELPHIDIUM

ELPHIDIUM

ELPHIDIUM

ELPHIDIUM

ELPHIDIUM

DENTALINA

FISSURINA

F I SSURINA

FISSURINA

FISSURINA

FISSURINA

FISSURINA

HOEGLUNDINA

AL ABAMINA

AL ABAMINA

AL ABAMINA

AL ABAMINA

AL ABAMINA

AL ABAMINA

AL ABAMINA

AL ABAMINA

AL ABAMINA

AL ABAM I NA

AL ABAMINA

AL ABAMINA

AL ABAMINA

ALABAMINA

$A L A B A M I N A$

AL ABAMINA

AL ABAMINA

AL ABAMINA

ALABAMINA

AL ABAMINA

AL ABAMINA

AL ABAM INA

AL ABAMINA

AL ABAMINA

HOEGLUNDINA

HOEGLUNDINA

HOEGLUNDINA
Specific Name

POEYANUM

POEYANUM

POEYANUM

POEYANUM

POEYANUM

POEYANUM

POEYANUM

POEYANUM

POEYANUM

POEYANUM

POEYANUM

POEYANUM

POEYANUM

POEYANUM

POEYANUM

RUGULOSUM

RUGULOSUM

RUGULOSUM

RUGUL OSUM

RU GULOSUM

RU EULOSUM

RUGULOSUM

RUGULOSUM

SAGRUM

EX CAVATUM

POEYANUM

POEYANUM

POEYANUM

POEYANUM

POEYANUM

POEYANUM

POEYANUM

POEYANUM

POEYANUM

EXCAVATUM

EX CAVATUM

EXCAVATUM

EXCAVATUM

EX CAVATUM

EXCAVATUM

EXCAVATUM

EXCAVATUM

EXCAVATUM

EXCAVATUM

EXCAVATUM

EXCAVATUM

EXCAVATUM

EXCAVATUM

EXCAVATUM

EXCAVATUM

EXCAVATUM

GUATERI

EXCAVATUM

EXCAVATUM

EXCAVATUM

EXCAVATUM

EXCAVATUM

EXCAVATUM

CONMUNIS

OREIGNYANA

OR BIGNYANA

OREIGNYANA

ORBIGNYANA

OREIGNYANA ANTILLEA

OREIGNYANA ANTILLEA

ELEGANS

DE CORATA

DE CORATA

DE CORATA

DE CORATA

DE CORATA

DE CORATA

DE CORATA

DE CORATA

DE CORATA

DE CORATA

DECORATA

DE CORATA

DE CORATA

DE CORATA

DE CORATA

DE CORATA

DE CORATA

DE CORATA

DE CORATA

DE CORATA

DE CORATA

DE CORATA

DE CORATA

DE CORATA

ELEGANS

ELEGANS

\section{Locality}

NE GULF OF MEXICO

MISSISSIPPI SOUND

NW GULF OF MEXICO

L. DE TERMINOS, CAMPECHE

NW GULF OF MEXICO

NE GULF OF MEXICO

NE GULF OF MEXICO

NE GULF OF MEXICO

NE GULF OF MEXICO 


\section{Publication}

16736 CUSHMAN 1931 16737 PARKER 1954

16738 LUDWICK WALTON 1957

16739 PHLEGER 1955 A

16740 PHLEGER 1955A

16741 PARKER 1954

16742 PARKER 1954

16743 PARKER 1954

16744 PHLEGER $1955 \mathrm{~A}$

16745 PHLEGER 1955A

16746 PHLEGER $1955 \mathrm{~S}$

16747
16748 PHLEGER $1955 \mathrm{~A}$
16749 PARER $1955 \mathrm{~A}$

16749 PARKER 1954

16750 PARKER 1954

16751 PARKER 1954

16752 PARKER 1954

16753 PARKER 1954

16755 LANKFORD 1959

16756 PFLUM FRERICHS 1976 16757 PFLUM FRERICHS 1976 16758 PFLUM FRERICHS 1976 16759 PFLUM FRERICHS 1970 16760 PFLUM FRERICHS 1976 16761 PFLUM FRERICHS 1976 16762 PFLUM FRERICHS 1976 16763 PARKER 1954

16764 PFLUM FRERICHS 1976 16765 PFLUM FRERICHS 1976 16766 PFLUM FRERICHS 1976 16767 PFLUM FRERICHS 1976 16768 PFLUM FRERICHS 1976 16769 PFLUM FRERICHS 1976 16770 PFLUM FRERICHS 1976 16771 PFLUM FRERICHS 1976 16772 PFLUM FRERICHS 1976 16773 PFLUM FRERICHS 1976 16774 PFLUM FRERICHS 1976 16775 PFLUM FRERICHS 1976 16776 PFLUM FRERICHS 1976 16777 PFLUM FRERICHS 1976

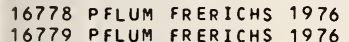
16780 PARKER 1954

16781 PFLUM FRERICHS 1976 16782 PFLUM FRERICHS 1976 16783 PFLUM FRERICHS 1976 16784 PFLUM FRERICHS 1976 16785 PFLUM FRERICHS 1976 16786 PFLUM FRERICHS 1976 16787 PFLUM FRERICHS 1976 16789 PFLUM FRERICHS 1976

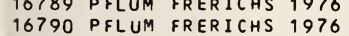
16791 PFLUM FRERICHS 1976 16792 PFLUM FRERICHS 1976 16793 PFLUM FRERICHS 1976 16794 PFLUM FRERICHS 1976 16795 PFLUM FRERICHS 1976 16796 PFLUM FRERICHS 1976 16797 PFLUM FRERICHS 1976 16798 PFLUM FRERICHS 1976 16799 PFLUM FRERICHS 1976 16800 PFLUM FRERICHS 1976 16801 PFLUM FRERICHS 1976 16802 PFLUM FRERICHS 1976 16803 PFLUM FRERICHS 1976 16804 PFLUM FRERICHS 1976 16805 PFLUM FRERICHS 1976 16806 PFLUM FRERICHS 1976 16807 PFLUM FRERICHS 1976 16808 PFLUM FRERICHS 1976 16809 PFLUM FRERICHS 1976 16810 PFLUM FRERICHS 1976 16811 PFLUM FRERICHS 1976 16812 PFLUM FRERICHS 1976 16813 PFLUM FRERICHS 1976 16814 PFLUM FRERICHS 1976

16815 PARKER 1954

16816 PARKER 1954

16817 PARKER 1954

6818 PARKER 1954

6819 PARKER 1954

16820 PARKER 1954

16821 PHLEGER 1955A

16822 PHLEGER 1955 A

16823 PARKER 1954

16824 PARKER 1954

16825 PARKER 1954

16826 PARKER 1954

16827 PARKER 1954

16828 PARKER 1954

16829 PARKER 1954

16830 PARKER 1954
Generic Name

HOEGLUNDINA

EP I S TOM I NELLLA

EP ISTOMINELLA

EPISTOMINELLA

EP ISTOM I NELLA

EPISTOMINELLA

EPISTOMINELL A

EPISTOMINELLA

EP ISTOMINELLLA

EP ISTOMINELLA

EPISTOMINELL A

EPISTOMINELL A

EP ISTOM I NE LLA

EPISTOMINELLA

EP ISTOMINELLA

EP ISTOMINELLA

EP IS TOMINELL A

EP ISTOMINELLA

EP IST OMI NELL L A

EP ISTOMINELLA

EP IST OMINELLA

EPISTOMINELLA

EPISTOMINELLA

EPISTOMINELLA

EP ISTOMI NELL A

EPISTOMINELLA

EPIS TOMINELL A

EPISTOMINELLA

EP IS TOMI NELLA

EPISTOMINELLA

EP ISTOMINELLA

EPISTOMINELLA

EP IST OMINELL A

EP ISTOMINELLA

EP IS TOMINELLA

EP ISTOMINELL A

EPISTOMINELL A

EPISTOMINELL A

EPISTOMINELLA

EPISTOMINELLA

EP ISTOMINELLA

EP ISTOMINELLA

EP IST OMINE LL A

EP IS TOMI NE LLA

EP ISTOMINELL A

EP ISTOMINELLA

EP IS TOMINELL A A

EP IS TOM INELLA

EPISTOMINELLA

EPISTOMINELLA

EP ISTOM I NELL LA

EP ISTOMINELLA

EP IS TOM I NELLA

EP ISTOMINELLA

EP ISTOMI NELLA

EP IS TOMI NELL LA

EP ISTOMI NEL LA

EP ISTOMINELLA

EPISTOMINELLA

EPISTOMINELLA

EP IS TOM I NELLA

EP IS TOMI NELL LA

EP IS TOMI NELLLA

EP ISTOMI INELLA

EP IS T OM I NELLLA

EP ISTOMI NELL A

EP ISTOM I NE LLA

EP ISTOMI NELLA

EPISTOMI NELLA

EP ISTOMI NELLA

EPISTOMINELLA

EPIST OMINELLA

EP IS TOMI NELL A

EP IS TOM INELL

EP ISTOMINELLA

EP I STOMI NE LLA

EP IST OM I NELLLA

EP ISTOMINELL A

EP ISTOMINELLA

EPISTOMINELLA

EP IST OMINELL

EPISTOMINELLA

EP IS TOM I NELLLA

EP IS TOMINELLLA

EP ISTOMINELLA

EP ISTOMINELLA

EP ISTOMINELLA

EP IS TOM I NELL A

OS ANGULLARIA

OSANGUL ARIA

OSANGULARIA

OS ANGULARIA
Specific Name

ELEGANS

EXIGUA

EXIGUA

EXIGUA

EXIGUA

EXIGUA

EXIGUA

EXIGUA

EXIGUA

EXIGUA

EXIGUA

EXIGUA

EXIGUA

EXIGUA

EXIGUA

EXIGUA

EXIGUA

EXIGUA

EXIGUA

EXIGUA

EXIGUA

EXIGUA

EXIGUA

EXIGUA

EXIGUA

EXIGUA

EXIGUA

EXIGUA

EXIGUA

EXIGUA

EXIGUA

EXIGUA

EXIGUA

EXIGUA

EXIGUA

EXIGUA

EXIGUA

EXIGUA

EXIGUA

EXIGUA

EXIGUA

EXIGUA

EXIGUA

EXIGUA

EXIGUA

EXIGUA

EXIGUA

EXIGUA

EXIGUA

EXIGUA

EXIGUA

EXIGUA

EXIGUA

EXIGUA

EXIGUA

EXIGUA

EXIGUA

EXIGUA

EXIGUA

EXIGUA

EXIGUA

EXIGUA

EXIGUA

EXIGUA

EXIGUA

EXIGUA

EXIGUA

EXIGUA

EXIGUA

EXIGUA

EXIGUA

EXIGUA

EXIGUA

EXIGUA

EXIGUA

EXIGUA

EXIGUA

EXIGUA

EXIGUA

EXIGUA

EXIGUA

EXIGUA

EXIGUA

EXIGUA

EXIGUA

EXIGUA

RUGOSA

RUGOSA

RUGOSA

RUGOSA

Locality

NE GULF OF MEXICO

NE GULF OF MEXICO

NE GULF OF MEXICO

N GULF OF MEXICO

$N$ GULF OF MEXICO

NE GULF OF MEXICO

NE GULF OF MEXICO

NE GULF OF MEXICO

$N$ GULF OF MEXICO

$N$ GULF OF MEXICO

$N$ GULF OF MEXICO 


\section{Publication}

16831 PARKER 1954 16832 DARKER 1954 16833 PARKER 1954 16834 PARKER 1954 16835 PARKER 1954 16836 PARKER 1954 16837 PARKER 1954 16838 PARKER 1754 16839 PARKER 1254 16840 PARKER 1954

16841 PARKER 1954 16842 PARKFR 1954 16843 PARKER 1954 16844 PARKER 1054 16845 PARKER 1954 16846 PARKER 1254 16847 PHLEGFR 1956 16848 PHLEGER 1956 16849 PARKFR 1254
16850 PHLEGER 1956 16850
16851 PALEGER 1956 16851 PARKER 1954
16852 PARKER 1954 16853 PARKER 1954

16854 PARKER 1954

16855 PARKER 1954

16856 PARKER 1954

16857 PAPKER 1954

16858 PARKER 1954

16859 ANDERSEN 1961

16860 ANDERSEN 1961

16862 ANDERSEN 1961

16863 WARREN 1957

16864 PARKER 1954

16865 PARKER 1054

16866 PARKER 1954

16867 PARKER 1954

16868 PHLEGER 1955A

16869 POAG 1976

16870 PHLEGER 19558

16871 LUDWICK WALTON 1957

16872 LANKFORD 1959

16873 ANDERSFN 1961

16874 ANDERSEN 1961

16875 PARKER 1954

16876 PARKER 1954

16877 PHLEGER 1956

16878 BOCK 1976

16879 PARKER DHLEGER PEIRSON 1953

16880 ANDERSEN 1961

16881 PARKER DHLEGER PEIRSON 1953

16882 WARREN 1956

16883 ANDERSFY 1961

16884 PARKER 1954

16885 ANDERSEN 196

16886 PARKER 1954

16887 PARKER 1954

16888 DARKER 1954

16889 AYALA-CASTANARES SEGURA 1968 PALMERINELLA

16890 AKERS 1052

16891 WARREN 1357

16892 PHLEGER LANKFORD 1957

16893 KANE 1052

16894 KANE 1967

16895 WARREN 1956

16896 AYALA-CAS
16897 POAG 1976

16898 POAG 1976

16899 PARKER 1954

16900 LUDWICK WALTON 1957

16901 PARKER 1954

16902 PARKFR 1254

16903 PARKER 1954

16904 PARKER 1954

16905 PHLEGER 1951 A

16906 PHLEGER $1951 \mathrm{~A}$

16907 PARKER 1954

16908 PARKER 1954

16909 PARKER 1954

16910 PHLEGER $1951 \mathrm{~A}$

16911 PHLEGER $1951 \mathrm{~A}$

16912 PHLEGER $1951 \mathrm{~A}$

16913 PHLEGER 1951A

16914 PHLEGER $1951 \mathrm{~A}$

16915 PHLEGER 1951A

16916 PHLEGER 1951A

16917 PHLEGER 1951 A

16918 PHLEGER 1951 A

16919 PARKER 1954

16920 PARKER 1954

16921 PHLEGER 1951 A

16922 PHLEGER $1951 \mathrm{~A}$

16923 PHLEGER 1951

16924 PHLEGER 1951 A
16925 BANDY 1954
Generic Name

OS ANGULARIA

OS ANGULARIA

OSANGULARIA

OSANGUL ARIA

OS ANGUL ARIA

OS ANGUL ARIA

OSANGULARIA

OSANGULARIA

EP IS TOM I NELL A

EP IST OM I NE LLA

EP ISTOMINELLA

EP ISTOMINELLA

EP IST OM I NELL L

EP I STOMINELLA

EPISTOMINELLA

EP ISTOMINELLA

EP ISTOMINELLA

EP ISTOMINELLA

EP ISTOMINELLA

EPIST OMINE LL A

EPIST OMINELLA

EP IST OM I NELLA

EP IS TOMINE LLA

EP ISTOMINELL A

EP IST OMINELLA

EP ISTOMINELLA

EP IST OMINELLA

EP IST OMI NELLA

EP IS I OMINE LL A

EPISTOMINELLA

EP IS TOMINELLA

EPISTOMINELLA

EPIST OMINELLA

EP ISTOMINELLA

EP IST OMINELLA

EP I STOM I NELL

EP ISTOMINELLA

EP ISTOMINELL A

EP IS T OMINELLA

EPISTOMINELLA

EPISTOMINELLA

EP ISTOMINELLA

EP IS TOMINELL

EPISTOMINELLA

EPISTOMINELLA

EP ISTOMINELLA

EP IS TOMINELLA

EPISTOMINELLA

EPIST OMINELLA

EP IST OM I NELL

EP IS TOM I NE LLA

PALMERINELLA

PALMERINELLA

PALMER I NELLA

PA LMERINELLA

PALMER INELLA

PALMERINELLA

PALMERINELLA

PALMER INELLA

PAL MERI NELL A

EP ONIDES

EPONIDES

EPONIDES

EP ONI DES

EPONIDES

EPONIDES

EPONIDES

EPONIDES

EPONIDES

EP ONIDES

EPONIDES

EP ONIDES

EP ONIDES

EP ONIDES

EP ONIDES

EPONIDES

EPONIDES

EP ONIDES

EP ONIDES

EP ONIDES

EPONIDES

EPONIDES

EP ONI DES

EP ONIDES

EPONIDES

EPONIDES

EPONIDES
Specific Name

RUGOSA

RUEOSA

RUGOSA

RUGOSA

RUGOSA

RUGOSA

RUGOSA

RUGOSA

RUGOSA

RUGOSA

VI TREA

VI TREA

VI TREA

VITREA

VI TREA

VITREA

VI TREA

VI TREA

VI TREA

VI TREA

VITREA

VI TREA

VI TREA

VI TREA

VI TREA

VI TREA

VI TREA

VITREA

VITREA

VI TREA

VI TREA

VI TREA

VI TREA

VI TREA

VI TREA

VI TREA

VI TREA

VI TREA

VI TREA

VITREA

VI TREA

VI TREA

VI TREA

VITREA

VI TREA

VI TREA

VI TREA

VI TREA

VI TREA

VITREA

VI TREA

VI TREA

VITREA

GARDENISLANDENSIS

GARDENISLANDENS IS

GARDENISLANDENSIS

GARDENISLANDENSIS

GARDENISLANDENSIS

GARDENISLANDENSIS

GARDENISLANDENSIS

GARDENISLANDENS IS

GARDENISLANDENSIS

PAL.MERAE

ANTILLARUM

AN TILL ARUM

AN TILLARUM

AN TILLARUM

ANTILLARUM

ANTILLARUM

ANTILLARUM

ANTILLARUM

AN TILLARUM

AN TILLARUM

AN TILLARUM

ANTILLARUM

ANTILLARUM

ANTILLARUM

ANTILLARUM

ANTILLARUM

AN TILLARUM

AN TILLARUM

ANTILLARUM

AN TILLARUM

ANTILLARUM

ANTILLARUM

ANTILLARUM

AN TILLARUM

ANTILLARUM

ANTILLARUM

AN TILLARUM

Locality

NE GULF OF MEXICO NE GULF OF MEXICO NE GULF OF MEXICO

NE GULF OF MEXICO

NE GULF OF MEXICO

NE GULF OF MEXICO

NE GULF OF MEXICO

NE GULF OF MEXICO

NE GULF OF MEXICO

NE GULF OF MEXICO

NE GULF OF MEXICO

NE GULF OF MEXICO

NE GULF OF MEXICO

NE GULF OF MEXICO 
Publication

16926 BANDY 1954 16927 BANDY 1954 16928 BANDY 1954 16929 BANDY 1956 16930 BANDY 1956 16931 BANDY 1956 16932 BANDY 1956 16933 BANDY 1956 16934 BANDY 1956 16935 KELLOUGH 1956 16936 KELLOUGH 1956 16937 KELLOUGH 1956 16937 KELLOUGH 1956 16939 KELLOUGH 1956 16940 KELLOUGH 1956 16941 PHLEGER 1951 A 16942 PHLEGER $1951 \mathrm{~A}$ 16943 BANDY 1954 16944 BANDY 1954 16945 PHLEGER 1951 A 16946 PARKER 1954 16947 CREAGER 1958 16948 PHLEGER 1956 16949 PHLEGER 1956 16950 PHLEGER 1956

16951 BOCK 1976

16952 BOCK 1976

16953 CREAGER 1958

16954 BOCK 1976

16955 PHLEGER 1951A

16957 KELLOUGH 1956

16958 BANDY 1956

16959 BANDY 1956

16960 BANDY 1956

16961 BANDY 1956

16962 BANDY 1956

16963 BANDY 1956

16964 BANDY 1956

16965 CUSHMAN 1931

16966 BANDY 1956

16967 BANDY 1956

16968 BANDY 1956

16969 CUSHMAN 1931

16970 SEGURA 1963

16971 CREAGER 1958

16972 PHLEGER 1955B

16973 PHLEGER 19S1A

16974 PHLEGER $1951 \mathrm{~A}$

16975 PHLEGER 1951A

16976 PHLEGER 1951A

16977 PHLEGER 1951A

16978 PHLEGER $1951 \mathrm{~A}$

16979 PHLEGER 1951A

16980 PHLEGER $1951 \mathrm{~A}$

16981 PHLEGER 1951A

16982 PHLEGER 1951A

16983 PHLEGER 1951A

16984 DHLEGER 1951A

16985 PHLEGER 1951 A

16986 PHLEGER 1951A

16987 KELLOUGH 1956

16988 KELLOUGH 1956

16989 KELLOUGH 1956

16990 KELLOUGH 1956

16991 KELLOUGH 1956

16992 PHLEGER $1951 \mathrm{~A}$

16993 PHLEGER $1951 \mathrm{~A}$

$\begin{array}{ll}16994 & \text { PHLEGER } 1951 A \\ 16995 & \text { PHLEGER } 1954\end{array}$

16996 PHLEGER 1954

16997 PHLEGER 1951A

16998 CREAGER 1958

16999 CREAGER 1958

17000 NORTON 1930

17001 CUSHMAN 1931

17002 PFLUM FRERICHS 1976

17003 PFLUM FRERICHS 1976

17004 PFLUM FRERICHS 1976

17005 PFLUM FRERICHS 1976

17006 PFLUM FRERICHS 1976

17007 PFLUM FRERICHS 1976

17008 PFLUM FRERICHS 1976

17009 PFLUM FRERICHS 1976

17010 CREAGER 1958

17011 PARKER 1954

17012 PARKER 1954

17013 PARKER 1954

17014 PARKER 1954

17015 PARKER 1954

17016 PARKER 1954

17017 PARKER 1954

17018 PFLUM FRERICHS 1976

17019 PFLUM FRERICHS 1976

17020 PFLUM FRERICHS 1976
Generic Name

EPONIDES

EPONIDES

EPONIDES

EP ONIDES

EP ONIDES

EPONIDES

EPONIDES

EPONIDES

EPONIDES

EPONIDES

EPONIDES

EPONIDES

EPONIDES

EP ONIDES

EPONIDES

EPONIDES

EPONIDES

EPONIDES

EPONIDES

EPONIDES

EPONIDES

EPONIDES

EPONIDES

EPONIDES

EPONIDES

EPONIDES

EPONIDES

EPONIDES

EPONIDES

EPONIDES

EPONIDES

EPONIDES

EPONIDES

EPONIDES

EPONIDES

EPONIDES

EPONIDES

EPONIDES

EPONIDES

EPONIDES

EPONIDES

EPONIDES

EPONIDES

NE OEPONIDES

EPON I DES

BUCCELLA

BUCCELLA

BUCCELLA

BUCCELLA

BUCCELLA

BUCCELLA

BUCCELLA

BUCCELLA
BUCCELLA

BUCCELLA

BUCCELLA

BUCCELLA

BUCCELLA

BUCCELLA

BUCCELLA

BUCCELLA

BUCCELLA

BUCCELLA

BUCCELLA

BUCCELLA

BUCCELLA

BUCCELLA

BUCCELLA

BUCCELLA

BUCCELLA

BUCCELLA

EPONIDES
POROEPONIDES

EPONIDES

EPONIDES

EPONIDES

EPONIDES

EPONIDES

EPONIDES

EPONIDES

EPONIDES

EPONIDES

EPONIDES

EPONIDES

EPONIDES

EPONIDES

EPONIDES

EPONIDES

EPONIDES

EPONIDES

EPONIDES

EPONIDES
Specific Name

ANTILLARUM

ANTILLARUM

AN TILLARUM

ANTILLARUM

AN IILLARUM

ANTILLARUM

ANTILLARUM

AN TILLARUM

ANTILLARUM

AN TILLARUM

ANTILLARUM

AN.TILLARUM

AN TILLARUM

AN TILLARUM

AN TILLARUM

AN TILLARUM

ANTILLARUM

AN TILLARUM

AN TILLARUM

ANTILLARUM

AN TILLARUM

ANTILLARUM

AN TILLARUM

AN TILLARUM

AN TILLARUM

AN TILLARUM

AN TILLARUM

AN TILLARUM

ANTILLARUM

AN TILLARUM

AN TILLARUM

ANTILLARUM

AN TILLARUM

AN TILLARUM

ANTILLARUM

AN TILLARUM

AN TILLARUM

AN TILLARUM

ANTILLARUM

AN TILLARUM

AN TILLARUM

CORYELLI

MATAMOROS, MEXICO

GAVIOTAENSIS BAY OF CAMPECHE

HANNAI

HANNAI

HANNAI

HANNAI

HANNAI

HANNAI

HANNAI

HANNAI

HANNAI

HANNAI

HANNAI

HANNAI

HANNAI

HANNAI

HANNAI

HANNAI

HAANAI

HANNAI

HANNAI

HANNAI

HANNAI

HA ANAI

HANNAI

HANNAI

HANNAI

HANNAI

IN CERTA

LATERALIS

POLIUS

POLIUS

POLIUS

POLIUS

POLIUS

POLIUS

POLIUS

POLIUS

POLIUS

POLIUS

POLIUS

POLIUS

POLIUS

POLIUS

POLIUS

POLIUS

POLIUS

POLIUS

POLIUS

Locality

NW GULF OF MEXICO

NW GULF OF MEXICO

NW GULF OF MEXICO

NE GULF OF MEXICO

NE GULF OF MEXICO

NE GULF OF MEXICO

NE GULF OF MEXICO

NE GULF OF MEXICO

W GULF OF MEXICO

NW GULF OF MEXICO

Lat. Long. 


\section{Publication}

17021 PFLUM FRERICHS 1976 17022 PFLUM FRERICHS 1976 17023 PFLUM FRERICHS 1976 17024 PFLUM FRERICHS 1976 17025 PFLUM FRERICHS 1976 17026 PFLUM FRERICHS 1976 17027 PHLEGER 19518

17028 PARKER 1954

17029 LUDWICK WALTON 1957

$17030^{\circ}$ PHLEGER 1955A

17031 PHLEGER 1955A

17032 PARKER 1954

17033 PARKER 1954

17034 PARKER 1954

17035 PHLEGER 1955 A

17036 PHLEGER 1955A
17037 PFLUM FRERICHS 1976

17038 PFLUM FRERICHS 1976

17039 PFLUM FRERICHS 1976

17040 PARKER 1954

17041 PFLUM FRERICHS 1976

17042 PARKER 1954

17043 PARKER 1954

17044 PARKER 1954

17045 PHLEGER 1955A

17046 PHLEGER 1951B

17047 PARKER 1954

17048 PARKER 1954

17049 PARKER 1954

17050 PARKER 1954

17051 PFLUM FRERICHS 1976

17052 PFLUM FRERICHS 1976

17053 PFLUM FRERICHS 1976

17054 PFLUM FRERICHS 1976

17055 PFLUM FRERICHS 1976

17056 PFLUM FRERICHS 1976

17057 PFLUM FRERICHS 1976

17058 PFLUM FRERICHS 1976

17059 PFLUM FRERICHS 1976

17060 PFLUM FRERICHS 1976

17061 PFLUM FRERICHS 1976

17062 PFLUM FRERICHS 1976

17063 PFLUM FRERICHS 1976

17064 PFLUM FRERICHS 1976

17065 PFLUM FRERICHS 1976

17066 PFLUM FRERICHS 1976

17067 PFLUM FRERICHS 1976

17068 PFLUM FRERICHS 1976

17069 PFLUM FRERICHS 1976

17070 PFLUM FRERICHS 1976

17071 PFLUM FRERICHS 1976

17072 PFLUM FRERICHS 1976

17073 PFLUM FRERICHS 1976

17074 PFLUM FRERICHS 1976

17075 PFLUM FRERICHS 1976

17076 PFLUM FRERICHS 1976

17077 PFLUM FRERICHS 1976

17078 PFLUM FRERICHS 1976

17079 PFLUM FRERICHS 1976

17080 PFLUM FRERICHS 1976

17081 PFLUM FRERICHS 1976

17082 PFLUM FRERICHS 1976

17083 PFLUM FRERICHS 1976

17084 PFLUM FRERICHS 1976

17085 PFLUM FRERICHS 1976

17086 NORTON 1930

17087 CREAGER 1958

17088 CREAGER 1958

17089 LOEP 1965

17090 BOCK 1976

17091 PFLUM FRERICHS 1976

17092 PFLUM FRERICHS 1976

17093 PFLUM FRERICHS 1976

17094 PFLUM FRERICHS 1976

17095 PFLUM FRERICHS 1976

17096 PFLUM FRERICHS 1976

17097 PFLUM FRERICHS 1976

17098 PFLUM FRERICHS 1976

17099 PFLUM FRERICHS 1976

17100 PFLUM FRERICHS 1976

17101 PFLUM FRERICHS 1976

17102 PFLUM FRERICHS 1976

17103 PFLUM FRERICHS 1976

17104 PFLUM FRERICHS 1976

17105 PFLUM FRERICHS 1976

17106 PFLUM FRERICHS 1976

17107 PFLUM FRERICHS 1976

17108 PFLUM FRERICHS 1976

17109 PHLEGER 1951A

17110 PHLEGER 1951A

17111 PHLEGER $1951 \mathrm{~A}$

17112 PFLUM FRERICHS 1976

17113 PFLUM FRERICHS 1976

17114 PFLUM FRERICHS 1976

17115 PFLUM FRERICHS 1976
Generic Name

EPONIDES

EPONIDES

EPONIDES

EPONIDES

EPONIDES

EPONIDES

EPONIDES

EPONIDES

EPONIDES

EPONIDES

EPONIDES

EP ONIDES

EPONIDES

EPONIDES

EPONIDES

EPONIDES

EPONIDES

EPONIDES

EPONIDES

EPONIDES

EPONIDES

EPONIDES

EPONIDES

EPONIDES

EPONIDES

EPONIDES

EPONIDES

EPONIDES

EPONIDES

EPONIDES

EPONIDES

EPON IDES

EPONIDES

EPONIDES

EPONIDES

EPONIDES

EPONIDES

EP ONIDES

EP ONIDES

EPONIDES

EPONIDES

EPONIDES

EPONIDES

EPONIDES

EPONIDES

EPONIDES

EPONIDES

EPONIDES

EP ONIDES

EPONIDES

EPONIDES

EPONIDES

EP ONIDES

EPONIDES

EPONIDES

EPONIDES

EPONIDES

EP ON IDES

EP ONIDES

EP ONIDES

EPONIDES

EP ONIDES

EPONIDES

EPONIDES

EPONIDES

EPONIDES

EPONIDES

EPONIDES

EPONIDES

EP ONIDES

EPONIDES

EPONIDES

EPONIDES

EPONIDES

EPONIDES

EPONIDES

EPONIDES

EPONIDES

EPONIDES

EPONIDES

EPONIDES

EPONIDES

EPONIDES

EPONIDES

EP ONIDES

EPONIDES

EPONIDES

EPONIDES

EPONIDES

EPONIDES

EPONIDES

EPONIDES

EPONIDES

EPONIDES

EPONIDES
Specific Name

POLIUS

PLIUS

POLIUS

POLIUS

POLIUS
POLIUS

POLIUS

POLIUS

POLIUS

POLIUS

POLIUS
POLIUS

POLIUS

POLIUS

POLIUS

POLIUS

POLIUS

POLIUS
POLIUS

POLIUS

POLIUS

POLIUS

POLIUS

POLIUS

POLIUS
POLIUS

POLIUS

POLIUS

POLIUS

POLIUS

POLIUS

POLIUS

POLIUS

POLIUS

POLIUS

POLIUS

POLIUS

POLIUS

POLIUS

POLIUS

POLIUS

POLIUS

POLIUS

POLIUS

POLIUS

POLIUS

POLIUS

POLIUS

POLIUS

POLIUS

POLIUS

POLIUS

POLIUS

POLIUS
POLIUS

POLIUS

POLIUS

POLIUS

POLIUS

POLIUS

POLIUS
POLIUS

PY EMAEA

RE GULARIS

REGULARIS

RE GULARIS

RE GUL ARIS

RE GULAR IS

RE GULAR IS

RE GULAR IS

REGULARIS

RE GULAR IS

REGULARIS

RE GULAR IS

REGULARIS

RE GULAR IS

RE GULARIS

REGULAR IS

RE GULARIS

RE GULARIS

RE GULAR IS

RE GULAR IS

RE GULARIS

RE GULARIS

RE GULARIS

RE GULARIS

REGULARIS

RE GULARIS

RE GULARIS

RE GULAR IS

Locality

CENTRAL GULF OF MEXICO CENTRAL GULF OF MEXICO CENTRAL GULF OF MEXICO

CENTRAL GULF OF MEXICO

CENTRAL GULF OF MEXICO

CENTRAL GULF OF MEXICO

SIGSBEE DEEP

NE GULF OF MEXICO

NE GULF OF MEXICO

$N$ GULF OF MEXICO

$N$ GULF OF MEXICO

NE GULF OF MEXICO 


\section{Publication}

17116 PFLUM FRERICHS 1976

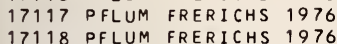
17118 PFLUM FRERICHS
17119 PHLEGER 195\%A

17120 PFLUM FRERICHS 1976 17121 PFLUM FRERICHS 1976 17122 PFLUM FRERICHS 1976 17123 PFLUM FRERICHS 1976 17124 PFLUM FRERICHS 1976 17125 LEHMANN 1957

17126 PHLEGER 1951A

17127 PHLEGER 1951A

17128 PHLEGER 1951A

17129 PHLEGER 1951A

17130 PHLEGER 1951A
17131 PHLEGER 1951A

17132 PARKER 1954

17133 LUDWICK WALTON 1957

17134 PHLEGER 1955A

17135 PHLEGER 1955A

17136 PHLEGER 1951A

17137 PHLEGER 1951A

17138 PHLEGER 1951A

17139 PHLEGER 1951A

17140 PHLEGER $1951 \mathrm{~A}$

17141 PHLEGER 1951A

17142 PHLEGER 1951A

17143 PHLEGER 1951A

17144 PHLEGER 1951A

17145 PHLEGER $1951 \mathrm{~A}$

17146 PHLEGER 1951A

17147 PHLEGER 1951A

17149 PARKER 1954

17150 PARKER 1954

17151 PARKER 1954

17152 PARKER 1954

17153 PARKER 1954

17154 PARKER 1954

17156 PARKER 1954

17157 CUSHMAN 1931

17158 NORTON 1930

17159 LUDWICK WALTON 1957

17160 PARKER 1954

17161 PARKER 1954

17163 PARKER 1954

17164 PARKER 1954

17165 LOEP 1965

17166 PARKER 1954

17167 PARKER 1954

17168 PARKER 1954

17169 PARKER 1954

17170 SEGURA 1963

17171 PARKER 1954

17172 PARKER 1954

17173 LEHMANN 1957

17174 KELLOUGH 1956

17176 PARKER 1954

17177 PARKER 1954

17178 PARKER 1954

17179 PFLUM FRERICHS 1976

17180 PFLUM FRERICHS 1976

17181 PFLUM FRERICHS 1976

17182 PFLUM FRERICHS 1976

17183 PFLUM FRERICHS 1976

17184 PFLUM FRERICHS 1976

17185 PFLUM FRERICHS 1976

17186 PFLUM FRERICHS 1976

17187 PARKER 1954

17188 PARKER 1954

17189 LUDWICK WALTON 1957

17190 PHLEGER 1955A

17191 PHLEGER 1955A

17192 PHLEGER 1955A

17193 PHLEGER 1951B

17194 PHLEGER 1955A

17195 PHLEGER 1951A

17196 PHLEGER $1951 \mathrm{~A}$

17197 PHLEGER 1951A

17198 PHLEGER 1951A

17199 PHLEGER 1951A

17200 PARKER 1954

17201 PARKER 1954

17202 BOCK 1976

17203 ANDERSEN 1961

17204 PFLUM FRERICHS 1976

17205 PFLUM FRERICHS 1976

17206 PFLUM FRERICHS 1976

17207 PFLUM FRERICHS 1976

17208 PHLEGER 1951A

17209 PHLEGER 1951A

\section{Generic Name}

EPONIDES

EPONIDES

EPONIDES

EP ONIDES

EPONIDES

EP ONIDES

EPONIDES
EP ONIDES

EP ONIDES
EPONIDES

EPONIDES

EPONIDES

EPONIDES

EPONIDES

EPONIDES

EP ONI DES

EPONIDES

EP ONIDES

EP ONIDES

EPONIDES

EPONIDES

EPONIDES

EPONIDES

EPONIDES

EPONIDES

EPONIDES

EPONIDES

EP ONIDES

EPONIDES

EPONIDES

EPONIDES

EPONIDES

EPONIDES

EPONIDES

EPONIDES

EP ONIDES

EPONIDES

EPONIDES

EPONIDES

EPONIDES

EPONIDES

EPONIDES

EPONIDES

EPONIDES

EPONIDES

EPONIDES

EP ONIDES

EPONIDES

EPONIDES

EPONIDES

EPONIDES

EPONIDES

EPONIDES

EPONIDES

EPONIDES

EPONIDES

EPONIDES

EPONIDES

EP ONIDES

EP ONIDES

EPONIDES

EPONIDES

EPONIDES

EPONIDES

EP ONIDES

EPONIDES

EPONIDES

EPONIDES

EPONIDES

EPONIDES

EPONIDES

EPONIDES

EPONIDES

EPONIDES

EPONIDES

EP ONIDES

EP ONIDES

EPONIDES

EPONIDES

EPONIDES

EPONIDES

EPONIDES

EPONIDES

EPONIDES

EPONIDES

EPONIDES

EP ONIDES

EPONIDES

EPONIDES

EPONI DES

EP ONI DES
EPONIDES

EPONIDES

EPONIDES

EPONIDES
Specific Name

RE GULARIS

RE GULAR IS

RE GULARIS

RE GULARIS

REGULARIS

REGULARIS

REGULARIS

REGULARIS

RE GULARIS

REGULARIS

RE GULARIS

RE GULARIS

RE GULARIS

REGULARIS

REGULARIS

RE GULARIS

RE GULARIS

REGULARIS

RE GULARIS

RE GULARIS

RE GULARIS

RE GULARIS

REGULARIS

RE GULARIS

RE GULARIS

REGUL AR IS

RE EULARIS

RE GULARIS

RE GUL AR I S

RE GULARIS

RE GUL ARIS

RE GULARIS

REGULARIS

RE EULARIS

RE GULARIS

RE GULARIS

RE GULAR IS

RE GULAR IS

RE GULARIS

REGULARIS

REGULAR IS

REPANDUS

REPANDUS

REPANDUS

REPANDUS

REFANDUS

REFANDUS

REPANDUS

REPANDUS

REPANDUS

REPANDUS

REPANDUS

REFANDUS

REPANDUS

REFANDUS

REFANDUS

REPANDUS

REFANDUS

TENERA

TUMIDULUS

TUNIDULUS

TUNIDULUS

TUNIDULUS

TUMIDULUS

TUNIDULUS

TUNI DULUS

TUNIDULUS

TUNIDULUS

TUNI DULUS

TUNIDULUS

TUNI DULUS

TUNI DULUS

TUNIDULUS

TUNI DULUS

TUNIDULUS

TUNIDULUS

TUNIDULUS

TUNI DULUS

TUNI DULUS

TUNI DULUS

TUNIDULUS

TUNIDULUS

TUMI DULUS

TUNIDULUS

TUNIDULUS

TUNIDULUS

TUNIDULUS

TUNI DULUS

TUNIDULUS

TUNIDULUS

TUNI DULUS

TUNIDULUS

TUNIDULUS

TUNI DULUS

\section{Locality}

NW GULF OF MEXICO

NW GULF OF MEXICO

NW GULF OF MEXICO

NW GULF OF MEXICO

NW GULF OF MEXICO

NW GULF OF MEXICO

NW GULF OF MEXICO

$N W$ GULF OF MEXICO

NW GULF OF MEXICO 


\section{Publication}

17211 PHLEGER 1951A 17212 PHLEGER $1951 \mathrm{~A}$ 17213 PHLEGER 1951A 17214 PHLEGER $1951 \mathrm{~A}$ 17215 PHLFGFR $1955 \mathrm{~A}$ 17216 PARKER 1254

17217 PFLUM FRERICHS 1976 17218 PFLUM FRERICHS 1976 17219 PFLIJM FRERICHS 1976 17221 PFLUM FRERICHS 1976 17222 PFLUM FRERICHS 1976 17223 PFLUM FRERICHS 1976 17224 PFLUM FRERICHS 1976 17225 PFLUM FRERICHS 1976 17226 PFLUM FRERICHS 1976 17227 PFLUM FRERICHS 1976 17228 PARKER 1254 17229 PARKER 1754 17230 PARKER 1754 17231 PARKER 1454

17232 PARKER 1754
17232 PFLUM FRERICHS 1976 17234 PFLUM FRERICHS 1976 17235 PHLEGER $1951 \mathrm{~A}$

17236 PFLUM FRERICHS 1976 17237 PFLUiA FRERICHS 1976 17238 PFLUM FRERICHS 1976 17239 PFLUM FRERICHS 1976 17240 PARKER 1954

17241 PARKER 1954

17242 PARKER 1254
17243 PFLUM FRERICHS 1976

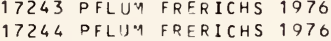
17245 PFLUM FRERICHS 1976 17246 PFLUM FRERICHS 1976 17247 PARKER 1954

17248 PARKER 1954

17249 PARKER 1754

17250 PARKER 1754

17251 PFLUM FRERICHS 1976 17252 PFLUM FRERICHS 1976 17253 PFLUM FRERICHS 1976 17254 PFLUM FRERICHS 1976 17255 PFLUM FRERICHS 1976 17256 PFLUM FRERICHS 1976 17257 PFLIUM FRERICHS 1976 17258 PARKER 1954 17259 PARKER 1754
17260 PARKER 1254 17260 PARKER 1054

17262 PFLUM FRERICHS 1976 17263 PFLUM FRFRICHS 1976 17264 PFLUM FRFRICHS 1976 17265 PFLUM FRERICHS 1976 17266 PHLEGER $1951 \mathrm{~A}$

17267 PHLEGER $1951 \mathrm{~A}$

17268 PHLEGER $1951 \mathrm{~A}$

17269 PFLIJM FRERICHS 1976 17270 PFLUM FRERICHS 1776 17271 PFLUM FRERICHS 1976 17272 PFLUM FRERICHS 1976 17273 PFLUM FRERICHS 1976 17274 PFLUM FRERICHS 1976 17275 PFLUM FRERICHS 1976 17276 PFLUM FRERICHS 1976 17277 PHLEGER 1956

17278 PARKER 1954

17279 PFLUA FRERICHS 1976 17280 PFLUM FRERICHS 1976 17281 PFLUM FRERICHS 1976 17282 PFLUM FRERICHS 1976 17283 PFLUM FRERICHS 1976 17284 PFLUM FRERICHS 1976 17285 PFLUM FRERICHS 1976 17286 PFLIJM FRERICHS 1976 17287 PFLUM FRERICHS 1976 17288 PFLUM FRERICHS 1976 17289 PFLUM FRERICHS 1976 17290 PFLUM FRERICHS 1976 17291 AYALA-CASTANARES 1963 17292 PARKER 1754

17293 PARKER 1954

17294 PFLUM FRERICHS 1976 17295 PFLUM FRERICHS 1976 17296 PFLUM FRERICHS 1976 17297 PARKER 1954

17298 PARKEP 1354

17299 PHLEGER 1955 A

17300 PHLEGER 1951A

17301 PHLEGER 1955A

17302 PHLEGER 1951 A

17303 PHLEGER $1951 \mathrm{~A}$

17305 PHLEGER 1951A

\section{Generic Name}

EPONIDE

EPONIDES

EPONIDES

EPONIDES

EPONIDES

EPONIDES

EPONIDES

EPONIDES

EPONIDES

EPONIDES

EPONIDES

EPONIDES

EPONIDES

EPONIDES

EPONIDES

EPONIDES

EPONIDES

EPONIDES

EPONIDES

EPONIDES

EP ONIDES

EPONIDES

EPONIDES

EPONIDES

EPONIDES

EPONIDES

EPONIDES

EPONIDES

EPONIDES

EPONIDES

EPONIDES

EPONIDES

EPONIDES

EPONIDES

EPONIDES

EPONIDES

EPONIDES

EPONIDES

EP ONIDES

EPONIDES

EPONIDES

EPONIDES

EPONIDES

EPONIDES

EPONIDES

EPONIDES

EPONIDES

EPONIDES

EPONIDES

EPONIDES

EPONIDES

EPONIDES

EPONIDES

EPONIDES

EPONIDES

EPONIDES

EP ONIDES

EPONIDES

EPONIDES

EP ONI DES

EPONIDES

EPONIDES

EPONIDES

EPONIDES

EPONIDES

EP ONIDES

EPONIDES

EPONIDES

EPONIDES

EPONIDES

EPONIDES

EPONIDES

EPONIDES

EPONIDES

EPONIDES

EPONIDES

EPONIDES

EPONIDES

EPONIDES

EPONIDES

EPONIDES

EP ONIDES

EPONIDES

EPONIDES

EPONIDES

EPONIDES

EPONIDES

EP ONIDES

EPONIDES

EPONIDES

EPONIDES

EPONIDES

EPONIDES

EP ONIDES

\section{Specific Name}

TUNIDULUS

TUNIOULUS

TUNIDULUS

TUN.IDULUS

TUNIDULUS

TUNIDULUS

TUNIDULUS

TUNIDULUS

TUNIDULUS

TUNIDUL US

TUNIDULUS

TUNIDULUS

TUNIDULUS

TUNIDULUS

TUNIDULUS

TUNIDULUS

TUNIDULUS

TUNIDULUS

TUNIDULUS

TUNIDULUS

TUNIDULUS

TUNIDULUS

TUNIDULUS

TUMIDULUS

TUMIDULUS

TUNIDULUS

TUNIDULUS

TUNI DULUS

TUNIDULUS

TURGIDUS

TURGIDUS

TURG IDUS

TURGIDUS

TURGIDUS

TURG I DUS

TURGIDUS

TURGIDUS

TURG I DUS

TURG I DUS

TURGIDUS

TURG I DUS

TURGIDUS

TUFGIDUS

TURG I DUS

IUFGIDUS

TURGIDUS

TURGI DUS

TURGIDU

TURG I DU

TURGI DUS

TURGIDUS

TURGI DUS

TURGIDUS

TURG I DUS

TU RG I DUS

TURGIDUS

TURGIDUS

IURG I DUS

TURG IDUS

TURG I DUS

TURG I DUS

TURGIDUS

TURG I DUS

TURGI DUS

TURGI DUS

TURG I DUS

TURGIDUS

TURGI DUS

TURGI DUS

TURG I DUS

TURGIDUS

TURGI DUS

TURGIOUS

TURGIDUS

TURGIDUS

TURGIDUS

TURGIDUS

IURGIDUS

TURGI DUS

TURGIDUS

TURGIDUS

TURGIDUS

TURGIDUS

TURGIDUS

TURGI DUS

TURG I DUS

TURGI DUS

TURGIDUS

TURGIDUS

TURGIDUS

TURGIDUS

TURGI DUS

IURGIDUS

TURGIOUS

TURGI DUS

\section{Locality}

NW GULF OF MEXICO

NW GULF OF MEXICO 


\section{Publication}

17306 PHLEGER 1951A

17307 PHLEGER $1951 \mathrm{~A}$

17308 PHLEGER 1951A

17309 PHLEGER $1951 \mathrm{~A}$

17310 PHLEGER 1951 A

17311 PHLEGER $1951 \mathrm{~A}$

17312 PHLEGER 1951A

17313 PHLEGER $1951 \mathrm{~A}$

17314 PHLEGER $1951 \mathrm{~A}$

17315 PARKER 1954

17316 PFLUM FRERICHS 1976

17317 PFLUM FRERICHS 1976

17318 PFLUM FRERICHS 1976

17319 PFLUM FRERICHS 1976

17320 PARKER 1954

17321 PARKER 1954

17322 PARKER 1954

17323 PARKER 1954

17324 PHLEGER 1955 A

17325 PHLEGER $1951 \mathrm{~A}$

17326 PHLEGER $1951 \mathrm{~A}$

17327 PARKER 1954

17328 PARKER 1954

17329 PARKER 1954

17330 PARKER 1954

17331 PHLEGER 1955A
17332 LUDWICK WALTON 1957

17333 PHLEGER 1955 A

17334 PFLUM FRERICHS 1976

17335 PFLUM FRERICHS 1976

17336 PHLEGER 1951 A

17337 PHLEGER $1955 \mathrm{~A}$

17338 PHLEGER 1955 A

17339 PFLUM FRERICHS 1976

17340 PFLUM FRERICHS 1976

17341 PFLUM FRERICHS 1976

17342 PFLUM FRERICHS 1976

17343 PFLUM FRERICHS 1976

17344 PHLEGER $1951 \mathrm{~A}$

17345 PHLEGER $1951 \mathrm{~A}$

17346 PHLEGER 1951A

17347 PHLEGER 1951A

17348 PHLEGER $1951 \mathrm{~A}$

17349 PHLEGER $1951 \mathrm{~A}$

17351 PFLUM FRERICHS 1976

17352 PHLEGER 1951A

17353 PHLEGER $1951 \mathrm{~A}$

17354 PHLEGER 1955 A

17355 PHLEGER 1955 A

17356 PHLEGER $1955 \mathrm{~A}$

17357 PHLEGER $1951 \mathrm{~A}$

17358 PHLEGER 1951A

17359 PHLEGEP $1951 \mathrm{~A}$

17360 PHLEGER 1951A

17361 PHLEGER 1951A

17362 PHLEGER 1951A

17363 PHLEGER $1951 \mathrm{~A}$

17364 PHLEGER $1951 \mathrm{~A}$

17365 PHLEGER 1951A

17366 PARKER 1954

17367 PHLEGER 1951A

17368 PHLEGER $1951 \mathrm{~A}$

17369 PHLEGER 1951A

17370 PHLEGER $1951 \mathrm{~A}$

17371 CREAGER 1958

17372 PHLEGER 1951A

17373 PHLEGER $1951 \mathrm{~A}$

17374 PHLEGER 1951 A

17375 PHLEGER $1951 \mathrm{~A}$

17376 PHLEGER $1951 \mathrm{~A}$

17377 PHLEGER $1951 \mathrm{~A}$

17378 PHLEGER 1951A

17379 PHLEGER $1951 \mathrm{~A}$

17380 PHLEGER $1951 \mathrm{~A}$

17381 PHLEGER 1951A

17382 PHLEGER $1951 \mathrm{~A}$

17383 PHLEGER 1951 A

17384 PHLEGER 1951 A

17385 PHLEGER 1951A

17386 PHLEGER 1951A

17387 CREAGER 1958

17388 CREAGER 1958

17389 PHLEGER 1956

17390 CREAGER 1958

17391 CREAGER 1958

17392 PHLEGER $1951 \mathrm{~A}$

17393 PHLEGER 1951A

17394 PHLEGER 1951A

17395 PHLEGER 1951A

17396 PHLEGER $1951 \mathrm{~A}$

17397 PHLEGER 1951A

17398 PHLEGER 1951A

17399 PHLEGER 1951A
Generic Name

Specific Name

TURGIDUS

TURGIDUS

TURGIDUS

TURG I DUS

TURGIDUS

TURG I DUS

TURGIDUS

TURGIDUS

TURGI DUS

TURGIDUS

TURGIDUS

TURGI DUS

TURGIDUS

TURGIDUS

TURGIDUS

TURGIDUS

TURGIDUS

TURGIDUS

TURGI DUS

TURGIDUS

TURGI DUS

TURGIDUS

TURGIDUS

TURGI DUS

TURGIDUS

TURGIDUS

TURGIDUS

TURGI DUS

TURGIDUS

TURGIDUS

TURGIDUS

TURGIDUS

TURG I UUS

TURGIDUS

TURG I DUS

TURGIDUS

TURGIDUS

TURGIDUS

TURGIDUS

TURGIDUS

TURGIDUS

TURGIDUS

TURGIDUS

TURGIDUS

TURG IDUS

TURGIDUS

TURGIDUS

TURGIDUS

TURGIDUS

TURGIDUS

TURGIDUS

TURGIDUS

TURGIDUS

TURG I DUS

TURGIDUS

TURGIDUS

TURGIDUS

TURGIDUS

TURGIDUS

TURGIDUS

UMEONATUS

UMEONATUS

UMBONATUS

UMEONATUS

UMEONATUS

UMEONATUS

UMEONATUS

UMEONATUS

UMEONATUS

UMEONATUS

UMBONATUS

UMEONATUS

UMEONATUS

UMEONATUS

UMEONATUS

UMBONATUS

UMBONATUS

UMEONATUS

UMEONATUS

UMEONATUS

UMEONATUS

UMBONATUS

UMBONATUS

UMBONATUS

UMBONATUS

UMBONATUS

UMEONATUS

UMEONATUS

UMEONATUS

UMEONATUS

UMEONATUS

UMEONATUS

UMEONATUS

\section{Locality}

Lat. Long.

NW GULF OF MEXICO

NW GULF OF MEXICO

NW GULF OF MEXICO

$N W$ GULF OF MEXICO

NW GULF OF MEXICO

NW GULF OF MEXICO

NW GULF OF MEXICO

NW GULF OF MEXICO

NW GULF OF MEXICO

NE GULF OF MEXICO

NW GULF OF MEXICO

NW GULF OF MEXICO

NW GULF OF MEXICO

NW GULF OF MEXICO

NE GULF OF MEXICO

NE GULF OF MEXICO

NE GULF OF MEXICO

NE GULF OF MEXICO

$N$ GULF OF MEXICO

NW GULF OF MEXICO

$N W$ GULF OF MEXICO

NE GULF OF MEXICO

NE GULF OF MEXICO

NE GULF OF MEXICO

NE GULF OF MEXICO

$N$ GULF OF MEXICO

NE GULF OF MEXICO

$N$ GULF OF MEXICO

NW GULF OF MEXICO.

NW GULF OF MEXICO

NW GULF OF MEXICO

$N$ GULF OF MEXICO

NW GULF OF MEXICO

$N W$ GULF OF MEXICO

NW GULF OF MEXICO

NW GULF OF MEXICO

NW GULF OF MEXICO

NW GULF OF MEXICO

NW GULF OF MEXICO

NW GULF OF MEXICO

NW GULF OF MEXICO

$N W$ GULF OF MEXICO

NW GULF OF MEXICO

NW GULF OF MEXICO

NW GULF OF MEXICO

NW GULF OF MEXICO

NW GULF OF MEXICO

$N$ GULF OF MEXICO

$N$ GULF OF MEXICO

NW GULF OF MEXICO

NW GULF OF MEXICO

NW GULF OF MEXICO

NW GULF OF MEXICO

NW GULF OF MEXICO

NW GULF OF MEXICO

NW GULF OF MEXICO

NW GULF OF MEXICO

$\mathrm{NW}$ GULF OF MEXICO

NE GULF OF MEXICO

NW GULF OF MEXICO

$N$ W GULF OF MEXICO

NW GULF OF MEXICO

$N$ W GULF OF MEXICO

BAY OF CAMPECHE

NW GULF OF MEXICO

NW GULF OF MEXICO

$X I C O$

NW GULF OF MEXICO

NW GULF OF MEXICO

NW GULF OF MEXICO

NW GULF OF MEXICO

NW GULF OF MEXICO

NW GULF OF MEXICO

NW GULF OF MEXICO

NW GULF OF MEXICO

NW GULF OF MEXICO

NW GULF OF MEXICO

NW GULF OF MEXICO

NW GULF OF MEXICO

BAY OF CAMPECHE

BAY OF CAMPECHE

NW GULF OF MEXICO

BAY OF CAMPECHE

BAY OF CAMPECHE

NW GULF OF MEXICO

NW GULF OF MEXICO

NW GULF OF MEXICO

NW GULF OF MEXICO

NW GULF OF MEXICO

NW GULF OF MEXICO

NW GULF OF MEXICO

NW GULF OF MEXICO

NW GULF OF MEXICO

$2825 \mathrm{~N} 09149 \mathrm{~W}$

$2750 \mathrm{~N} 09305 \mathrm{~W}$

$\begin{array}{llll}27 & 32 \mathrm{~N} & 093 & 05 \mathrm{~W} \\ 27 & 47 \mathrm{~N} & 091 & 55 \mathrm{~W}\end{array}$

$2508 \mathrm{~N} 09336 \mathrm{~W}$

$2645 \mathrm{~N} 09406 \mathrm{~W}$ 


\section{Publication}

17401 PHLEGER 1951A 17402 PHLEGER $1951 \mathrm{~A}$ 17403 PHLEGER 1951 A 17404 PHLEGER $1951 \mathrm{~A}$ 17405 PHLEGER 1951 A 17406 PHLEGER $1951 \mathrm{~A}$ 17407 CREAGER 1958 17408 PHLEGER 1951 A 17409 PHLEGER 1951A 17410 PHLEGER 1951A 17411 PHLEGER 1951A 17412 PHLEGER 1951A 17413 PHLEGER $1951 \mathrm{~A}$ 17414 PHLEGER 1951A 17415 POAG 1972

17416 CUSHMAN $1922 \mathrm{~A}$

17417 PFLUM FRERICHS 1976 17418 PFLUM FRERICHS 1976 17419 PFLUM FRERICHS 1976 17420 PFLUM FRERICHS 1976 17421 PFLUM FRERICHS 1976 17422 PFLUM FRERICHS 1976 17423 PFLUM FRERICHS 1976 17424 PFLUM FRERICHS 1976 17425 PFLUM FRERICHS 1976 17426 PFLUM FRERICHS 1976 17427 PFLUM FRERICHS 1976 17428 PFLUM FRERICHS 1976 17429 PFLUM FRERICHS 1976 17430 PFLUM FRERICHS 1976 17431 BOCK 1976

17432 PFLUM FRERICHS 1976 17433 PFLUM FRERICHS 1976 17434 PFLUM FRERICHS 1976 17435 PFLUM FRERICHS 1976 17436 PFLUM FRERICHS 1976 17437 PFLUM FRERICHS 1976 17438 PFLUM FRERICHS 1976 17439 PFLUM FRERICHS 1976 17440 PFLUM FRERICHS 1976 17441 PFLUM FRERICHS 1976 17442 PFLUM FRERICHS 1976 17443 KELLOUGH 1956

17444 KELLOUGH 1956

17445 PFLUM FRERICHS 1976 17446 PFLUM FRERICHS 1976 17447 PFLUM FRERICHS 1976 17448 PFLUM FRERICHS 1976 17449 PFLUM FRERICHS 1976 17450 PFLUM FRERICHS 1976 17451 PFLUM FRERICHS 1976 17452 PFLUM FRERICHS 1976 17453 PFLUM FRERICHS 1976 17454 PFLUM FRERICHS 1976 17455 PFLUM FRERICHS 1976 17456 PFLUM FRERICHS 1976 17457 PFLUM FRERICHS 1976 17458 PFLUM FRERICHS 1976 17459 PFLUM FRERICHS 1976 17460 PFLUM FRERICHS 1976 17461 PFLUM FRERICHS 1976 17462 PFLUM FRERICHS 1976 17464 POAG 1976

17465 PFLUM FRERICHS 1976 17466 PFLUM FRERICHS 1976 $\$ 7467$ PFLUM FRERICHS 1976 17468 PFLUM FRERICHS 1976 17469 PFLUM FRERICHS 1976 17470 PFLUM FRERICHS 1976 17471 PFLUM FRERICHS 1976 17472 PFLUM FRERICHS 1976 17473 PFLUM FRERICHS 1976 17474 PFLUM FRERICHS 1976 17475 PFLUM FRERICHS 1976 17476 PFLUM FRERICHS 1976 17477 PFLUM FRERICHS 1976 17478 PFLUM FRERICHS 1976 17479 PFLUM FRERICHS 1976 17480 PFLUM FRERICHS 1976 17481 PFLUM FRERICHS 1976 17482 PFLUM FRERICHS 1976 17483 PFLUM FRERICHS 1976 17484 PFLUM FRERICHS 1976 17485 PFLUM FRERICHS 1976 17486 PFLUM FRERICHS 1976 17487 PFLUM FRERICHS 1976 17488 PFLUM FRERICHS 1976 17489 PFLUM FRERICHS 1976 17490 PFLUM FRERICHS 1976 17491 PFLUM FRERICHS 1976 17493 BOCK 1976

17494 PFLUM FRERICHS 1976 17495 PFLUM FRERICHS 1976

\section{Generic Name}

EPONIDES

EPONIDES

EPONIDES

EPONIDES

EPONIDES

EPONIDES

EPONIDES

EPONIDES

EPONIDES

EPONIDES

EP ON I DES

EPONIDES

EPONIDES

EPONI UES

UV I GER I NA

FI SCHER INELLA

F I SSURINA

FI SSURINA

FISSURINA

FI SSUR INA

FISSURINA

FISSURINA

F I SSURINA

FISSURINA

FISSURINA

FI SSURINA

FISSURINA

FISSURINA

FISSURINA

FISSURINA

FISSURINA

FISSURINA

FISSURINA

FISSURINA

FI SSURINA

FISSURINA

FISSURINA

FI SSURINA

I SSURINA

FI SSURINA

FISSURINA

FI SSURINA

ISSURINA

I SSURINA

FISSURINA

F I SSURINA

FI SSURINA

FISSURINA

FISSURINA

FI SSURINA

F I SSURINA

FI SSURINA

F I SSURINA

FI SSURINA

NONI ONELLA

NONIONELLA

NONIONELLA

NONI ONELLA

NONIONELLA

NONI ONELLA

NONIONELLA

NONI ONELLA

FLORILUS

FLORILUS

FLORILUS

FLORILUS

FLORILUS

FLOR ILUS

FLORILUS

FLORILUS

FLORILUS

FLORILUS

FL ORILUS

FLORILUS

FLORILUS

FLORILUS

FLORILUS

FLORILUS

FLORILUS

FLORILUS

FLORILUS

FLORILUS

FLORILUS

FLORILUS

FLORILUS

FLORILUS

FLORILUS

FLORILUS

FLORILUS

NONIONELLA

FLORILUS

FLORILUS
Specific Name

UMEONATUS

UMEONATUS

UMBONATUS

UMEONATUS

UMBONATUS

UMEONATUS

UMBONATUS

UM BONATUS

UMBONATUS

UMBONATUS

UMEONATUS

UMBONATUS

PARVULA

OUBIA

AR ADASI I

ARADASII

ARADASII

AR ADASII

AR ADASII

ARADASI I

FORMOSA

FORMOSA

FORMOSA

FORMOSA

FORMOSA

FORMOSA

FORMOSA

FORMOSA

FO RMOSA

FO RMOSA

FORMOSA

FORMOSA

FORMOSA

FORMOSA

O RMOSA

ORBIGNYANA

OREIGNYANA

OREIGNYANA

PUNCTATA

STRIATOPUNCTATA

TENUISSIMA

TE AUISS IMA

TE AUISSIMA

TE NUISSIMA

TE NUISSIMA

TENUISSIMA

TENUISSIMA

TE NUI SSIMA

TENUISSIMA

TENUISSIMA

TENUISSIMA

TENUISSIMA

AT LANTI CA

A TLANTI CA

ATLANTI CA

AT LANTI CA

ATLANTI CA

AT LANTI CA

AT LANTICA

AT LANTI CA

AT LANT I CA

CLAVATUS

CLAVATUS

CLAVATUS

CLAVATUS

CLAVATUS

CLAVATUS

CLAVATUS

CLAVATUS

CLAVATUS

CLAVATUS

CLAVATUS

CLAVATUS

CLAVATUS

CLAVATUS

CLAVATUS

CLAVATUS

CLAVATUS

CLAVATUS

CLAVATUS

CLAVATUS

CLAVATUS

CLAVATUS

CLAVATUS

CLAVATUS

CLAVATUS

CLAVATUS

CLAVATUS

GRATELOUPI

SCAPHUM
SCAPHUM

\section{Locality}

NW GULF OF MEXICO

$N W$ GULF OF MEXICO

NW GULF OF MEXICO

NW GULF OF MEXICO

NH GULF OF MEXICO 


\section{Publication}

17496 PFLUM FRERICHS 1976 17497 PFLUM FRERICHS 1976 17498 PFLUM FRERICHS 1976 17499 PFLUM FRERICHS 1976 17500 PFLUM FRERICHS 1976 17501 PFLUM FRERICHS 1976 17502 PFLUM FRERICHS 1976 17503 PFLUM FRERICHS 1976 17503 PFLUM FRERICHS 1976 17504 PFLUM FRERICHS 1976 17506 PFLUM FRERICHS 1976 17507 PFLUM FRERICHS 1976 17508 PFLUM FRERICHS 1976 17509 PFLUM FRERICHS 1976 17510 PFLUM FRERICHS 1976 17511 ANDERSEN 1961

17512 ANDERSEN 1961

17513 PFLUM FRERICHS 1976 17514 PFLUM FRERICHS 1976 17515 BANOY 1956

17516 CREAGER 1958

17517 CUSHMAN 1923

17518 CUS HMAN 1923

17519 CUSHMAN 1923

17520 CUSHMAN 1923

17521 CUSHMAN 1923

17522 BOCK 1976

17523 BOCK 1976

17524 BOCK 1976

17525 BOCK 1976

17526 SEGURA 1963

17528 BOCK 1976

17529 BOCK 1976

17530 POAG 1972

17531 AYALA-CASTANARES 1963

17532 PFLUM FRERICHS 1976

17533 PFLUM FRERICHS 1976

17534 LYNTS PFISTER 1967

17535 PFLUM FRERICHS 1976

17536 PFLUM FRERICHS 1976

17537 PFLUM FRERICHS 1976

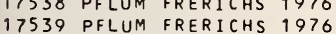

17540 PFLUM FRERICHS 1976 17541 PFLUM FRERICHS 1976 17542 PFLUM FRERICHS 1976 17543 PFLUM FRERICHS 1976 17544 PFLUM FRERICHS 1976 17545 PFLUM FRERICHS 1976 17546 PFLUM FRERICHS 1976 17547 PFLUM FRERICHS 1976 17548 PFLUM FRERICHS 1976 17549 PFLUM FRERICHS 1976 17550 PFLUM FRERICHS 1976 17551 PFLUM FRERICHS 1976 17552 PFLUM FRERICHS 1976 17553 PFLUM FRERICHS 1976 17554 PFLUM FRERICHS 1976 17555 PFLUM FRERICHS 1976 17556 PFLUM FRERICHS 1976 17557 PFLUM FRERICHS 1976 17558 PFLUM FRERICHS 1976 17559 PFLUM FRERICHS 1976 17560 PFLUM FRERICHS 1976 17561 PFLUM FRERICHS 1976 17562 PFLUM FRERICHS 1976 17563 PFLUM FRERICHS 1976 17564 PFLUM FRERICHS 1976 17565 PFLUM FRERICHS 1976 17566 PFLUM FRERICHS 1976 17567 PFLUM FRERICHS 1976 17568 PFLUM FRERICHS 1976 17569 AYALA-CASTANARES 1963 17570 SEGURA 1963

17571 BOCK 1976

17572 BANDY 1956

17573 BANDY 1956

17574 BOCK 1976

17575 ANDERSEN 1961

17576 KELLOUGH 1956

17577 BANDY 1956

17578 BANDY 1956

17579 CREAGER 1958

17580 PHLEGER 1956

17581 PARKER 1954

17582 PARKER 1954

17583 PARKER 1954

17584 BANDY 1956

17585 BANDY 1956

17586 BANDY 1956

17587 BANDY 1956

17588 PHLEGER 1951 A

17589 BANDY 1956
17590 BANDY 1956
Generic Name Specific Name

SCAPHUM

FLORILUS

FRANCES ITA

FRANCESITA

FR ANCES ITA

FRANCESITA

FRANCESITA

FRANCES ITA

FRANCESITA

FRANCES I TA

FRANCESITA

FRANCESITA

FRANCESITA

FRANCES ITA

FR ONDI I ULAR IA

RONDICULARIA

FR ONDI I ULARI A

FRONDI CULARIA

FRONDICULARIA

FRONDICULARIA

FRONDICULARIA

FR OND I CULARIA

FRONDICULARIA

FRONDICULARIA

FRONDICULARIA

FURSENKOINA

FURSENK OINA

FURSE NKO INA

FURSENKOINA

FURSENKOINA

FURSENKOINA

FURSENKOIN

FURSE NKO INA

FURSENKOINA

FURSENKOINA

FURSENKOINA

FURSENKOINA

FURSENKOINA

FURSENKOINA

FURSENK OINA

FU RSENKOINA

FURSENKOINA

FURSENKOINA

FURSENKOINA

FURSENKOINA

FURSENK OINA

FURSENKOINA

FURSENKOINA

FURSENKOINA

FURSENKOINA

FURSENKOINA

FURSENKOINA

FURSENKOINA

FURSENKOINA

FURSENKOINA

FURSENKOINA

FURSENKOINA

FURSENKOINA

FURSENKOINA

FURSENKOINA

FURSENKOINA

FURSENKOINA

FURSENKOINA

FURSENKOINA

FURSENKOINA

FURSENKOINA

FURSENKOINA

FURSENKOINA

FURSENKOINA

FURSENKOINA

FURSENKOINA

FURSENKOINA

FURSENKOINA

FURSENKOINA

FURSENKOINA

GAUDRYINA

GAUDRYINA

GAUDRYINA

GAUDRYINA

GAUDRYINA

GAUDRYINA

GAUDRYINA

GAUDRYINA

GAUDRYINA

GAUDRYINA

GAUDRYINA

GAUDRYINA

GAUDRYINA

GAUDRYINA

GAUDRYINA

GAUDRYINA

GAUDRYINA

GAUDRYINA

GAUDRYINA
ADVENA

ADVENA

ADVENA

AD VENA

ADVENA

ADVENA

ADVENA

AD VENA

AD VENA

ADVENA

AD VENA

ADVENA

ADVENA

SAGITTULA

SAGITTULA

SAGITTULA

SAGITTULA

SAGITTULA

SAGIITTULA

SAGITTULA

SAGITTULA

SAGITTULA

LO EBLICHI

CONPRESSA

MEXICANA
PONTONI
PONTONI

PONTONI

PONTONI

PONTON

POATONI

PONTONI

PONTONI

PONTONI

PONTONI

PUNCTATA

SCHRE IBER I ANA

SCHREIBERSIANA

SC HRE I BER SI ANA

SCHREIBER SI ANA

SC HRE IBERSI ANA

SC HRE I BER SI ANA

SCHRE I BER SI ANA

SC HRE I BER S I AN A

SC HRE I BER SI ANA

SCHREIBER SI ANA

SCHRE IBER SI ANA

SCHRE I BER S I ANA

SCHREIBERSI ANA

SCHRE IBER SI ANA

SENINUDA

SENINUDA

SENINUDA

SENINUDA

SENINUDA

SENINUDA

SENINUDA

SENINUDA

SENINUDA

SENINUDA

SENINUDA

SENINUDA

SENINUDA

SENINUDA

SENINUDA

SENINUDA

SENINUDA

SENINUDA

SENINUDA

SPINICOSTATA

SPINICOSTATA

SP INI COSTATA

AE QUA

AE QUA

AE QUA

$A E Q \cup A$

$A E Q \cup A$

AEQUA

$A E Q \cup A$

AE QUA

$A E Q U A$

AE QUA

$A E G \cup A$

$A E Q U A$

AE QUA

AEGUA

$A E Q U A$

AE QUA

$A E Q U A$

Locality

Lat. Long.

NW GULF OF MEXICO

NW GULF OF MEXICO

NH GULF OF MEXICO

NW GULF OF MEXICO

CENTRAL GULF OF MEXICO

CENTRAL GULF OF MEXICO

CENTRAL GULF OF MEXICO

CENTRAL GULF OF MEXICO

CENTRAL GULF OF MEXICO

CENTRAL GULF OF MEXICO

CENTRAL GULF OF MEXICO 


\section{Publication}

17591 BANDY 1956 17592 PHLEGER 1951 A 17593 PHLEGER 1951A 17594 PHLEGER 1951A 17595 PHLEGER 1951 A 17596 PHLEGER 1951A 17597 PHLEGER 1951A 17598 PARKER 1954 17599 PARKER 1954 17600 PARKER 1954

17601 PARKER 1954

17602 LANKFORD 1959

17603 LUDHICK HALTON 1957

17604 CREAGER 1958

17605 CREAGER 1958

17606 CREAGER 1958

17607 CUSHMAN 19228

17608 CREAGER 1958

17609 CUSHMAN 19228

17610 CREAGER 1958

17611 CUSHMAN 19228

17612 CUSHMAN $1922 \mathrm{~B}$

17613 PFLUM FRERICHS 1976

17614 CREAGER 1958

17615 CUSHMAN 19228

17616 PFLUM FRERICHS 1976

17617 CUSHMAN 19228

17618 PFLUM FRERICHS 1976

17619 PFLUM FRERICHS 1976

17620 PFLUM FRERICHS 1976

17621 PARKER 1954

17622 PARKER 1954

17623 PARKER 1954

17624 PHLEGER $1951 \mathrm{~A}$

17625 PHLEGER 1951A

17626 PHLEGER 1951A

17627 PHLEGER 1951A

17628 PHLEGER $1951 \mathrm{~A}$

17629 PHLEGER 1951A

17630 PARKER 1954

17631 PARKER 1954
17632 PARKER 1954

17633 LUDHICK WALTON 1957

17634 PFLUM FRERICHS 1976

17635 PFLUM FRERICHS 1976

17636 PFLUM FRERICHS 1976

17637 CUSHMAN 19228

17638 CUSHMAN 19228

17639 CUSHMAN $1922 \mathrm{~B}$

17640 CUSHMAN 19228

17641 CUSHMAN 19228

17642 CUSHMAN 19228

17643 CUSHMAN 19228

17644 CUSHMAN 19228

17645 CUSHMAN 19228

17646 CUSHMAN 19228

17647 CREAGER 1958

17648 PARKER PHLEGER PEIRSON 1953

17649 PARKER PHLEGER PEIRSON 1953

17650 PARKER PHLEGER PEIRSON 1953

17651 PARKER PHLEGER PEIRSON 1953

17652 PHLEGER 1954

17653 PHLEGER 19558

17654 PHLEGER 1954

17655 PHLEGER 1954

17656 PHLEGER 1954

17657 PHLEGER $1965 \mathrm{C}$

17658 PHLEGER $1965 \mathrm{~A}$

17659 WALTON 1964

17660 KANE 1967

17661 LEHMANN 1957

17662 WALDRON 1963

17663 LANKFORD 1959

17664 WARREN 1957

17665 PHLEGER 1954

17666 BENDA PURI 1962

17667 HALTON 1960

17668 PHLEGER 19658

17669 PHLEGER $1965 \mathrm{~B}$

17670 HARREN 1956

17671 PARKER PHLEGER PEIRSON 1953

17672 PARKER PHLEGER PEIRSON 1953

17673 PHLEGER 1956

17674 PHLEGER 1956

17675 PARKER PHLEGER PEIRSON 1953

17676 PHLEGER 1956

17677 PHLEGER 1956

17678 PHLEGER 1956

17679 CREAGER 1958

17680 PARKER 1954

17681 PFLUM FRERICHS 1976

17682 PFLUM FRERICHS 1976

17683 PARKER 1954

17684 PARKER 1954

17685 PARKER 1954

\section{Generic Name}

GAUDRYINA

GAUDRYINA

GAUDRYINA

GAUDRYINA

GAUDRYINA

GAUDRYINA

GAUDRYINA

GAUDRYINA

GAUDRYINA

GAUDRYINA

GAUDRYINA

GAUDRYINA

KARRERIELLA

KARRERI ELL

KARRERIELLA

KARRERI ELLA

KARRERI ELL A

KARRERIELLA

KARRERI ELLA

KARRERI ELLA

GA UDRYINA

GAUDRYINA

GAUDRYINA

GAUDRYINA

GAUDRYINA

GAUDRYINA

GAUDRYINA

GAUDRYINA

GAUDRYINA

GAUDRYINA

GAUDRYINA

GAUDRYINA

GAUDRY I NA

GAUDRYINA

GAUDRYINA

GAUDRYINA

GAUDRYINA

GAUDRYINA

GAUDRYINA

GAUDRYINA

GAUDRYINA

GAUDRYINA

GAUDRYINA

GAUDRYINA

KARRER I ELLA

KARRERI ELLA

KARRERI ELLA

KARRER I ELLA

KARRERI ELLA

KARRER I ELLA

KARRER I ELLA

KARRERIELLA

KARRERI ELL

GAUDRYINA

GAUDRYINA

GAUDRYINA

GAUDRYINA

GAUDRYINA

GAUDRYINA

GAUDRYINA

GAUDRYINA

GAUDRYINA

GAUDRYINA

GAUDRYINA

GAUDRYINA

GAUDRYINA

GAUDRYINA

GAUDRYINA

GAUDRYINA

GAUDRYINA

GAUDRYINA

GAUDRYINA

GAUDRYINA

GAUDRYINA

GAUDRYINA

GAUDRYINA

GAUDRY INA

GAUDRYINA

GAUDRYINA

GAUDRYINA

GAUDRYINA

GAUDRYINA

GAUDRYINA

GAUDRYINA

GAUDRYINA

GAUDRYINA

GAUDRYINA

GA UDRYINA

GAUDRYINA

GAUDRYINA

GAUDRYI NA

GAUDRYINA
Specific Name

AEQUA

AE QUA

AEQUA

AE QUA

AEQUA

AEQUA

AE QUA

AE GUA

AE QUA

AEQUA

AEQUA

AP I CULARIS

API CULARIS

APICULARIS

AP ICULARIS

AP ICULARIS

AP I CULARIS

AP I CULAR IS

API CULARIS

API CULARIS

ATLANTI CA

AT LANTICA

ATLANTICA

AT LANTICA

ATLANTICA

AT LANTI CA

A T LANTI CA

AT LANTICA

ATLANTICA

ATLANTICA

AT LANTI CA

A T LANTICA

A TLANTI CA

ATLANTICA

A T LANTI CA

ATLANTI CA

AT LANTICA

A TLANTICA

AT LANTI CA

AT LANTI CA

AT LANTI CA

A T LANTI CA

A T LANTICA

NOVANGLIAE

BRADYI

BRADYI

BRADYI

BR ADYI

BRADYI

BRADYI

BRADYI

BR ADYI

CH ILOSTOMA

COMPRESSA

EXILIS

EXILIS

EXILIS

EXILIS

EXILIS

EXILIS

EXILIS

EXILIS

EXILIS

EXILIS

EXILIS
EXILIS

EXILIS

EXILIS

EXILIS

EXILIS

EXILIS

EXILIS

EXILIS

EXILIS

EXILIS

EXILIS

EXILIS

EXILIS

EXILIS

EXILIS

EXILIS

EXILIS

EXILIS

EXILIS

EX IL IS
FL INT I

FL INT I I

FL INTII

FL INTII

FL INTI

FL INTI

FL INTI I

\section{Locality}

NE GULF OF MEXICO

NW GULF OF MEXICO

NH GULF OF MEXICO

NH GULF OF MEXICO

NW GULF OF MEXICO

NH GULF OF MEXICO

NW GULF OF MEXICO 


\section{Publication}

17686 PARKER 1954

17687 PFLUM FRERICHS 1976 17688 PFLUM FRERICHS 1976 17689 PFLUM FRERICHS 1976

17690 PARKER 1954

17691 PARKER 1954

17692 PARKER 1954

17693 PARKER 1954

17694 CREAGER 1958

17695 CUSHMAN 19228

17696 CUSHMAN 19228

17697 PARKER 1954

17698 PARKER 1954

17699 PARKER 1954

17700 PFLUM FRERICHS 1976

17701 PFLUM FRERICHS 1976

17702 PFLUM FRERICHS 1976

17703 PFLUM FRERICHS 1976

17704 PFLUM FRERICHS 1976

17705 PARKER 1954

17706 PARKER 1954

17707 PARKER 1054

17708 PARKER 1754

17709 PARKER 1954

17711 PFLUM FRERICHS 1976

17712 PARKER 1954

17713 PARKER 1954

17714 PARKER 1954

17715 PFLUM FRERICHS 1976

17716 PFLUM FRERICHS 1976

17717 PFLUM FRERICHS 1976

17718 PFLUM FRERICHS 1976

17719 PFLUM FRERICHS 1976

17720 PARKER 1954

17721 PARKER 1954

17722 PARKER 1954

17723 PARKER 1954

17724 BANDY 1956

17725 BANDY 1956

17726 BANDY 1956

17727 CUSHMAN 1918
17728 CUSHMAN 1918

17728 CUSHMAN 1918
17729 CUSHMAN 1918

17730 CUSHMAN 1918

17731 BANDY 1956

17732 BANDY 1956

17733 ANDERSEN 1961

17734 PFLUM FRERICHS 1976

17735 PFLUM FRERICHS 1976

17736 PFLUM FRERICHS 1976

17737 PFLUM FRERICHS 1976

17738 PFLUM FRERICHS 1976

17739 PFLUM FRERICHS 1976

17740 PFLUM FRERICHS 1976

17741 PFLUM FRERICHS 1976

17742 PFLUM FRERICHS 1976

17743 PFLUM FRERICHS 1976

17744 PFLUM FRERICHS 1976

17745 PFLUM FRERICHS 1976

17746 PFLUM FRERICHS 1976

17747 PFLUM FRERICHS 1976

17748 PFLUM FRERICHS 1976

17749 PFLUM FRERICHS 1976

17750 PFLUM FRERICHS 1976

17751 PFLUM FRERICHS 1976

17752 PARKER 1954

17753 PARKER 1954

17754 PHLEGER 1955 A

17755. PHLEGER 1955A

17756 PFLUM FRERICHS 1976

17757 PFLUM FRERICHS 1976

17758 PFLUM FRERICHS 1976

17759 PFLUY FRERICHS 1976

17760 PFLUM FRERICHS 1976

17761 PFLUM FRERICHS 1976

17762 PFLUM FRERICHS 1976

17763 PFLUM FRERICHS 1976

17764 PFLUM FRERICHS 1976

17765 PFLUM FRERICHS 1976

17766 PFLUM FRERICHS 1976

17767 PFLUM FRERICHS 1976

17768 PARKER 1954

17769 PARKER 1954

17770 PARKER 1954

17771 PFLUM FRERICHS 1976

17772 PARKER 1954

17774 PARKER 1954

17775 PARKER 1954

17776 PARKER 1954

17777 PARKER 1954

17778 LUDWICK WALTON 1957

17779 PHLEGER 1955A

17780 PHLEGER 1955A
Generic Name Specific Name

FL IN T I I

FL IN T I I

FL INTII

FL IN TI I

FL INTII

FL INTII

FL INT I I

FL INT I I

FL INT I I

FL INT I I

MINUTA

MI NUTA

MI NUTA

MINUTA

MI NUTA

MINUTA

MINUTA

MINUTA

MINUTA

MINUTA

MINUTA

MINUTA

MINUTA

MI NUTA

MI AUTA

MI NUTA

MINUTA

MI NUTA

MINUTA

MI $\cap U T A$

MI UUTA

MI AUTA

MI NUTA

MINUTA

MINUTA

MINUTA

ST AVENSIS

ST AVENSIS

ST AVENSIS

VAEANS

VAGANS

VAGANS

VAGANS

CONATULA

COMATULA

LAEVIGATA

LAEVIGATA

LAEVIGATA

LAEVIGATA

LAEVIGATA

LAEVIGATA

LAEVIGATA

AF FINIS

AF FINIS

AF FINIS

AFFINIS

AFFINIS

AFFINIS

AFFINIS

AFFINIS

AF FINIS

AFFINIS

AFFINIS

AFFINIS

AFFINIS

AF FINIS

AFFINIS

AFFINIS

AFFINIS

AFFINIS

AFFINIS

AFFINIS

AF FINIS

AFFINIS

AFFINIS

AFFINIS

AFFINIS

AF FINIS

AFFINIS

AF FINIS

AFFINIS

AF FINIS

AFFINIS

AFFINIS

AF FINIS

AF FINIS

AFFINIS

AF FINIS

AFFINIS

AF FINIS

AFFINIS

AFFINIS

\section{Locality}

Lat. Long.

NE GULF OF MEXICO

CENTRAL GULF OF MEXICO

CENTRAL GULF OF MEXICO

NW GULF OF MEXICO

NE GULF OF MEXICO

NE GULF OF MEXICO

NE GULF OF MEXICO

NE GULF OF MEXICO

BAY OF CAMPECHE

NE GULF OF MEXICO

NE GULF OF MEXICO

NE GULF OF MEXICO

NE GULF OF MEXICO

NW GULF OF MEXICO

NW GULF OF MEXICO

NW GULF OF MEXICO

NW GULF OF MEXICO

NW GULF OF MEXICO

NE GULF OF MEXICO

NE GULF OF MEXICO

NE GULF OF MEXICO

NE GULF OF MEXICO

NE GULF OF MEXICO

NE GULF OF MEXICO

NW GULF OF MEXICO

NE GULF OF MEXICO

NE GULF OF MEXICO

NE GULF OF MEXICO

NW GULF OF MEXICO

NW GULF OF MEXICO

$N W$ GULF OF MEXICO

NW GULF OF MEXICO

NW GULF OF MEXICO

NE GULF OF MEXICO

NE GULF OF MEXICO

NE GULF OF MEXICO

NE GULF OF MEXICO

NE GULF OF MEXICO

NE GULF OF MEXICO

NE GULF OF MEXICO

NE GULF OF MEXICO

NE GULF OF MEXICO

NE GULF OF MEXICO

NE GULF OF MEXICO

NE GULF OF MEXICO

$M$ ISS ISSIPPI DELTA

CENTRAL GULF OF MEXICO

NW GULF OF MEXICO

NW GULF OF MEXICO

NW GULF OF MEXICO

NW GULF OF MEXICO

$N W$ GULF OF MEXICO

NW GULF OF MEXICO

NW GULF OF MEXICO

NW GULF OF MEXICO

NW GULF OF MEXICO

NW GULF OF MEXICO

$N W$ GULF OF MEXICO

NW GULF OF MEXICO

NW GULF OF MEXICO

NW GULF OF MEXICO

NW GULF OF MEXICO

NW GULF OF MEXICO

NW GULF OF MEXICO

NE GULF OF MEXICO

NE GULF OF MEXICO

$N$ GULF OF MEXICO

NW GULF OF MEXICO

NW GULF OF MEXICO

NW GULF OF MEXICO

NW GULF OF MEXICO

NW GULF OF MEXICO

NW GULF OF MEXICO

NW GULF OF MEXICO

NW GULF OF MEXICO

$N W$ GULF OF MEXICO

$N_{W}$ GULF OF MEXICO

NW GULF OF MEXICO

NW GULF OF MEXICO

NE GULF OF MEXICO

NE GULF OF MEXICO

NE GULF OF MEXICO

NW GULF OF MEXICO

NE GULF OF MEXICO

NE GULF OF MEXICO

NE GULF OF MEXICO

NE GULF OF MEXICO

NE GULF OF MEXICO

NE GULF OF MEXICO

NE GULF OF MEXICO

GULF OF MEXICO

$N$ GULF OF MEXICO

$2944 N 086 \quad 41 \mathrm{~W}$ $\begin{array}{llll}28 & 35 N & 089 & 16 W \\ 28 & 33 N & 089 & 13 W\end{array}$ $2653 \mathrm{~N} 092 \quad 17 \mathrm{~W}$ $2530 \mathrm{~N} 08459 \mathrm{H}$ $2546 \mathrm{~N} 084 \quad 12 \mathrm{~W}$ $2658 \mathrm{~N} 086 \quad 22 \mathrm{~W}$ 


\section{Publication}

17781 PHLEGER 1955 A

17782 PHLEGER 1955 A

17783 PHLEGER 1955 A

17784 PHLEGER 1955 A

17785 PARKER 1954

17786 PARKER 1954

17787 PARKER 1956

17788 PFLUM FRERICHS 1976 17789 PFLUM FRERICHS 1976 17790 PFLUM FRERICHS 1976 17791 PFLUM FRERICHS 1776 17792 PFLUM FRERICHS 1976 17793 PFLUM FRERICHS 1976 17794 PFLUM FRERICHS 1976 17795 PFLUM FRERICHS 1976 17796 PFLUM FRERICHS 1976 17797 PFLUM FRERICHS 1976 17798 PFLUM FRERICHS 1976 17799 PFLUM FRERICHS 1976 17800 PFLUM FRERICHS 1976 17801 PFLUM. FRERICHS 1976 17802 PFLUM FRERICHS 1976 17803 PFLUM FRERICHS 1976 17804 PFLUM FRERICHS 1976 17805 PFLUM FRERICHS 1976 17806 PFLUM FRERICHS 1976 17807 PFLUM FRERICHS 1976 17808 CREAGER 1958

17809 PFLUM FRERICHS 1976 17810 PFLUM FRERICHS 1976 17811 PFLUM FRERICHS 1976 17812 PFLUM FRERICHS 1976 17813 PARKER 1954

17814 PARKER 1954

17815 PARKER 1754

17816 PARKER 1954

17817 PARKER 1954

17818 PFLUM FRERICHS 1976 17819 PFLUM FRERICHS 1976 17820 PFLUM FRERICHS 1976 17821 PFLUM FRERICHS 1976 17822 PFLUM FRERICHS 1976 17823 PFLUM FRERICHS 1976 17824 PFLUM FRERICHS 1976 17825 PFLUM FRERICHS 1976 17826 PFLUM FRERICHS 1976 17827 PFLUM FRERICHS 1976 17828 PFLUM FRERICHS 1976 17829 LANKFORD 1959

17830 PARKER 1954

17831 PARKER 1954

17832 PARKER 1954

17833 PARKER 1954

17834 PFLUM FRERICHS 1976 17835 PFLUM FRERICHS 1976 17836 PFLUM FRERICHS 1976 17837 PFLUM FRERICHS 1976 17838 PFLUM FRERICHS 1976 17839 PFLUM FRERICHS 1976 17840 PFLUM FRERICHS 1976 17841 PFLUM FRERICHS 1976 17842 PFLUM FRERICHS 1976 17843 PFLUM FRERICHS 1976 17844 PFLUM FRERICHS 1976 17845 PFLUM FRERICHS 1976 17846 PFLUM FRERICHS 1976 17847 PFLUM FRERICHS 1976 17848 PFLUM FRERICHS 1976 17849 PFLUM FRERICHS 1976 17850 PFLUM FRERICHS 1976 17851 PFLUM FRERICHS 1976 17852 PFLUM FRERICHS 1976 17853 PFLUM FRERICHS 1976 17854 PFLUM FRERICHS 1976 17855 PFLUM FRERICHS 1976 17856 PFLUM FRERICHS 1976 17857 PFLUM FRERICHS 1976 17858 PFLUM FRERICHS 1976 17859 PFLUM FRERICHS 1976 17860 PFLUM FRERICHS 1976 17861 PFLUM FRERICHS 1976 17862 PFLUM FRERICHS 1976 17863 PFLUM FRERICHS 1976 17864 PFLUM FRERICHS 1976 17865 PFLUM FRERICHS 1976 17866 PFLUM FRERICHS 1976 17867 PFLUM FRERICHS 1976 17868 PFLUM FRERICHS 1976 17869 PFLUM FRERICHS 1976 17870 PFLUM FRERICHS 1976 17871 PFLUM FRERICHS 1976 17872 PFLUM FRERICHS 1976 17873 PFLUM FRERICHS 1976 17874 PFLUM FRERICHS 1976
17875 PFLUM FRERICHS 1976
Generic Name

BULIMINA

BULIMINA

BULIMINA

BULIMINA

BULIMINA

BULIMINA

BULIMINA

BULIMINA

BULIMINA

BULIMINA

BULIMINA

BULIMINA

BULIMINA

BULIMINA

BULIMINA

BULIMINA

BULIMINA

BULIMINA

BULIMINA

BULIMINA

BULIMINA

BULIMINA

BULIMINA

BULIMINA

BULIMINA

BULIMINA

BULIMINA

BULIMINA

BULIMINA

BULIMINA

BULIMINA

BULIMINA

BULIMINA

BULIMINA

BULIMINA

BULIMINA

BULIMINA

BULIMINA

BULIMINA

BULIMINA

BULIMINA

BULIMINA

BULIMINA

BULIMINA

BULIMINA

BULIMINA

BULIMINA

GLOBOBULIMINA

GL OBOBULIMINA

GLOBOBULIMINA

GL OBOBUL IM INA

GL OBOBULIMINA

GL OBOBUL IMINA

GLOBOBULIMINA

GLOBOBU LIMINA

GL OBOBUL IMINA

GL OBOBULIMINA

GL OBOBULIMINA

GL OBOBUL IM IN

GL OBOBULIMINA

GL OBOBUL IM I NA

GLOBOBULIMINA

GL OBOBULIMINA

GL OBOBULIMINA

GL OBOBUL IMIN

GL OBOBULIMINA

GL ОBOBUL IM I NA

GLOBOBULIMINA

GL OB OBUL IMINA

GL OBOBULIMINA

GL OBOBULIMINA

GL OBOBULIMINA

GL OBOBUL IMI NA

GL OBOBULIMINA

GL OB OBUL IMINA

GL OBOBUL IM INA

GL OBOBUL IM INA

CASS IDULINA

CASSI DULINA

CASSIDULINA

CASSIDULINA

CASSI DULINA

CASS I DULINA

CASSIDULINA

CASSIDULINA

CASSIDULINA

CASSI DUL INA

CASSIDULINA

CASSIDULINA

CASSIDULINA

CASSI DUL INA

CASSIDULINA

CASSIDULINA

CASSIDULINA
Specific Name

AFFINIS

AF FINIS

AF FINIS

AF FINIS

AFFINIS

AF FINIS

AF FINIS

AFFINIS

AF FINIS

AFFINIS

AFFINIS

AF FINIS

AF FINIS

AFFINIS

AFFINIS

AFFINIS

AF FINIS

A F FINIS

AF FINIS

AFFINIS

AFFINIS

AFFINIS

AFFINIS

AFFINIS

AFFINIS

AFFINIS

AFFINIS

AFFINIS

AF FINIS

AFFINIS

AFFINIS

AFFINIS

AFFINIS

AF FINIS

AF FINIS

AFFINIS

AFFINIS

AFFINIS

AFFINIS

MISSISSIPPIENSIS

MI SSISSIPPIENSIS

MISSISSIPPIENSIS

MISSISSIPPIENSIS

MISSISSIPPIENSIS

OVUL A

OVILA

OVLLA

OVULA

OVULA

OVULA

OVLLA

OVULA

OVLLA

OVULA

OVULA

OVULA

OVULA

OVLLA

OVULA

PYRULA SPINESCENS

PYRULA SPINESCENS

PYRULA SPINESCENS

PYRULA SPINESCENS

PYRULA SPINESCENS

PYRULA SPINESCENS

PYRULA SPINESCENS

PYRULA SPINESCENS

PYRULA SPINESCENS

CRASSA

CR ASSA

CRASSA

CRASSA

CR ASSA

CR ASSA

CR ASSA

CR ASSA

CR ASSA

CRASSA

CRASSA

CRASSA

CRASSA

CR ASSA

CRASSA

CR ASSA

Locality

Lat. Long.

N GULF OF MEXICO

$N$ GULF OF MEXICO

$N$ GULF OF MEXICO

$N$ GULF OF MEXICO

NE GULF OF MEXICO

NE GULF OF MEXICO

NE GULF OF MEXICO

CENTRAL GULF OF MEXICO

CENTRAL GULF OF MEXICO

CENTRAL GULF OF MEXICO 
Publication

17876 PFLUM FRERICHS 1976 17877 PFLUM FRERICHS 1976 17878 PFLUM FRERICHS 1976 17879 PFLUM FRERICHS 1976 17880 PFLUM FRERICHS 1976 17881 PFLUM FRERICHS 1976 17882 PFLUM FRERICHS 1976 17883 PFLUM FRERICHS 1976 17884 PFLUM FRERICHS 1976 17885 PFLUM FRERICHS 1976 17886 PFLUM FRERICHS 1976 17887 PFLUM FRERICHS 1976 17888 PFLUM FRERICHS 1976 17889 PFLUM FRERICHS 1976 17890 PFLUM FRERICHS 1976 17891 PFLUM FRERICHS 1976 17892 PFLUM FRERICHS 1976 17893 PFLUM FRERICHS 1976

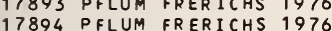

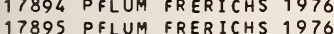
17896 PFLUM FRERICHS 1976 17897 PFLUM FRERICHS 1976 17898 PFLUM FRERICHS 1976 17899 PFLUM FRERICHS 1976 17900 PFLUM FRERICHS 1976 17901 PFLUM FRERICHS 1976 17902 PFLUM FRERICHS 1976 17903 PFLUM FRERICHS 1976 17904 PFLUM FRERICHS 1976 17905 PFLUM FRERICHS 1976 17906 PFLUM FRERICHS 1976 17907 PFLUM FRERICHS 1976 17908 PFLUM FRERICHS 1976 17909 PFLUM FRERICHS 1976 17910 PFLUM FRERICHS 1976 17911 PFLUM FRERICHS 1976 17912 PFLUM FRERICHS 1976 17913 PFLUM FRERICHS 1976 17914 PFLUM FRERICHS 1976 17915 PFLUM FRERICHS 1976 17916 PFLUM FRERICHS 1976 17917 PFLUM FRERICHS 1976 17918 PFLUM FRERICHS 1976 17919 PFLUM FRERICHS 1976 17920 PFLUM FRERICHS 1976 17921 PFLUM FRERICHS 1976 17922 PFLUM FRERICHS 1976 17923 PFLUM FRERICHS 1976 17924 PFLUM FRERICHS 1976 17925 PFLUM FRERICHS 1976 17926 PFLUM FRERICHS 1976 17927 PFLUM FRERICHS 1976 17928 PFLUM FRERICHS 1976 17929 PFLUM FRERICHS 1976 17930 PFLUM FRERICHS 1976 17931 PFLUM FRERICHS 1976 17932 PFLUM FRERICHS 1976 17933 PFLUM FRERICHS 1976 17934 PFLUM FRERICHS 1976 17935 PFLUM FRERICHS 1976 17936 PFLUM FRERICHS 1976 17937 PFLUM FRERICHS 1976 17938 PFLUM FRERICHS 1976 17939 PFLUM FRERICHS 1976 17940 PFLUM FRERICHS 1976 17941 PFLUM FRERICHS 1976 17942 PFLUM FRERICHS 1976 17943 PFLUM FRERICHS 1976
17944 PFLUM FRERICHS 1976 17945 PFLUM FRERICHS 1976 17946 PFLUM FRERICHS 1976 17947 PFLUM FRERICHS 1976 17948 PFLUM FRERICHS 1976 17949 PFLUM FRERICHS 1976 17950 PFLUM FRERICHS 1976 17951 PFLUM FRERICHS 1976 17952 PFLUM FRERICHS 1976 17953 PFLUM FRERICHS 1976 17954 PFLUM FRERICHS 1976 17955 PFLUM FRERICHS 1976 17956 PFLUM FRERICHS 1976 17957 PFLUM FRERICHS 1976 17958 PFLUM FRERICHS 1976 17959 PFLUM FRERICHS 1976 17960 PFLUM FRERICHS 1976 17961 PFLUM FRERICHS 1976 17962 PFLUM FRERICHS 1976 ( 17964 PFLUM FRERICHS 1976 17965 PFLUM FRERICHS 1976 17966 PFLUM FRERICHS 1976 17967 PFLUM FRERICHS 1976 17968 PFLUM FRERICHS 1976 17969 PFLUM FRERICHS 1976 17970 PFLUM FRERICHS 1976
Generic Name

CASSIDULINA

CASSIDULINA

CASSIOULINA

CASSIDULINA

CASSIDULINA

CASSIDULINA

CASSIDULINA

CASSIDULINA

CASSIDULINA

CASSIDULINA

CASSIDULINA

CASSIDULINA

CASSIDULINA

CASSIDULINA

CASSIDULINA

CASSIDULINA

CASSIDULINA

CASSIDULINA

CASSIDULINA

CASSIDULINA

CA SSIDULINA

CASSIDULINA

CASSIDULINA

CASSIDULINA

CA SSIDULINA

CASSIDULINA

CASSIDULINA

CASSIDULINA

CASSIDULINA

CASSIDULINA

CASSIDULINA

CASSIDULINA

CASSIDULINA

CASSI DULINA

CASSIDULINA

GL OBOCASSIDUL INA

GLOBOCASSIDULINA

GL OBOCASSIDULINA

GLOBOCASSIDULINA

GL OBOCAS SIDULINA

GL OBOCASSIDULINA

GL OBOCAS SI D UL INA

GLOBOCASSIDULINA

GL OBOCASSIDULINA

GL OBOCASSIDULINA

GL OBOCASSIDULINA

GL OBOCASSIDULINA

GL OBOCASSIDULINA

GL OBOCASSI DULINA

GL OBOCASSIDULINA

GLOBOCASSIDULINA

GL OBOCA SSIDULINA

GL OBOCASSI DULINA

GL OBOCASSI DULINA

GLOBOCASSIDULINA

GLOBOCASSIDULINA

GLOBOCASSI DULINA

GLOBOCASSIDULINA

GL OBOCASSIDULINA

GL OBOCASSIDULINA

GL OBOCASSIDULINA

GL OBOCASSIDULINA

GLOBOCASSIDULINA

GL OBOCASSIDULINA

GL OBOCASSIDULINA

GL OBOCASSIDULINA

GLOBOCASSI DULINA

GL OBOCAS SI DULINA

GLOBOCASSIDULINA

GL OBOCASSIDULINA

GLOBOCASSIDULINA

GL OBOCASSI DULINA

GL OBOCASSIDULINA

GLOBOCASSIDULINA

GL OBOCASSIDULINA

GL OBOCASSIDULINA

GLOBOCASSIDULINA

GL OBOCASSIDULINA

GLOBOCASSIDULINA

GLOBOCAS SIDULINA

GLOBOCAS SIDULINA

GLOBOCASSIDULINA

GLOBOCASSIDULINA

GL OBOCASSIDULINA

GLOBOCASSIDULINA

GL OBOCASSIDULINA

GL OBOCASSIDULINA

GL OBOCASSIDULINA

GLOBOCASSIDULINA

GLOBOCASSIDULINA

GL OBOCASSIDULINA

GLOBOCAS SIDULINA

GLOBOCASSIDULINA

GLOBOCASSIDULINA
Specific Name

Locality

Lat. Long.

CRASSA

CRASSA

CRASSA

CRASSA

CRASSA

CRASSA

CRASSA

CRASSA

CRASSA

CRASSA

CRASSA

CRASSA

CRASSA

CRASSA

CRASSA

CRASSA

CRASSA

CRASSA

CRASSA

CRASSA

CRASSA

CRASSA

CRASSA

CRASSA

CRASSA

CRASSA

CRASSA

CR ASSA

CR ASSA

GLOBULOSA

MOLUCCENSIS

MOLUCCENS IS

MOLUCCENS IS

MOLUCCENS IS

MOLUCCENS IS

MOLUC CENSIS

MOLUCCENSIS

MOLUCCENS IS

MOLUCCENSIS

MOLUCCENS IS

MOLUCCENS IS

MURRHYNA

MURRHYNA

MURRH YNA

MURRHYNA

MURRHYNA

MURRHYNA

MURRHYNA

MURRHYNA

MURRHYNA

MURRHYNA

MURRHYNA

MURRHYNA

MURRHYNA

MURRHYNA

MURRHYNA

MURRHYNA

MURRHYNA

PACIFICA

PACIFICA

PACIFICA

PACIFICA

PACIFICA

PACIFICA

PACIFICA

PACIFICA

PACIFICA

PACIFICA

PACIFICA
PACIFICA

PACIFICA

PACIFICA

PACIFICA

PACIFICA

PACIFICA

PACIFICA

PACIFICA

PACIFICA

PACIFICA

PACIFICA

PACIFICA

PACIFICA

PACIFICA

NW GULF OF MEXICO NW GULF OF MEXICO

CENTRAL GULF OF MEXICO

CENTRAL GULF OF MEXICO

CENTRAL GULF OF MEXICO

CENTRAL GULF OF MEXICO

NH GULF OF MEXICO

CENTRAL GULF OF MEXICO 


\section{Publication}

17971 PFLUM FRERICHS 1976 17972 PFLUM FRERICHS 1976 17973 PFLUM FRERICHS 1976 17974 PFLUM FRERICHS 1976 17975 PFLUM FRERICHS 1976 17976 PFLUM FRERICHS 1976 17977 PFLUM FRERICHS 1976 17978 PFLUM FRERICHS 1976 17979 PFL UM FRERICHS 1976 17980 PFLUM FRERICHS 1976 17981 PFLUM FRERICHS 1976 17982 PFLUM FRERICHS 1976 17983 PFLUM FRERICHS 1976 17984 PFLUM FRERICHS 1976 17985 PFLUM FRERICHS 1976 17986 PFLUM FRERICHS 1976 17987 PFLUM FRERICHS 1976 17988 PFLUM FRERICHS 1976 17989 PFLUM FRERICHS 1976 17990 PFLUM FRERICHS 1976 17991 PFLUM FRERICHS 1976 17992 PFLUM FRERICHS 1976 17993 PFLUM FRERICHS 1976 17994 PFLUM FRERICHS 1976 17995 PFLUM FRERICHS 1976 17996 PFLUM FRERICHS 1976 17997 PFLUM FRERICHS 1976 17998 PFLUM FRERICHS 1976 17999 PFLUM FRERICHS 1976 18000 PFLUM FRERICHS 1976 18001 PFLUM FRERICHS 1976 18002 PFLUM FRERICHS 1976 18003 PFLUM FRERICHS 1976 18004 PFLUM FRERICHS 1976 18005 PFLUM FRERICHS 1976 18006 PFLUM FRERICHS 1976 18007 PFLUM FRERICHS 1976 18008 PFLUM FRERICHS 1976 18009 PFLUM FRERICHS 1976 18010 PFLUM FRERICHS 1976 18011 PFLUM FRERICHS 1976 18012 PFLUM FRERICHS 1976 18013 PFLUM FRERICHS 1976 18014 PFLUM FRERICHS 1976 18015 PFLUM FRERICHS 1976 18016 PFLUM FRERICHS 1976 18017 PFLUM FRERICHS 1976 18018 PFLUM FRERICHS 1976 18019 PFLUM FRERICHS 1976 18020 PFLUM FRERICHS 1976 18021 PFLUM FRERICHS 1976 18022 PFLUM FRERICHS 1976 18023 PFLUM FRERICHS 1976 18024 PFLUM FRERICHS 1976 18025 PFLUM FRERICHS 1976 18026 PFLUM FRERICHS 1976 18027 PFLUM FRERICHS 1976 18028 PFLIJM FRERICHS 1976 18029 PFLUM FRERICHS 1976 18030 PFLUM FRERICHS 1976 18031 PFLUM FRERICHS 1976 18032 LEROY HODGKINSON 1975 18033 PFLUM FRERICHS 1976 18034 PFLUM FRERICHS 1976 18035 PFLUM FRERICHS 1976 18036 PFLUM FRERICHS 1976 18037 PFLUM FRERICHS 1976 18038 PFLUM FRERICHS 1976 18039 PFLUM FRERICHS 1976 18040 PFLUM FRERICHS 1976 18041 PFLUM FRERICHS 1976 18042 PFLUM FRERICHS 1976 18043 PFLUM FRERICHS 1976 18044 PFLUM FRERICHS 1976 18045 LEROY HODGKINSON 1975 18046 PARKER 1954 18047 PARKER 1954 18048 PARKER 1954 18049 PARKER 1954 18050 PARKER 1954 18051 PARKER 1954 18052 SEGURA 1963 18053 PHLEGER 1951A 18054 PHLEGER 1951A 18055 PHLEGER 1951A 18056 PHLEGER 1951 A 18057 PFLUM FRERICHS 1976 18058 PFLUM FRERICHS 1976 18059 PFLUM FRERICHS 1976 18060 PFLUM FRERICHS 1976 18061 PFLUM FRERICHS 1976 18062 PFLUM FRERICHS 1976 18063 PHLEGER 1951A

18064 LEROY HODGKINSON 1975 18065 PFLUM FRERICHS 1976

\section{Generic Name}

GLOBOCASSIDULINA GLOBOCASSIDULINA GLOBOCASSI DULINA GL OBOCASSI DULINA GL OBOCASSIDULINA GL OBOCAS SI DULINA GL OBOCAS SIDUL INA GL OBOCAS SIDULINA GLOBOCAS SI DULINA CASSIDULINA

CASSIDULINA

CASSIDULINA

CASSI DULINA

CASSI DUL INA

CASSIDULINA

CASSI DULINA

CASSIDULINA

CASSIDULINA

CASSIDULINA

CASSI DULINA

CASSIDULINA

CASSIDULINA

CASSIDULINA

CASS IDUL INA

CASSIDULINA

CASSIDULINA

CASSIDULINA

CASSIDULINA

CASSIDULINA

CASS IDULINA

CASSIDULINA

CASSIDULINA

CASSIDULINA

CASSIDULINA

CASSIDULINA

CASSIDULINA

CASSIDULINA

CASS I DULINA

CASSIDULINA

CASSIDUL INA

CASSI DUL INA

CA SSIDULINA

CASSIDULINA

CASSIDULINA

CASSIDULINA

CASSIDULINA

CASSIDULINA

CASSIDULINA

CASSIDULINA

CASS I DULINA

CASSIDULINA

CASSIDULINA

CASSIDULINA

CASSIDULINA

CASSIDULINA

CASSIDULINA

CASSIDULINA

CASSIDULINA

CASSIDULINA

CA SSIDULINA

CASSIDULINA

CASSIDULINA

CASSIDULINA

CASS I DULINA

CASS I DUL INA

CASSIDULINA

CASSIDULINA

CASSIDULINA

CASSIDULINA

CASSIDULINA

CASSIDULINA

GL OBOTEXTULARIA

GLOBOTEXTULARIA

GL OBUL INA

GL OBUL INA

GL OBULINA

GL OBULINA

GLOBULINA

GLOBULINA

GL OBUL I NA

GL OMOSPIRA

GL OMOSPI RA

GL OMOSPIRA

GL OMOSP I RA

GLOMOSPIRA

GL OMOSPIRA

GL OMOSP IRA

GL OMOSPIRA

GL OMOSP I RA

GL OMOSPIRA

GL OMOSPIRA

GL OMOSPIRA

GL OMOSP IRA
Specific Name

PACIFICA

$P A C$

PACIFICA

PACIFICA

PACIFICA

PACIFICA

PACIFICA

SUBGLOBOSA

SUEGLOBOSA

SUEGLOBOSA

SUEGL OBOSA

SUBGL OBOSA

SUBGL OBOSA

SU EGL OBOSA

SUEGL OBOSA

SUEGLOBOSA

SUBGL OBOSA

SUBGL OBOSA

SUBGL OBOSA

SUEGL OBOSA

SUEGL OBOSA

SUBGL OBOSA

SUBGL OBOSA

SUBGLOBOSA

SUBGL OBOSA

SU EGL OBOSA

SUEGLOBOSA

SU BGL OBOSA

SUEGL OBOSA

SUBGLOBOSA

SUEGL OBOSA

SUEGLOBOSA

SU EGL OBOSA

SUBGL OBOSA

SUBGL OBOSA

SUEGL OB OSA

SUEGL OBOSA

SUEGL OBOSA

SUBGLOBOSA

SUEGL OBOSA

SUBGLOBOSA

SUEGLOBOSA

SU EGL OBOSA

SUBGL OBOSA

SUEGLOBOSA

SUBGLOBOSA

SUBGLOBOSA

SUEGLOBOSA

SUEGLOBOSA

SUBGL OBOSA

SUEGLOBOSA

SUBGL OBOSA

SUEGL OBOSA

SUEGL OBOSA

SU BGL OBOSA

SU EGLOBOSA

SUEGL OBOSA

SUEGLOBOSA

SUEGL OBOSA

SUBGL OBOSA

SUBGLOBOSA

SUEGL OBOSA

SUBGL OBOSA

SUEGL OBOSA

SU BGL OBOSA

SUBGL OBOSA

SUBGLOBOSA

SUBGLOBOSA

SUEGLOBOSA

SUEGL OBOSA

SUBGL OB OSA

AN CEPS

AN CEPS

CARIBAEA

CARIBAEA

CARIBAEA

CARIBAEA

CARIBAEA

CARIBAEA

GIEBA

CHAROIDES

CHAROIDES

CHAROIDES

CHAROIDES

CHAROIDES

CHAROIDES

CHAROIDES

CHAROIDES

CHAROIDE

CHAROIDES

CHAROIDES

CHAROIDES

\section{Locality}

NW GULF OF MEXICO

NH GULF OF MEXICO 


\section{Publication}

18066 PFLUM FRERICHS 1976 18067 PFLUM FRERICHS 1976 18068 PFLUM FRERICHS 1976

18069 PFLUM FRERICHS 1976 18070 PFLUM FRERICHS 1976 18071 PFLIJM FRERICHS 1976 18072 PFLUM FRERICHS 1976 18073 PFLUM FRERICHS 1976 18074 PFLUM FRERICHS 1976 18075 PFLUM FRERICHS 1976 18076 PFLUM FRERICHS 1976 18077 PFLUM FRERICHS 1976 18078 PFLUM FRERICHS 1976 18079 PFLUM FRERICHS 1976 18080 PFLUM FRERICHS 1976 18081 PFLUM FRFFICHS 1976 18081 PFLUM FREKICHS 1976

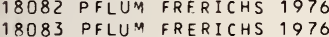
18083 PFLUM FRERICHS 1976
18084 PFLUM FRERICHS 1976 18085 PFLUM FRERICHS 1976 18086 PFLUM FRERICHS 1976 18087 DFLUM FRERICHS 1976 18088 PFLUM FRERICHS 1976 18089 PFLUM FRERICHS 1976 18090 PFLUM FRERICHS 1976 18091 PARKER 1956

18092 PFL IJM FRERICHS 1976

18093 PHLEGER 1951 A

18094 PHLEGER 1951A

18095 PHLEGER 1951 A

18096 PHLEGER 1951 A

18097 PHLEGER 1951 A

18098 PHLEGER $1951 \mathrm{~A}$

18099 PHLEGER 1951 A

18100 PHLEGER 1951 A

18101 PHLEGER 1951 A

18102 PHLEGER 1951A

18103 PHLEGER 1951 A

18104 PHLEGER $1951 \mathrm{~A}$

18105 PHLEGER $1951 \mathrm{~A}$

18106 PHLEGER 1951A

18108 PHLEGER 1951A

18108 PHLEGER $1951 \mathrm{~A}$
18109 PHLEGER $1951 \mathrm{~A}$

18110 PARKER 1954

18111 PARKER 1954

18112 PARKER 1954

18113 PARKER 1954

18114 PARKER 1954

18115 PFLUM FRERICHS 1976

18116 PARKER 1954

18117 PARKER 1954
18118 PARKER 1954

18118 PARKER 1954
18119 PFLUM FRERICHS 1976

18120 PFLUM FRERICHS 1976

18121 PFLUM FRERICHS 1976

18122 PFLUM FRERICHS 1976

18123 PFLUM FRERICHS 1976

18124 PFLUM FRERICHS 1976

18125 LUDWICK WALTON 1957

18126 PHLEGER 1951B

18127 PHLEGER $1951 \mathrm{~B}$

18128 PHLEGER 1951A

18129 PHLEGER 1951A

18130 PHLEGER $1951 \mathrm{~A}$

18131 PHLEGER 1951A

18132 PHLEGER $1951 \mathrm{~A}$

18133 PARKER 1954

$18135^{\circ}$ PHLEGER 1951 A

18136 PARKER 1954

18137 PHLEGER 1951 A

18138 PHLEGER 1951 A

18139 PHLEGER $1951 \mathrm{~A}$

18140 PHLEGER 1951A

18142 PFLUM FRERICHS 1976

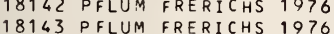

18144 PFLUM FRERICHS 1976 18145 PFLUM FRERICHS 1976 18146 PFLUM FRERICHS 1976
18147 PFLUM FRERICHS 1976 18147 PFLUM FRERI

18169 PFLUM FRERICHS 1976 18150 PFLUM FRERICHS 1976 18151 PFLUM FRERICHS 1976 18152 PFLUM FRERICHS 1976 18153 PFLUM FRERICHS 1976 18154 PFLUM FRERICHS 1976 18155 PFLUM FRERICHS 1976 18156 PARKER 1954

18157 PARKER 1954

18158 PARKER 1954

18159 PARKER 1954

18160 PARKER 1954
Generic Name

GL OMOSPIRA

GLOMOSPIRA

GL OMOSPIRA

GL OMOSPIRA

GL OMOSPIRA

GLOMOSPIRA

GL OMOSPIRA

GLOMOSPIRA

GLOMOSPIRA

GL OMOSPIRA

GL OMOSPIRA

GL OMOSPIRA

GL OMOSPI RA

GLOMOSPIRA

GL OMOSPIRA

GL OMOSP IRA

GLOMOSPIRA

GLOMOSPIRA

GL OMOSPIRA

GL OMOSPIRA

GL OMOSP I RA

GL OMOSPIRA

GL OMOSPIRA

GL OMOSPI RA

GL OMOSPIRA

GLOMOSPIRA

GLOMOSPIRA

GL OMOSPIRA

GL OMOSP I RA

GLOMOSPIRA

GL OMOSPIRA

GLOMO SPIRA

GL OMOSP IRA

GL OMOSPIRA

GL OMOSP IRA

GL OMOSP IRA

GL OMOSPIRA

GL OMOSPI RA

GL OMOSPIRA

GLOMOSPI RA

GLOMOSPIRA

GL OMOSPIRA

GL OMOSPIRA

GL OMOSPIRA

GL OMOSPIRA

GL OMO SP I RA

GL OMOSPIRA

GL OMOSP IRA

GLOMOSPIRA

GL OMOSP IRA

GL OMOSPIRA

GL OMO SPI RA

GL OMOSP IRA

GL OMOSP I RA

GL OMOSPIRA

GL OMOSPIRA

GL OMOSPIRA

GL OMOSPIRA

GL OMOSP I RA

GL OMOSP IRA

GL OMOSP I RA

GL OMOSPIRA

GL OMOSP I RA

GL OMOSPIRA

GL OMOSPIRA

GL OMOSPIRA

GL OMOSPIRA

GL OMOSPI RA

GL OMOSPI RA

GL OMOSPIRA

GL OMOSPIRA

GLOMOSPIRA

GL OMOSPI RA

GLOMOSPIRA

GL OMOSPIRA

GL OMOSPIRA

GL OMOSP I RA

GL OMOSPI IRA

GLOMOSPIRA

GL OMOSP I RA

GL OMOSPIRA

GL OMOSPIRA

GL OMOSPIRA

GL OMOSPIRA

GL OMOSPIRA

GLOMOSPI RA

GL OMOSPIRA

GL OMO SPIRA

GLOMOSPIRA

GLOMOSPIRA

GL OMOSPIRA

GL OMOSPIRA

GL OMOSPIRA

GL OMOSPIRA

GLOMOSPIRA
Specific Name

CHAROIDES

CHAROIDES

CHAROIDES

CHAROIDES

CHAROIDES

CHAROIDES

CHAROIDES

CHAROIDES

CHAROIDES

CHAROIDES

CHAROIDES

CHAROIDES

CHAROIDES

CHAROIDES

CHAROIDES

CHAROIDES

CHAROIDES

CHAROIDES

CHAROIDES

CHAROIDES

CHAROIDES

CHAROIDES

CHAROIDES

CHAROIDES

CHAROIDES

CHAROIDES

CHAROIDES

CHAROIDES

CHAROIDES

CHAROIDES

CHAROIDES

CHAROIDES

CHAROIDES

CHAROIDES

CHAROIDES

CHAROIDES

CHAROIDES

CHAROIDES

CHAROIDES

CHAROIDES

CHAROIDES

CHAROIDES

CHAROIDES

CHAROIDES

CHAROIDES

CHAROIDES

CHAROIDES

CHAROIDES

CHAROIDES

CHAROIDES

CHAROIDES

CHAROIDES

CHAROIDES

CHAROIDES

CHAROIDES

CHAROIDES

CHAROIDES

CHAROIDES

CHAROIDES

CHAROIDES

CHAROIDES

CHAROIDES

CHAROIDES

CHAROIDES

CHAROIDES

CHAROIDES

CHAROIDES

CHAROIDES

CHAROIDES

CHAROIDES

CHAROIDES

CHAROIDES

CHAROIDES

CHAROIDES

CHAROIDES

CHAROIDES

CHAROIDES

CHAROIDES

CHAROIDES

CHAROIDES

CHAROIDES

CHAROIDES

CHAROIDES

CHAROIDES

CHAROIDES

CHAROIDES

CHAROIDES

CHAROIDES

CHAROIDES

CHAROIDES

CHAROIDES

CHAROIDES

CHAROIDES

CHAROIDES

CHAROIDES

Locality

Lat. Long.

NW GULF OF MEXICO

NW GULF OF MEXICO

NW GULF OF MEXICO 


\section{Publication}

18161 PARKER 1954

18162 PARKER 1954

18163 PARKER 1954

18164 PARKER 1954

18166 PFLUM FRERICHS 1976 18167 PFLUM FRERICHS 1976 18168 PFLUM FRERICHS 1976

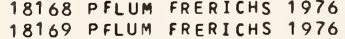
18170 PARKER 1954

18171 PFLUM FRERICHS 1976 18172 PFLUM FRERICHS 1976 18173 PFLUM FRERICHS 1976 18174 PFLUM FRERICHS 1976 18175 PFLUM FRERICHS 1976 18176 PFLUM FRERICHS 1976 18177 PFLUM FRERICHS 1976 18178 PFLUM FRERICHS 1976 18179 PFLUM FRERICHS 1976 18180 PFLUM FRERICHS 1976 18181 PFLUM FRERICHS 1976 18182 PFLUM FRERICHS 1976 18183 PFLUM FRERICHS 1976 18184 PFLUM FRERICHS 1976 18185 PFLUM FRERICHS 1976 18186 CUSHMAN 1918

18187 CUSHMAN 1918

18188 PARKER 1954

18189 PARKER 1954

18190 PARKER 1954

18191 PARKER 1954

18192 PARKER 1954

18193 PARKER 1954

18194 PARKER 1954

18195 PFLUM FRERICHS 1976

18196 PARKER 1954

18197 PARKER 1954

18198 PARKER 1956

18199 PARKER 1954

18200 PFLUM FRERICHS 1976 18201 PFLUM FRERICHS 1976 18202 PFLUM FRERICHS 1976 18203 PFLUM FRERICHS 1976 18204 PFLUM FRERICHS 1976 18205 PFLUM FRERICHS 1976 18206 PFLUM FRERICHS 1976 18207 PFLUM FRERICHS 1976 18208 PFLUM FRERICHS 1976 18209 PFLUM FRERICHS 1976 18210 PFLUM FRERICHS 1976 18211 PARKER 1954

18212 PFLUM FRERICHS 1976 18213 PFLUM FRERICHS 1976 18214 PFLUM FRERICHS 1976 18215 PFLUM FRERICHS 1976 18216 PFLUM FRERICHS 1976 18217 PFLUM FRERICHS 1976 18218 PFLIIM FRERICHS 1976 18219 PFLUM FRERICHS 1976 18220 PFLUM FRERICHS 1976 18221 PFLUM FRERICHS 1976 18222 PFLUM FRERICHS 1976 18223 PFLUM FRERICHS 1976 18224 PFLUM FRERICHS 1976 18225 PFLUM FRERICHS 1976 18226 PFLUM FRERICHS 1976 18227 PFLUM FRERICHS 1976

18228 PARKER 1954

18229 PHLEGER 1955 A

18230 PARKER 1954

18231 PARKER 1954

18232 PARKER 1954

18233 CREAGER 1958

18234 PHLEGER 1955A

18235 PHLEGER 1955A

18236 LUDWICK WALTON 1957

18237 PARKER 1954

18238 PARKER 1954

18239 PARKER 1954

18240 PARKER 1954

18241 PARKER 1954

18242 BANDY 1956
18243 WALTON 1960

18244 SEGURA 1963

18245 BANOY 1956

18246 SHIFFLETT 1961

18247 SHEPARD MOORE 1955

18248 SHEPARD MOORE 1955

18269 LEHMANN 1957

18250 PARKER 1954

18251 PARKER 1956

18252 PARKER 1956

18253 LANKFORD 1959

18255 PHLEGER 1954

\section{Generic Name Specific Name}

CHAROIDES

CHAR OIDES

CHAROIDES

CHAROIDES

CHAROIDES

GORDIALIS

GORDI AL IS

GORDIALIS

GORDIALIS

GOROIALIS

GORDIALIS

GORDIALIS

GORDIALIS

GORDIALIS

GORDIALIS

GOROIALIS

GOROIALIS

GORDIALIS

GORDIALIS

GORDIALIS

GOROIAL IS

GORDIALIS

GORDIALIS

GORDIALIS

GORDIALIS

GORDIALIS

GORDIALIS

GORDIALIS

GORDIALIS

GORDIALIS

GORDIALIS

GOROIALIS

GOROIALIS

GORDIALIS

GORDIALIS

GORDIALIS

GORDIALIS

GORDIALIS

GORDIALIS

GOROIAL IS

GORDIALIS

GORDIALIS

GORDIALIS

GORDIALIS

GORDIALIS

GORDIALIS

GOROIALIS

GORDIALIS

GORDIALIS

GORDIALIS

GORDIALIS

GORDIALIS

GORDIALIS

GORDIALIS

GOROIALIS

GORDIALIS

GORDIALIS

GORDIALIS

GOROI ALIS

GORDIALIS

MISSISSIPPIENSIS

MISSISSIPPIENSIS

MISSISSIPPIENSIS

MISSISSIPPIENSIS

MISSISSIPPIENSIS

MISSISSIPPIENSIS

MISSISSIPPIENSIS

MI SSISSIPPIEN IS

MISSISSIPPIEN SIS

MISSISSIPPIENSIS

MISSISSIPPIENSIS

MISSISSIPPIENSIS

MISSISSIPPIENSIS

AUSTRALIS

AUSTRALIS

AU STRALIS

AUSTRALIS

AUSTRAL IS

AUSTRALIS

AUSTRAL IS

AUSTRALIS

AUSTRALIS

AU STRALIS

AUSTRALIS

AUSTRALIS

AUSTRALIS

\section{Locality}

NE GULF OF MEXICO

NE GULF OF MEXICO

NE GULF OF MEXICO

NE GULF OF MEXICO

NE GULF OF MEXICO

CENTRAL GULF OF MEXICO

CENTRAL GULF OF MEXICO

CENTRAL GULF OF MEXICO

CENTRAL GULF OF MEXICO

NE GULF OF MEXICO

CENTRAL GULF OF MEXICO

CENTRAL GULF OF MEXICO

CENTRAL GULF OF MEXICO

CENTRAL GULF OF MEXICO

CENTRAL GULF OF MEXICO

CENTRAL GULF OF MEXICO

CENTRAL GULF OF MEXICO

CENTRAL GULF OF MEXICO

CENTRAL GULF OF MEXICO

CENTRAL GULF OF MEXICO

CENTRAL GULF OF MEXICO

CENTRAL GULF OF MEXICO

CENTRAL GULF OF MEXICO

CENTRAL GULF OF MEXICO

CENTRAL GULF OF MEXICO

NE GULF OF MEXICO

NE GULF OF MEXICO

NE GULF OF MEXICO

NE GULF OF MEXICO

NE GULF OF MEXICO

NE GULF OF MEXICO

NE GULF OF MEXICO

NE GULF OF MEXICO

NE GULF OF MEXICO

CENTRAL GULF OF MEXICO

NE GULF OF MEXICO

NE GULF OF MEXICO

NE GULF OF MEXICO

NE GULF OF MEXICO

NW GULF OF MEXICO

$N H$ GULF OF MEXICO

NH GULF OF MEXICO

NW GULF OF MEXICO

$N W$ GULF OF MEXICO

NH GULF OF MEXICO

NW GULF OF MEXICO

NW GULF OF MEXICO

NW GULF OF MEXICO

NW GULF OF MEXICO

NW GULF OF MEXICO

NE GULF OF MEXICO

NH GULF OF MEXICO

$N H$ GULF OF MEXICO

NW GULF OF MEXICO

NW GULF OF MEXICO

NW GULF OF MEXICO

NW GULF OF MEXICO

NH GULF OF MEXICO

NH GULF OF MEXICO

NW GULF OF MEXICO

NW GULF OF MEXICO

NW GULF OF MEXICO

NW GULF OF MEXICO

NW GULF OF MEXICO

NH GULF OF MEXICO

NW GULF OF MEXICO

NH GULF OF MEXICO

NE GULF OF MEXICO

$N$ GULF OF MEXICO

NE GULF OF MEXICO

NE GULF OF MEXICO

NE GULF OF MEXICO

BAY OF CAMPECHE

$N$ GULF OF MEXICO

$N$ GULF OF MEXICO

NE GULF OF MEXICO

NE GULF OF MEXICO

NE GULF OF MEXICO

NE GULF OF MEXICO

NE GULF OF MEXICO

NE GULF OF MEXICO

NE GULF OF MEXICO

MISSISSIPPI SOUND

MATAMOROS, MEXICO

NE GULF OF MEXICO

HEALD BANK, G. OF MEXICO

CENTRAL TEXAS COAST

CENTRAL TEXAS COAST

TEXAS GULF COAST

NE GULF OF MEXICO

NE GULF OF MEXICO

NE GULF OF MEXICO

$M I S S I S S I P P I$ DELTA

MISSISSIPPI SOUND

$N$ GULF OF MEXICO

Lat. Long.

$2900 \mathrm{~N} 08654 \mathrm{~W}$ $\begin{array}{llll}29 & 44 N & 086 & 41 W \\ 29 & 15 N & 087 & 55 W\end{array}$ $2850 \mathrm{~N} 08736 \mathrm{~W}$ $2746 \mathrm{~N} 089$ 16W $2736 \mathrm{~N} 08837 \mathrm{~W}$ $27 \quad 32 \mathrm{~N} 088 \quad 32 \mathrm{~W}$ $27 \quad 42 \mathrm{~N} 088 \quad 41 \mathrm{H}$ $2806 N 088 \quad 52 W$ $2530 \mathrm{~N} 08459 \mathrm{~W}$ $2833 N 08913 W$ 


\section{Publication}

18256 PARKER 1754 18258 PARKER PHLEGER PEIRSON 1953 18259 BOCK 1976

18260 PARKER 1954

18261 PARKER 1954

18262 PARKER 1954

18263 PARKER 1954

18264 LUDWICK WALTON 1957

18265 PARKER PHLEGER PEIRSON 1953

18266 ANDERSON 1968

18267 KELLOUGH 1956

18268 PARKER 1954

18269 PARKER PHLEGER PEIRSON 1953

18270 BANDY 1956

18271 BANDY 1956

18272 BANDY 1956

18273 BANDY 1056

18274 BANDY 1956

18275 BANDY 1956

18276 BANDY 1956

18277 AYALA-CASTANARES SEGURA 1968

18278 BANDY 1956

18279 BANDY 1956

18280 BANDY 1956

18281 BANDY 1956

18282 BANDY 1956

18283 BANDY 1956

18284 BANDY 1956

18285 BANDY 1956

18286 BANDY 1956

18287 BANDY 1956

18288 BOCK 1976

18289 BOCK 1976

18290 NORTON 1930

18291 SEGURA 1963

18292 NORTON 1930

18293 ANDERSEN 1961
18294 BANDY 1954

18294
18295 BANDY 1954

18296 BANDY 1954

18297 BANDY 1954

18298 DAVIS 1964

18299 BANDY 1954

18300 SANDY 1954

18301 ANDERSEN 19

18302 POST 1951
18303 NORTON 1930

18304 NORTON 1930

18305 BANDY 1956

18306 CUSHMAN 1931

18307 BANDY 1956

18308 BANDY 1956

18309 BANDY 1956

18310 BANDY 1956

18311 BANDY 1956

18312 BOCK 1976

18313 PARKER 1954

18314 PARKER 1954

18315 PARKER 1954

18316 BANDY 1956

18317 BANDY 1956

18318 BANDY 1956

18319 BENDA PURI 1962

18320 BANDY 1956

18321 BANDY 1956

18322 BANDY 1956

18323 CUSHMAN 1931

18324 PARKER 1954

18325. PARKER 1954

18326 PARKER 1954

18327 LUDWICK WALTON 1957

18328 BANDY 1956

18329 BANDY 1956

18330 BANDY 1956

18331 BANDY 1956

18332 BANDY 1956

18333 BANDY 1956

18334 BANDY 1956

18335 BANDY 1956

18336 PFLU'A FRERICHS 1976

18337 PFLUM FRERICHS 1976

18338 PFLUM FRERICHS 1976

18339 PFLUM FRERICHS 1976

18340 PFLUM FRERICHS 1976

18341 PFLUM FRERICHS 1976

18342 PFLUM FRERICHS 1976

18343 PFLUM FRERICHS 1976

18344 PFLUM FRERICHS 1976

18345 PFLUM FRERICHS 1976

18346 PFLUM FRERICHS 1976

18347 PFLUM FRERICHS 1976

18348 PFLUM FRERICHS 1976

18349 PFLUM FRERICHS 1976

18350 PFLUM FRERICHS 1976

\section{Generic Name}

GUTTUL INA

GUTTULINA

GUTTULINA

GUTTULINA

GUTTULINA

GUTTULINA

GUTTULINA

GUTTULINA

GUTTULINA

GUTTULINA

GUTTUL INA

GUTTULINA

GUTTUL INA

GUTTULINA

GUTTULINA

GUTTULINA

GUTTULINA

GUTTULINA

GUTTULINA

GUTTUL I NA

GUTTULINA

GUTTULINA

GUTTULINA

GUTTULINA

GUTTULINA

GUTTULINA

GUTTUL I NA

GUTTULINA

GUTTULINA

GUTTULI INA

GUTTUL INA

GUTTUL INA

GUTTULINA

GUTTULINA

GUTTULINA

GUTTULINA

GUTTUL I NA

GUTTULI INA

GUTTUL INA

GUTTUL I NA

GUTTULINA

GUTTULINA

GUTTULINA

GUTTULINA

GYPSINA

GYPSINA

GYPS INA

GYPSINA

GYPSINA

GYPSINA

GYPSINA

GYPSINA

GYPSINA

GYPS INA

GYPSINA

GYPSINA

GYPS INA

GYPSINA

GYPSINA

GYPSINA

GYPSINA

GYPSINA

GYPSINA

GYPSINA

GYPSINA

GYPSINA

GYPSINA

GYPSINA

GYPSINA

GYPSINA

GYPSINA

GYPSINA

GYPSINA

GYPSINA

GYPS INA

GYPSINA

GYROIDINA

GYROIDINA

GYROIDINA

GYROIDINA

GYROIDINA

GYROIDINA

GYROIDINA

GYROIDINA

GYROIDINA

GYROIDINA

GYROIDINA

GYROI INA

GYROIDINA

GYROIDINA

GYROIDINA
Specific Name

AUSTRALIS

AUSTRALIS

AUSTRALIS

AUSTRALIS

AUSTRALIS

AUSTRALIS

AUSTRALIS

AUSTRALIS

AUSTRALIS

AUSTRALIS

AU STRALIS

AU STRALIS

AUSTRALIS

AUSTRALIS

AUSTRALIS

AU STRALIS

AUSTRALIS

AUSTRALIS

AUSTRALIS

AUSTRALIS

AUSTRALIS

AUSTRALIS

AUSTRALIS

AUSTRALIS

AUSTRALIS

AU STRALIS

AUSTRALIS

AUSTRALIS

AU STRAL IS

AUSTRALIS

AUSTRALIS

HI RSUTA

LAEVIS

OBLONGA

PRCBLEMA

PR CBLEMA

PULCHELLA

AU STRALIS

AUSTRALIS

AUSTRALIS

AUSTRALIS

AU STRALIS

AU STRALIS

SPICAEF ORMI

AU STRALIS

GL OBULUS

GL CBULUS

VESICULAR IS

VESICULAR IS

VE SICULAR IS

VESI CULAR IS

VESICULARIS

VESI CULAR IS

VESICULAR IS

VESI CULAR IS

VE SI CUL AR IS

VE SICULAR IS

VESI I ULAR IS

VESI CULARIS

VESICULARIS

VESICULARIS

VESICULARIS

VE SICULARIS

VESICULARIS

VESICULAR IS

VESICULARIS

VESI CULARIS

VESICULARIS

VE SI CULAR IS

VESI CULAR IS

VESICULAR IS

VESICULAR IS

VESICULARIS

VESI CULAR IS

VE SICULAR IS

VESICULAR IS

VESICULAR IS

VESICULAR IS

ALTIFORMIS ACUTA

AL TIFORMIS ACUTA

AL TIFORMIS ACUTA

AL TIFORMIS ACUTA

ALTIFORMIS ACUTA

AL TIFORMIS ACUTA

AL TIFORMIS ACUTA

AL IFORMIS ACUTA

AL IFORMIS ACUTA

AL TIFORMIS ACUTA

AL IIFORMIS ACUTA

ALTIFORMIS ACUTA

ALTIFORMIS ACUTA

AL IIFORMIS ACUTA

ALTIFORMIS ACUTA

Locality

NE GULF OF MEXICO

MATAGORDA BAY, TEXAS

TEXAS GULF COAST

NE GULF OF MEXICO

NE GULF OF MEXICO

NE GULF OF MEXICO

NE GULF OF MEXICO

NE GULF OF MEXICO 
Publication

18351 PFLUM FRERICHS 1976 18352 PFLUM FRERICHS 1976 18353 PFLUM FRERICHS 1976 18354 PFLU 9 FRERICHS 1976 18355 PFLUM FRERICHS 1976 18356 PFLUM FREPICHS 1976 18357 PFLUM FRERICHS 1976 18358 PFLUN, FRERICHS 1976 18359 PFLUM FREFICHS 1976
18360 PFLUM FRERICHS 1976 18361 PFLUM FRERICHS 1276 1836? PFLUM FRERICHS 1976 18363 PFLIJM FRERICHS 1976 18364 PFLUM FREKICHS 1976 18365 PFLUM FRERICHS 1976 18366 PFLUM FRERICHS 1976 18367 PFLUM FRERICHS 1976 18368 PFLUM FRERICHS 1976 18369 PFLUIA FRERICHS 1976 18370 PFLUM FRFRICHS 1976 18371 PFLUM FRERICHS 1776 18372 PFLUM FRERICHS 1976 18373 PFLUM FRERICHS 1976
18374 PFLUM FDERICHS 1976 18375 PFLUM FREKICHS 1976 18376 PFLUM FRERICHS 1976 18377 PFLUM FRERICHS 1976 18378 PFLUM FRERICHS 1976 18379 PFLUM FRERICHS 1976 18380 PFLUM FRERICHS 1976 18381 PFLUM FRERICHS 1976 18382 PFLUM FREKICHS 1976 18383 PFLUM FRERICHS 1976 18384 PFLIIM FRERICHS 1976 18385 PFLUM FRERICHS 1976 18386
18387 PFLUM FRERICHS 1976
18388 PFLUM FRERICHS 1976 18388 PFLUM FRERICHS 1976 18389 PFLUM FRERICHS 1976 18390 PFLUM FRERICHS 1976 18391 PFLUM FRERICHS 1976 18392 PFLUM FRERICHS 1976 18393 PFLUM FPERICHS 1976 18394 PFLUM FRERICHS 1976 18395 PFLUM FRERICHS 1976 18396 PFLUM FRERICHS 1976 18397 PFLUM FRERICHS 1976 18398 PFLUM FRERICHS 1976 18399 PFLUM FRERICHS 1976 18400 PFLUM FRERICHS 1976 18401 PFLUM FRERICHS 1976 18402 PFLUM FRERICHS 1976 18403 PFLUM FRERICHS 1976 18404 PFLUM FRERICHS 1976 18405 PFLUM FRERICHS 1976 18406 PFLUM FRERICHS 1976 18407 PFLIJM FRERICHS 1976 18408 PFLUM FRERICHS 1970 18409 PFLUM FRERICHS 1976 18410 PFLUM FRERICHS 1976 18411 PFLUM FRERICHS 1976 18412 PFLUM FRERICHS 1976 18413 PFLIJM FRERICHS 1976 18414 PFLUM FRERICHS 1976 18415 PFLUM FRFRICHS 1976 18416 CREAGER 1959 18417 CREAGEP 1958 18419 CREAGER 1958 18420 CREAGER 1958 18421 CREAGER 1958 18422 CREAGER 1958 18423 CREAGEP 1958 18424 CREAGER 1958 18425 PARKER 1954 18427 PARKER 1954 18428 PARKER 1954 18429 PARKER 1954 18430 PARKER 1954 18431 PARKER 1954

18433 PAPKER 1954

18434 PARKER 1754

18435 PHLEGER 1955 A

18436 PARKER 1954

18437 PARKER 1954
18438 PARKER 1954

18439 PHLEGER 1951A

18440 PHLEGER 1951 A

18441 PHLEGER 1955 A
18442 PFLUM FRERICHS 1976

18442 PFLUM FRERICHS 1976
18443 PHLEGER $1955 \mathrm{~A}$

18444 PFLUM FRERICHS 1976

18445 PFLUM FRERICHS 1976
Generic Name

GYROIDINA

GYROIDINA

GYROIDINA

GYROI JINA

GYROIDINA

GYROIDINA

GYROIDINA

GYROIDINA

GYROIDINA

GYROIDINA

GYROIDINA

GYROIDINA

GYRO I D INA

GYROI DINA

GYRO I D INA

GYROIOINA

GYROI OINA

GYROID INA

GYROID INA

GYROIDINA

GYROIDINA

GYROIDINA

GYROIDINA

GYRO I I INA

GYROID INA

GYROID INA

GYROIDINA

GYROIDINA

GYROI DINA

GYROIDINA

GYROIDINA

GYROIDINA

GYROIDINA

GYROIDINA

GYROIDINA

GYROIDINA

GYRO I D INA

GYROIDINA

GYROI DINA

GYROI DINA

GYRO I I INA

GYROIDINA

GYROI DINA

GYROIDINA

GYROI DINA

GYROI DINA

GYROI D INA

GYROI D INA

GYROIDINA

GYROIDINA

GYROIDINA

GYROI D INA

GYROIDINA

GYROI DINA

GYROI DINA

GYROIDINA

GYROIDINA

GYROIDINA

GYROI DINA

GYROIDINA

GYROIDINA

GYROIDINA

GYROID INA

GYROIDINA

GYROIDINA

GYROIDINA

GYROIDINA

GYROID INA

GYROIDINA

GYROIDINA

GYROIDINA

GYROIDINA

GYRO ID INA

GYROI DINA

GYRO I D INA

GYROI DINA

GYROI OINA

GYROIDINA

GYROIDINA

GYROI DINA

GYROIDINA

GYROIDINA

GYROIDINA

GYROIDINA

GYRO I D INA

GYROIDINA

GYROIDINA

GYROIDINA

GYROIDINA
Specific Name

AL TIFORMIS ACUTA

AL TIFORMIS ACUTA

AL TIFORMIS ACUTA

AL IIFORMIS ACUTA

AL TIFORMIS ACUTA

ALTIFORMIS ACUTA

AL TIFORMIS ACUTA

AL TIFORMIS ACUTA

AL TIFORMIS ACUTA

ALTIFORMIS ACUTA

AL TIFORMIS ACUTA

AL TIFORMIS ACUTA

ALTIFORMIS ACUTA

AL TIFORMIS CUSHMANI

AL IIFORMIS CUSHMANI

AL TIFORMIS CUSHMANI

AL TIFORMIS CUSHMAN

AL TIFORMIS CUSHMAN

AL TIFORMIS CUSHMANI

ALTIFORMIS CUSHMANI

AL TIFORMIS CUSHMAN

AL IIFORMIS CUSHMANI

AL TIFORMIS CUSHMAN

AL TIFORMIS CUSHMAN

AL TIFORMIS CUSHMAN

ALTIFORMIS CUSHMANI

AL TIFORMIS CUSHMANI

AL IIFORMIS CUSHMANI

AL IFORMIS CUSHMANI

AL TIFORMIS CUSHMANI

AL TIFORMIS CUSHMANI

AL TIFORMIS CUSHMAN I

AL IIFORMIS CUSHMANI

AL TIFORMIS CUSHMANI

AL TIFORMIS CUSHMANI

AL IIFORMIS CUSHMANI

AL TIFORMIS CUSHMAN

AL TIFORMIS CUSHMAN

ALTIFORMIS CUSHMANI

AL IIFORMIS CUSHMANI

ALTIFORMIS CUSHMANI

AL IIFORMIS CUSHMANI

AL TIFORMIS CUSHMANI

AL TIFORMIS CUSHMANI

AL TIFORMIS CUSHMAN

ALTIFORMIS CUSHMANI

AL IFORMIS CUSHMAN

ALIIFORMIS CUSHMANI

AL TIFORMIS CUSHMANI

AL TIFORMIS CUSHMAN

AL TIFORMIS CUSHMANI

ALTIFORMIS CUSHMANI

ALTIFORMIS CUSHMANI

AL TIFORMIS CUSHMANI

ALTIFORMIS CUSHMAN

AL IIFORMIS CUSHMANI

ALIIFORMIS CUSHMANI

ALIIFORMIS CUSHMAN

AL TIFORMIS CUSHMANI

ALTIFORMIS CUSHMANI

AL IIFORMIS CUSHMANI

AL TIFORMIS CUSHMANI

APICULARIS

LANARCKIANA

LANARCKIANA

LANARCKIANA

LAMARCKIANA

LANARCKIANA

MALRYAE

MALRYAE

MALRYAE

MAL'RYAE

NEOSOLDAN I I

NE CSOLDAN I I

NECSOLDAN I I

NE OSOLDANII

NE OSOLDANII

NECSOLDANI I

NE OSOLDANII

NE CSOLDAN I I

NE CSOLDANII

NE CSOLDAN I I

NE OSOLDAN I I

NEOSOLDANII

NE CSOLDAN I I

NEOSOLDAN I I

OREICULAR IS

OREICULAR IS

OREICULAR IS

OREICULARIS

OREICULAR IS

OREICULAR IS

OREI CULAR IS

Locality

CENTRAL GULF OF MEXICO

CENTRAL GULF OF MEXICO

CENTRAL GULF OF MEXICO

CENTRAL GULF OF MEXICO

CENTRAL GULF OF MEXICO

CENTRAL GULF OF MEXICO

CENTRAL GULF OF MEXICO

CENTRAL GULF OF MEXICO

$N W$ GULF OF MEXICO

NW GULF OF MEXICO

NW GULF OF MEXICO

NW GULF OF MEXICO

NW GULF OF MEXICO

$N W$ GULF OF MEXICO

$N W$ GULF OF MEXICO

CENTRAL GULF OF MEXICO 
Publication

19446 PHLEGER 1951A

18447 PHLEGER 1951A

18448 PHLEGER 1951A

18449 PHLEGER 1951A

18450 PFLUM FRERICHS 1976

18451 PFLUM FRERICHS 1976

18452 PFLUM FRERICHS 1976

18453 PFLUM FRERICHS 1976

18454 PFLUM FRERICHS 1976

18455 PFLIMM FRERICHS 1976

18456 PFLUM FRERICHS 1976 18457 PHLEGER 1951A

18458 PFLUM FRERICHS 1976 18459 PFLUM FRERICHS 1976 18460 PFLUM FRERICHS 1976 18461 PFLUM FRERICHS 1976 18462 PFLUM FRERICHS 1976 18463 PFLUM FRERICHS 1976 18464 PFLUM FRERICHS 1976

18465 PHLEGER 1951 A

18466 PHLFGER 1951A

18467 PHLEGER $1951 \mathrm{~A}$

18468 PHLEGER $1951 \mathrm{~A}$

18469 PHLEGER 1951A

18470 PFLUM FRERICHS 1976

18471 PFLUM FRERICHS 1776

18472 PFLUM FRERICHS 1976

18473 PHLEGER 1951A

18474 PHLEGER $1951 \mathrm{~A}$

18475 PHLEGER 1951 A

18476 PHLEGER 1951A

18477 PHLEGER 1951A

18478 PARKER 1954

18479 PARKER 1954

18480 PARKER 1954

18481 PARKER 1954

18482 PARKER 1954

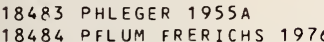

18485 PARKER 1954

18486 PARKER 1954

18487 PARKER 1954

18488 LUDWICK WALTON 1957

18489 PHLEGER 1955A

18490 PHLEGER 1955 A

18491 FHLEGER 1955A

18492 PHLEGER 1955A

18493 PARKER 1954

18494 PARKER 1954

18495 PARKER 1954

18496 PHLEGER $1951 \mathrm{~A}$

18497 PARKER 1954

18498 PARKER 1954

18499 PARKER 1954

18500 PARKER 1954

18501 PHLEGER 1951A

18502 PHLEGER 1951A

18503 PHLEGER 1951A

18504 PHLEGER 1951A

18505 PHLEGER 1951 A

18506 PHLEGER 1951 A

18507 PHLEGER 1951 A

18508 PFLUM FRERICHS 1976

18509 PFLUM FRERICHS 1976

18510 PFLUM FRERICHS 1976

18511 PFLUM FRERICHS 1976

18512 PFLUM FRERICHS 1976

18513 PFLUM FRERICHS 1976

18514 PFLU:Y FRERICHS 1976

18515 PFLUM FRERICHS 1976 18516 PFLUM FRERICHS 1976 18517 PFLUM FRERICHS 1976 18518 PARKER 1954

18519 PARKER 1954

18520 PARKER 1954

18521 PARKER 1954

18522 PFLUM FRERICHS 1976 18523 PFLUM FRERICHS 1976 18524 PFLUM FRERICHS 1976 18525 PFLUM FRERICHS 1976 18526 PFLUM FRERICHS 1976 18527 PFLU ' FRERICHS 1976 18528 PFLUM FRERICHS 1970 18529 PFLUM FRERICHS 1976 18530 PFLUM FRERICHS 1976 18531 PFLUM FRERICHS 1976 18532 PFLUM FRERICHS 1976 18533 PFLUM FRERICHS 1976 18534 PFLUM FRERICHS 1976 18535 PFLUM FRERICHS 1976 18536 PFLUM FRERICHS 1976 18537 PARKER 1954

18538 PARKER 1054

18539 PARKER 1954

18540 PFLUM FRERICHS 1976
Generic Name

Specific Name

Locality

Lat. Long.

GYROIDINA

GYROIDINA

GYROIDINA

GYROIDINA

GYROI D INA

GYROIDINA

GYROIDINA

GYROIDINA

GYROIDINA

GYROID INA

GYROIDINA

GYROIDINA

GYROIDINA

GYROIDINA

GYROI D INA

GYROIDINA

GYROIDINA

GYROIDINA

GYROID INA

GYROIDINA

GYROIDINA

GYROIDINA

GYROIDINA

GYROIDINA

GYROIDINA

GYROID INA

GYROIDINA

GYROIDINA

GYROIDINA

GYROIDINA

GYROIDINA

GYROID INA

GYROIDINA

GYROID INA

GYROIDINA

GYROIDINA

GYROID I NA

GYROIDINA

GYROIDINA

GYROIDINA

GYROID INA

GYROID INA

GYROIDINA

GYROI D INA

GYROIDINA

GYROIDINA

GYROIDINA

GYROIDINA

GYROIDINA

GYROIDINA

GYROIDINA

GYROIDINA

GYROID I NA

GYROIDINA

GYROIDINA

GYROID INA

GYROIDINA

GYROIDINA

GYROIDINA

GYROIDINA

GYROI DINA

GYROID I NA

GYROIDINA

GYROIDINA

GYROIDINA

GYROIDINA

GYROIDINA

GYROIDINA

GYROIDINA

GYROIDINA

GYROIDINA

GYROIDINA

GYROIDINA

GYROIDINA

GYROIDINA

GYROI DINA

GYROIDINA

GYROIDINA

GYROIDINA

GYROIDINA

GYROIDINA

GYROIDINA

GYROIDINA

GYROIDINA

GYROIDINA

GYROIDINA

GYROIDINA

GYROIDINA

GYROIDINA

GYROIDINA

GYROIDINA

GYROIDINA

GYROIDINA

GYROIDINA

GYROIDINA
OREICULAR IS

OREICULARIS

OREI CULAR IS

OREICULAR IS

OREICULARIS

OREICULARIS

OREICULARIS

OREICULARIS

OREICULARIS

OREI I ULAR IS

OREICULAR IS

OREICULAR IS

OREICULAR IS

OREICULARIS

OREICULARIS

OREICULARIS

OREICULARIS

OREICULAR IS

OREICULAR IS

OREICULARIS

OREICULAR IS

OREICULAR IS

OREICULARIS

OREICULAR IS

OREICULAR IS

OREICULAR IS

OREICULAR IS

OREICULAR IS

OREICULARIS

OREICULAR IS

OREICULARIS

OREICULARIS

OREICULARIS

OREICULARIS

OREICULAR IS

OREICULAR IS

ORE ICULAR IS

OREI CULAR IS

OREICULAR IS

OREICULAR IS

OREICUL AR IS

OREICULARIS

OREICULARIS

OREICULARIS

OREICULAR IS

OREI CULARIS

OREICULARIS

OREICULAR IS

OREICULARIS

OREICULAR IS

OREICULAR IS

OREICULARIS

OREICULAR IS

OREICULAR IS

OREICULARIS

OREICULARIS

OREICULAR IS

OREICULAR IS

OREICULAR IS

OREICULARIS

OREICULARIS

OREICULARIS

OREI CULARIS

OREICULAR IS

OREICULARIS

OREICULAR IS

OREICULAR IS

OREICULAR IS

OREICULARIS

OREI CUL AR IS

OREICULAF IS

OREICULARIS

OREICULAR IS

OREICULARIS

OREICULARIS

OREICULARIS

OREICULARIS

OREICULAR IS

OREICULARIS

OREICULAR IS

OREI CULAR IS

OREICULAR IS

OREICULARIS

OREICULAR IS

OREICULARIS

OREICULAR IS

OREICULAR IS

OREICULAFIS

OREICULARIS

OREICULARIS

OREICULARIS

OREICULAR IS

OREICULAR IS

OREICULAR IS
OREICULARIS

NW GULF OF MEXICO 
Publication

18541 PFLUM FRERICHS 1976 18542 PFLUM FRERICHS 1976 18543 PFLUM FRERICHS 1976 18544 PFLUM FRERICHS 1976 18545 PFLUM FRERICHS 1976 18546 PFLUM FRERICHS 1976 18547 PFLUM FRERICHS 1976 18548 PFLUM FRERICHS 1976 18549 PFLUM FRERICHS 1976 18550 PFLUM FRERICHS 1976 18551 PFLUM FRERICHS 1976 18552 PFLUM FRERICHS 1976 18553 PFLUM FRERICHS 1976 18554 PFLUM FRERICHS 1976 18555 PFLUM FRERICHS 1976 18556 PFLUM FRERICHS 1976 18557 PFLUM FRERICHS 1976 18558 PFLUM FRERICHS 1976 18559 PFLUM FRERICHS 1976 18560 PFLUM FRERICHS 1976 18561 PFLUM FRERICHS 1976 18562 CUSHYAN 1931

18563 CUSHMAN 1931

18564 PFLUM FRERICHS 1976 18565 PFLUM FRERICHS 1976 18566 PFLUM FRERICHS 1976 18567 PFLUM FRERICHS 1976 18568 PFLUM FRERICHS 1976 18569 PFLUM FRERICHS 1976 18570 PFLUM FRERICHS 1976 18571 PFLUM FRERICHS 1976 18572 PFLUM FRERICHS 1976 18573 PFLUM FRERICHS 1976 18574 PHLEGER $1951 \mathrm{~A}$

18575 PARKER 1954

18576 PHLEGER $1951 \mathrm{~A}$

18577 PHLEGER $1951 \mathrm{~A}$ 18578 PHLEGER 1951A 18579 PHLEGER 1951 A 18580 PHLEGER 1951 A 18581 PHLEGER 1951A 18582 PHLEGER 1951A 18583 PHLEGER 1951A 18584 PHLEGER $1951 \mathrm{~A}$ 18585 PHLEGER $1951 \mathrm{~A}$ 18586 PHLEGER 1951 A 18587 PHLEGER 1951A 18588 CREAGER 1958 18589 CREAGER 1958 18590 CREAGER 1958 18591 PHLEGER $1951 \mathrm{~A}$ 18592 PHLEGER $1951 \mathrm{~A}$ 18593 PHLEGER $1951 \mathrm{~A}$ 18594 PHLEGER $1951 \mathrm{~A}$ 18595 PHLEGER 1951A 18596 PHLEGER $1951 \mathrm{~A}$ 18597 PHLEGER 1951A 18598 PHLEGER $1951 \mathrm{~A}$ 18599 PHLEGER 1951A 18600 PHLEGER $1951 \mathrm{~A}$ 18601 CREAGER 1958 18602 CREAGER 1958 18603 CREAGER 1958 18604 CREAGER 1958 18605 CREAGER 1958 18606 CREAGER 1958

18607 PFLUM FRERICHS 1976 18608 PFLUM FRERICHS 1976 18608 PFLUM FRERICHS 1976 18609 PFLUM FRERICHS 1776
18610 DFLUM FRERICHS 1976 18611 PFLUM FRERICHS 1976 18612 PFLUM FRERICHS 1976 18613 PFLUM FRERICHS 1976 18614 PFLUM FRERICHS 1976 18615 PFLUM FRERICHS 1976 18616 PFLUM FRERICHS 1976 18617 PFLUM FRERICHS 1976 18618 PFLUM FRERICHS 1976 18619 PFLUM FRERICHS 1976 18620 PFLUM FRERICHS 1976 18621 PFLUM FRERICHS 1976 18622 PFLUM FRERICHS 1976 18623 PFLUM FRERICHS 1976 18624 PFLUM FRERICHS 1976 18625 PFLUM FRERICHS 1976 18626 PFLUM FRERICHS 1976 18627 PFLUM FRERICHS 1976 18628 PFLUM FRERICHS 1976 18629 PFLUM FRERICHS 1976 18630 PFLUM FRERICHS 1976 18631 PFLUM FRERICHS 1976 18632 PFLUM FRERICHS 1976 18633 PFLUM FRERICHS 1976 18634 PFLUM FRERICHS 1976 18635 PFLUM FRERICHS 1976
Generic Name

GYROI DINA

GYROIDINA

GYROIDINA

GYROIDINA

GYROIDINA

GYROIDINA

GYROIDINA

GYROIDINA

GYROIDINA

GYROIDINA

GYROIDINA

GYROIDINA

GYROIDINA

GYROIDINA

GYROIDINA

GYROI DINA

GYROIDINA

GYROIDINA

GYROIDINA

GYROIDINA

GYROIDINA

GYROIDINA

GYROI DINA

GYROIDINA

GYROIDINA

GYROIDINA

GYROIDINA

GYROIDINA

GYROIDINA

GYRO I D INA

GYROIDINA

GYROIDINA

GYROIDINA

GYROI DINA

GYROIDINA

GYROIDINA

GYROIDINA

GYROIDINA

GYROIDINA

GYROIDINA

GYROIDINA

GYROIDINA

GYROIDINA

GYROIDINA

GYROI DINA

GYROIDINA

GYROIDINA

GYROIDINA

GYROI DINA

GYROIDINA

GYROIDINA

GYROI DINA

GYROIDINA

GYROIDINA

GYROIDINA

GYROIDINA

GY RO I D INA

GYROI DINA

GYROIDINA

GYROI DINA

GYROIDINA

GYROI DINA

GYROIDINA

GYROI DINA

GYROIDINA

GYROIDINA

GYROIDINA

GYROIDINA

GYROIDINA

GYROIDINA

GYROIDINA

GYROIDINA

GYROIDINA

GYROIDINA

GYROIDINA

GYROIDINA

GYROIDINA

GYROIDINA

GYROIDINA

GYROIDINA

GYROIDINA

GYROIDINA

GYROIDINA

GYROIDINA

GYROIDINA

GYROIDINA

GYROIDINA

GYROIDINA

GYROIDINA

GYROIDINA

GYROIDINA

GYROIDINA
Specific Name

OREICULAR IS

ORBICULARIS

OREICULAR IS

OREICULAR IS

OREICULARIS

OREICULARIS

OREICULARIS

OREICULARIS

OREICULARIS

OREI CULAR IS

OREICULAR IS

OREICULAR IS

OREICULARIS

OREICULARIS

OREICULAR IS

OREI CULAR IS

OREI CULAR IS

OREICULAR IS

OREI CULARIS

SOLDANII

SOLDANII

SOLDANII

SOLDANII

SOLDANII

SOLDANII

SOLDANII

SOLDANII

SOLDANII

SOLDANII

SOLDANII

AL TIF ORMIS

AL TIFORMIS

ALTIFORMIS

AL TIFORMIS

AL TIFORMIS

AL TIFORMIS

AL TIFORMIS

AL TIFORMIS

AL TIFORMIS

AL TIFORMIS

AL TIFORMIS

AL TIFORMIS

AL TIFORMIS

AL TIFORMIS

ALTIFORMIS

AL TIFORMIS

AL TIFORMIS

AL TIFORMIS

AL TIF ORMIS

AL TIFORMIS

AL TIF ORMIS

AL TIF ORMIS

AL TIF ORMIS

AL TIFORMIS

AL TIFORMIS

AL TIF ORMIS

ALTIFORMIS

AL TIFORMIS

AL TIFORMIS

AL TIF ORM I S

AL TI FORMIS

UMBONATA

UMEONATA

UMBONATA

UMEONATA

UMEONATA

UMBONATA

UMBONATA

UMBONATA

UMBONATA

UMBONATA

UMEONATA

UMEONATA

UMEONAT A

UMEONATA

UMBONATA

UMBONATA

UMEONATA

UMBONATA

UMEONATA

UMBONATA

UMEONATA

UM EONATA

UMEONATA

UMEONATA

UMBONATA

UMEONATA

UMBONATA

Locality

Lat. Long.

$N W$ GULF OF MEXICO

$N W$ GULF OF MEXICO

NW GULF OF MEXICO

NW GULF OF MEXICO

CENTRAL GULF OF MEXICO

NW GULF OF MEXICO 


\section{Publication}

18636 PFLU:A FRERICHS 1976 18637 PFLUM FRERICHS 1976 18638 PFLUM FRERICHS 1976 18630 PFLUM FRERICHS 1976 18640 PFLUM FRERICHS 1976 18641 PFLUM FRERICHS 1976 18642 PFLUM FRERICHS 1976 18643 PFLUM FRERICHS 1976 18644 PFLUM FRERICHS 1976 18645 PFLUM FRERICHS 1976 18646 PFLUM FRERICHS 1976 18647 PFLUM FRERICHS 1976 18648 PFLU:A FRERICHS 1976 18649 PFLUM FRERICHS 1976 18650 PFLUM FRERICHS 1976 18651 PFLUM FRERICHS 1976 18652 PFLUM FRERICHS 1976 18653 PFLUM FRERICHS 1976 18654 PFLUM FRERICHS 1976 18655 PFLUM FRERICHS 1976 18656 PFLUM FRERICHS 1976
18657 PFLUM FRERICHS 1976 18657 PFLUM FRERICH

18659 PARKER 1954

18659 PARKER 1954
18660 PARKER 1954

18661 PARKER 1954

18662 PARKER 1954

18663 PARKER 1956

18664 PARKER 1954

18665 PARKER 1054

18666 PARKER 1954

18667 PARKER 1954

18668 PARKER 1954

18669 PARKER 1954

18670 PARKER 1954

18671 PARKER 1954

18672 PARKER 1954

18673 CUSHMAN $1922 \mathrm{~A}$

18674 LEROY HODGKINSON 1975

18675 PFLUM FRERICHS 1976

18676 PFLUM FRERICHS 1976

18677 PFLUM FRERICHS 1976

18678 PFLUM FRERICHS 1976

18679 PFLUM FRERICHS 1976

18680 PFLUM FRERICHS 1976

18681 BANDY 1956

18682 BANDY 1956

18683 PFLUM FRERICHS 1976

18684 PFLUM FRERICHS 1976

18685 PFLUM FRERICHS 1976

18686 BANDY 1956

18687 BANDY 1956

18688 BANDY 1956

18689 BANDY 1956

18690 LAMB 1972

18691 KELLOUGH 1956

18692 KELLOUGH 1956

18693 BANDY 1956

18694 BANDY 1956

18695 BANDY 1956

18696 BANDY 1956

18697 BANDY 1956

18698 BANDY 1956

18699 BANDY 1956

18700 KELLOUGH 1956

18701 KELLOUGH 1956

18702 KELLOUGH 1956

18703 BANDY 1956

18704 BANDY 1956

18705 BANDY 1956

18706 SANDY 1956

18707 ANDERSEN 1961

18708 PFLUM FRERICHS 1976

18709 PFLUM FRERICHS 1976

18710 SEGURA 1963

18711 LANKFORD 1959

18712 BANDY 1956

18713 SANDY 1956

18714 BANDY 1956

18715 BANDY 1956

18716 BANDY 1956

18717 BANDY 1956

18718 BANDY 1956

18719 AYALA-CASTANARES 1963

18720 ANDERSON 1968

18721 KELLOUGH 1956

18722 KELLOUGH 1956

18723 BANDY 1956

18726 AYALA-CASTANARES SEGURA 1968

18726 PFLUM FRERICHS 1976

18727 PFLUM FRERICHS 1976

18728 ANDERSEN 1961

18729 POAG 1976

18730 KELLOUGH 1956
Generic Name

GYROI DINA

GYROIDINA

GYROIDINA

GYROIDINA

GYROIDINA

GYROIDINA

GYROIDINA

GYROIDINA

GYROIDINA

GYROIDINA

GYROIDINA

GYROIDINA

GYROIDINA

GYROIDINA

GYROIDINA

GYROIDINA

GYROIDINA

GYROIDINA

GYROIDINA

GYROIDINA

GYROIDINA

GYROIDINA

GYROIDINA

GYROIDINA

GYROIDINA

GYROIDINA

GYRO IDINA

GYROIDINA

GYROIDINA

GYROIDINA

GYROIDINA

GYROIDINA

GYROIDINA

HALYPHYSEMA

HALYPHYSEMA

DISCORB I NELLA

DI SCORB INELLA

DISCORBINELLA

DISCORBINELLA

DI SCORB I NELL L

DI SCORB INELLA

DISCORBINELLA

DISCORBINELLA

D ISCORBINELLA

D I SCORB INELLA

D I SCORB INELLA

HANZ AWA I A

HANZAWAIA

HANZ AWA I A

HANZ AWA I A

HANZAWAIA

HANZ AWA I A

HANZAWA I A

HANZAWAIA

HANZAWAIA

HANZ AWA I A

HANZAWAIA

HANZAWAIA

HANZAWAIA

HANZAWAIA

HANZ AWA I A

HANZAWAIA

HANZ AWAIA

HANZAWAIA

HANZ AWA I A

HANZAWAIA

HANZ AWA IA

HANZ AWA I A

HANZAWAIA

HA VZ AWA IA

HANZAWAIA

HANZAWAIA

HANZAWAIA

HA VZAWAIA

HANZ AWAIA

HANZ AWA I A

HANZ AWAI A

HANZ AWA I A

HANZAWAIA

HANZAWAIA

HANZAWAIA

HANZAWA I A

HANZA NAIA

HANZAWR

HANZ AWAIA

HANZAWAIA
Specific Name

Locality

Lat. Long.

UMEONATA

UMEONATA

UMEONATA

UMEONATA

UMEONATA

UMEONATA

UMEONATA

UMEONATA

UMEONAT A

UMEONATA

UMEONATA

UMEONATA

UMEONATA

UMEONATA

UMEONATA

UMEONATA

UMEONATA

UMEONATA

UMEONATA

UMEONATA

AL TIFORMIS

AL TIFORMIS

AL TIFORMIS

AL TIFORMIS

AL TIFORMIS

AL TIFORMIS

AL IIFORMIS

AL TIFORMIS

AL TIFORMIS

AL TIF ORMIS

AL TIFORMIS

AL TIFORMIS

AL TIF ORMIS

AL TIFORMIS

ALTIFORMIS

AD VENA

TUNANOWICZII

BE RTHELOT I

BERTHELOT I

BERTHELOTI

BERTHELOTI

BERTHELOTI

BERTHELOTI

BERTHELOT

BERTHELOTI

BERTHELOTI

BERTHELOTI

BE RTHELOTI

COACENTRICA

CONCENTRICA

CONCENTRICA

CONCENTRI CA

COACENTRI CA

CONCENTRI CA

COACENTRI CA

COACENTRICA

CONCENTRICA

COACENTRICA

CONCENTRI CA

COACENTRI CA

COACENTRI CA

COACENTRICA

CONCENTRI CA

CONCENTRI CA

CONCENTRICA

CONCENTRICA
COACENTRI CA

CONCENTRICA

COACENTRICA

CONCENTRICA

CONCENTRICA

COACENTRI CA

COACENTRI CA

CONCENTRI CA

COACENTRICA

COACENTRICA

CONCENT

CONCENTRI CA

CONCENTRICA

CONCENTRICA

CONCENTRI CA

CONCENTRI CA

COACENTRI CA

CONCENTRICA

CONCENTRICA

CONCENTRICA

CONCENTRI CA

COACENTRI CA

CONCENTRI CA

CONCENTRICA

CONCENTRI CA

CONCENTRICA

STFATTONI

STRATTON

CENTRAL GULF OF MEXICO

CENTRAL GULF OF MEXICO

NW GULF OF MEXICO

NW GULF OF MEXICO

NW GULF OF MEXICO

NW GULF OF MEXICO

NW GULF OF MEXICO

NW GULF OF MEXICO

NW GULF OF MEXICO 


\section{Publication}

18731 KELLOUGH 1956

18732 BANDY 1956

18733 BANDY 1956

18734 BANDY 1956

18735 BANDY 1956

18736 BANDY 1956

18737 BANDY 1956

18738 BANDY 1956

18739 BANDY 1956

18740 BOCK MDORE 1963

18741 WAL TON 1960

18742 PHLEGER 1956

18743 PHLEGER 1956

18744 LEHMANN 1957

18745 SHIFFLETT 1961

18746 PFLUM FRERICHS 1976

18747 BANDY 1954

18748 LANKFORD 1959

18749 SEGURA 1963

18750 AYALA-CASTANARES 1963

18751 BANDY 1954

18752 LOEP 1965

18753 SANDY 1956

18754 BANDY 1954

18755 BANDY 1954

18756 BANDY 1956

18757 BANDY 1956

18758 BANDY 1954

18759 BANDY 1954

18760 BANDY 1956

18761 BANDY 1956

18762 BANDY 1956

18763 BANDY 1956

18764 BANDY 1956

18765 BANDY 1950

18766 KELLOUGH 1956

18767 KELLOUGH 1956

18768 KELLOUGH 1956

18769 KELLOUGH 1956

18770 BOCK 1976

18771 BOCK 1976

18772 BOCK 1976

18773 PHLEGER 1956
18774 PHLEGER 1956

18775 PHLEGER 1956

18776 BOCK 1976

18777 POAG SWEET 1972

18778 BANDY 1956

18779 BANDY 1956

18780 BANDY 1956

18781 BANDY 1956

18782 BANDY 1956

18783 BANDY 1956

18784 BANDY 1956

18785 KELLOUGH 1956

18786 BOCK 1976

18787 BOCK 1976

18788 CUSHMAN 1920

18789 CUSHMAN 1920

18790 CUSHMAN 1920

18791 CUSHMAN 1920

18792 PFLUM FRERICHS 1976

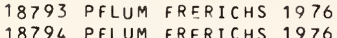

18794 PFLUM FRERICHS
18795 CREAGER 1958

18796 PFLUM FRERICHS 1976

18797 PFLUM FRERICHS 1976

18798 PFLUM FRERICHS 1976 18799 PFLUM FRERICHS 1976 18800 PFLUM FRERICHS 1976 18801 PFLUM FRERICHS 1976 18802 PFLUM FRERICHS 1976 18803 PFLUM FRERICHS 1976 18804 PFLUM FRERICHS 1976 18805 PFLUM FRERICHS 1976 18806 PFLUM FRERICHS 1976 18807 PFLUM FRERICHS 1976 18808 CREAGER 1958

18809 CREAGER 1958

18810 PFLUM FRERICHS 1976 18811 PFLU:1 FRERICHS 1976 18812 PFLUM FRERICHS 1976 18813 PFLUM FRERICHS 1976 18814 PFLUM FRERICHS 1976 18815 PFLUM FRERICHS 1976 18816 PFLUM FRERICHS 1976 18817 PFLUM FRERICHS 1976

18818 PARKER 1954

18819 PARKER 1954

18820 PARKER 1954

18821 PARKER 1954

18822 PHLEGER 1955 A

18823 PHLEGER 1951 A

18824 PHLEGER 1951A

18825 PHLEGER 1951A

\section{Generic Name \\ Specific Name}

HANZ AWA I A

HANZ AWA I A

HANZ AWAI A

HANZ AWAI A

HANZAWAI A

HANZ AWA I A

HANZAWAI A

HANZ AWAIA

HANZ AWA I A

HANZ AWAIA

HANZA WA IA

HANZ AWAI A

AWA I A

HANZ AWAIA

HANZ AWA I A

HANZ AWA IA

HANZAWAIA

HANZ AWAI A

HANZ AWAI A

HANZ AWA I A

HANZ AWA I A

HANZ AWAI A

HANZ AWA I A

HANZ AWA I A

HANZ AWAI A

HANZ AWA I A

HANZ AWAIA

ANZ AWAIA

HANZ AWAIA

HANZ AWA I A

HANZ AWA I A

HANZ AWA I A

HANZ AWA I A

HANZ AWA I A

HANZ AWA I A

HANZ AWA I A

HANZ AWAI A

HANZ AWAI A

HANZ AW A I A

HANZ AWA I A

HANZ AWA I A

HANZ AWA I A

HANZ AWA I A

HANZ AWAI A

HANZ AWA I A

HANZ AWA I A

HANZ AWA I A

HANZ AWA I A

HANZ AWA I A

HANZ AWA I A

HANZ AWAIA

HANZ AWA I A

AMMOBACULITES

AMMOBACULITES

AMMOBAC ULITES

AMMOBACULITES

CRIBROSTOMOIDES

CRIBROSTOMOIDES

CR IBROSTOMOIDES

CR IBROSTOMOI DES

CRIBROSTOMOIDES

CRIBROSTOMOIDES

CRIBROSTOMOIDES

CRIBROSTOMOIDES

CRIBROS TOMOIDES

CRIBROSTOMO IDES

CRIBROSTOMOIDES

CRIBROSTOMOIDES

CRIBROSTOMOIDES

CRIBROSTOMOI DES

CRIBROST OMOIDES

CRIBROSTOMOIDES

CR IBROS TOMOI DES

CRIBROSTOMOIDES

CRIBROSTOMOIDES

CRIBROSTOMOIDES

CR IBROS TOMOIDES

CRIBR OS TOMOIDES

CRIBROSTOMOIDES

CRIBROSTOMOIDES

CRIAROSTOMOIDES

CR IBROST OMOIDES

CRIBROS TOMOI DES

CRIBROSTOMOI DES

CRIBROSTOMOIDES

CR IBROSTOMOIDES

CRIBROS TOMOIDES

CRIBROSTOMOIDES

CRIBROSTOMOIDES

CRIBROSTOMOIDES
STRATTON

STRATTONI

STRATTONI

STRATTONI

STRATTON I

STRATTONI

STRATTONI

STRATTON I

STRATTONI

STRATTONI

STRATTONI

STRATTONI

STRATTONI

ST FATTON

STRATTON I

STRATTONI

ST RATTONI

STRATTONI

STRATTONI

STRATTONI

STRATTONI

STRATTON

STRATTONI

ST KATTONI

ST RATTONI

ST FATTON

STRATTONI

ST FATTONI

STRATTON I

STRATTONI

STRATTONI

ST RATTONI

STFATTONI

STRATTONI

ST FAT TONI

STRATTON

STRATTONI

ST FATTONI

STRATTONI

STRATTONI

ST RATTONI

STRATTONI

STRATTONI

STRATTONI

ST FATTONI

STRATTONI

STRATTONI

STRATTON

STRATTONI

STRATTONI

STRATTONI

STRATTONI

STRATTONI

STRATTONI

STRATTON I

STRATTONI

LI TUOLINOIDEUM

LI TUOLINOIDEUM

LI TUOL INUIDEUM

LI TUOL I NO IDEUM

SUEGL OB OSUM

SUEGLOBOSUM

SUEGL OBOSUM

SUEGL OBOS UM

SUEGL OBOS UM

SUEGLOBOSUM

SUBGL OB OS UM

SUEGL OBOS UM

SUEGL OBOSUM

SUEGL OBOS UM

SUEGL OBOSLM

SUBGL OBOSUM

SUEGLOBOSUM

SUEGL OBOSUM

SUEGLOBOSUM

SUEGL OBOSUM

SUEGL OBOSUM

SUBGL OBOSUM

SUEGLOBOS UM

SUEGLOBOSUM

SUEGL OBOSUM

SUEGLOBOSUM

SUEGLOBOSUM

SUBGL OBOS UM

SUEGL OBOSUM

SUEGL OBOSUM

SUEGLOBOM

SUEGL OBOSUM

SUEGL OB OSUM

SUEGL OBOS UM

SUEGL OBOS UM

SU BGL OBOS UM

SUEGL OBOSUM

SUEGLOBOSUM

\section{Locality}

NW GULF OF MEXICO

NE GULF OF MEXICO

NE GULF OF MEXICO

NE GULF OF MEXICO

NE GULF OF MEXICO

NE GULF OF MEXICO 


\section{Publication}

18826 PHLEGER 1951 A 18827 PHLEGER $1955 \mathrm{~A}$

18828 PHLEGER 1951A 18829
18830 PFLUUM FRERICHS 1976

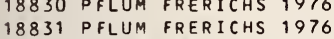
18832 PFLUM FRERICHS 1976 18833 PFLUM FRERICHS 1976 18834 PFLUM FRERICHS 1976 18835 PFLUM FRERICHS 1976 18836 PFLUM FRERICHS 1976 18837 PFLUM FRERICHS 1976 18838 BOCK 1976

18839 PARKER 1954

18840 PARKER 1954

18841 PARKER 1954

18842 PARKER 1954

18843 PARKER 1954

18844 PARKER 1954

18845 PARKER 1954

18846 PFLUM FRERICHS 1976 18847 PFLUM FRERICHS 1976 18848 PFLUM FRERICHS 1976 18849 PFLUM FRERICHS 1976 18850 PARKER 1954

18851 PARKER 1954

18852 PARKER 1954

18853 PARKER 1954

18854 PARKER 1954

18855 PARKER 1954

18856 PARKER 1954

18858 PARKER 1954

18859 PHLEGER $1955 \mathrm{~A}$

18860 PHLEGER 1955A

18861 PHLEGER $1955 \mathrm{~A}$

18862 PHLEGER 1955A

18863 PHLEGER 1955A

18864 PARKER 1954

18865 PARKER 1954

18866 PFLUM FRERICHS 1976 18867 PFLUM FRERICHS 1976 18868 PFLUM FRERICHS 1976 18869 PFLUM FRERICHS 1976 18870 PFLUM FRERICHS 1976 18871 PFLUM FRERICHS 1976 18872 PFLUM FRERICHS 1976 18873 PFLUM FRERICHS 1976 18874 PFLUM FRERICHS 1976 18875 PFLUM FRERICHS 1976 18876 PFLUM FRERICHS 1976 18877 PFLUM FRERICHS 1976 18878 PHLEGER 1951 A

18879 PFLUM FRERICHS 1976 18880 PFLUM FRERICHS 1976 18881 PFLUM FRERICHS 1976 18882 PFLUM FRERICHS 1976 18883 PFLUM FRERICHS 1976 18884 PFLUM FRERICHS 1976 18885 PFLUM FRERICHS 1976 18886 PFLUM FRERICHS 1976 18887 PFLUM FRERICHS 1976 18888 PFLUM FRERICHS 1976 18889 PFLUM FRERICHS 1976 18890 PFLUM FRERICHS 1976 $\begin{array}{lll}18891 & \text { PFLUM FRERICHS } & 1976 \\ 18892 & \text { PFLUM FRERICHS } & 1976\end{array}$ 18893 PHLEGER 1951 A 18894 PHLEGER 1951A 18895 PHLEGER $1951 \mathrm{~A}$

18896 PFLUM FRERICHS 1976 18897 PFLUM FRERICHS 1976 18898 PFLUM FRERICHS 1976 18899 PFLUM FRERICHS 1976 18900 PHLEGER 1951 A 18901 PHLEGER $1951 \mathrm{~A}$ 18902 PHLEGER 1951 A 18903 PHLEGER 1951A 18904 PHLEGER 1955 A 18905 PFLUM FRERICHS 1976 18906 PFLUM FRERICHS 1976 18907 PFLUM FRERICHS 1976 18908 PHLEGER 1951 A 18909 PHLEGER 1951 A 18910 PHLEGER 1951A 18911 PHLEGER 1951A 18912 PHLEGER 1951A 18913 PHLEGER 1951 A 18914 PHLEGER 1951A 18915 PHLEGER 1951A 18916 PHLEGER $1951 \mathrm{~A}$ 18917 PHLEGER 1951A 18918 PHLEGER 1951A 18919 PHLEGER 1951 A 18920 PHLEGER 1951A
Generic Name

CR IBROSTOMOIDES CRIBROSTOMOIDES CR IBR OS TOMO IDES CRIBROSTOMOIDES CRIBROS TOMOI DES CRIBROSTOMOIDES CRIBROSTOMOIDES CRIBROSTOMOIDES CR IBROS TOMO IDES CRIBROSTOMOIDES CRIBROSTOMOIDES CR IBROSTOMOIDES CR IBR OS TOMOIDES CR IBROST OMOIDES CRIBROS TOMOIDES CR IBROS TOMOIDES CR IBROSTOMOI DES CRIBROSTOMOIDES CRIBROSTOMOIDES CRIBROSTOMOIDES CR IBROSTOMOIDES CR IBROSTOMOIDES CRIBROSTOMOIDES CR IBROSTOMOIDES CR IBROS TOMOIDES CR IBROSTOMOIDES CRIBROSTOMOIDES CR IBROS TOMOIDES CR IBROSTOMOIDES CRIBR OS TOMOIDES CRIBROSTOMOIDES CRIBROS TOMOIDES CRIBROS TOMOIDES CRIBROSTOMOIDES CRIBROSTOMOIDES CRIBROSTOMOIDES CR IBROSTOMOIDES CR IBROS TOMOIDES CRIBROS TOMOIDES CR IBROSTOMOIDES CR IBROSTOMOIDES CRIBR OS TOMOIDES CRIBROS TOMOIDES CR IBROSTOMO I DES CR IBROS TOMOIDES CRIBROSTOMOIDES CRIBROS TOMO I DES CRIBROS TOMOIDES CRIBROSTOMOIDES CRIBROSTOMOIDES CR IBROS TOMO IDES CRIBROSTOMOIDES CRIBROSTOMOIDES CRIBROSTOMOIDES CRIBROSTOMOIDES CRIBROS TOMOIDES CR IBROS TOMOI DES CRIBROS TOMOIDES CR IBROSTOMOIDES CRIBROS TOMOIDES CR IBROS TOMO I DES CRIBROS TOMOIDES CRIBROSTOMOIDES CR IBROSTOMOIDES CRIBROSTOMOIDES CRIBROSTOMOIDES CRIBROS TOMOIDES CRIBROSTOMOIDES CRIBROSTOMOIDES CRIBROSTOMOIDES CRIBROSTOMOIDES CR IBROS TOMO IDES CR IBROS TOMOIDES CR IBROS TOMOIDES CRIBROSTOMOIDES CRIBROS TOMOIDES CR IBROS TOMOIDES CRIBROSTOMOIDES CRIBROSTOMOIDES CRIBROSTOMOIDES CRIBROSTOMOIDES CRIBROS TOMO I DES CRIBROS TOMOIDES CRIBROS TOMOIDES CRIBROSTOMOIDES CR IBR OSTOMOIDES CRIBROSTOMOIDES CRIBROSTOMOIDES CRIBROSTOMOIDES CRIBROSTOMOIDES CRIBROSTOMOIDES CR IBROSTOMOIDES CR IBROS TOMOIDES CR IBROSTOMOIDES CRIBROSTOMOIDES CRIBROSTOMOIDES CRIBROSTOMOIDES CRIBROSTOMOIDES
Specific Name

Locality

Lat. Long.

SUBGL OBOSUM SUEGL OBOSUM SUEGLOBOSUM SUEGLOBOSUM SUEGL OBOSUM SUBGLOBOSUM SUEGL OB OS UM SUBGL OB OSUM SUEGLOBOSUM SUEGLOBOSUM SU BGL OB OSUM SUBGL OBOS UM SU BGLOB OS UM SUEGLOBOSUM SUBGLOBOSUM SU BGL OB OS UM SUEGL OBOSUM SUEGLOB OSUM SUEGL OBOSUM SUEGL OBOSUM SU BGLOB OSUM SUBGLOBOSUM SU BGL OBOSUM SUBGLOBOSUM SUEGL OBOSUM SUEGLOBOSUM SUEGL OBOSUM SUBGL OBOSUM SUEGLOBOSUM SU EGL OB OS UM SUEGLOB OSUM SUBGLOBOSUM SUEGL OBOSUM SU EGL OB OS UM SUBGL OB OSUM SUEGL OB OS UM SUEGL OB OSUM SUEGL OBOSUM SUEGLOBOS UM SU EGL OBOS UM SUBGLOBOSUM SUEGLOBOSUM SUEGLOBOSUM SU BGL OB OS UM SUEGLOBOS UM SUBGL OBOS UM SU EGL OBOSUM SU EGLOBOSUM SUEGL OBOSUM SUEGL OBOSUM SU BGL OB O SUM SUEGLOBOSUM SUEGLOBOSUM SUBGL OB OS UM SUEGLOBOSUM SU BGLOBOSUM SU BGL OB OSUM SUEGLOBOSUM UEGLOBOSUM SU BGL OB OS UM SUEGL OBOSUM SUBGLOB OS UM SUEGLOB OS UM SUEGLOBOSUM SU BGL OB OSUM SUEGL OB OSUM SUEGLOBOSUM SUEGL OB OSUM SUEGLOBOSUM SUEGL OBOSUM SUBGL OB OSUM SUEGL OBOSUM SUEGLOBOSUM SUBGL OBOSUM SUEGLOBOSUM SUEGL OBOSUM SUEGL OBOSUM SUEGL OBOSUM SUEGLOBOSUM SU BGL OBOS UM SUEGL OBOSUM SUEGL OBOSUM SUEGLOBOS UM SUEGL OBOSUM SU BGL OBOS UM SUEGL OBOSUM SU BGL OBOSUM SUBGL OBOSUM SU EGL OB OSUM SU BGL OBOSUM SUBGLOBOSUM SUEGLOBOSUM SUBGL OB OSUM SUEGLOBOSUM 


\section{Publication}

18921 PHLEGER $1951 \mathrm{~A}$ 18922 PHLEGER $1951 \mathrm{~A}$ 8924 PHLEGER 1951 18924 PHLEGER 1951 A 18926 RANDY 1954 18927 BANDY 1954 18928 BANDY 1954 18929 BANDY 1954

18930 BANDY 1954

18931 BANDY 1954

18932 KORNFELD 1931

18933 KORNFELD 1931

18934 KORNFELD 1931

18936 PFLUM FRERICHS 1976

18937 PFLUM FRERICHS 1976

18938 PFLUM FRERICHS 1976

18939 PFLUM FRERICHS 1976 18940 PFLUM FRERICHS 1976 18941 PFLU1 FRERICHS 1976 18942 PFLUM FRERICHS 1976 18943 PFLUM FRERICHS 1976

18944 CUSHMAN 1920

18945 CUSHMAN 1920

8946 CUSHMAN 1920

18947 CUSHMAN 1920

18948 CUSHMAN 1920

18950 PHLEGER 1951 A

18951 PHLEGER 1951A

18952 PHLEGER $1951 \mathrm{~A}$

18953 PHLEGER 1951A

18954 PHLEGER 1951 A

18955 PHLEGER $1951 \mathrm{~A}$

18956 PHLEGER 1951A

18957 PHLEGER 1951A

18958 PHLEGER 1951A

18959 PHLEGER $1951 \mathrm{~A}$

18960 PHLEGER 1951 A

18961 PHLEGER $1951 \mathrm{~A}$

18962 PHLEGER $1951 \mathrm{~A}$

18963 PHLEGER $1951 \mathrm{~A}$

18964 KANE 1962

18965 KANE 1967

18966 WARREN 1957

18967 WANTLAND 1969

18968 LANKFORD 1959

18969 WARREN 1956

18970 WALDRON 1963

18971 OTVOS 1978

18972 ANDERSEN 1952

18973 ANDERSEN 1952

18974 BANDY 1956

18975 BANDY 1956

18976 BANDY 1956

18977 BANDY 1956

18978 BANDY 1956

18979 CUSHMAN 1920

18980 CUSHMAN 1920

18981 CUSHMAN 1920

18982 ANDERSEN 1961

18983 CUSHMAN 1920

18984 CUSHMAN 1920

18985 CUSHMAN 1920

18986 CUSHMAN 1920

18987 CUSHMAN 1920

18988 CUSHMAN 1920

18989 CUSHMAN 1920

18990 CUSHMAN 1920

18991 PFLUM FRERICHS 1976

18992 PFLUM FRERICHS 1976 18993 PFLUM FRERICHS 1976 18994 PFLUM FRERICHS 1976 18995 PFLUM FRERICHS 1976 18996 PFLUM FRERICHS 1976 18997 PFLUM FRERICHS 1976 18998 PFLUM FRERICHS 1976 18999 PFLUM FRERICHS 1976 19000 PFLUM FRERICHS 1976 19001 PFLUM FRERICHS 1976 19002 PFLUM FRERICHS 1976 19003 PFLUM FRERICHS 1976 19004 PFLUM FRERICHS 1976 19005 PFLUM FRERICHS 1976 19006 PFLUM FRERICHS 1976 19007 PFLUM FRERICHS 1976 19008 PFLUM FRERICHS 1976 19009 PFLUM FRERICHS 1976 19010 PFLUM FRERICHS 1976 19011 PFLUM FRERICHS 1976 19012 PFLUM FRERICHS 1976 19013 PFLUM FRERICHS 1976 19015 PFLUM FRERICHS 1976

\section{Generic Name}

CRIBROSTOMOIDES CRIBROS TOMOIDES CR IBROS TOMOIDES CR IBROS TOMOIDES CRIBROSTOMO IDES HAPLOPHRAGMOIDES HAPLOPHRAGMOIDES HAPLOPHRAGMOIDES HAPLOPHRAGMOI DES HAPLOPHRAGMOI DES HAPLOPHRAGMOIDES HAPLOPHRAGMOIDES HAPL OPHRAGMOI DES HAPLOPHRAGMOIDES HAPLOPHRAGMOIDES HAPL OPHRAGMOI DES HAPLOPHRAGMOIDES HAPLOPHRAGMOIDES HAPL OPHRAGMOIDES HAPLOPHRAGMOIDES HAPLOPHRAGMOIDES HAPLOPHRAGMOIDES HAPLOPHRAGMOIDES HAPLOPHRAGMOIDES HAPLOPHRAGMOIDES HAPL OPHRAGMOIDES HAPLOPHRAGMOIDES HAPLOPHRAGMOIDES HAPLOPHRAGMOIDES ADERCOTRYMA ADERCOTRYMA ADERCOTRYMA ADERCOTRYMA ADERCOTRYMA ADERCOTRYMA

ADERCOTRYMA A DERCOTRYMA ADERCOTRYMA ADERC OTRYMA ADERCOTRYMA ADERCOTRYMA ADERCOTRYMA

HAPLOPHRAGMOIDES HAPLOPHRAGMOIDES HAPLOPHRAGMOI DES HAPLOPHRAGMOI DES HAPL OPHRAGMOIDES HAPLOPHRAGMOIDES HAPLOPHRAGMOIDES HAPLOPHRAGMOIDE HAPLOPHRAGMOIDES RAGMOIDES HAPL OPHRAGMOIDES HAPLOPHRAGMOI DES HAPLOPHRAGMOIDES HAPLOPHRAGMOIDES HAPLOPHRAGMOIDES HAPLOPHRAGMOIDES CRIBROS TOMOIDES CRIBROSTOMOIDES CR IBROSTOMOIDES HAPLOPHRAGMOIDES HAPL OPHRAGMOIDES HAPL OPHR AGMO IDES HAPLOPHRAGMOIDES HAPLOPHRAGMOIDES HAPLOPHRAGMOIDES HAPLOPHRAGMOI DES HAPL OPHRAGMOIDES HAPLOPHRAGMOIDES HAPLOPHRAGMOIDES HAPLOPHRAGMOIDES HAPLOPHRAGMOIDES HAPL OPHRAGMOI DES HAPL OPHRAGMOI DES HAPLOPHRAGMOIDES HAPLOPHRAGMOIDES HAPLOPHRAGMOIDES HAPLOPHRAGMOIDES HAPLOPHRAGMOIDES HAPLOPHRAGMOIDES HAPL OPHRAGMOIDES HAPL OPHRAGMOIDES HAPLOPHRAGMOIDES HAPLOPHRAGMOIDES HAPLOPHRAGMOI DES HAPLOPHRAGMOIDES HAPL OPHR AGMOIDES HAPLOPHRAGMOI DES HAPLOPHRAGMOIDES HAPLOPHRAGMOI DES HAPLOPHRAGMOIDES HAPLOPHRAGMOIDES HAPLOPHRAGMOIDES HAPLOPHRAGMOIDES HAPLOPHRAGMOIDES HAPLOPHRAGMOI OES
HAPLOPHRAGMOI DES

\section{Specific Name}

SU BGL OBOS UM

SUEGLOBOSUM

SUEGLOBOSUM

SUEGL OBOSUM

MEXI CANA

MEXICANA

MEXICANA

MEXI CANA

MEXI CANA

MEXI CANA

MEXICANA

COLUMBIENSIS

CORONATUS

CORONATUS

CORONATUS

CORONATUS

CORONATUS

CORONATUS

CORONATUS

EMACIATUM

EMAC I ATUM

EMACI ATUM

EMACIATUM

EMAC I ATUM

GL CMERATA

GL OMERATA

GL CMERATA

GLOMERATA

GL OMERATA

GL CMERATA

GL CMERATA

GL OMERATA

GLOMERATA

GL CMERATA

GL CMERATA

GLOMERATA

GL OMERATA

MA IL AENS IS

MANILAENS IS

MAMILAENS IS

MAN ILAENSI

MA ILAENS IS

MAAILAENS IS

MANILAENSIS

MAAILAENS IS

MAAILAENSIS

MAAILAENSIS

MEXICANA

MEXICANA

MEXICANA

MEXICANA

ME XI CANA

NI TIDUM

NI TIDUM

NI TIDUM

PLANISSIMA

RIAGENS

RI A GENS

RINGENS

RI AGENS

RI^GENS

SC I TULUM

SPHAERILOCULUS

SPHAERILOCULUS

SPHAERILOCULUS

SPHAERILOCULUS

SPHAERILOCULUS

SPHAERILOCULUS

SPHAERILOCULUS

SPHAERILOCULUS

SPHAERI LOCULUS

SPHAERILOCULUS

SPHAERILOCULUS

SPHAERI LOCULUS

SPHAERILOCULUS

SPHAERILOCULUS

SPHAERILOCULUS

SPHAER ILOCULUS

SPHAERILOCULUS

SPHAERILOCULUS

SPHAERILOCULUS

SPHAERILOCULUS

SPHAERILOCULUS

SPHAERILOCULUS

SPHAERILOCULUS

SPHAERILOCULUS

SP HAERILOCULUS
SP HAERILOCULUS

Locality

NW GULF OF MEXICO

NW GULF OF MEXICO

NW GULF OF MEXICO

$N W$ GULF OF MEXICO

NW GULF OF MEXICO

NW GULF OF MEXICO 


\section{Publication}

19016 PFLUM FRERICHS 1976 19017 PFLUM FRERICHS 1976 19018 PFLUM FRERICHS 1976 19019 PFLUM FRERICHS 1976 19020 PFLUM FRERICHS 1976 19021 PFLUM FRERICHS 1976 19022 PFLUM FRERICHS 1976 19023 PFLUM FRERICHS 1976 19024 PFLUM FRERICHS 1976 19025 PFLUM FRERICHS 1976 19026 PFLUM FRERICHS 1976 19027 PFLUM FRERICHS 1976 19028 PFLUM FRERICHS 1976 19029 PFLUM FRERICHS 1976 19030 PFLUM FRERICHS 1976 19031 PFLUM FRERICHS 1976 19032 PFLUM FRERICHS 1976 19033 PFLUM FRERICHS 1976 19034 PFLUM FRERICHS 1976 19035 PFLUM FRERICHS 1976 19036 PFLUM FRERICHS 1976 19037 PFLUM FRERICHS 1976 19038 PFLUM FRERICHS 1976 19039 PFLUM FRERICHS 1976 19040 PFLUM FRERICHS 1976 19041 PFLUM FRERICHS 1976 19042 PFLUM FRERICHS 1976
19043 PFLUM FRERICHS 1976 19044 CUSHMAN 1920 19045 PHLEGER 19558 19046 PHLEGER 1954

19047 PHLEGER 1954

19048 PHLEGER 1954

19049 PHLEGER 1954

19050 PHLEGER $1965 \mathrm{C}$

19051 WALTON 1960

19052 OTVOS 1978

19053 CUSHMAN 1920

19054 ANDERSEN 1952

19055 ANDERSEN 1952

19056 ANDERSEN 1952

9057 LANKFORD 1959

19058 WALDRON 1963

9060 KANE 1962

19061 WARREN 1956

19062 WANTLAND 1969

19063 PHLEGER $1965 \mathrm{C}$

19064 WARREN 1957

19065 CUSHMAN 1920

19066 CUSHMAN 1920

19067 CUSHMAN 1920

19068 CUSHMAN 1920

19069 CUSHMAN 1922

19070 NORTON 1930

19071 NORTON 1930

19072 CUSHMAN $1922 \mathrm{~A}$

19073 NORTON 1930

19074 PHLEGER $1965 \mathrm{~A}$

19075 PHLEGER 1965 A

19076 PHLEGER 1965 A

19077 PHLEGER 1965 A

19078 PHLEGER $1965 \mathrm{~A}$

19079 PHLEGER 1965 A

19080 PHLEGER 1965A

19081 PFLUM FRERICHS 1976

19082 PFLUM FRERICHS 1976

19083 PFLUM FRERICHS 1976
19084 PFLUM FRERICHS 1976

19085 PFLUM FRERICHS 1976

19086 BENDA PURI 1962

19087 NORTON 1930

19088 CUSHMAN 1930

19089 CUSHMAN 1922 A

19090 LEROY HODGKINSON 1975

19091 PFLUM FRERICHS 1976

19092 PFLUM FRERICHS 1976

19093 CREAGER 1958

19094 CREAGER 1958

19095 CREAGER 1958

19096 PFLUM FRERICHS 1976

19097 PFLUM FRERICHS 1976

19098 PFLUM FRERICHS 1976

19099 PFLUM FRERICHS 1976

19100 PFLUM FRERICHS 1976

19101 PFLUM FRERICHS 1976

19102 PFLUM FRERICHS 1976

19103 PFLUM FRERICHS 1976

19104 PFLUM FRERICHS 1976

19105 PFLUM FRERICHS 1976

19106 PFLUM FRERICHS 1976

19107 BANDY 1956

19108 BANDY 1956

19109 PFLUM FRERICHS 1976

19110 PFLUM FRERICHS 1976
Generic Name

HAPLOPHRAGMOIDES HAPLOPHRAGMOIDES HAPLOPHRAGMOIDES HAPLOPHRAGMOIDES HAPLOPHRAGMOIDES HAPL OPHRAGMOIDES HAPLOPHRAGMOIDES HAPLOPH RAGMOIDES HAPLOPHRAGMOIDES HAPLOPHRAGMOIDES HAPLOPHRAGMOIDES HAPLOPHRAGMOIDES HAPLOPHRAGMOI DES HAPLOPHRAGMOIDES HAPLOPHRAGMOIDES HAPL OPHRAGMOI DES HAPLOPHRAGMOIDES HAPLOPHRAGMOIDES HAPLOPHRAGMOIDES HAPLOPHRAGMOIDES HAPLOPHRAGMOIDES HAPLOPHRAGMOIDES HAPLOPHRAGMOIDES HAPLOPHRAGMOIDES HAPLOPHRAGMOIDES HAPLOPHRAGMOIDES HAPL OPHRAGMOIDES HAPL OPHRAGMOIDES CRIBROSTOMOIDES HAPLOPHRAGMOIDES HAPL OPHRAGMOIDES HAPL OPHRAGMOIDES HAPLOPHRAGMOIDES HAPLOPHRAGMOIDES HAPLOPHRAGMOIDES HAPLOPHRAGMOIDES HA PL OPHRAGMOIDES HAPLOPHRAGMOIDES HAPLOPHRAGMOIDES HAPL OPHRAGMOIDES HAPL OPH RAGMOIDES HAPL OPHRAGMOI DES HAPL OPHRAGMOI DES HA PL OPHRAGMOIDES HAPL OPHRAGMOI DES HAPLOPHRAGMOIDES HAPLOPHRAGMOIDES HAPL OPH RAGMOI DES HAPL OPHRAGMOIDES HAPLOSTI CHE HAPLOST I CHE HAPLOSTICHE

HAPLOSTICHE

HA UERINA

HAUERINA

HAUERINA

HAUERINA

HA UER INA

HELENINA

HELEN INA

HELENINA

HELENINA

HELENINA

HE RONAL LEN I A

HERONAL LEN I A

HE RONALLEN

HERONALLENIA

HE RONALLEN I A

HE RON ALLEN I A

HETEROSTEG INA

HETEROS TEG INA

HE TEROS TEG IN A

HOEGLUNDINA

HOEGLUNDINA

HOEGLUNDINA

HOEGLUNDINA

HOEGLUNDINA

HOEGLUNDINA

HOEGLUNDINA

HOEGLUNDINA

HOEGLUNDINA

HOEGLUNDINA

HOEGLUNDIN A

HOEGLUNDINA

HOEGLUNDINA

HOEGLUNDINA

HOEGLUNDINA

HOEGLUNDINA

HOEGLUNDINA

HOEGLUNDINA

HOEGLUNDINA

HOEGLUNDINA

HOEGLUNDINA
Specific Name

SP HAERI LOCULUS

SPHAERILOCULUS

SPHAERILOCULUS

SPHAERILOCULUS

SPHAERI LOCULUS

SP HAERILOCULUS

SPHAERILOCULUS

SPHAERILOCULUS

SPHAERILOCULUS

SPHAERILOCULUS

SPHAERILOCULUS

SPHAERILOCULUS

SPHAERILOCULUS

SPHAERILOCULUS

SPHAERILOCULUS

SPHAERILOCULUS

SPHAERILOCULUS

SPHAE RI LOCULUS

SPHAERI LOCULUS

SPHAERILOCULUS

SPHAERILOCULUS

SPHAERILOCULUS

SPHAER I LOCULUS

SPHAERILOCULUS

SPHAERILOCULUS

SPHAERILOCULUS

SPHAERI LO CULUS

SPHAERILO CULUS

SUBGLOBOSUM

SUEINVOL UTUM

SUEINVOLUTUM

SUBINVOLUTUM

SUBINVOLUTUM

SUBINVOLUTUM

SUBINVOLUTUM

SUEINVOLUTUM

SUEINVOLUTUM

TR ULLISSATA

WI LBER I I

WI LBERTI

WI LBERT I

WI LBERT I

WI LBERTI

WI LBERTI

WILBERT I

WI LBERT I

WILBERTI

HI LBER TI

DUBIA

DUBIA

DUBIA

BR ADYI

BRADYI

FRAGILISS IMA

ORNATISSIMA

ORNATISSIMA

AN CER SEN

AN DERSEN I

AN DERSENI

AN CER SEN

AN DER SEN I

GEMMATA

GEMMATA

GENMATA

GE MMATA

GE MMA TA

LINGULATA

ANTILLARUM

AN TILLARUM

ELEGANS

EL EGANS

ELEGANS

ELEGANS

EL EGANS

ELEGANS

ELEGANS

ELEGANS

ELEGANS

ELEGANS

ELEGANS

ELEGANS

ELEGANS

ELEGANS

ELEGANS

ELEGANS

ELEGANS

ELEGANS

ELEGANS

Locality

Lat. Long.

CENTRAL GULF OF MEXICO

CENTRAL GULF OF MEXICO

$\mathrm{NW}$ GULF OF MEXICO

NW GULF OF MEXICO

$N W$ GULF OF MEXICO

$N W$ GULF OF MEXICO

NW GULF OF MEXICO 


\section{Publication}

19111 BANDY 1956 19112 PFLUM FRERICHS 1976 19113 PFLUM FRERICHS 1976 19114 PFLUM FRERICHS 1976 19115 PHLEGER 1955 A

19116 PFLUM FRERICHS 1976 19117 PFLUM FRERICHS 1976 19118 PFLUM FRERICHS 1976 19119 PFLUM FRERICHS 1976 19120 PFLUM FRERICHS 1976 19121 PFLUM FRERICHS 1976 1912 ? PFLUM FRERICHS 1976 19123 PFLUM FRERICHS 1976 19124 PFLUM FRERICHS 1976 19125 PFLUM FRERICHS 1976 19126 PFLUM FRERICHS 1976 19127 PFLUM FRERICHS 1976 19128 PFLUM FRERICHS 1976 19129 PFLUM FRERICHS 1976 19130 PFLUM FRERICHS 1976 19131 PFLUM FRERICHS 1976 19132 PFLUM FRERICHS 1976 19133 PFLUM FRERICHS 1976 19134 PFLUM FRERICHS 1976 19135 PFLUM FRERICHS 1976 19136 PFLUM FRERICHS 1976 19137 PFLUM FRERICHS 1976 19138 PFLUM FRERICHS 1976 19139 PFLUM FRERICHS 1976 19140 DFLUM FRERICHS 1976 19141 PFLUM FRERICHS 1976 19142 PFLUM FRERICHS 1976 19143 PARKER 1954

19144 PHLEGER $1951 \mathrm{~A}$

19145 PFLUM FRERICHS 1976 19146 PFLUM FRERICHS 1976 19147 PFLUM FRERICHS 1976 19148 PFLUM FRERICHS 1976 19149 PFLUM FRERICHS 1976 19150 PFLUM FRERICHS 1976 19151 PFLUM FRERICHS 1976 19152 PFLUM FRERICHS 1976 19153 PFLUM FRERICHS 1976 19154 PFLUM FRERICHS 1976 19155 PFLUM FRERICHS 1976 19156 PFLUM FRERICHS 1976 19157 PFLUM FRERICHS 1976 19158 PFLUM FRERICHS 1976 19159 PFLUM FRERICHS 1976 19160 PFLUM FRERICHS 1976 19161 PFLUM FRERICHS 1976 19162 PFLUM FRERICHS 1976 19163 PFLUM FRERICHS 1976 19164 PFLUM FRERICHS 1976 19165 PFLUM FRERICHS 1976 19166 PFLUM FRERICHS 1976 19167 PFLUM FRERICHS 1976 19168 CREAGER 1958

19169 PFLUM FRERICHS 1976 19170 PFLUM FRERICHS 1976 19171 PFLUM FRERICHS 1976 19172 PFLUM FRERICHS 1976 19173 PFLUM FRERICHS 1976 19174 PFLUM FRERICHS 1976 19175 PFLUM FRERICHS 1976 19176 PARKER 1954 19177 PHLEGER 1951A 19178 PHLEGER 1951A 19179 PHLEGER $1951 \mathrm{~A}$ 19180 PARKER 1954 19181 PARKER 1954 19182 PARKER 1954

19183 PFLUM FRERICHS 1976 19184 PHLEGER 1955A 19185 PHLEGER 1951A 19186 PHLEGER 1951A 19187 PHLEGER 1951A 19188 PHLEGER 1951A 19189 PHLEGER 1951A 19190 PARKER 1954 19191 PARKER 1954 19192 PARKER 1954 19193 PARKER 1954 19194 PARKER 1954 19195 PARKER 1954 19196 PARKER 1954 19197 LUDWICK WALTON 1957 19198 PARKER 1954 19199 LANKFORD 1959 19200 PARKER 1954 19201 PARKER 1954 19202 CREAGER 1958 19203 CREAGER 1958 19204 PHLEGER $1951 \mathrm{~A}$
19205 PHLEGER $1951 \mathrm{~A}$
Generic Name

HOEGLUNDINA HOEGLUNDINA HOEGLUNDINA HOEGLUNDINA HOEGLUNDINA HOEGLUNDINA HOEGLUNDINA HOEGLUNDINA HOEGLUNDINA HOEGLUND INA HOEGLUNDINA HOEGLUNDINA HOEGLUNDINA HOEGLUNDINA HOEGLUNDINA HOEGLUNDINA HOEGLUNDINA HOEGLUNDINA HOEGLUNDINA HOEGLUNDINA HOEGLUNDINA HOEGLUNDINA HOEGLUNDINA HOEGLUNDINA HOEGLUNDINA HOEGLUNDINA HOEGLUNDINA HOEGLUNDINA HOEGLUNDINA HOEGLUNDINA HOEGLUNDINA HOEGLUNDINA HOEGLUNDINA HOEGLUNDINA HOEGLUNDINA HOEGLUNDINA HOEGLUNDINA HOEGLUNDINA HOEGLUNDINA HOEGLUNDINA HOEGLUNDINA HOEGLUNDINA HOEGLUNDINA HOEGLUNDINA HOEGLUNDINA HOEGLUNDINA HOEGLUNDINA HOEGLUNDINA HOEGLUNDINA HOEGLUNDINA HOEGLUNDINA HOEGLUNDINA HOEGLUNDINA HOEGLUNDIN HOEGLUN DINA HOEGLUNDINA HOEGLUNDINA HOEGLUNDINA HOEGLUND INA HOEGLUNDIN HOEGLUNDINA HOEGLUNDINA HOEGLUNDINA HOEGLUNDINA HOEGLUNDINA HOEGLUNDINA HOEGLUNDINA HOEGLUNDINA HOEGLUNDINA HOEGLUNDINA HOEGLUNDINA HOEGLUNDINA HOEGLUNDINA HOEGLUNDINA HOEGLUNDINA HOEGLUNDINA HOEGLUNDINA HOEGLUNDINA HOEGLUNDIN HOEGLUNDIN HOEGLUND INA HOEGLUNDINA HOEGLUNDINA HOEGLUNDINA HOEGLUNDINA HOEGLUNDIN HOEGLUNDINA HOEGLUNDINA HOEGLUNDINA HOEGLUNDINA HOEGLUNDINA HOEGLUNDINA HOEGLUNDINA HOEGLUNDINA
Specific Name

\section{ELEGANS}

ELEGANS

ELEGANS

ELEGANS

ELEGANS

ELEGANS

ELEGANS

ELEGANS

ELEGANS

ELEGANS

ELEGANS

ELEGANS

ELEGANS

ELEGANS

ELEGANS

ELEGANS

ELEGANS

ELEGANS

ELEGANS

ELEGANS

ELEGANS

ELEGANS

ELEGANS

ELEGANS

ELEGANS

ELEGANS

ELEGANS

ELEGANS

ELEGANS

ELEGAN

ELEGANS

ELEGANS

ELEGANS

ELEGANS

ELEGANS

ELEGAN

ELEGANS

EL EGANS

ELEGANS

ELEGANS

ELEGANS

ELEGANS

ELEGANS

ELEGANS

ELEGANS

ELEGANS

ELEGANS

ELEGANS

ELEGAN

ELEGANS

ELEGANS

ELEGANS

ELEGANS

ELEGANS

ELEGANS

ELEGANS

ELEGANS

ELEGANS

ELEGANS

ELEGANS

ELEGAN

ELEGANS

ELEGANS

ELEGANS

ELEGANS

ELEGANS

ELEGANS

ELEGAN

ELEGANS

ELEGANS

ELEGANS

ELEGANS

ELEGANS

ELEGANS

ELEGANS

ELEGANS

ELEGANS

ELEGANS

ELEGANS

ELEGAN

ELEGANS

ELEGANS

ELEGANS

ELEGANS

ELEGANS

ELEGANS

Locality

NE GULF OF MEXICO NW GULF OF MEXICO $N W$ GULF OF MEXICO $N W$ GULF OF MEXICO $N$ GULF OF MEXICO

NW GULF OF MEXICO $N W$ GULF OF MEXICO NW GULF OF MEXICO NW GULF OF MEXICO 


\section{Publication}

19206 PHLEGER 1951A

19207 CREAGFR $195 \%$

9208 PARKER 1954

19209 PARKFR 1954

19210 PARKER 1954

19212 PARKFR 1354

19213 PARKER 1954

19214 PARKER 1254

19215 PHLEGER $1951 \mathrm{~A}$

19216 CREAGER 1959

19217 CRFAGER 195

19218 CREAGER 1958

19219 CRFAGFR 1959

19220 CREAGFR 1958

19221 CREAGEP 1959

19222 CREAGER 195

19223 CREAGER 1958

19224 CREAGER 1958

19226 PHLEGFR 1951 A

19227 PHLEGFR $1951 \mathrm{~A}$

19228 PHLEGER $1951 \mathrm{~A}$

19229 PHLFGER $1951 \mathrm{~A}$

19230 PHLEGER $1951 \mathrm{~A}$

19231 PHLEGER $1951 \mathrm{~A}$

19232 PHLEGER 1951A

19233 PHLEGER $1951 \mathrm{~A}$

19234 PHLEGFR $1951 \mathrm{~A}$

19235 PHLEGFR $1951 \mathrm{~A}$
19236 PHLEGER $1951 \mathrm{~A}$

19237 PHLESER 1955 A

19238 PHLFGER $1951 \mathrm{~A}$

19239 PHLEGER 1955A

19240 PHLEGER $1951 \mathrm{~A}$

19241 PHLEGER $1951 \mathrm{~A}$

19242 CUSH'AAN $1922 \mathrm{~A}$
19243 NORTON 1930

19244 PFLUM FRERICHS 1976

19245 LEROY HODGKINSON 1975

19246 PFLUM FRERICHS 1976

19247 PFLUM FRFRICHS 1976

19248 PFLUM FRERICHS 1976

19249 PFLUM FRERICHS 1976

19250 PFLUM FRERICHS 1776

19251 PFLU'1 FRFRICHS 1976

19252 PFLIIM FRERICHS 1976

19253 PFLUM FRERICHS 1976

19254 PFLUM FRERICHS 1976

19255 PFLUA FRERICHS 1776

19256 PFLUM FRERICHS 1976

19257 PFLUM FRERICHS 1976

19258 PFLUM FRERICHS 1976

19259 PFLUM FRERICHS 1976

19260 PFLUM FRERICHS 1976

19261 PFLUM FRERICHS 1976

19262 PFLUM FRERICHS 1976

19263 PFLUM FRERICHS 1976

19264 PFLUM FRERICHS 1976

19265 PFLUM FRFRICHS 1776

19266 PFLUM FRERICHS 1976

19267 PFLUM FRERICHS 1976

19268 PFLUM FRERICHS 1976

19269 PFLU' FRERICHS 1976

19270 PFLUM FRERICHS 1976

19271 PFLUM FRERICHS 1976

19272 PFLUM FRERICHS 1976

19273 PFLUM FRERICHS 1976

19274 PFLUM FRERICHS 1976

19275 PFLUM FRERICHS 1976

19276 PFLUM FRERICHS 1976

19277 PFLUM FRERICHS 1976

19278 PFLUM FRERICHS 1976

19279 PFLUM FRERICHS 1976

19280 PFLUM FRFRICHS 1976

19281 PFLUM FRERICHS 1976

19282 PFLUM FRERICHS 1976

19283 PFLUM FRERICHS 1976

19284 PFLUM FRERICHS 1976

19285 PFLUM FRERICHS 1976

19286 PFLUM FRERICHS 1976

19287 PFLUM FRERICHS 1976

19288 PFLUM FRERICHS 1976

19289 PFLUM FRFRICHS 1976

19290 PFLUM FREKICHS 1976

19291 PFLUM FRFRICHS 1976

19292 PFLUM FRERICHS 1976

19293 LEROY HODGKINSON 1975

19294 PFLUM FRERICHS 1976

19295 PFLUUM FRERICHS 1976

19296 PFLUM FRERICHS 1976

19297 PFLUM FRERICHS 1976

19298 PFLUM FRERICHS 1976

19299 PFLUM FRERICHS 1976

19300 CUSHMAN 1920
Generic Name

HOEGLUNDINA

HOEGLUNDINA

HOEGLUNDINA

HOEGLUNDINA

HOEGLUNDINA

HOEGLUND INA

HOEGLUND INA

HOEGLUND INA

HOFGLUNDINA

HOEGLUNDINA

HOEGLUNDINA

HOEGLUNDINA

HOEGLUNDINA

HOEGLUNDINA

HOEGLUNDINA

HOEGLUNDINA

HOEGLUNDINA

HOEGLUNDINA

HOEGLUNDINA

HOEGLUNDINA

HOEGLUNDINA

HOEGLUNDINA

HOFGLUNDINA

HOEGLUN: D INA

HOEGLUND INA

HOEGLUND INA

HOEGLUNDINA

HOEGLUND INA

HOEGLUNDIIIA

HOFGLUN DINA

HOEGLUNDINA

HOEGLUNDINA

HOEGLUNDINA

HOEGLUNDINA

HOEGLIJNDINA

HOEGLUNDINA

HOMOTREMA

HOMOTREMA

HORMOSINA

HORMOS INA

HORMOSINA

HORMOSINA

HORMOS INA

HORMOS INA

HORMOSINA

HORMOS INA

HORMOS I NA

HORMOS INA

HORMOS INA

HORMOSI NA

HORMOS INA

HORMOS INA

HORMOS INA

HORMOS INA

HORMOSINA

HORMOSINA

HORMOSINA

HORMOS I NA

HORMOS INA

HORMOSINA

HORMOSINA

HORMOSINA

HORMOS INA

HORMOS INA

HORMOSINA

HORMOSINA

HORMOSINA

HORMOS INA

HORMOS I N

HORMOS I NA

HORMOSINA

HORMOS I NA

HORMOSINA

HORMOSINA

HORMOS INA

HORMOS IN

ORMOS IN

HORMOSI NA

HORMOSINA

HORMOS INA

HORMOS INA

HORMOS INA

HORMOS INA

HORMOS INA

HORMOSINA

HORMOS I NA

HORMOSIN

HORMOS INA

HORMOSINA

HORMOS INA

HORMOSINA

HORMOSINA

HORMOS I NA

HORMOS INA

HORMOS INA

HORMOSINA

HORMOS INA
Specific Name

ELEGANS

ELEGANS

ELEGANS

ELEGANS

ELEGANS

ELEGANS

ELEGANS

ELEGANS

ELEGANS

ELEGANS

ELEGANS

ELEGANS

ELEGANS

ELEGANS

ELEGANS

ELEGANS

ELEGANS

ELEGANS

ELEGANS

LEGANS

ELEGANS

ELEGANS

ELEGANS

ELEGANS

ELEGAVS

ELEGANS

ELEGANS

ELEGANS

ELEGANS

ELEGANS

ELEGANS

ELEGANS

ELEGANS

ELEGANS

ELEGANS

RUERUM

RUERUM

CARPENTERI

CARPENTER I

CARPENTERI

CARPENTER I

CARPENTERI

CARPENTERI

CARPENTER I

CARPENTER I

CARPENTER I

CARPENTER I

CARPENTER I

CA RPENTERI

CARPENTER I

CARPENTER I

CARPENTER I

CARPENTER I

CARPENTER I

CARPENTER I

CARPENTER I

CARPENTER I

CA FPENTER I

CARPENTER I

CARPENTER I

CARPENTER I

CARPENTER I

CARPENTER I

CA FPENTER I

DI STANS DELICATULA

DI STANS DELICATULA

DI STANS DELICATULA

DI STANS DELICATULA

DI STANS DEL ICATULA

DI STANS DELICATULA

DI STANS DELICATULA

DI STANS DELICATULA

GL CBULIFERA

GL CBUL IFERA

GL OBULIFERA

GL OBULIFERA

GL OBULIFERA

GLOBULIFERA

GLCBUL IFERA

GL CBULIFERA

GL OBULIFERA

GLOBULIFERA

GL OBULIFERA

GLCBULIFER

GLCBUL IFERA

GL OBUL IFERA

GLOBUL IFER

GLOBULIFERA

GLCBUL

GLCBULIFERA

GLCBULIFERA

Locality

NW GULF OF MEXICO 


\section{Publication}

19301 PFLUM FRERICHS 1976 19302 PFLUM FRERICHS 1976 19303 PFLUM FRERICHS 1976 19304 PFLUM FRERICHS 1976 19305 PFLU M FRERICHS 1976 19306 PFLUM FRERICHS 1976 19307 LEROY HODGKIVSON 1975 19308 CUSHMAN 1920 19309 CUSHMAN 1920 19310 CUSHMAN 1920 19311 CUSHMAN 1920 19312 CUSHMAN 1920 19313 CUSHMAN 1923

19314 PFLUM FRERICHS 1976 19315 PFLU'A FRERICHS 1976 19316 PFLUM FRERICHS 1976 19317 CUSHMAN 1920

19318 CUSHMAN 1920

19319 CUS 4 MAN 1920

19320 PFLUM FRERICHS 1976

19322 PFLUM FRERICHS 1976 19323 PFLUM FRERICHS 1976 19324 PFLUM FRERICHS 1976 19325 PFLUM FRERICHS 1976 19326 PFLUM FRERICHS 1976 19327 PFLUM FRERICHS 1976 19328 PFLUM FRERICHS 1976 19329 PFLUM FRERICHS 1976 19330 PFLUM FRERICHS 1976 19331 PFLUM FRERICHS 1976 19332 PFLUM FRERICHS 1976 19333 CUSHMAN 1920

19334 C USHMAN 1920

19335 PFLUM FRERICHS 1976 19336 PFLUM FRERICHS 1976 19337 PFLUM FRERICHS 1976 19338 PFLUM FRERICHS 1976 19339 PFLIJM FRERICHS 1976 19340 PFLUM FRERICHS 1976 19341 PFLUM FRERICHS 1976 19342 PFLUM FRERICHS 1976 19343 PFLUM FRERICHS 1976 19344 PFLUM FRERICHS 1976

19345 CUSHMAN 1918

19346 CUSHMAN 1918

19347 CUSHMAN 1919

19348 PFLUM FRERICHS 1976 19349 PFLUM FRERICHS 1976 19350 CUSHMAN 1918

19351 CUSHMAN 1918

19352 PFLUM FRERICHS 1976

19353 LEROY HODGKINSON 1975

19354 CUSHMAN 1918

19355 PFLUM FRERICHS 1976 19356 PFLUM FRERICHS 1976 19357 PFLUM FRERICHS 1976 19358 PFLUM FRERICHS 1976 19359 PFLUM FRERICHS 1976 19360 PFLUM FRERICHS 1976 19361 PFLUM FRERICHS 1976 19362 PFLUM FRERICHS 1976 19363 PFLIJM FRERICHS 1976 19364 PFLUM FRERICHS 1976 19365 PFLUM FRERICHS 1976 19366 PFLUM FRERICHS 1976 19367 PFLUM FRERICHS 1976 19368 PFLUM FRERICHS 1976 19369 PFLUM FRERICHS 1976 19370 PFLUM FRERICHS 1976 19371 LEROY HODGKINSON 1975 19372 PFLUM FRERICHS 1976
19373 PFLUM FRERICHS 1976 19373 PFLUM FRERICHS 1976
19374 PFLUM FRERICHS 1976 19375 PFLUM FRERICHS 1976 19376 CUSHMAN 1918

19377 CUSHMAN 1918

19378 PFLUM FRERICHS 1976 19379 PFLUM FRERICHS 1976 19380 PFLUM FRERICHS 1976 19381 PFLUM FRERICHS 1976 19382 PFLUM FRERICHS 1976 19383 PFLUM FRERICHS 1976 19384 PFLUM FRERICHS 1976 19385 PFLUM FRERICHS 1976 19386 PFLUM FRERICHS 1976 19387 CUSHMAN 1922 A

19388 PFLUM FRERICHS 1976 19389 PFL'JM FRERICHS 1976 19390 PHLEGER 1965 A

19391 PARKER PHLEGER PEIRSON 1953 19392 SHEPARD MOORE 1955

19393 OTVOS 1978

19394 PHLEGER LANKFORD 1978

19395 PHLEGER 1965A
Generic Name

HORMOS INA

HORMOS INA

HORMOSINA

HORMOS I NA

HORMOSINA

HORMOSINA

HORMOSINA

HORMOSINA

HORMOS INA

HORMOSINA

HORMOSINA

HORMOS INA

HORMOS INA

HORMOS I NA

HORMOSINA

HORMOS INA

HORMOS INA

HORMOSINA

HORMOSINA

HORMOSINA

HORMOSINA

HORMOSINA

HORMOS INA

ORMOS INA

HORMOS INA

HORMOS INA

HORMOS INA

HORMOSINA

HORMOSINA

HORMOS INA

HORMOS INA

HORMOS INA

HORMOS INA

HY PERAMMINA

HYPERAMMIN

HYPER AMMINA

HYPERAMM INA

HYPER AMMINA

HYPERAMMINA

HY PERAMMINA

HYPERAMMINA

HYPERAMMINA

HYPERAMMINA

HYPERAMMINA

HYPERAMN INA

HYPERAMMINA

HY PERAMMINA

HYPERAMMINA

HY PERAMMIN

HYPERAMMINA

HYPER A MMIN A

HYPERAMMINA

HYPERAMMINA

HYPERAMMINA

HY PERAMMINA

HYPERAMMINA

HYPERAMMINA

HYPERAMMINA

HYPERAMMINA

HYPERAMMINA

HYPERAMMINA

HY PERAMMIN

HYPERAMMINA

HYPERAMMINA

HYPERAMMIN

HYPERAMMINA

HYPERAMMIN A

HYPERAMMIN

HYPERAMMINA

HY PE RAMMINA

HYPERAMMIN

HYPERAMMINA

HYPERAMMINA

HYPERAMMIN

HYPERAMMINA

HY PER AMMINA

HY PERAMMINA

HYPERAMMINA

IR IDIA

I SLANDIELLA

I SLANDIELLA

J A DAMMINA

JADAMMINA

JA DAMM I NA

$J$ A DAMM I NA

JADAMMINA

J A DAMMINA
Specific Name

GL OBULIFERA

GL OBUL IFERA

GL CBUL I FERA

GL OBUL I FERA

GL CBUL IFERA

GL CBUL I FERA

MONILE

MONILE

OVALIFORMIS

OVALIFORMIS

OVALI I ORM IS

OV ALI FORM IS

OVICULA

OVICULA

OVICULA

OVICULA

OVICULA

OVICULA

OVICULA

OVICULA

OVICULA

OVICULA

OVICULA

OVICULA

OVICULA

OVICULA

OVICULA

OVICULA

OVICULA

OVICULA

OVICULA

OVICULA MEXICANA

OVICULA MEXICANA

CYLINDRICA

CYLINDRICA

CYLINDRICA

CYLINDRICA

CYLINDRICA

CYLINDRICA

CYLINDRICA

CYLINDRICA

CYLINDRICA

DISTORTA

EL CNGATA

EL ONGATA

FRIABILIS

FRIABILIS

FRIABILIS

FRIABILIS

FRIABILIS

FRIABILIS

FRIABILIS

FRIABILIS

FRIABILIS

FR IABIL IS

FRIABILIS

FRIABILIS

FRIABILIS

FRIABIL IS

FRIABILIS

FRIABILIS

FRIABILIS

FRIABILIS

FR IABILIS

FRIABIL IS

FRIABILIS

FRIABILIS

FRIABILIS

LAEVIGATA

LAEVIGATA

LAEVIGATA

LAEVIGATA

LAEVIGATA

LAEVIGATA

LAEVIGATA

LAEVIGATA

LAEVIGATA

LAEVIGATA

LAEVIGATA

LAEVIGATA

LAEVIGATA

LAEVIGATA

LAEVIGATA

LAEVIGATA

NORCROSSI AUSTRALIS

NORCROSSI AUSTRALIS

POLYSTOMA

POLYSTOMA

POLYSTOMA

POLYSTOMA

POLYSTOMA

POLYSTOMA

Locality

CENTRAL GULF OF MEXICO

N * GULF OF MEXICO

Nd GULF OF MEXICO

NW GULF OF MEXICO

NW GULF OF MEXICO

NW GULF OF MEXICO

$N$ GULF OF MEXICO

NE GULF OF MEXICO

NE GULF OF MEXICO

NE GULF OF MEXICO 


\section{Publication}

19396 PHLEGER 1965 A 19397 PFLUM FRERICHS 1976 19398 PFLUM FRERICHS 1976 19399 PFLUM FRERICHS 1976 19400 PFLUM FRERICHS 1976 19401 PFLUM FRERICHS 1976 19402 PFLUM FRERICHS 1976 19403 PFLUM FRERICHS 1976 19404 PFLUM FRERICHS 1976 19405 PFLUM FRERICHS 1976 19406 PFLUM FRERICHS 1976 19407 PFLUM FRERICHS 1976 19408 PFLUM FRERICHS 1976 19409 PFLUM FRERICHS 1976 19410 PFLUM FRERICHS 1976 19411 PFLUM FRERICHS 1976 19412 PFLUM FRERICHS 1976 19413 PFLUM FRERICHS 1976 19414 PFLUM FRERICHS 1976 19415 PFLUM FRERICHS 1976 19416 PFLUM FRERICHS 1976 19417 PFLUM FRERICHS 1976 19418 PFLUM FRERICHS 1976 19419 PFLUM FRERICHS 1976 19420 PFLUM FRERICHS 1976 19421 PFLUM FRERICHS 1976 19422 PFLUM FRERICHS 1976 19423 PFLUM FRERICHS 1976 19424 PFLUM FRERICHS 1976 19425 PFLUM FRERICHS 1976 19426 PFLUM FRERICHS 1976 19427 PFLUM FRERICHS 1976 19428 PFLUM FRERICHS 1976 19429 PFLUM FRERICHS 1976 19430 PFLUM FRERICHS 1976 19431 PFLUM FRERICHS 1976 19432 LEROY HODGKINSON 1975 19433 PFLUM FRERICHS 1976 19434 PFLUM FRERICHS 1976 19435 PFLUM FRERICHS 1976 19436 PFLUM FRERICHS 1976 19437 PFLUM FRERICHS 1976 19438 PFLUM FRERICHS 1976 19439 PFLUM FRERICHS 1976 19440 PFLUM FRERICHS 1976 19441 PFLUM FRERICHS 1976 19442 PFLUM FRERICHS 1976 19443 PFLUM FRERICHS 1976 19444 PFLUM FRERICHS 1976 19445 PFLUM FRERICHS 1976 19446 PFLUM FRERICHS 1976 19447 PFLUM FRERICHS 1976 19448 PFLUM FRERICHS 1976 19449 PFLUM FRERICHS 1976 19450 PFLUM FRERICHS 1976 19451 PFLUM FRERICHS 1976 19452 PFLUM FRERICHS 1976 19453 PFLUM FRERICHS 1976 19454 PFLUM FRERICHS 1976 19455 PFLUM FRERICHS 1976 19456 PFLUM FRERICHS 1976 19457 PFLUM FRERICHS 1976 19458 PFLUM FRERICHS 1976 19459 PFLUM FRERICHS 1976 19460 PFLUM FRERICHS 1976 19461 PARKER 1954

19462 PARKER 1954

19463 PFLUM FRERICHS 1976 19464 PFLUM FRERICHS 1976 19465 PFLUM FRERICHS 1976 19466 C-REAGER 1958

19467 CREAGER 1958

19468 CREAGER 1958

19469 CREAGER 1958

19470 PARKER 1954

19471 PFLUM FRERICHS 1976 19472 PFLUM FRERICHS 1976 19473 PFLUM FRERICHS 1976 19474 PARKER 1954

19475 PARKER 1954

19476 PARKER 1954

19477 PARKER 1954

19478 PARKER 1954

19479 PFLUM FRERICHS 1976 19480 PFLUM FRERICHS 1976 19481 PFLUM FRERICHS 1976 19482 PFLUM FRERICHS 1976 19483 PFLUM FRERICHS 1976 19484 PARKER 1954

19485 PARKER 1954

19486 PARKER 1954

19487 PARKER 1954

19488 PARKER 1954

19489 PFLUM FRERICHS 1976

19490 PFLUM FRERICHS 1976
Generic Name

J A DAMM I NA

KARRER I ELLA

KARRERI ELLA

KARRERI ELLA

KARRERI ELLA

KARRERI ELLA

KARRERI ELLA

KARRERIELLA

KARRER I ELLA

KARRERI ELLA

KARRERIELLA

KARRER I ELL'A

KARRER I ELLA
KARRERIELLA

KARRERIELLA

KARRER I ELLA

KARRERI ELLA

KARRER I ELLA

KARRERIELLA

KARRERIELLA

KARRER I ELLA

KARRERI ELLA

KARR ER I ELLA

KARRERI ELLA

KARRER I ELLA

KARRERIELLA

KARRERI ELLA

KARRER I ELLA

KARRERI ELLA

KARRERIELLA

KARRERI ELLA

KARRER I ELLA

KARRERI ELLA

KARRERI ELLA

KARRER I ELLA

KARRER IELLA

KARRER I ELLA

KARRERIELLA

KARRERI ELLA

KARRER IELLA

KARRERIELLA

KARRER I ELLA

KARRERI ELLA

KARRERI ELLA

KARRERI ELLA

KARRERIELLA

KARRERIELLA

KARRERI ELLA

KARRER I ELLA

KARRERI ELLA

KARRERI ELLA

KARRER I ELLA

KARRER I ELLA

KARRER IELLA

KARRER I ELLA

KA RR ER I ELLA

KARRERI ELLA

KA RRER I ELL A

KARRER I ELLA

KARRER I ELLA

KARRERI ELLA

KARRER I ELLA

KARRERI ELLA

KARRERI ELLA

KARRER I ELL A

KARRER IELLA

KARRER I ELLA

KARRERI ELLA

KARRER I ELLA

KARRERI ELLA

KARRER I ELLA

KARRERI ELLA

KARRER I ELLA

KARRER I ELLA

KARRER I ELLA

KARRERI ELLA

KARRER I ELL A

KARRERI ELLA

KARRER I ELLA

KARRERIELLA

KARRERI ELLA

KARRER I ELLA

KARRERI ELLA

KARRER I ELLA

KARRER I ELL A

KARRERI ELLA

KARRERI ELLA

KARRER I ELL A

KARRER IELLA

KARRERI ELLA

KARRER I ELLA

KARRER I ELLA

KARRER I ELLA

KARRERI ELLA A
Specific Name

Locality

POLYSTOMA

APICULARIS

APICULARIS

APICULARIS

API IULARIS

APICULARIS

AP I CULARIS

APICULARIS

APICULARIS

APICULARIS

API CULARIS

APICULARIS

APICULARIS

APICULARIS

APICULARIS

APICULARIS

APICULARIS

APICULARIS

APICULARIS

APICULARIS

APICULARIS

APICULARIS

APICULARIS

APICULARIS

APICULARIS

APICULARIS

APICULARIS

APICULARIS

APICULARIS

APICULARIS

APICULARIS

APICULARIS

APICULARIS

APICULARIS

APICULARIS

APICULARIS

API CULARIS

APICULARIS

APICULARIS

APICULARIS

APICULARIS

API CULARIS

APICULARIS

APICULARIS

APICULARIS

APICULARIS

APICULARIS

APICULARIS

APICULARIS

AP ICULARIS

APICULARIS

APICULARIS

APICULARIS

APICULARIS

APICULARIS

AP I CULAR IS

AP ICULARIS

API I ULARIS

APICULARIS

APICULARIS

APICULARIS

APICULARIS

APICULARIS

AP I CULARIS

APICULARIS

BRADYI

BRADY

BRADYI

BRADYI

BRADYI

BRAOYI

BRADYI

BRADYI

BRADYI

BRADYI

BRADYI

BRADYI

BRADYI

BRADYI

BRADYI

BRADYI

BRADYI

BRADYI

BRADY I

BRADYI

BRADYI

BRADYI

BRADYI

BRADYI

BRADYI

BRADYI

BRADYI

BRADY I

BRADY

BRADYI

ALLYN'S BIGHT, TEXAS

CENTRAL GULF OF MEXICO 


\section{Publication}

19491 PFLUM FRERICHS 1976 19492 PFLUM FRERICHS 1976 19493 PFLUM FRERICHS 1976 19494 PFLUM FRERICHS 1976 19495 PFLUM FRERICHS 1976 19496 PARKER 1954

19497 PFLUM FRERICHS 1976 19498 PFLUM FRERICHS 1976 19499 PFLUM FRERICHS 1976 19500 PFLUM FRERICHS 1976 19501 PFLUM FRERICHS 1976 19502 PFLUM FRERICHS 1976 19503 PFLUM FRERICHS 1976 19504 PFLUM FRERICHS 1976 19505 PFLUM FRERICHS 1976 19506 PFLUM FRERICHS 1976 19507 LEROY HODGKINSON 1975 19508 PHLEGER $1951 \mathrm{~A}$ 19509 PHLEGER 1951 A 19510 PFLUM FRERICHS 1976 19511 PFLUM FRERICHS 1976 19512 ANDERSEN 1961

19513 CREAGER 1958

19514 PFLUM FRERICHS 1976 19515 PFLUM FRERICHS 1976 19516 PFLUM FRERICHS 1976 19517 PFLUM FRERICHS 1976 19518 BANDY 1956 19519 LOEP 1965

19520 PFLUM FRERICHS 1976 19521 BANDY 1956

19522 PFLUM FRERICHS 1976 19523 PFLUM FRERICHS 1976 19524 PFLUM FRERICHS 1976 19525 PFLUM FRERICHS 1976 19526 PFLUM FRERICHS 1976 19527 PFLUM FRERICHS 1976 19528 PHLEGER 1951A

19529 PHLEGER 1951A

19530 PHLEGER 1951 A

19531 PFLUM FRERICHS 1976 19532 PFLUM FRERICHS 1976 19533 PFLUM FRERICHS 1976 19534 PFLUM FRERICHS 1976 19535 PFLUM FRERICHS 1976 19536 PHLEGER 1951A

19537 PFLUM FRERICHS 1976 19538 PARKER 1954 19539 PARKER 1954 19540 PHLEGER 1951 A 19541 PHLEGER $1951 \mathrm{~A}$ 19543 PHLEGER 1951 A 19543 PHLEGER 1951 A 19545 CUSHMAN 1923 19546 CUSHMAN 1923 19547 CUSHMAN 1923 19548 LEROY HODGKINSON 1975 19549 BOCK 1976

19550 CUSHMAN 1923

19551 CUSHMAN 1923

19552 CUSHMAN 1923

19553 CUSHMAN 1923

19554 CUSHMAN 1923

19555 CREAGER 1958

19556 CUSHMAN 1923

19558 CUSHMAN 1923

19559 ANDERSEN 1961

19560 CREAGER 1958

19561 CREAGER 1958

19562 CREAGER 1958

19563 ANDERSEN 1961

19564 ANDERSEN 1961

19565 ANDERSEN 1961

19566 ANDERSEN 1961

19567 PFLUM FRERICHS 1976 19568 PFLUM FRERICHS 1976 19569 PFLUM FRERICHS 1976 19570 PFLUM FRERICHS 1976 19571 PFLUM FRERICHS 1976 19572 PFLUM FRERICHS 1976 19573 PFLUM FRERICHS 1976 19574 PFLUM FRERICHS 1976 19575 PFLUM FRERICHS 1976 19576 PFLUM FRERICHS 1976 19577 CREAGER 1958

19578 PFLUM FRERICHS 1976 19579 PFLUM FRERICHS 1976 19580 PFLUM FRERICHS 1976 19581 PFLUM FRERICHS 1976 19582 PFLUM FRERICHS 1976 19583 PFLUM FRERICHS 1976 19584 PFLUM FRERICHS 1976 19585 PFLUM FRERICHS 1976

\section{Generic Name \\ Specific Name}

KARRERI ELLA

KARRERIELLA

KARRERI ELL A

KARRERI ELLA

KARRERIELLA

KARRERI ELLA

KARRERIELLA

KARRERI ELLA

KARRERIELLA

KARRERI ELLA

KARRERIELLA

KARRERIELLA

KARRERI ELL A

KARRERI ELLA

KARRER IELL A

KARRERI ELLA

KARRERIELLA

KARRERIELLA

KARRERIELLA

KARRER IELLA

KARRERIELLA

KARRERI ELL A

KARRER IELL A

KARRERIELLA

KARRER I ELLA

KARRER IELLA

KARRERIELLA

KARRER I ELLA

KARRERI ELLA

KARRERIELLA

KARRER I ELLA

KARRER IELLA

KARRERIELLA

KARRERI ELLA

KARRER I ELL A

KARRERI ELLA

KARRER I ELLA

KARRER I ELL A

KARRERIELLA

KARRERIELLA

KARRERIELLA

KARRER I ELLA

KARRER I ELLA

KARRER I ELLA

KARRERI ELLLA

KARRERIELLA

KARRER I ELLA

KARRER IELLA

KARRERI ELLA

KARRER I ELL A

KARRERI ELLLA

KARRER I ELLA

LAGENA

LAGENA

LAGENA

LAGENA

LAGENA

FISSUR INA

FI SSURINA

FI SSURINA

FI SSURINA

FI SSUR INA

OOLINA

LAGENA

LAGENA

LAGENA

LAGENA

OOLINA

OOLINA

OOLINA

LAGENA

LAGENA

LAGENA

LAGENA

LAGENA

LAGENA

LAGENA

LAGENA

LAGENA

LAGENA

LAGENA

LAGENA

LA GENA

LA GENA

LAGENA

LAGENA

LA GENA

LAGENA

LA GENA

LAGENA

LAGENA

LAGENA

LAGENA
BR ADY I

BRADYI

BRADYI

BRADYI

BRADYI

BRADYI

BRADYI

BRADY

BRADY

BRADY

BR ADYI

BRADYI

BRADYI

BRADYI

BRADYI

BRADY

BR ADY I

BRADYI

BRADYI

BRADYI

BRADY

BRADYI

BRADY

BRADY I

BRADYI

BR ADY I

BRADYI

BRADYI

BRADYI

BRADYI

BRADYI

BRADYI

BRADYI

BR ADYI

BRADY

BRADYI

BRADYI

BRADYI

BRADYI

BRADYI

BRADYI

BRADYI

BRADYI

BR ADY I

BRADY

BRADYI

BR ADYI

BRADYI

BRADY

AP IOPLEURA

AP IOPLEUR A

AP I OP LEUR A

AP IOPLEUR A

DI STOMA

FL INT IANA

FL INT I ANA

FL INTIANA

FL INTI I ANA

FL INT I ANA

GL CBOSA

CLAVATA

CLAVATA

CLAVATA

HALSTEADI

HEXAGONA

HEXAG ONA

HEXAGONA

HI SPI DULA

INUSITATA

SULCATA

LAEVIS

LAEVIS

LAEV IS

LAEVIS

LAEVIS

LAEVIS

LAEVIS

LAEVIS

LAEVIS

LAEVIS

LAEVIS

LAEVIS

LAEVIS

LAEVIS

LAEVIS

LAEVIS

LAEVIS

LAEVIS

LAEVIS

LAEVIS

\section{Locality}

NW GULF OF MEXICO

NH GULF OF MEXICO

NW GULF OF MEXICO

NW GULF OF MEXICO

NW GULF OF MEXICO 


\section{Publication}

19586 PFLUM FRERICHS 1976 19587 BENDA PURI 1962

19588 CUSHMAN 1923

19589 CUSHMAV 1923

19590 CUSHMAN 1923

19591 CUSHMAN 1923

19592 CUSHMAN 1923

19593 ANDERSEN 1961
19594 ANDERSEN 1961

19595 CUSHMAN 1923

19596 BOCK 1976

19597 ANDERSEN 1961

19598 ANDERSEN 1961

19599 BOCK 1976

19600 ANDERSEN 1961

19601 CUSHMAN 1923

19603 PFLUM FRERICHS 1976

19603 PFLUM FRERICHS 1976

19604 PFLUM FRERICHS 1976
19605 PFLUM FRERICHS 1976

19606 BANDY 1954

19607 BANDY 1954

19608 BANDY 1954

19609 SANDY 1954

19610 BANDY 1954

$\begin{array}{lll}19611 & \text { PFLUM FRERICHS } & 1976 \\ 19612 & \text { PFLUM FRERICHS } & 197.6\end{array}$

19613 LANKFORD 1959

19614 PFLUM FRERICHS 1976

19615 PFLUM FRERICHS 1976

19616 PFLUM FRERICHS 1976

19617 PFLUM FRERICHS 1976

19618 PFLUM FRERICHS 1976

19619 PFLUM FRERICHS 1976

19620 PFLUM FRERICHS 1976

19621 PFLUM FRERICHS 1976

19622 PFLUM FRERICHS 1976

19623 PFLUM FRERICHS 1976

19624 PFLUM FRERICHS 1976

19625 PFLUM FRERICHS 1976

19626 PFLUM FRERICHS 1976

19627 PFLUM FRERICHS 1976

19628 PFLUM FRERICHS 1976

19629 PFLUM FRERICHS 1976

19630 PFLUM FRERICHS 1976

19631 PFLUM FRERICHS 1976

19632 PFLUM FRERICHS 1976

19633 PFLUM FRERICHS 1976

19634 PFLUM FRERICHS 1976

19635 PFLUM FRERICHS 1976

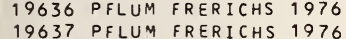

19637 PFLUM FRERICHS 1976
19638 PFLUM FRERICHS 1976

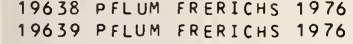

19640 PFLUM FRERICHS 1976

19641 PFLUM FRERICHS 1976

19642 PFLUM FRERICHS 1976

19643 PFLUM FRERICHS 1976

19644 PFLUM FRERICHS 1976

19645 PFLUM FRERICHS 1976

19646 PFLUM FRERICHS 1976

19647 PFLUM FRERICHS 1976

19648 PFLUM FRERICHS 1976

19649 PFLUM FRERICHS 1976

19650 PFLUM FRERICHS 1976

19651 PFLUM FRERICHS 1976

19652 PFLUM FRERICHS 1976

19653 PFLUM FRERICHS 1976

19654 PFLUM FRERICHS 1976

19655 PFLUM FRERICHS 1976

19656 PFLUM FRERICHS 1976

19657 PFLUM FRERICHS 1976

19658 BANDY 1956

19659 BANDY 1956

19660 LEHMANN 1957

19661 PFLUM FRERICHS 1976

19662 PFLUM FRERICHS 1976

19663 PFLUM FRERICHS 1976

19664 PFLUM FRERICHS 1976

19665 PFLUM FRERICHS 1976

19666 PFLUM FRERICHS 1976

19667 PFLUM FRERICHS 1976

19668 PHLEGER 1951A

19669 PFLUM FRERICHS 1976

19670 PFLUM FRERICHS 1976

19671 PFLUM FRERICHS 1976

19672 PFLUM FRERICHS 1976

19673 PFLUM FRERICHS 1976

19674 PFLUM FRERICHS 1976

19675 PFLUM FRERICHS 1976

19676 PARKER 1954

19677 PARKER 1954

19678 PARKER 1954

19679 PARKER 1954

19680 PARKER 1954
Generic Name

LAGENA

OOL INA

FISSURINA

F I SSURINA

FISSURINA

F I SSUR INA

LAGENA

LA GENA

LAGENA

LAGENA

LAGENA

LAGENA

LAGENA

LAGENA

LAGENA

LAGENA

LA GENA

LAGENA

LAGENA

LA GENA

LAGENA

SACCAMMINA

SACCAMM INA

SA C CAMM I NA

SACCAMMINA

SACCAMM I NA

SACCAMMINA

SACCAMMINA

SACCAMMINA

SACCAMMINA

SACCAMM I NA

SACCAMM I NA

SACCAMM I NA

SACCAMM I NA

SACCAMMINA

SACCAMMI NA

SACCAMMINA

SACCAMMINA

SACCAMM I NA

SACCAMMI NA

SACCAMMINA

SACCAMMINA

SACC AMM INA

SAC CAMMINA

SACCAMM INA

SACCAMM INA

SACCAMMINA

SACCAMM I NA

SACCAMMINA

SACCAMM I NA

SACC AMMINA

SACCAMMINA

SACCAMMINA

SACCAMMINA

SACCAMM INA

SACCAMM I NA

SACCAMMINA

SA CC AMM I NA

SACCAMM I NA

SACCAMMINA

SACCAMMINA

SACCAMMINA

SACCAMMINA

SACCAMM INA

SACCAMMI NA

SACCAMM I NA

SACCAMMINA

SACCAMMINA

AMPHICORYNA

AMPHICORYNA

LAMARC KINA

LATICAR ININA

LATICARININA

LATICARININA

LATICAR ININA

LATICAR ININA

LATICARININA

LATI CAR IN INA

LA TI CAR ININA

LAIICAR ININA

LATI CAR ININA

LATICAR ININA

LATI CARININA

LATICAR ININA

A TICARININA

LATICAR ININA

LATICAR ININA

LA TICAR ININA

LATICARININA

LATICARININA
Specific Name

LAEVIS

LAEVIS

LONG ISPINA

MA RG INATA

MARGINATA

MARG INATA

MARGINATA

MEXI CANA

OREIGNYANA

SENISTRIA TA

SPICATA

SPIRATA

STRIATA

STRIATA

SUELAGENO IDES

SUBLAGENOIDES

SULCATA

SULCATA

SULCATA

LAEVIS

LAEVIS

LAEVIS

LAEVIS

LAEVIS

AT LANTI CA

A T LANTICA

A TLANTICA

A T LANTICA

AT LANTI CA

A TLANTICA

A T LANTI CA

A TLANTICA

ATLANTICA

AT LANTI CA

A T LANT I CA

ATLANTICA

A TLANTICA

A TLANTICA

A TLANTICA

AT LANTICA

A TLANTICA

A TLANTICA

ATLAN I I

A TLANTICA

A T LANTICA

ATLANTICA

AT LANTI CA

A T LANTI CA

A T LANTICA

AT LANTICA

AT LANTICA

ATLANTICA

AT LANTI CA

A T LAN I I CA

A T LANTICA

A T LAN T I CA

A T LANTI CA

A T LANT I CA

AT LANTICA

AT LANTICA

AT LANTICA

ATLANTICA

ATLANTICA

A T LANTICA

AT LANTICA

SCALARIS

SCALARIS

A TLANTICA

PALPERATA

PAUPERATA

PALPERATA

PAUPERATA

PAUPERATA

PALPERATA

PAUPERATA

PALPERATA

PALPERATA

PALPERATA

PA UPERATA

PALPERATA

PALPERATA

PALPERATA

PALPERATA

PALPERATA

PAUPERATA

PAUPERATA

\section{Locality}

CENTRAL GULF OF MEXICO

CAPE ROMANO, FLA

NE GULF OF MEXICO

NE GULF OF MEXICO

NE GULF OF MEXICO

NE GULF OF MEXICO

NE GULF OF MEXICO

MISSISSIPPI DELTA

MISSISSIPPI DELTA

NE GULF OF MEXICO

NE GULF OF MEXICO

MISSISSIPPI DELTA

MISSISSIPPI DELTA 


\section{Publication}

19681 PARKER 1954 19682 PARKER 1954 19683 PARKER 1954

19684 LOEP 1965

19685 LOEP 1965

19686 PFLUM FRERICHS 1976

19687 PFLUM FRERICHS 1976

19688 PFLUM FRERICHS 1976

19680 PFLUM FRERICHS 1976

19690 PFLUM FRERICHS 1976

19691 PFLUM FRERICHS 1976

19692 PFLUM FRERICHS 1976

19693 PFLUM FRERICHS 1976

19694 PFLUM FRERICHS 1976

19695 PFLUM FRERICHS 1976

19696 PFLUM FRFRICHS 1976

19697 PFLUM FRERICHS 1976

19698 PFLUM FRERICHS 1976

19699 PFLUM FRERICHS 1976

19700 PFLUM FRERICHS 1976

19701 PFLUM FRERICHS 1976

19702 PFLUM FRERICHS 1976

19703 PFLUM FRERICHS 1976

19704 LEROY HODGKINSON 1975

19705 PHLEGER $1951 \mathrm{~A}$

19706 PARKER 1954

19707 CREAGER 1958

19708 PFLUM FRERICHS 1976

19709 PFLUM FRERICHS 1976

19710 PFLUM FRERICHS 1976

19711 PFLUM FRERICHS 1976

19712 PFLUM FRERICHS 1976

19713 PARKER 1954

19714 PARKER 1954

19715 PARKER 1954

19716 PHLEGER 1955A

19717 PFLUM FRERICHS 1976

19718 PFLUM FRERICHS 1976

19719 PFLUM FRERICHS 1976

19720 PFLUM FRERICHS 1976

19721 PHLEGER 1951A

19722 PARKER 1954

19723 PARKER 1954

19724 PARKER 1954

19725 PARKER 1954

19726 PARKER 1954

19727 PFLUM FRERICHS 1976

19728 PFLUM FRERICHS 1976

19729 PFLUM FRERICHS 1976

19730 CREAGER 1958

19731 CREAGER 1958

19732 CREAGER 1958

19733 CREAGER 1958

19734 CREAGER 1958

19735 CREAGER 1958

19736 CREAGER 1958

19738 PHLEGER 1955A

19739 PHLEGER 1955 A

19740 PHLEGER 1951A

19741 PHLEGER $1951 \mathrm{~A}$

19742 PHLEGER $1951 \mathrm{~A}$

19743 PHLEGER $1951 \mathrm{~A}$

19744 PHLEGER $1951 \mathrm{~A}$

19745 PHLEGER 1951A

19746 PHLEGER 1951A

19747 PHLEGER 1951A

19748 PHLEGER $1951 \mathrm{~A}$

19749 PHLEGER 1951A

19750 PHLEGER $1951 \mathrm{~A}$

19751 PHLEGER $1951 \mathrm{~A}$

19752 PHLEGER $1951 \mathrm{~A}$

19753 PARKER 1954

19754 PHLEGER 1951 A

19755 PHLEGER $1951 \mathrm{~A}$

19756 PHLEGER $1951 \mathrm{~A}$

19757 PHLEGER 1955 A

19758 PHLEGER 1955A

19759 PHLEGER 1955 A

19760 PHLEGER 1955 A 19761 PARKER 1954

19762 PFLUM FRERICHS 1976

19763 PFLUM FRERICHS 1976

19764 PFLUM FRERICHS 1976 19765 PFLUM FRERICHS 1976 19766 PFLUM FRERICHS 1976 19767 PFLUM FRERICHS 1976 19768 PFLUM FRERICHS 1976 19769 PFLUM FRERICHS 1976 19770 PFLUM FRERICHS 1976 19771 PFLUM FRERICHS 1976 19772 PFLUM FRERICHS 1976 19773 PFLUM FRERICHS 1976 19774 PFLUM FRERICHS 1976 19775 PFLUM FRERICHS 1976
Generic Name

LATICARININA

LATICARININA

LATICARININA

LATICAR ININA

LATICAR ININA

LATICAR ININA

LATICARININA

LATICAR ININA

LATICAR ININA

LATICAR ININA

LATICARININA

LATICAR ININA

LATICAR ININA

LATICARININA

LATICAR ININA

LATICARININA

LATICAR ININA

LATICAR ININA

LATICARININA

LATICAR ININA

LATI CAR ININA

LATICAR ININA

LATICARININA

LATICARININA

LATI CAR ININA

LATICAR ININA

LATICARININA

LATICARININA

LATICAR ININA

LATICARININA

LATICARININA

LATI CAR ININA

LATICARININA

LATICARININA

LATICARININA

LATICARININA

LATICAR ININA

LATICARININA

LATICAR ININA

LATICAR ININA

LATI CAR ININA

LATICAR ININA

LATICAR ININA

LATICAR ININA

LATICARININA

LATICAR ININA

LATICARININA

LATICAR ININA

LA TICAR ININA

LATICARININA

LATICAR ININA

LATI CAR ININA

LATICARININA

LATICAR ININA

LATICAR ININA

LATI CAR IN IN A

LATICARININA

LATICARININA

LATI CAR ININA

LATICARININA

LATI CAR ININA

LATI C AR ININA

LATICARININA

LATICAR ININA

LATICARININA

LATI CAR ININA

LATICAR ININA

LATICARININA

LATICAR ININA

LATICAR ININA

LATICARININA

LATICARININA

LATICAR ININA

LATICARININA

LATICAR ININA

LATICAR I NI NA

LATICAR ININA

LA TICARININA

LATICAR ININA

LATICARININA

LATICAR ININA

LATICAR ININA

LATICAR ININA

AATICAR ININA

LATICARININA

LAIICARININA

LATICARININA

LATICARININA

LATICAR ININA

LATICARININA

LATICAR ININA

LATI CAR ININA

LATICARININA
Specific Name

PALPERATA

PALPERATA

PA UPERATA

PALPERATA

PAUPERATA

PALPERATA

PALPERATA

PALPERATA

PALPERATA

PAUPERATA

PALPERATA

PALPERATA

PALPERATA

PALPERATA

PALPERATA

PAUPERATA

PALPERATA

PALPERATA

PALPERATA

PALPERATA

PALPERATA

PA UPERATA

PALPERATA

PALPERATA

PALPERATA

PALPERATA

PAUPERATA

PAUPERATA

PA UPERATA

PALPERATA

PALPERATA

PALPERATA

PALPERATA

PALPERATA

PALPERATA

PA UPERATA

PALPERATA

PALPERATA

PALPERATA

PALPERATA

PALPERATA

PALPERATA

PALPERATA

PALPERATA

PALPERATA

PALPERATA

PALPERATA

PALPERATA

PAUPERATA

PAUPERATA

PALPERATA

ALPERATA

PALPERATA

PALPERATA

PALPERATA

PALPERATA

PALPERATA

PALPERATA

PALPERATA

PALPERATA

PAUPERATA

PALPERATA

PALPERATA

PALPERATA

PALPERATA

PALPERATA

PALPERATA

PAUPERATA

PAUPERATA

PALPERATA

PALPERATA

PALPERATA

PALPERATA

PALPERATA

PAUPERATA

PALPERATA

PALPERATA

PALPERATA

PALPERATA

PAUPERATA

PALPERATA

PALPERATA

PALPERATA

PALPERATA

PALPERATA

PALPERATA

PALPERATA

PALIPERATA

PAUPERATA

PALPERATA

Locality

NE GULF OF MEXICO

NE GULF OF MEXICO

NE GULF OF MEXICO

$N W$ GULF OF MEXICO

NW GULF OF MEXICO 
Publication

19776 PFLUM FRERICHS 1976 19777 PFLUM FRERICHS 1976 19778 CREAGER 1958

19779 CREAGER 1958

19780 CREAGER 1958

19781 CREAGER 1958

$\begin{array}{lll}19782 & \text { PFLUM FRERICHS } & 1976 \\ 19783 & \text { PFLUM FRERICHS } & 1976\end{array}$

19784 PFLUM FRERICHS 1976

19785 PFLUM FRERICHS 1976

19786 PFLUM FRERICHS 1976

19787 PFLUM FRERICHS 1976

19788 PFLUM FRERICHS 1976

19789 PFLUM FRERICHS 1976

19790 CUSHMAN 1931

19791 CUSHMAN 1931

19792 CUSHMAN 1931

19794 PFLUM FRERICHS 1976

19795 CUSHMAN 1931

19796 PFLUM FRERICHS 1976

19797 CREAGER 1958

19798 LEHMANN 1957

19799 PFLUM FRERICHS 1976

19800 PFLUM FRERICHS 1976

19801 PFLUM FRERICHS 1976

19802 PFLUM FRERICHS 1976

19803 PFLUM FRERICHS 1976

19804 PFLUM FRERICHS 1976

19805 PFLUM FRERICHS 1976

19806 PFLUM FRERICHS 1976

19807 PFLUM FRERICHS 1976

19808 PFLUM FRERICHS 1976

19809 PFLUM FRERICHS 1976

19810 PFLUM FRERICHS 1976

19811 PFLUM FRERICHS 1976

19812 BOCK 1976

19813 PFLUM FRERICHS 1976 19814 PFLUM FRERICHS 1976 19815 PFLUM FRERICHS 1976 19816 PFLUM FRERICHS 1976 19817 PFLUM FRERICHS 1976 19818 PFLUM FRERICHS 1976 19819 PFLUM FRERICHS 1976 19821 LEROY HODGKINSON 1975 19822 PFLUM FRERICHS 1976 19822 PFLUM FRERICHS 1976 19824 PFLUM FRERICHS 1976 19825 PFLUM FRERICHS 1976 19826 PFLUM FRERICHS 1976 19827 PFLUM FRERICHS 1976 19828 PFLUM FRERICHS 1976 19829 PFLUM FRERICHS 1976 19830 PFLUM FRERICHS 1976 19831 PFLUM FRERICHS 1976 19832 BOCK 1976

19833 PFLUM FRERICHS 1976 19834 PFLUM FRERICHS 1976 19835 PFLUM FRERICHS 1976 19836 PFLUM FRERICHS 1976 19837 PFLUM FRERICHS 1976 19838 PFLUM FRERICHS 1976 19839 PFLUM FRERICHS 1976 19840 PFLUM FRERICHS 1976 19841 PFLUM FRERICHS 1976 19842 PFLUM FRERICHS 1976 19843 PFLUM FRERICHS 1976 19844 PFLUM FRERICHS 1976

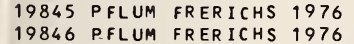
19847 PFLUM FRERICHS 1976 19848 PFLUM FRERICHS 1976 19849 PFLUM FRERICHS 1976 19850 PFLUM FRERICHS 1976 19851 BOCK 1976

19852 PFLUM FRERICHS 1976 19853 PFLUM FRERICHS 1976 19854 BOCK 1976

19855 PFLUM FRERICHS 1976 19856 PFLUM FRERICHS 1976 19857 PFLUM FRERICHS 1976 19858 PFLUM FRERICHS 1976 19859 PFLUM FRERICHS 1976 19860 PFLUM FRERICHS 1976 19861 PFLUM FRERICHS 1976 19862 PFLUM FRERICHS 1976 19863 PFLUM FRERICHS 1976 19864 PFLUM FRERICHS 1976 19865 PFLUM FRERICHS 1976 19866 PARKER 1954

19867 PHLEGER 1956

19868 PFLUM FRERICHS 1976

19869 ANDERSEN 1961

19870 BOCK 1976
Generic Name

Specific Name

LATI I AR ININA

LATI CAR ININA

LATI CARININA

LATICAR ININA

LATICARININA

LATICARININA

LATICAR ININA

LA I I CAR ININA

LATICARININA

LATICARININA

LATICARININA

LATICARININA

LATICARININA

LATICAR ININA

LATICARININA

LATICARININA

LATICAR ININA

LATI CARININA

LATICARININA

LATICARININA

LA I I CAR ININA

LENTICULINA

LENT I CUL INA

LENT I CUL INA

LENTI CULINA

LENT I CULINA

LENTI CULINA

LENT I CUL INA

LENT I CULINA

LENT I CUL INA

LENT I CULINA

LENT I CULINA

LENT I CUL INA

LENT I CULINA

LENT I CULINA

LENT I CUL INA

LENTICULINA

LENT I CUL INA

LENT I CUL INA

LENT ICULINA

LENTICULINA

LENTICULINA

LENTICULINA

LENT I CUL INA

LENT I CUL INA

LENT I CUL INA

LENT I CUL INA

LENT I CUL INA

LENT I CUL INA

LENT I CUL INA

LENT I CUL INA

LENTI CUL INA

LENT I CUL INA

LENTI CULINA

LENT I CULINA

LENT I CULINA

LENT I CUL INA

LENTI CUL INA

LENTI CULINA

LENTI CUL INA

LENT I CUL INA

LENT I CULINA

LENT I CULINA

LENT I CULINA

LENT I CUL INA

LENT I CULINA

LENT I CULINA

LENTI CULINA

LENTI CULINA

LENTI I UL INA

LENT I CUL INA

LENTI CUL INA

LENT I CULINA

LENTICULINA

LENT I CUL INA

LENT I CULINA

LENT I CUL INA

LENTI I ULLINA

LENTI CUL INA

LENTI CULINA

LENT I CULINA

LENTICULINA

LENTICULINA

LENT I CULINA

LENT I CULL INA

LENTI CULINA

LENTI CULINA

LENT I CUL INA

LENTI CULINA

LENT I CULINA

LENTI CULINA

LENTICUL INA

LENT I CULINA

LENTICULINA
Locality

CENTRAL GULF OF MEXICO CENTRAL GULF OF MEXICO BAY OF CAMPECHE BAY OF CAMPECHE BAY OF CAMPECHE BAY OF CAMPECHE

CENTRAL GULF OF MEXICO CENTRAL GULF OF MEXICO CENTRAL GULF OF MEXICO CENTRAL GULF OF MEXICO CENTRAL GULF OF MEXICO CENTRAL GULF OF MEXICO CENTRAL GULF OF MEXICO CENTRAL GULF OF MEXICO NE GULF OF MEXICO NE GULF OF MEXICO NE GULF OF MEXICO BAY OF CAMPECHE

CENTRAL GULF OF MEXICO

NE GULF OF MEXICO

CENTRAL GULF OF MEXICO

BAY OF CAMPECHE

TEXAS GULF COAST

NW GULF OF MEXICO

NW GULF OF MEXICO

NH GULF OF MEXICO

NH GULF OF MEXICO

NH GULF OF MEXICO

NH GULF OF MEXICO

CENTRAL GULF OF MEXICO

CENTRAL GULF OF MEXICO

CENTRAL GULF OF MEXICO

CENTRAL GULF OF MEXICO

CENTRAL GULF OF MEXICO

CENTRAL GULF OF MEXICO

CENTRAL GULF OF MEXICO

NE GULF OF MEXICO

NH GULF OF MEXICO

NH GULF OF MEXICO

NH GULF OF MEXICO

NH GULF OF MEXICO

NH GULF OF MEXICO

NH GULF OF MEXICO

NH GULF OF MEXICO

NH GULF OF MEXICO

$N$ GULF OF MEXICO

NH GULF OF MEXICO

NH GULF OF MEXICO

NH GULF OF MEXICO

NH GULF OF MEXICO

NH GULF OF MEXICO

NH GULF OF MEXICO

NH GULF OF MEXICO

NH GULF OF MEXICO

NH GULF OF MEXICO

NH GULF OF MEXICO

NE GULF OF MEXICO

CENTRAL GULF OF MEXICO

CENTRAL GULF OF MEXICO

CENTRAL GULF OF MEXICO

NH GULF OF MEXICO

NH GULF OF MEXICO

CENTRAL GULF OF MEXICO

CENTRAL GULF OF MEXICO

CENTRAL GULF OF MEXICO

CENTRAL GULF OF MEXICO

CENTRAL GULF OF MEXICO

CENTRAL GULF OF MEXICO

CENTRAL GULF OF MEXICO

CENTRAL GULF OF MEXICO

CENTRAL GULF OF MEXICO

CENTRAL GULF OF MEXICO

CENTRAL GULF OF MEXICO

CENTRAL GULF OF MEXICO

CENTRAL GULF OF MEXICO

NE GULF OF MEXICO

NH GULF OF MEXICO

CENTRAL GULF OF MEXICO

NE GULF OF MEXICO

NH GULF OF MEXICO

CENTRAL GULF OF MEXICO

CENTRAL GULF OF MEXICO

CENTRAL GULF OF MEXICO

NW GULF OF MEXICO

NW GULF OF MEXICO

CENTRAL GULF OF MEXICO

CENTRAL GULF OF MEXICO

NW GULF OF MEXICO

NW GULF OF MEXICO

NW GULF OF MEXICO

NE GULF OF MEXICO

NW GULF OF MEXICO

NW GULF OF MEXICO

PEREGRINA MISSISSIPPI DELTA

Lat. Long.

$2645 \mathrm{~N} 088 \quad 19 \mathrm{~W}$ $\begin{array}{llll}25 & 41 \mathrm{~N} & 087 & 55 \mathrm{~W} \\ 20 & 44 \mathrm{~N} & 092 & 41 \mathrm{H}\end{array}$ $1927 \mathrm{~N} 09355 \mathrm{~W}$ $2010 \mathrm{~N} 094 \quad 15 \mathrm{~W}$ $1906 \mathrm{~N} 09437 \mathrm{~W}$ 


\section{Publication}

19871 PARKER 1954

19872 PARKER 1954

19874 PARKER 1954

19875 PARKER 1954

19876 PFLUM FRERICHS 1976 19877 PFLUM FRERICHS 1976 19878 PFLUM FRERICHS 1976 19879 PFLUM FRERICHS 1976 $19880^{\circ}$ PFLUM FRERICHS 1976 19881 PFLUM FRERICHS 1976 19882 PHLEGER 1951A 19883 PHLEGER 1951A 19884 PHLEGER 1951A

19885 PFLUM FRERICHS 1976 19886 PFLUM FRERICHS 1976 19887 PFLUM FRERICHS 1976 19888 PFLUM FRERICHS 1976 19889 PFLUM FRERICHS 1976 19890 PFLUM FRERICHS 1976 19891 PFLUM FRERICHS 1976 19892 PFLUM FRERICHS 1976 19893 PFLUM FRERICHS 1976 19894 PFLUM FRERICHS 1976 19895 PFLUM FRERICHS 1976 19896 PFLUM FRERICHS 1976 19897 PFLUM FRERICHS 1976 19898 PFLUM FRERICHS 1976 19899 PFLUM FRERICHS 1976 19900 PFLUM FRERICHS 1976 19901 PFLUM FRERICHS 1976 19902 PFLUM FRERICHS 1976 19903 PFLUM FRERICHS 1976 19904 PFLUM FRERICHS 1976 19905 PFLUM FRERICHS 1976 19906 PFLUM FRERICHS 1976 19907 PFLUM FRERICHS 1976 19908 PHLEGER $1951 \mathrm{~A}$ 19909 PHLEGER 1951A 19910 PFLUM FRERICHS 1976 19911 PFLUM FRERICHS 1976 19912 PFLUM FRERICHS 1976 19913 PFLUM FRERICHS 1976 19914 PFLUM FRERICHS 1976 19915 PFLUM FRERICHS 1976 19916 PHLEGER 1951A 19917 PHLEGER $1951 \mathrm{~A}$ 19918 PFLUM FRERICHS 1976 19919 PFLUM FRERICHS 1976 19920 PFLUM FRERICHS 1976 19921 PFLUM FRERICHS 1976 19922 PHLEGER 1951A 19923 PHLEGER 1951A 19924 PHLEGER 1951A 19925 PHLEGER 1951A 19926 PHLEGER 1951 A 19927 PFLUM FRERICHS 1976 19928 PFLUM FRERICHS 1976 19929 PFLUM FRERICHS 1976 19930 PARKER 1954 19931 PARKER 1954 19932 PARKER 1954 19933 PARKER 1954 19934 PARKER 1954 19935 PARKER 1954 19936 PARKER 1954 19937 PARKER 1954 19938 PARKER 1954 19939 PARKER 1954 19940 LANKFORD 1959 19941 LUDWICK WALTON 1957 19942 PARKER 1954 9943 PHLEGER 1951 A 19944 PHLEGER 1951A 19945 PHLEGER 1951A 19946 PHLEGER 1951A 19947 PHLEGER 1951A 19948 PHLEGER $1951 \mathrm{~A}$ 19949 PHLEGER 1951A 19950 PHLEGER 1951A 19951 PHLEGER 1951 A 19952 PHLEGER 1951A 19953 PHLEGER $1951 \mathrm{~A}$ 19954 PHLEGER $1951 \mathrm{~A}$ 19955 PHLEGER 1951A 19956 PHLEGER 1951 A 19957 PHLEGER 1951 A 19958 PHLEGER 1951A 19959 PHLEGER 1951A 19960 PHLEGER 1951 A 19961 PHLEGER $1951 \mathrm{~A}$ 19962 PFLUM FRERICHS 1976 19963 PFLUM FRERICHS 1976 19964 PFLUM FRERICHS 1976 19965 PARKER 1954
Generic Name

LENTI CUL INA

LENT I CULINA

LENTI CULINA

LENTICULINA

LENTI CULINA

LENTICULINA

LENTI CULINA

LENTI CULINA

LENT ICULINA

LENT I CULINA

LENTICULINA

LENTI CULINA

LENTI C UL INA

LENTI CULINA

LENTI CULINA

LENTICULINA

LENTI CULINA

LENT I CULINA

LENTI CUL INA

LENTI CULINA

LENTICULINA

LENTICULINA

LENTI CUL INA

LENTI CULINA

LENTI CULINA

LENTI CULINA

LENTI CUL INA

LENTI CUL INA

LENTI CULINA

LENTICULINA

LE NT I CUL INA

LENTICULINA

LENT I CULINA

LENT ICULINA

LENT I CUL INA

LENTI CULINA

LENTI CUL INA

LENT I CULINA

LENT I CUL INA

LENTI CUL INA

LENTI CULINA

LENTI CUL INA

LENTI CULINA

LE NTI CUL INA

LENTI CUL INA

LENTI CUL INA

LENTICULINA

LENTI CULINA

LENT I CULINA

LENT I CULINA

LENTI CULINA

LENT I CUL INA

LENTI CULINA

LENTI CUL INA

LENTI I UL INA

LENTI CULINA

LENT I CULINA

LENT I CUL INA

LENT I CUL INA

LENTI CUL INA

LENTI CULINA

LENT I CULINA

LENTI CULINA

LENTI CUL INA

LENTI CUL INA

LENTI C ULINA

LENTI CULINA

LENT I CULINA

LENTI CUL INA

LENTICULINA

LENT I CULINA

LENTI CULINA

LENTI CULINA

LENT I CUL INA

LENTI CULINA

LENT I CULINA

LENTI CULINA

LENTI CUL INA

LENT I CUL INA

LENT I CUL INA

LENTI CULINA

LENTICULINA

LENTICULINA

LENT I CULINA

LENTICULINA

LENT I CUL IN A

LENTI CUL INA

LENT I CUL INA

LENTI CUL INA

LENTI CULINA

LE NT I CULINA

LENTI CULIN

LENT I CUL INA
Specific Name

PEREGRINA

PEREGRINA

PEREGRINA

PEREGRINA

PEREGRINA

PEREGRINA

PEREGRINA

PEREGRINA

PEREGRINA

PEREGRINA

PEREGR INA

PEREGR INA

PE REGR I NA

PEREGRINA

PEREGRINA

PEREGRINA

PE REGRINA

PEREGRINA

PEREGRINA

PEREGR INA

PEREGRINA

PEREGR INA

PEREGRINA

PEREGR INA

PE FEGR INA

PEREGRINA

PE REGR INA

PEREGRINA

PEREGRINA

PEREGRINA

PEREGRINA

PE FEGR I NA

PEREGRINA

PE REGR INA

PEREGRINA

PEREGRINA

PEREGRINA

PEREGRINA

PE REGRI NA

PEREGRINA

PEREGRINA

PE REGRINA

PEREGRINA

PEREGRINA

PEREGRINA

PE REGR I NA

PEREGRINA

PE RE GR INA

PEREGR I NA

PEREGR INA

PEREGRINA

PEREGR INA

PERE GR I NA

PEREGRINA

PEREGR INA

PEREGRINA

PEREGR I NA

PEREGRINA

PEREGRINA

PEREGRINA

PEREGRINA

PEREGRINA

PEREGR I NA

PEREGRINA

PEREGRINA

PEREGRINA

PEREGRINA

PE RE GR INA

PEREGRINA

PEREGRINA

PEREGRINA

PEREGRINA

PEREGR INA

PEREGRINA

PEREGRINA

PEREGRINA

PEREGRINA

PEREGRINA

PEREGRINA

PE FEGR INA

PEFEGRINA

PEREGRINA

PEREGRINA

PERE GR INA

PE RE GRI NA

PEREGRINA

PEREGRINA

PEREGRINA

PEREGRINA

PEREGR INA

PEREGRINA

PEREGRINA

Locality

NE GULF OF MEXICO NE GULF OF MEXICO

NE GULF OF MEXICO

NE GULF OF MEXICO

NE GULF OF MEXICO 
Publication

19966 PFLUM FRERICHS 1976 19967 PFLUM FRERICHS 1976 19968 PFLUM FRERICHS 1976 19969 PFLUM FRERICHS 1976 19970 PFLUM FRERICHS 1976 19971 PFLUM FRERICHS 1976 19972 PFLUM FRERICHS 1976 19973 PFLUM FRERICHS 1976 19974 PFLUM FRERICHS 1976 19975 PFLUM FRERICHS 1976 19976 PFLUM FRERICHS 1976 19977 PFLUM FRERICHS 1976 19978 PFLUM FRERICHS 1976 19979 PFLUM FRERICHS 1976 19980 PFLUM FRERICHS 1976 19981 PFLUM FRERICHS 1976 19982 PFLUM FRERICHS 1976 19983 PFLUM FRERICHS 1976 19984 PFLUM FRERICHS 1976 19985 PFLUM FRERICHS 1976 19986 BOCK 1976

19987 ANDERSEN 1961

19988 PFLUM FRERICHS 1976

19989 BANDY 1956

19990 BANDY 1956

19991 CUSHMAN 1923

19992 CUSHMAN 1923

19993 PFLUM FRERICHS 1976 19994 PFLUM FRERICHS 1976 19995 PFLUM FRERICHS 1976 19996 PFLUM FRERICHS 1976 19997 PFLUM FRERICHS 1976 19998 PFLUM FRERICHS 1976 19999 PFLUM FRERICHS 1976 20000 PFLUM FRERICHS 1976 20001 PFLUM FRERICHS 1976 20002 PFLUM FRERICHS 1976 20003 PFLUM FRERICHS 1976 20004 PFLUM FRERICHS 1976 20005 PFLUM FRERICHS 1976 20006 PFLUM FRERICHS 1976 20007 LEROY HODGKINSON 1975 20008 PFLUM FRERICHS 1976 20009 PFLUM FRERICHS 1976 20010 PFLUM FRERICHS 1976 20011 PFLUM FRERICHS 1976 20012 CUSHMAN 1920

20013 PFLUM FRERICHS 1976 20014 PFLUM FRERICHS 1976 20015 PFLUM FRERICHS 1976 20016 PFLUM FRERICHS 1976 20017 CUSHMAN 1920

20018 PFLUM FRERICHS 1976 20019 PFLUM FRERICHS 1976 20020 PFLUM FRERICHS 1976 20021 PFLUM FRERICHS 1976 20022 PARKER 1954

20023 PARKER 1954

20024 PARKER 1954

20025 PARKER 1954

20026 PARKER 1954

20027 PARKER 1954

20028 PARKER 1954

20029 PARKER 1954

20030 PARKER 1954

20031 PARKER 1954

20032 PARKER 1954

20033 PARKER 1954

20034 PARKER 1954
20035 PARKER 1954

20036 PARKER 1954

20037 PARKER 1954

20038 ANDERSEN 1961

20039 BANDY 1956

20040 BANDY 1956

20041 BANDY 1956

20042 BANDY 1956

20043 BANDY 1956

20044 BANDY 1956

20045 BANDY 1956

20046 BANDY 1956

20047 BANDY 1956

20048 BANDY 1956

20049 BOCK 1976

20050 BANDY 1956
20051 BANDY 1956

20052 BANDY 1956

20053 BANDY 1956

20054 BANDY 1956

20055 BANDY 1956

20056 BANDY 1956

20057 BANDY 1956

20058 BANDY 1956

20059 BANDY 1956

20060 BANDY 1956
Generic Name

LENT I CULINA

LENTI CULINA

LENT I CULINA

LENTICULINA

LENTI CULINA

LENT I CUL INA

LENTI CUL INA

LENTI CUL INA

LENT ICULINA

LENT ICULINA

LENTI CULINA

LENT I CULINA

LENT I CULINA

LENTI CUL INA

LENTI CUL INA

LENTICULINA

LENTI CULINA

LENT I CULINA

LENTI CULINA

LENTI C UL INA

LI EBUSELLA

LIEBUSELLA

LINGUL INA

LINGUL INA

LI NGUL INA

LINGUL INA

LINGULINA

LI TUOTUBA

LI TUOTUBA

LITUOTUBA

LITUOTUBA

LI TUOTUBA

LI TUOTUBA

LI TUOTUBA

LI TUOTUBA

LITUOTUBA

LI TUOTUBA

LI TUOTUBA

LI TUOTUBA

LI TUOTUBA

LI TUOTUBA

LI TUOTUBA

LI TUOTUBA

LITUOTUBA

LI TUOTUBA

LI TUOTUBA

LI TUOTUBA

LI TUOTUBA

LI TUOTUBA

LITUOTUBA

LI TUOTUBA

LI TUOTUBA

LI TUOTUBA

LI TUOTUBA

RECTOBOLIVINA

RECTOBOLIVINA

RECTOBOL IVINA

RECTOBOL IVINA

RECTOBOLIVINA

RECTOBOLIVINA

RECTOBOLIVINA

RECTOBOL IVINA

RECTOBOL IV INA

RECTOBOL IVINA

RECTOBOLIVINA

RECTOBOL IVINA

RECTOBOLIVINA

RECTOBOLIVINA

RECTOBOL IVINA

RE CTOBOLIVINA

BOLIVINA

RECTOBOLIVINA

RECTOBOL IVINA

RECTOBOLIVINA

BOLIVINA

BOLIVINA

BOLIVINA

BOLIVINA

BOLIVINA

BOLIVINA

BOLIVINA

RECTOBOLIVINA

MARG I NUL INA

MARG INUL INA

MARG INUL INA

MARG INUL INA

MARG INUL INA

MARGINUL INA

MARG INUL INA

MARG I NUL INA

MARG INUL INA

MARG I NUL INA

MARG INUL INA
Specific Name

PEREGRINA

PEREGRINA

PEREGRINA

PEREGRINA

PE REGRINA

PEREGRINA

PEFEGRINA

PEREGRINA

PE FEGRINA

PEREGRINA

PEREGRINA

PEREGRINA

PEFEGRINA

PEREGRINA

PE REGRINA

PEREGRINA

PEFEGRINA

PEFEGRINA

PEFEGRIN

RO TULATA

SOLDANII

SOLDANII

CARINATA

CARINATA

SENINUDA

SENINUDA

SENINUDA

LI TUIFORMIS

LI TUIFORM IS

LI TUI FORMIS

LI TUIFORM IS

LI TUIFORN IS

LITUIFORMIS

LI TUIFORMIS

LI TUIFORMIS

LI TUIFORM IS

LI TUIFORMIS

LI TUIFORMIS

I TUIFORMIS

LI TUIFORM IS

LI TUI FORMIS

LI TUIFORM IS

LI TUI FORMIS

LI TUIFORM IS

LI TUIFORMIS

I TUIFORM IS

LI TUIFORMIS

LI TUIFORMIS

LI TUIFORMIS

LI TUIFORMIS

LI TUIFORMIS

LI TUIFORM IS

LI TUIFORMIS

LI TUIFORMIS

LI TUIFORM IS

AB RUPT A

ABRUPTA

AB RUPTA

ABRUPTA

AB RUPTA

AB RUPTA

AB RUPTA

AB FUPTA

ABRUPTA

ABRUPTA

AB RUPTA

AB FUPTA

ABRUPTA

ABRUPTA

ABRUPTA

AB RUPTA

SUBSPINESCENS

MA YORI

MA YORI

MAYORI

SUESPINESCENS

SUBSPINESCENS

SUESPINES CENS

SUESP INES CENS

SUESPINE

SUESPINES CENS

SUESPINESCENS

SUESPINES CENS

AB RUPTA

ADVENA

ADVENA

ADVENA

ADVENA

ADVENA

ADVENA

AD VENA

ADVENA

ADVENA

ADVENA

ADVENA

ADVENA

Locality

NW GULF OF MEXICO

NW GULF OF MEXICO

NW GULF OF MEXICO

$N \backsim$ GULF OF MEXICO 


\section{Publication}

20061 BANDY 1956

20062 BANDY 1956

20063 VAUGHAN 1918

20064 BOCK 1976
20065 ANDERSEN 196

20066 CUSHMAN 1923

20067 PFLUM FRERICHS 1976

20068 BANDY 1956

20069 LANKFORD 1959

20070 PARKER 1954

20071 PHLEGER 1951 A

20072 PARKER 1954

20073 PARKER 1954

20074 PARKER 1954

20075 PHLEGER 1951A

20076 PHLEGER 1951 A

20077 PHLEGER 1951A

20078 PHLEGER 1951A

20079 PHLEGER $1951 \mathrm{~A}$

20080 PHLEGER 1951A

20081 PHLEGER $1951 \mathrm{~A}$

20082 PHLEGER 1951A

20083 PHLEGER $1951 \mathrm{~A}$

20084 PHLEGER 1951A

20085 PHLEGER 1951A

20086 PHLEGER 1951A

20087 PHLEGER 1951A

20088 PHLEGER 1951A

20089 CREAGER 1958

20090 PARKER 1954

20091 PHLEGER $1951 \mathrm{~A}$

20092 PHLEGER $1951 \mathrm{~A}$

20093 PHLEGER $1951 \mathrm{~A}$

20095 PARKER 1954

20096 LUDWICK WALTON 1957

20097 PHLEGER $1951 \mathrm{~A}$

20098 ANDERSEN 1961

20099 LEROY HODGKINSON 1975

20100 ANDERSEN 1961

20101 KELLOUGH 1956

20102 KELLOUGH 1956

20103 KELLOUGH 1956

20104 PHLEGER 1951 A

20105 PHLEGER 1951A

20106 KELLOUGH 1956

20107 KELLOUGH 1956

20108 PHLEGER 1951 A

20109 PHLEGER 1951 A

20110 BOCK 1975

20111 CREAGER 1958

20112 PHLEGER 1951A

20113 PHLEGER 1951A

20115 PHLEGER 1951A

20116 ANDERSEN 1961

20117 CUSHMAN 1923

20118 CUSHMAN 1923

20119 CUSHMAN 1923

20120 CREAGER 1958

20121 CREAGER 1958

20122 CREAGER 1958

20123 CREAGER 1958

20124 CREAGER 1958

20125 PFLUM FRERICHS 1976 20126 PFLUM FRERICHS 1976 20127 PFLUM FRERICHS 1976 20128 PFLUM FRERICHS 1976 20129 PFLUM FRERICHS 1976 20130 PFLUM FRERICHS 1976 20131 PFLUM FRERICHS 1976 20132 ANDERSEN 1961

20133 BOCK 1976

20134 BANDY 1956

20135 ANDERSEN 1961

20136 PFLUM FRERICHS 1976

20137 PFLUM FRERICHS 1976

20138 PFLUM FRERICHS 1976 20139 PFLUM FRERICHS 1976 20140 PFLUM FRERICHS 1976 20141 BANDY 1956

20142 BANDY 1956

20143 BANDY 1956

20144 BANDY 1956

20145 PFLUM FRERICHS 1976 20146 PFLUM FRERICHS 1976 20147 PFLUM FRERICHS 1976 20148 PFLUM FRERICHS 1976 20149 PFLUM FRERICHS 1976 20150 PFLUM FRERICHS 1976 20151 PFLUM FRERICHS 1976 20152 PFLUM FRERICHS 1976 20153 ANDERSEN 1961 20154 PFLUM FRERICHS 1976
20155 PFLUM FRERICHS 1976
Generic Name

MARGI NUL INA

MARGINUL INA

MARGINUL INOPSIS

MARG INUL INA

MARGINUL INA

MARG INUL INA

MARGINUL INA

MARGINUL INA

MARGINUL INOPSIS

MARGINUL INOPSIS

MARGINUL INOPSIS

MARGINUL INOPSIS

MARGINUL INOPSIS

MARGINUL INOPSIS

MARG I NUL INOPS IS

MARGINUL INOPSIS

MARGINUL INOPSIS

MARGINUL INOPSIS

MARGINUL INOPS IS

MARGINUL INOPS IS

MARGINUL INOPSIS

MARG I NUL INOPSIS

MARGINULINOPSIS

MARGINUL INOPSIS

MARGINUL INOPSIS

MARGI NUL INOPS IS

MARGI NUL INOPS IS

MARGI NUL INOPS IS

MARGINUL INOPSIS

MARGINULINOPSIS

MARGINUL INOPSIS

MARGI NUL INOPSIS

MARG I NUL INOPS IS

MARGINUL INOPSIS

MARGINUL INOPSIS

MARG INUL INOPS IS

MARGINUL INOPSIS

MARGINUL INA

MARGINUL INA

MARG I NUL INA

MARG I NUL INA

MARGINUL INA

MARGINUL INA

MARGINUL INA

MARG INUL INA

MARGI NUL INA

MARGINUL INA

MARG INUL INA

MARG I NUL INA

MARG I NUL INA

MARG INUL INA

MARGINUL INA

MARGINUL INA

MARGINUL INA

MARGINULINA

MARGINUL INA

MARGINUL INA

MARGINUL INA

MARGINUL INA

MARGINULINOPS IS

MARG INUL INOPS IS

MARG INULINOPSIS

MARGI NUL INOPS IS

MARGI NUL INOPSIS

MARG I NUL INA

MARG INUL INA

MARGINUL INA

MARG INUL INA

MARGINUL INA

MARGI NUL INA

MARGINUL INA

MARG INUL INA

MARGINUL INA

MARG INUL INOPSIS

MARGINULINOPSIS

MARGINULINOPSIS

MARG INULINOPSIS

MARGI NUL INOPS IS

MARGI NUL INOPS IS

MARGINUL INOPSIS

MARGINUL INOPS IS

MARGINUL INOPS IS

MARG I NUL INOPS IS

MARGINUL INOPSIS

MARGI NUL INOPS IS

MARGI NUL INOPS IS

MARGINUL INOPS IS

MARG I NUL INOPS IS

MARGINUL INOI

MARGINUL INOPSIS

MARG INUL INOPSIS

MARGINUL INOPSIS

MARGINUL INOPSIS

MARGINULINOPSIS

MARGINULINOPSIS
Specific Name

ADVENA

DENSI COSIATA

GLABRA

GL ABRA

GL ABRA OBESA

HA TTKENI

MARGINULI NOIDES

MARG I NUL I NOIDES

MA FG I NUL INOIDES

MARG I NUL I NO IOES

MARG I NUL I NO I DES

MARGINUL I NO IDES

MARG INULINOIDES

MARGINULINOIDES

MARGINULINOIDES

MARGI NULI NOIDES

MARGINULI NOIDES

MARGI NULINOIDES

MA RGI NUL I NOIDES

MARG I NUL I NO I DES

MARGINULINOIDES

MARGINULINOIDES

MARGI NULINOIDES

MARG INUL I NOIDES

MA RG I NULI NO IOES

MARG I NUL I NOIDES

MARGINULINOIDES

MARGINULINOIDES

MARGINUL I NOIDES

MARGINULINOIDES

MARG I NULI NO I DES

MARG INUL I NOIDES

MARGINUL I NO IDES

MARGINULINOIDES

MARGINULI NOIDES

GLABRA OBESA

GLABRA OBESA

PERPROCERA

PLANATA

PL ANATA

PLANATA

PLANATA

PL ANATA

PLANATA

PLANATA

PL ANATA

PL ANATA

PLANATA

PLANATA

PLANATA

PLANATA

PLANATA

STRIATULA

STRIATULA

STRIATULA

STRIATULA

SUBACULEATA GLABRATA

SUEACULEATA GLABRATA

SUEACULEATA GLABRATA

SUEACULEATA GLABRATA

SUEACULEATA GLABRATA

TENUIS

TENUIS

TENUIS

TENUIS

TENUIS

TENUIS

TENUIS

VILLA

DENSICOSTATA

MARGINULINOIDES

MARGINULI NOIDES

MA RG I NUL INOIDES

MARG I NULI NOIDES

MARG I NULI NO IOES

MARGINUL INOIDES

SUBACULEATA GLABRATA

SUEACULEATA GLABRATA

SUEACULEATA GLABRATA

SUEACULEATA GLABRATA

SUEACULEATA GLABRATA

SUEACULEATA GLABRATA

SUEACULEATA GLABRATA

SUEACULEATA GLABRATA

SUEACULEATA GLABRATA

SUBACULEATA GLABRATA

SUEACULEATA GLABRATA

SUEACULEATA GLABRATA

SUBACULEATA GLABRATA

SUEACULEATA GLABRATA

SUEACULEATA GLABRATA

Locality

NE GULF OF MEXICO

NE GULF OF MEXICO

FLORIOA KEYS

NE GULF OF MEXICO

MISSISSIPPI DELTA

NE GULF OF MEXICO 


\section{Publication}

20156 PFLUM FRERICHS 1976 20157 PFLUM FRERICHS 1976 20158 PFLUM FRERICHS 1976 20159 PFLUM FRERICHS 1976 20160 PFLUM FRERICHS 1976 20161 PFLUM FRERICHS 1976 20162 PFLUM FRERICHS 1976 20163 PFLUM FRERICHS 1976 20164 PFLUM FRERICHS 1976 20165 PFLUM FRERICHS 1976 20166 PFLUM FRERICHS 1976 20167 PFLUM FRERICHS 1976 20168 PFLUM FRERICHS 1976 20169 PFLUM FRERICHS 1976 20170 PFLUM FRERICHS 1976 20171 PFLUM. FRERICHS 1976 20172 PFLUM FRERICHS 1976 20173 PFLUM FRERICHS 1976 20174 PFLUM FRERICHS 1976 20175 PFLUM FRERICHS 1976 20176 PFLUM FRERICHS 1976 20177 PFLUM FRERICHS 1976 20178 PFLUM FRERICHS 1976 20179 PFLUM FRERICHS 1976 20180 PFLUM FRERICHS 1976 20181 PFLUM FRERICHS 1976 20182 PFLUM FRERICHS 1976 20183 PFLUM FRERICHS 1976 20184 PFLUM FRERICHS 1976 20185 PFLUM FRERICHS 1976 20186 PFLUM FRERICHS 1976 20187 PFLUM FRERICHS 1976 20188 PFLUM FRERICHS 1976 20189 PFLUM FRERICHS 1976 20190 PFLUM FRERICHS 1976 20191 PFLUM FRERICHS 1976 20192 PFLUM FRERICHS 1976 20193 PFLUM FRERICHS 1976 20194 PFLUM FRERICHS 1976 20195 PFLUM FRERICHS 1976 20196 PFLUM FRERICHS 1976 20197 PFLUM FRERICHS 1976 20199 PFLUM FRERICHS 1976 20199 PFLUM FRERICHS 1976 20200 PFLUM FRERICHS 1976 20201 PFLUM FRERICHS 1976 20202 PFLUM FRERICHS 1976 20203 PFLUM FRERICHS 1976 20204 PFLUM FRERICHS 1976 20205 PFLUM FRERICHS 1976 20206 PFLUM FRERICHS 1976 20207 PFLUM FRERICHS 1976 20208 PFLUM FRERICHS 1976 20209 PFLUM FRERICHS 1976 20210 PFLUM FRERICHS 1976 20211 PFLUM FRERICHS 1976 20212 PFLUM FRERICHS 1976 20213 PFLUM FRERICHS 1976 20214 PFLUM FRERICHS 1976 20215 PFLUM FRERICHS 1976 20216 PFLUM FRERICHS 1976 20217 PFLUM FRERICHS 1976 20218 PFLUM FRERICHS 1976 20219 PFLUM FRERICHS 1976 20220 PFLUM FRERICHS 1976 20221 PFLUM FRERICHS 1976
20222 PFLUM FRERICHS 1976 20222 PFLUM FRERICHS

20224 NORTON 1930

20225 POST 1951

20226 NORTON 1930

20227 CUSHMAN $1922 \mathrm{~A}$

20228 DAVIS 1956

20229 SHIFFLETT 1961

20230 LEHMANN 1957

20231 SHIFFLETT 1961

20232 SEGURA 1963

20233 PHLEGER LANKFORD 1957

20234 BANDY 1954

20235 BANDY 1954

20236 KORNFELD 1931

20237 PARKER PHLEGER PEIRSON 1953 20238 BANDY 1954

20239 AYALA-CASTANARES SEGURA 1968 20240 BANDY 1954

20241 PARKER PHLEGER PEIRSON 1953 20242 PARKER PHLEGER PEIRSON 1953
20243 PARKER PHLEGER PEIRSON 1953 20243 PARKER PHL

20245 KORNFELD 1931

20246 PARKER PHLEGER PEIRSON 1953 20247 POST 1951

20248 SHENTON 1957

20249 KORNFELD 1931

20250 PARKER PHLEGER PEIRSON 1953
Generic Name

MA RG I NUL INOPS IS MARGINUL INOPSIS MARGINUL INOPS IS MARGINUL INOPSIS MARG I NUL INOPSIS MARG INUL INOPS IS MARG INUL INOPSIS MARGINUL INOPS IS MARGINUL INOPSIS MARSI PELLA MARS I PELLA MARSIPELLA MARSIPELLA

MARS IPELLA

MARS I PELLA

MARSIPELLA

MARTINOTTIELLA

MARTINOTTIELLA

MART I NOTTIELLA

MARTINOTTIELLA

MART INOTTI ELLA

MARTINOTTIELLA

MARTINOTTIELLA

MARTINOTTIELLA

MARTINOTTIELLA

MART I NOTTIELLA

MARTINOTTIELLA

MART INOT TIELLA

MARTINOTTIELLA

MART INOTTIELLA

MARTINOTTIELLA

MARTINOTTIELLA

MARTINOTTIELLA

MARTINOTTIELLA

MART INOTTIELLA

MARTINOTTIELLA

MARTINOTTIELLA

MARTI NOTTIELLA

MARTINOTTIELLA

MART INOT TI ELLA

MARTINOTTIELLA

MARTINOTTIELLA

MART I NOT TIELLA

MARTINOTIIELLA

MARTI NOT TIELLA

MARTINOTTIELLA

MART INOTTIELLA

MART INOTTIELLA

MARTINOTTIELLA

MART INOTTIELLA

MART INOTTIELLA

MART INOTTIELLA

MART I NOTTIELLA

MARTINOTTIELLA

MARTINOTTIELLA

MARTINOTTIELLA

MARTINOT TIELLA

MARTINOTTIELLA

MARTINOT TIELLA

MARTINOTTIELLA

MART I NOTTIELLA

MART INOTIIELLA

MARTINOTTIELLA

MART INOTIIELLA

MARTINOTTIELLA

MART I NOTTIELLA

MART INOTTIELLA

MASSILINA

MASS I L INA

MASSILINA

MASSILINA

MASSILINA

MASSILINA

MASSILINA

MASSILINA

MASSILINA

MASSILINA

MASS ILINA

MASS ILINA

MASSILINA

MASSILINA

MASSILINA

MASSILINA

MASSILINA

MASS ILINA

MASSILINA

MASSILINA

MASSILINA

MASSILINA

MASSILINA

MASSILINA

MASSILINA

MASSILINA

MASSILINA
Specific Name

SUEACULEATA GLABRATA SUEACULEATA GLABRATA

SUEACULEATA GLABRATA

SUEACULEATA GLABRATA

SUEACULEATA GLABRATA

SU EACULEATA GLABRATA

SUEACULEATA GLABRATA

SUEACULEATA GLABRATA

SUEACULEATA GLABRATA

EL ONGATA

EL ONGATA

EL ONGATA

EL ONGATA

EL CNGATA

EL CNGATA

EL CNGATA

COMMUNIS

CONMUNIS

CONMUNIS

OC CIDENTALIS

OCCIDENTALIS

OC CIDENTALIS

OC CIDENTALIS

OC CIDENTALIS

OC CIDENTALIS

OC CIDENTALIS

OC CIDENTALIS

OC CIDENTALIS

OCCIDENTALIS

OC CIDENTALIS

OC CIDENTALIS

OC CIDENTALIS

OC CIDENTALIS

OC CIDENTALIS

OC CIDENTALIS

OC CIDENTALIS

OC CIDENTALIS

OCCIDENTALIS

OC CIDENTALIS

OC CIDENTALIS

OC CIDENTALIS

OC CIDENTALIS

OC CIDENTALIS

OCCIDENTALIS

OC CIDENTALIS

OC CIDENTALIS

OC CIDENTALIS

OC CIDENTALIS

OC CIDENTALIS

OC CIDENTALIS

OC CIDENTALIS

OC CIDENTALIS

OC CIDENTALIS

OC CIDENTALIS

OC CIDENTALIS

OC CIDENTALIS

OC CIDENTALIS

OCCIDENTALIS

OC CIDENTALIS

OCCIDENTALIS

OC CIDENTALIS

OC CIDENTALIS

OC CIDENTALIS

OC CIDENTALIS

OC CIDENTALIS

OC CIDENTALIS

OC CIDENTALIS

AL VEOLINI FORM IS

ANAECTENS

ANAECTENS

CRENATA

CRENATA

IN AEQUAL IS

IN AEQUAL IS

PE RUVIANA

PERUVIANA

PE RUVI IANA

PE RUVI IANA

PE RUVIANA

PE RUVI ANA

PE RUVIANA

PE RUVIANA

PERUVIANA

PE RUVI ANA

PE RUVI IANA

PE RUVIANA

PE RUVIANA

PE RUV I ANA

PERUVIANA

PE RUVI ANA

PE RUVIANA

PE RUVIANA

PERUVIANA

PE RUVIANA

PE RUVIANA

Locality

Lat. Long.

NW GULF OF MEXICO

NW GULF OF MEXICO 


\section{Publication}

20251 PHLEGER 1950

20252 PARKER PHLEGER PEIRSON 1953 20253 PHLEGER 1965 A

20254 PARKER PHLEGER PEIRSON 195 20255 PARKER PHLEGER PEIRSON 1953 20256 PARKER PHLEGER PEIRSON 1953 20257 PHLEGER 1965 A

20258 PHLEGER 1965A

20259 PHLEGER LANKFORD 1957

20260 SEGURA 1963

20261 LEHMANN 1957

20262 PARKER PHLEGER PEIRSON 1953 20263 PARKER PHLEGER PEIRSON 195 20264 PARKER PHLEGER PEIRSON 1953 20265 PARKER PHLEGER PEIRSON 1953 20266 SHENTON 1957

20267 ANDERSEN 1961

20268 PFLUM FRERICHS 1976 20269 PFLUM FRERICHS 1976 20270 PFLUM FRERICHS 1976 20271 PFLUM FRERICHS 1976 20272 PFLUM FRERICHS 1976 20273 PFLUM FRERICHS 1976 20274 PFLUM FRERICHS 1976 20275 PFLUM FRERICHS 1976 20276 PFLUM FRERICHS 1976 20277 PFLUM FRERICHS 1976 20278 PFLUM FRERICHS 1976 20279 PFLUM FRERICHS 1976 20280 PFLUM FRERICHS 1976 20281 PFLUM FRERICHS 1976 20282 PFLUM FRERICHS 1976 20283 PFLUM FRERICHS 1976 20284 PFLUM FRERICHS 1976 20285 PFLUM FRERICHS 1976 20286 PFLUM FRERICHS 1976 20287 PFLUM FRERICHS 1976 20288 PFLUM FRERICHS 1976 20289 PFLUM FRERICHS 1976 20290 PFLUM FRERICHS 1976 20291 PFLUM FRERICHS 1976 20292 PFLUM FRERICHS 1976 20293 PFLUM FRERICHS 1976 20294 SHEPARD MOORE 1955 20295 LANKFORD 1959 20296 PHLEGER 1955B 20297 PHLEGER 1965 A 20298 WARREN 1957

20299 POAG 1976

20300 KANE $196 ?$

20301 PHLEGER 1954

20302 PHLEGER 1954

20303 PHLEGER 1954

20304 PHLEGER 1954

20305 PHLEGER LANKFORD 1957

20306 PHLEGER $1965 \mathrm{SC}$

20307 PHLEGER 1954

20308 KANE 1962

20309 WALDRON 1963

20310 PARKER PHLEGER PEIRSON 1953 20311 PARKER PHLEGER PEIRSON 1953 20312 PHLEGER 1956

20313 LEHMANN 1957 . 20314
20315 PARKER PHLEER PHLEGER PEIRSON 1953 20316 WANTLAND 1969

20317 POST 1951

20318 PARKER PHLEGER PEIRSON 1953 20319 POST 1951

20320 PARKER PHLEGER PEIRSON 1953 20321 PARKER PHLEGER PEIRSON 1953 20322 PHLEGER 1965A 20323 PHLEGER 1965 A 20324 PHLEGER 1965 A 20325 PHLEGER 1965A 20326 PHLEGER 1965A 20327 PHLEGER 1965 A 20328 PHLEGER 1965 A 20329 WARREN 1956 20330 BENDA PURI 1962 20331 BENDA PURI 1962 20332 LAMB 1972

20333 PHLEGER 1965 A

20334 BENDA PURI 1962

20335 PHLEGER 19658

20336 PHLEGER 19653

20337 PHLEGER 1965A

20338 ANDERSON 1968

20340 AYALA-CASTANARES 1963

20341 PHLEGER LANKFORD 1978

20342 PARKER PHLEGER PEIRSON 1953 20363 OTVOS 1378

20344 WALTON 1960

20345 LEROY HODGKINSON 1975
Generic Name

MASSILINA

MASSIL INA

MASSILINA

MASSILINA

MASSILINA

MASSILINA

MASSILINA

MASSILINA

MASSILINA

MASS ILINA

MASSILINA

MASS I L INA

MASS I LINA

MASSILINA

MELONIS

MELONIS

MELONIS

MELONIS

MELONIS

MELONIS

MELONIS

MELONIS

MELONIS

MELONIS

MELON IS

MELONIS

MELONIS

$M E L O N I S$

MELONIS

MELONIS

MELONIS

MELONIS

ME LON IS

MELONIS

MELONIS

MELONIS

MELONIS

MELONIS

MELONIS

MIL I AMMINA

MI LI AMM I NA

M I LI AMM I NA

MI LI AMMI NA

MIL I AMM INA

MI L I AMM I NA

MILI AMM I NA

M I LI AMM I NA

MI LI AMM I NA

MI LIAMM INA

I L I AMM I NA

M I LI AMM I NA

M I LI AMM I NA

M I L I AMM I NA

MI L I AMM I NA

MI L I AMM I NA

MIL I AMM I NA

MI L I AMM I NA

MI L I AMM I NA

MI LI AMMINA

MI LI AMMINA

MI L I AMM I NA

MI L I A MM I NA

MI LI AMM I NA

MI I AMM I NA

MIL I AMM I NA

M I L I AMM I NA

MI L I AMM I NA

MI LI AMM I NA

MI L I AMM I NA

MI L I AMM I NA

M I L I AMM I NA

MILI AMM INA

MI L I AMM INA

M I LI AMM I NA

MI L I AMM I NA

MI L I AMM INA

MI LI AMMINA

MI LI AMM INA

M I LI AMM I NA

IL I AMM INA

MIL I AMM INA

M I L I AMM I NA

M I L I AMM I NA

M I I AMM I NA

MI L I AMM I NA

MI L I AMM I NA

MI LI OL I NELL A
Specific Name

PERUVIANA

PERUVIANA

PRCTEA

PRCTEA

PROTEA

PRCTEA

PRCTEA

PRCTEA

PRCTEA

PRCTEA

PROTEA

QUADRANS

STLCKEYI

BARLEEANUS

BARLEEANUS

BARLEEANUS

BARLEEANUS

BARLEEANUS

BARLEEANUS

BARLEEANUS

BARLEEANUS

PONPILIOIDES

PONPILIOIDES

PONPILIOIDES

PONPILIOIDES

PONPILIOIDES

PONPILIOIDES

PONPILIOIDES

PONPILIOIDES

PONPILIOIDES

PONPILIOIDES

PONPILIOIDES

PONPILIOIDES

PONPILIOIDES

POMPILIOIDES

PONPILIOIDES

PONPILIOIDES

PONPILIOIDES

FUSCA

FUSCA

FUSCA

FUSCA

FUSCA

FUSCA

FUSCA

FUSCA
FUSCA

FUSCA

FUSCA

FUSCA

FUSCA

FUSCA

FUSCA

FUSCA

FUSCA

FUSCA

FUSCA

FUSCA

FUSCA

FUSCA

FUSCA

FUSCA

FUSCA

FUSCA

FUSCA

FUSCA

FU SCA

FUSCA

FUSCA

FUSCA

$F \cup S C A$
$F \cup S C A$

FUSCA

FU SCA

FUSCA

FUSCA

FUSCA

FUSCA

FUSCA

FUSCA

FUSCA

FU SCA

FUSCA

FUSCA

FUSCA

FUSCA

AN TARCTICA

Locality

Lat. Long.

CENTRAL TEXAS BAY

CORPUS CHRISTI BAY, TEXAS

TEXAS GULF COAST

TEXAS GULF COAST

TEXAS GULF COAST

ALLYN'S BIGHT, TEXAS

PASS CAVALLO, TEXAS

TEXAS GULF COAST

MATAMOROS, MEXICO

TEXAS GULF COAST

TEXAS GJLF COAST

TEXAS GULF COAST

TEXAS GULF COAST 
Publication

20346 OTVOS 1978 20347 PHLEGER 19658 20348 POST 1951

20349 BOCK 1976

20350 BOCK 1976

20351 BOCK 1976

20352 ANDERSEN 1961

20353 PHLEGER 1965 A

20355 WARREN 1957

20356 PHLEGER 1965 A

20357 PHLEGER 1965A

20358 PHLEGER 1965 A

20359 PHLEGER 1965 A

20360 PHLEGER 1965A

20361 PHLEGER 1965 A

20362 PHLEGER 1965A

20363 PHLEGER 1965 A

20365 PHLEGER 1965 A

20366 PHLEGER 1965 A

20367 PHLEGER 1965A

20368 PHLEGER 1965A

20369 PHLEGER 1965A

20370 AYALA-CASTANARES SEGURA 1968 20371 PHLEGER 1965 A

20372 PHLEGER 1965 A

20373 PFLUM FRERICHS 1976

20374 LEROY HODGKINSON 1975

20375 PFLUM FRERICHS 1976

20376 LYNTS PFISTER 196?

20377 ANDERSEN 1961

20378 CUSHMAN 1922 A

20379 BENDA PURI 1962

20380 NORTON 1930

20381 CUSHMAN 1930
20382 ANDERSEN 1961

20383 . BOCK 1976

20384 BOCK 1976

20385 BOCK 1976

20385 BOCK 1976
20386 BOCK 1976

20387 ANDERSEN 1961

20388 AYALA-CASTANARES 1963 20389 LOEP 1965

20390 ANDERSEN 1961

20391 PFLUM FRERICHS 1976

20392 PFLUM FRERICHS 1976

20393 PFLUM FRERICHS 1976

20394 PFLUM FRERICHS 1976

20395 PFLUM FRERICHS 1976

20396 PFLUM FRERICHS 1976

20397 PFLUM FRERICHS 1976

20398 PFLUM FRERICHS 1976

20399 PFLUM FRERICHS 1976

20400 PFLUM FRERICHS 1976

20401 ANDERSEN 1961

20402 PFLUM FRERICHS 1976

20403 PFLUM FRERICHS 1976

20404 PFLUM FRERICHS 1976

20405 PFLUM FRERICHS 1976

20406 PFLUM FRERICHS 1976

20407 PFLUM FRERICHS 1976

20408 PFLUM FRERICHS 1976 20409 PFLUM FRERICHS 1076 20410 PFLUM FRERICHS 1976 20411 PFLUM FRERICHS 1976 20412 PFLUM FRERICHS 1976 20413 PFLUM FRERICHS 1976 20414 PFLUM FRERICHS 1976 20415 PFLUM FRERICHS 1976 20416. PFLUM FRERICHS 1976 20417 PFLUM FRERICHS 1976 20418 PFLUM FRERICHS 1976 20419 PFLUM FRERICHS 1976 20420 PFLUM FRERICHS 1976 20421 PFLUM FRERICHS 1976 20422 PFLUM FRERICHS 1976 20423 PFLUM FRERICHS 1976 20424 CUSHMAN $1922 \mathrm{~A}$

20425 BANDY 1954

20426 BANDY 1954

20427 BANDY 1956

20428 BANDY 1954 20429 BANDY 1956 20430 BANDY 1954 20431 BANDY 1954 20432 BANDY 1956 20433 BANDY 1956 20434 BANDY 1956 20435 BANDY 1956 20436 BANDY 1956 20437 BANDY 1956 20438 BANDY 1956 20439 BANDY 1956 20440 BANDY 1956
Generic Name

MI LIOL INELL A

MILIOL INELLA

MILIOL INELLA A

MILIOL INELLA

MILIOLI INELLA

MILIOLINELLA

MILIOL INELL A

MI L I OL I NELL A

MILIOL I NELLA A

MILIOLL INELLA

MILI OL I NELLA

MILIOL I NELL A

MILIOL INELLLA

MILIOL INELL A

MILIOL INELLA A

MILIIOL I NELL A

MILIOL INELLA

MILIOLINELLA

MI I IOL I NELL A

MI LIOL I NELL A

MILIOL INELLA A

MILIOLINELLA

MILIOLINELLA

MILIOLINELLA

MILI OL INELLA

MILIOL I NELLA

MI LIOL I NELL A

MI L I OL I NELL A

MONALYSIDIUM

MONALYSIDIUM

MONALYSIDIUM

MONALYS I DIUM

ROSALINA

NEOCONORBINA

NEOCONORBINA

NEOCONORBINA

NEOCONORBINA

NE OCONORBINA

NEOCONORBINA

EP ONIDES

EPONIDES

NEOEPONIDES

NEOEPONIDES

NEOEPONIDES

NEOEPONIDES

NE OE PONIDES

NEOEPONIDES

NE OEPONIDES

NE OEPONIDES

NEOEPONIDES

NE OE PONI DES

EPONIDES

NODELLLUM

NODELLUM

NODELLUM

NODELLUM

NODELL UM

NODELLUM

NODELLUM

NODELLUM

NODELLUM

NODELLUM

NODELLUM

NODELLUM

NODELLUM

NODELLUM

NODELLUM

NODELLUM

NODELLUM

NODELLUM

NODELLUM

NODELLUM

NODELLLUM

NODELLUM

NO DOBACULARIA

NODOBACULARI ELL A NODDBACULAR IELLA NODOBACULAR IELLA NODOBACULARIELLA NODOBACULARIELLA NODOBACULARIELLA NODOBACULARIELLA NO DOBACULAR I ELLA NODOBACULARIELLA NODOBACULAR IELLA NODOBACULAR IELLLA NODOBACULAR IELA NODOBACULAR I ELLA
NODOBACULAR IELLA NODOBACULAR IELLA NODOBACULAR IELLA NODOBACULAR IELLA NODOBACULARIELLA
Specific Name

CI RCULARIS

CI PCULARIS

CI RCULARIS

CI RCULARIS

FI CHTEL IANA

LAEIOSA

LAEIOSA

MI CROSTOMA

MI CROSTOMA

MI CROSTOMA

MICROSTOMA

MI CROS TOMA

MICROSTOMA

MI CROSTOMA

MI CROSTOMA

MI CROSTOMA

MI CROSTOMA

BLIQUINODA

B

OBLIQUINODA

OBLIQUINODA

OBLIQUINODA

OB LIQUINODA

OBLIQUINODA

OBLIQUINODA

OBLIQUINODA

SUBROTUNDA

SUBROTUNDA

SUBROTUNDA

SUEROTUNDA

WARRENI

POLITUM

POLITUM

POLITUM

POLITUM

FLCRIDENS IS

TERQUEMI

TERQUEMI

TERQUEMI

TERQUEMI

TERQUEM I

TERQUEMI

AN TILL ARUM

ANTILLARU

CORYELLI

CORYELLI

CORYELLI

CORYELLI

CORYELLI

CORYELLI

CORYELLI

CORYELLI

CORYELLI

CORYELLI

REGULAR IS

MENBRANAC EUM

MENBRANACEUM

MENBRANAC EUM

MENBRANAC EUM

MENBRANAC EUM

MENBRANAC EUM

MEMBR ANACEUM

MEMBRANACEUM

MENBRANACEUM

MENBRANAC EUM

MEMBRANAC EUM

MEMBRANAC EUM

MEMBRANACEUM

MENBRANAC EUM

MENBRANAC EUM

MENBRANACEUM

MEMBRANAC EUM

MENBRANACEUM

MENBRANAC EUM

MENBRANACEUM

MEMBRANAC EUM

ME MBR ANAC EUM

TI BIA

ATLANTICA

ATLANTI ICA

ATLANTICA

ATLANTICA

ATLANTICA

ATLANTICA

ATLANTICA

AT LANTI I A

AT LANTICA

ATLANTICA

ATLANTICA

ATLANTICA

ATLANTICA

ATLANTICA

AT LANTICA

AT LANTICA

Locality

Lat. Long.

L. PONTCHARTRAIN, LA.

WHITEWATER B.. SW FLA.

SOUTH TEXAS COAST

NE GULF OF MEXICO

NE GULF OF MEXICO

NE GULF OF MEXICO 
Publication

20441 BANDY 1956

20442 BANDY 1956

20444 BANDY 1956

20444 BANDY 1956

20445 BANDY 1956

20447 BANDY 1956

20448 BANDY 1956

20449 BANDY 1956

20450 BANDY 1956

20451 BENDA PURI 1962

20452 KELLOUGH 1956

20453 PARKER 1954

20454 PARKER 1954

20455 BOCK 1976

20456 PARKER 1954

20457 PARKER 1954

20458 LUDWICK WAL
20459 PARKER 1954

20460 PARKER 1954

20461 PARKER 1954

20462 PARKER 1954

20463 PARKER 1954

20464 PARKER 1954

20465 PARKER 1954

20466 PARKER 1954

20467 PARKER 1954

20468 PARKER 1954

20469 DAVIS 1964

20470 SHIFFLETT 1961

20471 ANDERSEN 1961

20472 BANDY 1956

20473 BANDY 1956

20474 BANDY 1956

20475 BANDY 1956

20476 CUSHMAN 1923

20477 ANDERSEN 1961

20478 ANDERSEN 1961

20479 CUSHMAN 1923

20480 PFLUM FRERICHS 1976

20481 WARREN 1956

20482 WARREN 1957

20483 CUSHMAN 1923

20484 CUSHMAN 1923

20485 CUSHMAN 1923

20486 CUSHMAN 1923

20487 CUSHMAN 1923

20488 CUSHMAN 1923

20489 CUSHMAN 1923

20490 CUSHMAN 1923

20491 CUSHMAN 1923

20492 CUSHMAN 1923

20493 CUSHMAN 1923

20494 CUSHMAN 1923

20495 CUSHMAN 1923

20496 CUSHMAN 1923

20497 CUSHMAN 1923
20498 CUSHMAN 1923

20498 CUSHMAN 1923
20499 CUSHMAN 1923

20500 LEROY HODGKINSON 1975

20501 CUSHMAN 1923

20502 CUSHMAN 1923

20503 CUSHMAN 1923

20504 ANDERSEN 1961

20505 CUSHMAN 1923

20506 CUSHMAN 1923

20507 CREAGER 1958

20508 PARKER 1954

20510 PARKER 1954

20511 PARKER 1954

20511 PARKER 1954

20513 PARKER 1954

20514 PARKER 1954

20515 PARKER 1954

20516 PARKER 1954

20517 CREAGER 1958

20518 CUSHMAN 1923

20519 CUSHMAN 1923

20520 PFLUM FRERICHS 1976

20521 PFLUM FRERICHS 1976

20522 PFLUM FRERICHS 1976

20523 PHLEGER 1951A

20524 PHLEGER 1951A

20525 ANDERSEN 1961

20526 CUSHMAN 1923

20527 CUSHMAN 192

20528 BOCK 1976

20529 PHLEGER 1951 A

20530 PHLEGER 1951 A

20531 PHLEGER 1951A

20532 PHLEGER 1951A

20533 PHLEGER 1951 A

20534 PHLEGER 1951 A
20535 PHLEGER $1951 \mathrm{~A}$
Generic Name

NODOBACULAR IELLA NODOBACULAR I ELLA

NO DOBACULAR IELLA

NODOBAC ULAR IELLA

NO DOBACUL ARIELL A

NODOBACULAR IELLA

NODOBACULARIELLA

NODOBACULAR I ELLA

NODOBACULAR IELLA

NODOBAC ULAR IELLA

NODOBACULAR IELLA

NODOBACULARIELLA

NODOBAC ULAR IELLA

NODOBACULAR IELL

NO DOBAC UL AR I ELL A

NO DOBACULAR IELLA

NODOBACULAR I ELLA

NO DOBACULARI ELLA

NODOBACULAR IELLA

NODOBA CULAR IELLA

NO DOBAC ULAR I ELLA

NODOBACULAR IELLA

NODOBACULAR IELLA

NODOBACULAR IELLA

NODOBAC ULAR IELLA

NODOBACULAR IELLA

NODOBA CULAR I ELLA

NO DOBA CULAR I ELL

NODOBACULARIELLA

NODOBAC ULAR IELLA

NODOBACULARIELLA

NO DOBACULARIELLA

NO DOBACULARIELLA

NO DOBA C ULARIELL

NODOBACULARIELLA

DENTAL I NA

NODOSARIA

NODOSAR I A

NODOSARIA

DENTAL INA

NODOSARI A

NODOSARIA

NODOSARIA

NODOSAR I A

NODOSARIA

NODOSARI A

NODOSAR I A

DE NT AL I NA

DENTAL INA

DENTALINA

DENTAL INA

DENTALINA

DENTAL I NA

DENT AL I NA

DENTALINA

NODOSARIA

DENTALINA

DENTALINA

DENTAL INA

DENTALINA

DENTALINA

DENTALINA

DENTAL INA

NODOSARIA

NODOSARIA

NODOSAR I A

NODOSARI A

NODOSARIA

NODOSAR I A

NODOSAR IA

NODOSAR I A

NODOSAR I A

NODOSARIA

NODOSAR I A

NODOSARIA

NODOSARI A

NODOSARI A

PSEUDONODOSARIA

PSEUDONODOSARIA

NO DOSARI A

NODOSAR I A

NODOSARIA

NODOSARIA

NODOSAR I A

NODOSARIA

NO DOSAR I A

NODOSAR IA

NODOSAR IA

NODOSAR I A

NODOSARIA

NODOSARI I

NODOSARIA

NODOSARIA

NODOSARIA

NODOSARIA
Specific Name

A T LANTI CA

AT LANTI CA

ATLANTICA

AT LANTI CA

AT LANTI CA

A T LANTI CA

A T LANT I CA

A T LANTICA

A T LANT I CA

AT LANTICA

AT LANTI CA

CASSIS

CASSIS

CASSIS

CASSIS

CASSIS

CASSIS

CASSIS

CASS IS

CASS IS

CASSIS

CASSIS

CASSIS

CASS IS

CASSIS

CASSIS

CASSIS

CASSIS

CASSIS

CONVEXIUS CULA

MEXI CANA

MEXI CANA

MEXICANA

MEXI CANA

ADVENA

AL BATROSS I

ATLANTICA

A T LANTI CA

CALOMORPHA

CATESBYI

CA TESBY I

CONATULA

COMATULA

COMATULA

COMATULA

COMATULA

COMMUNIS

COMMUNIS

COMMUNIS

COMMUNIS

CONSOBR INA EMACIATA

CONSOBRINA EMACIATA

CONSOBR INA EMACIATA

CONSOBRINA EMACIATA

FARCIMEN

FILIFORMIS

FI LIFORMI S

FI LIFORMIS

FL INT I I

FL INTII

FL INTII

FL INTI

FUSTA

HIRSUTA ACULEATA

HIRSUTA ACULEATA

HISPI DA

$H$ I SPIDA

H I SPIDA

HI SPIDA

HI SPIDA

HISPIDA

HISPIDA

HISPIDA

HISPIDA

HISPIDA

IN TERCELL UL AR IS

TORRI DA

TORRI DA

LA MNUL I FERA

LAMNULIFERA

LANNULIFERA

PYFULA

PYRULA

PYRULA

PYRULA

PYRULA

PYRULA

PYRULA

PYRULA

PYRULA

PYRULA

PYRULA

PYRULA

PYRULA

Locality

NE GULF OF MEXICO

NE GULF OF MEXICO

MIS SISSIPP I DELTA

NE GULF OF MEXICO

NE GULF OF MEXICO

NE GULF OF MEXICO

NE GULF OF MEXICO 


\section{Publication}

20536 PHLEGER 1951A 20537 PHLEGER 1951A 20538 PHLEGER 1951A 20539 PHLEGER 1951A 20540 PHLEGER 1951A 20541 CUSHMAN 1923 20542 CUSHMAN 1923 20543 CUSH MAN 1923 20544 CUSHMAN 1922A 20545 CREAGER 1958 20546 PHLEGER 1951A 20547 PHLEGER 1951A 20548 CUSHMAN 1923 20549 CUSHMAN 1923 20550 CUSHMAN 1923 20551 CUSHMAN 1923 20552 CUSHMAN 1923 20553 CUSHMAN 1923 20554 PHLEGER 1951 A 20555 PHLEGER 1951A 20556 PHLEGER $1951 \mathrm{~A}$ 20557 PHLEGER $1951 \mathrm{~A}$ 20558 PHLEGER 1951A 20559 PHLEGER 1951A 20560 PHLEGER 1951A 20561 PHLEGER 1951A 20562 PHLEGER $1951 \mathrm{~A}$ 20563 PHLEGER 1951 A 20564 PHLEGER 1951A 20565 PHLEGER $1951 \mathrm{~A}$ 20566 PHLEGER 1951A 20567 PHLEGER $1951 \mathrm{~A}$ 20568 PHLEGER 1951A 20569 PHLEGER $1951 \mathrm{~A}$ 20570 PHLEGER 1951A 20571 CUSHMAN 1923 20572 CUSHMAN 1923 20573 CUSHMAN 1923
20574 KELLOUGH 1956 20575 VAUGHAN 1918 20576 CREAGER 1958 20577 CUSHMAN 1923 20579 CREAGER 1958 20580 CUSHMAN 1923 20581 CUSHMAN 1923 20582 BANDY 1956 20583 BANDY 1956 20584 BANDY 1956 20585 BANDY 1956 20586 BANDY 1956 20587 BANDY 1956 20588 ANDERSEN 1961 20589 CREAGER 1958 20590 CREAGER 1959 20592 SHENTON 1957 20593 CREAGER 1958 20593 CREAGER 1958

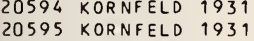
20596 PHLEGER 1951A 20597 PHLEGER 1951A 20598 PHLEGER 1951 A 20599 PHLEGER 1951A 20600 PHLEGER 1951A 20601 PHLEGER 1951 A 20602 PHLEGER $1951 \mathrm{~A}$ 20603 KORNFELD 1931 20604 PHLEGER $1951 \mathrm{~A}$ 20605 PHLEGER 1951A 20606 PHLEGER 1951A 20607 KORNFELD 1931 20608 PHLEGER 1951A 20609 PHLEGER $1951 \mathrm{~A}$ 20610 PHLEGER 1951A 20611 KORNFELD 1931 20612 PHLEGER 1951A 20613 BOCK 1976 20614 OTVOS 1978 20615 BOCK 1976 20616 PARKER 1954 20617 PARKER 1954 20618 PARKER 1954 20619 PARKER 1954 20620 PARKER 1954 20621 PARKER 1954 20622 PHLEGER 1956 20623 PARKER 195 20624 PARKER 1954 20625 PARKER 1954 20626 PARKER 1954 20627 PARKER 1954 20628 PARKER 1954 20629 PARKER 1954
20630 LUDWICK WALTON 1957
Generic Name

NODOSARIA

NODOSAR I A

NODOSARIA

NODOSARIA

NODOSARIA

NODOSARIA

NODOSARIA

PSEUDONODOSARIA

AMPHI CORYNA

NODOSAR IA

NODOSAR I A

NODOSARIA

NODOSARI A

NODOSARI A

NODOSAR I A

NODOSARIA

NODOSAR I A

NODOSARIA

NODOSARIA

NODOSARIA

NODOSARI A

NODOSARIA

NODOSARIA

NODOSARIA

NODOSAR IA

NODOSAR I A

NODOSAR IA

NODOSAR I A

NODOSARIA

NODOSARIA

NODOSARIA

NODOSAR I A

NODOSARIA

NODOSAR I A

DENTAL INA

DENTALINA

NODOSAR IA

NODOSARIA

NODOSARI A

NODOSAR I A

NODOSAR IA

NODOSARIA

NODOSAR IA

NODOSARIA

NODOSARI A

NONION

NONION

NONION

NONI ON

NONION

NONION

ME LON IS

HAYNESINA

HAYNESINA

HAYNES INA

HAYNESINA

HAYNESINA

HAYNESINA

HAYNESINA

HAYNESINA

HAYNESINA

HAYNESINA

HAYNESINA

HAYNES INA

HAYNES INA

HAYNESINA

HAYNESINA

HAYNESINA

HAYNESINA

HAYNESINA

HAYNES INA

HAYNES INA

HA YNESINA

HAYNESINA

HAYNESINA

HAYNESINA

HAYNESINA

HA YNESINA

HA YNES I NA

NONION

NONION

NONION

NONION

NONION

NONION

NONION

NONION

NONION

NONION

NONION

NONION

NONION

NONION

NONION
Specific Name

Locality

PYRULA

PYFULA

PYRULA

PYRULA

PYRULA SEMIRUGOSA

PYRULA SEMIRUGOSA

PYRULA SEMIRUGOSA

SUEANNULATA

SE FARANS

SUBL INE AT A

SUELINEATA

SUELINEATA

SUBL INEATA

SUELINEATA

SUELINEAT A

SUELINEATA

SUELINEAT A

SUBLINEATA

SUEL INEATA

SUELINEATA

SUELINEATA

SUBLINEATA

SUBL INEATA

SUBLINEATA

SUELINEATA

SUEL INEATA

SUELINEATA

SUEL INEATA

SUBLINEATA

SUELINEATA

SUEL INEATA

SUBSOLUTA

SUESOLUTA

VERTEBRAL IS

VERTEBRALIS

VERTEBRAL IS

ALEATROSS I

ALEATROSSI

ALEATROSSI

ALEATROSSI

ALBATROSS

ALBATROSS

AFFINIS

AFFINIS

AFFINIS

AFFINIS

AFFINIS

AFFINIS

BARLEEANUS

GERMANICA

GE RMANICA

GEFMANICA

GERMANICA

GERMANICA

GE RMAN I CA

GE RMAN I CA

GE RMANICA

GE FMANI CA

GE RMANICA

GE FMANICA

GE RMANI CA

GE FMANI CA

GERMANICA

GERMAN I CA

GERMANICA

GERMANI CA

GERMANI CA

GERMANI CA

GE RMANICA

GERMANI CA

GE FMANICA

GERMANI CA

GE RMANI C A

GERMANICA

GERMAN I CA

FORMOSUM

FORMO SUM

FO RMOSUM

FO FMOSUM

FO FMOSUM

FORMOSUM

FORMOSUM

FORMOSUM

FORMOSUM

FORMOSUM

FORMOSUM

FORMOSUM

FORMOSUM

FORMOSUM

FORMOSUM TOR TUG AS

NW GULF OF MEXICO NW GULF OF MEXICO NW GULF OF MEXICO NW GULF OF MEXICO NW GULF OF MEXICO NE GULF OF MEXICO NE GULF OF MEXICO NE GULF OF MEXICO 


\section{Publication}

20631 PARKER 1954 20632 PARKER 1954 20633 LEHMANN 1957 20634 LEHMANN 1957 20635 PHLEGER 1951 A 20636 PHLEGER 1951A
20637 PHLEGER 1951 A 20638 PHLEGER $1951 \mathrm{~A}$ 20639 PHLEGER 1951 A 20640 PHLEGER 1951A 20641 PHLEGER 1951A 20642 PHLEGER 1951A 20643 PHLEGER 1951A 20644 PHLEGER $1951 \mathrm{~A}$ 20645 KORNFELD 1931 20646 NORTON 1930 20647 CUSHMAN 1930 20648 PHLEGER 1951 A 20649 AYALA-CASTANARES 1963 20650 BENDA PURI 1962 20651 PHLEGER 1951 A 20652 PHLEGER 1951A 20653 PHLEGER 1951A 20654 PHLEGER $1951 \mathrm{~A}$ 20655 PHLEGER 1951A 20656 PHLEGER $1951 \mathrm{~A}$ 20657 PHLEGER 1951A 20658 PHLEGER $1951 \mathrm{~A}$ 20659 PHLEGER $1951 \mathrm{~A}$ 20660 PHLEGER 1951A 20661 PHLEGER $1951 \mathrm{~A}$ 20662 PHLEGER 1951A 20663 PHLEGER 1951A 20664 PHLEGER $1951 \mathrm{~A}$ 20665 POST 1951 20666 LEHMANN 1957 20667 POST 1951

20668 PHLEGER $1951 \mathrm{~A}$ 20669 PHLEGER $1951 \mathrm{~A}$ 20670 PHLEGER 1951 A 20671 PHLEGER $1951 \mathrm{~A}$ 20672 PHLEGER $1951 \mathrm{~A}$ 20673 PHLEGER 1951A 20674 PHLEGER $1951 \mathrm{~A}$ 20675 PHLEGER $1951 \mathrm{~A}$ 20676 PHLEGER 1951A 20677 PHLEGER 1951A 20678 PHLEGER 1951A 20679 PHLEGER 1951A 20680 PHLEGER 1951B 20681 LUDHICK WALTON 1957

20682 PHLEGER 1951A 20683 PHLEGER $1951 \mathrm{~A}$ 20684 PHLEGER 1951A 20685 PHLEGER $1951 \mathrm{~A}$ 20686 PHLEGER $1951 \mathrm{~A}$ 20687 PHLEGER 1951A 20688 PHLEGER 1951 A 20689 PHLEGER 1951A 20690 PHLEGER 1951A 20691 PHLEGER 1951A 20692 PHLEGER $1951 \mathrm{~A}$ 20693 PHLEGER 1955A 20694 PHLEGER $1955 \mathrm{~A}$ 20695 PHLEGER 1955 A 20696 PHLEGER 1951A 20697 PHLEGER 1951 A 20698 PHLEGER 1951A 20699 PHLEGER $1951 \mathrm{~A}$ 20700 PARKER 1954

20701 PARKER 1954

20702 PARKER 1954 20703 PARKER 1954 20704 PHLEGER $1951 \mathrm{~B}$ 20705 PHLEGER 1951A 20706 PHLEGER $1951 \mathrm{~A}$ 20707 PHLEGER 1951A 20708 KELLOUGH 1956 20709 KELLOUGH 1956 20710 PARKER 1954 20711 PARKER 1954 20712 PARKER 1954 20713 PARKER 1954

20714 PARKER 1954

20715 CREAGER 1958

20716 NORTON 1930

20717 PHLEGER LANKFORD 1978

20718 BENDA PURI 1962

20719 CREAGER 1958

20720 CREAGER 1958

20721 OTVOS 1978

20722 PHLEGER 1956

20723 PARKER 1954

20724 PARKER PHLEGER PEIRSON 195

20725 PARKER PHLEGER PEIRSON 1953
Generic Name

NONION

NONION

HAYNES I NA

ELPHIDIUM

NONIONELLA

NONIONELLA

NONIONELLA

NONIONELLA

NONIONELLA

NONIONELLA

NONIONELLA

NONIONELLA

NONI ONELLA

NONIONELLA

NONIONELLA

NONIONELLA

NONIONELLA

NONI ONELLA

NONIONELLA

NONI ONELL LA

NONIONELLA

NONIONELLA

NONIONELLA

NONIONELLA

NONIONELLA

NONIONELLA

NONI ONELLA

NONIONELLA

NONIONELL LA

NONIONELLA

NONIONELLA

NONIONELLA

HA YNESINA

HAYNESINA

HAYNESINA

MELON I

MELONIS

MELONIS

MELONIS

MELONIS

MELONIS

MELONIS

MELONIS

MELONIS

MELONIS

MELONIS

MELONIS

MELONIS

MELONIS

MELONIS

ME LONIS

MELONIS

MELONIS

MELONIS

MELONIS

MELONIS

MELONIS

MELONIS

MELONIS

MELONIS

MELONIS

MELONIS

MELONIS

MELONIS

MELONIS

MELONIS

$M E L O N I S$

MELONIS

MELONIS

MELONIS

MELONIS

MELONIS

MELONIS

MELONIS

MELONIS

MELONIS

MELONIS

MELONIS

MELONIS

MELONIS

MELONIS

MELONIS

MELONIS

FLORILUS

NONIONELLA

NONI ONELLA

NONI ONEL LA

NONIONELLA

NONIONE LLA

NONI ONELL LA

NONI ONELLA

NONIONELLA
Specific Name

FORMOSUM

FO RMOSUM

GERMANICA

GRATELOUPI

GRATEL OUP

GR ATEL OUPI

GRATELOUP

GR ATEL OUP

GRATEL OUP I

GRATELOUPI

GR ATELOUP I

GRATELOUP I

GR A TE LOUP I

GRATELOUP I

GR ATELOUP

GRATELOUP

GRATELOUP

GRATELOUP

GRATEL OUP

GRATELOUP I

GRATELOUP I

GR ATELOUP

GR ATELOUP

GRATELOUPI

GR ATEL OUP I

GRATEL OUP I

GRATELOUP

GR ATE LOUP

GRATELOUPI

GRATEL OUP I

PAUCILOCULA

PAUCILOCULA

PALCILOCULA

POMPILIOIDES

POMPILIOIDES

POMPILIOIDES

PONPILIOIDES

POMPILIOIDES

PONPILIOIDES

PONPILIOIDES

PONPILIOIDES

POMPILIOIDES

PONPILIOIDES

PONPILIOIDES

PONPILIOIDES

PORPILIOIDES

POMPILIOIDES

PONPILIOIDES

PONPILIOIDES

PORPILIOIDES

PONPILIOIDES

POMPILIOIDES

PONPILIOIDES

PONPILIOIDES

POMPILIOIDES

PONPILIOIDES

PONPILIOIDES

PONPILIOIDES

PONPILIOIDES

PONPILIOIDES

PORPILIOIDES

POMPILIOIDES

POMPILIOIDES

PONPILIOIDES

PONPILIOIDES

PONPILIOIDES

PONPILIOIDES

PONPILIOIDES

POMPILIOIDES

POMPILIOIDES

PONPILIOIDES

PONPILIOIDES

POMPILIOIDES

POMPILIOIDES

PONPILIOIDES

PORPILIOIDES

PONPILIOIDES

PORPILIOIDES

POMPILIOIDES

POMPILIOIDES

POMPILIOIDES

SCAPHUM

GE RMANI CA

AT LANTICA

ATLANTICA

ATLANTICA

A TLANTICA

A T LANTICA

AT LANTI I A

ATLANTICA

\section{Locality}

NE GULF OF MEXICO

NE GULF OF MEXICO

TEXAS GULF COAST

TEXAS GULF COAST

$\mathrm{NH}$ GULF OF MEXICO

NH GULF OF MEXICO

NH GULF OF MEXICO

NW GULF OF MEXICO 
Publication

20726 PHLEGER 1956 20727 PHLEGER 1956 20728 PARKER 1754 20729 PHLFGER 1956 20730 BANDY 1956 20731 BANDY 1956 20732 SANDY 1956 20733 BANDY 1956 20734 BANDY 1956 20735 PARKER 1954 20736 BANDY 1954 20737 BANDY 1956 20738 BANDY 1954 20739 WARREN 1956 20740 LOEP 1965 20741 WALTON 1964

20742 KELLOUGH 1956

20743 PHLEGER 19658

20744 KELLOUGH 1956

20745 BENDA PURI 1962

20746 BANDY 1954

20747 AYALA-CASTANARES SEGURA 1968 20748 BANDY 1354

20749 BANDY 1954

20750 KELLOUGH 1956

20751 KELLOUGH 1956

20752 KELLOUGH 1956

20753 KELLOUFH 1956

20754 BANDY 1956

20755 AYALA-CASTANARES 1963

20756 BANDY 1954

20757 LOEP 1965

20758 WALTON 1960

20759 ANDERSON 1968

20760 KELLOUGH 1956

20761 PHLEGER 19658

20762 PHLEGEP 1956

20763 PARKER PHLEGER PEIRSON 1953

20764 PARKER 1954

20765 PARKER 1954

20766 PARKER 1954

20767 PARKER 1954

20768 PARKER 1954

20769 PARKER 1954

20770 PARKER 1954

20771 PARKER 1954

20772 PARKER 1954

20773 PARKER 1954

20774 PHLEGER LANKFORD 1957

20775 PHLEGER 1954

20776 PHLEGER 1955 A

20777 LUDWICK WALTON 1957

20778 PHLEGER 1954

20779 PHLEGER 1955 A

20780 PARKER PHLEGER PEIRSON 1953 20781 PARKER 1954

20782 PARKER 1954

20783 PARKER 1954

20784 BOCK 1975

20785 BOCK 1976

20786 PARKER 1954

20787 PARKER 1954

20788 BOCK 1976

20789 BOCK 1976

20790 BOCK 1976

20791 PARKER PHLEGER PEIRSON 1953

20792 CREAGER 1958

20793 PHLEGER 1951A

20794 PHLEGER 1951A

20795 PHLEGER 1951A

20796 PHLEGER 1951A

20797 PHLEGER 1951A

20798 PHLEGER 1951A

20799 PHLEGER 1951A

20800 PHLEGER 1951A

20801 BANDY 1956

20802 PARKER 1954

20803 BANDY 1956

20804 BANDY 1956

20805 PHLEGER 1951A

20806 PHLEGER 1951A

20807 PALIS 1964

20808 PHLEGER 1951 A

20809 PHLEGER 1951A

20810 PHLEGER 1951A

20811 PHLEGER 1951A

20812 PHLEGER 1951A

20813 PHLEGER 1951A

20814 PHLEGER 1951A

20815 PHLEGER 1951A

20816 LANKFORD 1959

20817 BANDY 1956

20818 BANDY 1956

20819 BANDY 1956

20820 BANDY 1956
Generic Name

NONIONELLA

NONI ONELLA

NONIONELLA

NONIONELLA

NONIONELLA

NONIONELLA

NONIONELLA

NONIONELLA

NONIONELLA

NONIONELLA

NONIONELLA

NONIONELLA

NONIONELLA

NONIONELLA

NONIONEL LA

NONIONELLA

NONIONELLA

NONIONELLA

NONIONELLA

NONI ONELLA

NONIONELLA

NONIONELLA

NONI ONELLA

NONIONELLA

NONI ONELLA

NONIONELLA

NONIONELLA

NONIONELLA

NONIONELLA

NONI ONELLA

NONIONELLA

NONI ONELLA

NONI ONELLA

NONI ONELLA

NONIONELLA

NONI ONELLA

NONIONELLA

NONIONELLA

NONIONELLA

NONIONELLA

NONIONELLA

NONI ONELLA

NONI ONELLA

NONI ONELLA

NONIONELLA

NONIONELLA

NONIONELLA

NONI ONELLA

NONIONELLA

NONI ONELLA

NONIONELLA

NONIONELLA

NONIONELLA

NONIONELLA

NONI ONELLA

NONIONELLA

NONIONELLA

NONIONELLA

NONIONEL LA

NONIONELLA

NONI ONEL LA

NONIONELLA

NONI ONELLA

NONIONELLA

NONI ONELLA

NONIONELLA

NEL LA

NONIONELLA

NONIONELLA

NONIONELLA

NONI ONELLA

NONIONELLA

NONIONELLA

NONIONELLA

NONI ONELLA

NONIONELLA

NONI ONELLA

NONI ONELLA

NONIONELLA

NONIONELLA

NONI ONELLA

NONIONELLA

NONI ONELLA

NONI ONELLA

NONIONELLA

NONIONELLA

NONIONELLA

NONI ONELLA

NONI ONELLA

NONIONELLA

NONI ONELLA

NONI ONELLA

NONIONELLA
Specific Name

Locality

A T LANTI CA

A T LANTICA

A TLANTICA

ATLANTICA

A TLANTI CA

A TLANTICA

A TLANTICA

A T LANTICA

A TLANTICA

A TLANTICA

AT LANTICA

A T LANTI CA

A TLANTICA

A T LANTICA

A TLANTICA

A TLANTICA

A TLANTICA

A TLANTICA

A T LANTI CA

ATLANTI CA

A T LANTI CA

ATLANTICA

A TLANTICA

A TLANTICA

A T LANTICA

A T LANTI CA

A TLANTICA

A T LAN I ICA

A T LANTICA

ATLANTICA

A TLANTICA

ATLANTICA

A TLANTICA

A T LANTI CA

AT LANTICA

A T LANTI CA

A T LANTICA

A TLANTICA

A T LAN I I CA

A TLANTICA

A T LANTICA

A TLANTI CA

A TLANTICA

A TLANTICA

A TLANTICA

AT LANTICA

A T LANTICA

A T LANTI CA

A TLANTI CA

A T LANTI CA

AT LANTICA

A TLANTICA

AT LANTICA

A TLANTICA

A T LANTICA

ATLANT

A TLANTICA
A TLANTI CA

ATLANTICA

ATLANTICA

A T LANTICA

A TLANTICA

A TLANTICA

A TLANTI CA

A T LANTICA

A TLANTICA

A TLANTICA

A TLANTI CA

ATLANTICA

AT LANTICA

A TLANTICA

ATLANTICA

A TLANTICA

A TLANTICA

AT LANTICA

A TLANTICA

ATLANTICA

A T LANTI CA

ATLANTICA

A TLANTICA

ATLANTICA

A ILANTICA

ATLANTICA

AT LANTICA

A TLANTICA

AT LANTICA

A TLANTICA

ATLANTICA

NW GULF OF MEXICO

CENTRAL TEXAS.BAYS

NE GULF OF MEXICO

$N W$ GULF OF MEXICO

NE GULF OF MEXICO

NE GULF OF MEXICO

NE GULF OF MEXICO

NE GULF OF MEXICO

NE GULF OF MEXICO 


\section{Publication}

20821 WARREN 1957

20822 PARKER 1954

20823 PHLEGER 1951A

20824 PHLEGER 1951A

20825 PHLEGER 1955 A

20826 BANDY 1956

20827 PHLEGER 1955 B

20828 PHLEGER $1951 \mathrm{~A}$

20829 KANE 1967

20830 PHLEGER 1951 A

20831 PHLEGER 1951 A

20832 PHLEGER 1951 A

20833 SEGURA 1963

20834 SHIFFLETT 1961

20835 PHLEGER 1951A

20836 BANDY 1956

20837 WARREN 1956
20838 ANDERSEN 1961

20839 ANDERSEN 1961

20840 ANDERSEN 1961

20841 WARREN 1957

20842 ANDERSEN 1961

20843 ANDERSEN 1961

20844 ANDERSEN 1961

20845 ANDERSEN 1961

20846 ANDERSEN 1961

20847 ANDERSEN 1961

20848 BANDY 1956

20849 BANDY 1956

20850 BANDY 1956

20851 BANDY 1956

20852 BANDY 1956

20853 BANDY 1956

20854 BANDY 1956

20855 BANDY 1956

20856 DAVIS 1964

20857 BANDY 1956

20858 BANDY 1956

20859 BANDY 1956

20860 BANDY 1956

20861 BANDY 1956

20862 BANDY 1956

20863 BANDY 1956

20864 BANDY 1956

20865 PHLEGER 1951 A

20866 PHLEGER 1955 B

20867 PHLEGER 1951A

20868 PHLEGER $1951 \mathrm{~A}$

20869 PHLEGER $1951 \mathrm{~A}$

20870 LANKFORD 1959

20871 PARKER 1954

20872 PARKER 1954

20873 LUDWICK WALTON 1957

20874 PHLEGER 1954

20875 PHLEGER 1955 A

20876 PARKER 1954

20877 PARKER 1954

20878 PARKER 1954

20879 PARKER 1954

20880 PARKER 1954

20881 PARKER 1954

20882 PHLEGER 1951A

20883 PHLEGER $1951 \mathrm{~A}$

20884 PHLEGER $1951 \mathrm{~A}$

20885 PHLEGER $1951 \mathrm{~A}$

20886 PHLEGER 1951A

20887 PHLEGER 1951 A

20888 PHLEGER $1951 \mathrm{~A}$

20889 PHLEGER $1951 \mathrm{~A}$

20890 PHLEGER $1951 \mathrm{~A}$

20891 PHLEGER $1951 \mathrm{~A}$

20892 PHLEGER $1951 \mathrm{~A}$

20893 PHLEGER $1951 \mathrm{~A}$

20894 PHLEGER 1951 A

20895 PHLEGER $1951 \mathrm{~A}$

20896 PHLEGER 1951A

20897 PHLEGER $1951 \mathrm{~A}$

20898 PFLUM FRERICHS 1976

20899 PFLUM FRERICHS 1976

20900 SEGURA 1963

20901 PHLEGER $1951 \mathrm{~A}$

20902 PHLEGER $1951 \mathrm{~A}$

20903 PARKER 1954

20904 PFLUM FRERICHS 1976

20905 PARKER 1954

20906 PHLEGER 1951 A

20907 PHLEGER 1951 A

20908 PFLUM FRERICHS 1976

20909 PFLUM FRERICHS 1976

20910 PFLUM FRERICHS 1976

20911 AYALA-CASTANARES 1963

20912 BENDA PURI 1962

20913 KELLOUGH 1956

20914 KELLOUGH 1956

20915 ANDERSON 1968
Generic Name

NONI ONE LLA

NONIONELLA

NONIONELLA

NONI ONELLA

NONIONELLA

NONIONELLA

NONIONELLA

NONIONELLA

NONI ONELLA

NONIONELLA

NONIONELLA

NONI ONELLA

NONI ONELLA

NONI ONELLA

NONIONELLA

NONIONELLA

NONI ONELLA

NONIONELLA

NONI ONELLA

NONIONELLA

NONIONELLA

NONI ONELLA

NONIONELLA

NONIONELLA

NONIONELLA

NONIONELLA

NONI ONELLA

NONIONELLA

NONIONELLA

NONIONELLA

NONIONELLA

NONIONELLA

NONIONELLA

NONIONELLA

NONIONELLA

NONIONELLA

NONIONELLA

NONIONELLA

NONI ONELLA

NONIONELLA

NONIONELLA

NONIONEL LA

NONIONELLA

NONIONELLA

NONI ONELLA

NONIONELLA

NONI ONELLA

NONI ONELLA

NONIONELLA

NONIONELLA

NONI ONELLA

NONIONELLA

NONI ONELLA

NONI ONELLA

NONI ONELLA

NONI ONELLA

NONIONELLA

NONIONELLA

NONIONELLA

NONIONELLA

NONIONELLA

NONI ONELLA

NONI ONELLA

NONIONELLA

NONI ONEL LA

NONI ONELLA

NONIONELLA

NONIONELLA

NONI ONELLA

NONI ONELLA

NONIONELLA

NONIONELLA

NONI ONELLA

NONI ONELLA

NONI ONELLA

NONI ONELLA

NONIONELLA

NONI ONELLAA

NONIONELLA

NONI ONELLA

NONIONELLA

NONI ONELLA

NONI ONELLA

NONI ONELLA

NONI ONELLA

NONIONELLA

NONIONELLA

NONIONELLA

NONIONELLA

NONIONELLA

NONI ONELLA

NONI ONELLA

NONIONELLA

NONI ONELLA

NONIONELLA
Specific Name

ATLANTICA

ATLANTICA

ATLANTICA

ATLANTICA

A TLANTICA

ATLANTICA

A TLANTICA

A TLANTICA

AT LANTICA

A TLANTICA

ATLANTICA

ATLANTICA

A TLANTICA

ATLANTICA

ATLANTIC

AURI

AURIS

AURIS

AURIS

AURIS

AURIS

AURIS

AURIS

AURIS

OPIMA

GRATELOUPI

GRATELOUPI

GRATELOUPI

GRATELOUPI

GRATELOUPI

GRATELOUPI

GRATELOUP :

GRATELOUPI

GRATEL OUPI

GRATELOUP I

GRATELOUP I

GRATEL OUPI

GRATELOUP

GRATELOUP I

GRATELOUP I

GRATEL OUP I

GRATELOUPI

OP IMA

OP IMA

OP IMA

OP IMA

OPIMA

OP IMA

OP IMA

OP IMA

OP IMA

OPIMA

OP IMA

OP IMA

OPIMA

OP IMA

OP IMA

OP IMA

OPIMA

OP IMA

OP IMA

OPIMA

OP IMA

OP IMA

OP IMA

OP IMA

OPIMA

OP IMA

OP IMA

OP IMA

OP IMA

OPIMA

OP IMA

OP IMA

OPIMA

OP IMA

OPIMA

OP IMA

OP IMA

OP IMA

OPIMA

OP IMA

OPIMA

OP IMA

OP IMA

OPIMA

OP IMA

OP IMA

OPIMA

OP IMA

OP IMA

OP IMA

Locality

SE LOUISIANA

NE GULF OF MEXICO

NW GULF OF MEXICO

$N$ GULF OF MEXICO 
Publication

20916 KELLOUGH 1956 20917 PFLUM FRERICHS 1976 20918 PFLUM FRERICHS 1976 20919 PFLUM FRERICHS 1976 20920 PFLUM FRERICHS 1976 20921 PFLUM FRERICHS 1976 20922 PFLUM FRERICHS 1976 20923 PFLUM FRERICHS 1976 20924 PFLUM FRERICHS 1976 20925 PFLUM FRERICHS 1976 20926 WALTON 1960 20927 PHLEGER 1951A 20928 PHLEGER 1951A 20929 PARKER PHLEGER PEIRSON 1953 20930 PHLEGER 1956 20931 PHLEGER 1956 20932 PHLEGER 1956 20933 PHLEGER 1956 20934 POAG 1972

20935 PARKER 1954 20936 PARKER 1954 20937 PARKER 1954 20938 PARKER 1954

20939 PARKER PHLEGER PEIRSON 1953 20940 PARKER PHLEGER PEIRSON 1953 20941 BOCK 1976

20942 CREAGER 1958

20943 PHLEGER 1956

20944 PARKER PHLEGER PEIRSON 1953 20945 PARKER 1954

20946 PARKER 1954

20947 PARKER 1954

20948 CREAGER 1958

20949 OTVOS 1978

20950 PARKER PHLEGER PEIRSON 1953 20951 BOCK 1976

20952 PARKER PHLEGER PEIRSON 1953 20953 CUSHMAN 1922 A

20954 VAUGHAN 1918

20955 VAUGHAN 1918

20956 PARKER PHLEGER PEIRSON 1953 20957 POAG SWEET 1972

20958 PHLEGER 1956

20959 PHLEGER 1956

20960 PHLEGER 1956

20961 PHLEGER 1956

20962 SHEPARD MOORE 1955

20963 PARKER 1954

20964 PARKER 1954

20965 PARKER 1954

20966 PARKER 1954

20967 PARKER 1954

20968 PARKER 1954

20969 LANKFORD 1959

20970 PHLEGER 19558

20971 BOCK 1976

20972 CUSHMAN 1922A

20973 BOCK 1976

20974 BOCK 1976

20975 LEROY HODGKINSON 1975

20976 PARKER 1954

20977 PARKER 1954

20978 PARKER 1954

20979 PARKER 1954

20980 PARKER 1954

20981 PARKER 1954

20982 ANDERSEN 1961

20983 BOCK 1976

20984 ANDERSEN 1961

20985 LEROY HODGKINSON 1975

20986 PFLUM FRERICHS 1976

20987 PFLUM FRERICHS 1976

20988 PFLUM FRERICHS 1976

20989 BOCK 1976

20990 ANDERSEN 1961

20991 BENDA PURI 1962

20992 VAUGHAN 1918

20993 VAUGHAN 1918

20994 VAUGHAN 1918

20995 CUSHMAN 1922A

20996 VAUGHAN 1918

20997 CUSHMAN $1922 \mathrm{~A}$

20998 CUSHMAN 1922A

20999 VAUGHAN 1918

21000 VAUGHAN 1918

21001 PFLUM FRERICHS 1976

21002 PFLUM FRERICHS 1976

21003 PFLUM FRERICHS 1976

21004 PFLUM FRERICHS 1976

21005 PFLUM FRERICHS 1976

21006 PFLUM FRERICHS 1976

21007 PFLUM FRERICHS 1976

21008 PFLUM FRERICHS 1976

21009 PFLUM FRERICHS 1976

21010 PFLUM FRERICHS 1976
Generic Name

NONIONELLA

NONIONELLA

NONI ONELLA

NONIONELLA

NONIONELLA

NONIONELLA

NONIONELLA

NONIONELLA

NONI ONELLA

NONI ONELLA

NONIONELLA

NONI ONELLA

NONI ONELLA

NONIONELLA

NONIONELLA

NONI ONELLA

NONI ONELLA

NONI ONELLA

NONIONELLA

NONI ONELLA

NONI ONELLA

NONI ONELLA

NONI ONELLA

NONIONELLA

NONI ONELLA

NONI ONELLA

NONI ONELLA

NONIONELLA

NONIONELLA

NONIONELLA

NONI ONELLA

NONI ONELLA

NONI ONELLA

NONI ONELLA

ONI ONELLA

NONI ONELLA

FLORILUS

ME LONIS

NOUR I A

NOUR I A

NOUR I A

NOUR I A

NOUR I A

NOUR IA

NOURIA

NOUR IA

NOURIA

NOUR IA

N OUR I A

NOUR IA

NOUR I A

NOUR I A

NOUR I A

NOUR I A

NUBE CUL AR I A

NUBE CUL ARIA

NUBE CUL INA

NUMMOLOCUL INA

NUMMOL OCUL INA

NUMMOLOCUL INA

NUMMOL O CUL INA

NUMMOLOCULINA

NU MMOL OCUL INA

NUMMOL OCUL INA

OOLINA

OOLINA

OOLINA

OOLINA

OOLINA

DOLINA

OOLINA

OOLINA

OOLINA

CORNULOCULINA

ARCHAIAS

ARCHAIAS

ARCHAIAS

ARCHAIAS

ARCHAIAS

ARCHAIAS

AMPHISORUS

SORITES

SORITES

ORIDORSALIS

ORIDORSALIS

ORIDORSALIS

ORIDORSALIS

ORIDORSALIS

OR IDORSALIS

OR IDORSALIS

ORIDORSALIS

ORIDORSALIS

ORI DORSALIS
Specific Name

OP IMA

OPIMA

OP IMA

OP IMA

OP IMA

OP IMA

OP IMA

OP IMA

OPIMA

OP IMA

OP IMA

OP IMA

OP IMA

OP IMA

OP IMA

OP IMA

OP IMA

OP IMA

OP IMA

OP IMA

OP IMA

OP IMA

OPIMA

OP IMA

OP IMA

OP IMA

OP IMA

OP IMA

OP IMA

OP IMA

OP IMA

OP IMA

OP IMA

GRATEL OUP I

SC APHUM

BARLEEANUS

POLYMORPH INOI DES

POLYMORPH INOIDES

POLYMORPH INOIDES

POLYMORPH INOIDES

POLYMORPH INOIDES

POLYMORPH INOIDES

POLYMORPH INOIDES

POLYMORPH INOIDES

POLYMORPH INOIDES

POLYMORPHINOIDES

POLYMORPHINOIDES

POLYMORPH INOIDES

POLYMORPH INOIDES

POLYMORPH INOIDES

POLYMORPH IN OI DES

POLYMORPH INOIDES

LUCIFUGA

DI VERICATA

CONTRARIA

IRREGULARIS

IR FE GULAR IS

IR RE GULAR IS

IRRE GULAR IS

IR REGULAR IS

IRREGUL AR IS

CAUDIGERA

HE XAGONA

HE XAGONA

LONG I SP INA

LONG ISPINA

LONGISPINA

LONGISPINA

MELO

MELO

IN CONST ANS

AN GULATUS

AN GUL ATUS

AN GULATUS

ANGULATUS

COMPRESSUS

COMPRESSUS

HE MPR I CHII

MA FG INALIS

MA RG INAL IS

SI DEBOTTOMI

SI DEBOTTOMI

SI CEBOTTOMI

SI DEBOTTOMI

SI DEBOTTOMI

SIDEBOT TOMI

SI DEBOT TOMI

SI CEBOTTOMI

TENER STELLATUS

Locality

Lat. Long.

NW GULF OF MEXICO

CENTRAL GULF OF MEXICO

CENTRAL GULF OF MEXICO

CENTRAL GULF OF MEXICO

CENTRAL GULF OF MEXICO

CENTRAL GULF OF MEXICO 


\section{Publication}

21011 PFLUM FRERICHS 1976 21012 PFLUM FRERICHS 1976 21013 PFLUM FRERICHS 1976 21014 PFLUM FRERICHS 1976 21015 PFLUM FRERICHS 1976 21016 PFLUM FRERICHS 1976 21017 PFLUM FRERICHS 1976 21018 PFLUM FRERICHS 1976 21019 PFLUM FRERICHS 1976 21020 PFLUM FRERICHS 1976 21021 PFLUM FRERICHS 1976 21022 PFLUM FRERICHS 1976 21023 PFLUM FRERICHS 1976 21024 PFLUM FRERICHS 1976 21025 PFLUM FRERICHS 1976 21026 PFLUM FRERICHS 1976 21027 PFLUM FRERICHS 1976 21028 PFLUM FRERICHS 1976 21029 PFLUM FRERICHS 1976 21030 PFLUM FRERICHS 1976 21031 PFLUM FRERICHS 1976 21032 PFLUM FRERICHS 1976 21033 PFLUM FRERICHS 1976 21034 PFLUM FRERICHS 1976 21035 PFLUM FRERICHS 1976 21036 PFLUM FRERICHS 1976 21037 PFLUM FRERICHS 1976
21038 PFLUM FRERICHS 1976 21038 PFLUM FRERICHS 1976
21039 PFLUM FRERICHS 1976 21040 PFLUM FRERICHS 1976 21041 PFLUM FRERICHS 1976 21042 PFLUM FRERICHS 1976 21043 PFLUM FRERICHS 1976 21044 PFLUM FRERICHS 1976 21045 PFLUM FRERICHS 1976 21046 PFLUM FRERICHS 1976 21047 PFLUM FRERICHS 1976 21048 PFLUM FRERICHS 1976 21049 PFLUM FRERICHS 1976 21050 PFLUM FRERICHS 1976 21051 PFLUM FRERICHS 1976 21052 PFLUM FRERICHS 1976 21053 PFLUM FRERICHS 1976 21054 PFLUM FRERICHS 1976 21055 PFLUM FRERICHS 1976 21056 PFLUM FRERICHS 1976 21057 PFLUM FRERICHS 1976 21058 PFLUM FRERICHS 1976 21059 PFLUM FRERICHS 1976 21060 PFLUM FRERICHS 1976 21061 PFLUM FRERICHS 1976 21062 PFLUM FRERICHS 1976 21063 PFLUM FRERICHS 1976 21064 LEROY HODGKINSON 1975 21065 PFLUM FRERICHS 1976
21066 PFLUM FRERICHS 1976 21066 PFLUM FRERICHS 1976
21067 PFLUM FRERICHS 1976 21068 PFLUM FRERICHS 1976 21069 PFLUM FRERICHS 1976 21070 PFLUM FRERICHS 1976 21071 PFLUM FRERICHS 1976 21072 PFLUM FRERICHS 1976 21073 PFLUM FRERICHS 1976 21074 PFLUM FRERICHS 1976 21075 PFLUM FRERICHS 1976 21076 PFLUM FRERICHS 1976 21077 PFLUM FRERICHS 1976 21078 PFLUM FRERICHS 1976 21079 PFLUM FRERICHS 1976 21080 PFLUM FRERICHS 1976 21081 PFLUM FRERICHS 1976 21082 PFLUM FRERICHS 1976 21084 PFLUM FRERICHS 1976 21085 PFLUM FRERICHS 1976 21086 PFLUM FRERICHS 1976 21087 PFLUM FRERICHS 1976 21088 PFLUM FRERICHS 1976 21089 PFLUM FRERICHS 1976 21090 PFLUM FRERICHS 1976 21091 PFLUM FRERICHS 1976 21092 PFLUM FRERICHS 1976 21093 PFLUM FRERICHS 1976 21094 PFLUM FRERICHS 1976 21095 PFLUM FRERICHS 1976 21096 PFLUM FRERICHS 1976 21097 PFLUM FRERICHS 1976 21098 PFLUM FRERICHS 1976 21099 PFLUM FRERICHS 1976 21100 PFLUM FRERICHS 1976 21101 PFLUM FRERICHS 1976 21102 PFLUM FRERICHS 1976 21103 PFLUM FRERICHS 1976 21104 PFLUM FRERICHS 1976 21105 PFLUM FRERICHS 1976
Generic Name

ORIDORSALIS ORIDORSALIS ORIDORSALIS OR IDORSALIS ORIDORSALIS OR IDORSALIS ORIDORSALIS ORIDORSALIS ORIDORSALIS ORIDORSALIS ORIDORSALIS ORIDORSALIS OR IDORSALIS ORIDORSALIS ORIDORSALIS OR IDORSALIS OR IDORSALIS ORIDORSALIS ORIDORSALIS OR IDORSAL IS OR IDORSALIS ORIDORSAL IS ORIDORSALIS ORIDORSAL IS ORIDORSALIS OR IDORSALIS OR IDORSALIS OR IDORSALIS ORIDORSALIS ORIDORSALIS OR IDORSALIS ORIDORSALIS ORIDORSALIS ORIDORSALIS ORIDORSALIS ORIDORSALIS OR IDORSALIS ORIDORSALIS ORIDORSALIS ORIDORSALIS OR IDORSALIS ORIDORSALIS OR IDORS AL IS ORIDORSALIS OR IDORSAL IS OR IDORSALIS ORIDORSALIS ORIDORSALIS OR IDORSALIS ORIDORSALIS EPONIDES EP ONIDES EPONIDES EPONIDES

EPONIDES

EP ONIDES

EPONIDE

EPONIDES

EPONIDES

EPONIDES

EP ONIDES

EPONIDES

EP ONIDES

EPONIDES

EP ONIDES

EPONIDES

EPONIDES

EPONIDES

EP ONIDES

EPONIDES

EPONIDES

EPONIDES

EPONIDES

EPONIDES

EP ONIDES

EPONIDES

EPONIDES

EPONIDES

EPONIDES

EPONIDES

EPONIDES

EP ONIDES

EPONIDES

EPONIDES

EP ONIDES

EPONIDES

EPONIDES

EPONIDES

EPON IDES

EP ONIDES

EPONIDES

EPONIDES

EP ONI DES

EPONIDES

EPONIDES
Specific Name

TENER STELLATUS

TEAER STELLATUS

TENER STELLATUS

TENER STELLATUS

TENER STELLATUS

TENER STELLATUS

IENER STELLATUS

TENER STELLATUS

TENER STELLATUS

TENER STELLATUS

TENER STELLATUS

TENER STELLATUS

TENER STELLATUS

TENER STELLATUS

TENER STELLATUS

TENER STELLATUS

ENER STELLATUS

TENER STELLATUS

TENER STELLATUS

TENER STELLATUS

TENER STELLATUS

TENER STELLATUS

TENER STELLATUS

TENER STELLATUS

TENER STELLATUS

TENER TENER

TENER TENER

TENER TENER

TENER TENER

TENER TENER

TENER TENER

IENER TENER

TENER TENER

TENER TENER

TENER TENER

TENER T T NER

TENER TENER

TENER TENER

TENER TENER

TENER TENER

TEAER TENER

TENER TENER

TENER TENER

TENER TENER

TENER TENER

TENER TENER

TENER TENER

TENER TENER

UMBONATUS

UMEONATUS

UMEONATUS

UMBONATUS

UMBONATUS

UMBONATUS

UMEONATUS

UMEONATUS

UMEONATUS

UMBONATUS

UMEONATUS

UMEONATUS

UMBONATUS

UMEONATUS

UMBONATUS

UMBONATUS

UMEONATUS

UMEONATUS

UMBONATUS

UMBONATUS

UMBONATUS

UMBONATUS

UMEONATUS

UMEONATUS

UMEONATUS

UMEONATUS

UMBONATUS

UMBONATUS

UM EONATUS

UMEONATUS

UMBONATUS

UMEONATUS

UMBONATUS

UMEONATUS

UMEONATUS

UMBONATUS

UMEONATUS

UMBONATUS

UMEONATUS

UMEONATUS

UMEONATUS

UMBONATUS

UMBONATUS

UMBONATUS

UMEONATUS

Locality

NW GULF OF MEXICO

NW GULF OF MEXICO

NH GULF OF MEXICO

$N W$ GULF OF MEXICO 


\section{Publication}

21106 PFLUM FRERICHS 1976 21107 PFLUM FRERICHS 1976 21108 PFLUM FRERICHS 1976 21109 PFLUM FRERICHS 1976 21110 PFLUM FRERICHS 1976 21111 PFLUM FRERICHS 1976 21112 ANDERSEN 1961

21113 PFLUM FRFRICHS 1976 21114 PFLUM FRERICHS 1976 21115 PFLUM FRERICHS 1976 21116 PFLUM FRERICHS 1976 21117 PFLUM FRERICHS 1976 21118 PFLUM FRERICHS 1976 21119 PFLUM FRERICHS 1976 21120 PFLUM FRERICHS 1976 21121 PFLUM FRERICHS 1976 21122 PARKER 1954

21123 PFLUM FRERICHS 1976 21124 PFLUM FRERICHS 1976 21125 PFLUM FRERICHS 1976 21126 PFLUM FRERICHS 1976 21127 PFLUM FRERICHS 1976 21128 PFLUM FRERICHS 1976 21129 PFLUM FRERICHS 1976 21130 PFLUM FRERICHS 1976 21131 PFLUM FRERICHS 1976 21132 PFLUM FRERICHS 1976 21133 PFLUM FRERICHS 1976 21134 PFLUM FRERICHS 1976 21135 PFLUM FRERICHS 1976 21136 PFLUM FRERICHS 1976 21137 PFLUM FRERICHS 1976 21138 PFLUM FRERICHS 1976 21139 PFLUM FRERICHS 1976 21140 PFLUM FRERICHS 1976 21141 PFLUM FRERICHS 1976 21142 PFLUM FRERICHS 1976 21143 PFLUM FRERICHS 1976 21144 PFLUM FRERICHS 1976 21145 PFLUM FRERICHS 1976 21146 LOEP 1965

21147 LOEP 1965

21148 BOCK 1976

21149 PARKER 1954

21150 PARKER 1954

21151 PARKER 1954

21152 PARKER 1954

21153 PARKER 1954

21154 PARKER 1954

21155 PARKER 1954

21156 PFLUM FRERICHS 1976 21157 PFLUM FRERICHS 1976 21158 PFLUM FRERICHS 1976 21159 PFLUM FRERICHS 1976 21160 PFLUM FRERICHS 1976 21161 PFLUM FRERICHS 1976 21162 PARKER 1954

21163 PHLEGER 1955A

21164 PARKER 195

21165 PHLEGER 1955A

21166 PHLEGER 1955A

21167 PHLEGER 1955A

21168 PHLEGER 1955A

21160 PHLEGER 1955 A

21170 PHLEGER 1955A

21171 PARKER 1954

21172 PARKER 1954

21173 PARKER 1954

21174 PARKER 1954

21175 PARKER 1954

21176 PARKER 1054

21177 PARKER 1054

21178 PARKER 1954

21179 PFLUM FRERICHS 1976 21180 PFLUM FRERICHS 1976 21181 PFLUM FRERICHS 1976 21182 PFLUM FRERICHS 1976 21183 PFLUM FRERICHS 1976 21184 PFLUM FRERICHS 1976 21185 PFLUM FRERICHS 1976 21186 PFLUM FRERICHS 1976 21187 PFLUM FRERICHS 1976 21188 PFLUM FRERICHS 1976 21189 PFLUM FRERICHS 1976 21190 PFLUM FRERICHS 1976 21191 PFLUM FRERICHS 1976 21192 PFLUM FRERICHS 1976 21193 PFLUM FRERICHS 1976 21194 PFLUM FRERICHS 1976 21195 PFLUM FRERICHS 1976 21196 PFLUM FRERICHS 1976 21197 PFLUM FRERICHS 1976 21198 PFLUM FRERICHS 1976 21199 PARKER 195

21200 PFLUM FRERICHS 1976
Generic Name

EPONIDES

EPONIDES

EPONIDES

EPONIDES

EPONIDES

OR IDORS AL IS

OR THOMORPH INA

ORTHOMORPH INA

ORTHOMORPHINA

ORTHOMORPHI VA

ORTHOMORPH INA

ORTHOMORPH INA

ORTHOMORPH INA

ORTHOMORPHINA

OS ANGULARIA

OSANGULARIA

OS ANGULARI A

OS ANGUL ARI A

OS ANGUL ARI

OSANGULAR IA

OSANGULARIA

OS ANGULARIA

OSANGULARI

OSANGULARIA

OS ANGUL ARI A

OS ANGUL ARIA

OSANGULARIA

OSANGUL ARI A

OSANGUL ARIA

OS ANG UL ARI

OS ANGUL ARI A

OSANGULARIA

OS ANGUL ARI A

OSANGULARIA

OSANGULARIA

OSANGUL ARI

OS ANGULARIA

OSANGULARIA

OSANGULARIA

OSANGULARIA

OSANGULARIA

OS ANGUL AR I A

OS ANGUL ARIA

OSANGULARIA

OS ANGULARIA

OS ANGULARIA

OSANGULARI A

OS ANGULARIA

OSANGULARIA

OS ANGULARI

OS ANGULARIA

OS ANGULARIA

OS ANGUL ARI A

OS ANGUL AR I A

OS ANG UL ARI A

OS ANGULARI

OS ANGULARIA

OS ANGUL ARIA

OS ANGULARIA

OS ANGUL ARI A

OS ANGUL ARI A

OS ANGULARIA

OS ANGULARIA

OS ANGUL ARI I

OS ANGULARIA

OS ANGULARIA

OSANGULARIA

OS ANGUL ARI A

OS ANGUL ARI A

OSANGUL ARIA

OS ANGUL ARIA

OS ANGULARIA

OSANGULARIA

OSANGULAR IA

OSANGULARIA

OS ANGULARIA

OSANGULARI

OSANGULARIA

OS ANGUL AR I A

OS ANGULARIA

OS ANGULARIA

OS ANGUL ARI A

OS ANGULARI A

OSANGULARIA

OS ANGUL ARIA

OS ANG UL ARI A

OS ANGULARIA

OS ANGULARI A

OS ANGULARIA

OS ANGUL ARIA

OSANGUL ARIA

OS ANGUL ARIA

OS ANGUL ARI A

OS ANGUL ARI A
Specific Name

Locality

UMEONATUS

UMEONATUS

UMEONATUS

UMEONATUS

WE ST I

GUTTIFERA

GUTTIFERA

GUTT IFERA

GUTTIFERA

GUTTIFERA

GUTTIFERA

GUTT IFERA

CULTUR

CULTUR

CULTUR

CULTUR

CULTUR

CULTUR

CULTUR

CULTUR

CULTUR

CULTUR

CULTUR

CULTUR

CULTUR

CULTUR

CULTUR

CULTUR

CULTUR

CULTUR

CULTUR

CULTUR

CULTUR

CULTUR

CULTUR

CULTUR

CULTUR

CULTUR

CULTUR

CULTUR

CULTUR

CULTUR

CULTUR

CULTUR

CULTUR

CULTUR

CULTUR

CULTUR

CULTUR

CULTUR

CULTUR

CULTUR

CULTUR

CULTUR

CULTUR

CULTUR

CULTUR

CULTUR

CULTUR

CULTUR

CULTUR

CULTUR

CULTUR

CULTUR

CULTUR

CULTUR

CULTUR

CULTUR

CULTUR

CULTUR

CULTUR

CULTUR

CULTUR

CULTUR

CULTUR

CULTUR

CULTUR

CULTUR

CULTUR

CULTUR

CULTUR

CULTUR

CULTUR

CULTUR

CENTRAL GULF OF MEXICO

CENTRAL GULF OF MEXICO CENTRAL GULF OF MEXICO CENTRAL GULF OF MEXICO CENTRAL GULF OF MEXICO CENTRAL GULF OF MEXICO

MISSISSIPPI DELTA $N$ W GULF OF MEXICO NW GULF OF MEXICO 


\section{Publication}

21201 PFLUM FRERICHS 1976 21202 PFLUM FRFPICHS 1976 21203 PFLU: FRERICHS 1976 21204 PFLUM FRERICHS 1776 21205 PFLUM FFERICHS 1976 21206 PFLUM FREFICHS 1976 21207 LEROY HODGKINSJN 1975 21208 PFLUM FRFRICHS 1976 21209 PFL IM FRERICHS 1976 21210 PFLUM FRERICHS 1976 21211 PFLUM FRERICHS 1976 21212 PFLUM FRERICHS 1976 21213 PFLUM FRERICHS 1976 21214 PFLUM FREKICHS 1976 21215 PFLUM FRERICHS 1976 21216 PFLUM FRERICHS 1976 21217 PFLU' FRERICHS 1976 21218 PFLUM FRERICHS 1976 21220 PFLUM FPERICHS 1976 21221 PFLUM FRERICHS 1976 21222 PFLUM FRFRICHS 1976 21223 PFLUM FRERICHS 1976 21224 PFLUM FRERICHS 1976 21225 PFLUM FRERICHS 1976 21226 PFLUM FREFICHS 1976 21228 DFLUM FRERICHS 1976 21229 DFLUM FRERICHS 1976 21230 PFLUM FRERICHS 1976 21231 PFLUM FRERICHS 1976 21232 PFLUM FRERICHS 1976 21234 PFLUM FRERICHS 1976 21235 PFLUM FRERICHS 1976 21236 PFLUM FRERICHS 1976 21237 PFLUM FRERICHS 1976 21238 PFLUM FRERICHS 1976 21239 PFLIJM FRERICHS 1976 21240 PFLUM FRERICHS 1976 21241 PFLUM FRERICHS 1976 21242 PFLU'A FRERICHS 1976 21243 PFLUM FRERICHS 1976 21244 PFLUM FRERICHS 1976 21245 PFLUM FRERICHS 1976 21246 PFLUIA FRERICHS 1976 21248 OTVOS 1978

21249 WANTLAND 1969

21250 BOCK 1076

21251 LANKFORD 1959

21252 SHEPARD MOORE 1755

21253 PHLEGER 1965 A

21254 PHLEGER 1965 A

21255
21256 PHLEGER
21965 HLER 1965 A

21257 LEHMANN 1957

21258 PHLEGER 1960

21259 SEGURA 1263

21261 PARKER PHLEGER PEIRSON 1953

21262 PARKER PHLEGER PEIRSON 1953

21263 SHENTON 195 ?

21264 PARKER PHLEGER PEIRSON 1953 21265 PHLEGER 1965 A

21266 PHLEGER 1965 A

21268 PARKER PHLEGER PEIRSON 1953 21269 PARKER PHLEGER PEIRSON 1953 21270 AYALA-CASTANARES 1963

21271 AYALA-CASTANARES SEGURA 1968 21272 PHLEGER 1956

21273 PARKER PHLEGER PEIRSON 1953 21274 PARKER PHLESER PEIRSON 1953 21275 PHLEGE? 1965 A

21276 POAG 1978

21278 ANDERSEN 195

21279 PFLUM FRERICHS 1976

21280 PFLU'A FRERICHS 1976

21281 PFLUM FRERICHS 1976

21282 PFLUM FREKICHS 1976

21283 PFLUM FRERICHS 1976

21284 PFLUM FRERICHS 1976

21285 PFLIJM FRERICHS 1976

21286 PFLUM FRERICHS 1976

21287 CREAGER 1958

21288 CREAGER 1953

21289 CREAGER 1958

21290 CREAGER 1958

21291 PHLEGER 1951 A
21292 PHLEGER 1951 A

21292 PHLEGER 1951 A
21293 CREAGER 1953

21294 CREAGER 1958

21295 CREAGER 1958

\section{Generic Name}

OS ANGUL ARIA

OSANGULARIA

OS ANGULARIA

OSANGULARIA

OS ANGULARIA

OSANGULARIA

OS ANGULARIA

OS ANGUL AR I A

OS ANGULARIA

OS ANGUL ARI A

OSANGULARIA

OSANGULARIA

OSANGULARIA

OS ANGULARIA

OS ANGUL ARIA

OS ANGUL ARIA

OS ANGUL ARI A

OS ANGULAR I A

OS ANGULARIA

OS ANGULARI A

OS ANGULARIA

OSANGULARI A

OS ANGUL ARI A

OS ANGULARI A

OS ANGULARI

OSANGULARIA

OSANGUL ARI A

OSANGULARIA

OSANGUL ARI A

OS ANGULARIA

OS ANGULARI A

OS ANGULARIA

OS ANGULARI A

OS ANGUL ARI A

OS ANGULARIA

OS ANGULARI A

OSANGULARI A

OS ANGULARIA

OSANGULARIA

OSANGUL ARIA

OS ANGUL ARI A

OSANGULARI A

OSANGULARI A

OS ANGUL ARI A

OSANGULARI A

OS ANGUL ARI A

OS ANGUL ARIA

PALMERINELLA

PALMERINELLA

PA LMERINELLA

PALMERINELLA

PALMERINELLA

PALMERINELLA

PALMERINELLA

PALMERINELLA

PALMERINELLA

PALMERINELLA

PALMERINELLA

PALMERINELLA

PALMERINELLA

PALMERINELLA

PALMERINELLA

PALMERINELLA

PALMERINELLA

PALMER INELLA

PALMERI NELLA

PALMERI NELLA

PALMER INELLA

PALMERINELLA

PALMERINELLA

PALMERINELLA

PALMERINELLA

PALMERI NNELLA

PALMERINELLA

PALMERINELLA

PALMERINELLA

PALMERINELLA

PARAFISSURINA

PARAFISSUR INA

PARAFISSURINA

PARAFISSUR IIA

PARAFISSURINA

PARAF IS SUR INA

PARAFISSURINA

PARAFISSURI NA

PARAF ISSUR INA

OSANGULARI A

OS ANGUL ARI A

OS ANGULARIA

OS ANGULARIA

OSANGULARIA

OSANGULARIA

OS ANGULARIA

OS ANGUL ARI

OS ANGULARI A
Specific Name

CULTUR

CULTUR

CULTUR

CULTUR

CULTUR

CULTUR

CULTUR

RU GOSA

RUGOSA

$R \cup G O S A$
$R \cup G O S A$

RUEOSA

$R \cup G O S A$

RUGOSA

RUGOSA

RUEOSA

$R \cup G O S A$

RUGOSA

RUGOSA

RUGOSA

$R \cup$ COSA

RUGOSA

$R \cup G O S A$

$R \cup G O S A$

$R U \in O S A$

RUEOSA

RUGOSA

RU GOSA

$R \cup G O S A$

$R \cup G O S A$

RU COSA

RUGOSA

RUGOSA

RUGOSA

$R \cup \in O S A$

$R \cup \in O S A$

$R \cup G O S A$

RUGOSA

RUGOSA

RUGOSA

$R \cup G O S A$

RUGOSA

GARDENISLANDENSIS

GARDENISLANDENSIS

GARDENISL AN DENS IS

GARDENISLANDENSIS

PALMERAE

PALMERAE

LMERAE

PALMER,

PALMERAE

PALMERAE

PALMERAE

PALMERAE

PALMERAE

PALMERAE

PALMERAE

PALMERAE

PALMERAE

PALMERAE

PALMERAE

PALMERAE

PALMERAE

PALMERAE

PALMERAE

PALMERAE

PALMERAE

PALMERAE

PALMERAE

GARDENISLANDENSIS

PALMERAE

LATERALIS

LATERALIS

LATERALIS

LATERALIS

LATERALIS

LATERALIS

LATERALIS

LATERALIS

LATERALIS

CULTUR

CULTUR

CULTUR

CULTUR

CULTUR

CULTUR

CULTUR

Locality

$N W$ GULF OF MEXICO

NW GULF OF MEXICO

NW GULF OF MEXICO

$N W$ GULF OF MEXICO

NW GULF OF MEXICO

NW GULF OF MEXICO

$N$ GULF OF MEXICO

NW GULF OF MEXICO

N. GULF OF MEXICO

NW GULF OF MEXICO

$N W$ GULF OF MEXICO

$N W$ GULF OF MEXICO

NW GULF OF MEXICO

NW GULF OF MEXICO

NW GULF OF MEXICO

NW GULF OF MEXICO 


\section{Publication}

21296 CREAGER 1958 21297 CREAGER 1958 21298 PHLEGER 1951 A 21299 PHLEGER 195.1A 21300 PHLEGER 1951A 21301 PHLEGER $1951 \mathrm{~A}$ 21302 PHLEGER $1951 \mathrm{~A}$ 21303 PHLEGER 1951A 21304 PHLEGER $1951 \mathrm{~A}$ 21305 PHLEGER $1951 \mathrm{~A}$ 21306 PHLEGER 1951A 21307 PHLEGER 1951A 21308 PHLEGER $1951 \mathrm{~A}$ 21309 PHLEGER 1951A 21310 PHLEGER $1951 \mathrm{~A}$ 21311 CREAGER 1953 21312 CREAGER 1958 21313 PHLEGER $1951 \mathrm{~A}$ 21314 PHLEGER 1951A 21315 CREAGER 1958 21316 PHLEGER 1951A 21317 PHLEGER 1951A 21318 PHLEGEP $1951 \mathrm{~A}$ 21319 CREAGER 1958 21320 CREAGER 1958 21321 PHLEGER $1951 \mathrm{~A}$ 21322 PHLEGER 1951A
21323 ANDERSEN 1961 21324 BOCK 1976

21325 PFLUM FRERICHS 1976

21326 SANDY 1956

21327 BANDY 1956

21328 BANDY 1956

21329 LUDWICK. WALTON 1957

21330 BANDY 1956

21331 BANDY 1956

21332 BANDY 1956

21333 ANDERSEN 196
21334 CUSHMAN 1918

21334 CUSHMAN 1918
21335 CUSHMAN 1918

21336 CUSHMAN 1918

21337 CUSHMAN 1918

21338 CUSHMAN $1922 \mathrm{~A}$

21339 NORTON 1930

21340 BOCK 1976

21341 CUSHMAN 1930

21342 CUSHMAN 1930
21343 NORTON 1930

21344 CUSHMAN $1922 \mathrm{~A}$

21345 BOCK 1976

21346 SEGURA 1063

21347 BOCK 1976

21348 CUSHMAN $1922 \mathrm{~A}$

21349 CUSHMAN 1930

21350 KELLOUGH 1956

21351 CUSHMAN 1922

21353 VAUGHAN 1918

21354 CUSHMAN $1922 \mathrm{~A}$

21355 DAVIS 1964

21356 BENDA PURI 1962

21357 BOCK 1976

21358 CUSHMAN 1930

21359 NORTON 1930

21360 CUSHMAN $1922 \mathrm{~A}$

21361 BOCK 1976

21362 CREAGER 1958

21363 DAVIS 1964
21364 BANDY 1956

21365 CUSHMAN $1922 \mathrm{~A}$

21366 3ANDY 1956

21367 BANDY 1956

21368 SANDY 1956

21369 SANDY 1956

21370 BANDY 1956

21371 BANDY 1956

21372 BANDY 1956

21373 BANDY 1956

21374 WALTON 1960

21375 CUSHMAN 1930

21376 NORTON 1930

21377 BANDY 1956

21378 BANDY 1956

21379 BANDY 1956

21380 BANDY 1956

21381 BANDY 1956

21382 BANDY 1956

21383 BANDY 1956
21384 CUSHMAN 1920

21384 CUSHMAN 1920
21385 CUSHMAN $1922 \mathrm{~A}$

21386 NORTON 1730

21387 DAVIS 1964

21388 CUSHMAN 1931

21389 BENDA PURI 1962

21390 NORTON 1930
Generic Name

OS ANGULARIA

OSANGULARIA

OSANGULARIA

OS ANGULARIA

OSANGULARI A

OS ANGUL ARI A

OSANGULARI A

OS ANGULARIA

OS AN

OS ANGUL ARIA

OSANGULARIA

OS ANGULARIA

OS ANGULARI

OS ANGULARIA

OS ANGULARIA

OS ANGUL ARI A

OS ANGUL ARIA

OSANGULARIA

OSANGULARIA

OSANGULARIA

OSANGULARIA

OSANGULARIA

OS ANGULARIA

OS ANGUL ARIA

OSANGULARI

PATELLINA

PAVONINA

PAVONINA

PA VONINA

PAVONINA

PAVONINA

PAVONINA

PAYONINA

PAVONINA

PAVONINA

PELOSINA

PELOSINA

PELOSINA

PELOSINA

PENEROPLIS

PENEROPLIS

PENEROPLIS

PENEROPLIS

PENEROPLIS

PENEROPLIS

PENEROPLIS

PENEROPLIS

PENEROPLIS

PENEROPLIS

PENEROPLIS

PENEROPLIS

PENEROPLIS

PENEROPLIS

PENEROPLIS

PENEROPLIS

PENEROPLIS

PENEROPLIS

PENEROPLIS

PENEROPL IS

PENEROPLIS

PENEROPLIS

PENEROPLIS

PENEROPLIS

PENEROPLIS

PENEROPLIS

PENEROPLIS

PENEROPLIS

PENEROPLIS

PENEROPLIS

PENEROPLIS

PENEROPLIS

PENEROPLIS

PENEROPLIS

PENEROPLIS

PENEROPLIS

PENEROPL IS

PENEROPLIS

PENEROPLIS

PENEROPLIS

PENEROPLIS

PENEROPLIS

PENEROPLIS

PENEROPLIS

PENEROPLIS

PENEROPLIS
PLACOPSILINA

PLANISPIRINA

PLANISPIRINA

PLANORBULINA

PLANORBULINA

PLANORBULINA

PLANORBULINA
Specific Name

Locality

CULTUR

CULTUR

CULTUR

CULTUR

CULTUR

CULTUR

CULTUR

CULTUR

CULTUR

CULTUR

CULTUR

CULTUR

CULTUR

CULTUR

CULTUR

CULTUR

CULTUR

CULTUR

CULTUR

CULTUR

CULTUR

CULTUR

CULTUR

CULTUR

CULTUR

CULTUR

CORRUGATA

a TLANTICA

A TLANTICA

a LANTICA

A TLANTICA

A TLANTICA

ATLANTICA

AT LANTICA

ATLANTICA

ATLANTICA

CYLINDRICA

CYLINDRICA

VARIABILIS

VARIABILIS

AR IETINUS

AR IETINUS

BRADYI

BRADY

CAFINATUS

CARINATUS

CARINATUS

CARINATUS

CARINATUS

CARINATUS

CYLINDRACEUS

DISCOIDEUS

DI SCOIDEUS

DISCOIDEUS

LAEVIGATUS

PERTUSUS

PERTUSUS

PERTUSUS

PERTUSUS

PERTUSUS

PERTUSUS

PERTUSUS

PLANATUS

PROTEUS

PRCTEUS

PRCTEUS

PRCTEUS

PROTEUS

PROTEUS

PROTEUS

PPCTEUS

PRCTEUS

PROTEUS

PRCTEUS

PRCTEUS

PRCTEUS

PRCTEUS

PRCTEUS

PRCTEUS

PRCTEUS

PROTEUS

PRCTEUS

PRCTEUS

PRCTEUS

PRCTEUS

PRCTEUS

CENOMANA

AURICULATA

AURICULATA

ACERVALIS

ACERVALIS

ACERVALIS

ACERVALIS

BAY OF CAMPECHE

BAY OF CAMPECHE

NW GULF OF MEXICO

$N W$ GULF OF MEXICO

NW GULF OF MEXICO

NW GULF OF MEXICO

$N W$ GULF OF MEXICO

$N W$ GULF OF MEXICO

NW GULF OF MEXICO

NW GULF OF MEXICO

NW GULF OF MEXICO

NW GULF OF MEXICO 


\section{Publication}

21391 CUSHMAN 1922 A

21392 BANDY 1956

21393 BANDY 1956

21394 BANDY 1956

21395 BANDY 1956

21396 BANDY 1956

21397 BANDY 1956

21398 KELLOUGH 1956

21399 KELLOUGH 1956

21400 KELLOUGH 1956
21401 KELLOUGH 1956

21401 KELLOUGH 1956
21402 KELLOUGH 1956

21403 BANDY 1954

21404 BANDY 1956

21405 BANDY 1954

21406 LOEP 1965

21407 KELLOUGH 1956

21408 BANDY 1956

21409 BANDY 1956

21411 BANDY 1956

21412 BANDY 1956

21413 BANDY 1956

21414 BANDY 1956

21415 BANDY 1956

21416 BANDY 1956

21418 BANDY 1954

21419 BANDY 1956

21420 BANDY 1956

21421 PARKER 1954

21422 PARKER 1954

21423 LUDWICK WALTON 1957

21424 PARKER 1954

21425 PARKER 1954

21426 PARKER 1954

21427 BANDY 1956

21428 ANDERSEN 1961

21429 CUSHMAN 1931

21430 CUSHMAN 193

21431 BOCK 1976

21432 BOCK 1976

21433 BOCK 1976

21434 PARKER 1954

21435 BANDY 1956

21436 BANDY 1956

21437 PARKER 1954

21438 PARKER 1954

21439 PARKER 1954

21440 PHLEGER $1951 \mathrm{~A}$

21441 PHLEGER 1951A

21442 PHLEGER 1951A

21443 PHLEGER 1951 A

21444 PHLEGER 1951A

21445 PHLEGER 1951A

21446 PHLEGER 1951A

21447 PHLEGER 1951 A

21448 PHLEGER 1951A

21449 PHLEGER 1951A

21450 PHLEGER 1951A

21451 PARKER 1954

21452 PARKER 1954

21453 PARKER
21954
21454 PARKER 1954

21455 CUSHMAN 1922 A

21456 NORTON 1930

21457 PARKER 1954

21458 PHLEGER 1951A

21459 PHLEGER 1951A

21460 PFLUM FRERICHS 1976

21461 PFLUM FRERICHS 1976

21462 PFLUM FRERICHS 1976
21463 PFLUM FRERICHS 1976

21464 CREAGER 1958

21464 PARAER 1958

21466 PARKER 1954

21467 PARKER 1954

21468 PARKER 1954

21469 PARKER 1954

21470 PHLEGER 1951 A

21471 PHLEGER 1951A

21472 PHLEGER 1951A

21473 PHLEGER 1951A

21474 PHLEGER 1951A

21475 PHLEGER 1951 A

21476 PHLEGER 1951 A

21477 PHLEGER $1951 \mathrm{~A}$

21479 PFLUM FRERICHS 1976

21480 PFLUM FRERICHS 1976

21481 PFLUM FRERICHS 1976

21482 PFLUM FRERICHS 1976

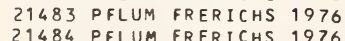

21485 AYALA-CASTANARES 1963

\section{Generic Name}

PLANORBULINA

PLANORBULINA

PLANORBULINA

PLANORBULINA

PLANORBUL INA

PLANORBULINA

PLANORBULINA

PLANORBULINA

PLANORBULINA

PLANORBULINA

PLANORBULINA

PLANORBULINA

PLANORBULINA

PLANORBULINA

PLANORBULINA

PL ANORBULINA

PLAN ORBULINA

PLANORBULINA

PLANORBULINA

PLANORBUL INA

PLANORBULINA

PLANORBULINA

PLANORBULINA

PLANORBULINA

PLANORBULINA

PLANORBULINA

PLANORBULINA

PLANORBULINA

PLANORBUL INA

PLANORBULINA

PLANORBULINA

PLANORBULINA

PLANORBULINA

PLANORBULINA

PLANORBULINA

PLANORBULINA

PLANORBULINA

PL ANORBULINA

PLANORBULINA

PLANORBULINA

PLANORBULINA

PLANORBULINA

PLANORBULINA

PL ANORBULINA

PLANORBUL INA

PLANORBULINA

PLANORBULINA

PLANORBULINA

PLANORBULINA

PLANORBULINA

PLANORBULINA

PLANORBULINA

PLANORBULINA

PLANORBULINA

PL ANORBULINA

PLANORBUL INA

PLANORBULINA

PLANORBULINA

PLANORBULINA

PLANORB ULINA

PLANORBULINA

PLANORBULINA

PLANORBULINA

PLANORBULINA

PLANORBULINA

PLANORBULINELLA

PLANUL INA

PLANUL INA

PLANULINA

PLANULINA

PLANULINA

PL ANULINA

PLANULINA

PLANULINA

PLANULINA

PLANULINA

PLANULINA

PLANUL INA

PLANULINA

PLANULINA

PL ANULINA

PLANULINA

PLANULINA

PLANUL INA

PLANULINA

PLANULINA

PLANUL INA

PLANULINA

PLANULINA

PLANULINA

PLANULINA

PLANULINA

PLANULINA

PLANULINA

PL ANUL INA
Specific Name

ACERVALIS

ME DITERRANENS IS

ME DITERRANENSIS

ME CITERRANENS IS

ME DITERRANENSIS

ME DITERRANENS IS

ME DITERRANENS IS

ME DITERRANENS IS

MECITERRANENSIS

ME DITERRANENSIS

ME OITERRANENS IS

ME CITERRANENSIS

ME DITERRANENSIS

ME DITERRANENSIS

ME DITERRANENSIS

ME DITERRANENS IS

ME DITERRANENSIS

ME OITERRANENS IS

ME DITERRANENSIS

ME CITERRANENSIS

ME CITERRANENSIS

ME DITERRANENSIS

ME DITERRANENSIS

ME DITERRANENS IS

ME CITERRANENSIS

ME CITERRANENS IS

ME DITERRANENSIS

ME DITERRANENSIS

ME DITERRANENSIS

ME DITERRANENSIS

ME CITERRANENS IS

ME CITERRANENS IS

ME OITERRANENSIS

ME DITERRANENSIS

ME CITERRANENS IS

ME DITERRANENS IS

ME CITERRANENS IS

ME CITERRANENSIS

ME DITERRANENS IS

ME DITERRANENS IS

ME DITERRANENS IS

MEDITERRANENSIS

MECITERRANENSIS

ME DITERRANENSIS

ME DITERRANENS IS

ME CITERRANENS IS

MECITERRANENSIS

ME DITERRANENS IS

ME DITERRANENSIS

ME DITERRANENSIS

ME DITERRANENSIS

ME DITERRANENS IS

ME DITERRANENSIS

MEDITERRANENSIS

ME DITERRANENSIS

ME DITERRANENS IS

ME DITERRANENSIS

ME CITERRANENS IS

ME DITERRANENSIS

ME DITERRANENSIS

ME DITERRANENS IS

ME DITERRANENS IS

ME DITERRANENS IS

LARVATA

AR IMINENS IS

AR IMINENS IS

AR IMINENS IS

AR IMINENSIS

AR IMINENS IS

AR IMINENSIS

AR IMINENSIS

AR IMINENS IS

AR IMINENS IS

ARIMINENS IS

ARIMINENSIS

AR IMINENSIS

AR IMINENS IS

AR IMINENSIS

AR IMINENSIS

AR IMINENS IS

AR IMINENSIS

AR IMINENS IS

AR IMINENS IS

AR IMINENS IS

AR IMINENS IS

AR IMINENS IS

AR IMINENS IS

AR IMINENS IS

AR IMINENS IS

AR IMINENS IS

AR IMINENSIS

AR IMINENS IS

AR IMINENS IS

\section{Locality}

Lat. Long.

TORTUGAS

NE GULF OF MEXICO

NE GULF OF MEXICO

NE GULF OF MEXICO

NE GULF OF MEXICO 


\section{Publication}

21486 PARKER 1954 21487 PHLEGER 1951 A 21488 PFLUM FRERICHS 1976 21489 PFLUM FRERICHS 1976 21490 PARKER 1954

21491 PFLUM FRERICHS 1976

21492 PFLUM FRERICHS 1976 21493 PFLUM FRERICHS 1976 21494 PFLUM FRERICHS 1976 21495 PFLUM FRERICHS 1976 21496 PFLUM FRERICHS 1976 21497 PARKER 1954 21498 PARKER 1954

21499 PARKER 1954

21500 BOCK 1976

21501 PFLUM FRERICHS 1976

21502 PFLUM FRERICHS 1976

21503 PHLEGER 1951 A

21504 PARKER 1954

21505 LUDWICK WALTON 1957

21506 PARKER 1954

21507 PHLEGER 1956

21503 PHLEGER 1956

21509 PHLEGER 1956

21510 BOCK 1776

21511 BOCK 1976

21512 BOCK 1976

21513 PHLEGER 1956
21514 PARKER 1954

21514 PARKER 1954
21515 PARKER 1954

21516 PARKER 1954

21517 PARKER 1254

21518 AYALA-CASTANARES 1963

21519 KELLOUGH 1956

21520 KELLOUGH 1956

21521 KELLOUGH 1956

21522 KELLOUGH 1956

21524 KELLOUGH 1956

21525 CREAGER 1958

21526 CREAGER 1958

21527 PHLEGER 1951A

21528 PHLEGER $1951 \mathrm{~A}$

21529 PHLEGER 1951

21531 PARKER 1954

21532 PARKER 1954

21533 PHLEGER $1951 \mathrm{~A}$

21534 PHLEGER $1951 \mathrm{~A}$

21535 PHLEGER 1951 A

21536 PHLEGER $1951 \mathrm{~A}$

21537 PHLEGER $1951 \mathrm{~A}$

21538 PHLEGER $1951 \mathrm{~A}$

21539 PHLEGER $1951 \mathrm{~A}$

21540 PHLEGER $1951 \mathrm{~A}$

21541 PHLEGER 1951A

21542 PHLEGER 1951 A

21543 PARKER 1954

21544 PARKER 1954

21545 PARKER 1954

21546 PARKER 1954

21547 PARKER 1954

21548 PARKER 1954

21549 PHLEGER $1951 \mathrm{~A}$

21550 LANKFORD 1959

21551 PHLEGER 1951 A

21552 PHLEGER 1951A

21553 PHLEGER 1951A

21554 PFLUM FRERICHS 1976

21555 ANDERSEN 1961

21556 PHLEGER 1951 A

21557 PHLEGER $1951 \mathrm{~A}$

21558 PHLEGER 1951A

21559 PHLEGER 1951A

21560 PHLEGER $1951 \mathrm{~A}$

21561 PHLEGER 1951A

21562 PFLUM FRERICHS 1976

21563 PHLEGER 1951 A

21564 LUDWICK WALTON 1957

21565 PARKER 1954

21566 PFLUM FRERICHS 1976

21567 PFLUM FRERICHS 1976

21568 PFLUM FRERICHS 1976

21569 LOEP 1965

21570 BANDY 1956

21571 BANDY 1956

21572 BANDY 1956

21573 CREAGER 1958

21574 CREAGER 1958

21575 CUSHMAN 1931

21576 PARKER 1954

21577 PARKER 1954

21578 PARKER 1954

21579 PHLEGER 1951

21580 PHLEGER $1951 \mathrm{~A}$

\section{Generic Name}

PLANULINA

PLANUL INA
PLANULI INA

PLANULINA

PLANULINA

PL ANULINA

PLANUL INA

PL ANUL INA

PL ANUL INA

PLANUL INA

PLANUL INA

PLANULINA

PLANULINA

PLANUL INA

PLANULINA

PL ANULINA

PLANULINA

PL ANULINA

PLANULINA

PLANULINA

PLANULINA

PL ANULINA

PLANULINA

PLANULINA

PLANULINA

PLANULINA

PLANULINA

PL ANUL INA

PL ANULINA

PLANULINA

PLANULINA

PLANULINA

PLANULI INA

PLANULINA

PL ANUL I NA

PLANULINA

PLANULINA

PLANULINA

PL ANULI INA

PLANULINA

PLANULINA

PLANULINA

PLANULINA

PL ANUL INA

PLANUL INA

PL ANUL INA

PLANUL INA

PLANUL INA

PLANULINA

PLANULINA

PL ANULINA

PLANULINA

PL ANULINA

PLANULI INA

PL ANULINA

PL ANULIINA

PLANUL INA

PL ANUL INA

PLANULINA

PLANULINA

PLANULINA

PL ANUL INA

PL ANUL INA

PLANULINA

PLANUL INA

PLANULI INA

PLANULI INA

PLANULINA

PLANULINA

PLANULINA

PLANULINA

PLANULINA

PL ANUL INA

PLANULINA

PLANULINA

PL ANUL INA

PLANULINA

PLANULINA

PLANULINA

PLANUL INA

PLANULINA

PLANUL INA

PLANUL INA

PLANULINA

PL ANUL INA

PLANULINA

PLANULINA

PLANULINA

PLANULINA

PLANULINA

PL ANUL INA

PLANUL INA

PLANUL INA

PLANULINA

PLANUL INA
Specific Name

AR IMINENS IS

AR IMINENS IS

AR IMINENS IS

A R IMINENS IS

AR IMINENS IS

$A R$ IMINENS IS

AR IMINENS IS

ARIMINENS IS

AR IMINENS IS

AR IMINENS IS

AR IMINENS IS

AR IMINENS IS

AR IMINENS IS

AR IMINENS IS

AR IMINENS IS

AR IMINENS IS

ARIMINEN

EX XRNA

EXCRNA

EXCRNA

EXCRNA

EXCRNA

EXCRNA

EXORNA

EXCRNA

EXCRNA

EXCRNA

EXCRNA

EXCRNA

EXORNA

EX CRNA

EX CRNA

EXCRNA

EXORNA

EXORNA

EXORNA

EXORNA

EX ORNA

EXCRNA

EXORNA

EXCRNA

EXORNA

EXORNA

EXORNA

EXORNA

EXCRNA

EXORNA

EXORNA

EXORNA

EXORNA

EXCRNA

EXCRNA

EXCRNA

EXORNA

EXCRNA

EXCRNA

EX CRNA

EX CRNA

EXCRNA

EXORNA

EX CRNA

EXCRNA

EXCRNA

EXCRNA

EXCRNA

EXCRNA

FOVEOLATA

FOVEOLATA

FOVEOLATA

FOVEOLATA

FOVEOLATA

FOVEOLATA

FOVEOLATA

FOVEOLATA

FOVEOLATA

FOVEOLATA

FOVEOLATA

FOVEOLATA

FOVEOLATA

FOVEOLATA

FOVEOLATA

FOVEOLATA

F OVEOLATA

FOVEOLATA

FOVEOLATA

FOVEOLATA

FOVEOLATA

FOVEOLATA

OLATA

FOVEOLATA

FOVEOLATA

FOVEOLATA

FOVEOLATA

FOVEOLATA

F OVEOLATA

\section{Locality}

Lat. Long. 


\section{Publication}

21581 CREAGER 1958

21582 PARKER 1954

21583 PHLEGER 1955A

21584 CUSHMAN 1931

21585 PARKER 1954

21586 PARKER 1954

21587 PARKER 1954

21588 PARKER 1954

21589 PFLUM FRERICHS 1976

21591 PFLUM FRERICHS 1976

21592 PFLUM FRERICHS 1976

21593 PFLUM FRERICHS 1976

21594 ANDERSEN 1961

21595 BANDY 1956

21596 BANDY 1956

21597 BANDY 1956

21598 BANDY 1956

21599 BANDY 1956

21600 BANDY 1956

21601 BANDY 1956

21602 BANDY 1956

21603 BANDY 1956

21604 BANDY 1956

21605 BANDY 1956

21606 BANDY 1956

21607 BANDY 1956

21608 BANDY 1956

21609 BANDY 1956

21610 BANDY 1956

21611 BANDY 1956

21612 BANDY 1956

21613 BANDY 1954

21614 BANDY 1954

21616 LIDZ LIDZ 1966

21617 BANDY 1954

21618 BANDY 1956

21619 BANDY 1956

21620 PHLEGER $1951 \mathrm{~A}$

21621 PHLEGER $1951 \mathrm{~A}$

21622 PHLEGER $1951 \mathrm{~A}$

21623 PHLEGER $1951 \mathrm{~A}$

21624 PHLEGER 19518

21625 PHLEGER 19518

21626 PHLEGER 1951 A

21627 PHLEGER 1951 A

21628 PHLEGER 1951A

21629 PHLEGER 1951A

21630 PHLEGER 1951A

21631 PHLEGER 1951A

21632 PHLEGER $1951 \mathrm{~A}$

21633 PHLEGER $1951 \mathrm{~A}$

21634 PHLEGER 1951A

21635 PHLEGER 1951 A

21636 PARKER 1954

21637 PARKER 1954

21638 PARKER 1954

21639 PARKER 1954

21640 PARKER 1954

21641 PHLEGER 1955A

21642 PHLEGER 1955 A

21643 PARKER 1954

21644 PARKER 1954

21645 PARKER 1954

21646 PARKER 1954

21647 PARKER 1954

21648 PARKER 1954

21649 PARKER 1954

21650 PARKER 1954

21651 PARKER 1954

21652 PHLEGER 1955 A

21653 PARKER 1954

21654 PARKER 1954

21655 PARKER 1954

21656 CREAGER 1958

21657 PARKER 1954

21658 PARKER 1954

21659 PFLUM FRERICHS 1976

21660 PFLUM FRERICHS 1976

21661 PFLUM FRERICHS 1976

21662 PFLUM FRERICHS 1976

21663 PFLUM FRERICHS 1976

21664 PFLUM FRERICHS 1976

21665 PFLUM FRERICHS 1976

21666 PFLUM FRERICHS 1976

21667 PFLUM FRERICHS 1976

21668 PFLUM FRERICHS 1976

21669 PFLUM FRERICHS 1976

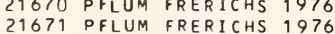

21672 PFLIM FRERICHS 1976

21673 PFLUM FRERICHS 1976

21674 PFLUM FRERICHS 1976

21675 CUSHMAN 1923
Generic Name

PL ANUL INA

PLANULI NA

PL ANULI INA

PLANULINA

PLANULINA

PLANULINA

PL ANUL INA

PLANUL INA

PLANULINA

PLANULINA

PLANUL INA

PLANULINA

PL ANUL INA

PL ANUL INA

PLANULINA

PL ANUL INA

PLANULINA

PLANULI INA

PLANULINA

PLANULI NA

PL ANULINA

PLANULINA

PLANULINA

PLANULI NA

PLANUL INA

PLANULI INA

PL ANULINA

PLANULINA

PLANUL INA

PLANULI INA

PL ANUL INA

PLANULINA

PLANULINA

PLANUL INA

PLANULINA

PLANULINA

PLANULINA

PLANULINA

PLANUL INA

PLANULINA

PLANULINA

PLANULINA

PL ANUL INA

PL ANUL INA

PLANULINA

PLANULINA

PL ANUL INA

PLANULINA

PLANULINA

PL ANULINA

PLANULINA

PLANULINA

PL ANUL INA

PLANUI INA

PLECTINA

PLECTINA

PLECTINA

PLECTINA

PLECTINA

PLECTINA

PLECTINA

PLECTINA

PLECTINA

PLECTINA

PLECTINA

PLECTINA

PLECTINA

PLECTINA

PLECTINA

PLECTINA

PLECTINA

PLECTINA

PLECTINA

PLECTINA

PLECTINA

PLECTINA

PLECTINA

PLEUROSTOMELLA

PLEUROSTOMELLA

PLEUR OS TOMELLA

PLEUROSTOMELLA

PLEUR OSTOMELLA

PLEUROS TOMELLA

PLEUR OS TOMELLA

PLEUROSTOMELLA

PLEUR OST OME LL A

PLEUROS TOMELLA

PLEUROSTOMELLA

PLEUROSTOMELLA

PLEUROSTOMELLA

PLEUROS TOME LLA

PLEUROSTOMELLA

PLEUROSTOMELLA

GL OBUL INA
Specific Name

FOVEOLATA

FOVEOLATA

FOVEOLATA

FOVEOLATA

FOVEOLATA

FOVEOLATA

FOVEOLATA

FOVEOLATA

FOVEOLATA

FOVEOLATA

FOVEOLATA

FO VEOLATA

MERA

ORAATA

ORNATA

ORNATA

OR NATA

ORNATA

ORNATA

ORNATA

ORNATA

ORNATA

ORNATA

ORNATA

ORNATA

ORNATA

ORNATA

ORNATA

ORNAT A

ORAATA

ORNATA

ORNATA

OR NATA

ORNATA

ORNATA

ORNATA

ORNATA

ORNATA

WUELLERSTORF I

WUELLERSTORFI

WUELLER STORF

WUELLERSTORF

WU ELLERSTORFI

WU ELLERST ORFI

WUELLERSTORF

WUELLERSTORF

WUELLERSTORF I

WUELLERSTORF

WUELLERSTORFI

WUELLERSTORF I

WUELLERSTORFI

WUELLERSTORF

WUELLERSTORFI

APICULARIS

APICULARIS

APICULARIS

AP I CULARIS

AP ICULARIS

AP I CULAR IS

APICULARIS

API CULARIS

APICULARIS

APICULARIS

APICULARIS

AP ICULARIS

AP ICULARIS

AP I CULARIS

APICULARIS

APICULARIS

APICULARIS

APICULARIS

APICULARIS

AP I CULARIS

APICULARIS

APICULARIS

AP I CULARIS

BOLIVINOI DES

BOLIVINOIDES

BOLIVINOIDES

BOLIVINOIDES

BOLIVINOIDES

BOLIVINOIDES

BOLIVINOIDES

BOLIVINOIDES

BOLIVINOIDES

BOLIVINOIDES

BOLIVINOIDES

BOLIVINOIDES

BOLIVINOIDES

BOLIVINOIDES

BOLIVINOIDES

BOLIVINOIDES

EQLALIS

Locality

Lat. Long.

BAY OF CAMPECHE

NE GULF OF MEXICO

$N$ GULF OF MEXICO

NE GULF OF MEXICO 


\section{Publication}

21676 CUSHMAN 1922A

21677 CUSHMAN $1922 \mathrm{~A}$

21678 NORTON 1930

21679 BANDY 1956

21680 BANDY 1956

21681 BANDY 1956

21682 CUSHMAV $1922 \mathrm{~A}$

21683 BANDY 1956

21684 BANDY 1956
21685 BANDY 1956

21685 BANDY 1956

21687 BANDY 1956

21688 CUSHMAN $1922 \mathrm{~A}$

21689 NORTON 1930

21690 CUSHMAN $1922 \mathrm{~A}$

21691 VAUGHAN 1918

21692 CUSHMAN $1922 \mathrm{~A}$

21693 CUSHMAN $1922 \mathrm{~A}$

21694 CUSHMAN $1922 \mathrm{~A}$

21695 VAUGHAN 1918

21696 VAUGHAN 1918

21697 VAUGHAN 1918

21698 VAUGHAN 1918

21699 BANDY 1956

21700 BANDY 1956

21701 BANDY 1956

21702 BANDY 1956

21703 BANDY 1956

21704 BANDY 1956

21705 BANDY 1956

21706 BANDY 1956

21707 BANDY 1956

21708 BANDY 1956

21709 BANDY 1956

21710 BANDY 1956

21711 BANDY 1956

21712 BANDY 1956

21713 BANDY 1954

21714 BOCK 1976

21715 LEHMANN 1957

21716 BANDY 1954

21717 BANDY 1954

21719 BANDY 1954

21719 KELLOUGH 1956

21720 KELLOUGH 1956

21721 LOEP 1965

21722 BENDA PURI 1962

21723 ANDERSEN 1961

21724 BANDY 1954

21725 KELLOUGH 1956

21726 BANDY 1954

21727 BANDY 1954

21728 BANDY 1954

21729 KELLOUGH 1956

21730 ANDERSEN 1961

21731 BENDA PURI 1962

21732 POAG 1976

21733 PARKER 1954

21734 PARKER 1954

21735 LANKFORD 1959

21736 PARKER 1954

21737 PARKER 1954

21738 BANDY 1954

21739 BANDY 1956

21740 BANDY 1954

21741 BANDY 1954

21742 BANDY 1954

21743 PARKER 1954

21744 PARKER 1954

21745 PARKER 1954

21746 PARKER 1954

21747 PARKER 1954

21748 PHLEGER 1954

21749 PARKER 1354

21750 LUDWICK WAL

21752 BOCK 1976

21753 PHLEGER 1956

21754 PHLEGER 1956

21755 PHLEGER 1956

21756 PHLEGER 1956

21757 PARKER PHLEGER PEIRSON 1953

21758 PARKER 1954

21759 BANDY 1954

21760 BANDY 1956

21761 BANDY 1954

21762 BANDY 1956

21763 BANDY 1956

21764 PARKER 1954

21765 BANDY 1956

21766 PHLEGER 19558

21767 SHIFFLETT 1961

21768 PHLEGER $1951 \mathrm{~A}$

21769 PHLEGER $1951 \mathrm{~A}$
Generic Name

Specific Name

Locality

Lat. Long.

GL OBUL INA

LARYNGOSIGMA

GUTT ULINA

GUTTULINA

GUTTUL INA

GUTTULINA

GUTTULINA

GUTTULINA

GUTTULINA

GUTTULINA

GUTTULINA

GUTTULINA

GUTTULINA

GUTTULINA

ELPHIDIUM

ELPHIDIUM

ELPHIDIUM

ELPHIDIUM

ELPHIDIUM

ELPHIDIUM

ELPHIDIUM

ELPHIDIUM

ELPHIDIUM

POROEPONIDES

POROEPONIDES

POROEPONIDES

POROEPONIDES

POROEPONIDES

POROEPONIDES

POROEPONIDES

POROEPONIDE

POROEPONIDES

POROEPONIDES

POROEPONIDES

POROEPONIDES

POROEPONIDES

POROEPONIDES

POROEPONIDES

POROEPONIDES

POROEPONIDES

POROEPONIDES

POROEPONIDES

POROEPONIDES

POROEPONIDES

POROEPONIDES

POROEPONIDES

POROEPONIDES

POROEPONIDES

POROEPONIDES

POROEPONIDES

SORITES

SORITES

SORITES

SORITES

SORITES

SORITES

HAYNESINA

SACCAMMINA

SACCAMMINA

SACCAMMINA

SACCAMMINA

SACCAMM

SACCAMMINA

SACCAMMINA
SACCAMMINA

SACCAMM I NA

SACCAMM I NA

SACCAMMINA

SACCAMM I NA

SACCAMMINA

SACCAMMINA

SACCAMM INA

SACCAMM INA

SACC AMMI NA

SACCAMMINA

SACCAMMINA

SACCAMV

SACCAMMINA

SACCAMM INA
SACCAMM INA

SACCAMMINA

SACCAMM INA

SACCAMMINA

SACCAMMINA

SACCAMMINA

SACCAMMINA

SACCAMMINA

SACCAMMINA

SACCAMMINA

SACCAMM INA

SACCAMMINA

SACCAMMINA

SACCAMMINA
SACCAMMINA

SACCAMMINA
SACCAMMINA

SACCAMMINA

SACCAMM INA

SACCAMM INA
$G$ I BBA

LACTEA

PULCHELLA

PULCHELLA

PULCHELLA

PULCHELLA

PULCHELLA

PU LCHELLA

PULCHELLA

PULCHELLA

PULCHELLA

AUSTRALIS

A DVENUM

CR I SPUM

DI SCOIDALE

MACELLUM

POEYANUM

POEYANUM

POEYANUM

POEYANUM

CRIBROREPANDUS

CR IBROREPANDUS

CRIBROREPANDUS

CRIBROREP ANDUS

CRIBROREPANDUS

CR IBROREPANDUS

CR IBROREPAN DUS

CR IBROREPANDUS

CR IBROREPAN DUS

CRIEROREPANDUS

CR IBROREPANDUS

CRIBROREPANDUS

CR IBROREPANDUS

CR IBROREPAN DUS

A TERALIS

LATERALIS

LATERALIS

LATERALIS

LATERALIS

LATERALIS

LATERALIS

LATERALIS

LATERALIS

LA TERALIS

LATERALIS

CRIBROREPANDUS

OREITOLITOIDES

OREITOLITOIDES

ORBITOLITOIDES

OREITOLITOIDES

OREITOL ITOIDES

OREITOLITOIDES

GERMANICA

A T LANTI CA

A T LANTICA

ATLANTICA

A TLANTICA

AT LANTICA

AT LANTI CA

A TLANTI CA

A TLANTICA

ATLANTICA

A T LANTI ICA

A TLANTICA

A T LANTI CA

AT LANTICA

ATLANTICA

A T L AN T I CA

ATLANTICA

ATLANTICA

A TLANTICA

ATLANT ICA

A TLANTICA

A TLANTICA

AT LANTICA

ATLANTICA

A T LANTICA

A TLANTICA

ATLANTICA

ATLANTICA

ATLANTICA

A T LANTICA

A T LANTICA

ATLANTICA

AT LANTI CA

AT LANTICA

AT TANTICA

ATLANTICA

AT LANTICA

ATLANTICA
TORTUGAS

TORTUG AS

TORTUGAS, FLA

NE GULF OF MEXICO

NE GULF OF MEXICO 


\section{Publication}

21771 PHLEGER 1951 A 21772 PHLEGER $1951 \mathrm{~A}$ 21773 PHLEGSR 1451 A 21775 PHLESER 1951A 21776 PHLEGER $1951 \mathrm{~A}$ 21777 PHLEGER 1951 A 21778 PHLEGER 1951 A 21779 PHLEGER 1951 A 21780 PHLEGER $1951 \mathrm{~A}$ 21781 PHLEGER $1951 \mathrm{~A}$ 2178 ? PHLEGER 1951A 21783 PHLEGER $1951 \mathrm{~A}$
21784 PHLEGED $1951 \mathrm{~A}$ 21785 PHLEGER $1951 \mathrm{~A}$ 21786 PHLEGEP $1951 \mathrm{~A}$ 21788 PHLEGER $1951 \mathrm{~A}$ 21789 PHLEGEP 1951A 21790 PARKER 1254 21791 PARKER 1754 21792 PARKER 1254 21794 PARKER 1054 21795 PARKER 1954 21796 KELLOUTH 1956 21797 KELLOUGH 1756 21798 CUSHMAN 1918
21799 CUSHMAN 1918 21800 PHLEGER 1951A 21801 PHLEGEQ 19514 21802 PHLEGER $1951 \mathrm{~A}$ 21903 PHLEGER $1951 \mathrm{~A}$

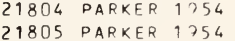
21806 PARKE? 1954

21807 KELLOUSH 1956 21808 PHLEGER 1951A $2180^{\circ}$ PHLEGER $1951 \mathrm{~A}$ 21810 PHLEGER 1951A 21811 PHLEGER 1951A 21812 PHLEGER 1951A 21814 PHLEGER $1951 \mathrm{~A}$ 21815 PHLEGER $1951 \mathrm{~A}$ 21816 PHLEGER $1951 \mathrm{~A}$ 21817 PHLEGER 1951A 21818 DHLFGED 1951A 21819 PHLEGER 1951A 2182 PHLEGER 1951A 21822 PHLEGER 1951A 21823 PHLEGER 1951A 21824 PHLEGEQ $1951 \mathrm{~A}$ 21825 PHLEGER 1951A 21826 PHLEGER $1951 \mathrm{~A}$ 21828 PHLEGER $1951 \mathrm{~A}$ 21829 PARKER 1954 21830 PARKER 1954 21831 PARKER 1254 21832 PARKER 1754 21833 PARKER 1254 21834 PHLEGER $1951 \mathrm{~A}$ 21835 PHLFGFR $1951 \mathrm{~A}$ 21836 PHLEGEP $1951 \mathrm{~A}$ 21837 PARKER 1954 21838 PARKER 1954
21839 PHLEGER $1951 \mathrm{~A}$ 21840 PHLEGER $1951 \mathrm{~A}$ 21841 PARKER 1254 21842 PHLEGED 1951A 21843 PHLEGER $1951 \mathrm{~A}$ 21844 PHLEGEF $1951 \mathrm{~A}$ 21845 PHLEGER $1951 \mathrm{~A}$ 21846 PHLEGER $1951 \mathrm{~A}$ 21848 PHLEGER 1951A 21849 PARKER 1254 21850 PARKER 1754 21851 PARKER 1254 21852 PARKER 1754 21853 PARKER 1254 21855 PARKER 1954 21856 PARKER 1254 21857 PHLEGER 1954 21858 PHLEGER $1955 \mathrm{~B}$ 21859 PARKER P ILEGER PFIRSON 1953 21860 PHLEGER 1954

21861 PARKER PHLEGER PEIRSON 1953 2186? PHLEGER 1954

21863 SHEPARD 190 OOE 1955

21864 OTVOS 1078
Generic Name

SACCAMMINA

SACCAMMINA

SACCAMMINA

SACCAMMINA

SACCAAM I NA

SACCAMMINA

SACCAMMI NA

SACCAMM I NA

SACCAMMINA

SACCAMMINA

SACCAMMIINA

SACCAMMI NA

SACCAMMI NA

SACCA AM I NA

SACCAMMINA

SACCAMMINA

SACCAMMINA

SACCAMMINA

SACCAAM INA

SACCAMMINA

SACCAMMI NA

SACCAMMINA

SACCAMM INA

SACCAMMINA

SACCA,MMINA

SACCAMMINA

SACC AMM INA

SACCAMMINA

SAC CAMMI INA

SACCA MM INA

SACCAMMINA

SACCAMMINA

SACCAMMINA

SACCAMMI NA

SACCAMMI NA

SACCAMMINA

SACCAMMINA

SAC CAMMI NA

SACCAMMINA

SACCAMMI NA

SACCAMMI NA

SACCAMM I NA

SACCAMM I NA

SACCAMMINA

SACCAMMI NA

SAC CAMMINA

SACCAMM I NA

SAC CAMMINA

SACCAMM I NA

SACCAMMINA

SACCAMMINA

SACCAMM I NA

SACCAMMINA

SACCAMMINA

SAC CAMMI NA

SACCAMMINA

SACCAMMI NA

SACCAMM I NA

SACCAMM INA

SACCAMM I NA

SACCAMMINA

SACCAMMI NA

SACCAMM I NA

SACCAMMI NA

SACCAMMINA

SACCAMMINA

SACCAMM I NA

SACCAMMI NA

SAC C AMM I NA

SACCAMMI NA

SACCAMMI NA

SACCAMMI NA

SACCAMMI NA

SACCAMM I NA

SACCAMMI NA

SACCAMMINA

SACCAMMINA

SACCAMM I NA

SACCAMM INA

SAC CAMM INA

SACCAMM I NA
SACCAMM INA

SACCAMM I NA

SACCAMM I NA

\section{Specific Name}

ATLANTICA

ATLANTICA

A TLANTI CA

ATLANTICA

AT LANTICA

ATLANTICA

ATLANTI CA

ATLANTICA
ATLANTICA

ATLANTICA

ATLANTICA

ATLANTICA

A ILANTICA

ATLANTICA

A TLANTI I A

A TLANTICA

ATLANTICA

ATLANTICA

A T LANTI CA

A TLANTICA

AT LANTICA

AT LANTICA

atlantica

ATLANTICA

AT LANTI I A A

A TLANTI CA

A TLANTICA

ATLANTI CA

ATLANTICA

AT LANTICA

ATLANTICA

ATLANTICA

ATLANTI CA

ATLANTICA

ATLANTICA

ATLANTICA

ATLANTICA

A TLANTICA

A TLANTICA

ATLANTICA

ATLANTICA

ATLANTICA

ATLANTICA

ATLANTICA

ATLANTICA

ATLANTICA

at Lantica

A TLANTICA

ATLANTI ICA

A TLANTICA

A TLANTI CA

ATLANTICA

ATLANTICA

ATLANTICA

A TLANTICA

AT LANTI I CA

A TLANTI CA

ATLANTICA

ATLANTI CA

ATLANTICA

ATLANTICA
ATLANTICA

ATLANTICA

AT LANTI I A

ATLANTICA

ATLANTICA

A TLANTICA

ATLANTICA

ATLANTI CA

ATLANTICA

ATLANTICA

ATLANTICA

ATLANTICA

ATLANTICA
ATLANTICA

ATLANTICA

AT LANTICA

A TLANTI I A

ATLANTICA

ATLANTICA

ATLANTICA

ATLANTICA

LA GENARI A

LA GENARIA

LAGENARIA

LAGENARIA

LAGENARIA

LAGENARIA

LA GENARIA

LAGENARI A

LAGENARIA

\section{Locality}

NW GULF OF MEXICO

NW GULF OF MEXICO

NW GULF OF MEXICO

NW GULF OF MEXICO

NW GULF OF MEXICO

NW GULF OF MEXICO

NW GULF OF MEXICO

$N W$ GULF OF MEXICO

NW GULF OF MEXICO

NW GULF OF MEXICO

$N W$ GULF OF MEXICO

NW GULF OF MEXICO

NW GULF OF MEXICO

NW GULF OF MEXICO

$N$ W GULF OF MEXICO

NW GULF OF MEXICO

NW GULF OF MEXICO

NW GULF OF MEXICO

NW GULF OF MEXICO

NE GULF OF MEXICO

NE GULF OF MEXICO

NE GULF OF MEXICO

$\mathrm{NW}$ GULF OF MEXICO

NE GULF OF MEXICO

NE GULF OF MEXICO

NW GULF OF MEXICO

NW GULF OF MEXICO

NE GULF OF MEXICO 


\section{Publication}

211866 CUSHMAN 1918 21867 CUSHMAN 1918 21868 PHLEGER 1965 A 21869 PHLEGER 1905 A 21870 CUSHMAN 1918 21871 CUSHMAN 1918 21872 BANDY 1956 21873 BANDY 1956 21873 BANDY 1956
21874 WARREN 1056 21875 WARREN 1957 21876 PARKER PHLEGER PEIRSON 1953 21877 SHEPARD MOORE 1.955

21878 LANKFORD 1959

21879 PHLEGER $1951 \mathrm{~A}$

21880 PHLEGER 1951A

21881 PARKER 1954

21882 PARKER 1954

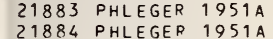

21885 PHLEGER 1951A

21886 PHLEGER 1951A

21887 PHLEGER 1951 A

21888 PHLEGER 1951A

21889 PHLEGER 1951A

21890 PHLEGER 1951A

21891 PHLEGER $1951 \mathrm{~A}$

21892 PHLEGER $1951 \mathrm{~A}$

21893 PHLEGER $1951 \mathrm{~A}$

21894 PHLEGER 1951A

21895 PHLEGER 1951A

21896 PHLEGER 1951A

21897 PFLUM FRERICHS 1976

21898 CREAGER 1958

21899 CREAGER 1958

21900 CREAGER 1958

21901 PFLUM FRERICHS 1976

21902 PFLUM FRERICHS 1976

21903 PFLUM FRERICHS 1976

21904 PFLUM FRERICHS 1976

21905 PFLUM FRERICHS 1976

21906 PFLUM FRERICHS 1976

21907 PFLIJM FRERICHS 1976

21908 PFLUM FRERICHS 1976

21909 PFLUM FRERICHS 1976

21910 PHLEGER 1951A

21911 PHLEGER $1951 \mathrm{~A}$

21912 PARKER 1954

21913 CREAGER 1958

21914 PARKER 1954

21915 PHLEGER 1951A

21916 PFLUM FRERICHS 1976

21917 PFLUM FRERICHS 1976

21918 PFLUM FRERICHS 1976

21919 PFLUM FRERICHS 1976

21920 PFLUM FRERICHS 1976

21921 PFLUM FRERICHS 1976

21922 CREAGER 1958

21923 PARKER 1954

21924 PARKER 1954

21925 PFLUM FRERICHS 1976

21926 PARKER 1954

21927 PARKER 1954

21928 PARKER 1954

21929 PHLEGER 1951A

21930 PHLEGER $1951 \mathrm{~A}$

21931 PARKER 1954

21932 KELLOUGH 1956

21933 KELLOUGH 1956

21935 KELLOUGH 1956

21936 ANDERSEN 1961

21937 PFLUM FRERICHS 1976

21938 PFLUM FRERICHS 1976

21939 PARKER 1954

21940 PARKER 1954

21941 CREAGER 1958

21942 PARKER 1954

21943 CREAGER 1958

21944 PARKER 1954

21945 PARKER 175

21946 PARKER 1954

21947 LUDWICK WALTON 1957

21948 PARKER 1954

21949 WARREN 1957

21950 PHLEGER 1955A

21951 LUDWICK WALTON 1957

21952 PARKER 1954

21953 LANKFORD 1959

21954 PARKER 1954

21955 PARKER 1954

21956 PARKER 1954

21957 PARKER 1954

21958 PARKER 1954

21959 PARKER 1954
21960 PARKER 1954
Generic Name Specific Name

TESTACEA

SACC AMM INA

SACCAMMINA

PROTOSCHISTA
PROTOSCHISTA

PSAMMOSPHAERA

PSAMMOSPHAERA

CLAVUL INA

CLAVULINA

CLAVUL INA

CLAVUL INA

CLAVUL INA

CLAVUL INA

CLAVUL INA

CLAVULINA

CLAVULINA

CLAVULINA

CL AVULINA

CLAVULINA

CLAVULINA

CLAVULINA

CLAVULINA

CL AVUL INA

CLAVULINA

CLAVUL INA

CLAVUL INA

CLAVULINA

CLAVULINA

CLAVULINA

CLAVULINA

CLAVULINA

CLAVULINA

CLAVULINA

CLAVULINA

CLAVUL INA

CLAVULINA

CL AVUL INA

CL AVUL INA

CLAVUL INA

CL AVUL INA

CLAVULINA

CLAVUL INA

CL AVUL INA

CLAVUL I NA

CLAVULINA

CLAVUL INA

CLAVULINA

CLAVULINA

CLAVULINA

CLAVULINA

CLAVULINA

CLAVULINA

CLAVULINA

CLAVULINA

CLAVUL INA

CLAVULINA

CLAVULINA

CLAVULINA

CLAVULINA

CL AVULINA

CL AVULINA

CLAVULINA

CLAVULINA

CLAVULINA

CLAVULINA

CLAVULINA

CLAVULINA

CLAVULINA

CLAVULINA

CLAVULINA

CLAVULINA

CLAVULINA

CLAVULINA

CLAVULINA

CLAVULINA

CL AVUL INA

CL AVUL INA

CLAVULINA

CLAVULINA

CLAVULINA

CLAVULINA

CLAVULINA

CLAVULINA

CLAVULINA

HELENINA

EPONIDES

EPONIDES

EPONIDES

EPONIDES

EPONIDES

EPONIDES

EPONIDES

EPONIDES

EPONIDES

EPONIDES

EPONIDES
Locality

Lat. Long.

NE GULF OF MEXICO

NE GULF OF MEXICO

PASS CAVALLO, TEXAS

PORT ALTO, TEXAS

NE GULF OF MEXICO

NE GULF OF MEXICO

NE GULF OF MEXICO

NE GULF OF MEXICO

BURAS SE LOUISIANA

SE LOUISIANA

TEXAS GULF COAST

CENTRAL TEXAS COAST

MISSISSIPPI DELTA

NW GULF OF MEXICO

NW GULF OF MEXICO

NE GULF OF MEXICO

NE GULF OF MEXICO

NW GULF OF MEXICO

$N W$ GULF OF MEXICO

NW GULF OF MEXICO

NW GULF OF MEXICO

NW GULF OF MEXICO

NW GULF OF MEXICO

NW GULF OF MEXICO

$N W$ GULF OF MEXICO

$\mathrm{NW}$ GULF OF MEXICO

NW GULF OF MEXICO

NW GULF OF MEXICO

NW GULF OF MEXICO

$N W$ GULF OF MEXICO

NW GULF OF MEXICO

NW GULF OF MEXICO

BAY OF CAMPECHE

BAY OF CAMPECHE

NW GULF OF MEXICO

NW GULF OF MEXICO

NW GULF OF MEXICO

NW GULF OF MEXICO

CENTRAL GULF OF MEXICO

NW GULF OF MEXICO

NW GULF OF MEXICO

NW GULF OF MEXICO

NW GULF OF MEXICO

NW GULF OF MEXICO

NW GULF OF MEXICO

NE GULF OF MEXICO

BAY OF CAMPECHE

NE GULF OF MEXICO

NW GULF OF MEXICO

NW GULF OF MEXICO

NW GULF OF MEXICO

NW GULF OF MEXICO

$\mathrm{NW}$ GULF OF MEXICO

NW GULF OF MEXICO

NW GULF OF MEXIC

BAY OF CAMPECHE

NE GULF OF MEXICO

NE GULF OF MEXICO

CENTRAL GULF OF MEXICO

NE GULF OF MEXICO

NE GULF OF MEXICO

NW GULF OF MEXICO

NW GULF OF MEXICO

NE GULF OF MEXICO

NW GULF OF MEXICO

NW GULF OF MEXICO

NW GULF OF MEXICO

MISSISSIPPI DELTA

CENTRAL GULF OF MEXICO

CENTRAL GULF OF MEXICO

NE GULF OF MEXICO

NE GULF OF MEXICO

BAY OF CAMPECHE

NE GULF OF MEXICO

BAY OF CAMPECHE

NE GULF OF MEXICO

NE GULF OF MEXICO

NE GULF OF MEXICO

NE GULF OF MEXICO

NE GULF OF MEXICO

SE LOUISIANA

$N$ GULF OF MEXICD

NE GULF OF MEXICO

NE GULF OF NEXICO

MISSISSIPPI DELTA

NE GULF OF MEXICO

NE GULF OF MEXICO

NE GULF OF MEXICO

NE GULF OF MEXICO

NE GULF OF MEXICO

$2844 \mathrm{~N} 086 \quad 18 \mathrm{~W}$

$2708 \mathrm{~N} 08808 \mathrm{~W}$

$2822 \mathrm{~N} 096 \quad 24 \mathrm{~W}$

$2838 \mathrm{~N} 096 \quad 25 \mathrm{~W}$

$2805 \mathrm{~N} 08756 \mathrm{~W}$

$\begin{array}{llll}28 & 43 \mathrm{~N} & 087 & 15 \mathrm{~W}\end{array}$

$2810 N 084$ W 


\section{Publication}

21961 PARKER 1954 21962 PARKER 1954 21963 PARKER 1954
21964 PHLEGER 1955 A 21965 PARKER 1954 21966 PHLEGER 1955 A 21967 PHLEGER 1955 A 21968 CREAGER 1958 21969 CREAGER 1958 21970 CREAGER 1958 21971 CREAGER 1958 21972 CREAGER 1958 21973 CREAGER 1958 21974 PARKER 1954 21975 PARKER 1954 21976 PHLEGER 1955A
21977 PHLEGER 1955A 21978 PARKER 1954 21979 PARKER 1954 21980 PARKER 1954 21981 PARKER 1954 21982 PARKER 1954 21983 PARKER 1954
21984 PHLEGER 1955 A 21985 PARKER 1954 21986 CREAGER 1958 21987 CREAGER 1958 21988 CREAGER 1958 21989 CREAGER 1958 21990 CREAGER 1958 21991 PARKER 1954 21992 PARKER 1954 21993 PARKER 1954 21994 LOEP 1965 21995 CREAGER 1958 21996 PARKER 1954 21997 PARKER 1954 21998 PARKER 1954 22000 LUDWICK WALTON 1957 22001 PARKER 1954

22002 CREAGER 1958 22003 CREAGER 1958 22004 PHLEGER $1951 \mathrm{~A}$ 22005 PARKER 1954 22006 PARKER 1954 22007 LOEP 1965 22008 PHLEGER $1951 \mathrm{~A}$ 22009 PARKER 1954 22010 PHLEGER 1951 A 22011 PHLEGER $1951 \mathrm{~A}$ 22012 PHLEGER 1951A 22013 PHLEGER 1951A 22014 PHLEGER 1951A 22015 PHLEGER $1951 \mathrm{~A}$ 22016 PFLUM FRERICHS 1976 22017 PFLUM FRERICHS 1976 22018 PFLUM FRERICHS 1976 22019 ANDERSEN 1961

22020 PFLUM FRERICHS 1976 22021 BOCK 1976

22022 BOCK 1976

22023 LEROY HODGKINSON 1975 22024 ANDERSEN 1961 22025 ANDERSEN 1961 22026 ANDERSEN 1961 22027 PHLEGER 1951A 22028 PHLEGER 1951A 22029 PHLEGER 1951A 22030 PHLEGER 1951A 22031 PHLEGER 1951B 22032 PHLEGER $1951 \mathrm{~A}$ 22033 PHLEGER 1951 A 22034 PHLEGER $1951 \mathrm{~A}$ 22035 PHLEGER 1951A 22036 PHLEGER 1951A 22037 PHLEGER $1951 \mathrm{~A}$ 22038 PHLEGER 1951A 22040 DAVIS 1964

22041 PHLEGER 1951A 22042 PHLEGER $1951 \mathrm{~A}$ 22043 PHLEGER $1951 \mathrm{~A}$ 22044 PHLEGER $1951 \mathrm{~A}$ 22045 PHLEGER $1951 \mathrm{~A}$ 22046 PHLEGER $1951 \mathrm{~A}$ 22047 PHLEGER $1951 \mathrm{~A}$ 22049 PHLEGER 1951 A 22050 PHLEGER 1951A 22051 PHLEGER $1951 \mathrm{~A}$ 22052 PHLEGER $1951 \mathrm{~A}$ 22053 PHLEGER $1951 \mathrm{~A}$ 22054 PHLEGER 1951 A
Generic Name

EPONIDES

EP ONIDES

EPON IDES

EPONIDES

EPONIDES

EPONIDES

EPONIDES

EPONIDES

EPONIDES

EPONIDES

EPONIDES

EPONIDES

EPONIDES

EPONIDES

EPONIDES

EPONIDES

EPONIDES

EPONIDES

EPONIDES

EPONIDES

EPONIDES

EPONIDES

EPONIDES

EPONIDES

PONIDE

EPONIDES

EPONIDES

EPONIDES

EPONIDES

EPONIDES

EPONIDES

NODOSARIA

NODOSARIA

NODOSARIA

NODOSARIA

NODOSAR IA

NODOSARIA

NODOSARIA

NODOSAR I A

NO DOSARIA

NODOSARIA

NODOSARIA

NODOSARIA

NODOSARIA

NODOSARIA

NODOSAR IA

NODOSAR IA

NODOSAR IA

NODOSARIA

NODOSAR I A

NODOSARI A

NODOSARIA

NODOSARIA

NODOSAR IA

NODOSARIA

NODOSARIA

NODOSAR I A

NODOSAR IA

RECTOBOL IVINA

RECTOBOLIVINA

PSEUDONODOSARIA

NONI ONELLA

NONI ONELLA

NONI ONELLA

AL ABAMINA

AL ABAMINA

AL ABA MINA

AL ABAMI NA

ALABAMINA

AL ABAMINA

AL ABAMINA

AL ABAMINA

AL ABAMINA

ALABAMINA

AL ABAMINA

AL AB AMINA

ALABAMINA

AL AB AMINA

EP ISTOMINELLA

EP ISTOM INELLA

EP ISTOMINELLA

EP ISTOMINELLA

EPISTOMINELLA

EP IST OMI NELLA

EP IST OM INE LLA

EPIST OMINELLA

EPISTOMINELLA

EPISTOMINELL

EP IST OMI NELLA

EP ISTOMI NELLA

EP ISTOMINELLA

EPISTOMINELLA

EP ISTOMINELLA

\section{Specific Name}

UMEONATUS

UMEONATUS

UMBONATUS

UMEONATUS

UMEONATUS

UMBONATUS

UMBONATUS

UMBONAT US

UMBONATUS

UMBONAT US

UMEONATUS

UMBONATUS

UMEONATUS

UM BONATUS

UMEONATUS

UMEONATUS

UMEONATUS

UMEONATUS

UMBONATUS

UMBONATUS

UMEONATUS

UMEONATUS

UMEONATUS

UMBONATUS

UMEONATUS

UMBONATUS

UMEONATUS

UMEONATUS

UMBONATUS

UMEONATUS

UMEONATUS

UMEONATUS

UMEONATUS

COMATULA

CONATULA

CONATULA

COMATULA

CONATULA

CONATULA

CONATULA

CONATULA

COMATULA

COMATULA

CONATULA

COMATULA

CONATULA

COMATULA

COMATULA

COMATULA

CONATULA

COMATULA

CONATULA

COMATULA

CONATULA

CONATULA

COMATULA

CONATULA

CONATULA

CONATULA

COMATULA

MAYORI

PORRECTA

TORR I DA

AT LANTICA

GRATEL OUP

DE CORATA

DE CORATA

DE CORATA

DE CORATA

DE CORATA

DE CORATA

DE CORATA

DE CORATA

DE CORATA

DE CORATA

DE CORATA

DECORATA

DE CORATA

DE CORATA

EXIGUA

EXIGUA

EXIGUA

EXIGUA

EXIGUA

EXIGUA

EXIGUA

EXIGUA

EXIGUA

EXIGUA

EXIGUA

EXIGUA

EXIGUA

EXIGUA

EXIGUA

Locality

NE GULF OF MEXICO

NE GULF OF MEXICO

NE GULF OF MEXICO

$N$ GULF OF MEXICO

NE GULF OF MEXICO

$N$ GULF OF MEXICO

$N$ GULF OF MEXICO

BAY OF CAMPECHE

BAY OF CAMPECHE 


\section{Publication}

22056 PHLEGER $1951 \mathrm{~A}$ 22057 PHLEGER 1951 22058 PHLEGER $1951 \mathrm{~A}$ 22059 PHLEGER $1951 \mathrm{~A}$ 22060 PHLEGER $1951 \mathrm{~A}$ 22061 PHLEGER 1951A 22062 PHLEGER 1951 A 22063 PHLEGER $1951 \mathrm{~A}$ 22064 PHLEGER 1951 22065 PHLEGER $1951 \mathrm{~A}$ 22066 PHLEGER 1951 A 22067 PHLEGER $1951 \mathrm{~A}$ 22068 PHLEGER 1951A 22069 PHLEGER 1951A 22070 PHLEGER 1951 A 22071 PHLEGER $1951 \mathrm{~A}$ 22072 PHLEGER $1951 \mathrm{~A}$ 22073 PHLEGER 1951 A 22074 PHLEGER $1951 \mathrm{~A}$ 22075 PHLEGER 1951A 22076 PHLEGER 1951 A 22077 PHLEGER 1951A 22078 PHLEGER 1951 A 22079 PHLEGER $1951 \mathrm{~A}$ 22080 CREAGER 1958

22081 CREAGER 1958

22082 CREAGER 1958

22083 PHLEGER $1951 \mathrm{~A}$

22084 PHLEGER $1951 \mathrm{~A}$

22085 PHLEGER 1951 A

22086 PHLEGER 1951 A

22087 PHLEGER $1951 \mathrm{~A}$

22083 PHLEGEP 1951 A

22089 PHLEGER 1951A

22090 PHLEGER 1951A

22091 PHLEGER $1951 \mathrm{~A}$

22092 PHLEGER $1951 \mathrm{~A}$

22093 PHLEGER 1951 A

22094 PHLEGER $1951 \mathrm{~A}$

22096 PHLEGER 1951 A

22097 PHLEGER 1951A

22098 PHLEGER 1951 A

22099 PHLEGER $1951 \mathrm{~A}$

22100 PHLEGER $1951 \mathrm{~A}$

22101 PHLEGER 1951A

22102 PHLEGER 1951A

22103 PHLEGER 1951A

22104 PHLEGER $1951 \mathrm{~A}$

22105 PHLEGER 1951A

22106 PFLUM FRERICHS 1976

22107 PFLUM FRERICHS 1976

22108 FRERICHS 1969

22109 PFLUM FRERICHS 1976

22110 PFLUM FRERICHS 1976

22111 PFLUM FRERICHS 1976

22112 PFLUM FRERICHS 1976

22113 PFLUM FRERICHS 1976

22114 PFLUM FRERICHS 1976

22115 PFLUM FRERICHS 1976

22116 PFLUM FRERICHS 1976

22117 PFLUM FRERICHS 1976

22118 FRERICHS 1969

22119 PFLUM FRERICHS 1976

22120 PFLUM FRERICHS 1976

22121 PFLUM FRERICHS 1976

22122 PFLUM FRERICHS 1976

22123 PFLUM FRERICHS 1976

22124 PFLUM FRERICHS 1976

22125 PFLUM FRERICHS 1976

22126 PFLUM FRERICHS 1976

22127 PFLUM FRERICHS 1976

22128 PFLUM FRERICHS 1976

22129 PFLUM FRERICHS 1976

22130 PFLUM FRERICHS 1976

22131 PFLUM FRERICHS 1976

22132 PFLUM FRERICHS 1976

22133 PFLUM FRERICHS 1976

22134 PFLUM FRERICHS 1976

22135 PFLUM FRERICHS 1976

22136 PFLUM FRERICHS 1976

22137 PFLUM FRERICHS 1976

22138 PFLUM FRERICHS 1976

22139 PFLUM FRERICHS 1976

22140 PHLEGER 1951A

22141 PFLUM FRERICHS 1976

22142 PHLEGER $1951 \mathrm{~A}$

22143 PHLEGER $1951 \mathrm{~A}$

22144 PHLEGER $1951 \mathrm{~A}$

22145 PHLEGER 1951A

22146 PHLEGER 1951 A

22147 PHLEGER 1951 A

22148 PHLEGER 1951A

22149 PHLEGER $1951 \mathrm{~A}$
22150 PHLEGER $1951 \mathrm{~A}$
Generic Name Specific Name

EXIGUA

EP IS TOM I NELL A

EP ISTOMINELLA

EP ISTOMINELLA

EP ISTOM I NELLA

EP ISTOMINE LLA

EP ISTOMINE LLA

EP IST OMINELLA

EPISTOMINELLA

EP ISTOMINELLA

EP I ST OMINELLA

EP ISTOM INELLA

EPISTOMINELLA

EPISTOMINELLA

EP IS TOM I NELL

EP I STOM I NE LLA

EP ISTOMINELLA

EP ISTOMI NELLA

EPISTOMINELLA

EP ISTOMINELLA

EP ISTOMINELLA

EP ISTOMINELLA

EP ISTOMINELLA

EP IS TOMI NELLA

EPISTOMINELLA

EP ISTOMINELLA

EP ISTOMINELLA

OS ANGULARIA

OS ANGULARI A

OS ANGULARIA

OS ANGULARIA

OS ANGUL ARIA

OS ANGULARI A

OS ANGULARIA

OS ANGULARIA

OS ANGUL ARI A

OSANGULARIA

OS ANGULLARIA

OS ANGULARIA

OS ANGULARIA

OSANGULARIA

OSANGULARIA

OSANGULARIA

OS ANGUL ARIA

OSANGULARIA

OSANGULARIA

OSANGULARIA

OS ANGULARIA

OS ANGUL ARI A

PSEUDOTROCHAMMINA

PSEUDOTROCHAMMINA

PSEUDOTROCHAMMINA

PSEUDOTROCHAMMINA

PSEUDOTROCHAMMINA

PSEUDOTROCHAMMINA

PSEUDOTROC HAMMINA

PSEUDOTROCHAMMINA

PSEUDOTROCHAMMINA

PSEUDOTROCHAMMINA

PSEUDOTROCHAMMINA

PSEUDOTROCHAMMINA

PSEUDOTROCHAMMINA

PSEUDOTROCHAMMINA

PSEUDOTROCHAMMINA

PS EUDOTROCHAMMINA

PSEUDOTROCHAMMINA

PSEUDOTROCHAMMINA

PSEUDOTROCHAMMINA

PSEUDOTROCHAMMINA

PSEUDOTROCHAMMINA

PSEUDOTROCHAMMINA

PSEUDOTROCHAMMINA

PSEUDOTROCHAMMINA

PSEUDOTROCHAMMINA

PSEUDOTROCHAMMINA

PSEUDOTROCHAMMINA

PSEUDOTROCHAMMINA

PSEUDOTROCHAMMINA

PSEUDOTROCHAMMINA

PSEUDOTROCHAMMINA

PULLENIA

PULLENIA

PULLENIA

PULLENIA

PULLENIA

PULLENIA

PULLENIA

PULLENIA

PULLENIA

PULLENIA

PULLENIA

PULLENIA

PULLENIA
Locality

Lat. Long.

VW GULF OF MEXICO

NW GULF OF MEXICO

NW GULF OF MEXICO

NW GULF OF MEXICO

NW GULF OF MEXICO

NW GULF OF MEXI

NW GULF OF MEXICO

NW GULF OF MEXICO

NW GULF OF MEXICO

$N$ W GULF OF MEXICO

NW GULF OF MEXICO

$N W$ GULF OF MEXICO

NW GULF OF MEXICO

NW GULF OF MEXICO

NW GULF OF MEXICO

NW GULF OF MEXICO

NW GULF OF MEXICO

NW GULF OF MEXICO

NW GULF OF MEXICO

NW GULF OF MEXICO

NW GULF OF MEXICO

NW GULF OF MEXICO

BAY OF CAMPECHE

BAY OF CAMPECHE

NW GULF OF MEXICO

NW GULF OF MEXICO

NW GULF OF MEXICO

NW GULF OF MEXICO

NW GULF OF MEXICO

NW GULF OF MEXICO

NW GULF OF MEXICO

NW GULF OF MEXICO

NW GULF OF MEXICO

$N W$ GULF OF MEXICO

NW GULF OF MEXICO

$N \&$ GULF OF MEXICO

NW GULF OF MEXICO

NW GULF OF MEXICO

NW GULF OF MEXICO

NW GULF OF MEXICO

NW GULF OF MEXICO

$N W$ GULF OF MEXICO

NW GULF OF MEXICO

N\& GULF OF MEXICO

NW GULF OF MEXICO

NW GULF OF MEXICO

NW GULF OF MEXICO

CENTRAL GULF OF MEXICO

CENTRAL GULF OF MEXICO

CENTRAL G. OF MEXICO

NW GULF OF MEXICO

NW GULF OF MEXICO

NW GULF OF MEXICO

NW GULF OF MEXICO

NW GULF OF MEXICO

NW GULF OF MEXICO

NW GULF OF MEXICO

CENTRAL GULF OF MEXICO

NW GULF OF MEXICO

CENTRAL G. OF MEXICO

NW GULF OF MEXICO

CENTRAL GULF OF MEXICO

CENTRAL GULF OF MEXICO

NW GULF OF MEXICO

NW GULF OF MEXICO

NW GULF OF MEXICO

NW GULF OF MEXICO

$N W$ GULF OF MEXICO

NW GULF OF MEXICO

NW GULF OF MEXICO

NW GULF OF MEXICO

Nh GULF OF MEXICO

N. GULF OF MEXICO

NW GULF OF MEXICO

NW GULF OF MEXICO

NW GULF OF MEXICO

NW GULF OF MEXICO

NW GULF OF MEXICO

NW GULF OF MEXICO

NW GULF OF MEXICO

NW GULF OF MEXICO

$N W$ GULF OF MEXICO

NW GULF OF MEXICO

$\mathrm{Nh}$ GULF OF MEXICO

$\mathrm{NW}$ GULF OF MEXICO

NW GULF OF MEXICO

N. GULF OF MEXICO

Wh GULF OF MEXICO

$N_{W}$ GULF OF MEXICO

NW GULF OF MEXICU

NW GULF OF MEXICO

$2718 \mathrm{~N} 09614 \mathrm{~W}$ $\begin{array}{llll}26 & 59 N & 096 & 11 \mathrm{~W} \\ 27 & 30 \mathrm{~N} & 095 & 10 \mathrm{~W}\end{array}$ $2633 \mathrm{~N} 09440 \mathrm{~W}$ $2658 \mathrm{~N} 09557 \mathrm{~W}$ $2710 \mathrm{~N} 09622 \mathrm{~W}$ $2825 \mathrm{~N} 09149 \mathrm{~W}$ 
Publication

22151 PHLEGER $1951 \mathrm{~A}$ 22152 PHLEGER 1951A 22153 PHLEGER 1951A 22154 PHLEGER 1951 A 22155 PHLEGER 1951A 22156 LUDWICK WALTON 1957 22157 PARKER 1954 22158 PARKER 1954 22159 PHLEGER $1951 \mathrm{~A}$ 22160 PHLFGER 1951A 22161 PHLEGER $1951 \mathrm{~A}$ 22162 PFLUM FRERICHS 1976 22163 PFLUM FRERICHS 1976 22164 PFLUM FRERICHS 1976 22165 PFLUM FRERICHS 1976 22166 PFLUM FRERICHS 1976 22167 PHLEGER 1951A 22168 PHLEGER $1951 \mathrm{~A}$ 22169 PHLEGER 1951A 22170 PFLUM FRERICHS 1976 22171 PHLEGER 1951A

22172 PFLUM FRERICHS 1976 22173 PFLUM FRERICHS 1976 22174 PFLUM FRERICHS 1976 22175 PFLUM FRERICHS 1976 22176 PFLUM FRERICHS 1976 22177 PFLUM FRERICHS 1976 22178 PFLUM FRERICHS 1976 22179 PFLUM FRERICHS 1976 22180 PFLUM FRERICHS 1976 22181 PFLUM FRERICHS 1976 22182 PFLUM FRERICHS 1976 22183 PFLUM FRERICHS 1976 22184 PFLUM FRERICHS 1976 22185 PFLUM FRERICHS 1976 22186 PFLUM FRERICHS 1976 22187 PFLUM FRERICHS 1976 22188 PFLUM FRERICHS 1976 22189 PFLUM FRERICHS 1976 22190 PFLUM FRERICHS 1976 22191 PFLUM FRERICHS 1976 22192 PFLUM FRERICHS 1976 22193 PFLUM FRERICHS 1976 22194 PFLUM FRERICHS 1976 22195 PHLEGER $1951 \mathrm{~A}$ 22196 PHLEGER 1951A 22197 PFLUM FRERICHS 1976 22198 PHLEGER 1951A

22199 PFLUM FRERICHS 1976 22200 PFLUM FRERICHS 1976 22201 PFLUM FRERICHS 1976 22202 PFLUM FRERICHS 1976 22203 PHLEGER 1951A

22204 PFLUM FRERICHS 1976 22205 PFLUM FRERICHS 1976 22206 PARKER 1954

22207 PARKER 1954

22208 PFLUM FRERICHS 1976 22209 PFLUM FRERICHS 1976 22210 PFLUM FRERICHS 1976 22211 ANDERSEN 1961

22212 LOEP 1965

22213 LOEP 1965

22214 PFLUM FRERICHS 1976 22215 PFLUM FRERICHS 1976 22216 PFLUM FRERICHS 1976 22217 PHLEGER 1951A

22218 PFLUM FRERICHS 1976 22219 PFLUM FRERICHS 1976 22220 PFLUM FRERICHS 1976 22221 CREAGER 1958 22222 PARKER 1954
22223 PARKER 1954 22224 CREAGER 1958 22225 CREAGER 1958 22226 CREAGER 1958 22227 CREAGER 1958 22228 CREAGER 1958 22229 CREAGER 1958 22230 PARKER 1954 22231 PARKER 1954 22232 PARKER 1954 22233 PARKER 1954 22234 PARKER 1954 22235 PARKER 1954 22236 PARKER 1954 22237 PARKER 1954 22238 PARKER 1954 22239 PARKER 1954

22240 PFLUM FRERICHS 1976 22241 PARKER 1954

22242 PARKER 1954

22243 PARKER 1954

22244 PARKER 1954
22245 PARKER 1954
Generic Name

PULLENI

NI A

PULLENIA

PULLENIA

PULLENIA

PULLENIA

PULLENIA

PULLENIA

PULLENIA

PULLENIA

PULLENIA

PULLENIA

PULLENIA

PULLENIA

PULLENIA

PULLENIA

PULLENIA

PULLENIA

PULLENIA

PULLENIA

PULLENIA

PULLENIA

PULLENIA

PULLENIA

PULLENIA

PULLENIA

PULLENIA

PULLENIA

PULLENIA

PULLENIA

PULLENIA

PULLENIA

PULLENIA

PULLENIA

PULLENIA

PULLENIA

PULLENIA

PULLENIA

PULLENIA

PULLENIA

PULLENIA

PULLENIA

PULLENIA

PULLENIA

PULLENIA

PULLENIA

PULLENIA

PULLENIA

PULLENIA

PULLENIA

PULLENIA

PULLENIA

PULLENIA
PULLENIA

PULLENIA

PULLENIA

PULLENIA

PULLENIA

PULLENIA

PULLENIA

PULLENIA

PULLENIA

PULLENIA

PULLENIA

PULLENIA

PULLENIA

PULLENIA

PULLENIA

PULLENIA

PULLENIA

PULLENIA

PULLENIA

PULLENIA

PULLENIA

PULLENIA

PULLENIA

PULLENIA

PULLENIA

PULLENIA

PULLENIA

PULLENIA

PULLENIA

PULLENIA

PULLENIA

PULLENIA

PULLENIA
PULLENIA

PULLENIA

PULLENIA

PULLENIA
Specific Name

BULLOIDES

BULLOIDES

BULLOIDES

BULLOIDES

BULLOIDES

BULLOIDES

BULLOIDES

BULLOIDES

BULLOIDES

BULLOIDES

BULLOIDES

BULLOIDES

BULLOIDES

BULLOIDES

BULLOIDES

BULLOIDES

BULLOIDES

BULLOIDES

BULLOIDES

BULLOIDES

BULLOIDES

BULLOIDES

BULLOIDES

BULLOIDES

BULLOIDES

BULLOIDES

BULLOIDES

BULLOIDES

BULLOIDES

BULLOIDES

BULLOIDES

BULLOIDES

BULLOIDES

BULLOIDES

BULLOIDES

BULLOIDES

BULLOIDES

BULLOIDES

BULLOIDES

BULLOIDES

BULLOIDES

BULLOIDES

BULLOIDES

BULLOIDES

BULLOIDES

BULLOIDES

BULLOIDES

BULLOIDES

BULLOIDES

BULLOIDES

BULLOIDES

BULLOIDES

BULLOIDES

BULLOIDES

BULLOIDES

BULLOIDES

BULLOIDES

BULLOIDES

BULLOIDES

BULLOIDES

BULLOIDES

BULLOIDES

BULLOIDES

BULLOIDES

BULLOIDES

BULLOIDES

BULLOIDES

BULLOIDES

BULLOIDES

BULLOIDES

BULLOIDES

BULLOIDES

BULLOIDES

BULLOIDES

BULLOIDES

BULLOIDES

BULLOIDES

BULLOIDES

BULLOIDES

BULLOIDES

BULLOIDES

BULLOIDES

BULLOIDES

BULLOIDES

BULLOIDES

BULLOIDES

BULLOIDES

BULLOIDES

BULLOIDES

BULLOIDES

BULLOIDES

BULLOIDES

BULLOIDES

BULLOIDES

BULLOIDES

Locality

Lat. Long.

NW GULF OF MEXICO

NW GULF OF MEXICO

NW GULF OF MEXICO

NW GULF OF MEXICO

NW GULF OF MEXICO

NE GULF OF MEXICO

IVE GULF OF MEXICO

NE GULF OF MEXICO

NW GULF OF MEXICO 
Publication

22246 PARKER 1954 22247 PARKER 1954
22248 PFLUM FRERICHS 1976 22248 PFLUM FRERI

22250 PFLUM FRERICHS 1976 22251 PFLUM FRERICHS 1976 22252 PFLUM FRERICHS 1976 22253 PFLUM FRERICHS 1976

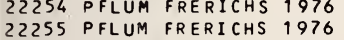
22255 PFLUM FRERICHS
22256 PFLUM FRERICHS 1976 22257 PFLUM FRERICHS 1976 22258 PFLUM FRERICHS 1976 22259 PFLUM FRERICHS 1976 22260 PFLUM FRERICHS 1976 22261 PFLUM FRERICHS 1976 22262 PFLUM FRERICHS 1976 22263 PFLUM FRERICHS 1976 22264 PFLUM FRERICHS 1976 22265 PFLUM FRERICHS 1976 22266 PFLUM FRERICHS 1976 22267 PFLUM FRERICHS 1976 22268 PFLUM FRERICHS 1976 22269 PFLUM FRERICHS 1976 22270 PFLUM FRERICHS 1976 22271 PFLUM FRERICHS 1976 22272 PFLUM FRERICHS 1976 22273 PFLUM FRERICHS 1976 22274 PFLUM FRERICHS 1976 22275 PFLUM FRERICHS 1976 22276 PFLUM FRERICHS 1976 22277 PFLUM FRERICHS 1976 22278 PFLUM FRERICHS 1976 22279 PHLEGER 1951A

22280 PHLEGER 1951A

22281 PFLUM FRERICHS 1976

22282 PFLUM FRERICHS 1976

22283 PFLUM FRERICHS 1976

22284 PFLUM FRERICHS 1976

22285 PFLUM FRERICHS 1976

22286 PFLUM FRERICHS 1976

22288 PFLUM FRERICHS 1976

22289 PFLUM FRERICHS 1976

22290 PFLUM FRERICHS 1976

22291 PFLUM FRERICHS 1976

22292 PFLUM FRFRICHS 1976

22293 PFLUM FRERICHS 1976

22294 PFLUM FRERICHS 1976

22295 PFLUM FRERICHS 1976

22296 PFLUM FRERICHS 1976

22297 PARKER 1954

22298 PARKER 1954

22299 PARKER 1954

22300 PARKER 1954

22301 PARKER 1954

22302 PARKER 1954

22303 PFLUM FRERICHS 1976

22304 PARKER 1954

22305 PARKER 1954

22306 PARKER 1954

22307 PARKER 1954

22308 PARKER 1954

22309 PARKER 1954

22310 PARKER 1954

22311 PHLEGER $1951 \mathrm{~A}$
22312 PHLEGER $1951 \mathrm{~A}$

22313 PHLEGER $1951 \mathrm{~A}$

22314 PHLEGER 1951A

22315 PHLEGER 1951A

22316 PHLEGER 1951A

22317
22318 PHLEGER
PHLEER 1951A
$251 \mathrm{~A}$

22319 PHLEGER 1951A

22320 PHLEGER 1951 A

22321 PHLEGER 1951A

22322 PHLEGER 1951A

22323 PHLEGER 1951A

22324 PHLEGER 1951A

22325 PHLEGER 1951A

22326 PHLEGER 1951A

22327 PHLEGER $1951 \mathrm{~A}$

22328 PHLEGER $1951 \mathrm{~A}$

22329 PARKER 1954

22330 PARKER 1954

22331 PARKER 1954

22332 PHLEGER 1951 A

22333 PHLEGER 1951A
22334 PFLUM FRERICHS 1976

22335 PFLUM FRERICHS 1976

22336 PFLUM FRERICHS 1976

22337 PFLUM FRERICHS 1976

22338 PFLUM FRERICHS 1976

22339 PFLUM FRERICHS 1976

22340 PFLUM FRERICHS 1976
Generic Name

Specific Name

Locality

Lat. Long.

PULLENIA

PULLENIA

PULLENIA

PULLENIA

PULLENIA

PULLENIA

PULLENIA

PULLENIA

PULLENI A

PULLENIA

PULLENIA

PULLENIA

PULLENIA

PULLENIA

PULLENIA

PULLENIA

PULLEN I A

PULLENIA

PULLENIA

PULLENIA

PULLENIA

PULLEN I A

PULLENIA

PULLENIA

PULLENIA

PULLENIA

PULLENIA

PULLENIA

PULLENIA

PULLENIA

PULLENIA

PULLENIA

PULLENIA

PULLENIA

PULLENIA

PULLENI A

PULLENIA

PULLENIA

PULLENIA

PULLENIA

PULLENIA

PULLENIA

PULLENIA

PULLENIA

PULLENIA

PULLENIA

PULLENIA

PULLENIA

PULLENIA

PULLENIA

PULLENIA

PULLENIA

PULLEN I A

PULLENIA

PULLENIA

PULLENIA

PULLENI A
PULLENI A

PULLENIA

PULLENIA

PULLENIA

PULLENIA

PULLEN IA

PULLENIA

PULLENIA

PULLENIA

PULLENIA

PULLENIA

PULLENIA

PULLENIA

PULLENIA

PULLENIA

PULLENIA

PULLENIA

PULLENIA

PULLENIA

PULLENIA

PULLENIA

PULLENIA

PULLENIA

PULLENIA

PULLENIA

PULLENIA

PULLENIA
PULLENIA

PULLENIA

PULLENIA

PULLENIA

PULLENIA

PULLENIA

PULLENIA

PULLENIA

PULLENIA

PULLENIA
BULLOIDES

BULLOIDES

BULLOIDES

BULLOIDES

OSLOENSIS

OS LOENSIS

OS LOENSIS

OSLOENSIS

OS LOENSIS

OS LOENS IS

OSLOENSIS

OS LOENSIS

OS LOENSIS

OSLOENSIS

OSLOENS IS

OSLOENSIS

OS LOENSIS

OS LOENSIS

OS LOENSIS

OSLOENSIS

OS LOENSIS

OS LOENSIS

OSLOENSIS

OSLOENSIS

OSLOENSIS

OS LOENSIS

OSLOENSIS

OS LOENS IS

OS LOENSIS

OSLOENSIS

OS LOENS IS

QU INQUEL OBA

QU INQUE LOBA

QU INQUELOBA

QU INQUE LOBA

QU INQUELOBA

QUINQUELOBA

QUINQUELOBA

QU INQUELOBA

QU INQUELOBA

QUINQUELOBA

QUINQUELOBA

QU INQUE LOBA

QUINQUELOBA

QU INQUELOBA

QU INQUELOBA

QU INQUELOBA

QU INQUE LOBA

QU INQUELOBA

QUINQUELOBA

QU INQUELOBA

QU INQUE LOBA

QUINQUELOBA

QUINQUELOBA

QUINQUELOBA

QU INQUE LOBA

QU INQUELOBA

QU INQUELOBA

QU INQUELOBA

QU INQUELOBA

QU INQUELOBA

QU INQUELOBA

QU INQUE $L B A$

QU INQUEL) BA

QU INQUELOBA

QU INQUELOBA

QU INQUE LOBA

QU INQUE LOBA

QU INQUELOBA

QU INQUEL OBA

QU INQUELOBA

QU INQUELOBA

QU INQUE LOBA

QUINQUELOBA

QU INQUE LOBA

QUINQUELOBA

QU INQUELOBA

QUINQUELOBA

QU INQUELOBA

QU INQUELOBA

QU INQUEL OBA

QU I NQUELOBA

QUINQUELOBA

QU INQUELOBA

QU INQUELOBA

QU INQUELOBA

QU INQUEL OBA

QUINQUELOBA

QU INQUELOBA

QU INQUELOBA

QU INQUELOBA

QUINQUELOBA

QU INQUELOBA

QU INQUELOBA

QU INQUELOBA
NE GULF OF MEXICO

NE GULF OF MEXICO

CENTRAL GULF OF MEXICO

NE GULF OF MEXICO

NH GULF OF MEXICO

NH GULF OF MEXICO

NW GULF OF MEXICO

NH GULF OF MEXICO

NH GULF OF MEXICO 


\section{Publication}

22341 PFLUM FRERICHS 1976 22342 PFLUM FRERICHS 1976 22343 PHLEGER $1951 \mathrm{~A}$ 22344 PHLEGER $1951 \mathrm{~A}$ 22346 LEPOY HODGKINSON" 1975 22347 PHLEGER $1951 \mathrm{~A}$ 22348 PHLEGER 1951 A 22349 PHLEGER 1951A 22350 PHLEGER 1951 A 22351 PHLEGER $1951 \mathrm{~A}$ 22352 PHLEGER 1951A 22353 PHLEGER 1951 A 22354 PHLEGER 1951 A 22355 PHLEGER 1951A 22356 PHLEGER 1951A 22357 PHLEGER $1951 \mathrm{~A}$ 22358 PHLEGER $1951 \mathrm{~A}$

22359 PFLUM FRERICHS 1976 22360 PFLUM FRERICHS 1976 22361 PFLUM FRERICHS 1976 22362 PFLUM FRERICHS 1976 22363 PFLUM FRERICHS 1976 22364 PFLUM FRERICHS 1976 22365 PFLUM FRERICHS 1976 22366 PFLUM FRERICHS 1976 22367 PFLUM FRERICHS 1976 22368 PFLUM FRERICHS 1976 22369 PFLUM FRERICHS 1976 22370 PFLUM FRERICHS 1976 22371 PFLUM FRERICHS 1976 22372 PFLUM FRERICHS 1976 22373 PFLUM FRERICHS 1976 22374 PFLUM FRERICHS 1976 22375 PARKER 1954 22376 CREAGER 1958 22377 CREAGER 1958 22378 CREAGER 1959 22379 AOCK 1976

22380 CREAGER 1958

22381 PFLUM FRERICHS 1976 22382 PFLUM FRERICHS 1976 22383 BANDY 1956

22384 CREAGER 1958

22385 CREAGER 1958

22386 CREAGER 1958

22387 PARKER 1954

22388 PHLEGER 1956

22389 PARKER 1954

22390 PARKER 1954

22392 PARKER 1954

22393 PARKER 1954

22394 PARKER 1954

22395 PARKER 1954

22396 PARKER 1954

22397 PFLUM FRERICHS 1976 22398 PFLUM FRERICHS 1976 22399 PFLUM FRERICHS 1976 22400 PFLUM FRERICHS 1976 22401 PFLUM FRERICHS 1976 22402 PFLUM FRERICHS 1976 22403 PFLUM FRERICHS 1976 22404 PFLUM FRERICHS 1976 22405 PFLUM FRERICHS 1976 22406 PFLUM FRERICHS 1976 22407 PFLUM FRERICHS 1976 22408 PFLUM FRERICHS 1976 22409 PFLUM FRERICHS 1976 22410 PFLUM FRERICHS 1976 22411 PFLUM FRERICHS 1976 22412 PFLUM FRERICHS 1976 22413 PFLUM FRERICHS 1976 22414 PFLUM FRERICHS 1976 22415 PFLUM FRERICHS 1976 22416 PFLUM FRERICHS 1976 22417 PFLUM FRERICHS 1976 22418 PFLUM FRERICHS 1976 22419 PFLUM FRERICHS 1976 22420 ANDERSEN 1961

22421 PFLUM FRERICHS 1976 22422 PFLUM FRERICHS 1976 22423 PFLUM FRERICHS 1976 22424 PFLUM FRERICHS 1976 22425 PFLUM FRERICHS 1976 22426 PFLUM FRERICHS 1976 22427 PFLUM FRERICHS 1976 22428 PFLUM FRERICHS 1976 22429 PFLUM FRERICHS 1976 22430 PFLUM FRERICHS 1976 22431 PFLUM FRERICHS 1976 22432 PFLUM FRERICHS 1976 22433 PFLUM FRERICHS 1976 22434 PFLUM FRERICHS 1976 22435 PFLUM FRERICHS 1976

\section{Generic Name}

PULLENIA

PULLENIA

PULLENIA

PULLENIA

PULLENIA

PULLENIA

PULLENIA

PULLENIA

PULLENIA

PULLENIA

PULLENIA

PULLENIA

PULLENIA

PULLENIA

PULLENIA

PULLENIA

PULLENIA

PULLENIA

PULLENIA

PULLENIA

PULLENIA

PULLENIA

PULLENIA

PULLENIA

PULLENIA

PULLENIA

PULLENIA

PULLENIA

PULLENIA

PULLENIA

PULLENIA

PULLENIA

PULLENIA

PULLENIA

PULLENIA

PULLENIA

PULLENIA

PULLENIA

PULLENIA

PULLENIA

PULLNIA

PULLENIA

PULLENIA

PULLENIA

PULLENIA

PULLENIA

PULLENIA

PULLENIA

PULLENIA

PULLENIA

PULLENIA

PULLENIA

PULLENIA

PULLENIA

PULLENIA

PULLENIA

PULLENIA

PULLENIA

PULLENIA

PULLENIA

PULLENIA

PULLENIA

PULLENIA

PULLENIA

PULLENIA

PULLENIA

PULLENIA

PULLENIA

PULLENIA

PULLENIA

PULLENIA

PULLENIA

PULLENIA

PULLENIA

PULLENIA

PULLENIA

PULLENIA

PULLENIA

PULLENIA

PULLENIA

PULLENIA

PULLENIA

PULLENIA

PULLENIA

PULLENIA

PULLENIA

PULLENIA

PULLENIA

\section{Specific Name}

QU INQUELOBA

QU INQUE LOBA

QU INQUE LOBA

QU INQUELOBA

QU INQUELOBA

QU INQUELOBA

QUINQUELOBA

QU INQUELOBA

QU INQUELOSA

QU INQUELOBA

QU INQUELOBA

QU INQUELOBA

QU INQUELOBA

QU INQUELOEA

QU INQUELOBA

QU INQ UEL OBA

QU INQUE LOBA

QU INQUELOBA

QU INQUEL OBA

QU INQUELOEA

QU INQUELOBA

QU INQUELOBA

QU INQUELOBA

QU INQUELOBA

QU INQUELOBA

QU INQUE LOBA

QU INQUELOBA

QU INQUELOBA

QU INQUELOBA

QU INQUELOBA

QU INQUELOEA

QU INQUELOBA

QU INQUELOBA

QU INQUELOBA

QU INQUELOBA

QU INQUELOBA

QU INQUELOEA

QU INQUEL OBA

QU INQUELOBA

QU INQUELOBA

QUINQUELOBA

QU INQUELOBA

QU INQUELOBA

QU INQUELOBA

QU INQUELOEA

QU INQ UEL OBA

QU INQUELOBA

QU INQUELOBA

QU INQUE LOBA

QU INQUELOBA

QU INQUEL OBA

QUINQUELOBA

QUINQUELOBA

QU INQUELOEA

QU INQUELOBA

QU INQ UE LOBA

QU INQUELOSA

QUINQUELOBA

QU INQ UELOBA

QU INQUELOBA

QU INQUELOBA

QU INQUELOBA

QU INQUELOBA

QU INQUELOBA

QU INQUELOBA

QU INQUELOBA

QUINQUELOBA

QU INQUELOBA

QUINQUELOBA

QU INQUELOBA

QU INQUELOBA

QU INQUELOBA

QU INQUELOBA

QUINQUELOBA

QU INQUELOBA

QU INQUELOBA

QU INQUE LOBA

QU INQUELOBA

QU INQUE LOBA

SUESPHAER ICA

SUESPHAER ICA

SUESPHAER ICA

SUESPHAER ICA

SUESPHAER ICA

SUESPHAERICA

SUESPHAER ICA

SUESPHAER ICA

SUESPHAER ICA

SUESPHAER ICA

SUESPHAERICA

SUESPHAER ICA

SUBSPHAER ICA

SUESPHAER ICA

SUESPHAER ICA

\section{Locality}

NW GULF OF MEXICO

NW GULF OF MEXICO

NW GULF OF MEXICO

NW GULF OF MEXICO

$\mathrm{NW}$ GULF OF MEXICO

$N$ GULF OF MEXICO 


\section{Publication}

22436 PFLUM FRERICHS 1976 22437 PFLUM FRERICHS 1976 22438 PFLUM FRERICHS 1976 22439 PFLUM FRERICHS 1976 22440 PFLUM FRER ICHS 1976

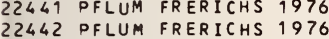
22443 PFLUM FRERICHS 1976 22444 PFLUM FRERICHS 1976 22445 PFLUM FRERICHS 1976 22446 PFLUM FRERICHS 1976 22447 PFLUM FRERICHS 1976 22448 PFLUM FRERICHS 1976 22449 PFLUM FRERICHS 1976 22450 PFLUM FRERICHS 1976 22451 PFLUM FRERICHS 1976 22452 PFLUM FRERICHS 1976 22453 PFLUM FRERICHS 1976 22454 PFLUM FRERICHS 1976 22455 PFLUM FRERICHS 1976 22456 PFLUM FRERICHS 1976
22457 LEROY HODGINSON 1975 22457 LEROY HODGKINSON 197 22459 PFLUM FRERICHS 1976 22460 PFLUM FRERICHS 1976 22461 PFLUM FRERICHS 1976 22462 PFLUM FRERICHS 1976 22463 PFLUM FRERICHS 1976 22464 PFLUM FRERICHS 1976 22465 PFLUM FRERICHS 1976 22466 PFLUM FRERICHS 1976

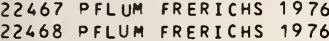
22468 PFLUM FRERICHS 1976
22469 PFLUM FRERICHS 1976 22470 PFLUM FRERICHS 1976 22471 PFLUM FRERICHS 1976 22472 PFLUM FRERICHS 1976 22473 PFLUM FRERICHS 1976 22474 PFLUM FRERICHS 1976 22475 PFLUM FRERICHS 1976 22476 PFLUM FRERICHS 1976 22477 PFLUM FRERICHS 1976 22478 PFLUM FRERICHS 1976 22479 PFLUM FRERICHS 1976 22480 PFLUM FRERICHS 1976 22481 PFLUM FRERICHS 1976 22482 PFLUM FRERICHS 1976 22483 PFLUM FRERICHS 1976 22484 PFLUM FRERICHS 1976 22485 PFLUM FRERICHS 1976 22486 PFLUM FRERICHS 1976 22487 PFLUM FRERICHS 1976 22488 PFLUM FRERICHS 1976 22489 PFLUM FRERICHS 1976 22490 PFLUM FRERICHS 1976 22491 PFLUM FRERICHS 1976 22492 PFLUM FRERICHS 1976 22493 PFLUM FRERICHS 1976 22494 PFLUM FRERICHS 1976 22495 PFLUM FRERICHS 1976 22496 PFLUM FRERICHS 1976 22497 PFLUM FRERICHS 1976 22498 PFLUM FRERICHS 1976 22499 PFLUM FRERICHS 1976

22500 PFLUM FRERICHS 1976

22501 PFLUM FRERICHS 1976

22502 PFLUM FRERICHS 1976

22503 PFLUM FRERICHS 1976

22504 VAUGHAN 1918

22505 VAUGHAN 1918

22506 DAVIS 1964

22507 ANDERSEN 1961

22508 NORTON 1930
22509 ANDERSEN 1961

22510 BANDY 1954

22511 BANDY 1954

22512 BANDY 1954

22513 DAVIS 1964

22514 BANDY 1954

22515 BANDY 1954

22516 BANDY 1954
22517 BANDY 1954

22518 LEROY HODGKINSON 1975

22519 KELLOUGH 1956

22520 BANDY 1956

22521 BANDY 1956

22522 BANDY 1956

22523 BOCK 1976

22524 BANDY 1956
22525 BANDY 1954

22526 BANDY 1954

22527 BANDY 1954

22528 BANDY 1956

22529 LANKFORD 1959

22530 NORTON 1930
Generic Name

PULLENIA

PULLENIA

PULLENIA

PULLENIA

PULLENIA

PULLENIA

PULLENIA

PULLENIA

PULLENIA

PULLENIA

PULLENIA

PULLENIA

PULLENIA

PULLENIA

PULLENIA

PULLENIA

PULLENIA

PULLENIA

PULLENIA

PULLENIA

PULLENIA

PULLENIA

PULLENIA

PULLENIA

PULLENIA

PULLENIA

PULLENIA

PULLENIA

PULLENIA

PULLENIA

PULLENIA

PULLENIA

PULLENIA

PULLENIA

PULLENIA

PULLENIA

PULLENIA

PULLENIA

PULLENIA

PULLENIA

PULLENIA

PULLENIA

PULLENIA

PULLENIA

PULLENIA

PULLENIA

PULLENIA

PULLENIA

PULLENIA

PULLENIA

PULLENIA

PULLENIA

PULLENIA

PULLENIA

PULLENIA

PULLENIA

PULLENIA

PULLENIA

PULLENIA

PULLENIA

CANCRIS

HOEGLUNDINA

EPONIDES

PENEROPLIS

PYRGO

PYRGO

PYRGO

PYRGO

PYRGO

PYRGO

PYRGO

PYRGO

PYRGO

PYRGO

PYRGO

PYRGO

PYRGO

PYRGO

PYRGO

PYRGO

PYRGO

PYRGO

PYRGO

PYRGO

PYRGO
Specific Name

SUBSPHAERICA

SUESFHAERICA

SUESPHAER ICA

SUESPHAER ICA

SUESPHAER ICA

SUESPHAERICA

SUESPHAERICA

SUESPHAERICA

SUESPHAERICA

SUESPHAER ICA

SUESPHAERICA

SUESPHAER ICA

SUESPHAER ICA

SUESPHAERICA

SUESPHAERICA

SUESPHAER ICA

SUBSPHAERICA

SUESPHAERICA

SUESPHAERICA

SUESPHAERICA

SUESPHAER ICA

SUESPHAER ICA

SU BSPHAERICA

SUESPHAERICA

SUESPHAER ICA

SUESPHAERICA

SUESPHAER ICA

SU $B$ P HAER ICA

SUESPHAERICA

TRINITATENS IS

TRINITATENS IS

TRINITATENS IS

TR INI TA TENS IS

TR INI TATENS IS

TR INITATENSIS

TRINITATENS IS

TR INI TATENS IS

TR INITATENS IS

TRINITATENS IS

TR INI TATENS IS

TR INITATENSIS

TRINI TATENS IS

TR INI TATENS IS

TR INITATENS IS

TRINITATENS IS

TRINITATENSIS

TR INI TA TENSIS

TRINITATENSIS

TR INI TATENS IS

TR INI TATENSIS

TRINITATENS IS

TR INI TATENS IS

TR INITATENS IS

TRINI TATENSIS

TR INITATENS IS

TRINI TATENS IS

TR INITATENS IS

TR INITATENS IS

TRINITATENS IS

TR INITATENS IS

TR INI TATENS IS

TR INITATENS IS

TRINITATENS IS

TR INITATENS IS

TR INI TATENS IS

TR INI TATENS IS

AURI CULA

ELEGANS

IN CERATUS

PROTEUS

AN OMALA

CARINATA

CLYPEATA

CLYPEATA

CLYPEATA

CLYPEATA

COMATA

CONATA

COMATA

COMATA

COMATA

COMATA

COMATA

COMATA

COMATA

COMATA

COMATA

COMATA

COMATA

CONATA

CONATA

DENTI CULATA

Locality

Lat. Long.

NW GULF OF MEXICO NW GULF OF MEXICO NW GULF OF MEXICO

NW GULF OF MEXICO

NW GULF OF MEXICO

NU GULF OF MEXICO

CENTRAL GULF OF MEXICO

CENTRAL GULF OF MEXICO

CENTRAL GULF OF MEXICO

CENTRAL GULF OF MEXICO

CENTRAL GULF OF MEXICO

CENTRAL GULF OF MEXICO

CENTRAL GULF OF MEXICO

NW GULF OF MEXICO

NH GULF OF MEXICO

NW GULF OF MEXICO

NH GULF OF MEXICO

NW GULF OF MEXICO 


\section{Publication}

22531 BOCK 1976

22533 PFLUM FRERICHS 1976

22534 CREAGER 1958

22535 PFLUM FRERICHS 1976

22536 PFLUM FRERICHS 1976

22537 PFLUM FRERICHS 1976

22538 PFLUM FRERICHS 1976

22539 PFLUM FRERICHS 1976

22540 CUSHMAN 1929

22541 PFLUM FRERICHS 1976

22542 PFLUM FRERICHS 1976

22543 PFLUM FRERICHS 1976

22544 PFLUM FRERICHS 1976

22545 PFLUM FRERICHS 1976

22546 PFLUM FRERICHS 1976

22547 BOCK 1976

22548 LEROY HODGKINSON 1975

22549 PFLUM FRERICHS 1976

22550 PFLUM FRERICHS 1976

22551 PFLUM FRERICHS 1976

22552 PFLUM FRERICHS 1976

22553 PFLUM FRERICHS 1976

22554 PFLUM FRERICHS 1976

22555 PFLUM FRERICHS 1976

22556 PFLUM FRERICHS 1976

22557 PFLUM FRERICHS 1976
22558 LEROY HODGKINSON 1975

22559 BOCK 1976

22560 PFLUM FRERICHS 1976

22561 PFLUM FRERICHS 1976

22562 PFLUM FRERICHS 1976

22563 PFLUM FRERICHS 1976

22564 PFLUM F.RERICHS 1976

22565 PFLUM FRERICHS 1976

22566 BOCK 1976

22567 PFLUM FRERICHS 1976

22568 PFLUM FRERICHS 1976

22569 PFLUM FRERICHS 1976

22570 PFLUM FRERICHS 1976

22571 PFLUM FRERICHS 1976

22572 PFLUM FRERICHS 1976

22573 PFLUM FRERICHS 1976

22574 PFLUM FRERICHS 1976

22575 PFLUM FRERICHS 1976

22576 PFLUM FRERICHS 1976

22577 PFLUM FRERICHS 1976

22578 PFLUM FRERICHS 1976

22579 PFLUM FRERICHS 1976

22581 PFLUM FRERICHS 1976

22581 PFLUM FRERI
22582 NORTON 1930

22583 LEROY HODGKINSON 1975

22584 PFLUM FRERICHS 1976

22585 PFLUM FRERICHS 1976

22586 NORTON 1930

22587 CREAGER 1958

22588 PFLUM FRERICHS 1976

22589 PARKER 1954

22590 PFLUM FRERICHS 1976

22591 PFLUM FRERICHS 1976

22592 PFLUM FRERICHS 1976

22593 PFLUM FRERICHS 1976

22594 PFLUM FRERICHS 1976

22595 PFLUM FRERICHS 1976

22596 PFLUM FRERICHS 1976

22597 PFLUM FRERICHS 1976

22598 PFLUM FRERICHS 1976

22599 PFLUM FRERICHS 1976

22600 PFLUM FRERICHS 1976

22601 PFLUM FRERICHS 1976

22602 PFLUM FRERICHS 1976

22603 PFLUM FRERICHS 1976

22604 PFLUM FRERICHS 1976

22605 PFLUM FRERICHS 1976

22606 PFLUM FRERICHS 1976

22607 PFLUM FRERICHS 1976

22608 PFLUM FRERICHS 1976

22609 PARKER 1954

22610 PARKER 1954

22611 PARKER 1954

22612 PARKER 1954

22613 PARKER 1954

22614 PARKER 1954

22615 PARKER 1954

22616 PARKER 1954

22617 PFLUM FRERICHS 1976

22618 PFLUM FRERICHS 1976

22619 PFLUM FRERICHS 1976

22620 PFLUM FRERICHS 1976

22621 PFLUM FRERICHS 1976

22622 PFLUM FRERICHS 1976

22623 PFLUM FRERICHS 1976

22624 PFLUM FRERICHS 1976

22625 PFLUM FRERICHS 1976

Generic Name

PYRGO

PYRGO

PYRGO

PYRGO

PYRGO

PYRGO

PYRGO

PYRGO

PYRGO

PYRGO

PYRGO

PYRGO

PYRGO

PYRGO

PYRGO

PYRGO

PYRGO
PYRGO

PYRGO

PYRGO

PYRGO

PYRGO

PYRGO

PYRGO

PYRGO

PYRGO

PYRGO

PYRGO

PYRGO

PYRGO

PYRGO

PYRGO

PYRGO

PYRGO

PYRGO

PYRGO

PYRGO

PYRGO

PYRGO

PYRGO

PYRGO

PYRGO

PYRGO

PYRGO

PYRGO

PYRGO

PYRGO

PYRGO

PYRGO

PYRGO

PYRGO

PYRGO

PYRGO

PYRGO

PYRGO

PYRGO

PYRGO

PYRGO

PYRGO

PYRGO

PYRGO

PYRGO

PYRGO

PYRGO

PYRGO

PYRGO

PYRGO

PYRGO

PYRGO

PYRGO

PYRGO

PYRGO

PYRGO

PYRGO

PYRGO

PYRGO

PYRGO

PYRGO

PYRGO

PYRGO

PYRGO

PYRGO

PYRGO
Specific Name

DEATI CULATA

DEFRESSA

DEPRESSA

DEPRESSA

DEFRESSA

DEPRESSA

DEFRESSA

DEPRESSA

DEPRESSA

DE PRESSA

DEPRESSA

DEPRESSA

DEPRESSA

DEPRESSA

DEPRESSA

DEFRESSA

DEFRESSA

DEPRESSA

DEPRESSA

ELCNGATA

EL CNGATA

EL CNGATA

EL ONGATA

ELCNGATA

EL CNGATA

EL CNGATA

EL ONGATA

EL ONGATA

ELCNGATA

ELCNGATA

ELCNGATA

EL ONGATA

FO FNASINI I

LUCERNULA

LUCERNULA

LU CERNULA

LUCERNULA

LU CERNULA

LUCERNULA

LUCERNULA

LUCERNULA

LU CERNULA

LUCERNULA

LUCERNULA

LU CERNULA

LUCERNULA

LU CERNULA

LU CERNULA

LU CERNULA

LUCERNULA

LUCERNULA

LU CERNULA

MI LLETT I I

MURRH INA

MURRH INA

MURRH INA

MURRHINA

MURRHINA

MURRH INA

MURRH INA

MURRHINA

MURRHINA

MU RRH INA

MURRH INA

MU FRH INA

MURRH INA

MURRHINA

MURRHINA

MURRH INA

MURRHINA

MURRH INA

MURRH INA

MURRHINA

MURRH INA

MURRH INA

MURRH INA

MURRHINA

MURRH INA

MURRH INA

MURRH INA

MURRHINA

MURRH INA

MURRH INA

MURRH INA

MURRH INA

MURRH INA

MURRHINA

MURRH INA

MURRHINA

MURRHINA

MURRHINA
MURRHINA

Locality

Lat. Long.

NE GULF OF MEXICO

NE GULF OF MEXICO

CENTRAL GULF OF MEXICO

BAY OF CAMPECHE

$N W$ GULF OF MEXICO

NW GULF OF MEXICO

$N W$ GULF OF MEXICO

NW GULF OF MEXICO

NW GULF OF MEXICO

NE GULF OF MEXIC

CENTRAL GULF OF MEXICO

CENTRAL GULF OF MEXICO

CENTRAL GULF OF MEXICO

CENTRAL GULF OF MEXICO

CENTRAL GULF OF MEXICO 


\section{Publication}

22626 PFLUM FRERICHS 1976 22627 PFLUM FRERICHS 1976 22628 PFLUM FRERICHS 1976 22629 PFLUM FRERICHS 1976 22630 PFLUM FRERICHS 1976 22631 PFLUM FRERICHS 1976 22631
22632
PFLLUM FRERICHS 1976 22633 PFLUM FRERICHS 1976 22633
$2 F L U M$ 22635 PFLUM FRERICHS 1976 22636 PFLUM FRERICHS 1976 22637 PFLUM FRERICHS 1976 22638 PFLUM FRERICHS 1976 22639 PFLUM FRERICHS 1976 22640 PFLUM FRERICHS 1976 22641 PFLUM FRERICHS 1976 22642 PFLUM FRERICHS 1976 22643 PFLUM FRERICHS 1976 22644 CREAGER 1958

22645 CUSHMAN 1929

22646 CUSHMAN 1929

22647 CUSHMAN 1929

22648 PFLUM FRERICHS 1976

22649 PHLEGER $1951 \mathrm{~A}$

22651 PHLEGER 1951A

22652 PHLEGER 1951 A

22653 PHLEGER $1951 \mathrm{~A}$

22654 PHLEGER $1951 \mathrm{~A}$

22655 PHLEGER 1951 A

22656 PFLU 1 FRERICHS 1976

22657 PFLUM FRERICHS 1976

22658 PHLEGER 1951A

22659 PHLEGER 1951A

22660 PHLEGER 1951A

22661 PHLEGER 1951A

22662 PHLEGER $1951 \mathrm{~A}$

22664 PFLUM FRERICHS 1976

22665 PHLEGER $1951 \mathrm{~A}$

22666 PHLEGER 1951A

22667 PHLEGER 1951A
22668 PFLUM FRERICHS 1976

22669 PFLUM FRERICHS 1976

22670 PFLUM FRERICHS 1976

22671 PFLUM FRERICHS 1976

22672 PFLUM FRERICHS 1976

22673 PFLUM FRERICHS 1976

22674 LEROY HODGKINSON 1975

22675 PHLEGER $1951 \mathrm{~A}$

22676 PHLEGER $1951 \mathrm{~A}$

22677 PARKER 1954

22678 PFLUM FRERICHS 1976

22679 PFLUM FRERICHS 1976

22680 PFLUM FRERICHS 1976

22681 LUDWICK WALTON 1957

22682 PARKER 1954

22683 PARKER 1954

22684 PARKER 1954

22685 PARKER 1954

22686 PARKER 1954

22687 PARKER 1954

22688 PARKER 1954

22689 PARKER 1954

22690 PARKER 1954

22691 PARKER 1954

22692 PARKER 1954

22693 BANDY 1956

22694 BANDY 1956

22695 BANDY 1956

22696 ANDERSEN 1961

22697 BANDY 1956

22698 BANDY 1956

22699 KELLOUGH 1956

22700 CREAGER 1958

22701 KELLOUGH 1956

22702 KELLOUGH 1956

22703 KELLOUGH 1956

22704 PHLEGER $1951 \mathrm{~A}$

22705 CREAGER 1958

22706 BOCK 1976

22707 PARKER 1954

22708 PARKER 1954

$\begin{array}{lll}22709 & \text { CREAGER } & 1958 \\ 22710 & \text { CREAGER } & 1958\end{array}$

22711 PARKER 1954

22712 PARKER 1954

22713 PARKER 1954

22714 PARKER 1954

22715 PARKER 1954

22716 PARKER 1954

22717 LUDWICK WALTON 1957

22718 PARKER 1954

22720 PARKER 1954
Generic Name Specific Name Locality

\begin{tabular}{|c|c|c|c|c|c|}
\hline PYRGO & MURRH INA & ULF & \multicolumn{3}{|c|}{ IEXICO } \\
\hline PYRGO & MURRH INA & CENTRAL & GULF & of & MEXICO \\
\hline PYRGO & MURRHINA & CENTRAL & GULF & of & MEXICO \\
\hline PYRGO & MURRHINA & CENTRAL & GULF & OF & MEXICO \\
\hline PYRGO & MURRHINA & CENTRAL & GULF & OF & MEXICO \\
\hline PYRGO & MURRHINA & CENTRAL & GULF & OF & MEXICO \\
\hline PYRGO & MU RRH INA & CENTRAL & GULF & of & MEXICO \\
\hline PYRGO & MURRH INA & CENTRAL & GULF & OF & MEXICO \\
\hline PYRGO & MURRHINA & CENTRAL & GULF & OF & MEXICO \\
\hline PYRGO & MU RRH I NA & CENTRAL & GULF & of & MEXICO \\
\hline PYRGO & MU RRH I NA & CENTRAL & GULF & OF & MEXICO \\
\hline PYRGO & MURRHINA & CENTRAL & GULF & OF & MEXICO \\
\hline PYRGO & MURRHINA & CENTRAL & GULF & of & MEXICO \\
\hline PYRGO & MU RRH I NA & CENTRAL & GULF & of & MEX I CO \\
\hline PYRGO & MURRHINA & CENTRAL & GULF & OF & MEXICO \\
\hline PYRGO & MURRHINA & CENTRAL & GULF & $O F$ & MEXICO \\
\hline PYRGO & MU RRH I NA & CENTRAL & GULF & OF & MEXICO \\
\hline PYRGO & MURRHINA & NH GULF & $O F M E$ & $=X I C$ & \\
\hline
\end{tabular}

BAY OF CAMPECHE

NE GULF OF MEXICO

NE GULF OF MEXICO

NE GULF OF MEXICO

CENTRAL GULF OF MEXICO

NW GULF OF MEXICO

N GULF OF MEXICO

NH GULF OF MEXICO

NH GULF OF MEXICO

NH GULF OF MEXICO

NW GULF OF MEXICO

NW GULF OF MEXICO

NW GULF OF MEXICO

NW GULF OF MEXICO

NH GULF OF MEXICO

NH GULF OF MEXICO

NW GULF OF MEXICO

NW GULF OF MEXICO

NH GULF OF MEXICO

NW GULF OF MEXICO

CENTRAL GULF OF MEXICO

NH GULF OF MEXICO

NH GULF OF MEXICO

NH GULF OF MEXICO

NW GULF OF MEXICO

NW GULF OF MEXICO

NH GULF OF MEXICO

NW GULF OF MEXICO

NW GULF OF MEXICO

NH GULF OF MEXICO

$N$ GULF OF MEXICO

NH GULF OF MEXICO

NW GULF OF MEXICO

NE GULF OF MEXICO

NH GULF OF MEXICO

NW GULF OF MEXICO

NW GULF OF MEXICO

NE GULF OF MEXICO

NE GULF OF MEXICO

NE GULF OF MEXICO

NE GULF OF MEXICO

NE GULF OF MEXICO

NE GULF OF MEXICO

NE GULF OF MEXICO

NE GULF OF MEXICO

NE GULF OF MEXICO

NE GULF OF MEXICO

NE GULF OF MEXICO

NE GULF OF MEXICO

NE GULF OF MEXICO

NE GULF OF MEXICO

MISSISSIPPI DELTA

NE GULF OF MEXICO

NE GULF OF MEXICO

NH GULF OF MEXICO

BAY OF CAMPECHE

NH GULF OF MEXICO

NH GULF OF MEXICO

NH GULF OF MEXICO

NH GULF OF MEXICO

BAY OF CAMPECHE

NE GULF OF MEXICO

NE GULF OF MEXICO

NE GULF OF MEXICO

BAY OF CAMPECHE

BAY OF CAMPECHE

NE GULF OF MEXICO

NE GULF OF MEXICO

NE GULF OF MEXICO

NE GULF OF MEXICO

NE GULF OF MEXICO

NE GULF OF MEXICO

NE GULF OF MEXICO

NE GULF OF MEXICO

NE GULF OF MEXICO

NE GULF OF MEXICO

\section{Lat. Long.}

$2734 \mathrm{~N} 09213 \mathrm{H}$ $27 \quad 48 \mathrm{~N} 088 \quad 44 \mathrm{H}$ $2742 \mathrm{~N} 08841 \mathrm{H}$ $2755 \mathrm{~N} 088 \quad 50 \mathrm{~W}$ $2742 \mathrm{~N} 08839 \mathrm{~W}$ $2810 \mathrm{~N} 088 \quad 57 \mathrm{~W}$ $2803 N 08852 \mathrm{~W}$ $2755 \mathrm{~N} 08850 \mathrm{~W}$ $2812 \mathrm{~N} 08858 \mathrm{~W}$ $2816 \mathrm{~N} 08901 \mathrm{H}$ $2819 \mathrm{~N} 08902 \mathrm{~W}$ $2814 \mathrm{~N} 088 \quad 59 \mathrm{~W}$ $2834 \mathrm{~N} 089 \quad 15 \mathrm{~W}$ $28 \quad 31 \mathrm{~N} 089 \quad 10 \mathrm{~W}$ $27 \quad 14 \mathrm{~N} 088 \quad 20 \mathrm{~N}$ $2732 \mathrm{~N} 088 \quad 32 \mathrm{~W}$ $27 \quad 36 \mathrm{~N} 088 \quad 37 \mathrm{~W}$ $2716 \mathrm{~N} 092 \quad 26 \mathrm{~W}$ $1928 \mathrm{~N} 095$ 06 $2830 N \quad 088$ O2W $2908 N 08808 W$ $2804 \mathrm{~N} 088 \quad 52 \mathrm{~W}$ $\begin{array}{llll}27 & 16 \mathrm{~N} & 090 & 21 \mathrm{~W} \\ 26 & 01 \mathrm{~N} & 088 & 03 \mathrm{~W}\end{array}$ $2751 \mathrm{~N} 09033 \mathrm{~W}$ $2747 \mathrm{~N} 09155 \mathrm{H}$ $2825 \mathrm{~N} 09149 \mathrm{~W}$ $2750 N 09305$ $2633 \mathrm{~N} 094 \quad 40 \mathrm{H}$ $2656 \mathrm{~N} 09220 \mathrm{~W}$ $2613 \mathrm{~N} 092$ 00W $2730 \mathrm{~N} 09510 \mathrm{~W}$ $2820 \mathrm{~N} 095 \mathrm{OHH}$ $2710 \mathrm{~N} 09622 \mathrm{~W}$ $2718 \mathrm{~N} 09614 \mathrm{H}$ $2645 \mathrm{~N} 09406 \mathrm{~W}$ $2746 \mathrm{~N} 094 \quad 47 \mathrm{~W}$ $2816 \mathrm{~N} 089 \mathrm{OH}$ $2729 \mathrm{~N} 09355 \mathrm{~W}$ $2740 \mathrm{~N} 094$ OOW $2732 \mathrm{~N} 09305 \mathrm{~N}$ $2535 \mathrm{~N} 091$ 30W $2737 \mathrm{~N} 09544 \mathrm{~W}$ $2600 \mathrm{~N} 09138 \mathrm{H}$ 26 S7N $09220 \mathrm{H}$ $2642 \mathrm{~N} 09214 \mathrm{~V}$ $2743 \mathrm{~N} 090 \quad 03 \mathrm{~W}$ $2622 \mathrm{~N} 096 \quad 40 \mathrm{~W}$ $2500 \mathrm{~N} 09455 \mathrm{~W}$ $2728 \mathrm{~N} 09539 \mathrm{~W}$ $2735 \mathrm{~N} 095 \quad 42 \mathrm{~W}$ $2723 \mathrm{~N} 095 \quad 35 \mathrm{~W}$ $2920 \mathrm{~N} 08746 \mathrm{~W}$ $2952 \mathrm{~N} 08815 \mathrm{~W}$ $2601 \mathrm{~N} 088$ 03W $2850 N 08736$ $29 \quad 15 \mathrm{~N} 087 \quad 55 \mathrm{~W}$ $29 \quad 34 \mathrm{~N} 088 \quad 01 \mathrm{H}$ $2944 \mathrm{~N} 086 \quad 41 \mathrm{~W}$ $2909 \mathrm{~N} 086 \quad 34 \mathrm{H}$ $28 \quad 14 \mathrm{~N} 087 \quad 04 \mathrm{~W}$ $2900 N 086$ S4W $2822 N 086 \quad 14 \mathrm{~W}$ $2738 \mathrm{~N} 08634 \mathrm{~W}$ $2937 N 08804 \mathrm{~N}$ $2612 \mathrm{~N} 083394$ $2858 \mathrm{~N} 089$ 09. $2810 N 084 \quad 41 \mathrm{~W}$ $2809 \mathrm{~N} 08406 \mathrm{~W}$ $2840 N 09433 W$ $1928 \mathrm{~N} 095$ 06W $2811 \mathrm{~N} 09416 \mathrm{~W}$ $2810 \mathrm{~N} 094 \quad 17 w$ $\begin{array}{llll}28 & 10 N & 094 & 17 * \\ 28 & 19 N & 092 & 58 W\end{array}$ $20 \quad 37 N 092 \quad 23 \mathrm{~W}$ $2900 N 085$ OON $2802 \mathrm{~N} 085 \quad 20 \mathrm{~W}$ $25 \quad 46 \mathrm{~N} 084 \quad 12 \mathrm{~W}$ $2009 \mathrm{~N} 092 \quad 13 \mathrm{~W}$ $\begin{array}{llll}20 & 13 N & 092 & 08 W \\ 29 & 09 N & 086 & 34 \mathrm{~W}\end{array}$ $24 \quad 15 N \quad 087554$ $2934 \mathrm{~N} 088$ OIH $2920 \mathrm{~N} 088 \quad 40 \mathrm{~W}$ $\begin{array}{llll}29 & 57 N & 087 & 50 W \\ 29 & 52 N & 088 & 15 W\end{array}$ $2920 \mathrm{~N} 087 \quad 66 \mathrm{~W}$ $2920 \mathrm{~N} 08536 \mathrm{~W}$ $2822 \mathrm{~N} 086 \quad 16 \mathrm{~W}$ $2900 N 08654 \mathrm{H}$ 


\section{Publication}

22721 PARKER 1954 22722 PARKER 195 22723 PARKER 1954 22724 PARKER 1954 22725 LANKFORD 1959 22726 PHLEGER 1951A 22727 PHLEGER $1951 \mathrm{~A}$ 22728 PHLEGER $1951 \mathrm{~A}$ 22729 PHLEGER $1951 \mathrm{~A}$ 22730 PHLEGER $1951 \mathrm{~A}$ 22731 PHLEGER 1951A 22732 PHLEGER $1951 \mathrm{~A}$ 22733 PHLEGER $1951 \mathrm{~A}$ 22734 PHLEGER $1951 \mathrm{~A}$ 22735 PHLEGER $1951 \mathrm{~A}$ 22736 PHLEGER 1951A 22737 PHLEGER 1951A 22739 PHLEGER 1951 A 22740 PHLEGER 1951A 22741 PHLEGER 1951A 22742 PHLEGER $1951 \mathrm{~A}$ 22743 PHLEGER $1951 \mathrm{~A}$ 22744 PHLEGER 1951A 22745 PHLEGER 1951A 22746 CREAGER 1958 22747 CREAGER 1958 22748 PHLEGER 1956 22749 PARKER 1354 22751 PARKER 1954 22752 ANDERSEN 1961 22753 GANDY 1956 22754 BANDY 1956 22755 BANDY 1956 22756 BANDY 1956 22757 BANDY 1956 22758 BANDY 1956 22760 BANDY 1956 22761 AANDY 1956 22762 BANDY 1956 22763 ANDERSEN 1961

22764 PFLUM FRERICHS 1976 22765 PFLUM FRERICHS 1976 22766 PFLUM FRERICHS 1976 22767 PFLUM FRERICHS 1976 22769 PFLUM FRERICHS 1976 22769 PFLUM FRERICHS 1976 22770 PFLUM FRERICHS 1976 22771 PFLUM FRERICHS 1976 22772 PFLUM FRERICHS 1976 22773 PFLUM FRERICHS 1976 22774 PFLUM FRERICHS 1976 22775 PFLUM FRERICHS 1976 22776 PFLUM FRERICHS 1976 22777 PFLUM FRERICHS 1976 22778 PFLUM FRERICHS 1976 22779 PFLUM FRERICHS 1976 22780 PFLUM FRERICHS 1976 22781 PFLUM FRERICHS 1976 22782 PFLUM FRERICHS 1976 22783 PFLUM FRERICHS 1976 22784 CUSHMAN 1929

22785 CUSHMAN 1929 22786
22787 PFLUUM FRERICHS
2976 22788 PFLUM FRERICHS 1976 22789 CREAGER 1958

22790 SHIFFLETT 1961

22791 NORTON 1930

22792 BENDA PURI 1962

22793 SOCK 1976

22794 PFLIJM FRERICHS 1976

22795 CREAGER 1958

22796 CREAGER 1958

22798 PFLUM FRERICHS 1976

22799 PFLUM FRERICHS 1976

22800 ANDERSEN 1961

22801 PFLUM FRERICHS 1976 22802 PFLUM FRERICHS 1976 22803 PFLUM FRERICHS 1976 22804 PFLUM FRERICHS 1976 22805 PFLUM FRERICHS 1976 22806 PFLIJM FRERICHS 1976 22807 PFLUM FRERICHS 1976 22808 PFLUM FRERICHS 1976 22809 PFLUM FRERICHS 1976 22810 LEROY HODGKINSON 1975 22811 PFLUM FRERICHS 1976 22812 NORTON 1930

22813 NORTON 1930

22814 BANDY 1956

22815 BANDY 1956
Generic Name Specific Name

PYRGO

PYRGO

PYRGO

PYRGO

PYRGO

PYRGO
PYRGO

PYRGO

PYRGO

PYRGO

PYRGO

PYRGO

PYRGO

PYRGO

PYRGO

PYRGO

PYRGO

PYRGO

PYRGO

PYRGO

PYRGO

PYRGO

PYRGO

PYRGO

PYRGO

PYRGO

PYRGO

PYRGO

PYRGO

PYRGO

PYRGO

PYRGO

PYRGO

PYRGO

PYRGO

PYRGO

PYRGO

PYRGO

PYRGO

PYRGO

PYRGO

PYRGO

PYRGO

PYRGO

PYRGO

PYRGO

PYRGO

PYRGO

PYRGO

PYRGO

PYRGO

PYRGO

PYRGO

PYRGO

PYRGO

PYRGO

PYRGO

PYRGO
PYRGO

PYRGO

PYRGO

PYRGO

PYRGO

PYRGO

P RGO

PYRGO

PYRGO

PYRGO

PYRGOELLA

PYRGOELLA

PYRGOELLA

PYRGOELLA

PYRGOELLA

PYRGOELLA

PYRGOELLA

PYRGOELLA

PYRGOELLA

PYRGOELLA

PYRGOELLA

PYRGOELLA

PYRGOELLA

PYRGOELLA

LARYNGOSIGMA

PYRULINA

QUINQUE LOCUL INA

QU INQUELOCULINA
NA SUTA

NA SUTA

NA SUTA

NA SUTA

NA SUTA

NASUTA

NA SUTA

NASUTA

NA SUTA

NA SUTA

NA SUTA

NASUTA

NA SUTA

NA SUTA

NA SUTA

NA SUTA

NA SUTA

NA SUTA

NA SUTA

NA SUIA

NA SUTA

NA SUTA

NA SUTA

NASUTA

NA SUTA

NA SUTA

WI LLIAMSONI

PERUVIANA

PERUVIANA

PERUVIANA

PE RUVIANA

PERUVIANA

PERUVIANA

PE RUVI I NA

PERUVIANA

NASUTA

SARSII

SAFSII

SAFSII

SARSII

SAFSII

SARSII

SARSII

SARSII

SAFSII

SARSII

SARSII

SERRATA

SERRATA

SERRAT

SERRAT

SERRATA

SERRATA

SERRATA

SERRATA

SERRATA

SERRATA

SERRATA

SEFRAT

SERRATA

SUESPHAERICA

SUESPHAERICA

SUESPHAERICA

SUESPHAER ICA

SUESPHAERICA

TUEULOSA

TUEULOSA

VESPERT IL IO

SPHAE RA

SPHAERA

SPHAERA

SPHAERA

SPHAERA

SPHAERA

SPHAERA

SPHAERA

SPHAERA

SPHAERA

SPHAERA

SPHAERA

SPHAERA

SPHAERA

LACTEA

VI TREA

AGGLUTINANS

AGGLUTINANS

\section{Locality}

NE GULF OF MEXICO NE GULF OF MEXICO NE GULF OF MEXICO NE GULF OF MEXICO MISSISSIPPI DELTA NW GULF OF MEXICO NW GULF OF MEXICO NW GULF OF MEXICO NW GULF OF MEXICO NW GULF OF MEXICO NW GULF OF MEXICO NW GULF OF MEXICO Nh GULF OF MEXICO NW GULF OF MEXICD NW GULF OF MEXICO $N W$ GULF OF MEXICO NW GULF OF MEXICO $N W$ GULF OF MEXICO NW GULF OF MEXICO NH GULF OF MEXICO NW GULF OF MEXICO NW GULF OF MEXICO NW GULF OF MEXICO 


\section{Publication}

22816 BANDY 1956

22817 BANDY 1956

22818 NORTON 19301966

22819 LIDZ LIOZ 1966
22820 VAUGHAN 1918

22821 VAUGHAN 1918

22822 VAUGHAN 1918

22823 CUSHMAN $1922 \mathrm{~A}$

22824 DAVIS 1964

22825 BANDY 1956

22826 BANDY 1956

22827 BANDY 1956

22828 BENDA PURI 1962

22829 BANDY 1956

22830 BANDY 1956

22831 BANDY 1956

22832 BANDY 1956

22833 BANDY 1956

22834 BANDY 1956,966

22836 BANDY 1956

22837 BANDY 1956

22838 BANDY 1956

22839 BANDY 1956

22840 BANDY 1956

22841 CUSHMAN 1922 A

22842 NORTON 1930
22843 DAVIS 1964

22843 DAVIS 1964
22844 KORNFELO 1931

22845 KORNFELD 193

22846 KORNFELD 1931

22847 KORNFELD 1931

22848 NORTON 1930

22849 KORNFELD 1931

22850 BOCK 1976

22851 SOCK 1976

22852 PARKER 1954

22853 BANOY 1956

22854 LEHMANN 1957

22855 BANDY 1956

22856 BANDY 1956

22857 BANDY 1956

22858 PHLEGER $1951 \mathrm{~A}$

22859 PHLEGER 1951 A

22860 PHLEGER 1951 A

22861 PHLEGER 1951A

22862 PHLEGER $1951 \mathrm{~A}$

22863 PHLEGER 1951

22864 PARKER 1954

22865 PARKER 1954

22866 PARKER 1954

22867 ANDERSEN 196

22868 PARKER 1954

22869 PARKER 1954

22870 PARKER 1954

22871 PARKER 1954

22872 PHLEGER 1951 A

22873 PARKER 1954

22874 BANDY 1956

22875 BANDY 1956

22876 BANDY 1956

22877 BANDY 1956

22878 BANDY 1956

22879 BANDY 1956

22880 BANDY 1956

22881 DAVIS 1964

22882 BANDY 1956

22883 BANDY 1956

22884 BANDY 1956

22885 BANDY 1956

22886 LOEP 1965

22887 BENDA PURI 1962

22888 KELLOUGH 1956

22889 KELLOUGH 1956

22890 KELLOUGH 1956

22891 KELLOUGH 1956

22892 KELLOUGH 1956

22893 AYALA-CASTANARES 1963

22894 BANDY 1956

22895 BANDY 1956

22896 BANDY 1956

22897 POST 1951

22898 CUSHMAN $1922 \mathrm{~A}$

22899 NORTON 1930

22900 NORTON 1930

22901 BANDY 1956

22902 BANDY 1956

22903 BANDY 1956

22904 BENDA PURI 1962

22905 BANDY 1956

22906 BENDA PURI 1962

22907 BANDY 1956

22908 BANDY 1956

22909 BANDY 1956

22910 BANDY 1956
Generic Name

QUINQUEL OCUL INA QUINQUE LOCUL INA QUINQUE LOCULINA QU INQUELOCUL INA QUINQUELOCUL INA QU INQUEL OCULINA QUINQUELOCULINA QUINQUELOCULINA QUINQUE LOCUL INA QUINQUE L OCUL INA QU INQUE LOCULINA QUINQUEL OCUL INA OUINOUEL OCULINA QU INQUEL OCULINA QUINQUELOCUL INA QU INQUELOCUL INA QUINQUELOCUL INA QUINQUELOCULINA QUINQUELOCUL INA QUINQUELOCULINA QU INQUELOCUL INA QU INQUE LOCULINA QU INQUE LOCUL INA QUINQUELOCULINA QUINQUE LOCULINA QU INQUE LOCULI INA QU INQ UE L OC UL INA QU INQUE LOCUL INA QU INQUE LOCUL INA QU INQUEL OCUL INA QU INQUE LOCULINA QUINQUEL OCUL INA QUINQUEL OCUL INA QU INQUELOCULINA QU INQUE LOCUL INA QU INQUEL OCUL INA QUINQUE LOCULINA QU INQUE L OCUL INA QU INQUE LOCUL INA QU INQUEL OC UL INA QU INQUE LOCULINA QU INQUE LOCULINA QUINQUELOCUL INA QUINQUE LOCULINA QU INQUE LOCUL INA QUINOUEL OCUL I NA QUINQUEL OC UL INA QU INQUELOCULINA QU INQUE LOCUL INA QU INQUEL OCUL INA QU INQUELOCUL INA QU INQUELOCULINA QUINOUELOCUL INA QU INQUEL OCUL INA QU INQUELOCULINA QU INQUE LOCULINA QUINQUEL OCUL INA QU INQUE LOCULINA QUINQUE LOCULINA QUINQUE L OCULI INA QU INQUEL OCUL INA QU INQUE LOCULI INA QU INOUE LOCULINA QU INOUELOCULINA QU INQUELOCUL INA QUINQUELOCULINA QU INQUEL OCULINA QU INQUEL OCULINA QU INOUELOCUL I NA QUINQUELOCULINA QUINQUEL OCULINA QU INQUEL OCUL INA QUINQUEL OC ULINA QUINQUE LOCULINA QU INQUELOCULINA QU INQUELOCULINA QU INQUEL OC ULI INA QUINQUELOCULINA QU INQUELOCUL INA QU INQUELOCUL INA QU INQUEL OCUL INA QU INQUELOCULINA QU INQUELOCULINA QU INQUE LOCUL INA QUINQUELOCULINA QU INQUELOCULINA QU INQUE LOCUL INA QU INQUEL OCUL INA QU INQUELOCULINA QU INOUELOCULINA QU INQUE L OCUL INA QU INQUE LOCULINA QU INQUEL OCUL INA QUINQUELOCULINA
Specific Name

AG GLUTINANS

AGGLUTINANS

AG GLUTINANS

AGGLUTINANS

AG GLUTINANS

AGGLUTINANS

AGGLUTINANS

AG GLUTINANS

AG GLUTINANS

AG GLUTINANS

AG GLUTINANS

AGGLUTINANS

AGGLUTINANS

AGGLUTINANS

AKAERIANA

AKAER IANA

AK NER I ANA

AKNERIANA

AK AER IANA

AK NER I ANA

AK NER I ANA

AKNER I ANA

AKNER IANA

AL VEOLINIFORMIS

ANTILLARUM

ANTILLARUM

AUBERIANA

AUEERIANA

AUEERIANA

AUEERIANA

AUBER IANA

AUEERIANA

BI CARINATA

B I COSTATA

BI COSTATA

BI COSTATA

BI COSTATA

Bi costata

B I COSTATA

BI COSTATA

Bi COSTATA

B I COSTATA

B I COSTATA

B I costata

BI COSTATA

B I COSTATA

OI COSTATA

BI COSTATA

oicostata

BI costata

Bi costata

o I costata

o I costata

oi costata

Bi costata

o I costata

oi costata

o I COSTATA

B I COSTATA

o I costata

OI COSTATA

B I COSTATA

BI COSTATA

B I COSTATA

B I costata

B I COSTATA

B I COSTATA

B I COSTATA

B I COSTATA

B I costata

B I COSTATA

o I costata

BI COSTATA

BI COSTATA

BI COSTATA

B I COSTATA

oI costaTA

B I COSTATA

B I DENTATA

BI DENTATA

BI DENTATA

BOUEANA

BOSCIANA

BOSCIANA

BOSCIANA

BOSCIANA

BOSCIANA

BOSCIANA

BOSCIANA

BOSCIANA

BOSCIANA

BOSCIANA

\section{Locality}

Lat. Long.

NE GULF OF MEXICO

NE GULF OF MEXICO

TORTUGAS, FLA

VERACRUZ REEFS 


\section{Publication}

22911 BANDY 1956 22912 BANDY 1956 22913 BANDY 1956

22914 BANDY 1956

22915 BOCK 1976

22916 PFLUM FRERICHS 1976

22917 BANDY 1956

22918 BANDY 1956

22919 BANDY 1956

22920 SANDY 1956

22921 BANDY 1956

22922 BANDY 1956

22923 BANDY 1956

22924 BANDY 1956

22925 BANDY 1956

22926 BANDY 1956

22927 BANDY 1956

22928 BANDY 1956

22930 CUSHMAN 1922 A

22930 CUSHMAN 1922 A
22931 NORTON 1930

22932 SHIFFLETT 1961

22933 LEHMANN 1957

22934 POST 1051

22935 POST 1951

22936 CUSHMAN 1922 A

22937 BENDA PURI 1962

22938 CUSHMAN 1922 A

22939 KANE 1967

22940 PARKER 1954

22941 PARKER 1954

22942 KANE 1962

22943 SEGURA 1963

22944 PARKER 1954

22945 PARKER 1954

22946 PARKER 1954

22947 SHEPARD MOORE 1955

22948 SHIFFLETT 1961

22949 PARKER 1954

22950 PARKER 1954

22951 PARKER 1954

22952 PHLEGER 1951A

22953 PHLEGER 1951A

22954 PHLEGER 1951A

22955 PHLEGER 1951A

22956 PHLEGER 1951A

22957 PHLEGER 1951A

22958 PHLEGER 1951A

22959 SHENTON 1957

22960 PARKER PHLEGER PEIRSON 1953

22961 BANDY 1956

22962 PARKER 1954

22963 PARKER 1954

22964 PARKER PHLEGER PEIRSON 1953

22965 PARKER PHLEGER PEIRSON 1953

22966 PHLEGEP 1956

22967 PARKER PHLEGER PEIRSON 1953

22968 PHLEGER 1951A

22969 PARKER 1954

22970 LANKFORD 1959

22971 PHLEGER 1956

22972 PHLEGER 1956

22973 PHLEGER 1956

22974 BOCK 1976

22975 KELLOUGH 1956

22976 KELLOUGH 1956

22977 KELLOUGH 1956

22978 KELLOUGH 1956

22979 BANDY 1954

22980 AYALA-CASTANARES 1963

22981 LOEP 1965

22982 AYALA-CASTANARES SEGURA 1968

22983 BANDY 1954

22984 DAVIS 1964

22985 BENDA PURI 1962

22986 WALTON 1964

22987 PHLEGER $1951 \mathrm{~A}$

22988 PHLEGER 1955

22989 PHLEGER 1951A

22990 BANDY 1956

22991 BANDY 1954

22992 BANDY 1954

22993 BANDY 1956

22994 BANDY 1954

22995 BANDY 1954

22996 BANDY 1956

22997 BANDY 1956

22998 BANDY 1956

22999 BANDY 1956

23000 BANDY 1956

23001 SANDY 1956

23002 BANDY 1956

23003 WALTON 1960

23004 BANDY 1956
23005 OTVOS 1978
Generic Name

QUINQUELOCULINA QUINQUELOCULINA QU INQUELOCULINA QUINQUELOCULINA QU INQUELOCULINA 3U INQUEL OCUL INA QU INQUELOCULINA QUINQUELOCUL INA QU INQUELOC UL INA QUINQUELOC UL INA QUINQUELOCULINA QUINQUE LOCUL INA QI) INQUELOCULINA QUINQUELOCULINA QU INQUELOCULINA QU INQUELOCULINA QU INQUELOCUL INA QU INQUELOCUL INA QU INQUELOCULINA QU INQUE LOCULINA QU INQUEL OCUL INA QUINQUELOCULINA QUINQUELOCUL INA QUINQUEL OCUL INA QUINQUELOCULINA QUINQUEL OCULINA QUINQUELOCUL INA QU INQUELOC UL I NA QU INQUEL OCUL INA QUINQUEL OC UL INA QU INQUE LOCUL INA QU INQUEL OCULINA QU INQUEL OCULINA QUINQUEL OCULINA QUINQUELOCULINA QU INQUEL OC UL INA QU INQUE LOC UL INA QU INQUEL OCUL INA QU INQUEL OCUL I NA QU INQUELOCUL INA QUINQUELOCULINA QU INQUEL OC UL INA QUINQUELOC UL INA QU INQUELOCULINA QUINQUELOCULINA QUINQUEL OCUL INA QU INQUELOCULINA QUINQUELOCUL INA QU INQUEL OCUL INA QU INQUEL OCULINA QU INQUEL OCUL INA QU INQUE LOCUL INA QU INQUEL OCUL INA QU INQUELOCULINA QUINQUELOCUL IN QUINQUEL OC UL INA QU INQUEL OC ULINA QUINQUEL OCUL INA QU INQUEL OCUL INA QUINQUEL OCUL INA QU INQUE LOCUL INA QU INQUEL OC UL INA QU INQUE L OCUL INA QU INQUEL OC UL INA QU INQUE L OCUL INA QU INQUEL OC UL INA QU INQUELOCUL INA QUINQUELOCULI NA QU INQUE LOCULINA QUINQUEL OCUL INA QU INQUEL OCUL INA QUINQUEL OCULINA QU INQUE LOCUL INA QU INQUELOCULINA QUINQUEL OCUL INA QU INQUE LOCULINA QU INQUELOCULINA QUINQUE LOC UL INA QUINQUELOCULINA QU INQUE LOCULINA QUINGUELOCUL INA QU INQUEL OCUL INA QUINQUELOCULINA QUINQUEL OC UL INA QUINQUELOCULINA QUINQUELOCULINA QU INQUE LOCUL INA QU INQUEL OCUL INA QUINQUELOCUL INA QUINQUE LOC UL INA QUINQUEL OC UL INA QUINQUEL OCUL INA QU INQUEL OCUL INA QUINQUEL OCULINA QUINQUELOCULINA
Specific Name

BOSCIANA

BO SCIANA

BOSCIANA

BOSCIANA

BOSCIANA

EOSCIANA

BO SCIANA

BOSCI ANA

BOSCIANA

BOSCIANA

BOSCIANA

BO SCIANA

SOSCIANA

BOSCIANA

BOSCI ANA

BOSCIANA

BOSCIANA

BOSCIANA

BRADYANA

BRADYANA

CANDEIANA

CANDEIANA

CA $A D E I A N A$

CANDE IANA

CA ADE I ANA

CA TALINENSIS

COLLUMNOSA

CONPTA

CONPTA

CONPTA

CONPTA

CONPTA

CONPTA

CONPTA

CONPTA

CONPTA

CONPTA

CONPTA

CONPTA

CONPTA

CONPTA

CONPTA

CONPTA

CONPTA

CONPTA

CONPTA

CONPTA

CONPTA

CONPTA

CONPTA

CONPTA

CONPTA

CONPTA

CONPT A

CONPTA

CONPTA

CONPTA

CONPTA

CONPTA

CONPTA

CONPTA

CONPTA

CONPTA

CONPTA

CONPTA

CONPTA

CONPTA

CONPTA

CONPTA

CONPTA

CONPTA

CONPTA

CONPTA

CONPTA

CONPTA

CONPTA

CONPTA

CONPTA

CONPTA

CONPTA

CONPTA

CONPTA

CONPTA

CONPTA

CONPTA

CONPTA

CONPTA

CONPTA

CONPTA

CONPTA

CONPTA

COMPTA

CONPTA

CONPTA

Locality

NE GULF OF MEXICO

NE GULF OF MEXICO

NE GULF OF MEXICO 
Publication

23006 BANDY 1956

23007 BANDY 1956

23008 BANDY 1956

23009 BANDY 1956

23010 BANDY 1956

23011 BANDY 1956

23012 BANDY 1956

23013 BANDY 1956

23014 BANDY 1956

23015 BANDY 1956

23016 ANDERSEN 196
23017 BANDY 1956

23017 BANDY 1956

23019 LEHMANN 1957

23020 SEGURA 1963

23021 CUSHMAN 1922A

23022 KORNFELD 1931

$\begin{array}{lll}23023 & \text { KORNFELD } & 1931 \\ 23024 & \text { KORNFELD } & 1931\end{array}$

23024 KORNFELD 1931

23025 KORNFELD 1931

23027 KORNFELD 1931

23028 POST 1951

23029 POST 1951

23030 NORTON 1930

23031 LANKFORD 1959

23032 KANE 1967

23033 PARKER PHLEGER PEIRSON 1953

23034 PARKER PHLEGER PEIR SON 1953

23035 PARKER PHLEGER PEIRSON 1953

23036 PARKER PHLEGER PEIRSON 1953

23037 PARKER PHLEGER PEIRSON 1953

23038 PHLEGER 1956

23039 BENDA PURI 1962

23040 PARKER PHLEGER PEIR SON 1953

23041 BOCK 1976

23042 PARKER PHLEGER PEIRSON 1953

23043 NORTON 1930

23044 WALTON 1960

23045 PHLEGER LANKFORD 1957

23046 SEGURA 1963

23047 LEHMANN 1957

23048 PHLEGER 19558

23049 DAVIS 1964

23050 NORTON 1930

23051 LEHMANN 1957

23052 BENDA PURI 1962

23053 BANDY 1956

23054 BANDY 1956

23055 BANDY 1956

23056 BANDY 1956

23057 BOCK 1976

23058 BANDY 1956

23059 BANDY 1956

23060 BANDY 1956

23061 DAVIS 1964

23062 PARKER PHLEGER PEIRSON 1953

23063 AYALA-CASTANARES SEGURA 1968

23064 AYALA-CASTANARES 1963

23065 NORTON 1930

23066 PARKER PHLEGER PEIRSON 1953

23067 PARKER PHLEGER PEIRSON 1953

23068 PHLEGER 1956

23069 PARKER PHLEGER PEIRSON 1953

23070 PARKER PHLEGER PEIRSON 1953

23071 PARKER PHLEGER PLIRSON 195

23072 PARKER PHLEGER PEIRSON 1953

23073 PARKER PHLEGER PEIRSON 1953

23074 CUSHMAN $1922 \mathrm{~A}$

23075 PHLEGER LANKFORD 1957

23076 LANKFORD 1959

23077 LEHMANN 1957

23078 KANE 1967

23079 KANE 196

23080 PHLEGER 1960

23081 SEGURA 1963

23082 WALTON 1964

23083 PHLEGER 19558

23084 ANDERSEN 1961

23085 NORTON 1930

23086 BOCK 1976

23087 BOCK 1976

23088 PARKER 1954

23089 PARKER 1954

23090 LOEP 1965

23091 BANDY 1956

23092 BENDA PURI 1962

23093 PARKER 1954

23094 BANDY 1956

23095 BANDY 1956

23096 BANDY 1756

23097 KELLOUGH 1956

23098 SEGURA 1963

23099 LANKFORD 1959

23100 SANDY 1956
Generic Name

QU INQUELOCUL INA QU INQUELOCUL INA QU INQUELOCULINA QUINQUE LOCULINA QUINQUELOCULINA QUINQUEL OCUL INA QUINQUEL OC UL INA QUINQUE LOCULINA QU INQUE LOCULINA QU INQUELOCUL I NA QU INQUELOCULINA QU INQUELOCULINA QUINQUEL OCUL INA QU INQUE LOCUL INA QU INQUE LOCULINA QU INQUE L OCUL INA QU INQUEL OCULINA QUINQUEL OCUL INA QU INQUEL OCUL INA QU INQUE LOCULINA QU INQUE L OC ULINA QUINQUE L OCUL INA QU INQUE LOCU LINA QUINQUEL OCULINA QUINQUELOCULINA QUINQUE LOCUL INA QUINQUE LOCULINA QU INQUEL OCUL INA QUINQUEL OCULINA QUINQUEL OC ULINA QU INQUE LOCUL INA QU INQUELOCULINA QUINQUELOCULINA QUINQUEL OCULINA QUINQUEL OCULINA QU INQUELOCULINA QU INQUE LOCULINA QUINQUE LOC UL INA QU INQUELOCUL INA QUINQUEL OCULINA QUINQUELOCULINA QU INQUEL OCULINA QU INQUE LOCUL INA QU INQUE LOCUL INA QU INQUELOCUL INA QU INQUE LOCUL INA QU INQUELOCULINA QU INQUE LOCUL INA QUINQUELOCUL INA QU INQUE LOC UL INA QU INQUELOCULINA QU INQUELOCULINA QUINQUELOCULINA QU INQUE LOCULINA QU INQUELOCUL INA QUINQUELOCUL INA QUINQUE LOCULINA QUINQUELOC ULINA QUINQUELOCUL INA QU INQUEL OC UL INA QU INQUE LOCUL INA QU INQUEL OCUL INA QU INQUEL OC UL INA QU INQUEL OCULINA QUINQUELOCULI INA QU INQUE LOCUL INA QU INQUE LOC UL INA QUINQUE LOC ULINA QU INQUE LOCULINA QU INQUE LOC UL INA QUINQUELOCULINA QU INQUE LOCUL INA QUINQUELOCULINA QU INQUE LOCULINA QU INQUE LOCUL INA QUINOUELOCUL INA QU INQUELOCULINA QU INQUE LOCUL INA QUINQUELOCULINA QU INQUELOCULI INA QU INQUE LOCULINA SI PHONAPER TA

SIPHONAPERTA

SI PHONAPERTA

SI PHONAPER TA

SIPHONAPERTA

SIPHONAPER TA

SI PHONAPERTA

SI PHONAPERTA

SI PHONAPERTA

SI PHONAPER TA

SI PHONAPERTA

SI PHONAPERTA

SIPHONAPERTA

SI PHONAPERTA

Specific Name

Locality

Lat. Long.

CONPTA

COMPTA

CONPTA

CONPTA

CONPTA

CONPTA

COMPTA

CONPTA

CONPTA

COMPTA

COMPTA

CO STATA

COSTATA

COSTATA

COSTATA

COSTATA

COSTATA

COSTATA

COSTATA

COSTATA

COSTATA

COSTATA

COSTATA

CULTRATA

CULTRATA

CULTRATA

CULTRATA

CULTRATA

CULTRATA

CULTRATA

CULTRATA

CULTRATA

CULTRATA

CULTRATA

CULTRATA

CULTRATA

CULTRATA

CUVIERIANA

CUVIERIANA

DURRANDII

DUTEMPLEI

DU TEMPLEI

DU TEMPLEI

DU TEMPLEI

DUTEMPLEI

DUTEMPLE I

DU TEMPLEI

DU TEMPLEI

UTEMPLE

EL ONGATA

FUNAFUTIENS IS

ENS IS

FUNAF UTIENSIS

FUNAFUTIENS IS

FUNAFUTIENS IS

FUAAFUTIENSIS

FUNAFUTIENSIS

FUNAFUTIENSIS

FUAAFUTIENSIS

FUNAFUTIENSIS

FUNAFUTIENS IS

FUNAFUTIENS IS

FUNAFUTIENS IS

FUAAFUTIENSIS

FUNAFUTIENS IS

FUNAFUT IENSIS

FUNAFUTIENS IS

FUNAFUTIENSIS

FUNAFUTIENS IS

FUNAFUTIENSIS

FUNAFUTIENSIS

FUNAFUTIENSIS

GARRET T I

GL ABRATA

GRACILIS

HORRIDA

HORR I DA

HORRIDA

HORR IDA

HORRIDA

HORRIDA

HORR IDA

HORRIDA

HORRIDA

HORRI DA

HORRI DA

HORRI DA

NE GULF OF MEXICO

NE GULF OF MEXICO

NE GULF OF MEXICO

NE GULF OF MEXICO

NE GULF OF MEXICO

NE GULF OF MEXICO 


\section{Publication}

23101 BANDY 1956

23102 BANDY 1956

23103 BANDY 1956

23104 AYALA-CASTANARES 1963

23105 BANDY 1956

23106 BANDY 1956

23107 KELLOUGH 1956

23108 KELLOUGH 1956

23109 KELLOUGH 1956

23110 KELLOUGH 1956

23111 LUDWICK WALTON 1957

23112 PARKER 1054

23113 PARKER 1954

23115 PARKER 1954

23116 PARKER 1954

23117 PARKER 1954

23118 PHLEGER 1951A

23119 PHLEGER 1951A

23120 PHLEGER 1951A

23121 PHLEGER 1951A

23122 PHLEGER 1951A

23123 PHLEGER 1951A

23124 PHLEGER 1951A

23125 PHLEGER 1951A

23126 PHLEGER 1951A

23127 PHLEGER 1951A

23129 PHLEGER 1951A

23130 PARKER 1954

23131 PARKER 1954

23132 PARKER 1954

23133 PARKER 1954

23134 PHLEGER 1951A

23135 PHLEGER 1951A

23136 PHLEGER 1951A

23137 BANDY 1956

23138 BANDY 1956

23139 BANDY 1956

23141 BENDA PURI 1962

23142 BANDY 1956

23143 BANDY 1956

23144 BANDY 1956

23145 BANDY 1956

23146 BANDY 1956

23147 BANDY 1956

23148 BANDY 1956

23149 BANDY 1956

23150 CUSHMAN 1922 A

23151 BOCK 1976

23152 LYNTS PFISTER 1967

23153 PHLEGER $1965 \mathrm{~B}$

23154 NORTON 1930

23155 PHLEGER 1965B

23156 BOCK 1976

23157 BOCK 1976

23158 BOCK 1976

23159 PARKER PHLEGER PEIR SON 1953

23160 PHLEGER 1951A

23161 PHLEGER 1951A

23162 PHLEGER 1951A

23163 PHLEGER 1951A

23164 PHLEGER 1951 A

23165 PHLEGER 1951A

23166 PHLEGER 1951A

23167 PHLEGER 1951A

23168 PHLEGER 1951A

23169 PHLEGER 1951A

23170 PHLEGER 1951A

23171 PHLEGER 1951A

23172 SHEPARD MOORE 1955

23173 PHLEGER $1951 \mathrm{~A}$

23174 LEHMANN 1957

23175 BANDY 1954

23176 KELLOUGH 1956

23177 KELLOUGH 1956

23178 KELLOUGH 1956

23179 KELLOUGH 1956

23180 KELLOUGH 1956

23181 BENDA PURI 1962

23182 WALTON 1964

23183 LOEP 1965

23184 BANDY 1956

23185 PARKER 1954

23186 NORTON 1930

23187 WALTON 1960

23188 KELLOUGH 1956

23189 KELLOUGH 1956

23190 PHLEGER 19658

23191 BANDY 1954

23192 BANDY 1956

23193 AYALA-CASTANARES 1963

23194 BANDY 1954
Generic Name

SI PHON APER TA

SI PHONAPERTA

SIPHONAPERT A

SIPHONAPERTA

SI PHONAPERTA

SI PHONAPER TA

SI PHONAPERTA

SI PHONAPERTA

SI PHON APERT A

SIPHONAPERTA

SIPHONAPERTA

SI PHONAPERT A

SI PHONA PERTA

SIPHONAPERTA

SIPHONAPERTA

SI PHONAPER TA

SIPHONAPERTA

SI PHONAPERTA

SI PHONAPER TA

SIPHON APER TA

SI PHONAPERTA

SI PHONAPERTA

SI PHONAPER TA

SI PHONAPERT A

SI PHONAPER T A

SIPHONAPERT

SI PHONAPERTA

SI PHONAPERTA

SIPHONAPERT A

SI PHONAPERTA

SIPHONAPERTA

SI PHONAPER TA

SI PHON A PERTA

SI PHONAPERT A

SIPHONAPERTA

SI PHONAPER TA

QU INQUE LOC UL INA

QU INQUE LOC UL INA

QUINQUE LOC UL INA

QUINQUE LOCULINA

QU INQUE LOCULINA

QU INQUE L OC UL INA

QUINQUELOCUL INA

QU INQUE LOCULINA

QU INQUELOCULIN

QU INQUEL OC UL INA

QU INQUE LOCULINA

QU INQUE LOCULINA

QU INQUEL OC ULINA

QUINQUE LOC ULINA

QU INQUE LOCUL INA

QUINQUE LOCULINA

QU INQUE L OC UL INA

QU INQUE L OC UL INA

QU INQUEL OCULINA

QUINQUE L OC ULINA

QUINQUELOCULINA

QU INQUE LOCULINA

QUINQUEL OC ULI INA

QUINQUELOCULINA

QU INQUE LOCUL INA

QU INQUELOCUL INA

QU INQUEL OCUL INA

QU INQUELOCULINA

QU INQUELOCULINA

QU INQUEL OCUL INA

QU INQUELOCULINA

QUINQUEL OCULINA

QU INQUELOC UL INA

QUINQUELOCULINA

QUINQUE LOCULINA

QU INQUE LOCULINA

QU INQUEL OCUL INA

QU INQUE LOCULINA

QU INQUELOCULINA

QUINQUE LCULINA

QUINQUEL OCULINA

QUINQUE LOCULINA

QUINQUELOCULINA

QUINQUELOCULINA

QUINQUELOCULINA

QUINOUEL OCULINA

QUINQUELOCULINA

QU INQUE LOCULI NA

QU INQUELOCULINA

QUINQUE L OCULINA

QU INQUE LOC UL I NA

QU INOUE LOCULINA

QUINQUELOCULINA

QU INQUELOCULINA

QU INQUEL OC UL INA

QU INQUEL OCULINA

QU INQUEL OCUL INA

QUINQUEL OCULINA

QU INQUE LOCULINA
Specific Name

Locality

ORRIDA

ORRIDA

HORRIDA

HORRIDA

HORRIDA

HORR IDA

HORR I DA

HORRIDA

HORRIDA

HORRIDA

HORR I DA

HORR I DA

HORR IDA

HORR IDA

HORR I DA

HORRIDA

HORRIDA

ORRIDA

HORRIDA

HORR I DA

HORR I DA

HORRI DA

HORRIDA

HO RR I DA

HORR I DA

HORR I DA

HORR I DA

HORR I DA

HO RR I DA

HORRI DA

HORR I DA

JUGOSA

JUGOSA

JUGOSA

GOSA

JUGOSA

JUGOSA

JUGOSA

JUGOSA

JUGOSA

UGOSA

COSA

JUGOSA

KE RIMBATICA PHILIPPINENSIS

LAEVIGATA

LAEVIGATA

LEVVIGATA

LAEVIGATA

LAEVIGATA

LAMARCKIANA

LAMARCKIANA

LAMARCKIANA

LAMARCKIANA

LAPARCKIANA

LANARCKIANA

LANARCKIANA

LAMARCKIANA

LAMARCKIANA

LANARCKIANA

LANARCKIANA

LAYARCKIANA

LANARCKIANA

LAMARCKIANA

LAMARCKIANA

LANARCKIANA

LAMARCKIANA

LAMARCKIANA

LANARCKIANA

LANARCKIANA

LANARCKI ANA

LANARCKIANA

LAMARCKIANA

LANARCKIANA

LANARCKIANA

LANAR CKIANA

LANARCKIANA

LANARCKIANA

LANARCKIANA

LAMARCKIANA

LANAR CKIANA

LANARCKIANA

LAPARCKIANA

MARCKIANA

LANARCKI ANA

NE GULF OF MEXICO

NE GULF OF MEXICO

NE GULF OF MEXICO

L. DE TERMINOS, CAMPECHE

NE GULF OF MEXICO

NE GULF OF MEXICO

$N$ GULF OF MEXICO 


\section{Publication}

23196 BANDY 1954

23198 AYALA-CASTANARES SEGURA 1968 QUINQUELOCULINA

23199 BANDY 1956

23200 BANOY 1956

23201 BANDY 1956

23202 BANDY 1956

23203 BANDY 1956

23206 BANDY 1956

23205 BANDY 1956

23206 BANDY 1956

2320 ? BANDY 1956

23208 BANDY 1056

23209 PARKER 1954

23210 PHLEGER 1951A

23211 PARKER PHLEGER PEIRSON 1953

23212 PHLEGER 1956

23213 PARKER PHLEGER PEIRSON 1953

23216 PARKER PHLEGER PEIRSON 1953

23215 BANDY 1956

23216 BANDY 1056

23217 BANDY 1956

23218 BANDY 1956

23219 ANDERSEN 1961

23220 AANDY 1956

23221 BANDY 1956

23222 BANDY 1956

23223 PARKER 1954

23224 PARKER 1354

23226 PARKER PHLEGER PEIRSON 1953

23227 PHLEGER 1956

23228 LYNTS PFISTER 1967

23229 PHLEGER 1956

23230 BOCK 1976

23231 BOCK 1976

23232 BANDY 1956

23233 BANDY 1956

23234 BANDY 1956

23235 BANDY 1956

23236 BANDY 1956

23237 BANDY 1956

23238 KANE 1967

23239 WALDRON 1963

23240 CUSHMAN 1922 A

23241 SEGURA 1963

23242 BANDY 1956

23243 BANDY 1956

23244 BANDY 1956

23245 KANE 1962

23246 PHLEGER 1951A

23247 PHLEGER 1951A

23248 PHLEGER 1951A

23249 SHIFFLETT 1961

23250 PHLEGER LANKFORD 1957

23251 PARKER 1954

23252 PARKER 1954

23253 LANKFORD 1959

23254 PARKER 1954

23255 PARKER 1954

23256 PARKER 1954

23257 PARKER 1954

23258 PARKER 1954

23259 PARKER 1954

23260 PARKER 1954

23261 PARKER 1954

23262 PARKER 1954

23263 DAVIS 1964

23264 PARKER 1954

23265 LIDZ LIDZ 1966

23266 NORTON 1930

23267 NORTON 1930

23269 SHEPARD MOORE 1955

23270 BANDY 1956

23271 CUSHMAN $1922 \mathrm{~A}$

23272 SEGURA 1963

23273 LEHMANN 1957

23274 PHLEGER 1965 B

23275 PHLEGER 1965 A

23276 PHLEGER 1965 A

23277 BOCK 1976

23278 PARKER PHLEGER PEIRSON 1953

23279 BENDA PURI 1962

23280 PHLEGER 1965 A

23281 ANDERSON 1968

23282 PHLEGER 1965 A

23283 PHLEGER 1965A

23284 PHLEGER 1965 B

23285 PHLEGER 1965 A

23286 PARKER PHLEGER PEIRSON 1953

23287 PARKER PHLEGER PEIRSON 1953

23288 BANDY 1956

23289 BANDY 1956

23290 PHLEGER LANKFORD 1957 Generic Name QU INQUELOCULINA QUINQUE LOCULINA

Specific Name

LANARCKIANA

LANARCKIANA

LANARCKI ANA

QUINQUELOCUL INA

QUINQUELOCULINA

QUINQUELOCULINA

QUINQUELOCULINA

QU INQUE LOC UL I NA

QU INQUE LOC ULINA

QUINQUELOC UL INA

QUINQUE LOCULINA

QU INQUEL OC UL INA

QU INQUE LOCULINA

QU INQUE LOC ULI INA

QUINQUEL OCULINA

QUINQUE LOCUL I NA

QU INQUE L OCUL INA

QUINQUELOCULINA

QUINQUE LOCULINA

QU INQUE LOCULINA

QU INQUELOCULINA

QU INQUEL OC UL INA

QU INQUE LOC UL I NA

QU INQUE LOC UL INA

QU INQUE L OC UL INA

QU INQUE LOCUL INA

QUINQUELOCULINA

QU INQUE LOCULINA

QU INQUELOCUL INA

QU INQUE LOC UL INA

QU INQUE LOCULINA

QUINQUEL OCULI INA

QUINQUE L OCULINA

QUINQUE LOCULINA

QUINQUE LOCULINA

QU INQUE LOCUL INA

QU INQUE LOCULINA

QU INQUE LOC UL INA

QU INQUELOCULINA

QU IN QUE LOCUL INA

QU INQUE L OC UL INA

QUINQUE LOCULINA

QUINQUE LOCULINA

QU INQUE LOCUL INA

QUINQUELOCUL INA

QU INQUEL LC UL INA

QU IN QUE LOCULINA

QU INQUEL OC UL INA

QU INQUE LOC UL INA

QU INQUE LOCUL INA

QU INQUEL OC UL INA

QU INQUE LOCULINA

QU INQUE L OC ULINA

QU INQUELOC ULI INA

QU INQUE LOC UL I NA

QUINQUE LOCUL INA

QUINQUE LOCUL INA

QU INQUE LOC UL INA

QU INQUELOC UL I NA

QUINQUE LOCULINA

QU INQUE LOC UL INA

QUINQUEL OCUL INA

QU INQUE LOC UL INA

QUINQUE LOCULINA

QU INQUE L OCULINA

QUINQUE L OCULINA

QUINQUEL OC UL INA

QUINQUE LOCULI INA

QUINQUEL OC UL INA

QU INQUE L OC UL I NA

QU INQUE LOCULINA

QU INQUE LOCUL INA

QU INQUELOC UL INA

QU INQUELOCUL INA

QUINQUELOCULINA

QU INQUE LOCUL INA

QU INQUEL OCULINA

QU INQUE LOCUL INA

QU INQUELOCULINA

QU INQUE LOCUL INA

QU INQUE LOCULI NA QU INQUELOCUL INA

QU INQUELOCUL INA

QUINQUELOCULINA

QU INQUE LOC ULINA

QU INQUEL OC UL INA

QUINQUEL OCULINA

QUINQUELOCULINA

QU INQUELOC UL INA

QU INQUEL OCULINA

QUINQUELOCUL INA

QUINQUE LOCULINA

QU INQUE LOCULINA

QU INQUEL OC UL INA

QU INQUE LOCULINA
Locality

Lat. Long.

NW GULF OF MEXICO

Nh GULF OF MEXICO

LAGUNA MADRE, NE TEXAS

NE GULF OF MEXICO

NE GULF OF MEXICO

NE GULF OF MEXICO

NE GULF OF MEXICO

NE GULF OF MEXICO

E GULF OF MEXICO

NE GULF OF MEX

NE GULF OF MEXICO

NE GULF OF MEXICO

NE GULF OF MEXICO

NE GULF OF MEXICO

NW GULF OF MEXICO

TEXAS GULF COAST

$N W$ GULF OF MEXICO

TEXAS GULF COAST

TEXAS GULF COAST

NE GULF OF MEXICO

NE GULF OF MEXICO

NE GULF OF MEXICO

NE GULF OF MEXICO

$M I S S I S S I P P I$ DELTA

TAMPA BAY, FLA.

PINE IS. SOUND, FLA

NE GULF OF MEXICO

NE GULF OF MEXICO

NE GULF OF MEXICO

NE GULF OF MEXICO

TEXAS GULF COAST

NW GULF OF MEXICO

ORY TORTUGAS

NW GULF OF MEXICO

NE GULF OF MEXICO

NE GULF OF MEXICO

CHARLOTTE HARBOUR, FLA.

NE GULF OF MEXICO

NE GULF OF MEXICO

NE GULF DF MEXICO

NE GULF OF MEXICO

NE GULF OF MEXICO

SABINE LAKE, TEXAS

MISSISSIPPI DELTA

TORTUG AS

MATAMOROS, MEXICO

NE GULF OF MEXICO

TAMPA BAY, FLA.

NE GULF OF MEXICO

SABINE LAKE, TEXAS

NW GULF OF MEXICO

NW GULF OF MEXICO

NW GULF OF MEXICO

HEALO BANK, G. OF MEXICO

TEXAS GULF COAST

NE GULF OF MEXICO

NE GULF OF MEXICO

MISSISSIPPI DELTA

NE GULF OF MEXICO

NE GULF OF MEXICO

NE GULF OF MEXICO

NE GULF OF MEXICO

NE GULF OF MEXICO

NE GULF OF MEXICO

NE GULF OF MEXICO

NE GULF OF MEXICO

NE GULF OF MEXICO

CAMPECHE BANK, MEXICO

NE GULF OF MEXICO

VERACRUZ REEFS

TORTUGAS, FLA

TORTUGAS,

CENTRAL TEXAS COAST

TAMPA BAY, FLA.

TORTUGAS

MATAMOROS, MEXICO

IEXAS GULF COAST

TEN THOUSAND IS, SW FLA.

COPANO BAY, TEXAS

LAVACA BAY, TEXAS

NE GULF OF MEXICO

TEXAS GULF COAST

CAPE ROMANO, FLA.

MUSTANG LAKE, TEXAS

MISSISSIPP I SOUND

PASS CAVALLO. TEXAS

COLORADO R. DELTA, TEXAS

WHITEWATER B.. SW FLA.

PORT ALTO, TEXAS

TEXAS GULF COAST

TEXAS GULF COAST

PINE IS. SOUND, FLA.

CHARLOTTE HARBOUR, FLA.

TEXAS GULF COAST 
Publication

23291 DAVIS 1964 23292 NORTON 1930 23293 WALTON 1960 23294 BANDY 1956 23295 BANDY 1956

23296 PARKER PHLEGER PEIRSON 1953 23297 PHLEGER 1965 A 23298 BENDA PURI 1962

23299 PHLEGER 1965 A

23300 WALTON 1964

23301 BANDY 1956

23302 BANDY 1956

23303 BANDY 1956

23304 BANDY 1956

23306 AYALA-CASTANARES 1963

23307 AYALA-CASTANARES SEGURA 1968 23308 PHLEGER 1965 A

23309 BANDY 1956

23310 BANDY 1956

23311 PARKER PHLEGER PEIRSON 1953 23312 PARKER PHLEGER PEIRSON 1953 23313 PHLEGER 1956

23314 PARKER PHLEGER PEIRSON 1953 23315 SHENTON 1957

23316 PARKER PHLEGER PEIRSON 1953 23317 PHLEGER 1960

23318 PARKER 1954

23319 PARKER 1954

23320 PARKER 1954

23321 PARKER 1954

23322 PARKER 1954

23323 PARKER 1954

23325 BOCK 1976

23326 PARKER 1954

23327 AYALA-CASTANARES 1963

23328 BANDY 1956

23329 PFLUM FRERICHS 1976

23330 NORTON 1930

23331 PARKER 1954

23332 PARKER 1954

23333 PARKER 1954

23334 CUSHMAN 1922A

23335 LEHMANN 1957
23336 PFLUM FRERICHS 1976

23337 DAVIS 1964

23338 PARKER 1954

23339 SEGURA 1963

23340 VAUGHAN 1918

23341 WALTON 1960

23342 AYALA-CASTANARES 1963

23343 AYALA-CASTANARES SEGURA 1968 23344
23345 PARKER PHLEGER PEIRSON 1953 23346 BANDY 1956

23346 BANDY 1956

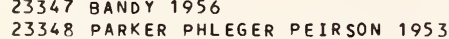
23349 BANDY 1956

23350 PHLEGER 1956

23351 BANDY 1956

23352 PARKER PHLEGER PEIRSON 1953 23353 PARKER PHLEGER PEIRSON 1953 23354 PARKER PHLEGER PEIRSON 1953 23355 PHLEGER 1960

23356 PARKER PHLEGER PEIRSON 1953 23357 PARKER PHLEGER PEIRSON 1953 23358 PARKER PHLEGER PEIRSON 1953 23359 PHLEGER 19558

23360 SEGURA 1963

23361 SHEPARD MOORE 1955

23362 LEHMANN 1957

23363 PHLEGER LANKFORD 1957

23364 WALDRON 1963

23365 PARKER 1954

23366 PARKER 1954

23367 LIDZ LIDZ 1966

23368 ANDERSEN 1961
23369 WALTON 1964

23369 WALTON 1964
23370 PARKER 1954

23371 PARKER 1954

23372 PARKER 1954

23373 BOCK 1976

23374 PARKER 1954

23375 WALTON 1960

23376 NORTON 1930

23377 LIDZ LIDZ 1966

23378 LEHMANN 1957

23379 NORTON 1930

23380 WALTON 1960

23381 POST 1951

23382 KORNFELD 1931

23383 KORNFELD 1931

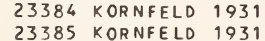

Generic Name

QU INQUE LOCULINA QUINQUE LOCUL INA QUINQUELOCULINA QU INQUE L OCULI INA QUINQUEL OC ULI INA QUINQUELOCULINA QU INQUE LOCULINA QUINQUE LOCUL INA QU INQUE LOCULINA QUINQUEL OCUL INA QUINQUE LOCULINA QU INQUE LOCULINA QUINQUELOCULINA QUINQUELOCUL INA QU INQUELOCULINA QUINQUELOCULINA QUINQUE LOCUL INA QU INQUE LOCUL INA QUINQUELOCULINA QU INQUE LOCUL INA QU INQUE LOC UL INA QU INQUE LOC UL INA QUINQUEL OCULINA QUINQUEL OCULINA QUINQUE LOCULINA QU INQUELOCULINA QUINQUE LOCULINA QU INQUE LOC UL INA QUINQUE LOCULINA QU INQUE LOCUL INA QU INQUE LOCULINA QU INQUE LOC UL INA QU INQUE LOC UL INA QU INQUE LOCUL INA QU INQUELOCULINA QU INQUE LOCUL INA QUINQUE LOCULINA QU INQUE LOC UL INA QU INQUE LOCULINA QUINQUELOCULINA QU INQUELOCULINA QU INQUE LOCUL INA QU INQUEL OCUL INA QU INQUE LOC UL INA QU INQUE LOCULINA QU INQUE LOC ULINA QU INQUEL OCUL INA QU INQUE LOCUL INA QUINQUE LOC UL INA QU INQUE LOC UL INA QU INQUELOCUL INA QUINQUELOCUL INA QU INQUE LOCULINA QUINQUELOCULINA QU INQUELOCULINA QUINQUE LOCUL INA QU INQUE LOCULINA QUINQUEL OCULINA QU INQUE LOCULINA QU INQUE LOCULINA QU INQUE LOCUL INA QUINQUE LOCULINA QU INQUE LOCULINA QU INQUE LOCULINA QUINQUELOCULINA QU INQUEL OCULINA QUINQUE LOCULINA QUINQUELOCUL INA QU INQUE LOCUL INA QUINQUE LOC ULINA QU INQUEL OCUL INA QU INQUE LOCUL INA QUINQUELOCUL INA QUINQUE LOCUL INA SI PHONAPERT A

SI PHONAPERTA

SI PHONAPER TA

SIPHONAPERTA

SI PHONAPERTA

SI PHONAPERTA

SIPHONAPERTA

SI PHONA PER TA

SI PH ONAPERTA

SI PHONAPERTA

SIPHON APERTA

QU INQUE L OCUL INA

QUINQUEL OCUL INA

QUINQUEL OCULINA

A R T I CUL I NA

QUINQUELOCULINA QUINQUELOCULINA QUINQUELOCULINA QUINQUELOCULINA QU INQUE LOC UL INA QU INQUEL OC UL INA
Specific Name

POEYANA

POEYANA

DOEANA

POEYANA

POEYANA

POEYANA

POEYANA

POEYANA

OEYANA

POEYANA

POEYANA

POEYANA

POEYANA

POEYANA

POEYANA

POEYANA

POEYANA

POEYANA

POEYANA

POEYANA

POEYANA

POEYANA

POEYANA

POLYGONA

POLYGONA

POLYGONA

POLYGONA

PO LYGONA

POLYGONA

POLYGONA

POLYGONA

POLYGONA

POLYGONA

POLYGONA

POLYGONA

POLYGONA

L Y

POLYGONA

PO LYGONA

POLYGONA

POLYGONA

POLYGONA

RETICULATA

RHCDIENSIS

RHCDIENSIS

RH COIENSIS

RHCDIENSI

RHCDIENSIS

RHCDIENSIS

RHCDIENSIS

RH CDIENSIS

RHCDIENSIS

RH COIENSIS

RH COIENSIS

RHCDIENSIS

RHCDIENSIS

RHCDIENSIS

RHCDIENSIS

RHCDIENSIS

RH CDIENSIS

RHCDIENSIS

RHODIENSIS

RHODIENSIS

RHCDIENSIS

RHCDIENSIS

SA EULOSA

SA EULOSA

SA BULOSA

SABULOSA

SAEULOSA

SA BULOSA

SA BUL OSA

SAEULOSA

SA EUL OSA

SAEULOSA

SAEULOSA

SAMOAENSIS

SAMOAENSIS

SA TANENSIS

SC FOBICULATA

SENINULA

SE NINULA

SE INUL A

SENINULA

SE IINULA

Locality

CAMPECHE BANK, MEXICO

TORTUGAS, FLA

MISSISSIPPI SOUND

NE GULF OF MEXICO

NE GULF OF MEXICO

TEXAS GULF COAST

ALLYN S BIGHT, TEXAS

CAPE ROMANO, FLA.

TAMPA-SARASOTA BAY, FLA.

NE GULF OF MEXICO

NE GULF OF MEXIICO

NE GULF OF MEXICO

NE GULF OF MEXICO

NE GULF OF MEXICO 


\section{Publication}

23386 KORNFELD 1931

23387 KORNFELD 1931

23388 SHIFFLETT 1961

23389 KORNFELD 1931

23390 KORNFELD 1931

23391 KORNFELD 1931

23392 LEHMANN 1957

23393 KANE 1967

23394 KANE 1952

23395 PARKER PHLEGER PEIRSON 1953

23396 PARKER PHLEGER PEIR SON 1953

23397 SHEPARD MOORE 1955

23398 PFLUM FRERICHS 1976

23399 PHLEGER 1965 A

23400 DHLEGER 1965 A

23401 SEGURA 1963

2340 ? PHLEGER LANKFORD 1957

23403 PHLEGER 1956

23404 PARKER PHLEGER PEIRSON 1953

23405 PARKER PHLEGER PEIRSON 1953

23406 PARKER PHLEGER PEIRSON 1953

23407 PFLUM FRERICHS 1976

23408 PFLUM FRERICHS 1976

23409 PARKER PHLEGER PEIRSON 1953

23410 PHLEGER 1956

23411 PHLEGER 1956

23412 PHLEGER 1956

23413 PARKER PHLEGER PEIRSON 1953

23414 SHENTON 1957

23415 PARKER PHLEGER PEIRSON 1953

23416 BOCK 1976

23417 WALTON 1964

23418 PHLEGER 1965 A

23419 BENDA PURI 1962

23420 BENDA OURI 1962

23421 PHLEGER 1965 A

23422 PHLEGER 1965 A

23423 ANDERSON 1968

23424 PHLEGER 1965 A

23425 PHLEGER 1965 A

23426 AYALA-CASTANARES 1963

23427 AYALA-CASTANARES SEGURA 1968

23428 LEHMANN 1957

23429 NORTON 1930

23430 CUSHMAN $1922 \mathrm{~A}$

23431 NORTON 1930

23432 LEHMANN 1957

23433 POST 1951

23434 CUSHMAN 1922A

23435 NORTON 1930

23436 AYALA-CASTANARES 1963

23437 BOCK 1976

23438 BANDY 1954

23439 BANDY 1954

23440 BANDY 1954

23441 BANDY 1954

23442 BANDY 1954

23443 PHLEGER 1965 A

23444 PHLEGER $1965 \mathrm{~B}$

23445 PHLEGER $1965 \mathrm{~A}$

23446 PHLEGER 1965 A

23447 PHLEGER 1965 A

23448 PHLEGER 1965 A

23449 PHLEGER $1965 \mathrm{~A}$

23450 BOCK 1976

23451 ANDERSEN 1961

23452 NOR TON 1930

23453 CUSHMAN 1922A

23454 SEGURA 196
23455 DAVIS 1964

23455 DAVIS 1964
23456 NORTON 1930

23457 PFLUM FRERICHS 1976

23458 PFLUM FRERICHS 1976

23459 PARKER 1954

23460 PARKER 1954
23461 PFLUM FRERICHS 1976

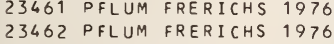

23463 PARKER 1954

23464 PARKER 1954

23465 PFLUM FRERICHS 1976

23466 PFLUM FRERICHS 1976

23467 PFLUM FRERICHS 1976

23468 PFLUM FRERICHS 1976

23469 PFLUM FRERICHS 1976

23470 PFLUM FRERICHS 1976

23471 PFLUM FRERICHS 1976

23472 PFLUM FRERICHS 1976

23473 PFLUM FRERICHS 1976

23474 PFLUM FRERICHS 1976

23475 PFLUM FRERICHS 1976

23476 PFLUM FRERICHS 1976

23477 PARKER 1954

23478 PARKER 1954

23479 PFLUM FRERICHS 1976

23480 PFLUM FRERICHS 1976

\section{Generic Name}

QUINQUELOCULINA

QUINQUEL OCUL INA QUINQUELOCULINA QUINQUEL OCULINA QU INQUEL OCUL INA QUINQUEL OCULINA QU INQUEL OCUL INA QU INQUEL OCUL INA QUINQUEL OC UL INA QU INQUE LOCUL INA QUINQUE LOCUL INA QU INQUELOCUL INA QUINQUE LOCULINA QU INQUE L OCUL INA QUINQUELOCULINA QU INQUEL OCUL INA QU INQUEL OCUL INA QU INQUE LOCULINA QU INQUEL OCUL INA QU INQUEL OCUL INA QU INQUEL OCULINA QUINQUELOCULINA QU INQUELOCUL INA QUINQUELOCULINA QUINQUEL OCUL INA QUINQUEL OC ULINA QU INQUEL OCUL INA QU INGUEL OC UL INA QUINQUELOCULINA QU INQUELOCULINA QUINQUELOCULINA QUINQUEL OCUL INA QUINQUELOC UL INA QUINQUEL OCULINA QUINQUEL OCUL INA QUINQUELOCUL INA QUINQUELOCULINA QU INQUEL OC UL INA QUINQUEL OCUL INA QU INQUE LOCULINA QU INQUEL OC UL INA U INQUELOC ULINA QU INQUELOCULINA QU INQUELOCUL INA QUINQUELOCULINA QUINQUEL OCUL INA QU INQUELOCULINA QU INQUE LOCULINA QU INQUEL OCUL I NA QU INQUELOCUL INA QU INQUEL OC UL INA QU INQUELOCULINA QU INQUEL OCUL INA QU INQUEL OC UL INA QUINQUEL OCUL INA QU INQUELOCUL INA QU INQUEL OCUL INA QUINQUELOCULINA QU INQUELOC ULI INA QU INQUEL OCUL INA QUINQUELOCULINA QUINQUELOCULINA QU INQUEL OCUL INA QUINQUELOCULINA QUINQUELOC UL INA QU INQUELOCULINA QU INQUEL OCUL INA QUINQUEL OCUL INA QU INQUE LOCUL INA QU INQUEL OCUL INA QU INQUELOCULINA QUINQUEL OC UL INA QU INQUEL OCUL INA QU INQUE LOCUL INA QUINQUEL OCULINA QUINQUEL OC UL INA QU INQUEL OCULINA QU INQUEL OC UL INA QU INQUEL OC UL INA QU INQUE LOCULINA QU INQUELOCUL INA QIJ INQUEL OCUL INA QU INQUEL OCUL INA QUINQUELOCULINA QUINQUELOCULINA QU INQUE LOCULINA QUINQUEL OCUL INA QUINQUEL OC UL INA QUINQUEL OCUL INA QUINQUELOCULINA QUINQUELOCULINA QUINQUELOCULINA QU INQUELOCUL INA QUINQUEL OC UL INA QUINQUEL OC UL I NA
Specific Name

SENINULA

SENINULA

SENINULA

SENINULA

SEN I NULA

SEN INULA

SENINULA

SENINULA

SENINULA

SENINULA

SENINULA

SENINULA

SENINULA

SENINULA

SENINULA

SEN INULA

SENINULA

SENINULA

SENINULA

SEN INULA

SENINULA

SENINULA

SENINULA

SEN INULA

SENINULA

SENINULA

SENINULA

SENINULA

SENINULA

SENINULA

SEMINULA

SENINULA

SENINULA

SENINULA

SENINULA

SENINULA

SEN I NULA

SENINULA

SENINULA

SEN INULA

SENINULA

SENINULA

JU EOSA

STRIATA

STRIATA

SUEARENAR IA

SUBCARINATA

SUEPOEYANA

SUEPOEYANA

SUEPOEYANA

SUEPOEYANA

SUEPOEYANA

SUEQUADRA

SUEQUADRA

SUEQUADRA

SUEQUADRA

SUEQUADRA

TEAAGOS

TE AAGOS

TENAGOS

TENAGOS

TE NAGOS

TE $\wedge A G O S$

TE $\wedge A G O S$

TE^AGOS

TI PSWORD I

TR ICAR INA TA

TR ICARINATA

TR I CAR INATA

TR ICARINATA

UNDOSA

ENUSTA

VEAUSTA

VEA UST TA

VENUSTA

VE NUSTA

VE NUSTA

VENUSTA

ENUSTA

VENUSTA

VENUSTA

E NUSTA

VENUSTA

VENUSTA

VENUSTA

ENUSTA

VENUSTA

VENUSTA

VE NUSTA

VENUSTA

VENUSTA

VE NUSTA

VENUSTA

\section{Locality}




\section{Publication}

23481 PARKER 1954

23482 PARKER 1954

23483 SHIFFLETT 1961

23484 PFLUM FRERICHS 1976

23485 PFLUM FRERICHS 1976

23486 PFLUM FRERICHS 1976

23487 PFLUM FRERICHS 1976

23488 PFLUM FRERICHS 1976

23489 PFLUM FRERICHS 1976

23490 NORTON 1930

23491 PFLUM FRERICHS 1976

23492 PFLUM FRERICHS 1976

23493 PFLIJM FRERICHS 1976

23494 PFLUM FRERICHS 1976

23495 SEGURA 1963

23496 PFLUM FRERICHS 1976

23497 PFLUM FRERICHS 1976

23498 PFLUM FRERICHS 1976

23499 PFLUM FRERICHS 1976

23500 PFLUM FRERICHS 1976

23501 PFLUM FRERICHS 1976

23502 PFLUM FRERICHS 1976

23503 PFLUM FRERICHS 1976

3504 PFLUM FRERICHS 1976

05 PFLUM FRERICHS 1976

23506 PFLUM FRERICHS 1976
23507 PFLUM FRERICHS 1976

23508 PFLUM FRERICHS 1976

23509 PFLUM FRERICHS 1976

23510 PFLUM FRERICHS 1976

23512 PARKER PHLEGER PEIRSON 1953

23512 PARKER PHLEGER PEIRSON 1953

23514 PARKER PHLEGER PEIRSON 1953

23515 LEHMANN 1957

23516 PARKER PHLEGER PEIRSON 1953

23517 PHLEGER LANKFORD 1957

23518 PHLEGER 1960

23519 SEGURA 1963

23520 PARKER PHLEGER PEIRSON 1953

23521 AYALA-CASTANARES 1963

23522 PARKER PHLEGER PEIRSON 1953

23523 PARKER PHLEGER PEIRSON 1953

23524 PARKER PHLEGER

23525 PHLEGER $1965 \mathrm{~B}$

23527 LEROY HODGKINSON 1975

23529 PFLUM FRERICHS 1976

23529 PFLUM FRERICHS 1976

23530 SEGURA 1963

23532 PARKER 1954

23533 PARKER 1954

23534 LUDWICK WALTON 1957

23535 WARREN 1957

23536 LANKFORD 195

23538 SHEPARD MOORE 1955

23539 PARKER 1954

23540 PARKER 1954

23541 PARKER 1954

23542 PARKER 1954

23543 PARKER 1954

23544 BANDY 1956

23545 BANDY 1956

23546 BANDY 1956

23547 BANDY 1956

23548 BANDY 1956

23549 BANDY 1956

23550 PARKER 1954

23552 ANDERSEN 196

23553 BANDY 1956

23554 BANDY 1956

23555 BANDY 1954

23556 BANDY 1954

23558 BANDY 1956

23559 PARKER 1954

23560 PARKER 1954

23561 PHLEGER 1956

23562 PARKER 1054

23563 PHLEGER 1956

23565 PANDY 1954

23566 BANDY 1954

23567 WARREN 1956

23568 LOEP 1965

23569 BANDY 1954

23570 BANDY 1954

23571 BOCK 1975

2357? PARKER PHLEGER PEIRSON 1953

23573 PHLEGER 1956

23574 PHLEGER 1956

\section{Generic Name}

QU INQUELOCUL INA QU INQUE LOCUL INA QUINQUELOCULINA QU INQUELOCULINA QU INQUEL OCUL INA QU INQUEL OCULINA QU INQUELOCULINA QUINQUELOCULINA QU INQUELOCULINA QU INQUELOCULINA QU INQUEL OCUL INA QU INQUELOCULINA QU INQUELOCUL INA QU INQUEL OCULINA QU INQUELOCUL INA QUINQUEL OCULINA QU INQUE LOCUL INA QU INQUELOCULINA QUINQUELOCUL INA QU IVQUE LOCUL INA QU INQUELOCULINA QU INQUELOCULINA QU IVQUEL OCUL INA QU INQUEL OCULINA QU INQUELOCULINA QU INQUELOCUL INA QU INQUELOCULINA QU INQUELOCULINA QU INQUELOCUL INA QU INQUEL OCULINA QU INQUELOCUL INA QU INQUE LOCUL INA QU INQUELOCUL INA QU INQUELOCULINA QUINQUELOCULINA QU INQUELOCULINA QU INQUEL OCUL INA QU INQUEL OCUL INA QU INQUE LOCUL INA QU INQUE LOCUL INA QUINQUELOCUL INA QU INQUEL OCUL INA QU INQUEL OCULINA QU INQUELOCULINA QU INQUE L OC UL I NA RAMULINA

RAMUL IN

RAMULINA

RECTOBOLIVINA RECTOBOLIVINA RECTOSOLIVINA RECTOBOL IVIVA RECTOBOLIVIVA RECTOBOLIVINA RECTOBOLIVINA RECTOBOL IVINA RECTOBOLIVINA RECTOBOLIVINA RECTOBOL IV INA RECTOBOLIVINA RECTOBOLIVINA RECTOBOLIVINA RECTOBOLIVINA RECTOBOLIVINA RECTOBOLIVINA RECTOBOLIVINA RECTOBOLIVINA RECTOBOLIVINA RECTOBOLIVIVA RECTOBOLIVINA RECTOBOL IVINA RECTOBOL IV INA RECTOBOL IV INA RECTOBOLIVINA RECTOBOLIVI VA RECTOBOLIVINA RECTOBOLIV INA RECTOBOL IVINA RECTOBOL IVI I A RECTOBOLIVINA RECTOBOL IVINA RECTOBOLIVINA RECTOBOLIVINA RECTOBOLIVINA RECTOBOLIVINA RECTOBOL IV INA RECTOBOLIVINA RECTOBOL IVINA RECTOBOLIVIVA RECTOBOLIVINA RECTOBOLIVIVA RECTOBOL IV INA RECTOBOLIVINA RECTOBOLIVINA RECTOBOLIVINA

\section{Specific Name}

VENUSTA

VENUSTA

VULGARIS

VUGARIS

VULGARIS

VULGARIS

VULGARIS

VULGARIS

VULGARIS

ULGARIS

UULARIS

VULGARIS

VULGARIS

VULGARIS

VULGARIS

VULGARIS

ULGARIS

VULGARIS

VULGARIS

VULGARIS

WEAVER

WE AVER

WEAVERI

WEAVER

WEAVERI

WEAVERI

WEAVER I

EAVERI

WIESNER

WI ESVER I

WI ESNERI

WI ESNER I

WIESNER

WI ESNER I

WI ESNERI

WIESNER

WI ESNER I

I ESNER I

I I SNER I

GL CBULIFERA

GL OBULIFERA

GL CBULIFERA

AD VENA

D VENA

D VENA

ADVENA

ADVENA

ADVENA

ADVENA

ADVENA

ADVENA

AD VENA

ADVENA

AD VENA

ADVENA

AD VENA

ADVENA

DVENA

ADVENA
ADVENA

ADVENA

A DVENA

ADVENA

ADVENA

AD VENA

ADVENA

ADVENA

ADVENA

ADVENA

ADVENA

AD VENA

ADVENA

$A D V E N A$

ADVENA

ADVENA

ADVENA

ADVENA

ADVENA

ADVENA

ADVENA

AD VENA

ADVENA

AD VENA

AD VENA

ADVENA

DI MORPHA

\section{Locality}

NE GULF OF MEXICO

NE GULF OF MEXICO

HEALD BANK, G. OF MEXICO

NW GULF OF MEXICO

CENTRAL GULF OF MEXICO

CENTRAL GULF OF MEXICO

CENTRAL GULF OF MEXICO

NW GULF OF MEXICO

CENTRAL GULF OF MEXICO

TORTUGAS, FLA

CENTRAL GULF OF MEXICO

CEVTRAL GULF OF MEXICO

CENTRAL GULF OF MEXICO 


\section{Publication}

23576 PFLUM FRERICHS 1976 23577 PFLUM FRERICHS 1976 23578 PFLUM FRERICHS 1976 23579 PARKER 1954

23580 PARKER 1954

23581 PARKER 1954

23582 PARKER 1954

23583 PARKER 1954

23584 PFLUM FRERICHS 1976

23585 PFLUM FRERICHS 1976

23586 PFLUM FRERICHS 1976

23587 PFLUM FRERICHS 1976

23588 PFLUM FRERICHS 1976

23589 PFLUM FRERICHS 1976

23590 PFLUM FRERICHS 1976

23591 PFLUM FRERICHS 1976

23592 PFLUM FRERICHS 1976

23593 PFLUM FRERICHS 1976

23594 PFLUM FRERICHS 1976

23595 PFLUM FRERICHS 1976

23596 PFLUM FRERICHS 1976

23597 LANKFORD 1959

23598 LEROY HODGKINSON 1975

23599 PFLUM FRERICHS 1976

23600 PFLUM FRERICHS 1976

23601 PFLUM FRERICHS 1976

23602 PFLUM FRERICHS 1976

23603 PFLUM FRERICHS 1976

23604 PFLUM FRERICHS 1976

23605 PFLUM FRERICHS 1976

23606 PFLUM FRERICHS 1976

23607 PFLUM FRERICHS 1976

23608 PFLUM FRERICHS 1976

23609 PFLUM FRERICHS 1976

23610 PFLUM FRERICHS 1976

23611 PFLUM FRERICHS 1976

23612 PFLUM FRERICHS 1976

23613 PFLUM FRERICHS 1976

23614 PFLUM FRERICHS 1976

23615 PFLUM FRERICHS 1976

23616 PFLUM FRERICHS 1976

23617 PFLUM FRERICHS 1976

23618 PFLUM FRERICHS 1976

23619 PFLUM FRERICHS 1976

23620 PELUM FRERICHS 1976

23621 PFLUM FRERICHS 1976

23622 PFLUM FRERICHS 1976

23623 PFLUM FRERICHS 1976

23624 PFLUM FRERICHS 1976

23625 PFLUM FRERICHS 1976

23626 PFLUM FRERICHS 1976

23627 PFLUM FRERICHS 1976

23628 PFLUM FRERICHS 1976

23629 PFLUM FRERICHS 1976

23630 PFLUM FRERICHS 1976

23631 PFLUM FRERICHS 1976

23632 PFLUM FRERICHS 1976

23633 PFLUM FRERICHS 1976

23634 PFLUM FRERICHS 1976

23635 PFLUM FRERICHS 1976

23636 PFLUM FRERICHS 1976

23637 PFLUM FRERICHS 1976

23638 PFLUM FRERICHS 1976

23639 PFLUM FRERICHS 1976

23640 CUSHMAN 1920

23641 CUSHMAN 1920

23642 LEROY HODGKINSON 1975

23643 PFLUM FRERICHS 1976

23644 PARKER 1954

23645 PARKER 1954

23646 LUOWICK WALTON 1957

23647 PARKER 1954

23648 PARKER 1954

23649 PARKER 1954
23650 PARKER 1954

23651 PARKER 1954

23652 PARKER 1954

23653 PARKER 1954

23654 PARKER 1954

23655 PARKER 1954

23656 CUSHMAN 1920

23657 CUSHMAN 1920

23658 CUSHMAN 1920

23660 PFLUM FRERICHS 1976

23661 PHLEGER 1951A

23662 PHLEGER $1951 \mathrm{~A}$

23663 PHLEGER 1951A

23664 PFLUM FRERICHS 1976

23665 PHLEGER 1951 A

23666 PHLEGER 1951A

23667 PHLEGER 1951A

23668 PHLEGER $1951 \mathrm{~A}$

23669 PHLEGER $1951 \mathrm{~A}$
23670 PFLUM FRERICHS 1976
Generic Name

RECTOBOL IVINA RECTOBOLIVINA RECTOBOLIVINA

RECTOBOLIVINA RECTOBOLIVINA

RECTOBOLIVINA

RECTOBOLIVINA

RECTOBOL IV INA

RECTOBOL IVINA

RECTOBOLIVINA

RECTOBOLIVINA

RECTOBOLIVINA

RECTOBOLIV INA

RECTOBOLIVINA

RECTOBOL IVINA

RECTOBOLIVINA

RECTOBOLIVINA

RECTOBOLIVINA

RECTOBOLIVINA

RECTOBOLIVINA

RECTOBOLIVINA

RECTUVIGER INA

RE CURVOIDES

RE CURVOIDES

RECURVOIDES

RECURVOIDES

RE CURVOIDES

RE CURVOIDES

RECURVOIDES

RECURVOIDES

RECURVOIDES

RECURVOIDES

RECURVOIDES

RE CURVOIDES

RE CURVOIDES

RECURVOIDES

RECURVOIDES

RE CURVOI DES

RECURVOIDES

RECURVOIDES

RE CURVOIDES

RECURVOIDES

RECURVOIDES

RECURVOIDES

RECURVOIDES

RECURVOI DES

RE CURVOIDES

RE CUR VOIDES

RECURVOIDES

RECURVOIDES

RE CURVOIDES

RECURVOIDES

RE CURVOIDES

RECURVOIDES

RECURVOIDES

RECURVOIDES

RECURVOIDES

RE CURVOIDES

RECURVOIDES

RECURVOIDES

RE CURV OIDES

RECURVOIDES

RE CUR VOIDES

RECURVOIDES

RE OPHAX

RE OPHAX

REOPHAX

RE OPHAX

RE OPHAX

RE OPHAX

RE OPHAX

REOPHAX

RE OPHAX

REOPHAX

RE OPHAX

RE OPHAX

REOPHAX

REOPHAX

RE OPHAX

RE OPHAX

REOPHAX

RE OPHAX

RE OPHAX

RE OPHAX

RE OPHAX

RE OPHAX

RE OPHAX

RE OPHAX

REOPHAX

RE OPHAX

REOPHAX

REOPHAX

RE OPHAX
Specific Name

Locality

Lat. Long.

DI MORPHA

DIMORPHA

DIMORPHA

DI MORPHA

DI NORPHA

DI NORPHA

DINORPHA

DINORPHA

DIMORPHA

DI MORPHA

DINORPHA

DI NORPHA

DINORPHA

DINORPHA

DI NORPHA

DI MORPHA

DI MORPHA

OIMORPHA

DINORPHA

DI MORPHA

NI COLI

CONTORTUS

CONTORTUS SCITULUS

COATORTUS SCITULUS

COATORTUS SCITULUS

CONTORTUS SCITULUS

CONTORTUS SCITULUS

CONTORTUS SCITULUS

CONTORTUS SCITULUS

CONTORTUS SCITULUS

CONTORTUS SCITULUS

COATORTUS SCITULUS

COATORTUS SCITULUS

CONTORTUS SCITULUS

COATORTUS SCITULUS

COATORTUS SCITULUS

COATORTUS SCITULUS

COATORTUS SCITULUS

COATORTUS SUBGLOBOSUS

COATORTUS SUBGLOBOSUS

CONTORTUS SUBGLOBOSUS

CONTORTUS SUBGLOBOSUS

CONTORTUS SUBGLOBOSUS

CONTORTUS SUBGLOBOSUS

CONTORTUS SUBGLOBOSUS

COATORTUS SUBGLOBOSUS

COATORTUS SUBGLOBOSUS

CONTORTUS SUBGLOBOSUS

CONTORTUS SUBGLOBOSUS

CONTORTUS SUBGLOBOSUS

CONTORTUS SUBGLOBOSUS

COATORTUS SUBGLOBOSUS

COATORTUS SUBGLOBOSUS

COATORTUS SUBGLOBOSUS

CONTORTUS SUBGLOBOSUS

CONTORTUS SUBGLOBOSUS

CONTORTUS SUBGLOBOSUS

COATORTUS SUBGLOBOSUS

COATORTUS SUBGLOBOSUS

CONTORTUS SUBGLOBOSUS

CONTORTUS SUBGLOBOSUS

CONTORTUS SUBGLOBOSUS

CONTORTUS SUBGLOBOSUS

ADLNCUS

ADUNCUS

AG GLUTINATUS

BACILLARI

AGGLUTINATUS

AG GLUTINATUS

AG GLUTINATUS

AGGLUTINATUS

AG GLUTINATUS

A GGLUTINATUS

AGELUTINATUS

AGGLUTINATUS

AG GLUTINATUS

AG GLUTINATUS

AG GLUTINATUS

AGELUTINATUS

AG GLUTINATUS

DEATALINI FORMIS

DENTAL IN I FORMIS

DENTALINI FORMIS

DENTAL INI FORMIS

DEATALINI FORMIS

DENTALINI FORMIS

DE NTALINI FORMIS

DE NTALINIFORMIS

DE ATALINI FORMIS

DENTAL IN I FORMIS

DEATALINIFORMIS

DENTALINI FORMIS

DENTALINIFORMIS

DE ATALINIFORMIS

NW GULF OF MEXICO

NW GULF OF MEXICO

NW GULF OF MEXICO

NE GULF OF MEXICO 


\section{Publication}

23671 PHLEGER 1951A 23672 PHLEGER 1951 A 23673 PHLEGER 1951 A 23674 PHLEGER $1951 \mathrm{~A}$ 23675 PHLEGER $1951 \mathrm{~A}$ 23676 PHLEGER 1951 A 23677 PHLEGER 1951 A 23678 PHLEGER $1951 \mathrm{~A}$ 23679 PHLEGER 1951 A 23680 PHLEGER 1951 A

23681 PFLUM FRERICHS 1976 23682 PFLUM FRERICHS 1976 23683 PFLUM FRERICHS 1976 23684 PFLUM FRERICHS 1976 23685 PFLUM FRERICHS 1976 23686 DFLUM FRERICHS 1976 23687 PFLUM FRERICHS 1976 23688 PFLUM FRERICHS 1976 23689 PFLUM FRERICHS 1976 23690 PFLUM FRERICHS 1976 23691 PHLEGER $1951 \mathrm{~A}$

23692 PFLUM FRERICHS 1976 23693 PFLUM FRERICHS 1976 23694 PFLUM FRERICHS 1976 23695 PHLEGER $1951 \mathrm{~A}$

23696 PFLUM FRERICHS 1976 23697 PFLUM FRERICHS 1976 23698 PFLUM FRERICHS 1976 23699 PFLUM FRERICHS 1976 23700 PFLUM FRERICHS 1976 23701 PFLUM FRERICHS 1976 23702 PFLUM FRERICHS 1976 23703 PFLUM FRERICHS 1976 23704 PHLEGER $1951 \mathrm{~A}$

23705 PFLUM FRERICHS 1976 23706 PFLUM FRERICHS 1976 23707 PFLUM FRERICHS 1976 23708 PFLUM FRERICHS 1976 23709 PFLUM FRERICHS 1976 23710 PFLUM FRERICHS 1976 23711 PFLUM FRERICHS 1976 23712 PFLUM FRERICHS 1976 23713 PFLUM FRERICHS 1976 23714 PFLUM FRERICHS 1976 23715 PFLUM FRERICHS 1976 23716 PFLUM FRERICHS 1976 23717 PFLUM FRERICHS 1976 23718 PFLUM FRERICHS 1976 23719 PFLUM FRERICHS 1976 23720 PFLUM FRERICHS 1976 23721 PFLUM FRERICHS 1976 23722 PFLUM TRERICHS 1976 23723 PFLUM FRERICHS 1976 23724 PFLUM FRERICHS 1976 23725 PFLUM FRERICHS 1976 23726 PFLUM FRERICHS 1976 23727 PFLUM FRERICHS 1976 23728 PFLUM FRERICHS 1976 23729 PFLUM FRERICHS 1976 23730 PFLUM FRERICHS 1976 23731 PFLUM FRERICHS 1976 23732 PFLIJM FRERICHS 1976 23733 PFLUM FRERICHS 1976 23734 PFLUM FRERICHS 1976 23735 PFLUM FRERICHS 1976 23736 PFLUM FRERICHS 1976 23737 PFLUM FRERICHS 1976 23738 PFLUM FRERICHS 1976 23739 DFLUM FRERICHS 1976 23740 PFLUM FRERICHS 1976 23741 PFLUM FRERICHS 1976 23742 PFLUM FRERICHS 1976 23743 PFLUM FRERICHS 1976 23744 PFLUM FRERICHS 1976 23745 PFLUM FRERICHS 1976 23746 PFLUM FRERICHS 1976 23747 PFLUM FRERICHS 1976 23748 PFLUM FRERICHS 1976 23749 PFLUM FRERICHS 1976 23750 PFLUM FRERICHS 1976 23751 PFLUM FRERICHS 1976 23752 PFLUM FRERICHS 1976 23753 PARKER 1954

23754 PARKER 1954

23755 OFLUM FRERICHS 1976 23756 PFLUM FRERICHS 1976 23757 PARKER 1954

23758 PARKER 1954

23759 PARKER 1954

23760 PARKER 1954

23761 PARKER 1954

23762 PARKER 1954

23763 DARKER 1954

23765 PFLUM FRERICHS 1976
Generic Name

RE OPHAX

RE OPHAX

REOPHAX

RE OPHAX

RE OPHAX

REOPHAX

RE OPHAX

REOPHAX

REOPHAX

REOPHAX

RE OPHAX

REOPHAX

REOPHAX

RE OPHAX

RE OPHAX

REOPHAX

REOPHAX

REOPHAX

REOPHAX

REOPHAX

REOPHAX

RE OPHAX

REOPHAX

RE OPHAX

REOPHAX

RE OPHAX

RE OPHAX

RE OPHAX

RE OPHAX

REOPHAX

RE OPHAX

REOPHAX

RE OPHAX

REOPHAX

REOPHAX

REOPHAX

REOPHAX

REOPHAX

RE OPHAX

REOPHAX

RE OPHAX

RE OPHAX

REOPHAX

REOPHAX

REOPHAX

REOPHAX

REOPHAX

RE OPHAX

RE OPHAX

RE OPHAX

RE OPHAX

RE OPHAX

RE OPHAX

REOPHAX

RE OPHAX

RE OPHAX

RE OPHAX

REOPHAX

RE OPHAX

RE OPHAX

RE OPHAX

REOPHAX

REOPHAX

REOPHAX

RE OPHAX

RE OPHAX

RE OPHAX

REOPHAX

REOPHAX

RE OPHAX

RE OPHAX

RE OPHAX

REOPHAX

REOPHAX

RE OPHAX

REOPHAX

REOPHAX

RE OPHAX

RE OPHAX

RE OPHAX

RE OPHAX

RE OPHAX

RE OPHAX

RE OPHAX

RE OPHAX

REOPHAX

RE OPHAX

REOPHAX

RE OPHAX
Specific Name

DE ATALINIFORMIS

DENTALINIFORMIS

DEATALIN IFORMIS

DE ATALINI FORMIS

DEATALINI FORMIS

DEATALINI FORMI

DENTALINIFORMIS

DEATALINIFORMIS

DEATALINI FORMIS

DEATALINI FORMIS

DEATALINI FORMI

DENTALINI FORMIS

DE ATALINI FORMIS

DE ATALINI FORMIS

DENTALINIFORMIS

DENTALINI FORMIS

DEATALINIFORMIS

DEATALINI FORMI

DEATAL IN I FORMIS

DE ATALINIFORMIS

DENTALINIFORMIS

DE ATALINI FORMIS

DE A TAL IN I FORMI

DEATALINI FORMIS

DEATALINIFORMIS

DE NTALINIFORMIS

DE NTALINI FORMIS

DEATALINIFORMIS

DENTALINIFORMIS

DEATALINIFORMIS

DE MTALINI FORMI

DENTALINI FORMIS

DEATALINI FORMIS

DEATALINIFORMIS

DENTALINIFORMIS

DEATALINI FORMIS

DEATALINI FORMIS

DENTAL INI FORMIS

DENTALINIFORMIS

DENTALINI FORMIS

DE TALINIFORMIS

DE ATALIN I FORMIS

DEATALINIFORMIS

DENTALINI FORMIS

DI STANS

DI STANS

DI STANS

DI STANS

DI STANS

DI STANS

DI STANS

DI STANS

DI STANS

DI STANS

DI STANS

DI STANS

DI STANS DELICATULUS DI STANS DELICATULUS DI STANS DELICATULUS DI STANS DELICATULUS DI STANS DELICATULUS DI STANS DELICATULUS DI STANS DELICATULUS DI STANS DELICATULUS DI STANS DELICATULUS DI STANS DELICATULUS DISTANS DELICATULUS DI STANS DELICATULUS DI STANS DELICATULUS DI STANS DELICATULUS DISTANS DELICATULUS DI STANS DELICATULUS DI STANS DELICATULUS DI STANS DELICATULUS DISTANS DELICATULUS DI STANS DELICATULUS DI STANS DELICATULUS DI STANS DELICATULUS DI STANS DELICATULUS DI STANS DELICATULUS DI STANS DELICATULUS DI STANS DELICATULUS DI STANS DELICATULUS DI STANS DELICATULUS DI STANS DELICATULUS DI STANS DELICATULUS DI STANS DEL ICATULUS DI STANS DELICATULUS DI STANS DELICATULUS DI STANS DEL ICATULUS DI STANS DEL ICATULUS DI STANS DELICATULUS DI STANS DEL ICATULUS DI STANS DELICATULUS

\section{Locality}

Lat. Long.

NW GULF OF MEXICO

NW GULF OF MEXICO

NW GULF OF MEXICO

NW GULF OF MEXICO 


\section{Publication}

23766 PFLUM FRERICHS 1976 23767 PFLUM FRERICHS 1976 23768 PFLUM FRERICHS 1976 23769 PARKER 1954

23770 PARKER 1954

23771 PARKER 195

23772 PFLUM FRERICHS 1976 23773 PFLUM FRERICHS 1976 23774 PFLUM FRERICHS 1976 23775 PFLUM FRERICHS 1976 23776 PFLUM FRERICHS 1976 23777 PARKER 1954

23778 PFLUM FRERICHS 1976 23779 PFLUM FRERICHS 1976 23780 PFLUM FRERICHS 1976 23781 PFLUM FRERICHS 1976 23782 PFLUM FRERICHS 1976 23783 LUDWICK WALTON 1957 23784 PARKER 1954

23785 PARKER 1954

23786 PARKER 1954

23787 PARKER 1954

23788 PARKER 1954

23789 PARKER 1954
23790 PARKER 1954

23791 PARKER 1954

23792 PARKER 1954

23793 PARKER 1954

23794 PARKER 1954

23795 LUDWICK WALTON 1957

23796 PARKER 1954

23797 PARKER 1954

23798 PARKER 1954

23799 PARKER 1954

23800 PARKER 1954

23801 PARKER 1954

23802 PARKER 1954

23803 PARKER 1954

23804 PARKER 1954

23805 PARKER 1954

23806 PARKER 1954

23807 PARKER 1954

23808 PARKER 1954

23809 PARKER 1954

23810 PARKER 1954

23811 PARKER 1954

23812 PARKER 1954

23813 PARKER 1954

23814 LUDWICK WALTON 1957

23815 PARKER 1954

23816 PARKER 195

23817 BOCK 1976

23818 PARKER 1954

23819 PARKER 1954

23820 PARKER 1954

23821 PARKER 1954
23822 PARKER 1954

23823 PHLEGER LANKFOR D 1957

23824 LANKFORD 1959

23825 PHLEGER 1955 B

23826 BOCK 1976

23827 SEGURA 1963

23828 WALTON 1960

23829 PHLEGER $1965 \mathrm{C}$

23830 PHLEGER LANKFORD 1978

23831 PARKER PHLEGER PEIRSON 1953

23832 PARKER PHLEGER PEIRSON 1953

23833 PHLEGER 1965 A

23834 WALTON 1964

23835 BENDA PURI 1962

23836 PHLEGER 19658

23837 PHLEGER 1965 A
23838 PHLEGER 1965 B

23838 PHLEGER 19658

23839 PARKER PHLEGER PEIRSON 1953

23840 PARKER PHLEGER PEIRSON 1953

23841 PARKER PHLEGER PEIRSON 1953

23842 PARKER PHLEGER PEIRSON 1953

23843 PFLUM FRERICHS 1976

23844 PFLUM FRERICHS 1976

23845 PFLUM FRERICHS 1976

23846 PFLUM FRERICHS 1976

23847 PFLUM FRERICHS 1976

23848 CUSHMAN 1920

23849 BOCK 1976

23850 LEROY HODGKINSON 1975

23851 CUSHMAN 1920

23852 CUSHMAN 1920

23853 NORTON 1930

23854 PFLUM FRERICHS 1976

23855 PFLUM FRERICHS 1976

23856 PFLUM FRERICHS 1976

23857 PFLUM FRERICHS 1976

23858 PFLUM FRERICHS 1976

23859 PFLUM FRERICHS 1976
Generic Name

RE OPHAX

REOPHAX

RE OPHAX

RE OPHAX

REOPHAX

RE OPHAX

RE OPHAX

RE OPHAX

RE OPHAX
RE OPHAX

RE OPHAX

RE OPHAX

RE OPHAX

RE OPHAX

RE OPHAX

RE OPHAX

RE OPHAX

RE OPHAX

RE OPHAX

REOPHAX

REOPHAX

RE OPHAX

RE OPHAX

RE OPHAX

RE OPHAX

RE OPHAX

RE OPHAX

RE OPHAX

RE OPHAX

RE OPHAX

RE OPHAX

RE OPHAX

RE OPHAX

RE OPHAX

RE OPHAX

RE OPHAX

RE OPHAX

RE OPHAX

RE OPHAX

RE OPHAX

RE OPHAX

RE OPHAX

REOPHAX

RE OPHAX

RE OPHAX

REOPHAX

RE OPHAX

RE OPHAX

RE OPHAX

RE OPHAX

RE OPHAX

RE OPHAX

RE OPHAX

RE OPHAX

REOPHAX

RE OPHAX

RE OPHAX

REOPHAX

REOPHAX

REOPHAX

RE OPHAX

RE OPHAX

REOPHAX

REOPHAX

RE OPHAX

REOPHAX

RE OPHAX

RE OPHAX

RE OPHAX

RE OPHAX

REOPHAX

REOPHAX

RE OPHAX

RE OPHAX

RE OPHAX

REOPHAX

REOPHAX

REOPHAX

RE OPHAX

RE OPHAX

RE OPHAX

RE OPHAX

REOPHAX

REOPHAX

REOPHAX

RE OPHAX

RE OPHAX

RE OPHAX

REOPHAX

RE OPHAX
Specific Name

DI STANS DELICATULUS DI STANS DELICATUL US DI STANS DELICATULUS DI STANS DELICATULUS DI STANS DELICATULUS DI STANS DELICATULUS DI STANS DELICATULUS DI STANS DELICATULUS DI STANS DEL ICATULUS DI STANS DELICATULUS DISTANS DELICATULUS GUTTIFER

GUTTIFER

GUTTIFER

GUTTIFER

GUTTIFER

GUTTIFER

GUTTIFER

GUTTIFER

GUTTIFER

GUTTIFER

GUTTIFER

HISPIDULUS

HI SPI DUL US

HI SP I DUL US

HI SPIDULUS

HISPIDULUS

HISPIDULUS

HI SPIDULUS

HI SPIDULUS

HISPIDULUS

HI SPIDULUS

HISPIDULUS

HI SPI DUL US

HI SPIDULUS

HI SPIDULUS

HI SPI DULUS

HI SPI DULUS

HI SPIDULUS

HISPIDULUS

HISPIDULUS

HISPIDULUS

HISPI DULUS

HISPIDULUS

HI SPIDULUS

HI SPIDULUS

I R FEGULARIS

IR REGULAR IS

IR REGULAR IS

I R RE GULAR IS

IR REGULAR IS

IRREGULAR IS

I RREGULAR IS

I R REGULAR IS

IR REGULAR IS

IR RE GULAR IS

NANA

NANA

NA^A

NA $\wedge$ A

NA $\wedge$ A

NA A A

NANA

NANA

NA AA

NA AA

NANA

NA^A

NANA

NANA

NANA

NA $A$ A

NA AA

NANA

NANA

NANA

NO DUL OSA

NODULOSA

NO DUL OSA

NODUL OSA

NODULOSA

NO DULOSA

NO DULOSA

NODULOSA

NO DUL OSA

NODULOSA

NO DULOSA

P I LUL I FER

PILULIFER

PI UULIFE

PILULIFER

PILULIFER

PILUL IFER

PI LULIFER

Locality

Lat. Long.

CENTRAL GULF OF MEXICO CENTRAL GULF OF MEXICO NW GULF OF MEXICO NE GULF OF MEXICO NE GULF OF MEXICO NE GULF OF MEXICO

CENTRAL GULF OF MEXICO

CENTRAL GULF OF MEXICO

CENTRAL GULF OF MEXICO 


\section{Publication}

23861 PFLUM FRERICHS 1976 23862 PFLUM FRERICHS 1976 23863 PFLUM FRERICHS 1976 23864 PFLUM FRERICHS 1976 23865 PFLUM FRERICHS 1976 23866 PFLIM FRERICHS 1976 23867 CUSHMAV 1920

23868 CUSHMAN 1920

23869 PFLUM FRERICHS 1976 23870 PFLUM FRERICHS 1976 23871 PFLUM FRERICHS 1976 23872 PFLUM FREKICHS 1976 23873 PFLUM FRERICHS 1976 23874 PFLUM FRERICHS 1976 23875 PFLUM FRERICHS 1976 23876 PFLUM FRERICHS 1976 23877 PFLU M FRERICHS 1976 23878 PFLUM FRERICHS 1976 23879 PFLUM FRERICHS 1976 23880 PFLUM FRERICHS 1976 23881 PFLUM FPERICHS 1976 23882 PFLUM FRERICHS 1976 23883 PFLUM FRERICHS 1976 23884 PFLUM FRERICHS 1976 23885 PHLEGER $1951 \mathrm{~A}$ 23886 PFLUM FRERICHS 1976 23887 PHLEGEP $1951 \mathrm{~A}$ 23888 PHLEGER $1951 \mathrm{~A}$ 23889 PHLEGER 1951A 23890 PHLEGER $1951 \mathrm{~A}$ 23891 PHLEGER 1951 A 23892 PHLEGER $1951 \mathrm{~A}$ 23893 PARKER 1954 23894 PARKER 1954 23895 PHLEGER 1951 A 23896 PFLUM FRERICHS 1976 23897 PFLUM FRERICHS 1976 23898 PFLUM FRERICHS 1976 23899 PFLUM FRERICHS 1976 23900 PFLUM FRERICHS 1976 23901 PFLUM FRERICHS 1976 23902 PFLUM FRERICHS 1976 23903 PFLU भ FRERICHS 1976 23904 PFLUM FRERICHS 1976 23905 PFLUM FRERICHS 1976 23906 PFLUM FRERICHS 1976 23907 PFLUM FRERICHS 1976 23908 PFLUM FRERICHS 1976 23909 PHLEGER $1951 \mathrm{~A}$

23910 PHLEGER $1951 \mathrm{~A}$

23911 PFLUM FRERICHS 1976

23912 PARKER 1954

23913 PARKER 1054
23914 PARKER 1054

23914 PARKER 1954
23915 PFLUM FRERICHS 1976 23916 PFLUM FRERICHS 1976 23917 PFLUM FRERICHS 1976 23918 PFLUM FRERICHS 1976 23919 PFLUM FRERICHS 1976 23920 PFLUM FRERICHS 1976 23921 PFLUM FRERICHS 1976 23922 PFLUM FRERICHS 1976 23923 PFLUM FRERICHS 1976 23924 PFLUM FRERICHS 1976 23925 PFLUM FRERICHS 1976 23926 PFLUM FRERICHS 1976 23927 PFLUM FRERICHS 1976 23928 PFLUM FRERICHS 1976 23929 PFLUM FRERICHS 1976 23930 PFLUM EREFICHS 1976 23931 PFLUM FRERICHS 1976 23932 PARKER 1954

23933 PFLUM FRERICHS 1976 23934 PFLUM FRERICHS 1976 23935 PFLUM FRERICHS 1976 23936 PFLUM FRERICHS 1976 23937 PFLUM FRERICHS 1976 23938 PFLUM FRERICHS 1976 23939 PHLEGER $1951 \mathrm{~A}$ 23940 PARKER 1754 23941 PHLEGER $1951 \mathrm{~A}$ 23942 PHLEGER $1951 \mathrm{~A}$ 23943 PHLEGER 1951 A 23945 LUDWICK NALTON 1957 23946 PARKER 1254 23947 PARKFR 1054 23948 PARKER 1254 23949 PHLEGFR $1951 \mathrm{~A}$ 23950 PHLEGER $1951 \mathrm{~A}$ 23951 PHLEGER 1951 A 23953 PFLUM FRERICHS 1976 23954 PFLUM FRERICHS 1976 23955 PFLUM FRERICHS 1976
Generic Name

RE OPHAX

REOPHAX

RE JPHAX

RE OPHAX

REOPHAX

RE OPHAX

RE OPHAX

RE OPHAX

RE OPHAX

REOPHAX

RE OPHAX

REOPHAX

REOPHAX

RE OPHAX

REOPHAX

REOPHAX

REDPHAX

REOPHAX

REOPHAX

REOPHAX

RE OPHAX

RE OPHAX

RE OPHAX

RE OPHAX

REOPHAX

REOPHAX

REOPHAX

RE OPHAX

REOPHAX

RE OPHAX

REOPHAX

REOPHAX

RE OPHAX

REOPHAX

REOPHAX

REOPHAX

REOPHAX

REOPHAX

REOPHAX

REOPHAX

RE OPHAX

RE OPHAX

RE OPHAX

RE OPHAX

RE OPHAX

RE OPHAX

RE OPHAX

RE OPHAX

RE OPHAX

REOPHAX

REOPHAX

RE OPHAX

RE OPHAX

RE OPHAX

RE OPHAX

REOPHAX

REOPHAX

REOPHAX

REOPHAX

REOPHAX

REOPHAX

RE OPHAX

REOPHAX

RE OPHAX

REOPHAX

RE OPHAX

RE OPHAX

RE OPHAX

RE OPHAX

RE OPHAX

RE OPHAX

RE OPHAX

REOPHAX

RE OPHAX

RE OPHAX

REOPHAX

RE OPHAX

RE JPHAX

RE OPHAX

REOPHAX

RE OPHAX

REOPHAX

RE OPHAX

RE OPHAX

REOPHAX

RE OPHAX

RE JPHAX

REOPHAX
Specific Name

PI LULIFER

PI LULIFER

PI LULIFER

PI LUL IFER

PI LULIFER

PI LULIFER

PI LUL IFER

PI LULIFER

PILULIFER

PILULIFER

PILULIFER

PILULIFER

PI LULIFER

PI LULIFER

PILULIFER

PILULIFER

PILULIFER

PI LULIFER

PILUL IFER

PI LUL IFER

PI LULIFER

SCCRPIURUS

SCCRPIURUS

SC CRPIURUS

SC CRPIURUS

SCCRPIURUS

SCCRPIURU

SC CRPIURUS

SCCRPIURUS

SCCRPIURUS

SCCRPIURUS

SCCRPIURUS

SCCRPIURUS

SCCRPIURUS

SC CRPIURUS

SCORPIURUS

SC CRPIURUS

SCCRPIURUS

SC CRPIURUS

SC CRPIURUS

SC CRPIURUS

SC CRPIURUS

SC CRPIURUS

SCCRPIURUS

SC CRPIURUS

SC CRPIURUS

SC CRPIURUS

SC CRPIURUS

SC CRPIURUS

SCCRPIURUS

SCCRPIURUS

SCCRPIURUS

SCORPIURUS

SC CRPIURUS

SCCRPIURUS

SC CRPIURUS

SCCRPIURUS

SC CRPIURJS

SCORPIURUS

SC CRPIURUS

SCCRPIURUS

SCCRPIURUS

SC CRPIURUS

SCCRPIURUS

SC CRPIURUS

SC CRPIURUS

SC CRPIURU

SC CRPIURUS

SCCRPIURUS

SC CRPIURUS

SC CRPIURUS

SC CRPIURUS

SCCRPIURUS

SC CRPIURU

SC CRPIURUS

SCORPIURUS

SC CRPIURUS

SCCRPIURUS

SCCRPIURUS

SC CRPIURUS

SC CRPIURUS

SC CRPIURUS

SC CRPIURU

SCCRPIURU

SCCRPIURUS

SCCRPIURUS

SC CRPIURUS

\section{Locality}

NW GULF OF MEXICO

NW GULF OF MEXICO

NW GULF OF MEXICO

NW GULF OF MEXICO

$N W$ GULF OF MEXICO

NW GULF OF MEXICO

NE GULF OF MEXICO

NE GULF OF MEXICO

CENTRAL GULF OF MEXICO

CENTRAL GULF OF MEXICO

CENTRAL GULF OF MEXICO

CENTRAL GULF OF MEXICO

CENTRAL GULF OF MEXICO

NW GULF OF MEXICO 


\section{Publication}

23956 PFLUM FRERICHS 1976 23957 PFLUM FRFRICHS 1976 23958 PFLUM FRERICHS 1976 23959 PFLUM FRERICHS 1976 23960 BANDY 1956

33961 PFLUM FRERICHS 1976

23962 PHLEGER $1951 \mathrm{~A}$

23963 PHLEGER $1951 \mathrm{~A}$

23964 PHLEGER 1951A

23965 PFLUM FRERICHS 1976

23966 PFLUM FRERICHS 1976

23967 PFLUM FRERICHS 1976

23968 VAUGHAN 1918

23960 SOCK 1976

23970 PHLEGER 1956

23971 PARKER 1954

23972 PFLUM FRERICHS 1976

23973 PHLEGER $1951 \mathrm{~A}$

23974 PHLEGER $1951 \mathrm{~A}$

23975 PHLEGER $1951 \mathrm{~A}$

23976 PHLEGER $1951 \mathrm{~A}$

23977 PHLEGER $1951 \mathrm{~A}$

23978 PHLEGER $1951 \mathrm{~A}$

23979 PHLEGER 1951A

23980 PHLEGER $1951 \mathrm{~A}$

23981 LUDWICK WALTON 1957

23982 LEROY HODGKINSON 1975

23983 PFLUM FRERICHS 1976

23984 PFLUM FRERICHS 1976

23985 PFLUM FRERICHS 1976

23986 PFLUM FRERICHS 1976

23987 PFLUM FRERICHS 1976

23988 PFLUM FRERICHS 1976

23989 PFLUM FRERICHS 1976

23990 PFLUM FRERICHS 1976

23991 PFLUM FRERICHS 1976

23992 PFLUM FRERICHS 1976

23993 PFLUM FRERICHS 1976

23994 PFLUM FRERICHS 1976

23995 PFLUM FRERICHS 1976

23996 PFLUM FRERICHS 1976

23997 PFLUM FRERICHS 1976

23998 PFLU Y FRERICHS 1976

23999 PFLUM FRERICHS 1976

24000 PFLUM FRERICHS 1976

24001 PFLUM FRERICHS 1976

24002 PFLUM FRERICHS 1976

24003 PFLUM FRERICHS 1976

24004 PFLUM FRERICHS 1976

24005 PFLUM FRERICHS 1976

24006 PFLUM FRERICHS 1976

24007 PFLUM FRERICHS 1976

24008 PFLUM FRERICHS 1976

24009 BANDY 1956

24010 BANDY 1956

24011 PARKER 1954

24012 BANDY 1956

24013 PARKER 1954

24014 BANDY 1956

24015 BANDY 1956

24016 BANDY 1956

24017 BANDY 1956

24018 BANDY 1956

24019 BANDY 1956

24020 BANDY 1956

24021 CREAGER 1958

24022 WALTON 1960

24023 PHLEGER 1956

24024 POAG SWEET 197
24025 PHLEGER 1956

24026 PARKER PHLEGER PEIRSON 1953

24027 PARKER PHLEGER PEIRSON 1953

24028 PHLEGER 1956

24029 PARKER 1954

24030 PARKER 1954

24031 PARKER 1954

24032 PHLEGER $1951 \mathrm{~A}$

24033 PHLEGER 1951 A

24034 DAVIS 1964

24035 PHLEGER $1951 \mathrm{~A}$

24036 PHLEGER 1951A

24037 BANDY 1956

24038 BANDY 1954

24039 BANDY 1956

24040 BANDY 1954

24041 BANDY 1954

24042 BANDY 1956

24043 BANDY 1954

24044 BANDY 1954

24045 KELLOUGH 1956

24046 WARREN 1956

24047 LOEP 1965

24048 BANDY 1956

24049 AYALA-CASTANARES 1963

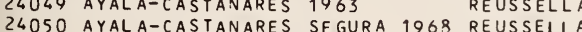

REOPHAX

REOPHAX

REOPHAX

REOPHAX

REOPHAX

REOPHAX

REOPHAX

RE OPHAX

RE OPHAX

RE OPHAX

REOPHAX

REOPHAX

REOPHAX

RE OPHAX

REOPHAX

RE OPHAX

REOPHAX

REOPHAX

REOPHAX

RE OPHAX

RE OPHAX

REOPHAX

REOPHAX RE USSELLA

REUSSELLA

RE US SELLA

REUSSELLA

REUSSELLA

RE USSELLA

REUSSELLA

RE USSELLA

RE USSELLA

REUSSELLA

RE USSELLA

REUSSELLA

REUSSELLA

REUSSELLA

REUSSELLA

RE US SELLA

REUSSELLA

REUSSELLA

RE USSELLA

REUSSELLA

REUSSELLA

REUSSELLA

RE USSELLA

RE USSELLA

RE US SELLA

REUSSELLA

RE USSELL L

REUSSELLA

REUSSELLA

REUSSELLA

RE USSELLA

REUSSELLA

RE USSELLA

REUSSELLA

REUSSELLA

RE USSELLA

RE USSELLA

REUSSELLA

RE USSELLA

REUSSELLA
Generic Name

Specific Name

Locality

RETI CUL OPHRAGMIUM RETICULOPHRAGMIUM RE TICULOPHRAGMIUM RE TI CUL OPHRAGMIUM RE I C ULOPHRAGMIUM RETICULOPHRAGMIUM RE II CULOPHRAGMIUM RE TICULOPHRAGMIUM RE TI CUL OPHRAGMIUM RETI CUL OPHRAGMIUM RETI CUL OPHRAGMIUM RETICULOPHRAGMIUM RETI CULOPHRAGMIUM RETI CUL OPHR AGMIUM RETICULOPHRAGMIUM RE TI CUL OPHRAGMIUM RE TI CUL OPHRAGMIUM RE TI CULOPHRAGMIUM RE II CULOPHR AGMIUM RETI CUL OPHRAGMIUM RETI CUL OPHRAGMIUM RETI CULOPHRAGMIUM RETI CUL OPH RAGMIUM RETI CULOPHRAGMIUM RE I I ULOPHRAGMIUM
SCCRPIURUS

SCCRPIURUS

SC CRPIURUS

SCCRPIURUS

SC CRPIURUS

SC CRPIURUS

SC CRPIURUS

SC CRPIURUS

SC CRPIURUS

SC CRPIURUS

SCORPIURUS

SCCRPIURUS

SCCRPIURUS

SCCRPIURUS

SCCRPIURUS

SC CRPIURUS

SC CRPIURUS

SC CRPIURUS

SCCRPIURUS

SC CRPIURUS

SC ORPIURUS

SC CRPIURUS

SC CRPIURUS

SC CRPIURUS

SC CRPIURUS

SCCTTII

VENEZUELANUM

VEAEZUELANUM

VE AEZUELANUM

VENEZUELANUM

VENEZUELANUM

VENEZUELANUM

VENEZUELANUM

VENEZUELANUM

VENE ZUELANUM

VENEZUELANUM

VENEZUELANUM

VE $A E Z U E L A N U M$

VENEZUELANUM

VENEZUELANUM

VENEZUELANUM

VE $A E Z U E L A N U M$

VENEZUELANUM

VENEZUELANUM

VENEZUELANUM

VENEZUELANUM

VENEZUELANUM

VEAEZUE LANUM

VE NEZUELANUM

VENEZUELANUM

VENEZUELANUM

AT LANTI CA

AT LAN TI CA

AT LANTICA

A T LAN TI CA

AT LANTI CA

AT LANTICA

A TLANTICA

A T LANTI CA

A T LANTI CA

A T LANTI CA

ATLANTICA

A T LANTICA

A T LANTICA

A T LANTICA

A T LANTI CA

A T LAN T I C A

AT LANTICA

ATLANTICA

A TLANTICA

A TLANTICA

ATLANTICA

ATLANTICA

AT LANTICA

A T LANTI CA

AT LANTICA

AT LANTICA

A T LANTICA

A TLANTICA

ATLANTICA

AT LANTICA

A TLANTICA

ATLANTICA

AT LANTICA

ATLANTICA

A TLANTICA

AT LANTI CA

A TLANTICA

ATLANTICA

ATLANTICA

ATLANTICA

AT LANTICA

A TLANTICA

AT LANTI CA

CENTRAL GULF OF MEXICO

CENTRAL GULF OF MEXICO

CENTRAL GULF OF MEXICO

CENTRAL GULF OF MEXICO

NE GULF OF MEXICO

CENTRAL GULF OF MEXICO

NW GULF OF MEXICO 


\section{Publication}

24051 BANDY 1956 24052 BANDY 1956 24053 BANDY 1954 24054 KELLOUGH 1956 24055 KELLOUGH 1956 24056 KELLOUGH 1956 24057 BANDY 1956 24058 BANDY 1956 24059 BANDY 1956 24060 BANDY 1956 24061 SANDY 1956 24062 BANDY 1956 24063 KELLOUGH 1956 24064 KELLOUGH 1956 24065 PHLEGER 1956 24066 SHIFFLETT 1961 24067 PHLEGER 1951A 24068 SEGURA 1963 24069 PHLEGER $1951 \mathrm{~A}$ 24070 PHLEGER 1951A 24071 PHLEGER $1951 \mathrm{~A}$ 24072 LUDWICK WALTON 1957 24073 PHLEGER 1956 24074 WARREN 1957 24075 SHEPARD MOORE 1955 24076 PFLUM FRERICHS 1976 24077 PFLUM FRERICHS 1976 24078 BOCK 1076

24079 PARKER PHLEGER PEIRSON 1953 24080 BOCK 1976 24081 BOCK 1976 24082 PARKER 1954 24083 PARKER 1954

24084 PARKER 1954 24085 PHLEGER 1954 24086 LANKFORD 1959 24087 PARKER 1954 24088 PARKER 1954 24089 PARKER 1954 24090 PARKER 1954 24091 PARKER 1954 24092 PARKER 1954 24093 PARKER 1954 24094 PHLEGER 1951A 24095 PHLEGER 1951A 24096 PHLEGER 1951A 24097 PHLEGER 1951A 24098 PHLEGER $1951 \mathrm{~A}$ 24099 PHLEGER 1951A 24100 PHLEGER 1951A 24101 PHLEGER 1951A 24102 PHLEGER 1951A 24103 PHLEGER 1951A 24104 PHLEGER 1951 A 24105 PHLEGER 1951A 24106 PHLEGER 1951A 24107 PHLEGER 1951A 24108 PHLEGER 1951 A 24109 PHLEGER $1951 \mathrm{~A}$ 24110 PARKER PHLEGER PEIRSON 1953 24111 BOCK 1976

24112 ANDERSEN 1961

24113 NORTON 1930
24114 CUSHMAN 1918

24115 PFLUM FRERICHS 1976 24116 CUSHMAN 1918

24117 PFLUM FRERICHS 1976 24118 PFLUM FRERICHS 1976 24119 PFLUM FRERICHS 1976 24120 PFLUM FRERICHS 1976 24121 PFLUM FRERICHS 1976 24122 PFLUM FRERICHS 1976 24123 PFLUM FRERICHS 1976 24124 PFLUM FRERICHS 1976 24125 PFLUM FRERICHS 1976 24126 PFLUM FRERICHS 1976 24127 PFLUM FRERICHS 1976 24128 PFLUM FRERICHS 1976 24129 PFLUM FRERICHS 1976 24130 PFLUM FRERICHS 1976 24131 PFLUM FRERICHS 1976 24132 PFLUM FRERICHS 1976 24133 PFLUM FRERICHS 1976 24134 PFLUM FRERICHS 1976 24135 PFLUM FRERICHS 1976 24136 PFLUM FRERICHS 1976 24137 PFLUM FRERICHS 1976 24138 PFLUM FRERICHS 1976 24139 PFLUM FRERICHS 1976 24140 PFLUM FRERICHS 9976 24141 PFLUM FRERICHS 1976 24142 PFLUM FRERICHS 1976 24143 PFLUM FRERICHS 1976 24144 PFLUM FRERICHS 1976 24145 PFLUM FRERICHS 1976
Generic Name

REUSSELLA

REUSSELLA

REUSSELLA

REUS SELLA

REUSSELLA

REUSSELLA

REUSSELLA

RE USSELLA

RE USSELLA

RE US SELLA

REUSSELLA

RE USSELLA

RE USSELLA

REUSSELLA

REUSSELLA

REUSSELLA

REUSSELLA

REUSSELLA

REUSSELLA

REUSSELLA

REUSSELLA

REUSSELLA

RE USSELLA

REUSSELLA

RE USSELLA

REUSSELLA

REUSSELLA

RE USSELLA

REUSSELLA

REUSSELLA

REUSSELLA

REUSSELLA

RE USSELLA

REUSSELLA

REUSSELLA

REUSSELLA

RE USSELLA

REUSSELLA

REUSSELLA

REUSSELLA

REUSSELLA

REUSSELLA

RE USSELLA

REUSSELLA

RE USSELLA

RE USSELLA

REUSSELLA

REUSSELLA

REUSSELLA

REUS SELLA

REUSSELLA

REUSSELLA

REUSSELLA

REUSSELLA

REUSSELLA
REUSSELLA

REUSSELLA

REUSSELLA

RE USSELLA

RE USSELLA

REUSSELLA

RHABDAMMINA

RHABDAMMINA

RHABDAMMINA

RHABDAMMINA

RHABDAMMINA

RHABDAMMINA

RHABDAMMINA

RHABDAMMINA

RHABDAMMINA

RHABDAMMINA

RHABDAMMINA

RH ABDAMMINA

RHABDAMMINA

RHABDAMMINA

RHABDAMMINA

RHABDAMMINA

RHABDAMMINA

RHABDAMMINA

RHABDAMMINA

RHABDAMMINA

RHABDAMMINA

RHABDAMMINA

RH ABDAMMINA

RHABDAMMINA

RHABDAMMINA

RHABDAMMINA

RHAB DAMMINA

RHABDAMMINA

RHABDAMMIN

RHABDAMMINA

RHABDAMMINA
Specific Name

Locality

ATLANTICA

a TLNTICA

ATLANTICA

AT LANTI I A

ATLANTICA

ATLANTICA

ATLANTICA

ATLANTICA

ATLANTICA

ATLANTICA

ATLANTICA

ATLANTICA

ATLANTICA

ATLANTICA

AT LANTI CA

ATLANTICA

ATLANTICA

AT LANTICA

ATLANTICA

ATLANTICA

ATLANTICA

ATLANTICA

ATLANTICA

a L LANTICA

ATLANTI ICA

A TLANTICA

ATLANTICA

ATLANTICA

A L LANTI I CA

ATLANTICA

A TLANTICA

ATLANIICA

at LANTICA

ATLANTICA

A TLANTICA

AT LANIICA

AT LANTI CA

AT LANTICA

ATLANIICA

ATLANTICA

ATLANTI CA

ATLANTICA

AT LANTI CA

ATLANII CA

ATLANTICA

ATLANTICA

A TLANTI C A

A TLANTICA

AT LANTI CA

ATLANTICA

ATLANTICA

ATLANTICA

ABYSSORUM

ABYSSORUM

ABYSSORUM

ABYSSORUM

ABYSSORUM

ABYSSORUM

ABYSSORUM

AB YS SORUM

ABYS SORUM

ABYSSORUM

ABYS SORUM

ABYSSORUM

AB YSSORUM

ABYSSORUM

ABYS SORUM

ABYSSORUM

ABYSSORUM

AB YSSORUM

ABYSSORUM

ABYSSORUM

AB YSSORUM

ABYSSORUM

AB YSSORUM

ABYSSORUM

ABYSSORUM

ABYSSORUM

ABYSSORUM

AB YS SORUM

ABYSSORUM

ABYSSORUM

ABYSSORUM
ABYSSORUM

NE GULF OF MEXICO

NE GULF OF MEXICO

NW GULF OF MEXICO

NW GULF OF MEXICO

NW GULF OF MEXICO

NW GULF OF MEXICO

NE GULF OF MEXICO

NE GULF OF MEXICO

NE GULF OF MEXICO

NE GULF OF MEXICO

NE GULF OF MEXICO

NE GULF OF MEXICO

$N W$ GULF OF MEXICO

$N W$ GULF OF MEXICO

NW GULF OF MEXICO 
Publication

24146 LEROY HODGKINSON 1975 24147 PFLUM FRERICHS 1976 24148 PFLUM FRERICHS 1976 24149 PFLUM FRERICHS 1976 24150 PFLUM FRERICHS 1976 24151 PFLUM FRERICHS 1976 24152 PFLUM FRERICHS 1976 24153 PFLUM FRERICHS 1976 24154 PFLUM FRERICHS 1976 24155 PFLUM FRERICHS 1976 24156 PFLUM FRERICHS 1976 24157 PFLUM FRERICHS 1976 24158 PFLUM FRERICHS 1976 24159 CUSHMAN 1918

24160 PFLUM FRERICHS 1976 24161 PFL'UM FRERICHS 1976 24162 CUSHMAN 1918

24163 CUSHMAN 1918

24164 CUSHMAN 1918

24165 LEROY HODGKINSON 1975

24166 CUSHMAN 1918

24167 PFLUM FRERICHS 1976

24168 LEROY HODGKINS ON 1975

24169 PFLUM FRERICHS 1976

24170 PFLUM FRERICHS 1976

24171 PFLUM FRERICHS 1976

24172 PFLUM FRERICHS 1976

24173 PFLUM FRERICHS 1976

24174 PFLUM FRERICHS 1976

24175 PFLUM FRERICHS 1976

24176 PFLUM FRERICHS 1976

24177 PFLUM FRERICHS 1976

24178 PFLUM FRERICHS 1976
24179 PFLUM FRERICHS 1976

24180 PFLUM FRERICHS 1976

24181 PFLUM FRERICHS 1976

24182 PFLUM FRERICHS 1976

24183 PFLUM FRERICHS 1976

24184 PFLUM FRERICHS 1976

24185 PFLUM FRERICHS 1976

24186 PFLUM FRERICHS 1976

24187 PFLUM FRERICHS 1976

24188 CUSHMAN 1918

24189 CUSHMAN 1918
24190 PFLUM FRERICHS 1976

24191 PFLUM FRERICHS 1976

24192 PFLUM FRERICHS 1976

24193 PFLUM FRERICHS 1976

24194 PFLUM FRERICHS 1976

24195 PFLUM FRERICHS 1976

24196 PFLUM FRERICHS 1976

24197 CUSHMAN 1918

24198 CUSHMAN 1918

24199 PFLUM FRERICHS 1976

24200 PFLUM FRERICHS 1976

24201 PFLUM FRERICHS 1976

24202 PFLUM FRERICHS 1976

24203 PFLUM FRERICHS 1976

24204 PFLUM FRERICHS 1976

24205 PFLUM FRERICHS 1976

24206 PFLUM FRERICHS 1976

24207 PFLUM FRERICHS 1976

24208 PFLUM FRERICHS 1976

24209 PFLUM FRERICHS 1976

24210 PFLUM FRERICHS 1976

24211 PFLUM FRERICHS 1976

24212 PFLUM FRERICHS 1976

24213 PFLUM FRERICHS 1976

24214
24215 PFLUM

24216 PFLUM FRERICHS 1976

24217 PFLUM FRERICHS 1976

24218 PFLUM FRERICHS 1976

24219 NORTON 1930

24220 PFLUM FRERICHS 1976

24221 PFLUM FRERICHS 1976

24222 PFLUM FRERICHS 1976

24223 PFLUM FRERICHS 1976

24224 PFLUM FRERICHS 1976

24225 PFLUM FRERICHS 1976

24226 PFLUM FRERICHS 1976

24227 PFLUM FRERICHS 1976

24228 PFLUM FRERICHS 1976

24229 PFLUM FRERICHS 1976

24230 PFLUM FRERICHS 1976

24231 PFLUM FRERICHS 1976

24232 PFLUM FRERICHS 1976

24233 PFLUM FRERICHS 1976

24234 PFLUM FRERICHS 1976

24235 PFLUM FRERICHS 1976

24236 PFLUM FRERICHS 1976

24237 PFLUM FRERICHS 1976

24238 PFLUM FRERICHS 1976

24239 PFLUM FRERICHS 1976

24240 PFLUM FRERICHS 1976
Generic Name

RHABDAMMINA

RHABDAMMINA

RHABDAMMINA

RHABDAMMINA

RHABDAMMINA

RHABDAMMINA

RHABD AMMINA

RHABDAMMINA

RHABDAMMINA

RHABD AMMINA

RHABDAMMINA

RH ABDAMMINA

RHABDAMMINA

RHABDAMMINA

RHABDAMMINA

RH ABD AMMINA

RH ABDAMMINA

RH ABDAMMINA

RHABDAMMINA

RHABDAMMINA

RHABDAMMINA

RHABDAMMINA

RHABDAMMINA

RH ABD AMM IN A

RHABDAMMINA

RH ABDAMMINA

RHABDAMMINA

PHABDAMMINA

RHABDAMMINA

RHABDAMMINA

RHABDAMMINA

RH ABD AMMINA

RH ABDAMMINA

RHABDAMMINA

RHABDAMMINA

RHABDAMMINA

RHABDAMMINA

RHABDAMMINA

RHABDAMMINA

RH ABDAMMINA

RH ABDAMMINA

RH ABDAMMINA

RH ABDAMM INA

RH ABDAMMINA

RH ABDAMMINA
RHABDAMMINA

RHABDAMMINA

RH ABDAMMINA

RHABDAMMINA

RHABDAMMINA

RH ABD AMMINA

RHABDAMMINA

RHABDAMMINA

RHABDAMMINA

RHABDAMMINA

RHABD AMM INA

RHABDAMMINA

RHABDAMMINA

RHABDAMMINA

RHABDAMMINA

RHABDAMMINA

RHABDAMMINA

RHABDAMMINA

RH ABDAMMINA

RHABDAMMINA

RH ABD AMMINA

RHABDAMMINA

RHABDAMMINA

RHABDAMMINA
RHABDAMMINA

RHABDAMMINA

RH I ZAMMINA

RH IZ AMM INA

RHIZ AMM I NA

RH I Z AMM INA

RH I Z AMM I NA

RH I Z AMM I NA

RH IZ AMM I NA

RHIZ AMM I NA

RH IZ AMM I NA

RH I Z AMM I NA

RHIZ AMM I NA

RHIZ AMMINA

RHIZAMMINA

RH I Z AMMINA

RH IZ AMM I NA

RH I ZAMMINA

RHIZ AMM I NA

RHIZAMMINA

RHIZ AMMINA

RH I ZAMM INA

RH IZ AMM INA

RHIZ AMMINA

RHI I AMMINA

RH IZAMM I NA

RH IZ AMM I NA
Specific Name

Locality

Lat. Long.

AB YS SORUM

ABYSSORUM

ABYSSORUM

AB YSSORUM

ABYSSORUM

$A B$ YS SORUM

AB YS SORUM

ABYSSORUM

ABYS SORUM

ABYSSORUM

ABYS SORUM

AB YS SORUM

AB YSSORUM

AB YSSORUM

ABYSSORUM RADIATA

DI SCRETA

DI SCRETA

DI SCRETA

DI SCRETA

LINEARIS

LINEARIS

LI AEARIS

LI NEARIS

LI NEARIS

LINEARIS

LIAEARIS

LINEAR IS

LINEARIS

LI NEAR IS

LINEAR IS

LINEARIS

LINEARIS

LINEAR IS

LI NEARIS

LINEARIS

LINEARIS

LINEARIS

LINEARIS

LINEARIS

LINEARIS

LI NEARIS

LINEAR IS

LINEARIS

LIAEARIS

LINEARIS

LINEARIS

LINEARIS

LINEARIS

LINEARIS

LINEARIS

LINEARIS

LINEARIS

LINEAR IS

LINEARIS

LINEARIS

LINEARIS

LINEARIS

LINEARIS

LINEARIS

LINEARIS

LI NEARIS

LI NEARIS

LINEARIS

LI NEARIS

LINEARIS

LINEAR IS

LINEARIS

AL GAE F ORM IS

AL GAE FORM IS

AL GAEFORMIS

AL GAEFORMIS

AL G AE FORM IS

AL GAEFORMIS

AL GAEFORM IS

AL GAE FORMIS

AL GAEFORMIS

AL GAE F ORMIS

AL GAE FORMIS

AL GAEFORMIS

AL GAEFORMIS

AL GAEFORMIS

AL GAE FORM IS

AL GAE FORMIS

AL GAE FORMIS

AL GAEFORMIS

AL GAE FORM IS

AL GAEFORMIS

AL GAE FORM IS

AL GAE F ORMIS

AL GAEF ORMIS

AL GAE F ORM IS

AL GAE FORMIS

N GULF OF MEXICO

NW GULF OF MEXICO

NW GULF OF MEXICO

NW GULF OF MEXICO

NW GULF OF MEXICO

CENTRAL GULF OF MEXICO 


\section{Publication}

24241 PFLUM FRERICHS 1976 24242 PFLUM FRERICHS 1976 24243 CUSHMAN 1918

24244 PARKER 1954

24245 LUDWICK WALTON 1957 24246 PARKER 1954

24247 PARKER 1954

24248 PARKER 1954

24249 PARKER 1954

24250 PARKER 1954

24251 PARKER 1054

24252 PARKER 1954

24253 PARKER 1954

24254 PARKER 1954 PFLUM FRERICHS 1976

24255 PFLUM FRERICHS
242756

24257 PFLUM FRERICHS 1976

24258 PFLUM FRERICHS 1976

24259 PFLUM FRERICHS 1976

24260 PFLUM FRERICHS 1976

24261 PFLUM FRERICHS 1976

24262 PFLUM FRERICHS 1976

24263 PFLUM FRERICHS 1976

24264 PFLUM FRERICHS 1976

24265 PFLUM FRERICHS 1976

24266 PFLUM FRERICHS 1976

24267 PFLUM FRERICHS 1976

24268 PFLUM FRERICHS 1976

24269 PFLUM FRERICHS 1976

24270 PFLUM FRERICHS 1976

24271 PFLUM FRERICHS 1976 24272 PFLUM FRERICHS 1976 24273 PFLUM FRERICHS 1976 24274 PFLUM FRERICHS 1976 24275 PFLUM FRERICHS 1976 24276 PFLUM FRERICHS 1976 24277 PFLUM FRERICHS 1976 24278 PFLUM FRERICHS 1976 24279 ANDERSEN 1961

24280 BOCK 1976

24281 PFLUM FRERICHS 1976

24282 ANDERSEN 1961

24283 BANDY 1956

24284 ANDERSEN 1961

24285 BANDY 1956

24286 BANDY 1956

24287 NORTON 1930

24288 LANKFORD 1959

24289 BANDY 1956

24290 BANDY 1956

24291 BANDY 1956

24292 BANDY 1956

24293 BANDY 1956

24294 ANDERSEN 1961

24295 ANDERSEN 1961

24296 ANDERSEN 1961

24297 ANDERSEN 1961

24298 ANDERSEN $196^{\circ}$

24299 BANDY 1956

24300 BANDY 1956

24301 BANDY 1956

24302 BANDY 1956

24303 BANDY 1956

24304 BANDY 1956
24305 SEGURA 1963

24306 LEHMANN 1957

24307 BOCK 1976

24308 PARKER 1954

24309 PARKER 1954

24310 PARKER 1954

24311 PARKER 1954

24312 PARKER 1954

24313 LUDWICK WALTON 1957

24314 PARKER 1954

24315 PARKER 1954

24316 PARKER 1954

24317 PARKER 1954

24318 PARKER 1954

24319 PARKER 1954

24320 PARKER 1954

24321 PARKER 1954

24322 BOCK 1976

24323 BOCK 1976

24324 BOCK 1976

24325 BOCK 1976

24326 BOCK 1976

24327 BOCK 1976

24329 PARKER 1954

24330 PARKER 1954

24331 PARKER 1954

24332 PARKER 1954

24333 PARKER 1954

24334 PARKER 1954

24335 PARKER 1954
Generic Name

RHIZ AMM INA

RHIZAMMINA

RHIZAMMINA

ROBERTINOIDES

ROBERTINOIDES

ROBERTINOIDES

ROBERTINOIDES

ROBERTINOIDES

ROBERTINOIDES

ROBERIINOIDES

ROBERTINOIDES

ROBERTINOIDES

ROBERTINOIDES

ROBERTINOIDES

ROBERTINA

ROBER I INA

ROBERIINA

ROBERTINOIDES

ROBER IINOIDES

ROBERTINOIDES

ROBERTINOIDES

ROSERIINOIDES

ROBERIINOIDES

ROBERI INOIDES

ROBERTINOIDES

ROBER I NOIDES

ROBERTINOIDES

ROBERTINOIDES

ROBERIINOIDES

ROBERTINOIDES

ROBERTINOIDES

ROBERTINOIDES

ROBERTINOIDES

ROBER IINOIDES

ROBERT INOIDES

ROBER I INOIDES

ROBERIINOI DES

ROBERTINOIDES

ROBER IINOIDES

ROBERTINOIDES

ROBERTINOIDES

LENTI CULINA

LENTI CULINA

LENTI CUL INA

LENTI CULINA

LENTI CUL INA

LENT I CULINA

LENT I CULINA

LENT I CULINA

LENTI CULINA

LENTI CULINA

LENT I CUL INA

LENTI CUL INA

LENT I CUL INA

LENT I CULINA

LENT I CUL INA

LEN I CUL INA

LENTI CULINA

LENT I CUL INA

LENT I CUL INA

LENTICULINA

LENTI CULINA

LENT I CULINA

LENTI CUL INA

AMMON IA

AMMONIA

ROSALINA

DISCORBINELLA

DISCORBINELLA

DI SCORBI NELLA

DI SCORB INELLA

DI SCORBINELLA

DI SCORBINELLA

DISCORB I NE LLA

DISCORBINELLA

DI SCORB I NE LLA

DISCORB INELLA

DI SCORBINELLA

DI SCORB INELLA

DI SCORBINELLA

DI SCORBINELLA

ROSALINA

ROSALINA

ROSAL INA

ROSALINA

ROSALINA

ROSALINA

ROSALINA

ROSAL INA

ROSAL INA

ROSALINA

ROSALINA

ROSAL INA

ROSALINA

ROSALINA
Specific Name

AL GAE FORMIS

AL GAEFORM IS

I N O IV ISA

BR ADY I

BRADYI

BRADYI

BR ADYI

BRADYI

BRADYI

BRADYI

BRADYI

BRADYI

BRADYI

BRADY I

OC EANICA

OCEANICA

OC EANICA

BR ADYI

BRADYI

BR ADYI

BR ADY

BRADYI

BRADYI

BRADYI

BR ADY I

BR ADYI

BRADY

BRADYI

BR ADYI

BRADYI

BRADYI

BRADYI

BRADYI

BRADY

BR ADYI

BRADYI

BRADYI

BRADYI

BRADYI

BRADY

ANTILLEA

CALCAR

CALCAR

CALCAR

CALCAR

CALCAR

CALCAR

CALCAR

CALCAR

CALCAR

CALCAR

CONVERGENS

CULTRATUS

FALCIFER

IOTA

LOWMANI

SERPENS

ST EPHENSON I

ST EPHENSONI

ST EPHENSONI

STEPHENSONI

SUEORBICULARIS

SUEORBI CULARIS

ROLSHAUSEN I

ROLSHAUSENI

BAHAMAENS IS

BERTHELOTI

BERTHELOTI

BERTHELOT I

BE RTHELOTI

BERTHELOTI

BERTHELOTI

BERTHELOTI

BERTHELOT I

BERTHELOTI

BERTHELOTI

BERTHELOTI

BERTHELOT I

BERTHELOTI

BERTHELOT I

BULBOSA

FL OR I DANA

FL OR I DANA

FL OR I DANA

FL CR I DANA

FLCR I DANA

FL CRIDANA

COACINNA

COACINNA

COACINNA

COACINNA

COACINNA

COACINNA

COACINNA

Locality

Lat. Long.

NW GULF OF MEXICO 


\section{Publication}

24336 PARKER 1954 24337 PARKER 1954
24339 PARKER 1954 24339 PARKER 1954 24340 PARKER 1954

24341 LUDWICK WALTON 1957

24342 PARKER 1954

24343 PARKER 1954

24344 SEGURA 1963

24345 KELLOUGH 1956

24346 PARKER 195

24347 AYALA-CASTANARES 1963

24348 PARKER 1954

24349 PARKER 1954

24350 PARKER 1954

24351 PHLEGER 1956

24352 OHLEGER 1956

24353 PARKER 1954

24354 PHLEGER 1956

24355 PHLEGER 1956

24356 PARKER 1954

24357 PARKER 1954

24358 BOCK 1976

24359 SEGURA 1963

24360 PHLEGER LANKFORD 1957

24361 PARKER 1954

2436 ? LUDWICK WALTON 1957

24363 PARKER 1954

24364 PARKER 1354

24365 PHLEGER 1965 B

24366 PHLEGER 19658

24367 BENDA PURI 1962

24368 WALTON 1964

24369 AYALA-CASTANARES SEGURA 1968

24370 AYALA-CASTANARES 1963

24371 PHLEGER 1956

24372 PHLEGER 1956

24373 PARKER 1954

24374 PHLEGER 1965 A

24375 PARKER 1954

24376 PARKER 1954

24377 PARKER 1954

24378 PARKER 1954

24379 PARKER 1954

24380 PARKER 1954

24381 BOCK 1976

24382 PARKER 1954

24383 PARKER 1954

24384 PARKER 1954

24385 PARKER 1954

24386 PARKER 1954

24387 PHLEGER 1956

24388 PHLEGER 1956

24389 PHLEGER 1956

24390 BOCK 1976

24391 PARKER 1954

24392 PARKER 1954

24393 PARKER 1954

24394 LUOWICK WALTON 1957

24395 PARKER 1954

24396 PARKER 1954

24397 PARKER 1954

24398 PARKER 1954

24399 PARKER 1354

24400 PARKER 1954

24401 PARKER 1954

24402 PARKER 1954

24403 WALTON 1964

24405 PARKER 1954

24406 PARKER 1954

24407 PARKER 1954

24408 PARKER 1954

24409 PARKER 1954

24410 PARKER 1954

24411 PARKER 1954

24412 PARKER 1954

24413 PARKER 195

24414 PARKER 1954

24415 PARKER 1954

24416 PARKER 1954

24417 PARKER 1954

24418 PARKER 1954

24419 PARKER 1954

24420 PARKER 1954

24421 PARKER 1954

24422 LUDWICK WALTON 1957

24423 PARKER 1954

24424 ANDERSEN 1961

24425 PARKER 1954

24426 PARKER 1954

24427 LUDWICK WALTON 1957

24428 PARKER 195

24429 PARKER 1954

24430 PARKER 1954
Generic Name Specific Name

CONCINNA

CONCINNA

CONCINVA
CONCINNA

CONCINNA

COACINNA

COACINNA

CONCINNA

CONCINNA

CONCINNA

CONCINNA

CONCINNA

COACINNA

COACINNA

CONCINNA

CONCINNA

CONCINNA

CONCINNA

COACINNA

CONCINNA

COACINNA

CONCINNA

FL CRIDANA

FLCRIDANA

FLCRIDANA

FL ORIDANA

FL CRIDANA

FLCRIDANA

FL CRIDANA

FLCRIDANA

FLCRIDANA

FLCRI DANA

FL CRIDANA

FLCRIDANA

FLCRIDANA

FL CRIDANA

FLCRIDANA

FLCRIDANA

FL ORIDANA

FLCRIDANA

FL ORIDANA

FLCRIDANA

FLCRIDANA

FLCRIDANA

FL CRIDANA

FL CRIDANA

FLCRIDANA

FLCRIDANA

FLCRIDANA

FL CRIDANA

FL CRIDENS IS

FLORIDENS IS

FLCRIDENS IS

FLCRIDENS IS

FLCRIDENSIS

FL CRIDENS IS

FLCRIDENS IS

FL CRIDENS IS

FLCRIDENS IS

FLCRIDENS IS

WI LLIAMSONI

WI LLIAMSONI

WI LL I AMSONI

WI LLIAMSONI

WILLIAMSONI

WI LL I AMSONI

W LL IAMSONI

WI LL I AMSON I

WI LL I AMSONI

WILLIAMSONI

WILLIAMSON I

WI LL I AMSON I

WI LL I AMSON I

WI LLI AMSONI

WI LL I AMSON I

WI LL I AMSON I

WI LL I AMSON I

WI LL I AMSONI

WI LL I AMSONI

WILLIAMSONI

WI LL I AMSCNI

WILLIAMSONI

WILLIAMSONI

SUEZENSIS

SUEZENSIS

SUEZENSIS

SUEZENSIS

SUEZENSIS

SUEZENSIS

\section{Locality}

Lat. Long.

NE GULF OF MEXICO

NE GULF OF MEXICO

NE GULF OF MEXICO

NE GULF OF MEXICO

NE GULF OF MEXICO

NE GULF OF MEXICO

NE GULF OF MEXICO

NE GULF OF MEXICO

MATAMOROS, MEXICO

NW GULF OF MEXICO

NE GULF OF MEXICO

L. DE TERMINOS, CAMPECHE

NE GULF OF MEXICO

NE GULF OF MEXICO

NE GULF OF MEXICO

$N W$ GULF OF MEXICO

$N W$ GULF OF MEXICO

NE GULF OF MEXICO

NW GULF OF MEXICO

Nh GULF OF MEXICO

NE GULF OF MEXICO

NE GULF OF MEXICO

NE GULF OF MEXICO

MATAMOROS, MEXICO

TEXAS GULF COAST

E GULF OF MEXICO

NE GULF OF MEXICO

NE GULF OF MEXICO

NE GULF OF MEXICO

TEN THOUSAND IS., SW FLA.

WHITEWATER B.. SW FLA.

CAPE ROIHANO, FLA.

TAMPA-SARASOTA BAY, FLA.

LAGUNA MADRE, NE TEXAS

L. DE TERMINOS, CAMPECHE

NW GULF OF MEXICO

$N W$ GULF OF MEXICO

NE GULF OF MEXICO

PORT ALTO, TEXAS

NE GULF OF MEXICO

NE GULF OF MEXICO

NE GULF OF MEXICO

NE GULF OF MEXICO

NE GULF OF MEXICO

NE GULF OF MEXICO

NE GULF OF MEXICO

NE GULF OF MEXICO

NE GULF OF MEXICO

NE GULF OF MEXICO

NE GULF OF MEXICO

NE GULF OF MEXICO

CENTRAL TEXAS BAYS

$N W$ GULF OF MEXICO

$N W$ GULF OF MEXICO

NE GULF OF MEXICO

NE GULF OF MEXICO

NE GULF OF MEXICO

NE GULF OF MEXICO

NE GULF OF MEXICO

NE GULF OF MEXICO

NE GULF OF MEXICO

NE GULF OF MEXICO

NE GULF OF MEXICO

NE GULF OF MEXICO

NE GULF OF MEXICO

NE GULF OF MEXICO

NE GULF OF MEXICO

TAMPA-SARASOTA BAY, FLA.

NE GULF OF MEXICO

NE GULF OF MEXICO

NE GULF OF MEXICO

NE GULF OF MEXICO

NE GULF OF MEXICO

NE GULF OF MEXICO

NE GULF OF MEXICO

NE GULF OF MEXICO

NE GULF OF. MEXICO

NE GULF OF MEXICO

NE GULF OF MEXICO

NE GULF OF MEXICO

NE GULF OF MEXICO

NE GULF OF MEXICO

NE GULF OF MEXICO

NE GULF OF MEXICO

NE GULF OF MEXICO

NE GULF OF MEXICO

NE GULF OF MEXICO

NE GULF OF MEXICO

$M$ ISSISSIPPI DELTA

NE GULF OF MEXICO

NE GULF OF MEXICO

NE GULF OF MEXICO

VE GULF OF MEXICO

NE GULF OF MEXICO

$2926 \mathrm{~N} 08840 \mathrm{~W}$

$2858 \mathrm{~N} 088 \quad 47 \mathrm{~W}$

$2957 \mathrm{~N} 08756 \mathrm{~W}$

$29 \quad 15 \mathrm{~N} 087 \quad 55 \mathrm{~W}$

$2934 \mathrm{~N} 088$ O1W

$2827 \mathrm{~N} 08922 \mathrm{~W}$

$2744 \mathrm{~N} 08916 \mathrm{~W}$

$2550 \mathrm{~N} 09638 \mathrm{~W}$ 


\section{Publication}

24431 PARKER 1954 24432 PARKER 1954

24434 PFLUM FRERICHS 1976

24435 PFLUM FRERICHS 1976

24436 PFLUM FRERICHS 1976

24437 PFLUM FRERICHS 1976

24438 AYALA-CASTANARES 1963

24439 PARKER 1954

$24440^{\circ}$ PHLEGER 1956

24441 PHLEGER 1956

24442 PARKER 1954

24443 PHLEGER 1956
24444 BOCK 1976

24445 PARKER 1954

24446 PARKER 1954

24447 PARKER 1954

24448 PARKER 1954

24449 PARKER 1954

24450 PARKER 1954
24451 PARKER 1954

24452 PARKER 1954

24453 PARKER 1954

24454 PARKER 1954

24455 PHLEGER 1954

24456 LUDWICK WALTON 1957

24457 PARKER PHLEGER PEIRSON 1953 24458 SHENTON 1957

24459 PARKER PHLEGER PEIRSON 1953 24460 PHLEGER 1956

24461 PHLEGER 1954

24462 PARKER 1954

24463 PARKER 1954
24464 PARKER 1954

24465 POST 1951

24466 PARKER 1954

24467 PARKER 1954

24468 PHLEGER 19558

24469 CUSHMAN $1922 \mathrm{~A}$

24470 SHEPARD MOORE 1955

24471 CREAGER 1958

24472 CREAGER 1958

24473 POST 1951

24474 KELLOUGH 1956

24475 KELLOUGH 1956

$\begin{array}{ll}24476 & \text { KELLOUGH } \\ 24477 & \text { KELLOUGH } 1956\end{array}$

24478 NORTON 1930

24479 PARKER 1954

24480 PARKER 1954

24481 PARKER 1954

24482 PHLEGER 1956

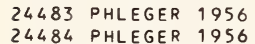

24485 PHLEGER 1956

24486 PARKER PHLEGER PEIRSON 1953

24487 PARKER PHLEGER PEIRSON 1953

24488 PARKER PHLEGER PEIRSON 1953

24489 PARKER PHLEGER PEIRSON 1953

24490 PARKER PHLEGER PEIRSON 1953

24491 PARKER PHLEGER PEIRSON 1953

24492 PARKER PHLEGER PEIRSON 1953

24493 PARKER 1954

24494 HALTON 1964

24495 KELLOUGH 1956

24496 KELLOUGH 1956
24497 KORNFELD 1931

24498 KORNFELD 193

24499 KORNFELD 1931

24500 KORNFELD 1931

24501 KORNFELD 1931

24502 WARREN 1956

24503 PHLEGER 1951 A

24504 PHLEGER $1951 \mathrm{~A}$

24505 PHLEGER 1951A

24506 PHLEGER 1951

24507 PHLEGER 1951 A

24509 PHLEGER 1951A

24510 PHLEGER 1951A

24511 KORNFELD 193

24512 KORNFELD 1931

24513 KORNFELD 1931

24514 KORNFELD 1939

24515 KORNFELD 1931

24516 KORNFELD 1939

24517 KORNFELD 193

24518 KORNFELD 193

24519 KORNFELD 1931

24520 KORNFELD 1931

24521 KORNFELD 1939

24522 PHLEGER $1951 \mathrm{~A}$

24523 KORNFELD 1931

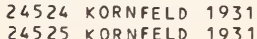

Generic Name

ROSALINA

ROSALINA

ROSALINA

ROSALINA

ROSALINA

ROSALINA

ROSALINA

ROSAL IN A

ROSALINA

ROSALINA

ROSALINA

ROSALINA

ROSAL INA

ROSALINA

ROSALINA

ROSALINA

ROSALINA

ROSALINA

ROSAL INA

ROSALINA

AMMON I A

AMMON I A

AMMON I A

AMMONIA

AM MONIA

AMMON I A

AMMON I A

AMMON IA

AMMMONIA

AMMON I A

A MMON I A

AMMON I A

AMMONI A

AM YON I A

AMMONI

AMMON I A

AMMON I A

AMMONI A

AMMON I A

AMMONIA

A MMON I A

AMMONIA

AMMONIA

AMMON I A

AMMONI A

A MMON I A

AMMONIA

AMMON I A

AM MON I A

AMMONIA

AMMONIA

AMMON I A

AMMON I A

A MMON I A

A MMON I A

AMMONIA

AMMONI A

AMMONI A

AMMONIA

AMMONI A

AMMONIA

AMMON I A

AMMON IA

AMMON I A

A MMON I A

AMMON IA

AMMON I A

AMMON I A

AMMONIA

AMMON I A

AMMONIA

AMMON I A

AMMONIA

AMMONIA

AMMON I A

AMMONI A

AMMON IA

AMMONIA

AMMON IA

AMMONIA

AMMON I A

AMMONI A

AMMONIA

AMMONIA

AMMONIA

AMMON I A

AMMON I A

AMMONI A

AMMON IA

AMMON I A

AMMON I A
Specific Name

SUEZENSIS

SUEZENSIS

SUEZENSIS

SUEZENSIS

SUEZENSIS

SUEZENSIS

SUEZENSIS

SUEZENSIS

SUEZENSIS

SUEZENS IS

SUEZENSIS

SUEZENSIS

SUEZENSIS

SUEZENSIS

SUEZENSIS

SUEZENSIS

SUEZENSIS

SUEZENSIS

SUEZENSIS

SUEZENSIS

BE CCARI I

BE CCARII

BECCARII

BECCARII

BECCARII

BE CCARII

BE CCARII

BE CCARII

BECCARII

BE CCARII

BE CCARII

BE CCARI I

BE CCARII

BE CCARII

BE CCARII

BE CCARII

BECCARII

BE CCARII

BECCARII

BE CCAR I I

BE CCARII

BE CCARII

BE CCARII

BECCARII

BE CCARII

BE CCARI I

BE CCARII

BE CCARII

BECCARII

BECCARII

BECCARII

BECCARII

BE CCARII

BE CCARII

BECCARII

BECCARII

BECCARII

BE CCARII

BE CCARII

BECCARI I

BECCARII

BE CCARII

BECCARII

BE CCARII

BE CCARII

BECCARII

BECCARI I

BECCARII

BECCARII

BECCARII

BECCARII

BE CCARII

BE CCARII

BE CCARII

BECCARII

BE CCAR I I

BE CCARII

BECCARII

BECCARII

BE CCARII

BECCARII

BE CCARII

BECCARII

BECCARII

BE CCARII

BE CCAR I I

BE CCAR II

BECCARII

BE CCARII

BE CCARII

BECCARII
BE CCARII

BECCARII

Locality

NE GULF OF MEXICO

NE GULF OF MEXICO

NE GULF OF MEXICO

$N W$ GULF OF MEXICO

NW GULF OF MEXICO

CENTRAL GULF OF MEXICO

CENTRAL GULF OF MEXICO

L. DE TERMINOS, C

$N W$ GULF OF MEXICO

$N W$ GULF OF MEXICO

NE GULF OF MEXICO

NW GULF OF MEXICO

NE GULF OF MEXICO

NE GULF OF MEXICO

NE GULF OF MEXICO 


\section{Publication}

24526 PHLEGER $1951 \mathrm{~A}$ 24527 PHLEGER $1951 \mathrm{~A}$ 24528 PHLEGER 1951A 24529 KORNFELD 1931 24530 PHLEGER 1951A 24531 PHLEGER 1951A 24532 PHLEGER 1951A 24533 PHLEGER 1951A 24534 KORNFELD 1931 24535 KORVFELD 1931 24536 PHLEGER $1951 \mathrm{~A}$ 24537 PHLEGER $1951 \mathrm{~A}$ 24538 WARREN 1957

24539 SHIFFLETT 1961

24540 PHLEGER $1951 \mathrm{~A}$

24541 PHLEGER $1951 \mathrm{~A}$

24542 PHLEGER $1951 \mathrm{~A}$

24543 SHIFFLETT 1961

24544 PHLEGER 1951 A

24546 LOWMAN 1949

24547 WARREN 1957

24548 PHLEGER $1951 \mathrm{~A}$

24549 PHLEGER $1951 \mathrm{~A}$

24550 PHLEGER $1951 \mathrm{~A}$

24551 PHLEGER $1951 \mathrm{~A}$

24552 PHLEGER 1951A

24553 PHLEGER $1951 \mathrm{~A}$

24554 PHLEGER $1951 \mathrm{~A}$

24555 PHLEGER $1951 \mathrm{~A}$

24556 PHLEGER $1951 \mathrm{~A}$

24557 PHLEGER 1951A

24558 PHLEGER 1951A

24559 PHLEGER $1951 \mathrm{~A}$

24560 WARREN 1956

24561 CUSHMAN 1931
24562 DHLEGER 1951 A

24563 POST 1951

24564 POST 1951

24565 KORNFELD 1931

24566 KORNFELD 1931

24567 KORNFELD 1931

$\begin{array}{lll}24568 & \text { KORNFELD } & 1931 \\ 24569 & \text { KORNFELD } & 1931\end{array}$

24570 KORNFELD 1931

24571 PHLEGER 1956

24572 PARKER PHLEGER PEIRSON 1953

24573 PHLEGER $1951 \mathrm{~A}$

24574 PHLEGER $1951 \mathrm{~A}$

24575 PHLEGER $1951 \mathrm{~A}$

24576 PHLEGER 1956

24578 PHLEGER 1956

24579 SHENTON 1957

24580 PARKER PHLEGER PEIRSON 1953

24581 PHLEGER $1951 \mathrm{~A}$

24582 PHLEGER $1951 \mathrm{~A}$

24583 WARREN 1957

24584 PHLEGER $1951 \mathrm{~A}$

24585 PHLEGER 1951A

24586 PHLEGER $1951 \mathrm{~A}$

24587 PHLEGER 1951A

24588 WARREN 1956

24589 PHLEGER $1951 \mathrm{~A}$

24590 PHLEGER $1951 \mathrm{~A}$

24591 PHLEGER $1951 \mathrm{~A}$

24592 KELLOUGH 1956

24593 PHLEGER $1951 \mathrm{~A}$

24594 PHLEGER $1951 \mathrm{~A}$

24595 PHLEGER 1951A

24596 CREAGER 1958

24597 PHLEGER 1956

24598 PHLEGER 1956

24599 PARKER PHLEGER PEIRSON 1953

24600 PHLEGER 1956

24601 PHLEGER $1951 \mathrm{~A}$

24602 PHLEGER 1956

24603 PARKER PHLEGER PEIRSON 1953

24604 LOEP 1965

24605 WARREN 1956

24606 PHLEGER $1951 \mathrm{~A}$

24607 PHLEGER 1951 A

24608 PHLEGER 1951A

24609 WARREN 1957

24610 PHLEGER 1954

24611 PHLEGER 19558

24612 PHLEGER $1951 \mathrm{~A}$

24613 SHIFFLETT 1961

24614 SHEPARD MOORE 1955

24615 PARKER PHLEGER PEIRSON 1953 24616 PARKER PHLEGER PEIRSON 1953 24617 PARKER PHLEGER PEIRSON 1953 24618 CUSHMAN 1931

24619 NORTON 1930

24620 CREAGER 1958

\section{Generic Name \\ Specific Name}

AMMON I

AMMON I A

AMMONIA

A MMONIA

AMMONIA

AMMONIA

AMMONIA

AM MON I A

AMMONIA

AMMON IA

AMMONIA

AMMONIA

AMMON I A

AM YONIA

A MMONI A

AMMONIA

AMMON I A

AMMON I A

AMMONIA

A MMONIA

AMMON IA

AMMONIA

AMMON I A

A MMONIA

AMMONIA

AMMONIA

AMMONI A

AMMONIA

AMMONIA

A MMON I A

AMMONIA

AMMONIA

AMMONIA

A MMONI A

AMMON I A

AMMONIA

A MMON I A

A MMONIA

AMMONI A

AMMONI A

AMMONI A

AMMON IA

AMMON IA

AMMONI

AMMONIA

AMMON IA

AMMON I A

AMMONI A

MMONIA

AMMONIA

A MMONI A

MMONIA

AMMONI A

AMMON I A

AMMONIA

AMMON I A

AMMONI A

AMMONIA

AMMON I A

AMMON I A

A MMON I A

AMMONI A

MMONI A

AMMONI A

AMMON I A

AMMON I A

AMMONIA

AMMON IA

AMMONI A

GAVELINOPS IS

AM MON I A

AMMONIA

AMMONIA

A MMON I A

AMMONIA

AMMONIA

AMMONIA

AMMON I A

A MMONI A

A MMON I A

AMMONIA

AMMONIA

AMMON I A

AMMON I A

AMMON I A

AMMONIA

A MMON I A

AMMONIA

AMMONI A

AM, MONIA

DISCORBIS

AMMONIA
BECCARI I

BECCARII

BECCARII

BE CCARII

ECCARII

BECCARII

BECCARII

BECCARII

BECCARII

BECCARII

BECCARII

BECCARII

BECCARI I

BECCARII

BECCARII

BECCAR I I

BECCARII

BECCARII

BECCARII

BECCARI I

BECCARI I

BECCARII

BECCARI I

BECCARI I

BECCARII

BECCARII

BECCARII

BECCARI I

BECCARII

BECCARII

BE CCARII

BECCARII

BECCARI I

BECCARII

BE CCAR I I

BECCARII

BECCARI I

BECCARI I

PAUCILOCULATA

PALCILOCULATA

PAUCILOCULATA

PAUCILOCULATA

PAUCILOCULATA

PALCILOCULATA

PAUCILOCULATA

PAUCILOCULATA

PALCILOCULATA

PAUCILOCULATA

PAUCILOCULATA

PALCILOCULATA

PAUCILOCULATA

PAUCILOCULATA

PAUCILOCULATA

PAUCILOCULATA

PAUCILOCULATA

PA LCILOCULATA

PAUCILOCULATA

PAUCILOCULATA

PALCILOCULATA

PALCILOCULATA

PALCILOCULATA

PALCILOCULATA

PALCILOCULATA

PRAEGER I

ROLSHAUSENI

ROLSHAUSENI

ROLSHAUSENI

ROLSHAUSENI

ROLSHAUSENI

ROLSHAUSENI

ROLSHAUSENI

ROLSHAUSENI

ROLSHAUSENI

ROLSHAUSENI

ROLSHAUSENI

ROLSHAUSENI

ROLSHAUSENI

ROLSHAUSENI

ROLSHAUSENI

ROLSHAUSENI

ROLSHAUSENI

ROLSHAUSENI

ROLSHAUSENI

ROLSHAUSENI

ROLSHAUSEN I

ROSEA

TRANSLUCENS

Locality

NW GULF OF MEXICO

NW GULF OF MEXICO

NW GULF OF MEXICO

TEXAS GULF COAST

$N$ WULF OF MEXICO

NW GULF OF MEXICO

NW GULF OF MEXICO

NW GULF OF MEXICO

LOUISIANA GULF COAST

TEXAS GULF COAST 


\section{Publication}

24621 PARKER 1954 24622 PARKER 1954

24623 PHLEGER $1955 \mathrm{~A}$

24624 PHLEGER 1955 A

24625 PHLEGER 1951A

24626 PHLEGER $1951 \mathrm{~A}$

24627 PHLEGER $1951 \mathrm{~A}$

24628 PHLEGER $1951 \mathrm{~A}$

24629 PHLEGER 1955 A

24630 PARKER 1954

24631 PARKER 1954

24632 PARKER 1954

24633 PARKER 1954

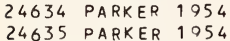

24636 PARKER 1954

24637 PARKER 1754

24638 PARKER 1954

24639 PARKER 1954

24640 PARKER 1954

24641 PARKER 1954

24642 PHLEGER $1951 \mathrm{~A}$

24644 PHLEGER 1951 A

24645 PHLEGER 1951 A

24646 CREAGER 1958

24647 CREAGER 1958

24648 PHLEGER $1951 \mathrm{~A}$

24649 PHLEGER $1951 \mathrm{~A}$

24650 PHLEGER 1951 A

24651 PHLEGER 1951A

24652 PHLEGER $1951 \mathrm{~A}$
24653 PHLEGER $1951 \mathrm{~A}$

24654 PHLEGER $1951 \mathrm{~A}$

24655 PHLEGER $1951 \mathrm{~A}$

24656 PARKER 1954

24657 PARKER 1754

24658 CREAGER 1958

24659 CREAGER 1958

24660 PARKER 1954

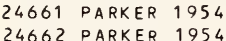

24663 PARKER 1954

24664 PARKER 1954

24665 PHLEGER 1955A

24666 PHLEGER 1951 A

24667 PHLEGER 1951

24668 PHLEGER $1951 \mathrm{~A}$

24669 PHLEGER $1951 \mathrm{~A}$

24670 PHLEGER $1951 \mathrm{~A}$

24671 PHLEGER 1951A

24672 PHLEGER $1955 \mathrm{~A}$

24673 PHLEGER 1955 A

24674 PARKER 1954

24675 PARKER 1954

24676 PHLEGER $1951 \mathrm{~A}$

24677 PHLEGER 1951

24678 ANDERSEN 196

24679 PARKER 1954

24680 PARKER 1954

24681 PARKER 1954

24682 PARKER 1954

24683 PARKER 1954

24684 PARKER 1954

24685 PARKER 1954

24686 PARKER 1954

24687 PARKER 1954

24688 PARKER 1954

24689 PARKER 1954

24690 PARKER 1954

24691 LUDWICK WALTON 1957

24692 PHLEGER 1955 A

24693 PHLEGER 1955 A

24694 PARKER 1954

24695 PARKER 1954

24696 PARKER 1954

24697 PARKER 1954

24698 PARKER 1954

24699 PARKER 1954

24700 PARKER 1954

24701 PARKER 1954

24702 PFLUM FRERICHS 1976

24703 PFLUM FRERICHS 1976

24704 PFLUM FRERICHS 1976

24705 BANDY 1956

24706 BANDY 1956

24707 AYALA-CASTANARES 1963

24708 BANDY 1956

24709 BANDY 1956

24710 BANDY 1956

24711 PFLUM FRERICHS 1976

24712 BENDA PURI 1962

24713 POAG 1972

24714 LIDZ LIDZ 1966

24715 PFLUM FRERICHS 1976

\section{Generic Name}

AMMONIA

AMMONIA

AMMONIA

AMMONIA

AMMONIA

AMMONIA

AMMON I A

AMMON I A

AMMONIA

AMMON I A

AMMONIA

AMMON I A

AMMONIA

AMMON I A

AMMONIA

AMMON I A

AMMONIA

AMMONIA

AMMON I A

AMMONI A

AMMON I A

AMMONIA

AMMON IA

AMMON IA

AMMONIA

AMMONIA

AMMONIA

AM MONONIA

AMMONIA

A MMONIA

AMMONIA

AMMON I A

AMMONIA

AMMONIA

AMMONIA

AMMONIA

AMMONIA

AMMONI A

AMMON I A

AMMON I A

AMMONIA

AMMONIA

AM YONIA

AM MONIA

AMMON I A

AMMONIA

AMMONI A

AMMON IA

AMMON I A

AMMONI A

AMMONIA

A MMONIA

AMMONIA

AMMONI A

AMMONIA

AMMONIA

VALVULI NER IA

VALVULINER I A

VALVULI NER I A

VALVULINER IA

VALVUL INER I A

VALVUL I NER I A

VALVULINER I A

VAL VUL INER I A

VALVUL INER I A

VALVULINER I A

VALVUL INER I A

VALVUL INER I A

VALVUL INER I A

VALVULINERIA

VALVULINER I A

VALVULINER IA

VALVULINER I A

VALVUL INER IA

VALVUL INER I A

VALVUL INER I A

VALVUL INER IA

VALVULINER I A

VALVULINER I A

VA LVUL INER I A

GA VELINOPS IS

GAVELINOPS IS

GAVELINOPS IS

GAVELINOPS IS

GAVELINOPS IS

GAVELINOPS IS

GAVELINOPS IS

GAVELINOPS IS

GAVELINOPS IS

GAVELINOPS IS

DI SCORBIS

DI SCORB IS

DISCORBIS

AMMONIA

\section{Specific Name}

TR ANSLUCENS

TRANSLUCENS

TRANSLUCENS

TRANSLUCENS

TRANSLUCENS

TRANSLUCENS

TRANSLUCENS

TRANSLUCENS

TRANSLUCENS

TR ANSLUCENS

TR ANSLUCENS

TR ANSLUCENS

TRANSLUCENS

TRANSLUCENS

TRANSLUCENS

TRANSLUCENS

TRANSLUCENS

TRANSLUCENS

TRANSLUCENS

TRANSLUCENS

TRANSLUCENS

TRANSLUCENS

TR ANSLUCENS

TRANSLUCENS

TRANSLUCENS

TRANSLUCENS

TRANSLUCENS

TRANSLUCENS

TRANSLUCENS

TR ANSLUCENS

TRANSLUCENS

TR ANSLUCENS

TRANSLUCENS

TRANSLUCENS

TRANSLUCENS

TRANSLUCENS

TRANSLUCENS

TRANSLUCENS

IRANSLUCENS

TRANSLUCENS

TRANSLUCENS

TRANSLUCENS

TRANSLUCENS

TR ANSLUCENS

TRANSLUCENS

TRANSLUCENS

TRANSLUCENS

TRANSLUCENS

TRANSLUCENS

TRANSLUCENS

TRANSLUCENS

TRANSLUCENS

TR ANSLUCENS

TRANSLUCENS

TRANSLUCENS

TRANSLUCENS

TR ANSLUCENS

LAEVIGATA

LAEVIGATA

LAEVIGATA

LAEVIGATA

LAEVIGATA

LAEVIGATA

LAEVIGATA

LAEVIGATA

LAEVIGATA

LAEVIGATA

LAEVIGATA

LAEVIGATA

LAEVIGATA

LAEVIGATA

LAEVIGATA

LAEVIGATA

LAEVIGATA

LAEVIGATA

LAEVIGATA

LAEVIGATA

LAEVIGATA

LAEVIGATA

LAEVIGATA

LAEVIGATA

BA SIL ICA

BA SILICA

BA SILICA

BA SILICA

BASILICA

BASILICA

BASILICA

BAS IL ICA

BA SILICA

ROSEA

ROSEA

ROSEA

TRANSLUCENS

\section{Locality}

NE GULF OF MEXICO 
Publication

24716 PFLUM FRERICHS 1976 24717 PFLUM FPERICHS 1976 24718 PFLUM FRERICHS 1976 24719 PFLUM FRERICHS 1976 24720 PFLIJM FRERICHS 1976 24721 PFLUM FRERICHS 1976 24722 PFL'JM FRERICHS 1976 24723 PFLUM FRERICHS 1976 24724 PFLUM FRERICHS 1976 24725 PFLUM FRERICHS 1976 24726 PFLUM FRERICHS 1976 24727 PFLUM FRERICHS 1976 24728 PFLUM FRERICHS 1976 24729 PFLUM FPERICHS 1976 24730 PFLUM FRERICHS 1976 24731 PFLUM FRERICHS 1976 24732 PFLUM FRERICHS 1976 24733 PFLUM FRERICHS 1976 24734 PFLUM FRERICHS 1976 24735 PFLUM FRERICHS 1976 24736 PFLUM FRERICHS 1976 24737 PFLUM FRERICHS 1976 24738 PFLUM FRERICHS 1976 24739 PFLUM FRERICHS 1976 24740 PFLUM FRERICHS 1976 24741 PFLU1 FRERICHS 1976 24742 PFLUM FRERICHS 1976 24743 PFLUM FRERICHS 1976 24744 PFLUM FRERICHS 1976 24745 PFLUM FRERICHS 1976 24746 PFLUM FRERICHS 1976 24747 PFLUM FRERICHS 1976 24748 PFLUM FRERICHS 1976 24749 PFLUM FRERICHS 1976 24750 PFLUM FRERICHS 1976 24751 PFLUM FRERICHS 1976 24752 PFLUM FRERICHS 1976 24753 PFL'JM FRERICHS 1976 24754 PFLUM FRERICHS 1970 24755 PFLUM FRERICHS 1976 24756 PFLUM FRERICHS 1976 24757 PFLUM FRERICHS 1976 24758 PFLUM FRERICHS 1976 24759 PFLUM FRERICHS 1976 24760 PFLIJM FRERICHS 1976 24761 PFLUM FPERICHS 1976 24762 PFLUM FRERICHS 1976 24763 PFLUM FRERICHS 1976 24764 PFLUM FRERICHS 1976 24765 PFLUM FRERICHS 1976 24766 PFLUM FRERICHS 1976 24767 PFLUM FRERICHS 1976 24768 PFLUM FRERICHS 1976 24769 PFLUM FRERICHS 1976 24770 PFLUM FRERICHS 1976 24771 PFLUM FRERICHS 1976 24772 PFLUM FRERICHS 1976 24773 PFLUM FRERICHS 1976 24774 PFLUM FRERICHS 1976 24775 PFLUM FRERICHS 1976 24776 LEROY HODGKINSON 1975 24777 PFLUM FRERICHS 1976 24778 PFLUM FRERICHS 1976 24779 CUSHMAN 1918 24780 CUSHMAN 1918 24781 VAUGHAN 1918 24782 CUSHMAN 1918 24783 CUSHMAN 1918 24784 CUSHMAN 1918

24785 PFLUM FRERICHS 1976 24786 PFLUM FRERICHS 1976 24787 PFLUM FRERICHS 1976 24788 PFLUM FRERICHS 1976 24789 PFLUM FRERICHS 1976 24790 PFLUM FRERICHS 1976 24791 PFLUM FRERICHS 1976 24792 PFLUM FRERICHS 1976 24793 PFLUM FRERICHS 1976 24794 PFLU'4 FRERICHS 1976 24795 PFLUM FRERICHS 1976 24796 PFLUM FRERICHS 1976 24797 PFLUM FRERICHS 1976 24798 PFLUM FRFRICHS 1976 24799 PFLUM FRERICHS 1976 24800 PFLUM FRERICHS 1976 24801 PFLUM FREPICHS 1976 24802 PFLUM FRERICHS 1976 24803 PFLUM FRERICHS 1976 24804 PFLUM FRERICHS 1976 24805 PFLUM FRERICHS 1976 24806 PFLU 4 FRERICHS 1976 24807 PFLUM FRERICHS 1976 24808 PFLUM FRERICHS 1076 24809 PFLUM FRERICHS 1976 24810 PFLUM FRERICHS 1976
Generic Name Specific Name

Locality

Lat. Long.

A.YMONI A

TR ANSLUCENS

TRANSLUCENS

AMMONIA

AMMONI A

A YMONI A

A MMONIA

A MMONI A

AMMONIA

A MMONIA

AMMONIA

A MMONI A

AMMONI A

AMMON I A

AMMONIA

AMMON IA

AMMON I A

AMMONI A

AMMONIA

A MMON I A

AMMON I A

A MMON I A

A.YMONIA

AMMON I A

AMMONIA

AMMONI A

AMMONIA

AMMONI A

AMMONIA

A MMONIA

A M MON I A

AMMONIA

AMMON I A

AMMONIA

AMMONIA

A M MON I A

AM YDNI A

AMMONI A

AMMON I A

AMMONI A

AMMON I A

AMMONIA

AMMONI A

A MMONI A

AMMON IA

AMMONIA

AMMON I A

AMMONIA

AMMON I A

AMMON I A

A MMONI A

AMMON I A

AMMONIA

SACCAMMINA

SACCAMMINA

SACCAMMINA

SACCAMMI NA

SACCAMMINA

SACCAMM I NA

SACCAMM I NA

SACCAMM INA

SACCAMM INA

SACCORHIZA

SACCORHIZA

SACCORHIZA

SACCORHIZA

SACCORHIZA

SACCORHIZA

SACCORHIZA

SACCORHIZA

SACCORHIZA

SACCORHIZA

SACCORHIZA

SACCORHIZA

SACCORHIZA

SACCORHIZA

SACCORHIZA

SACCORHIZA

SACCORHIZA

SACCORHIZA

SACCORHIZA

SACCORHIZA

SACCORH IZA

SACCORHIZA

SACCORHIZA

SACCORHIZA

SACCORHIZA

SACCORHIZA

SACCORH I ZA

SACCORH I ZA

SACCORHIZA
CENTRAL GULF OF MEXICO

NW GULF OF MEXICO

NW GULF OF MEXICO

NW GULF OF MEXICO

NW GULF OF MEXICO

NW GULF OF MEXICO

$N W$ GULF OF MEXICO

NW GULF OF MEXICO

NW GULF OF MEXICO

NW GULF OF MEXICO

NW GULF OF MEXICO

NW GULF OF MEXICO

CENTRAL GULF OF MEXICO

NW GULF OF MEXICO

CENTRAL GULF OF MEXICO

CENTRAL GULF OF MEXICO

CENTRAL GULF OF MEXICO

CENTRAL GULF OF MEXICO

CENTRAL GULF OF MEXICO

CENTRAL GULF OF MEXICO

CENTRAL GULF OF MEXICO

CENTRAL GULF OF MEXICO

NW GULF OF MEXICO

NW GULF OF MEXICO

NW GULF OF MEXICO

NW GULF OF MEXICO

NW GULF OF MEXICO

NH GULF OF MEXICO

NW GULF OF MEXICO

NW GULF OF MEXICO

$N W$ GULF OF MEXICO

NW GULF OF MEXICO

NW GULF OF MEXICO

NW GULF OF MEXICO

NW GULF OF MEXICO

NW GULF OF MEXICO

NW GULF OF MEXICO

NW GULF OF MEXICO

$N W$ GULF OF MEXICO

$N W$ GULF OF MEXICO

NW GULF OF MEXICO

$N W$ GULF OF MEXICO

NW GULF OF MEXICO

CENTRAL GULF OF MEXICO

CENTRAL GULF OF MEXICO

CENTRAL GULF OF MEXICO

CENTRAL GULF OF MEXICO

CENTRAL GULF OF MEXICO

$N W$ GULF OF MEXICO

NW GULF OF MEXICO

NW GULF OF MEXICO

CENTRAL GULF OF MEXICO

NW GULF OF MEXICO

NW GULF OF MEXICO

NW GULF OF MEXICO

NW GULF OF MEXICO

CENTRAL GULF OF MEXICO

CENTRAL GULF OF MEXICO

CENTRAL GULF OF MEXICO

$N$ GULF OF MEXICO

NW GULF OF MEXICO

NW GULF OF MEXICO

NE GULF OF MEXICO

NE GULF OF MEXICO

FLORIDA KEYS

NE GULF OF MEXICO

NE GULF OF MEXICO

CENTRAL GULF OF MEXICO

CENTRAL GULF OF MEXICO

CENTRAL GULF OF MEXICO

CENTRAL GULF OF MEXICO

CENTRAL GULF OF MEXICO

CENTRAL GULF OF MEXICO

NW GULF OF MEXICO

NW GULF OF MEXICO

NW GULF OF MEXICO

NW GULF OF MEXICO

NW GULF OF MEXICO

NW GULF OF MEXICO

NW GULF OF MEXICO

$\mathrm{NW}$ GULF OF MEXICO

NW GULF OF MEXICO

$N W$ GULF OF MEXICO

NH GULF OF MEXICO

NH GULF OF MEXICO

NW GULF OF MEXICO

NW GULF OF MEXICO

NW GULF OF MEXICO

NW GULF OF MEXICO

NW GULF OF MEXICO

$N W$ GULF OF MEXICO

NW GULF OF MEXICO

RANOSA

RANOSA $\begin{array}{lllll}28 & 33 N & 089 & 13 W \\ 27 & 38 N & 095 & 45 W\end{array}$ $2651 \mathrm{~N} 09216 \mathrm{~W}$ $2735 \mathrm{~N} 09544 \mathrm{~W}$ $2656 \mathrm{~N} 09220 \mathrm{~W}$ $26 \quad 52 \mathrm{~N} 092 \quad 17 \mathrm{~W}$ $2654 \mathrm{~N} 09218 \mathrm{~W}$ 


\section{Publication}

24811 PFLUM FRERICHS 1976 24812 PFLUM FRERICHS 1976 24813 PFLUM FRERICHS 1976 24814 PFLUM FRERICHS 1976 24815 PFLUM FRERICHS 1976 24816 PFLUM FRERICHS 1976 24817 PFLUM FRERICHS 1976 24818 PFLUM FRERICHS 1976 24819 PFLUM FRERICHS 1976 24820 PFLUM FRERICHS 1976 24821 PFLUM FRERICHS 1976 24822 PFLUM FRERICHS 1976 24823 PFLUM FRERICHS 1976 24824 PFLUM FRERICHS 1976 24825 PFLUM FRERICHS 1976 24826 PFLUM FRERICHS 1976 24827 PFLUM FRERICHS 1976 24828 PFLUM FRERICHS 1976 24829 PFLUM FRERICHS 1976 24830 PFLUM FRERICHS 1976 24831 PFLUM FRERICHS 1976 24832 PFLUM FRERICHS 1976 24833 PFLUM FRERICHS 1976 24834 PFLUM FRERICHS 1976 24835 PFLUM FRERICHS 1976 24836 PFLUM FRERICHS 1976 24837 PFLUM FRERICHS 1976 24838 PFLUM FRERICHS 1976 24839 PFLUM FRERICHS 1976 24840 PFLUM FRERICHS 1976 24841 PFLUM FRERICHS 1976 24842 PFLUM FRERICHS 1976 24843 CUSHMAN 1918

24844 PFLUM FRERICHS 1976 24845 PFLUM FRERICHS 1976 24846 PFLUM FRERICHS 1976 24847 PFLUM FRERICHS 1976 24848 PFLIJM FRERICHS 1976 24849 PFLUM FRERICHS 1976 24850 PFLUM FRERICHS 1976 24851 CUSHMAN 1918

24852 BOCK 1976

24853 BANDY 1956

24854 BANDY 1956

24855 ANDERSEN 196
24856 SOCK 1976

24857 PFLUM FRERICHS 1976

24858 ANDERSEN 1961

24859 ANDERSEN 1961

24860 BOCK 1976

24861 ANDERSEN 1961

24862 CREAGER 1958

24863 CREAGER 1958

24864 CREAGER 1958

24865 CREAGER 1958

24866 CREAGER 1958

24867 CREAGER 1958

24868 CREAGER 1958

24869 CREAGER 1958

24870 NORT ON 1930

24871 PHLEGER 1956

24872 PARKER 1954

24874 PARKER 1954

24875 PARKER 1954

24876 PARKER 1954

24877 PARKER 1954

24878 PARKER 1954

24879 PARKER 1954

24880 PARKER 1954

24881 PARKER 1954

24882 PARKER 1954

24883 PARKER 1954

24884 PARKER 1954

24885 PARKER 1954

24886 PARKER 1954

24887 PARKER 1954

24888 PARKER 1954

24889 PARKER 1954

24890 BANDY 1954

24891 BANDY 1954

24892 BANDY 1954

$\begin{array}{llll}24893 & \text { BANDY } 1954 & \\ 24894 & \text { BENDA PUQI } 1962\end{array}$

24894 BENDA PUQI
24895 BANDY 1954

24896 BANDY 1954

24897 ANDERSEN 1961

24898 PHLEGER $1951 \mathrm{~A}$

24899 DHLEGER 1951A

24900 PHLEGER 1951A

24901 ANDERSEN 1961

24902 PHLEGER 1951 A

24903 PHLEGER 1951 A

24904 PHLEGER $1951 \mathrm{~A}$
Generic Name

SACCORHIZA

SACCORHIZA

SACCORHIZA

SACCORHIZA

SACCORHIZA

SACCORHIZA

SACCORHIZA

SACCORHIZA

SACCORHIZA

SACCORHIZA

SACCORHIZA

SACCORHIZA

SACCORHIZA

SACCORHIZA

SACCORHIZA

SACCORHIZA

SACCORHIZA

SACCORHIZA

SACCORHIZA

SACCORHIZA

SACCORHIZA

SACCORHIZA

SACCORHIZA

SACCORHIZA

SACCORHIZA

SACCORHIZA

SACCORHIZA

SACCORHIZA

SACCORHIZA

SACCORHIZA

SACCORHIZA

SACCORHIZA

SACCORHIZA

SACCORHIZA

SACCORHIZA

SACCORHIZA

SACCORHIZA

SAGRINA

SARACENARI A

SARACENARI A

SARACENARIA

SARACENARIA

SARACENARI A

SARACENARIA

SARACENARI A

SARACENARIA

SARACENARIA

MARTINOTTIELLA

MARTINOTTIELLA

MARTINOTTIELLA

MARTINOTTIELLA

MARTINOTTIELLA

MART INOTTIELLA

MARTINOTTIELLA

MARTINOTTIELLA

SC HLUMBERGERINA

SEABROOKIA

SEABROOKIA

SEABROOKIA

SEABROOKIA

SE ABROOKIA

SEABROOKIA

SEABROOKIA

SEABROOKIA

SEABROOKIA

SEABR OOKIA

SE ABROOKIA

SEABROOKIA

SEABROOKIA

SEABROOKIA

SEABROOKIA

SE ABROOKIA

SEABROOKIA

SE ABROOKIA

SEABROOK IA

SPIROSI GMO I L I NA

SP IROS IGMO IL INA

SPIROS IGMOIL INA

SPIROS I GMOILINA

SPIROSIGMOILINA

SPIROSI GMOILINA

SPIROS I GMO I L INA

SPIROS I GMOI L INA

SP IROS I GMO I L I NA

SPIROSIGMOILINA

SPIROS I GMOILINA

SPIROS I GMO I L INA

SPIROSIGMOIL INA

SPIROS I GMO IL INA

SP IROS I GMO I L INA

SPIROSI GMOIL INA
Specific Name

RANOSA

RANOSA

RANOSA

RANOSA

RANOSA

RANOSA

RANOSA

RANOSA

RANOSA

RANOSA

RANOSA

RANOSA

RANOSA

RANOSA

RANOSA

RANOSA

RANOSA

RANOSA

RANOSA

RANOSA

RANOSA

RANOSA

RANOSA

RANOSA

RANOSA

RANOSA

RANOSA

RANOSA

RANOSA

RANOSA

RANOSA

RANOSA

RANOSA

AMFLA

AMFLA

AMFLA

I T ALICA

I T ALI I A

LATIFRONS JAMAICENSIS

LATIFRONS

ME XICANA

OC CI DENTALIS

OC CIDENTALIS

OC CIDENTALIS

OC CI DENTALIS

OC CIDENTALIS

OC CIDENTALIS

OC CIDENTALIS

OC CIDENTALIS

AL VEOLINIFORMIS

EARLANDI

EA FLANDI

EARLANDI

EARLANDI

EARLANDI

EARLANDI

EA RLAND I

EARLANDI

EARLANDI

EA RLANDI

EARLANDI

EARLANDI

EARLANDI

EARLANDI

EARLANDI

EARLANDI

EA FLANDI

AN TILLARUM

ANTILLARUM

AN TILLARUM

ANTILLARUM

AN TILLARUM

AN TILLARUM

AN TILLARUM

DISTORTA

DI STORTA

DI STORTA

DI STORTA

DI STORTA

DI STORTA

DI STORTA

DI STORTA

DI STORTA

Locality

NW GULF OF MEXICO

$N W$ GULF OF MEXICO

$N W$ GULF OF MEXICO

NW GULF OF MEXICO

NW GULF OF MEXICO

NW GULF OF MEXICO

NW GULF OF MEXICO

$N W$ GULF OF MEXICO

$N W$ GULF OF MEXICO

NW GULF OF MEXICO

NW GULF OF MEXICO

$N W$ GULF OF MEXICO

$N W$ GULF OF MEXICO

$N W$ GULF OF MEXICO 


\section{Publication}

24906 PHLEGER $1951 \mathrm{~A}$ 24907 PHLEGER $1951 \mathrm{~A}$ 24908 PHLEGER 1951A 24909 PHLEGER $1951 \mathrm{~A}$ 24910 PHLEGER 1951 A 24911 PHLEGER 1951A 24912 PHLEGER 1951 A 24913 PHLEGER $1951 \mathrm{~A}$ 24914 PHLEGER 1951A 24916 PHLEGER $1951 \mathrm{~A}$ 24917 PHLEGER 1951 A 24918 PHLEGER $1951 \mathrm{~A}$ 24919 PHLEGER $1951 \mathrm{~A}$ 24920 PHLEGER 1951A 24921 PHLEGER 1951A 24922 PHLEGER 1951A 24923 PHLEGER 1951A 24924 PHLEGER 1951A 24925 BOCK 1976 24926 PARKER 1954 24927 PARKER 1954 24928 PARKER 1954 24929 PARKER 1954 24930 PARKER 1954
24931 LUDWICK WALTON 1957 24931 LUDWICK WALTON
24932 LANKFORD 1959 24933 PARKER 1954 24934 PARKER 1954 24935 PARKER 1954 24936 PARKER 1954 24937 PHLEGER 1951A 24938 PHLEGER $1951 \mathrm{~A}$ 24939 PHLEGER 1951A 24940 PHLEGER $1951 \mathrm{~A}$ 24941 PARKER 1954 24942 PARKER 1954 24943 PARKER 1954 24944 PARKER 1954 24945 PARKER 1954 24946 PHLEGER 1956
24947 PHLEGER 1951 A 24947 PHLEGER $1951 \mathrm{~A}$
24948 PHLEGER $1951 \mathrm{~A}$ 24949 PHLEGER 1951A 24950 PHLEGER 1951A 24951 PHLEGER 1951A 24952 PHLEGER 1951 A 24953 PHLEGER 1951A 24954 PHLEGER 1951A 24955 PFLUM FRERICHS 1976 24956 PHLEGER $1951 \mathrm{~A}$ 24957 CUSHMAN 1929 24958 PHLEGER 1951A 24959 PHLEGER $1951 \mathrm{~A}$ 24960 PHLEGER 1951A 24961 PHLEGER 1951A 24962 PHLEGER $1951 \mathrm{~A}$ 24963 PHLEGER 1951A 24964 PHLEGER 1951 A 24965 PHLEGER 1951A 24966 PHLEGER 1951A 24967 PHLEGER 1951A 24968 PHLEGER 1951A 24969 PHLEGER 1951A 24970 PHLEGER 1951 A 24971 PHLEGER $1951 \mathrm{~A}$ 24972 PHLEGER 1951 A 24973 PHLEGER $1951 \mathrm{~A}$ 24974 PARKER 1954 24975 CUSHMAN 1929 24976 CUSHMAN 1929 24977 BENDA PURI 1962 24978 PFLUM FRERICHS 1976 24979 CUSHMAN 1929 24980 CUSHMAN 1929 24981 PARKER 1954 24982 PARKER 1954 24983 PHLEGER 1955A 24984 PARKER 1954 24985 PARKER 1954 24986 PARKER 1954 24987 PARKER 1954 24988 PARKER 1954 24989 PARKER 1954 24990 PARKER 1954 24991 PARKER 1954 24992 PARKER 1954 24993 PARKER 1954
24994 PHLEGER 1951 A $24995^{\circ}$ PHLEGER 1955 A 24996 PARKER 1954 24997 PARKER 1954 24998 PARKER 1954 24999 PFLUM FRERICHS 1976 25000 PFLUM FRERICHS 1976

\section{Generic Name}

SPIROSI GMOILINA SPIROSIGMOIL INA SPIROSI GMOILINA SPIROSIGMOILINA SPIROS I GMOIL INA SPIROSIGMOILINA SPIROSI GMOIL INA SPIROSIGMOILINA SP IROS IGMOIL INA SPIROSIGMOIL INA SPIROS IGMOIL INA SPIROSIGMOIL INA SPIROSIGMOILINA SPIROSIGMOILINA SPIROSIGMOIL INA SPIROSIGMOIL INA SPIROSIGMOIL INA SPIROS I GMOIL INA SPIROSIGMOILI NA SPIROSIGMOILINA SPIROSI GMOILINA SPIROS I GMOIL INA SPIROSIGMOIL INA SP IROSI GMOIL INA SPIROSI GMOIL INA SPIROSIGMOIL INA SPIROSIGMOILINA SPIROS I GMOILINA SPIROSIGMOILINA SPIROSIGMOILINA SPIROSIGMOIL INA SPIROSIGMOILINA SPIROS I GMOIL INA SPIROSI GMOIL INA SPIROSIGMOIL INA SPIROSI GMOIL INA SPIROS IGMO IL INA SPIR OSIGMOIL INA SPIROS I GMOIL INA SP IROS I GMO I L INA SPIROSI GMOI L INA SI GMOILOPSIS SI GMOIL OPS I S SI GMOILOPSIS SI GMOILOPSIS SIGMOILOPSIS SIGMOIL OPSI SI GMOILOPS IS SI GMOIL OPS IS SI GMOIL OPSIS

SI GMOILOPSIS SI GMOILOPS IS SIGMOIL OPSIS SI GMO IL OPS IS SI GMOIL OPS I SI GMOIL OPSIS SI GMOIL OPS IS SIGMOILOPSIS SI GMOILOPSIS SI GMOILOPSI SI GMOIL OPS I SI GMOIL OPSI SI GMOILOPS IS SI GMOIL OPSIS SI GMOIL OPS IS SI GMOIL OPS I SI GMOILOPS IS SI GMOIL OPSI SI GMOILOPS IS SI GMOILOPSIS SI GMOIL OPS IS SI GMOILOPS IS SI GMOILOPSI SI GMOILOPS IS SI GMOILOPSI SI GMOILOPSIS SI GMOILOPS IS SI GMOILOPS IS SIGMOILOPS IS SI GMOILOPSIS SI GMOILOPSI SI GMOIL OPS I SI GMOIL OPSIS SI GMOILOPSIS SI GMOILOPS IS SI GMO IL OPS IS SI GMOILOPSI IIGMOILOPSIS SI GMOILOPS IS SI GMOILOPSIS SI GMOILOPS IS SI GMOIL OPS IS SI GMOILOPS IS SI GMO IL INA SI GMO IL INA
Specific Name

Locality

Lat. Long.

DISTORTA

DISTORTA

DI STORTA

DI STORTA

DISTORTA

DI STORTA

DI STORTA

DISTORTA

DISTORTA

DI STORTA

DISTORTA

DISTORTA

DISTORTA

DISTORTA

DISTORTA

DI STORTA

DISTORTA

DI STORTA

DISTORTA

DI STORTA

DI STORTA

DISTORTA

DISTORTA

DISTORTA

DISTORTA

DI STORTA

DISTORTA

DISTORTA

DISTORTA

DI STORTA

DISTORTA

DISTORTA

DISTORTA

DISTORTA

DI STORTA

DISTORTA

DISTORTA

DISTORTA

DI STORTA

SC HL UMBER GER I

SCHLUMBERGERI

SC HLUMBERGERI

SC HLUMBERGER I

SCHLUMBERGERI

SCHLUMBERGERI

SC HLUMBERGERI

SC HLUMBERGERI

SC HLUMBER GER I

SC HLUMBERGERI

SCHLUMBER GERI

SCHLUMBERGERI

SC HLUMBER GER I

SC HLUMBERGER I

SC HLUMBER GER I

SC HLUMBERGERI

SCHLUMBERGERI

SCHLUMBERGERI

SC HLUMBER GER I

SC HLUMBER GERI

SC HLUMBER GE RI

SC HLUMBER GE RI

SC HLUMBER GE RI

SC HLUMBER GE RI

SC HLUMBER GERI

$S$ C HLUMBER GERI

SC HLUMBERGERI

SC HLUMBER GER I

SC HLUMBER GER I

SC HLUMBERGERI

SC HL UMBERGE RI

SC HLUMBER GERI

SC HLUMBERGERI

SC HLUMBER GER I

SC HLUMBERGER

SC HLUMBER GER I

SC HLUMBERGE RI

SCHLUMBERGERI

SCHLUMBER GER

SC HLUMBER GER

SC HLUMBER GER

SCHL UMBER GER

SCHLUMBERGER I

SC HLUMBERGER

SCHLUMBER GERI

SCHLUMBERGER

SC HLUMBER GE RI

SC HLUMBERGER I

SC HLUMBER GER I

SC HLUMBER GE R

SC HLUMBER GER I

SC HLUMBERGERI

SI GNO IDEA

SI EMO I DEA

NW GULF OF MEXICO NW GULF OF MEXICO NW GULF OF MEXICO 


\section{Publication}

25001 PFLUM FRERICHS 1976

25002 BANDY 1956

25003 SENDA PURI 1962

25004 SANDY 1956

25005 RANDY 1950

25006 BANDY 1956

25007 BANDY 1956

25008 BANDY 1956

25009 BANDY 1956

25010 BANDY 1956

25011 BANDY 1956

25012 BANDY 1956

25013 BANDY 1956

25014 PARKER 1954

25015 BANDY 1956

25017 BANDY 1956

25018 BENDA PURI 1962

25019 PARKER 1754

25020 PARKER 1954

25022 PARKER 1954

25023 PARKER 1954

25024 PARKER 1954

25025 BOCK 1976

25026 PARKER 1954

25027 PARKER 1954

25029 PARKER 1954
25030 PARKER 1954

25031 ANDERSEN 1961

25032 LEROY HODGKINSON 1975

25033 PFLUM FRERICHS 1976

25034 PFLUM FRERICHS 1976

25035 ANDERSEN 1961

25036 PFLUM FRERICHS 1976

25037 PFLUM FRERICHS 1976

25038 PFLUM FRERICHS 1976

25039 PFLUM FRERICHS 1976

25040 PFLUM FRERICHS 1976

25041 PFLUM FRERICHS 1976

25042 PFLUM FRERICHS 1976

25043 PFLUM FRERICHS 1976

25044 PFLUM FRERICHS 1976

25045 PFLUM FRERICHS 1976

25046 PFLUM FRERICHS 1976

25047 PFLUM FRERICHS 1976

25048 PFLUM FRERICHS 1976

25049 PFLUM FRERICHS 1976

25050 PFLUM FRERICHS 1976

25051 PFLUM FRERICHS 1976

25052 PFLUM FRERICHS 1976

25053 PFLUM FRERICHS 1976

25054 PFLUM FRERICHS 1976

25055 PFLUM FRERICHS 1976

25056 PFLUM FRERICHS 1976

25057 PFLUM FRERICHS 1976

25058 PFLUM FRERICHS 1976

25059 PFLUM FRERICHS 1976

25060 PFLUM FRERICHS 1976

25061 PFLUM FRERICHS 1976

25062 PFLUM FRERICHS 1976

25063 PFLUM FRERICHS 1976

25064 PFLUM FRERICHS 1976

25065 PFLUM FRERICHS 1976

25066 PFLUM FRERICHS 1976

25067 PFLUM FRERICHS 1976

25068 PFLUM FRERICHS 1976

25069 PFLUM FRERICHS 1976

25070 PFLUM FRERICHS 1976

25071 PFLUM FRERICHS 1976

25072 PFLUM FRERICHS 1976

25073 PFLUM FRERICHS 1976

25074 PFLUM FRERICHS 1976

25076 PFLIII FRERICHS 1976

25077 PFLUM FRERICHS 1976

25078 PFLUM FRERICHS 1976

25079 PFLUM FRERICHS 1976

25080 PFLUM FRERICHS 1976

25081 PFLUM FRERICHS 1976

2508? PFLUM FRERICHS 1976

25083 PFLUM FRERICHS 1976

25084 PFLUM FRERICHS 1976

25085 PFLUM FRERICHS 1976

25086 PFLUM FRERICHS 1976

25087 PFLUM FRERICHS 1976

25088 PFLUM FRERICHS 1976

25089 PFLUM FRERICHS 1976

25090 PFLUM FRERICHS 1976

$\begin{array}{lll}25091 & \text { PFLUM FRERICHS } & 1976 \\ 25092 & \text { PFLUM FRERICHS } & 1976\end{array}$

25093 PFLUM FRERICHS 1976

25094 PFLUM FRERICHS 1976

25095 PFLUM FRERICHS 1976
Generic Name

SI GMO IL INA

QUINQUEL OCULINA

QU INQUEL OCUL INA

QUINQUELOCULINA

QU INQUEL OCULINA

QU INQUELOCULINA

QU INQUEL OCUL INA

QU INQUELOCUL INA

QUINQUELOCULINA

QU INQUEL OCUL INA

QU INQUELOCULINA

QU INQUE LOC UL I NA

QUINQUEL OCULINA

SI GMOIL INA

SIGMOILINA

S I GMOILINA

SI GMOIL INA

SI GMO IL INA

SI GMOILINA

SI GMOIL INA

SI GMO IL INA

SI GMO IL INA

SI GMOIL INA

S I GMOIL I NA

S IGMOILINA

SI GMO I L INA

SI GMOILINA

SI GMOIL INA

SI GMO IL INA

SIGMOILINA

SI GMOILOPS IS

SI GMOILOPS IS

SI GMOILOPS I S

SI GMOILOPS IS

SI GMOILOPSIS

SI GMOIL OPS IS

SI GMOILOPS IS

SI GMOILOPS IS

SI GMOILOPSIS

SI GMOIL OPSIS

SI GMOILOPS IS

SIGMOIL OPSIS

SI GMOILOPS IS

SI GMOILOPSIS

SI GMOILOPS IS

SI GMOILOPS IS

SI GMOILOPS I S

SI GMOIL OPS I S

SIGMOIL OPS IS

SIGMOILOPS IS

SI GMOILOPS IS

SI GMOILOPSIS

SI GMOIL OPSIS

SI GMOILOPS IS

SI GMOILOPS IS

SIGMOILOPSIS

SI GMOILOPSIS

SI GMOIL OPS IS

SIGMOILOPSIS

SI GMOILOPS IS

SI GMOILOPS IS

SI GMO ILOPS IS

SI GMOILOPS IS

SI GMOILOPSIS

SI GMOILOPS IS

SI GMOILOPSIS

SIGMOILOPS IS

SI GMOILOPS IS

SI GMOILOPS IS

SI GMOILOPSI S

SI GMOILOPSIS

SI GMOILOPS IS

SI GMOILOPS IS

SI GMOILOPSIS

SI GMOILOPS IS

SIGMOILOPS IS

SI GMOILOPSIS

SI GMOILOPS IS

SI GMOILOPS IS

SI GMOILOPS IS

SI GMOILOPS IS

SI GMOILOPS IS

SI GMOILOPS IS

SI GMOILOPS IS

SI GMOILOPS IS

SI GMOILOPS IS

SI GMOIL OPS IS

SIGMOILOPSIS

SI GMOILOPS IS

SI GMOILOPSIS

SI GMOILOPS IS

SI GMOILOPS IS

SI GMOILOPS IS

SI GMO ILOPS IS

SI GMOILOPS IS
Locality

Lat. Long.

S I GMOI DEA

SUEPOEYANA

SUBPOEYANA

SUEPOEYANA

SUEPOEYANA

SUEPOEYANA

SUEPOEYANA

SUBPOEYANA

SUEPOEYANA

SUEPOEYANA

SUEPOEYANA

TENUIS

TEAUIS

TENUIS

TENUIS

TENUIS

TEAUIS

TENUIS

TENUIS

TENUIS

TENUIS

TENUIS

TENUIS

TENUIS

TENUIS

TENUIS

FL INTII

SC

SCHLUMBERGER

SCHLUMBERGERI

SC HLUMBERGER

SC HLUMRERGER

SC HLUMBER GERI

SC LUMBERGERI

SC LUMBERGER

SCHLUMBERGER

SC LUMBERGERI

SCHLUMBERGERI

SC HLUMBER GERI

SC HLUMBERGERI

SC KLUMBERGERI

SCHLUMBER GER

SC HLUMBERGERI

SCHLUMBERGER

SCHLUMBERGER I

SC LUUMBRGERI

SC HLUMBERGER I

SC HLUMBERGER

SC HLUMBER GER

SCHLUMBER GER

SCHLUMBERGER

SCHLUMBER GERI

SCHLUMBERGERI

S C HLUMBER GER

SC HLUMBERGER

SCHLUMBERGERI

SCHLUMBERGERI

SCHLUMBERGERI

SCHLUMBERGER

$S$ C HLUMBER GER I

SC FLUMBER GER I

SC HLUMBERGER

SCHLUMBERGERI

SCHLUMBERGERI

SCHLUMBERGER I

SC HLUMBERGERI

SC HLUMBER GER I

SCHLUMBERGER I

SC HLUMBER GERI

SCFLUMBERGERI

SC HLUMBER GER I

SC HLUMBERGER I

SC HLUMBER GER I

SC FLUMBERGERI

SC HLUMBERGERI

SC HLUMBERGERI

SCHLUMBERGER I

SC HLUMBERGERI

SC HLUMBERGERI

SC HLUMBERGER I

SCFLUMBERGER

SCHLUMBERGERI

SCHLUMBERGERI

SCHLUMBERGERI

SC HLUMBERGERI

SC HLUMBERGERI

SCHLUMBERGERI

SC HLUMBERGER I

SC HLUMBERGERI

NW GULF OF MEXICO

NE GULF OF MEXICO

CAPE ROMANO, FLA.

NE GULF OF MEXICO

NE GULF OF MEXICO

NE GULF OF MEXICO

NE GULF OF MEXICO

NE GULF OF MEXICO 
Publication

25096 PFLUM FRERICHS 1976 25097 PFLUM FRERICHS 1976 25098 PFLUM FRERICHS 1976 25099 PFLUM FRERICHS 1976 25100 PFLUM FRERICHS 1976 25101 PFLUM FRERICHS 1976 25102 PFLUM FRERICHS 1976 25103 PFLUM FRERICHS 1976 25104 PFLUM FRERICHS 1976 25105 PFLUM FRERICHS 1976 25106 PFLUM FRERICHS 1976 25107 NORTON 1930

25108 CUSHMAN 1922 A

25109 CUSHMAN 1922A

25110 PFLUM FRERICHS 1976

25111 PHLEGER 1951A

25112 PFLUM FRERICHS 1976

25113 CREAGER 1958

25114 CREAGER 1958

25115 CREAGER 1958

25116 PFLUM FRERICHS 1976

25117 CREAGER 1958

25118 PHLEGER 1956

25119 PARKER 1954

25120 PARKER 1954

25121 PARKER 1954

25122 PARKER 1954

25123 PFLUM FRERICHS 1976

25124 PFLUM FRERICHS 1976

25125 PFLUM FRERICHS 1976

25126 PFLUM FRERICHS 1976

25127 PFLUM FRERICHS 1976

25128 BANDY 1956

25129 BANDY 1956

25130 PFLUM FRERICHS 1976

25131 PARKER 1954

25132 PARKER 1954

25133 PARKER 1954

25134 LANKFORD 1959

25135 PHLEGER 1951A

25136 PHLEGER 1951A

25137 PFLUM FRERICHS 1976

25138 PFLUM FRERICHS 1976

25139 PFLUM FRERICHS 1976

25140 PFLUM FRERICHS 1976

25149 PFLUM FRERICHS 1976 25142 PFLUM FRERICHS 1976
25143 PFLUM FRERICHS 1976 25143 PFLUM FRERICHS 1976 25145 PFLUM FRERICHS 1976 25146 PFLUM FRERICHS 1976 25147 PARKER 1954

25148 PARKER 1954

25149 BOCK 1976

25150 CREAGER 1958

25151 CREAGER 1958

25152 CREAGER 1958

25153 BANDY 1956

25154 BANDY 1956
25155 BANDY 1956

25156 BANDY 1956

25157 BANDY 1956

25158 BANDY 1956

25159 BANDY 1956

25160 CREAGER 1958

25161 BANDY 1956

25162 BANDY 1956

25163 PHLEGER $1951 \mathrm{~A}$

25165 PHLEGER 1951A

25166 PHLEGER 1951A

25167 PHLEGER 1951A

25168 PHLEGER 1951A

25169 PHLEGER 1951A

25170 PHLEGER 1951A

25171 PHLEGER 1951A

25172 PHLEGER 1951A

25173 PHLEGER 1951A

25174 PHLEGER $1951 \mathrm{~A}$

25175 PHLEGER 1951A

25176 PHLEGER 1951A

25177 PHLEGER $1951 \mathrm{~A}$

25178 DAVIS 1964

25179 PFLUM FRERICHS 1976

25180 PFLUM FRERICHS 1976

25181 CREAGER 1958

25182 CREAGER 1958

25183 CREAGER 1958

25184 NORTON 1930

25185 CUS HMAN 1931

25186 KELLOUGH 1956

25187 KELLOUGH 1956

25188 KELLOUGH 1956

25189 KELLOUGH 1956

25190 KELLOUGH 1956
Generic Name

Specific Name

SI GMOILOPS IS

SI GMOILOPS IS

SIGMOILOPSIS

SI GMOILOPS IS

SIGMOIL OPS I S

SI GMOILOPSIS

SI GMOILOPS IS

SI GMO IL OPSI

SI GMOILOPSIS

SIGMOILOPSIS

SIGMOILOPSIS

RECTOBOLIVINA

RECTOBOLIVINA

RECTOBOLIVINA

SI PHON INA

SI PHONINA

SI PHONINA

SI PHONI NA

SI PHON I NA

SIPHONINA

SI PHON INA

SI PHONINA

SI PHONINA

SIPHONINA

SIPHONINA

SI PHONINA

SIPHON I NA

SI PHONI NA

SI PHONINA

SI PHONINA

SIPHONINA

SI PHONINA

SI PHONINA

SI PHON IN A

SI PHON INA

SIPHONINA

SI PHONINA

SI PHONINA

SI PHONINA

SIPHON I NA

SI PHONINA

SI PHONINA

SIPHONINA

SI PHON INA

SI PHONINA

SIPHONINA

SI PHON INA

SI PHONINA

SI PHON I NA

SI PHONINA

SI PHONINA

SI PHONINA

SI PHONINA

SI PHONINA

SI PHON I NA

SIPHONINA

SI PHONINA

SIPHONINA

SI PHON I NA

SI PHON INA

SIPHONINA

SIPHONINA

SI PHON I NA

SI PHON INA

SI PHONINA

SI PHON I NA

SI PHON I NA

IPHON I NA

SIPHONINA

SI PHONINA

SI PHONINA

SI PHON I NA

SI PHON INA

SI PHONINA

SI PHONINA

SI PHON I NA

SIPHONINA

SI PHON INA

SI PHON I NA

SI PHON I NA

SI PHONINA

SI PHONINA

SI PHONINA

SIPHONINA

SIPHONINA

SIPHONINA

SI PHONINA

SIPHONINA

SIPHONINA

SI PHONINA

SI PHON INA

SI PHON INA

SI PHONINA

SI PHONINA
SC HLUMBERGERI

SCHLUMBERGERI

SCHLUMBERGERI

SCHLUMBERGERI

SC HLUMBER GERI

SC HLUMBERGERI

SC HLUMBERGERI

SC HLUMBERGERI

SC HLUMBERGERI

SC HLUMBER GERI

AD VENA

ADVENA

RAPHANUS

BRADYANA

BRADY ANA

BRADYANA

BRADYANA

BR ADY ANA

BR ADYANA

BRADYANA

BRADYANA

BRADYANA

BR ADYANA

BRADYANA

BRADYANA

BR ADYANA

BR ADYANA

BRADYANA

BR ADYANA

BRADYANA

BRADYANA

BRADYANA

BR ADYANA

BRADYANA

BRADYANA

BRADYANA

BRADYANA

BRADYANA

BR ADYANA

BRADYANA

BR ADY ANA

BR ADYANA

BR ADYANA

BRADYANA

BR ADYANA

BRADYANA

BRADYANA

BR ADYANA

BR ADY ANA

BRADYANA

BRADYANA

BRADYANA

BR ADYANA

BRADYANA

BRADYANA

BR ADYANA

BR ADYANA

BR ADY ANA

BR ADYANA

BR ADYANA

BR ADYANA

BR ADYANA

BR ADYANA

BRADYANA

BRADYANA

BRADYANA

BR ADYANA

BRADYANA

BRADYANA

BR ADYANA

BRADYANA

BRADYANA

BRADYANA

BR ADYANA

BR ADYANA

BR ADYANA

BR ADYANA

BR ADYANA

BR ADYANA

BR ADYANA

BR ADYANA

BRADYANA

PULCHRA

PULCHRA

PULCHRA

PULCHRA

PULCHRA

PULCHRA

ULCHRA

PULCHRA

PULCHRA

PULCHRA

Locality

CENTRAL GULF OF MEXICO CENTRAL GULF OF MEXICO CENTRAL GULF OF MEXICO CENTRAL GULF OF MEXICO CENTRAL GULF OF MEXICO CENTRAL GULF OF MEXICO 


\section{Publication}

25191 KELLOUGH 1956

25192 ANDERSEN 1961
25193 PFLUM FRERICHS 1976

25194 CREAGER 195

25195 LOEP 1965

25197 BOCK 1976

25198 PHLEGER 1951A

25199 PFLUM FRERICHS 1976

25200 PFLUM FRERICHS 1976

25201 PHLEGER 1951A

25202 PHLEGER 1951A

25203 PHLEGER 1951 A

25204 PHLEGER 1951A

25205 PHLEGER 1951A

25206 PHLEGER 1951A

25207 PHLEGER 1951A

25208 PHLEGER $1951 \mathrm{~A}$

25209 PARKER 1954

25210 LUDWICK WALTON 1957

25211 PARKER 1954

25212 PHLEGER 1951A

25213 PHLEGER 1951A

25214 PHLEGER 1951A

25215 PHLEGER 1951A

25216 PHLEGER 1951A

25217 PARKER 1954

25218 PARKER 1954

25219 PARKER 1954

25220 PARKER 1954

25221 PARKER 1954

25222 PHLEGER 1951 A

25223 PHLEGER 1951A

25224 PHLEGER 1951 A

25225 CUSHMAN 1922A

25226 PHLEGER 1951 A

25227 PARKER 1954

25228 CREAGER 1958

25229 PHLEGER 1951 A

25231 PFLUM FRERICHS 1976

25232 PFLUM FRERICHS 1976

25233 PFLUM FRERICHS 1976

25234 PHLEGER 1951 A

25235 PARKER 1954

25236 PARKER 1954

25237 PHLEGER 1956

25238 PHLEGER 1951A

25239 PHLEGER 1951 A

25240 PHLEGER 1955A

25241 PHLEGER 1951 A

25242 DAVIS 1964

25243 PHLEGER 1951A

25244 PARKER 1954

25245 PHLEGER 1951A

25246 PARKER 1954

25247 PARKER 1954
25248 PARKER 1954

25249 PARKER 1954

25250 PFLUM FRERICHS 1976

25251 PFLUM FRERICHS 1976

25252 PFLUM FRERICHS 1976

25253 ANDERSEN 1961

25254 CREAGER 1958

25255 PFLUM FRERICHS 1976

25256 PFLUM FRERICHS 1976

25257 PFLUM FRERICHS 1976

25258 PFLUM FRERICHS 1976

25259 PFLUM FRERICHS 1976

25260 ANDERSEN 1961

25261 PARKER 1954

25262 PFLUM FRERICHS 1976

25263 PFLUM FRERICHS 1976

25264 PARKER 1954

25265 PARKER 1954

25266 PARKER 1954

25267 LUDHICK WALTON 1957

25268 PARKER 1954

25269 PFLUM FRERICHS 1976

25270 PFLUM FRERICHS 1976

25271 PFLUM FRERICHS 1976

25272 PFLUM FRERICHS 1976

25273 PARKER 1954

25274 LEROY HODGKINSON 1975

25275 PARKER 195

25276 BANDY 1956

25277 PFLUM FRERICHS 1976

25278 PFLUM FRERICHS 1976

25279 PFLUM FRERICHS 1976

25280 PFLUM FRERICHS 1976

25281 PFLUM FRERICHS 1976

25282 PFLUM FRERICHS 1976

25283 PFLUM FRERICHS 1976

25284 PFLUM FRERICHS 1976

25285 PFLUM FRERICHS 1976
Generic Name

SIPHONINA

SI PHONINA

SI PHONINA

SI PHONINA

SI PHONINA

SI PHONINA

SIPHONINA

SI PHONINA

SI PHON INA

SI PHON INA

SI PHON INA

SI PHON I NA

SI PHONINA

SI PHONINA

SI PHONINA

SI PHONINA

SI PHONINA

SI PHONINA

SI PHON INA

SI PHONINA

SI PHON I NA

SI PHONINA

SI PHONINA

SI PHON INA

SI PHONINA

SI PHONINA

SI PHONINA

SI PHON INA

SI PHONINA

SI PHONINA

SIPHONINA

SI PHONINA

SI PHONINA

SI PHON INA

SIPHONINA

SI PHONINA

SI PHONINA

SI PHON INA

SI PHONINA

SIPHON I NA

SI PHONINA

SI PHONINA

SI PHONINA

SI PHON I NA

SI PHONINA

SI PHON I NA

SI PHONINA

SI PHONINA

SI PHONINA

SI PHONINA

SI PHON I NA

SI PHONINA

SI PHONINA

SI PHON INA

SI PHON I NA

SI PHON I NA

SI PHON I NA

SI PHON I NA

SI PHONINA

SIPHOTEXTULARIA

SIPHOTEXTULARIA

SIPHOTEXTULARIA

SIPHOTEXTULARIA

SI PHOTEXTUL ARIA

SIPHOTEXTULARIA

SIPHOTEXTULARIA

SIPHOTEXTULARIA

SIPHOTEXTULARIA

SIPHOTEXTULARIA

SIPHOTEXTULARIA

SIPHOTEXTULARIA

SIPHOTEX TULARIA

SIPHOTEXTULARIA

SI PHOTEXTULARIA

SI PHOTEXTULARIA

SI PHOTEXTULARIA

SI PHOTEXTULARIA

SI PHOTEXTULARIA

SIPHOTEXTULARIA

SI PHOTEXTULARIA

SI PHOTEXTULARIA

SIPHOTEXTULARIA

SIPHOTEXTULARIA

SI PHOTEX TULARIA

SI PHOTEXTULARIA

SI PHOTEXTULAR IA

SIPHOTEXTULAR IA

SI PHOTEXTUL AR IA

SI PHOTEXTULAR IA

SIPHOTEXTULARIA

SI PHOTEXTULARIA

SI PHOTEXTULARIA

SIPHOTEXTULARIA

SI PHOT EXTULAR IA

SIPHOTEXTULAR IA

SI PHOTEXTULAR IA
Specific Name

PULCHRA

PULCHRA

PULCHRA

PULCHRA

PULCHRA

PULCHRA

PULCHRA

PULCHRA

PULCHRA

PULCHRA

PULCHRA

PULCHRA

PULCHRA

PULCHRA

PULCHRA

PULCHRA

PULCHRA

PULCHRA

PULCHRA

PULCHRA

PULCHRA

PULCHRA

PULCHRA

PULCHRA

PULCHRA

PULCHRA

PULCHRA

PULCHRA

PULCHRA

PULCHRA

PULCHRA

PULCHRA
PULCHRA

PULCHRA

PULCHRA

PULCHRA

PULCHRA

PULCHRA

PULCHRA

PULCHRA

PULCHRA

PULCHRA

PULCHRA

PULCHRA

PULCHRA

PULCHRA

PULCHRA

PULCHRA

PULCHRA

PULCHRA

PULCHRA

PULCHRA

PULCHRA

AFFINIS

AFFINIS

AFFINIS

AFFINIS

AFFINIS

AFFINIS

AFFINIS

AFFINIS

AFFIN IS

AFFINIS

CONCAV

CURTA

UURTA

CURTA

CURTA

CURTA

CURTA

CURTA

CURTA

CURTA

CURTA

CURTA

CURTA

CURTA

CURTA

CURTA

OL IANAENS IS

ROLSHAUSENI

ROLSHAUSENI

ROLSHAUSENI

ROLSHAUSEN I

ROLSHAUSENI

ROLSHAUSEN I

ROLSHAUSENI

ROLSHAUSENI

ROLSHAUSENI

Locality

Lat. Long.

NW GULF OF MEXICO MISSISSIPPI DELTA NH GULF OF MEXICO BAY OF CAMPECHE

NH GULF OF MEXICO NW GULF OF MEXICO NE GULF OF MEXICO 


\section{Publication}

25286 PFLUM FRERICHS 1976 25287 PFLUM FRERICHS 1976 25288 PFLUM FRERICHS 1976 25289 PFLUM FRERICHS 1976 25290 PFLUM FRERICHS 1976 25291 PFLUM FRERICHS 1976 25292 PFLUM FRERICHS 1976 25293 PFLUM FRERICHS 1976 25294 PARKER 1954

25295 PARKER 1954

25296 PARKER 1954

25297 PARKER 1954

25298 PHLEGER 1955 A

25299 PFLUM FRERICHS 1976

25300 PFLUM FRERICHS 1976

25301 PFLUM FRERICHS 1976

25302 PHLEGER 1955 A

25303 PFLUM FRERICHS 1976

25304 PFLUM FRERICHS 1976

25305 PFLUM FRERICHS 1976

25306 PFLUM FRERICHS 1976

25307 PFLUM FRERI

25308 PARKER 1954

25309 PARKER 1954

25310 PARKER 1954

25311 PARKER 1954

25312 PARKER 1954

25313 CREAGER 1958

25314 BOCK 1976

25315 PARKER 1954

25316 PARKER 1954

25317 PFLUM FRERICHS 1976

25318 PFLUM FRERICHS 1976

25319 ANDERSEN 1961

25320 PFLUM FRERICHS 1976

25321 PFLUM FRERICHS 1976

25322 PFLUM FRERICHS 1976

25323 PFLUM FRERICHS 1976

25324 PFLUM FRERICHS 1976

25325 PFLUM FRERICHS 1976

25326 PFLUM FRERICHS 1976

25327 PFLUM FRERICHS 1976

25328 PFLUM FRERICHS 1976

25329 PFLUM FRERICHS 1976

25330 PFLUM FRERICHS 1976

25331 PFLUM FRERICHS 1976

25332 PFLUM FRERICHS 1976

25333 PFLUM FRERICHS 1976

25334 PFLUM FRERICHS 1976

25335 PFLUM FRERICHS 1976

25336 PFLUM FRERICHS 1976

25337 PFLUM FRERICHS 1976

25338 PFLUM FRERICHS 1976

25339 PFLUM FRERICHS 1976

25340 PFLUM FRERICHS 1976

25341 PFLUM FRERICHS 1976

25342 PFLUM FRERICHS 1976

25343 BOCK 1976

25344 NORTON 1930

25345 CUSHMAN 1930

25346 BANDY 1956

25347 BANDY 1956

25348 BANDY 1956

25350 BANDY 1956

25350 BANDY 1956
25351 BANDY 1956

25352 BANDY 1956

25353 BANDY 1956

25354 BANDY 1956

25355 BANDY 1956

25356 BANDY 1956

25357 BANDY 1956

25358 BANDY 1956

25359 BANDY 1956

25360 BANDY 1956

25361 BANDY 1956

25362 BANDY 1956

25363 BANDY 1956

25364 BANDY 1956

25365 BANDY 1956

25366 BANDY 1956

25367 BANDY 1956
25368 BANDY 1956

25369 CREAGER 1958

25370 CREAGER 1958

25371 PFLUM FRERICHS 1976

25372 CREAGER 1958

25373 CREAGER 1958
25374 CREAGER 1958

$\begin{array}{lll}25374 & \text { CREAGER } & 1958 \\ 25375 & \text { CREAGER } & 1958\end{array}$

25376 CREAGER 1958

25377 CREAGER 1958

25378 CREAGER 1958

25379 PARKER 1954

25380 PARKER 1954
Generic Name

SI PHOTEXTUL AR IA SI PHOTEXTULARIA

SI PHOTE X TULAR IA

SI PHOTEX TULARIA

SI PHOTEXTULAR IA

SI PHOTEXTULARIA

SIPHOTEXTULARIA

SI PHOTEXTULARIA

SI PHOTEXTULAR IA

SIPHOTEXTULAR IA

SIPHOTEXTULARIA

SI PHOTEXTULAR IA

SIPHOTEXTULARIA

SI PHOTEXTULARIA

SI PHOTEXTUL AR IA

SIPHOTEXTULARIA

SI PHOTEXTULAR IA

SI PHOTEXTULAR IA

SIPHOTEXTULARIA

SI PHOTEXTULARIA

SI PHOTEXTULAR IA

SI PHOTEXTULARIA

SI PHOTEX TULARIA

SI PHOTEXTULAR IA

SI PHOTEXTULAR IA

SI PHOTEXTULARIA

SI PHOTEXTULAR IA

SIPHOTEXTULARIA

SI PHOTEXTULARIA

SIPHOTE X TUL AR IA

SI PHOTEXTULAR IA

SIPHOTEXTULARIA

SI PHOTEXTULARIA

SI PHOTEX TUL ARIA

SI PHOTROCHAMMINA

SI PHOTR OCHAMMINA

SI PHOTR OCHAMMINA

SI PHOTR OCHAMMINA

SI PHOTR OCHAMM INA

SI PHOTR OCHAMMINA

SI PHOTROCHAMMINA

SI PHOTR OCH AMMINA

SI PHOTROCHAMMINA

SI PHOTR OCHAMMINA

SI PHOTR OCHAMMINA

SI PHOTROCHAMMINA

SI PHOTROCHAMMINA

SI PHOTR OCHAMMINA

SI PHOTROCHAMMINA

SI PHOTR OCHAMM INA

SI PHOTR OCHAMMINA

SI PHOTROCHAMMINA

SI PHOTR OCHAMM INA

S I PHOTR OCHAMM INA

SI PHOTR OCHAMM INA

SI PHOTR OCHAMM INA

SI PHOTR OCHAMMINA

SORITES

SORITES

SORITES

SORITES

SORITES

SORITES

SORITES

SORITES

SORITES

SORITES

SORITES

SORITES

SORITES

SORITES

SORITES

SORITES

SORITES

SORITES

SORITES

SORITES

SORITES

SORITES

SORITES

SORITES

SORITES

SORITES

SPHAEROIDINA

SPHAEROIDINA

SPHAEROIDINA

SPHAEROIDINA

SPHAEROIDINA

SPHAEROIDINA

SPHAEROIDINA

SPHAEROIDINA

SPHAEROIDINA

SPHAEROIDINA

SPHAEROIDINA

SPHAEROIDINA
Specific Name

Locality

Lat. Long.

ROLSHAUSEN

ROLSHAUSEN.

ROLSHAUSENI

ROLSHAUSENI

ROLSHAUSENI

ROLSHAUSENI

ROLSHAUSENI

ROLSHAUSENI

ROLSHAUSENI

ROLSHAUSENI

ROLSHAUSENI

ROLSHAUSENI

ROLSHAUSENI

ROLSHAUSENI

ROLSHAUSENI

ROLSHAUSENI

ROLSHAUSENI

ROLSHAUSENI

ROLSHAUSEN

ROLSHAUSENI

ROLSHAUSENI

ROLSHAUSENI

ROLSHAUSENI

ROLSHAUSENI

ROLSHAUSENI

ROLSHAUSENI

ROLSHAUSENI

ROESHAUSENI

ROLSHAUSENI

ROLSHAUSENI

ROLSHAUSENI

SALLCYANA

SQLAMATA

SQLAMATA

SQLAMATA

SQUAMATA

SQLAMATA

SQLAMATA

SQLAMATA

SQLAMATA

SQLAMATA

SQLAMATA

SQUAMATA

SQUAMATA

SQLAMATA

SQLAMATA

SQLAMATA

SQUAMATA

SQLAMATA

SQLAMATA

SQLAMATA

SQLAMATA

SQLAMATA

SQLAMATA

SQLAMATA

HOFKER I

MARGINALIS

MARG INAL IS

OREITOLITOIDES

OREITOLITOIDES

ORE I TOL ITOIDES

OREITOLITOIDES

OREITOLITOIDES

OREITOLITOIDES

OREITOLITOI DES

ORBITOLITOIDES

OREITOLITOIDES

OREITOLITOIDES

ORBITOLITOIDES

OREITOLIT

OREITOLITOIDES

OREITOLITOIDES

OREITOLITOIDES

OREITOLITOIDES

OREITOLITOIDES

OREITTOLITOIDES

OREITOLITOIDES

OREITOLITOIDES

OREITOLITOIDES

ORBITOLITOIDES

OREITOLITOIDES

BULLOIDES

BULLOIDES

BULLOIDES

BULLOIDES

BULLOIDES

OULLOIDES

BULLOIDES

GULLOIDES

BULLOIDES

BULLOIDES

BULLOIDES

BULLOIDES

NW GULF OF MEXICO 


\section{Publication}

25381 PARKER 1954 25382 PARKER 1954 25383 PARKER 1954

25384 PFLUM FRERICHS 1976 25385 PFLUM FRERICHS 1976 25386 PFLUM FRERICHS 1976 25387 PFLUM FRERICHS 1976 25388 PFLUM FRERICHS 1976 25389 PFLUM FRERICHS 1976 25390 PFLUM FRERICHS 1976 25391 PFLUM FRERICHS 1976 25392 PFLUM FRERICHS 1976 25393. PFLUM FRERICHS 1976 25394 PFLUM FRERICHS 1976 25395 PFLUM FRERICHS 1976 25396 PFLUM FRERICHS 1976 25397 PFLUM FRERICHS 1976 25398 PFLUM FRERICHS 1976 25399 PFLUM FRERICHS 1976 25400 PHLEGER 1955A

25401 LUDWICK WALTON 1957 25402 PHLEGER 1955 A

25403 PARKER 1054

25404 PARKER 1954

25405 PARKER 1954

25406 PHLEGER 1955 A

25407 PFLUM FRERICHS 1976 25408 PFLUM FRERICHS 1976 25409 PFLUM FRERICHS 1976 25410 PFLUM FRERICHS 1976 25411 PFLUM FRERICHS 1976 25412 PFLUM FRERICHS 1976 25413 PFLUM FRERICHS 1976 25414 PFLUM FRERICHS 1976 25415 PFLUM FRERICHS 1976 25416 PARKER 1954 25417 PARKER 1954 25418 PARKER 1954 25419 PARKER 1954 $\begin{array}{lll}25420 & \text { CREAGER } & 1958 \\ 25421 & \text { CREAGER } & 1958\end{array}$ $\begin{array}{lll}25421 & \text { CREAGER } & 1958 \\ 25422 & \text { CREAGER } & 1958\end{array}$

25423 PFLUM FRERICHS 1976 25424 PFLUM FRERICHS 1976 25425 PFLUM FRERICHS 1976 25426 PFLUM FRERICHS 1976 25427 PFLUM FRERICHS 1976 25428 PFLUM FRERICHS 1976 25429 PFLUM FRERICHS 1976 25430 PFLUM FRERICHS 1976 25431 PFLUM FRERICHS 1976 25432 PFLUM FRERICHS 1976 25433 PFLUM FRERICHS 1976 25434 PFLUM FRERICHS 1976 25435 PFLUM FRERICHS 1976 25436 PFLUM FRERICHS 1976 25437 PFLUM FRERICHS 1976 25438 PFLUM FRERICHS 1976 25439 PFLUM FRERICHS 1976 25440 PFLUM FRERICHS 1976 25441 PFLUM FRERICHS 1976 25442 PFLUM FRERICHS 1976 25443 PFLUM FRERICHS 1976 25444 PARKER 1954

25445 PFLUM FRERICHS 1976 25446 PFLUM FRERICHS 1976 25447 PFLUM FRERICHS 1976 25448 PFLUM FRERICHS 1976 25449 PFLUM FRERICHS 1976 25450 PFLUM FRERICHS 1976 25451 PFLUM FRERICHS 1976 25452 DFLUM FRERICHS 1976 25453 PFLUM FRERICHS 1976 25454 PFLUM FRERICHS 1976 25455 PFLUM FRERICHS 1976 25456 PFLUM FRERICHS 1976 25457 CREAGER 1958 25458 CREAGER 1958 25459 CREAGER 1958 25460 CREAGER 1958 25461 LOEP 1965 25462 LOEP 1965 25463 ANDERSEN 1961 25464 PFLUM FRERICHS 1976 25465 CREAGER 1958 25466 PARKER 1954 25467 PHLEGER 1956 25468 PARKER 1954 25469 PARKER 1954 25470 PARKER 1954 25471 PARKER 1954 25472 PARKER 1954

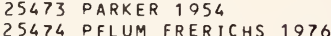
25475 PFLUM FRERICHS 1976

\section{Generic Name}

SPHAEROIDINA SPHAEROI DINA SPHAEROIDINA SPHAEROIDINA SPHAEROIDINA SPHAEROIDINA SPHAEROIDINA SPHAEROIDINA SPHAEROIDINA SPHAEROI DINA SPHAEROIDINA SPHAEROIDINA SPHAEROIDINA SPHAEROIDINA SPHAEROIDINA SPHAEROIDINA SPHAEROIDINA SPHAEROIDINA SPHAEROIDINA SPHAEROIDINA SPHAEROIDINA SPHAEROI DINA SPHAEROIDINA SPHAEROIDINA SPHAEROIDINA SPHAEROI DINA SPHAEROIDINA SPHAEROIDINA SPHAEROIDINA SPHAEROIDINA SPHAEROIDINA SPHAEROIDINA SPHAEROIDINA SPHAEROIDINA SPHAEROIDINA SPHAEROIDINA SPHAEROIDINA SPHAEROIDINA SPHAER OI DINA SPHAEROIDINA SPHAEROI DINA SPHAEROIDINA SPHAEROIDINA SPHAEROIDINA SPHAEROIDINA SPHAEROIDINA SPHAEROIDINA SPHAEROIDINA SPHAEROIDINA SPHAEROIDINA SPHAEROI DINA SPHAEROIDINA SPHAEROIDINA SPHAEROIDINA SPHAEROIDINA SPHAEROIDINA SPHAEROIDINA SPHAEROIDINA SPHAER OIDINA SPHAEROIDINA SPHAEROIDINA SPHAEROIDINA SPHAEROIDINA SPHAEROIDINA SPHAEROI DINA SPHAEROI DINA SPHAER OIDINA SPHAEROIDINA SPHAEROIDINA SPHAEROIDINA SPHAEROIDINA SPHAEROIDINA SPHAEROIDINA SPHAEROIDINA SPHAEROI DINA SPHAEROI DINA SPHAEROI DINA SPHAEROIDINA SPHAEROIDINA SPHAEROIDINA SPHAEROIDINA SPHAEROIDINA SPHAEROIDINA SPHAEROIDINA SPHAEROIDINA SPHAEROIDINA SPHAEROIDINA SPHAEROIDINA SPHAER OI DINA SPHAEROIDINA SPHAEROIDINA SPHAEROIDINA SPHAER OIDINA SPHAEROIDINA SPHAEROIDINA

\section{Specific Name}

BULLOIDES

BULLOIDES

BULLOIDES

BULLOIDES

BULLOIDES

BULLOIDES

BULLOIDES

BULLOIDES

BULLOIDES

BULLOIDES

BULLOIDES

BULLOIDES

BULLOIDES

BULLOIDES

BULLOIDES

BULLOIDES

BULLOIDES

BULLOIDES

BULLOIDES

BULLOIDES

BULLOIDES

BULLOIDES

BULLOIDES

BULLOIDES

BULLOIDES

BULLOIDES

BULLOIDES

BULLOIDES

BULLOIDES

BULLOIDES

BULLOIDES

BULLOIDES

BULLOIDES

BULLOIDES

BULLOIDES

BULLOIDES

BULLOIDES

BULLOIDES

BULLOIDES

BULLOIDES

BULLOIDES

BULLOIDES

BULLOIDES

ULLOIDES

BULLOIDES

BULLOIDES

BULLOIDES

BULLOIDES

BULLOIDES

BULLOIDES

BULLOIDES

BULLOIDES

BULLOIDES

BULLOIDES

BULLOIDES

BULLOIDES

BULLOIDES

BULLOIDES

BULLOIDES

BULLOIDES

BULLOIDES

BULLOIDES

BULLOIDES

BULLOIDES

BULLOIDES

BULLOIDES

BULLOIDES

BULLOIDES

BULLOIDES

BULLOIDES

ULLOIDES

BULLOIDES

BULLOIDES

BULLOIDES

BULLOIDES

BULLOIDES

BULLOIDES

BULLOIDES

BULLOIDES

BULLOIDES

BULLOIDES

BULLOIDES

BULLOIDES

BULLOIDES

BULLOIDES

BULLOIDES

BULLOIDES

BULLOIDES

BULLOIDES

BULLOIDES

BULLOIDES

BULLOIDES

BULLOIDES

BULLOIDES
BULLOIDES

\section{Locality}


Publication

25476 PFLUM FRERICHS 1976 25477 PFLUM FRERICHS 1976 25478 PFLUM FRERICHS 1976 25479 PFLUM FRERICHS 1976 25480 CREAGER 1958

25481 PARKER 1954

25482 PARKER 1954

25483 PARKER 1954

25484 PARKER 1954

25485 PARKER 1954

25486 PARKER 1954

25487 PARKER 1954

25488 PARKER 1954

25489 PARKER 1954

25490 CREAGER 1958
25491 SHIFFLETT 1961

25491 SHIFFLETT
25492 BOCK 1976

25493 BOCK 1976

25494 BOCK 1976

25495 KORNFELD 1931

25496 DAVIS 1964

25497 BOCK 1976

25498 PARKER 1954

25499 PARKER 1954

25500 PARKER 1954

25501 PARKER 1954

25502 PARKER 1954

25503 PFLUM FRERICHS 1976

25504 LUDHICK WALTON 1957

25505 PARKER 1954

25506 PARKER 1954

25507 CUSHMAN 1922A

25508 PARKER 1954

25509 PARKER 1954

25510 ANDERSEN 1969

25511 HALTON 1964

25512 AYALA-CASTANARES 1963

25513 LEHMANN 1957

25514 CUSHMAN 1931

25515 PFLUM FRERICHS 1976

25516 NORTON 1930

25517 PARKER 1954

25518 PARKER 1954

25519 DAVIS 1964

25520 CUSHMAN 1930

25522 NORTON 1930

25523 CUSHMAN $1922 \mathrm{~A}$

25524 KELLOUGH 1956

25525 KELLOUGH 1956

25526 ANDERSEN 1961

25527 PFLUM FRERICHS 1976

25528 AYALA-CASTANARES 1963

25529 KELLOUGH 1956

25530 NORTON 1930

25531 LANKFORD 1959

25532 NORTON 1930

25533 BOCK 1976

25534 CUSHMAN $1922 A$

25535 VAUGHAN 1918

25536 BOCK 1976

25537 CUSHMAN $1922 \mathrm{~A}$

25538 NORTON 1930

25539 CUSHMAN $1922 \mathrm{~A}$

25540 NORTON 1930

25541 ANDERSEN 1961

25542 ANDERSEN 1961

$\begin{array}{ll}25543 & \text { BENDA PURI } 1962 \\ 25544 & \text { BENDA PURI } 1962\end{array}$

25545 AYALA-CASTANARES 1963

25546 BANDY 1956

25547 SANDY 1956

25548 BANDY 1956

25549 BANDY 1956

25550 BANDY 1956

25551 BANDY 1956

25552 BANDY 1956

25553 BANDY 1956

25554 BANDY 1956

25555 DAVIS 1964

25556 BANDY 1956

25557 BANDY 1956

25558 BENDA PURI 1962

25559 BENDA PURI 1962

25560 CUSHMAN $1922 \mathrm{~A}$

25561 PARKER 1954

25562 PARKER 1954

25563 PARKER 1954

25564 PARKER 1954

25565 PARKER 1954

25566 PARKER 1954

25567 VAUGHAN 1918

25568 WALTON 1960

25569 LUDWICK WALTON 1957

25570 PARKER 1954
Generic Name

SPHAEROIDINA

SPHAEROIDINA

SPHAEROIDINA

SPHAEROI DINA

SPHAEROI DINA

SPHAEROIDINA

SPHAEROIDINA

SPHAEROIDINA

SPHAEROIDINA

SPHAEROI DINA

SPHAEROI DINA

SPHAEROIDINA

SPHAEROI IINA

SPIR ILLINA

SPIRILLINA

SPIRILLINA

SPIRILLINA

SPIRILLINA

SPIR ILL I NA

SPIRILLINA

SPIRILLINA

SPIRILLINA

SPIRILLINA

SPIR I LL I NA

SPIRILLINA

SPIRILLINA

SP IR ILL INA

SPIRILLINA

SPIRILL INA

SPIRILLINA

SPIRILL INA

SP IR I LL I NA

SPIR I LL INA

SPIRILLINA

SPIRILLINA

SPIRILLINA

SPIRILLINA

SPIRILL INA

SPIRILLINA

SPIRILLINA

SPIR ILLINA

SPIRILLINA

SPIROLINA

SPIROLINA

SPIROLINA

SPIROLINA

SPIROLOCUL INA

SPIROL OCUL I NA

SPIROLOCULINA

SPIROLOCULINA

SPIROLOCUL INA

SP IROL OCUL INA

SPIROLOCUL INA

SPIROLOCULINA

SPIROL OCUL INA

SPIROLOCUL INA

SP I RO: OCUL INA

SPIROLOCULI NA

SPIROLOCUL INA

SPIROL OCUL INA

SPIROL OCULINA

SPIROL OCULINA

SPIROLOCULINA

SPIROLOCUL INA

SPIROLOCULINA

SPIROL OCULINA

SPIROLOCULINA

SPIROLOCULINA

SPIROL OCUL INA

SPIROLOCUL INA

SPIROL OCULINA

SPIROL OCUL INA

SPIROLOCULINA

SPIROLOCULINA

SP IROLOCUL INA

SPIROLOCULINA

SPIROLOCUL INA

SPIROLOCULINA

SPIROLOCULINA

SPIROL OCUL INA

SPIROL OCUL INA

SPIROLOCUL INA

SPIROLOCULINA

SPIROLOCUL INA

SPIROLOCUL INA

SPIROLOCULINA

SPIROL OCULINA

SPIROLOCUL INA

SPIROL OC ULI INA

SPIROL OCUL INA

SPIROL OCULI INA

SPIROL OCUL IN

SPIROLOCULINA
Specific Name

Locality

Lat. Long.

BULLOIDES

BULLOIDES

BULLOIDES

BULLOIDES

BULLOIDES

COMPACTA

COMPACTA

COMPACTA

CONPACTA

CONPACTA

CONPACTA

CONPACTA

CONPACTA

CONPACTA

DE CORATA

DE CORATA

DE CORATA

DENTI CULATA

ORAATA

VIVIPARA

VI VIPARA

VI VIPARA

VIVIPARA

VI VIPARA

VIVIPARA

VI VIPARA

VI VIPARA

VIVIPARA

VIVIPARA

VIVIPARA

VIVIPARA

VIVIPARA

VIVIPARA

VI VIPARA

VIVIPARA

VIVIPARA

VIVIPARA

VI VIPARA

VIVIPARA

VI VIPARA

VI VIPARA

AR IET INA

AR IETINA

AR IETINA

CYLINDRACEA

AN TILLARUM

AN TILLARUM

AN TILLARUM

AN TILLARUM

ANTILLARUM

AN TILLARUM

AN TILLARUM

ANTILLA RUM

ANTILLARUM ANGULATA

ANTILLARUM ANGULATA

ANTILLARUM ANGULATA

ARENARI A

ARENATA

ARENATA

AR ENATA

CADUCA

CADUCA

DENTATA

DEATATA

DENTATA

DENTATA

DENTATA

DEPRESSA

DEPRESSA

DEFRESSA

DEPRESSA

DEPRESSA

DEPRESSA

DEPRESSA

DEPRESSA

DEPRESSA

DEPRESSA

DEFRESSA

DEPRESSA

DEPRESSA

DEPRESSA

EXIMIA

GRATA

GRATA

GRATA

GR ATA

GRATA

GRATA

GRATA

GR ATA

GR ATA

CENTRAL GULF OF MEXICO

CENTRAL GULF OF MEXICO

CENTRAL GULF OF MEXICO

CENTRAL GULF OF MEXICO

BAY OF CAMPECHE 
Publication

25571 PARKER 1954

25572 BOCK 1976

25573 PARKER 1954

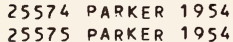

25576 CUSHMAN 1922 A

25577 NORTON 1930

25578 POST 1951

25579 LEHMANN 1957

25580 CUSHMAN $1922 \mathrm{~A}$
25581 NORTON 1930

25582 CUSHMAN 1922 A

25583 NORTON 1930

25584 PARKER 1954

25585 PARKER 195
25586 BOCK 1976

25587 LUDWICK WALTON 1957

25588 PARKER 1954

25589 PARKER 1954

25590 PARKER 1954

25591 PARKER 1954

25592 PARKER 1954

25593 PARKER 1954

25594 PARKER 1954

25595 PARKER 1954

25596 PARKER 1954

25598 PARKER 1954

25598 PARKER 1954

25600 BANDY 1956

25601 PARKER 1954

25602 PARKER 1954

25603 PARKER 1954

25604 LUDWICK HALTON 1957

25605 PARKER 1954

25606 PARKER 1954

25607 PHLEGER 1951 A

25608 PARKER 1954

25610 PARKER 1954

25611 BOCK 1976

25612 CREAGER 1958

25613 BANDY 1956

25614 BANDY 1956

25615 BANDY 1956

25616 BANDY 1956

25617 BANDY 1956

25618 BANDY 1956

25619 NORTON 1930

25620 PFLUM FRERICHS 1976 25621 PFLUM FRERICHS 1976 25622 PFLUM FRERICHS 1976 25623 PFLUM FRERICHS 1976 25624 PFLUM FRERICHS 1976 25625 PFLUM FRERICHS 1976 25625 PFLUM FRERICHS 1976 25627 PFLUM FRERICHS 1976 25628 PFLUM FRERICHS 1976 25629 PFLUM FRERICHS 1976 25630 PFLUM FRERICHS 1976 25631 PFLUM FRERICHS 1976 25632 PFLUM FRERICHS 1976 25633 PFLUM FRERICHS 1976 25634 PFLUM FRERICHS 1976 25635 PFLUM FRERICHS 1976 25636 PFLUM FRERICHS 1976 25637 PFLUM FRERICHS 1976 25638 PFLUM FRERICHS 1976 25630 PFLUM FRERICHS 1976 25640 PFLUM FRERICHS 1976 25641 PFLUM FRERICHS 1976 25642 PFLUM FRERICHS 1976 25644 PFLUM FRERICHS 1976 25645 PFLUM FRERICHS 1976 25645 PFLUM FRERICHS 1976
25646 PFLUM FRERICHS 1976 25647 PFLUM FRERICHS 1976 25648 PFLUM FRERICHS 1976 25649 PFLUM FRERICHS 1976 25650 PFLUM FRERICHS 1976 25651 PFLUM FRERICHS 1976 25652 PFLUM FRERICHS 1976 25653 PFLUM FRERICHS 1976 25654 PFLUM FRERICHS 1976 25655 PFLUM FRERICHS 1976 25656 PFLUM FRERICHS 1976 25657 PFLUM FRERICHS 1976 25658 PFLUM FRERICHS 1976 25659 PFLUM FRERICHS 1976 25660 PFLUM FRERICHS 1976 25661 PFLUM FRERICHS 1976 25662 PFLUM FRERICHS 1976 25663 PFLUM FRERICHS 1976 25664 PFLUM FRERICHS 1976 25665 PFLUM FRERICHS 1976
Generic Name

SPIROLOCULINA

SPIROL OCUL INA

SPIROL OCUL INA

SPIROL OCUL INA

SP I ROL OCUL INA

SPIROL OCUL INA

SPIROL OCUL INA

SPIROL OCUL INA

SPIROLOCULINA

SPIROL OCUL INA

SPIROL OCUL INA

SPIROLOCUL INA

SPIROL OCUL INA

SPIROL OCUL INA

SPIROL OCULINA

SPIROL OCUL INA

SPIROL OCUL INA

SPIROL OCULINA

SPIROL OCUL INA

SP IROL OCUL INA

SP IROL OCUL INA

SPIROL OCUL INA

SPIROL OCUL INA

SPIROLOCUL INA

SPIROL OCUL INA

SPIROLOCUL INA

SPIROL OCUL INA

SPIROL OC ULINA

SPIROPLECTAMMINA

SPIROPL ECTAMM INA

SPIROPLECTAMMINA

SPIROPLE CTAMMINA

SPIROPLECTAMMINA

SPIROPL ECTAMMINA

SPIROPLECTAMMINA

SPIROPLECTAMMINA

SPIROPL ECTAMMINA

SPIROPLECT AMMINA

SPIROPLECTAMMINA

SPIROPLECTAMMINA

SPIROPLECTAMMINA

SPIROPL ECTAMMINA

SPIROPLECTAMMINA

SPIROPLECTAMMINA

SPIROPL ECTAMMINA

SPIROPLECTAMMINA

SPIROPLECTAMMINA

SPIROPLECTAMMINA

SPIROPLECTAMMINA

SPIROSIGMOILINA

SPIROSI I MOILINA

SP IROS I GMO ILINA

SPIROSIGMOIL INA

SPIROSIGMOILINA

SPIROSIGMOILINA

SPIROSIGMOILINA

SPIROSIGMOILINA

SPIROS I GMO IL INA

SPIROSIGMOIL INA

SPIROSIGMOIL INA

SPIROSI GMOILINA

SPIROSI GMOIL INA

SPIROS I GMO IL INA

SPIROS I GMOIL INA

SP IROS I GMOIL INA

SPIROSIGMOILINA

SPIROSIGMOIL INA

SPIROSIGMOILINA

SPIROSIGMOILINA

SPIROS I GMOILINA

SPIROS I GMOIL I NA

SPIROSIGMOIL INA

SPIROS IGMOILINA

SPIROSI GMOIL INA

SPIROSIGMOIL INA

SPIROS IGMO IL INA

SPIROSI GMOILINA

SPIROS I GMOIL INA

SP IR OS I GMOIL INA

SPIROSIGMOIL INA

SPIROSI GMOILINA

SPIR OS IGMOILINA

SPIROSIGMOILI INA

SPIROSI GMOIL INA

SPIROS I GMOIL INA

SPIROS I GMOIL INA

SPIROS I GMO I I INA

SP I ROS I GMO IL INA

SPIROS IGMOIL INA

SPIROSIGMOILINA

SPIROS I GMOIL INA

SPIROSIGMOILINA

SPIROSIGMOIL INA

SPIROSI GMOIL INA

SPIROS IGMOILINA
Specific Name

GRATA

GR ATA

GRATA

GRATA

GRATELOUP I

GRATELOUPI

MANIFESTA

MANIFES

ORAATA

ORAATA

PL ANULATA

PL ANULATA

SOLDANI

SOLDANII

SOLDANII

SOLDANII

SOLDANII

SOLDANII

SOLDANII

SOLDANII

SOLDANII

SOLDANII

SOLDANII

SOLDANI I

SOLDANI

SOLDANI I

FLCRIDANA

FL ORI DANA

FLCRIDANA

FL ORI DANA

FL ORI DANA

FL CR IDANA

FLCRI DANA

FL OR IDANA

FL OR I DANA

FL OR I DANA

FL ORIDANA

FL CRIDANA

FL ORI DANA

FL OR IDANA

FL OR I DANA

FL ORI DANA

FL ORIDANA

FL CRI DANA

WR IGHTI

DI STORTA

DISTORTA

DI STORTA

DI STORTA

DI STORTA

DI STORTA

DISTORTA

DI STORTA

DISTORTA

DISTORTA

DISTORTA

DI STORTA

DISTORTA

DI STORTA

DI STORTA

DISTORTA

DISTORTA

STORTA

DI STORTA

DISTORTA

DISTORTA

DISTORTA

DI STORTA

DI STORTA

DISTORTA

DISTORTA

DISTORTA

DI STORTA

DI STORTA

DI STORTA

DISTORTA

DI STORTA

DI STORTA

DI STORTA

DI STORTA

DI STORTA

DISTORTA

DI STORTA

DI STORTA

DI STORTA

DI STORTA

DISTORTA

DI STORTA

Locality

NE GULF OF MEXICO

NE GULF OF MEXICO

NE GULF OF MEXICO

NE GULF OF MEXICO

NE GULF OF MEXICO

TORTUGAS

TORTUGAS, FLA

SOUTH TEXAS COAST

TEXAS GULF COAST

TORTUGAS

TORTUGAS, FLA

TORTUGAS

TORTUGAS, FLA

NE GULF OF MEXICO 
Publication

25666 PFLUM FRERICHS 1976 25667 PFLUM FRERICHS 1976 25668 PFLUM FRERICHS 1976 25669 PFLUM FRERICHS 1976 25670 PFLUM FRERICHS 1976 25671 PFLUM FRERICHS 1976 25672 PFLUM FRERICHS 1976 25673 PFLUM FRERICHS 1976 25674 PFLUM FRERICHS 1976 25675 PFLUM FRERICHS 1976 25676 PFLUM FRERICHS 1976 25677 PFLUM FRERICHS 1976 25678 PFLUM FRERICHS 1976 25679 PFLUM FRERICHS 1976 25680 PFLUM FRERICHS 1976 25681 PFLUM FRERICHS 1976 25682 PFLUM FRERICHS 1976 25683 PFLUM FRERICHS 1976 25684 PFLUM FRERICHS 1976 25685 PFLUM FRERICHS 1976 25686 PFLUM FRERICHS 1976 25687 PFLUM FRERICHS 1976 25688 PFLUM FRERICHS 1976 25689 PFLUM FRERICHS 1976 25690 PFLUM FRERICHS 1976 25691 PFLUM FRERICHS 1976 25692 PFLUM FRERICHS 1976 25693 PFLUM FRERICHS 1976 25694 PFLUM FRERICHS 1976 25695 PFLUM FRERICHS 1976 25696 PFLUM FRERICHS 1976 25697 PFLUM FRERICHS 1976 25698 PFLUM FRERICHS 1976 25699 PFLUM FRERICHS 1976 25700 PFLUM FRERICHS 1976 25701 PFLUM FRERICHS 1976 25702 PFLUM FRERICHS 1976 25703 PFLUM FRERICHS 1976 25704 PHLEGER 1956

25705 PARKER 1954

25706 PARKER 1954

25707 PARKER 1954

25708 PARKER 1954

25709 PHLEGER 1956

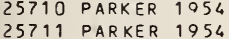

25712 PARKER 1954

25713 PARKEQ 1954

25714 PHLEGER 1956

25715 PARKER 1954

25716 PARKER 1954

25717 PARKER 1954

25718 PHLEGER 1956

25719 PARKER 1054

25720 PARKER 1954

25722 PARKER 1954

25723 PARKER 1954

25724 PARKER 1954

25725 PARKER 1954

25726 PARKER 1954

25727 PARKER 1954

25728 PARKER 1954

25729 PARKER 1954

25730 PARKER 1954

25731 BANDY 1956

25732 ANDERSEN 196

25733 BANDY 1956

25734 PFLUM FRERICHS 1976

25735 LUDWICK NALTON 1957

25736 CUSHMAN 1918

25737 CUSHMAN 1918

25738 BENDA PURI 1962

25739 LEHMANN 1957

25740 LANKFORD 1959

25741 KANE 1967

25742 WALTON 1960

25743 PHLEGER LANKFORD 1957

25744 PHLEGER 1960

25745 KANE 1962

25746 BANDY 1954

25747 BANDY 1954

25748 BANDY 1954

25749 BENDA PURI 1962

25750 BENDA PURI 1962

25751 BANDY 1954

25752 BANDY 1954

25753 BENDA PURI 1962

25754 BANDY 1954

25755 BENDA PURI 1962

25756 ANDERSEN 1961

25757 ANDERSEN 1961

25758 ANDERSEN 1961
25759 BENDA PURI 1962

25759 BENDA PURI
25760 AKERS 1952
Generic Name

Specific Name

Locality

Lat. Long.

SPIROS I GMOIL INA

SPIROSIGMO IL INA

SPIROS I GMO IL INA

SPIROSIGMOIL INA

SPIROSI GMO IL INA

SPIROS I GMO IL INA

SPIROS I GMOIL INA

SPIROSI GMO IL INA

SPIROS I GMOILINA

FURSENKOINA

FURSENKOINA

FURSENKOINA

FURSENK OINA

FURSENK OINA

FURSENKOINA

FURSENKOINA

FURSENK OINA

FURSENK OINA

FURSENKO IVA

FURSENK OINA

FURSENK OINA

FURSENKOINA

FURSENKOINA

FURSENKOINA

FURSENK OINA

FURSENKO INA

FURSENKO INA

FURSENKOINA

FURSENK OINA

FURSENKOINA

FURSENKOINA

FURSENKOINA

FURSENKOINA

FURSENKOINA

FURSENKOINA

FURSENKOINA

FURSENKOINA

FURSENKOINA

STETSONIA

STETSONIA

STETSONIA

STETSONIA

STETSONIA

STETSONIA

STETSONIA

STETSONIA

STETSON IA

STETSONIA

STETSONIA

STETSONIA

STETSONIA

STET SON I A

STETSON IA

STETSONIA

STETSONIA

STETSONIA

STETSONIA

STETSONIA

STET SON IA

STET SON I A

STETSONIA

STETSONIA

STETSONIA

STETSONIA

STETSONIA

ST OMATORBINA

ST OMATOR BINA

STOMATORBINA

ST OMATORBINA

ST OMATORBINA

STORTHOSPHAERA

STORTHOSPHAERA

DI STORTA

DI STORTA

DI STORTA

DISTORTA

DISTORTA

DI STORTA

DI STORTA

DI STORTA

LOEBLICHI

LO EBL ICH I

LOEBLICHI

LOEBL ICHI

LOEBLICHI

LOEBLICHI

LO EBL I C H I

LOEBLICH I

LOEBLICHI

LOEBLICHI

LOEBLICHI

LOEBLICH I

LOEBL I CH I

$\angle O E B L I C H I$

$\angle O E B L I C H I$

$\angle O E B L I C H I$

LOEBLICHI

LOEBL ICH I

LOEBL ICHI

LOEBL ICH I

LOEBLICH I

LOEBL ICHI

LOEBLICHI

LOEBL I CHI

LOEBL ICHI

LOEBLICH I

LOEBLICHI

LOEBL ICHI

LOESLICHI

MI $\triangle U T A$

MI NUTA

MI NUTA

MI NUTA

MINUTA

MINUTA

MI NUTA

MI UTA

MI AUTA

MI NUTA

MINUTA

MI NUTA

MI NUTA

MI NUTA

MI NUTA

MINUTA

MINUTA

MINUTA

MI NUTA

MINUTA

MI NUTA

MINUTA

MI NUTA

MI NUTA

MI NUTA

MI NUTA

MI NUTA

CONCENTRICA

CONCENTRICA

CONCENTRI CA

CONCENTRICA

CONCENTRICA

AL EI DA

ALEIDA

BE CCARI I

BECCARI

BECCARI I

BECCARI

BE CCAR II

BE CCAR I I

BECCARI I

BE CCARII

BE CCARI

BECCARI

BECCARI I

BE CCARI

BECCARI I

BECCARII

BE CCARII

BECCARII

BECCARI I

BECCARII

BECCARII

BECCARI I

BECCARI

BECCARI I

AMMON I A

AMMONIA

AMMONIA

NW GULF OF MEXICO

NW GULF OF MEXICO

NH GULF OF MEXICO

NW GULF OF MEXICO

NW GULF OF MEXICO

NW GULF OF MEXICO

$N W$ GULF OF MEXICO

$N W$ GULF OF MEXICO

$N W$ GULF OF MEXICO

$N W$ GULF OF MEXICO

$N W$ GULF OF MEXICO

NW GULF OF MEXICO

$N W$ GULF OF MEXICO

$N W$ GULF OF MEXICO

$N W$ GULF OF MEXICO

$N W$ GULF OF MEXICO

NW GULF OF MEXICO

NW GULF OF MEXICO

NW GULF OF MEXICO

NW GULF OF MEXICO

$N W$ GULF OF MEXICO

CENTRAL GULF OF MEXICO

CENTRAL GULF OF MEXICO

CENTRAL GULF OF MEXICO

CENTRAL GULF OF MEXICO

CENTRAL GULF OF MEXICO

NW GULF OF MEXICO 


\section{Publication}

25761 ANDERSEN 196 25762 ANDERSEN 196 25764 ANDERSEN 1961 25765 ANDERSEN 1961 25766 KANE 1052 25767 BRADSHAW 1757 25768 BENDA PURI 1962 25769 WALDRON 1963 25770 KANE 1967 25771 KANE 1962 25772 LEHMANN 1357 25773 BENDA PURI 1962 25774 BANDY 1954 25776 BANDY 1054 25777 BANDY 1954 25778 BANDY 1954 25779 KANE 1967 25780 KANE 196? 25781 BANDY 1054 25782 BANDY 1956 25783 BANDY 1956 25784 SANDY 1956 25785 BANDY 1056 25786 BANDY 1056 25787 BANDY 1956 25788 BANDY 1056 25789 BANDY 1956 25790 BANDY 1956 25791 BANDY 1050 25792 ARNAL 1955 25793 WALDRON 1963 25794 BANDY 1956 25795 BANDY 1256 25796
25797 25797 ARNAL 1955
25798 BANDY 1956 25799 BANDY 1956 25800 BANDY 1956 25801 BANDY 1956 25802 BANDY 1956 25803 BANDY 1956 25804 BANDY 1956 25805 BANDY 1956 25806 BANDY 1956 25807 BANDY 1956 25808 BANDY 1956 25809 BANDY 1956 25810 BANDY 1956 25811 BANDY 1956 25812 WARREN 1957
25813 LANKFDR 1959 25813 LANKFORD 1959
25814 PFLUM FREKICHS 1976 25815 VAUGHAN 1918 25816 NORTON 1930 25817 KELLOJGH 1956 25818 CUSHMAN 19228 25819 LEHMANN 1957 25820 CREAGER 1958 25821 OTVOS 1978 25822 KORNFELD 1931 25823 KORNFELD 1931 25824 BOCK 1976

25825 BOCK 1976

25826 DAVIS 1964 25827 SEGURA 1963 25828 CUS4MAN 1922 A 25829 CREAGER 1958 25830 CREAGER 1958 25831 LEROY HODGKINSON 1975 25832 LEHMANN 1957
25833 CUSHMAN 19228 25833 CUSHMAN 1922 25835 VAUGHAN 1918 25836 CREAGER 1958 25837 CUSHMA:N 19228 25838 CUSHMAN 19228 25839 ANDERSEN 1961 25840 ANDERSE: 1961 25841 PARKER 1954 25843 PARKER 1054

25844 PFLUM FRERICHS 1976 25845 BANDY 1956 25846 BANDY 1956 25847 BANDY 1956 25848 SANDY 1956 25849 BANDY 1956 25850 BANDY 1956 25851 BANDY 1256 25852 KELLOUSH 1956 25853 KELLOUGH 1956 25854 KELLOUGH 1956
Generic Name

AMMONI A

AMMONI A

AMMONIA

AMMONIA

A MMON I A

AMMONIA

AMMONIA

AMMONIA

AMMONIA

AMMONIA

AMMONIA

AMMONIA

AMMONIA

AMMONI A

AM MONIA

AMMONIA

AMMONIA

A YMONIA

AM MONIA

A MMONIA

AMMONIA

AM YONIA

AMMONIA

AMMONIA

AMMONIA

AMMONIA

AMMONIA

AMMONIA

AMMONIA

AMMONIA

AMMONI A

AMMONIA

AMIMONIA

AMMON I A

AMMONIA

AMMONIA

AMMONIA

AMMONIA

AMMONIA

A MMONIA

AMMONIA

AMMONIA

SULCOPHAX

SULCOPHAX

TECHNITELLA

TE XT ULARIA

TEXTULARIA

TEXTULARIA

TEXTULARIA

TEXTULARIA

TEXTULARIA

TEXTULARIA

TEXTULARIA

TEXTULAR IA

TEXTULARIA

TEXTULARIA

TE XTULARIA

TEXTULARIA

TEXTULARIA

TEXTULARIA

TEXTULARIA

TEXTULARIA

TEXTULARIA

TEXTULARIELLA

TEXTULARIELLA

TEXTULARIELLA

TEXTULARIELLA

TEXTULARIELLA

TEXTULARIELL

TEXTULARIA

TEXTULARIA

TEXTULARIA

TEXTULARIA

TEXTULAR IA

TEXTULARIA

TEXTULARIA

TEXTULARIA

TEXTULARIA

TEXTULARIA

TEXTULARIA

TEXTULARIA

TEXTULARIA

TEXTULARIA

TEXTULARIA

TEXTULARIA
Specific Name

BECCARI I

BE CCARII

BE CCARI I

BECCARII

BECCARI I

GE CCARII

BECCARII

PA CILOCULATA

PAUCILOCULATA

PAUCILOCULATA

PALCILOCULATA

ROLSHAUSENI

ROLSHAUSEN

ROLSHAUSENI

ROLSHAUSENI

ROLSHAUSENI

ROLSHAUSENI

ROLSHAUSEN I

ROLSHAUSENI

$\forall E C C A R I I$

BECCARII

BECCARI

BECCARII

BECCAR I I

BECCARII

BECCARII

BECCARI I

BECCARII

BECCARII

BECCARII

BECCARII

BECCARII

BECCARI

BECCARII

BECCARII

BECCARII

BECCARI

BECCARI I

BECCARII

BECCARI I

BECCARI

BECCARII

BE CCAR I I

BE CCAR I

BECCARII

BECCARI I

PALUSTRIS

PALUSTRIS

LE EUMEN

AG GLUTINANS

A GELUTINANS

AG GLUTINANS

AGGLUTINANS

A G GLUTINANS

A G GLUTI NANS

A G GLUTINANS

AGELUTINANS

AGGLUTINANS

AG GLUTINANS

A G GLUTINANS

A G GLUT INANS

AGGLUTINANS

A G GLUTINANS

ALEATROSS I

ALEATROSS I

ASFERA

AURA

BARRETTII

BA RRETTII

BARRETTII

BARRETTII

BARRETTII

BARRETTI I

CALVA

CANDEIANA

CANDEIANA

CANDE IANA

CA DDEIANA

CANDEIANA

CA ADE I ANA

C A $\triangle D E I A N A$

$C A \cap D E I A N A$

C ANDE IANA

CANDEIANA

C ANDE I ANA

CA NDE IANA

CANDE I ANA

CANDEIANA

CANDE IANA

Locality

MISSISSIPPI DELTA MISSISSIPPI DELTA MISSISSIPPI DELTA MISSISSIPPI DELTA MISSISSIPPI DELTA SABINE LAKE, TEXAS SAN ANTONIO B.. TEXAS CAPE ROMANO, FLA.

MISSISSIPPI DELTA

SABINE LAKE, TEXAS SABINE LAKE, TEXAS TEXAS GULF COAST CAPE ROMANO. FLA. NW GULF OF MEXICO

NW GULF OF MEXICO

NW GULF OF MEXICO

NW GULF OF MEXICO

NW GULF OF MEXICO

SABINE LAKE, TEXAS 


\section{Publication}

25856 PARKER 1954 25857 PARKER 1954

25858 PARKER 1954

25859 PARKER 1954

25860 PARKER 1754

25862 PFLUM FRERICHS 1976

25863 CUSHMAN 1922 A

25864 LUDWICK WALTON 1957

25865 KELLOUGH 1956

25866 KELLOUGH 1956

25867 BENDA PURI 1962

25868 WALTON 1964

25869 BANDY 1956

25870 BANDY 1956

25871 BANDY 1956

25872 BANDY 1956

25873 KELLOUGH 1956

25874 BANDY 1956

25875 BANDY 1956

25876 BANDY 1956

25877 BANDY 1956

25878 NORTON 1930

25879 LIDZ LIDZ 1966

25880 BOCK 1976

25881 BANDY 1954

25882 BANDY 1954

25883 BANDY 1954

25884 BANDY 1956

25885 BANDY 1956

25886 BANDY 1956

25887 BANDY 1954

25888 BANDY 1954

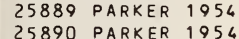

25891 PARKER 1954

25892 PARKER 1954

25893 PARKER 1954

25894 BANDY 1954

25895 NORTON 1930

25896 CUSHMAN $1922 \mathrm{~B}$

25897 BANDY 1956

25898 BANDY 1956

25899 BANDY 1956

25900 BANDY 1956

25901 BANDY 1956

25902 BANDY 1956

25903 BANDY 1956

25904 BANDY 1956

25905 BANDY 1956

25907 CUSHMAN $1922 \mathrm{~A}$

25908 BANDY 1956

25909 BANDY 1956

25910 LUDWICK WALTON 1957

25911 DAVIS 1964

25912 BANDY 1956

25913 BANDY 1956

25914 BANDY 1956

25915 ANDERSEN 1961

25916 BANDY 1956

25917 PARKER 1954

25918 PARKER 1954

25919 PARKER 1954

25920 PARKER 1954

25921 CREAGER 1958

25922 BOCK 1976

25923 BOCK 1976

25924 PARKER 1956

25925 PARKER 1954

25926 PARKER 1954

25927 PARKER 1954

25928 PARKER 1954

25929 PARKER 1954

25930 PARKER 1954
25931 LEHMANN 1957

25931 LEHMANN 1957

25932 LANKFORD 1959

25934 PARKER 1954

25935 PFLUM FRERICHS 1976

25036 PFLUM FRERICHS 1976

25937 PFLUM FRERICHS 1976

25938 PFLUM FRERICHS 1976

25939 PFLUM FRERICHS 1976

25940 PARKER 1954

25941 PARKER 1954

25942 PARKER 1954

25943 PARKER 1954

25944 PARKER 1954

25945 PARKER 195

25946 BOCK 1976

25947 PFLUM FRERICHS 1976

25948 PFLUM FRERICHS 1976

25949 PHLEGER $1965 \mathrm{~A}$

25950 PHLEGER 1965 A

\section{Generic Name \\ Specific Name}

TEXTULARIA

TEXTULARIA

TEXTULARIA

TEXTULARIA

TEXTULARIA

TE XTULARIA

TEXTULARIA

TEXTULARIA

TEXTULARIA

TEXTULARIA.

TEXTULARIA

TEXTULARIA

TEXTULARIA

TEXTULARIA

TEXTULARIA

TEXTULARIA

TE XTULARIA

TEXTULARIA

TEXTULARIA

TEXTULARIA

TEXTULARIA

TEXTULARIA

TEXTULARIA

TEXTULARIA

TEXTULARIA

TEXTULARIA

TEXTULARIA

TEXTULARIA

TEXTULARIA

TEXTULARIA

TEXTULARIA

TE XTULARIA

TEXTULARIA

TEXTULARIA

TEXTULARIA

TEXTULARIA

TEXTULARIA

TEXTULARIA

TEXTULARIA

TEXTULARIA

TEXTULARIA

TEXTULARIA

TEXTULARIA

TEXTULARIA

TEXTULARIA

TEXTULARIA

TEXTULARIA

TEXTULARIA

TEXTULARIA

TEXTULARIA

TEXTULARIA

TEXTULARIA

TEXTULARIA

TEXTULARIA

TEXTULARIA

TEXTULARIA

TE XTULARIA

TEXTULARIA

TEXTULARIA

TEXTULARIA

TEXTULARIA

TEXTULARIA

TEXTULARIA

TEXTULARIA

TEXTULARIA

TEXTULARIA

TEXTULARIA

TEXTULAR IA

TEXTULARIA

TEXTULARIA

TEXTULARIA

TEXTULARIA

TEXTULARIA

TEXTULARIA

TEXTULARIA

TEXTULARIA

TEXTULARIA

TEXTULARIA

TEXTULARIA

TEXTULARIA

TEXTULARIA

TEXTULARIA

TEXTULARIA

TEXTULARIA

TEXTULARIA

TEXTULARIA

TEXTULARIA

TEXTULAR IA

TEXTULARIA

TEXTULARIA

TEXTULARIA

TEXTULARIA

TEXTULAR IA

TEXTULARIA
CANDEIANA

C A NDEIANA

C A $\triangle D E I A N A$

CA $A D E I A N A$

CANDEIANA

CANDEIANA

CA DDE I ANA

CANDEIANA

CANDE I ANA

$C A \wedge D E I A N A$

CANDE I ANA

CANDEIANA

CANDE I ANA

C ANDEIANA

CA ADE I ANA

CANDEIANA

CANDEIANA

CANDEIANA

CA $\triangle$ DE I ANA

CANDE IANA

CA D DEIANA

CANDEIANA

CANDEIANA

CANDEIANA

C A NDE I ANA

CA $\triangle D E I A N A$

CANDE I ANA

CANDEIANA

C A NDE I ANA

CANDE I ANA

CANDEIANA

CA ADE I ANA

CANDEI ANA

CANDE IANA

CANDE IANA

CANDEIAN

CONICA

CONICA

CONICA

CONICA

CONICA

CONICA

CONICA

CONICA

CONICA

CONICA

CONICA

CONICA

CONICA

COAICA

CONICA

CONICA

CONICA

CONICA

CONICA

CONICA

CONICA

CONICA

COAICA

CONICA

CONICA

CONICA

CONICA

CONICA

CONICA

COAICA

CONICA

CONICA

COAICA

CONICA

CONICA

CONICA

CONICA

EARLANDI

EARLANDI

EARLANDI

EARLANDI

EARLANDI

EARLANDI

EARLANDI

EARLANDI

EARLANDI

EARLANDI

EARLANDI

EARLANDI

EARLANDI

EARLANDI

EARLANDI

EARLANDI

EARLANDI
EARLANDI

\section{Locality}

Lat. Long.

NE GULF OF MEXICO

NE GULF OF MEXICO

NE GULF OF MEXICO

NE GULF OF MEXICO

NE GULF OF MEXICO 


\section{Publication}

25951 PHLEGER 19658

25952 PFLUM FRERICHS 1976

25953 LEHMANN 1957

25954 SHIFFLETT 1961

25955 PFLUM FRERICHS 1976

25956 PHLEGER 1955 A

25957 PHLEGER 1955 A

25958 PARKER 1954

25959 PHLEGER 1955 A

25960 PHLEGER 1955 A

25961 CUSHMAN 19228

25962 NORTON 1930

25963 CUSHMAN 19228

25964 CUSHMAN 1922A

25965 PHLEGER 1951 A

25966 PHLEGER $1951 \mathrm{~A}$

25967 PHLEGER 1951A

25968 PHLEGER 1951A

25969 PHLEGER $1951 \mathrm{~A}$

25970 PHLEGER 1951A

25971 PARKER 1954

25972 PARKER 1954

25973 PHLEGER $1951 \mathrm{~A}$

25974 PHLEGER 1951A

25975 PHLEGER 1951A

25976 PHLEGER 1951A

25977 PHLEGER 1951A

25978 PHLEGER 1951A

25979 PARKER 1954

25980 PARKER 1954

25981 PARKER 1954

25982 PFLUM FRERICHS 1976

25983 PFLUM FRERICHS 1976

25984 BANDY 1956

25985 BANDY 1956

25986 BANDY 1956

25987 CREAGER 1958

25988 PARKER 1954

25989 PARKER 1954

25990 BANDY 1956

25991 PARKER 1954

25992 PHLEGER 1951A

25993 CUSHMAN 19228

25994 CUSHMAN 19228

25995 BANDY 1956

25996 BANDY 1956

25997 BANDY 1956

25998 BANDY 1956

26000 BANDY 1956

26001 PARKER 1954

26002 LUDWICK WALTON 1957

26003 PARKER 1954

26004 PARKER 1954

26005 BOCK 1976

26006 CREAGER 1958

26007 BENDA PURI 1962

26008 NORTON 1930

26009 VAUGHAN 1918

26010 NORTON 1930

26011 ANDERSEN 1961

26012 CREAGER 1958

26013 SHIFFLETT 1961

26014 LIDZ LIDZ 1966

26015 PHLEGER 1951

26016 SEGURA 9963

26017 PHLEGER 1951A

26018 CUSHAAN $1922 \mathrm{~A}$

26019 PHLEGER 1951 A

26020 PHLEGER 1951A

26021 PHLEGER $1951 \mathrm{~A}$

26022 PHLEGER $1951 \mathrm{~A}$

26023 CREAGER 1958

26024 CREAGER 1958

26025 LIDZ LIDZ 1966

26026 PHLEGER 1951A

6027 PHLEGER 1951A

6028 PHLEGER $1951 \mathrm{~A}$

26029 PHLEGER 1951A

26030 PHLEGER 1951A

26031 PHLEGER 1951A

.6032 CREAGER 1958

26033 PARKER 1954

20034 PARKER 1954

26035 PARKER 1954

26036 PARKER 1954

26037 PARKER 1954

6038 PARKER 1954

6039 PHLEGER 1951A

26040 PHLEGER 1951A

26041 BANDY 1956

$\angle 6042$ BANDY 1956

26043 NORTON 1930

26045 BANDY 1956
Generic Name

Specific Name

TEXTUL ARIA

TEXTULARIA

TEXTULARIA

TEXTULARIA

TEXTULARIA

TEXTULARIA

TEXTULARIA

TEXTULARIA

TEXTULARIA

TEXTULARIA

TEXTULARIA

SPIROPLECTAMMINA

SPIROPLE CT AMMINA

SPIROPLECTAMMINA

TEXTULARIA

TEXTULAR IA

TEXTULARIA

TEXTULARIA

TEXTULARIA

TEXTULARIA

TEXTULARIA

TEXTULARIA

TEXTULARIA

TEXTULARIA

TEXTULARIA

TEXTULARIA

TEXTULARIA

TEXTULARIA

TEXTULARIA

TEXTULARIA

TEXTULARIA

TEXTULARIA

TE XTULARIA

TEXTULARIA

TEXTULARIA

TEXTULARIA

TEXTULARIA

TEXTULARIA

TEXTULARIA

TEXTULARIA

TEXTULARIA

TE XTULARIA

TEXTULARIA

TEXTULARIA

TEXTULARIA

TEXTULARIA

TEXTULARIA

TEXTULARIA

TEXTULARIA

TEXTULARIA

TEXTULARIA

TEXTULARIA

TEXTULARIA

TEXTULARIA

TEXTULARIA

TEXTULARIA

TEXTULARIA

TEXTULARIA

TEXTULARIA

TEXTULARIA

TEXTULARIA

TEXTULARIA

TEXTULARIA

TEXTULARIA

TEXTULARIA

TEXTULARIA

TEXTULARIA

TEXTULARIA

TEXTULARIA

TEXTULARIA

TEXTULARIA

TEXTULARIA

TEXTULARIA

TEXTULARIA

TEXTULARIA

TEXTULARIA

TEXTULARIA

TEXTULARIA

TEXTULARIA

TEXTULARIA

TEXTULARIA

TEXTULARIA

TEXTULARIA

TEXTULARIA

TEXTULARIA

TEXTULARIA

TEXTULARIA

TEXTULARIA

EXTULARIA

I EXTULARIA

TEXTULARIA

TEXTULARIA

TE XTULARIA

TEXTULARIA

TEXTULARIA
EARLANDI

EARLANDI

EARLANDI

EARLANDI

EARLANDI

EARLANDI

EARLANDI

EARLANDI

EARLANDI

EARLANOI

FL INTII CURTA

FL CRI DANA

FLCRIDANA

FLORIDANA

FOLIACEA OCCIDENTALIS

FOLIACEA OCCIDENTALIS

FOLIACEA OCCIDENTALIS

FOLIACEA OCCIDENTALIS

FOLIACEA OCCIDENTALIS

FOLIACEA OCCIDENTALIS

FOLIACEA OCCIDENTALIS

FOLIACEA OCCI DENTALIS

FOLIACEA OCCIDENTALIS

FOLIACEA OCCIDENTALIS

FOLIACEA OCCIDENTALIS

FOLIACEA OCCIDENTALIS

FOLIACEA OCCIDENTALIS

FOLIACEA OCCIDENTALIS

FOLIACEA OCCIOENTALIS

FOLIACEA OCCIDENTALIS

FOLIACEA OCCIOENTALIS

FOLIACEA OCCIDENTALIS

FOLIACEA OCCIDENTALIS

FOLIACEA OCCIDENTALIS

FOLIACEA OCCIDENTAL IS

FOLIACEA OCCIDENTALIS

FOLIACEA OCCIDENTALIS

FOLIACEA OCCIDENTALIS

FOLIACEA OCCIDENTALIS

FOLIACEA OCCIDENTALIS

FOLIACEA OCCIDENTALIS

FOLIACEA OCCIDENTALIS

FOLIACEA OCCIDENTALIS

FOLIACEA OCCIDENTALIS

FOLIACEA OCCIDENTALIS

FOLIACEA OCCIDENTALIS

FOLIACEA OCCIDENTALIS

FOLIACEA OCCIOENTALIS

FOLIACEA OCCIDENTALIS

FOLIACEA OCCIDENTALIS

FOLIACEA OCCIDENTALIS

FOLIACEA OCCIDENTALIS

FOLIACEA OCCIDENTALIS

FOLIACEA OCCIDENTALIS

FOLIACEA OCCIDENTALIS

GOESI I

GR AMEN

GR AMEN

GR AMEN

HALER I

KERIMBAENSIS

MAURYAE

MA YOR I

MA YOR I

MAA YOR I

MAYORI

MAYYOI

MA YOR I

MA YORI

MA YOR I

MAYOR I

MAYORI

MA YOR I

MA YOR I

MA YORI

MA YORI

MAYOR I

MA YOR I

MA YOR I

MA YOR I

MA YOR I

MA YOR I

IA Y YOR I

MA YOR I

IAA YORI

AA YORI

MA YOR I

MA YOR I

MA YOR I

IA A YOR I

MA YORI

MA YOR I

Locality

Lat. Long.

WHITEWATER B.. SW FLA.

CENTRAL GULF OF MEXICO 


\section{Publication}

26046 BANDY 1956

26047 WAL TON 1960

26048 ANDERSEN 1961

26049 BANDY 1956

26050 BANDY 1954

26051 BANDY 1956

26052 BANDY 1954

26053 BANDY 1956

26054 BANDY 1954

26055 BANDY 1954

26056 BANDY 1956

26057 BANDY 1954

26058 PARKER 195

26060 PARKER 1954

26061 PARKER PHLEGER PEIRSON 1953

26062 PARKER PHLEGER PEIRSON 1953

26063 PARKER PHLEGER PEIRSON 1953

26064 PARKER PHLEGER PEIRSON 1953

26065 PHLEGER 1956

26066 PHLEGER 1956

26067 PHLEGER 1956

26068 PHLEGER 1956

26069 CREAGER 1958

26070 BOCK 1976

26071 CREAGER 1958

26072 BOCK 1976

26073 BOCK 1976

26074 LUDWICK WALT
26075 PHLEGER 1954

26076 WARREN 1057

26077 LANKFORD 1959

26078 PARKER 195

26079 PARKER 1954

26080 PARKER 1954

26081 BANDY 1954

26082 BANDY 1956

26083 BANDY 1956

26084 BANDY 1956

26085 BANDY 1956

26086 BANDY 1056

26087 BENDA PURI 1962

26088 LOEP 1965

26089 KELLOUGH 1956

26090 KELLOUGH 1956

26091 KELLOUGH 1956

26092 KELLOUGH 1956

26093 KELLOUGH 1956

26094 BANDY 1956

26095 KELLOUGH 1956

26096 KELLOUGH 1956

26097 BANDY 1956

26098 BANDY 1956

26099 LOEP 1965

26100 WARREN 1956

26101 PFLUM FRERICHS 1976

26102 PHLEGER 1951A

26103 PFLUM FRERICHS 1976

26104 PFLUM FRERICHS 1976

26105 PHLEGER 1951A

26106 PHLEGER 1951 A

26107 PHLEGER 1951A

26108 PHLEGER 1951A

26109 PHLEGER $1951 \mathrm{~A}$

26110 PFLUM FRERICHS 1976

26111 PFLUM FRERICHS 1976

26112 CUSHMAN $1922 \mathrm{~B}$

26113 CUSHMAN $1922 \mathrm{~B}$

26114 CUSHMAN 19228

26115 CUSHMAN $1922 B$

26116 PHLEGER 1951A

26117 PFLUM FRERICHS 1976

26118 PFLUY FRERICHS 1976

26119 CREAGER 1958

26120 CREAGER 1958

26121 CREAGER 1958

26122 ANDERSEN 1961

26123 PHLEGER 1951A

26124 PHLEGER 1951A

26125 LUDWICK WALTON 1957

26126 ANDERSEN 1961

26127 LANKFORD 1959

26128 WARREN 195

(46129 ANDERSEN 1961

26130 CUSHMAN 19228

(26131 BANDY 1956

26132 BANDY 1956

26133 BANDY 1956

26134 CUSHMAN 19228

26135 CUSHMAN 1922A

26136 VAUGHAN 1918

26137 BANDY 1956

?26138 BANDY 1956

26139 BANDY 1956

26140 BANDY 1956
Generic Name Specific Name

Locality

Lat. Long.

TEXTULARIA

MA YOR I

TEXTULARIA MAYORI

TEXTULARIA MAYORI

TEXTULARIA MAYORI

TEXTULARIA MAYORI

TEXTULARIA MAYORI

TEXTULARIA

TEXTULARIA MAYORI

TEXTULARIA MAYORI

TEXTULARIA MAYORI

TEXTULARIA MAYORI

TEXTULARIA MAYORI

TEXTULARIA MAYORI

TEXTULARIA MAYORI

$\begin{array}{ll}\text { TEXTULARIA } & \text { MAYORI } \\ \text { TEXTULARIA } & \text { MAYORI }\end{array}$

TEXTULARIA MAYORI

TEXTULARIA MAYORI

TEXTULARIA MAYORI

TEXTULARIA MAYORI

TEXTULARIA MAYORI

TEXTULARIA MAYORI

TEXTULARIA MAYORI

TEXTULARIA MAYORI

TEXTULARIA MAYORI

TEXTULARIA MAYORI

TEXTULARIA MAYORI

TEXTULARIA MAYORI

TEXTULARIA MAYORI

TEXTULARIA MAYORI

TEXTULARIA MAYORI

MAYOR I

TEXTULARIA MAYORI

TEXTULARIA MAYORI

TEXTULARIA MAYORI

TEXTULARIA MAYORI

TEXTULARIA MAYORI

TEXTULARIA MAYORI

TEXTULARIA MAYORI

TEXTULARIA MAYORI

TEXTULARIA MAYORI

TEXTULARIA

TEXTULARIA MAYORI

TEXTULARIA MAYORI

TEXTULARIA MAYORI

TEXTULARIA MAYORI

TEXTULARIA MAYORI

TEXTULARIA MAYORI

TEXTULARIA MAYORI

TEXTULARIA

TEXTULAR IA

TEXTULARIA

TEXTULARIA

TEXTULARIA

TEXTULARIA

TEXTULARIA

TEXTULARIA

TEXTULARIA

TEXTULARIA

TEXTULARIA

TEXTULARIA

TEXTULARIA

TEXTULARIA

TEXTULARIA

TEXTULARIA

TEXTULAR IA

TEXTULARIA

TEXTULARIA

TEXTULARIA

TEXTULARIA

TEXTULARIA

TEXTULARIA

TEXTULARIA

TEXTULARIA

TEXTULARIA

TEXTULARIA

TEXTULARIA

TEXTULARIA

TEXTULARIA

TEXTULARIA

TEXTULARIA

TEXTULARIA

TEXTULARIA

TEXTULARIA

TEXTULAR IA

TEXTULARIA

TEXTULARIA

TEXTULARIA

TEXTULARIA
NE GULF OF MEXICO

MISSISSIPPI SOUND

MISSISSIPPI DELTA

NE GULF OF MEXICO

NW GULF OF MEXICO

NE GULF OF MEXICO

Nh GULF OF MEXICO

NE GULF OF MEXICO

NW GULF OF MEXICO

NW GULF OF MEXICO

NE GULF OF MEXICO

NW GULF OF MEXICO

NE GULF OF MEXICO

NE GULF OF MEXICO

NE GULF OF MEXICO

TEXAS GULF COAST

TEXAS GULF COAST

TEXAS GULF COAST

TEXAS GULF COAST

NW GULF OF MEXICO

NW GULF OF MEXICO

NW GULF OF MEXICO

BAY OF CAMPECHE

NE GULF OF MEXICO

BAY OF CAMPECHE

NE GULF OF MEXICO

NE GULF OF

NE GULF OF MEXICO

SE LOUISIANA

MISSISSIPPI DELTA

NE GULF OF MEXICO

NE GULF OF MEXICO

NE GULF OF MEXICO

NW GULF OF MEXICO

NE GULF OF MEXICO

NE GULF OF MEXICO

NE GULF OF MEXICO

NE GULF OF MEXICO

NE GULF OF MEXICO

CAPE ROMANO, FLA.

NW GULF OF MEXICO

$N W$ GULF OF MEXICO

$N W$ GULF OF MEXICO

NW GULF OF MEXICO

NW GULF OF MEXICO

NW GULF OF MEXICO

NE GULF OF MEXICO

NW GULF OF MEXICO

NW GULF OF MEXICO

NE GULF OF MEXICO

NE GULF OF MEXICO

$\mathrm{NW}$ GULF OF MEXICO

BURAS SE LOUISIANA

NW GULF OF MEXICO

NW GULF OF MEXICO

NW GULF OF MEXICO

NW GULF OF MEXICO

NW GULF OF MEXICO

NW GULF OF MEXICO

NW GULF OF MEXICO

$N W$ GULF OF MEXICO

NH GULF OF MEXICO

NW GULF OF MEXICO

CENTRAL GULF OF MEXICO

NE GULF OF MEXICO

NE GULF OF MEXICO

NE GULF OF MEXICO

NE GULF OF MEXICO

NW GULF OF MEXICO

NW GULF OF MEXICO

NW GULF OF MEXICO

BAY OF CAMPECHE

BAY OF CAMPECHE

BAY OF CAMPECHE

MISSISSIPPI DELTA

NW GULF OF MEXICO

NW GULF OF MEXICO

NE GULF OF MEXICO

MISSISSIPPI DELTA

MISSISSIPPI DELTA

SE LOUISIANA

MISSISSIPPI DELTA

NE GULF OF MEXICO

NE GULF OF MEXICO

VE GULF OF MEXICO

NE GULF OF MEXICO

NE GULF OF MEXICO

TORTUGAS

FLORIDA KEYS

CAL OOSAHATCHEE R., FLA.

CHARLOTTE HARBOUR, FLA.

NE GULF OF MEXICO

NE GULF OF MEXICO
$2619 N 082 \quad 22 W$

$3 \mathrm{C} 18 \mathrm{~N} 086 \quad 40 \mathrm{~N}$

$2858 \mathrm{~N} 08909 \mathrm{~W}$

$2929 \mathrm{~N} 085 \quad 45 \mathrm{~W}$

$2850 \mathrm{~N} 09320 \mathrm{~W}$

$30 \quad 06 \mathrm{~N} 085 \quad 44 \mathrm{~W}$

29 SON 093 OOW

$2917 N 08546 \mathrm{~W}$

$2850 \mathrm{~N} 09345 \mathrm{~W}$ 


\section{Publication}

26141 BANDY 1956 26142 BANDY 1956 26143 BANDY 1956 26144 BANDY 1956 26145 BANDY 1956 26146 BANDY 1956 26147 LEHMANN 1957 26148 ANDERSEN 1961 26149 VAUGHAN 1918 26150 ANDERSEN 1961 26151 BAN DY 1956 26152 BANDY 1956 26153 KELLOUGH 1956 26154 KELLOUGH 1956
26155 LOEP 1965 26155 LOEP 1965
26156 PFLUM FRERICHS 1976 26157 BOCK 1976 26158 BANDY 1956 26159 BANDY 1956 26160 BANDY 1956 26161 BANDY 1956 26162 KELLOUGH 1956 26163 CREAGER 1958 26164 CUSHMAN 1918 26165 CUSHMAN 1918 26166 PFLUM FRERICHS 1976 26167 PFLUM FRERICHS 1976 26168 PFLUM FRERICHS 1976 26169 PFLUM FRERICHS 1976 26170 PFLUM FRERICHS 1976 26172 LEROY HODGKINSON 1975 26173 PFLUM FRERICHS 1976 26174 PFLUM FRERICHS 1976 26175 PFLUM FRERICHS 1976 26176 PFLUM FRERICHS 1976 26177 PFLUM FRERICHS 1976 26178 PFLUM FRERICHS 1976 26179 PFLUM FRERICHS 1976 26180 PFLUM FRERICHS 1976 26181 PFLUM FRERICHS 1976 26182 PFLUM FRERICHS 1976 26183 PFLUM FRERICHS 1976 26184 PFLUM FRERICHS 1976 26185 PFLUM FRERICHS 1976 26186 PFLUM FRERICHS 1976 26187 PFLUM FRERICHS 1976 26188 PFLUM FRERICHS 1976 26189 PFLUM FRERICHS 1976 26190 LEROY HODGKINSON 1975 26191 LEROY HODGKINSON 1975 26192 OTVOS 1978

26193 WANTLAND 1969

26194 PHLEGER 1965 A 26195 PHLEGER 1965 A 26196 PHLEGER 1965A 26197 PHLEGER 1965 A 26198 PHLEGER $1965 \mathrm{C}$ 26199 PARKER 1954 26200 PARKER 1954 26201 PARKER 1954 26202 PARKER 1954 26203 PARKER 1954

26205 PFLUM FRERICHS 1976 26206 PARKER 1954

26207 PFLUM FRERICHS 1976 26208 PFLUM FRERICHS 1976 26209 PFLUM FRERICHS 1976 26210 PFLUM FRERICHS 1976 26211 PFLUM FRERICHS 1976 26212 PFLUM FRERICHS 1976 26213 PFLUM FRERICHS 1976 26214 PFLUM FRERICHS 1976 26215 PFLUM FRERICHS 1976 26216 PFLUM FRERICHS 1976 26217 PFLUM FRERICHS 1976 26218 PFLUM FRERICHS 1976 26219 PFLUM FRERICHS 1976 26220 PFLUM FRERICHS 1976 26221 LEROY HODGKINSON 1975 26222 PFLUM FRERICHS 1976 26223 PFLUM FRERICHS 1976 26224 PFLUM FRERICHS 1976 26225 PFLUM FRERICHS 1976 26226 PARKER 195 26227 PFLUM FRERICHS 1976 26229 LUDWICK WALTON 1957 26230 PFLUM FRERICHS 1976 26231 PARKER 1954 26232 PARKER 1954 26233 PARKER 1954 26234 PARKER 1954 26235 PFLUM FRERICHS 1976

\section{Generic Name}

TEXTULARIA

TEXTULARIA

TEXTULARIA

TEXTULARIA

TEXTULARIA

TEXTULARIA

TEXTULARIA

TEXTULARIA

TEXTULAR IELLA

TEXTULARIELLA

TEXTULARIELLA

TEXTULARIELLA

TEXTULAR IELLA

TEXTULAR IELLA

TE XTULAR IELLA

TEXTULAR IELLA

TEXTULAR IELLA

TEXTULAR IELLA

TE XTULARIELLA

TEXTULAR IELLA

TEXTULARIA

TEXTULARIA

THUR AMM I NA

THUR AMM I NA

HURAMM I NA

THUR AMM I NA
THURAMM I NA

THURAMMINA

THURAMM I NA

THURAMM I NA

TH UR AMM I NA

THURAMMI NA

THURAMMINA

THURAMMI NA

THUR AMM I NA

THURAMM I NA

THUR AMM I NA

THUR AMM I NA

THUR AMM I NA

THUR AMM I NA

THUR AMM I NA

THUR AMM I NA

THURAMM I NA

THURAMM I NA

THURAMM INA

HUR AMM I NA

THUR AMM I NA
THUR AMM I NA

THUR AMM I NA

THUR AMM I NA

TIPHOTROCHA

TIPHOTROCHA

TIPHOTROCHA

TIPHOTR OCHA

TIPHOTROCHA

TI PHOTROCHA

TIPHOTR OCHA

TOLYPAMMINA

TOLYPAMMINA

TOLYPAMMINA

TOLYPAMMINA

TOLYPAMMINA

TOLYPAMMINA

TOLYPAMMINA

TOLYPAMMINA

TOLYPAMMINA

TOLYPAMMINA

TOLYPAMMINA

TOLYPAMMINA

TOLYPAMMINA

TOLYPAMMINA

TOLYPAMMINA

TOLYPAMMINA

TOLYPAMMINA

TOLYPAMMINA

TOLYPAMMINA

OLYPAMM INA

OLYPAMMINA

TOLYPAMMINA

TOLYPAMMINA

TOLYPAMMINA

TOLYPAMMINA

TOLYPAMM INA

TOLYPAMMINA

TOLYPAMMINA

TOLYPAMM INA

TOLYPAMM INA

TOLYPAMM INA

TOLYPAMMINA

TOLYPAMMINA

TOLYPAMMINA

TOLYPAMMINA

TOLYPAMMINA

\section{Specific Name}

SECASENSIS

SE CASENSI

SE CASENS IS

SE CASENSIS

SECASENSIS

SE CASENSIS

SERANENSIS

SI CA

PSEUDOTROCHUS

BARRETTII

BARRETTII

BARRETTII

BARRETTII

BARRETTII

BARRETTII

BARRETTII

BA RRETTII

BARRETTII

BARRETTII

BARRETTII

BARRETTII

CONICA

PSEUDOTROCHUS

FAVOSA

PAPILLATA

PAFILLATA

PAPILLATA

PAPILLATA

PAPILLATA

PAPILLATA

PAPILLATA

PAPILLATA

PAPILLATA

PAPILLATA

PAPILLATA

PAPILLATA

PAFILLATA

PAPILLATA

PAPILLATA

PAPILLATA

PAPILLATA

PAFILLATA

PAPILLATA

PAPILLATA

PAPILLATA

PAFILLATA

PAFILLATA

PAFILLATA CARIOSA

PAPILLATA CASTANEA

CONPRIMATA

COMPR IMATA

CONPRIMATA

CONPRIMATA

CONPRIMATA

COMPR IMATA

CONPRIMATA

SC RAUDINN I

SCHAUDINNI

SCHAUDINNI

SC HAUDINN I

SCHAUDINNI

SCHAUDINN I

SC HAUDINN I

SC HAUDINN I

SCHAUDINN I

SC HAUDINN I

SC HAUDINN I

SC HAUDINN I

SCHAUDINN I

SCHAUDINN I

SCHAUDINN I

SC MAUDINNI

SC HAUDINN

SC HAUDINN

SC HAUDINN I

SCHAUDINN

SC HAUDINN

SC HAUDINN I

SC HAUDINNI

SCHAUDINN I

SC HAUDINN

SCHAUDINN I

SC HAUDINNI

SC HAUDINN I

SCHAUDINN

SC HAUDINN I

SC HAUDINN

SC HAUD INN I

SC HAUDINN I

SC HAUDINN I

SC HAUDINN

SCHAUDINN I

\section{Locality}

TAMPA BAY, FLA.

TAMPA BAY, FLA.

NE GULF OF MEXICO

NE GULF OF MEXICO

NE GULF OF MEXICO

NE GULF OF MEXICO

TEXAS GULF COAST

$M I S S I S S I P P I$ DELTA 


\section{Publication}

26236 PFLUM FRERICHS 1976 26237 PFLUM FRERICHS 1976 26238 PFLIJM FRERICHS 1976 26239 LEROY HODGKINSON 1975 26240 PFLU 9 FRERICHS 1976 26241 DFLUM FRERICHS 1976 26242 PFLUM FRERICHS 1976 26243 PFLUM FRERICHS 1976 26244 PFLUM FRERICHS 1976 26245 PFLUM FRERICHS 1976 26246 PFLUM FRERICHS 1976 26247 PFLUM FRERICHS 1976 26248 PFLUM FRERICHS 1976 26249 PFLUM FRERICHS 1976 26250 PFLUM FRERICHS 1976 26251 PFLUM FRERICHS 1976 26252 PFLUM FRERICHS 1976 26253 PFLUM FRERICHS 1976 26254 PFLUM FRERICHS 1976 26255 PFLUM FRERICHS 1976 26256 PFLUM FRERICHS 1976 26257 PFLUM FRERICHS 1976 26258 PFLUM FRERICHS 1976 26259 PFLUM FRERICHS 1976 26260 PFLUM FRERICHS 1976 26261 PFLUM FRERICHS 1976 26262 PFLUM FRERICHS 1976 26263 PFLUM FRERICHS 1976 26264 KELLOUGH 1956 26265 KELLOUGH 1956 26266 ANDERSEN 1961 26267 CUSHMAN 1922A 26268 BOCK 1976

26269 BOCK 1976

26270 POAG 1972

26271 PARKER 1954

26272 PARKER 1954

26273 PFLUM FRERICHS 1976 26274 PFLUM FRERICHS 1976 26275 PARKER 1954

26276 PHLEGER 1956

26277 PARKER 1954

26278 PARKER 1956

26279 PARKER 1954

26280 PARKER 1954

26281 PHLEGER 1951A

26282 PHLEGER 19514

26283 CUSHMAN 1923

26284 CUSHMAN 1923

26285 CUSHMAN 1923

26286 PHLEGER 1951A

26287 PARKER 1954

26288 PARKER 1954

26289 PFLUM FRERICHS 1976

26290 PFLUM FRERICHS 1976

26291 PFLUM FRERICHS 1976

26292 PFLUM FRERICHS 1976

26293 PFLUM FRERICHS 1976

26294 PFLUM FRERICHS 1976

26295 PFLUM FRERICHS 1976

26296 PARKER 1954

26297 PHLEGER 1951A

26298 PHLEGER 1951A

26299 PFLUM FRERICHS 1976

26300 PFLUM FRERICHS 1976

26301 PFLUM FRERICHS 1976

26302 PFLUM FRERICHS 1976

26303 PFLUM FRERICHS 1976

26304 PFLUM FRERICHS 1976

26305 PFLUM FRERICHS 1976

26306 PFLUM FRERICHS 1976

26307 PFLUM FRERICHS 1976

26308 PFLUM FRERICHS 1976

26309 PFLUM FRERICHS 1976

26310 PFLUM FRERICHS 1976

26311 PFLUM FRERICHS 1976

26312 PFLUM FRERICHS 1976

26313 PFLUM FRERICHS 1976

26314 PFLUM FRERICHS 1976

26315 PARKER 1954

26316 BOCK 1976

26317 PARKER 1954

26318 PARKER 1354

26319 PFLUM FRERICHS 1976

26320 PFLUM FRERICHS 1976

26321 PFLUM FRERICHS 1976

26322 PFLUM FRERICHS 1976

26323 PHLEGER 1951 A

26324 PHLEGER 1951A

26325 PHLEGER 1951 A

26326 PHLEGER 1951A

26327 PHLEGER $1951 \mathrm{~A}$

26328 PARKER 1954

26329 PARKER 1954

26330 PARKER 1954
Generic Name

Specific Name

Locality

Lat. Long.

TOLYPAMM IN A

TOLYPAMMINA

TOLYPAML INA

TOSAIA

TOSAIA

TOSAIA

TOSAIA

TOSAIA

TOSAIA

TOSAIA

TOSAIA

TOSAIA

TOSAIA

TOSAIA

TOSAIA

TOSAIA

TOSAIA

TOSAIA

TOSAIA

TOSAIA

TOSAIA

TOSAIA

TOSAIA

TOSAIA

CYMBALOPORETTA

CYMBALOPORETTA

CYMBALOPORETTA

ROSALINA

ROSALINA

TR IFAR INA

TRIFARINA

TRIFARINA

TR IFARINA

TRIFARINA

TR IFAR INA

TRIFARINA

TR I FAR INA

TRIFAR INA

TR IFARINA

TR I FAR INA

TR IFAR INA

TR IFARINA

TRIFARINA

TRIFARINA

TR IFAR INA

TRIFAR INA

TR IFAR INA

TR IFARINA

TR I FAR I NA

TR IFARINA

TR IFAR INA

TR IFAR INA

TR I FAR INA

TRIFARINA

TRIFARINA

TR IFARINA

TR IFARINA

TRIFARINA

TR IFARINA

TR IFAR INA

TR I FAR I NA

TR IFAR INA

TR IFAR INA

TR IFAR INA

TR IFAR INA

TR IFARINA

TR IFARINA

TR IFAR INA

TRIFAR INA

TR IFARINA

TR IFAR INA

TRIFARINA

TR IFARINA

TR IFARINA

TR IFARINA

TR IFAR I NA

TR IFARINA

TR I FAR I NA

TR IFAR INA

TR I FAR INA

TR IFAR INA

TR IFARINA

TR IFARINA

TR IFARINA

TR IFAR INA

TR IFARINA

TR IFAR INA

TR IFAR INA

TR IFAR I NA

TR IFAR INA

TR IFAR INA
SC HAUDINN I

VAGANS

WE AVER I

WEAVERI

WE AVER

WEAVERI

WE AVER I

WE AVER I

WEAVER

WE AVERI

WEAVER

WE AVERI

WE AVER I

$\checkmark E A V E R$

WE AVERI

WEAVERI

WE AVER

WE AVERI

WE AVER I

WEAVER I

WE AVER I

WE AVERI

AT LANTICA

ATLANTICA

GLOBULARIS

GL CBULARIS

BELLA

BR ADY I

BR ADYI

BRADYI

BRADYI

BRADYI

BRADYI

BR ADYI
BR ADYI

BR ADYI
BR ADYI

BRADYI

BRADYI

BR ADYI

BR ADY I

BRADYI

BR ADYI

BR ADYI

BRADYI

BRADYI

BRADYI

BR ADYI

BRADYI

BR ADY I

BRADYI

BRADYI

BRADYI

BRADYI

BRADYI

BRADYI

BR ADY I

BRADYI

BRADYI

BRADYI

BRADYI

BRADYI

BR ADYI

BRADYI

BRADYI

BRADYI

BR ADYI

BR ADYI

BRADYI

BRADYI

BRADYI

BRADYI

BR ADYI

BR ADYI

BRADYI

BRADYI

BRADYI

BRADYI

BR ADYI

BR ADY I

BRADYI

BRAOY

BRAOYI

BR ADYI
BRADYI
SC HAUDINN I

SCHAUDINN I

$N W$ GULF OF MEXICO

NW GULF OF MEXICO

CENTRAL GULF OF MEXICO

$N$ GULF OF MEXICO

$N W$ GULF OF MEXICO

$N \backsim$ GULF OF MEXICO

$N W$ GULF OF MEXICO

NW GULF OF MEXICO

NH GULF OF MEXICO

NW GULF OF MEXICO 


\section{Publication}

26331 PHLEGER 1951 A 26332 PHLEGER 1951 A 26334 PHLEGER 1951 A 26335 PHLEGER $1951 \mathrm{~A}$ 26336 PHLEGER $1951 \mathrm{~A}$ 26337 PHLEGER $1951 \mathrm{~A}$ 26338 PHLEGER $1951 \mathrm{~A}$ 26339 PHLEGER 1951 A 26340 PHLEGER 1951 A 26341 PHLEGER 1951 A

26342 LUDWICK WALTON 1957

26343 PHLEGER $1951 \mathrm{~A}$

26344 PHLEGER 1951

26345 LEROY HODGKINSON 1975

26346 BOCK 1976

26347 QQE

26348 BANDY 1956

26349 BANDY 1956

26350 BANDY 1956

26351 BOCK 1976
26352 CUSHMAN 1922

26353 NORTON 1930

26354 PARKER 1954

26355 PARKER 1954

26356 PARKER 1954

26357 PARKER 1954

26358 PARKER 1954

26359 PARKER 1954

26360 PARKER 1954

26361 WALTON 1964

26362 BOCK 1976

26363 PARKER 1954

26364 PARKER 1954

26365 PARKER 1954

26366 PARKER 1954

26367 SHIFFLETT 1961

26368 LUDWICK WALTON 1957

26369 PARKER 1954

26370 PARKER 1954

26371 LANKFORD 1959

26372 DAVIS 1964

26373 NORTON 1930

26374 CUSHMAN $1922 \mathrm{~A}$

26375 BENDA PURI 1962

26376 KELLOUGH 1956

26377 SEGURA 1963

26378 NORTON 1930

26379 KELLOUGH 1956

26380 KELLOUGH 1956

26381 KELLOUGH 1956

26382 CUSHMAN $1922 \mathrm{~A}$

26383 LEHMANN 1957

26384 NORTON 1930

26385 DAVIS 1964

26386 CUSHMAN $1922 \mathrm{~A}$

26387 DAVIS 1964

26388 NORTON 1930

26389 BENDA PURI 1962

26390 PARKER PHLEGER PEIRSON 1953

26391 PARKER PHLEGER PEIRSON 1953

26392 PARKER PHLEGER PEIRSON 1953

26393 BOCK 1976

26394 CUSHMAN 1922 A

26395 BOCK 1976

26396 ANDERSEN 196

26397 NORTON 1930

26398 CUSHMAN 1922

26399 DAVIS 1964

26400 NORTON 1930

26401 DAVIS 1964

26402 NORTON 1930

26403 VAUGHAN 1918

26404 VAUGHAN 1918
26405 CUSHMAN 1922 A

26406 POST 1951

26407 BENDA PURI 1962

26408 BANDY 1956

26409 BANDY 1956

26410 BANDY 1956

26411 BANDY 1956

26412 BOCK 1976

26413 BANDY 1956

26414 KORNFELD 1931

26415 DAVIS 1964

26416 WARREN 1957

26417 KORNFELD 1931

26418 KORNFELD 193

26419 SEGURA 1963

26420 CUSHMAN 1922A

26421 PHLEGER 1960

26422 SHIFFLETT 1961

26423 BENDA PURI 1962

26424 BENDA PURI 1962

26425 NORTON 1930
Generic Name

TR IFAR INA

TR IFAR I NA

TR IFAR INA

TR I FAR I NA

TR IFAR INA

TR IFAR I NA

TR IFAR INA

TRIFARINA

TR IFAR INA

IR IFAR INA

TRIFARINA

TR IFAR I NA

TRIFARINA

TR ILOCUL INA

IRILOCULINA

TRILOCULINA

TRILOCULINA

TRILOCULINA

TR IL OCULINA

TR ILOCULINA

TR ILOCUL INA

TR ILOCULINA

TR ILOCULINA

TR ILOCULINA

TRILOCULINA

TR I LOCULINA

TRIL OCUL INA

TR ILOCULINA

TRILOCULINA

TRILOCULINA

TRILOCULINA

TR ILOCUL INA

TR ILOCULINA

TRILOCULINA

TRILOCULINA

TRI LOCULINA

TRILOCULINA

TRILOCULINA

TRILOCULINA

TR I LOCULINA

TRILOCULINA

TRILOCULINA

MI LIOL INELLA

MI LIOLINELLA

MI LI OL I NELLA

MI L I OL I NELL A

MI LIOLINELLA

MI LI OLI NELLA

MI LIOLINELLA

MI LIOLINELL

TRILOCULINA

MILIOLINELLA

MILIOLINELLA

MI LIOLINELLA

TRILOCULINA

TRILOCULINA

TRILOCULINA

TRILOCULINA

TRILOCULINA

TR I LOCULINA

TRILOCULINA

TRILOCULINA

TRILOCULINA

TRI LOCULINA

TRILOCULINA

TRIL OCUL INA

TRILOCULINA

TRILOCULINA

TRILOCULINA

TRI LOCULINA

TRILOCUL INA

TRILOCULINA

TRILOCULINA

TRILOCULINA

TRILOCULINA

TRILOCULINA

TR ILOCULINA

TRILOCULINA

TRILOCULINA

TR ILOCULINA

TRILOCULINA

TRILOCULINA

TRILOCULINA

TRILOCULINA

TRILOCULINA

TR ILOCULINA

TR I LOCULINA

TRIL OCULINA

TRILOCULINA

TR ILOCULINA

TRILOCULINA
Specific Name

Locality

NW GULF OF MEXICO

NW GULF OF MEXICO

NW GULF OF MEXICO

NW GULF OF MEXICO

NW GULF OF MEXICO

NW GULF OF MEXICO

NW GULF OF MEXICO

NW GULF OF MEXICO

$N W$ GULF OF MEXICO

$\mathrm{NW}$ GULF OF MEXICO

NW GULF OF MEXICO

NE GULF OF MEXICO

NW GULF OF MEXICO

NW GULF OF MEXICO

$\checkmark$ GULF OF MEXICO

NE GULF OF MEXICO

NE GULF OF MEXICO

NE GULF OF MEXICO

NE GULF OF MEXICO

TAMPA BAY, FLA.

NE GULF OF MEXICO

TORTUGAS

TORTUGAS, FLA

NE GULF OF MEXICO

NE GULF OF MEXICO

NE GULF OF MEXICO

NE GULF OF MEXICO

NE GULF OF MEXICO

NE GULF OF MEXICO

NE GULF OF MEXICO

TAMPA-SARASOTA BAY, FLA.

NE GULF OF MEXICO

NE GULF OF MEXICO

NE GULF OF MEXICO

NE GULF OF MEXICO

NE GULF OF MEXICO

HEALD BANK, G. OF MEXICO

NE GULF OF MEXICO

NE GULF OF MEXICO

NE GULF OF MEXICO

MISSISSIPPI DELTA

CAMPECHE BANK, MEXICO

TORTUGAS, FLA

TORTUG AS

CAPE ROMANO, FLA.

NW GULF OF MEXICO

MATAMOROS, MEXICO

TORTUGAS, FLA

NW GULF OF MEXICO

NW GULF OF MEXICO

NW GULF OF MEXICO

TORTUG AS

TEXAS GULF COAS

TORTUGAS, FLA

CAMPECHE BANK, MEXICO

TORTUGAS

CAMPECHE BANK, IAEXICO

TORTUGAS, FLA

CAPE ROMANO, FLA.

TEXAS GULF COAST

TEXAS GULF COAST

TEXAS GULF COAST

NE GULF OF MEXICO

TORTUGAS

NE GULF OF MEXICO

MISSISSIPPI DELTA

TORTUGAS, FLA

TOR TUG AS

CAMPECHE BANK, MEXICO

TORTUGAS,

CAMPECHE BANK, MEXICO

TORTUGAS, FLA

FLORIDA KEYS

FLORIDA KEY

TORTUGAS

SOUTH TEXAS COAST

CAPE ROMANO, FLA.

NE GULF OF MEXICO

NE GULF OF MEXICO

NE GULF OF MEXICO

NE GULF OF MEXICO

NE GULF OF MEXICO

NE GULF OF MEXICO

TEXAS GULF COAST

CAMPECHE BANK, MEXICO

SE LOUISIANA

TEXAS GULF COAST

TEXAS GULF COAS

MATAMOROS, MEXICO

TORTUGAS

LAGUNA MADRE, TEXAS

HEALD BANK, G. OF MEXICO

CAPE ROMANO, FLA.

CAPE ROMANO, FLA.

TORTUGAS, FLA

Lat. Long.

$2746 \mathrm{~N} 09447 \mathrm{~W}$ $2718 \mathrm{~N} 096 \quad 14 \mathrm{~W}$ $2759 \mathrm{~N} 096 \quad 06 \mathrm{~W}$ $2659 \mathrm{~N} 096 \quad 11 \mathrm{~W}$ $2820 \mathrm{~N} 09519 \mathrm{~W}$ $2723 \mathrm{~N} 09534 \mathrm{~W}$ 


\section{Publication}

26426 POST 1951

26427 KORNFELD 1931

26428 CUSHMAN 1922 A

26429 NORTON 1930

26430 DAVIS 1964

26431 CUSHMAN 1922 A

26432 NORTON 1930

26433 BOCK 1976
26434 CUSHMAN 1922 A

26435 NORTON 1930

26436 LEHMANN 1957

26437 PHLEGER $1955 \mathrm{~B}$

26438 LANKFORD 1959

26439 PARKER PHLEGER PEIRSON 1953

26440 PHLEGER LANKFORD 1957

26441 KANE 1967

26442 KANE 1962

26443 PARKER PHLEGER PEIRSON 1953

26444 PARKER PHLEGER PEIR SON 1953

26445 PARKER PHLEGER PEIRSON 1953

26446 PARKER PHLEGER PEIRSON 1953

26447 PHLEGER 1956

26448 PARKER PHLEGER PEIRSON 1953

26449 PHLEGER $1965 \mathrm{~A}$

26450 PHLEGER $1965 \mathrm{~A}$

26451 ANDERSON 1968

26452 BENDA PURI 1962

26453 PHLEGER 1965 A

26454 PHLEGER $1965 \mathrm{~A}$

26455 PHLEGER 1965A

26456 PARKER PHLEGER PEIRSON 1953

26457 PARKER PHLEGER PEIRSON 1953

26458 PARKER PHLEGER PEIRSON 1953

26459 OTVOS 1978

26460 WALTON 1960

26461 WALTON 1964

26462 PHLEGER 1965 A

26463 DAVIS 1964

26464 SANDY 1954

26465 BANDY 1954

26466 BANDY 1954

26467 BANDY 1954

26468 BANDY 1954

26469 BANDY 1954

26470 SHIFFLETT 1961

26471 BENDA PURI 1962

26472 SEGURA 1963

26473 SHIFFLETT 1961

26474 NORTON 1930

26475 CUSHMAN $1922 \mathrm{~A}$

26476 NORTON 1930

26477 PFLUM FRERICHS 1976

26478 PFLUM FRERICHS 1976

26479 PFLUM FRERICHS 1976

26480 CUSHMAN $1922 \mathrm{~A}$

26481 SEGURA 1963

26482 PARKER 1954

26483 PHLEGER 1955 A

26484 PARKER 1954

26485 PARKER 1954

26486 LANKFORD 1959

26487 PFLUM FRERICHS 1976

26488 PFLUM FRERICHS 1976

26489 PFLUM FRERICHS 1976

26490 PFLUM FRERICHS 1976

26491 PFLUM FRERICHS 1976

26492 PFLUM FRERICHS 1976

26493 PFLUM FRERICHS 1976

26494 PFLUM FRERICHS 1976

26495 PARKER 1954

26496 PARKER 1954

26497 PARKER 1954

26498 PARKER 1954

26499 PARKER 1954

26500 PARKER 1954

26501 BOCK 1976

26502 PFLUM FRERICHS 1976

26503 PFLUM FRERICHS 1976

26504 ANDERSEN 1961

26505 PFLUM FRERICHS 1976

26506 PFLUM FRERICHS 1976

26507 PFLUM FRERICHS 1976

26508 PARKER 1954

26509 PFLUM FRERICHS 1976

26510 PARKER 1954

26511 PARKER 1954

26512 PARKER 1954

26513 PARKER 1954

26514 PFLUM FRERICHS 1976

26515 PHLEGER 1955 A

26516 PHLEGER 1955A

26517 PFLUM FRERICHS 1976

26518 BANDY 1956

26519 WALTON 1964

26520 BANDY 1956

\section{Generic Name}

TRILOCULINA

TRILOCULINA

TRILOCULINA

TRILOCULINA

TRILOCULINA

TRILOCULINA

TRILOCUL INA

TRILOCULINA

TRILOCULINA

TRILOCULINA

TRILOCULINA

TRILOCUL INA

TRILOCULINA

TRILOCULINA

TRILOCUL INA

TRILOCULINA

TRILOCULINA

TRILOCULINA

TR ILOCULINA

TRILOCULINA

TRILOCULINA

TRILOCULINA

TRILOCULINA

TRILOCULINA

TRILOCULINA

TRIL OCULINA

TRILOCULINA

TRI LOCULINA

TRILOCULINA

TRILOCULINA

TRILOCULINA

TRILOCUL INA

TR ILOCULINA

TRILOCULINA

TRILOCULINA

TRILOCULINA

TRILOCULINA

TRILOCULINA

TRILOCULINA

TRILOCULINA

TRILOCULINA

TRILOCULINA

TRILOCULINA

TRILOCULINA

TR ILOCULINA

TRILOCULINA

TR ILOCULINA

TR ILOCULINA

TRILOCULINA

TRI LOCULINA

TRILOCULINA

TRILOCULINA

TR I LOCUL INA

TRILOCULINA

TRILOCULINA

TRILOCULINA

TRILOCULINA

TRILOCULINA

TRILOCULINA

TRILOCULINA

TRILOCULINA

TR ILOCULINA

TRILOCULINA

TRILOCULINA

TRILOCUL INA

TRILOCULINA

TRILOCULINA

TRILOCUL INA

TRILOCULINA

TRILOCULINA

TRILOCULINA

TRILOCULINA

TRILOCULINA

TRILOCULINA

TR ILOCULINA

TRILOCULINA

TR ILOCULINA

TRILOCULINA

TRILOCULINA

TRILOCULINA

TRI I OCUL INA

TRILOCULINA

TR ILOCULINA

TP. I LOCULINA

TRILOCULINA

TRILOCULINA

TRILOCULINA

TR ILOCUL INA

TRILOCULINA

TRILOCULINA

TRILOCULINA

TRILOCULINA

TRILOCULINA
Specific Name

OBLONGA

OB LDNGA

PL ANC I ANA

PL ANCI ANA

QU ADRILATERAL IS

QUADRILATERAL IS

RO TUNDA

RO TUNDA

RO TUNDA

SI DEBOT TOMI

SI DEBOTTOMI

SI CEBOTTOMI

SI DEBOTTOMI

SI DEBOTTOMI

SI CEBOTTOMI

SI DEBOTTOMI

SI DEBOTTOMI

SI CEBOT TOMI

SI DEBOTIOMI

SI CEBOTTOMI

SI DEBOTTOMI

SI DEBOTTOMI

SI DEBOTTOMI

SI DEBOT TOMI

SI DEBOTTOMI

SI DEBOTTOMI

SI DEBOT TOMI

SI DEBOT TOMI

SI DEBOTTOMI

SI CEBOTTOMI

SI DEBOTTOMI

SI CEBOTTOMI

SI CEBOTTOMI

SI DEBOT TOMI

SI DEBOT TOMI

SI DEB OT TOMI

SQLAMOSA

SQLAMOSA

SQLAMOSA

SQLAMOSA

SQLAMOSA

SQLAMOSA

SQLAMOSA

SQLAMOSA

STRIATOTR IGONULA

SU BORBI CULARIS

SUBORBI CULARIS

TE RQUEMIANA

TR ANSVERSESTR I ATA

TR ANS VERS ES TR I ATA

TR ICARINATA

TR ICARINATA

TR ICARINATA

TRICARINATA

TR ICARINATA

TR ICARINATA

TR ICARINATA

TR ICARINATA

TR ICARINATA

TR ICARINATA

TRICARINATA

TR ICARINATA

TR ICARINATA

TR ICARINATA

TR I CARINATA

TR ICARINATA

TR ICARINATA

TR ICARINATA

TR I CARINATA

TR ICARINATA

TR ICARINATA

TR ICARINATA

TR ICARINATA

TR ICARINATA

TR ICARINATA

TR ICARINATA

TR ICARINATA

TR ICARINATA

TRICARINATA

IR ICARINATA

TR I CARINATA

IR ICARINATA

TR ICARINATA

TR ICAR INA TA

TR ICARINATA

IR ICARINATA

TR ICARINATA

TR I CARINATA

TR ICARINATA

TR ICARINATA

TR ICARINATA

TR IGONULA

TRIGONULA

Locality

Lat. Long.

SOUTH TEXAS COAST

LOUISIANA GULF COAST

TORTUGAS 


\section{Publication}

26521 BENDA PURI 1962

26522 BANDY 1956

26523 BANDY 1956

26525 BANDY 1956

26526 NORTON 1930

26527 BANOY 1956

26528 PFLUM FRERICHS 1976

26529 PFLUM FRERICHS 1976

26530 BANDY 1956

26531 BANDY 1956

26532 BANDY 1956

26533 PFLUM FRERICHS 1976

26534 PFLUM FRERICHS 1976

26535 SHIFFLETT 1961

26536 SEGURA 1963

26537 CUSHMAN 1922 A

26538 BOCK 1976

26539 BANDY 1956

26540 BANOY 1956

26541 BANDY 1956

26542 BANDY 1956

26543 PFLUM FRERICHS 1976

26544 PFLUM FRERICHS 1976

26545 PFLUM FRERICHS 1976

26546 PFLUM FRERICHS 1976

26547 PFLUM FRERICHS 1976

26548 PFLUM FRERICHS 1976

26549 PFLUM FRERICHS 1976

26550 ANDERSEN 1961

26551 BANDY 1954

26552 BANDY 1956

26553 BANDY 1956

26554 BANDY 1954

26555 AYALA-CASTANARES 1963

26556 BANDY 1954

26558 PFLUM FRERICHS 1976

26559 BANDY 1956

26560 BANDY 1956

26561 PARKER PHLEGER PEIRSON 1953

26562 PARKER PHLEGER PEIRSON 1953

26563 POST 1951

26564 KELLOUGH 1956

26565 ANDERSON 1968

26566 BANDY 1956

26567 BANDY 1956

26568 BANDY 1954

26569 BANDY 1954

26570 BANDY 1956

26571 BANDY 1956

26572 BANDY 1954

26573 KANE 1967

26574 PHLEGER 19658

26575 PARKER PHLEGER PEIRSON 1953

26576 PHLEGER 1956

26577 KANE 1962

26578 SE GURA 1963

26579 PARKER PHLEGER PEIRSON 1953

26580 PHLEGER 1960

26581 PARKER PHLEGER PEIRSON 1953

26582 BENDA PURI 1962

26583 BENDA PURI 1962

26584 BENDA PURI 1962

26585 PARKER PHLEGER PEIRSON 1953

26586 PHLEGER 1965

26587 PARKER PHLEGER PEIRSON 1953

26588 PARKER PHLEGER PEIRSON 1953

26589 PARKER PHLEGER PEIRSON 1953

26590 PFLUM FRERICHS 1976

26591 PFLUM FRERICHS 1976

26592 PFLUM FRERICHS 1976

26593 PFLUM FRERICHS 1976

26594 PFLUM FRERICHS 1976

26595 PFLUM FRERICHS 1976

26596 PFLUM FRERICHS 1976

26597 PFLUM FRERICHS 1976

26598 PFLUM FRERICHS 1976

26599 PFLUM FRERICHS 1976

26600 PFLUM FRERICHS 1976

26601 BOCK 1976

26602 PFLUM FRERICHS 1976

26603 PFLUM FRERICHS 1976

26604 PFLUM FRERICHS 1976

26605 PFLUM FRERICHS 1976

26606 PFLUM FRERICHS 1976

26607 CREAGER 1958

26608 PFLUM FRERICHS 1976

26609 PFLUM FRERICHS 1976

26610 PHLEGER 1951 A

26611 PHLEGER 1951 A

26612 NORTON 1930

26613 PHLEGER 1951 A

26614 PHLEGER $1951 \mathrm{~A}$
26615 PHLEGER $1951 \mathrm{~A}$

\section{Generic Name}

TRILOCULINA

TRILOCULINA

TR ILOCULINA

TRILOCULINA

TRIL OCUL INA

TRILOCULINA

TRILOCULINA

TRILOCULINA

TRILOCULINA

TRILOCULINA

TRILOCULINA

TR ILOCULINA

TRILOCULINA

TRILOCULINA

TRILOCULINA

TRILOCULINA

TRILOCUL INA

TRILOCULINA

TRILOCULINA

TRILOCULINA

TRILOCULINA

TRILOCULINA

TRILOCULINA

TRILOCULINA

TRILOCULINA

TRIL OCULINA

TR ILOCUL INA

TRILOCULINA

TRILOCULINA

TRILOCULINA

TRILOCULINA

TRIL OCULINA

TRILOCULINA

TRILOCUL INA

TR IL OCULINA

TRILOCUL INA

TRILOCUL INA

TRILOCUL INA

TRILOCULINA

TR IL OCUL INA

TRILOCULINA

TRILOCULINA

TRIL OCUL INA

TRILOCULINA

TRIL OCUL INA

TRILOCULINA

TRILOCUL INA

TRILOCULINA

TRILOCULINA

TR ILOCUL INA

TRILOCULINA

MILIOL INELLA

MI LI OL I NELL A

M I LIOLINELLA

MI LI OL I NELLA

MILIOL INELLA

MILI OL INELLA

MILIOL INELLA

MILIOLINELLA

MILIOL INELLA

MILIOLINELLA

MI L I OL INELLA

MILIOL INELLA

MILIOLINELLA

MILIOL INELLA

MILI OL INELLA

MI L I OLINELLA

TRITAXIS

TRITAXIS

TRITAXIS

TRITAXIS

TRITAXIS

TRITAXIS

TRITAXIS

TRITAXIS

TRITAXIS

TR ITAXIS

TROCHAMMINA

TROCHAMMINA

TROCHAMMINA

TROCHAMMINA

TROCHAMMINA

TROCHAMM INA

TROCHAMMINA

TROCHAMMINA

TROCHAMMINA

TROCHAMMINA

TROCHAMMINA

TROCHAMMINA

TROCHAMMINA

TROCHAMMINA

TROCHAMMINA

TROCHAMMINA
Specific Name

TR IGONULA

TR IGONULA

TR I GONULA

IR IGONULA

TR I GONULA

TR IGONULA

TR IGONULA

TR IGONULA

TR I GONULA

TR IGONUL A

TR IGONULA

TR IGONUL A

TR IGONUL $A$

TR IGONULA

TR I GONUL A

TR IGONULA

TR I GONULA

TR I GONUL A

TRIGONULA

TR I GONUL A

TR I GONULA

TR IGONULA

TR IGONULA

TR I GONULA

TR IGONULA

TR IGONULA

TR I GONULA

TR IGONULA

TR IGONULA

TR I GONULA

TR IGONULA

TR I GONULA

TR IGONULA

TR I GONULA

TR IGONULA

TRIGONULA

TR IG ONUL A

TR IGONULA

TR I GONULA

TR I GONUL A

TR IGONULA

TR IGONULA

TR I GONULA

TR I GONULA

TR I GONULA

TR IGONULA

TR IGONULA

TR IGONULA

TR I GONULA

TR IGONULA

TR IGONULA

OBLIQUINODA

OBLIQUINODA

OBLIQUINODA

OBLIQUINODA

OBLIQUINODA

OBLIQUINODA

OBLIQUINODA

OBLIQUINODA

OBLIQUINODA

OB LIQUINODA

OBLIQUINODA

OBLIQUINODA

OBLIQUINODA

OBLIQUINODA

OBLIQUINODA

OBLIQUINODA

CONICA

CONICA

COAICA

CONICA

COAICA

FUSCA

FUSCA

FUSCA

FUSCA

FUSCA

ADVENA

AD VENA

ADVENA

ADVENA

A DVENA

ADVENA

ADVENA

ADVENA

A D VENA

ADVENA

ADVENA

ADVENA

ADVENA

ADVENA

AD VENA

AD VENA

\section{Locality}

CAPE ROMANO, FLA.

NE GULF OF MEXICO

CAL OOSAHATCHEE R., FLA. 


\section{Publication}

26616 PHLEGER 1951A 26617 PHLEGER $1951 \mathrm{~A}$ 26618 PHLEGER 1951A 26619 PHLEGER $1951 \mathrm{~A}$ 26620 PHLEGER 1951A 26621 PHLEGER 1951A 26622 PHLEGER 1951A 26623 PHLEGER 1951 A 26624 PARKER 1954 26625 PHLEGER $1951 \mathrm{~A}$ 26626 PHLEGER $1951 \mathrm{~A}$ 26627 PHLEGER 1951A 26628 PHLEGER 1951 A 26629 PARKER 1954 26630 PARKER 1954 26631 PARKER 1954 26632 PARKER 1954 26633 PARKER 1954

26634 LUDWICK WALTON 1957

26635 PFLUM FRERICHS 1976

26636 CUSHMAN $1922 \mathrm{~A}$

26637 PHLEGER 1951 A

26638 PFLUM FRERICHS 1976

26639 PHLEGER 1954

26640 PHLEGER 195

26641 KANE 1967

26642 KANE 1962

26643 SHEPARD MOORE 1955

26644 WALORON 1963

26645 WARREN 1956

26646 PARKER PHLEGER PEIRSON 1953

26647 PHLEGER 1956

26648 PHLEGER 1954

26649 WARREN 1957

26650 PHLEGER 1954

26651 PFLUM FRERICHS 1976

26652 PFLUM FRERICHS 1976

26653 LEROY HODGKINSON 1975

26654 CUSHMAN 1920

26655 CUSHMAN 1920

26656 CUSHMAN 1920

26657 CUSHMAN 1920

26658 CUSHMAN 1920

26659 PFLUM FRERICHS 1976

26660 PFLUM FRERICHS 1976

26661 PFLUM FRERICHS 1976

26662 CUSHMAN 1920

26663 CUSHMAN 1920

26664 CUSHMAN 1920

26665 PFLUM FRERICHS 1976

26666 PFLUM FRERICHS 1976

26667 PFLUM FRERICHS 1976

26668 PFLUM FRERICHS 1976

26669 PFLUM FRERICHS 1976

26670 PFLUM FRERICHS 1976

26671 PFLUM FRERICHS 1976

26672 PFLUM FRERICHS 1976

26673 PFLUM FRERICHS 1976

26674 PFLUM FRERICHS 1976

26675 PFLUM FRERICHS 1976

26676 PFLUM FRERICHS 1976

26677 PARKER 1954

26678 PARKER 1954

26679 CUSHMAN 1920

26680 PFLUM FRERICHS 1976

26681 PFLUM FRERICHS 1976

26682 PFLUM FRERICHS 1976

26683 PARKER 1954

26684 PARKER 1954

26685 PFLUM FRERICHS 1976

26686 PFLUM FRERICHS 1976

26687 PFLUM FRERICHS 1976

26688 PFLUM FPERICHS 1976

26689 PFLUM FRERICHS 1976

26690 PFLUM FRERICHS 1976

26691 PFLUM FRERICHS 1976

26692 PFLUM FRERICHS 1976

26693 PFLUM FRERICHS 1976

26694 PFLUM FRERICHS 1976

26695 PFLUM FRERICHS 1976

26696 PFLUM FRERICHS 1976

26697 PFLIJM FRERICHS 1976

26698 PFLUM FRERICHS 1976

26699 PFLUM FRERICHS 1976

26700 PFLUM FRERICHS 1976

26701 PFLUM FRERICHS 1976

26702 PFLUM FRERICHS 1976

26703 PFLUM FRERICHS 1976

26704 PFLUM FRERICHS 1976

26705 PARKER 1954

26706 PARKER 1954

26707 PARKER 1954

26708 PARKER 1954

26709 PFLUM FRERICHS 1976

26710 PFLUM FRERICHS 1976

\section{Generic Name \\ Specific Name}

TR OCHAMMINA

TROCHAMMINA

TROCHAMMINA

TROCHAMMINA

TROCHAMMINA

TROCHAMMINA

TROCHAMMINA

TROCHAMMINA

TROCHAMMINA

TROCHAMMINA

TROCHAMMINA

TROCHAMMINA

TROCHAMMINA

TROCHAMMINA

TROCHAMMINA

TROCHAMMINA

TROCHAMMINA

TRDCHAMMINA

TROCHAMMINA

TROCHAMM INA

TI PHOTROCHA

TI PHOTROCHA

TIPHOTROCHA

TIPHOTROCHA

TIPHOTROCHA

TI PHOTROCHA

TI PHOTR OCHA

TI PHOTROCHA

TIPHOTROCHA

TIPHOTROCHA

IIPHOTR OCHA

TIPHOTROCHA

TROCHAMMINA

TROCHAMMINA

TROCHAMMINA

TROCHAMMINA

TROCHAMMINA

TROCHAMMINA

TROCHAMMINA

TROCHAMMINA

TROCHAMMINA

TROCHAMMINA

TROCHAMMINA

TROCHAMMINA

TROCHAMMINA

TROCHAMMINA

TROCHAMMINA

TROCHAMMINA

TROCHAMMINA

TROCHAMMINA

TROCHAMMINA

TROCHAMMINA

TROCHAMMINA

TROCHAMMINA

TROCHAMMINA

TROCHAMMINA

TROCHAMMINA

TROCHAMMINA

IROCHAMMINA

TROCHAMMINA

TROCHAMMINA

TROCHAMMINA

TROCHAMMINA

TROCHAMMIN A

TROCHAMMINA

TROCHAMMINA

TROCHAMMINA

TROCHAMMINA

TROCHAMMINA

TROCHAMMINA

TROCHAMMINA

TROCHAMMINA

TROCHAMMINA

TROCHAMMINA

TR OCHAMMINA

TROCHAMMINA

TROCHAMMINA

TROCHAMMINA

TROCHAMMINA

TROCHAMMINA

TROCHAMMINA

TROCHAMMINA

TROCHAMMINA

TR OCHAMMINA

TROCHAMMINA

TROCHAMMINA
TR OCHAMMINA

TR OCHAMMINA
TROCHAMMINA

TROCHAMMINA

TROCHAMMINA
TROCHAMMINA
ADVENA

ADVENA

A DVENA

A DVENA

ADVENA

A DVENA

ADVENA

ADVENA

A DVENA

AD VENA

ADVENA

A D VENA

ADVENA

ADVENA

ADVENA

ADVENA

A D VENA

ADVENA

ADVENA

ADVENA

ADVENA

A D VENA

CONPRIMATA

CONPRIMATA

CONPRIMATA

CONPRIMATA

CONPRIMATA

CONPR IMATA

CONPRIMATA

CONPRIMATA

CONPR IMATA

CONPRIMATA

CONPRIMATA

CONPR IMATA

CONGL OBATA

COAGL OBATA

GL CBIGER IN I F ORMIS

GL CBIGERINI FORMIS

GL CBIGERINI FORMIS

GL CBIGERINI FORMIS

GL CBIGERINI FORMIS

GL CBULOSA

GL CBUL OSA

GL CBUL OSA

GL CBUL OSA

GL CBULOSA

GL CBULOSA

GL CBULOSA

GL OBULOSA

GL OBULOSA

GL CBULOSA

GL CBULOSA

GL CBULOSA

GL OBULOSA

GL CBULOSA

GL CBULOSA

GL CBUL OSA

GL CBULOSA

GLOBULOSA

GL CBULOSA

GL CBULOSA

GL CBULOSA

GL OBULOSA

GL CBULOSA

GL OBULOSA

GLOBULOSA

GL CBULOSA

GL OBULOSA

GL OBULOSA

GL CBULOSA

GL CBULOSA

GL CBULOSA

GL CBULOSA

GL CBULOSA

GL CBULOSA

GL CBULOSA

GL CBULOSA

GLCBULOSA

GL CBULOSA

GL CBULOSA

GLCBULOSA

GL CBULOSA

GL CBULOSA

GLOBULOSA

GL CBULOSA

GL CBULOSA

GLCBULOSA

GLCBULOSA

GL CBULOSA

GL CBULOSA

GL CBULOSA

GL CBULOSA

GLCBULOSA

GL OBULOSA

\section{Locality}

NW GULF OF MEXICO

NW GULF OF MEXICO

$N W$ GULF OF MEXICO 


\section{Publication}

26711 PFLUM FRERICHS 1976 26712 PFLUM FRERICHS 1976 26713 PFLUM FRERICHS 1976 26714 PFLUM FRERI.CHS 1976 26715 DARKER 195 26716 PARKER 1954 26717 PFLUM FRERICHS 1976 26718 PFLUM FRERICHS 1976 26719 PARKER 1954 26720 PARKER 1954 26721 PARKER 1954

26722 LUDWICK WALTON 1957 26723 PFLUM FRERICHS 1976 26724 PARKER 1954

26725 SHEPARD MOORE 1955

26726 LEHMANN 1957

26727 PHLEGER $1965 \mathrm{C}$

26728 PHLEGER 1954

26729 LANKFORD 1959

26730 WALORON 1963

26731 PHLEGER 1965 A

26732 PHLEGER 1965 A

26733 PHLEGER $1965 \mathrm{~A}$

26734 PHLEGER $1965 \mathrm{~A}$

26735 PHLEGER 1965 A

26736 PHLEGER 1965 A

26737 PHLEGER 1965 A

26738 CUSHMAN 1920

26739 OTVOS 1978
26740 PHLEGER LANKFORD 1978

26741 POST 1951

26742 KANE 1967

26743 KANE 1962

26744 PHLEGER 1954

26745 PHLEGER 1954

26746 PHLEGER 1954

26747 LOEP 1965

26748 PHLEGER $1965 \mathrm{~A}$

26749 WARREN 1957

26750 PHLEGER 19558

26751 PARKER PHLEGER PEIRSON 1953

26752 PARKER PHLEGER PEIRSON 1953

26753 BOCK 1976

26754 BENDA PURI 1962

26755 WARREN 1956

26756 KORNFELD 1931

26757 KORNFELD 1931

26758 KORNFELD 1931

26759 KORNFELD 1931

26760 KORNFELO 1931

26761 KORNFELD 1931

26762 KORNFELD 1931

26763 PARKER 1954

26764 PARKER 1954

26765 PFLUM FRERICHS 1976

26766 PFLUM FRERICHS 1976

26767 PFLUM FRERICHS 1976

26768 PFLUM FRERICHS 1976

26769 PARKER 1954

26770 PARKER 1954

26771 PFLUM FRERICHS 1976

26772 PFLUM FRERICHS 1976

26773 PFLUM FRERICHS 1976

26774 PFLUM FRERICHS 1976

26775 PARKER 1954

26776 PARKER 1954

26777 PFLUM FRERICHS 1976

26778 PFLUM FRERICHS 1976

26779 PFLUM FRERICHS 1976

26780 PARKER 1954

26781 PFLUM FRERICHS 1976

26782 PFLUM FRERICHS 1976

26783 PFLUM FRERICHS 1976

26784 PARKER 1954

26785 PARKER 1954

26786 PARKER 1954

26787 PARKER 1954

26788 PARKER 1954

26789 PARKER 1954

26790 PARKER 1954

26791 PFLUM FRERICHS 1976

26792 PARKER 1954

26793 PFLUM FRERICHS 1976 26794 PFLUM FRERICHS 1976 26795 PFLUM FRERICHS 1976 26796 PFLUM FRERICHS 1976 26797 PFLUM FRERICHS 1976 26798 PFLUM FRERICHS 1976 26799 PFLUM FRERICHS 1976 26800 PFLUM FRERICHS 1976 26801 PFLUM FRERICHS 1976 26802 PFLUM FRERICHS 1976 26803 PFLUM FRERICHS 1976 26804 PFLUM FRERICHS 1976 26805 PFLIJM FRERICHS 1976
Generic Name

TROCHAMMINA

TROCHAMMINA

TROCHAMMINA

TROCHAMMINA

TROCHAMMINA

TROCHAMMINA

TROCHAMMINA

TROCHAMMINA

TROCHAMMINA

TROCHAMMINA

TROCHAMMINA

TROCHAMMINA

TROCHAMMINA

TROCHAMMINA

TROCHAMMINA

TROCHAMMINA

TROCHAMMINA

TROCHAMMINA

TROCHAMMINA

TROCHAMMINA

TROCHAMMINA

TROCHAMMINA

TROCHAMMINA

TROCHAMMINA

TROCHAMMINA

TROCHAMMINA

TROCHAMMINA

TROCHAMMINA

IROCHAMMINA

TROCHAMMINA

IROCHAMMINA

TROCHAMMINA

TROCHAMMINA

TROCHAMMINA

I ROCHAMMINA

TROCHAMMINA

TROCHAMMINA

TROCHAMMINA

TROCHAMMINA

TROCHAMMINA

TROCHAMMINA

TROCHAMMINA

TR OCHAMMINA

TROCHAMMINA

TROCHAMMINA

ARENOPARRELLA

ARENOPARRELLA

ARENOPARRELLA

ARENOPARRELLA

ARENOPARRELLA

ARENOPARRELLA

ARENOPARRELLA

TROCHAMMINA

TR OCHAMMINA

TROCHAMMINA

TROCHAMMINA

TROCHAMMINA

TROCHAMMINA

TROCHAMMINA

TROCHAMMINA

TROCHAMMINA

TROCHAMMINA

TROCHAMMINA

TROCHAMMINA

TROCHAMMINA

TROCHAMMINA

TROCHAMMINA

TROCHAMMINA

TROCHAMMINA

TROCHAMMINA

TROCHAMMINA

TROCHAMMINA

TROCHAMMINA

TROCHAMMIN

TROCHAMMIN

TROCHAMMINA

TROCHAMMINA

TROCHAMMINA

TROCHAMMINA

TROCHAMMINA

TROCHAMMINA

TROCHAMMINA

TROCHAMMINA

TROCHAMMINA

TROCHAMMINA

TROCHAMMINA

TROCHAMMINA

TROCHAMMINA

TROCHAMMINA

TROC HAMMINA

TROCHAMMINA

TROCHAMMINA

TROCHAMMINA

TROCHAMMINA
Specific Name

GL CBULOSA

GL CBULOSA

GL OBULOSA

GL CBULOSA

GL OBULOSA

GL CBULOSA

GL CBULOSA

GL CBULOSA

GL CBULOSA

GL CBULOSA

GL CBULOSA

GL OBULOSA

GL CBULOSA

GL CBULOSA

I NFLATA

IN FLATA

IN FLAT

IN FLATA
INFLATA

IN FL ATA

IN FLATA

IN FLATA

IN FLATA

IN FLATA

IN FLATA

IN FL ATA

IN FLATA

IN FLATA

IN FLATA

IN FLATA

IN FLATA

I N FL ATA

IN FLATA

NFLATA

NFLAT

IN FLATA

IN FLATA

IN FLATA

IN FLATA

IN FLATA

FLATA

IN FLATA

IN FLATA

MEXICANA

ME XICANA

MEXICANA

MEXICANA

MEXICANA

$J A P O N I C A$

JAPONICA

JAPONICA

JAFONICA

JAFONICA

JAPONICA

$J A P O N I C A$

JAPONICA

JAFONICA

JAFONICA

JAFONICA

JAFONICA

JAFONICA

JAFONICA

JAFONICA

JAFONICA

AAPONICA

JAPONICA

JAFONICA

JAFONICA

JAFONICA

JAFONICA

JAFONICA

JAFONICA

JAFONICA

JAPONICA

JAPONICA

JAPONICA

JAPONICA

JAFONICA

JAFONICA

JAPONICA

JAPONICA

JAPONICA

JAFONICA

JAFONICA

JAFONICA

JAPONICA

JAPONICA

JAPONICA

JA FONICA

Locality

NW GULF OF MEXICO

NW GULF OF MEXICO

NW GULF OF MEXICO

NW GULF OF MEXICO

NE GULF OF MEXICO

NE GULF OF MEXICO

NW GULF OF MEXICO 


\section{Publication}

26806 PFLUM FRERICHS 1976 26807 PFLUM FRERICHS 1976 26808 PFLUM FRERICHS 1976 26809 PFLUM FRERICHS 1976 26810 PFLUM FRERICHS 1976 26811 PFLUM FRERICHS 1976 26812 PFLUM FRERICHS 1976 26813 PFLUM FRERICHS 1976 26814 PFLUM FRERICHS 1976 26815 PFLUM FRERICHS 1976 26816 PFLUM FRERICHS 1976 26817 PFLUM FRERICHS 1976 26818 PFLUM FRERICHS 1976 26819 PFLUM FRERICHS 1976 26820 PFLUM FRERICHS 1976 26821 PFLUM FRERICHS 1976 26822 BANDY 1956

26823 PHLEGER 1954

26824 PHLEGER 1954

26825 WARREN 1957

26826 SEGURA 1963

26827 WALTON 1960

26828 WARREN 1956

26829 LANKFORD 1959

26830 KANE 1967

26831 KANE 1962

26832 LEHMANN 1957

26833 WALDRON 1963

26834 WARREN 1957
26835 WANTLAND 1969

26836 PHLEGER 1954

26837 PHLEGER 1954

26838 PHLEGER 1954

26839 PARKER PHLEGER PEIRSON 1953

26840 PARKER PHLEGER PEIRSON 1953

26841 PHLEGER $1965 \mathrm{C}$

26842 PHLEGER 1955 B

26843 WALTON 1960

26844 WARREN 1956

26845 PHLEGER 1965 A

26847 PARKER PHLEGER PEIRSON 1953

26848 LANKFORD 1959

26849 PHLEGER 1954

26850 HALTON 1964

26851 WALTON 1960

26852 PARKER 1954

26853 PARKER 1954

26854 PARKER 1954

26855 PARKER 1954

26856 PARKER 1954

26857 LUDHICK WALTON 1957

26858 PARKER 1954

26859 PARKER 1954

26860 WALTON 1964

26861 BANDY 1956

26862 NORTON 1930

26863 BENDA PURI 1962

26864 BENDA PURI 1962

26865 PARKER 1954

26866 PARKER 1954

26867 PARKER 1954

26868 PARKER 1954

26869 PARKER 1954

26870 PARKER 1954

26871 PARKER 1954

26872 PARKER 1954

26873 PARKER 1954

26875 LUDWICK WALTON 1957

26876 PARKER 1954

26877 LEROY HODGKINSON 1975

26878 PFLUM FRERICHS 1976

26879 PFLUM FRERICHS 1976

26880 PFLUM FRERICHS 1976

26881 CUSH'AAN 1920

26882 PFLUM FRERICHS 1976

26883 PFLUM FRERICHS 1976

26884 PFLUM FRERICHS 1976

26885 PFLUM FRERICHS 1976

26886 PFLUM FRERICHS 1976

26887 PARKER 1954

26888 PFLUM FRERICHS 1976

26889 PFLUM FRERICHS 1976

26890 PFLUM FRERICHS 1976

26891 PFLUM FRERICHS 1976

26892 PFLUM FRERICHS 1976

26893 PFLUM FRERICHS 1976

26894 PFLUM FRERICHS 1976

26895 PFLUM FRERICHS 1976

26896 PFLUM FRERICHS 1976

26897 PFLUM FRERICHS 1976

26898 PFLUM FRERICHS 1976

26899 PFLUM FRERICHS 1976

26900 PFLUM FRERICHS 1976
Generic Name

TR OCHAMMINA

TR OCHAMMINA

TROCHAMMINA

TROCHAMMINA

TROCHAMMINA

TROC HAMMINA

TR OCHAMMINA

TROCHAMMINA

TROCHAMMINA

TROCHAMMINA

TROC HAMMINA

TROCHAMMINA

TROCHAMMINA

TROCHAMMINA

TROCHAMMINA

TROCHAMMINA

TROCHAMMINA

TROCHAMMINA

TROCHAMMINA

TROCHAMMINA

TROCHAMMINA

TROCHAMMINA

TROCHAMMINA

TROCHAMMINA

TROCHAMMINA

TROCHAMMINA

TROCHAMMINA

TROCHAMMINA

TROCHAMMINA

TROCHAMMINA

TROCHAMMINA

TROCHAMMINA

TROCHAMMINA

TROCHAMMINA

TROCHAMMINA

TROCHAMMINA

TROCHAMMINA

TROCHAMMINA

TROCHAMMINA

TROCHAMMINA

TROCHAMMINA

TROCHAMMINA

TROCHAMMINA

TROCHAMMINA

TROCHAMMINA

TROCHAMMINA

TROCHAMMINA

TROCHAMMINA

TROCHAMMINA

TROCHAMMINA

TROCHAMMINA

TROCHAMMINA

TROCHAMMINA

TROCHAMMINA

TROCHAMMINA

TROCHAMMINA

TROCHAMMINA

TROCHAMMINA

TROCHAMMINA

TROCHAMMINA

TROCHAMMINA

TROCHAMMINA

TROCHAMMINA

TROCHAMMINA

TROCHAMMINA

TROCHAMMINA

TROCHAMMINA

TROCHAMMINA
TROCHAMMINA

TROCHAMMINA

TROCHAMMINA

TR OCHAMMINA

TROCHAMMINA

TROCHAMMINA

TROCHAMMINA

TROCHAMMINA

TROCHAMMINA

TROCHAMMINA

TROCHAMMINA

TROCHAMMINA

TROCHAMMINA

TROCHAMMINA

TROCHAMMINA

TROCHAMMINA

TROCHAMMINA

TROCHAMMINA

TROCHAMMINA

TROC HAMMINA

TROCHAMMINA

TROCHAMMINA

TROCHAMMINA
Specific Name

JAPONICA

JAFONICA

JAFONICA

JAPONICA

JAPONICA

JAPONICA

JAPONICA

JAFONICA

JAPONICA

JAPONICA

JAPONICA

JAPONICA

JAPONICA

JAPONICA

JAPONICA

JAPONICA

LAEVIGATA

LAEVIGATA

LOEATA

LOEATA

LOEATA

LOBATA

LOEATA

MACRESCENS

MACRESCENS

MACRESCENS

MACRESCENS

MACRESCENS

MACRESCENS

MACRESCENS

MACRESCENS

MACRESCENS

MACRESCENS

MACRESCENS

MACRESCENS

MACRESCENS

MACRESCENS

MACRESCENS

MACRESCENS

MACRESCENS

MACRESCENS

MACRESCENS

MACRESCENS

MULT ILOCULATA

OCHRACEA

QUADRIL OBA

UADRILOBA

QUADRILOBA

QUADRILOBA

QUADRILOBA

QUADRIL OBA

QUADRILOBA

QUADRILOBA

ROTAL IF ORMIS

SI MPL ISSIMA

SQUAMATA

SQLAMATA

SQUAMATA

SQUAMATA

SQLAMATA

SQLAMATA

SQUAMATA

SQLAMATA

SQLAMATA

SQUVAMATA

SQLAMATA

SQLAMATA

SQUAMATA

SQUamata

SUEGLABRA

SUEGLABRA

SURGLABRA

SUETURBINATA

SUBTURBINATA

SUBTURBINATA

SUETURBINATA

SUETURBINATA

TASMANICA

TASMANICA

TASMANICA

TASMANICA

TASMANICA

TASMANICA

TASMANICA

TASMANICA

TASMAN I CA

TASMANI CA

TA SMANICA

TA SMANICA

TA SMANICA

TASMANICA

TA SMANICA

Locality

Lat. Long.

NW GULF OF MEXICO

NW GULF OF MEXICO

NH GULF OF MEXICO

NH GULF OF MEXICO

NW GULF OF MEXICO

NW GULF OF MEXICO

NW GULF OF MEXICO

$N$ WULF OF MEXICO

NH GULF OF MEXICO 


\section{Publication}

26901 PFLUM FRERICHS 1976 26902 PFLUM FRERICHS 1976 26903 PFLUM FRERICHS 1976 26904 PFLUM FRERICHS 1976 26905 PFLUM FRERICHS 1976 26906 PARKER 1954

26907 PARKER 1954

26908 PARKER 1954

26909 PARKER 1954

26910 PFLUM FRERICHS 1976 26911 PFLUM FRERICHS 1976 26912 PFLUM FRERICHS 1976 26913 PFLUM FRERICHS 1976 26914 PFLUM FRERICHS 1976 26915 PFLUM FRERICHS 1976 26916 PFLUM FRERICHS 1976 26917 PARKER 1954

26918 PFLUM FRERICHS 1976 26919 PARKER 1954

26920 PARKER 1954

26921 PARKER 1954

26922 PARKER 1054

26923 PFLUM FRERICHS 1976 26924 PFLUM FRERICHS 1976 26925 PARKER 1954

26926 PARKER 1954

26927 CUSHMAN 1920

26928 KANE 1962

26929 KANE 1967

26930 WARREN 1956
26931 WANTLAND 1969

26932 WARREN 1957

26933 WANTLAND 1969

26934 CUSHMAN 1920

26935 CUSHMAN 1920

26936 LEROY HODGKINSON 1975

26937 CUSHMAN 1920

26938 CUSHMAN $1922 \mathrm{~A}$

26939 CUSHMAN 1922

26940 DAVIS 1964

26941 CUSHMAN $1922 \mathrm{~A}$

26942 CUSHMAN $1922 \mathrm{~A}$

26943 VAUGHAN 1918

26944 CUSHMAN $1922 \mathrm{~A}$
26945 PFLUM FRERICHS 1976

26946 PFLUM FRERICHS 1976

26947 PFLUM FRERICHS 1976

26948 PFLUM FRERICHS 1976

26949 PFLUM FRERICHS 1976 26950 PFLUM FRERICHS 1976 26951 PFLUY FRERICHS 1976 26952 PFLUM FRERICHS 1976 26953 CUSHMAN 1923

26954 PFLUM FRERICHS 1976 26955 PFLUM FRERICHS 1976 26956 PFLUM FRERICHS 1976 26957 PFLUM FRERICHS 1976 26958 CUSHMAN $1922 \mathrm{~A}$

26959 PFLUM FRERICHS 1976 26960 PFLUM FRERICHS 1976 26961 PFLUM FRERICHS 1976 26962 PFLUM FRERICHS 1976 26963 PFLUM FRERICHS 1976 26964 PFLUM FRERICHS 1976 26965 PARKER 1954 26966 PARKER 1954 26967 PARKER 1954 26968 PARKER 1954 26969 PFLUM FRERICHS 1976 26970 PFLUM FRERICHS 1976 26971 PFLUM FRERICHS 1976 26972 PFLUM FRERICHS 1976 26973 PFLUM FRERICHS 1976 26974 PARKER 1954

26975 PFLUM FRERICHS 1976 26976 PARKER 1954

26977 PFLUM FRERICHS 1976 26978 PFLUM FRERICHS 1976 26979 PFLUM FRERICHS 1976 26980 PFLUM FRERICHS 1976 26981 PFLUM FRERICHS 1976 26982 PFLUM FRERICHS 1976 26983 PFLUM FRERICHS 1976 26984 PFLUM FRERICHS 1976 26985 PARKER 1954

26986 PFLUM FRERICHS 1976 26987 PARKER 1954

26988 PARKER 1954

26989 PARKER 1954

26990 PARKER 1954

26991 PARKER 195

26992 PARKER 1954

26993 CREAGER 1958

26994 CREAGER 1958

26995 LOEP 1965
Generic Name

TROCHAMMINA

TROCHAMMINA

TROCHAMMINA

TROCHAMMINA

TROCHAMMINA

TROCHAMMINA

TROCHAMNINA

TROCHAMMINA

TROCHAMMINA

TROCHAMMINA

TROCHAMMINA

TROCHAMMINA

TROCHAMMINA

TROCHAMMINA

TROCHAMMINA

TROCHAMMINA

TROCHAMMINA

TROCHAMMIN

TROCHAMMINA

TROCHAMMINA

TROCHAMMINA

TROCHAMMINA

TROCHAMMINA

TROCHAMMINA

TROCHAMMINA

TROCHAMMINA

TROCHAMMINA

TROCHAMMIN ITA

TROCHAMMIN ITA

TROCHAMMINITA

TROCHAMMIN ITA

TROCHAMMINITA

TROCHAMMINI TA

TROCHAMMINOIDES

TROCHAMMINOIDES

TROCHAMMINOIDES

TROCHAMMINOIDES

CIBICIDES

CIBICIDES

ROSALINA

ROSALINA

ROSALINA

DISCORBIS

DISCORBIS

UVIGER INA

UV IGERINA

UVIGERINA

UV I GER INA

UVIGERINA

UVIGERINA

UVIGERINA

UVIGERINA

UV IGER INA

UV IGER INA

UV IGER I NA

UVIGERINA

UVIGER I NA

TR IFAR INA

UV I GER INA

UV IGER INA

UVIGERINA

UV IGERINA

UV IGER INA

UV IGER INA

UV I GER I NA

UV IGER I NA

UV I GER I NA

UVIGERINA

UVIGERINA

UV IGER INA

UV IGERINA

UVIGERINA

UVIGER INA

UVIGERINA

UV IGER INA

UV I GERINA

UV IGER I NA

UVIGERINA

UV IGERINA

UV IGERINA

UVIGERINA

UVIGER INA

UV IGERINA

UV IGER INA

UVIGERINA

UVIGERINA

UV IGER INA

UVIGERINA

UVIGER INA

UV IGER INA

UV IGER INA

UVIGER I NA

UVIGER INA

UV IGER I NA

UV IGERINA
Specific Name

T A SMANICA

TA SMANICA

TA SMANICA

TA SMANICA

TA SMANICA

TA SMANICA

TA SMANI CA

TA SMANICA

TASMANI CA

TA SMANICA

TA SMANICA

TA SMANICA

TA SMANICA

TA SMANI CA

TA SMANICA

TA SMANICA

TA SMANICA

TA SMANICA

TA SMANI CA

TASMANICA

TA SMANICA

TA SMANICA

TA SMANICA

I R REGULARIS

I RREGULARIS

IRREGULAR IS

IRREGULAR IS

I RREGULAR IS

SALSA

PROTEUS

PRCTEUS

PRCTEUS

PRCTEUS

ADVENUM

AN TILLARUM

C A $\triangle D E I A N A$

CA DDE I ANA

CORA

ROSEA

ROSEA

AMPULLACEA

AMFULLACEA

AM FULLACEA

AMPULLACEA

AM FULLACEA

AM PULLACE

AM FULLACE

AM FULLACEA

AMPULLACEA

AMPULLACEA

AM FULLACEA

AM FULLACEA

AMPULLACEA

AN GULOSA

AUEER I ANA

AUEERIANA

AUEERIANA

AUEERIANA

AUEER I ANA

AUEER I ANA

AUEERI ANA

AUEERI ANA

AUEER I ANA

AUEERI ANA

AUEERIANA

AUEER I ANA

AUEERI ANA

A UEERI ANA

AUEER I ANA

AUEERI ANA

AUEERI ANA

AUEERIANA

AUEER I ANA

$A \cup E E R I A N A$

AUEERIANA

AUEERIANA

AUEER I ANA

AUEERIANA

A U BER I ANA

AUEER IANA

AUEERI ANA

AUEERIANA

AUEERI AN A

AUEERI ANA

AUEERI ANA

AUEERIANA

AUEERI ANA

AUEERIANA

BELLULA

BE LLULA

Locality

NW GULF OF MEXICO

NW GULF OF MEXICO

NW GULF OF MEXICO

NW GULF OF MEXICO

CENTRAL GULF OF MEXICO

NE GULF OF MEXICO 
Publication

26996 CUSHMAN 1923

26997 CUSHMAN 1923

26998 CREAGER 1958

26999 PHLEGER $1951 \mathrm{~A}$

27000 PHLEGER 1951A

27001 PHLEGER 1951A
27002 PHLEGER 1951A

27003 PHLEGER 1951A

27004 PHLEGER 1951A

27005 PHLEGER 1951A

27006 LOEP 1965

27007 PHLEGER 1951 A

27008 PHLEGER 1951A

27009 PHLEGER 1951A

27010 PHLEGER 1951A

27011 PHLEGER $1951 \mathrm{~A}$

27012 PHLEGER $1951 \mathrm{~A}$

27013 PHLEGER 1951 A

27014
27015
PHLEGER 1951A

27015 PHLEGER $1951 \mathrm{~A}$

27017 PHLEGER 1951A

27018 PHLEGER 1951A

27019 PHLEGER 1951A

27020 PHLEGER 1951A

27021 PHLEGER 1951A

27022 PHLEGER $1951 \mathrm{~A}$

27023 PHLEGER 1951A

27024 PHLEGER $1951 \mathrm{~A}$

27025 PHLEGER 1951A

27026 PHLEGER 1951A

27027 PHLEGER 1951A

27028 PHLEGER 1951A

27029 ANDERSEN 196

27030 BANDY 1956

27031 BENDA PURI 1962

27032 BANDY 1956

27033 PHLEGER 1951A

27034 PHLEGER $1951 \mathrm{~A}$

27035 BANDY 1956

27036 PFLUM FRERICHS 1976

27037 PHLEGER $1951 \mathrm{~A}$

27038 PHLEGER $1951 \mathrm{~A}$

27039 BANDY 1956

27040 ANDERSEN 1961

27041 CREAGER 1958

27042 CREAGER 1958

27043 CREAGER 1958

27044 BOCK 1976

27045 CREAGER 1958

27046 PARKER 1954

27047 PARKER 1954

27048 PARKER 1954

27049 PHLEGER 1951 A

27050 PHLEGER 1951A

27051 PHLEGER 1951 A

27052 PARKER 1954

27053 PHLEGER $1951 \mathrm{~A}$

27054 PARKER 1954

27055 LUOWICK WALTON 1957

27056 PARKER 1954

27057 PARKER 1954

27058 LEROY HODGKINSON 1975

27059 PFLUM FRERICHS 1976

27060 PFLUM FRERICHS 1976

27061 PFLUM FRERICHS 1976

27062 PFLUM FRERICHS 1976

27063 PFLUM FRERICHS 1976

27064 PFLUM FRERICHS 1976

27065 PFLUM FRERICHS 1976

27066 PFLUM FRERICHS 1976

27067 PFLUM FRERICHS 1976

27068 PFLUM FRERICHS 1976

27069 PFLUM FRERICHS 1976

27070 PFLUM FRERICHS 1976

27071 PFLUM FRERICHS 1976

27072 PFLUM FRERICHS 1976

27073 PFLUM FRERICHS 1976

27074 PFLUM FRERICHS 1976

27075 BANDY 1956

27076 BENDA PURI 1962

27077 BANDY 1956

27078 KELLOUGH 1956

27079 KELLOUGH 1956

27080 LOEP 1965

27081 SANOY 1956

27082 BANDY 1956

27083 CREAGER 1958

27084 CREAGER 1958

27085 CREAGER 1958

27086 CREAGER 1958

27087 PHLEGER 1951A

27088 PARKER 1954

27089 PHLEGER $1951 \mathrm{~A}$

27090 PARKER 1954
Generic Name

UVIGERINA

UV IGERINA

UVIGERINA

UV IGER INA

UV I GER I NA

UVIGERINA

UV IGER INA

UV IGER INA

UVIGERINA

UVIGERINA

UV IGERINA

UV IGER INA

UV IGERINA

UVIGER INA

UV IGER I NA

UVIGERINA

UVIGERINA

UV IGER INA

UV I GER INA

UV IGERINA

UV IGER INA

UVIGERINA

UVIGER INA

UVIGERINA

UVIGER INA

UVIGERINA

UVIGER INA

UV I GERINA

UV I GER I NA

UV IGER INA

UVIGERINA

UVIGER INA

UV I GER INA

UV IGER IN A

UV IGER INA

UV I GER INA

UVIGERINA

UV IGERINA

UVIGERINA

UV IGER I NA

UVIGERINA

UV IGERINA

UVIGERINA

UVIGERINA

UVIGERINA

UVIGERINA

UV IGERINA

UV IGERINA

UV IGER INA

UVIGERINA

UV IGERINA

UVIGERINA

UVIGERINA

UV IGER INA

UVIGERINA

UVIGERINA

UVIGER INA

UV IGERINA

UVIGERINA

UV IGER INA

UV IGER INA

UVIGER INA

UV IGERINA

UVIGERINA

UVIGER INA

UV IGER INA

UVIGER I NA

UVIGER INA

UVIGERINA

UVIGER INA

UVIGERINA

UVIGERINA

UVIGER I NA

UVIGERINA

UV IGER INA

UVIGERINA

UVIGER INA

UV I GER I NA

UV IGER INA

UV I GER I NA

UV IGER INA

UV IGERINA

UV IGERINA

UVIGER INA

UVIGERINA

UV IGERI NA

UV IGERINA

UV I GERINA

UVIGER INA

UVIGERINA

UVIGERINA

UVIGER INA

UV IGER I N

UV IGERIN

UVIGERINA
Specific Name

Locality

Lat. Long.

BELLULA

BELLULA

BELLULA

BE LLULA

BE LLULA

BE LLULA

BELLULA

BE LLULA

BELLULA

BE LLULA

BE LLULA

BELLULA

BE LLULA

BELLULA

BELULA

BELLULA

BE LLULA

BE LLULA

BELLULA

BE LLULA

BELLULA

BELLULA

BELLULA

BE LLULA

BE LLULA

BE LLULA

BE LLULA

BE LLULA

BELLULA

BE LLULA

BELLULA

FL IN T I I

FL INTII

FL INT I I

FLINTII

FL IN I I I

FLINTII

FL INT I I

FL INTII

FL INTII

FL IN TI I

FLINT I I

FL INT II

FL INT I I

FL INT I I

FL IN I I

FL INT I I

F L IN T I I

FL INTI I

FL INT I I

FL INTI I

FL INT I I

FL INTII

FL IN TI I

HI SP I DA

HI SPIDA

HI SPIDA

$H I S P I D A$

HI SPIDA

HISPIDA

HI SPIDA

I SPIDA

HI SPIDA

HI SPIDA

H I SPI DA

HISPIDA

HI SPIDA

H SPIDA

HI SP IDA

HI SPIDOCOSTATA

HI SPIDOCOSTATA

HI SPIDOCOSTATA

HISPIDOCOSTATA

H I SPIDOCOSTATA

HI SPIDOCOSTATA

H I P IDOCOSTATA

HI SPIDOCOSTATA

HI SPIDOCOSTATA

HISPIDOCOSTATA

HISPIDOCOSTATA

HI SPI DOCOSTATA

HI SPIDOCOSTATA

HI SPIDOCOSTATA

I SPIDOCOSTATA

HI SPIDOCOSTATA

NE GULF OF MEXICO

NE GULF OF MEXIC

BAY OF CAMPECHE

NW GULF OF MEXICO

NW GULF OF MEXICO

NW GULF OF MEXICO

NW GULF OF MEXICO

NW GULF OF MEXICO

NW GULF OF MEXICO

NW GULF OF MEXICO

NW GULF OF MEXICO 


\section{Publication}

27091 PHLEGER 1951A 27092 PHLEGER 1951A 27093 PARKER 1954 27094
27095 PARKER 1954
2709 CRER 1958 \begin{tabular}{ll}
27095 & CREAGER \\
27096 & 1958 \\
\hline
\end{tabular} $\begin{array}{lll}27096 & \text { CREAGER } & 1958 \\ 27097 & \text { CREAGER } & 1958\end{array}$ $\begin{array}{lll}27097 & \text { CREAGER } & 1958 \\ 27098 & \text { CREAGER } & 1958\end{array}$ 27099 CREAGER 1958 27100 CREAGER 1958 27101 CREAGER 1958 27102 CREAGER 1958 27103 CREAGER 1958 27104 CREAGER 1958 27105 PHLEGER $1951 \mathrm{~A}$ 27106 PHLEGER 1951A 27107 PHLEGER $1951 \mathrm{~A}$ 27108 PARKER 1954

27109 CREAGER 1958 27110 CREAGER 1958 27111 CREAGER 1958 27112 CREAGER 1958 27113 CREAGER 1958 27114 CREAGER 1958 27115 CREAGER 1958 27116 PARKER 1954

27117 PHLEGER 1951A 27118 PHLEGER $1951 \mathrm{~A}$ 27119 PHLEGER 1951A 27120 PHLEGER 1951A 27121 PHLEGER 1951A 27122 PHLEGER 1951A 27123 PARKER 1954 27124 PARKER 1954
27125 PARKER 1954 27126 PARKER 1054 27127 PARKER 1954 27128 PARKER 1954 27129 LUDWICK WALTON 1957 27130 PARKER 1954 27131 BOCK 1976 27132 PARKER 1954 27133 PARKER 1954 27134 PARKER 1954 27135 PARKER 1954 27136 PARKER 1954 27137 PARKER 1954 27138 PARKER 1954 27139 PARKER 1954 27140 PHLEGER 1956 27142 CUSHMAN 1923 27143 CREAGER 1958 27144 CREAGER 1958
27145 ANDERSEN 1961 27146 PHLEGER 1956 27147 PARKER 1954 27148 PHLEGER 1956 27149 CREAGER 1958 27150 PARKER 1954 27151 PARKER 1954 27152 PARKER 1954 27154 PHLEGER 1956 27155 PARKER 1754 27156 PARKER 1954 27157 PARKER 1954 27158 PARKER 1954
27159 PARKER 1954 27160 PARKER 1954 27161 PARKER 1954 27162 LUDWICK WALTON 1957 27163 LANKFORD 1959 27164 PARKER 1954 27165 PARKER 1954 27166 PARKER 1954 27167 CREAGER 1958 27168 CREAGER 1958 27169 CREAGER 1958 27170 PARKER 1954 27171 PARKER 1954 27172 PARKER 1954 27173 PARKER 1954 27175 PARKER 1954 27176 WARREN 1957 27177 PHLEGER 1955 A 27178 PARKER 1954 27179 PARKER 1954 27180 PARKER 1754 27181 PARKER 1954 27182 PARKER 1954 27183 PHLEGER $1951 \mathrm{~A}$ 27185 PHLEGER 1951A

\section{Generic Name}

UV IGER I NA UVIGERINA UVIGERINA UVIGERINA UV I GER I NA UVIGERINA UV IGER INA UVIGERINA UV IGERINA UV IGER INA UVIGERINA UV IGERINA UVIGERINA UV IGER INA UV IGER I NA UV IGERINA UV IGERINA UV IGERINA UV IGERINA UVIGER INA UV IGER INA UVIGERINA UVIGERINA UV IGER INA UV IGERINA UVIGER INA UV IGER I NA UV IGERINA UV IGER I NA UVIGERINA UV IGER INA UV IGER INA UV IGERINA UV IGERINA UVIGERINA UV IGER INA UVIGERINA UVIGER INA UVIGERINA UV IGER INA UV I GER INA UV IGER INA UV I GER I NA UVIGERINA UV IGERINA UV I GER INA UV IGERINA UVIGERINA UVIGER INA UV IGERINA UVIGERINA UVIGERINA UV IGERINA UVIGERINA UVIGERINA UVIGERINA UVIGER INA UV IGER INA UV IGER INA UVIGERINA UV IGER INA UV IGERINA UV IGER INA UV IGERINA UV IGER INA UV IGER I NA UVIGERINA UV IGER INA UV I GER INA UV I GER INA UVIGERINA UV IGER INA UVIGERINA UV I GER I NA UVIGERINA UVIGERINA UV IGERINA UVIGERINA UVIGERINA UVIGERINA UV IGER I NA UVIGERINA UV IGER INA UV IGER INA UVIGERINA UV IGERINA UV IGERINA UV IGERINA UV IGER INA UVIGERINA UV IGERINA UVIGERINA UV IGERINA

\section{Specific Name}

HISPIDOCOSTATA HI SPIDOCOSTATA HISPIDOCOSTATA H ISPIDOCOSTATA HISPIDOCOSTATA HI SPIDOCOSTATA HI SPIDOCOSTATA HI SPIDOCOSTATA HISPIDOCOSTATA HI SPIDOCOSTATA HI SPIDOCOSTATA HI SPIDOCOSTATA HISPIDOCOSTATA HI SPIDOCOSTATA HI SPIDOCOSTATA HI SPIDOCOSTATA HI SPIDOCOSTATA HI SPIDOCOSTATA HISPIDOCOSTATA HI SPIDOCOSTATA HISPIDOCOSTATA HI SPIDOCOSTATA HI SPIDOCOSTATA HISPIDOCOSTATA HISPIDOCOSTATA HISPIDOCOSTATA HI SPIDOCOSTATA HI SPI DOCOSTATA HI SPIDOCOSTATA HI SPIDOCOSTATA H I SPIDOCOSTATA BELLULA BELLULA BELLULA BELLULA BELLULA BELLULA BELLULA BELLULA BELLULA BELLULA BELLULA BELLULA BELLULA BELLULA BELLULA BELLULA BELLULA BELLULA OC CIDENTALIS

PARVULA

PARVULA

PARVULA

PARVULA

PARVULA

PARVULA

PARVULA

PARVULA

PARVULA

PARVULA

PA RVULA

PARVULA

PARVULA

PARVULA

PARVULA

PARVULA

PARVULA

PARVULA

PARVULA

PARVULA

PARVULA

PARVULA

PARVULA

PARVULA

PARVULA

PEREGRINA PEREGRINA PEREGRINA PEREGRINA PEREGRINA PEREGRINA PEREGRINA PEREGRINA PEREGRINA PE REGRINA PEREGRINA PEREGR INA PEREGRINA PEREGRINA PEREGRINA PEREGRINA

Locality

Lat. Long.

NW GULF OF MEXICO NW GULF OF MEXICO NE GULF OF MEXICO NE GULF OF MEXICO BAY OF CAMPECHE BAY OF CAMPECHE BAY OF CAMPECHE BAY OF CAMPECHE BAY OF CAMPECHE BAY OF CAMPECHE 
Publication

27186 PHLEGER 1951A 27187 PHLESED $1951 \mathrm{~A}$ 27188 PHLEGE2 $1951 \mathrm{~A}$ 27189 DHLEGEF 1951A 2719 ก PHLEGER 1951A 27191 PHLEGED $1951 \mathrm{~A}$ 27192 PHLEGER $1951 \mathrm{~A}$ 27193 PHLEGER 1951A 27194 PHLEGED 1951A 27195 PHLEGER $1951 \mathrm{~A}$ 27196 PHLEGER $1951 \mathrm{~A}$ 27197 PHLEGED 1951A 27198 PHLEGED 1951A 27199 PHLEGER 1951A 27200 PHLEGER 1951 A 27201 PHLEGER $1951 \mathrm{~A}$ 2720? PHLEGER 1951A 27203 PHLEGER $1951 \mathrm{~A}$
27204 PHLEGED $1951 \mathrm{~A}$ 27205 PHLEGER $1951 \mathrm{~A}$ 27206 DHLEGED 1951A 27207 PHLEGER 1955A 27208 PHLEGER 1955 A 27209 PHLEGE 1951 A 27210 PFLUM FRERICHS 1976 27211 PFLUM FPERICHS 1976 27212 PFLUM FRCRICHS

27213 PHLEGEP 1951 A 27214 PHLEGEQ 1951 A
27215 PFLIIM FRERICHS 1976 27216 PFLU M FERICHS 1976 27217 PHLEGER 1951 A 27218 PHLEGER $1955 \mathrm{~A}$ 27219 PHLEGED 1955A 27220 PHLEGED $1955 \mathrm{~A}$ 27221 PHLEGER 1951A 27222 PHLEGER 1955 A 27223 PHLEGEP 1951A 27224 PHLEGER $1951 \mathrm{~A}$ 27225 CREAGER 1958
27226 CREAGEP 1958 27227 CREAGER 1958 27228 PARKER 1254 27229 PARKER 1954 27230 PARKER 1754 27231 PARKER 1954 27232 PARKER 1954

27234 PHLEGER 1951 A 27234
27235
PHLEGER 27236 PHLEGEP 1951A 27237 PFLUM FRERICHS 1976 27238 PHLEGER 1951 A 27239 PHLEGER 1951 A 27240 PHLEGER 1951 A 27241 PHLEGER $1955 \mathrm{~A}$ 27242 PHLEGER $1955 \mathrm{~A}$
27243 PHLEGER $1955 \mathrm{~A}$ 27243 PHLEGER $1955 \mathrm{~A}$
27244 PHLFGER $1951 \mathrm{~A}$ 27245 PFLUM FRERICHS 1976 27246 PFLUM FRERICHS 1976 27247 WARREN 1756

27248 PFLUM FRERICHS 1976 27249 LOEP 1065

27250 LOEP 1965

27251 PFLUM FRERICHS 1976 27252 LOEP 1965

27253 PFLUM FRERICHS 1976 27254 PFLIJM FRERICHS 1976 27255 CREAGER 1958 $27256^{\circ}$ CREAGER 1958 27257 CREAGED 1958 27258 CREAGER 1958 27259 CREAGED 1758 27260 CREAGER 1958 27261 CUSHMAN 1923

27262 PFLUM FRERICHS 1976 27263 PFLUM FRERICHS 1976 27264 CREAGER 1953

27265 CREAGER 1958

27266 PFLUM FRERICHS 1976 27267 PFLUM FRERICHS 1976 27268 PFLUM FRERICHS 1976 27269 PFLUM FRERICHS 1976 2727 O PFLUM FRERICHS 1976 27271 PFLUM FDERICHS 1976 27272 DFLUM FRERICHS 1976 27273 PFLUM FRERICHS 1976 27274 DFLIJM FRERICHS 1976 27275 PFLUM FRERICHS 1976 27276 PFLUM FRERICHS 1976 27277 PFLUM FRERICHS 1976 27278 PFLUM FRERICHS 1376 27279 PFLUM FRERICHS 1976 27280 PFLUM FRERICHS 1976
Generic Name

UVIGER I NA UV IGERINA UVIGERINA

UVIGER INA

UVIGERINA

UVIGERINA

UVIGERINA

UVIGERINA

UV IGERINA

UVIGER INA

UVIGERINA

UVIGERI NA

UV IGER I NA

UVIGERINA

UVIGERINA

UV IGER INA

UVIGERINA

UV IGER I NA

UV IGER I NA

UV IGER I NA

UV IGER I NA

UV IGER I NA

UV IGER INA

UVIGERINA

UVIGERINA

UVIGER I NA

UVIGERINA

UV IGERINA

UV IGER INA

UV IGER I NA

UVIGERINA

UV I GER I NA

UV IGERINA

UV IGERINA

UVIGER I NA

UVIGER INA

UV IGERINA

UVIGERINA

UVIGERINA

UV IGERINA

UV IGER I NA

UVIGERINA

UV I GER I NA

UVIGERINA

UVIGERINA

UV IGER I NA

UVIGERI NA

UVIGERINA

UV IGER I NA

UV IGER I NA

UVIGERINA

UV IGER INA

UV IGER I NA

UVIGERINA

UV IGER I NA

UV IGER I NA

UVIGER I NA

UV I GER I NA

UVIGER INA

UV I GER I NA

UV IGER I NA

UV IGER I NA

UVIGERINA

UV IGER INA

UVIGERINA

UVIGERINA

UVIGERINA

UVIGERINA

UVIGER I NA

UVIGER INA

UVIGER INA

UV IGER I NA

UV IGER I NA

UVIGERINA

UV IGER I NA

U VIGER INA

UVIGER INA

UV IGER I NA

UVIGERINA

UV IGER I NA

UVIGER INA

UV I GER I NA

UV IGER INA

UV IGER INA

UV IGER INA

UVIGER INA

UV IGER INA

UVIGER INA

UV IGER INA
Specific Name

Locality

NW GULF OF MEXICO

NW GULF OF MEXICO

NW GULF OF MEXICO

NW GULF OF MEXICO

NW GULF OF MEXICO

NW GULF OF MEXICO

NW GULF OF MEXICO

NW GULF OF MEXICO

NW GULF OF MEXICO

NW GULF OF MEXICO

NW GULF OF MEXICO

NW GULF OF MEXICO

NW GULF OF MEXICO

NW GULF OF MEXICO

NW GULF OF MEXICO

NW GULF OF MEXICO

NW GULF OF MEXICO

NW GULF OF MEXICO

NW GULF OF MEXICO

NW GULF OF MEXICO

NW GULF OF MEXICO

$N$ GULF OF MEXICO

$N$ GULF OF MEXICO

NW GULF OF MEXICO

NW GULF OF MEXICO

NW GULF OF MEXICO

NW GULF OF MEXICO

NW GULF OF MEXICO

NW GULF OF MEXICO

NW GULF OF MEXICO

NW GULF OF MEXICO

NW GULF OF MEXICO

$N$ GULF OF MEXICO

$N$ GULF OF MEXICO

$N$ GULF OF MEXICO

NW GULF OF MEXICO

$N$ GULF OF MEXICO

NW GULF OF MEXICO

NW GULF OF MEXICO

BAY OF CAMPECHE

BAY OF CAMPECHE

NAY GULF OF MEXICO

NE GULF OF MEXICO

NE GULF OF MEXICO

NE GULF OF MEXICO

NE GULF OF MEXICO

NE GULF OF MEXICO

NW GULF OF MEXICO

NW GULF OF MEXICO

NW GULF OF MEXICO

CENTRAL GULF OF MEXICO

NW GULF OF MEXICO

NW GULF OF MEXICO

NW GULF OF MEXICO

$N$ GULF OF MEXICO

$N$ GULF OF MEXICO

$N$ GULF OF MEXICO

NW GULF OF MEXICO

CENTRAL GULF OF MEXICO

CENTRAL GULF OF MEXICO

BURAS SE LOUISIANA

NW GULF OF MEXICO

NW GULF OF MEXICO

NW GULF OF MEXICO

NW GULF OF MEXICO

NW GULF OF MEXICO

NW GULF OF MEXICO

NW GULF OF MEXICO

BAY OF CAMPECHE

BAY OF CAMPECHE

BAY OF CAMPECHE

BAY OF CAMPECHE

BAY OF CAMPECHE

BAY OF CAMPECHE

NE GULF OF MEXICO

CENTRAL GULF OF MEXICO

CENTRAL GULF OF MEXICO

BAY OF CAMPECHE

BAY OF CAMPECHE

CENTRAL GULF OF MEXICO

CENTRAL GULF OF MEXICO

CENTRAL GULF OF MEXICO

CENTRAL GULF OF MEXICO

CENTRAL GULF OF MEXICO CENTRAL GULF OF MEXICO CENTRAL GULF OF MEXICO CENTRAL GULF OF EXICO CENTRAL GULF OF MEXICO CENTRAL GULF OF MEXICO CENTRAL GULF OF MEX CENTRAL GULF OF MEXIC CENTRAL GULF OF MEXICO CENTRAL GULF OF MEXICO

Lat. Long.

$2709 \mathrm{~N} 094 \quad 17 \mathrm{~W}$ $2820 \mathrm{~N} 09504 \mathrm{~W}$ $2730 \mathrm{~N} 09510 \mathrm{~W}$ $2742 \mathrm{~N} 09426 \mathrm{~W}$ $2814 \mathrm{~N} 09438 \mathrm{~W}$ $2718 \mathrm{~N} 09614 \mathrm{~W}$ $2659 \mathrm{~N} 09611 \mathrm{~W}$ $2759 \mathrm{~N} 09606 \mathrm{~W}$ $2738 \mathrm{~N} 09547 \mathrm{~W}$ $2755 \mathrm{~N} 09620 \mathrm{~W}$ 


\section{Publication}

27281 PFLUM FRERICHS 1976 27282 PFLUM FRERICHS 1976 27283 PFLUM FRERICHS 1976 27284 PFLUM FRERICHS 1976 27285 PFLUM FRERICHS 1976 27286 PFLUM FLERICHS 1976 27287 PFLUM FRERICHS 1976 27288 PFLUM FRERICHS 1976 27289 DFLUM FRERICHS 1976 27290 PFLUM FRERICHS 1976 27291 PFLUM FDERICHS 1976 27292 PFL IM M FRERICHS 1970 27293 PFLU A FRERICHS 1976 27294 PFLUM FRERICHS 1976 27295 PFLUM FRERICHS 1976 27296 PFLUM FDERICHS 1976 27297 PFLU:A FRERICHS 1976
27298 PFLU 9 FRERICHS 1976 27299 PFLUM FRERICHS 1976 27300 PFLUM FRFRICHS 1976 27301 PFLUM FRERICHS 1976 27302 PFLUM FRERICHS 1976 27303 PFLUM FRERICHS 1976 27304 PFLUM FRERICHS 1976 27305 PFLU A FRERICHS 1976 27306 PFLUM FRERICHS 1976 27307 PFLU:A FRERICHS 1976 27308 PFLUM FRERICHS 1976 27309 PFLUM FRERICHS 1976 27311 PFLUM FRERICHS 1976 27312 PFLU APERICHS 1976 27313 PFLUM FRERICHS 1976 27314 PFLUM FRERICHS 1976 27315 PFLUM FRERICHS 1976 27316 PFLUM FRERICHS 1976 27317 PFLUM FRERICHS 1976 27318 PFLUM FRERICHS 1976 27319 PFLUM FRERICHS 1976 27320 PFLUM FRERICHS 1976 27321 PFLUM FRERICHS 1976 27322 PFLIM FRERICHS 1976 27323 PFLUM FRFRICHS 1976 27324 PFLUM FRERICHS 1976 27325 PFLUM FRERICHS 1976 27326 PFLUM FRERICHS 1976 27327 PFLUM FRERICHS 1976 27328 PFLUM FRERICHS 1976

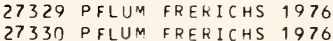
27330 PFLUM FRERICHS 1976
27331 PFLUM FRERICHS 1976 27332 PFLUM FRERICHS 1976 27333 PFLUM FRERICHS 1976 27334 PFLUM FRERICHS 1976 27335 PFLUM FRERICHS 1976 27336 PFLU 1 FRERICHS 1976 27337 PFLIJM FPERICHS 1976 27338 PFLUM FRERICHS 1976 27339 PFLUM FRERICHS 1976 27340 PFLUM FRERICHS 1976 27341 PFL'JM FRERICHS 1976 27342 PFLUM FRERICHS 1976 27343 PFLUM FPERICHS 1976 27344 PFLUM FRERICHS 1976 27345 PFLUM FRERICHS 1976 27346 PFLUM FRERICHS 1976 27347 PFLUM FRERICHS 1976 27349 PFLUM FRERICHS 1976 27350 PFLUM FRERICHS 1976 27351 PFLUM FRERICHS 1976 27352 PFLUM FRERICHS 1976 27353 PFLUM FRERICHS 1976 27355 PFLUM FRERICHS 1976 27356 PFLUM FRFRICHS 1976 27357 PFLUM FRERICHS 1976 27358 PFLUM FRERICHS 1976
27359 PFLUM FRERICHS 1976 27360 PHLEGER 1951A 27361 PHLEGER 1959 A 27362 PHLEGER $1951 \mathrm{~A}$ 27363 PHLEGER $1951 \mathrm{~A}$ 27364
27365
PHLEGER $1951 \mathrm{~A}$ 27366 PHLEGER $1951 \mathrm{~A}$ 27367 PHLEGEQ 1951A 27369 PHLEGEQ 1951 A 27370 PHLEGER $1951 \mathrm{~A}$ 27371 PHLEGER $1951 \mathrm{~A}$
27372 PHLEGER $1951 \mathrm{~A}$ 27373 PHLEGED $1951 \mathrm{~A}$ 27374 PHLEGER $1951 \mathrm{~A}$ 27375 PHLEGEP. $1951 \mathrm{~A}$
Generic Name

UVIGERINA UVIGERINA UV IGER INA UVIGER I NA UV IGER INA UV IGER INA UVIGERINA UVIGERINA UVIGERINA UVIGER I NA UVIGERINA UV IGER INA UVIGER INA UVIGERINA UVIGERINA UVIGERINA UV IGER INA UVIGERINA UVIGERINA UV IGER INA UV IGERINA UV IGER INA UVIGERINA UV I GER INA UV I GER I NA UVIGERINA UV IGER I NA UVIGERINA UVIGERINA UVIGERINA UVIGERINA UV IGER INA UV IGERINA UVIGERINA UV IGER INA UV IGER INA UVIGERINA UV IGER INA UVIGER I NA UVIGERINA UV IGERINA UV I GER I NA UVIGER INA UVIGERINA UVIGER I INA UV IGER INA UV IGERINA UVIGERINA UVIGERINA UVIGERINA UVIGERINA UVIGERINA UVIGERINA UVIGERINA UVIGERINA UV IGERINA UVIGERINA UV IGERINA UV IGER I NA UVIGERINA UVIGERINA UV IGER INA UV IGER I NA UVIGERINA UV I GER INA UV IGERINA UVIGERINA UVIGERINA UVIGERINA UVIGERINA UVIGERINA UVIGERINA UVIGERI VA UVIGERINA UVIGERINA UVIGERINA UVIGERINA UV IGER I NA UVIGERINA UVIGERI NA UVIGERINA UVIGERINA UVIGER INA UVIGERI NA UVIGERINA UVIGERINA UV IGER INA UVIGERINA UVIGERINA UVIGERI VA UVIGERINA UVIGERINA UVIGERINA UV IGERINA UV IGER I NA
Specific Name

PEREGRINA DIRUPTA PEREGRINA DIRUPTA PEREGRINA DIRUPTA PEREGRINA OIRUPTA PEREGRINA DIRUPTA PEREGRINA DIRUPTA PEREGRINA DIRUPTA PEREGRINA DIRUPTA PEREGRINA DIRUPTA PEREGRINA DIRUPTA PEREGRINA DIRUPTA PEREGRINA DIRUPTA PEREGRINA DIRUPTA PEREGRINA DIRUPTA PEREGRINA DIRUPTA PEREGRINA DIRUPTA PEREGRINA DIRUPTA PEREGRINA OIRUPTA PEREGRINA DIRUPTA PEREGRINA DIRUPTA PEFEGRINA DIRUPTA PEREGRINA DIRUPTA PEREGRINA DIRUPTA PEREGRINA DIRUPTA PEREGRINA DIRUPTA PEREGRINA DIRUPTA PEREGRINA DIRUPTA PEREGRINA DIRUPTA PEFEGRINA DIRUPTA PEREGRINA DIRUPTA PEREGRINA DIRUPTA PEREGRINA DIRUPTA PEREGRINA DIRUPTA PEREGRINA DIRUPTA PEREGRINA DIRUPTA PEREGRINA DIRUPTA PEREGRINA DIRUPTA PEREGRINA DIRUPIA PEREGRINA DIRUPTA PEFEGRINA DIRUPTA PEREGRINA DIRUPTA PEREGRINA DIRUPTA PEREGRINA DIRUPTA PEREGRINA DIRUPIA PEREGRINA DIRUPTA PEREGRINA DIRUPTA PE REGRINA DIRUPTA PEREGRINA DIRUPTA PEREGRINA DIRUPTA PEREGRINA DIRUPTA PEREGRINA DIRUPTA PEREGRINA DIRUPTA PEREGRINA DIRUPTA PEREGRINA DIRUPTA PEREGRINA DIRUPTA PEREGRINA DIRUPTA PEREGRINA DIRUPTA PEREGRINA DIRUPTA PEREGRINA DIRUPTA PEREGRINA DIRUPTA PEREGRINA MEDITERRANEA PEREGRINA MEDITERRANEA PEREGRINA MEDITERRANEA PEREGRINA MEDITERRANEA PEREGRINA MEDITERRANEA PEREGRINA MEDITERRANEA PEREGRINA MEDITERRANEA PEREGRINA MEDITERRANEA PEREGRINA MEDITERRANEA PEREGRINA MEDITERRANEA PEREGRINA MEDITERRANEA PEREGRINA MEDITERRANEA PEREGRINA MEDITERRANEA PEREGRINA MEOITERRANEA PEFEGRINA MEDITERRANEA PEREGRINA MEDITERRANEA PEREGRINA MEDITERRANEA PEREGRINA MEDITERRANEA PEREGRINA MEDITERRANEA PARVULA PAFVULA

PARVULA

PARVULA

PARVULA

PARVULA

PARVULA

PARVULA

PARVULA

PARVULA

PARVULA

PA FVULA

PARVULA

PARVULA

Locality

Lat. Long.

NW GULF OF MEXICO

CENTRAL GULF OF MEXICO

CENTRAL GULF OF MEXICO

CENTRAL GULF OF MEXICO

CENTRAL GULF OF MEXICO

CENTRAL GULF OF MEXICO

NW GULF OF MEXICO

NW GULF OF MEXICO

NW GULF OF MEXICO

NW GULF OF MEXICO 
Publication

27376 PHLEGER 1951A 27377 PHLEGER 1951 A 27378 PHLEGER 1951 A 27379 PHLEGER 1951A 27380 PHLEGER $1951 \mathrm{~A}$ 27381 CUSHMAN 1923 27382 CUSHMAN 1923 27383 CUSHMAN 1923 27384 CUSHMAN 1923 27385 CUSHMAN 1923

27386 CUSHMAN 1923 27387 PHLEGER 1951A 27388 CUSHMAN 1923

27389 CUSHMAN 1923

27390 CUSHMAN 1923

27391 PHLEGER 1951A

27392 CUSHMAN 1923

27393 CUSHMAN 1923
27394 CUSHMAN 1923

27395 PFLUM FRERICHS 1976

27396 PFLUM FRERICHS 1976

27397 PHLEGER $1951 \mathrm{~A}$

27398 PHLEGER 1951 A

27399 PFLUM FRERICHS 1976

27400 PFLUM FRERICHS 1976

27401 PFLUM FRERICHS 1976

27402 PFLUM FRERICHS 1976

27403 PFLUM FRERICHS 1976

27404 ANDERSEN 1961

27405 PFLUM FRERICHS 1976

27406 PFLUM FRERICHS 1976

27407 PFLUM FRERICHS 1976

27408 PFLUM FRERICHS 1976

27409 PFLUM FRERICHS 1976

27410 PFLUM FRERICHS 1976

27411 PFLUM FRERICHS 1976

27412 PFLUM FRERICHS 1976

27413 PFLUM FRERICHS 1976

27414 PFLUM FRERICHS 1976

27415 PFLUM FRERICHS 1976

27416 PFLUM FRERICHS 1976

27417 PFLUM FRERICHS 1976

27418 PFLUM FRERICHS 1976

27419 PFLUM FRERICHS 1976

27420 PFLUM FRERICHS 1976

27421 PFLUM FRERICHS 1976

27422 LEROY HODGKINSON 1975

27423 PFLUM FRERICHS 1976

27424 PFLUM FRERICHS 1976

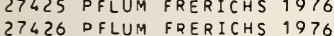

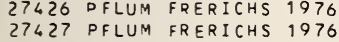

27428 PFLUM FRERICHS 1976

27429 PFLUM FRERICHS 1976

27430 PFLUM FRERICHS 1976

27431 PFLUM FRERICHS 1976

27432 PFLUM FRERICHS 1976

27433 PFLUM FRERICHS 1976

27434 PFLUM FRERICHS 1976

27435 PFLUM FRERICHS 1976

27436 PFLUM FRERICHS 1976

27437 PFLUM FRERICHS 1976

27438 PFLUM FRERICHS 1976

27439 PFLUM FRERICHS 1976

27440 PFLUM FRERICHS 1976

27441 PFLUM FRERICHS 1976

27442 PFLUM FRERICHS 1976

27443 PFLU'A FRERICHS 1976

27444 PFLUM FRERICHS 1976

27445 PFLUM FRERICHS 1976

27446 PFLUM FRERICHS 1976

27447 VAUGHAN 1918

27448 CUSHMAN 1923

27449 CUSHMAN 1923

27450 LEROY HODGKINSON 1975

27451 NORTON 1930

27452 ANDERSEN 1961

27453 LOEP 1965

27454 CUSHMAN 19228

27455 CUSHMAN 19228

27456 CUSHMAN 19228

27457 CUSHMAN 1922A

27458 CUSHMAN 1922

27459 DAVIS 1964

27460 NORTON 1930

27461 PFLUM FRERICHS 1976

27462 PFLUM FRERICHS 1976

27463 PFLUM FRERICHS 1976

27464 PFLUM FRERICHS 1976

27465 PFLUM FRERICHS 1976

27466 PFLUM FRERICHS 1976

27467 PFLU Y FRERICHS 1976

27468 PFLUM FRERICHS 1976

27469 PFLUM FRERICHS 1976

27470 PFLUM FRERICHS 1976
Generic Name

Specific Name

Locality

Lat. Long.

UV I GER I N

UVIGER INA

UVIGERINA

UVIGERINA

UVIGERINA

UVIGERINA

UVIGERINA

UVIGERINA

UVIGERINA

UVIGERINA

UVIGERINA

UVIGERINA

UVIGERINA

UVIGERINA

UVIGERINA

UVIGERINA

UVIGERINA

UVIGERINA

UV I GER I NA

UVIGERI VA

UVIGER INA

UVIGER INA

UVIGER INA

UVIGERINA

UVIGERINA

UVIGERINA

UV IGER INA

UV IGER I NA

UVIGERINA

UVIGER INA

UVIGERINA

UVIGER INA

UV IGER I NA

UVIGER I NA

UVIGERINA

UVIGERI NA

UVIGERINA

UV IGER INA

UVIGER INA

UVIGERINA

UV IGER INA

UV I GERINA

UVIGER IN A

UVIGER INA

UV I GER I NA

UV IGERINA

UVIGERINA

UV IGER INA

UVIGER I NA

UV IGER I NA

UVIGER INA

UV IGER I NA

UVIGERINA

UVIGERI NA

UVIGER I NA

UVIGER INA

UVIGERIN A

UVIGERINA

UVIGERINA

UVIGERINA

UV IGER I NA

UV IGER I NA

UV IGERINA

UVIGER I NA

UV IGERINA

UVIGER I NA

UV IGER INA

UV I GER INA

UV IGER INA

UVIGERI NA

UV IGERINA

UV IGER INA

VAGINUL INA

VAGINUL INA

VAG INUL INA

VAG INUL I NA

MARG INUL INA

MARG INUL INA

TRITAXIS

TRITAXIS

TRITAXIS

VALVULINA

VALVULINA

VALVULINA

VALVULINA

VALVULINER I A

VALVULINER I A

VALVULINERIA

VALVULINER IA

VALVULI INER I A

VALVULINER I A

VALVULINER IA

VALVULINER IA

VALUULINER IA

VALVULINER I A
PA FVULA

PARVULA

PARVULA

PA RVULA

PAFVULA

PA FVULA

PA RVULA

PARVULA

PARVULA

PAFVULA

PARVULA

PAFVULA

PARVULA

PARVULA

PA KVULA

PARVULA

PARVULA

PARVULA

PARVULA

PA FVULA

PARVULA

PE FEGRINA

PEREGRINA

PEREGRINA

PEREGRINA

SELSEYENSIS

SEATICOSA

SEATICOSA

SEATI COSA

SENTI COSA

SEATICOSA

SEATI COSA

SEATICOSA

SEATI COSA

SENTICOSA

SEATICOSA

SENTI COSA

SEATI COSA

SENTI COSA

SP INI COST ATA

SPINICOSTATA

SPINI COSTATA

SPINI COSTATA

SPINI COSTATA

SPINICOSTATA

SP INICOSTATA

SP INI COSTAT

SP INI COSTATA

SPINI COSTATA

SPINICOSTATA

SP INI COSTATA

SPINICOSTATA

SP IN I COSTATA

SP INICOST AT A

SP INI COSTATA

SP INICOSTATA

SPINICOSTAT

SP IN I COSTATA

SP INI COSTATA

SP INI COSTA TA

SPINI COST AT

SP INI COSTATA

SP INICOSTATA

SPINICOSTATA

SPINICOSTATA

SP INI COSTATA

SP INI COSTATA

SP INICOSTATA

FL INT II

LE GUMEN

LE GUMEN

LE GUMEN

A MER I CANA

PLANATA

PL ANATA

CONICA

CONICA

CONICA

OVIEDOIANA

OVIEDOI AN A

OVIEDOIANA

OVIEDOIANA

CONPLANATA

CONPLANATA

CONPLANATA

CONPLANATA

CONPLANATA

CONPLANATA

CONPLANATA

CONPLANATA

CONPLANATA

CONPLANATA
Nh GULF OF MEXICO

$\mathrm{NW}$ GULF OF MEXICO

NW GULF OF MEXICO

NW GULF OF MEXICO

NW GULF OF MEXICO 


\section{Publication}

27471 PFLUM FRERICHS 1976 27472 PFLUM FRERICHS 1976 27473 PFLUM FRERICHS 1976 27474 PFLUM FPERICHS 1976 27475 PFLUM FRERICHS 1976 27476 PFLUM FRERICHS 1976 27477 PFLUM FRERICHS 1976 27478 PFLUM FRERICHS 1976 27479 PFLUM FRERICHS 1976 27480 PFLUM FRERICHS 1976 27481 PFLUM FRERICHS 1976 27482 PFLUM FRERICHS 1976 27483 PFLUM FRERICHS 1976 27484 DFLUM FRERICHS 1976 27485 PFLUM FRERICHS 1976 27486 PFLUM FRERICHS 1976 27487 PHLEGER 1951 A 27488 PHLEGER 1951A 27489 PFLUM FRERICHS 1976 27490 PFLUM FRERICHS 1976 27491 PFLUM FRERICHS 1376 27492 PHLEGER 1951A 27493 PHLEGER 1951A 27494 PHLEGER $1951 \mathrm{~A}$ 27495 PHLEGER 1951A 27496 PHLEGER 1951 A 27497 PFLUM FRERICHS 1976 27498 PFLUM FRERICHS 1976 27499 PFLUM FRERICHS 1976 27500 PFLUM FRERICHS 1976 27501 PFLUM FRERICHS 1976 27502 PFLUM FRERICHS 1976 27503 PFLUM FRERICHS 1976 27504 PHLEGER 1951A 27505 PHLEGER 1951A 27506 PFLUM FRERICHS 1976 27507 PFLUM FRERICHS 1976 27508 PFLIJM FRERICHS 1976 27509 PFLUM FRERICHS 1976 27510 PFLUM FRERICHS 1976 27511 PFLUM FRERICHS 1976 27512 PFLUM FRERICHS 1976 27513 PFLUM FRERICHS 1976 27514 PFLUM FRERICHS 1976

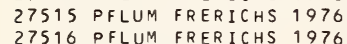
27516 PFLUM FRERICH 27518 PHLEGER 1951 A 27519 PHLEGER 1951A 27520 PHLEGER 1951A 27521 PHLEGER 1951A 27522 PHLEGER 1951 A 27523 PFLUM FRERICHS 1976 27524 PFLUM FRERICHS 1976 27525 PFLUM FRERICHS 1976 27526 PHLEGER 1951A 27527 PHLEGER 1951A 27528 PHLEGER 1951 A 27529 PHLEGER 1951 A 27530 PHLEGER 1951A

27531 PFLUM FRERICHS 1976 27532 PFLUM FRERICHS 1976 27533 PFLUM FRERICHS 1976 27534 PFLUM FRERICHS 1976 27535 PFLUM FRERICHS 1976 27536 PFLUM FRERICHS 1976 27537 PFLUM FRERICHS 1976 27538 PFLUM FRERICHS 1376 27539 PFLUM FRERICHS 1976 27540 PFLUM FRERICHS 1976 27541 PFLUM FRERICHS 1976 27542 PFLUM FRERICHS 1976 27543 PFLUM FRERICHS 1976 27544 PFLUM FRERICHS 1976 27545 PFLUM FRERICHS 1976 27546 PFLUM FRERICHS 1976 27547 PHLEGER $1951 \mathrm{~A}$ 27548 PHLEGER $1951 \mathrm{~A}$ 27549 PFLUM FRERICHS 1976 27550 PHLEGER 1951A 27551 PHLEGER $1951 \mathrm{~A}$

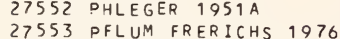
27553 PFLUM FRERICHS
27554 PHLEGER 1955A 27555 PHLEGER 1955 A 27556 PHLEGER 1955 A 27557 PARKER 1054 27559 PARKER 1954 27560 BOCK 1976 27561 PARKER 1954 27562 ANDERSEN 1961 27563 PARKER 1954 27564 PHLEGER $1955 \mathrm{~A}$
Generic Name

VALVULINERIA VAL VUL INER I A VALVULINER I A VALVULINER IA VALVULINERIA VALVULINERIA VALVULINERIA VALVULI NERI A VALVULINER IA VALVULINER IA VALVULINERIA VALVULINERIA VALVULINERIA VALVULINERIA VALVULINER IA VALVULINER IA VALVULINER I A VALVULINER I A VALVULINER I A VALVULINER IA VALVULINERIA VALVULINER IA VAL VULINERI A VALVULINER I A VALVULINER IA VALVULINERI A VALVULINER IA VALVULI NER I A VALVULINERIA VALVULINERIA VALVULINER IA VALVULINER IA VALVULINER I A VALVULINERIA VALVULINER I A VALVULI NER I A VALVULINER IA VALVULINERI A VALVULINER I A VALVULINER I A VALVULINERIA VALVULINER IA VALVULINER I A VALVULINER IA VALVULINER I A VALVULINERI A VALVULINER IA VALVULINERI VALVULINERIA VALVULINER I A VALVULINERIA VAL VUL INER I A VALVULINER I A VALVULINER I A VALVULINER IA VALVULINER IA VALVULINER I A VALVULINERIA VALVULINERI A VALVULINER I A VALVULINER I A VALVULINER I A VALVUL INER IA VALVULINER IA VALVULINERIA VALVULINERIA VALVULINER I A VALVULINER I A VALVULINERI A VALVULINER I A VALVULINER IA VALVULINERI A VALVULINERIA VALVUL INER I A VALVULI NER I A VALVULINER I A VALVULI NERI A VALVUL INERIA VALVULINER I A VALVULI NER I A VALVULINER I A VALVULINERI A VALVULI NER I A VALVULINER I A VALVULINERIA VALVULINER I A VALVULINER I A VALVULI NER IA VALVULINERIA
Specific Name

CONPLANATA

CONPLANATA

CONPLANATA

CONPLANATA
CONPLANATA

CONPLANATA

CONPLANATA

CONPLANATA

CONPLANATA

CONPLANATA

CONPLANATA

CONPLANATA

CONPLANATA

LAEVIGATA

LAEVIGATA

LAEVIGATA

LAEVIGATA

LAEVIGATA

LA EVIGATA

LAEVIGATA

LAEVIGATA

LAEVIGATA

LAEVIGATA

LAEVIGATA

LAEVIGATA

LAEVIGATA

LAEVIGATA

LAEVIGATA

LAEVIGATA

LAEVIGATA

LAEVIGATA

DVIGATA

LAEVIGATA

LAEVIGATA

LAEVIGATA

LAEVIGATA

LAEVIGATA

LAEVIGATA

LAEVIGATA

LAEVIGATA

LAEVIGATA

LAEVIGATA

LAEVIGATA

LAEVIGATA

LAEVIGATA

LAEVIGATA

LAEVIGATA

LAEVIGATA

LAEVIGATA

LAEVIGATA

LAEVIGATA

LAEVIGATA

LAEVIGATA

LAEVIGATA

LAEVIGATA

LAEVIGATA

LAEVIGATA

LAEVIGATA

LAEVIGATA

LAEVIGATA

LAEVIGATA

LAEVIGATA

LAEVIGATA

LAEVIGATA

LAEVIGATA

LAEVIGATA

LAEVIGATA

LAEVIGATA

LAEVIGATA

LAEVIGATA

LAEVIGATA

LAEVIGATA

LA EVIGATA

LAEVIGATA

MEXI CANA

MEXICANA

MEXI CANA

MEXICANA

MEXI CANA

MEXICANA

MEXICANA

MEXICANA

MEXICANA

MEXICANA

Locality

Lat. Long.

CENTRAL GULF OF MEXICO CENTRAL GULF OF MEXICO CENTRAL GULF OF MEXICO

CENIRAL GULF OF MEXICO CENTRAL GULF OF MEXICO CENTRAL GULF OF MEXICO CENTRAL GULF OF MEXICO CENTRAL GULF OF MEXICO CENTRAL GULF OF MEXICO CENTRAL GULF OF MEXICO CENTRAL GULF OF MEXICO CENTRAL GULF OF MEXICO CENTRAL GULF OF MEXICO CENTRAL GULF OF MEXICO CENTRAL GULF OF MEXICO CENTRAL GULF OF MEXICO NW GULF OF MEXICO 
Publication

27566 PARKER 1954 27567 PARKER 1954

27568 PHLEGER 1955A

27569 PHLEGER 1955

27570 PARKER 1954

27571 PARKER 1954

27573 CREAGER 1958

27574 PFLUM FRERICHS 1976

27574 PFLUM FRERICHS 1976
27575 PFLUM FRERICHS 1976

27576 PFLUM FRERICHS 1976

27577 CREAGER 1958

27578 CREAGER 1958

27579 PFLUM FRERICHS 1976

27580 PFLUM FRERICHS 1976 27581 PFLUM FRERICHS 1976

27582 PFLUM FRERICHS 1976 27583 PFLUM FRERICHS 1976 27584 PFLUM FRERICHS 1976 27585 PFLUM FRERICHS 1976 27586 PFLUM FRERICHS 1976 27587 PFLUM FRERICHS 1976 27588 PFLUM FRERICHS 1976 27589 PFLUM FRERICHS 1976 27590 PFLUM FRERICHS 1976 27591 PARKER 1954

27592 PARKER 1954

27593 PARKER 1954

27594 PARKER 1954

27595 PARKER 1954

27596 PARKER 1954

27597 LUDWICK WALTON 1957

27598 PARKER 1954

27599 PARKER 1954

27600 PARKER 1954

27601 PARKER 1954

27602 PFLUM FRERICHS 1976

27603 PFLUM FRERICHS 1976

27604 PFLUM FRERICHS 1976

27605 PFLUM FRERICHS 1976

27606 PFLUM FRERICHS 1976

27607 PARKER 1954

27608 PARKER 1954

27609 CREAGER 1958

27610 PFLUM FRERICHS 1976 27611 PFLUM FRERICHS 1976 27612 PFLUM FRERICHS 1976 27613 PFLUM FRERICHS 1976 27614 PFLUM FRERICHS 1976 27615 PFLUM FRERICHS 1976 27616 PARKER 1954

27617 PFLUM FRERICHS 1976 27618 PFLUM FRERICHS 1976 27619 PFLUM FRERICHS 1976 27620 PFLUM FRERICHS 1976 27621 PFLUM FRERICHS 1976 27622 PFLUM FRERICHS 1976 27623 PFLUM FRERICHS 1976 27624 PFLUM FRERICHS 1976 27625 CREAGER 1958

27626 CREAGER 1958

27627 PARKER 1954

27628 PHLEGER 1956

27629 PARKER 1954

27630 PARKER 1954

27631 PFLUM FRERICHS 1976

27632 PFLUM FRERICHS 1976 27633 PARKER 1954

27634 PFLUM FRERICHS 1976 27635 PFLUM FRERICHS 1976 27636 PFLUM FRERICHS 1976 27637 PFLUM FRERICHS 1976 27638 PFLUM FRERICHS 1976 27639 PFLUM FRERICHS 1976 27640 PFLUM FRERICHS 1976 27641 PARKER 1954

27642 PARKER 1954

27643 PARKER 1954

27644 PFLUM FRERICHS 1976 27645 PFLUM FRERICHS 1976 27646 PFLUM FRERICHS 1976 27647 PFLUM FRERICHS 1976 27648 PFLUM FRERICHS 1976 27649 PFLUM FRERICHS 1976 27650 PFLUM FRERICHS 1976 27651 PFLUM FRERICHS 1976 27652 PFLUM FRERICHS 1976 27653 PFLUM FRERICHS 1976 27654 PFLUM FRERICHS 1976 27655 PFLUM FRERICHS 1976 27656 PFLUM FRERICHS 1976 27657 PFLUM FRERICHS 1976 27658 PFLUM FRERICHS 1976 27659 PFLUM FRERICHS 1976 27660 PFLUM FRERICHS 1976
Generic Name

VALVULINERIA VALVULINER IA VALVULINERIA VALLVULINER IA VALVULINERIA VALVULINERIA VALVULINER IA VALVULI NER IA VALVUL I NER IA VALVULINER I A VALVULINER IA VALVULINER I A VALVULI NER I A VALVULINER I A VALVULINERIA VALVULI NERI A VALVUL INER IA VALVULINERIA VALVUL INER IA VALVULINER I A VALVUL I NER I A VALVUL INER I A VALVUL INER I A VALVULINER I A VALVULINERIA VALVULINER I A VALVUL INERI A VALVUL I NER I A VALVULINER I A VALVULINERIA VALVULINERIA VALVULINER I A VALVUL I NER I A VALVULI NER I A VALVULI NER I A VALVULINER I A VALVULINER I A VAL VULINER I A VALVULINERI VALVULINER IA VALVUL INER I A VALVULINER I A VALVULINER IA VALVULINERIA VALVULINERIA VALVULINER I A $\checkmark A L V U L I N E R$ I A VALVUL INER I A VALVULINERIA VALVUL INERIA VALVULINER I A VALVULINER I A VALVUL INER I VALVULINER IA VALVUL INER I A VALVUL I NER I A VALVULINERI A VALVUL INER I A VALVULINER IA VALVULINERI A VALVUL I NER I A VALVULINER I A VALVUL INER I A VALVUL I NER I A VALVULINER I A VALVULINER I A VALVULINER I A VALVULINER I A VALVUL INER I A VALVULINER IA VALVUL INER I A VALVUL INER I A VALVULINER IA VALVUL INER IA VALVUL INERIA VALVULINER I A VALVULINER I A VAL VULINERIA VALVUL I NER I VALVUL INER I A VALVUL INER I A VAL LULINER IA VALVUL INER IA VALVUL I NER I A VALVULINER IA VALVUL I NER I A $\checkmark A L V U L I N E R$ I VALVUL INER I VALVUL I NER I A VALVUL INER I A VALVULINER IA VALVULINER IA VALVULINER IA VALVULINER IA VALVUL I NER I A
VALVUL INER I A
Specific Name

Locality

Lat. Long.

MEXI CANA

MEXICANA

MEXICANA

ME XI CANA

MEXICANA

MEXICANA

MINUTA

MINUTA

MINUTA

MINUTA

M I NUTA

MINUTA

MINUTA

MI NUTA

MINUTA

MINUTA

MINUTA

MI NUTA

MINUTA

MI NUTA

MINUTA

MI NUTA

MI NUTA

MINUTA

MI NUTA

MINUTA

MINUTA

MI AUTA

MI NUTA

MI NUTA

II NUTA

MI NUTA

MINUTA

MINUTA

MINUTA

MI NUTA

MI AUTA

MI NUTA

MI NUTA

MINUTA

MI NUTA

INUTA

MI NUTA

MI NUTA

MI NUTA

MINUTA

MI NUTA

MINUTA

MINUTA

MI NUTA

MINUTA

MI AUTA

MI NUTA

MINUTA

MINUTA

MINUTA

MI NUTA

MINUTA

MINUTA

MINUTA

MI AUTA

MI NUTA

MI NUTA

MINUTA

MI NUTA

MINUTA

OP IMA

OP IMA

OP IMA

OP IMA

OP IMA

OPIMA

OP IMA

OP IMA

OP IMA

OP IMA

OPIMA

OP IMA

OP IMA

OP IMA

OPIMA

OP IM

OP IMA

NE GULF OF MEXICO

NE GULF OF MEXICO

$N$ GULF OF MEXICO

$N$ GULF OF MEXICO

NE GULF OF MEXICO 


\section{Publication}

27661 PFLUM FRERICHS 1976 27662 PFLUM FRERICHS 1976 27663 NORTON 1930

27664 CUSHMAN 19228

27665 CUSHMAN 19228

27666 CUSHMAN 19228

27667 CUSHMAN 19228

27668 CUSHMAN 19228

27669 CUSHMAN $1922 \mathrm{~B}$

27670 CUSHMAN 19228

27671 CUSHMAN 19228

27672 CUSHMAN 19228

27673 CUSHMAN 19228

27674 KELLOUGH 1956

27675 CUSHMAN 1922A

27676 DAVIS 1964

27677 NORTON 1930

27678 NORTON 1930
27679 CUSHMAN $1922 \mathrm{~A}$

27680 NORTON 1930

27681 PAR KER 1954

27683 PARKER 1954

27684 PARKER 1954

27685 PARKER 1954

27686 PARKER 1954

27687 PARKER 1954

27688 PARKER 1954

27689 PARKER 1954

27690 PHLEGER 1955 A

27691 PHLEGER 1955A

27692 PARKER 1954

27693 PARKER 1954
27694 PHLEGER 1956

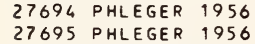

27696 PARKER 1954

27697 PARKER 1954

27698 PHLEGER 1951A

27699 PHLEGER 1951A

27700 PHLEGER 1951A

27701 PHLEGER 1951A

27702 PARKER 1954

27703 PARKER 1954

27704 PARKER 1954

27705 PARKER 1954

27706 PARKER 1954

27707 CREAGER 1958

27708 PARKER 1954

27709 PARKER 1954

27710 PARKER 1954

27711 KELLOUGH 1956

27712 ANDERSEN 1961

27713 PHLEGER 1951 A

27714 PARKER 1954

27715 PHLEGER 1956

27716 PHLEGER 1956

27718 LUDWICK WALTON 1957

27719 LANKFORD 1959

27720 PARKER 1954

27721 PARKER 1954

27722 PARKER 1954

27723 PARKER 1954

27724 PARKER 1954

27725 PARKER 1954

27726 PARKER 1954

27727 PARKER 1954

27728 PARKER 1954

27729 PARKER 1954

27730 PARKER 1954

27731 PARKER 1954

27732 PARKER 1954

27733 PARKER 1954

27734 PARKER 1954

27735 PHLEGER 1955A

27736 PHLEGER 1955A

27737 PHLEGER 1955A

27738 PHLEGER 1955A

27739 PHLEGER 1951A

27740 PHLEGER 1951A

27741 PHLEGER 1951A

27742 PHLEGER 1951A

27743 PHLEGER $1951 \mathrm{~A}$

27744 PHLEGER 1951A

27745 PHLEGER 1951A

27746 PHLEGER $1951 \mathrm{~A}$

27747 PHLEGER 1951A

27748 PHLEGER 1951A

27749 PHLEGEF 1951A

27750 PHLEGER 1951 A

27751 PHLEGER 1951A

27753 PHLEGER 1951 A

27754 PHLEGER 1951 A

27755 PHLEGER 1951 A

\section{Generic Name \\ Specific Name}

VALVULINERIA

VALVULINER IA

EGGERELLA

EGGERELLA

EGGERELLA

EGGERELLA

EGGERELLA

EGGERELLA

EGGERELLA

EGGERELLA

EGGERELLA

EGGERELLA

EGGERELLA

RE USSELLA

NODOBACULAR IELLA

NODOBACULARIELLA

NO DOBACULAR IELLA

NODOBACULAR IELLA

NODOBACULAR IELLA

FRANCES ITA

FRANCESITA

FRANCESITA

FRANCESITA

FRANCES I TA

FRANCES ITA

FRAN CES ITA

FRANCESITA

FRAN CES I TA

FRANCESI TA

FRANCES ITA

FRANCESITA

FRANCESITA

FURSENKOINA

FURSENK OINA

FURSENKOINA

FURSENKOINA

FURSENKOINA

FURSENKOINA

FURSENK OINA

FURSENK OINA

FURSENKOIN

FURSENKOINA

FURSENK OINA

FURSENK OINA

FURSENK OINA

FURSENKOINA

FURSENKOINA

FURSENKOINA

FURSENKOINA

FURSENK OINA

FURSENKOINA

FURSENK OINA

FURSENK OINA

FURSENKOIN

FURSENKOINA

FURSENKOINA

FURSENK OINA

FURSENK OINA

FURSENK OINA

FURSENK OINA

FURSENKOINA

FURS ENK OINA

FURSENK INA

FURSENKOINA

FURSENKOINA

FURSENKOINA

FURSENKOIN

FURSENKOINA

FURSENKOINA

FURSENK OINA

FURSENK OINA

FURSENKOINA

FURSENKOINA

FURSENK OINA

FURSENKOINA

FURSENK OINA

FURSENK OINA

FURSENKOINA

FURSENKOINA

FURSENKOINA

FURSENKOINA

FURSENKOINA

FURSENKOINA

FURSENKOINA

FURSENKOINA

FURSENKOINA

FURSENKOINA

FURSENKOINA

FURSENKOINA

FURSENKOINA

FURSENKOINA

FURSENKOINA
OP IMA

OP IMA

VI LAR DE BOANA

AF FIXA

AF IXA

AFFIXA

BRADYI

BRADYI

BRADYI

BRADYI

BRADY

PR CPINQUA

PROPINQUA

A T LANTICA

AT LANTICA

ATLANTICA

ATLANTICA

AT LANTICA

ADVENA

AD VENA

ADVENA

A DVENA

AD VENA

AD VENA

ADVENA

AD VENA

ADVENA

ADVENA

ADVENA

ADVENA

LOEBLICHI

LOEBL ICHI

LOEBL ICH I

LOEBL ICHI

LOEBL I CHI

LOEBL ICHI

LOEBLICHI

LOEBLICHI

LOEBLICHI

LOEBLICHI

LOEBLICHI

LOEBL ICH I

LOEBLICHI

LOEBLICHI

LOEBL ICHI

LOEBL ICHI

LOEBLICHI

LOEBLICHI

LOEBLICHI

LOEBL ICH I

LOEBLICHI

LOEBL ICH I

LOEBL ICH I

LOEBL ICHI

LOEBL I CHI

LOEBLICHI

LOEBL ICHI

LOEBLICHI

LOEBL ICHI

LOEBL I CHI

LOEBLICHI

LOEBLICHI

LOEBLICHI

LOEBLICHI

LOEBLICHI

LOEBL ICH I

LOEBL ICHI

LOEBLICHI

LOEBLI I CHI

LOEBLICHI

LOEBLICHI

LOEBL ICH I

LOEBLICHI

LOEBLICHI

LOEBL ICH I

LOEBLICHI

LOEBL ICHI

LO EBL I C H I

LOEBLICHI

LOEBL ICHI

LOEBLICHI

LOEBLICHI

LOEBLICHI

LOEBLICHI

LOEBLICHI

LOEBL I CHI

LOEBLICHI

LOEBLICHI

LOEBLICHI

LOEBLICHI

LOEBLICHI

LO EBL I C H I

Locality

NW GULF OF MEXICO

NW GULF OF MEXICO

TORTUGAS, FLA

NE GULF OF MEXICO

NE GULF OF MEXICO

NE GULF OF MEXICO

NE GULF OF MEXICO

NE GULF OF MEXICO 


\section{Publication}

27756 PHLEGER 1951A 27757 PHLEGER 1951A 27758 PHLEGER 1951A 27759 PHLEGER 1951A 27760 PHLEGER 1951A 27761 PHLEGER 1951A 27762 PHLEGER 1951A 27763 PHLEGER 1951A 27764 PHLEGED $1951 \mathrm{~A}$ 27765 PHLEGER $1951 \mathrm{~A}$ 27766 PHLEGER 1951A 27767 PHLEGER 1951A 27768 PHLEGER 1951A 27769 PHLEGER 1951A 27770 CUSHMAN 19228 27771 CREAGER 1958 27772 CREAGER 1958 27773 PARKER 1954 27773 PARKER 1954
27774 PARKER 1954

27775 CUSHMAN 19228

27776 ANDERSEN 1961 27777 PARKER 1954

27778 PARKER 1954

27779 PARKER 1954

27780 CUSHMAN 19228

$2: 781$ PHLEGER 1951A

27782 PHLEGER 1951A

27783 PHLEGER 1951A

27784 PHLEGER 1951A

27785 PHLEGER 1951A

27786 PHLEGER 1951A

27787 PHLEGER 1951A

27788 PHLEGER 1951A

27789 PHLEGER $1951 \mathrm{~A}$
27790 PHLEGER $1951 \mathrm{~A}$

27791 PARKER 1954

27792. PARKER 1754

27793 PARKER 1954

27794 PHLEGER 1955A

27795 PHLEGER 1955A

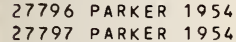

27798 PHLEGER $1951 \mathrm{~A}$

27799 PHLEGEP $1955 \mathrm{~A}$

27800 PHLEGER 1951A

27801 PHLEGER 1951A

27802 PHLEGER 1951A

27803 PHLEGER $1951 \mathrm{~A}$

27804 PHLEGER $1951 \mathrm{~A}$

27805 PHLEGER 1951A

27806 PHLEGER $1951 \mathrm{~A}$

27807 PARKER 1954

27808 PARKER 1954

27809 LANKFDRD 1959

27810 PARKER 1954

27811 PARKER 1954
27812 LUDWICK WALTON 1957

27813 LANKFORD 1959

27814 PHLEGER 1954

27815 PHLEGER 1954

27816 PARKER 1954

27817 PHLEGEQ 1951A

27818 PHLEGER $1951 \mathrm{~A}$

27819 PHLEGER $1951 \mathrm{~A}$

27820 PHLEGER $1951 \mathrm{~A}$
27821 PHLEGER $1951 \mathrm{~A}$

27821 PHLEGER 1951 A
27822 PHLEGER 1951A

27823 LANKFORD 1959

27824 LUDWICK WALTON 1957

27825 WARREN 1957

27826 PARKER 1954

27827 PARKER 1954

27828 PARKER 1954

27829 PARKER 1954

27830 PARKER 1954
27831 PHLEGER 1951 A

27831 PHLEGER $1951 \mathrm{~A}$

27832 PHLEGER $1951 \mathrm{~A}$

27833 PHLEGER $1951 \mathrm{~A}$

27834 PHLEGER $1951 \mathrm{~A}$

27835 PHLEGER 1951A

27836 PARKER 1954

27837 PARKER 1954

27838 PARKER 1954

27839 PARKER 1954
27840 WALTON 1960

27841 PARKER 1954

27842 PARKER 1954

27842 PARKER 1954 PARKER PHLEGER PEIRSON 1953

27844 CREAGER 1958

27845 CREAGER 1958

27846 KELLOUGH 1956

27847 PHLEGER 1956

27848 PHLEGER 1956

27849 PHLEGER 1956

27850 PARKER 1954
Generic Name

FURSENKOINA

FURSENKOINA

FURSENKOINA

FURSENKOINA

FURSENKOINA

FURSENKOINA

FURSENKOINA

FURSENKOINA

FURSENKOINA

FURSENKOINA

FURSENK OINA

FURSENKOINA

FURSENKOINA

FURSENK OINA

FURSENK OINA

FURSENKOINA

FURSENKOINA

FURSENKOINA

FURSENKOINA

FURSENK OINA

FURSENKOINA

FURSENKOINA

FURSENKOINA

FURSENKOINA

FURSENKOINA

FURSENKOINA

FURSENK OINA

FURSENK OINA

FURSENKOINA

FURSENKOINA

FURSENKOINA

FURSENK OINA

FURSENK OINA

FURSENKOINA

FURSENK OINA

FURSENK OINA

FURSENKOINA

FURSENKOINA

FURSENKOINA

FURSENK OINA

FURSENKOINA

FURSENKOINA

FURSENKOINA

FURSENKOINA

FURSENKOINA

FURSENKOINA

FURSENKOINA

FURSENK OINA

FURSENKOINA

FURSENKOINA

FURSENKOINA

FURSENKOINA

FURSENKOINA

VI RGUL INELLA

FURSENK OINA

FURSENK OINA

FURSENKOINA

FURSENKOINA

FURSENKOINA

FURSENK OINA

FURSENKOINA

FURSENKOINA

FURSENKOINA

FURSENKOINA

FURSENKOINA

FURSENKOINA

FURSENK OINA

FURSENKOINA

FURSENKOINA

FURSENKOINA

FURSENKOINA

FURSENKOINA

FURSENK OINA

FURSENKOINA

FURSENKOINA

FURSENKOINA

FURSENKOINA

FURSENKOINA

FURSENKOINA

FURSENKOINA

FURSENKOINA

FURSENKOINA

FURSENKOINA

FURSENKOINA

FURSENK OINA

FURSENKOINA

FURSENK OINA

FURSENK OINA

FURSENKOINA

FURSENKOINA

FURSENKOINA
Specific Name

LO EBLICHI

LOEBLICHI

LOEBLICH I

LO EBL ICH I

LOEGLICHI

LOEBL ICHI

LOEBLICHI

LOEBL I CH I

$\angle O E B L I C H I$

LOEBLICHI

LOEBLICHI

LOEBL ICHI

LOEBL ICHI

CONPRESSA

CONPRESSA

CONPRESSA

MEXICANA

MEXICANA

MEXICANA

MEXICANA

ME XICANA

MEXICANA

MEXICANA

MEXICANA

MEXICANA

MEXICANA

ME XICANA

MEXICANA

MEXICANA

MEXICANA

MEXICANA

MEXICANA

MEXICANA

MEXICANA

MEXICANA

MEXICANA

MEXICANA

MEXICANA

MEXI CANA

MEXICANA

MEXICANA

MEXICANA

MEXICANA

MEXICANA

MEXICANA

MEXICANA

MEXICANA

MEXICANA

MEXICANA

MEXICANA

ME XICANA

MEXICANA

ME XICANA

MEXICANA

PERTUSA

PONTONI

PONTONI

PONTONI

PONTONI

PONTONI

PONTONI

PONTONI

POATONI

PONTONI

POATONI

PONTONI

PONTONI

POATONI

POATON

PONTONI

POATONI

PONTONI

PONTONI

PONTONI

PONTONI

POATON

PONTONI

PONTONI

PONTONI

POATONI

PONTONI

PONTONI

PONTONI

POATONI

POA TON

PONTONI

PONTONI

POATONI

PONTONI

PONTONI

PONTONI

PONTONI

Locality

NW GULF OF MEXICO

NW GULF OF MEXICO

NW GULF OF MEXICO

NW GULF OF MEXICO

NW GULF OF MEXICO

NW GULF OF MEXICO

$N W$ GULF OF MEXICO

NW GULF OF MEXICO

NW GULF OF MEXICO

NW GULF OF MEXICO

NW GULF OF MEXICO

$\mathrm{NW}$ GULF OF MEXICO 


\section{Publication}

27851 PHLEGER 1956

27852 PARKER PHLEGER PEIRSON 1953 27853 PARKER PHLEGER PEIRSON 1953 27854 PARKER PHLEGER PEIRSON 1953 27855 KELLOUGH 1956 27856 KELLOUGH 1956 27857 KELLOUGH 1956 27858 KELLOUGH 1956 27859 PHLEGER $1951 \mathrm{~A}$ 27860 PHLEGER $1951 \mathrm{~A}$ 27861 PHLEGER $1951 \mathrm{~A}$ 27862 PHLEGER 1951 A 27863 PHLEGER $1951 \mathrm{~A}$ 27864 PHLEGER 1951 A 27865 KELLOUGH 1956 27866 LOEP 1965

27867 WARREN 1956 27868 PHLEGER $1951 \mathrm{~A}$ 27869 PHLEGER $1951 \mathrm{~A}$ 27870 PHLEGER $1951 \mathrm{~A}$ 27871 PHLEGER 1951A 27872 PHLEGER 1951 A 27873 ANDERSEN 1961 27874 ANDERSEN 1961 27875 SHEPARD $1100 R E 1955$ 27876 KELLOUGH 1956 27877 PHLEGER 1951 A 27878 PHLEGER $1951 \mathrm{~A}$ 27879 PHLEGER $1951 \mathrm{~A}$
27880 PHLEGER $1951 \mathrm{~A}$

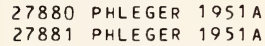
27882 PHLEGER $1955 \mathrm{~B}$ 27883 PHLEGER $1951 \mathrm{~A}$ 27884 PHLEGER $1951 \mathrm{~A}$ 27885 PARKER 1954 27886 PARKER 1954 27887 PARKER 1954 27888 PARKER 1954 27889 PAPKER 1954 27890 PARKER 1954 27891 PARKER 1954 27892 PARKER 1954

27893 LUDWICK WALTON 1957 27894 PARKER 1954 27895 ANDERSEN 1961 27896 ANDERSEN 1961 27897 CUSHMAN $1922 \mathrm{~A}$ 27898 SHIFFLETT 1961 27899 DAVIS 1964 27900 PARKER 195 27901 PARKER 1954 27902 PARKER 1954 27903 PARKER 1954 27904 NORTON 1930 27905 BENDA PURI 1962 27906 PARKER 1954 27907 PARKER 195 27908 PARKER 195 27909 PARKER 195 27910 PAPKER 1954 27911 BANDY 1956 27912 BANDY 1956 27913 BANDY 1956 27914 BANDY 1956 27915 BANDY 1956 27916 BANDY 1956 27918 BANDY 1956 27919 BANDY 1956 27920 BANDY 1956 27921 BANDY 1956 27922 BANDY 1956 27923 BANDY 1954 27924 BANDY 1954 27925 BANDY 1956
27926 BANDY 1956 27926
27927 BANDY 1956
BANDY 1954 27928 BENDA PURI 1962 27929 BANDY 1956 27930 SANDY 1956 27931 BANDY 1956 27932 SANDY 1956 27933 BANDY 1954 27934 BANDY 1954 27935 CREAGER 1958 27936 PHLEGER 1956 27937 PHLEGER 1956 27938 KELLOUGH 1956 27939 PHLEGER $1951 \mathrm{~A}$ 27940 PHLEGER 1951A 27941 PHLEGER $1951 \mathrm{~A}$ 27942 PHLEGER $1951 \mathrm{~A}$ 27943 PHLEGER $1951 \mathrm{~A}$ 27945 PHLEGER 1956
Generic Name

Specific Name

FURSENKOINA

FURSENK OINA

FURSENK OINA

FURSENKOINA

FURSENK OINA

FURSENKOINA

FURSENKOINA

FURSENK OINA

FURSENKOINA

FURSENK OINA

FURSENK OINA

FURSENKOINA

FURSENKOINA

FURSENKOINA

FURSENK OINA

FURSENKOINA

FURSENKOINA

FURSENKOINA

FURSENKOINA

FURSENKOINA

FURSENK O INA

FURSENK OINA

FURSENK OINA

FURSENKOINA

FURSENK OIN

FURSENKOINA

FURSENK OINA

FURSENKOINA

FURSENKOINA

FURSENK OINA

FURSENK OINA

FU RSENK OINA

FURSENK OINA

FURSENK OINA

FURSENKOINA

FURSENKOINA

FURSENKOINA

FURSENKOINA

FURSENKOINA

FURSENKOINA

FURSENKOINA

FURSENKOINA

FURSENKOINA

FURSENKOINA

FURSENKOINA

FURSENKOINA

FURSENKOINA

FURSENKOINA

FURSENK OINA

FURSENK OINA

FURSENKOINA

FURSENKO INA

FURSENK OINA

FURSENKOINA

FURSENK OINA

FURSENKOINA

FURSENK OINA

FURSENKOINA

FURSENK OINA

FURSENKOINA

FURSENKOINA

FURSENK OINA

FURSENKOINA

FURSENKOIN

FURSENK OINA

FURSENKOINA

FURSENKOINA

FURSENKOINA

FURSENK OINA

FURSENKOINA

FURSENKOINA

FURSENKOINA

FURSENKOINA

FURSENK OINA

FURSENKOINA

FURSENK OINA

FURSENK OINA

FURSENKOINA

FURSENK OINA

FURSENKOINA

FURSENKOINA

FURSENKOINA

FURSENKOINA

FURSENKOINA

FURSENKOINA

FURSENKOINA

FURSENKOINA

FURSENK OINA

FURSENK OINA

FURSENKO INA

FURSENKOIN

FURSENK OINA

FURSENK OINA

FURSENK OINA

FURSENKOINA
PONTONI

PONTONI

PONTONI

PONTONI

POATON

PONTONI

PONTON

PONTON

PONTONI

PONTON

PONTON

POATONI

PONTON

PONTONI

PONTONI

POATONI

PONTON

PONTON

PONTON

POATONI

PONTON

PONTONI

PONTON

PONTONI

PONTON

PONTON

PONTONI

PONTONI

POATONI

PONTON

PONTON

PONTON

PONTONI

PUACTATA

PUNCTATA

PUNCTATA

PUNCTATA

PUNCTATA

PUNCTATA

PUNCTATA

PUNCTATA

PUNCTATA

PUNCTATA

PUNCTATA

PUACTATA

PUACTATA

PUNCTATA

PUACTATA

PUNCTATA

PUNCTATA

PUNICTATA

PUACTATA

PUNCTATA

PUACTATA

PUNCTATA

SC HRE I BER SI ANA

SC HRE IBERSI ANA

SCHREIRER SI ANA

SC PRE IBER SI ANA

SCFRE IBER SI ANA

SCHRE IBER SI ANA

SCHREIBER SI ANA

SCHREIBER SI ANA

SCHRE IBER SI ANA

SCHREIBER SI ANA

SCHREIBER SI ANA

SC $P R E I B E R$ SI ANA

SC HRE IBER SI ANA

SC HRE IBER S I ANA

SC HRE IBER SI ANA

SC HRE IBER SI ANA

SCHREIBER SI ANA

SCHREIBER S I ANA

SC HREIBER SIANA

SC HRE IBER SI ANA

SC HRE IBER SI ANA

SCHRE IBER S I AN A

SCFREIBER SI ANA

SC HRE IBERSI AN

SP INICOSTATA

SPINICOSTATA

SPINICOSTATA

SPINICOSTATA

SP INI COSTATA

SPINICOSTATA

SP INI COSTATA

SPINICOSTATA

SPINICOSTATA

SP INICOSTATA
SPINI COSTATA

Locality

Lat. Long.

NW GULF OF MEXICO

TEXAS GJLF COAST

TEXAS GULF COAST

TEXAS GULF COAST

NW GULF OF MEXICO

NW GULF OF MEXICO

NW GULF OF MEXICO

$N W$ GULF OF MEXICO 


\section{Publication}

27946 PARKER DHLEGER PEIRSON 1953 27947 PHLEGE? $1951 \mathrm{~A}$ 27948 PHLEGED 1951 A 27949 PHLEGFP $1951 \mathrm{~A}$ 27950 PHLEGEP $1951 \mathrm{~A}$ 27951 PHLEGER 1951 A 27951 PHLEGED 1951 A 27953 PHLEGER 1959 A 27954 PHLFGER $1951 \mathrm{~A}$ 27955 PHLEGER $1951 \mathrm{~A}$ 27956 SHEPAR? MOORE 1955

27957 PHLEGER $1051 \mathrm{~A}$ 27058 PHLEGED $1951 \mathrm{~A}$ 27959 DHLFGED $1051 \mathrm{~A}$ 27960 VAUSHAN: 1913 27961 PHLEGER 1951 A 27962 PARKER 1754

27963 PARKER 1354

27964 PARKER 1954

27965 PHLEGER $1951 \mathrm{~A}$

27966 PHLEGER $1951 \mathrm{~A}$

27967 PHLEGER $1951 \mathrm{~A}$

27968 PHLEGED 1955 A

27969 PHLEGED $1951 \mathrm{~A}$

27970 PARKER 1954

27971 PARKER 1354

27972 PHLEGER $1951 \mathrm{~A}$

27973 PARKER 1254

27974 PARKER 1754

27975 PARKER 1754

27976 PHLEGER $1955 \mathrm{~A}$

27977 PARKER 1954

27978 PARKER 1954

27979 PHLEGER 1951 A

27980 PARKER 1954

27981 PHLEGER $1951 \mathrm{~A}$

27982 PHLEGFR 1951A

27983 PHLEGER 1951 A

27984 PHLEGE $1951 \mathrm{~A}$

27985 PHLEGER 1951 A

27986 BENDA PURI 1962

27987 BANDY 1956

27988 BANDY 1956

27989 AN!DERSFN 1961

27990 BANDY 1956

27991 SHIFFLETT 1961

27992 PARKER 1954

27993 PARKER 1754

27994 PARKER 1954

27995 PARKER 1754

27996 PARKER 1254

27997 PARKER 1054

27998 PARKER 1754

27999 PARKER 1954

28000 PARKER 1954

28001 PARKER 1954

2800? PARKER 1954

28003 PARKER 1954

28004 BOCK 1976

28005 WALTON 1960

28006 BANDY 1950

28007 PARKER 1054

\section{Generic Name}

FURSENKOINA

FURSENKOINA FURSENKOINA FUPSENK OINA FURSENKOINA FURSENKOINA FURSENK OINA

FURSENKOINA FURSENKOINA FURSENK OINA FUPSENKOINA FURSENKOINA FURSENKOINA FURSENKOINA FURSENKOINA FUPSENKOINA FURSENK OINA FURSENK OINA FURSENKOINA FURSENK OINA FURSENKOINA FURSENK O INA FURSENKOINA FUPSENKOINA FURSENKOINA FURSENK OINA FURSENKOINA FURSENK OINA FURSENKOINA FURSENKOINA FURSENKOINA FURSENK OINA FURSENK OINA FURSENK OINA FURSENKOINA FURSENKOINA FURSENKOINA FURSENK OINA FURSENKOINA FURSENKO INA WI ESNERELLA WI ISSNERELLA WIESNERELLA WI ESNERELLA WI ESNERELLA WI ESNEPELLA WIESNERELLA WI ESNERELLA

WI ESNERELLA

WIESNERELLA

WI ESNERELLA

WI ESNERELLA

WI ESNERELLA

WI ESNERELLA

WI ESNERELLA

WIESNERELLA

WI ESNERELLA

WI ESNERELLA

WI ESNERELLA

WI ESNERELLA

WIESNERELLA

WIESNERELLA
Specific Name

SPINICOSTATA

SPINI COSTATA

SPINICOSTATA

SPINICOSTATA

SPINICOSTATA

SPINICOSTATA

SPINICOSTATA

SPINI COSTATA

SPINICOSTATA

SPINICOSTATA

SPINICOSTATA

SP INICOSTATA

SPINICOSTATA

SQLAMOSA

TESSELLATA

TESSELLATA

TESSELLATA

TESSELLATA

TE SSELLATA

TESSELLATA

TESSELLATA

TESSELLATA

TESSELLATA

TESSELLATA

TE SSELLATA

TE SSELLATA

TESSELLATA

TESSELLATA

TESSELLATA

TESSELLATA

TESSELLATA

TE SSELLATA

TE SSELLATA

TESSELLATA

TESSELLATA

TESSELLATA

TESSELLATA

TESSELLATA

TESSELLATA

AURI CULATA

AUFI CULATA

AURI CULATA

AUFICULATA

AUFICULATA

AUFI CULAT A

AURICULATA

AURICULATA

AURI CULATA

AURI CULATA

AURICULATA

AURICULAT A

AURI CULATA

AUFICULATA

AURICULATA

AURI CULATA

AURI CULATA

AURI CULATA

AURICULATA

AURICULATA

AURICULAT

AURICULATA

\section{Locality}

TEXAS GULF COAST

NW GULF OF MEXICO

NW GULF OF MEXICO

NW GULF OF MEXICO

NW GULF OF MEXICO

NW GULF OF MEXI

NW GULF OF MEXICO

NW GULF OF MEXICO

NW GULF OF MEXICO

NW GULF OF MEXICO

CENTRAL TEXAS COAST

NW GULF OF MEXICO

NW GULF OF MEXICO

NW GULF OF MEXICO

DRY TORTUGAS

NW GULF OF MEXICO

NE GULF OF MEXICO

NE GULF OF MEXICO

NE GULF OF MEXICO

NW GULF OF MEXICO

NW GULF OF MEXICO

NW GULF OF MEXICO

$N$ GULF OF MEXICO

NW GULF OF MEXICO

NE GULF OF MEXICO

NE GULF OF MEX

NW GULF OF MEXICO

NE GULF OF MEXICO

NE GULF OF MEXICO

NE GULF OF MEXICO

$N$ GULF OF MEXICO

NE GULF OF MEXICO

NE GULF OF MEXICO

NW GULF OF MEXICO

NE GULF OF MEXICO

NW GULF OF MEXICO

NW GULF OF MEXICO

NW GULF OF MEXICO

NW GULF OF MEXICO

NW GULF OF MEXICO

CAPE ROMANO, FLA.

NE GULF OF MEXICO

NE GULF OF MEXICO

MISSISSIPPI DELTA

NE GULF OF MEXICO

HEALD BANK, G. OF MEXICO

NE GULF OF MEXICO

NE GULF OF MEXICO

NE GULF OF MEXICO

NE GULF OF MEXICO

NE GULF OF MEXICO

NE GULF OF MEXICO

NE GULF OF MEXICO

NE GULF OF MEXICO

NE GULF OF MEXICO

NE GULF OF MEXICO

NE GULF OF MEXICO

NE GULF OF MEXICO

NE GULF OF MEXICO

MISSISSIPPI SOUND

NE GULF OF MEXICO

NE GULF OF MEXICO

Lat. Long.

$2810 \mathrm{~N} 09635 \mathrm{~W}$ $2806 \mathrm{~N} 09407 \mathrm{~W}$ $2852 \mathrm{~N} 094 \quad 42 \mathrm{~W}$ $2853 \mathrm{~N} 09245 \mathrm{~W}$ $2820 \mathrm{~N} 09504 \mathrm{~W}$ $2746 \mathrm{~N} 094 \quad 47 \mathrm{~N}$ $2820 \mathrm{~N} 09519 \mathrm{~W}$ $2755 \mathrm{~N} 09620 \mathrm{~W}$ $2759 \mathrm{~N} 09606 \mathrm{~W}$ $2718 \mathrm{~N} 09614 \mathrm{~W}$ $2800 \mathrm{~N} 09640 \mathrm{~W}$ $26 \quad 22 \mathrm{~N} 096 \quad 40 \mathrm{~W}$ $2730 \mathrm{~N} 09642 \mathrm{~W}$ $2710 \mathrm{~N} 096 \quad 22 \mathrm{~W}$ $2434 \mathrm{~N} 08250 \mathrm{~W}$ $2647 \mathrm{~N} 09556 \mathrm{~W}$ $28 \quad 48 \mathrm{~N} 08925 \mathrm{~W}$ $2825 \mathrm{~N} 088$ 20W $2858 \mathrm{~N} 08847 \mathrm{~W}$ $2729 \mathrm{~N} 09355 \mathrm{~W}$ $2742 \mathrm{~N} 09426 \mathrm{~W}$ $2705 \mathrm{~N} 09210 \mathrm{~W}$ 2818 N $08920 \mathrm{~W}$ $2732 \mathrm{~N} 09305 \mathrm{~N}$ $2802 \mathrm{~N} 085 \quad 20 \mathrm{~W}$ $2530 \mathrm{~N} 08459 \mathrm{~W}$ $2710 \mathrm{~N} 09622 \mathrm{~W}$ $29 \quad 15 \mathrm{~N} 08755 \mathrm{~W}$ $2850 N 08736 \mathrm{~W}$ $2744 \mathrm{~N} 089 \quad 16 \mathrm{~W}$ $2802 \mathrm{~N} 08919 \mathrm{~W}$ $2900 N 08654 \mathrm{~W}$ 


\section{Catalog 3}

\section{Unsynonymized Species}

\begin{tabular}{|c|c|}
\hline ADERCOTRYMA & GLOMERATA \\
\hline ADERCOTRYMA & GLOMERATUM \\
\hline ALABA MINA & OECORATA \\
\hline ALFREOOS IL VESTRIS & LEVINSONI \\
\hline ALLOGROMIA & LATI COLLARIS \\
\hline ALLOMORPHINA & TRIGONA \\
\hline ALVEOLINA & PULCHRA \\
\hline ALVEOL OPHR AGMIUM & NITIOUM \\
\hline ALVEOL OP HR AGMIUM & RINGENS \\
\hline ALVEOLOPHR AGMIUM & SCITULUM \\
\hline ALVEOLOP HR AGMIUM & SUBGLOBOSUM \\
\hline ALVEOL OPHRAGMIUM & WIESNERI \\
\hline AL VEOVAL VUL INE LLA & POZONENSIS \\
\hline AMMOASTUTA & INEPTA \\
\hline AMMOASTUTA & SALSA \\
\hline AMMOBACULITES & AGGLUTINANS \\
\hline AMMOBACULITES & AMER ICANUS \\
\hline AMMOBACULITES & ARENARIUS \\
\hline AMMOBACULITES & CRASSUS \\
\hline AMMOBACULITES & CYLINOROIDES \\
\hline AMMOBACULITES & DILATATUS \\
\hline AMMOBACULI TES & DIVERSUS \\
\hline AMMOBACULITES & EXIGUUS \\
\hline AMMOSACUL I TES & EXIL IS \\
\hline AMMOBACULITES & FILI F ORMIS \\
\hline AMMOBACUL I TES & FOLIACEUM \\
\hline AMMOBACUL I TES & FOLIACEUS \\
\hline AMMOBACULI TES & REOPHACIFORMIS \\
\hline AMMOBACULITES & SALSUS \\
\hline AMMOBACULITES & SALSUS OISTINCTUS \\
\hline AMMOBACUL I TES & SUBCATENULATUS \\
\hline AMMOBACULITES & TENU I MARGO \\
\hline AMMOOISCOIDES & TURBINATUS \\
\hline AMMOOISCUS & ANGUILLAE \\
\hline AMMOOISCUS & INCERTUS \\
\hline AMMOOISCUS & PLANORBIS \\
\hline AMMODISCUS & TENUIS \\
\hline AMMOFL INTINA & TRIHEORA \\
\hline $\begin{array}{l}\text { AMMOGLOBIGERINOIDES } \\
\text { AMMOL AGEVA }\end{array}$ & $\begin{array}{l}\text { DEHISCENS } \\
\text { CLAVATA }\end{array}$ \\
\hline AMMOMARG INUL INA & FOLIACEA \\
\hline AMMON I A & BECCARII \\
\hline AMMONIA & BECCARII PARKINSONIANA \\
\hline AMMONI A & BECCARII SOBRINA \\
\hline AMMON I A & BECCARII TEPIOA \\
\hline AMMONIA & PARKINSONIANA TEPIOA \\
\hline AMMONIA & PARKINSONIANA TYPICA \\
\hline AMMONIA & ROLSHAUSENI \\
\hline AMMONIA & TRANSLUCENS \\
\hline AMMOS CALAR IA & FLUVIALIS \\
\hline AMMOS CALAR IA & PSEUDOSPIRALIS \\
\hline AMMOS CAL AR IA & TENU I MARGO \\
\hline AMM OSPHAER OIOINA & SPHAEROIOIVIFORMIS \\
\hline AMMOTI UM & OILATATUM \\
\hline AMMOTIUM & FRAGILE \\
\hline AMMOTIUM & MULTILOCULATUM \\
\hline AMMOTIUM & PALUSTRE \\
\hline AMMOTIUM & PSEUDOCASSIS \\
\hline AMMOTIUM & SALSUM \\
\hline AMMOTIUM & SALSUM EMACIATUM \\
\hline AMMOTI UM & SALSUM EXILE \\
\hline AMMOTIUM & SALSUM TUMIOUM \\
\hline AMMOTIUM & SALSUM TYPICUM \\
\hline AMMOT IUM & SUBOIRECTUM \\
\hline AMPHI CORYNA & CAMACHOI \\
\hline AMPHI CORYNA & HISPIOA \\
\hline AMPHI CORYNA & ROEOERERI \\
\hline AMPHI CORYNA & SCALARIS \\
\hline AMPHICORYNA & SEPARANS \\
\hline AMPHICORYNA & SUBL INEATA \\
\hline AMP HISORUS & DUPLEX \\
\hline AMPHISORUS & HEMPR ICHII \\
\hline AMPHISTEGINA & GI BBOSA \\
\hline AMPHISTEGINA & LESSONII \\
\hline AMPHORINA & MOLLIS \\
\hline A MPHOR INA & PURII \\
\hline ANGULOGERINA & ANGULOSA \\
\hline ANGULOGERINA & BELLA \\
\hline ANG ULOGERINA & JAMAICENSIS \\
\hline ANGULOGERINA & OCCI OENTALIS \\
\hline ANOMAL INA & AMMONOIDES \\
\hline ANOMAL INA & CORONATA \\
\hline ANOMALINA & CORPULENTA \\
\hline $\begin{array}{l}\text { ANOMAL INA } \\
\text { ANOMALINA }\end{array}$ & $\begin{array}{l}\text { EOWAROSIANA } \\
\text { FOVEOLAIA }\end{array}$ \\
\hline
\end{tabular}

\begin{tabular}{|c|c|}
\hline ANOMALINA & GLOBUL OSA \\
\hline ANOMALINA & GROSSERUGOSA \\
\hline ANOMALINA & 10 \\
\hline ANOMALINA & MEXICANA \\
\hline ANOMALINOIOES & CORPULENTUS \\
\hline ANOMALINOIOES & MEXICANA \\
\hline APIOPTERINA & AVGUSTA \\
\hline APIOPTERINA & EXTENSA \\
\hline ARCHAIAS & AOUNCA \\
\hline AQCHAIAS & ANGULATUS \\
\hline ARCHAIAS & COMPRESSA \\
\hline ARCHAIAS & COMPRESSUS \\
\hline ARENOPARRELLA & MEXICANA \\
\hline ART I CUL INA & AN TILLAR UM \\
\hline ARTI ICULINA & CONICO-ARTI CULATA \\
\hline ART I CUL IVA & LINEATA \\
\hline ART I CUL INA & MAYORI \\
\hline ARTI CUL INA & MEXICANA \\
\hline ARTI CUL INA & MUCRONATA \\
\hline ART I CUL INA & PACIFICA \\
\hline ART I CUL INA & SAGRA \\
\hline ARTI CUL IVA & SULCATA \\
\hline ASCHEMONELLA & RAMULIFORMIS \\
\hline ASCHEMONE LLA & SCABRA \\
\hline ASTACOL US & $\begin{array}{l}\text { CREPIOUL US } \\
\text { OVATUS }\end{array}$ \\
\hline $\begin{array}{l}\text { ASTACOLUS } \\
\text { ASTERIGERINA }\end{array}$ & $\begin{array}{l}\text { OVATUS } \\
\text { CARINATA }\end{array}$ \\
\hline ASTRONONION & TUMIOUM \\
\hline ASTRORHIZA & VERMIF ORMIS \\
\hline BATHYSI PHON & FIL I FORMIS \\
\hline BATHYSI PHON & RUFUS \\
\hline BIF ARINA & DECORATA \\
\hline BIGENER INA & $\begin{array}{l}\text { IRREGULARIS } \\
\text { NODOSARIA }\end{array}$ \\
\hline B I GE NER INA & $\begin{array}{l}\text { NOOOSARIA } \\
\text { NOOOSARIA TEXTULARIJIOEA }\end{array}$ \\
\hline $\begin{array}{l}\text { BIGENER IVA } \\
\text { BIGENER INA }\end{array}$ & $\begin{array}{l}\text { NOOOSARIA TEXTULARIJIOEA } \\
\text { PENNATULA }\end{array}$ \\
\hline BI GENER INA & ROBUSTA \\
\hline BIGENER INA & TEXTULARIOIOEA \\
\hline BILOCUL IVA & DENTICULATA STRIOLATA \\
\hline BILOCULINA & MILLETTII \\
\hline BILOCULINA & SUBSPHAERICA \\
\hline BILOCUL INELLA & $L A B I A T A$ \\
\hline BILOCUL IVELLA & TOODAE \\
\hline BISACCIU & IMBR ICATUM \\
\hline BOL I VINA & ALATA \\
\hline BOLIVINA & ALBATROSSI \\
\hline BOL I VINA & BARBATA \\
\hline BOL I VINA & BEYRICHI ALATA \\
\hline BOL IVINA & COMPACTA \\
\hline BOL IVINA & OAGGARIUS \\
\hline BOLIVINA & FRAGILIS \\
\hline BOL I VIN A & GOES II \\
\hline$B O L I V I N A$ & HASTATA \\
\hline $\begin{array}{l}\text { BOLIVINA } \\
\text { BOLIVINA }\end{array}$ & $\begin{array}{l}\text { INFLATA } \\
\text { LANCEOLATA }\end{array}$ \\
\hline BOLIVINA & LIMBATA \\
\hline BOL I VINA & LIMBATA COSTULATA \\
\hline BOL I VINA & LOWMANI \\
\hline BOL I VINA & MAYORI \\
\hline BOL IVINA & MEXICANA \\
\hline BOL IVINA & MINIMA \\
\hline BOLIVINA & OROINARIA \\
\hline BOL IVINA & PAULA \\
\hline BOL I VINA & PSEUDOPLICATA \\
\hline BOL IVINA & PULCHELLA \\
\hline BOL I VINA & PULCHELLA PRIMITIVA \\
\hline BOLIVINA & PUNCTATA \\
\hline BOL I VINA & PUSILLA \\
\hline$B O L I V I N A$ & QUAORATA \\
\hline BOL I VINA & RHOMBOIOALIS \\
\hline BOL I VINA & SEMINUDA \\
\hline BOLIVINA & SIMPLEX \\
\hline BOL I VINA & SPATHULATA \\
\hline BOLIVINA & SPICATA \\
\hline BOLIVINA & SPINATA \\
\hline BOL IVINA & STRIATA MEXICANA \\
\hline BOLIVINA & STRI AT ULA \\
\hline BOL IVINA & STRIATULA SPINATA \\
\hline BOL I VINA & SUBAENARIENSIS \\
\hline BOLIVINA & SUBAENARIENSIS MEXICANA \\
\hline BOL I VINA & SUBEXCAVATA \\
\hline BOLIVINA & SUBSPINESCENS \\
\hline$B O L I V I N A$ & TRANSLUCENS \\
\hline BOL I VINA & VARIABILIS \\
\hline BOL IVINITA & QUAORILATERATA \\
\hline
\end{tabular}


BOL IVINITA

BORELIS

BRI ZAL INA

BRI ZAL INA

BRI ZAL INA

BRI ZALINA

BRI ZAL INA

BR I ZAL INA

BRI ZALINA

BR I ZAL INA

SR I ZAL INA

BR I ZALINA

BRI ZALINA

BRI ZALINA

BUC CELLA

BUL IMINA

BUL IM INA

BUL IMINA

BUL IM INA

BUL IMINA

BUL IMINA

BUL IMINA

BUL IMINA

BUL IMINA

BULIMINA

BUL IMINA

BUL IMINA

BUL IMINA

BULIMINA

BUL IMINA

BUL IMINEL - A

BULIMINEL-A

BUL IMINELLA

BUL IMINEL - A

BUL IMINELLA

BULIMINOIDES

CANCRIS

CANCRIS

CANCRIS

CARTER INA

CASSIDULINA

CASSIOULINA

CASSIDULINA

CASSIDULINA

CASSIDUL INA

CAS SIDULINA

CASSIDULINA

CASSIOULINA

CASSIDUL INOIDES

CASSIDULINOIDES

CASSIDULINOIDES

CASSI DULINOIDES

CASSIOULINOIDES

CHILOSTOME LLA

CHILOSTOMELLA

CHRYSALIOI NELLA

CHRYSALIOINELLA

CIBICIDES

CIBICIOES

CIBICIDES

CIBICIDES

CIBICIDES

CIBICIDES

CIBICIDES

CIBICIDES

CIBICI DES

CIBICIDES

CIBICIDES

CIBICIDES

CIBICIDES

CIBICIDES

CIBICIDES

CIBICIDES

CIBICIOES

CIBICIDES

CIBICIDES

CIBICIDES

CIBICIDES

CIBICIDES

CIBICIDES

CIBICIDES

CIBICIDES

CIBICIDES

CIBICIDES

CIBICIDES

CIBICIDES

CIBICIDES

CIBICIDES

CIBICIOINA

CIBICIDINA

CIBICIDOIDES

CIBICIDOIOES

CIBICIDOIOES

CLAVUL INA

CLA VUL INA
RHOMBOIOALIS

PULCHRA

BARBATA

FRAG ILIS

GOES I I

HASTATA

LANCEOLATA

LOWMAN I

MI NIMA

PAULA

DULCHELLA PR IMITIVA

SPINATA

STRIATULA

SUBSPINESCENS

HANNAI

ACULEATA

AFFINIS

ALAZANENSIS

BARBATA

BASSENDORFENSIS

BUCHIANA

INFLATA MEXI CANA

MARG INATA

OVATA

PUPOIDES

PYRULA SPINESCENS

ROSTRATA ALA ZANENS IS

SPICATA

STRIATA MEXI CANA

TENUIS

BASSENDORFENSIS

ELEGANTISSIMA

EXILIS
MORGANI

SUBTERES

WILL IAMSONI ANA

AURI CULA

OBLONG

$S A G R A$

SPICULOTESTA

CARINATA

CRASSA

CRASSA

CURVATA

LAEVIGATA

LAEVIGATA CARINATA

NEOCARINATA

NORCROSSI AUSTRALIS

SUBGLOBOSA

BRADYI

MEXI CANA

MEXICANUS

PARKERI ANUS

TENU IS

OOL INA

OVOIDEA

DIMORPHA

POPEI

ADVENA

AMERI CANA STRATTONI

ANTILLARUM

BANTAMENSIS

BRADYI

CONCENTRICA

CONCENTRICUS

CORA

C ORPULENTUS

OEPRIMUS

FLORI DANA

FLORI OANUS

KULLENBERG I

LOBATULA

LOBATULUS

MOLL IS

PROTUBERANS

PSEUDOUNGER I ANA

PSEUDOUNGER I ANA IO

PSEUDOUNGERI ANUS

REFULGENS

ROBERTSONIANA

ROBERTSONIANUS

ROBUSTUS

RUGOSA

RUGOSUS

RUGOSUS

TUMI OULA

UMBONATUS

UNGERIANA
WUELLERSTORF

STRATTONI

LOBATULUS

ROBERTSONIANUS

RUGOSUS

B I CARINATA

COMMUNIS
CLAVULINA

CLAVUL INA

CLAVULINA

CLAVULINA

CLAVULINA

CLAVUL INA

CLAVULINA

CONORBINA

CORNULO CUL INA

CORNUSPIRA

CORNUSPIRA

CORNUSPIRA

CORNUSPIRA

CORNUSPIROIDES

CORNUSPIROIDES

CORYPHOSTOMA

CORYPHOSTOMA

CORYPHOSTOMA

CORYPHOSTOMA

CORYPHOSTOMA

CRI B ROB IGENERINA

CRIBROE LPHIDIUM

CRIBROELPHIDIUM

CRIBROELPHIOIUM

CRI BROELPHIOIUM

CRIBROE LPH IOIUM

CRIBROE LDHIDIUM

CRI BROE LOHIOIUM

CRIBROELOHIOIUM

CRIBROE LPHIDIUM

CRIBROPYRGO

CRIBROS TOMOIDES

CRI BROS TOMOI DES

CRIBROSTOMOIDES

CRIBROSTOMOIDES

CRIBROS TOMOIDES

CRIBROSTOMOIDES

CRIBROS TOMOIDES

CRIBROS TOMOIDES

CRI BROS TOMOIDES

CRIBROS TOMOIDES

CRISTELLARIA

CRISTELLARIA

CRISTELLARIA

CRISTELLARIA

CRISTELLARIA

CRISTELLARIA

CRISTELLARIA

CRISTELLARIA

CRISTELLARIA

CRISTELLARIA

CRISTELLARIA

CRISTELLARIA

CRIS TELLARIA

CRISTELLARIA

CRISTELLARIA

CRISTELLARIA

CRISTELLARIA

CRISTELLARIA

CRISTELLAR IA

CRISTEL LARIA

CRITHIONINA

CRUCILOCULINA

CYCLLAMM INA

CYCLLAMMINA

CYCL AMM INA

CYCLAMMINA

CYCLOGYRA

CYCLOGYRA

CYMBALOPORA

CYMBAL OPJRETTA

CYMBALOPJRETTA

CYSTAMMINA

DENT AL I NA

DEN TAL INA

DENTALINA

DENT AL I NA

DENTALINA

DENTALINA

OENTAL I NA

DENT AL I NA

DENTAL!NA

OISCOPULVINUL INA

DIS CORBIVA

DIS CORBINA

DISCORB IS

DISCORB IS

OIS CORB IS

DIS CORB IS

DIS CORB IS

DIS CORB IS

DISCORB IS

DISCORE IS

OIS CORB IS

FL IN TI ANA

GRACILIS

HUMILIS MEXICANA

MEXI CANA 


\begin{tabular}{|c|c|}
\hline DISCORBIS & FLORIDANA \\
\hline DISCORBIS & FLORIDANUS \\
\hline DIS CORBIS & FLORIDENSIS \\
\hline DISCORBIS & MIRA \\
\hline OISCORBIS & NITIDA \\
\hline DIS CORBIS & ORBICULARIS \\
\hline DIS CORBIS & PATELLIFORMIS \\
\hline DISCORBIS & ROSEA \\
\hline D IS CORB IS & RUGOSA \\
\hline DIS CORBIS & SUBARAUCANA \\
\hline DISCORBIS & SUEZENSIS \\
\hline DIS COR IN OPS IS & AGUAYOI \\
\hline DOROTHIA & CARIBAEA \\
\hline DOROTHIA & PS EUDOTURRIS \\
\hline DOROTHIA & $S C A B R A$ \\
\hline EGGERELLA & AFFIXA \\
\hline EGGERELLA & BRADYI \\
\hline EGGERELLA & PROPINQUA \\
\hline $\begin{array}{l}\text { EGGERELLA } \\
\text { EHRENBERGINA }\end{array}$ & $\begin{array}{l}\text { SCABRA } \\
\text { PUPA }\end{array}$ \\
\hline EHRENBERGI NA & SPINEA \\
\hline EHRENGERGINA & TRIGONA \\
\hline ELPHIDIUM & ADVENA \\
\hline ELPHIDIUM & ADVENUM \\
\hline ELPHIDIUM & ARTI CULATUM \\
\hline ELPHIDIUM & DELICATULUM \\
\hline ELPHIDIUM & DISCOIDALE \\
\hline ELPHID IUM & DISCOIDALIS \\
\hline ELPHIDIUM & EXCAVATUM \\
\hline ELPHIDIUM & FIMBR I A TULUM \\
\hline ELPHIDIUM & GALVESTONENSE \\
\hline ELPHIDIUM & GALVESTONENSE MEXI CANUM \\
\hline ELPHIDIUM & GALVESTONENSE TYPICUM \\
\hline ELPHIDIUM & GALVESTONENS IS \\
\hline ELPHIDIUM & GALVESTONENS IS GALVESTONENS I \\
\hline ELPHIDIUM & GALVESTONENS IS KOEBOEENSE \\
\hline ELPHIDIUM & GUNTERI \\
\hline ELPHIDIUM & GUNTERI DELI CATULUM \\
\hline ELPHIDIUM & GUNTERI GALVESTONENSE \\
\hline ELPHIDIUM & GUNTERI GAL VESTONENSIS \\
\hline ELPHIDIUM & GUNTERI GUNTER I \\
\hline ELPHIDIUM & GUNTERI SALSUM \\
\hline ELPHIDIUM & GUNTERI TYPI CUM \\
\hline ELPHIDIUM & INCERTUM \\
\hline ELPHIDIUM & INCERT,UM MEX IC ANA \\
\hline ELPHIOIUM & INCERTUM MEXICANUM \\
\hline ELPHIDIUM & KOEBOEENSE \\
\hline ELPHIDIUM & LIMOSUM \\
\hline ELPHIDIUM & MACELLA \\
\hline ELPHIOIUM & MATAGORDANUM \\
\hline ELPHIDIUM & MEXI CANUM \\
\hline ELPHIDIUM & MORENOI \\
\hline ELPHIDIUM & OCEANI CUM \\
\hline ELPHIDIUM & POEYANA \\
\hline ELPHIDIUM & POEYANUM \\
\hline ELPHIDIUM & RUGULOSUM \\
\hline ELPHIDIUM & SAGRUM \\
\hline ELPHIDIUM & SELSEYENSE \\
\hline ELPHIDIUM & TRANSLUCENS \\
\hline ELPHIDIUM & TUMIDUM \\
\hline ENANT I ODEN TAL INA & COMMUN IS \\
\hline ENT OS OLENIA & ORBI GNYANA \\
\hline ENT OS OLEN I A & ORBIGNYANA ANTILLEA \\
\hline EPISTOMINA & ELEGANS \\
\hline EPISTOMINE LLA & DECORATA \\
\hline EPISTOMINELLA & ELEGANS \\
\hline EPISTOMINELLA & $E X I G \cup A$ \\
\hline EPISTOMINELLA & RUGOSA \\
\hline EPISTOMINELLA & VITREA \\
\hline EPONIDELLA & GARDENISLANDENSIS \\
\hline EPONIDELLA & PALMERAE GARDENISLANDENS IS \\
\hline EPONIDELLA & PALMERAE PALMERAE \\
\hline EPONIDES & ANTILLARUM \\
\hline EPONIDES & CORYELLI \\
\hline EPONIDES & GAVIOTAENSIS \\
\hline EPONIDES & HANNAI \\
\hline EPONIDES & IN CERTA \\
\hline EPONIDES & LATERALIS \\
\hline EPONIDES & POLIUS \\
\hline EPONIDES & PYGMAEA \\
\hline EPONIDES & REGULAR IS \\
\hline EPONIDES & REPANDA \\
\hline EPONIDES & REPANDUS \\
\hline EPONIDES & TENERA \\
\hline EPONIDES & TUMI DUL US \\
\hline EPONIDES & TURGIDUS \\
\hline EPONIDES & UMBONATUS \\
\hline EUUVIGERINA & PAR VULA \\
\hline FIS CHER INA & DUBIA \\
\hline FIS SUR INA & ARADASII \\
\hline FISSURINA & FORMOSA \\
\hline FISSURINA & ORBIGNYANA \\
\hline FISSURINA & PUNCTATA \\
\hline $\begin{array}{l}\text { FIS SURINA } \\
\text { FISSURINA }\end{array}$ & $\begin{array}{l}\text { STRIATOPUNCTATA } \\
\text { TENUIS SIMA }\end{array}$ \\
\hline
\end{tabular}

FLORILUS

FLORILUS

FLORILUS

FLORILUS

FRAN CES ITA

FRONDICULARIA

FRONDICULARIA

FRON DIC ULARIA

FURS ENKOINA

FURS ENK OINA

FURSENK OINA

FURSENKOINA

FUR SENK OINA

FURS ENK OINA

FURS ENK OINA

FUR S ENK OINA

GAUDRYINA

GAUDRYINA

GAUDRYINA

GAUDRYINA

GAUDRYINA

GAUDRYINA

GAUDRYINA

GAUDRYINA

GAUDRYINA

GAUDRYINA

GAUDRYINA

GIRVANEL_. A

GLANDUL IVA

GLANDUL INA

GLOBOBULIMINA

GLOBOBULIMINA

GLOBOBULIMINA

GLOBOBULIMINA

GLOBOCASS I DUL INA

GLOBOCASS I DUL INA

GLOBOCASS IDUL INA

GLOBOCASS IDULINA

GLOBOCASS IDULINA

GLOBOCASS IDUL INA

GLOBOTE XTULARIA

GLOBULINA

GLOBULINA

GLOMOSP IRA

GLOMOSP IRA

GOESELLA

GUTT ULI NA

GUTT ULINA

GUTTULINA

GUTTULINA

GUTTULINA

GUTT UL INA

GUTTULINA

GUTTULINA

GUT TUL INA

GYPS INA

GYPS INA

GYROIDINA

GYROIDINA

GYRO IDINA

GYRO IDINA

GYROIDINA

GYRO IDINA

GYROIDINA

GYROIDINA

GYROIDINA

GYROIDINA

GYROIDINOIDES

HAL I PHY SE MA

HAL YPHY SEMA

HAN Z AWA IA

HAN Z AWA IA

HAN Z AWA IA

HAPL OPHRAGMIUM

HAPL OPHRAGMO IDES

HAPL OPHRA GMOI DES

HAPL OPHRAGMOIDES

HAPL OPHRA GMO IDES

HAPLOPHRA GMOIDES

HAPLOPHRAGMOIDES

HAPLOPHRAGMOIDES

HAPLOPHRAGMOIDES

HAPL OPHRA GMOIDES

HAPL OPHRA GMOIDES

HAPL OPHRAGMOIDES

HAPL OPHRAGMOIDES

HAPLOPHRAGMOIDES HAPLOPHRAGMO IMOIDES HAPL OPHRA GMOIDES HAPLOPHRA GMOIDES HAPL OPHRAGMOIDES HAPL OSTICHE

HAUERINA

HAUERIN A
ATLANTICUS

CLAVATUS

GRAT EL OUPI

SCAPHUS

ADVENA

COMPRESSA

SAGITTULA

SAGITTULA LANCEOLATA

COMPLANATA

COMPRESSA

MEXICAN

PONTONI

PUNCTATA

SCHREIBERSIANA

SEMINUDA

SPINICOSTATA

AEQUA

APICULAR IS

ATLANTICA

BACCATA NOVANGLIAE

BRADYI

CHILOS TOMA

EXILIS

FLIN I I

STAVENSIS

VAGANS

COMATULA

AFFINIS

MISSISSIPPIENS IS

OVULA

PYRULA SPINESCENS

CRASSA

GLOBULOSA

MOLUCCENSIS

MURRHYNA

PAC I I I CA

SUBGLOBOSA

ANCEPS

CARIBAEA

GIBBA

CHAROIDES

GORDIALIS

MISSISSIPPIENSIS

AUSTRALIS

HIRSUTA

LAEVIS

OBLONGA

PROBLEMA

PUL CHELLA

REGINA

SPICAEFORMIS

SPICAEFORMIS AUSTRALIS

GLOBULUS

VES I CULAR IS

ALTIFORMIS ACUTA

ALTIFORMIS CUSHMANI

API CUL AR IS

LAMARCKI ANA

MAURYAE

NEOS OL DANII

ORBI CULARIS

SOLDAN II

SOLDANII ALTIFORMIS

UMBONATA

SOLDANII ALTIFORMIS

ADVENA

TUMANOWI C ZII

BERTHELOTI

CONCENTRICA

STRATTON I

LITUOL INOIDEUM

BRAOYI

CANARIENSIS MEXICANA

COLUMBIENSE

CORONATUS

EMACIATUM

GLOMERATUM

MANILAENSIS

MEXICANA

II I DUM

PLAN IS SIMA

RINGENS

SCITULUM

SPHAER IL OCULUM

SPHAERILOCULUS

SUBGLOBOSUM

SUB I NV OL UTUM

TRULLISSATA

WILBER I I

DUBIA

BRADYI

FRAG IL IS SIMA 


\begin{tabular}{|c|c|}
\hline HAUER I NA & ORNATISSIMA \\
\hline HELEN I NA & ANDERSENI \\
\hline HER ON ALLEN I A & GEMMATA \\
\hline HER ON A LLEN I A & LINGULATA \\
\hline HETEROSTEG INA & ANT I LLARUM \\
\hline HOE GLUNDINA & ELEGANS \\
\hline HOMOTREMA & RUBRUM \\
\hline HORMOS INA & CARPENTERI \\
\hline HORMOS INA & DISTANS DELICATULA \\
\hline HORMOS INA & GLOBUL IFERA \\
\hline HOR MOS INA & MONILE \\
\hline HORMOS INA & OVALIFORMIS \\
\hline HORMOS INA & OVICULA \\
\hline HORMOS INA & OVICULA MEXI CANA \\
\hline HYPERAMMINA & CYLINDRICA \\
\hline HYPERAMMINA & DISTORTA \\
\hline HYPERAMMINA & EL ONGATA \\
\hline HYPERAMM IN A & FRIABILIS \\
\hline HYPERAMM I NA & LAEVIGATA \\
\hline I RI D I A & DI APHANA \\
\hline I SLANDIELLA & NORCROSSI AUSTRALIS \\
\hline JADAMMINA & DOLYSTOMA \\
\hline KARRERIELLA & APICULARIS \\
\hline KARRERIELLA & BRADYI \\
\hline $\begin{array}{l}\text { LAGENA } \\
\text { LAGENA }\end{array}$ & $\begin{array}{l}\text { A CUTICOSTA } \\
\text { APIOPLEURA }\end{array}$ \\
\hline LAGENA & DISTOMA \\
\hline LAGENA & FLINTIANA \\
\hline LAGENA & GLOBOSA \\
\hline LAGENA & GRACILLIMA \\
\hline LAGENA & HALSTEADI \\
\hline LAGENA & HEXAGONA \\
\hline LAGENA & HISPIDULA \\
\hline LAGENA & INUS ITATA \\
\hline LAGENA & LAEVICOSTATA \\
\hline LAGENA & LAEVIS \\
\hline LAGENA & LONG ISPINA \\
\hline LAGENA & MARGINATA \\
\hline LAGENA & MEXICANA \\
\hline LAGENA & NE BUL OSA \\
\hline LAGENA & ORBIGNYANA CARIBAEA \\
\hline LAGENA & SEMISTRIATA \\
\hline LAGENA & SPICATA \\
\hline LAGENA & SPIRATA \\
\hline LAGENA & STRIATA \\
\hline LAGENA & SUBLAGENOIDES \\
\hline LAGENA & SULCATA \\
\hline LAGENA & TENUIS \\
\hline LA GENA MM I N A & A TLANTICA \\
\hline LAGENAMM IN A & DIFFLUGIFORMIS \\
\hline LAGENONODOSARI A & SCALARIS \\
\hline LAMARCKINA & ATLANTICA \\
\hline LATICARININA & PAUPERATA \\
\hline LENTI CUL INA & ARTI CULATA \\
\hline LENTICULINA & CALCAR \\
\hline LENTI CUL INA & COMPRESSA \\
\hline LENTI CUL INA & GIBBA \\
\hline LENTI CUL INA & IOTA \\
\hline LENTI CUL INA & ORBICULARIS \\
\hline LENTI CUL INA & $\begin{array}{l}\text { PEREGR INA } \\
\text { ROTULATA }\end{array}$ \\
\hline $\begin{array}{l}\text { LENTI CUL INA } \\
\text { LIEBUSELLA }\end{array}$ & $\begin{array}{l}\text { ROTULATA } \\
\text { SOLDANII }\end{array}$ \\
\hline LINGUL INA & CARINATA \\
\hline LINGUL INA & SEMINUDA \\
\hline LITUOTUBA & LITUIF ORMIS \\
\hline LOXOSTOMUM & ABRUPTUM \\
\hline LOXOSTOMUM & GE LB I \\
\hline LOXOSTOMUM & MAYORI \\
\hline LOXOSTOMUM & $\begin{array}{l}\text { SUBSPINESCENS } \\
\text { TRUNCATUM }\end{array}$ \\
\hline $\begin{array}{l}\text { LOXOSTOMUM } \\
\text { MARG INUL INA }\end{array}$ & $\begin{array}{l}\text { TRUNCATUM } \\
\text { ADVENA }\end{array}$ \\
\hline MARGINULINA & $\begin{array}{l}\text { ADVENA } \\
\text { COSTATA }\end{array}$ \\
\hline MARGINUL INA & GLABRA \\
\hline MARGINUL INA & GLABRA OBESA \\
\hline MARGI NUL INA & HANTKENI \\
\hline MARGINUL INA & MARG INUL INO I DES \\
\hline MARG I NUL INA & OBESA \\
\hline MARG INUL INA & PERPROCERA \\
\hline MARGINUL INA & PLANATA \\
\hline MARGI NUL INA & STRIATULA \\
\hline MARG INUL INA & SUBACULEATA GLABRATA \\
\hline MARGINUL INA & TENUIS \\
\hline MARGI NUL INA & VILLA \\
\hline MARGINUL INOPS IS & DENS I COSTATA \\
\hline MARGINULINOPSIS & MARG INUL INOI DES \\
\hline MAF G INUL INOPS IS & SUBACULEATA \\
\hline MARGINUL INOPS IS & SUBACULEATA GLABRATA \\
\hline MARSIPELLA & ELONGATA \\
\hline MARTI NOTTI ELLA & COMMUNIS \\
\hline MARTINOTTIELLA & OCCIDENTALIS \\
\hline MASSILINA & AL VEOLINIFORMIS \\
\hline MASSILINA & ANNECTENS \\
\hline MASSILINA & CRENATA \\
\hline MASSILINA & INAEQUALIS \\
\hline MASSILINA & PERUVIANA \\
\hline
\end{tabular}

\begin{tabular}{|c|c|}
\hline MASS IL I NA & PROTEA \\
\hline MASS ILI NA & QUADRANS \\
\hline MASSILINA & STUCKEYI \\
\hline MELONIS & BARLEEANUS \\
\hline MELONIS & POMPILICIDES \\
\hline MILI AMM INA & FUSCA \\
\hline MIL I OLI NE LLA & ANTARCTICA \\
\hline MIL I OL I NELLA & CIRCULARIS \\
\hline M I L I OL I NE LLA & FICHTELIANA \\
\hline MILIOLINELLA & LABIOSA \\
\hline MIL I OL I NE LLA & MICROSTOMA \\
\hline MIL I OL I NE LLA & OBLI QU INODA \\
\hline MIL IOLINELLA & SUBROTUNDA \\
\hline M IL I OLI NE LLA & WARREN I \\
\hline MONALYS IOIUM & POL I TA \\
\hline MONALYSIDIUM & POLI TUM \\
\hline NEOCONORBINA & FLORIDENSIS \\
\hline NEOCONORB INA & ORBI CULARIS \\
\hline NEOCONORBINA & TERQUEMI \\
\hline NEOE PON IDES & ANT I LLARUM \\
\hline NEOEPON IDES & CORYELLI \\
\hline NEOEPON IDES & REGULARIS \\
\hline NODELLUM & MEMBRA NACEUM \\
\hline NODOBACULARIA & $T I B I A$ \\
\hline NODOBACULARIELLA & $\begin{array}{l}\text { ATLANTICA } \\
\text { CASSIS }\end{array}$ \\
\hline NOD OBAC UL ARI ELLA & $\begin{array}{l}\text { CASSIS } \\
\text { CONVEXIUSCULA }\end{array}$ \\
\hline NODOBACUL ARI ELLA & $\begin{array}{l}\text { CONVEXIUSCULA } \\
\text { MEXICANA }\end{array}$ \\
\hline & $\begin{array}{l}\text { MEXICANA } \\
\text { ADVENA }\end{array}$ \\
\hline $\begin{array}{l}\text { NODOSAR IA } \\
\text { NODOSARIA }\end{array}$ & ALBATROSSI \\
\hline NOD OSARIA & ATLANTICA \\
\hline NODOSAR IA & CALOMORPHA \\
\hline NODOSAR IA & CATESBYI \\
\hline NODOSAR IA & COMATULA \\
\hline NODOSAR IA & COMMUNIS \\
\hline NODOSARIA & CONSOBRINA EMACIATA \\
\hline NODOSAR IA & FARCIMEN \\
\hline NOD OSAR IA & FIL IFORMIS \\
\hline NODOSAR IA & FL IN TI I \\
\hline NODOSAR IA & FUSTA \\
\hline NODOSARIA & \\
\hline $\begin{array}{l}\text { NODOSAR IA } \\
\text { NODOSARIA }\end{array}$ & $\begin{array}{l}\text { HISPIDA } \\
\text { INTERCELLULARIS }\end{array}$ \\
\hline NODOSARIA & LAEVIGATA TORRIDA \\
\hline NODOSARIA & LAMNULIFERA \\
\hline NOD OSAR IA & PYRULA \\
\hline NODOSAR IA & PYRULA SEMIRUGOSA \\
\hline NODOSAR IA & ROTUNDATA \\
\hline NODOSAR IA & SCALAR IS SEPARANS \\
\hline NODOSAR IA & SUBL INEATA \\
\hline NODOSAR IA & SUBSOLUTA \\
\hline NODOSAR IA & VERTEBRALIS \\
\hline NODOSAR IA & VERTEBRALIS ALBATROSSI \\
\hline NON I ON & AFFINIS \\
\hline NONION & BARLEEANUS \\
\hline NONION & DEPRESSULA \\
\hline NONION & DEPRESSULA MATAGORDANA \\
\hline NONION & DEPRESSULUM MATAGORDANUM \\
\hline NONION & FORMOS UM \\
\hline NONION & GERMAN I CUM \\
\hline NONION & GRANOSUM \\
\hline NONION & GRATELOUPI \\
\hline NONION & PAUCILOCULUM \\
\hline NON I ON & POMPILIOIDES \\
\hline NONION & SCAPHA \\
\hline NONION & TISBURYENSIS \\
\hline NONI ONELLA & ATLANTICA \\
\hline NONI ONELLA & AURIS \\
\hline NONI ONE LLA A & BASILOBA \\
\hline NONI ONE LL·A & GRATEL OUPI \\
\hline NONI ONE LLA & OPIMA \\
\hline NONIONI NA & GRATELOUPI \\
\hline NONI ONINA & SCAPHA \\
\hline NON I ON I NA & UMBILICATULA \\
\hline NOURIA & POLYMORPHINOIDES \\
\hline NUBE CUL ARIA & ANTILLARUM \\
\hline NUBE CUL AR IA & LUCIFLUGA \\
\hline NUBE CUL INA & DIVERICATA \\
\hline NUMMOLOCJLINA & CONTRARIA \\
\hline NUMMOLOCJLINA & IRREGULARIS \\
\hline OOL INA & CAUDIGERA \\
\hline OOL INA & HEXAGONA \\
\hline OOL I NA & LONG ISPINA \\
\hline OOL I NA & MELO \\
\hline OPHTHAL MI DIUM & INCONS TANS \\
\hline ORB I CUL INA & $\triangle O U N C A$ \\
\hline ORB I CUL IVA & COMPRESSA \\
\hline ORB I TOL ITES & DUPLEX \\
\hline ORBITOL ITES & MARG INALIS \\
\hline ORIDORS AL IS & SIDEBOTTOMI \\
\hline ORIDORS AL IS & TENER STFLLATUS \\
\hline ORIDORSALIS & TENER TENER \\
\hline ORIDORSALIS & TENER UMBONATUS \\
\hline ORI DORS AL IS & WES T I \\
\hline
\end{tabular}


OSANGULARIA

OSANGULARI A PALMERINELLA PALME RINELLA PALMERINELLA PAL MER INFL LA PARAFISSUR INA PARRELLA PATELLINA PAVONINA

PAVONINA

PELOSINA

PEL OSINA

PENEROPLIS

PENEROPLIS

PENEROPLIS

PENEROPL IS

PENEROPLIS

PENEROPLIS

PEN EROPL IS

PENEROPLIS

PENEROPLIS

PLACOPSILINA

PLANISPIRINA

PLANORBULINA

PLANORBULINA

PLANORBULINELLA

PLANUL INA

PLANULINA

PLANULINA

PLANULINA

PLANUL INA

PLANULINA

PLECTINA

PLEUROSTOMELLA

POL YMORPHINA

POL YMORPHINA

POL YMORPHINA

POLYMORPHINA

POLYMORPHINA

POLYSTOMELLA

POL YSTOMELLA

POLYSTOMELLA

POLYSTOMELLA

POLYSTOMELLA

POLYSTOMELLA

POROEPONIDES

POROEPONIDES

POROEPONIDES

PRAESORITES

PROTELPHIDIUM

PROTEONINA

PROTEONINA

PROTEONINA

PROTEONINA

PROTEONINA

PROTOSCHISTA

PSAMMOSPHAERA

PSEUDOCL AV UL INA

PSEUDOCLAVULINA

PSEUDOCLAVUL INA

PSEUDOCL AV UL INA

PSEUDOEPONIDES

PSE UDOEPON IDES

PSEUDOGL AN DULINA

PSEUDONODOSARI A

PSEUDONODOSARI A

PSEUDONODOSARIA

PSEUDONODOSARIA

PSEUDONONION

PSEUDONONI ON

PSEUDOPARRELLA

PSEUDOPARRELLA

PSEUDOPARRELLA

PSEUDOTROCHAMMINA

PSEUDOTR OC HAMMINA

PULLENIA

PULLENIA

PULLENIA

PULLENIA

PULLENIA

PULLEN IA

PULVINUL INA

PULVINUL INA

PULVINUL IN

PUTEOLINA

PYRGO

PYRGO

PYR

PYRGO

PYRGO

PYRGO

PYRGO

PYRGO

PYRGO
CULTUR

RUGOSA

GARDENISLANDENSIS

PALMERAE

PALMERAE GARDENISLANDENSIS

PALMERAE TYPICA

LATERALIS

CULTUR

CORRUGATA

A TLANTICA

MIOCENICA

CYLINDRICA

VARIABILIS

ARIETINUS

BRADYI

CARINATUS

CYLINDRACEUS

DISCOIDEUS

LAEVIGATUS

PERTUSUS

PLANATUS

PROTEUS

CENOMANA

AURICULATA

ACERVALIS

MEDITERRANENSIS

LARVATA

AR IMINENSIS

EXORNA

FOVE OLATA

MERA

ORNATA

WUELLERSTORFI

API CULAR IS

BOLIVINOIDES

EQUALIS

GIBB A

LACTEA

PULCHELLA

REGINA

A DVENA

C RISPA

DISCOIDALIS

MACELLA

POEYANA

STRI ATOPUNCTATA

CRIBROREPANDUS

LATERALIS

REPANDUS

ORBITOLITOIDES

MATAGOR DANUM

ATLANTI CA

COMPRIMA

DIFFLUGIFORM IS

LAGENARIA

FINDENS

PARVA

CONSTANS

GRAC ILIS

MEXICANA

NOVANGLIAE

ANDERSEN I

UMBONATUS

COMATULA

COMATULA

MAYORI

PORRECTA

TORRIDA

ATLANTICUS

GRATELOUP

DECORATA

EXIGUA

RUGOSA

MEXICANA

TRILOBA

BULLOIDES

OSLOENSIS

QUINQUELOBA

SUBCARINATA

SUBSPHAERICA

TR IN ITATENS IS

AURI CULA

ELEGANS

INCERATA

PROTEA

ANOMALA

C ARINATA

CLYPEATA

COMATA

COMATUS

DENT I CULATA

DEPRESSA

EL ONGATA

FORNASIN II
PYRGO

PYRGO

PYRGO

PYRGO

PYRGO

PYRGO

PYRGO

PYRGO

PYRGO

PYRGO

PYRGOELLA

PYRULINELLA

PYRULINELLA

QUIN QUE LOC UL INA

QUIN QUELO CUL INA

QUINQUE LOCUL INA

QUIN QUE LO CUL INA

QUINQUE LOCUL INA

QUINQUELOCUL INA

QUINQUELOCULINA

QUINQUE LOCUL IN

QUINQUE LOCULINA

QUINOUE LO CUL INA

QUIN QUE LI CUL INA

QUINOUELOCUL INA

QUIN QUE LO CUL INA

QUINQUELOCUL INA

QUIN QUELOCUL INA

QUIN QUE LOCUL INA

QUINOUELOCUL INA

QUIN QUE LOCUL INA

QUINQUE LOCUL INA

QU IN QUE LO CUL INA

QUIN QUE LOCUL IN

QUIN QUE LJCUL INA

QUIN QUELJ CULINA

QUIN QUE LOCUL INA

QUIN QUE LOCUL INA

QUIN QUELO CUL INA

QUI NQUELOCUL INA

QUI N QUE LOC UL IN A QUINQUE LOCUL INA QUIN QUE LO C UL INA QUINQUE LOCULINA QUIN QUELOCUL INA QUINQUELOCUL INA QUIN QUE LOCULINA QUINQUELOCUL INA QUINQUE LOCUL INA QUINQUE LOCUL INA QUINQUELOCUL INA QUINQUE LOCUL INA QUIN QUE LOCUL INA QUINQUE LOCUL INA QUIN QUELO CUL INA QUIN QUE LOCUL INA QUIN QUE LOCUL INA QUINOUELOCUL INA QUINOUELOCUL INA QUINOUELJCUL INA QUINQUELOCUL INA QUINQUE LOCULINA QUINQUE LO CUL INA QUIN QUE LOCUL INA QUINQUE LOCULINA QUINQUELDCL QUINQUE LOCUL INA QUINQUELOCUL INA QUIN QUE LOCUL IN QUINQUE LOCUL INA QUINQUELOCUL INA QUI NQUE LOCUL INA QUIN QUE LO CUL INA RAMULINA RECTOBOLIVINA RECTOBOLIVINA REC TUVI GE RINA RECURVOIDES RECURVOIDES RECURVOIDES

REOPHAX

REOPHAX

REOPHAX

RE OP HAX

REOPHAX

REOPHAX

REOPHAX

REOPHAX

REOPHAX

REOPHAX

REOPHAX

REOPHAX

REOPHAX

LUCERNULA

MILLETTI

MURRHINA

NASUTA 


\begin{tabular}{|c|c|}
\hline REOPHAX & NODULOSA \\
\hline REOPHAX & NODULOSUS \\
\hline REOPHAX & PILULIFER \\
\hline REOPHAX & SCORPIURUS \\
\hline REOPHAX & SCOTTII \\
\hline RETICULOPHRAGMIUM & VENEZUELANUM \\
\hline REUSSELLA & ATLANTICA \\
\hline REUSSELLA & MIOCENICA \\
\hline $\begin{array}{l}\text { REUSSIA } \\
\text { RHABOAMMINA }\end{array}$ & $\begin{array}{l}\text { SPINULOSA } \\
\text { ABYSSORUM }\end{array}$ \\
\hline RHA BDAMMINA & ABYSSORUM RADIATA \\
\hline RHABDAMMINA & DISCRETA \\
\hline RHABOAMM INA & LINEARIS \\
\hline RHIZAMMINA & ALGAEFORMIS \\
\hline RHIZAMMINA & I NDI VISA \\
\hline ROBERTINA & BRADYI \\
\hline ROBERTINA & OCEANICA \\
\hline ROBERTINOIDES & BRADYI \\
\hline $\begin{array}{l}\text { ROBULUS } \\
\text { ROBULUS }\end{array}$ & $\begin{array}{l}\text { 8OWDENENSIS } \\
\text { CALCAR }\end{array}$ \\
\hline ROBULUS & CONVERGENS \\
\hline ROBULUS & CULTRATUS \\
\hline ROB ULUS & FALCIFER \\
\hline ROBULUS & IOTUS \\
\hline ROBULUS & LOWMANI \\
\hline ROBULUS & SERPENS \\
\hline ROBULUS & STEPHENSONI \\
\hline ROBULUS & SUBORBICULARIS \\
\hline ROLSHAUSENIA & ROLSHAUSENI \\
\hline ROSAL I NA & BAHAMAENSIS \\
\hline ROSALINA & BERTHELOTI \\
\hline ROSALINA & BUL BOSA \\
\hline ROSALINA & COLUMBIENSIS \\
\hline ROSALINA & CONCINNA \\
\hline ROSALINA & FL ORIDANA \\
\hline ROSALINA & FLORIDENSIS \\
\hline ROSALINA & PARKERAE \\
\hline ROSALINA & SUEZENSIS \\
\hline ROTALIA & BECCARII \\
\hline ROTALIA & BECCARII PARKINSONIANA \\
\hline ROTALIA & BECCARII TEPIDA \\
\hline ROTALIA & PAUCILOCULATA \\
\hline ROTALIA & PRAEGERI \\
\hline ROTALIA & ROLSHAUSENI \\
\hline ROTALIA & ROSEA \\
\hline $\begin{array}{l}\text { ROT ALIA } \\
\text { ROTAMORPHINA }\end{array}$ & $\begin{array}{l}\text { TRANSLUCENS } \\
\text { GLABRA }\end{array}$ \\
\hline ROTAMORPKINA & LAEV IGATA \\
\hline ROTORBINELLA & BASILICA \\
\hline ROTORBINELLA & ROSACEA \\
\hline ROT ORB I NELLA & ROSEA \\
\hline ROTORBI NELLA & TRANSLUCENS \\
\hline SACCAMMINA & SOCIALIS \\
\hline SACCAMMINA & SPHAER I CA \\
\hline $\begin{array}{l}\text { SACCORHIZA } \\
\text { SAGRINA }\end{array}$ & $\begin{array}{l}\text { RAMOSA } \\
\text { PULCHELLA PRIYITIVA }\end{array}$ \\
\hline SARACENARI A & AMPLA \\
\hline SARACENARIA & ITALICA \\
\hline SARACENARIA & LAMPTONI \\
\hline SARACENARIA & LATIFORMIS JAMAICENSIS \\
\hline SARACENARIA & LATIFRONS \\
\hline SARACENARIA & MEXICANA \\
\hline SCHENCKI ELLA & OCCIOENTALIS \\
\hline SCHLUMBERGERINA & AL VEOLINIFORMIS \\
\hline SEA BROOKIA & EARLANDI \\
\hline SI GMOILINA & ANTILLARUM \\
\hline SI GMOILINA & DISTORTA \\
\hline SIGMOILINA & SCHLUMBERGER I \\
\hline SIGMOILINA & SIGMOIDEA \\
\hline SIGMOILIVA & SUBPOEYANA \\
\hline SI G MOI LINA & TENUIS \\
\hline SIGMOILOPSIS & FL IN T I I \\
\hline SIGMOILOPS IS & SC HLUMBERGER I \\
\hline SIPHOG EN ER INA & A DVENA \\
\hline SIPHOGENER INA & RAPHANUS \\
\hline SIPHONINA & BRADYANA \\
\hline SIPHON INA & PULCHRA \\
\hline SIPHOTEXTULARIA & AFFINIS \\
\hline SIPHOTEXTULARIA & CONCAVA \\
\hline SIPHOTEXTULARIA & CURTA \\
\hline SIPHOTEXTULARIA & OLIANAENSIS \\
\hline SIPHOTEXTULARIA & ROLSHAUSENI \\
\hline SIPHOTEXTULARIA & SAUL CYANA \\
\hline SIPHOTROCHAMMINA & SQUAMATA \\
\hline SORITES & HOFKER I \\
\hline SORITES & MARGINALIS \\
\hline SORITES & ORBITOLITOIDES \\
\hline $\begin{array}{l}\text { SPHAER OI OINA } \\
\text { SPHAER OI DINA }\end{array}$ & $\begin{array}{l}\text { BULLOIDES } \\
\text { COMPACTA }\end{array}$ \\
\hline SPI RI LLINA & DECORATA \\
\hline SPI RILLINA & DENTI CULATA \\
\hline SPIRILLINA & ORNATA \\
\hline SPIRILLINA & VI VIPARA \\
\hline SPI ROL INA & A R IET INA \\
\hline SPI ROL INA & ARIETINUS \\
\hline
\end{tabular}

\begin{tabular}{|c|c|}
\hline SPIR OL I NA & CYLINDRACEUS \\
\hline SPIROLOCULINA & ANTILLARUM \\
\hline $\begin{array}{l}\text { SPIROLOCULINA } \\
\text { SPIROLOCULINA }\end{array}$ & ANTILLARUM ANGULATA \\
\hline SPIROLOCJLINA & ARENATA \\
\hline SPIR OLOCULINA & CADUCA \\
\hline SPIROLOCULINA & DENTATA \\
\hline SPIROLOCULINA & DEPRESSA \\
\hline $\begin{array}{l}\text { SPIROLOCULINA } \\
\text { SPIROLOCULINA }\end{array}$ & $\begin{array}{l}\text { EXIMIA } \\
\text { GRATA }\end{array}$ \\
\hline SPIROLO CULINA & GRAT EL OUPI \\
\hline SPIROLOCJLINA & MANIFESTA \\
\hline SPIROLOCULINA & ORNATA \\
\hline SPIROLO CULINA & PLANUL ATA \\
\hline SPIROLOCULINA & SOLOANII \\
\hline SPI ROPL ECTAMMINA & FLORIOANA \\
\hline SPI ROPL ECTAMMINA & WRIGHTI \\
\hline SPIROSIGMOILINA & DISTORTA \\
\hline STA I NFORTHIA & COMPLANATA \\
\hline STETSON IA & MINUTA \\
\hline STOMATORB INA & CONCENTRICA \\
\hline STORTHOSDHAERA & ALBIOA \\
\hline $\begin{array}{l}\text { STREBLUS } \\
\text { STREBLUS }\end{array}$ & $\begin{array}{l}\text { BECCARII } \\
\text { BECCARII PARKINSONIANA }\end{array}$ \\
\hline $\begin{array}{l}\text { STREBLUS } \\
\text { STREBLUS }\end{array}$ & $\begin{array}{l}\text { BECCARII SOBRINA } \\
\text { BECCARII TEPIOA }\end{array}$ \\
\hline STREBLUS & $\begin{array}{l}\text { BECCARII TEPIDA } \\
\text { PARKINSONIANA }\end{array}$ \\
\hline STREBLUS & PAUCILOCULATA \\
\hline STREBLUS. & PAUCILOCULATUS \\
\hline $\begin{array}{l}\text { STREBLUS } \\
\text { STREBLUS }\end{array}$ & $\begin{array}{l}\text { ROLSHAUSENI } \\
\text { SOBRINUS }\end{array}$ \\
\hline STREBLUS & TEPIDA \\
\hline STREBLUS & TEPIDUS \\
\hline SULCOPHAX & PALUSTRIS \\
\hline TECHNITELLA & LEGUMEN \\
\hline TEXTULARIA & AGGLUT INANS \\
\hline TEXTULA RIA & ALBATROSSI \\
\hline TEXTULA RI A & ASPERA \\
\hline TEXTULARIA & $\begin{array}{l}\text { AURA } \\
\text { BARRETTII }\end{array}$ \\
\hline TEXTULARIA & $\begin{array}{l}\text { BARRETTII } \\
\text { CALVA }\end{array}$ \\
\hline TEXTULARIA & CANDEI ANA \\
\hline TEXTULARIA & CONICA \\
\hline TEXTULARIA & EARLANDI \\
\hline TEXTULARIA & FLINTII CURTA \\
\hline TEXTULARIA & FLORIOANA \\
\hline TEXTULARIA & FOLIACEA OCCIDENTALIS \\
\hline TEXTULARIA & GOES II \\
\hline TEXTULARIA & GRAMEN \\
\hline TEXTULARIA & HAUERII \\
\hline TEXTULARIA & KERI MB AENSIS \\
\hline $\begin{array}{l}\text { TEXTULARIA } \\
\text { TEXTULARIAA }\end{array}$ & $\begin{array}{l}\text { MAURYAE } \\
\text { MAYORI }\end{array}$ \\
\hline TEXTULARIA & MEXICANA \\
\hline TEXTULARIA & OCCIDENTALIS \\
\hline TEXTULARIA & PALUSTRIS \\
\hline TEXTULARIA & PARVUL A \\
\hline TEXTULARIA & PSEUDOTROCHUS \\
\hline TEXTULARIA & RUGOSA \\
\hline TEXTULARIA & SAGITTULA \\
\hline TEXTULARIA & $\begin{array}{l}\text { SECASENS IS } \\
\text { SERANENS IS }\end{array}$ \\
\hline $\begin{array}{l}\text { TEXTULARIA } \\
\text { TEXTULARIA }\end{array}$ & $\begin{array}{l}\text { SERANE NS IS } \\
\text { SICA }\end{array}$ \\
\hline TEXTULARIA & TROCHUS \\
\hline TEXTULARI ELLA & BARRETTII \\
\hline TEXTULARIELLA & CONICA \\
\hline TEXTULARIELLA & TROCHUS \\
\hline THUR AMM INA & FAVOSA \\
\hline THUR AMMIVA & PAPILLATA \\
\hline THURAMMIVA & PAPILLATA CARIOSA \\
\hline THURAMMIVA & PAPILLATA CASTANEA \\
\hline TIPHOTR OCHA & COMPRI WA TA \\
\hline TOL YPAM MINA & SCHAUDINNI \\
\hline TOL YPAMMINA & VAGANS \\
\hline TOSAIA & WEAVERI \\
\hline TRE TOMPHALUS & ATLANTICUS \\
\hline TRETOMPHALUS & BULLOIDES \\
\hline TRETOMPKALUS & PLANUS \\
\hline TR I F AR I NA & BELLA \\
\hline TRIFARINA & BRADYI \\
\hline TRI F ARI NA & CARINATA BRADYANA \\
\hline TRIF ARI NA & JAMAICENSIS \\
\hline TRIL OCULINA & AFFINIS \\
\hline TRILOCULINA & BELLATULA \\
\hline TRILOCULINA & BER UDEZI \\
\hline TRILOCULINA & BICARINATA \\
\hline TRILOCULINA & BREVIDENTAT \\
\hline TRILOCULINA & CANDEI ANA \\
\hline TRI LOCULINA & CARINATA \\
\hline TRILOCULINA & CIRCULARIS \\
\hline TRILOCULINA & CUNEATA \\
\hline TRILOCULINA & DENTATA \\
\hline TRILOCULINA & FICHTELIANA \\
\hline TRILOCULINA & FITERREI \\
\hline TRILOCULINA & FITERREI M \\
\hline
\end{tabular}




\begin{tabular}{|c|c|}
\hline TRILOCUL INA & GRACILIS \\
\hline TRILOCULINA & INSIGNIS \\
\hline $\begin{array}{l}\text { TRILOCUL INA } \\
\text { TRILOCULINA }\end{array}$ & $\begin{array}{l}\text { LABIOSA } \\
\text { LINNEIANA }\end{array}$ \\
\hline TRILOCULINA & LINNEIANA COMIS \\
\hline TRILOC UL INA & OBLONGA \\
\hline TRILOCUL INA & PLANCI ANA \\
\hline TRILOCULINA & QUADRILATERALIS \\
\hline TRI LOCUL INA & ROTUNDA \\
\hline TRILOCUL INA & SIDEBOTTOMI \\
\hline TRILOCUL INA & SQUAMOSA \\
\hline TRI LOCUL INA & STRIATOTRIGONULA \\
\hline TRI LOCUL INA & SUBORBICULARIS \\
\hline TRILOCULINA & TERQUEMI ANA \\
\hline TRILOCUL INA & TRANSVERSESTRIATA \\
\hline TRILOCUL INA & TRICARINATA \\
\hline TRILOCUL INA & TRIGONULA \\
\hline TRILOCUL INELLA & OBL I QUINODA \\
\hline TRITAXIS & CONICA \\
\hline TRITAXIS & FUSCA \\
\hline TROCHAMMINA & ADVENA \\
\hline TROCHAMM INA & COMPRIMATA \\
\hline TROCHAMM INA & CONGLOBATA \\
\hline TROCHAMMINA & GLOBIGERINIFORMIS \\
\hline TROCHAMM INA & GLOBUL OSA \\
\hline TROCHAMMINA & INFL ATA \\
\hline TROCHAMM IN A & INFLATA MEXI CANA \\
\hline TROCHAMM INA & JAPONICA \\
\hline TROCHAMM INA & LAEVIGATA \\
\hline TROCHAMM INA & LOBATA \\
\hline TROCHAMMINA & MACRESCENS \\
\hline TROCHAMM INA & MULTILOCULATA \\
\hline TROCHAMMINA & OCHRACEA \\
\hline TROCHAMM INA & QUADRILOBA \\
\hline TROCHAMM INA & ROTALIFORMIS \\
\hline TROCHAMMINA & SIMPLISSIMA \\
\hline TROCHAMMINA & SQUAMATA \\
\hline TROCHAMMINA & SUBGLABRA \\
\hline TROCHAMMINA & SUBTURBINATA \\
\hline TROCHAMM INA & TASMANICA \\
\hline TROCHAMM IN A & TURBINATA \\
\hline TROCHAMMINITA & IRREGULARIS \\
\hline TROCHAMM IN ITA & SALSUS \\
\hline TROCHAMMIN OI DES & PROTEUS \\
\hline TRUNCATULINA & ADVENA \\
\hline TRUNCATUL I NA & ANTILLARUM \\
\hline TRUNCATUL INA & CANDEIANA \\
\hline TRUNCATULINA & CORA \\
\hline TRUNCATULI NA & ROSEA \\
\hline UV I GER INA & AMPULLACEA \\
\hline
\end{tabular}

\begin{tabular}{|c|c|}
\hline UVIGERINA & ANGULOSA \\
\hline UVIGER I NA & AUBERIANA \\
\hline $\begin{array}{l}\text { UVI GER I NA } \\
\text { UVI GER INA }\end{array}$ & $\begin{array}{l}\text { AUBERIANA LAEVIS } \\
\text { BELLULA }\end{array}$ \\
\hline UVI GER I NA & FLINTII \\
\hline UVI GER I NA & HISPIDA \\
\hline UVI GERINA & HISPIDOCOSTATA \\
\hline UVIGERINA & LAEVIS \\
\hline UVIGERINA & OCCIDENTALIS \\
\hline UVI GERI NA & PARVULA \\
\hline UVIGERINA & PEREGRINA \\
\hline UVIGERINA & PEREGRINA DIRUPTA \\
\hline UVI GERINA & PEREGRINA MEDITERRANEA \\
\hline UVIGERINA & PEREGR INA PARVULA \\
\hline UVI GER I NA & PEREGR INA PEREGRINA \\
\hline UVIGERINA & SELSEYENSIS \\
\hline UVIGERINA & SENTICOSA \\
\hline UVI GER I NA & SPINICOSTAT \\
\hline UVI GERINA & TENU IS TRIATA \\
\hline VAG INUL INA & LEGUMEN \\
\hline VAG INUL INA & LINEAR IS \\
\hline VAGINUL INOPSIS & PLANATA \\
\hline VALVULINA & CONICA \\
\hline VAL VUL I NA & OVIEDOIANA \\
\hline VAL VUL I NE R IA & COMPLANATA \\
\hline VAL VUL I NE RIA & LAEVIGATA \\
\hline VAL V UL I NER IA & MEXI CANA \\
\hline VAL VUL I NE RI A & MINUTA \\
\hline VAL V UL I NE R I A & OPIMA \\
\hline VAL VUL I NE R I A & VILARDEBOANA \\
\hline VERNEUILINA & AFFIXA \\
\hline VERNEUILINA & BRADYI \\
\hline VERNEUILINA & PROPINQUA \\
\hline VERNEUI LINA & SPINUL OSA \\
\hline VER TEBR AL-INA & CASSIS \\
\hline VERTEBR AL INA & CASSIS MUCRONATA \\
\hline VERT EBR AL I NA & STRIATA \\
\hline VIRGUL I NA & ADVENA \\
\hline VIRGULINA & COMPLANATA \\
\hline VIRGULINA & COMPRESSA \\
\hline VIRGUL INA & MEXICANA \\
\hline VIRG ULINA & PERTUSA \\
\hline VIRG UL INA & PONTONI \\
\hline VIRGULI NA & PUNCTATA \\
\hline VIRGUL INA & SCHREIBERS I ANA \\
\hline VIRGUL I NA & SPINICOSTATA \\
\hline VIRG UL I NA & SQUAMOSA \\
\hline VIRG UL I NA & TESSELLATA \\
\hline WIE S NER ELLA & AUR I CULATA \\
\hline
\end{tabular}




\section{Catalog 4}

\section{Synonymized Species}

\begin{tabular}{|c|c|}
\hline ADERC OTRYMA & GLOMERATA \\
\hline ALABAM INA & DECORATA \\
\hline ALFRE DOSILVESTRIS & LEVINSONI \\
\hline ALL OGR OMIA & LATICOLLARIS \\
\hline ALL OMORPHINA & TRIGONA \\
\hline AL VEOVALVULINELLA & POZONENSIS \\
\hline AMMOASTUTA & INEPTA \\
\hline AMMOASTUTA & SALSA \\
\hline AMMOBACULITES & AGGLUT INANS \\
\hline AMMOBACULITES & AMER I CANUS \\
\hline AMMOBACULITES & ARENARIUS \\
\hline AMMOBACULI TES & CRASSUS \\
\hline AMMOBACULITES & CYLINDROIDES \\
\hline AMMOBACULITES & DIVERSUS \\
\hline AMMOBACULITES & EXIGUUS \\
\hline AMMOBACULITES & FILIFORMIS \\
\hline AMMOBACULITES & LITUOL INOIDEUM \\
\hline AMMOBACULITES & REOPHACIFORMIS \\
\hline AMMODISCOIDES & TURBINATUS \\
\hline AMMOD I SCUS & ANGU I LLAE \\
\hline AMMODISCUS & INCERTUS \\
\hline AMMODISCUS & PLANORBIS \\
\hline AMMODI SCUS & TENUIS \\
\hline AMMOFL INTINA & TR IHEDRA \\
\hline AMMOGLOBIGERINOIDES & DEHISCENS \\
\hline AMMOL AGENA & CLAVATA \\
\hline AMM OMARG INUL INA & FLUVIALIS \\
\hline AMMOMARG INUL INA & FOLIACEA \\
\hline AMMON I A & BECCARII \\
\hline AMMONI A & PAUCILOCULATA \\
\hline AMMONI A & ROLSHAUSENI \\
\hline AMMONI A & TRANSLUCENS \\
\hline AMMOSC AL AR IA & PSEUDOSPIRALIS \\
\hline AMMOSC AL AR I A & TE NU IMARGO \\
\hline AMMOSPHAER OIDINA & SPHAEROIOINIFORMIS \\
\hline AMMOT I UM & CASSIS \\
\hline AMMOT I UM & MULT ILOCULATUM \\
\hline AMMOTIUM & SALSUM \\
\hline AMMOT I UM & SUBDIRECTUM \\
\hline AMPHICORYNA & CAMACHOI \\
\hline AMPHI CORYNA & HISPIDA \\
\hline AMPHIC ORYNA & ROEDERERI \\
\hline AMPHICORYNA & SCALARIS \\
\hline AMPHI CORYNA & SEPARANS \\
\hline AMPHI CORYNA & SUBL INEATA \\
\hline AMP HISORUS & HEMPR I CHII \\
\hline AMPHISTEGINA & GIBBOSA \\
\hline A NOMAL INA & AMMONOIDES \\
\hline ANOMAL INA & CORONATA \\
\hline ANOMAL INA & GLOBULOSA \\
\hline ANOMAL INOI OES & MEXICANA \\
\hline ARCHAIAS & ANGULATUS \\
\hline ARCHAIAS & COMPRESSUS \\
\hline ARENOPARRE LLA & MEXICANA \\
\hline ART ICULINA & ANTILLARUM \\
\hline ART ICULINA & CONICO-ARTICUL ATA \\
\hline ARTICULINA & LINEATA \\
\hline ART ICULINA & MAYORI \\
\hline ART I CULINA & MUCRONATA \\
\hline ARTICULINA & PACIFICA \\
\hline ARTICULINA & SAGRA \\
\hline ARTI CULINA & SCROBICULATA \\
\hline ART I CULINA & SULCATA \\
\hline ASC HE MONELLA & RAMUL I F ORMIS \\
\hline A SC HEM ONELLA & $S C A B R A$ \\
\hline ASTACOLUS & ALBATROSSI \\
\hline ASTACOLUS & CREPIDULUS \\
\hline ASTACOLUS & LATIFRONS \\
\hline ASTACOLUS & LIMBATA \\
\hline ASTACOLUS & OVATUS \\
\hline ASTACOLUS & SCHOENBACHI \\
\hline AST ER I GE RI NA & CARINATA \\
\hline ASTRONONION & TUMIDUM \\
\hline ASTRORHIZA & VERMIF ORMIS \\
\hline BATHYSIPHON & FILIFORMIS \\
\hline BATHYS IPHON & RUFUS \\
\hline BI GENERINA & IRREGULARIS \\
\hline BI GENER I NA & PENNATULA \\
\hline BI GENER INA & ROBUSTA \\
\hline BI GENER INA & TEXTULAR IOIDEA \\
\hline BILOCUL I NELLA & LABIATA \\
\hline BIL OCULINELLA & TODDAE \\
\hline BISACCIUM & I MBR I CA TUM \\
\hline$B O L$ IV INA & ALATA \\
\hline BOL IVINA & ALBATROSSI \\
\hline
\end{tabular}

\begin{tabular}{|c|c|}
\hline BOLIVINA & BARBATA \\
\hline BOL IVINA & COMPACTA \\
\hline BOL IVINA & DAGGARIUS \\
\hline BOL I VINA & FRAGILIS \\
\hline BOLIVINA & GOESII \\
\hline BOL IVINA & HASTATA \\
\hline BOLI I INA & INFLATA \\
\hline BOL IVINA & LOWMAN I \\
\hline BOL IVINA & MIN I MA \\
\hline BOLIVINA & ORDINARIA \\
\hline BOLIVINA & PAULA \\
\hline BOLIVINA & PSEUDOPLICATA \\
\hline BOLIVINA & PUNCTATA \\
\hline BOLIVINA & PUSILLA \\
\hline BOL I VINA & QUADRATA \\
\hline BOL I VINA & SEMINUDA \\
\hline BOLIVINA & SPATHULATA \\
\hline BOL IVINA & SPICATA \\
\hline BOL I VINA & STRIATULA \\
\hline BOL IVINA & STRIATULA SPINATA \\
\hline BOLIVINA & SUBAENARIENSIS \\
\hline BOL IVINA & SUBAENARIENSIS MEXICANA \\
\hline BOLIVINA & SUBEXCAVATA \\
\hline BOLIVINA & SUBSPINESCENS \\
\hline$B O L I V I N A$ & TRANSLUCENS \\
\hline BOL IVINA & VARIABILIS \\
\hline BOL I VINIIA & QUADRILATERATA \\
\hline BOL IVINITA & RHOMBOIOALIS \\
\hline BORELIS & PULCHRA \\
\hline BUC CELLA & HANNAI \\
\hline BUL I MINA & ACULEATA \\
\hline BUL I MINA & AFFINIS \\
\hline BUL I MINA & AL AZ ANENSIS \\
\hline BUL I MINA & BARBATA \\
\hline BUL I MINA & BUCHIANA \\
\hline BUL I MINA & EXILIS \\
\hline BUL IMINA & INFL AT A MEXICANA \\
\hline BUL I MINA & MARG INATA \\
\hline $\begin{array}{l}\text { BUL I MINA } \\
\text { BULIMINA }\end{array}$ & PUPOIDES \\
\hline BUL I MINA & PYRULA SPINESCENS \\
\hline BUL IMINA & SPICATA \\
\hline BUL IMINA & TENUIS \\
\hline BUL IMINELLA & BASSENDORFENSIS \\
\hline BUL I MINELLA & ELEGANTISSIMA \\
\hline BUL I MINELLA & SUBTERES \\
\hline BULIMINOI DES & WILL IAMSONI ANA \\
\hline CANCRIS & AURI CULA \\
\hline CANCRIS & $\begin{array}{l}\text { OBLONGA } \\
\text { SAGRA }\end{array}$ \\
\hline $\begin{array}{l}\text { CANCRIS } \\
\text { CARTERINA }\end{array}$ & $\begin{array}{l}\text { SAGRA } \\
\text { SPICUL OTESTA }\end{array}$ \\
\hline CASSIDULINA & CARINATA \\
\hline CASSIDULINA & CRASSA \\
\hline CASSIDULINA & CURVATA \\
\hline CASSIDULINA & LAEVIGATA \\
\hline CASSIDULINA & NEOC AR IN ATA \\
\hline CASSIDULINA & SUBGLOBOSA \\
\hline CASSIDULINOIOES & BRADYI \\
\hline CASSIOULINOIOES & MEXICANUS \\
\hline CASSIDULINOIDES & PARKERIANUS \\
\hline CASSIDULINOIDES & TENUIS \\
\hline CHILOST OMELLA & OOL INA \\
\hline CHILOSTOMELLA & OVOIDEA \\
\hline CHRYSAL ID INELLA & DIMORPHA \\
\hline CHRYSAL ID INELLA & POPEI \\
\hline CIBICIOES & ADVENUM \\
\hline CIBICIOES & ANTILLARUM \\
\hline CIBICIDES & BANTAMENSIS \\
\hline CIBICIDES & BRADYI \\
\hline CIBICIDES & CORA \\
\hline CIBICIDES & CORPULENTUS \\
\hline CIBICIDES & $\begin{array}{l}\text { DEPRIMUS } \\
\text { FLORIDANUS }\end{array}$ \\
\hline CIBICIDES & $\begin{array}{l}\text { FLORIDANUS } \\
10\end{array}$ \\
\hline $\begin{array}{l}\text { CIBICIOES } \\
\text { CIBICIOES }\end{array}$ & KULLLNBERGI \\
\hline CIOICIOES & LOBATULUS \\
\hline CIBICIDES & MOLLIS \\
\hline CIBICIOES & PROTUBERANS \\
\hline CIBICIDES & PSEUDOUNGER IANUS \\
\hline CIBICIOES & REFULGENS \\
\hline CIBICIOES & ROBERTSONIANUS \\
\hline CIBICIOES & RUGOSUS \\
\hline CIBICIOES & UMBONATUS \\
\hline CLAVULINA & BICARINATA \\
\hline CLAVULINA & COMMUN IS \\
\hline
\end{tabular}


CLAVUL INA

CLAVUL INA

CLA VUL INA

CLA VUL INA

CLA VUL INA

CLAVUL INA

CORNULOCUL INA

CORNUSPIROIDES

CORYPHOSTOMA

CORYPHOSTOMA

CR I BRO BI GE NER INA

CRI BROPYRG O

CR IBROSTOMOIDES

CRIBROSTOMOIDES

CRIBROSTOMOIDES

CRIBROSTOMOIDES

CRI BROSTOMOIDES

CRI THIONINA

CRUCILOCUL INA

CYCLAMMINA

CYCLAMMINA

CYCLAMMINA

CYCLOGYRA

CYCLOGYRA

CYCLOGYRA

CYMBALOPORA

CYMBAL OPORETTA

CYMBAL OPORETTA

CYMBALOPORETTA

CYSTAMMINA

DENTAL INA

DENTAL INA

DENTAL INA

DENTAL INA

DENTAL INA

DENTALINA

DENTAL INA

DENTAL INA

DENTAL INA

DENTALINA

DENTAL INA

OIS CORBINELLA

DIS CORBIS

DISCORBIS

DISCORBIS

DISCORBIS

DISCORINOPSIS

DOROTHIA

DOROTHIA

DOROTHIA

EGGERELLA

EGGERELLA

EGGERELLA

EHRENBERGINA

EHRENBERGINA

EHRENBERGIN

ELPHIOIUM

ELPHIDIUM

ELPHIDIUM

ELPHIDIUM

ELPHIOIUM

ELPHIDIUM

ELPHIOIUM

ELPHIDIUM

ELPHIDIUM

ELPHIDIUM

ELPHIDIUM

ELPHIDIUM

ELPHIDIUM

ELPHIDIUM

ELPHIDIUM

ELPHIDIUM

ELPHIDIUM

EPI STOMINE LLA

EPISTOMINELLA

EPISTOMINELLA

EPONIDES

EPONIDES

EPONIDES

EPONIDES

EPONIDES

EPONIDES

EPONIDES

EPONIDES

EPONIDES

EPONIDES

EPONIDES

EPONIDES

FIS CHERINELLA

FISSURINA

FIS SUR INA

FISSUR INA

F IS SUR INA

IS SUR INA

F IS SURINA
ILINTI ANA

GRACILIS

MEXI CANA

NOVANGLIAE

OCCIDENTAL I

TR ICAR INATA

I NCONSTANS

FOLIACEA

SPINESCENS

ZANZ IBAR ICA

PARKERAE

ROBUSTA

LOBATUS

NITIDUM

SUBGLOBOSUM

UMBILICATUS

WI ESNER I

PISUM

TR IANGULARIS

CANCELLATA

PAUC ILOCULATA

PUSILLA

I N CERTA

INVOL VENS

PLANORBIS

POEYI

A TLANT I CA

BRADYI

SQUAMMOSA

PAUC ILOCULATA

A DVENA

CALOMORPHA

COMMUN IS

CONSOBR INA EMACIATA

CUVIERI

FILIFORMIS

FL INTII

INORNATA BRADYENSIS

INTORTA

SUBEMACIATA

SUBSOLUTA

BERTHELOTI

AUBERII

$M I R A$

ROSEA

RUGOSA

RUGOSA

AGUAYOI

CARIBAEA
PSEUDOTURRI

$S C A B R A$

$A F F I X A$

BRADYI

PROPINQUA

PUPA

SPINEA

TRIGONA

A DVENUM

AR I I CULATUM

CRISPUM

DELICATULUM

DISCOIDALE

EXCAVATUM

FIMBRI ATULUM

GALVESTONENSE

GUNTER I

KOEBOEENSE

KUGLERI

MACELLUM

MEXICANUM

MORENOI

POEYANUM

RUGULOSUM

$S A G R U M$

EXIGUA

RUGOSA

VI TREA

ANTI LLARUM

GAVIOTAENSIS

IN CERATUS

IN CER TA

POLIUS

PYGMAEA

REGULARIS

REPANDUS

TENERA

TUMI DULUS

TURGIDUS

UMBONATUS

DUBI A

ARADASII

FL INTI I ANA

FORMOSA

MARGINATA

ORBI GNYANA

ORBIGNYANA ANTILLEA
F IS SURINA

FIS SUR INA

F I SSURINA

FLORILUS

FLORILUS

FRANCES ITA

FRONDICULARIA

FRONDICULARIA

FURSENK OINA

FURSENKOINA

FURSENKOINA

FURSENKOINA

FURSENKOINA

FURSENK OINA

FURSENKOINA

FURS ENK OINA

FURSENK OINA

FURSENKOINA

GAUDRYINA

GAUDRYINA

GAUDRYINA

GAUDRYINA

GAUDRYINA

GAUDRYINA

GAUDRYINA

GAVELIN OPS IS

GAVELIN OP SIS

GLABRATELLA

GLANDUL INA

GLOBOBULIMINA

GLOBOBULIMINA

GLOBOBULIMINA

GLOBOCASS IDULINA

GLOBOCASS IDULINA

GLOBOCASS IDULINA

GLOBOCASS I DULINA

GLOBOTE XT ULARIA

GLOBUL INA

GLOBULINA

GLOBULINA

GLOMOSPIRA

GLOMOSPIRA

GOE SELLA

GUT T UL I NA

GUTTUL INA

GUTTULINA

GUTTUL INA

GUT TULINA

GUTT ULI INA

GUTT ULINA

GYPS INA

GYPS INA

GYROIDINA

GYROIDINA

GYRO ID I NA

GYRO IDINA

GYROIOINA

GYRO IDINA

GYRO ID INA

GYRO IDINA

GYROIDINA

GYRO I D I NA

HAL YPHY SEMA

HAL Y PHY SEMA

HAN 2 AWA IA

HAN Z AWA IA

HAPLOPHRAGMOIDES

HAPLOPHRAGMOIDES

HAPL OPHRAGMOIDES

HAPL OPHRAGMOIDES

HAPL OPHRAGMOIDES

HAPL OPH RA GMO IDES

HAPL OPHRAGMOIDES

HAPL OPHRAGMO IDES

HAPLOPHRAGMOIDES

HAPL OPHRAGMO IDES

HAPL OPHRAGMOIDES

HAPLOPHRAGMOIDES

HAPLOPHRAGMOIDES

HAPLOST ICHE

HAUERINA

HAUERINA

HAUERINA

HAYNESINA

HAYNESINA

HELENINA

HER ONAL LEN IA

HERONALLENIA

HETEROS TE GINA

HOE GLUN DINA

HOMOTREMA

HORMOSINA

HORMOSINA

HORMOSI NA

HORMOS INA

PUNCTATA

STR I AT OPUNCTATA

TENU IS SIMA

CLAVATUS

ADVENA 
HORMOSINA

HORMOS INA

HORMOS IN A

HYPERAMMINA

HYPER AMMIN A

HYPER AMMIN A

HYPER AMMINA

HYPERAMMIN A

IRIDIA

ISLANDIELLA

JADAMM INA

KARRERIELL A

KARRERIELLA

KARRERIELL A

KARRERIELLA

LAGENA

LAGENA

LAGENA

LAGENA

LAGENA

LAGENA

LAGENA

LAGENA

LAGENA

LAGENA

LAGENA

LAGENA

LAGENA

LAGENA

LAGENA

LAGENA

LAGENA

LAMARCKINA

LAR YNGOS IGMA

LATICAR ININA

LEN TI CUL INA

LENT I CUL INA

LENTI CUL INA

LENTI CUL INA

LENTI CUL INA

LENTI CUL INA

LEN TI CUL INA

LENTI CUL INA

LENTICUL INA

LENTI CULINA

LENTI CULINA

LENTICULINA

LENTI CUL INA

LENTI CUL INA

LENTICULINA

LENTI CUL INA

LENTI CUL INA

LENTI CUL INA

LENTI CUL INA

LIE BUSELLA

LINGUL INA

LINGULINA

LITUOTUBA

MARGINUL INA

MARGINULINA

MAR GINUL INA

MARGINUL INA

MARGINUL INA

MARG I NUL INA

MARG INUL INA

MARGINUL INA

MARGINUL INA

MARGINUL INOPSIS

MARGINUL INOPSIS

MARGINUL INOPSIS

MARSIPELLA

MARTINOTTIELLA

MAR I INOTTIELLA

MASSILINA

MASSILINA

MASSILINA

MASSILINA

MASSILINA

MASSILINA

MASSILINA

MASSILINA

MEL ON IS

MEL ONIS

MIL I AMMINA

MIL IOL INELLA

MIL IOL INELLA

MIL IOL INELLA

MIL IOL INELLA

MIL IOL INELLA

MIL IOL INELLA

MIL IOLINELLA

MILIOLINELLA

MONALYSIDIUM

NEOCONORBINA

NEOEPONIDES
OVALIFORMIS

OVICULA

OVICULA MEXICANA

CYLINDRICA

DISTORTA

ELONGATA

FRIABILIS

LAEVIGATA

DI APHANA

NORCROSSI AUSTRALIS

POLYSTOMA

APICULARIS

BRADYI

CHILOSTOMA

NOVANGLIAE

APIOPLEURA

CLAVATA

DISTOMA

GRACILIS

HALSTEADI

HISPIOULA

INUS ITATA

LAEVIS

MEXI CANA

NE BULOSA

PURII

SEMISTRIATA

SPICATA

SPIRATA

STRIATA

SUBLAGENOI DES

SULCATA

A TLANTICA

LACTEA

PAUPERATA

ANTILLEA

CALCAR

COMPRESSA

CONVERGENS

CULTRATUS

FALCIFER

FORMOSA

$G I B B A$

IOTA

LOWMAN I

UUCIDA

ORBI CULARIS

PEREGRINA

ROTULATA

SERPENS

STEPHENSON I

SUBMAMILLIGERA

SUBORBICULARIS

TORRIDA

SOLDANII

CARINATA

SEMINUDA

LITUIFORMIS

ADVENA

GLABRA

GLABRA OBESA

HANTKEN I

PERPROCERA

PLANATA

STRIATULA

TENUIS

VI LLA

DENSI COSTAT A

MARG INUL INO I DES

SUBACULEATA GLABRATA

ELONGATA

COMMUNIS

OCCIDENTALIS

AL VEOLINIFORMIS

ANNE CTENS

CRENATA

INAEQUALIS

PERUVIANA

PROTEA

QUADRANS

QUADRANS

STUCKEYI
BARLEEANUS

POMPILIOIDES

FUSCA

ANTARCTI CA

CIRCULARIS

FI CHTEL I ANA

LABIOSA

MICROSTOMA

OBLI QUINODA

SU BR OTUNDA

WARRENI

POLITUM

TFRQUEMI

CORYELLI
NODELLUM

NODOBACUL ARIA

NODOBACUL ARIELLA

NODOBACULARIELLA

NODOBACULARI ELLA

NODOBACUL ARIELLA

NODOBACUL ARIELLA

NODOSAR IA

NODOSAR IA

NODOSAR IA

NODOSAR IA

NODOSAR IA

NODOSAR IA

NODOSAR IA

NODOSAR IA

NODOSAR IA

NODOSAR IA

NODOSAR IA

NODOSAR IA

NODOSAR IA

NODOSAR IA

NON I ON

NONI ON

NONI ONE LLA

NONI ONE LLA

NON I ONE LLA

NONI ONE LLA

NOUR IA

NUBE CUL AR IA

NUBE CUL AR IA

NUBE CUL INA

NUMMOLO CULINA

NUMMOLO CULINA

OOL INA

OOL INA

OOL INA

OOLINA

OOL INA

ORIDORSALIS

ORIDORSALIS

ORI DORS ALIS

ORIOORS AL IS

ORT HOMO RP HINA

OSANGULAR I A

OSANGUL ARIA

PALMERINELLA

PALMERINELLA

PARAFIS SURINA

PATELLINA

PAVONINA

PELOSINA

PELOSINA

PENEROPLIS

PENEROPLIS

PENEROPLIS

PENEROPLIS

PENEROPLIS

PENEROPLIS

PENEROPLIS

PENEROPL

PENEROPLIS

PLACOPS IL INA

PLANISPIRINA

PLANORBUL INA

PLANORB UL INA

PLANORBUL INELLA

PLANULINA

PLANULINA

PLANULINA

PLANULINA

PLANULINA

PLANULINA

PLANULINA

PLECTINA

PLEUROS TOMELLA

POROEPONIDES

POROEPONIDES

PROTOSC HISTA

PSAMMOSPHAERA

PSEUDON OD OSARIA

PSEUDON DDOSARIA

PSEUDOT ROCHAMMINA

PSEUDOTROCHAMMINA

PULLENIA

PULLENIA

PULLENIA

PULLENIA

PULLENIA

PYRGO

PYRGO

PYRGO

PYRGO

PYRGO

PYRGO

PYRGO

MEMBRANACEUM

TIBIA

ATLANTICA

CASS IS

CONVEXIUSCULA 


\begin{tabular}{|c|c|}
\hline PYRGO & ELONGATA \\
\hline PYRGO & FORNAS IN II \\
\hline PYRGO & LUCERNULA \\
\hline PYRGO & MILLETTII \\
\hline PYRGO & MURRHINA \\
\hline PYRGO & NASUTA \\
\hline PYRGO & PERUVIANA \\
\hline PYRGO & SARSII \\
\hline PYRGO & SERRATA \\
\hline PYRGO & SUBSPHAERICA \\
\hline PYRGO & TUBULOSA \\
\hline PYRGO & VESPERTILIO \\
\hline PYRGO & WILL I AMS ONI \\
\hline PYRGOELLA & SPHAERA \\
\hline PYRULINA & ANGUSTA \\
\hline PYRULINA & EXTENSA \\
\hline PYRULINA & VITREA \\
\hline QUINQUEL OCULINA & AGGLUTINANS \\
\hline QUINQUELOCULINA & A KNER I A NA \\
\hline QUINQUEL OC UL INA & AL VEOL IN IFORMIS \\
\hline QUINQUELOCULINA & ANTILLARUM \\
\hline QUINQUELOCULINA & AUBERIANA \\
\hline QUINQUEL OC UL INA & BI CARINATA \\
\hline QUINQUELOCULINA & BICOSTATA \\
\hline QUINQUEL OCULINA & BI DENTATA \\
\hline QUINQUEL OCULINA & BOSCIANA \\
\hline QUINQUELOC UL INA & BOUE ANA \\
\hline QUINQUEL OC UL INA & BRADYANA \\
\hline QUINQUEL OC UL INA & CANDEIANA \\
\hline QUI NQUELOCULINA & CATALINENSIS \\
\hline QUINQUEL OC UL INA & COLLUMNOSA \\
\hline QUINQUELOCULINA & COMPTA \\
\hline QUINQUELOCULINA & COSTATA \\
\hline QUINQUEL OC UL INA & CULTRATA \\
\hline QUINQUELOCULINA & CUVIERIANA \\
\hline QUI NQUEL OCUL INA & DURRANDII \\
\hline QUI NQUELOC UL INA & DUTEMPLEI \\
\hline QUINQUELOC UL INA & EL ONGATA \\
\hline QUINQUEL OC UL INA & FUNAFUTIENS IS \\
\hline QUINQUELOCULINA & GARRETTII \\
\hline QUINQUEL OCULINA & GLABRATA \\
\hline QUINQUEL OC UL INA & GRAC IL IS \\
\hline QUINQUELOC ULINA & JUGOSA \\
\hline QUINQUELOCULINA & KERIMBATICA PHILIPPINENSIS \\
\hline QUINQUELOCULINA & LAEVIGATA \\
\hline $\begin{array}{l}\text { QUINQUEL OC UL INA } \\
\text { QUINQUELOCUL INA }\end{array}$ & $\begin{array}{l}\text { LAMARCK I ANA } \\
\text { LAMARCK I ANA INFLATA }\end{array}$ \\
\hline $\begin{array}{l}\text { QUINQUEL OCUL INA } \\
\text { QUINQUEL OC UL INA }\end{array}$ & $\begin{array}{l}\text { LIMBATA } \\
\text { PARKERI OCC IDENTAL IS }\end{array}$ \\
\hline QUINQUEL OC ULINA & POEYANA \\
\hline QUINQUEL OCUL INA & POLYGONA \\
\hline QUINQUELOCULINA & PULCHELLA \\
\hline QUINQUELOC UL INA & RETICULATA \\
\hline QUI NQUEL OC UL INA & RHODIENSIS \\
\hline QUINQUELOCULINA & SAMOAENSIS \\
\hline QUINQUEL OC ULINA & SAWANENS IS \\
\hline QUINQUEL OC ULINA & SEMINULA \\
\hline QUINQUELOCUL INA & STRIATA \\
\hline QUINQUEL OCULINA & SUBARENARIA \\
\hline QUINQUELOCULINA & SUBCARINATA \\
\hline QUINQUEL OC UL INA & SUBPOEYANA \\
\hline QUINQUEL OC UL INA & SUBQUADRA \\
\hline QUINQUELOCULINA & TENAGOS \\
\hline QUINQUELOC UL INA & TIPSWOROI \\
\hline QUINQUEL OC UL INA & TRICAR INATA \\
\hline QUINQUEL OC ULINA & UNDOSA \\
\hline QUI NQUELOC UL INA & VENUSTA \\
\hline QUINQUEL OC UL INA & VULGARIS \\
\hline QUINQUEL OC ULINA & WEAVERI \\
\hline QUINQUEL OC UL INA & WIESNERI \\
\hline RAMUL INA & GL OBULIFERA \\
\hline RECTOBOL IV INA & ABRUPTA \\
\hline RECTOBOL IVINA & ADVENA \\
\hline RECTOBOL IVINA & DIMORPHA \\
\hline RECTOBOL IV INA & LIMBATA \\
\hline REC TOBOL IVINA & MAYORI \\
\hline RECTOBOL IVINA & PORRECTA \\
\hline RECTOBOL IVINA & RAPHANUS \\
\hline REC TUVIGER INA & N I COL I \\
\hline RECURVOIDES & CONTORTUS \\
\hline REC UR VOIDES & CONTORTUS SCITULUS \\
\hline RECURVOIDES & CONTORTUS SUBGLOBOSUS \\
\hline REOPHAX & ADUNCUS \\
\hline REOPHAX & AGGLUTINATUS \\
\hline REOPHAX & BACILLARIS \\
\hline REOPHAX & DENT ALINIFORMIS \\
\hline REOPHAX & DISTANS \\
\hline REOPHAX & DISTANS DEL ICATULUS \\
\hline REOPHAX & GUTTIFER \\
\hline REOPHAX & HISPIDULUS \\
\hline REOPHAX & IRREGULARIS \\
\hline REOPHAX & NANA \\
\hline REOPHAX & NODULOSA \\
\hline REOPHAX & PILULIFER \\
\hline & \\
\hline
\end{tabular}

\begin{tabular}{|c|c|}
\hline REOPHAX & SCOTTII \\
\hline RET I CUL OPHRAGMIUM & VENEZUELANUM \\
\hline REUS SEL LA & ATLANTICA \\
\hline RHAB DAMMINA & ABYS SORUM \\
\hline RHAB DAMMINA & ABYSSORUM RADIATA \\
\hline RHABDAMMINA & DISCRETA \\
\hline RHABDAMMINA & LINEAR IS \\
\hline RHI 2 AMM IN A & ALGAEFORMIS \\
\hline RHI 2 AMM IN A & INDIVISA \\
\hline ROBERTI NA & OCEANICA \\
\hline ROBERTINO I DES & BRADYI \\
\hline ROSALINA & ADVENA \\
\hline ROSALINA & BAHAMAENSIS \\
\hline ROSALINA & $B U L B O S A$ \\
\hline ROSALINA & CANDEI ANA \\
\hline ROSALINA & CONC INNA \\
\hline ROSALINA & CORA \\
\hline ROSALINA & FLORIDANA \\
\hline ROSALINA & FLORIDENSIS \\
\hline ROSALINA & GLOBULARIS \\
\hline ROSALINA & SUBARA UCANA \\
\hline ROSALINA & SUEZENSIS \\
\hline ROSALINA & WILL IAMSONI \\
\hline SAC CAMM INA & ATLANTICA \\
\hline SACC AMM INA & LAGENARIA \\
\hline SACCAMM INA & SOCIALIS \\
\hline SACC AMM INA & SPHAER ICA \\
\hline SAC CAMM INA & TEST ACEA \\
\hline SACCORH IZA & RAMOSA \\
\hline SAGRINA & PULCHELLA \\
\hline SARA CEN AR I A & AMPLA \\
\hline SAR A CEN AR I A & ITAL I CA \\
\hline SAR A CEN AR I A & LAMPTONI \\
\hline SARA CEN AR I A & LATIFRONS \\
\hline SARA CEN AR I A & LATIFRONS JAMAICENSIS \\
\hline SARACENAR IA & MEXI CANA \\
\hline SCHL UMB ER GE R INA & AL VEOLINIF ORMIS \\
\hline SEABROOKIA & EARLANDI \\
\hline SIGMOIL INA & SIGMOIDEA \\
\hline SIGMOIL INA & TENUIS \\
\hline SIGMOILOPSIS & FL I NTII \\
\hline SIGMOIL OPS IS & SCHL UMBERGER I \\
\hline SIPHONAPERTA & HORRIDA \\
\hline SIPHONAPERTA & SABULOSA \\
\hline SIPHONINA & BRADYANA \\
\hline SIPHONINA & PULCHRA \\
\hline SIPHOTE XTULARIA & AFFINIS \\
\hline $\begin{array}{l}\text { SIPHOTEXTULARIA } \\
\text { SIPHOTEXTULARIA }\end{array}$ & $\begin{array}{l}\text { CONCAVA } \\
\text { CURTA }\end{array}$ \\
\hline SIPHOTE XT ULARIA & OLIANAENSIS \\
\hline SIPHOTE XT ULARIA & ROLSHAUSENI \\
\hline SIPHOTE XTULARIA & SAUL CYANA \\
\hline SIPHOTR OCHAMMINA & SQUAMATA \\
\hline SOR I TES & HOFKER I \\
\hline SORITES & MARG INAL IS \\
\hline SORITES & ORBI TOLITOIDES \\
\hline SPHAERO ID INA & BULLOIDES \\
\hline SPHAERO IO INA & COMPACTA \\
\hline SPIRILL INA & DECORATA \\
\hline SPI RILL IN A & DENT I CULATA \\
\hline SPIRILL INA & ORNATA \\
\hline SPIR ILL INA & VIVIPARA \\
\hline SPIROLINA & AR IE TINA \\
\hline SPI ROL I NA & CYLINDRACEA \\
\hline SPIROLOCULINA & ANT I LLARUM \\
\hline SPIROLOCULINA & ANTILLARUM ANGULATA \\
\hline SPI ROLOCULINA & AR EN AR IA \\
\hline SPIROLOCULINA & ARENATA \\
\hline SPIROLOCULINA & $C A D \cup C A$ \\
\hline SPIROLOCULINA & DENTATA \\
\hline SPIROLOCULINA & DEPRESSA \\
\hline SPIROLOCULINA & EXIMIA \\
\hline SPIROLOCULINA & GRATA \\
\hline SPIROLOCULINA & GRATEL OUPI \\
\hline SPIROLOCULINA & MANIFESTA \\
\hline SPIROLOCULINA & ORNATA \\
\hline SPIROLOCULINA & PLANUL ATA \\
\hline SPIROLOCULINA & SOLDANII \\
\hline SPIROPL ECTAMMINA & FLOR I DANA \\
\hline SPIROPLECTAMMINA & WR IGHTI \\
\hline SPIROSIGMOILINA & ANTI LL AR UM \\
\hline SPIROSIGMOILINA & DISTORTA \\
\hline STETSON IA & MINUTA \\
\hline STOMATORBINA & CONCENTRICA \\
\hline STORTHOSPHAERA & $A L B I D A$ \\
\hline SULCOPHAX & PALUSTRIS \\
\hline TECHNIT ELLA & LE GU ME N \\
\hline TEXTULA RIA & AGGLUT INANS \\
\hline TEXT ULARIA & ALBATROSSI \\
\hline TEXTULA RIA & ASPERA \\
\hline TEXTULARIA & AURA \\
\hline TEXTULA RI A & $\begin{array}{l}\text { CALVA } \\
\text { CANDEI ANA }\end{array}$ \\
\hline TEXTULA RIA & $\begin{array}{l}\text { CANDEI ANA } \\
\text { CONICA }\end{array}$ \\
\hline $\begin{array}{l}\text { TEXTULARIA } \\
\text { TEXTULARIA }\end{array}$ & $\begin{array}{l}\text { CONICA } \\
\text { EARLAND }\end{array}$ \\
\hline
\end{tabular}




\begin{tabular}{|c|c|}
\hline TEXTULARIA & FLINTII CURTA \\
\hline TEXTULARIA & FOLIACEA OCCIDENTALIS \\
\hline TEXTUL ARIA & GOES I I \\
\hline TEXTUL ARIA & GR AMEN \\
\hline TEX TUL AR I A & HAUER I I \\
\hline TEXTULARIA & KERIMBAENSIS \\
\hline TEXTULAR I A & MAURYAE \\
\hline TEXTULARIA & MAYORI \\
\hline TEXTUL ARI A & MEXICANA \\
\hline TEXTULARIA & PALUSTRIS \\
\hline TEXTULAR IA & PARVULA \\
\hline TEXTULAR IA & PSEUDOTROCHUS \\
\hline TEX TUL AR I A & $R \cup G O S A$ \\
\hline TEXTULARIA & SAGITTULA \\
\hline TEXTULARIA & SECASENS IS \\
\hline TEXTULAR IA & SERANENSIS \\
\hline TEXTULARIA & S I CA \\
\hline TEXTULAR IELLA & BARRETTII \\
\hline THURAMMINA & FAVOSA \\
\hline THU RAMMINA & PAPILLATA \\
\hline THURAMMINA & PAPILLATA CARIOSA \\
\hline THURAMMINA & PAPILLATA CASTANEA \\
\hline TIPHOTROCH A & COMPRIMATA \\
\hline TOL YPAMMINA & SCHAUDINNI \\
\hline TOL YPAMM IN A & VAGANS \\
\hline TOSAIA & WEAVERI \\
\hline TRIFARINA & ANGULOSA \\
\hline TR I FAR INA & BELLA \\
\hline TRI FAR INA & BRADYI \\
\hline TRIFAR INA & CARINATA BRADYANA \\
\hline TRI FAR INA & JAMAICENSIS \\
\hline TR I FAR INA & OCCIDENTALIS \\
\hline TRILOCULINA & AFFINIS \\
\hline TRILOCUL INA & BELLATULA \\
\hline TRI LOCUL INA & BERMUDEZI \\
\hline TRI LOCUL INA & BI CARINATA \\
\hline $\begin{array}{l}\text { TRILOCUL INA } \\
\text { TRILOCULINA }\end{array}$ & BREVIDENTATA \\
\hline $\begin{array}{l}\text { TRILOCULINA } \\
\text { TRILOCUL INA }\end{array}$ & $\begin{array}{l}\text { CANDEIANA } \\
\text { CARINATA }\end{array}$ \\
\hline TRILOCUL INA & CUNEATA \\
\hline TRILOCUL INA & DENTATA \\
\hline TRILOCUL INA & FI TERREI \\
\hline TRILOCUL INA & FITERREI MENINGOI \\
\hline TRI LOC UL INA & GRACILIS \\
\hline TRI LOCUL INA & INSIGNIS \\
\hline TRI LOCUL INA & $\angle A B I O S A$ \\
\hline TRILOCUL INA & LINNEIANA \\
\hline TRI LOCUL IN A & LINNEIANA COMIS \\
\hline TRI LOCUL IN A & OBLONGA \\
\hline TRILOCUL INA & PLANCIANA \\
\hline TR I LOCUL INA & QUADRILATERALIS \\
\hline TRI LOCUL INA & ROTUNDA \\
\hline TRILOCUL INA & SIDEBOTTOMI \\
\hline TR I LOCUL IN A & SQUAMOSA \\
\hline TRI LOC ULINA & STRIATOTRIGONULA \\
\hline
\end{tabular}

TRILOCULINA TRILOCULINA TRILOCULINA TRILOCULINA TRILOCULINA TRITAXIS TRITAXIS

TROCHAM MI NA TROCHAM MINA TROCHAMMINA TRO C HAMMI NA TROCHAMMINA TROCHAM MINA TROCHAMMI NA TROCHAMMI NA TROCHAMMINA MMIN A TROC HAM MINA TROCHAMMI NA TROCHAMMINA TROCHAMMINA TROCHAMMINA TROCHAMMINA TROCHAMMINA TROCHAMMINA TROCHAMMINA TROCHAMMINIT A

TROCHAMMINITA

TROCHAMMI NOIDES

UVI GER I NA

UVI GERINA

UVI GERINA

UVI GER INA

UVI GERINA

UVIGERINA

UVI GERINA

UVIGERINA

UVI GER I NA

UVI GER I NA

UVI GERINA

UVI GERINA

UVIGERINA

UVIGERINA

VAG I NUL IN

VAG I NUL INA

VAL VULINA

VAL V UL I NER I A

VAL VUL I NER I A

VALVUL INER IA

VALVULINERIA

VAL VUL INE RIA

VALV ULI NER I A

VALVUL I NERIA

VIRG ULINELLA

WIE SNERELLA
SUBORB ICULARIS

TERQUEMIANA

TRAN SVERSESTRIATA

TR I CAR INATA

TR I GONULA

CONICA

COUSCA

ADVENA

AOVENA

GLOB I GER INI FORMIS

GLOBULOSA

INFLAT A

JAPONICA

LAEVIGATA

LOBATA

MACRESCENS

MULT ILOCULATA

OCHRACEA

QUADRI LOBA

ROTALI FORMIS

SIMPLISSIMA

SQUAMATA

SUBGLABRA

SUBTURBINAT A

TASMANICA

TURBINATA

IRREGULARIS

SALSA

PROT EUS

AMPULLACEA

AUBERI ANA

BELLULA

FL IN T I I

HISPIDA

HISPIDOCOSTATA

OCCIDENTALIS

PAR VULA

PEREGR INA

PEREGRINA DIRUPTA

PEREGRINA MEDITERRANEA

SELSEYENSIS

SENTI COSA

SPINICOSTATA

AMER I C ANA

LEGUMEN

OVIEDOIANA

BRADY:

COMPLANATA

LAEV IGATA

MEXI CANA

MINUTA

OP IMA

VILARDEBOANA

PERT USA

AUR I CULATA 



\section{REQUIREMENTS FOR SMITHSONIAN SERIES PUBLICATION}

Manuscripts intended for series publication receive substantive review within their originating Smithsonian museums or offices and are submitted to the Smithsonian Institution Press with approval of the appropriate museum authority on Form SI-36. Requests for special treatment-use of color, foldouts, casebound covers, etc.-require, on the same form, the added approval of designated committees or museum directors.

Review of manuscripts and art by the Press for requirements of series format and style, completeness and clarity of copy, and arrangement of all material, as outlined below, will govern, within the judgment of the Press, acceptance or rejection of the manuscripts and art.

Copy must be typewritten, double-spaced, on one side of standard white bond paper, with $11 / 4$ " margins, submitted as ribbon copy (not carbon or xerox), in loose sheets (not stapled or bound), and accompanied by original art. Minimum acceptable length is 30 pages.

Front matter (preceding the text) should include: title page with only title and author and no other information, abstract page with author/title/series/etc., following the established format, table of contents with indents reflecting the heads and structure of the paper.

First page of text should carry the title and author at the top of the page and an unnum. bered footnote at the bottom consisting of author's name and professional mailing address.

Center heads of whatever level should be typed with initial caps of major words, with extra space above and below the head, but with no other preparation (such as all caps or underline). Run-in paragraph heads should use period/dashes or colons as necessary.

Tabulations within text (lists of data, often in parallel columns) can be typed on the text page where they occur, but they should not contain rules or formal, numbered table heads.

Formal tables (numbered, with table heads, boxheads, stubs, rules) should be submitted as camera copy, but the author must contact the series section of the Press for editorial attention and preparation assistance before final typing of this matter.

Taxonomic keys in natural history papers should use the alined-couplet form in the zoology and paleobiology series and the multi-level indent form in the botany series. If cross-referencing is required between key and text, do not include page references within the key, but number the keyed-out taxa with their corresponding heads in the text.

Synonymy in the zoology and paleobiology series must use the short form (taxon, author, year:page), with a full reference at the end of the paper under "Literature Cited." For the botany series, the long form (taxon, author, abbreviated journal or book title, volume, page, year, with no reference in the "Literature Cited") is optional.

Footnotes, when few in number, whether annotative or bibliographic, should be typed at the bottom of the text page on which the reference occurs. Extensive notes must appear at the end of the text in a notes section. If bibliographic footnotes are required, use the short form (author/brief title/page) with the fult reference in the bibliography.

Text-reference system (author/year/page within the text, with the full reference in a "Literature Cited" at the end of the text) must be used in place of bibliographic footnotes in all scientific series and is strongly recommended in the history and technology series: "(Jones, 1910:122)" or ". . . Jones (1910:122)."

Bibliography, depending upon use, is termed "References," "Selected References," or "Literature Cited." Spell out book, journal, and article titles, using initial caps in all major words. For capitalization of titles in foreign languages, follow the national practice of each language. Underline (for italics) book and journal titles. Use the colon-parentheses system for volume/number/page citations: "10(2):5-9." For alinement and arrangement of elements, follow the format of the series for which the manuscript is intended

Legends for illustrations must not be attached to the art nor included within the text but must be submitted at the end of the manuscript-with as many legends typed, double. spaced, to a page as convenient.

Illustrations must not be included within the manuscript but must be submitted separately as original art (not copies). All illustrations (photographs, line drawings, maps, etc.) can be intermixed throughout the printed text. They should be termed Figures and should be numbered consecutively. If several "figures" are treated as components of a single larger figure, they should be designated by lowercase italic letters (underlined in copy) on the illus. tration, in the legend, and in text references: "Figure 9 $\underline{\mathrm{b}}$." If illustrations are intended to be printed separately on coated stock following the text, they should be termed Plates and any components should be lettered as in figures: "Plate $9 \underline{b}$. " Keys to any symbols within an illustration should appear on the art and not in the legend.

A few points of style: (1) Do not use periods after such abbreviations as " $\mathrm{mm}$, $\mathrm{ft}$, yds, USNM, NNE, AM, BC." (2) Use hyphens in spelled-out fractions: "two thirds." (3) Spell out numbers "one" through "nine" in expository text, but use numerals in all other cases if possible. (4) Use the metric system of measurement, where possible, instead of the English system. (5) Use the decimal system, where possible, in place of fractions. (6) Use day/month/year sequence for dates: "9 April 1976." (7) For months in tabular list ings or data sections, use three-letter abbreviations with no periods: "Jan, Mar, Jun." etc.

Arrange and paginate sequentially EVERY sheet of manuscript-including ALL front matter and ALL legends, etc., at the back of the text-in the following order: (1) title page, (2) abstract, (3) table of contents, (4) foreword and/or preface, (5) text, (6) appendixes. (7) notes, (8) glossary, (9) bibliography, (10) index, (11) legends 


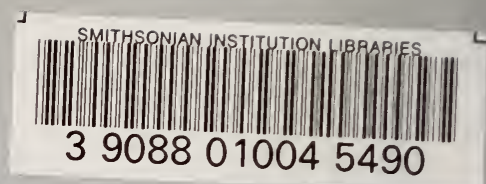

W7as

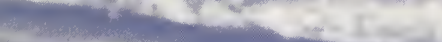

